
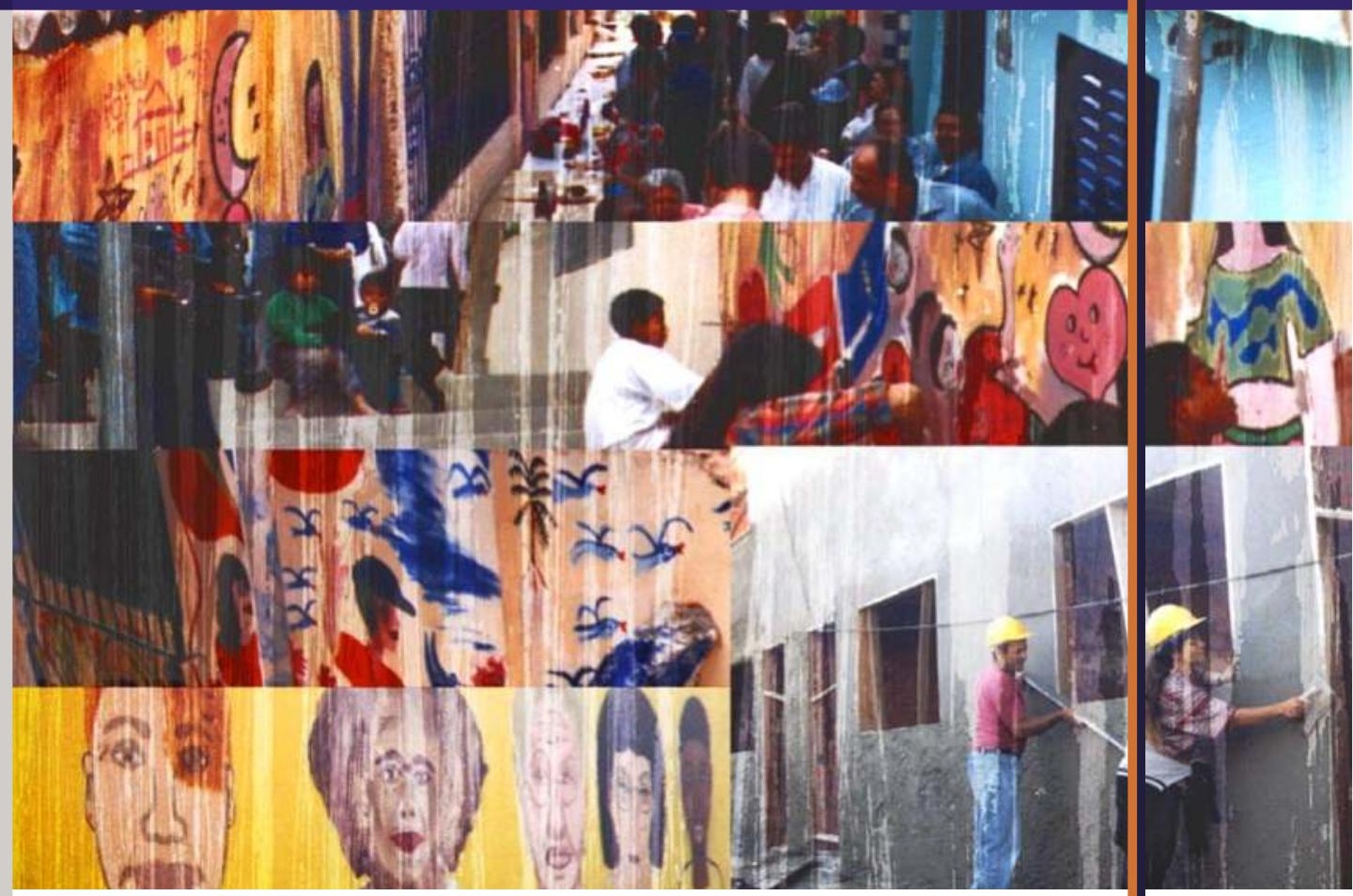

Giovanni Allegretti

\title{
Porto_Alegre una biografia territoriale
}

Ricercando la qualità urbana a partire dal patrimonio sociale 
Monografie

Scienze Tecnologiche 


\section{MONOGRAFIE SCIENZE TECNOLOGICHE}

1. Barbara Mazza, Le Corbusier e la fotografia. La vérité blanche, 2002

2. Information technology ed automazione del progetto, a cura di Carlo Biagini, 2002

3. Leonardo Casini, Enrico Marone, Silvio Menghini, La riforma della P.A.C. e la filiera olivicolo-olearia italiana, 2003

4. Leonardo Casini, Enrico Marone, Silvio Menghini, OCM seminativi: tendenze evolutive e assetto territoriale, 2003

5. E4 Thematic Network: Enchanging Engeneering Education in Europe, a cura di Claudio Borri, Francesco Maffioli, 2003

6. Paolo Ventura, Città e stazione ferroviaria. Seconda edizione rivista, 2004

7. Ecological design for an effective urban regeneration, edited by Dimitra Babalis, 2004

8. Winderful: Wind and Infrastructures : dominatine eolian risk for utilities and lifelines, edited by Gianni Bartoli, Francesco Ricciardelli, Vincenzo Sepe, 2004 


\section{Giovanni Allegretti}

\section{Porto_Alegre una biografia territoriale}

Ricercando la qualità urbana a partire dal patrimonio sociale

Firenze University Press

2005 
Porto_Alegre una biografia territoriale : ricercando la qualità urbana a partire dal patrimonio sociale: / Giovanni Allegretti. Firenze : Firenze university press, 2005.

(Monografie. Scienze Tecnologiche, 9)

http://digital.casalini.it/8884533120

ISBN 88-8453-312-0 (online)

711.409 (ed. 20)

Brasile-Urbanistica

(C) 2005 Firenze University Press

Università degli Studi di Firenze

Firenze University Press

Borgo Albizi, 28 - 50122 Firenze, Italy

http://epress.unifi.it/

Printed in Italy 
a Francesco, Giovanni, Teresa e Umberto

per avermi incoraggiato e criticato, per non aver mai interntto il dialogo, per l'assistenza materiale e morale e per avermi sopportato (con pazienza) quand'ero troppo assente ...e quand'ero troppo presente

Il volume è stato edito grazie al contributo del "Fondo Giovani Ricercatori", erogato dall'Università di Firenze nell'anno 2000 per la ricerca "Il recupero della 'città informale': tra spontaneismo e valori sociali dell'organizzazione spaziale".

La presente pubblicazione on-line ha dignità bibliografica autonoma e non costituisce la riproduzione, l'adattamento o la rielaborazione di preesistenti opere a stampa.

Progetto grafico, editing testi e immagini, post-editing, impaginazione e ottimizzazione per il web di Angelo M. Cirasino.

In copertina: decorazione della favela Vila Renascença I, dopo la regolarizzazione fondiaria; foto Allegretti e DEMHAB,1998 - elaborazione grafica di Simone Bellini. 
1. Inquadrando alcune scelte: temi e modalità espositive 13

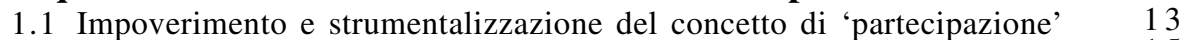

1.2 Perchè Porto Alegre? 15

$\begin{array}{lr}1.3 \text { Dal contenuto alla narrazione } & 19\end{array}$

$\begin{array}{ll}1.4 \text { L'articolazione del testo } & 21\end{array}$

SEZIONE PRIMA - LE CONDIZIONI AL CONTORNO 25

2. Il quadro internazionale: percorsi autonomi si toccano 27

$\begin{array}{ll}2.1 \text { L'inizio del dibattito sull'auto-aiuto } & 27\end{array}$

$\begin{array}{ll}2.2 \text { L'avvio di un'importante dibattito } & 29\end{array}$

2.3 Il percorso della Banca Mondiale: dalla negazione alla riscoperta della città $\quad 31$

2.4 Cambiare tutto perchè nulla cambi 35

2.5 Flessibilità vs. rigidità: verso uno sviluppo 'incrementale' 39

2.6 Un quadro in movimento 44

3. Il Brasile, palcoscenico di una trasformazione 53

3.1 Introduzione 53

3.2 L'esplosione della città informale e il mito della 'casa di proprietà' $\quad 55$

$\begin{array}{ll}3.3 \text { Città informale e disciplina urbanistica all'inizio del Novecento } & 61\end{array}$

3.4 Problema 'casa' e problema 'occupazioni': le prime risposte istituzionali 64

$\begin{array}{lll}3.5 & \text { Sotto la dittatura } & 66\end{array}$

3.6 Il tramonto della dittatura e il disimpegno della Nuova Repubblica $\quad 68$

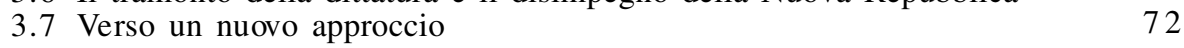

SEZIONE SECONDA - L'INDIVIDUALITÀ DI UNA CITTÀ TRA TERRITORIO E SOCIETÀ LOCALE $\quad 77$

4. Por to Alegre prima del 1989 - Lo sviluppo urbanistico tra immediatismo e programmazione

$\begin{array}{ll}4.1 \text { Una città al contempo anomala e rappresentativa } & 79\end{array}$

$\begin{array}{lr}4.2 \text { Una sintetica presentazione } & 80\end{array}$

4.3 Porto Alegre città di città: una singolare evoluzione urbana $\quad 82$

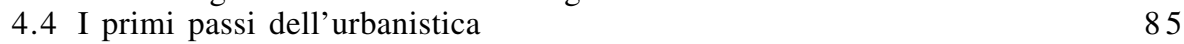

4.5 Lo 'spirito ribelle' e la città borghese $\quad 86$

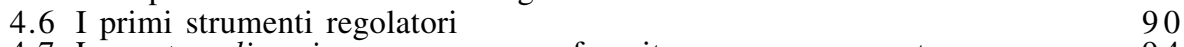

4.7 La metropolizzazione: un processo favorito ma non governato 94

4.8 Quali strumenti regolatori? 96

4.9 L'eredità del regime morente: il Piano Regolatore del $1979 \quad 99$

4.10La variante del 1987: l'affondamento delle certezze prepara il cambiamento 102

5. Por to Alegre prima del $\mathbf{1 9 8 9}$ - Le politiche dell'alloggio e il patrimonio urbano informale

5.1 Due percorsi paralleli artificialmente 'disgiunti'

5.2 Le politiche della casa a Porto Alegre nella prima metà del secolo

5.3 L'ambito municipale: dalla creazione del DMCP al tramonto della dittatura

5.4 L'ambito statale e i limiti delle politiche della casa

5.5 Primi studi e valutazioni sul patrimonio abitativo informale

5.6 Dal disconoscimento all'accettazione della 'dualità urbana'

5.7 Le strategie operative: da 'rimuovere per promuovere' a promuovere per rimuovere'

6. Por to Alegre prima del 1989 - Movimenti urbani e apertura delle Istituzioni locali

6.1 Il nascente protagonismo sociale nella Porto Alegre di fine Ottocento 149

6.2 Politica formale e protagonismo sociale: le occasioni di 'incontro' fino a metà del ' 900 
6.3 La società locale alla conquista di uno spazio sulla scena politico/amministrativa

6.4 Le Associazioni di Vicinato a Porto Alegre verso il tramonto del regime militare

6.5 Dalla protesta alla propositività: il nuovo protagonismo dei movimenti cittadini

6.6 Il Consiglio del Piano Regolatore di Porto Alegre: controllo sociale o apertura progressiva delle istituzioni all'ascolto degli abitanti?

6.7 Verso il rafforzamento degli istituti partecipativi: il dialogo tra l'Amministrazione Collares e i movimenti popolari

6.8 Quale destino per i neonati Consigli Popolari?

7. 1989: la città ad un bivio - Il Bilancio Partecipativo (O.P.), emblema del 'nuovo corso'

$\begin{array}{lll}\text { 7.1 Verso un concreto coinvolgimento dei cittadini nelle scelte urbane } & 177\end{array}$

7.2 Strutturazione e funzionamento del processo di Bilancio Partecipativo

7.3 L'organizzazione del dibattito pubblico: alcuni meccanismi puntuali

7.4 Tra tecnica e pedagogia: Regolamento Interno e 'criteri' di accoglimento delle richieste di investimento pubblico presentate dai cittadini nel BP

8. 1989: la città ad un bivio - Bilancio Partecipativo: introduzione ed evoluzione

8.1 Alle origini del Bilancio Partecipativo: il nuovo corso politico

8.2 La 'prima fase' del Bilancio Partecipativo: avvio e difficoltà d'insediamento

$8.3 \mathrm{La}$ 'seconda fase' del Bilancio Partecipativo: costruendo un'infrastruttura adeguata

8.4 La 'terza fase' del Bilancio Partecipativo: il consolidamento

8.5 La 'quarta fase' del Bilancio Partecipativo: modifica e ampliamento del processo

8.6 La 'quinta fase' del Bilancio Partecipativo: dal consolidamento all'autocritica

9. 1989: la città ad un bivio - Conquiste e difficoltà dell'OP: oltre la mera co-gestione del bilancio

9.1 Alcune domande

9.2 Il Bilancio Partecipativo come 'istituzione informale'

9.3 Quale spazio per il Bilancio Partecipativo sui mezzi di informazione?

9.4 Comunicazione e informazione: vari livelli per un impegno 'a due sensi'

9.5 Il forte impegno degli attori istituzionali

9.6 Un punto di incontro fra il cammino delle istituzioni e quello dei cittadini

9.7 L'incontro dell'OP con le diverse anime della città: un esempio di 'autoprogettualità'

9.8 L'obiettivo della 'equità distributiva'

258

10. 1989: la città ad un bi vio - Alcuni numeri dell'OP: superando la sterile contrapposizione tra qualità e quantità

10.1 Quale pubblico per il Bilancio Partecipativo?

10.2 Le tendenze al di là dei dati: l'O.P. e la distribuzione dei finanziamenti

10.3Esame comparato dei Piani di Investimento (1990-2002): la crescita dello sguardo sulla città nel suo complesso

10.4Oscillazione delle priorità tematiche di investimento: alcune riflessioni

10.5 Alcune trasformazioni qualitative nel meccanismo offerta-domanda

SEZIONE TERZA - IL DIALOGO TRA CITTÀ FORMALE E CITTÀ SPONTANEA

11. Città autocostruita e istituzioni verso il riconoscimento reciproco

11.1 La Porto Alegre informale oggi; dalla conoscenza al riconoscimento

11.2 Da baraccopoli a quartieri: nuovi strumenti per reintegrare la città spontanea

11.3Strumenti giuridici per la Regolarizzazione fondiaria: un panorama in trasformazione

11.4La sperimentazione di nuovi strumenti giuridici nell'esperienza di Porto Alegre 11.5 Alcune riflessioni 
12.2 Le molteplici strade della Politica della Casa

12.3 La regolarizzazione per tappe del commercio autorganizzato; un punto di vista alternativo sull'informale

12.4 La politica delle risorse umane

SEZIONE QUARTA - POLITICHE VISTE DA PROGETTI

13. Da "favelas" a "bairros": strategie a confronto 423

13.1 Il Programma di Regolarizzazione Fondiaria: verso un'azione integrata?

13.2 Il 'corpo a corpo' tra tecnici e abitanti: uno strumento indispensabile

13.3 Strategia della necessità e contro-strategie istituzionali: la regolarizzazione fondiaria da terreno di confronto a terreno d'incontro

13.4Gli 'interventi complementari' alla Regolarizzazione fondiaria

14. Reintegrando la città 'eccentrica': 5 storie di luoghi in trasformazione

14.1 Porto Alegre letta dal mutare di alcuni luoghi

14.2 Vila Campo da Tuca: cooperazione e non-finito

14.3 Rubem Berta: tra eterostrutturazione ed autoproduzione degli spazi abitati

14.4Il Loteamento Cavalhada: un progetto-pilota per l'integrazione degli interventi

14.5 Vila Planetario: atto pioniere per affermare il 'diritto dei poveri al centro'

14.6 Da Vila das Placas al Condominio dos Anjos: il sogno di essere 'normali'

15. Dalla gestione consensuale alla riprogettazione condivisa: la riscossa del territorio nel nuovo Piano di Sviluppo Urbano e Ambientale

15.1 Tra Civitas e Urbs: l'abitare come valore urbano

15.2Il nuovo PDDUA: un rovesciamento di prospettiva della tradizione pianificatoria

15.3 Il Progetto Integrato della Lomba: un percorso esemplare delle nuove sfide?

15.4Una imperfezione stimolante: alcune osservazioni conclusive

SEZIONE QUINTA - APPRENDENDO DAL SUD DEL MONDO

16. Una realtà in cammino

16.1 Un cambiamento in corso d'opera

16.2 Il Bilancio Partecipativo al di là dei propri limiti

16.3 Potere pubblico e città informale in una 'wild zone'

16.4 Verso un graduale superamento dei propri limiti

$16.5 \mathrm{Il}$ consolidamento di un patto sociale condiviso

633

17. Una conclusione aperta

17.1 La sfida di Porto Alegre

17.2 Porto Alegre dentro il quadro di riassestamento della democrazia liberale

17.3 Porto Alegre dentro il quadro in trasformazione delle politiche territoriali locali

Elenco degli acronimi e delle sigle usate nel testo

Dizionario della terminologia usata nel processo di Bilancio partecipativo

Il sistema dei Consigli Municipali nella 'città della partecipazione popolare'

Rete internazionale DRD (Démocratiser Radicalement la Démocratie): Griglia di esposizione e interpretazione di esperienze partecipative

Verso una nuova sensibilità diffusa? Una postilla 'italiana' 


\section{Ringraziamenti}

La scienza dalla quale proveniamo è una forma di conoscenza arrogante che riconosce conoscenze alternative solo nella misura in cui le può cannibalizzare; è un'attività corporativamente autonoma. [...] La disuguaglianza delle relazioni consiste nella ca pacità di una forma di conoscenza di convertire un'altra in risorsa o materia prima (B. de Sousa Santos, 2002, pp. 15-18).

Amo moltissimo il cinema. I miei film preferiti sono quelli dove i veri protagonisti non sono singoli personaggi, ma il pulsare di un'intera città.

Dalla categoria dei cinefili mi differenzio perché non amo trovare in un film le 'citazioni'. Non ho simpatia per il copyright, e credo che molte delle immagini più vivide costruite nel passato entrino naturalmente nella crescita personale di ogni regista, agendogli dentro per formarne la cultura visiva; perciò preferisco giudicare un'opera in base alla coerenza con cui riassorbe le sue fonti.

Scrivendo, ho fatto del mio meglio per identificare e citare tutti quegli scritti che mi hanno arricchito e fatto crescere, ma non giurerei di esser riuscito a identificarli tutti. Pertanto, chiedo scusa e ringrazio gli eventuali autori-ombra. Chiedo anche venia a coloro di cui ho citato brani; non sempre ho potuto indicare le pagine di riferimento. Questo libro è stato concepito su 'lunghe distanze', e - spesso - ho dovuto contare sulle versioni informatizzate dei testi a cui attingevo dati e riflessioni. E, come si sa, i numeri di pagina non corrispondono alla pubblicazione a stampa...

Anche per queste ragioni, questo libro è scritto in prima persona plurale. Ma non solo per questo.

Volevo, infatti, essere rispettoso di quel 'farsi plurale' che è la storia di una città, con le sue tante voci e i suoi punti di vista diversi, che ho scelto di esporre attraverso brani di interviste e 'dialoghi a distanza'.

E poi, questo libro non sarebbe mai nato senza le decine di persone che lo hanno reso possibile, dal momento dei primi studi fino alla stampa della prima copia (il 'pargolo'). Nominarle tutte sarebbe impossibile: mi ci vorrebbe un nuovo volume, e sono certo che rischierei, comunque, di dimenticarne molte.

Per questo ho deciso di non nominare personalmente tutti coloro a cui va la mia gratitudine (loro sanno chi sono!).

Farò solo tre deroghe, citando solo i nomi di battesimo (alla maniera brasiliana che tanto ho imparato ad amare).

La prima è per le 10 donne a cui questo libro è idealmente dedicato: Betania, Cleia, Cora, Eunice, Helena, Kelly, Jacqueline, Marli, Regina e Suzana. Sono loro che mi hanno aperto le porte e il cuore di Porto Alegre, con dedizione e competenza; sono loro le persone con cui ho più dialogato; sono loro, infine, le colonne e le metafore di un cambiamento possibile anche dentro la 'società tecnica' del Comune di Porto Alegre. 
La seconda deroga è per due persone che se ne sono andate prima che questo lavoro terminasse: Padre Oreste e Antonio, il mio 'pai brasileiro'. A loro devo parte della mia conoscenza di Porto Alegre, dialogo e bei ricordi.

La terza è per i miei familiari, per Alessandra, Simone, Giovanni e Cristiano, a cui devo l'impegno maggiore - al di qua dell'oceano - per dare una 'forma' a questo libro. Il parto ha avuto buoni ostetrici, pazienti e dediti. Soprattutto, grazie per aver sopportato con classe qualche mio nervosismo, e per aver attutito gli urti degli immancabili 'drammi informatici' dell'ultim'ora...

Con loro, ringrazio le tantissime amicizie brasiliane che questi 17 anni di soggiorni a Porto Alegre (è un numero che ritorna, il 17!) mi hanno lasciato. Sono il ricordo più bello che mi porterò sempre dietro, e che mi stimolerà $a$ consolidare e ravvivare anche le relazioni con i luoghi.

Ringrazio i professori del mio Dipartimento per gli spunti alla maturazione che mi hanno dato, attraverso le critiche costruttive, ma soprattutto attraverso la fiducia. Spero, nel tempo, di continuare a meritarmela (la seconda), e di acquisire quel di più di 'capacità di sintesi densa' che fa parte della raggiunta maturità del pensiero.

Ringrazio poi le mie prime laureate, i miei primi laureandi e specializzandi e gli alunni dei corsi a cui ho collaborato dal $2001 \mathrm{ad}$ oggi, per l'esplosivo miscuglio di affetto, rispetto e desiderio di crescere insieme nello scambio di opinioni. Stima e riconoscenza vanno anche alla 'consonanza ideale' e alla 'corrispondenza di studiosi sensi' che si è creata con docenti e rappresentanti delle tante università o istituzioni (lo IUAV di Venezia, La Sapienza e Roma III, il Politecnico, la Statale e la Bocconi di Milano, la Federico II di Napoli, l'Accademia di Belle Arti di Copenhagen, il Community Pride di Londra, UNIMONDO di Trento, le tante province e i tantissimi comuni italiani) che hanno creduto che la discussione sui temi al centro di questo libro potesse arricchire altri giovani e stimolare ognuno di noi ad impegnarci di più per cambiare le realtà in cui viviamo.

Un saluto caloroso ai tanti giovani e meno giovani del movimento per una diversa globalizzazione che mi hanno scaldato il cuore nei 3 Forum Sociali di Porto Alegre e all'European Social Forum di Firenze...certo di ritrovarli a Saint Denis, in India e nelle molte altre occasioni che ci aspettano per continuare a scambiarci idee e a condividere valori.

In particolare, ringrazio la DRD francese, che ha ampliato le mie amicizie e le mie occasioni di confronto, permettendomi di approfondire altre esperienze da cui ho potuto guardare a Porto Alegre con gli 'occhi nuovi' con cui il Marco Polo delle Città Invisibili di Italo Calvino guardava la sua Venezia, mentre attraversava le città del mondo.

PS = Papà, ti prometto che ora mi impegnerò a leggere il tuo ultimo libro per intero, per il piacere di continuare un dialogo su cui ci intendiamo bene, e non certo solo per ricambiare il tuo generoso impegno nel correggere le bozze di questo testo... 


\section{Nota introduttiva}

Ecco forse il grande rovesciamento che segna la soglia della maturità. È il momento in cui si scopre che il mondo non riserva altre risposte se non quelle che si ha il coraggio di fornirgli (D. De Rougemont, citato in V. Borghi, Progettazione come impresa sociale, Milano, Franco Ang eli, 2000).

Questo libro non è un epitaffio. Semplicemente perché l'esperienza che descrive non è morta.

Non lo è perché la nuova coalizione politica che dal gennaio 2005 governa la metropoli brasiliana di Porto Alegre, capitale dello Stato del Rio Grande do Sul, si è impegnata (seppur spostando l'accento dalla 'democratizzazione della democrazia' alla 'governance') a mantenere vivo un rapporto di codecisione che renda i cittadini protagonisti delle decisioni nell'impostazione delle politiche urbane.

Ma l'esperienza descritta nelle pagine seguenti non sarebbe morta neppure se la nuova amministrazione di Porto Alegre non mantenesse i suoi impegni con gli elettori. E questo perché con il suo esempio ha permesso l'avvio di centinaia di altre sperimentazioni a latitudini diverse del pianeta, oltre ad aver lasciato segni indelebili nella maturazione del senso civico degli abitanti e nella trasformazione culturale delle istituzioni locali.

Intransigenza sui principi e fiducia nell'intelligenza sociale sono i tratti salienti che hanno stimolato la mia immaginazione di adolescente quando - nel 1989 - ho cominciato a frequentare Porto Alegre e ad osservare la sua peculiare esperienza di governo locale.

Fin da subito, la città in rapida trasformazione mi ha colpito con un'immagine forte che richiamava i termini di quella relazione di complementarità e di reciproca influenza tra riflessione e azione trasformativa che Enrst Bloch (1959) ha dipinto con l'icastica espressione: "pensare significa oltrepassare". $\mathrm{Ci}$ sono tornato più volte negli anni successivi: alcune volte per studio, le ultime in occasione dei quattro Forum Sociali Mondiali che la città ha ospitato. E - in modo crescente - ho provato la suggestiva sensazione di una 'città 
10 pensante'. Una città pensante 'collettivamente' e in modo 'diffuso', proprio in quanto capace di 'oltrepassare' criticamente e per approssimazioni successive (coerenti ma graduali) i limiti e le regole di una gestione tradizionale del territorio, con l'obiettivo esplicito di mettere in moto e concertare la polifonia creativa di tutto il vasto fronte di soggetti che nel quotidiano costruiscono, modificano e reinterpretano i suoi diversi spazi, ricostruendo la politica urbana come 'luogo'.

Progressivamente, attraverso questa immagine forte e vivida che Porto Alegre è riuscita a trasmettermi, ha preso forma un sentimento complesso di attrazione: un misto di fascinazione, curiosità, incredulità e desiderio di 'denudamento' e di approfondimento critico dei dettagli che convergevano nel costruire questa immagine.

Un incontro determinato da vicende personali è divenuto il motore per stimolare una crescita in ambito professionale, quando ho deciso di dedicare tre anni di lavoro (1997/2000) a portare avanti uno 'studio di caso' significativo all'interno del Dottorato in Progettazione Urbana, Territoriale e Ambientale dell'Università di Firenze.

Questo testo non è una filiazione diretta della tesi discussa al termine del Dottorato, pur costituendo uno dei risultati di quel periodo di ricerca. È nato, piuttosto, come un modo per comunicare - in forma di dispensa - con studenti, laureandi e dottorandi che in questi anni vanno affrontando - in numero crescente - i temi della democratizzazione delle politiche territoriali. E, successivamente, ha assunto una fisionomia propria, desiderosa di porsi in dialogo più ampio con tutti coloro che sono interessati al tema.

In questo 'passaggio', si è fatta presente una difficoltà che aveva a che fare con il taglio disciplinare dato a questo dialogo. Per gli studenti di architettura e urbanistica che si occupano di progettazione nei contesti periferici e in via di sviluppo - infatti - tematiche come quelle della città autocostruita o 'informale' e procedimenti come la regolarizzazione fondiaria (strettamente connesse ai processi di democratizzazione della gestione territoriale) sono "pane quotidiano'.

Ma per tutti gli altri potenziali lettori non accade lo stesso. Così, risultava necessario affrontare alcune spiegazioni (spesso dettagliate) di contesto per poter rendere comprensibile a tutti il grado e la portata di innovazione di alcune pratiche di gestione territoriale sperimentate a Porto Alegre.

Le opportunità divulgative offerte dalle nuove tecnologie hanno permesso di dare una soluzione al dilemma che si poneva: privilegiare la diffusione di queste riflessioni ad un pubblico più vasto o il loro approfondimento? Scegliendo di pubblicare il testo in E-book - con la supervisione del Comitato Scientifico della Firenze University Press - in qualche modo si può venire incontro ad entrambe le esigenze, in una maniera 'democratica' che ben si lega al tema affrontato.

Al contempo, infatti, si può raggiungere un pubblico ampio e lasciargli la possibilità di scegliere quali parti del testo scaricare, in relazione ai propri specifici interessi di approfondimento. Per di più, si può raggiungere una rapidità di diffusione che non è secondaria, dal momento che il testo entra anche in alcuni dettagli tecnico-organizzativi ed espone dei dati quantitativi che possono - per la loro stessa natura - essere soggetti ad un rapido processo di invecchiamento. 
Per quanto riguarda i suoi contenuti nodali, il maggior contributo all'impostazione di questo libro è venuto da un periodo di 'decantazione' e di riflessione sul materiale utilizzato nella tesi di dottorato, reso possibile da un finanziamento 'Giovani Ricercatori' ottenuto dall'Università di Firenze per l'anno 2000-2001, ed integrato da altri studi e soggiorni di verifica fino al novembre 2002. Eventi esterni, succedutisi nel corso del nuovo periodo di studio, hanno determinato lo svilupparsi di un forte interessamento internazionale per Porto Alegre, per la sua più che decennale esperienza di riforma delle politiche e degli strumenti di gestione urbana, ed anche per altre esperienze consimili che - parallelamente o posteriormente - hanno preso avvio in altre città di continenti diversi, spesso con esplicito riferimento a risultati e trasformazioni della vicenda portoalegrense.

In tale contesto, la scarsa diffusione in Italia di altri studi approfonditi sull'esperienza di Porto Alegre, mi ha inaspettatamente garantito la possibilità di partecipare ad un vasto numero di seminari, convegni, lezioni, atelier e corsi di formazione sui temi della democratizzazione degli strumenti e delle politiche degli Enti Locali (sia in Italia che all'estero): questi hanno costituito un'irripetibile occasione per vivaci scambi di idee con altri professionisti, rappresentanti istituzionali, attivisti di movimenti urbani e ONG, e cittadini interessati ad essere soggetti attivi e consapevoli nella trasformazione dei propri territori di riferimento.

Simili opportunità - insieme all'offerta di contribuire al dibattito internazionale con vari scritti su riviste di taglio, ambito tematico e prospettive differenti - hanno, inoltre, costituito per me uno stimolo all'approfondimento di specifiche questioni di merito e all'ampliamento dell'orizzonte conoscitivo ad esperienze analoghe o complementari a quella esaminata a Porto Alegre. E, soprattutto, mi hanno fornito l'opportunità di mettere alla prova capacità di semplificazione comunicativa e articolazione di sfumature di significato, stimolandomi a parlare allo stesso tempo con linguaggi diversi a pubblici con appartenenza culturale ed interessi differenti. Spero che il testo porti traccia di questo periodo, a cui sento di dovere una buona parte della mia maturazione personale e professionale.

In particolar modo, sono grato ad occasioni di discussione che chiamerei 'di secondo livello', che mi hanno permesso di confrontarmi con persone ricche di idee e punti di vista già formati e maturi sui temi in discussione, aiutando$\mathrm{mi}$ anche ad individuare l'ossatura portante intorno a cui riarticolare ed arricchire in questo libro gli ambiti di ricerca al centro della tesi di dottorato e dei diversi articoli successivamente pubblicati.

Quando mi è stato chiesto se volessi dare a questo libro una struttura 'universitaria' o 'militante' ho avuto difficoltà a rispondere ad una contrapposizione che trovo artificiosa, nella misura in cui è alla mediazione del mio impegno nell'ambito scientifico che devo le opportunità di approfondimento su temi e fenomeni in stretta relazione con la realtà del vivere e dell'operare quotidiano, non solo mio personale, ma anche della comunità scientifica e professionale con cui ho avuto l'inaspettata fortuna di poter collaborare a partire dagli anni della mia tesi di laurea.

In tale prospettiva, ho cercato di dare al testo un'articolazione il più possibile 'scientificamente corretta' proprio per fornire a me stesso e ai lettori solidi strumenti utilizzabili nell' ambito di una 'militanza', intesa come impegno a 
contribuire a quella che Davi Smith (1993) ha definito la 'disiotizzazione della cittadinanza': ovvero alla creazione, sperimentazione e valutazione di pratiche di governo del territorio che possano stimolare i cittadini a uscire progressivamente da quel 'riflusso nel privato' (il concetto a cui si riferiva il greco antico con il termine 'idiotes') che - negli ultimi decenni - è stato indubbiamente favorito anche dal tradimento delle aspettative create da molti strumenti apparentemente o potenzialmente innovativi per la gestione dei territori e dei loro patrimoni sociali e culturali.

Potrà forse apparire un'ambizione eccessiva o persino presuntuosa: sono però certo dell'entusiasmo e dell'umiltà che hanno animato la mia ricerca di un orizzonte concreto da porre come meta finale alle mie riflessioni. Del resto, la stesura del libro si è accompagnata a una serie di parallele trasformazioni nelle modalità del mio impegno professionale che hanno indubbiamente interagito con essa: in particolare, l'affiancamento alla ricerca universitaria di un coinvolgimento professionale dentro processi di pianificazione territoriale e/o di riforma di alcune procedure decisionali di enti pubblici, connotatosi per una celere moltiplicazione e differenziazione dei contesti geografici, culturali e sociali di riferimento per la ricerca e/o l'azione in cui ero coinvolto.

Specialmente, credo che - nel corso del 2002 e del 2003 - un elemento importante di cambiamento sia stato rappresentato dal coinvolgimento nell'avvio delle prime, timide esperienze di applicazione parziale di procedure di Bilancio Partecipativo nel nostro Paese, a cui non sempre ho potuto rispondere in prima persona con lo stesso livello di impegno e costanza che avrei desiderato. Seppur la partecipazione a questi 'prodromi' di rinnovamento del rapporto tra istituzioni e cittadini nell'amministrazione del territorio non ha potuto intervenire a mutare radicalmente la struttura del testo, essa ha influito nello spingermi ad estrapolare, sottolineare e separare principi conduttori e condizionamenti locali o congiunturali dell'esperienza descritta, al fine di coglierne meglio i caratteri di valenza universale da poter emulare e adattare in contesti differenti da quelli di origine.

In tale ottica, il testo vorrebbe rappresentare un passo avanti rispetto alla tesi (i cui materiali ne hanno costituito la fonte di partenza) pur configurandosi anch'esso come un 'racconto di caso' secondo i principi di quella 'nuova narrazione' che Riccardo Petrella $(2000 ; 2001)$ ha più volte sottolineato come indispensabile per guidare verso modalità di rinnovamento delle politiche e degli approcci disciplinari all'interno del quadro di una società mondiale 'globalizzata' ma non necessariamente 'perduta' per quanto attiene alle possibilità di recupero e valorizzazione creativa delle sue 'energie da contraddizione' e dei suoi complessi patrimoni sociali e territoriali di ambito locale. 


\section{1 \\ Inquadrando alcune scelte: temi e modalità espositive}

\subsection{Impoverimento e strumentalizzazione del concetto di 'partecipazione'}

La partecipazione esprime nel modo più visibile il nostro senso di appartenenza al mondo. E la responsabilità inizia proprio dallo schierarsi nel mondo attivo, partecipe e consapevole" (Alberto Mellucci, 1994, pg. 16).

Questo libro narra la storia di un 'luogo' (la città brasiliana di Porto Alegre) e dei suoi cambiamenti recenti, tutt'ora in corso e quindi non sempre facilmente descrivibili né univocamente valutabili. La narrazione, a sua volta, è un'occasione per parlare di 'partecipazione virtuosa' degli abitanti alla costruzione e trasformazione di un territorio urbano, riservando un particolare interesse ad alcuni aspetti connessi alla politica della casa e al rinnovamento delle politiche urbanistiche.

Nelle intenzioni dell'autore, l'aggettivo 'virtuosa' non vuole tanto riferirsi agli esiti positivi ed innovatori raggiunti grazie a questa partecipazione (i quali saranno gradualmente esaminati nello sviluppo del testo, così come $\mathrm{i}$ limiti evidenziatisi nel corso dei processi) quanto piuttosto agli obiettivi e alle modalità con cui il coinvolgimento è andato prendendo forma.

A rigore, infatti, il termine 'partecipazione' - tanto più se isolato - tende a rappresentare oggi un universo così variegato di significati differenti da risultare quasi un contenitore vuoto, al punto da non invogliare neppure più al suo utilizzo, a meno che non sia per recuperarne la densità semantica originaria. Soprattutto negli ultimi anni, esso è stato stiracchiato all'interno di una vastissima gamma di sfumature teoriche e di riferimenti ad esperienze concrete diverse, in ambiti che spaziano dall'effettivo coinvolgimento decisionale dei cittadini nell'orientare importanti scelte urbanistiche e finanziarie, alla mera consultazione degli abitanti nelle fasi di definizione dei dettagli realizzativi di scelte avvenute con processi tutt'altro che 'partecipativi' (nel migliore dei casi frutto appena di concertazione in tavoli 'ristretti' alla presenza di singole organizzazioni della società civile, per lo più selezionate in modo tutt'altro che trasparente e/o significativamente rappresentativo dei tessuti sociali locali).

La ormai sterminata letteratura in tema di 'empowerment', 'cooperazione antagonista' (Friedman, 1992) e coinvolgimento dei cittadini nella costruzione del- 
14 le politiche e/o dei progetti territoriali non ha sostanzialmente scardinato l'analisi sintetica proposta negli anni Sessanta da Sherry Amstein, che nella sua 'Scala della partecipazione cittadina' aveva individuato 3 tipologie e 8 gradini principali di 'discorso' a cui ricondurre le accezioni del termine generalista di 'partecipazione': la non-partecipazione (che includerebbe la manipolazione e la partecipazione terapeutica), la pseudo-partecipazione o tokenism (che includerebbe la mera informazione dei cittadini e la consultazione) e la cessione di potere reale ai cittadini (che spazierebbe dalla delega di potere al controllo popolare). ${ }^{1}$

Nei concreti esempi di sperimentazione di politiche di 'empowerment e partecipazione' a cui la letteratura mondiale può fare riferimento, la gamma dei significati tende però, in genere, a ridursi drasticamente alle prime due categorie, pur contenendo talora 'germi compressi' degli ultimi due gradini. In particolare, nella pratica politica dell'ultimo decennio, la promozione di forme di partecipazione della cittadinanza alle scelte territoriali, ha teso ad essere riassorbita in un quadro concettuale impostato sull' asimmetria tra cessione di poteri e crescita delle responsabilità che caratterizza i diversi gradini di messa in opera del principio di sussidiarietà. ${ }^{2}$

Questo, per molte istituzioni locali di contesti diversi del pianeta, comporta generalmente l'accettazione dell'inspiegabile assioma per cui al globalizzarsi dei problemi si risponde con la localizzazione delle soluzioni e il deresponsabilizzarsi degli organi di governo superiori, senza che siano forniti in contropartita reali strumenti di autonomia (organizzativa e finanziaria) per far fronte ai nuovi compiti. L'esito di tale 'sbilanciamento' tende di solito a trasmettersi ai rapporti tra istituzioni locali e società civile, determinando un appiattimento corrispondente dell'accezione data al tema della 'partecipazione cittadina', ristretta - nei casi migliori - nei margini del 'tokenism' e in un'ottica di 'cessione di responsabilità' senza corrispondente 'cessione di poteri', ${ }^{3}$ quando non viene addirittura limitata a rappresentare un semplice elemento di 'marketing territoriale' o esplicitamente mirata alla 'costruzione del consenso'.

Le interpretazioni 'strumentali' e 'limitative' del ricorso a procedure di partecipazione diretta della società civile e di sue entità rappresentative per l'orientamento di politiche e progetti territoriali, nella pratica segnano la maggioranza delle esperienze. Esse tendono spesso a retroagire anche su molta della produzione teorica in materia partecipativa, in particolare su quel vasto ambito costituito dalle agende di principi, dagli schemi direttori e dalle raccomandazioni finali che sovente costituiscono l'unico esito visibile di incontri e commissioni di lavoro internazionali sui temi dell'habitat, dell'ambiente, delle politiche sociali o della 'governance'.

Così, non è infrequente ritrovare forme di 'strumentalismo partecipativo' suggellate in documenti di indirizzo di 'largo consumo' come l'Agenda XXI di Rio (1992) o l'Habitat Agenda di Istanbul (1996) ${ }^{4}$ a cui negli ultimi anni tendono sempre più costantemente ad attingere statuti di amministrazioni locali e documenti di programmazione redatti da livelli governativi diversi di moltissimi paesi. In vari di questi, il 'riduzionismo' interpretativo che connota le accezioni di termini come 'empowerment e partecipazione' si coniuga con la vaghezza onnicomprensiva e sovente sloganistica dei riferimenti allo 'sviluppo sostenibile', per lo più declinati solo in relazione alla crescita - ritenuta ormai inarrestabile - dei centri urbani.

In tale contesto, la 'partecipazione' è sì definita come un momento necessario dei processi decisionali di programmazione e planning, ma non tanto nel suo ruolo di 'definitore e orientatore di strategie', quanto piuttosto di utile strumento 
di gestione (management) dello sviluppo urbano e di realizzazione e mantenimento di stock abitativi e di servizi locali, specialmente negli insediamenti a basso reddito, laddove si esorta a garantire forme di concertazione che "includano le categorie svantaggiate" e "promuovano la rappresentatività degli interessi intergenerazionali". Ovviamente, rispetto ai documenti usciti da Summit Internazionali precedenti, (ad es. Habitat I di Vancouver, 1976), in quelli più recenti l'idea di partecipazione si è arricchita nel tempo di accezioni interpretative, coprendo ambiti di significato che vanno dalla creazione di nuove regole democratiche al decentramento amministrativo, dallo sviluppo del settore privato al recupero delle energie produttive di quello cosiddetto 'informale', dai contributi dati alla costruzione di sostenibilità (ambientale e contemporaneamente economica, politica e sociale) a quelli offerti alla 'costruzione di capacità' dei settori più marginali della popolazione, dal ruolo nella preservazione dei luoghi della memoria e dell'identità locale allo sviluppo della coscienza dei cittadini sul proprio ruolo nelle trasformazioni della società. Resta però la netta sensazione che "l'idea di partecipazione della cittadinanza sia un po' come mangiare spinaci: nessuno vi si oppone perché fanno bene",; ovvero che - anche volendo oltrepassare il mero richiamo rituale a qualcosa di cui non si può non parlare volendo essere 'politically correct' ${ }^{6}$ - i paradigmi di sviluppo alla base della lettura del territorio proposta dall' Agenda di Istanbul e dai suoi follow-up ne illuminino un'accezione essenzialmente 'strumentale' nell'ambito di un modello di globalizzazione economico-finanziaria basata sulla competitività delle città sul mercato internazionale mai radicalmente messa in dubbio, anzi ritenuta portatrice di opportunità e quindi di 'magnifiche sorti e progressive'. In tale quadro, la 'partecipazione cittadina' alle trasformazioni del territorio è essenzialmente letta come contributo offerto alla gestione dello stesso, piuttosto che come parte fondamentale di un approccio antagonista alla pianificazione (Friedman, 1992; Paba, 1996), di un coinvolgimento nei processi decisionali di tutto ciò che si discosta dal mercato (Giusti, 1995) o, addirittura, di una via alternativa allo sviluppo. L'ottica 'riduzionista' è tanto più leggibile laddove si parla di processi partecipativi in relazione all'housing, o ai servizi minimi necessari alle fasce deboli di abitanti. Essa pare, infatti, esaltata come 'riduttore di conflitti' e 'strumento di delega di responsabilità istituzionali', ovvero elemento di cui non è possibile fare a meno dato che Stato e mercato non sono stati finora (e difficilmente saranno) in grado di coprire le esigenze vitali di una fetta significativa di cittadini in questi settori, specie nei paesi periferici.

La 'partecipazione' entra così a far parte di pratiche strumentali di forzosa accettazione e valorizzazione di quanto autodeterminatosi sul territorio, sovente al di fuori di ogni regolamentazione di legge e di qualsiasi previsione pianificatoria, come avvenuto relativamente all'affermazione dell'importanza dell'economia informale e del self-help, ormai riconosciuti non solo nel mondo della cooperazione ma anche fra le istituzioni economiche e finanziarie internazionali (Osmont, 1995, 2002; Balbo, 1996, 2002).

\subsection{Perché Porto Alegre?}

La rapidità delle comunicazioni, la 'finanziarizzazione' dell'economia..., la riduzione dell'importanza del lavoro come fonte di identità installata sul territorio... ed anche l'estrema capacità di manipolare le informazioni, hanno alterato la qualità dell'impero ed aumentato l'importanza del territorio come spazio di produzione della società (Calame, Talmant, 2001, p. 14). 
16 In un quadro come quello brevemente delineato fin qui, perché questo libro si propone di contribuire all'approfondimento della conoscenza di esperienze di 'partecipazione virtuosa' attraverso l'esempio di Porto Alegre? E perché articola l'esposizione in forma di 'studio di caso', delineando così una sorta di 'monografia territoriale'?

Di seguito, cercherò di esporre le motivazioni principali che hanno guidato le due scelte, con l'avvertenza che esse non vanno considerate esaustive. Non solo per la maggiore complessità degli stimoli che le sostengono (e che troveranno progressivo disvelamento nel corso del testo), ma anche perché - per entrambe le scelte - le spiegazioni non sono forse tutte già ora riconducibili ad una sfera di 'razionalizzazione comunicabile', attenendo alcune ad una sorta di 'congenialità' e di 'adesione spontanea' dell'autore all'oggetto della ricerca.

A monte di ogni spiegazione che è possibile articolare, vi è senza dubbio una considerazione generale. Porto Alegre è una città del Sud del mondo, dalla cui esperienza indubbiamente possono venire forti stimoli di riflessione per un rinnovamento del 'fare politica' anche per il Nord del pianeta, ovvero per realtà di solito proterve, autocentrate ed abituate a non mettere in discussione l'assioma secondo cui i flussi di 'apprendimento' dovrebbero percorrere il mondo con direzione Sud-Nord mentre quelli di 'insegnamento' si assesterebbero nel verso che dal Nord giunge al Sud. L'auspicio che tale assioma possa venire progressivamente abbandonato non giustifica, ovviamente, l'aver circoscritto a Porto Alegre la scelta di campo, dato che il Sud del pianeta offre un numero elevato di esperienze dense e significative di apertura del governo del territorio alla partecipazione della società civile nelle sue molteplici articolazioni. È perciò necessario dar conto di ulteriori motivazioni.

La prima ragione si lega strettamente all'impostazione data all'esperienza di Porto Alegre. Il graduale processo di riforma in senso partecipativo delle politiche urbane e del funzionamento istituzionale è stato attivato da ormai 14 anni nella città brasiliana (e più di recente nello Stato di cui è capitale) a partire dalla creazione del cosiddetto 'Bilancio Partecipativo', una consistente riforma delle procedure di discussione del bilancio, ma anche di costruzione dei programmi locali di investimento economico e di ampliamento dell'autonomia delle fonti di finanziamento a disposizione dell'Ente Locale per una trasformazione delle politiche territoriali che desse a tutti i cittadini un ruolo decisionale di rilievo nella gerarchizzazione e nell'adozione delle stesse.

In tale ottica, il processo messo in atto a Porto Alegre costituisce un chiaro esempio in controtendenza rispetto ai modi più diffusi di coinvolgimento della cittadinanza nelle decisioni territoriali, che altrove si incentra spesso su posizioni di mera consultazione. Anche la seconda motivazione della scelta di Porto Alegre ha a che fare con la 'natura' degli obiettivi perseguiti nella riforma del complesso delle politiche cittadine, che non hanno messo l'accento sul loro contributo al 'rinnovamento strumentale' delle procedure di governo urbano, concentrando invece l'attenzione sull'apporto che erano in grado di offrire alla modifica 'dei contenuti' e dell'approccio complessivo al 'fare politica' in ambito locale.

Il reale significato della riforma innescata dal Bilancio Partecipativo risiede, infatti, nella spinta offerta alla ricostruzione di un rapporto di fiducia tra istituzioni e cittadini ormai logorato, fornita attraverso la 'ripoliticizzazione' del bilancio (de Souza Lopes, 2000), cioè restituendogli il contenuto di luogo politico in cui si tratta di decidere dei 'fini condivisi' del governo urbano, prima ancora che dell'ottimizzazione dei mezzi per il loro raggiungimento. L'esperienza sviluppa- 
ta negli ultimi 14 anni a Porto Alegre sembra aver quindi evitato che il 'mito della buona governance' si traducesse in 'strumento ideologico per una politica dello stato minimale' (Smouts, 1998) e contemporaneamente che la 'frenesia di «dialogo» con la "società civile»' si traducesse in quello che Cassen chiama 'un colpo di stato a piccoli passi' il cui unico obiettivo fosse 'non quello di modificare, sia pure minimamente, le politiche...ma quello di «spiegarle» meglio, mentre il numero di organizzazioni che beneficiano di un'udienza fa da garanzia' alla legittimazione di politiche decisioniste e nei fatti tutt'altro che realmente 'partecipative' (Cassen, 2001).

Letta nei suoi elementi principali di novità, la vicenda di Porto Alegre sottolinea una dimensione della politica ormai quasi 'inedita', dove il processo di riforma messo in atto pare incentrarsi, invece, sulla costruzione di rapporti di "sussidiarietà attiva" e sul recupero della 'logica di luogo' come nodo per una riscoperta 'dei principi della legittimazione e dell'obbligazione politica' (Revelli, 2001a) e 'del dovere di pertinenza" ${ }^{8}$ Inoltre, essa sottolinea a più riprese come la volontà politica e l'impegno costante delle istituzioni siano fattori imprescindibili non solo per l'attivazione ma per la sopravvivenza e la crescita della portata dei processi di riforma messi in campo, comportando questo un accrescimento di responsabilità - e non quindi una delega o una cessione della stessa - da parte di ogni governo che si faccia promotore di processi di trasformazione territoriale realmente partecipativi.

L'esperienza di Porto Alegre ha centrato il suo approccio innovatore sul nodo della 'co-gestione' delle trasformazioni territoriali, avendo come attori principali le amministrazioni municipale e statale, da un lato, e nuove forme di organizzazione autonoma della società civile dall'altro. Proprio i risultati raggiunti in poco più di un decennio (e il loro espandersi oggi in centinaia di altre realtà locali sudamericane ma non solo - attraverso formule di 'emulazione critica' delle sperimentazioni realizzate a Porto Alegre) invitano oggi a riflettere sulla lungimiranza delle conclusioni implicite nella lettura dei processi territoriali partecipativi proposta da Sherry Arnstein attraverso il filtro della 'Scala della partecipazione cittadina'. Essa resta, infatti, un valido strumento di analisi del reale, ma ponendo la 'delega di potere al popolo' nel suo gradino più elevato sembra non riconoscere alla cogestione il valore di opzione autonoma, sottostimando i vantaggi e il ruolo di 'mutuo apprendimento' che la continua 'tensione decisionale' tra abitanti e rappresentanti politici può produrre laddove sia valorizzata attraverso nuove modalità di governo e progettazione del territorio che riconoscono ad entrambi ruoli attivi paritari e complementari nel loro potenziale 'costruttivo'.

Una terza ragione che motiva la scelta del caso di Porto Alegre è legata alla leggibilità dei risultati che l'esperienza ha reso visibili e misurabili in questi anni, sia nell'ambito degli interventi 'di dettaglio' che delle scelte di portata 'strategica' per il territorio interessato. La possibilità di raccoglierne ed esporne i più significativi con un grado di elevata comprensibilità anche per chi si colloca come osservatore esterno a quel particolare processo territoriale, può rendere l'operazione utile, tanto più in un contesto come quello italiano dove ad un diffondersi di generici consensi e ammirate manifestazioni di interesse per l'esperienza di Porto Alegre non è mai corrisposto un contestuale aumento di impegno allo studio e all'approfondimento della conoscenza dei suoi elementi costitutivi, delle sue tappe di sviluppo, dei risultati evidenziati e degli eventuali limiti o errori che potrebbero esserle ascritti.

Inoltre, il variegato ventaglio di trasformazioni innescatesi a partire dalla 
costituzione del Bilancio Partecipativo - costituitosi come 'nodo' per la costruzione di un ampio sistema di 'apertura' al controllo diretto dei cittadini sui diversi istituti e le differenti procedure che presiedono alla gestione urbana - ha fatto convergere contestualmente sull'esperienza l'interesse e gli attestati di stima di settori dell'opinione pubblica molto diversi, i cui punti di vista si trovano generalmente in aperto contrasto.

Una quarta motivazione circa la scelta di Porto Alegre si trova, infine, legata ai peculiari patrimoni territoriali e sociali che caratterizzano la città, ovvero alla sua particolare conformazione in quanto 'caso' connotato da specificità uniche ma anche da elementi di forte condivisione con altri contesti. L'orientamento e la continuità politica che hanno caratterizzato la città dal gennaio '89 (data scelta come riferimento temporale per la parte più approfondita dell'analisi che il testo presenta) l'hanno segnalata come un esempio adatto a illustrare concretamente la possibilità di contrastare il teorema secondo cui una democrazia partecipativa sarebbe irrealizzabile nella complessità delle metropoli per la molteplicità degli interessi e il numero di abitanti presenti. L'attenzione della ricerca si è, pertanto, appuntata su questa esperienza, a partire dalla considerazione che la stessa complessità dei problemi è stata qui usata come sfida ed opportunità per la costruzione e il radicamento della partecipazione sociale alla costruzione delle politiche, in prima fila quelle urbanistiche e dell'housing centrate sulla ricostruzione di una relazione fra ambiti formali e informali dentro la città bipartita che da decenni è caratteristica strutturante del panorama urbano brasiliano e terzomondiale in genere, ${ }^{9}$ delle cui problematiche medie Porto Alegre è - per molti aspetti - estremamente rappresentativa.

Queste motivazioni si saldano in realtà in un'unica considerazione, ovvero il fatto che l'esperienza attivata a Porto Alegre presenta un'impostazione originale e modalità di sviluppo che nel tempo possono farla leggere come esempio 'radicale', come orizzonte e (per taluni aspetti) anche come 'punto di arrivo' che può rappresentare un'utile guida alla lettura di finalità, prospettive e rischi di un'apertura in senso realmente partecipativo dei processi di organizzazione, governo e trasformazione del territorio. Porto Alegre non costituisce un esempio isolato di trasformazione urbana a partire dalla riforma dei processi decisionali di carattere economico-finanziario; non è neppure temporalmente il primo, visto che la sua trasformazione è contestuale ad altre ancora in pieno sviluppo sia all'interno che all'esterno del Brasile. È però un esempio adatto per un'analisi paradigmatica, come riconosciuto anche dall'ONU inserendola tra le best practices premiate nel $1996 .{ }^{10}$ Pare, inoltre, difficile disconoscere come a Porto Alegre si siano sperimentate in questi anni pratiche che hanno cercato di dare un'interpretazione concreta (seppur volutamente e dichiaratamente 'di parte', e quindi 'sbilanciata' sotto il profilo dei 'principi adduttori') di concetti sovente fumosi come lo 'sviluppo locale', la 'sostenibilità', la 'democratizzazione istituzionale', le pratiche di 'cura' del territorio da parte delle comunità abitanti e soprattutto lo 'sviluppo sociale' inteso non come mero 'indicatore' di crescita e progresso urbano, ma come vero e proprio punto di svolta, ovvero come invito a rivedere oggetto e strumenti delle politiche urbane ai fini di un intervento pubblico più efficace e più giusto. ${ }^{11}$ In tale prospettiva, non è da sottostimare neppure il significativo spostamento dei modi di guardare alla povertà e delle strategie proposte per alleviarla che Porto Alegre ha propiziato, in sintonia con i numerosi documenti internazionali elaborati a partire dalla dichiarazione di Recife del marzo $1996 .{ }^{12}$ 


\subsection{Dal contenuto alla narrazione}

Le considerazioni sopra esposte evidenziano da sole come le ragioni di 'metodo' e di 'contenuto' che hanno motivato la scelta dell'esperienza di Porto Alegre come perno di questo libro, risultino inscindibilmente intrecciate. L'esempio risulta, infatti, metodologicamente significativo proprio in virtù dei contenuti che lo hanno animato e lo animano, determinandone i significati, la collocazione politica, l'approccio procedurale e - in ultima analisi - anche gran parte dei risultati e/o dei limiti che ne possono essere sottolineati.

Nei numerosi testi di analisi dei processi di Bilancio Partecipativo usciti in questi anni in diversi paesi, si può riscontrare una tendenza generale al disconoscimento - o, per lo meno, alla banalizzazione - della dimensione spaziale dei processi esaminati, relegata spesso nel ruolo di 'epifenomeno'. ${ }^{13}$ È come se molti ricercatori - quasi nel timore che l'accusa di 'determinismo geografico' potesse sminuire gli aspetti propositivi delle proprie analisi sul campo - avessero volontariamente sottostimato le interconnessioni tra gli spazi e i luoghi che ospitavano le trasformazioni esaminate e i risultati conseguiti attraverso di esse. Sottostimando condizionamenti e conseguenze di ambito spaziale, si è però corso il rischio opposto, ovvero quello di esprimere valutazioni incomplete o distorte su alcuni fenomeni indagati, nel momento in cui i processi di Bilancio Partecipativo sono risultati descritti come se operassero in un "vuoto" e non si contestualizzassero invece in un "pieno", ovvero in luoghi storicamente stratificati dove la spazialità ha inevitabilmente influito sullo strutturarsi delle relazioni sociali al centro dell'analisi. Anche sulla base di queste considerazioni, il presente testo muove dal desiderio di recuperare la dimensione 'territoriale' nella descrizione di uno specifico processo di Bilancio Partecipativo, nella convinzione che sia sempre possibile rintracciare l'esistenza di una 'dialettica socio-spaziale' che aiuta a pensare lo spazio come qualcosa che va oltre la produzione materiale strictu sensu per coinvolgere anche "la creazione e ricreazione costante delle proiezioni spaziali di relazioni di potere e di identità culturali spazialmente referenziate" così come "la forza delle immagini spaziali, delle territorialità e delle identità socio-spaziali influenza i progetti dell'uomo". ${ }^{14}$

Per questo, abbiamo scelto di concentrare il fuoco della descrizione sulla ricostruzione di un 'luogo'. Del resto, la stessa scelta della città di Porto Alegre come terreno privilegiato di indagine, è a suo tempo maturata anche in considerazione del fatto che - tra le più note esperienze di democratizzazione delle politiche territoriali di ambito locale - essa è non solo la più matura e strutturata, ma anche la più 'audace' ('ousada', come si direbbe in portoghese) sotto il profilo delle interrelazioni stabilite tra trasformazioni dello spazio e mutamenti delle relazioni sociali.

Per certi versi, la scelta metodologico/espositiva dello 'studio di caso' si pone in coerenza con questi obiettivi. ${ }^{15}$ Essa ha anche offerto un'ulteriore e interessante opportunità da sfruttare: ricostruire alcuni fili di 'una memoria in pericolo' in una città che mantiene nella sua cultura il ricordo forte di valori e ideali, ma dove spesso svanisce la memoria di importanti battaglie puntuali che per qualche ragione non sono divenute 'memoria ufficiale'.

Lo stimolo ad accettare di deviare parzialmente dai binari inizialmente immaginati per l'articolazione del testo, con l'obiettivo di ricostruire alcuni episodi-chiave per gli sviluppi delle trasformazione urbane di Porto Alegre, è venuto anche dall'ambito 
20 degli studi 'territorialisti' da cui l'autore proviene, dove viene tributata importanza al racconto, all'intervista e alla collazione di documenti informalmente prodotti, e dove si ritiene che mettere l'accento sulle "cose" - sulla materialità del "fare" - non significhi sottovalutare il valore delle "parole", del produrre discorso e, soprattutto, del "fare racconto" e del "tramandare memoria" (Revelli, 1999). ${ }^{16}$

Anche per questo, abbiamo scelto di concentrare l'esposizione su una descrizione eminentemente 'qualitativa' del percorso urbano che il libro analizza, relegando il più possibile alle appendici, ai grafici e alle tabelle di corredo i 'dati numerici' che supportano le analisi.

Le modalità espositive scelte non dissimulano la metodologia dell'osservazione partecipante che ha dato corpo ai contenuti del testo, affiancando alle ricerche negli archivi del Comune e dei Movimenti Popolari ${ }^{17}$ di Porto Alegre vari mesi di sopralluoghi in 'cantieri in trasformazione' della città e oltre 150 interviste (alcune 'aperte', altre più strutturate in rapporto a fattori diversi di opportunità) a personaggi-chiave delle Istituzioni ${ }^{18}$ leader comunitari, ${ }^{19}$ esponenti di movimenti urbani di base, di ONG, del professionismo locale e della Chiesa progressista. ${ }^{20}$

L'alternanza fra parti del testo più di commento ed altre a carattere maggiormente narrativo corrisponde ad una scelta precisa, legata alla volontà di spiegare in un'ottica 'evenemenzielle' (per parafrasare Braudel) eventi che paiono aver inciso notevolmente sulla trasformazione di alcuni elementi delle politiche analizzate, o sull'attuale riorientamento di alcune loro direttrici. I materiali foto-cartografici e le citazioni costituiscono parte essenziale delle riflessioni portate avanti nel testo. In particolare, molta dell'umanità che pulsa nelle interviste o nei resoconti di alcune assemblee politiche o riunioni tecniche a cui si è avuto modo di partecipare costituisce testimonianza fondamentale, specie considerando la necessaria umiltà e le cautele che un ricercatore straniero deve mostrare nell'avvicinarsi e nell'interpretare contesti solo in parte a lui familiari.

Alle voci di questa 'umanità interpretante' e in parte 'giudice dei processi che si svolgono sul suo territorio' abbiamo voluto lasciar ampio spazio, ${ }^{21}$ affinché l'esposizione di contenuti condivisi dall'autore rispettasse anche il modo di comunicarli scelto dagli intervistati. ${ }^{22}$ Non togliere immediatezza a queste voci, appariva, infatti, come un indispensabile segno di rispetto per il quotidiano costruirsi di scelte territoriali plurali e condivise che costituisce il principale 'nodo di senso' della recente storia urbana di Porto Alegre.

$\mathrm{Ci}$ auguriamo che i contenuti e l'articolazione del libro possano rappresentare uno stimolo per altri ricercatori ad affrontare ulteriormente i temi che ne costituiscono il perno, per arricchirli di nuove chiavi di lettura, non solo afferenti a 'sguardi disciplinari' e sensibilità diverse, ma anche concentrati su 'luoghi' e 'territori' differenti.

Il confronto tra 'luoghi' e 'pratiche' diverse può, infatti, rappresentare un importante valore aggiunto per la disamina e la costruzione di teorie e modelli di riferimento per riformare i modi di trasformazione dei territori mirando ad un più autentico coinvolgimento degli abitanti; e tanto più oggi che le sperimentazioni di nuove forme di democratizzazione istituzionale e di dialogo tra società istituente e società istituita $^{23}$ vanno moltiplicandosi e differenziandosi nel pianeta. $\mathrm{Ci}$ auguriamo che questo testo possa costituire un piccolo contributo utile ai fini di questo confronto, senza al contempo rinunciare né al suo valore di 
analisi critica di opportunità e limiti di un'esperienza storica contestualizzata (troppo sovente ridotta a 'mito' astorico e atopico) né al suo obiettivo di fornire elementi di ottimismo 'propositivo' attraverso la disamina di un 'progetto forte' in termini di originalità virtuosa delle scelte maturate e poi proposte a chi vorrà pazientemente esaminarne principi e motivazioni profonde.

Possibilmente senza cedere alla rischiosa mitologia della replicabilità assoluta a cui la superficiale pigrizia e l'acritica disposizione al compromesso di molti documenti internazionali tende oggi ad abituarci.

\subsection{L'articolazione del testo}

Come abbiamo visto, questo libro si propone di parlare di 'partecipazione virtuosa' a partire dalla narrazione di un esempio tutt'ora in corso (e, per giunta, in rapida evoluzione) che proviene dal Sud del Mondo. In quest'ottica cerca di trarre linfa da una struttura 'a clessidra' che parte da un ampio inquadramento di un contesto in transizione dentro cui l'esperienza è maturata, e nelle conclusioni si propone di riallargare brevemente l'orizzonte di riferimento, cercando di coinvolgere il lettore nella riflessione su alcuni passaggi nodali di quanto descritto, che potrebbero risultare utili nell'immaginare una trasposizione in ambiti territoriali differenti dei principi-guida che hanno orientato l'esperienza di Porto Alegre.

In quest'ottica, il testo è articolato in 5 sezioni ideali.

Le sezioni I e II si propongono di entrare nel tema scelto partendo da una ricostruzione della congiuntura sociale, politica ed economica e delle 'condizioni al contorno' del caso selezionato, includendo una panoramica dei modi con cui la Banca Mondiale, nell'ultimo trentennio, ha teso ad appropriarsi del dibattito sul self-help, contribuendo a modificare i panorami nazionali e locali soprattutto per quanto concerne l'intervento sulla città 'illegale', 'autocostruita' o - secondo il termine politicamente corretto oggi in voga - 'informale'. Queste due sezioni non sono da considerarsi meramente 'introduttive' o 'propedeutiche'. Esse si propongono, infatti, di 'entrare in tema' in maniera articolata, e di prporre già alcune riflessioni che torneranno nel resto del testo; soprattutto la sezione II dedicata alla storia di Porto Alegre e dei suoi movimenti popolari prima del 1989.

La Sezione III è dedicata ad analizzare i principali strumenti che Porto Alegre ha costruito o utilizzato in questi ultimi 14 anni per una riforma in senso partecipativo delle politiche territoriali (il Bilancio Partecipativo, quindi, ma non solo), spesso svolgendo un ruolo di 'apripista' in direzione di trasformazioni che hanno poi trovato grande seguito sia in Brasile che fuori.

La sezione IV tratta appunto di alcune di queste politiche, concentrandosi soprattutto su quelle dell' alloggio e della pianificazione urbanistica, nel tentativo di cogliere un importante momento di passaggio (tutt'ora in corso nell' esperienza di Porto Alegre) dalla gestione consensuale del territorio alla sua riprogettazione condivisa. E cerca di farlo a partire dal punto di vista di alcuni progetti, che permettono di offrire un giudizio più articolato a partire da un'adesione più concreta alla materialità e alle peculiarità di alcuni luoghi in trasformazione e del capitale sociale che li struttura. La sezione V ("Apprendendo dal Sud del mondo") cerca, infine, di evidenziare alcune linee di trasformazione attualmente in atto nelle politiche esaminate nel resto del testo, e di condensare quanto finora descritto intorno ad alcune riflessioni; nella speranza che esse possano simboleggiare un 'ponte' verso 
analoghe e costruttive trasformazioni anche nei nostri contesti di riferimento. Il testo è completato da alcune appendici, mirate (come l'elenco degli acronimi usati, o quello dei termini di riferimento del Bilancio Partecipativo) a facilitare la lettura o ad ampliare la riflessione con spunti che vanno al di là dei temi su cui il testo si concentra.

\section{Note}

${ }^{1}$ M. Lopes de Souza (2000) sottolinea che la scala di Arnstein resta valida anche riportando il giudizio sulle 'accezioni' date agli strumenti partecipativi nei termini dello schema concettuale proposto da Castoriadis (1990, 1996a), uno degli autori più utilizzati nella costruzione dei riferimenti teorici dei Bilanci Partecipativi, sulla scorta del quale la discriminante potrebbe individuarsi nei gradi di 'eteronomia' e 'autonomia collettiva' delle decisioni prese in un determinato ambito territoriale.

${ }^{2}$ Una significativa definizione di questo principio - oggi divenuto uno dei principi-guida dell'Unione Europea - si trova nell' articolo 3B del Trattato di Maastricht del 1992. Il concetto, seppur non il termine, è però ben più antico: Il principio di sussidiarietà é uno dei fondamenti della Dottrina Sociale della Chiesa. Di esso si trovano tracce già in autori come San Tommaso d'Aquino, nel padre del giusnaturalismo (Giovanni Althusius) e - in tempi più recenti - nella Rerum No varum (1891) di Leone XIII, e nell'enciclica Quadragesimo Anno (1931) di papa Pio XI.

${ }^{3}$ Il principio di sussidiarietà tende oggi ad essere letto a diversi livelli di articolazione, uno dei quali invita lo Stato a non intervenire laddove i cittadini e loro aggregazioni sociali (famiglia, associazioni ed altri cosiddetti “corpi intermedi") possono fare da soli, con la motivazione che l'uomo é principio, soggetto e fine della società e gli ordinamenti statali devono essere al suo servizio, lasciando che possa impegnare la propria creatività e iniziativa con senso di responsabilità personale e collettiva. Il riconoscimento di un diritto naturale degli individui a non vedersi spogliati del loro potere di esercitare ogni attività che sono in grado di svolgere per trasferirla invece alla comunità, verrebbe esteso per analogia anche alle organizzazioni sociali ed istituzionali, in base a considerazioni di giustizia e di opportunità sociale; dal momento che i legami sociali sono funzionali all'espressione delle capacità individuali, anche le organizzazioni minori non devono essere spogliate delle loro prerogative fin tanto che sono in grado di assolvere ai propri compiti. Il sacrificio dell' autonomia sarebbe giustificato solo se questo fosse il solo modo per raggiungere risultati altrimenti preclusi. Nel rispetto della radice latina del termine (da subsidium, aiuto) ogni intervento di ordine 'superiore' dovrà essere portato dal livello più vicino al cittadino e avere carattere di temporaneità, durando solamente il tempo necessario a consentire ai corpi sociali di tornare ad essere indipendenti. Uno dei nodi centrali ancora insufficientemente risolti dalle interpretazioni correnti è se la sussidiarietà implichi anche il mantenimento della sovranità da parte dei soggetti che raggiungono l'accordo (quindi implichi la sua revocabilità) oppure attraverso l'accordo stesso il trasferimento di sovranità divenga definitivo. Diverse sono anche le idee riguardo l'effettivo contenuto ed il conseguente raggio d'azione del principio, che in molti contesti nazionali (e ormai anche in vari documenti internazionali) tende ad essere esteso dal livello 'verticale' ad un livello definito di 'sussidiarietà orizzontale' in base a cui definire mansioni ed obblighi reciproci del pubblico, del privato e del cosiddetto 'terzo settore'.

${ }^{4}$ Il ridondante e confuso documento deve la sua genericità e la sua verbosa ridondanza (che tendono ad annacquare le migliori conquiste ivi codificate) ai molti navigati 'conferenzieri professionisti', agli 'insiders' di varie organizzazioni finanziarie internazionali che ivi ricoprivano ruoli-guida, alla forza di corporative categorie di tecnici che si occupano di problemi dell'habitat e del territorio (il cui linguaggio è generalmente ritenuto dei più sibillini) ed alla cooptazione di molte ONG nella 'tenda dell'ONU' che ha diminuito la 'tensione creativa' fra le prospettive istituzionali e non governative che aveva caratterizzato altri Vertici; ma vi è soprattutto la traccia delle numerose pressioni diplomatiche delle molte delegazioni nazionali orientate in direzioni contradditorie ma tutte per lo più mirate " $a d$ ottenere un documento non troppo compromettente per se stessi ed il più possibile compromettente per coloro il cui impegno dovrebbe andare a loro vantag gio" (Wakely, 1996).

${ }^{5}$ Arnstein, cita ta in D. Day (1997).

${ }^{6}$ Il riconoscimento che la città è prima di tutto dei cittadini che la abitano e che questi non possono non essere protagonisti del suo destino, è certamente una delle maggiori novità dell' Agenda Habitat, della quale è possibile dare due letture: una che seleziona i punti specifici in cui di partecipazione si parla, ed una seconda che li inserisce in quel contesto più vasto che scaturisce da una sua lettura complessiva, e dall'immagine di città che emerge dall'intero documento. Le due letture non sono ovviamente del tutto contraddittorie, ma affermazioni che prendendo alla lettera singoli passi del testo paiono netti e definitivi aprono invece conflitti e contraddizioni interne al summit e agli stessi docu- 
menti ufficiali prodotti?

${ }^{7}$ In cui i lacci con gli altri livelli non sono di puro trasferimento (Calame e Tasmant, 2001, p. 133).

${ }^{8}$ Cfr. Calame e Talmant, 2001,p. 148.

${ }^{9}$ Uso il termine per semplicità, ma dichiaro fin d'ora la mia avversità a questa forma di classificazione dei Paesi del mondo, così come all'ipocrita definizione di ‘Paesi in Via di Sviluppo' a cui cercherò di far riferimento il più raramente possibile nel testo, sebbene essa faciliti il raggruppamento di realtà diverse in base a problematiche affini concernenti il territorio, la giustizia sociale, la situazione finanziaria nazionale o il ruolo riconosciuto nei consessi internazionali.

${ }^{10}$ La descrizione fattane nello schedario della 'Together Foundation' (disponibile anche su Internet, con gradi diversificati di accesso all'informazione per i diversi tipi di utente) è anzi tutt'altro che esaustiva, e non risulta neppure 'attraente' per osservatori e studiosi che non conoscessero l'esperienza già da prima e sulla base di fonti più rappresentative e meglio curate. Per un commento su limiti e potenzialità della pratica della schedature delle 'esperienze eccellenti', cfr. Allegretti 2000a (cap. 2). ${ }_{11}$ Osserva Zetti (1998): “È esistita in passato una tradizione storicista, e anche un'idea marxista di ineluttabilità del progresso, che tendeva a compiere un'equazione fra efficacia e giustizia, oggi alla giustizia è stata sostituita l'idea di sostenibilità, per cui ciò che è efficace diviene allo stesso tempo sostenibile e, forse, giusto [... e e la sostenibilità diviene addirittura fonte di diritto, anche internazionale Non si ripropone più il dilemma fra società auto-diretta e razionalità strumentale(Limbdolm, 90), tipico di uno sviluppo che richiedeva l'industrializzazione e che in qualche misura poteva essere problema per il summit di Vancouver, bensì tra società auto-diretta e r azionalità globale finanziaria". ${ }^{12} \mathrm{~A}$ Recife si è convenuto che la pover tà non è più solo mancanza di potere d'acquisto o vita al minimo livello di sussistenza, ma anche "disprezzo della società, emarginazione nello spazio urbano, degrado ambientale, difficile accesso ai servizi, alle decisioni, alla giustizia, all'informazione all' istruzione e al diritto di cittadinanza", e che la città riflette la povertà della sua popolazione in processi di segregazione spaziale, ma anche in processi di "isolamento delle realtà che contano" applicati alla sfera sociale (Garau, 1996) marginalizzazione di alcune sue parti economicamente non vincenti, che dovrebbe essere combattuta, sempre secondo la dichiarazione di Recife, riconoscendo le capacità dei pover i e ripristinando la loro dignità. La stessa World Bank ha proposto di recente un passaggio da concetto di povertà urbana a quello di vulnerabilità (si veda in proposito Moser C., Confronting Crises: A Comparative Study of Household Responses to Poverty and Vulnerability in Four Poor urban Communities, Environmentally Sustainable Development Studies and Monographs Series n.8, Washington DC, World Bank 1996, o anche Bahar ouglu D., Becoming a citizen to be a partner in socially sustainable urban settlements, Town and World Planning Review, 19 (2) 1997).

${ }^{13} \mathrm{M}$. Souza (2000) sottolinea che questa banalizzazione corrisponde ad una difusa negligenza delle scienze sociali nei confronti dello spazio, particolarmente evidente nell' ambito della critica marxista. Autori come Lef ebvre (celebre padre della 'dialettica socio-spaziale', cfr. 1983), Harvey (1989) e Soja $(1980,1996)$ rappresentano evidentemente illustri eccezioni, che oggi vedono ampliarsi il seguito ai propri insegnamenti.

${ }^{14}$ M. Lopes de Souza (2000), pag. 40.

${ }^{15}$ La letteratura che si occupa di ricerca nelle scienze sociali e territoriali tende a identificare la strategia basata sul 'caso di studio' (CaSt) come la più adatta a descrivere processi di trasformazione in corso su cui il ricercatore ha scarso o nessun controllo e di cui interessa cogliere nessi causali e qualitativi fra fenomeni attraverso fonti multiple (Yin, 1984). In particolare, essa pare significativa per esaminare problemi legati alla pianificazione in momenti di crisi o passaggio e in relazione a politiche territoriali incentrate su approcci qualitativi ai problemi (Yin, 1993), e per processi decisionali di interazione con la comunità in ambiti di cui interessi capire le condizioni peculiari di contesto come componente strutturante del fenomeno analizzato. Il metodo del Cast è parso, pertanto, il più adatto a esaminare un ambito come quello delle trasformazioni in atto a Porto Alegre a seguito del mutare degli indirizzi internazionali e di molte realtà locali relativamente ai temi della democratizzazione istituzionale, ma anche dell' autocostruzione e della regolarizzazione fondiaria. Riguardo a tali questioni, infatti, tendono oggi ad essere evidenziati non più solo gli aspetti di generalizzabilità e replicabilità degli interventi, ma sempre più spesso le connessioni con le peculiarità d'uso degli strumenti normativi e gestionali in rapporto agli sviluppi delle società, dei territori e degli assetti istituzionali locali.

16 'Lo spazio pubblico è, per certi versi in primo luogo, uno spazio discorsivo e comunicativo. E' abitato e intessuto di simboli, di immagini, di parole. Si afferma e si consolida attraverso il linguaggio' (Revelli, 1999).

${ }^{17}$ Secondo quanto suggerito da Zaniratti (2000) nel seguito preferiremo la dicitura 'Movimento/i Popolare/i' a quella di Movimenti Sociali, per considerare l'insieme del Movimento Sindacale e Comunitario (specialmente le Associazioni di Vicinato, i Sem Terra, i Sem Teto, il Movimento di Lotta 
per la Casa ecc.), evitando però di includere nella definizione generica anche organizzazioni tipo Tradição Família e Propriedade (TFP - che ebbe un ruolo decisivo nella preparazione del golpe militare e oggi sopravvive con poche variazioni di impostazione), la Marcha com Deus pela Propriedade e pela Família del 1964 o os Caras Pintadas del 1992, che poco hanno a che vedere con movimenti di lotta permanente e di carattere classista, o articolati nella difesa di settori economicamente, politicamente, culturalmente, socialmente oppressi alla ricerca di un riscatto.

${ }^{18}$ Tra questi i tre Sindaci che hanno governato Porto Alegre fino al 2002.

${ }^{19}$ La scelta degli intervistati è stata coscientemente fatta tra persone già inserite nei sistemi di partecipazione cittadina. Dovendo il ricercatore imporsi delle scelte di campo per orientare il suo lavoro e il lettore, si è ritenuto che non fosse interessante intervistare esponenti della pur consistente massa di persone che non prendono parte alle diverse istanze di dialogo fra cittadini e istituzioni, o tecnici legati a metodi di lavoro tradizionalisti che a buon diritto possono ritenersi superati nei 14 anni di governo scelti come periodo privilegiato di esame.

${ }^{20}$ Principale obiettivo dei molti incontri con tecnici, amministratori comunali e rappresentanti dei movimenti urbani è stato solo in parte supplire alla mancanza di elaborazioni, memorie e commenti scritti, e di valorizzare la 'cultura della trasmissione orale' che sopravvive anche all'interno di molte Istituzioni brasiliane. Interessava, infatti, soprattutto mettere a confronto punti di vista differenti anche quelli dichiaratamente 'partigiani' che è stato necessario 'ri-tarare' e collocare in un contesto critico più ampio - non solo sull'esperienza del Bilancio Partecipativo, ma soprattutto sul suo peso nella trasformazione degli strumenti di intervento sulla cosiddetta 'città informale'. Questo era fattibile a patto di porre gli uni di fronte agli altri approcci e valutazioni della 'società civile', della 'società politica' e - ci si passi il neologismo - della 'società tecnica'. Per minimizzare il rischio di essere 'catturati' in una cerchia ristretta di persone in sostanziale armonia (rischio implicito nella natura della metodologia dell'osservazione partecipante) abbiamo contattato anche alcune autorevoli vocifuori dal coro (sia a livello di movimenti popolari che di opposizione politica e di critica interna alla coalizione del Fronte Popolare o ai suoi funzionari), e, soprattutto, si è condotto un lungo - e costoso - lavoro di ricerca presso l'archivio del principale quotidiano di Porto Alegre, che non hai mai sottaciuto la sua posizione di forte opposizione all'Amministrazione in carica. Dire che da queste 'voci off' si sono tratte notizie utili sarebbe insincero; i contrappunti significativi raccolti sono parsi sostanzialmente 'poveri', e non hanno offerto più spunti critici di quanti - con onesta capacità autocritica - sono giunti dall'interno delle stesse strutture comunali e dagli abitanti.

${ }^{21}$ Le 'testimonianze' raccolte in loco sono identificate da una ' $i$ ' che segue il cognome o il nome dell'intervistato e la data. In bibliografia le interviste citate costituiscono una voce separata.

${ }^{22}$ Per convenzione, si è scelto di controbattere le affermazioni citate, laddove non se ne condivida il senso o il modo di esprimerle, in tutto o in parte. Negli altri casi implicitamente facciamo nostre tesi, argomentazioni e modi di esposizione di altri, senza arrogarci il diritto di appropriarci di essi come se fosse una nostra personale elaborazione.

${ }^{23}$ Usiamo volutamente termini e categorie della rilettura che Castoriadis ha fatto delle tesi di Gramsci, per non impelagarci nel concetto ambiguo di società civile e nel suo antagonismo/complementarietà con le istituzioni. (1982) ha contestato su queste basi la capacità prefiguratrice delle teorie marxiste, sostenendo che - ad esempio - l'adozione di politiche appropriate può rallentare (e rendere solo parziale) la trasformazione delle case autocostruite in beni di scambio soggetti a rapida gentrificazione (ovvero al passaggio in mani via via più ricche con espulsione dei proprietari più poveri). 
Sezione Prima

\section{Le condizioni al contorno}





\section{II quadro internazionale: percorsi autonomi si toccano}

\subsection{L'inizio del dibattito sull'auto-aiuto}

Nel momento in cui l'edilizia, attività umana universale, viene ad essere definita in quanto problema, nasce un'industria dei problemi delle abitazioni, con un esercito di esperti [...] garanzia del fatto che il problema non verrà mai risolto. John Turner [...] appartiene a un gruppo di pensatori che, operando in campi diversi, spesso senza conoscersi, hanno riportato dai paesi poveri lezioni di valore immenso per i paesi ricchi (Colin Ward, in Turner, L'abitare autogestito, 1976).

L'impostazione del numero monografico dell'agosto 1963, dedicato dalla rivista Architectural Design (AD) a discutere alcuni esempi di edilizia popolare in Sudamerica e corredato di immagini-shock mai pubblicate prima, innescò un forte dibattito mantenutosi vivo per tutti gli anni ' 60 e parte dei ' 70 . Il curatore, John Turner, enfatizzò il significato universale di un'analisi della produzione 'informale' di alloggi, la "necessità vitale che le agenzie che si occupano di abitazione si accordino con le risorse e gli sforzi popolari” e il ruolo che andava riconosciuto al quotidiano miglioramento dell' ambiente della famiglia e della comunità locale - case, strade e soprattutto luoghi d'incontro - come "parte integrante e necessaria dello sviluppo economico".

La rivista puntava a mettere al centro della discussione il ruolo delle politiche abitative ed urbanistiche nei Paesi Terzi, la ridefinizione delle responsabilità dei professionisti coinvolti negli interventi e la necessità di riconoscere che l'autocostruzione rappresenta una soluzione istituzionalizzabile ai fini di una più rapida e soddisfacente fornitura di alloggi per gli strati più poveri della popolazione, in grado di coinvolgere i futuri abitanti nella costruzione del loro habitat e di renderli partecipi di un miglioramento progressivo dei servizi, dell'estetica e della gestione degli insediamenti anche potenziando le pratiche cooperative e di mutuo appoggio.

Il numero di $A D$ - attraverso schede e case-history - descriveva il processo che aveva portato il Governo peruviano a riconoscere che ciò che non si poteva cambiare andava perlomeno legalizzato, e a cominciare a concedere - dal 1963 - titoli di proprietà dei lotti occupati, ottenendo dalla Banca Interamerica- 
28 na di Sviluppo (BID) i prestiti per questa prima ingenua formalizzazione. ${ }^{1}$ Un punto fondamentale dell'impostazione del numero 8/63 di $A D$ era la sottolineatura delle speciali e importanti caratteristiche individuali di ogni contesto per rimarcare, anche analizzando o criticando i tentativi istituzionali di risposta al problema dell'alloggio, la necessità di forme di diffusione dei saperi tecnici che - tramite l'istruzione e l'esempio - portassero ad un rispetto delle caratteristiche estetico/culturali e dei modi di vita di ambito locale nella costruzione o nel miglioramento degli insediamenti. Veniva altresì apprezzato ogni impegno istituzionale mirato a promuovere lo sviluppo comunitario come strumento di democratizzazione della politica e veniva lodato il coraggio dei primi esperimenti istituzionali di costruzione di 'planned squatter settlement', sorta di 'Sites \& Services' ante litteram. ${ }^{2}$

Il numero 8/63 di $A D$ resta un approccio al tema dell'alloggio confinato settorialmente, mancando spesso di cogliere interconnessioni con più vaste problematiche socio-economiche o normative ${ }^{3}$ e con il cambiamento del ruolo dei poteri pubblici da finanziatori/costruttori a coordinatori/promotori, pur annunciato come auspicabile e inevitabile. Esso dà già la misura di un limite del pensiero turneriano che apparirà chiaro anche successivamente: mentre la pars destruens pare generalmente incontrovertibile nell'esprimere con incisività, creatività e chiarezza intuizioni diffuse sulla crisi del tradizionale sistema dell'housing, quella costruens appare troppo strettamente legata all'esperienza latinoamericana dell'autore, e pertanto necessita di lavori di innesto e potatura per adattarla a realtà differenti in cui la traduzione del metodo dell'autocostruzione dal terreno dell'abusivismo alla normalità di una prassi amministrativa legittima, contribuirebbe solo "a ricacciarci al di qua dell'era dell'edilizia sociale gestita da organizzazioni burocratiche centralizzate" ${ }^{4}$ Esso resta comunque di notevole significato nell'ambito dei dibattiti sull'housing per numerose ragioni:

1) l'esplicito rifiuto opposto dai suoi curatori a soluzioni populistiche, paternalistiche e caritative che "indulgono in progetti isolati", a pro di "una coltivazione di tutte le risorse individuabili" of ferte dai "reticoli laterali di informazione e decisione", per l'individuazione dell'edilizia come terreno di soluzioni piuttosto che come problema;

2) la polemica veemente contro ogni ricerca sterile in materia di tecniche e design che non possa essere effettivamente e diffusamente utilizzata a vantaggio dei cittadini più poveri $;^{5}$

3) il contributo offerto alla già vitale ma sotterranea discussione sul self-help e la partecipazione popolare, rilevando la necessità di esaminare come e perché risorse produttive sotto condizioni spontanee possano perdere la loro vitalità creativa e addirittura morire quando istituzionalizzate;

4) infine, per aver dato risalto anche in Occidente al dibattito sulle nuove frontiere da dare nei Paesi Terzi alle housing policies come luogo del lavoro dell'istituzione con la gente e non solo per la gente, dove dare fiducia e lasciare spazi reali di iniziativa alle famiglie partecipanti ai programmi abitativi e alle loro capacità autorganizzative, per mettere in atto una vera strategia di cooperazione fra i cittadini e il governo. ${ }^{6}$

I dibattiti innescati in seno alla comunità professionale e scientifica internazionale, saranno alimentati negli anni successivi dallo stesso Turner attraverso una serie di provocazioni e articoli su riviste di urbanistica e architettura 
di vari Paesi. ${ }^{7}$ In un clima animato in parallelo dalle enunciazioni di autori quali Illich, Goodman e Schumacher, esse finiranno per trovare - soprattutto in seguito all'intervento di Turner al Seminario dell'ONU di Pittsburgh sugli Insediamenti Incontrollati (1966) - alcuni punti di contatto con le teorizzazioni a carattere operativo sviluppate in seno ad alcune Istituzioni Internazionali, e talora per essere usate come legittimazione di forme di intervento pubblico più o meno discutibili in diverse nazioni.

\subsection{L'avvio di un importante dibattito}

Come osserva Van der Linden(1986), l'errore maggiore fatto da Turner e, soprattutto, dalla sua cerchia di seguaci è stato generalizzare ed internazionalizzare teorie sovente legate a doppio filo con contesti in cui privilegi relativi (come la disponibilità di aree e materiali di risulta offerti da centri storici fatiscenti, la disorganizzazione politica e legale e la tradizione fortemente politicizzata) costituivano elemento di 'riequilibrio' delle condizioni materiali di gruppi sociali in condizioni di estrema miseria. Le principali critiche ricevute dall'impostazione turneriana sono giunte dall'ambito neomarxista, essendo i suoi maggiori accusatori Pradilla (1979) e Burgess (1985). ${ }^{8}$ L'accusa principale mossa alla filosofia di Turner è stata di aver depoliticizzato al contempo la questione dell'alloggio (che, non essendo vista come isolabile dal modo di produzione capitalista, renderebbe un semplice palliativo ogni soluzione non mirata a ridurre a monte lo sfruttamento dei poveri) e lo Stato, legato anch'esso ai poteri dominanti e che - a meno di sue riforme radicali - difficilmente potrà intervenire a garantire un'equa distribuzione delle risorse e dell'accesso di tutti ad esse. In tal senso, la principale accusa mossa a Turner dai critici neomarxisti è di reazionarietà mascherata sotto le forme di una sorta di ingenuità; come se Turner fosse stato incapace di rendersi conto di come la teoria del self-help proposta avrebbe potuto solo essere saccheggiata nelle sue parti più 'convenienti' (come nella realtà avverrà con le strategie messe in atto dalla World Bank) da qualsiasi governo a matrice non socialista, interessato alla teoria dell'autogestione a motivo dei bassi costi e della possibilità di pacificazione sociale che introduce, mettendo a tacere parte delle richieste fino ad allora levate a gran voce dai cittadini più disagiati. ${ }^{9}$

Questo dibattito ha ben presto finito per diventare uno scontro di monologhi fra persone che parlavano linguaggi diversi (Van der Linden, 1986) $i^{10}$ anche $i$ tentativi di rivitalizzarlo compiuti da Turner e Burgess nel 1982 sono alla fine approdati ad un nulla di fatto. In ogni caso, il dibattito ha avuto poca eco al di fuori dei circoli accademici, non arrivando a fornire soluzioni alternative a quelle prospettate da Turner. Di queste, nel frattempo, si appropriavano però a fini operativi - alcune istituzioni internazionali. Il filone più interessante di prosecuzione del dibattito è stato quello rappresentato da Castells nel suo studio sui movimenti sociali (1982), e da Harms (1982), concentrato a sottolineare che il self-help non è un bene o un male in assoluto, ma piuttosto un Giano bifronte, un'arma a doppio taglio che può risolversi in risultati positivi o negativi talora difficilmente discernibili sia in relazione al pensiero dei teorici e dei pianificatori che del rapporto costi/benefici della popolazione coinvolta.

In ogni caso, l'idealizzazione del metodo della 'baracca abusiva' attribuita a Turner da alcuni detrattori si è dimostrata un'artificiosa forzatura, tesa a 
30 banalizzare e denigrare un'ipotesi organizzativa di politica della casa in realtà incentrata su una 'pianificazione centrale' dell'equo accesso per tutti alle risorse (terra, materiali, informazione, democrazia delle scelte) a scala locale, e su un successivo volontarismo organizzativo che può - e non necessariamente deve - sfociare nell'autocostruzione o perlomeno nell'autogestione della propria abitazione da parte di proprietari-abitanti. La necessità più volte espressa da Turner di pervenire a prassi legislative e amministrative 'leggere' prima di poter mettere in opera 'tecnologie leggere' (senza scontrarsi con le tradizionali rigidità né cadere nel puro e semplice lassaiz-faire), esprimeva in realtà la coscienza della necessità di una rivoluzione culturale e antiburocratica come pre-condizione per un'applicabilità dei metodi proposti nella maggior parte dei contesti dove la mancanza di improcrastinabili emergenze di grandi dimensioni consigliasse un passaggio graduale dalla sfera dell'essere osservata a quella del dover essere proposta.

Tra le critiche più fondate agli scritti di Turner, si può annoverare invece uno dei punti rimasti più in ombra nella sua opera: il tema cioè di tutte quelle attrezzature comunitarie "che fanno di una distesa di abitazioni un luogo di vita e di scambi sia materiali che immateriali", il cui significato "vada oltre la semplice esperienza della singola famiglia isolatamente intesa" (Ronza, 1978). La carenza di queste - non esplicitamente rilevata - nei contesti esaminati da Turner, non rappresenta, infatti, una giustificazione dell' 'assenza teorica', semmai dovrebbe allertare sul grado di inquinamento (id.) e di colonizzazione di una cultura popolare sradicata e messa sotto pressione da modelli di vita individualisti veicolati dall'ambiente cittadino e dai media come miti entrati ormai radicati nell'immaginario sociale collettivo.

Tale debolezza teorica ne illumina una ulteriore, tanto più grave se si volesse passare ad una generalizzazione delle teorie turneriane in contesti diversi: il rischio che la 'spontaneità' intesa meccanicamente si risolva in una conferma definitiva di un asservimento dei desiderata a modelli culturali in rapido avvicinamento a quegli schemi comportamentali e tipologici che parevano così lontani da quelli in vigore nelle aree occupate ed autocostruite da cui lo studio di Turner era partito. ${ }^{11}$ Ed è proprio questa seconda 'assenza' - quella dell'affermazione cioè di un necessario recupero identitario che preceda la ricostruzione autogestita degli ambienti abitativi - a rappresentare la debolezza maggiore della linea di metodo indicata da Turner, cioè quella che darà i maggior appigli alla Banca Mondiale per agganciarsi al suo pensiero.

Accanto ad essa si colloca poi la considerazione sulla validità teorica universale della tipologia di casa monofamiliare ampliabile ad un piano delineata da Turner come ideale per una 'totale autocostruzione', non certo proponibile in contesti densi o storicizzati. Anche in questo caso si evidenzia la necessità di riformulazione di alcuni principi-chiave (autocostruzione, variabilità nel tempo dell'alloggio, realizzazione graduale di questo e dei servizi di supporto e completamento) nel passaggio dall' ambito territoriale dove avvennero le prime formulazioni delle teorie di Turner a condizioni differenti. In quest'ottica, la ripresa di creatività culturale e di identità territoriale che Turner in alcune parti della sua opera adombra nell'insistere sulle caratteristiche differenti dei vari contesti, ${ }^{12}$ richiederebbe una componente previa di 'progettazione col$t a$ ' e una riforma normativa maggiori di quelle che lo stesso autore esplicitamente rileva, non ponendosi egli - ad esempio - né il problema del pericolo 
dell'ovvietà architettonica, né quello della continuità degli spazi, né quello della variabilità temporale delle tipologie di alloggio e dei bisogni (non solo naturali ma anche culturalmente o economicamente indotti) che nella realtà di ogni giorno stanno dietro ai modi di strutturazione delle abitazioni.

Infine, nel limitarsi ad un' analisi quasi settoriale del tema dell'alloggio, Turner non è sembrato porsi due questioni importanti come quella del significato degli aggregati sociali collettivi (quartieri, villaggi, città) che rappresentino qualcosa di più che semplici giustapposizioni di nuclei familiari, e la questione della gentrificazione, pur sostenendo egli una posizione che implicitamente pare far riferimento alla necessità di vincolare le case autoprodotte all'uso diretto dei loro realizzatori, sottraendole quindi ai meccanismi della rendita di posizione. Con queste premesse ha una sua validità la definizione di rivoluzione copernicana dimezzata con cui Ronza (1978) designa il corpus delle principali teorie di Turner sull'autogestione abitativa.

\subsection{Il percorso della Banca Mondiale: dalla negazione alla riscoperta del- la città}

Per dare una misura del quadro internazionale degli interventi sulla città - e soprattutto sul tema dell'housing - nel quale si colloca l'esperienza di Porto Alegre, può essere utile richiamare brevemente il percorso compiuto dalla Banca Mondiale, istituzione finanziaria internazionale che ha rivestito un ruolo importante nelle trasformazioni delle politiche urbane e dell'alloggio avvenute nell'ultimo trentennio.

Durante i suoi primi decenni di vita (come le altre Istituzioni Finanziarie Internazionali nate a Bretton Woods), ${ }^{13}$ la Banca Mondiale ha teso a disinteressarsi dei fenomeni urbani, compiendo l'errore di non applicare all'urbanizzazione la teoria dei rendimenti decrescenti che già da un secolo Ricardo aveva messo in relazione con lo sviluppo agricolo. Anzi, i forti investimenti in centrali energetiche o sistemi trasportistici che raramente toccavano le città hanno contribuito ad evidenziare - a contrariis - il disinteresse per le fasce più svantaggiate della cittadinanza e la concezione dello spazio urbano come mero supporto per la crescita alla scala macroeconomica, a dispetto di proclami contenuti in testi come Urbanisation (1972) che simulavano di attribuire a quei progetti un inesistente ruolo di 'gestione delle città'.

Per 25 anni, la Banca Mondiale ha diffuso una visione negativa delle città come luoghi privilegiati degli investimenti pubblici non produttivi sovvenzionati dallo Stato perché indispensabili strumenti di regolazione sociale (alloggi economici, attrezzature collettive a vocazione sociale ecc.). Ha teso perciò ad ignorarla - sia come oggetto di studio che di intervento globale -, leggendola prioritariamente come 'centro di consumo' e al massimo come supporto parziale dello sviluppo economico a cui si legavano grandi infrastrutture. Questo atteggiamento dicotomico, incentrato su una divisione dei ruoli fra lo Stato e gli investitori privati e tra le sfere della produzione e della riproduzione nell'attività economica, costituiva all'epoca un modo di operare comune, alla base di tutto il piano Marshall (1947-1952) in base a cui si è strutturato l'aiuto alla ricostruzione dell'Europa dopo la $\mathrm{II}^{\circ}$ Guerra mondiale.

È più o meno verso il 1970 che la città fa la sua comparsa tra gli 'oggetti di interesse' della Banca Mondiale, in virtù delle possibilità offerte ad evidenti 
economie di scala, assumendo un'importanza strategica crescente all'interno del movimento di globalizzazione dell'economia e degli scambi. Nel frattempo, organismi regionali come la CEE o il BID (Banca interamericana di sviluppo) si erano già impegnati in progetti legati al miglioramento dell'habitat; e altre branche del sistema internazionale dell'ONU come la FAO, l'UNICEF, l'UNESCO e l'OMS mostravano di interessarsi al tema. ${ }^{14}$ Il primo accenno corposo da parte della Banca Mondiale al problema dell'urbanizzazione risale al Rapporto annuale del 1970, mentre il primo interessamento 'ufficiale' per il settore degli interventi urbani data 1972, quando in un discorso pronunciato in Cile, il presidente dell'organismo multilaterale sostenne la necessità di interventi di miglioramento dei parametri di equità sociale e delle condizioni di vita dei più poveri abitanti delle città, al fine di renderli più produttivi (McNamara, 1982). Il secondo importante discorso sul 'settore urbano' fu quello pronunciato davanti all'Assemblea dei Capi di Govemo a Washington nel 1975, dove McNamara sostenne la necessità di rivalutare il ruolo delle città come 'attore storico' nei processi di sviluppo e di elaborare strategie per combattere la povertà urbana, centrandole su accresciute opportunità di guadagno nel settore informale, e impieghi nel settore moderno. ${ }^{15}$

Dopo ognuno dei due discorsi, i nuovi progetti della Banca - guidati dal motto 'giustizia sociale e produttività del lavoro' - furono esposti in altrettanti opuscoli che ancora oggi costituiscono tra i più importanti documenti 'sintetici' per comprenderne le linee di sviluppo: Urbanisation, del giugno 1972, e Habitat, sectorial policy, del 1975. Dopo quest'ultimo, i primi isolati esperimenti di intervento-pilota furono trasformati in modello operativo da generalizzare. La stessa terminologia usata subì una trasformazione: se dal 1972 si adottò la categoria esplicativa dell'urbanizzazione, dal 1978 si introdusse nei rapporti annuali quella di sviluppo urbano, e dal 1980 quella di urbanistica (o urbanismo) per indicare gli interventi nel settore urbano, per poi tornare nel 1994 alla categoria dello sviluppo urbano (Allegretti 2000a, Osmont 1995).

Attraverso una strate gia cognitiva ramificata ed articolata, la World Bank cercò strumenti di conoscenza puntuale delle realtà dove intervenire, nonostante l'interesse per la ricerca di 'strategie locali' sia sempre stato praticamente nullo. L'interesse manifestatosi nelle scienze sociali, dagli anni '50, per i fenomeni di urbanizzazione delle città dei Paesi in Via di Sviluppo era stato fatto proprio dall'UNESCO subito dopo la Conferenza di Abidjan del $1954^{16}$ anche attraverso la realizzazione di due opere regionali sullo stesso tema relative all'Urbanizzazione in Asia e America Latina. L'etnocentrismo metodologico' (Osmont, 1995) che aveva contraddistinto questo genere di analisi - sviluppandosi attraverso opposizioni che riducevano i fenomeni in termini di dualismo culturale e sociale (città/campi, permanenza/cambiamento, modernità/tradizione) - fu ripreso nel settore economico, dando vita a studi sulla marginalità urbana, il rapporto tra legale/illegale, e (in numero minore) sulle subculture urbane, le pratiche adattive di reinterpretazione e risemantizzazione dei vecchi modelli di sociabilità e le nuove creatività sociali. ${ }^{17}$ In seguito tese a svilupparsi un asse di studi legato alla ricerca operativa, il cui primo esempio di ambito internazionale fu il Rapporto delle $\mathrm{Na}$ zioni Unite sull'habitat in Africa del 1965, redatto sulla base delle teorie sullo sviluppo del momento ed articolato in una parte di stima dei bisogni (ispirata ad una visione pianificatoria ma corretta dalla considerazione della 
domanda solvibile), in una parte di programmazione apparentemente centrata sulla ricerca riguardante le norme costruttive adatte ai diversi modi di vita e alle istituzioni dei differenti Paesi (ma in realtà ispirata ad un preciso parallelo con i Paesi sviluppati), in una di esaltazione dell'industria edilizia come motore dello sviluppo, ed in una conclusiva ancora incapace di andar oltre lo stadio di raccomandazioni metodologiche e riassunto generale dei dati.

È proprio a questo filone che attinse la Banca Mondiale negli anni ' 70 , nel decidere di interessarsi all'intervento sulle città. Ciò avvenne in parallelo alla realizzazione della Conferenza dell'ONU di Vancouver dove fu ribadita una delle principali tesi della World Bank sugli "insediamenti umani come strumento di sviluppo che incide sulla produttività dei cittadini", ma fu anche affermata la necessità di adattare, con realismo, ogni intervento alle condizioni locali, associando direttamente le popolazioni interessate e i loro rappresentanti (specie le ONG) alle scelte e all'esercizio delle attività di sviluppo. Con la creazione dell'UNCHS di Nairobi si ebbe una graduale crescita della letteratura a carattere operativo e settoriale sugli interventi possibili, specie nell'ambito dell'habitat spontaneo e della riorganizzazione dei servizi urbani. Gli studi servirono anche "per dare una legittimazione ideologica agli interventi di organismi internazionali e per controllare dall'esterno le politiche nazionali dell'habitat" (Osmont, 1995, pag. 46).

Nell'ambito del sistema delle Nazioni Unite, la Banca Mondiale ha teso - a partire dal 1976 - a ritagliarsi un ruolo particolare di produttrice di una dottrina e di una strategia operativa lineare e martellante (che dovrà comunque modificarsi nel tempo a contatto con la realtà), lasciando ad altri organismi sia la produzione ideologica che la diffusione delle conoscenze più originali. Ma la conoscenza prodotta resterà sempre 'banalizzante' nei confronti dei territori descritti e portatrice di una visione parziale, al punto che la Banca deciderà di non pubblicare alcune valutazioni di progetti non ben riusciti, come nel caso del primo progetto urbano del Senegal. ${ }^{18}$

Dal punto di vista operativo, due furono le strategie complementari individuate dalla World Bank fin dal 1972 per intervenire sulla povertà urbana e sulle strutture fisiche cittadine. Definite nell'insieme 'approccio combinato' o 'twin approach' (Van der Linden 1986) esse ebbero da subito il chiaro obiettivo di tradurre settorialmente lo sviluppo nella gestione della città, e di costituirsi come progetti di trasformazione sociale attraverso:

1) il miglioramento e il recupero (upgrading) degli insediamenti spontanei infraurbani attraverso la regolarizzazione del loro stato di occupazione dei suoli e la fornitura di servizi 'di prossimità' a costi moderati (opzione che in contesti come quello africano suonava come rivoluzionaria se confrontata con la tradizione postcoloniale di sradicamento sistematico)

2) la realizzazione di schemi di accoglienza (i cosiddetti 'lotti urbanizzati', 'sites-and-services' o 'trames d'accueil') basati sulla drastica riduzione delle norme urbanistico/costruttive in vigore nel Paese per ottenere costi più bassi e garantire più ampie possibilità di accesso a fasce di popolazione a basso reddito, attraverso la fornitura di lotti semiurbanizzati e l'autocostruzione delle abitazioni da parte degli abitanti.

Entrambe erano viste come soluzioni pratiche, poco costose e complementari al problema degli alloggi, all'epoca ancora trattato da quasi tutti i Paesi (tanto dell'Occidente quanto dei Paesi Socialisti e del cosiddetto Terzo Mon- 
34 do) nei termini di costose e lente realizzazioni di edilizia popolare sempre più distanti (qualitativamente e quantitativamente) dalle necessità della maggioranza della popolazione. Soprattutto, erano viste come modi di permettere legalizzazione, sicurezza finanziaria e fornitura di un minimo di attrezzature e servizi, valorizzando il ricorso all'autocostruzione che da quasi 10 anni era al centro dell'animato dibattito teorico internazionale a cui si è accennato nei paragrafi precedenti.

Pur essendo l'argomento della lotta alla povertà urbana quello prevalente a livello di discorsi teorici, nella pratica il tema dominante restò costituito dalla 'crescita economica', a cui - fin dal 1970 - era considerata contribuire molto l'attività edilizia (capace di offrire opportunità lavorative a manovali non qualificati e di accrescere la domanda di materiali costruttivi).

Due apparvero invece fin da subito gli ostacoli principali opposti alla realizzazione dei due programmi: uno di ordine economico (la disponibilità di terreni, infrastrutture e materiali costruttivi), l'altro istituzionale (le regole sulla registrazione della proprietà, i regolamenti edilizi e le restrizioni imposte dallo 'zoning'). L'alloggio, in tal senso, rappresentò - fin dal rapporto annuale della Banca Mondiale del 1970 - la problematica emergente a cui spesso era tout court ridotta l'urbanizzazione, in una logica centrata sulla necessità d'integrazione all'interno del 'mondo moderno e sviluppato' di quei Paesi in via di Sviluppo ancora dotati di norme farraginose e vincolanti, di istituzioni di finanziamento dell'abitazione arretrate e di metodi antiquati di classificazione e distribuzione dei suoli, condizioni che finivano per favorire aiuti e sovvenzioni istituzionali a categorie sociali già doppiamente favorite dall'abitare in città e dai redditi elevati o medio-alti.

Il concetto-guida dei primi interventi della Banca Mondiale in ambito urbano è ben espresso dal neologismo 'affordability', ${ }^{19}$ che preconizzava la concessione ai più poveri di pre-finanziamenti da recuperare a carico dei beneficiari finali dei progetti per reinvestirli poi in nuovi interventi in un ciclo idealmente continuo di riproducibilità che - per essere efficace - non poteva situarsi fuori dal contesto dello sviluppo al contempo urbano e nazionale. Le precondizioni poste alla concessione dei singoli prestiti consistevano in 3 mutamenti politici fondamentali: la regolarizzazione finanziaria delle istituzioni richiedenti, la creazione di norme ridotte tese a favorire investimenti collettivi di minimo impatto per gli Enti promotori ${ }^{20}$ e la fine delle politiche di 'sgombero' degli insediamenti cittadini spontanei (déguerpissements in francese, o evictions in inglese). Il tutto mirava a favorire una regolarizzazione urbanistica e legale degli stessi insediamenti che col tempo restò il principale contenuto degli interventi finanziati, lasciando ai 'Sites \& Services' il ruolo di azioni complementari per riallocare le sole famiglie che non era possibile lasciare in 'loco' durante gli interventi di ristrutturazione e regolarizzazione degli insediamenti informali già in fase di consolidamento, obiettivo privilegiato di azioni intese a rafforzare lo spontaneo verificarsi di investimenti privati di valorizzazione e miglioramento degli alloggi da parte degli stessi residenti, resi possibili da una relativa sicurezza sulle possibilità di permanenza nell'area occupata o irregolarmente lottizzata. Nel rispetto di queste 'imposizioni esterne' ricondotte a principi di libera adesione volontaristica a pre-condizioni ben esplicitate in partenza, la World Bank finanziò tra il 1970 ed il 197510 progetti-pilota in diversi Paesi in Via 
di Sviluppo, di impegno medio oscillante fra i 2,5 e i 3 milioni di dollari e vincolati a cofinanziamenti o contropartite e alla messa a disposizione di personale tecnico da parte delle Istituzioni richiedenti il prestito attraverso la costituzione di unità operative ad hoc. Queste si posero come uno degli aspetti più originali dell'intervento della World Bank nel settore, pur finendo per conferire ai vari progetti un'aura di extraterritorialità in linea con l'operatività asettica e a-locale di stampo razional-modellistico tipica del modo di operare dell'istituzione finanziatrice.

In tutti i casi ${ }^{21}$ la lotta contro la povertà e per l'integrazione sociale - affidata ai meccanismi di "compensazione sociale" studiati dall'unità DSA ("Dimensione Sociale dell'Aggiustamento", oggi "Divisione della povertà e della politica sociale" $)^{22}$ della Banca Mondiale non appariva mirata alla risoluzione di contraddizioni sociali ma alla creazione di un quadro razionale - ritenuto automaticamente efficace - di sviluppo urbano, che riduceva la "questione sociale" a mero "problema sociale o urbano" prescindendo dalla messa in discussione dei rapporti di sfruttamento: esattamente ciò che in quegli anni anche Turner andava duramente contestando.

\subsection{Cambiare tutto perché nulla cambi}

Il 1978 segnò un punto di svolta nella crescita degli interventi urbani della World Bank, che passarono dallo 0,3\% del 1972 al 4,4\% sul totale dei prestiti concessi ai vari settori di intervento, concentrandosi sulla regolarizzazione fondiaria e così contribuendo a disegnare la tendenza mondiale ad appiattire sulla regolarizzazione della città spontanea tutti gli interventi destinati a risolvere le problematiche dell'housing.

Dal '79 una leggera crescita dell'impegno nel settore dei progetti integrati tentò di porre rimedio alle prime avvisaglie di fallimento di alcuni progetti precedentemente impiantati. Si comprese che l'errata interazione con le autorità dei Paesi finanziati aveva portato benefici a categorie sociali sovente diverse da quelle previste in origine ${ }^{23}$ e che il tasso di mobilità della popolazione beneficiaria degli interventi - spesso per la mancanza di controlli e misure sanzionatorie - rivelava un uso dei nuovi alloggi come beni di scambio (in media dal 40 al 60\%) che favoriva rapidi processi di gentrificazione di molti siti di intervento. Nel complesso, la Banca poté dirsi soddisfatta delle percentuali di interventi andati realmente a beneficio delle popolazioni urbane più povere solo in alcuni paesi dell'Africa e in America Latina. ${ }^{24}$

A questi motori della 'correzione di rotta' si aggiunse l'esame dei tassi di recupero dei costi (cost recovery) che raggiunsero il 100\% solo in 15 dei 25 progetti di 'Sites \& Services', e nel 50\% dei progetti di miglioria urbana, in molti casi - tra l'altro - solo grazie alla gentrificazione sociale dell'area interessata (Linn, 1983) e comunque con livelli decrescenti nel tempo. Inoltre, il recupero dei crediti da parte degli Stati che dovevano esserne i finanziatori risultò generalmente basso (solvente risultò quasi solo il Nordeuropea), mentre il tasso di rentabilité économique dei progetti (intesa quale promozione delle attività economiche legate alla costruzione di alloggi e all'urbanizzazione delle aree) risultò molto diverso da progetto a progetto, oscillando tra il 9,5 ed il $46 \%$ e senza che fosse esplicitato come fu calcolato. ${ }^{25}$ 
Come chiarisce il documento Learning by doing, elaborato nel 1983 in forma di valutazione comparata dei progetti fino ad allora messi in campo in vari Paesi del Terzo Mondo, le principali linee operative definite dalla Banca Mondiale tra il '70 e l' 80 indicarono l'impossibilità di attuare la strategia settoriale prevista se non 'calandola nel contesto dello sviluppo urbano e nazionale', il cui miglioramento aveva peraltro sempre costituito la reale giustificazione dell'intervento in un' area come l'habitat, di per sé 'improduttiva'.

Il ridirezionamento della strategia globale di intervento urbano della Banca Mondiale non solo non incise nel formulare meglio che cosa si intendesse per sviluppo $^{26}$ ma neppure nel modificare 'l'utopismo meccanicista' di 'un modello produttivista di società moderna che determina il modello di habitat' (Osmont, 1995) $;{ }^{27}$ tanto che, per oltrepassare le 'resistenze' incontrate nei diversi territori locali, ci si limitò a rafforzare la razionalità astratta ed eteronoma di un meccanismo d'intervento situato 'a monte' di ogni singola azione.

Anche il cambiamento di strategia adottato dalla Banca Mondiale negli anni ' 80 in direzione di interventi integrati e non limitati alla strutturazione fisica dello spazio si è, infatti, riprodotto uniformemente e contemporaneamente in ogni realtà, ovunque spostando l'interesse dal mondo degli interventi di strutturazione fisica del territorio ai meccanismi istituzionali e finanziari della gestione urbana, e dando luogo a progetti di cosiddetto 'sviluppo municipale' che - incentrandosi sul progressivo disimpegno degli Stati e sul decentramento dei poteri tecnici, politici, amministrativi e finanziari - in molti Paesi non riusciranno a imporsi prima degli anni ' $90^{28}$ per l'ostilità manifestata verso questa subdola forma di intrusione nella vita politico/istituzionale dei cosiddetti 'beneficiari', sottintesa nel passaggio dalle politiche dello 'sviluppo' a quelle 'dell'aggiustamento strutturale ${ }^{29}$ applicato sia agli stati che alle città.

Per imporre tale strategia, accanto al riorientamento e all'intensificazione degli studi macroeconomici sui singoli Paesi sviluppati, che di recente l'hanno portata ad autodefinirsi anche come la 'Banca del Sapere' (Osmont, 2002, pg. 15), a partire dal 1984 la World Bank mise in atto una diffusa strategia di collocamento di propri agenti come consulenti amministrativi ai vari livelli istituzionali, nei Paesi interessati ai crediti concessi, oltre a una di cooptazione di intellettuali scettici sugli 'aggiustamenti', mirata a favorire l'internazionalizzazione dell'accettazione (perlomeno da parte delle maggiori 'elites nazionali') di misure che la Banca non intendeva rimettere in discussione,. Quanto al tema della povertà (urbana ma anche rurale, nel tentativo di trovare una nuova integrazione degli interventi), negli ultimi 15 anni la World Bank ha puntato a garantire quantitativi minimi di servizi sociali e a mobilitare quanto i poveri hanno in maggiore abbondanza, ovvero la forza lavoro, suggerendo forme di intervento che solo in taluni Paesi hanno assunto formulazioni locali interessanti (è il caso dei 'mutirões' del Brasile, sorta di cooperative di aiuto reciproco). Ma soprattutto ha puntato a promuovere una conoscenza e una definizione migliore e più realistica - sia in ambito qualitativo che quantitativo - della povertà ${ }^{30}$ riconosciuta per la prima volta come eterogenea e al contempo ridotta ad un dato banalizzato, in qualche modo 'naturale' e parrebbe implicitamente - ineliminabile. Un dato sbandierabile ad hoc (MoriconiEbrard, 1996) per creare consenso generalizzato intorno a misure destinate a sradicarla, ma costruite sulla base ricattatoria di un aggiustamento strutturale che non si accetta di mettere in discussione. 
Nel complesso, quindi, la missione di riforma sociale di cui la Banca Mondiale si è sentita sempre più investita ${ }^{31}$ ha portato ad un'interpretazione della città appiattita soprattutto sul suo valore di riserva di manodopera, di 'popolazione utile' da rendere più produttiva attraverso una serie di investimenti di per sé improduttivi come quelli nei settori dell'abitazione, dell'educazione e della sanità. La tendenza a passare da un trattamento in termini meramente fisici e settoriali delle strutture dello spazio urbano ad una concezione della città come entità preminentemente sociale e politica, ha dato ai nuovi progetti (detti di 'sviluppo municipale') un carattere incentrato sulla 'gestione urbana locale', sui rapporti di potere fra gruppi sociali che strutturano la città, sulla ricostruzione delle normative municipali e dei rapporti con i livelli istituzionali superiori. Anche questo nuovo approccio - sviluppatosi per tutti gli anni ' 80 in parallelo ad un consistente aumento degli aiuti al settore urba$\mathrm{no}^{32}$ - si trovò davanti numerosi ostacoli, soprattutto venendo percepito - e tanto più in molti Paesi in via di Sviluppo - come una forte ingerenza negli affari interni, se non un vero e proprio 'ricatto' che portava dominazione eterodiretta in cambio di aiuti materiali e assistenza tecnica. Esso - pur configurandosi come dottrina settoriale - si è portato dietro una visione universalista trasformata in modello operativo esso stesso globale seppur frazionato in programmi settoriali d'intervento, in procedure rigide i cui mutamenti derivano da un adattamento della dottrina e del modello operativo, e non dal prendere in considerazione - al fine di migliorarne i risultati - le condizioni particolari della messa in opera. ${ }^{33}$ Il mutamento del modello operativo constatabile nel 1980 negli interventi urbani della World Bank è pertanto attribuibile solo ad una parallela trasformazione dell'approccio globale ai problemi della città e più in generale dello sviluppo, ma non denuncia una variazione di interesse per il tipo di intervento proponibile o per i contesti dove svilupparlo. Come ha ben sintetizzato Annik Osmont (1995, pp. 9-10):

$\mathrm{Si}$ constata che sono assenti, in questo processo [di trasformazione], i cittadini e le loro pratiche concrete, quelle che mettono in opera [...] per vivere e sopravvivere in città. Allo stesso modo, gli esperti della Banca si sono poco interessati, fino ad un'epoca recente, ai poteri pubblici 'autoctoni', i più spesso sospettati d'essere incompetenti, corrotti o non democratici, o delle tre cose insieme. Quest'ignoranza deliberata ha legittimato una similitudine correlativa dei progetti urbani dello stesso periodo, quale che fosse il loro luogo di realizzazione.

In tal senso la World Bank ha continuato a portare avanti in tutti i mutamenti operativi intervenuti, una tipologia di intervento sostanzialmente immodificata, di matrice tecnocratica e totalitaria. La stessa nozione di governance ${ }^{34}$ apparsa di recente come versione più attuale del modello di intervento della Banca Mondiale e sotto le specie di una corporate governance rigidamente gerarchizzata (Osmont, 2002) - rientra nella categoria degli 'statuti determinati a priori' per contesti differenti, ridotti al loro aspetto di matrice economicistica che guarda allo sviluppo come ad un problema 'tecnico' per il quale sarebbero necessarie e sufficienti (Osmont, 2002) alcune soluzioni a livello di pianificazione economica, politiche commerciali e trasformazione dell'infrastruttura istituzionale (Stiglitz, 2000).

Questa trasformazione delle strate gie di intervento della World Bank - ma non della filosofia generale - ha contribuito al rapido diffondersi a livello 
internazionale di un'idea dell'urbanistica più complessa e diversificata che nel passato, intesa quale disciplina che deve acquisire nuove competenze in materia fiscale, politica e di organizzazione dei processi, per poter intervenire non tanto sullo spazio della città quanto per produrre governabilità locale in grado di generare un funzionamento urbano "conforme a ciò che ci si attende in un complesso macroeconomico nazionale ristrutturato" (Osmont, 1995). Una disciplina che deve quindi creare "progetti urbani come funzione della produzione di un'impresa, l'impresa città' (ibidem), e mirare ad un'efficacia che solo può essere possibile a partire da una riforma delle istituzioni secondo il principio della sussidiarietà (cfr. cap. 1).

In tal senso, l'accento posto sulla necessità di decentramento dei poteri, come quello posto sull'empowerment e la partecipazione popolare o sul nuovo ruolo delle ONG locali quali intermediari tra cittadini e potere ${ }^{35}$ si è rivelato da subito una forma di "populismo caricaturale, 36 in quanto meramente strumentale e di grande utilità al fine di sostenere un'immutata ideologia 'sviluppista' in cui le città lavorano e si riorganizzano per offrire il loro contributo allo sviluppo economico anche attraverso la "pacificazione dei costi di transazione' e quello che Galbraith (1980) definisce come l'equilibrio della povertà. $^{37}$ Come ha osservato Stren (1993), lo stesso interesse finora dimostrato dalla World Bank per il paradigma 'localista' non supera l'ambito dell' allusione, cioè le sue accezioni politiche filtrate attraverso l'esperienza di macroeconomisti che vedono nello sviluppo urbano un semplice corollario di quello economico, nella 'capacità di governo' locale la dépendance della gestione alla scala nazionale, e nella lotta alla povertà urbana la possibilità di riscatto della 'purezza dello spirito liberale'.

Parimenti, al decentramento tecnico-amministrativo invocato dalla Banca Mondiale come pre-condizione per elargire prestiti, non corrisponde un reale interesse per una redistribuzione di poteri fra Stato e municipi che serva a valorizzare poteri e saperi locali: del resto la Banca ancor oggi resta fortemente centralizzatrice e tecnocratica nella sua azione globale.

In questo quadro, le strategie operative risultanti paiono sempre meno mirate ad obiettivi di trasformazione fisica, un po' meno mirate a deregolamentare $i$ meccanismi di produzione e scambio e sempre più legate a controllare le popolazioni e le loro strutture sociali specifiche 'al fine di ricondurle al modello unico, universale, della società della gestione' anche attraverso un'abile strategia di ricerca a carattere operativo che tende a confondere attori istituzionali e ricercatori e a declinare alle varie scale locali preoccupazioni di matrice macroeconomica (Osmont, 1995).

Solo oggi - a 6 anni dal vertice di Istanbul ed in seguito alle elaborazioni portate avanti all'interno di altri organismi internazionali (molti dei quali agenti in parallelo alla World Bank nell'ambito del sistema delle Nazioni Unite) si apre per la Banca Mondiale la possibilità di riprendere in esame e rivedere il concetto di 'locale' finora subordinato al buon governo e allo sviluppo macroeconomico. Ma solo accettando di modificare la propria ' $r e$ torica urbana conservatrice' (Hirschman, 1991) la Banca potrà mettere a frutto positivamente i potenti mezzi di cui dispone, a reale servizio della lotta ad ogni esclusione sociale, incontrandosi sul terreno di pratiche reali (e non proditoriamente mascherate a suo vantaggio) con i movimenti popolari e gli altri organismi più 'umili' di aiuto e cooperazione. Ma la rottura epistemolo- 
gica con il passato delle teorie e delle strategie d'intervento sul territorio della Banca Mondiale appare - purtroppo - ancora un miraggio, visto che anche il grande impulso alla ricerca urbana dato a partire dal 1989 ha spesso il sapore di una copertura solo fintamente aperta agli apporti di differenti 'donatori': nella realtà essa sembra piuttosto attenta a 'spoliticizzare' e 'tecnicizzare' il campo della gestione urbana per poter meglio intervenire su di esso senza essere accusata di ingerenza politica, come accaduto in passato.

\subsection{Flessibilità vs. rigidità: verso uno sviluppo 'incrementale'.}

L'improvviso e diffuso sviluppo parallelo del binomio composto dalla regolarizzazione degli insediamenti informali consolidati e dalla fornitura di lotti urbanizzati $^{38}$ è stato, forse, il risultato più tangibile dell'appropriazione che del dibattito sull'autogestione stimolato da John Turner è stata fatta dalle maggiori Istituzioni Internazionali.

La nuova ortodossia (come l'ha definita Peattie, 1982) fu quasi imposta a molti Paesi da un pool di organismi impegnati nella cooperazione bi o multilaterale (l'UNDP, l'AID, le Agenzie Nazionali Nordiche e soprattutto la Banca Mondiale). Essa era basata su concetti riguardo ai quali la mancanza di definizioni univoche e coerenti - come accade oggi con il concetto di 'sostenibilità' - rivelava 'a monte' una carenza di reale consenso su ciò che le nuove filosofie operative precisamente implicavano o escludevano, ${ }^{39}$ proprio mentre, nei fatti, evidenziavano il rapido mutare dei margini di libertà di movimento lasciati ai beneficiari.

Del resto, gli stessi fini che l'adozione dei Sites-and-Services si proponeva non sono mai apparsi univoci nella vasta letteratura sul tema, ${ }^{40}$ anzi spesso specie nei testi della World Bank - l'enfasi differente posta da singoli autori o specifici programmi di intervento nel sottolineare un particolare obiettivo andava inevitabilmente a discapito di un altro (è il caso del rafforzamento del settore delle costruzioni, che non poteva che cozzare con l'ampliamento dell'accesso all'alloggio per i più poveri, tenendo conto delle necessità del recupero dei costi e della riduzione dell'impegno istituzionale nel settore). Sotto il profilo delle realizzazioni concrete ${ }^{41}$ gli approcci utilizzati nel far accettare i nuovi interventi si dovettero differenziare molto, andando da quello semi-partecipativo di El Salvador (Bamberger, 1989), a quello impositivo usato a Delhi in un periodo di emergenza in cui gli abitanti di alcuni slums furono portati a forza nelle nuove 'cattedrali nel deserto'.

La nuova ortodossia evidenziò comunque problematiche spesso simili, a partire da quelle dell'ubicazione dei terreni e dell'incidenza sul bilancio familiare dei beneficiari che la necessità di un continuo ricorso ai trasporti provocava. La stessa Banca Mondiale - che contribuì in maniera determinante a far accettare ai governi nazionali la realizzazione di molti progetti (nondimeno vissuti come ricatti imposti dal forte potere contrattuale dell'organismo) - accettò alla fine di introdurre nelle sue preordinate schematizzazioni un vasto numero di variabili, che spesso trasferì da un contesto all'altro nel tentativo di rinnovare gli approcci operativi per costituirli come alternativa alle pratiche fino ad allora tentate per risolvere il problema dell'alloggio, neutralizzando al contempo alcune difficoltà incontrate. Nel complesso, i singoli programmi operativi avevano, infatti, lo scopo di fungere da leve per 
40 un cambiamento di mentalità che potesse rifondare l'approccio alla questione della casa nell'ambito della pianificazione urbana, tema - quest'ultimo quasi ignorato dalla World Bank.

Il lavoro più duro fatto dalla Banca Mondiale è stato 'vendere' l'idea dei 'Sites-\&-Services' attraverso ampie negoziazioni, e di riuscire a far sviluppare le fasi realizzative sui giusti binari. Specifiche contrattazioni dovettero essere compiute nei diversi contesti relativamente ai beneficiari e alle procedure per la loro selezione, e all'impegno delle autorità locali a lasciare indisturbati i cittadini informali, fatta eccezione per specifici casi identificati volta per volta. ${ }^{42}$

Lo stimolo offerto al rinnovamento delle politiche, indotto tramite progetti parzialmente etero-finanziati, è risultato alla fine quello meglio raggiunto attraverso la strategia scelta dalla Banca. Pur avendo di rado fatto apprendere alle Istituzioni nazionali e locali interessate come mettere in piedi programmi di azione efficienti, autofinanziabili e pertanto replicabili, ha comunque sortito l'effetto di diffondere un modo rinnovato di guardare ai settori informali della casa ed anche della produzione, come la riduzione generalizzata degli sgomberi in molti Paesi e l'apparentemento de facto dei mercati formale ed informale degli alloggi testimoniano.

Più discontinuo nei risultati è stato il tentativo di rafforzare le cornici istituzionali cittadine attraverso programmi ad hoc di consulenza e formazione professionale costituiti in occasione della realizzazione dei progetti di Sites\&-Services. Se - specie nel settore della regolarizzazione fondiaria - i programmi raramente sono riusciti a far breccia sulle tecnoburocrazie locali con i loro obiettivi 'rivoluzionari', hanno però veicolato l'idea in ambito politico, facendo sentire l'esigenza di nuove equipe e strutture amministrative specifiche (anche multidisciplinari) concentrate su singoli programmi e progetti per garantirne la migliore riuscita. Il più delle volte fu comunque omesso il passaggio, che la Banca si augurava ingenuamente di implicito automatismo, dall'accettazione dei nuovi progetti alla riformulazione delle politiche.

La formazione dei quadri tentata dalla World Bank non poteva, infatti, supplire alla mancanza di volontà politica verso una flessibilizzazione degli alti standard qualitativi fino ad allora richiesti ai progetti, ${ }^{43}$ e verso un cambiamento sostanziale degli approcci e delle procedure amministrative. Del resto, la rettifica delle imperfezioni dell'amministrazione, il più delle volte, non rientrava negli interessi diretti di chi ne era parte e che su questi difetti faceva magari leva per aumentare la sua piccola sfera di potere e diminuire l'incidenza della partecipazione dei cittadini. In tal senso l'accoglimento delle già ambigue direttive della World Bank sul 'nuovo corso' da dare alla politica degli alloggi fu attuato in molti Stati - almeno per tutti i primi anni di sperimentazione - in maniera selettiva e quindi riduttiva dei suoi potenziali positivi. L'enfasi fu posta, ad esempio, solo sugli aspetti più convenienti di progetti che già in partenza si interessavano solo di riflesso a migliorare le condizioni della povertà urbana; e gli stessi progetti-pilota finirono per restare 'isolati' nel loro ruolo di 'piloti senza un seguito', per di più parzialmente giustificando, con la loro semplice esistenza, la mancanza di programmi strutturati e a più vasto raggio di acquisizione di suoli o di riforma amministrativa.

Alcune trasformazioni nell'approccio al problema dell'alloggio si manifestarono solo dopo il programma di valutazione messo in atto dalla Banca 
Mondiale nel 1982, che prese in considerazione soprattutto gli esperimenti meno riusciti e limitatamente ai temi della scelta dell'ubicazione, del raggiungimento dei target-group e del cost-recovery, ignorando elementi di valutazione quali il grado di riuscita dell'integrazione fra il nuovo insediamento e il territorio circostante, o la 'condivisione' delle scelte (di massima e di dettaglio) da parte dei beneficiari. Tra le conclusioni dell'auto-valutazione emerse come l'eccesso di procedure e obblighi burocratici - disegnando un quadro molto diverso dalla 'libertà di costruire' propagandata da Turner e apparentemente fatta propria dalla World Bank - si erano dimostrati un potente deterrente al soddisfacimento della tipologia di beneficiari prevista da molti progetti. La lezione appresa fu cioè che l'irrigidimento e la formalizzazione data ad un processo che in origine aveva mirato ad emulare per fasi i modi del mercato informale di provvedere alla fornitura di alloggi a basso costo, avevano annullato i principali benefici per una popolazione che necessitava di dedicare il suo tempo e le sue energie per sopravvivere (Van der Linden, 1986). Un ulteriore dubbio sorto nella valutazione dei progetti riguardò i processi di selezione e monitoraggio dei futuri beneficiari che spesso affidati alle autorità locali - avevano teso a impedire una verifica dei redditi reali delle famiglie selezionate, mostrandosi già in partenza viziati da irregolarità frutto non necessariamente di amicizie, menzogne o corruzione, ma anche solo del desiderio di mostrare risultati visibili, per cui pareva necessario scegliere famiglie con redditi medio-bassi in grado di portare avanti in tempi brevi la costruzione. In chiusura del processo valutativo, la stessa Banca Mondiale dovette ammettere che:

Se la riduzione della povertà è il fine primario di un progetto, forse il tipo di programmi $[\ldots]$ sperimentati finora non sono i meccanismi più realistici per soddisfare simili obiettivi. Se migliorare l'efficienza del mercato degli alloggi è il fine primario, allora gli schemi di intervento attuali possono essere più facilmente giustificati [...] Il punto è semplicemente che gli obiettivi dell'housing e della povertà non possono essere facilmente raggiunti nell'ambito degli stessi interventi, e che questi fini dovrebbero essere individualmente indirizzati durante la progettazione e la realizzazione del progetto (Keare \& Parris, 1982, in Van der Linden, 1986).

L'analisi degli esperimenti di maggior successo - stabilendo i limiti della loro replicabilità - dette indicazioni convergenti sulla necessità di riformulare le rigide strategie di azione in maniera più flessibile e adattabile ai differenti contesti politici, sociali e territoriali, facendo emergere anche l'importanza che poteva rivestire il coinvolgimento nei progetti di ONG locali.

L'insieme di queste auto-valutazioni della Banca Mondiale su alcuni progetti di Sites-\&-Services di 'prima generazione', ha introdotto in quelli di 'seconda generazione' alcune nuove tendenze, che lentamente hanno provocato una trasformazione verso altre strategie operative, poi adottate in molti stati come 'variante' al cosiddetto 'twin approach' suggerito dalla Banca stessa. La tipologia di intervento balzata in questo frangente all'attenzione internazionale è stata indubbiamente quella degli IDS (gli Incremental Development Schemes o Planned Upgradable Sites) un tentativo di rinnovare dall'interno gli approcci allo 'sviluppo progressivo' degli insediamenti incorporando nuove istanze derivate dall'osservazione attenta e dalla convivenza con le aree di abitazione informale in progressiva ed apparentemente inarrestabile 
42 crescita ad ogni latitudine del pianeta. ${ }^{44}$ Anche se apparentemente potrebbe apparire un passo indietro rispetto ai Sites-and-Services (e lo è forse davvero, per quanto concerne l'arretramento ulteriore degli impegni del potere pubblico nel settore) l'IDS rappresenta in realtà una sua formula migliorativa, non solo in rapporto all'efficienza e al recupero dei costi, ma anche per la minore rigidità delle norme che regolano i progetti ed i processi costruttivi, in direzione di una trasformazione del rapporto fra istituzioni e assegnatari e di un migliore soddisfacimento dei variati e multiformi bisogni di questi ultimi in rapporto ai diversi contesti locali e patrimoni socio-territoriali dei contesti di intervento. L'IDS si caratterizza per uno spostamento di accento dell'impegno profuso dal potere pubblico, dalla fase del progetto e della realizzazione degli interventi precedenti il trasferimento dei beneficiari, a quella della gestione dei processi di costruzione progressiva di alloggi ed infrastrutture e di organizzazione della popolazione. ${ }^{45}$

Il nuovo modello IDS incorpora alcune delle 'tendenze in mutamento' che hanno segnato il nuovo approccio della Banca Mondiale a seguito dell'autovalutazione del 1982-83, tra cui:

a) La progressiva accettazione dell'autogestione del processo di costruzione dell'alloggio in sostituzione dell'enfasi inizialmente posta sull'autocostruzione, che recuperava l'idea di Turner che i benefici in termini economici e di qualità del prodotto-casa non si legano necessariamente all'autocostruzione, ma alla semplice garanzia di intervento decisionale ed organizzativo dei futuri abitanti sui processi di realizzazione dell'alloggio.

b) La sottolineatura della necessità di revisione dei criteri di selezione dei beneficiari, con il passaggio dagli 'indicatori poveri' legati al mero reddito familiare (spesso risultato falsato o compiacente) alla 'capacità di ammortizzare i costi' (Keare \& Parris, 1982)

c) La rinnovata attenzione alle strategie per mantenere in loco gli originali beneficiari. Questo implica ripensamenti sul concetto di affordability, l'eliminazione dei trasferimenti forzosi di 'popolazione baraccata' (come accaduto a Delhi e Manila) e soprattutto un rafforzamento dell'interdipendenza fra le due componenti del twin approach.

d) L'importanza conseguentemente attribuita all'affitto come modo per ampliare numericamente e qualitativamente $\mathrm{i}$ benefici del progetto a nuovi individui, e come possibilità di generare reddito per gli abitanti del nuovo insediamento, in grado di minimizzare il turn-over, rendere più efficiente il recupero dei costi e accelerare il completamento delle abitazioni. ${ }^{46}$

e) Il riconoscimento della necessità di mettere in mano i progetti ad istituzioni già esistenti (di cui valorizzare i margini creativi e le capacità - anche solo latenti - di efficienza e coordinamento) piuttosto che creare entità temporanee di gestione dei progetti costituite ad hoc che non solo possono entrare in conflitto con i poteri esistenti aumentando l'entropia nelle istituzioni attraverso la sovrapposizioni di nuovi e scoordinati livelli di comando, ma soprattutto finiscono per restare isolate dalle reali strutture di potere nel tentativo di scindere l'amministrazione dalla politica. ${ }^{47}$

f) La conseguente enfasi posta sulla formazione degli attori locali come condizione per la costruzione e il perfezionamento delle capacità di azione delle istituzioni. g) Il tentativo di coinvolgere il settore privato nella costruzione dei nuovi Sites-and-Services, anche attraverso la possibile mobilitazione di forze som- 
merse dell'ambito irregolare, spesso maggiormente capaci di (ed interessate a) lavorare con le abitazioni a basso costo ma non ancora riconosciute e accettate nelle loro potenzialità proprio mentre vengono accettati diffusamente gli insediamenti irregolari, cioè l'oggetto spesso della loro azione para-imprenditoriale (Drakakis-Smith, 1979). ${ }^{48}$

h) L'ampliamento del ventaglio di opzioni nei progetti per rispondere alla varietà di bisogni differenti che ruotano intorno all'alloggio, seppur (in questo caso) non tramite la concessione di libertà di movimento agli abitanti, ma appena per mezzo di una crescita di opzioni fisse e rigide in aggiunta alle tre originarie 'di base' (terra, sicurezza della proprietà, e servizi). L'acquisizione di una maggiore flessibilità (in sostituzione di una unilaterale riduzione degli standard) si lega in questo senso alla possibilità di immaginare nuovi target variegati e misti per i Sites-and-Services, che rendano l'offerta di alloggi più rispondente alla varietà della domanda, accentuino la sussidiarizzazione interrelata (Ayres, 1983) e allo stesso tempo evitino ai nuovi insediamenti di porsi come dei ghetti per categorie sociali uniche. ${ }^{49}$

i) L'attenzione posta a quanto i governi dei Paesi contraenti il prestito si impegnano a fare in materia di fornitura e distribuzione della terra.

j) La riduzione di molti ritardi constatati nella realizzazione dei progetti, attraverso un trasferimento dell'istanza 'terra' e dei relativi problemi alla fase di pre-progetto.

k) La nuova enfasi posta sui problemi dell'organizzazione comunitaria e della compartecipazione alle responsabilità di assestamento del progetto, che tradiva certo degli interessi di efficienza economica e funzionale, ma si poneva per la prima volta l'intento di ascoltare e osservare per apprendere desideri e soluzioni autoprodotte. E comunque cessa di considerare la partecipazione come un costo da valutare, vedendone più che altro l'aspetto di risorsa e la possibilità dell'istituzione di lavorare con e non solo per i cittadini (come Turner aveva affermato nel 1976).

L'ultima questione era già stata ambiguamente accennata fin dagli anni '70 ma poi messa in sottordine; il suo recupero avveniva in un clima di crescente interesse anche da parte di altre agenzie internazionali come l'UNCHS (1983). La nuova considerazione tributata al tema proveniva dall'osservazione di carenze nella manutenzione e nel recupero dei costi, e fu perciò affrontata in modo parziale, come un mezzo cioè per ottenere risultati migliori, e non come un fine in sé, un diritto o un'attività autogenerante, capace cioè di stimolare la partecipazione in altre sfere della vita (Yap, 1983).

In questa fase di 'ripensamento', la partecipazione venne quindi recuperata soprattutto come 'consensus building', cioè un' attività che le istituzioni decidono quando mettere in atto e quando evitare (UNCHS, 1984), una componente aggiuntiva di un progetto pre-formulato con procedimento top-down, e continuamente valutata in termini di costi/benefici, tenendo presente che l'organizzazione comunitaria è un costo che può causare ritardi (neppure bene accetto alle istituzioni nella misura in cui richiede la rinuncia ad una porzione di potere) e che i suoi benefici in termini di aumento della manutenzione, recupero dei crediti e potenziamento della rapidità di esecuzione non sono sempre di facile valutazione. In questo quadro interpretativo, esperienze di successo per l'alta partecipazione comunitaria come quelle sperimentate a El Salvador furono ritenute difficili da replicare ed incerte circa il ritorno degli investimenti aggiuntivi richiesti (Bamberger, 1979), oltre che 
44 sottovalutate nel loro potenziale di rafforzare solidarietà orizzontale e spirito cooperativo di comunità. Alla fine, l'unica vera forma di partecipazione incoraggiata sembrò quella nel lavoro di costruzione e nella condivisione dei pagamenti.

Ciò di cui la Banca è parsa non rendersi conto subito è che un'accettazione così evidentemente limitata (anche da una sfiducia nelle capacità delle istituzioni intermediarie e nell'abilità dei beneficiari) difficilmente potrebbe stimolare quell'investimento che gli stessi abitanti devono fare per partecipare, e che solo può essere stimolato dall'attesa di un qualcosa in cambio che non sembra voler essere però concesso. Un leggero 'slittamento' di accenti si avrà solo più di recente, quando (in corrispondenza di analoghe elaborazioni dell'UNCHS) la World Bank tenderà a promuovere maggiormente la partecipazione su vasta scala, pur sottolineandone utilitaristicamente soprattutto le implicazioni sulla distribuzione di potere e risorse.

\subsection{Un quadro in movimento}

Se l'approccio Sites-and-Services è solo riformista di natura e non minaccia lo statusquo capitalista, nelle sue conseguenze [...] solleva questioni basilari sulla redistribuzione delle risorse (Van der Linden, 1986).

L'osservazione di uno dei maggiori studiosi di quel twin approach che in più tappe la Banca Mondiale ha proposto (o imposto) a molti Paesi Terzi come stimolo ad un rinnovamento delle politiche urbane, ben sintetizza la commistione di conservazione e novità che ne è scaturita.

È ovviamente poco agevole giudicare oggi i progetti di Sites-\&-Services, specie quelli di 'prima generazione' concepiti come esperienze isolate, attuate da agenzie speciali senza vincoli con il territorio e la politica locale, e spesso dotate di extraterritorialità giuridico/urbanistica e al di fuori cioè di quei contesti reali e dei mercati delle costruzioni e delle terre l'inserimento nei quali sarebbe necessario a giudicare della fattibilità e della replicabilità dei progetti su vasta scala. La preoccupazione 'manageriale' della World Bank per il loro valore dimostrativo di progetti-pilota (giudicati dal solo punto di vista dell'efficienza da parte del promotore e non confrontati con il grado di soddisfazione degli assegnatari) introduce inoltre altre difficoltà di valutazione, legate a quadri critici troppo rosei e al monopolio dei dati, in ogni caso sempre tenuti a distanza dai contesti generali delle politiche nazionali di ogni singolo contesto interessato. ${ }^{50}$ Pare perciò incauto giudicare errate in toto le motivazioni teoriche che hanno presieduto alla nascita del twin approach, anche a causa dell'immensa varietà di risultati sia positivi che negativi che la loro attivazione ha generato nella realtà. Soprattutto lo è se, nel criticarne il limitato impatto sui più poveri dei poveri, e l'eventualità che i programmi da esso messi in atto si trasformino in baraccopoli pianificate e sponsorizzate dal governo, non si portano avanti realistiche proposte alternative. Avrebbe forse più senso cercare di capire quali benefici (o danni) a più vasto raggio il twin approach ha generato, diffondendo internazionalmente l'accettazione dell'informale - seppur come male necessario - da parte delle autorità pubbliche, sia per gli ambiti urbani in generale che per i poveri che li abitano. 
Senza voler entrare nel merito di questa difficile valutazione, va osservato che nel complesso il twin approach non sembra aver innescato quella serie di 'riforme urbane di portata maggiore' che si era proposto, seppur alcuni temi (e persino vocaboli) veicolati, come l'affordability, la replicability o il cost-recovery sono oggi entrati nell'uso comune anche attraverso i corsi di formazione diffusi sul territorio e i documenti internazionali prodotti dalla World Bank e da altre agenzie del sistema delle Nazioni Unite.

Un maggior successo rispetto ai Sites-and-Services - anche per una questione di costi medi 5 volte inferiori - ha, certo, caratterizzato la strategia dell'upgrading e della legalizzazione degli insediamenti informali, forse anche perché essa subisce le pressioni politiche di interi blocchi di elettori, certo più significativi di quelle delle popolazioni non-esistenti dei progetti di Sites-and-Services ancora da creare (Van der Linden, 1986). In ogni caso è da notare come il twin approach - pur non avendo inciso nel fermare i processi di crescita della città informale - li ha paradossalmente modificati in moltissimi ambiti locali, portando ad una trasformazione sia delle pratiche di occupazione dei suoli che dell'organizzazione spaziale nella città spontanea (si pensi alla regolarizzazione dei tracciati urbanistici assorbita dagli occupanti o dai suddivisori illegali di terreni come necessità per ipotecarsi futuri interventi di regolarizzazione). Questo cambiamento, oggi riscontrabile nelle pratiche di costruzione della città informale, è il risultato del convergere di differenti fattori che hanno progressivamente reso la situazione mondiale (e soprattutto terzomondiale) differente da quella che Turner - e dopo di lui la World Bank - usò come base per le sue teorizzazioni; e soprattutto molto variegata, al punto da aver creato situazioni dove persino l'accesso informale ai suoli e agli alloggi opera scelte selettive di natura economica e sociale. ${ }^{51}$

La diffusione delle valutazioni compiute dalla World Bank nel 1982 è stata utile per ridirezionare molti aspetti legati agli interventi della 'seconda generazione' di progetti (più vicini al modello definibile IDS) e per consolidare un movimento di consenso e accettazione diffusa del potenziale del cosiddetto 'approccio combinato' consolidandone ovunque soprattutto la componente dell'intervento ex-post sulla realtà informale (cioè la regolarizzazione fondiaria e urbanistica), complementare a quella ex-ante. Ma soprattutto ha avuto un ruolo forte nel promuovere il diffuso riconoscimento della necessità di un adattamento dei progetti a realtà locali differenziate, in linea con un'idea più concreta e flessibile di 'replicabilità'.

Questo ha da un lato generato l'inclusione di strumenti analoghi ai Sitesand-Services e agli IDS in 'pacchetti di opzioni possibili' e volontaristicamente selezionabili contenuti all'interno dei nuovi orientamenti dati alle politiche abitative (come vedremo nel caso di Porto Alegre), ma soprattutto ha portato ad un mutamento di ruolo della World Bank. Davanti alle proposte ricevute da istituzioni nazionali presentatesi con pacchetti autodefiniti di investimenti e progetti variati, la Banca Mondiale ha scelto di estendere i suoi finanziamenti a interi programmi di settore, diminuendo il proprio ruolo di supervisione e controllo sui singoli progetti ed ampliando al contempo la propria azione fuori dai semplici binari della politica abitativa. 
46 In questa 'trasmigrazione' di ruolo, l'interesse della Banca Mondiale è passato dall'enfasi sui diretti beneficiari e sui benefici dei singoli progetti alla valutazione degli effetti diretti sulle economie, che peraltro avevano costituito l'interesse di fondo costante (seppur sovente mascherato) della sua azione. Ovvero, nell'azione su più vasta scala (il cosiddetto wholesaling), la Banca Mondiale ha acquisito e diffuso - in particolare, dalla fine degli anni ' 90 - un interessamento di tipo 'integrato' per problemi interrelati a quello più 'fisico' della creazione degli alloggi, da un lato proponendo una maggiore collaborazione con il Fondo Monetario e l'Organizzazione Mondiale del Commercio (Allegretti U., 2002), dall'altro stabilendo una serie di 'pre-condizioni strutturali' per lo sviluppo locale di impostazione neoliberale (Osmont, 2002) incentrati sulla competitività, la riduzione dei costi di transazione, la buona gestione del territorio, la qualità della vita (livability) necessaria al funzionamento della città e la sua bankability, ovvero la capacità di evidenziare una gestione finanziaria seria e di incrementare le proprie entrate di ambito locale, anche per poter rientrare nei criteri di 'affidabilità di credito' (creditworthiness) della Banca e godere dell'accoglimento delle domande di finanziamento dell'istituzione o, addirittura, dei fondi di garanzia alle municipalità per accedere al mercato privato dei capitali.

In quest'ottica la Banca - che si pone come l'organismo internazionale che fornisce gli aiuti più importanti in campo urbano (e forse l'unico a vantare al contempo un approccio globale e operativo sui problemi posti dai fenomeni di urbanizzazione, Osmont, 2002) - è andata recentemente sostenendo il recupero di temi 'complementari' a quelli della strutturazione fisica dello spazio urbano, finora messi in ombra o mal presentati come il microcredito, l'accesso ai suoli, la democratizzazione delle istituzioni e la partecipazione popolare. E - parallelamente all'imposizione di strategie urbane nazionali di articolazione del contributo delle città allo sviluppo di ogni Paese finanziato - ha teso ad introdurre gradualmente un mutamento nei rapporti con le autorità nazionali e locali, recuperandole ad un ruolo propositivo nuovo, più legato ad istanze e soluzioni locali che la Banca ha tentato di promuovere e far conoscere aumentando le risorse destinate alla costruzione di capacità (capacity building $)^{52}$ e alla promozione di reti di attori locali per lo scambio di informazioni, conoscenze e pratiche eccellenti di intervento urbano e riduzione della povertà, attuate con il contributo attivo degli stessi strati sociali emarginati e delle organizzazioni di tipo 'comunitario'. Nel nuovo quadro, si comprende come mai la tappa successiva - suggellata nel 1999 dal cospicuo finanziamento offerto al programma Cities Alliance sia stato l'appoggio offerto dalla World Bank all'utilizzo della 'Pianificazione Strategica', intesa quale costruzione di "un progetto di città che unisce analisi e azioni pubbliche e private, e che definisce un quadro di mobilitazione e di cooperazione degli attori sociali urbani" (Borja, 1998). La nuova frontiera - ormai privilegiata rispetto ad ogni altra e tradottasi in nuove procedure di selezione delle città che possono aspirare ad ottenere il sostegno della Banca Mondiale per finanziare progetti inseriti nel proprio piano strategico - rientra anch'essa in una "strategia di pianificazione urbana del liberismo trionfante" (Osmont, 2002). L'idea centrale 
del partenariato tra attori non si confronta, infatti, col tema degli squilibri tra i loro diversi poteri contrattuali, lasciando implicitamente che i contenuti essenziali dei progetti vengano dettati dai partner più importanti (ovvero - quasi sempre - le multinazionali), mentre quelli più deboli finiscono per essere strumentalizzati legando la loro sorte alla capacità di mobilitare risorse a livello comunitario o con aiuti del Terzo Settore, mentre le stesse amministrazioni locali vedono svuotarsi rapidamente il contenuto politico delle proprie scelte, vincolate dalle strategie urbane ed economiche decise a livello nazionale e dagli obblighi di adottare forme di 'corporate governance' richieste dagli aggiustamenti strutturali,oltre che dal potere di contrattazione dei maggiori partner privati.

Queste trasformazioni, lente ma progressive, sono avvenute in parallelo alle conquiste teoriche portate a compimento nell'ambito di altri organismi del sistema delle Nazioni Unite, seppur con modalità spesso distorte, che lasciano trasparire dietro ogni affermazione compromessi ed interessi ben definiti e per nulla 'progressisti'.

Il perché abbiamo sentito la necessità di accennarne diffusamente - seppur con una carrellata non certo esaustiva - attiene a due ordini di ragioni:

1) tali trasformazioni rappresentano un quadro di riferimento indispensabile per comprendere il contesto evolutivo nazionale in cui l'esperienza di Porto Alegre si situa, e quindi anche per illuminare le peculiarità di approccio e contributo che quest'ultima va offrendo al rinnovamento delle politiche, e non solo in ambito locale;

2) le tendenze fin qui richiamate denotano nel loro complesso un passaggio dell'interesse dall'ambito del 'puramente fisico' a quello dell'analisi dei meccanismi di interazione e interrelazione fra attori e fattori che costruiscono i processi che le nuove politiche degli alloggi devono mirare ad incentivare, nel più ampio contesto delle politiche socio-territoriali.

Per certi versi - infatti - si può leggere nel corso dell'ultimo trentennio un processo di progressiva 'umanizzazione' degli obiettivi dei progetti messi in atto, che non significa conquista di una posizione di 'filantropia' (o antropofilia) da parte delle istituzioni finanziatrici, promotrici o attuatici dei progetti, ma lo slittamento dei programmi verso posizioni di maggior 'antropocentrismo', il più delle volte non in grado di scalzare obiettivi primari di natura utilitaristica e di marca economicista, ma comunque attenti al ruolo che in ogni progetto deve svolgere la persona rispetto agli altri obiettivi. In tale clima, anche laddove i destinatari dei progetti restano ancora concepiti come 'beneficiari' e l'ottica adottata dalla realizzazione finisce per essere quella dell'urgenza e dell'emergenza, nella sequenza dei fattori/obiettivo da organizzare e raggiungere progressivamente si può sovente riscontrare un graduale avvicinamento della componente 'umana' al primo gradino di interesse del progetto stesso. La schematizzazione proposta da Aliani, Yap e $\operatorname{Khan}^{53}$ e reinterpretata qui sotto lo chiarisce bene. Essa, ovviamente, non serve a esprimere sui progetti di ultima generazione dei giudizi di merito, che andranno riservati di volta in volta all'analisi dei singoli interventi urbani che prendono corpo nel quadro dei nuovi orientamenti internazionali. Può però costituire un utile supporto alla lettura delle pratiche che presenteremo nel seguito di questo testo. 
Schema delle sequenze dei fattori/obiettivo per la costruzione dell'habitat nelle formule tradizionali e non convenzionali.

\begin{tabular}{|c|c|c|}
\hline $\begin{array}{l}\text { Tipologia di } \\
\text { progetto }\end{array}$ & $\begin{array}{c}\text { Consecutività temporale dei fattori } \\
\text { organizzativi }\end{array}$ & Osservazioni \\
\hline $\begin{array}{l}\text { Sequenza } \\
\text { tradizionale* }\end{array}$ & $\begin{array}{l}\text { TERRA } \rightarrow \text { PERSONE } \rightarrow \\
\text { COSTRUZIONE } \\
\text { DELL'ALLOGGIO } \rightarrow \\
\text { INFRASTRUTTURE }\end{array}$ & $\begin{array}{l}\text { La sequenza si approssima a quella } \\
\text { che Turner, nei suoi studi sulla } \\
\text { costruzione della città medievale } \\
\text { (1986), indica come opzione } \\
\text { originaria. Oggi pare tipica delle } \\
\text { 'Lottizzazioni irregolari', ed è quella } \\
\text { messa a frutto dagli 'Incremental } \\
\text { Development Scheme' }\end{array}$ \\
\hline $\begin{array}{l}\text { Progetti } \\
\text { moderni* }\end{array}$ & $\begin{array}{c}\text { TERRA } \rightarrow \text { INFRASTRUTTURE } \rightarrow \\
\text { COSTRUZIONE } \\
\text { DELL'ALLOGGIO } \rightarrow \text { PERSONE }\end{array}$ & $\begin{array}{l}\text { Per Turner (1986), è una sequenza } \\
\text { distorta che crea scontri fra struttura } \\
\text { visibile (le costruzioni) e strutture } \\
\text { invisibili (proprietà, organizzazione } \\
\text { finanziaria e gestione) e tra queste due } \\
\text { e i bisogni e le priorità dei residenti, } \\
\text { costringendoli a vivere in case e } \\
\text { quartieri che altri, esterni, hanno } \\
\text { progettato e costruito per loro. }\end{array}$ \\
\hline $\begin{array}{l}\text { Approccio } \\
\text { 'Sites-and- } \\
\text { Services'* }\end{array}$ & $\begin{array}{c}\text { TERRA } \rightarrow \text { INFRASTRUTTURE } \rightarrow \\
\text { PERSONE } \rightarrow \text { COSTRUZIONE } \\
\text { DELL'ALLOGGIO }\end{array}$ & $\begin{array}{l}\text { Tale sequenza presenta un parziale } \\
\text { ritorno indietro: il percorso manca di } \\
\text { un'organizzazione preventiva della } \\
\text { popolazione, i cui desiderata non } \\
\text { saranno comunque presi in } \\
\text { considerazione che dopo } \\
\text { l'impostazione del piano urbanistico. }\end{array}$ \\
\hline $\begin{array}{l}\text { Occupazioni } \\
\text { informali } \\
\text { (squatting) } *\end{array}$ & $\begin{array}{c}\text { PERSONE } \rightarrow \text { TERRA } \rightarrow \\
\text { COSTRUZIONE } \\
\text { DELL'ALLOGGIO } \rightarrow \\
\text { INFRASTRUTTURAZIONE }\end{array}$ & $\begin{array}{l}\text { Tale sequenza è valorizzata dagli } \\
\text { interventi ex-post di upgrading, che } \\
\text { può prevedere (contestualmente o } \\
\text { meno) regolarizzazione fondiaria e } \\
\text { urbanistica, sia con formule di tipo } \\
\text { istituzionale che tramite cooperative } \\
\text { d'occupazione. } \\
\text { Nelle occupazioni di edifici (invece } \\
\text { che di terreni) la sequenza è } \\
\text { ovviamente variata, prevedendo o no } \\
\text { nei diversi casi l'infrastrutturazione, } \\
\text { la regolarizzazione e/o la } \\
\text { ristrutturazione degli alloggi, con o } \\
\text { senza procedure cooperative. }\end{array}$ \\
\hline $\begin{array}{l}\text { Approccio } \\
\text { 'cooperativo"* }\end{array}$ & $\begin{array}{c}\text { PERSONE } \rightarrow \text { TERRA } \rightarrow \\
\text { INFRASTRUTTURAZIONE } \rightarrow \\
\text { COSTRUZIONE } \\
\text { DELL'ALLOGGIO }\end{array}$ & $\begin{array}{l}\text { Potrebbe essere combinato con altri } \\
\text { approcci, mettendo gli abitanti come } \\
\text { primo fuoco del lavoro di } \\
\text { strutturazione dei programmi di } \\
\text { intervento e concentrando l'interesse } \\
\text { iniziale sulla pre-organizzazione della } \\
\text { popolazione 'beneficiaria' in } \\
\text { sostituzione di prospettive che oggi } \\
\text { lavorano individualmente con le } \\
\text { singole famiglie. }\end{array}$ \\
\hline \multicolumn{3}{|c|}{$\begin{array}{l}\text { Potenzialmente ogni sequenza potrebbe lavorare sulle singole fasi } \\
\text { attraverso procedure di partecipazione degli abitanti alle scelte }\end{array}$} \\
\hline
\end{tabular}

Ipotesi interpretativa riformulata sulla base del grafico U.N.C.H.S.-Habitat (1991) 


\section{Note}

1 Turner sottolinea esplicitamente che il difetto della Legge penviana del 1961 era di riconoscere gli insediamenti esistenti prima del settembre 1960, ma di lasciare gli altri in una sorta di limbo, senza avanzare previsioni o soluzioni-quadro per risolvere il problema degli alloggi in un prossimo futuro $(A D, 8 / 1963)$.

${ }^{2}$ Gli 'insediamenti di occupazione pianificati' erano pensati per rialloggiare in luoghi dotati di servizi collettivi minimi - e talora di trame costruttive intorno a cui sviluppare l'autocostruzione - gli abitanti degli slums più poveri, densi e disordinati (ritenuti non regolarizzabili), rivelando un approccio che cominciava a porre attenzione agli aspetti emergenziali della questione degli alloggi per gli strati più disagiati della popolazione. ${ }^{3}$ Solo nelle conclusioni appare un accenno al fatto che l'alloggio è uno dei tanti problemi che i poveri fronteggiano e che sarebbe opportuno orientarsi verso approcci più globali di quelli settorialmente limitati a risolvere il problema dell'housing. Il problema della 'legge', invece, verrà trattato da Tumer alla fine del testo L'abitare autogestito (1976), che si concluderà con la proposta di dare inizio a un programma di definizione di una legislazione di tipo proscrittivo, suscettibile di generare forme di autogoverno e aliena dal favorire programmi chiusi e categorici che definisce come assurdità mostruose (pag. 213).

${ }^{4}$ Cfr. Robi Ronza nella postfazione al libro L'abitare autogestito, pag. 221-231

5 Turner stigmatizza ricerche del genere come una perdita di tempo, resa più tragica quando le 'forze esecutive' - quelle della gente - stanno seminando i semi del caos urbano, a prezzo di costi e sacrifici immensi, semplicemente per mancanza di aiuto tecnico[...] Il sapere di coloro che hanno appreso dagli ugualmente trag ici risultati delle prime 'esplosioni urbane' in Europa a in qualsiasi altro luogo deve essere usato per evitare perdite grandi e permanenti (AD, 8/1963).

${ }^{6}$ Particolarmente lodati appaiono in tal senso tutti gli esperimenti (ad es. quelli Peruviani e quelli Venezuelani di Città Guayana) intesi a lasciare alle famiglie e alle comunità locali la massima libertà di usare le proprie risorse, attraverso un'anticipazione della sequenza costruttiva di solito messa in opera in queste condizioni. La citazione di un testo di Geddes del 1917 serve a sottolineare l'importanza da dare al fattore di crescita dello SPAZIO (ROOM) come elemento imprescindibile di possibile miglioramento per le condizioni familiari $(A D, 8 / 1963)$.

7 Turner ha sempre mostrato di non credere molto negli scritti; gli articoli pubblicati egli li dichiara 'estorti' con la minaccia che si avverasse il monito lanciato da Ivan Illich: 'senza scrivere seppellirai le tue idee sotto un mucchio di mattoni di fango peruviani'.

${ }^{8}$ Interessanti recensioni critiche dei termini del dibattito sviluppatosi tra i due poli sono contenute negli scritti di Van Lindert (1979), Yap (1982), e Niented e Van der Linden (1985).

${ }^{9}$ A questo proposito Van der Linden (1986) ha introdotto un interessante e originale parallelo tra la promozione del self-help housing ed il movimento top-down di metà ottocento che portò (con l'aiuto della Chiesa e il contributo di volontari in funzione antisocialista e di moralizzazione della working class, ma anche di 'compensazione' per la riduzione di alcuni diritti sindacali ai lavoratori) a disseminare le città europee di 'allottment garden' (orti urbani).

${ }^{10}$ Ciò che ha motivato per gran parte l'incomunicabilità è stato soprattutto che le tesi marxiste si svolgevano ad un livello teoretico di alta coerenza concentrato sul lungo termine, mentre Tumer era più legato ad una riflessione a medio e breve termine, considerati il lasso ideale per discutere della vita umana (Van der Linden, 1986). Conway (1982) ha contestato su queste basi la capacità prefiguratrice delle teorie marxiste, sostenendo che - ad esempio - l'adozione di politiche appropriate può rallentare (e rendere solo parziale) la trasformazione delle case autocostruite in beni di scambio soggetti a rapida gentrificazione (ovvero al passaggio in mani via via più ricche con espulsione dei proprietari più poveri).

${ }^{11}$ Ronza definisce questo rischio dell'autogestione come un Cavallo di Troia capace di rendere i ceti marginali dei ceti definitivamente subalterni (in Turner, 1978, pag. 226).

${ }^{12}$ Per certi versi, il tema dell'identità e del soggetto in Turner resta implicito, così come quello del significato dell'abitare, o meglio della risignificazione di questa esperienza dopo la rigida censura che essa ha subito e subisce nelle società industriali contemporanee (Ronza, 1978, pag. 230).

${ }^{13}$ Bretton Woods è la località del New Hampshire dove tra l'11 e il 22 luglio 1944 furono gettate le basi del sistema economico internazionale basato essenzialmente sul FMI e sulla World Bank, a sua volta composta di un gran numero di scatole cinesi (Brecher \& Costello, 
1996) come il BIRD, che gestisce in generale i prestiti e l'IDA, dal 1960 impegnata nel settore di alcuni crediti speciali soprattutto ai Paesi meno sviluppati. Cfr U. Allegretti, 2002.

${ }^{14}$ La creazione dell'UNCHS - al Vertice di Vancouver del 1976 - rappresentò il più forte segnale di attenzione ad un ambito di analisi potenzialmente in grado di distinguersi come polo attrattore e luogo di cordinamento di studi settoriali di campi diversi convergenti sul tema degli insediamenti umani.

${ }_{15}$ "Se le città non si occuperanno in una maniera più costruttiva della povertà, la povertà si occuperà in maniera più distruttiva delle città", è il passaggio più celebre del discorso (McNamara, 1982).

${ }^{16}$ Nell'occasione furono presentati 48 studi monografici sulle città dell' Africa Subsahariana, a dominante prevalentemente sociodemografica, e sociologica. A partire da questo periodo tende ad evidenziarsi una ripartizione dei compiti fra sociologi e antropologi (in genere concentrati a studiare le aree di campagna e i piccoli centri).

${ }^{17}$ In America Latina, il geografo brasiliano Milton Santos coniò a questo proposito la teoria dei due circuiti economici: quello superiore - il capitalismo - e quello inferiore, quello del sottosviluppo con le varianti e le contaminazioni attribuite al primo.

${ }^{18}$ La principale autovalutazione di progetti della World Bank risale al 1982 e riguarda 4 progetti-pilota lanciati tra il 1970 e il 1980 a El Salvador, Filippine, Zambia e Senegal (Kear \& Parris, 1982). Sul terzo - il meno riuscito - sarà pubblicato solo un rapporto di sintesi 'monco'.

${ }^{19} \mathrm{E}$ ' traducibile con 'fattibilità economica', pur perdendo così certe sfumature soggettive. ${ }^{20}$ Ad esempio lotti piccoli, punti di acqua e latrine pubbliche invece che individualizzate, illuminazione pubblica e strade non pavimentate.

${ }^{21}$ Per maggion dettagli cfr. Allegretti 2000a, e Osmont 1995.

${ }^{22}$ La DSA misura la povertà urbana proponendo un' articolazione tra 'poveri classici', 'nuovi poveri' e 'popolazioni vulnerabili', ed elabora ipotesi di interventi pubblici ad alta intensità di manodopera, come la riqualificazione dell'ambiente o la raccolta dei rifiuti. Il risultato è di "privare i governi della capacità di lottare contro la povertà e di trovare risposte originali adatte al contesto specifico, mettendo al tempo stesso in una condizione difficile le associazioni e le organizzazioni sociali che lavorano su questo terreno ma che, seguendo un approccio diverso, rischiano di non poter contare su alcun sostegno finanziario" (Osmont, 2002, pg. 19).

${ }^{23}$ Il $20 \%$ dei lotti urbanizzati finanziati dalla Banca Mondiale fino al 1985 vennero concessi a famiglie appartenenti agli scaglioni superiori di reddito della cittadinanza (Baum e altri, 1987).

${ }^{24}$ In America Latina - dove fu realizzato il maggior numero di interventi nel settore urbano (18 tra il 1972 e il 1980) essi tardarono ad essere accettati, tanto che solo 5 ne vennero impiantati prima del 1977.

${ }^{25}$ Del resto, per come furono strutturate ricerche e valutazioni, tutti i dati appaiono oggi incontestabili (Osmont, 1995); e comunque risulta piuttosto difficile valutare criticamente il reale impatto quantitativo e qualitativo avuto dai vari progetti sui diversi Paesi. ${ }^{26} \mathrm{La}$ nozione era solo indirettamente adombrata nell' articolo $1^{\circ}$ dello statuto dell'organismo internazionale scritto nel 1945 e modificato nel 1989 e da quello dell'IDA (la sua filiale per i Paesi meno sviluppati): esso passò ad indicare non più un lungo processo storico ma, tutt'a un tratto, un'immagine atemporale del mondo sviluppato, trasferita verso quelli che costituivano ancora il mondo sottosviluppato (Osmont, 1995).

${ }^{27}$ In tal senso risuona ironica la descrizione fatta dell'ormai ex-presidente della Banca Mondiale McNamara dal suo successore Senghor, che lo definì poeta dell'azione (McNamara, 1982).

${ }^{28}$ È il caso del Burkina Faso, che solo nel 1990 accetterà le proposte di aiuto formulate dalla World Bank nel 1987.

${ }^{29}$ Per 'aggiustamento' si intende il risanamento finanziario, la riformulazione delle politiche settoriali e di alcuni capisaldi normativi, la riduzione dei funzionari e la riforma amministrativa, cioè nel complesso 'l'aumento dell'efficacia del settore pubblico' (Osmont, 1995).

${ }^{30}$ Oltre 100 sono stati i Paesi al centro di monografie sul tema tra il 1993 ed il 1995, per un costo superiore ai 15 milioni di \$ (Osmont, 1995).

${ }^{31}$ Secondo Bretaudeau (1986), limitare uno studio della Banca Mondiale ai soli aspetti finanziari delle sue operazioni sarebbe ignorarne l'essenziale; essa ha sempre teso, infatti, a porsi un ruolo più vasto di semplice organismo finanziario interessato a facilitare gli investimenti di capitale consacrati a fini produttivi, divenendo una vera e propria istituzione 
di sviluppo, un'agenzia internazionale di expertise e consulenza, i cui prestiti vengono vincolati a delle riforme che servano a creare e radicare quel quadro istituzionale, tecnico e finanziario dello sviluppo così come concepito dalla Banca stessa.

${ }^{32}$ Dal 3\% del 1980 ad un 7-8\% medio del 1990 sul totale dei prestiti concessi dalla Banca (Osmont, 1995), pur sempre complessivamente insignificante pertanto. Nel 1992 il totale dei prestiti del BIRD e dei crediti dell'IDA concessi al settore urbanistico sono stati di 13 miliardi di dollari (cfr. Rapporto annuale della World Bank, 1992).

${ }^{33}$ Osmont (1995) pag. 9.

${ }^{34}$ Per la Banca Mondiale essa è "la maniera di esercitare il potere nella gestione delle risorse economiche e sociali in un paese in via di sviluppo" con un occhio attento a massimizzare il controllo sui costi di gestione (Osmont, 2002, pg. 17)

35 Il ruolo crescente delle ONG nell'ambito degli interventi della World Bank è un dato reale; se prima del 1988 esse venivano assunte come partner in una media di 15 progetti all'anno, nel 1988 la media sale a 50 e raggiunge i 73 nel 1993 e 114 nel 1994, come rivelano alcuni Progress report dal titolo Cooperation between World Bank and NGOs. ${ }^{36}$ Osmont (1995) usa questi termini, motivandoli implicitamente con alcune ironiche esposizioni, ad esempio quella del Kit di Arnesi dello Sviluppo Partecipativo destinato a Project Manager che - attraverso sessioni da 30 minuti a due ore - pretenderebbe di raccogliere informazioni utili sulle comunità locali, riducendo a tempi e modalità appunto caricaturali procedure complesse di interazione fra attori dei processi di trasformazione urbana. ${ }^{37}$ Osmont (2002) sostiene la concretezza dei rischi di 'strumentalizzazione della povertà' ai fini della legittimazione delle misure di aggiustamento strutturale, e della partecipazione, in particolare di quella dei giovani, coinvolti in modo temporaneo mei progetti della DSA della Banca Mondiale e poi abbandonatoi a se stessi (pg. 19).

${ }^{38}$ L'onnicomprensiva espressione 'Sites-and-Services' (o anche 'Site \& Service' o 'Siteand-services') ha un senso solo se definita per via negativa come una varietà di proposte di complessità differente aventi come comune denominatore la caratteristica di non arrivare mai a fornire ai beneficiari un alloggio completo, oltre ad alcuni assi portanti come la necessità di massimizzare il recupero dei costi sostenuti nell'approntamento del programma (cost-recovery). L'escamotage illumina sulla difficoltà di dare un giudizio complessivo su politiche che mancano di una base comune abbastanza forte da permettere di confrontarle con criteri paritetici di simmetria; a partire dalla definizione dei target-group, esplicitati come 'a basso reddito' nei testi dell'UNCHS e della World Bank, ma in altri casi solo sottintesi da espressioni come 'alloggi a basso costo' o 'abitazioni popolari', e comunque in talune occasioni circoscritti alternativamente a coloro che possiedono redditi fissi seppur bassi e a rappresentanti dello strato medio dei gruppi sociali caratterizzati da entrate ridotte (come si chiarisce in alcuni documenti ONU del 1976) o invece solo ad attuali abitanti delle baraccopoli cittadine (Van der Linden, 1986).

${ }^{39}$ Van der Linden (1986) ha messo a confronto le varie definizioni operative e teoriche date nel tempo dei 'lotti urbanizzati' evidenziando come esse siano passate da formule sintetiche che prevedevano solo la creazione di aree divise in lotti delimitati da strade e serviti da urbanizzazione primaria, a programmi complessi che includevano un coinvolgimento istituzionale nella fornitura di abitazioni (sotto le diverse forme di utility walls, roof frame, shell o core houses) e accesso all'occupazione, ai materiali o al credito per i futuri abitanti. I cosiddetti 'Sites-and-Services project' comprendevano addirittura il montaggio di parti dell'abitazione; altre formule - invece - sottolineavano il rapporto stretto esistente con i paralleli programmi di regolarizzazione fondiaria.

${ }^{40}$ Molti di quelli di volta in volta rimarcati (alloggiare i poveri, aumentare lo stock di abitazioni permanenti, limitare le spese pubbliche, reinstaurare un controllo pianificatorio di tipo formale, dare impulso al settore delle costruzioni, offrire opportunità di lavoro e microimprenditoria, accelerare la formazione del capitale per le famiglie a basso reddito, razionalizzare gli investimenti pubblici, ecc.) risultano confusi con i diversi mezzi da utilizzarsi.

${ }^{41}$ Che passarono dai 62 progetti finanziati del periodo 1972/1982 ai 90 del biennio 1986/87 (cfr. Allegretti, 2000a).

${ }^{42}$ Quanto appare dagli accordi siglati con i vari Stati è in genere la realizzazione di un compromesso, nel raggiungere il quale la World Bank paradossalmente sembra essersi comportata come paladina degli oppressi (Ayres, 1983). In realtà essa è riuscita a vincere le molte resistenze degli Stati nazionali all'adozione di programmi Sitesand-Services (intesi come emulazione di alcuni processi informali di fornitura di 
alloggi a basso costo), perché - come afferma la critica neomarxista - minimizzare le responsabilità dello Stato nella fornitura di alloggi ai più poveri serve a mantenere lo status-quo, evadendo discussioni su questioni fondamentali come la riforma urbana, la tassazione progressiva e la speculazione edilizia e fondiaria.

${ }^{43}$ Alcune ragioni di questa ostilità alla riduzione degli standard possono essere spiegate con l'educazione tradizionalista di molti tecnici, e con una preoccupazione eccessiva per l'aspetto estetico dei progetti su cui giocavano ragioni di prestigio politico e professionale Tra l'altro anche in alcuni Stati del primo mondo la battaglia per il raggiungimento di alti standard qualitativi urbanistici e architettonici era stata da poco vinta - come in Italia - e non era facile abbandonare così presto una conquista recente.

${ }^{44}$ L' Incremental Development Scheme in teoria non è un'opzione nuova, semmai un'opzione riscoperta e affinata. Sharma (1990) sottolinea che già negli anni '40 in India molti Municipal Acts prevedevano cosiddetti 'hutting grounds', e ne gli anni '60 in Turchia nacquero con lo stesso spirito le 'squatter prevention areas' che - mal amministrate - divennero comodi investimenti per arrampicatori e speculatori della classe media (Marcussen, 1982). Nel 1986, poi, John F. Turner ne rilanciò il 'ruolo salvifico' durante una conferenza internazionale, cosicchè oggi l'IDS rappresenta - dopo le prime sperimentazioni corrette in base agli errori evidenziati dalle passate esperienze - un modo di intervenire sulla politica degli alloggi offrendo nuove alternative alle suddivisioni illegali di terreni, attraverso la fornitura di lotti non infrastrutturati ad assegnatari stimolati verso forme di risparmio comunitario mirate al finanziamento e alla costruzione collettiva ed incrementale (per isolati o subquartieri) dei servizi e delle attrezzature necessarie, senza alcuna forma di sussidio diretto.

${ }^{45}$ Dato il carattere particolare dei primi progetti di IDS finora sperimentati ed il loro stretto legame con i contesti locali, ritengo che le indicazioni migliori per comprenderne la natura possano venire da una descrizione 'di caso': suggerirei a tal fine il caso di Hyderabad in Pakistan (best practice ONU per cui cfr. box 1 in Allegretti 2000a, corredato da ampi riferimenti bibliografici), che ha ormai oltre un decennio alle spalle ed una vasta letteratura critica che lo riguarda, e può aiutare a valutarne nel medio termine alcune conquiste innovative rispetto al modello dei Sites-and-Services.

${ }^{46}$ Questo riconoscimento de facto di una pratica diffusasi fin nel $40 \%$ dei casi - seppur irregolarmente (Swan et al., 1983) - porterà all'eliminazione delle norme restrittive che nei primi progetti-pilota vietavano affitti e subaffitti delle unità costruite; e garantirà implicitamente nuovi e più ampi benefici indiretti generati dai progetti sulla popolazione ed il sistema dell'abitazione nel suo complesso (Van der Linden, 1986).

${ }^{47}$ Questa ipotesi di scissione è contenuta in Laquian (1983).

${ }^{48}$ In tal senso alcuni tentativi compiuti a Bogotà nei tardi anni ' 70 con il coinvolgimento ufficiale di molti lottizzatori informali nella costruzione degli insediamenti detti 'Normas minimas' (in riferimento ad alcuni standard qualitativi imposti a chi si impegnava a partecipare), possono costituire un valido esempio da studiare ed emulare, per studiare formule intermedie fra gli insediamenti informali e quelli pensati dalle autorità nell'ambito delle nuove politiche dell'alloggio. Interventi simili sono stati tentati anche a Jakarta nei primi anni '80, pur con poca diffusione.

${ }^{49}$ L'utilizzo del cosiddetto 'Modello di Bertaud' che mette in relazione alle entrate familiari i costi degli elementi base e delle opzioni possibili per l'alloggio ai fini di un rapido calcolo dei costi è un'indicazione - per quanto ancora entro una formulazione rigida e matematica - di una volontà in questo senso, conscia delle complicazioni di tipo gestionale che la nuova tendenza alla flessibilizzazione dei parametri locativi e costruttivi introdurrà nei progetti (Van der Linden, 1986)

${ }^{50}$ Per di più, l'interesse della banca per la rapidità e la qualità d'esecuzione non può non aver alterato il concetto stesso di 'sviluppo progressivo' che sta alla base degli interventi, e che dovrebbe portare a valutazioni anch'esse progressive dei miglioramenti introdotti nel tempo, e non ad un giudizio statico dato su dati riferiti ai soli primi momenti di vita di ogni progetto.

${ }^{51}$ Già Turner, nel corso delle sue opere di 'seconda generazione', riconobbe la presenza di influenze distorcenti che motivavano eccezioni alle sue proposte di intervento, enumerando persino specifici Paesi dove condizioni non ottimali come la situazione politica, topografica, migratoria o la presenza di redditi infimi su vasta scala consigliava una riformulazione delle sue tesi (Turner, 1968).

${ }^{52}$ Il World Bank Institute ha questo scopo, e si reputa «l'arma segreta della Banca per facilitare il dialogo sulla govemance nei paesi in cui la negoziazione è difficile»(Osmont, 2002, pg. 24). ${ }^{53}$ Cfr. UNCHS-HABITAT, 1991. 


\section{3}

\section{Brasile, palcoscenico di una trasformazione}

\subsection{Introduzione}

Il consolidamento della democrazia nel Brasile contemporaneo è centrato più sull'esperienza democratica della società brasiliana che sull'istituzionalizzazione di diritti (Pacheco, 2001).

Se oggi il Brasile - considerato per gran parte del secolo scorso un paese alla periferia del pensiero teoretico-politico - è divenuto oggetto privilegiato di osservazione ed emulazione per contesti molto diversi, lo si deve forse anche al ruolo centrale che il tema della 'cittadinanza' ha avuto nell'ultimo quindicennio all'interno dell'agenda politica nazionale.

Infatti, principalmente attraverso la sperimentazione di 'pratiche' innovative in vari punti del suo territorio nazionale (prima ancora che in virtù di una coerente produzione teorica), il Brasile è stato in grado - dall'inizio degli anni ' 80 - di porre il proprio processo di democratizzazione politica al passo con un contesto internazionale attraversato da forti correnti decentralizzatici riguardanti la gestione dello Stato e delle politiche sociali, che hanno spesso generato una curiosa empatia tra agende "riformiste" $e$ "neoliberali" (Fedozzi, 1997, pag. 23). Recentemente (cfr. cap. 11), alcune delle pratiche innovative di gestione del territorio sperimentate a livello locale sono inoltre riuscite a dar forma e sostanza ad un rinnovamento del quadro nazionale delle politiche territoriali, che va in controcorrente rispetto alla ferma convinzione esposta da Hettne ne Le teorie dello sviluppo ('96), che cioè le politiche di austerità e di aggiustamento strutturale imposte dal FMI a molti Stati finiscano per ridurre la capacità [...] di progettare politiche alternative rivelando una capacità di condizionamento politicamente molto discutibile. $\mathrm{Nel}$ caso brasiliano, si può dire che "l'inaridimento progettuale" generato dai forti condizionamenti imposti nell'ultimo decennio da alcune istituzioni internazionali sia stato compensato a livello locale da esperienze 'creative' e 'riequilibranti', alcune delle quali persino replicate in contesti diversi con esiti interessanti. In tali esperienze, si è fatto spesso uso di nuovi strumenti di 
54 azione locale contestualizzata elaborati in stretta connessione con le caratteristiche storico/identitarie dei luoghi per cui erano stati creati, ma che con il tempo hanno evidenziato la possibilità di delinearsi come l'ossatura portante di un più ampio rinnovamento in senso progressista del quadro normativo nazionale, con particolare riguardo a quanto attiene al governo del territorio locale, e ai settori della pianificazione urbanistica e delle politiche della casa. Quest'ultima fase di sviluppo delle politiche territoriali brasiliane - che sarà il fuoco dei prossimi capitoli attraverso la descrizione delle recenti sperimentazioni della città di Porto Alegre - ha avuto come fulcro dell'impegno dei molteplici attori che lo hanno sostenuto la costruzione di ciò che in brasiliano si riassume nella parola 'cidadania', un concetto ampio che abbraccia le nostre circonlocuzioni di 'diritto di cittadinanza' (in senso oggettivo) e di 'senso di cittadinanza' (sentimento d'appartenenza con accezione soggettiva), disvelando un'accezione sostantiva e costruttiva della pratica della democrazia. Al contempo, le nuove pratiche tese a favorire una transizione virtuosa da una lunga tradizione autoritaria alle nuove sperimentazioni democratiche, in diversi ambiti locali hanno significato la ricerca del superamento dell'ambiguità del ricorso al decentramento e di alcuni dualismi connotanti della formazione sociale e politica brasiliana:

a) quello tra un quadro formale giuridico-instituzionale compatibile con una moderna società razional-democratica e pratiche socio-politiche di carattere patrimonialista/clientelare, incentrate sul 'jeitinho' e quindi sull'incapacità di separare le sfere 'pubblica' e 'privata' garantendo l'esercizio impersonale del potere, la prevalenza di regole universali di condotta e il rispetto di ogni forma di 'contratto sociale' nella gestione socio-statale (Fedozzi, 1997).

b) quello tra le pratiche 'formali' ed 'informali' di costruzione del territorio, rafforzato per lunghi anni dal persistere di una letteratura brasiliana marcata da un approccio dualistico alla questione della 'politica della casa', per lo più scisso da quello più generale delle politiche urbane e in ogni caso trattato come terreno di studio disgiunto o degli spazi dell'accumulazione o di quelli della miseria. ${ }^{2}$

Con simili obiettivi, molte delle esperienze brasiliane 'virtuose' dell'ultimo decennio risultano significative soprattutto se lette alla luce di un rapporto tra 'azione istituzionale riformatrice' e percorsi autonomi di 'trasformazione strutturale della società brasiliana', contenenti entrambi elementi di rottura e di continuità con i tradizionali modelli di dominazione patrimonial-burocratica che caratterizzano storicamente la gestione dello Stato in Brasile (Fedozzi, 1997). Questo dialettica tra conservazione e innovazione ha visto percorsi di elaborazione autonomi incrociarsi temporalmente con quelle forme di indicazione/imposizione provenienti da tendenze di sviluppo di ambito internazionale (quali il twin approach, cfr. cap. 2) come stimolo 'esterno' ad un rinnovamento delle politiche urbane. L'intreccio di questi differenti apporti allo sviluppo delle pratiche di trasformazione dei territori locali può meglio essere compreso ripercorrendo brevemente alcune tappe nodali del processo di urbanizzazione brasiliano, a partire da una lettura retrospettiva che concentri l'attenzione su alcune problematiche e fenomeni che rappresentano 'fuochi' essenziali del dibattito attuale.

È quanto cercheremo di proporre nei prossimi paragrafi, appoggiandoci ad 
alcuni degli studi brasiliani più interessanti di ambito geografico/urbanistico che da circa un decennio vanno acquisendo notorietà nel Paese, ${ }^{3}$ dopo che per oltre un trentennio molti dei testi più interessanti sono rimasti a lungo 'confinati' in ambito accademico, mentre quelli che hanno maggiormente circolato hanno proposto una visione 'incompleta'4 e spesso 'di parte', allineata cioè sul punto di vista del governo nazionale e delle sue agenzie specializzate nell'housing o nella pianificazione territoriale, e perciò incapaci di un' analisi critica oggettiva delle ultratrentennali politiche di 'non-risoluzio$n e$ ' delle emergenze e dei bisogni della cittadinanza nel campo delle politiche abitative e dei servizi urbani.

\subsection{L'esplosione della città informale e il mito della 'casa di proprietà'}

Ciò che oggi più colpisce nelle città brasiliane - come nella maggior parte delle città dei paesi periferici - è la segregazione urbana, ovvero il consumo differenziato dello spazio abitabile, la sua occupazione stratificata, l'organizzazione in zone spesso di 'grande omogeneità interna e di grande disparità della qualità spaziale' (Almeida, 1993) dove si tende a garantire flessibilità e diritto di scelta alle classi con maggior potere acquisitivo, relegando le altre categorie sociali nei ritagli spaziali da esse scartati, spesso conquistati per mezzo del fenomeno delle 'invasioni' o, più di recente, dalla crescita massiva di quello delle 'suddivisioni non autorizzate' o 'clandestinamente edificate', situate a metà strada tra illegalità e meccanismi di mercato.

Quando dagli anni '30 il modello di accumulazione dell'economia brasiliana si orientò verso l'espansione industriale e lo Stato avviò politiche per trasferire le risorse dal settore agro-esportatore a quello industriale e così regolare la relazione capitale-lavoro, lo sviluppo notevole delle città (specie lungo l'asse Sud-Sudest del 'Parco Industriale Nazionale' tra Rio e San Paolo) provocò una rapida trasformazione anche dei modi di abitare delle classi più povere della popolazione, in particolare del nuovo sottoproletariato in espansione e della forza-lavoro temporaneamente disoccupata che si addensava nei centri maggiori.

Così, mentre il livello di concentrazione nelle città passava dal $36,2 \%$ del 1950 al 75,5\% del 1991, le diverse modalità di 'subabitazione' si trasformavano e si rincorrevano come alternative privilegiate di abitazione per i ceti più disagiati, assumendo enfasi, modalità costruttive e caratteristiche variate nei diversi centri. Il fenomeno della cosiddetta 'favelizzazione' ${ }^{5}$ si è accentuato negli ultimi decenni soprattutto nelle 9 aree metropolitane del paese ${ }^{6}$ (Rizzo, 1997) dove i domicili in aree occupate illegalmente sono giunti a rappresentare il $78 \%$ del totale. Lo stesso modello escludente di occupazione dello spazio ha presto travalicato i confini metropolitani e ha preso piede "in altri punti dell'ambiente costruito, in una copia-farsa della commedia urbana brasiliana, molto più diabolica che divina" (Taschner, 1997).

Così, mentre la periferizzazione della popolazione metropolitana ${ }^{7}$ si è ovunque accentuata come fenomeno diffuso, anche le piccole città hanno cominciato a veder apparire favelas arrampicate sulle aree collinari o concentrate nei fondovalle inondabili. Se nel 1980 l'IBGE aveva rilevato raggruppamenti di abitazioni informali solo in 40 municipi con meno di 50.000 abitanti, nel 1991 questi erano diventati 209, concentrati soprattutto negli stati del Minar Gerais e del Rio Grande do Sul. Parallelamente, sul complesso delle 
abitazioni brasiliane, la percentuale complessiva dei domicili in favelas passava dall' $1,89 \%$ del 1980 al 3,28\% del '91 (corrispondente a oltre 1,14 milioni di abitazioni in favelas, con tasso di crescita del 7,65\% annuo), senza voler considerare che il censimento dell'IBGE era grandemente sottostimato, nella misura in cui la definizione di 'favela' adottata non considerava gli agglomerati con meno di 51 abitazioni.

Nel complesso, nel 1991 il numero di favelados [abitanti delle favelas] nel Paese ha raggiunto i 5,72 milioni, che rappresentano circa il 5,16\% della popolazione urbana e il 3,89\% di quella totale; numeri che certamente non fanno giustizia di tutti coloro che vivono nel quotidiano le difficoltà di risiedere in abitazioni irregolari, ma fanno i conti solo con quelli domiciliati in 'favelas', nella loro accezione ristretta di agglomerati su terreni 'invasi illegalmente' e abitati da un numero minimo prestabilito di famiglie. Oggi, del resto, si stima ufficialmente (con la certezza di forti errori 'per difetto') che, nel paese, oltre alle 808.000 famiglie residenti in abitazioni precarie, ve ne siano altri 3,3 milioni forzate alla coabitazione con altre, e 1,2 milioni incapaci di reggere i costi dell'affitto; cosicché il deficit di unità abitative familiari assommerebbe a oltre 5,4 milioni, una cifra che rappresenta il 14,5\% dello stock abitativo esistente del Brasile (Cfr. Fondazione João Pinheiro, 2000). Il fenomeno della sub- abitazione resta comunque difficilissimo da valutare nel suo complesso, anche visto che sono pochissimi nel Paese i comuni (persino nelle aree metropolitane) che possiedono un catasto completo delle favelas, periodicamente aggiornato in modo da permettere non solo una stima più veridica del fenomeno e della sua evoluzione, ma soprattutto una conoscenza dei domicili e della popolazione che vi risiede sotto il profilo 'qualitativo'.

\section{Box 1 - Le principali forme di 'sub-abitazione' in Brasile}

L' 'informale' e 1' 'abusivo' possono presentare molteplici forme e significati. Il mancato rispetto delle regole urbanistico/architettoniche è, infatti - come da noi - non solo una pratica di 'necessità' attribuibile agli strati più poveri della cittadinanza, ma anche un modo di agire adottato nei territori abitati dalle categorie sociali più agiate. Per queste ultime, anche in Brasile esistono forme di 'condono' - di competenza municipale - dietro pagamento di multe e accatastamento dei nuovi progetti. Quando si parla di 'città informale' o 'autocostruita', però, si intende però riferirsi e alle varie forme di 'squatting' (occupazione con costruzione ed autocostruzione) messe in atto in maniera spazialmente diffusa da gruppi sociali con ridotto potere di acquisto. In Brasile, le forme predominanti di risoluzione del problema dell'alloggio per tali gruppi variano sia con i luoghi che con il periodo storico. Taschner, mettendo insieme 20 anni di ricerche e politiche sulla città informale (1997), ne ha considerato 3 reiterantisi nel tempo e nello spazio:

1) I cortiços (abitazioni precarie affittate contemporaneamente a più famiglie che godono di servizi in comune) costituirono la prima forma di risposta alle carenze di alloggi durante tutto il lento processo di urbanizzazione e industrializzazione, dalla metà dell'Ottocento agli anni Trenta del Novecento. Il termine deriva dal portoghese antico, dove significava 'nido d'api' ed era spesso sostituito dalla parola spagnola 'casa de corredor' che ben rendeva l'idea di una sequenza di stanze abitate con un servizio in comune, per lo più in abitazioni fatiscenti dei centri storici maggiormente degradati. A Rio de Janeiro è conosciuto anche come cabeça de porco (testa di porco) a causa di un famoso cortiço carioca, simbolo dell'antro antitetico alla casa igienica dipinta dalla propaganda positivista o igienista di inizio secolo.

2) Le occupazioni illegali di terra (favelas oppure nuclei se con meno di 51 abita- 
zioni o se privi di una struttura organizzativa che li caratterizzi come 'favelas') sono i quartieri informali che insistono su aree pubbliche o private senza il consenso esplicito dei loro proprietari, e a seguire presentano altre numerose irregolarità giuridiche, urbanistiche, amministrative e finanziarie. Storicamente ebbero tempi diversi di sviluppo nelle varie località del Paese. A San Paolo fu intorno al 1961 (dopo il blocco degli affitti imposto dalla Lei do Inquilinato) che si ebbe un'estensione a macchia d'olio dell' area urbanizzata, ma solo negli anni ' 70 si ebbe la grande esplosione delle occupazioni. A Rio, le occupazioni illegali di terra si concentrarono da subito sui 'morros' [i rilievi montuosi che segnano il territorio cittadino], tollerate e spesso incentivate già a partire dagli anni '10; ed è proprio dalla prima di queste invasioni storicamente registrata (risalente al 1897) che si deve il nome stesso di 'favela'. A Belo Horizonte, città pianificata nel 1897 come centro amministrativo dello stato minerario del Minas Gerais, già due anni prima dell'inaugurazione figuravano aree invase da 3000 lavoratori incaricati di costruire la città, e stranamente non previsti come abitanti - neppure temporanei - dal piano costruttivo. Nel 1991 Belo Horizonte ha raggiunte i 400.000 favelados (20\% della popolazione) dando forma ad alcune delle prime esperienze pioniere di intervento diretto sulle aree occupate. Fu invece a Salvador Bahia, colpita negli anni '40 da un forte esodo rurale, che si ebbe la prima grande 'invasione organizzata', il primo grande atto politico dei favelados nella rivendicazione dei diritti alla casa. La città - abituata ad ospitare gli immigrati con soluzioni in affitto direttamente provenienti dalla tradizionale 'enfiteusi' (e che spesso confinavano le classi più povere nelle aree centrali degradate) - dovette far fronte tra il 1946 ed il 1950 a ben 26 invasioni organizzate che occuparono oltre 253 ettari del suo territorio. Già nel 1990 la città è arrivata a contare 357 nuclei invasi dove risiedeva almeno il $30 \%$ della popolazione (591.000 persone).

3) I 'loteamentos', ovvero lottizzazioni o parcellamenti periferici (irregolari o clandestini). Proliferanti a San Paolo già dagli anni '40, si sono estesi fino a diventare in molte città la forma predominante di risoluzione del problema dell'alloggio soprattutto per la classe medio-bassa, desiderosa di una duratura casa propria e di un'apparenza di vita più 'dignitosa'. Essi si caratterizzano per essere suddivisioni del terreno in lotti irregolari in relazione ai regolamenti edilizi e alle procedure amministrative, ma almeno non frutto di invasione e commercializzati legalmente (o pseudolegalmente, spesso facendo leva sulla buona fede dell'acquirente). Qualche sfumatura diversa smorza un po' quest'ultima affermazione, specie nei casi di ter reni acquistati da grileiros, cioè persone che 'vendono' terre di cui non sono proprietarie. In ogni caso tali compravendite permangono il più delle volte non correttamente registrate e pertanto si possono muovere obiezioni alla definizione qui riportata.

Esistono poi anche formule ibridate con le risposte che l'istituzione ha tentato nel tempo di proporre. In fondo, anche le occupazioni programmate di condomini e quartieri popolari non conclusi (caratteristiche di un movimento organizzato dei tardi anni '80) e le cosiddette 'città satellite' possono a loro modo essere considerate parte della storia delle invasioni, con il loro opposto modo di innestare soluzioni autorganizzate su soluzioni politiche, o - per converso - soluzioni ufficiali su scelte autonome di movimenti di lotta urbana o di singoli cittadini mossi dall'urgenza di dare soluzione al problema-casa.

L'esempio più classico è quello offerto da Brasilia, città pianificata per eccellenza, nei cui immediati dintorni erano state previste città temporanee per i lavoratori impegnati nella costruzione della nuova capitale. Secondo Jaccoud (1991) già dal 1958 nel maggiore di questi centri (Cidade Livre, oggi Núcleo Bandeirante) furono proibite nuove costruzioni e cominciarono le prime invasioni di terra, che costrinsero il Governo nel 1960 a dichiarare la necessità di rendere stabile e urbanizzare la città. La misura si rivelò presto insufficiente per il vasto numero di lavoratori che affluivano in cerca di impiego e quelli previsti come temporanei che decidevano di rimanere (così come accaduto a Belo Horizonte). Cosicché si dette impulso alla 
costruzione delle cosiddette città satellite, soluzione ibrida perché forzata da occupazioni spesso già spontaneamente avvenute (in contrasto con il carattere provvisorio degli accampamenti dei lavoratori e delle invasioni) ma configurantesi come iniziativa ufficiale, il cui impianto obbedisce a determinati piani e tracciati. Sempre nel 1958 - prima dell'inaugurazione di Brasilia - nacque Taguatinga dove furono spostati tutti gli invasori che avevano occupato terre dentro i limiti del 'Plano Piloto'; nel '59 fu la volta di Sobradinho, nel 1961 di Gama e nel 1971 venne creata Ceilândia il cui nome addirittura era un discendente diretto della politica delle rimozioni, provenendo da CEI - sigla della Campagna di Sradicamento delle Invasioni adottata dal Governo Federale. Nessuna di queste soluzioni riuscì comunque a bloccare il ricorso alle forme autorganizzate di lotta al problema della casa, come dimostrano gli oltre 40.000 abitanti di Vila Paranoà costituita nel 1957 dagli operai che costruirono la Diga di Brasilia, e le favelas di Vila Carroceiros, Areal, 110 Norte o Vila Planalto, quest'ultima nata tra la sede del governo e la residenza presidenziale con gesto politico nell'ubicazione strategica. Del resto il 'problema' da tempo risiedeva al di fuori del 'Piano Pilota', visto che già nel 1970 la popolazione delle città-satellite (i cui lotti tendevano sempre più a trasformarsi in cortiços sovraffollati) rappresentava il $65 \%$ della popolazione dello Stato e nel 1991 ha raggiunto il 75\% (Taschner, 1997).

Se i dati generali sulla città autocostruita e le sue recenti tendenze 'espansive' sono facilmente riconducibili alle diverse crisi economiche internazionali e brasiliane che - anche di recente - sono andate riflettendosi nella variazione degli indicatori di crescita tradizionali ${ }^{8}$ portando all'inflazione che nel 1994 il governo Cardoso ha tentato di arginare con il Piano Real (la nuova moneta che ha retto fino alle grandi crisi del gennaio 1999 e dell'estate 2002), vi sono comunque altri fattori 'strutturali' che influenzano i fenomeni di aumento della 'città informale'.

Tra questi, uno dei più interessanti riguarda i 'limiti autodistruttivi' del 'mito della casa propria' veicolato soprattutto durante la dittatura nel quadro di una "produzione capitalista [che] tende ad elevare lo standard di consumo dei lavoratori, ma nel mentre ha bisogno di dominarlo non solo nel luogo di lavoro, ma anche nell'ambito della residenza" facendo dell'abitazione "la componente più importante della cesta di consumo" della maggioranza dei lavoratori, che hanno mostrato di prediligere "l'eminazione degli sprechi ad essa legati (come l'affitto), facendo appello ad espedienti che caratterizzano un 'submercato' o 'mercato informale" piuttosto che a "forme capitaliste di produzione e commercializzazione” (Maricato, 1987).

In questa ottica di lettura, sarebbe paradossalmente possibile perfino accettare il termine 'scelta di vita' per caratterizzare alcuni aspetti del ricorso alle occupazioni in favelas, ai lotti irregolari o clandestini, all' autocostruzione e ai cosiddetti "cortiços" (cfr. Box 1). Nel tempo, infatti, i censimenti dell'Istituto Brasiliano di Geografia e Statistica hanno evidenziato una crescita dell'indice percentuale di case di proprietà abbastanza alto - anche all'interno della classe lavoratrice ${ }^{9}$ - per un paese con alta disparità dei redditi come il Brasile. Case di proprietà o - più spesso baracche di proprietà; qualcosa comunque che offra sicurezza psicologica e sensazione di progresso, e che da un primo momento in cui si caratterizza per il suo valore d'uso possa acquisire lo status di elemento di produzione di rendita (Rolnik e Bonduki, 1979). 


\section{BOX 2 - La scarsa rappresentatività dei da ti numerici nazionali sulla città informale}

La consistenza della città autocostruita nell' ambito nazionale brasiliano è difficilissima da valutare, cosicché molte delle analisi finora condotte mantengono uno scarso livello di rappresentatività. I censimenti decennali dell'IBGE (Istituto Brasiliano di Geografia e Statistica) hanno, ad esempio, un grosso difetto: a parte l'essere fondati sull'autodenuncia da parte degli stessi favelados (con problemi quindi di onestà, di livello scolare, di timore, sfiducia o di voglia di rivincita sulle istituzioni, ecc.) presentano dati sottostimati, nella misura in cui la definizione di 'favela' adottata non considera gli agglomerati con meno di 51 abitazioni (Cfr. IBGE - Base Operacional. Manual de Delimitação De Setores e Zonas de trabalho GR-7.01). La sottostima va in due direzioni: diminuisce il numero di abitazioni 'favelate', escludendo tutte quelle appartenenti agli agglomerati minori, e taglia fuori dalle "classifiche' dei livelli di informalità stilate dall'IBGE tutti i municipi che hanno solo favelas piccole. Se al primo errore si può porre rimedio, incrociando i dati con quelli dei singoli municipi, nel secondo caso spesso ben poco vi è da fare. Bisognerebbe municipio per municipio - verificare la presenza di altre rilevazioni a carattere locale ed integrare il quadro di lettura nazionale del problema. Vi sono tra l'altro amministrazioni che non mostrano nessun interesse a correggere le sottostime: ad es. Curitiba, che si presenta come campione di un'efficiente urbanistica di impianto strategico-funzionalista, non dà rilevanza pubblica alle ricerche sulla povertà nel comune e pare accontentarsi dei rilevamenti nazionali che la collocano come l'ultima delle metropoli brasiliane per numero di favela dos (1,5\% sulla popolazione totale) e che attestano lo scaricarsi del problema sui municipi circonvicini $(26,2 \%$ del totale dei favelados dello Stato).

Un esempio chiarificatore dei due problemi lo può offrire il caso di San Paolo, tra le poche città brasiliane a possedere da tempo un catasto completo delle favelas periodicamente aggiornato. I dati rilevati dal Comune nel 1987 rivelavano l'esistenza di 1592 agglomerati favelati (Prefeitura de São Paulo, 1989) contro i 629 valutati dall'IBGE nel 1991. Un esame più attento fatto dall' Amministrazione Erundina nel 1992 rivelò che delle 1805 favelas allora censite ben 1070 presentavano meno di 49 domicili al loro interno (Prefeitura Municipal de São Paulo, 1992); la sottostima della popolazione favelada dell'IBGE - che secondo il Comune di São Paulo nel 1980 er a stata del $24 \%$ e nel 1987 del $37 \%$ (Taschner, 1997) - risultò in quest'ultima analisi superiore al 59\%, nonostante in questo caso fosse da riferirsi al numero di favelas piuttosto che al numero degli abitanti. Senza contare il fatto che spesso i Censimenti IBGE considerano insediamenti che presentano continuità fisica come un unico insediamento, dimenticando cioè dati che la maggior conoscenza dell' ambito locale può invece rilevare, prendendo in carico differenze spesso consistenti fra aree invase contigue, oltre che dando valore alle percezioni 'soggettive' legate al senso di appartenenza degli abitanti al proprio 'habitat' inteso come 'luogo unico'. Per quanto attiene il 'peccato originale' della sottostima che la definizione di 'favela' dell'IBGE determina sulla valutazione dei comuni minori, Bueno (1995) ha rilevato come ben 8 dei 17 Comuni dello Stato di San Paolo - ricchi di piccole aree occupate da costruzioni abusive - fossero stati considerati privi di favelas nei rilevamenti condotti tra il 1980 e il 1991.

Raramente il tipo di inchieste finora condotte consentono una valutazione 'qualitativa' e ravvicinata delle aree studiate, fondamentale per capire i mutamenti dei termini del problema. Sta agli studi 'locali' più avanzati e multidisciplinari - che iniziano oggi ad essere condotti - permettere non solo una stima più veridica dei fenomeni numerici legati al problema delle varie forme di 'subabitazione' e della loro evoluzione, ma soprattutto una conoscenza dei domicili e della popolazione che vi risiede che sia in grado di suggerire le soluzioni caso per caso più indicate, invece di pretendere di elaborare metodi standardizzati di intervento da replicare alle diverse latitudini e nelle condizioni più diverse del paese. 
Al miglioramento degli aspetti di conoscenza dei fenomeni della cosiddetta 'subabitazione'potranno dare una mano le nuove pratiche partecipative e di 'corpo a corpo' che molti comuni negli ultimi 15 anni si sono mostrati capaci di attivare.

Ciò spiega perché questo libro tenda a soffermarsi maggiormente sugli aspetti qualitativi dell'organizzazione delle favelas e dell'intervento su di esse, piuttosto che spendere pagine ad esporre dati quantitativi spesso scarsamente significativi.

Maricato (1987) ha sottolineato e analizzato il significato del mito della 'casa propria' nelle politiche brasiliane della seconda metà del ' 900 che ne sfruttarono il ruolo ideologico conservatore senza peraltro offrire soluzioni e risposte alle necessità della popolazione più povera. Oggi che l'idea su cui tanto ha martellato il ventennio del regime militare (cominciato nel 1964) ha fatto breccia in maniera difficilmente reversibile nelle tendenze della popolazione brasiliana di ogni strato sociale, si può solo prendere atto che i presupposti da cui si era partiti nel diffonderla erano distorti, incompleti per parzialità, e poco lungimiranti. È vero, infatti, che l'ambizione alla proprietà privata dell'abitazione può costituirsi come elemento di divisione degli strati sociali inferiori, ad esempio rendendo sostanzialmente improponibili le forme di riscatto e regolarizzazione fondiaria intese a partire da una base di azione 'collettivistica' e 'comunitaria', come l'usucapione collettiva (Alfonsin B., 1997). Essa non ha però rappresentato un ostacolo determinante nell'impedire l'organizzazione degli stessi gruppi sociali, nel momento in cui essi hanno scoperto interessi comuni nei luoghi di residenza e di lavoro, o magari addirittura nel percorso eventuale tra l'una e l'altro (Harvey, 1982). Questo è forse ciò che il governo brasiliano non sembra aver compreso quando, nel chiudere nel 1986 il BNH (Banca Nazionale dell'Abitazione) ha rifiutato di rifondarlo come 'Banca dell'Abitazione e dello Sviluppo Urbano' come proposto dall'Istituto degli Architetti Brasiliani e da altre entità professionali e della società civile (Magadan, 1998i). Così facendo, ha consacrato la settorializzazione della 'housing policy', staccandola da quella urbana e separando la propagandata e poco realizzata politica del 'diritto alla casa' da quella del 'diritto alla città'.

Il risultato è stato che la crescente socializzazione delle condizioni urbane di vita ha introdotto un moto contrario rispetto all'individualismo del domicilio familiare, contrapponendovi la 'collettivizzazione crescente del consumo della città' (Maricato, 1987) che è andata organizzandosi per rispondere alla distribuzione asimmetrica e disuguale di attrezzature e servizi urbani sul territorio. Il cosiddetto effetto 'di vicinanza' e i benefici diretti e indiretti degli investimenti pubblici sulla valorizzazione dei suoli, hanno alla lunga determinato una lotta per disputarsi gli investimenti che si è tradotta in uno nuovo scontro sociale fra chi di essi necessita per sopravvivere o per migliorare condizioni precarie di vita e chi vuol solo appopriarsi della rendita prodotta dalla terra urbana. Così, verso la metà degli anni '80, in Brasile sono emersi quelli che Lojikine (1981) ha definito 'gli aspetti progressisti della socializzazione dei mezzi di consumo e di agglomerazione spaziale', residenti ad esempio nel carattere collettivo del consumo delle attrezzature e servizi. Ciò ha condotto a lotte collettive espressesi nei movimenti urbani che presero a svilupparsi con forza a partire dalla decadenza del regime militare ${ }^{10}$ canalizzando le proprie energie nel Movimento per la Riforma Urbana, che 
ha avuto notevole peso sull'elaborazione della Costituzione del 1988 e soprattutto - sul dettagliamento del suo capitolo sulla Riforma Urbana, realizzato con la Legge 10_257 del 2001 chiamata 'Statuto della città'.

In questo contesto la città brasiliana è divenuta palco di una lotta specifica sviluppatasi intorno all'ambiente costruito (Maricato, 1987), sullo sfondo della lotta maggiore fra capitale e lavoro. Per questa via, nemici generici sono stati in grado di divenire nemici specifici (ibidem), seppur non sempre gli strati di minor reddito della popolazione sono stati in grado di percepire direttamente come tali i proprietari di terre, l'industria delle costruzioni e il capitale immobiliare, sovente responsabili delle loro pessime condizioni di alloggio e di vita urbana; spesso si sono limitati a riconoscere come 'nemico specifico' il loro massimo rappresentante, cioè lo Stato, divenuto così l'obiettivo principale delle rivendicazioni dei movimenti urbani.

É in questa situazione che si sono trovati a dover agire i molti programmi 'decentrati' di intervento nel campo dell'abitazione che hanno preso avvio all'inizio degli anni '90, ormai ridotti a fantasmi visto che per lo più intervengono quasi solo nell'ambito della regolarizzazione della città spontanea, secondo quella forma di 'disimpegno istituzionale' o di 'realismo istituzionale' che la Banca Mondiale ha contribuito a diffondere già dalla metà degli anni '70 (Osmont, 1995).

Impostazioni come quelle proposte da varie coalizioni progressiste negli anni '90 (come nel caso di Porto Alegre) hanno puntato a trasformare queste lotte in 'progetto', mirando - prima ancora che a fornire una risposta al problema concreto dell'alloggio - a ribaltare i termini con cui la questione era stata finora posta. Hanno cioè mirato in primo luogo a scardinare l'ignoranza degli strati sociali più emarginati, a mettere a nudo le interrelazioni fra gli interessi che si sviluppano nella città e a ricostruire la percezione di un ruolo benigno dello Stato nei loro confronti attraverso una ricreazione filologica del senso stesso della parola 'cittadinanza'.

In sostanza - come centro e motore del loro programma - hanno cercato di gettare quella 'maschera' che le Istituzioni da decenni sventolavano nel tentativo di tener celato il controllo esercitato sulla città dal capitale immobiliare (Maricato, 1987) e che una società resa più democratica dall'inversione e dalla revisione collettiva delle sue priorità di intervento non potrebbe accettare se non a prezzo di forti contraddizioni e conflitti. ${ }^{11}$

\subsection{Città informale e disciplina urbanistica all'inizio del Novecento}

Visitare gli slum della capitale federale è sufficiente per farsi un'idea chiara del problema. Da essi, si può dire, vengono tutte le miserie morali e materiali e tutti i vizi. [...] Battersi contro gli slum è prender parte a una battaglia per innalzare la moralità e per migliorare la salute fisica della razza $[\ldots]$ In questo ambiente ripugnante, il lavoratore forma la propria famiglia e stabilisce la propria casa [...] e cresce l'odio contro coloro che egli ritiene responsabili della sua miseria [...] Le ragazze perdono il senso dell'onore e della dignità [...] Essi devono essere demoliti (Mendoza, cit. in Outtes, 1997).

La relazione presentata da uno dei fondatori dell'Instituto Central de Arquitetos di Rio al Primeiro Congresso de Habitaçao, tenutosi nel 1931 a San Paolo, evidenzia i pregiudizi e la paura delle masse popolari che all'inizio 
del '900 ispiravano molti dei professionisti coinvolti nel movimento che accompagnò la genesi del discorso urbanistico in Sud America, e specialmente nelle maggiori città del Brasile e dell'Argentina, impreparate ad accogliere in poco meno di 100 anni un'esplosione urbana che - in mancanza di dotazioni infrastrutturali adeguate - premeva sui centri storici, alla ricerca di una contiguità impossibile tra residenza e luoghi di lavoro.

\section{Popolazione delle maggiori città di Brasile e Argentina dal 1838 al 1928 (in migliaia di abitanti)}

\begin{tabular}{|c|c|c|c|c|c|c|c|c|c|c|}
\hline Città & $\mathbf{1 8 3 8}$ & $\begin{array}{c}\mathbf{1 8 7 0 /} \\
\mathbf{7 2}\end{array}$ & $\mathbf{1 8 9 0}$ & $\mathbf{1 8 9 3}$ & $\mathbf{1 9 0 0}$ & $\mathbf{1 9 0 6}$ & $\mathbf{1 9 1 0}$ & $\mathbf{1 9 1 4}$ & $\mathbf{1 9 2 0}$ & $\mathbf{1 9 2 8}$ \\
\hline Buenos Aires & 62 & 228 & 520 & 678 & - & 1063 & - & 1577 & 1738 & 2230 \\
\hline Recife & - & 117 & 112 & - & $\begin{array}{c}100 / 1 \\
13\end{array}$ & - & - & - & $\begin{array}{c}233 / \\
239\end{array}$ & 346 \\
\hline Rio de Janeiro & 137 & 275 & 523 & - & 688 & 811 & - & - & 1158 & - \\
\hline Rosario & 3 & 29 & - & 92 & 100 & - & 200 & 223 & 250 & 1910 \\
\hline San Paolo & 22 & 31 & 65 & - & 240 & 279 & - & - & 579 & 822 \\
\hline Porto Alegre & 16 & 34 & 52 & & 73 & & 130 & & 179 & $\begin{array}{c}200 / \\
210^{*}\end{array}$ \\
\hline
\end{tabular}

* Dati ottenuti per interpolazione, integrando Outtes (1997); Monteiro (1995), Souza e Muller (1997).

Già dalla fine dell'Ottocento, i fenomeni della città spontanea e delle occupazioni di terra andavano consolidandosi nei maggiori centri del continente. ${ }^{12}$ Lo spirito degli interventi statali mirati ad espellere dalle città i fenomeni di subabitazione avevano il fine di eliminare dalla struttura urbana gli ostacoli che si frapponevano allo sviluppo economico faticosamente raggiunto, riducendo l'impatto delle emergenze di sanità pubblica e facilitando la circolazione delle persone e delle merci attraverso i primi piani di ristrutturazione urbana. ${ }^{13}$ All'inizio si ricorse a soluzioni provvisorie, mentre l'idea di pianificazione urbana come progetto che prenda in considerazione l'intera città prese piede in Sud America solo nel corso dei primi due decenni del Novecento, ${ }^{14}$ dando origine ai primi piani sovente redatti con l'apporto determinante di professionisti di origine europea, che segnarono una svolta nel modo di pensare le città e intervenire su di esse.

Se, infatti, le esperienze precedenti si erano limitate ad aprire nuove strade per agevolare la circolazione o rinnovare i centri urbani degradati e intasati da favelas e cortiços, ora appariva evidente la volontà di tentare nuovi approcci fondati su una conoscenza dettagliata della situazione urbana e su indagini specifiche (su crescita demografica, condizioni sanitarie, epidemie del passato, sistemi fognari e di trasporto, e sulla stessa biografia della città) con l'aiuto di istituzioni appositamente create ed incaricate anche di studiare leggi e regolamenti edilizi nuovi. ${ }^{15}$ In questo periodo, l'urbanistica venne delineandosi come nuovo tipo di conoscenza, che conteneva un progetto di moralizzazione e regolazione sociale attraverso la gestione della città. La sua istituzionalizzazione come disciplina autonoma ebbe luogo, sia in Argentina che in Brasile, "nel corso di regimi statalisti e illiberali" (Outtes, 1997). ${ }^{16}$

I progetti che presero avvio in tale quadro politico puntavano quasi sempre a modificare gli atteggiamenti della popolazione inducendo in essa determina- 
te norme di comportamento quotidiano che dessero corpo ad un preciso ritratto delle città, della società e del potere istituzionale. Non è un caso che il ruolo svolto dalla cronaca nera nella costruzione dell'immagine dei criminali corrisponda esattamente alle descrizioni degli urbanisti sugli abitanti delle baraccopoli, spesso fatte passare come forma volontaria di autosegregazione dalla società 'deviata'. La stessa diffusa presenza di giornalisti all'interno delle Commissioni per i Piani Regolatori di molte città brasiliane all'inizio del '900 testimonia quanto la propaganda costituisse parte integrante del movimento per l'urbanistica, dominato dall'idea di un determinismo dell'ambiente sulla società che rendeva sua missione primaria l'invertire i processi che avevano introdotto note di 'indesiderabilità urbana'. E, infatti, i proclami fatti dalle colonne della prima rivista urbanistica brasiliana, Urbanismo e Viação (nome rivelatore del dualismo con cui erano lette le principali componenti della pianificazione cittadina) recitano che "L'obbiettivo principale della pianificazione urbana sono abitazioni salubri, luoghi di lavoro rispettosi dell'igiene, vivaci luoghi di svago e gusto estetico per la felicità dell'uomo. I pubblici Poteri dovranno provvedere grandi spazi liberi perché i poveri possano praticare gli sport e il giardinaggio e avvantaggiarsi del tempo libero, perché le statistiche hanno provato che dove ci sono parchi, piscine, piazze, campi da gioco, [...] la moralità è cambiata e la delinquenza minorile diminuisce". ${ }^{17}$

La riforma sociale apparve come il luogo e il modo per attuare il cambiamento, all'interno delle politiche urbane; ne è prova l'insieme degli interventi al $1^{\circ}$ Congreso Latinoamericano de la Vivienda Popular del 1939. I piani apparivano gli strumenti più consoni per migliorare le città, in virtù del loro punto di vista totalizzante, e tanto più col penetrare del positivismo (Godoy, 1923; Nachmann, 1977). ${ }^{18}$ Con uno sfasamento - neppure eccessivo - rispetto all'Europa, a partire dagli anni '20 la zonizzazione venne sistematicamente introdotta in Sudamerica, in ottemperanza ai dettami del taylorismo e della razionalità produttiva industriale applicata alla pianificazione urbana, pur essendo il contesto caratterizzato da economie ancora prevalentemente agricole in cui gran parte della popolazione viveva ancora fuori dalle pur elefantiache città principali.

La questione dell'alloggio restò a lungo il vero nodo dell'urbanistica, intesa all'epoca - specie in Brasile - come una sorta di ampliamento di scala dei problemi abitativi, usati come metro di giudizio sull'operato di amministrazioni che cominciavano ad essere oggetto di dure critiche centrate sul problema della necessità di una continuità del potere per garantire risultati visibili.

In questo quadro, la critica all'inefficacia istituzionale si tradusse spesso in un rifiuto della democrazia tout court, o almeno nel vagheggiamento di un modello di governo centralizzato con una struttura retta da tecnici. Del resto, mentre in Europa i fascismi erano alle porte, in Sudamerica il modello dittatoriale trionfava; e in Brasile furono spesso gli urbanisti - propugnatori della pianificazione controllata e centralizzata - a ricoprire il ruolo di Sindaci o assessori. ${ }^{19}$ Il Nazionalismo si costituì quindi come elemento di rilievo all'interno dell' Urbanistica del primo quarantennio del '900; una delle componenti dello 'spirito del tempo' che nutrì di sé molti movimenti, ${ }^{20}$ materializzandosi nell'idea di un'urbanistica a carattere nazionale, regionale e talora perfino indigeno, ${ }^{21}$ quella che Outtes (1997) definisce "pianificazione tupiniquim, adatta alle spiagge, alle foreste e alle pianure del territorio brasiliano $e$ in accordo con $i$ costumi e le tradizioni del paese”, che pur dette in 
64 Brasile alcuni dei migliori risultati fra le elaborazioni dell'epoca, come ad esempio nel caso di Porto Alegre.

Com'era prevedibile, di questo quadro entrarono ben presto a far parte anche i problemi razziali. In Brasile - dove pure il progetto di identità nazionale era apparentemente costruito sul tentativo di valorizzazione del melting pot l'idea di migliorare la razza nazionale fece capolino attraverso la nascita dell'Eugenetica che (dopo il $3^{\circ}$ Congresso Brasileiro de Hygiene del 1926) entrò prepotentemente nel discorso urbanistico. ${ }^{22}$ Venne così consolidandosi l'idea che l'urbanistica doveva porsi come il contraltare ad un contesto sociale ormai 'degenerato', come rimedio alle nefandezze di natura estetico/igienico/morale localizzate nelle insalubri abitazioni dei poveri; doveva, cioè, servire a rigenerare le condizioni di vita dell'umana società, specie 'incorniciando' una politica attenta della casa, nucleo fondante di città rinnovate e purificate. ${ }^{23}$

\subsection{Problema 'casa' e problema 'occupazioni': le prime risposte istituzionali}

Non si può tralasciare di sottolineare anche la capacità di lotta dei 'favelados' nella difesa del loro luogo e stile di vita. Dopo 100 anni di lotta, impiegando forme differenti di organizzazione e domanda politica, incluso il carnevale, la favela ha vinto. Da meno di due decenni è mutata la legislazione $[. .$.$] nessuno parla più di rimozione. Più recente-$ mente, i progetti di urbanizzazione e risanamento, frutto di piccole vittorie accumulate dal movimento dei 'favelados', fanno sorgere strade e piazze, più o meno pianificate, più o meno discusse con la popolazione locale (Zaluar e Alvito, 1998).

In Brasile, la posizione del potere pubblico nei confronti della crescita esplosiva delle favelas ha mostrato una visibile variazione di approccio solo a partire dall'ultimo ventennio. Come in molti paesi del mondo, da caso di polizia la città spontanea è diventata gradualmente un problema di assistenza sociale, e infine (anche in conseguenza delle direttive internazionali) oggetto di programmi inseriti nella politica della casa, specie una volta esauritesi tutte le altre forme di intervento pubblico in questo campo.

Come osservato da Leeds \& Leeds (1978), la natura della soluzione politica al problema della città informale ha sempre mostrato una tendenza a 'variare in senso direttamente proporzionale all'ideologia nazionale e all'ordine politico', prevalendo il principio di urbanizzazione in periodi di maggior apertura politica, e quello della rimozione durante i regimi autoritari. Pertanto, fino agli anni '70 l'unica politica esistente fu quella dello 'sradicamento' [erradicação], rivendicata come mezzo giusto di comportamento davanti all'impegno profuso nei programmi di promozione di quartieri popolari. Il fatto che tali programmi fossero lenti, burocratizzati e quantitativamente inadeguati alla dimensione del problema, e che alla fine non toccassero i segmenti della popolazione a cui erano stati diretti, non sembrò intaccare la correttezza di cui si ammantava quell'approccio risolutore.

Nel 1946 in Brasile fu creata la Fundação da Casa Popular, che fino alla sua soppressione all'inizio degli anni ' 60 produsse appena 4879 alloggi distribuiti su 12 stati. Parallelamente, i governi locali cominciarono a percepire il pericolo rappresentato dall'incontrollabile crescita delle occupazioni di terra e cercarono di fermarle con leggi di regolamentazione dei suoli o apposite commissioni. A Rio, la Commissione per l'Estinzione delle Favelas (creata nel 1948) realizzò un censimento conoscitivo dei favelados ${ }^{24}$ a Porto Alegre 
nel 1951 il Comune registrò l'esistenza di 56 invasioni che davano alloggio a 54.000 persone; a Belo Horizonte nel 1955 si costituì la Commissione di Desfavelamento che rilevò 35.000 favelados (7,4\% della popolazione). Persino a San Paolo, dove le favelas cresceranno soprattutto negli anni '70, nel 1957 furono registrati 141 nuclei irregolari che ospitavano 50.000 persone l'1,8\% della popolazione - stipate in 8500 baracche.

La fase delle politiche locali di 'constatazione' dell'entità del problema ebbe come feed-back la promulgazione della 'Lei das Favelas' (1956) che offriva ai Comuni linee di credito per miglioramenti dei servizi nelle aree di subabitazione. Il provvedimento - progressista per l'epoca - puntò sulla differenziazione dei programmi locali, che spesso comunque non riuscirono ad elaborare una linea comune neppure all'interno della stessa città. Nel caso di Rio, ad esempio, la Cruzada S. Sebastião (frutto di un accordo fra la Chiesa Cattolica e il Comune di Rio, già operante dal 1955) tendeva ad urbanizzare le favelas esistenti ${ }^{25}$ e addirittura realizzò il primo re-insediamento in loco lungo la spiaggia di Pinto, intervenendo poi contro lo sgombero di altre 3 favelas cittadine; al contempo, il Comune (sdoppiato nella sua azione) utilizzava la 'Lei das Favelas' per elaborare un progetto di trasferimento dei favelados in alloggi provvisori in attesa della costruzione di case in muratura, prima pensate nel luogo dove si trovava la favela e poi spostate più lontano (Taschner, 1997). Nascevano così i Parques Proletários, per alloggiare temporaneamente 8000 persone. ${ }^{26}$ La politica dei VHP (o quartieri di alloggiamento provvisorio) adottata a San Paulo negli anni '70 sarà un succedaneo di queste realizzazioni, che dichiarerà roboantemente di ispirarsi alle teorie di 'integrazione sociale' dell'ideologia funzionalista.

L'errore principale di questo approccio fu credere che la favela costituisse solo la prima alternativa di alloggio per l'immigrato, mera tappa necessaria dell'integrazione alla vita urbana. Coerentemente, i VHP e i Parques Proletários mirarono a diminuire 'il tempo obbligatorio' di attesa in favela fornendo per un anno un'infrastruttura di base, orientamento professionale e istruzione formale. A lungo non si comprese che spesso le favelas crescevano già più per pauperizzazione che per migrazione, costituendosi come punto di arrivo - e non di partenza - di un percorso di 'filtraggio discendente' dentro il processo di valorizzazione della terra urbana e dell'impoverimento della classe lavoratrice (Taschner,1997). Presupposti e metodi di quella politica risulteranno quindi errati, e l'improduttività delle reti sociali e lavorative costituite e poi troncate dalla scadenza dell'anno di contratto non sarà certo un aiuto all'integrazione.

La realizzazione più celebre dell'epoca 'populista' (1945/64) restano le 328 unità del quartiere Pedragulho a Rio, che nel 1952 ospitavano appena 17.000 persone incidendo in maniera minima sul problema dei favelados dell'allora capitale. La loro fama è dovuta, soprattutto, alla realizzazione dell'architetto Affonso Reidy che incorporò nell'opera i principi progettuali razionalisti dell'Unité d'Habitacion di Le Corbusier (pilotis, rue corredor, pareti vetrate, linee pure) che il Dipartimento per la Casa Popolare (DHP) tentò poi di estendere nella Gávea, progetto incompleto che nel 1982 sarà tagliato in due da un'autostrada.

La schizofrenia mostrata dai programmi di de-favelamento (essendo ancora prematuro parlare di politiche coerenti) cedette il posto al disinteresse mostrato per il problema durante il mandato di Kubitscheck (1956-61), concentrato sulla creazione di Brasilia e sui progetti di industrializzazione nel campo dell'auto, massimo obiettivo del suo 'Piano degli Obiettivi'. 


\subsection{Sotto la dittatura}

L'avvento dei militari nel 1964 non mutò molto le politiche dell'alloggio. Alla fine degli anni ' 60 furono semmai fattori esterni ad influenzarne la trasformazione, come la riforma urbana varata dalla rivoluzione cubana del '59, che aveva avuto forte eco in tutta l'America Latina, influenzando le proposte di Riforma Urbana messe in moto dal presidente brasiliano Goulart, deposto dal golpe approvato dagli Stati Uniti poco dopo aver varato la Riforma Agraria. Proprio per la paura che i principi propugnati dalla rivoluzione cubana facessero proseliti alla causa comunista, gli Stati Uniti vararono - infatti - un controprogramma di prestiti mirati a risolvere il problema dell'alloggio nei Paesi di tutta l'America Latina, gestiti dall'USAID (Agenzia per lo Sviluppo Internazionale), interessata ad accreditare una politica settoriale separata dallo sviluppo economico/sociale, per vincolare ancor di più quelle nazioni agli USA (Abrams, 1964).

Ciò determinò un cambio di enfasi sulla questione dell'alloggio, visto che il Congresso americano nel '62 riconobbe 'la correlazione fra alloggio e stabilità delle nazioni libere sottosviluppate del mondo', impiantando una politica di aiuti esclusivamente mirati alle città, che trasformava quello che prima era 'un problema fra i tanti' nell'ambito 'strategico nella conservazione della democrazia occidentale’ (Taschner, 1997). In tale quadro, in Brasile già nel 1962, furono costituite le COHABs (Compagnie Statali per l'Abitazione) per gestire i fondi USAID per il de-favelamento, enfatizzando la necessità delle rimozioni e del reinsediamento 'frammentato' ${ }^{27}$ in quartieri residenziali lontani, senza più riferimenti alle strategie della Cruzada S. Sebastião. Nacquero grossi quartieri intitolati ai 'salvatori' americani, di cui Vila Kennnedy a Rio rappresenta il prototipo, con casette isolate di 30/47 mq. ad oltre $30 \mathrm{~km}$ da dove abitavano i favelados 'rimossi' . 281966 l'Associazione Aliança para o Progresso - che aveva promosso la realizzazione di alcuni quartieri - concluse però essa stessa che simili ghetti suburbani rimettevano in discussione 'la costruzione intensiva di case economiche come migliore soluzione dei problemi della casa in America Latina' (cfr. Serran, 1976).

Durante tutto il periodo militare (1964/84), che vide passare il Brasile dal miracolo alla crisi economica, ${ }^{29}$ l'enfasi politica cadde sulla costruzione di alloggi da vendere attraverso la creazione del Sistema Finanziario dell'Abitazione (SFH) incentrato sulla collaborazione tra la Banca Nazionale dell'Abitazione (BNH) e l'industria edilizia civile. La politica della casa divenne semplice strumento per sminuire i possibili effetti del controllo dell'inflazione sull'occupazione, un sottoprodotto politicamente desiderabile di un intervento mirato altrove (Taschner, 1997). ${ }^{30}$ In tal modo si caratterizzò paradossalmente per l'assenza dei due agenti che avrebbero dovuto darle un senso: lo Stato e la maggioranza della popolazione (quella col reddito più basso che passò a rafforzare l'altra faccia della medaglia, accrescendo l'illegalità delle lottizzazioni clandestine, le invasioni di terra, i cortiços, l'autocostruzione e l'insalubrità urbana).

Così, mentre negli anni '70 il SFH passava ad investire soprattutto in opere di infrastrutturazione urbana (di cui erano clienti municipi e stati impoveriti dalla riforma tributaria) e lasciava ai sistemi di finanziamento privato (SBPE) la risoluzione del problema degli alloggi, le maggiori città vedevano una crescita esponenziale delle occupazioni di terra. È in quest'epoca che si consolidò quell'approccio schematico e duale al tema dell'abitazione - spazio di 
accumulazione o di miseria - che ha marcato gran parte della ricerca accademica brasiliana dell'ultimo trentennio.

Il periodo fu dominato dalla centralizzazione delle risorse e delle decisioni nelle mani del Governo Federale, mentre gli interventi di Stati e Comuni nel campo dell'Alloggio furono rarissimi. Di solito, la mancanza di infrastrutturazione in molti quartieri residenziali servì da pretesto per la progressiva traslazione di obiettivo dei finanziamenti, che tesero a concentrarsi via via sempre più su grandi opere di infrastrutturazione urbana che completassero - agli occhi anche degli scontenti beneficiari delle abitazioni - il collegamento tra le città e i 'deserti' dove il costo minore della terra consigliava di ubicare i nuovi quartieri. Si spiegano così la creazione del Sistema Finanziario di Risanamento (SFS) e dei Finanziamenti FINANSA per la costruzione di reti di urbanizzazione nel 1968 e l'autorizzazione del 1969 a finanziare con i FGTS (risparmi dei lavoratori) sistemi di approvvigionamento idrico e reti fognarie, oltre che la creazione nel 1971 del Piano Nazionale di Urbanizzazione primaria (PLANASA). A questi anni risale anche l' 'opportuna' trasformazione del BNH in impresa pubblica vincolata al Ministero dell'Interno come banca 'di seconda linea' (Maricato, 1987): ciò permetteva al BNH di trasferire ai suoi agenti finanziari - insieme ai fondi - la responsabilità per la riscossione dei pagamenti (in cerca di un'efficacia nella riscossione dei crediti dei mutuatari, fino ad allora fallimentare), liberando così l'organo che più di tutti rappresentava lo Stato dalle critiche degli utenti insoddisfatti.

Con il progetto CURA attivato nel $1972^{31}$ lo Stato entrò nell'arena del gioco immobiliare urbano dovuto all'aumento di valore dei suoli conseguente degli investimenti pubblici, e finì in molte realtà locali per incentivare solo la speculazione immobiliare (che simulava di voler combattere) di chi acquistava terreni durante l'elaborazione dei Piani Regolatori. La nascita nel 1975 dei Fondi di Appoggio allo Sviluppo dei Poli Economici (PRODEPO) ${ }^{32}$ oscurò i fondi mirati all'Urbanizzazione e alla dotazione di Attrezzature Comunitarie nei quartieri residenziali. Questa politica - abilmente preparata per gradi - raggiunse l'apice nel 1976, quando l'impegno finanziario profuso dal BNH nel settore dello sviluppo urbano toccò il picco massimo in corrispondenza di quello minimo nel campo dell'abitazione.

Nel complesso, durante tutta la sua vita, il SFH costruì 4,8 milioni di unità d'abitazione - delle quali 1,2 prodotte dalle COHAB locali - incrementando (fra il 1964 e il 1986) del 25,8\% il parco alloggi del Brasile intero. Una cifra in assoluto non disprezzabile (Taschner, 1997), se non fosse che le case delle COHAB non erano destinate specificamente ai favelados come invece i quartieri prodotti dai Dipartimenti Locali di Abitazione o con i fondi USAID, ma spesso finivano per offrire aiuto a persone con redditi familiari superiori ai 5 Salari Minimi mensili. ${ }^{33}$ Contemporaneamente, la politica di defavelamento si caratterizzò per la postura autoritaria, incentrata sulla rimozione forzata in collaborazione con le forze di polizia. Nella sola Rio de Janeiro, tra il 1962 ed il 1974 furono rimosse 80 favelas con 26.193 baracche censite che ospitavano 139.218 abitanti (Valladares, 1978) mentre per San Paolo è difficile trovare dati quantitativi. ${ }^{34}$ Negli anni, le ripetute crisi economiche attraversate dal Brasile, la scarsezza dei fondi stanziati ai vari livelli istituzionali, l'inadeguatezza degli affitti nei nuovi quartieri, l'aumento dei costi del trasporto per chi era rialloggiato lontano dai luoghi di origine, e non ultima 'l'incapacità degli sgomberati di adattarsi ai grandi quartieri residenziali periferici' (Bueno, 1995) fecero diminuire il potere acquisitivo delle famiglie a 
basso reddito, con conseguente ritorno alla favelas, previa 'vendita delle chiavi' degli appartamenti ('informale' perché non autorizzata dal potere pubblico gestore del parco alloggi). Questo fenomeno dimostrò l'inadeguatezza assoluta della politica abitativa che legittimava il 'pugno di ferro' contro gli occupanti di aree informali. Vari municipi - spinti anche dalle pressioni popolari incanalate attraverso le Associazioni di Vicinato - cominciarono ad adottare la politica della "vista grossa",35 riducendo le rimozioni ai soli casi in cui si aveva necessità assoluta di impiantare opere viarie o di infrastrutturazione urbana. Ci si iniziava, del resto, a rendere conto del fatto che le favelas nascevano per restare, come anche del fatto che per lo più i favelados erano lavoratori dei settori 'formali' e che i mercati di 'vendita delle chiavi' delle case popolari 'di passaggio' smascheravano il fallimento dei presupposti di integrazione 'sociale' delle politiche finora adottate, rendendo definitive le soluzioni pensate come transitorie, e viceversa. Già da metà degli anni '70, intanto, il crescere della povertà urbana - ormai intemazionalmente percepita come grande sfida del futuro (cfr. Dichiarazione di Habitat I del 1976) - aveva contribuito al formarsi di organizzazioni di favelados' in lotta per permanere in loco, a partire dalle rivendicazioni e dalle pressioni sul regime militare - sempre più debole e bisognoso di appoggio popolare - dell'accesso all'acqua e all'energia elettrica. Tali movimenti di opinione - appoggiati da settori progressisti della classe media - ottennero spesso concreti risultati, anche se soprattutto in termini di 'assistenza sociale', visto che il problema fondiario, legale e relativo alla politica della casa veniva presentato dalle autorità come una questione da risolversi su tempi lunghi, ed usato come 'arma politica di ricatto' da molte autorità locali.

La rivolta semi-fruttuosa per la rivendicazione del diritto alle attrezzature di base si estese dal 1981 anche alle occupazioni su suoli privati, con la creazione dei primi MUF, i Movimenti di urbanizzazione delle Favelas e delle CDF, le Centrali di Difesa del Favelado che davano consulenze nelle diffuse azioni di 'reintegrazione di proprietà' che transitavano nei tribunali ad opera soprattutto dei privati proprietari di terreni occupati.

\subsection{Il tramonto della dittatura e il disimpegno della Nuova Repubblica}

Le conclusioni superficiali e distorte del dibattito su 'come' e 'chi' beneficiare attraverso le politiche della casa non fermarono la crescita delle favelas in Brasile, ${ }^{36}$ lasciando campo a quel fenomeno di spoliazione urbana (Kowarick, 1979) che faceva da contrappunto allo sfruttamento salariale attraverso submercati informali tesi ad eliminare il costo dell'abitazione dal bilancio familiare del proletariato urbano. Il tutto avveniva sempre più con la sostanziale connivenza dello Stato, necessaria anche per permettere la parallela continuazione della politica ufficiale della Casa con il suo target medio-alto. Se anche di successo si potesse parlare per le realizzazioni del SFH (specie nella fase di espansione 1968/1979), esso si dovrebbe al fatto stesso di aver ignorato i settori della popolazione con minori possibilità di spesa e di aver trattato l'abitazione come una merce da prodursi e commercializzarsi in forme strettamente capitaliste, al punto di modificare il funzionamento del mercato dei suoli urbani, dove avvenne un cambiamento strutturale fondamentale: le ipoteche per i finanziamenti passarono dal terreno - come era pratica anteriore - ai futuri edifici, ponendo quindi il mercato dei terreni in stretto 
vincolo con il settore produttivo immobiliare.

Solo alla fine degli anni ' 70 il BNH riprese in mano la politica degli alloggi applicandovi massivamente le nuove tecniche costruttive sperimentate nelle grandi opere degli anni precedenti e mirate all'aumento della produttività del sistema, richiesto con crescente forza anche dai capitali stranieri operanti nel Paese. A determinare una correzione di tiro della politica abitativa furono - insieme - l'indebolimento del regime militare, le pressioni notate nelle elezioni (pur controllate) del 1974, la nascita dei primi movimenti urbani legati all'habitat autourbanizzato, la necessità di conquistare sostegno per le elezioni libere che parevano sempre più vicine e ineludibili, e soprattutto il restringersi generalizzato del potere d'acquisto con la crisi economica in corso.

In questo periodo il SFH - recependo le pressioni interne e delle maggiori Istituzioni Finanziarie Internazionali - creò programmi nuovi che attingevano a fasce di reddito di 3/7 Salari Minimi:

1) il PROMORAR, che dal giugno " 79 proponeva lo sradicamento delle favelas con la costruzione sostitutiva di case in muratura e regolarizzazione del possesso del suolo, unico programma federale mirato alla permanenza in $l o c o$, in unità standard di $25 \mathrm{mq}$ su terreni di $75 \mathrm{mq}$, con stanza polivalente, bagno e possibilità di ampliamento autoprodotto;

2) il PROFILURB, programma di finanziamento di lotti urbanizzati (del tipo Sites \& Services) creato nel giugno del 1975 sulla base delle insistenti pressioni della Banca Mondiale.

La fragilità del $\mathrm{SFH}$ si rivelò in tutta la sua profondità negli anni '80, quando la crisi - aumentando la disoccupazione - diminuì i fondi FGTS e i risparmi volontari dei lavoratori (che lo finanziavano). Nel solo 1984 le risorse dello stesso calarono del $35 \%$. L'ultimo sforzo fatto per diminuire i costi delle politiche dell'alloggio fu nel 1984 il programma 'João de Barro' (uccello che costruisce col fango il nido) ${ }^{37}$ per finanziare le costruzioni in mutirões autorganizzati o cooperative di 'auto-ajuda mútua'.

A quest'epoca di crisi annunciata risalgono le prime iniziative autonome di governi locali (municipali e statali), come il celebre mutirão 'truccato' di 1000 case costruite in un weekend a Goiania nell'ottobre $1983^{38}$ ed altre esperienze di relativo successo (sempre, in genere, nell'ambito dei mutirões) a San Paolo e nel Paranà. Simili alternative non alterarono il quadro delle politiche di defavelizzazione, che tra il 1981 e il 1982 vide ancora episodi di rimozioni forzate, seppur più radi e non del tutto vittoriosi. Dal 1984 in poi, il Governo Federale poco influì invece nella politica di defavelizzazione. L'ultimo grande intervento (mai completato) fu il Piano di Urbanizzazione delle Favelas del Maré a Rio de Janeiro nel 1985, che - nelle intenzioni doveva risolvere i problemi di alloggio di 75.000 persone.

Più estese furono le 'politiche compensatorie' di infrastrutturazione delle favelas messe in atto da varie amministrazioni periferiche che - nel quadro del 'twin approach' (cfr. § 2.3) - facevano pagare agli abitanti le tariffe minime di acqua e luce, indipendentemente dai consumi reali. Molte desistettero prima di essere completamente sperimentate, soprattutto per i bassi ritorni garantiti dai mutuatari (come nel caso del programma PROMORAR) o (come per l'ambizioso programma PROFAVELA di San Paolo) a causa delle difficoltà di coordinamento e dell'aumento dei costi generati dal desiderio di compiacere più strati della popolazione, ad esempio cedendo alle pressioni delle imprese in cerca 
70 di servizi che facevano ovunque optare per lo smembramento dei cantieri in sottocantieri tematici affidati a ditte diverse (Bueno, 1995).

L'avvento della Nuova Repubblica nel 1985 - almeno nei primi anni - non promosse rotture decisive con la dinamica 'lobbystica' del regime precedente, lasciando che i due terreni di dibattito e lotta politica circa la questione urbana restassero le eterne discussioni in seno all'Assemblea Nazionale Costituente e al Forum sulla proposta di Riforma Urbana, che solo nel luglio 2001 sono giunte ad un compromesso onorevole con l'approvazione dello 'Statuto della Città' . In questi anni, gli altissimi livelli di inadempienza dei mutuatari delle costruzioni popolari realizzate nel passato - circa il 50\% secondo Taschner (1997) - portarono alla decisione di chiudere il BNH (che ormai aveva un debito di 20 miliardi di dollari, circa il 6\% del PIL del Brasile) e passare i programmi in corso d'opera alla responsabilità della Caixa Economica Federal. Per far fronte alle richieste della popolazione più carente si dette avvio a una serie di programmi di aiuto - con buoni-pasto, buoni-latte o buoni-trasporto - gestiti in modo clientelistico dal SEAC (Secretaria Essencial de Ação Comunitaria) il cui programma abitativo - Programma Nazionale di Mutirões Residenziali - si proponeva di accudire ad una popolazione con reddito inferiore a 5 Salari Minimi con risorse a fondo perduto per la costruzione di 500.000 abitazioni attraverso cooperative di self-help. L'esatto numero di unità realizzate non è mai stato appurato, anche se Taschner (1997) le valuta intorno a 350.000. Fondi mal gestiti, finanziamenti troppo bassi rispetto all'andamento dell'inflazione, la frammentazione e il pessimo coordinamento dei vari livelli del potere pubblico fecero terminare il programma già con il governo Sarney. Pochissimo fu fatto anche dal Governo Collor nei 2 anni e mezzo di vita antecedenti l'impeachment. La riforma amministrativa del '90 smantellò aree importanti di intervento come quella della politica urbana (fu eliminato il CNDU, il Consiglio Nazionale di Sviluppo Urbano) e affidò ad un ministero di impianto assistenzialista - l'Azione Sociale - responsabilità come le politiche abitative e di risanamento urbano. Per altri versi, inaugurò una politica di dissociazione fra istanze macroeconomiche globali, concentrate nelle sfere centrali dello Stato, e politiche sociali, progressivamente decentrate e frammentate in un modo che ha favorito l'instaurarsi di nuove pratiche clientelari, e che fu usato per attenuare la pressione sullo Stato dei movimenti organizzati intorno a questioni di sopravvivenza, trasferendola alle sfere locali di governo.

Il PAIH (Piano di Azione Immediata per la casa), lanciato nel maggio del 1990, prevedeva 3 linee di azione: un programma di sostegno agli interventi municipali nel campo delle abitazioni popolari, un programma di unità residenziali finite e uno di lotti urbanizzati che (nonostante i diffusi fallimenti ormai constatati anche dalla World Bank) spesso contemplavano anche la cosiddetta 'cesta basica' [cestino di base] di materiali da costruzione. I tempi previsti per il programma slittarono da 180 a 540 giorni, mentre i costi unitari medi crescevano di $1 / 6$ riducendo le unità costruende da 245.000 a 210.000 cosa che invalidò l'intero programma (Azevedo, 1996).

Salendo al potere, il vice-presidente Itamar Franco portò avanti una stanca riforma che calcava i toni sulla necessità di decentrare e incentivare la creazione di Fondi e di Consigli Statali e Municipali. Le due proposte principali di Franco furono l'HABITAR BRASIL e il MORAR MUNICIPIO, incentrate sui temi del decentramento e della 'gestione popolare' e partecipativa che già alcuni comuni stavano a quell'epoca provando (ad esempio Porto Alegre, Belo Horizonte e San 
Paolo). Il piano di stabilizzazione economica (Plano Real) adottato dal primo governo Cardoso non permise però a questi programmi di decollare.

Nell'ultima fase storica, gli scampoli della politica federale degli alloggi sono stati gestiti dalla Caixa Economica Federal, che ha dovuto far fronte agli ultimi impegni e ai debiti dell'estinto BNH. Nei due governi Cardoso, i Piani Nazionali dell'Abitazione elaborati dall'Assessorato alla politica Urbana del Ministero della Pianificazione e del Bilancio si sono basati su un concetto di Deficit Abitativo estremamente sottostimato (DEMHAB, 1999): quello calcolato nel 1995 dal Centro di Studi Politici e Sociali della Fondazione João Pinheiro in riferimento alle due definizioni-cardine di abitazione precaria (senza condizioni di vivibilità) e coabitazione familiare (addensamento eccessivo, per giunta corretto interpolandolo con una definizione di ammissibilità fino a 3 persona per stanza da letto). ${ }^{39}$

$\mathrm{Nel} 2002$, il governo nazionale ha valutato un provvedimento sulla creazione di una Politica Nazionale della Casa mirata alla popolazione con reddito più basso (fino a 3 Salari Minimi) ma con misure di supporto anche per famiglie con entrate mensili dai 4 ai 10 Salari Minimi (cfr. Sofia, 2002). Il Progetto di Legge è stato realizzato sulla base di studi dell'Istituto di Ricerca Economica Applicata (IPEA), del Segretariato Speciale per lo Sviluppo Urbano (SEDU), dell'Università di Brasilia, della Banca Mondiale e della Fondazione per gli Investimenti Scientifici e Tecnologici (FINATEC) coordinati dalla Caixa Economica Federal. Esso comprendeva sgravi di natura tributaria e misure come il rilancio attraverso titoli di credito del Sistema Finanziario Immobiliare (in teoria esistente dal 1997 ma mai decollato) e la creazione di un Sistema Nazionale di Informazioni sulla Casa, di un Catasto Nazionale delle Informazioni di Natura Sociale, ma soprattutto di un Fondo Nazionale per l'Abitazione di Interesse Sociale (FIS) da finanziarsi attraverso fondi del bilancio federale, dei FGTS, dei libretti di risparmio e del FAT (Fundo de Amparo ao Trabalhador). Nulla di particolarmente, innovativo, quindi: tanto più che l'annuncio dato alla vigilia delle elezioni presidenziali dell'ottobre 2002 - non ha,poi, avuto seguito dopo la sconfitta della coalizione filogovernativa.

Per certi versi, la stessa ammirevole Costituzione del 1988 ha contribuito a dare l'ultimo colpo ai Programmi Nazionali sulla Casa, trasferendo fondi e competenze a Stati e Comuni ancora privi di strutture amministrative e tecniche per la loro gestione, in 'una forma selvag gia di trasmissione di responsabilità' (Taschner, 1997). Attualmente, quindi, nonostante le recenti promesse del $\mathrm{II}^{\circ}$ Governo Cardoso, è quasi impossibile parlare di politiche federali relative a favelas e cortiços; ogni Stato e ogni Municipio, infatti (a dispetto di una generale coerenza di fondo delle varie politiche in atto nel Paese), ha agito e continua ad agire in maniera indipendente e specifica nel suo 'locale'.

Comunque, già in occasione delle prime elezioni municipali libere del 1985, in molti comuni le favelas sono passate progressivamente ad essere un tema trattato nell'ambito delle politiche urbane e/o della casa, pur all'epoca notevolmente frammentate e settorializzate; non quindi più solo nell'ambito delle politiche di assistenza sociale, ma in maniera più integrata $o$ almeno plurisettoriale, nel quadro di una riorganizzazione dello spazio fisico dei territori urbani. Ad esempio, già il primo governo municipale Covas a S. Paolo e il Governo Collares a Porto Alegre cominciarono a mettere in cantiere - nel 1986 - le prime direttive per la riurbanizzazione e regolarizzazione fondiaria, seppur adottando concetti di demolizione totale con ricostruzione e rimozione temporanea degli abitanti. 


\subsection{Verso un nuovo approccio}

Nel marzo 1987, l'apertura del progetto di nuova Costituzione Federale ad emendamenti popolari - resa possibile dall'Assemblea Costituente - stimolò l'organizzazione di un Movimento Nazionale di riforma incentrato su un concetto di urbano inteso come luogo ideale di mediazione fra i livelli decisionali globali della società (statale, federale) e lo spazio quotidiano dell'alloggio, e quindi come scala ideale per l'esercizio della libertà politica. Questo Movimento ha cercato di unificare il dibattito precedente sulle questioni urbane, riunendo movimenti sociali ed entità professionali e accademiche, con l'obiettivo di accreditare una nozione di 'dignità di vita' legata all'ideale di accesso sociale alla città, che esprimeva l'ansia di un'effettiva democratizzazione dei suoli e della gestione urbana, congiunto al desiderio di rovesciare le direttrici che fino ad allora avevano portato ad una continua riproduzione dei processi di esclusione e a quello di sottolineare la priorità del diritto all'alloggio non come macchina per abitare ma come luogo dove si realizza continuamente la poesia della vita (Menegat, 1995).

Il Movimento ottenne l'inclusione nella Costituzione Federale del 1988 di un capitolo sulla Riforma Urbana (a cui si ispirarono poi quelli corrispondenti di molte Costituzioni Statali), e ha poi lavorato alla preparazione di una Legge specifica - entrata in vigore da pochi mesi - come anche all'organizzazione di un Forum Internazionale sulla Riforma Urbana durante il meeting ONU 'ECO '92' di Rio de Janeiro. Ma, soprattutto, ha svolto un ruolo importante nel suggerire alcune direttrici di azione ai movimenti politici più progressisti presentatisi sulla scena politica in occasione delle elezioni comunali indette nell'inverno del 1988.

Dopo queste, l'avvento nel 1989 di governi municipali guidati dal giovane partito del PT in alcune città simbolo (San Paolo, Belo Horizonte, Porto Alegre) permise una trasformazione importante nell'approccio all'intervento sulle favelas, attraverso misure come l'alienazione di terreni comunali agli abitanti-occupanti, leggi sulla concessione del Diritto Reale di Uso dei Suoli, strutture di consulenza gratuita per i favelados residenti in aree private che volevano tentare la via dell'usucapione o far ricorso contro le azioni di 'reintegrazione di proprietà'.

In tale congiuntura, accanto ai programmi di riurbanizzazione e consolidamento geotecnico delle zone autocostruite ne hanno visto progressivamente la luce altri per le aree di rischio (i cui abitanti necessitavano trasferimento in quartieri più sicuri) oltre che programmi di piccole migliorie - sia sugli spazi collettivi che sulle singole abitazioni - gestibili insieme agli abitanti. Ma, soprattutto, in accordo con i nuovi dettami della Costituzione del 1988, sono state rinnovate per tappe alcune politiche di gestione urbana, e il problema delle favelas ha cessato in molte città di essere trattato isolatamente, venendo simultaneamente letto in rapporto a diversi punti di vista più o meno integrati, spesso anche grazie a nuovi organismi comunali e statali nati per gestire e coordinare gli interventi di urbanizzazione, assistenza sociale e politica della casa.

Non si può dire che si sia messa in moto una 'politica della casa' ricca, perché non sarebbe stato possibile in un quadro economico internazionale e nazionale sempre più marcato da una 'sussidiarietà asimmetrica', che tende a decentrare responsabilità e risorse con ritmi diversi e incongruenti. Non sarebbe però veridico neppure parlare di una totale riduzione dell'urbanistica e della politica dell'al- 
loggio a quelle del risanamento e dell'urbanizzazione, sia per l'attenzione concentrata in molti ambiti locali sui temi del cooperativismo (con e senza autoaiuto nella costruzione), sia perché il problema delle trasformazioni fisiche ha teso sempre più ad essere associato a quello più generale dei diritti di cittadinanza e del coinvolgimento nella gestione urbana. La Legge sullo 'Statuto della Città' - di recente approvazione - costituisce una cornice importante per sistematizzare le esperienze tentate con tempi e modalità diverse da molte città brasiliane, nonché un aiuto a superare gli ostacoli legali e amministrativi (togliendo alibi a quelli dovuti alla carenza di volontà politica) che hanno finora giustificato la relativa 'timidezza' di molti tentativi di affrontare di petto e integratamente tali problematiche.

L'esperienza di Porto Alegre - al centro di questo libro - appartiene al novero delle esperienze 'apripista', che con la loro sperimentazione hanno contribuito maggiormente al consolidamento di quello che potrà costruire (e già oggi va costituendo) un importante quadro-guida di riferimento per altre amministrazioni interessate a contribuire alla costruzione di una società dove la logica del mercato non funzioni da piano regolatore (As cidades em movimento, 2001, p. 3).

A posteriori, si potrebbero rilevare alcune intuizioni che paiono aver costituito la base dell'esperienza di Porto Alegre e di altre simili, che hanno finito per venire incontro - con percorsi autonomi e autoctoni - ai nodi centrali dei Piani di Azione Globali raccomandati da documenti internazionali quali l'Agenda di Habitat II del 1996:

a) l'idea che le città non siano "oggetti" ma "soggetti mossi dall'azione umana" in cui pensare l'urbano come una risoluzione permanente di un campo di conflitti tra attori-abitanti ${ }^{40}$ sia l'unico modo di pianificare soluzioni efficaci per il territorio locale, dentro processi continui di monitoraggio, autovalutazione e riadattamento critico delle scelte;

b) l'idea che per superare il quadro di destrutturazione imperante sul territorio nazionale, sia necessario partire dal terreno della 'familiarità', terreno per eccellenza delle città che - non essendo costruzioni concettuali come lo Stato e l'Unione - rappresentano il luogo privilegiato dell'inclusione sociale immediata e dell'esercizio della cittadinanza come un compito etico ${ }^{41}$

c) l'idea che sia altresì imperativo uscire celermente dai limiti della 'familiarità', evitando il rischio di concepire le città come "isole" ma riconoscendo che qualsiasi battaglia politica al loro interno è indissociabile dalle lotte nazionali e globali;

d) l'idea che le città debbano farsi spazi di re-invenzione della democrazia non accontentandosi di far resistenza al modello neoliberale dominante ma ponendosi obiettivi di mobilitazione e costruzione di nuove forme di organizzazione sociale a partire dalle esperienze locali;

e) L'idea che molti degli obiettivi-simbolo della moderna pianificazione e gestione urbana (come qualità della vita e sostenibilità) non possano essere perseguiti in assenza di condizioni minime di dignità socio-economica, e che non possano neppure essere gettati nell'arena della discussione politica se non si parte da percorsi 'bottom-up' di valorizzazione dei patrimoni sociali locali, anche per rendere tali concetti comprensibili e condivisibili da tutti i cittadini. ${ }^{42}$

L'idea che - nell'affrontare il tema della 'partecipazione' - è fondamentale dotarsi di onestà intellettuale per ammettere che "mobilitare le persone per discutere parte della spesa pubblica non modifica" di per sé la "visione della città", e va inoltre supportato con un solido corpo di misure mirate a invertire le priorità di intervento pubblico sul territorio. ${ }^{43}$ 
${ }^{1}$ Fedozzi (1997, pag. 21) lo considera un vero proprio 'elemento portante dell'identità nazionale'. In italiano di uso corrente lo potremmo tradurre come 'aggiustatina', in quanto rappresenta una propensione strutturale all'adattamento di ogni norma e di ogni prassi (per via informale negoziata) alle convenienze degli attori in gioco.

${ }^{2}$ A lungo, pochi saggi critici hanno esaminato la legislazione nei processi urbani in Brasile, come se la ricerca giuridica - impregnata dell'ideologia dei diritti privati e dell'individualismo o per contro della teoria marxista dello Stato che vede nel diritto un mero strumento manipolato da un potere monolitico di stampo borghese - si rifiutasse di riconoscere l'esistenza stessa della legislazione urbanistica persino con obiettivi accademici, o lo leggesse come un campo indipendente della conoscenza, come qualcosa di neutrale rispetto al processo sociopolitico (Fernandes , 1995). Tra l'altro raramente si è considerato che gli spazi della miseria sono stati e sono mercato importante, ad esempio, per le industrie capitalistiche che producono materiali costruttivi.

${ }^{3}$ La densa letteratura urbanistica che va oggi rinascendo - spesso segnata dall'impegno dei suoi estensori nella politica attiva - si è proposta di riparare ad alcune falle del passato e di leggere in parallelo le problematiche della casa, della città informale e del mutare degli orizzonti della pianificazione urbana, soprattutto in riferimento alle esperienze di democratizzazione delle gestioni politico-amministrative di ambito locale messe in atto nell'ultimo decennio. Ai nomi di autori come Azevedo, Maricato, Bonduki, Singer, Rolnik, Kowarick, Jaccoud o il geografo Milton Santos (recentemente scomparso) vanno aggiunti gli studi collettivi di centri di ricerca particolarmente importanti per le loro produzioni di analisi 'sinottiche' tra serie di studi di caso e monografie territoriali, quali l'ONG "POLIS" (www.polis.org.br), l'Istituto "IBASE" (www.ibase.br) o l'Istituto FASE (www.fase.org.br). ${ }^{4}$ Colpisce, ad esempio, il poco peso dato all'ambiente costruito in relazione alla grande importanza che nel capitalismo brasiliano ha sempre rivestito l'industria delle Costruzioni, che intorno al 1980 occupava il 7,2\% della popolazione economicamente attiva, rendendo le città veri e propri soggetti - oltre che oggetti - della riproduzione dei più vari settori del capitale. Maricato (1987) sostiene che a questo disinteresse abbia contribuito la massiccia ondata di letteratura straniera le gata a 'Teorie e Pianificazione Urbana', assunta dagli studiosi brasiliani come verbo ma spesso incapace di individuare percorsi locali più adatti. Così, per recuperare i più interessanti punti di vista sulla città - e in particolare sul settore 'informale' che è andato notevolmente crescendo nel Paese negli ultimi 30 anni - è sovente necessario cercare altrove, ad esempio nelle biblioteche di economia, sociologia, antropologia e scienze sociali per poter comprendere il riorganizzarsi di ogni componente del capitale immobiliare davanti alla recessione economica (dalla costruzione, al finanziamento, ai diversi "produttori' di suoli) o avere chiarimenti sulle implicazioni socio-psicologiche legate all'autocostruzione o al crescere dei movimenti urbani e al loro ruolo nel trasformarsi delle battaglie per il 'diritto alla città', come per quello alla casa e all'accesso alla terra. ${ }^{5}$ Il termine italianizzato - oggi correntemente usato nella nostra letteratura - viene da 'favela', termine brasiliano per 'baraccopoli' (cfr. box 1).

${ }^{6}$ Le aree sono Belèm, Fortaleza, Recife, Salvador, Rio de Janeiro, S. Paolo, Belo Horizonte, Curitiba e Porto Alegre.

${ }^{7}$ Ancora nel censimento del 1991 le aree metropolitane accoglievano il $71,64 \%$ dei 'favelados', un po' meno dell' $80 \%$ del 1980 ma sempre moltissimi.

${ }^{8}$ Il PIL/ab - secondo i dati della World Bank - ha cominciato a decrescere dello - $0,5 \%$ annuo dal 1980 al 1991 ed il salario minimo prefissato ha perso solo nel decennio degli anni ' 80 il $46 \%$ del suo valore.

${ }_{9}^{9}$ Nella letteratura recente si parla di classe lavoratrice includendo i 'favelados' [baraccati] viste le ripetute indagini che dagli anni ' 50 comprovano la prevalenza di lavoratori - anche regolari - fra questi che fino ad allora erano percepiti solo come 'marginali' e 'vagabondi'.

${ }^{10}$ Per approfondimenti sul tema, cfr. Kowarick 1979 e 1987, Durham, 1984, Jacobi, 1989, Ribeiro A.C. Torres, 1991 e Scherer-Warren, 1993, Bueno, 1995; Menegat, 1995, Baierle, 1992, e 1998.

${ }^{11}$ Ciò non toglie (cfr. Maricato, intervento al FSM di Porto Alegre 2001) che per vari autori, anche in esperienze del genere, il campo delle lotte sviluppantisi intorno al problema dell'alloggio e delle condizioni di vita urbana continui globalmente a restare un luogo privilegiato della cooptazione e dell'esercizio dell'egemonia borghese.

${ }_{12}^{12}$ In Brasile il termine per designare le baraccopoli autocostruite (favela) nasce a Rio nel 1897 dalla baraccopoli costruita sulle colline della Provvidenza e di Santo Antonio dai 
soldati tornati da Canudos, una località del sertão di Bahia sede di una storica ribellione sedata nel sangue dalle truppe federali.

${ }^{13}$ A Rio, durante l'amministrazione Pereira Passos (1902-1906) un rinnovamento del centro urbano portò alla demolizione della collina del Senado e di molti cortiços, ma anche all'ampliamento del Porto, al collegamento dei quartieri di Copacabana e Jardim Botanico tramite il tunnel Leme e all'unificazione delle 3 società tramviarie nella Rio de Janeiro Tramways, Light and Power Company Ltd. A San Paolo i sindaci Prado (18991911) e poi Duprat (1911-1914) realizzarono i maggiori progetti. A Recife i maggiori interventi datano 1909/1917, mentre a Buenos Aires già dal 1889 erano iniziati gli sventramenti per costruire l'Avenida De Mayo. Sia a S. Paolo che a Buenos Aires e a Rosario (tra il 1890 e il 1910) imperversò l'opera dell'urbanista francese Bouvard.

${ }^{14}$ Per l'Argentina si suole indicare il 1906, quando l'arch. Christophersen affermò la necessità di un piano per Buenos Aires; in Brasile il 1911, quando in una conferenza tenuta dall'ingegner Victor Da Silva Freire alla Escola Polytechnica di San Paolo (pubblicata nella Revista Polytechnica, organo dell'associazione degli studenti) fu usata per la prima volta pubblicamente la parola urbanismo (Outtes, 1997).

15 A Buenos Aires, nel 1932 fu istituita l'Oficina del Plan de Urbanizacion, mentre a Porto Alegre già dal 1896 era attiva con simili compiti la Direzione delle Opere.

${ }^{16}$ In Argentina, durante i governi del generale Uiraburu (1930-1932) e dei presidenti Justo (19321938), Ortiz (1938-1940) e Castillo (1940-1942), mentre in Brasile in gran parte all'epoca di Vargas (1930-1945) e, in modo particolare, durante il periodo di dittatura detto Estado Novo (1937-1945).

${ }_{17}$ Citato in Outtes, 1997.

${ }^{18}$ Dal discorso dell'ingegner E. Doria al Congresso de Habitação del 1931 ("Ogni cosa dipenderà dall'organizzazione scientifica, dal taylorismo in azione") alle Jornadas de Habitação promosse dall'Instituto de Racionalização e Organização de Trabalho nel 1941, innumerevoli ne sono gli esempi.

${ }_{19} \mathrm{Nel}$ 1941, il direttore dell'Assessorato alle opre pubbliche del Pernambuco fieramente affermava: [...] prima del colpo di Stato del 10 novembre 1937, i politicanti dominavano le città [...].Oggi, però, l'atmosfera è differente e possiamo già sviluppare i nostri studi nei congressi e adottare vantaggiosamente le misure per l'igiene (Estelita, 1941).

${ }^{20}$ Si pensi - per il Brasile -all'organizzazione della Settimana delle arti moderne a San Paolo o al movimento inte gralista, ma anche al successo dei libri di Alberto Torres (da titoli evocativi come Il problema Nazionale Brasiliano o l'Organizzazione brasiliana) o alla Liga di Difesa Nazionale creata a San Paolo dal poeta Bilac (che sosteneva la necessità che l'esercito svolgesse un ruolo fondante nel sistema educativo nazionale).

${ }^{21} \mathrm{Nel}$ discorso da neo-sindaco di Belém, l'ingegner Cavalcanti scriveva: "Io non farò un'urbanistica d'importazione. Farò una pianificazione indigena, basata sull'antropogeografia della città, attenta alla gente, alla sua storia e al suo habitat; io vado a disegnare un piano che, fondato sul passato e sulla tradizione, soddisferà le necessità presenti e aprirà le porte sulle grandi e spaziose vie del futuro (Urbanismo e Viação, 26, 1943).

22 "Nelle favelas l'elemento etnico dominante sono i negri a cui si uniscono, per propria convenienza, altri elementi alienati ai margini della Società. La tendenza dei negri a isolarsi dalla civilizzazione bianca, a cui non vogliono essere sottomessi, è un fatto correntemente osservabile [...] II ritorno alla vita primitiva mette i negri in condizione di soddisfare le tendenze della loro razza, le loro pratiche feticiste, le loro danze, la macumba, ecc. Le favelas di Rio cosi come i mocambos di Recife sono perspicue sopravvivenze africane (Rotary Club di Rio, 1941).

${ }^{23}$ L'abitazione sociale non deve risolvere soltanto il caso particolare dei suoi abitanti. La questione deve essere riguardata in un'ottica sociale. Lo sviluppo della razza dipende anche da questo. La promiscuità dei cortiços genera una serie di pervertiti e delinquenti, contaminati da terribili malattie. La casa individuale, arieggiata e luminosa, graziosa e riposante, è la celula mater delle razze forti (A. Albuquerque, 1931).

${ }_{24} 139.000$ nel gennaio 1948 , divenuti 169.000 nel 1950 , cioè $7,1 \%$ della popolazione. 2512 furono quelle urbanizzate e 51 i progetti di rete tra il 1955 ed il 1960 secondo Valladares (1978).

${ }^{26}$ Il termine "Parco", da questo momento in poi, sarà associato in molte favelas, alla speranza di una qualità di vita migliore (Benetti, 1998). Vista la loro funzione di transizione furono anche ribattezzati 'Parking proletari'.

${ }^{27}$ Questo sfruttava la scarsa disponibilità di comunicazioni per spezzare la forza di eventuali reti politiche. 
${ }^{28}$ Sempre a Rio, Vila Aliança e Vila Esperança replicarono l'esempio, ospitando 39.000 persone (Tatschner, 1997).

${ }^{29}$ Maricato (1987) ricorda come il PIL crebbe dell'11,5\% tra il 1968 e il 1973 mentre dal 1983 iniziò una forte recessione economica, che portò la disoccupazione industriale in città come San Paolo al $20 \%$.

${ }^{30}$ Lo SFH si reggeva sui Fondi di Garanzia per Tempo di Servizio (FGTS, prelievo che costituiva una sorta di assicurazione contro la disoccupazione dei lavoratori) e su quelli dei Libretti di Risparmio. Il BNH amministrava queste risorse, strutturando - sotto l'azione lobbistica delle imprese di industria pesante - una rete di agenti finanziari privati, rafforzando il mercato immobiliare e l'industria edilizia per fornire alloggi a classi medio-alte (Maricato, 1987).

${ }^{31}$ Cfr. Maricato (1987) per il Progetto Comunità Urbana per il Recupero Accelerato, e il mutare di fuoco degli interventi del BNH con la diversificazione dei programmi 1973/ 74 seguita alla creazione dei Fondi Regionali di Sviluppo Urbano, e per Urbanizzazione (FIMURB), Sistemi Ferroviari (FETREN) e Pianificazione Urbana (FIPLAN).

${ }^{32}$ L'appoggio andò ad es. al Complesso Carbonchimico di Imbituba, all'aeroporto per Cargo di Tucuruí.

33 Il "salario minimo" nacque in Brasile a metà degli anni '30, istituito dalla Legge ${ }^{\circ}$ 185/ 1936 e regolamentato dal Decreto-Legge $n^{\circ} 399 / 1938$. Il Decreto $n^{\circ} 2162$ del $1^{\circ}$ maggio 1940 ne fissò 14 diversi valori nelle 22 regioni e nelle 50 sub-regioni in cui fu diviso lo Stato (nel 1940 tra il valore minore e maggiore c'era una relazione di 2,67 volte). Il 'salario minimo'serve per individuare le soglie di povertà e gli obblighi contrattuali del settore pubblico e privato; a tal fine muta ovviamente nel tempo. Il primo 'adeguamento' è avvenuto nel 1943, l'ultimo è del luglio 2002, quando è stato elevato a $200 \mathrm{R} \$$ per tener conto delle perdite di potere d'acquisto dovute all'inflazione). Esso costituisce in Brasile (come in molti altri paesi) un indicatore importante usato come base di molte politiche governative.

${ }^{34}$ Taschner, 1997, registra circa 4000 famiglie rimosse tra il 1971 e il 1979 , circa il $6 \%$ della popolazione favelata.

${ }^{35}$ In brasiliano significa 'fare lo gnorri', fingere di non vedere.

${ }^{36}$ Nel 1985 la World Bank stimò che in Brasile il sussidio creditizio per i mutuatari con reddito inferiore a 5 salari minimi era stato di 112 dollari all'anno.

${ }^{37}$ A San Paolo questo programma sperimentale, realizzò circa 3200 unità fino al 1986.

${ }^{38}$ Cfr Allegretti 2000 ( $\left.\$ 14.6 .1\right)$ e Maricato e Moraes (1986).

${ }^{39}$ Secondo i criteri di lettura adottati nel rilievo del 1995, il deficit rappresenterebbe appena il $14 \%$ del totale della popolazione brasiliana, con picchi del $78 \%$ nelle categorie tra 0 e 2 salari minimi, e del 16 tra 2 e 5 salari minimi. Lla Fondazione ha anche creato il concetto di necessità abitativa, che considera insieme il concetto di deficit e quello di abitazione inadeguata (cioè carente di almeno un servizio di base: acqua, fogna, elettricità o raccolta rifiuti); questo toccherebbe 18,7 milioni di famiglie nel Paese, cioè il $46,57 \%$ (con punte del $61,97 \%$ in quelle con reddito inferiore a due salari minimi) della popolazione totale. Il problema è l'uso politico distorto fatto dei concetti elaborati. L'ultimo aggiornamento dei dati della Fondazione João Pinheiro, risalente al 2000, valuta il deficit nel $14,5 \%$ dello stock abitativo brasiliano (5,4 milioni di case mancanti), e rileva che 1' $84 \%$ è da attribuirsi a fasce sotto i 3 Salari Minimi (600 R \$), l' $8,4 \%$ nella fascia da 3 a 5 Salari Minimi, il 5,4\% nella fascia tra i 5 e i 10 e il 2,2\% al di sopra dei 10 SM.

${ }^{40}$ I corsi vi sono tratti da Santos (2001, pag. 4), che specifica: L'approccio urbanistico è un intervenire sulle cose, facciamo un ponte, facciamo una nuova autostrada [...], costruiamo case. Questo modo di porsi [...] impedisce la conoscenza di cosa è l'organismo urbano, impedisce il piano. Da lì, la rinuncia al piano urbano [...] La città è un campo di forze" e così va letta "se la gente vuole essere progressista, vuole pensare al futuro".

${ }^{41}$ Ibidem.

42 "Qualità della vita, sviluppo sostenibile sono termini neoliberali. Ammazzano qualsiasi discussione. Perché sono terminali. Sono termini utilizzati nei discorsi dei politici che, nel momento di tradurli in opere, non sanno come farlo" (Santos 2001, pag. 5).

${ }^{43}$ In tale ottica, l'esperienza di Porto Alegre sembra essersi 'salvata' dalle critiche che Milton Santos ha mosso al suo Paese prima di morire, ponendo a discriminante del suo giudizio la comprensione, la codifica e la valorizzazione dell'azione popolare e del settore informale, e l'impegno-sfida "a passare dalla discussione della spesa pubblica alla discussione della città" per non consegnarla "alla logica del neoliberalismo, come sta accadendo in alcune città progressiste (Santos, 2001, pag. 7). 
Sezione Seconda

\section{L'individualità di una città tra territorio e società locale}





\section{4 \\ Porto Alegre prima del 1989: lo sviluppo urbanistico tra immediatismo e programmazione}

\subsection{Una città al contempo anomala e rappresentativa}

È difficile dire quando in Brasile ha cominciato a svilupparsi la coscienza che la favela 'non è una disfunzione del sistema, ma l'espressione fisica delle sue contraddizioni' (Taschner, 1997). L'ipotesi più probabile è che a determinare il cambiamento interpretativo in coincidenza con il tramonto del regime militare sia stata la convergenza tra le politiche 'esterne' di pressione della World Bank e l'impasse 'interno' su quale metodologia di azione adottare per la risoluzione del problema della casa, determinatosi all'inizio degli anni ' 80 , in quel 'limbo' che dopo il fallimento di anni di politiche al contempo autoritarie e paternaliste ha preceduto il decentramento delle responsabilità agli ambiti periferici della pubblica amministrazione. In ogni caso, è certo che il sostanziale 'slittamento del punto di vista' ha riguardato l'intero Paese, pur connotandosi nei diversi ambiti locali per anticipazioni e ritardi, e per un diverso grado di coscienza critica e volontà di approfondirne cause e possibili conseguenze.

Del percorso 'nazionale' che si è tentato di tracciare sommariamente nel capitolo precedente, le vicende della città di Porto Alegre costituiscono una fedele rappresentazione; almeno fino alle elezioni del 1988, ma parzialmente anche dopo, seppur con il ruolo particolare che ha attribuito alla città il collocarsi fra le esperienze-pioniere di rinnovamento dell'approccio al problema della città informale e - in connessione - delle politiche della casa e di quelle urbanistiche. L'oscillazione di Porto Alegre tra atipicità ed esemplarità (nel senso di capacità di rappresentare una situazione diffusa) non è solo un dato recente, ma ha scandito fin dai suoi esordi la storia della città, distintasi per alcune peculiarità che hanno certo svolto un ruolo primario nella costruzione di una prassi politica oggi esemplare per il suo potenziale di replicabilità in altri contesti, ma anche profondamente radicata nel territorio e nella tradizione socio-politica locale. Volendo riassumere sinteticamente alcune delle più significative continuità e discontinuità che possono interessare l'analisi sull'evoluzione del territorio portoalegrense rispetto alle tendenze maggioritarie del Brasile, si potrebbe sottolineare che: 
80 1) Per quanto concerne la conformazione del territorio, va certo ridimensionata la tentazione di ritenere Porto Alegre una città atipica nel panorama brasiliano, a motivo delle peculiarità della sua situazione geomorfologica. Essa presenta, infatti, affinità di ubicazione e conformazione naturale con altre città del Paese di dimensione medio-grande (ad es. Florianopolis o Rio) stretta com'è fra lagune, corsi d'acqua e promontori [morros] che frammentano la continuità dell'abitato. Anzi, sono proprio queste caratteristiche territoriali (area urbanizzabile ristretta, scomposta e disomogenea con presenza all'interno della Regione Metropolitana di centri abitati prossimi relativamente giovani, e non separati da ostacoli fisici né dalla progressiva saturazione dell'edificato) che hanno contribuito a far sì che Porto Alegre ben si prestasse ad incarnare al massimo grado quel processo di segregazione spaziale che ha segnato tutta la storia recente del Brasile urbano.

2) Tra gli elementi di maggiore rappresentatività 'media' vi sono comunque soprattutto alcuni sviluppi dell'Urbanistica nella Porto Alegre di inizio secolo, la fase di espansione urbana fronteggiata nell'ultimo cinquantennio in parallelo con il processo di industrializzazione del Paese e dell'intero Cono Sud dell'America Latina (cioè l'area di sviluppo del Mercosul), ma anche lo sviluppo della sua area metropolitana nell'ultimo trentennio, e le strategie di approccio al tema della città informale che hanno distinto l'amministrazione fino ad oltre la fine della dittatura.

3) L'atipicità di Porto Alegre risiede, invece, primariamente nella sua storia e nelle vicende politiche che l'hanno interessata e vista protagonista, sottolineandone un'evoluzione continua a tratti. Ubicata in un territorio che è stato l'habitat per eccellenza dei cosiddetti gaúchos (mitici 'eroi solitari' delle praterie desolate del Sudamerica la cui tradizione si è poi ibridata con varie ondate migratorie di origine europea),${ }^{1}$ Porto Alegre è sempre stata teatro politico di una strenua lotta fra maggioranze e opposizioni che ha prodotto lunghe fasi di regolare alternanza ma anche duraturi governi di caudillos, a partire dal lungo periodo di governo del Partito Repubblicano Riograndense (PRR, 1897/1937) La tendenziale autonomia politica dal 'centro' (specie dall'Unione) le ha garantito - (quasi unica città brasiliana insieme a Curitiba) di vedersi riconosciuto - già da un secolo prima della Costituzione del 1988 - il diritto di elaborare il suo statuto autonomamente dai modelli precostituiti dalle autorità nazionali. Tali peculiarità si sono coniugate con la capacità autorganizzativa mostrata nel corso dell'ultimo secolo dai movimenti popolari, esplosi nella loro forza d'incidenza politica dopo la dittatura. Nel corso del '900 istituzioni-chiave come la Chiesa o la stampa hanno, tra l'altro, rivestito un forte ruolo sia nei confronti di un'opera attenta di pedagogia sociale mirata alla creazione di una coscienza cittadina e di un nuovo immaginario sociale che della stessa strutturazione dello spazio urbano.

\subsection{Una sintetica presentazione}

Porto Alegre si localizza in una posizione geografica privilegiata, alla confluenza di varie regioni fisiografiche, tra terreni granitici e planizie di formazione alluvionale di grande instabilità (Mohr, 1998; Menegat, R., 1998) su cui l'occupazione umana si è indistintamente affermata, dando luogo a modalità d'uso e modelli di territorializzazione differenti, adattatisi con gradi 
diversi all'ambiente naturale, fino a provocare - nell'ultimo cinquantennio una decisa rottura della convivenza armonica tra le due componenti.

Il Comune occupa 476,30 kmq, 44,45 dei quali appartenenti ad isole. Situata - nelle sue parti pianeggianti - ad un'altitudine media di $10 \mathrm{~m}$. sopra il livello del mare, la città affaccia - con 70,02 Km. di coste - sul Lago Guaiba, da poco ribattezzato come tale, ma che fino al decennio scorso era chiamato Rio [fiume] trovandosi alla confluenza di una serie di corsi d'acqua che quasi si confondono incontrandosi, i maggiori dei quali sono il Rio Gravataí, il Rio dos Sinos, il Rio Caí e il Rio Jacuí (nel cui ampio delta si trovano una serie di isole abitate che fanno parte dal 1979 di un Parco Naturale Statale). Il Lago affaccia sulla Lagoa dos Patos [la Laguna delle Anatre], una rientranza naturale prospiciente l'oceano Atlantico all'estremità meridionale del Brasile, dove esso confina con l'Argentina e l'Uruguay. Il clima è di tipo subtropicale umido, con quattro stagioni ben definite e temperature variabili tra i $25^{\circ}$ e i $38^{\circ} \mathrm{C}$ estivi e i $2 \% 15^{\circ} \mathrm{C}$ invemali.

Il paesaggio, ricco di contrasti, è dominato da rocce appartenenti alla formazione detta Escudo Sul-Riograndense ed è caratterizzato da una conformazione orografica complessa, dove 40 promontori di rocce granitiche unite a depositi di arenaria del Quaternario [morros $]^{2}$ occupano il 65\% della superficie cittadina, frammentando l'abitato in diversi nuclei minori, spesso distanti e quasi autonomi fra loro. Queste caratteristiche geomorfologiche e idrografiche hanno avuto un notevole peso sull'evoluzione dell'organizzazione fisica della città, dalla sua fondazione ad oggi.

Amministrativamente, Porto Alegre è la capitale del Rio Grande do Sul, dagli anni '20 terzo Stato del Brasile per contributo al PIL nazionale ${ }^{3}$ la cui struttura economica (in un'area di confine con altri 3 Paesi della Comunità Economica del Mercosul) ha visto crescere nel tempo fra le sue principali voci di produzione di reddito sia il commercio transfrontaliero di beni prodotti in altre aree del Brasile, sia il settore terziario avanzato e l'agricoltura.

La stessa Porto Alegre - il cui prodotto interno è metà di quello della sua area metropolitana e oltre $1 / 6$ di quello dello Stato - è fra le poche capitali brasiliane (e l'unica nel Sud) a possedere una produzione agricola del 5\% all'interno dei confini comunali e - addirittura - il quartiere di Vila Nova è il principale produttore di pesche da tavola dell'intero Brasile. ${ }^{4}$

La città è comunque soprattutto un centro terziario di grande importanza, rappresentando ormai il settore (rispetto al 49\% degli anni '80) oltre il 64\% del reddito cittadino: di recente, vi è stata una forte crescita di microimprese anche nel settore del commercio, sia all'ingrosso che al dettaglio: un ambito di attività in cui la città eccelle su scala statale fin dal 1850 .

Intensa è stata la concentrazione urbana di attività economiche (soprattutto industriali/manifatturiere) fino al 1970, quando ancora Porto Alegre - oltre che il principale centro amministrativo della regione - produceva $1 / 4$ del totale del reddito statale, cifra calata al $17,36 \%$ già nel 1985 , e risalita poi grazie allo sviluppo del settore terziario. Le modifiche strutturali dell'economia nazionale hanno inciso notevolmente sulle finanze del Comune, le cui fonti di sostentamento dipendono in gran parte dal valore aggiunto prodotto dall'industria e dal commercio; vi ha inciso, inoltre, anche una riforma istituzionale del 1982 che non prevede più una redistribuzione finanziaria ai comuni direttamente proporzionale al loro contributo nella produzione di Valore 
82 Aggiunto Fiscale (VAF), riducendo questo criterio al solo $75 \%$, mentre il resto dei fondi 'ripassati' dai livelli istituzionali superiori è proporzionale ad altri fattori come la popolazione, l'area occupata, il numero di proprietà terriere, la produzione agricola. Tra il '92 e il ' 95 , il settore terziario è arrivato a contribuire con oltre il $60 \%$ al totale della struttura produttiva cittadina; in particolare il commercio - all'ingrosso e al dettaglio - ha assunto un ruolo leader in termini di produzione di reddito modernizzandosi e flessibilizzandosi in maniera notevole (Pozzobon, 1998). Il terziario superiore ha anche mostrato negli ultimi decenni una buona capacità di articolarsi con il settore industriale attraverso la ridefinizione di alcune funzioni (Carrion, 1993).

Del resto, nell'intera area metropolitana (dove all'inizio del decennio si è avuto un complessivo aumento dell'occupazione dell'ordine del 4,89\%) il settore secondario ha visto una progressiva riduzione del numero di addetti impegnati, a fronte delle oscillazioni del settore commerciale che si è consolidato nel 1994 in corrispondenza del Plano Real di adozione della nuova moneta, e della decisa crescita dei posti di lavoro generatisi nel ramo dei 'servizi domestici'. I dati esposti nelle figg. 5-6 possono offrire un quadro esaustivo delle peculiarità dell' organizzazione economica 'gaucha' (cioè dello Stato e della sua capitale), che si ripercuotono sulla composizione sociale della popolazione e sulla sua stratificazione, specialmente nell'area metropolitana sviluppatasi a partire dagli anni '60 con le particolari dinamiche che poi evidenzieremo. A partire dal 1992 si è riscontrato, in tutta la Regione Metropolitana di Porto Alegre, un calo della disoccupazione nel settore cosiddetto 'occulto', dovuto al notevole sviluppo dell'economia informale. Del pari, nel settore privato, vi è stata tra il '92 ed il '96 una crescita dei salari medi - soprattutto nel settore dei Servizi - per i lavoratori privi di libretto regolarmente registrato (sem carteira assinada). ${ }^{5}$ Questo insieme di condizioni ha prodotto un'apparente diminuzione della povertà a livello di redditi familiari, estrapolabile dalla riduzione subita tra il 1992 ed il 1995 dalla \% di famiglie rientrante nella fascia da 0 a 5 salari minimi, e dall'aumento di quelle con reddito superiore ai 20 salari minimi.

Oggi Porto Alegre ha una popolazione di 1.395 .959 abitanti $(2,91 \%$ dei quali residenti in area rurale $)^{6}$ che rappresentano il $13,7 \%$ di quella dello Stato $(10.187 .798$ ab. di cui residenti in aree urbane 8.317 .984 , cioè 1 ' $81,64 \%)$ e il $37,2 \%$ di quella della regione metropolitana. ${ }^{7}$ Nell'ultimo decennio, la capitale ha visto progressivamente calare il tasso di crescita geometrica della popolazione, aumentato però nel frattempo nei comuni dell'area Metropolitana.

\subsection{Porto Alegre città di città: una singolare evoluzione urbana}

Dal tardo Seicento, tutta la regione che oggi comprende il Rio Grande do Sul è stata a lungo un'area contesa fra portoghesi e spagnoli, interessati entrambi ad uno sbocco atlantico non lontano dal fiume Uruguay, da cui far transitare l'argento estratto in Bolivia e in altre zone non lontane. L'area risultò ancora più strategica dopo la scoperta delle ricche miniere d'oro del Minas Gerais brasiliano, il lavoro nelle quali creò domanda di nuovi prodotti come animali da carico, cuoio per confezionare utensili e carne per l'alimentazione degli schiavi. La grande presenza di bestiame brado in conseguenza della dissoluzione delle missioni del Tape nel '600 risul- 
tò fattore decisivo per la colonizzazione dell'area (Monteiro, 1995), la cui storia iniziò con un'occupazione portoghese di terre che gli Spagnoli non riconobbero come legittima ed anzi osteggiarono isolando quasi completamente la nuova colonia lusitana. ${ }^{8}$

Da Laguna, città di frontiera portoghese fondata tra il 1686 e il 1688 partì nel 1725 - per tentare l'occupazione del sud - la spedizione di João de Magalhaes, che non arrivò a creare dei centri abitati ma si ricavò dei significativi 'punti di ingresso' attraverso i domini spagnoli. Per tale via, si accamparono sul territorio alcuni coloni che venivano da Nord, non interessati a fermarsi stanzialmente costruendo dei villaggi, ma piuttosto a sfruttare la massiccia presenza di bestiame brado. ${ }^{9} \mathrm{Nel} 1740$ gli occupanti ricevettero un titolo provvisorio di proprietà che li riconosceva appunto come colonos de produção e non de povoamento (Macedo, 1993), avallando il particolare modello di conquista 'a fini produttivi' e 'non abitativi' che i 'conquistadores' avevano messo in atto. ${ }^{10}$ Il primo presidio militare fisso nell' area sorse solo nel 1737; da qui venne sollecitato l'arrivo di donne da Rio e anche - con la Carta Régia dell'Agosto 1746 - di coppie provenienti dalle isole Azzorre, che organizzarono piccole imprese agricole a conduzione familiare (Souza e Müller, 1997). Questi fatti contribuirono ad intensificare le lotte tra spagnoli e portoghesi, almeno fino al Trattato di Madrid del $1750,{ }^{11}$ quando la mediazione del diplomatico Alexandre de Gusmão ottenne che il Portogallo cedesse alla Spagna la Colonia di Sacramento in cambio di una parte delle Missioni Gesuitiche a sinistra del Rio Uruguai. Solo da quel momento il Portogallo prese possesso di questa regione in forza di diritto e non solo di occupazione; e la filosofia della permanenza temporanea lasciò in breve il posto a quella della strutturazione di insediamenti definitivi (Velasques 1993). Dal 1752, principalmente coppie delle Isole Azzorre presero a fermarsi nell'area, ${ }^{12}$ individuandola come punto intermedio strategico - favorito dalle condizioni naturali e legali - tra gli ormai importanti centri di Rio Grande e Rio Pardo. In attesa di una donazione di terre esse fondarono il centro abitato di S. Francisco do Porto dos Casais [il porto delle Coppie] ai margini del lago Guaiba che, comunicando con altri importanti corsi d'acqua, permetteva la penetrazione verso l'interno dello Stato. La possibilità di una permanenza in loco dei nuovi coloni fu garantita dalla Legge delle Sesmarias, che considerava pubbliche le aree estendentisi per 1650 metri (un quarto di lega) dal bordo dei fiumi navigabili.

Nel 1772 il piccolo villaggio divenne Parrocchia ${ }^{13}$ ottenendo una giurisdizione (ancora solo religiosa) e un registro dei battesimi su cui furono registrati i nuovi cittadini di Nossa Senhora da Madre de Deus, da lì a poco detti portoalegrensi dal nome di una città del Portogallo. ${ }^{14}$ Nel 1773 il nuovo centro parrocchiale - 1.500 abitanti - fu caricato dell'incombenza di diventare la capitale della Provincia. La nuova Capitale sarà riconosciuta come Vila [città] solo nel 1810, ma nel frattempo si trasformò in un porto di notevole importanza per il trasporto dei passeggeri e delle merci prodotte nella regione, specie grano e bestiame.

All'inizio della colonizzazione non si può parlare di un nucleo urbano, data la dispersione degli abitanti, l'inesistenza di strade e di demarcazioni dei lotti, la mancanza di un potere autonomo e la pratica di un'agricoltura di mera sussistenza. Ma, già a partire dal luglio 1772, cominciarono ad essere regolarizzate le aree per la residenza dei coloni delle Azzorre, accampati 
84 prevalentemente sulla penisola dove sorgerà il primo nucleo urbano. Sessanta coppie ricevettero 135 ettari, mentre venivano stabiliti anche i principali spazi di uso pubblico attraverso espropri compensati con aree di uguale dimensione nel tratto tra la laguna e l'oceano. La scacchiera di percorsi dentro le fortificazioni divenne più irregolare man mano che interessava il rilevato maggiore dove fu ubicato il centro civico. Nel 1794, gli abitanti vennero invitati a pavimentare le vie davanti alle loro case, specie lungo le tre direttrici principali che, partendo dalla punta della penisola, lo attraversavano in senso longitudinale incontrandosi davanti alla Porta della città (attuale Piazza Argentina).

Queste strade, che mutavano nome nel corso del loro svilupparsi, in riferimento alle peculiarità del terreno o alle attività importanti per la comunità che vi trovavano posto, avevano ancora all'epoca un aspetto precario (sovente erano tagliate da ruscelli, petraie e nuclei di vegetazione selvatica) che manterranno fino alla prima pavimentazione irregolare del $1840 .{ }^{15}$ Le celebrazioni religiose di piazza evidenziarono fin da subito segni di contaminazione e fusione della tradizione cattolica portoghese e delle Azzorre con tracce della cultura afro-brasiliana portata dagli schiavi. Luoghi come la Praça da Matriz [Chiesa Madre] divennero presto spazi-sintesi simbolicamente fondamentali, seppur poveri sotto il profilo formale, essendo in terreno battuto e segnati da una fonte pubblica.

Per le classi più povere 'tavernas e botequins' rappresentarono a lungo il principale luogo di ritrovo maschile, mentre gli spazi di socializzazione delle donne erano legati al mondo del lavoro domestico: lavatoi, piccole botteghe (quitandeiras), o i luoghi di ricevimento delle balie da latte e delle prostitute (Rocha, 1989). Ciò spiega le notevoli resistenze popolari che dal 1820 al 1830 si opposero al trasferimento delle piccole botteghe al di fuori dei percorsi abituali (Monteiro, 1995).

All'atto della sua fondazione, il terreno di Porto Alegre si presentava come un promontorio, ancora oggi caratterizzante la conformazione urbana e proteso sul lago Guaiba, a dividere le acque e il territorio in due porzioni che nel tempo hanno sempre interagito diversamente con i processi di sviluppo: quella nord - la portuale - più dinamica, e quella meridionale più arretrata. La conformazione orografica 'ad imbuto' del promontorio ha determinato nel tempo un convergere dei collegamenti con la regione in un unico punto, con la conseguenza di protrarre nel tempo grossi ingorghi di traffico nel centro cittadino. È stata sostanzialmente questa situazione a spingere la città, fin dalla meta dell'Ottocento, ad ampliare la sua area centrale mediante interramenti, iniziando dalla zona nord, passando per la definizione del porto nel 1922 e proseguendo sulla riva sud, ancora di recente oggetto di ritocchi e perfezionamenti della sua forma. Il susseguirsi di queste operazioni ha portato nel tempo la parte centrale di Porto Alegre a subire un ampliamento pari a tre volte la sua superficie iniziale (Souza, 1997). In tal modo la Rua da Praia [via della Spiaggia, ora Rua dos Andradas], ${ }^{16}$ così detta perché si trovava sulla riva del lago, con i successivi interramenti se ne è allontanata sempre di più e oggi non presenta nessuna relazione con l'acqua, trovandosi nel mezzo del centro cittadino, mentre il Porto è notevolmente avanzato rispetto alla posizione iniziale. La toponomastica 'popolare' - più di quella 'codificata' - invita oggi a ripercorrere alcune delle principali tappe storiche di costruzione della città. Di particolare pregnanza sono in tal senso i nomi di molti quartieri (sia di quelli 
formali che di quelli nati con processi irregolari), a partire dal più antico denominato Menino Deus (Gesù Bambino) in omaggio al protettore dei coloni provenienti dalle Azzorre che qui celebravano le loro feste popolari, per continuare con il Partenon, estensione Ottocentesca della zona sud che prese il nome da una rivista fondata da un gruppo di intellettuali amanti dell'arte classica. In appena due secoli, molte strade e luoghi hanno più volte cambiato nome ${ }^{17}$ ma in molti casi, nella cultura popolare, hanno mantenuto la denominazione originaria.

\subsection{I primi passi dell'urbanistica}

Negli ultimi anni del secolo XVIII Porto Alegre venne dotata delle prime necessarie attrezzature; l'Arsenale, le due fonti per il rifornimento d'acqua (l'utilizzo dei corsi fluviali si faceva sconsigliabile con l'addensarsi urbano che li usava come fogne), il carcere, l'infermeria pubblica e un magazzinoteatro sostituito - dopo un incendio da un locale per rappresentazioni teatrali e operistiche più sicuro (la Casa da Comédia, poi Ópera). Solo nel 1800 aprirono le prime scuole, mentre nel 1784 cominciarono i lavori per costruire il Palazzo del Governo in Praça da Matriz (edificio in stile coloniale demolito e ricostruito nel '900), e nel 1790 si conclusero quelli per la sede dell'Assemblea Provinciale. In Piazza della Forca, venne costruito il Pelourinho, una colonna con il simbolo della giustizia che divenne 'il luogo della ritualizzazione dell'ordine nella società coloniale' (Monteiro, 1995), davanti alla quale si eseguivano le sentenze e - in assenza di giornali - si diffondevano proclami e notizie. La Piazza della Dogana - l'antico Porto dos Casais - restò a lungo il centro portuale, 'intoccabile sotto lo sguardo vigile dei commercianti' che più volte ne impedirono lo spostamento altrove obbligando, anzi, il Comune a continue migliorie delle strutture che vi si affacciavano e dei servizi (Macedo, 1968). Le diverse opere richiesero la costruzione di alcune fornaci nella zona Nord, quella più attiva dove si moltiplicavano le attività portuali e commerciali. Intorno alla Rua da Praia sorse anche una ferriera, che serviva i cantieri vicini.

Nel frattempo il mutare della fisionomia dello Stato [Continente] di São Pedro diviso in 4 diverse giurisdizioni nel 1803 - portò ad un ridimensionamento delle funzioni di Porto Alegre che contava quattro parrocchie e 11.747 abitanti, cioè il $31,99 \%$ della popolazione dello Stato. La città venne riconosciuta anche formalmente come Vila, attraverso un solenne Atto di Fondazione [Auto de Criação] a cui l'11 dicembre 1810 partecipò tutta la popolazione.

Quando nel 1808 la Famiglia reale portoghese emigrò in Brasile per sfuggire alla conquista napoleonica, a Porto Alegre si era da poco terminata la costruzione di alcuni edifici fondamentali come il carcere e la Casa da Camâra, mentre - nonostante le pressioni fatte nel 1805 dal governatore preoccupato per il possibile manifestarsi di problemi di salute pubblica - nessuna area opportuna 'fuori dal centro abitato' era stata destinata a cimitero, e si continuava a seppellire nella piazza principale della città. ${ }^{18}$

In questi anni si distinse - all'interno di una politica urbana che sembrava agire 'per emergenze singole' - Diogo de Souza, matematico e capitano portoghese a cui si devono i primi tentativi di un 'trattamento paesaggistico dello spazio pubblico' (Macedo, 1993) e la costruzione del Caminho Novo, 
86 una delle 5 principali direttrici di penetrazione alla città ${ }^{19}$ su cui andavano sviluppandosi piccoli nuclei abitati,ormai divenuti i nuovi 'poli' della crescita cittadina. Le descrizioni più interessanti di questa fase della vita portoalegrense si trovano nei resoconti del viaggio di Auguste de Sant'Hilaire del 1820-21. ${ }^{20}$ In questo periodo fu intensa l'adesione di Porto Alegre - avamposto Brasiliano più meridionale a diretto contatto con le lotte che si svolgevano in Uruguay ${ }^{21}$ - ad alcuni eventi della rivolta liberale di Porto, in particolare alla creazione di giunte governative e all'entusiasmo per l'elaborazione della Costituzione portoghese che segnò il passaggio alla Monarchia Costituzionale e costrinse Don João VI a rientrare a Lisbona lasciando suo figlio in Brasile come reggente. ${ }^{22}$

Il 1821 viene ritenuto un anno 'molto importante per la coscientizzazione del portoalegrense nella sua adozione del Brasile come patria al posto del Portogallo' (Macedo, 1993), subito concretizzatasi con la cacciata - a furor di popolo - del brigadiere João Carlo de Saldanha e Daun, sospettato di complottare contro il Govemo Provisório 'costituito con il proposito di difendere una certa autonomia per gli abitanti del Rio Grande do Sul' (ibidem).

Nel 1822 a Porto Alegre venne riconosciuta realmente 'la condizione di città' e nel 1825 fu commissionata a José Pedro César una pianta ufficiale del territorio che aiutasse il potere pubblico a riordinare la maglia urbana per recuperare fondi dai terreni in enfiteusi, e servisse da base per lottizzarne altri. Lo stesso anno fu anche attivata una lotteria annuale per finanziare alcune istituzioni, come quelle per la custodia e il sostentamento dei bambini abbandonati, mentre nell'ambito del riordino della vita comunitaria fu emanata la prima Legge Organica municipale (1828), ovvero lo Statuto comprendente norme amministrative e fiscali. $\mathrm{Fu}$ anche pubblicato il primo $\mathrm{Co}$ dice delle deliberazioni Municipali (1829, modificato nel 1931) che conteneva 50 articoli riguardanti: i limiti urbani, quelli del centro cittadino (entro cui era necessario ricostruire 'in pietra o laterizi'- nel giro di 3 anni - tutte le facciate su strada), le norme di edificazione e sicurezza, i trasporti, la protezione degli schiavi e persino della fauna.

\subsection{Lo 'spirito ribelle' e la città borghese}

L'abdicazione di Don Pedro I in favore del figlio Pedro II (1831) mise a nudo l'alto numero di promesse che la Reggenza Brasiliana non aveva mantenuto. Proprio in questo periodo si sviluppò una forte corrente restauratrice avversa ad ogni ipotesi di Indipendenza, localizzata specialmente tra le alte cariche dell'esercito, che anche a Porto Alegre dettero vita ad una Sociedade Militar, in aperta opposizione alla neonata organizzazione nazionalista, la Sociedade Defensora da Liberdade e Independência Nacional, nata nel 1832. Nel crescere dello scontento popolare per l'eccessiva dipendenza della vita cittadina da funzionari di Rio de Janeiro che disconoscevano la realtà del Rio Grande e commettevano abusi attraverso gli esattori, emersero figure locali di grande prestigio, tra cui Bento Gonçalves. A partire dal 1833 il clima a Porto Alegre si fece incandescente, con una serie di rivolte che culminarono nella trionfale entrata in città di Gonçalves, del settembre 1835, e nella successiva guerra che cominciò nel febbraio del 1836 e - con alterne vicende - vide i ribelli trionfare fino almeno al $1840,{ }^{23}$ impedendo ai difensori della monarchia l'arrivo dei viveri in città. Durante l'assedio, i legalisti - 
oltre a distruggere i mulini a vento per non favorire gli assedianti - mutarono il Codice delle deliberazioni Comunali (1837) per permettere la continuità di erogazione nell'area assediata di alcuni servizi pubblici e mantenere la funzionalità urbana (Macedo, 1993).

Con la conclusione della Rivoluzione Farroupilha nel febbraio 1845, il sovrano Don Pedro II volle dimostrare l'interesse della corona per la Provincia di Porto Alegre e visitò per la prima volta la città, per l'occasione rinnovata negli intonaci e nei nomi delle strade e dotata di marciapiedi e pavimentazione stradale. Nell'occasione il Conte di Caxias, neopresidente della Provincia, fece ricostruire alcuni ponti fortemente danneggiati dopo la piena del 1833, e ordinò la ripresa dei lavori del Teatro São Pedro, portati a conclusione nel 1858 a prezzo di notevoli difficoltà, originate dal fatto che il progetto della piazza era giunto preconfezionato da Rio sul modello degli orientamenti francofili dell'epoca, e non era adatto al luogo che doveva ospitarlo.

La distruzione delle fortificazioni, posteriore alla fine della rivolta del 183545 , determinò una rapida crescita della città e la saldatura con alcuni nuclei abitati circostanti, mentre la ricostruzione del maggiore ponte - danneggiato dalla piena del 1833 - accelerò l'espansione verso sud. È questo un primo periodo di intensità per la vita culturale cittadina, con la formazione della società denominata Partenon Literário (1868/1899) che fu la punta di diamante del movimento intellettuale locale dove furono dibattuti i temi dei diritti delle donne e dei neri e quello della Repubblica.

In questo periodo maturarono alcuni orientamenti importanti legati alle trasformazioni urbane, come l'idea di creare nuovi quartieri di case basse circondate da giardini e andò acuendosi il fenomeno della 'contaminazione culturale'. Se tra il 1824 e il 1833 era giunto, infatti, un grande contingente di immigranti tedeschi ${ }^{24}$ (sistematisi principalmente nell'area dell'attuale comune di São Leopoldo), dopo il 1850 il flusso migratorio riprese, arricchendosi dopo il 1875 di una cospicua componente italiana ${ }^{25}$ che andò ad aggiungersi a quella tedesca ormai inseritasi a pieno titolo nella vita economica e sociale dell'area ed in grado di fare da intermediario fra i nuovi abitanti, i loro bisogni e le Istituzioni, anche attraverso la riorganizzazione dei commerci su scala regionale (Souza, 1997). Quando - in coincidenza con la proclamazione della Repubblica (1889) - prese avvio la fase di sviluppo industriale, gli immigrati tedeschi rappresentavano una delle componenti più cospicue della borghesia e - con i loro 78 stabilimenti - costituivano il $40 \%$ dei membri dell'Associazione Commerciale di Porto Alegre. ${ }^{26}$ La loro influenza fu così determinante anche sullo stile architettonico che Singer (1977) classifica questo periodo (fino al 1920) come la città dei tedeschi.

La rapida coscientizzazione portata da questa sommatoria di eventi e fenomeni culturali provocò celeri mutamenti anche relativamente al regime della schiavitù. Non appena promulgata la Lei do Ventre Livre che permetteva alle persone di colore di associarsi (25/9/1871), a Porto Alegre nacque la Sociedade Floresta Aurora, ancor'oggi attiva nel campo dei diritti umani e delle attività culturali e religiose delle minoranze. In questi anni Porto Alegre - anche a motivo della sua funzione amministrativa - acquisì una centralità che la rese referente politico per l'intero Stato, specie dopo aver dato i natali al Club Repubblicano (1878), al Partito Repubblicano Riograndense (1882) e al suo organo di stampa, A Federação (1884). In tale clima di fermento, il 
movimento abolizionista ottenne una revisione del Codice Municipale che definiva i lavoratori di condizione libera e prevedeva la necessità del preavviso di 10 giorni in caso di licenziamento. ${ }^{27}$

Come si deduce da una pianta cittadina datata criticamente attorno al 1870 (Macedo, 1993), fino a quest'epoca un solo nucleo abitato fuori dalle mura di Porto Alegre era considerato con dignità di quartiere (non dipendente cioè in tutto dalle funzioni svolte nel centro), quello del Menino Deus; gli altri ${ }^{28}$ erano nominati in relazione alla presenza di una cappella intorno a cui si raccoglievano poche case ${ }^{29} \mathrm{o}$ di case per il fine-settimana della nascente borghesia (Campos de Bom Fim) situate nella direzione in cui maggiormente andava espandendosi la città.

Dal 1864 fu attivato il servizio tranviario, con la maxambomba a vapore che serviva la zona Sud della città; nel 1873 fu sostituito dalla Companhia Carris de Ferro Porto-Alegrense a trazione animale (funzionante con maggiore continuità) e nel 1893 dalla Carris Urbanos de Porto Alegre che serviva anche aree della zona Nord. Al 1871 data il primo tratto di ferrovia Porto AlegreSão Leopoldo, costruita da inglesi e prolungata fino a Novo Hamburgo solo nel 1873, risolta la querelle su dove ubicare in città la stazione di testa. Legandosi a queste innovazioni e all'estrazione del carbone, dal 1867 fu attivato il servizio pubblico di distribuzione del gas per consumo domestico e pubblica illuminazione; l'appalto fu vinto da un imprenditore francese, ma fu il Comune a rilevarne presto l'attività, mantenuta fino al 1930. Già dal 1865 funzionava, invece, la Hidráulica Porto-Alegrense che forniva a varie zone della città acqua, mentre dal 1876 fu regolarizzato per legge il servizio di raccolta dei rifiuti e nel 1878 si iniziò a realizzare il sistema fognario. Le prime linee telefoniche arrivarono a Porto Ale gre dal 1886 (Oliveira, 1984). Parallelamente ci si pose il problema dello spazio pubblico, dello sport e della ricreazione ${ }^{30}$ e della protezione del patrimonio verde. Dal 1867 un servizio di vigilanza cercò di evitare la trasformazione in discarica di Praça da Matriz, e per renderla un giardino fu ideata l'anno dopo una speciale lotteria. In alternativa all'uso del verde, per garantire la salvaguardia di spazi pubblici fruibili, in molte piazze furono collocati circhi o arene provvisorie per corride e teatro.

L'ultimo decennio dell'Ottocento vide un'enorme espansione del perimetro urbano per i continui processi di rivalorizzazione dovuti al rapido espandersi dei servizi cittadini, che attirano anche nelle zone di margine classe media ed esercizi commerciali. Nel 1890 la popolazione di Porto Alegre contava 52.000 abitanti, divenuti 73 mila nel 1900 con una densità di 32 abitanti/mq (FEE, 1981). ${ }^{31}$ Il nucleo primitivo centrale subisce in quel periodo una rapida borghesizzazione, che culmina nello 'spettacolo delle vetrine' (Monteiro, 1995) consentito nel 1895 dall'introduzione dell'illuminazione elettrica da parte della Compagnia Fiat Lux, e nell'apertura (1897) della prima Facoltà Universitaria (Ingegneria), a cui seguiranno in breve Medicina, Odontoiatria e Giurisprudenza. La Grande Esposizione Statale del 1901 segnò l'inizio dell'urbanizzazione della Várzea, completa di numerosi servizi, tra cui 4 presidi medici, la linea ferroviaria per lo smaltimento dei rifiuti fino a Ponta do Dionisio e dal 1908 i primi tram elettrici.

La proclamazione della Repubblica (15 novembre 1889, data di cui fu sottolineata la filiazione diretta dalla Rivoluzione Francese di un secolo prima) 
provocò alterazioni nella toponomastica a furor di popolo ${ }^{32}$ e una nuova ondata di costruzioni pubbliche. Nel 1898 fu posata la prima pietra del Palazzo Municipale, progettato dall'architetto italiano J.L. Carrara Colfosco e terminato nel 1901, e a seguire furono inaugurati molti monumenti che ripercorrevano la storia della città e dei suoi fermenti indipendentisti e repubblicani, ${ }^{33}$ compresa una statua dedicata a Giuseppe e Anita Garibaldi nel 1913, omaggio al 'contributo italiano'.

Nel 1910, la popolazione cittadina arrivò a 115.000 abitanti portando Porto Alegre nel piccolo gruppo di città brasiliane con oltre 100.000 residenti. Fu l'inizio del cosiddetto 'quadriennio glorioso' (Doberstein, 1988) che vedrà molte realizzazioni architettoniche private e di pubblica utilità per lo più ispirate agli stilemi dell'architettura tedesca di impianto barocco e jugendstil.

Il 20 ottobre 1892 rappresenta una data significativa per Porto Alegre per la creazione della Segreteria dell'Intendenza Municipale composta da 7 sezioni, fra cui quella di Ingegneria che, nel 1896, venne trasformata in Direzione delle opere con compiti quali: ispezionare le costruzioni pubbliche e private ed il traffico della ferrovia creata per trasportare le deiezioni cloacali (visto che la rete di fognatura non copriva tutta l'area urbana), perfezionare la pianta del municipio, costruire e conservare pavimentazioni, ponti, vie e giardini pubblici (SMOV, 1985). Tra le novità, la presenza di giardini pubblici costituiva un richiamo all'influenza europea sul continente latinoamericano, ${ }^{34}$ il tema degli allineamenti degli edifici sulle vie rimpiazzava l'irregolarità morfologica del periodo coloniale, e la politica d'igiene mirava a minimizzare il deterioramento dell'ambiente urbano, non limitandosi solo al centro storico (come altrove) ma - sul modello parigino - ampliando l'azione all'intera città attraverso interventi integrati (viari, sanitari, di circolazione).

Per dar finalmente realizzazione alle trasformazioni che ancora dovevano essere portate avanti (soprattutto nell'area nord da recuperare al fiume), il sindaco Montuary istituì la Commissione di Miglioramento e Abbellimento della Capitale che - partendo da alcune indicazioni già fornite dall'ing. Heydtmann nel 1855 - elaborerà nel 1914 il primo piano urbanistico della città, tardando però a dargli attuazione, sia per la 'mancanza di una ferma volontà di cambiamento' (Monteiro, 1995) sia per l'intransigente volontà di adesione al principio 'comtiano' dell'equilibrio di bilancio.

La ricerca di prestiti esteri significativi (soprattutto in USA) fu invece intrapresa dal Governo Statale, che in quegli stessi anni porterà a termine un grande stralcio del progetto di interramento ulteriore della spiaggia sul Guaiba per potenziare il Porto e migliorare la navigazione fluviale attraverso lo Jacuí e i suoi affluenti, in parallelo al collegamento ferroviario con la città di Caxias. Queste opere daranno notevole impulso allo sviluppo industriale e commerciale nell' area (Singer, 1977).

La serie delle migliorie apportate in questo periodo (attraverso iniziative più in campo architettonico e dei servizi, che non urbanistico), non comporta comunque un riordino dello spazio globale della città che continua a perpetuare caratteristiche organizzative di impianto coloniale (Monteiro, 1995) mostrando la pochezza del 'modesto ingegnere' ossequioso 'agli ordini del partito e del Capo Supremo - Borges de Medeiros - che mai si avventurò in grosse imprese, sebbene ne avesse fatto progettare alcune' (Spalding, 1967). Sostenendo - come fece nel suo discorso di addio del '23 - che la gente 
90 avesse piuttosto bisogno di acque, fogne, pulizia ed illuminazione pubblica, il sindaco Montuary non realizzò nessun faraonico simbolo cittadino, ma fornì al suo successore Otávio Rocha - che governerà fino al 1829 - "la base necessaria per andare oltre nella rimodellazione più ampia dello spazio urbano di Porto Alegre'; e comunque lasciò una città migliore che al suo arrivo, dove il tasso di mortalità infantile (giusto per fornire un indicatore di benessere significativo all'epoca) si era abbassato, durante la sua amministrazione, da 32,25 a 17,90\% (Monteiro, 1995).

\subsection{I primi strumenti regolatori}

Ad inizio '900, le condizioni igienico-sanitarie in cui le maggiori realtà urbane si trovavano, spinsero molti governi locali brasiliani ad affrontare per la prima volta 'di petto' reali problemi di ordine, pulizia, igiene e circolazione che si aggravavano con l'addensarsi delle città. In particolare, si puntò a risolvere (spesso 'non alla radice' ma partendo dagli effetti) i problemi causati dal grande contingente di povertà che, per l'ideologia del potere, rappresentava qualcosa di 'immorale'. ${ }^{35}$

Innovazioni come il tram ebbero una funzione singolare nell'interazione della famiglia con la città (Barbosa de Araújo, 1993) mentre Rio de Janeiro, che già durante l'Impero rappresentava per il Brasile un punto di riferimento perché era la sede della corte, si trasformava nel paradigma nazionale 'vendendo l'immagine dell'immagine' dedotta dalla Parigi di epoca haussmaniana (Souza, 1994), e diffondendo nell'immaginario collettivo brasiliano un modello di organizzazione urbana e di vita cittadina traslato da modelli eteronomi. ${ }^{36}$

Porto Alegre era stata una delle prime città brasiliane a seguire questi orientamenti già a metà dell'Ottocento, e nel nuovo si trovò avvantaggiata per la presenza di strutture professionali in grado di facilitare l'elaborazione di strumenti di risoluzione complessiva dei problemi urbani. Prima dell'elaborazione di un vero 'piano regolatore' si potè procedere ad introdurre in città cambiamenti 'visibili' sulla scorta di un immaginario di modernità legato a quello di centri maggiori del vecchio continente. Nonostante il forte attivismo ottocentesco del municipio nella realizzazione di opere pubbliche (piani viari, pavimentazione della struttura cittadina in funzione dell'integrazione dei sobborghi), Porto Alegre entrò nella Repubblica con una forte impronta coloniale. L'adozione del Plano Geral des Melhoramentos del 1914 costituì quindi un evento cruciale visto che:

a) a livello di discorso globale, si pose come esempio significativo dei primi strumenti di regolazione dello sviluppo urbano elaborati in un paese periferico al mondo europeo, che aveva appena adottato una forma repubblicana di governo e che voleva cancellare al più presto possibile della schiavitù da poco tempo estinta (Souza, 1997) ed anche i segni di un passato urbano coloniale letto come pericolo per la costruzione della modernità. ${ }^{37}$ Esso si inserì appieno nel progetto di valorizzazione delle città e di modernizzazione di un paese dove le esigenze della nuova società borghese rendevano inevitabili continui cambiamenti socio/politici;

b) a livello di discorso nazionale, costituì il primo esempio conosciuto di piano regolatore brasiliano 'generale' per l'intera città;

c) a livello di discorso locale, dette la sua impronta alle trasformazioni della 
città per un intero secolo, rappresentando un "forte punto di riferimento per i piani successivi" (Souza, 1997).

Disegnato dall'architetto-ingegnere Moreira Maciel, primo diplomato della Scuola Politecnica di San Paolo nel 1904, il piano fu posto in esecuzione solo a partire dal 1924, significativamente in coincidenza con un cambio di gestione politica dopo 27 anni di continuità. Esso restituiva un'immagine della 'città desiderata' mutuata per grandi linee dalle realizzazioni d'oltreoceano del secolo precedente con l'ambizione di 'poter cambiare la società' (ibidem). Il fatto però che il piano (dopo essere riuscito a penetrare nell'immaginario della popolazione) sia stato progressivamente incorporato per stralci nei piani successivi che hanno segnato il lento processo di costruzione della città possibile - dimostrando notevole versatilità nell'adeguamento ai tempi - dà però testimonianza di un riuscito tentativo di 'adesione al luogo' dei principi-guida di questo strumento urbanistico, ${ }^{38}$ che gli dette modo di distinguersi nel panorama nazionale dell'epoca.

Il suo aspetto pionieristico sta proprio nell'essere stato uno dei primi piani del Paese che - pur operando innanzitutto per rinnovare il sistema viario della città - aveva di mira una riforma di carattere complessivo per risolvere i problemi urbani dei nuovi tempi, che spaziavano dal risanamento sociosanitario alla necessità di costruire nuove attrezzature (compresi parchi pubblici) fino all'abbellimento estetico, questione sottintesa nel tipo di interventi proposti. In questo senso il Piano di Maciel rappresentò un passo avanti rispetto alle proposte coeve di altre città latinoamericane. Pur risentendo dell'influenza di quanto realizzato negli anni precedenti a Rio dal sindaco Pereira Passos, si fece - infatti - portatore di una visione più ampia: "non solo il centro, nemmeno solo un viale, ma la relazione del centro con la periferia" (Souza, 1997). Inoltre, la ricerca del pittoresco attraverso l'accentuazione di tracciati curvi e poligonali più vicini all'originario stile coloniale della città, era una novità rispetto ai modelli haussmaniani sovente imitati acriticamente.

Il piano - nel suo 'realismo cosciente' - assunse caratteristiche che oggi definiremmo 'strategiche', focalizzando l'attenzione su processi e direttive generali (mentre lasciava i dettagli e le opere ai progetti successivi) secondo quanto auspicato dal potente Presidente dello Stato, il 'quasi-governatore a vita' Borges de Medeiros, che contemporaneamente ordinò l'avvio dei lavori per riorganizzare il sistema dei canali e ammodernare il porto adattandolo alle necessità della nuova rete di commerci di cui il Rio Grande do Sul veniva a trovarsi al centro. In sostanza, se nelle caratteristiche formali il piano Maciel subì l'influenza dell'urbanistica francese ${ }^{39}$ dal punto di vista strutturale esso riuscì ad identificarsi con le radici dei problemi di Porto Alegre, in quanto "la sua concezione generale muoveva da un'analisi oggettiva dell'evoluzione storica della città e delle sue necessità immediate e future" (Paiva, 1947). ${ }^{40}$

Per questo persino Paiva (urbanista vicino al Movimento Moderno che intervenne negli anni ' 40 nella riformulazione degli strumenti urbanistici cittadini) sottolineò la capacità del Piano del 1914 di evidenziare la funzione regionale ed il ruolo di emporio commerciale di Porto Alegre, e di intervenire sulle precarie condizioni sanitarie delle zone allagate, finendo per concludere che "questo lavoro (di così alta visione, che praticamente quasi tutte le soluzioni si sono successivamente presentate, e molte ancora oggi si presentano, come necessarie) nonostante sia un piano tipicamente viario [...] era basato su prin- 
92 cipi-guida ben definiti e realistici, al punto da adattarsi in maniera 'necessaria' alla città e da permanere valido fino ad oggi” (Paiva, 1947). ${ }^{41}$

Negli anni tra le due guerre, le trasformazioni strutturali che attraversarono il Rio Grande do Sul portandolo al terzo posto nel Paese per contributo alla formazione del reddito nazionale (Monteiro, 1995) richiesero la riorganizzazione degli spazi urbani (a partire da quelli della capitale Porto Alegre) simultaneamente scenario e attore delle trasformazioni politico-sociali, come territorio delle lotte per l'egemonia tra i diversi gruppi (id.). Il tentativo di modernizzare l'immaginario sociale in conformità con quello delle elite dirigenti, ricercò cambiamenti che mantenessero lo status quo politico davanti al nuovo galoppante sviluppo economico.

I 40 anni (1897/1937) di governo del Partito Repubblicano Riograndense (PRR) fecero proprio il principio comtiano della continuità amministrativa, sia in forma stretta che attraverso l'accezione della continuità nel cambiamento ${ }^{42}$ assestando un forte colpo alla modernizzazione delle infrastrutture urbane, al controllo dell'ordine e alla neutralizzazione dei conflitti, condizioni indispensabili per lo sviluppo economico promesso all'elettorato della borghesia commerciale e industriale.

Ciò richiese - a fronte dei nuovi modelli di vita urbana determinati dallo sviluppo e dai sempre maggiori contatti col mercato internazionale - un'analisi che tenesse conto della nuova socialità e della nuova estetica del vivere in comune nello spazio pubblico (Monteiro, 1995), attraverso la rimodellazione dei vecchi spazi cittadini e la creazione di nuovi (viali, parchi, piazze) che venissero incontro alle esigenze del nuovo cittadino, educato attraverso la stampa con un'opera attenta di pedagogia sociale che contribuì alla creazione di un nuovo immaginario sociale parzialmente pilotato nei suoi esiti (Rocha, 1989). La progressiva crescita di importanza della Subcommissione di Abbellimento urbano e l'alta percentuale di risorse destinate al suo operato rivelò ben presto l'importanza legittimatrice conferita all'elemento estetico (Monteiro, 1995), legato ai nuovi modelli borghesi di vita sociale che prevedevano anche l'ampliamento della vita sociale notturna permessa dai sistemi di illuminazione pubblica elettrica.

Attraverso una riforma del sistema tributario, nel 1925 si tentò di riorganizzare l'occupazione dello spazio urbano, punendo particolari attività nel centro, nel tentativo di nobilitarne e modernizzarne l'immagine e di estromettervi tutti coloro che vi risiedevano in condizione di difficoltà o precarietà. In questa direzione andavano sia le imposte sugli edifici (nel centro più alte per quelli più bassi e obsoleti) sia quelle sui veicoli, differenziate per cerchi urbani concentrici; con esse - fingendo di voler preservare le nuove pavimentazioni dai veicoli senza condizioni tecniche - si mirava ancora ad allontanare $\mathrm{i}$ più poveri dal centro, mentre varie opere di rimodellazione urbana parevano perseguire gli interessi del commercio e lo sfruttamento della borghesia negli spazi moderni (Monteiro, 1995). Anche la cura dei trasporti servì a direzionare la crescita della città nel modo richiesto dalle classi dominanti (le uniche ad avere libertà piena di movimento grazie ai mezzi privati) in parallelo alla costruzione di abitazioni operaie, spesso realizzate con ambiguità tale da fare il gioco degli speculatori immobiliari e degli affittuari, simulando di voler solo promuovere l'integrazione positivista degli operai nella società moderna (Bakos, 1986). 
Il nuovo ordine è costruito ai margini della partecipazione di ampi settori della società, come qualcosa dettato da una necessità esterna e non come espressione della volontà collettiva [...] L'ambiguità progressista-conservatrice di questo progetto di modernità provoca la perdita di parte della sovranità popolare in relazione alla costruzione e alla gestione dell' ambiente urbano, instaurando in modo autoritario un nuovo $[\ldots]$ modello di sociabilità nello spazio urbano $[\mathrm{e}]$ imprimendo un ritmo forzato alla costruzione dell'immaginario sociale, tramite la repressione di un passato vivido, in nome di un' utopia proiettata nel futuro [che creava] una perdita di riferimenti per la costruzione dell'identità e della memoria collettiva (Monteiro, 1995).

Quando nel 1928 Getulio Vargas (futuro ambizioso presidente nazionale) assunse la carica di Governatore del Rio Grande do Sul, Porto Alegre si caratterizzava per un'alta qualità della vita e - anche se molte delle opere erano state realizzate a costo di grandi spese lasciando la città piena di debiti con le banche internazionali, mentre settori come l'ospedaliero non erano riusciti a decollare nel friggere delle uova [...] il saldo era altamente positivo per la città, che aveva acquisito uno stato di metropoli di notevole importanza (Weimer, 1993).

Gli appoggi interni ottenuti dall'Estado Novo e il conseguimento di grossi prestiti dall'estero permisero a Porto Alegre di mettere mano - nel periodo di governo del Sindaco Loureiro da Silva - ad un gran numero di opere per il rimodellamento della città e dei suoi rapporti con i centri vicini (São Leopoldo, Gravataí e Tramandaí) a tutto discapito dei trasporti ferroviari e idroviari, ${ }^{43}$ in sintonia quindi con la politica statale messa in atto tra il ' 30 e il 1937 dal governo Flores de Cunha, centrata sul trasporto su gomma. Lungo i nuovi percorsi iniziarono ad addensarsi caoticamente gli impianti industriali ma anche le abitazioni operaie della futura area metropolitana, cosicché già nel 1935 fu chiesto ad Ubatuba de Farias e Edvaldo Paiva di formulare delle linee direttrici di sviluppo urbanistico lavorando sul concetto di "perimetro di irradiamento' "che più tardi si materializzerà nella prima perimetrale" (Salengue e Marques, 1993) e nella proposta di impiantare centri secondari nei quartieri come base per una struttura multipolare e decentralizzata.

Le previsioni restarono all'epoca il lavoro isolato di alcuni tecnici comunali e non ebbero né l'appoggio municipale, né l'infrastruttura amministrativa e logistica per fondare le proposte più scientificamente. Intanto, nel 1936, venne istituzionalizzata l'attività urbanistica a livello statale, con l'elaborazione dei primi Planos Diretores per i Municipi dell'Interno, affidati alla neonata Diretoria de Saneamento e Urbanismo all'interno della Secretaria Estadual de Obras Políticas.

Fallita l'esperienza non molto felice (Macedo, 1969) con l'architetto carioca Arnaldo Gladosch, a Porto Alegre si procedette all'istituzione (nel 1939) del primo Conselho do Plano Diretor - organo integrato e multidisciplinare in cui vi era spazio per le lobby professionali, l'esercito, la stampa e gruppi di 'amici della città' - che voleva rappresentare l'innovazione maggiore in direzione di una politica urbanistica dalle porte aperte orientata esclusivamente verso l'interesse della popolazione (Salengue e Marques, 1993) o - almeno si promosse come tale. Dopo un periodo di 'iato pianificatorio' ${ }^{44}$ (1938-1943), utilizzato per investimenti sulla qualificazione tecnica dei quadri, agli ingegneri-urbanisti Paiva e de Farias fu commissionato un Expediente urbano, una ricerca a vasto spettro sulla città - sul modello delle surveys inglesi - che toccava il settore economico, sociale e amministrativo, e che costituirà la base del Piano di Urbanizzazione da lì a poco messo in cantiere. 
94 Nel redigere il nuovo strumento, ci si concentrò soprattutto sulla zonizzazione funzionale (dividendo le aree residenziali in unità d'abitazione omogenee), sullo studio radiocentrico dei principali assi, perimetrali e radiali, sulla riforma del centro storico anche sotto il profilo paesaggistico, sul risanamento delle aree vallive spesso colpite da piene e allagamenti, ${ }^{45}$ sulla creazione di nuovi spazi verdi ${ }^{46}$ e attrezzature cittadine e sulla riforma della struttura amministrativa e tributaria. ${ }^{47}$

La crescita urbana tese a restare confusa e 'a salti', adeguandosi alla struttura per radiali e lasciando ampi vuoti urbani, mentre nulla fu previsto circa i volumi delle costruzioni nelle varie zone residenziali, commerciali (che andavano attestandosi naturalmente intorno alle aree più densamente abitate) e industriali: quest'ultime venivano riconfermate lungo gli accessi alla città.

Nel 1945, la realizzazione delle strade a percorrenza veloce per Canoas, Gravataí, Viamão, Belèm Velho e Belèm Novo e dei 13 tratti incompleti delle prime circonvallazioni previste consacrerà definitivamente l'orientamento verso il trasporto su gomma, che in tutto il Paese veniva incentivato anche per favorire l'ubicazione delle grosse industrie automobilistiche straniere. Il ponte sul Guaiba del 1960 che lega Porto Alegre alla zona meridionale del Rio Grande do Sul completerà il periodo delle grandi trasformazioni dei trasporti, presupposti al rapido stravolgimento urbano operato dal processo di metropolizzazione dell'area (Souza, Müller; 1997).

\subsection{La metropolizzazione: un processo favorito ma non governato.}

Lo sforzo nazionale di ristrutturazione dell'Economia cominciò nel secondo dopoguerra con la costruzione di Volta Redonda nel 1946, e la creazione della Compagnia Idroelettrica di São Francisco (1948), della Banca dello Sviluppo (BNDE), di quella del Nordest (entrambe nel 1952) e infine di quella dell'Abitazione, nata in coincidenza con l'avvento della Dittatura (1964). Con diverse sigle vennero adottati i piani di sviluppo economico governativi (Programa de Metas, Plano Trienal, PND I e II, PAEG ecc.) e - in parallelo alla creazione dei grandi progetti energetici nazionali (Piani Nazionali del Carbone e dell'Elettrificazione) - si ebbe una riorganizzazione totale dei sistemi autostradali, ferroviari e della navigazione, con l'eliminazione dei rami di collegamento improduttivi.

Parte del Rio Grande do Sul entrò in questo complesso periodo di trasformazioni con il suo sistema di agricoltura e allevamento tradizionale di supporto ai nuovi insediamenti industriali; la crisi si fece evidente negli anni ' 60 , a causa del frazionamento terriero e della mancanza di pratiche di rivitalizzazione dei suoli che ne rinvigorissero la produttività.

Un forte urbanesimo dalle campagne - alla ricerca di impiego come manodopera non specializzata - determinò una celere densificazione dei centri maggiori con modalità di occupazione spontanea e autocostruzione; lo seguì una seconda ondata migratoria interna - ancora fiduciosa nei destini del settore primario - che si mosse verso le aree di frontiera, soprattutto in direzione Argentina-Unuguay. ${ }^{48}$ L'introduzione della soia (prodotta in un periodo dell'anno che corrisponde al lasso vuoto fra i raccolti di altri paesi) sembrò offrire respiro all'economia riograndense, ma non riuscì a risollevare le sorti delle aree distanti dal capoluogo. Intorno agli anni '70 la politica di 
esenzioni fiscali cercò di svecchiare il pigro settore secondario, attraendo alcune industrie dinamiche come la Pirelli e la Coemsa, e dando avvio al progetto di creazione di un polo petrolchimico.

Queste macrotrasformazioni a livello statale spiegano i repentini cambiamenti strutturali che interessarono Porto Alegre a cavallo degli anni '60 e '70. La città era già molto cresciuta nel numero di abitanti nel decennio '40/ '50, passando da 275.658 a 394.151 abitanti, e conoscendo i primi fenomeni massicci di favelamento. Raggiunta quota 626.000 abitanti nel 1960 (quando la popolazione rurale dello Stato si abbassò a 15.000 unità), Porto Alegre conobbe un leggero assestamento che non le impedì comunque di raggiungere nel 1970 gli 885.545 abitanti $^{49}$ e di perdere il carattere di insieme centripeto, chiuso in sé (Souza e Müller, 1997), rendendosi conto che molti dei problemi sopraggiunti (di circolazione, infrastrutturali, di sanità) non erano più risolvibili operando solo in ambito comunale. Si entrò così nella fase di formazione dell'Area Metropolitana costituita insieme ai centri circonvicini, che reclamavano iniziative e soluzioni congiunte. Questa fu sperimentata come forma di integrazione fra scelte amministrative già prima di essere riconosciuta come istituto specifico dalla Legge Federale, e dotata del GERM, il Piano di Sviluppo Metropolitano.

Dal 1939 al 1980 l'apporto relativo di Porto Alegre al reddito del Rio Grande do Sul crebbe dal 17,57 al 22,08\% (Alonso, 1988): il graduale declino della produzione industriale ${ }^{50} \mathrm{fu}$ infatti compensato dal crescere delle attività terziarie, passate - nello stesso periodo - dal $21,07 \%$ al $30,73 \%$, con una ridefinizione produttiva che seguì quella della struttura generale dello Stato. Questo - attraverso la creazione di distretti industriali come Gravataí o Cachoeirinha - favorì il decentrarsi dell'industria verso altri centri della regione metropolitana dove i prezzi dei terreni per uso industriale erano (in assenza di un'eccessiva urbanizzazione e di congestione del traffico) minori.

Il dinamismo di Porto Alegre (pur restando più alto della media statale) tese così ad abbassarsi a vantaggio dell'area metropolitana. Le direttrici dell'espansione vennero progressivamente e schizofrenicamente determinate dalle nuove realizzazioni di strade a lunga percorrenza. Insieme alla concentrazione industriale (nata a ridosso del porto e del terminal ferroviario) si trasferirono fuori dai limiti urbani di Porto Alegre le abitazioni popolari ${ }^{51}$ e molte occupazione di terra. I centri vicini cominciarono ad equipaggiarsi per svolgere anche un ruolo terziario di supporto; esso rimase però patrimonio quasi esclusivo della capitale che - per adeguarsi alle nuove funzioni - espanse sensibilmente il settore residenziale, ${ }^{52}$ estese le reti di urbanizzazione fuori dall' area centrale in cui erano rimaste confinate, e cercò di completare tutte le opere viarie già previste dal piano del 1914.

Come nota Furtado (1993), dagli anni '50 anche a Porto Alegre il decentramento industriale e la crescente suburbanizzazione della manodopera meno retribuita entrarono in risonanza; quest'effetto moltiplicatore beneficiò da un lato del miglioramento dei trasporti, e dall'altro della tendenza a creare legami trasversali o di frangia tra le diverse periferie, dando avvio ad ondate successive di decentramento degli impianti industriali e delle residenze dei lavoratori. Ancora per un certo tempo alcune aree del centro storico (sicure del buon funzionamento dei trasporti radiali) non ebbero fretta di espellere i cosiddetti fenomeni di 'subabitazione' mentre l'elevata valorizzazione dei 
96 suoli conseguente alla rapida crescita economica e all'aumento della popolazione urbana restituiva la periferia ai capitalisti (id). In questo periodo di grandi opere si cominciò a delineare una complementarietà fra i programmi di ristrutturazione fisica e sociale (Souza e Müller, 1997), con l'obiettivo di riequilibrare i processi di periferizzazione e segregazione spaziale della classe lavoratrice, ormai segno distintivo del 'nuovo ordine sociale urbano'.

Intorno agli anni '60 si fece evidente la separazione fra l'area della produzione industriale propriamente detta - ormai assestatasi nell'hinterland di Porto Alegre - e quella amministrativa e delle vendite (Furtado, 1993) ubicata nel capoluogo insieme a quelle lavorazioni di piccola e media grandezza necessarie a soddisfare il mercato locale o che necessitavano di prossimità fisica coi consumatori e di 'relazioni interpersonali'. La crescita delle forme di impiego legate al terziario fu segnalata nel paesaggio urbano dal moltiplicarsi degli edifici ad uso non residenziale, o residenziale per classi medioalte, caratterizzati in entrambi i casi da tipologie nuove (con alto numero di piani). A partire dal centro storico le sostituzioni per gentrificazione ${ }^{53}$ si infittirono, mutando il profilo cittadino proprio mentre l'amministrazione investiva massicciamente nel settore dei trasporti per valorizzare con usi più nobili le aree del centro svuotate da chi si trasferiva o veniva persino ufficiosamente 'invitato' a invadere terreni meno costosi in periferia.

A partire dalla fine degli anni '60 e poi nel periodo dei grandi progetti di sviluppo economico e sociale (il Polo Petrolchimico, il Porto Secco e il Metrò di superficie) la percezione di un mancato intervento pubblico di riequilibrio delle tendenze economiche in atto, ingenerò anche a Porto Alegre - a livello della collettività urbana - l'emergere di un desiderio di riscatto delle relazioni umane con l'intorno (Velasques, 1993). Il movimento hippy fu tra i primi a ripensare le relazioni umane a livello di comportamento sociale, seguito dai primi gruppi di difesa dell'ambiente naturale e culturale alle scale più varie (id.). A distanza, e non certo stimolato dal 'confinamento sociale' di queste prime e quasi elitarie voci critiche, seguì il primo processo di riorganizzazione delle istituzioni governative per combattere inquinamento e degrado ambientale, inizialmente concentrato solo sulle azioni più direttamente legate alla salute pubblica (id). Alcune iniziative accademiche in collaborazione fra l'Università Federale e i programmi MAB (Man and the Biosphere) 11 e 13 dell'UNESCO proporranno più tardi uno studio puntuale della perdita di integrazione fisica fra spazi pubblici e ambiente naturale nella città, dovuta al processo di crescita verticale dell'edilizia e alla creazione di barriere funzionali e visuali ai margini del Guaíba come il muro di Mauá contro le piene e le strade costiere a scorrimento veloce (Velasques, 1984).

\subsection{Quali strumenti regolatori?}

Se non proprio 'guidati' nei loro esiti spaziali, i processi di trasformazione finora descritti furono almeno 'accompagnati' da alcuni strumenti urbanistici che nel dopoguerra subentrarono l'uno all'altro, giovandosi della collaborazione di professori e alunni della neonata Facoltà di Architettura della UFRGS (1952) che supportava il lavoro della Divisione di Urbanistica del Municipio, completamente riorganizzata nel 1954, anno a cui risale un se- 
condo Pre-progetto di PRG cittadino redatto da Edvaldo Paiva e Demétrio Ribeiro attingendo a molte delle idee di Le Corbusier e della 'Carta di Atene' redatta dal III Congresso CIAM.

Lo studio del ' 54 , centrato sull'identificazione delle quattro principali funzioni urbane (abitare, lavorare, circolare, ricrearsi), definì azzonamenti e usi del suolo, precisò i limiti delle unità di abitazione definiti dal traffico generale e rese obbligatoria la previsione di scuole e aree verdi al loro interno. Inoltre, cercò di sviluppare le condizioni per creare centri di quartiere, già diffusisi in alcune zone come tendenza spontanea e si arricchì di un lungo elenco di opere da realizzare in breve, proprio mentre la Legge Municipale 1233/54 sul regolamento delle divisioni dei lotti introduceva requisiti rigidi che supervalutavano i terreni centrali e innescava un flusso centrifugo delle fasce di popolazione più bassa verso i comuni adiacenti che non avevano simili leggi, provocando la fondazione di nuovi 'centri-dormitorio' come Cacoeirinha e Alvorada.

In conseguenza di queste tendenze, il Piano fu più volte aggiornato dal neoriformato Conselho do Plano Diretor fino al 1959, quando l'Amministrazione Meneghetti approvò il primo vero Piano Regolatore di Porto Alegre (Legge 2046/59) e il nuovo Regolamento Edilizio (Legge 2047/59).

Il mutare della politica 'regolatrice' del Comune aveva fino ad allora disegnato nelle differenti zone di Porto Alegre corpose variazioni della capacità costruttiva (fertilità dei suoli) ${ }^{54}$ che avevano raggiunto il culmine tra il 1952 e il 1959 quando in alcune parti della città era stata addirittura incentivata la costruzione di edifici di qualsiasi livello (Rovatti, 1993). ${ }^{55} \mathrm{Nel}$ '59 - con la definizione degli IA (gli indici di sfruttamento) - si finse di voler invertire la tendenza, ma la 'limitazione effettiva' prese piede solo tra il '60 e il '70, e con l'introduzione del 'concetto mitigatore' di 'aree non computabili ai fini del calcolo degli indici' o da utilizzarsi per 'uso collettivo' (ibidem).

Gli effetti dello strumento urbanistico varato nel '59 restarono ristretti alla zona più fortemente edificata, mentre venne varato uno strumento finanziario unico nel paese - il Fondo per il Plano Diretor - le cui risorse erano vincolate alle finalità del piano secondo una lista di priorità riviste ogni anno, che servirono a realizzare i primi espropri per ampliare la rete di scuole e costruire la $\mathrm{I}^{\circ}$ perimetrale (anello di circonvallazione stradale).

La decisione di affidare alla Giunta e al Consiglio del Piano Regolatore le scelte sul progressivo ampliamento dell'area abbracciata dal piano e sull'aggiornamento dei tracciati innescò un meccanismo di sovrautilizzo della prerogativa. Lo strumento regolatore fu così emendato più volte dopo la promulgazione di leggi municipali di settore o in rapporto al proseguire degli studi sull' area metropolitana ('61, '64, '67, '72 e '75/77) finché la catena di ampliamenti progressivi, la frammentarietà e l'incoerenza dei provvedimenti spinse il Comune a rivedere interamente il Plano Diretor cresciuto per tappe e modificato negli indici e negli standard in un'ottica di 'progressivismo realista' proporzionale all' estendersi della città. Parallelamente, il Fondo per il Plano Diretor perse la sua efficacia, visto che una riforma nazionale ritirò dal novero delle competenze comunali la riscossione dell'imposta di trasmissione dei beni fra vivi su cui si appoggiava.

Le prime vere trasformazioni programmate della struttura urbana si ebbero soprattutto a partire dal 1972, quando l'Amministrazione Thompson Flores 
98 iniziò la costruzione della Prima Perimetrale (concepita da Heydtmann già nel 1858) e della radiale Sud, e portò avanti il progetto di un parco fluviale detto Marinha do Brasil. La costruzione dell' Autostrada consacrò la zona Nord della città come 'Area industriale per antonomasia' (attirando in quel settore cittadino anche molte abitazioni popolari ed occupazioni di terra) anche se oggi il fenomeno si è esteso a Est, uscendo dai confini della città grazie agli incentivi fiscali offerti dai centri vicini e ad una politica di decongestionamento concordata dallo stato e dalla Municipalità di Porto Alegre.

La crescita continua della popolazione (che nel 1980 giunse a 1.125.477 abitanti per arrivare a $1.263 .403^{56}$ nel 1990) determinò la riorganizzazione dei servizi e del commercio; e presero forma aree caratterizzate da 'specializzazione', ${ }^{57}$ che hanno mutato aspetto con il sorgere dei primi Shopping Centre, i quali hanno in parte mutato il rapporto centro-periferia incentivando la crescita di quartieri residenziali di classe medio/alta anche lungo il Lago Guaiba, nella zona Sud della città.

Nell'ultimo trentennio, la trasformazione del Commercio a Porto Alegre è stata, del resto, inesorabile nel compiere il suo percorso parallelo a quello mondiale, pur senza rinunciare alle sue particolarità locali. I supermercati, espansisi negli USA già come risposta alla crisi del 1929, arrivarono a Porto Alegre agli inizi degli anni '50, quando ancora le fiere settimanali segnavano la vita dei quartieri e il mercato pubblico (sostituito di notte da quello 'libero') rappresentavano le fonti consuete dell'approvvigionamento dei cittadini. Nel 1953 aprì il primo supermercato della Companhia Real de Distribuição, oggi gestita dalla Holding JOSAPAR (la prima in fatturato nel Rio Grande do Sul, cfr. ABRAS).$^{58}$ Esso aprì la via ad una riorganizzazione del commercio, appoggiatosi a 4 diversi modelli di grande distribuzione, tra cui la rete Bonjour che funziona ancora come sistema di franchising legato al concetto dei 'negozi di vicinato' con piccole differenze locali in sintonia coi luoghi. L'antesignano degli Shopping Center fu la Galleria Chaves, che riuniva nel centro cittadino - in un asse chiuso di circolazione - negozi diversi in una prospettiva legata al relax e alla passeggiata. Il primo 'Shopping' (come sono chiamati qui comunemente) è stato nel 1970 il Centro Commerciale nell'Avenida João Pessoa, con caratteristiche organizzative abbastanza diverse dallo standard che andava diffondendosi nel Paese grazie all'ABRASCE (1'Associazione Brasiliana di quel tipo di distribuzione) e che ispirò l'Iguatemì (emulo dell'omonimo centro costituito a São Paulo nel 1966, il primo del Brasile, cfr. Pintaudi, 1987). Quest'ultimo, nato negli anni ottanta a $6 \mathrm{~km}$. dal centro, in breve si è posto come nodo aggregatore dell'area circostante, portando alla saturazione del tessuto circostante residenzializzato e all'alterazione funzionale dei maggiori assi viari della zona (come l'Av. Carlos Gomes) dove ha attratto altro commercio specialistico, servizi e terziario.

Su imitazione dell'Iguatemì hanno preso forma nel decennio successivo altri 'poli' del nuovo sviluppo urbano: il Rua da Praia (costruito nel centro storico, sventrando alcuni edifici) e - verso sud - il Praia De Belas e il BIG, realizzato durante l'Amministrazione Popolare (all'inizio del 1999) attraverso una 'operazione interrelata' di urbanistica concertata nel quartiere Cristal, che ha permesso il trasferimento degli abitanti di alcune favelas in un nuovo insediamento residenziale $(\S 13.4 .2)$. 


\subsection{L'eredità del regime morente: il Piano Regolatore del 1979}

Quanto dello sviluppo postbellico di Porto Alegre è stato realmente pianificato, è difficile a dirsi. Secondo Rovatti (1993), l'evoluzione di segno 'modernista' che ha segnato la scuola pianificatoria portoalegrense dagli anni '50 ha presto sostituito a dei pianificatori dello spazio che si consideravano medici della città e ammiratori delle riforme estetiche-viarie (Souza e Damasio, 1991), dei semplici 'disegnatori urbani confusi'.

La legge 2330/59 che istituiva il Plano Diretor di Porto Alegre restò in vigore fino al 1979, quando fu approvato il primo PDDU (Piano Direttore di Sviluppo Urbano) prodotto della rivisitazione della strumentazione urbanistica avvenuta attraverso il Programa de Reavaliação do Plano Diretor-PROPLAN portato avanti dall'Esecutivo Comunale tra il 1977 ed il 1979. Molti degli effetti del PRG del '59 si prolungarono comunque oltre la revoca, a causa dei diritti acquisiti da molti privati con progetti approvati anteriormente. In fase di gestazione del PDDU del '79 i tecnici dell'amministrazione approfondirono le relazioni fra società, città e piani urbanistici, ed elaborarono con sede nella Secretaria de Planejamento [il locale Assessorato all'Urbanistica] - il programma di revisione finanziato dalla linea di credito FIPLAN del BNH. Per 18 mesi il loro lavoro fu accompagnato da una Commissione Permanente del Consiglio Comunale e dalle consulenze offerte dall'Università e dagli Ordini degli Avvocati e degli Architetti, per la prima volta in collaborazione con la FRACAB, la Federazione delle Associazioni di Quartiere, espressione privilegiata del Movimento Popolare. Dopo 8 ulteriori mesi di discussione il PDDU fu approvato, con più di 200 emendamenti, con Legge 43/79.

Lo strumento - emendato da una variante che ne mutò 52 articoli nel 1987 su richiesta di un'apposita commissione del Consiglio Comunale - è stato variamente giudicato dagli analisti, che hanno assunto posizioni sovente antitetiche. Salengue e Marques (1993) - in una valutazione dello strumento e del suo processo costitutivo - hanno, infatti, teso a sottolinearne gli aspetti positivi; 1) la natura multidisciplinare e plurisettoriale del concepimento, caratterizzato da un lavoro costante di comunicazione fra i Dipartimenti Comunali; e accanto a questa un lodevole proposito di decentramento delle attrezzature urbane e delle attività di commercio e servizio, mirato a coniugare le virtù del suo sviluppo lineare con quelle del suo sviluppo polinucleare (cfr. Comas, 1993) e a sostituire parzialmente il modello di città-funzionale tipo Brasilia (o tipo le città gaúche di Atlântida o Capão Novo) ${ }^{59}$ con quello di 'città figurativa', federazione di quartieri con usi eterogenei (id.) non più definiti in base alle loro caratteristiche funzionali, semmai a quelle morfo-tipologiche e alle configurazioni di vissuto sociale;

2) l'aver consolidato la base giuridico-strumentale in un unico testo legale coerente che riordinava e rafforzava le carenti norme urbanistiche sparse nella legislazione brasiliana, offrendo contenuti anticipatori rispetto a progressi istituzionali solo successivamente consolidatisi a livello federale, quali le norme sul parcellamento dei suoli, la protezione ambientale, il trasferimento del potenziale edificatorio dei terreni, l'obbligatorietà delle licenze di abitabilità (habite-se), le imposte su immobili e terreni urbani (IPTU), ecc.; 3) il carattere permanente conferito all'attività pianificatoria urbana, incorporando meccanismi di adattamento a situazioni impreviste o sopraggiunte 
100 (e agli effetti del piano stesso) e contrapponendo all'idea di un piano chiuso quella di un processo continuo sotto la critica permanente della società, di un prodotto in costante rilettura che sempre ambisce a considerarsi risultato intermedio e perfettibile (art. 24 Legge 43/79) a disposizione delle integrazioni richieste dalla Secretaria do Planejamento e del Conselho do Plano Diretor; 4) l'innovativa creazione di meccanismi di consultazione e partecipazione della comunità ai processi di pianificazione configurantisi come il primo tentativo di levare dall'ambito esclusivo del potere municipale le decisioni urbanistiche attraverso la rappresentanza degli 'amici della città' nel Consiglio di Piano, e le audizioni di associazioni rappresentative dei cittadini circa le priorità locali e gli investimenti da farsi. Di questa 'apertura' viene comunque riconosciuto dai due autori il grado di insufficienza in quanto pratica partecipativa (ammesso dagli stessi tecnici comunali dell'epoca).

La maggioranza degli altri studiosi del PDDU del '79 criticano questa visione 'forzatamente rosea'. È innegabile che il PDDU del '79 sia stato il primo ad avere giurisdizione su tutto il territorio comunale, ad assumere un modello biofisico più complesso delle contingenze imposte all'occupazione cittadina dall'ambiente naturale e dalle sue particolarità locali, e anche il primo ad 'aprirsi' un minimo sia alla preoccupazione di regolarizzare i nuclei di subabitazione sia alla consultazione di rappresentanti organizzati di settori più ampi della cittadinanza. Nonostante tali 'innegabili progressi concettuali' (cfr. Comas, 1993), però, gli schemi viari delle previsioni urbanistiche precedenti furono quasi lasciati inalterati, e poche novità strutturali ha introdotto - sui principi della zonizzazione - la creazione dei 'moduli territoriali' in sostituzione del concetto di unità d'abitazione, e la creazione dei 'poli' legati da corridoi di commercio e servizi. Liedke e Ferretti (1993) criticano, poi, il piano per quanto esso riflette quel processo di 'scientificizzazione dei piani' avvenuto tra gli anni '60 e gli anni ' $70 .{ }^{60}$ Esso avrebbe, infatti, mostrato - a dispetto della sua presunta 'scientificità' - l'intima "debolezza della capacità predittiva” e poca lungimiranza (ibidem).

Già lo strumento regolatore del 1959 aveva incorporato per la prima volta a Porto Alegre - e anche in Brasile - la necessità di un'ampia quantificazione preliminare di numerose informazioni sulla città e i suoi abitanti (una vera rivoluzione quantitativa sul modello degli urban surveys anglosassoni, cfr. Liedke e Ferretti, 1993), ottenendo un risultato al contempo miope e ipermetrope che favoriva un trattamento 'oggettivo' della città (i cui cittadini erano visti come ideali e ridotti ad alcune necessità basilari) ma anche un'appropriazione inadeguata de risultati della quantificazione (id.). Le ricerche non erano, infatti, servite come dati di partenza da cui dedurre valori, ma si erano 'indotti' dei valori all'interno del piano legittimandoli con una ricerca sulla geo grafia apparente della città (Krafta, 1993), usando la pianificazione come mezzo di affermazione di un'idea preconcepita di città che sostituiva con riflessioni di Morfologia Urbana una corretta e necessaria spiegazione sulla produzione sociale dello spazio (Krafta, 1993).

Questo difetto non solo non venne meno nel Piano del '79, ma lo permeò con maggior malizia. Pur concepito anni dopo l'introduzione dei metodi di 'Approccio Sistemico', il nuovo PDDU ripropose, infatti, lo stesso dualismo fra base quantitativa e ideologica, non più però in un contesto di democrazia politica (come nel '59) ma in un quadro di autoritarismo dittatoriale. Ciò lo 
rese un esercizio di imposizione della volontà dello Stato, rappresentato da poche teste pensanti, sulla società, un progetto di città fatto ad immagine dei suoi estensori, quindi della classe media e della cosiddetta burocrazia funzionale; applicato però ad una società eterogenea e complessa (Liedke e Ferretti, 1993). Le conclusioni di molti altri teorici riguardano conseguenze forse prevedibili delle strategie adottate, e principalmente che:

1) l'intervento pianificatore imposto dal PDDU finiva per favorire la concentrazione monopolista nel processo di produzione dello spazio urbano portoalegrense usando modelli numerici per manipolare un modello figurativo (Liedke e Ferretti, 1993) a beneficio dei gruppi con maggiore capacità organizzativa e di ammortizzamento dei costi su vasta scala;

2) la zonizzazione e gli indici di sfruttamento introdotti come novità dal piano venivano incontro agli interessi dei gruppi legati all'industria edilizia civile ${ }^{61}$ dando al contempo un'interpretazione riduttiva della città, appiattita su una descrizione ed una regolamentazione fatte per mezzo di indicatori numerici e limitazioni d'uso che la trasformava in collezione empiricista di oggetti da disporre sul territorio secondo un ordine predefinito, tecnico e non integrato ai processi sociali e di gestione degli stessi (Krafta, 1993). Questo creava uno 'scarto' fra pianificazione e gestione urbana, proprio quando i segmenti più popolari della cittadinanza mostravano con la pratica delle rivendicazioni e delle azioni di lotta un approccio concreto e politicizzato (Liedke e Ferretti, 1993);

3) i passi indirizzati all'espansione e al mantenimento delle attrezzature collettive nelle UTR (Unità Territoriali Residenziali), associati alla politica di pagamento dei costi da parte degli usufruttuari delle stesse, non potevano che condurre all'espulsione indiretta delle fasce di minor reddito dalle aree di super-valorizzazione fondiaria, attraverso meccanismi di mercato. I tentativi fatti per tamponare questo esodo - come l'appoggio dato allo sviluppo di mutirões dal sindaco Collares, attraverso le risorse del Fondo Municipale di Sviluppo Urbano - si sono sovente rivelati dei meri palliativi, che cercavano di 'raddrizzare' con le politiche gli errori del piano;

4) la superficialità di molte ipotesi previsionali non poteva che condurre a vuoti pianificatori difficili da colmare; ciò è palese nell'eccessivo appoggiarsi alle scelte del BNH, soppresso nel 1986 senza che fossero state ipotizzate forme di 'tamponamento' in previsione della sua spesso annunciata scomparsa;

5) la creazione di Associazioni Comunitarie corrispondenti alle Unità Territoriali aveva il solo scopo di svuotare le associazioni esistenti per dare legittimazione formale al sistema pianificatorio;

6) i meccanismi partecipativi della popolazione portoalegrense nel Consiglio del Plano Diretor miravano essenzialmente ad una sorta di 'consensus building' nei confronti del piano stesso;

7) il reincorporamento e la legalizzazione delle aree di occupazione irregolare, pur prevista dal PDDU, sono stati fermati dall'introduzione del meccanismo della 'concessione reale d'uso' che permettendo il possesso e non la proprietà, bloccava il trasferimento - via mercato - delle parcelle di suolo urbano. L'aspetto positivo di argine alla gentrificazione delle aree regolarizzate è stato superato da un meccanismo ambiguo che aumenta la dipendenza dalla volontà politica dell'Amministrazione comunale, l'unica in grado di eliminare queste norme a pro del mercato, come ha dimostrato l'esperienza di Lajes nello Stato di Santa Catarina (Liedke e Ferretti, 1993); 
102 8) la pratica della 'vendita degli indici costruttivi' ha introdotto forme diffuse di contrattazione a 'debole grado di protezione' dalle scelte delle singole Amministrazioni, che - infatti - di volta in volta hanno potuto optare per una politica della casa per i meno abbienti, per una di re-industrializzazione (come nel vecchio Progetto per il Distretto Industriale del Bairro Restinga, oggi Parco Tecnologico) o piuttosto per faraonici progetti di bonifica e lottizzazione, come nell'area di riempimento lacustre di Praia de Belas, venduta a un grande Centro Commerciale (Ferretti, 1993);

9) infine, la mancata considerazione dei vasti e numerosi vuoti urbani - spesso classificati dai proprietari come immobili rurali per ottenere riduzioni delle tasse e usati come strategia di speculazione immobiliare - costituiva (Oliveira e Barcellos, 1987) un serio limite al sistema di ipotesi su cui il piano era basato, e contrastava con qualsiasi idea di funzione sociale della terra.

La conclusione raggiunta dalla maggioranza dei critici del PDDU del '79 è che esso si è orientato verso la nozione tecnocratica di 'massima razionalità possibile' in condizioni economiche tendenzialmente monopoliste, venendo incontro agli interessi dei grandi gruppi economici, finanziari e dell'edilizia civile seppur regolando in parte le loro aree e le loro forme di intervento (ibidem).

Simili critiche sferzano retrospettivamente gli stessi fondamenti teorici dello strumento regolatore, pur appuntandosi soprattutto sull'analisi degli effetti realmente avuti dal PDDU, anche quelli cioè ottenuti nello sforzo di conseguire il risultato opposto. ${ }^{62}$ In tal senso - nel migliore dei casi - la politica proposta dal PDDU è stata giudicata come miope $e^{63}$ perché non riconosceva l'origine sociale e conflittuale della spazialità e le sue problematiche di produzione e riproduzione; ma anche ipermetrope, nella misura in cui era proiezione illusoria di modelli mentali idealtipici, immagini incuranti delle specifiche condizioni della produzione dello spazio, che vorrebbero leggere la spazialità non 'come manifestazione reale delle relazioni sociali', ma semplicemente come il loro riflesso (Liedke e Ferretti, 1993). Nel peggiore dei casi, il PDDU avrebbe solo tentato di mascherare la "combinazione opportunista" tra "un discorso progressista di reale coinvolgimento sociale e una pratica platonica da cui un universo spaziale nasce completo e concluso, pronto per essere 'occupato' da una società che si presume perfezionerà le sue relazioni interne nella nuova abitazione (ibidem).

\subsection{La variante del 1987: l'affondamento delle certezze prepara il cam- biamento.}

Le misure adottate a Porto Alegre dal '79 apparivano coerenti con gli indirizzi generali del periodo, dal momento che ambivano a mettere in relazione produzione e configurazione del complesso urbano, finendo per accreditare sempre di più l'urbanista come promotore immobiliario cosciente (Del Rio, 1990). Il processo di modifica che nel 1987 portò alla definizione di una Variante al Piano del 1979, si risolse in una ricerca di trasformazioni che favorissero una nuova - seppur moderata - verticalizzazione della città, ritenuta automatica garanzia non solo di un miglior sfruttamento dei suoli e di aiuto all'industria edilizia, ma anche - di per sé - di una maggiore proporzionalità fra il numero di abitanti e i servizi disponibili (Rovatti, 1993). Di tutto il dibattito che li precedette, i risultati della revisione dell' '87 mo- 
strarono di aver lasciato in un canto è l'approccio sociale al problema che completava gli aspetti economici/estetici/funzionali del piano stesso, non prendendo in considerazione né i problemi della città informale né quelli relativi alla conclamata concentrazione fondiaria che nel 1986 era del $54 \%$ e vedeva lo $0,1 \%$ dei proprietari detenere il possesso di oltre il $20 \%$ dei vuoti urbani. Così facendo, il PDDU fu adattato ad essere una temporanea 'boccata d'aria' per l'Industria locale delle Costruzioni. ${ }^{64}$ Fenomeni come l'esplosione immobiliare nel Bairro Bela Vista costituirono ben presto la prova empirica in 'scala uno a uno' della transitorietà di questo sollievo e della pericolosità delle modifiche operate sulla morfologia urbana, oltre ad essere testimonianza vivente di una mancata ripresa della creatività dei progetti, certo non stimolata dalla riforma dell' '87 che fertilizzò il [suolo] urbano in modo disuguale facendo sì che alcuni, imprese e individui, guadagnassero da questo e che all'erario pubblico, quasi sempre, toccasse pagare il conto [...] assaltato da pratiche speculative (Rovatti, 1991).È di questo periodo il progetto promosso dal sindaco Collares per l'urbanizzazione di un'area di lungolago sottratta alle acque negli anni ' 60 , molto criticata (ma ugualmente realizzata) sia per ragioni ambientali e di diminuzione delle aree a verde, sia per la mancanza di correttezza nell'affidamento diretto dell'incarico ad un grosso studio di architettura locale, sia per ragioni sociali, in quanto richiedeva la rimozione delle 'subabitazioni' esistenti in loco e toglieva l'accesso, anche visivo, al lago per molte fasce di cittadini. Collares tentò anche di risolvere la crisi del centro cittadino nel suo complesso estendendone i confini e 'diluendone' i problemi con un'operazione imposta dall'alto che comprovò il poco peso che la comunità cittadina - insorta quasi compatta contro l'iniziativa aveva in rapporto al settore privato. Solo aree come la zona Sud (Tristeza, Ipanema) - già solidamente abitate da una popolazione di classe medio-alta ben organizzata contro i nuovi progetti - riuscirono a salvarsi dall'innalzamento degli indici fondiari, e quindi dalla nuova ondata di speculazione. Così, alle soglie degli anni '90 - quando l'avvento dell'Amministrazione Popolare ha introdotto le sue novità sostanziali nella gestione di Porto Alegre - il PDDU del '79 si presentava già molto vecchio. Sia giudicandolo alla luce dei nuovi precetti costituzionali federali e statali del 1988 e 1989 che a quella del nuovo Statuto Comunale del 1990, apparivano incongrue ai tempi le stesse modifiche introdotte nel 1987 dall'amministrazione Collares. Soprattutto, però, risultavano profondamente trasformate le condizioni al contorno, cioè il contesto nel quale il piano si doveva trovare ad operare sulla città. L'esaurirsi del modello autoritario-sviluppista di governo in parallelo alla crisi economica degli anni ' 80 aveva, infatti, portato alcune novità di cui la gestione della città doveva necessariamente tener conto, alcune delle quali emblematiche del 'nuovo corso' quali:

1) l'accelerazione della cosiddetta urbanizzazione escludente, caratterizzata da un picco nell'espansione di parcellamenti, lotti urbanizzati e quartieri irregolari in tutta la Regione Metropolitana, e particolarmente nel capoluogo; 2) l'espansione significativa dei movimenti sociali urbani (in tutto il Brasile, ma particolarmente nell' area portoalegrense) quali le prime ONG, i sindacati, le comunità religiose di base e - soprattutto - le associazioni di quartiere. Queste ultime (che a un certo punto si tentò di imbavagliare attraverso uno statuto.modello che non riuscì ad attecchire $)^{65}$ ebbero il loro momento di 
massimo sviluppo a metà degli anni '80, e intorno al 1988 diedero vita ad una forte ondata di protesta promuovendo invasioni di protesta in tutti i quartieri residenziali non terminati ${ }^{66}$ che si configurarono come nuove forme di intervento e lotta della popolazione sul problema della casa.

3) La chiusura del BNH nel 1986 per scarsità di risorse finanziarie e stagnazione relativa delle attività di edilizia civile, e la parallela cessazione dei programmi di credito rivolti a fasce a basso reddito (PROMORAR, PROFILURB ecc.) da casse statali e banche, che preferirono occuparsi di fasce di popolazione con rendita medio-alta. Questa trasformazione, privando lo Stato di alcuni dei suoi forti mezzi di convinzione sociale, non gli offriva, infatti, molte alternative all'apertura e alla ripartizione del potere, che attualmente sta - infatti - prendendo corpo con il nuovo progetto di estensione del Bilancio Partecipativo anche a livello sovracomunale.

4) La reintroduzione delle elezioni dirette per i Comuni delle Capitali nel 1985 che riportò la gestione urbana ad essere oggetto privilegiato di disputa nelle competizioni elettorali. ${ }^{67}$

5) Le proposte innovative che la rinvigorita competizione politica introdusse. A Porto Alegre esse riguardarono soprattutto la creazione legale dei Consigli Popolari da parte di Collares (nel 1988), lo studio di un nuovo Statuto Comunale [Legge Organica] che sarà approvato nell'aprile del 1990 e prenderà forma attraverso un Forum de Entidades di cui faranno parte anche le federazioni delle associazioni di vicinato (FRACAB e UAMPA) e la creazione del sistema del Bilancio Partecipativo [O.P.], mirato ad introdurre nella pratica la conciliazione dei principi della Legge di Sviluppo Urbano tra piano fisico, gestione ed implementazione finanziaria della città, e partecipazione della popolazione. Ovvero i tre pilastri di senso a cui - in teoria, ma solo in quella - si era ispirato anche il primo PDDU.

Tutte queste ragioni hanno portato di recente alla formulazione di un nuovo Piano Regolatore (cfr. cap. 14), dal momento che quello del '79 - pur con le trasformazioni apportategli nel 1987 (o forse proprio in virtù di quelle) - ha finito per risultare del tutto insoddisfacente alle esigenze della città e dei suoi abitanti. Al punto che persino i suoi difensori di allora lo hanno riconosciuto "complicato, incoerente, arbitrario, irrealista, scialacquatore, anacronistico, coercitivo dove potrebbe essere flessibile e negligente dove ci sarebbero ragioni per un maggior rigore” (Comas e Bohrer, 1998).

\section{Note}

${ }^{1}$ Il Gauchismo è un fenomeno tuttora molto vitale nel Rio Grande do Sul. Dal 1948 è sorto nella capitale Porto Alegre il CTG 35, il primo Centro di Tradizioni 'Gaúchas', il cui nome evoca la data d'inizio della Rivoluzione Farroupilha. Esso fungerà da modello per centinaia di altri centri nel Rio Grande do Sul che, oggi affiliati al Movimento Tradizionalista Gaúcho ha oltre 2 milioni di associati e 40 festival all'anno di musica nativa. L'immagine del Rio Grande do Sul è particolare. tradizionalmente è legata alla campagna, alla vita rurale e alle figure dei Gaúchos, cavalieri erranti per vasti spazi liberi; eppure oggi oltre il $75 \%$ della popolazione dello Stato è urbana.

${ }^{2}$ I principali simboli e riferimenti visuali cittadini sono il Morro di Santa Terza, di Santo Antônio, da Policia, da Companhia, do Pelado, do Osso e da Redonda, il Morro da Tapera, quello das Abertas, il Morro Petropolis, il Morro Santana e quelli di Belém, São Pedro, Espíndola e Extrema all'estremo Sud, ai bordi della Riserva Ecologica del Lami. ${ }^{3}$ Nel 1996 il contributo al PIL del Rio Grande do Sul è stato di 50,6 miliardi di R\$; 
quello dell'area metropolitana di Porto Alegre di 18,8 miliardi di $\mathrm{R} \$$, e quello cittadino di Porto Alegre di 8,3 miliardi di R\$. Grazie soprattutto all'apporto del settore dell'Agricoltura e dell'Allevamento (cresciuto del 23,9\% nell'ultimo triennio), tra il 1999 e il 2001 la crescita del PIL del Rio Grande do Sul è stata del 10,9\%, mentre quella nazionale brasiliana del 7,5\% (dati Fondazione di Economia e Statistica del Rio Grande do Sul, 2001).

${ }^{4}$ Porto Alegre socioeconômica, 1998.

${ }^{5} \mathrm{Nel}$ complesso però è da riscontrarsi una notevole disparità di redditi medi rispetto agli impiegati del settore pubblico, il cui stipendio fino al 1996 è risultato quasi doppio.

${ }^{6}$ IBGE (2001), Censo Demográfico 2000: Resultados do universo (2001), Rio de Janeiro. ${ }^{7}$ Idem (dati divulgati da FEE/RS).

${ }^{8} \mathrm{Nel}$ 1493, le bolle di Papa Alessandro VI Eximia divocionis e Inter coetera ave vano stabilito che fosse spagnolo ciò che si trovava ad ovest del meridiano ubicato cento leghe a ponente delle Azzorre e delle Isole di Capo Verde; ma già il trattato di Tordesilhas alterò queste misure in favore degli interessi porto ghesi. Le pressioni di Lisbona convinsero Papa Innocenzo XI ad estendere la diocesi di Rio De Janeiro fino al Rio Prata con la bolla Romani Participi del 1676. L'essere i nuovi nati sulla riva sinistra di questo fiume riconosciuti come portoghesi, fu interpretato dalla corona lusitana come una giustificazione alla fondazione (nel 1680) di una nuova colonia, quella di Sacramento, ubicata di fronte a Buenos Aires, che era stata trasformata in città dagli spagnoli esattamente un secolo prima.

9 A tal fine, anzi, la colonizzazione massiccia del territorio poteva solo risultare pregiudiziale.

${ }^{10}$ Souza e Müller 1997 datano a quest'epoca l'origine della società pastorale riograndense basata sulla grande proprietà con la sua gerarchizzazione, ma per altri versi anche con la sua caratteristica convivenza fra componenti della fattoria.

${ }_{11}$ Nel 1763 un'ondata di occupazione spagnola decreterà il definitivo fallimento del trattato, costringendo gli abitanti provenienti dalle Azzorre a spostarsi sulla riva sinistra del fiume Jacuí, dove fonderanno i nuclei abitati di Taquari, Triunfo e Santo Amaro, mentre la capitale della Provincia dall'occupata Rio Grande andrà a Viamão per 10 anni.

${ }^{12}$ Il centro fu elevato da Comandancia al rango di Vila nel 1747, divenendo sede del Consiglio (Camara) nel 1751.

${ }^{13}$ Monteiro (1995) sottolinea che fu la delimitazione ecclesiastica dell'area abitata (ai tempi della creazione della freguesia di São Francisco di Porto dos Casais) il primo riconoscimento ufficiale, elemento coagulante di una nuova entità.

${ }^{14}$ Il nome Porto Alegre appare per la prima volta in un atto ufficiale il 24/6/1773.

${ }^{15}$ Fuori dalle arterie maggiori, già acciottolate e dotate di illuminazione a olio, acqua, pulizia e pattugliamento di sorveglianza a partire dal 1779, resterà a lungo viva l'immagine dei 'becos', traverse dal percorso accidentato, strette e corte, caratterizzate dall'affacciarsi di casette di paglia e tronchi dove abitava la popolazione più povera: artigiani, osti, marinai, prostitute e liberti. I loro nomi erano legati ad attività quotidiane svolte in loco dagli abitanti. I 'largos' rappresentavano, invece, gli spazi di riunione della socialità pubblica, spazi polisemantici che rinforzavano i legami comunitari (Monteiro, 1995), dove si riversavano il lavoro, le feste e la religiosità popolare.

${ }^{16}$ Solo nella toponomastica di uso comune a Porto Alegre (che non corrisponde a quella ufficialmente registrata sulle carte) permane la memoria viva dell'antica struttura urbana, antecedente alle trasformazioni dell'ultimo secolo.

${ }^{17}$ Sovente a furor di popolo, come accadde a Rua do Príncipe e a Praça Conde d'Eu, ribattezzate dalla popolazione - durante il giubilo per la proclamazione della Repubblica - Rua da República e Praça 15 de Novembro.

${ }^{18}$ Per ragioni simboliche, solo dopo oltre 50 anni sarà presa la decisione di costruire un camposanto, laddove oggi sorge una vera e propria cittadella di cimiteri di confessioni religiose diverse (cfr. Allegretti, Verso una morte democratica? Un'esperienza brasiliana. In I Servizi Funerari $\left(\mathrm{n}^{\circ} 3 / 2000, \mathrm{n}^{\circ} 4 / 2000\right)$.

${ }^{19}$ Le altre erano: Estrada de Baixo, Caminho do Meio, estrada da Azenha (verso João Pessoa- Bento Gonçalves), Caminho do Rio (oggi Praia de Belas) che costeggiava la Lagoa de Viamão, oggi lago Guaiba, in direzione opposta al Caminho Novo. A quest'epoca le preoccupazioni sanitarie - concentrate sul risanamento della parte settentrionale del promontorio densamente abitata - suggerirono di costruire il caminho de gado, un percorso specifico che il bestiame doveva seguire per l'entrata in città e che si configurò come la sesta radiale d'accesso alla città (Macedo, 1993).

${ }^{20} \mathrm{E}$ poco più tardi in quelli dell'erudito francese Nicolau Dreys e di Arséne Isabelle che 
descriverà la piena del 1833.

${ }^{21}$ Solo negli anni '30 la Guerra Cisplatina termina con una pace: Brasile e Argentina danno all'Uruguay l'indipendenza.

${ }^{22}$ La rivolta di Porto in Portogallo cominciò a mutare i rapporti tra Brasile e madrepatria; a quegli anni risalgono i primi atti di censura alla nascente stampa portoalegrense, che già nel 1833 conterà 7 giornali suddivisi fra sostenitori dei movimenti politici della sinistra liberale, Caramurus e Farroupilhas, questi ultimi simpatizzanti della Repubblica.

${ }^{23}$ A questo periodo risale la prima pianta conosciuta di Porto Alegre datata Rio de Janeiro 1838, a cui ne seguì una seconda nel 1839 - realizzata in ambito locale- con qualche differenza nel tracciato delle fortificazioni.

${ }^{24}$ Souza e Müller (1997) ci informano che 1.032 ne giunsero tra il 1824 ed il 1825 ed altri 3.823 tra il 1826 ed il 1829, mentre fino al 1846 (negli anni della rivolta Farroupilha) il numero cala a 2.63; il totale di 7.491 persone si disloca per lo più in aree ancora non occupate, generando una nuova economia agricola diversificata basata sulla piccola proprietà.

${ }^{25}$ Eranno 60 mila gli immigrati italiani entrati tra il 1875 ed il 1889 e direttisi prevalentemente verso il sud per lavorare nell'agricoltura (in piccole proprietà) dove fondarono città, fin dal nome, molto legate alle comunità italiane.

${ }^{26}$ I Brasiliani di origine tedesca si distinsero soprattutto nell'industria della birra, della metallurgia e del cuoio. Nel 1926 fondarono la prima impresa aerea brasiliana: la Varig. ${ }_{27}$ Artt. 5 e 6, Legge provinciale 4 gennaio 1888 .

${ }^{28} \mathrm{Dal}$ loro novero escludiamo i nuclei di Belém Velho e Belém Novo, veri paesi a parte, molto distanti dalla città.

${ }^{29}$ Bairro dos Navegantes, de São Manoel, de São Miguel de Sant'Ana. Praia de Belas era detta Lago di Viamão.

${ }^{30}$ La pianta di J. C. Jacques del 1888 registrava 2 ippodromi (Menino Deus e Boa Vista), e quella successiva di A. Ahrons ben 4; altri 4 si trovavano sulle radiali di ingresso alla città al centro dei nuovi nuclei abitati in formazione, ovvero 'fuori pianta'. Nel 1899, nei Campos da Redenção fu organizzato un velódromo. Nel 1903 nascerà il Gremio Gremio Calcio (preclusa ai giocatori di colore) e nel 1909 l'Internacional, nel 1907 il primo cinema ('Recreio ideal').

${ }^{31}$ In quel periodo lo Stato del Rio Grande do Sul ne contava 850.000 divisi fra 58 comuni. Tra il 1910 ed il 1920 si registrò un tasso di crescita della popolazione del 6\% annuo.

${ }^{32}$ Nel 1899 il Consiglio Comunale ratificò la sostituzione di tutti i nomi che evocavano l'Impero.

${ }^{33}$ Macedo (1993) ha calcolato che il 10\% dei monumenti furono dedicati alla Rivoluzione Farroupilha.

${ }^{34}$ Fino al secolo XVIII i giardini appartenevano a palazzi o a conventi e la maggior parte degli spazi pubblici erano piazze, mentre la vegetazione faceva parte della campagna. La diffusione dei giardini in Brasile nell'Ottocento è legata all'influenza francese come si deduce dal ricorso alla simmetria e ad assi segnati da monumenti (Souza, 1997).

35 "Che la città dovesse sembrare moderna, anche se non lo era, faceva parte delle idee dell'epoca" (Souza, 1997).

${ }^{36}$ Proprio cominciando da Rio, le città brasiliane 'importarono' una dopo l'altra quell'immagine parigina che rappresentava agli occhi dei nuovi sudditi della Repubblica $i l$ simbolo delle lotte politiche per la libertà, l'uguaglianza e la fraternità, insomma, tutto il progetto di modemità del suo tempo (Souza, 1994).

${ }^{37} \mathrm{Dal} 1889$ [...] appoggiandosi alle idee di Comte, 'l'autoritarismo erudito' [...] esigeva l'abbattimento di tutto ciò che si identificasse con il vecchio, il tradizionale, l'antico, fossero edifici (come $i$ 'cortiços' o le case di legno), costumi o qualsiasi altra cosa, in nome della costruzione di quello spazio radicalmente nuovo che si conformasse alle necessità dello sviluppo economico, ai capricci della nuova estetica urbana $[. .$.$] in conformità$ con quell'ideale di modernità. [...] Dietro il discorso tecnico-razionale dell'igienizzazione e dell'abbellimento della città, emerge il desiderio dell'elite dirigente di organizzare, pianificare e disciplinare il nuovo contingente di forza-lavoro (Monteiro, 1995).

${ }^{38}$ Fin dai primordi, Porto Alegre ha dovuto adeguarsi alle particolari condizioni del suo territorio ortograficamente complesso. I rinterri e l'apertura di nuove vie riflettono le necessità di riordino ed espansione delle aree interne alla città, che nel corso del tempo hanno dato vita a proposte di trasformazione urbana spesso in anticipo sui tempi. Ad esempio, la proposta presentata nel 1858 dall'ingegnere municipale Frederico Heydtmann, di creare una via perimetrale che contornasse il centro (quasi con lo stesso tracciato dell' attuale, proposto dai piani del 1943 e 1959 e realizzato soltanto dopo il 1970) precede di qualche anno le 
elaborazioni di quelle realtà (Parigi e Vienna) poi divenute 'riferimento obbligato'.

${ }^{39}$ L'influenza dell'urbanistica francese si avverte esplicitamente nel piano Maciel, sia nei principi di base che orientano l'azione del progetto (igiene e abbellimento, vicini alla triade haussmanniana: Trasportare, Risanare, Attrezzare, anche se il terzo punto è qui notevolmente sottovalutato) che in principi ed esiti formali del disegno (avvicinamento di punti strategici mediante boulevard, articolazione degli assi mediante rondpoint, rafforzamento delle radiali e creazione di vie perimetrali o semiperimetrali, e visualizzazione barocca della via tramite le costruzioni lungo i suoi bordi).

${ }^{40}$ La vicenda del viale Borges de Medeiros è un esempio tipico di questa capacità del Piano Maciel di muoversi tra le influenze dell'urbanistica d'oltreoceano - giunte in ritardo attraverso le imitazioni di alcune capitali latinoamericane - e un'adesione alle specificità dell'ambito locale. Concepito come intervento di grande rappresentatività simbolica, per avvicinare e collegare la riva nord alla riva sud della città passando per il centro, fu realizzato solo alla fine degli anni '20. Ancor oggi una delle maggiori arterie cittadine, il viale richiese un lavoro più impegnativo del semplice allargamento della sede stradale, portando all'esecuzione di un profondo taglio nel terreno e alla costruzione di un viadotto trasversale (inaugurato nel 1932) per unire i due estremi della parte alta. L'aumento di costi e difficoltà fu giustificato con la necessità di introduzione di una linea tranviaria che collegasse le due rive del Lago Guaiba. Il modello francese fu realizzato su un territorio di topografia non agevole, con la costante preoccupazione di adattare il progetto al luogo, e di 'migliorare conservando' (Souza, 1997). Furono anche corretti i percorsi di vari torrenti e adeguati terrapieni e zone paludose ('ilhotas') attraverso la creazione di parchi e giardini (come il Farroupilha) affiancati a serre e altre attrezzature. ${ }^{41}$ A parte i lavori per l'ampliamento del porto conclusi nel 1922 unitamente a quelli del viale Mauá che lo costeggia, tutti gli altri interventi trovarono realizzazione tra il 1938 ed il 1943, nel periodo cioè della dittatura di Vargas (detta Estado Novo) durante la quale la realizzazione di opere pubbliche del genere previsto dal piano era vista come una forma di sostegno politico al Governo e al suo programma. Una situazione simile si ripeterà negli anni '70 sotto un'altra forte dittatura che realizzerà alcune ardite proposte del piano del 1914 ancora irrealizzato (il tunnel della circonvallazione stradale).

${ }^{42}$ La 'continuità nel cambiamento' fu teoricamente inaugurata con la riforma della Costituzione Statale del 1891, una delle condizioni imposte negli accordi di Pedras Altas dai partiti di opposizione che durante una rivoluzione del 1923 avevano fatto della non rieleggibilità delle massime cariche dello Stato e dei Municipi un cavallo di battaglia della lotta contro la mancanza di libertà determinata dallo strapotere del più volte rieletto Governatore del Rio Grande do Sul Borges de Medeiros. A Porto Alegre, dopo José Montuary (detto l'eterno intendente), fu eletto Otavio Rocha, che ebbe come vicesindaco il futuro sindaco Alberto Bins, industriale metallurgico di origine tedesca che aveva studiato in Inghilterra e che governerà dal 1928 al 1937, garantendo continuità a molti dei progetti iniziati o appena pianificati dal suo predecessore, grazie al mutare delle regole istituzionali nel periodo della dittatura dell'Estado Novo.

${ }^{43}$ Dopo l'ampliamento del Porto del 1922 e la costruzione dell'aeroporto nel 1926, ci si concentrò infatti sulla creazione dei 5,5 km. dell'Avenida Farrapos (1939-40) e poi della sua prosecuzione (l'autostrada BR-116).

${ }_{44}$ Salengue e Marques (1993).

${ }^{45}$ La canalizzazione - con rettifica del corso - di due torrenti pieni di anse come il Dilúvio e il Cascata modificarono la fisionomia del centro cittadino, già alterata dalla costruzione della Avenida Ipiranga lungo l'omonimo torrente.

${ }^{46}$ Questi passarono dai $211.000 \mathrm{mq}$ del 1937 agli 810.831 del 1941 (Souza e Müller, 1997). Il Parque Farroupilha dopo l'Expò del 1935 fu oggetto di un piano dell'urbanista francese Agache e dal 1939 venne ri-piantumato.

${ }^{47} \mathrm{Nel}$ frattempo furono ampliati del 14\% i limiti urbani (DL 25/1940) per ottenere maggiori ricavi dalle imposte (nel complesso in cento anni - dal 1839 - la città era passata da 296,6 a 7.311 ettari).

${ }_{48}$ Nel 1965, una Commissione Speciale dell'Assemblea Legislativa dello Stato redasse un allarmante rapporto intitolato "Sviluppo economico insufficiente del Rio Grande do Sul" (Souza e Müller, 1997).

49 1.548.140 erano allora gli abitanti dell'intero Stato (Souza e Müller, 1997).

${ }^{50}$ Dal 1959 al 1980 , in particolare, si è passati da un'incidenza del $26,3 \%$ ad una del 17,92\% (Alonso, 1988). 
${ }^{51}$ La costruzione della Bretella stradale BR-116 portò molti impianti a 'migrare' in direzione di Niterói-Canoas-Sapucaia e a posizionarsi poi sul litorale con lo sviluppo del nuovo asse d'accesso litoraneo, la BR-101. conseguentemente, vari quartieri popolari tesero a spostarsi verso est, verso i comuni di Cachoeirinha, Viamão, Bento Gonçalves, Alvorada. ${ }^{52}$ Questo assorbì quasi il 70\% delle licenze concesse dal Comune tra il '65 e il '67 (Souza e Müller, 1997).

${ }^{53}$ Il termine fu usato per la prima volta da Ruth Glass (1964) e rapidamente accolto e istituzionalizzato.

${ }^{54}$ Rovatti (1993) disegna 8 livelli di fertilità dei suoli (in coincidenza di cambiamenti significativi dal 1893 al 1987).

55 Se le giustificazioni ideologiche date ai primi provvedimenti adottati in città nel 1913 erano state di natura igienica ed estetica e quindi 'limitative', dal 1926 il Comune aveva cominciato a giocare la carta dello 'stimolo' all'occupazione intensiva dei lotti tanto che il Decreto Legge 1115/1942 riduceva addirittura per 10 anni le tasse sull'immobile a seconda del numero dei piani (abbattimento del $40 \%$ fino a 3 piani, $50 \%$ fino a 5, 60\% dai 6 piani in più). La Legge Municipale 1167/1953 ampliò notevolmente l'area di applicazione della 986/1952 anche ai principali corridoi urbani radiali.

${ }^{56} \mathrm{Nel} 1980$ in tutta l'Area Metropolitana la popolazione contava 2.252 .62 unità, divenute nel 1991 3.757.500.

${ }_{57}$ Farrapos per le auto, Osvaldo Aranha per i mobili, Independência per il vestiario.

${ }^{58}$ Mentre ad inizio secolo la creazione dei primi supermercati in Brasile era legata ai capitali stranieri, oggi quasi tutte le maggiori compagnie gestrici di supermercati nello Stato (Zaffari, Nacional, Real, Dosul) sono di origine locale, eccetto la Carrefour che dal 1976 opera nel settore alimentare (65\% del fatturato), catena di origine francese.

${ }^{59}$ Queste sono costruite su modelli di scacchiera ippodamea e zonizzate per funzioni prevalenti. Ad esempio, Capão Novo - nata nel 1981 sul litorale a $135 \mathrm{~km}$. da Porto Alegre - è una fredda unione di condomini residenziali di con grandi parchi costieri interamente pianificata, il cui regolamento prevede non 3 metri (come a Porto Alegre), ma almeno 14 tra ogni edificio, che non può occupare oltre il $30 \%$ del terreno ed è commercializzabile dall'unica società immobiliare detentrice dei terreni - il Grupo Capão Novo - solo a costruzione avvenuta (cfr. Veja/RS, São Paulo, ${ }^{\circ}$ del 27/3/1991).

${ }^{60}$ In questo periodo nacquero il primo organismo federale di ambito urbanistico (il SERFHAU, Servicio Federal de Habitação e Urbanismo) e - nello Stato - il Gruppo Esecutivo della Regione Metropolitana di Porto Alegre (GERM, poi divenuto Metroplan), ma anche la Commissione Nazionale di Politica Urbana e Regioni Metropolitane (la CNPU, poi sostituita dal CNDU, Consiglio Nazionale di Sviluppo Urbano) che propose una legge per regolare lo Sviluppo Urbano.

${ }^{61}$ Tali indici portarono alcuni mutamenti significativi anche nel paesaggio architettonico cittadino; ad esempio- non computando nell'indice di sfruttamento le proiezioni dei balconi, e non valutando fra i volumi i tetti inclinati al di sopra della gronda, generarono un enorme proliferare di chalet e di balconi che oggi caratterizzano l'aspetto della città costruita dopo il ' 79 offrendo elementi per un legame con la tradizione di immigrazione tedesco/italiana del secolo scorso (Silva, 1993). Simili norme fecero abbassare l'incidenza del costo dei terreni negli appartamenti di lusso.

${ }_{62} \grave{E}$ il caso dei minuziosi regolamenti che introdussero l'obbligo degli arretramenti stradali frontali e laterali e abolirono la distinzione tra dominio pubblico e privato sul fronte stradale, con l'illusione di creare strade/corridoio dai lati alberati ed edifici immersi nel verde da sogno lecorbusieriano (Comas, 1993; Turkienicz, 1993).

${ }_{63}^{63}$ Nel senso usato da Lefevbre (1974).

${ }^{64}$ Tra i 52 articoli modificati, fu - infatti - inserita la possibilità di raddoppio dell'altezza degli edifici nei quartieri residenziali, e la quadruplicazione di quelli commerciali.

${ }_{65}$ Sul problema dello Statuto-modello per le Associazioni Comunitarie vedi Ferretti, 1984.

${ }^{66}$ Soprattutto in quelli della COHAB, l'organismo statale con competenza sulla costruzione di alloggi popolari.

${ }^{67}$ Dopo le Amministrazioni non elette di Guilherme Villela (1975/84; sostenuto dai partiti ARENA E PDS) e João Dib (1984), a Porto Alegre fu eletto nel 1985 Alceu Collares (PDT) che governò fino al 1988. 

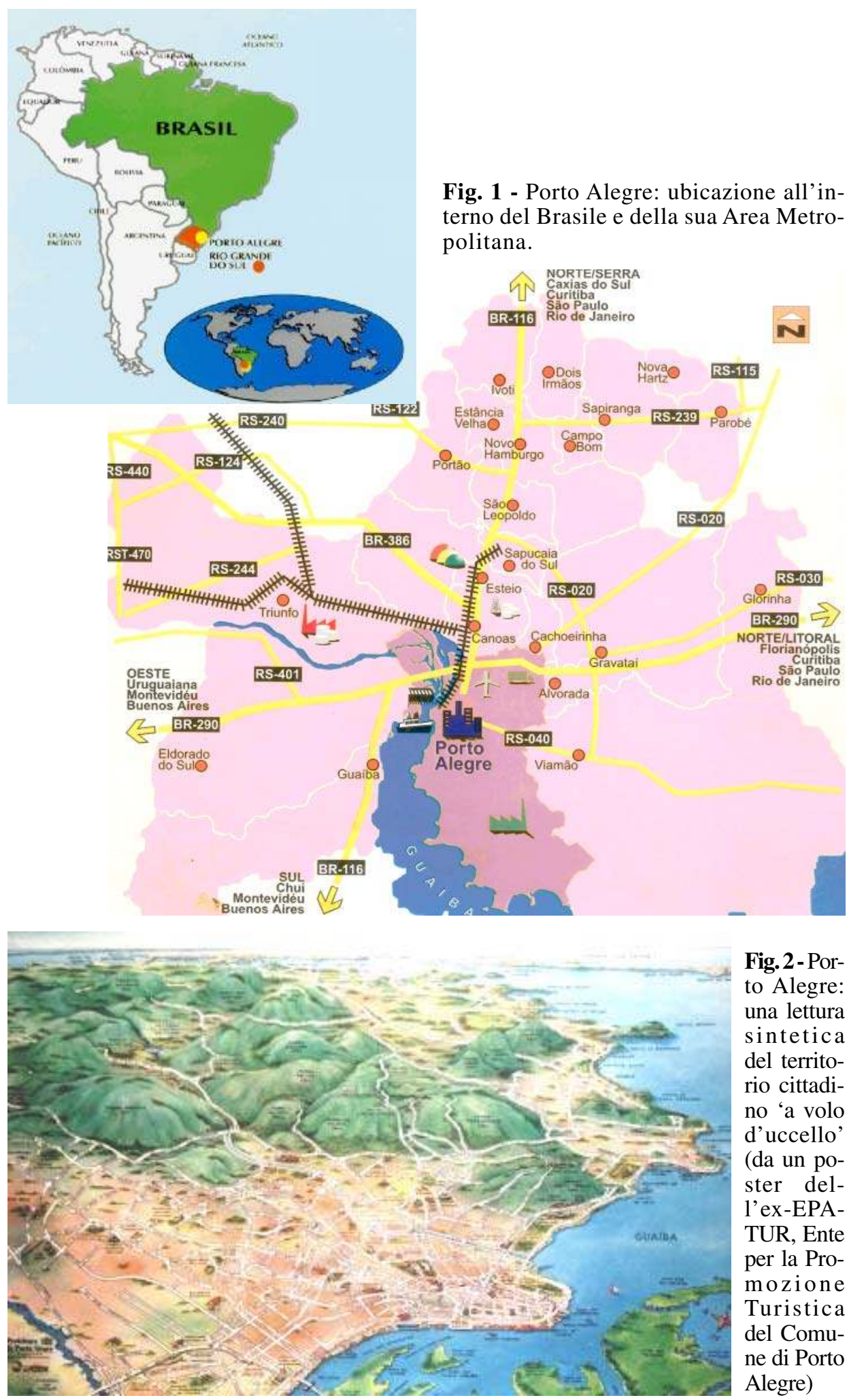

Fig. 2 - Porto Alegre: una lettura sintetica del territorio cittadino 'a volo d'uccello' (da un poster dell'ex-EPATUR, Ente per la Promozione Turistica del Comune di Porto Alegre) 


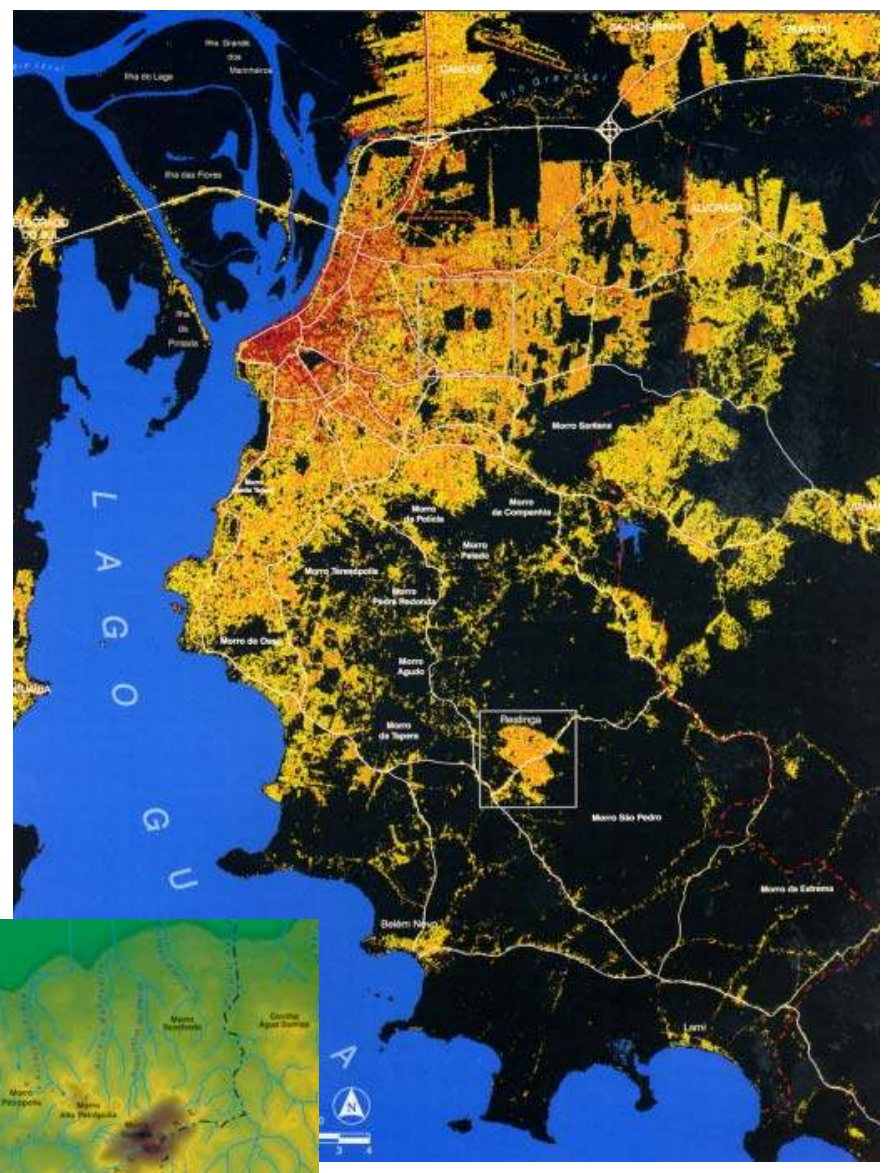

Fig. 3 - Porto Alegre: visione satellitare dell'agglomerato urbano e visione sintetica del territorio naturale (cartografie tratte da: R. Menegat, 1998) 

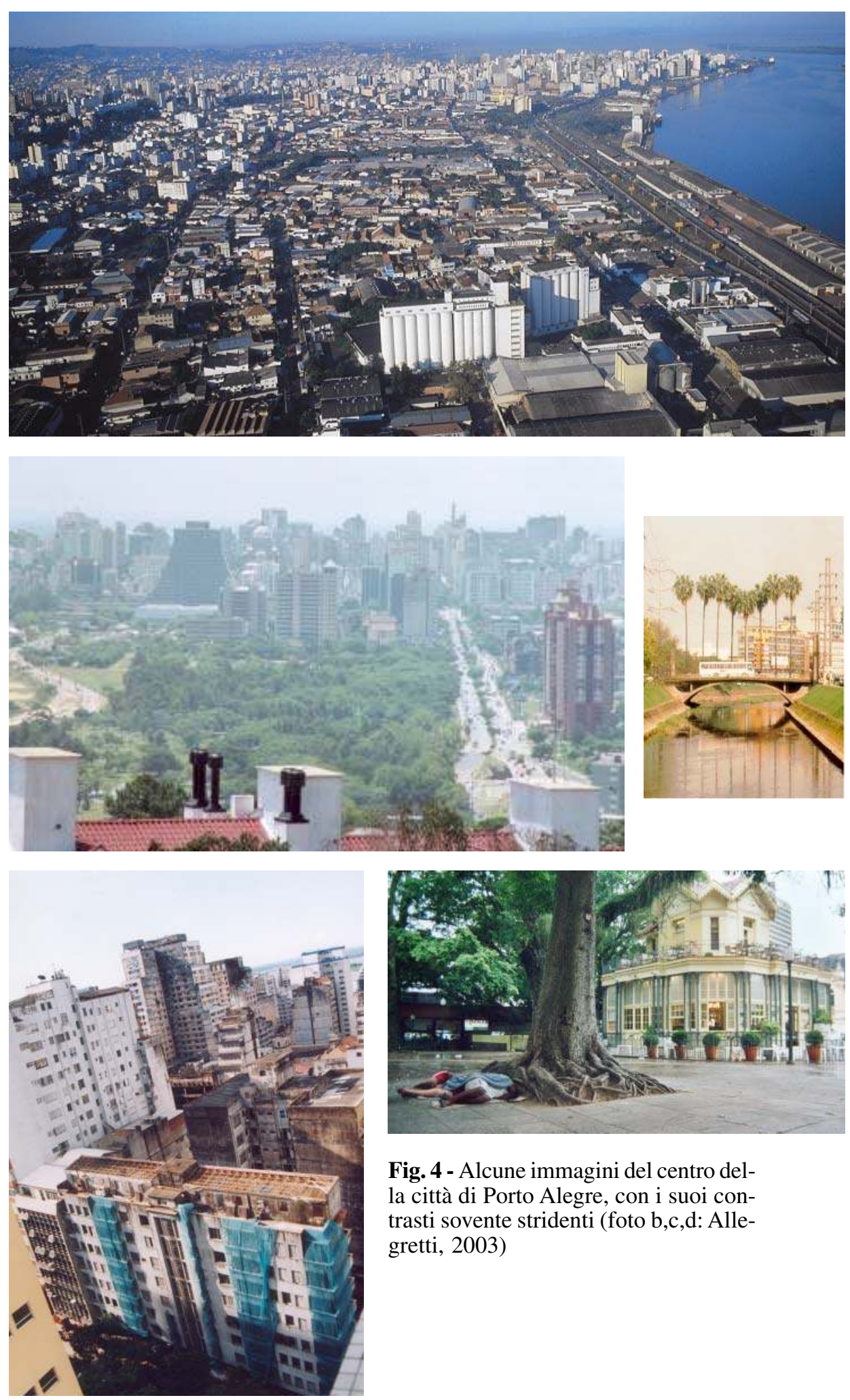

Fig. 4 - Alcune immagini del centro della città di Porto Alegre, con i suoi contrasti sovente stridenti (foto b,c,d: Allegretti, 2003) 
Fig. 5 - Porto Alegre nel suo territorio: produzione e lavoro (Dati FEE, 2001)

Composizione del reddito nello Stato del Rio Grande do Sul, nell'Area

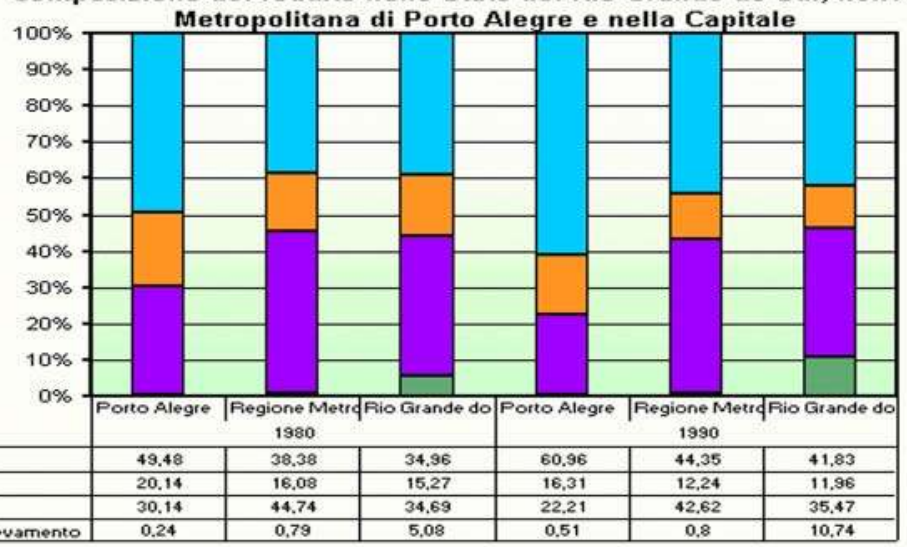

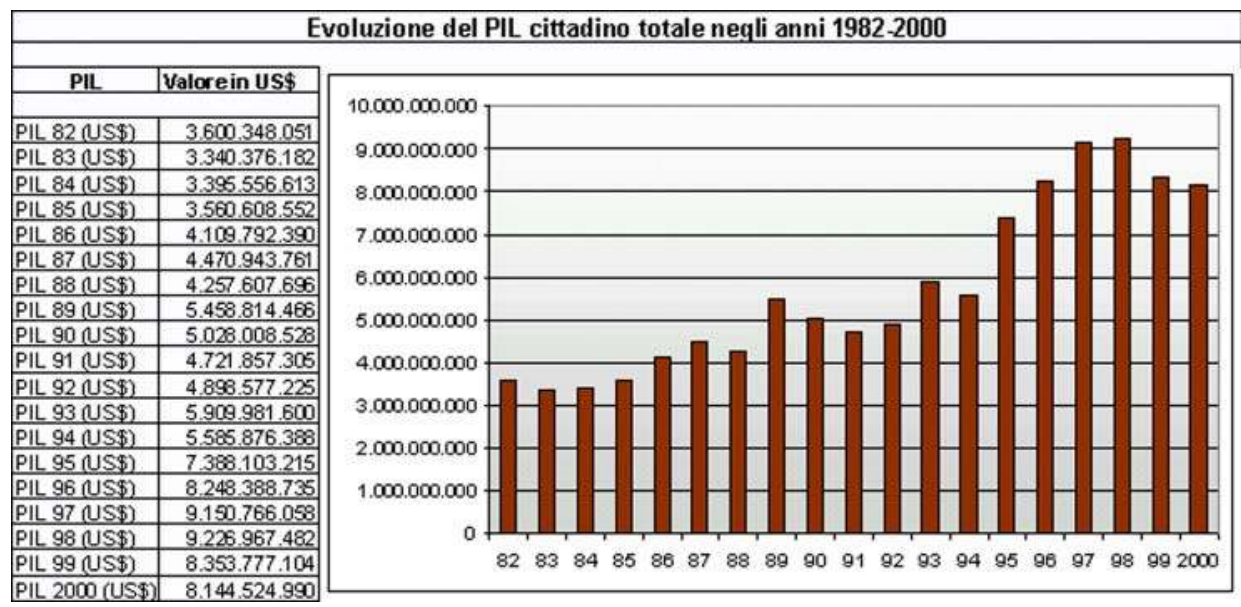

Indice del livello di occupazione per settore di attività economica nella Regione metropolitana di Porto Alegre, $1992 / 99$.

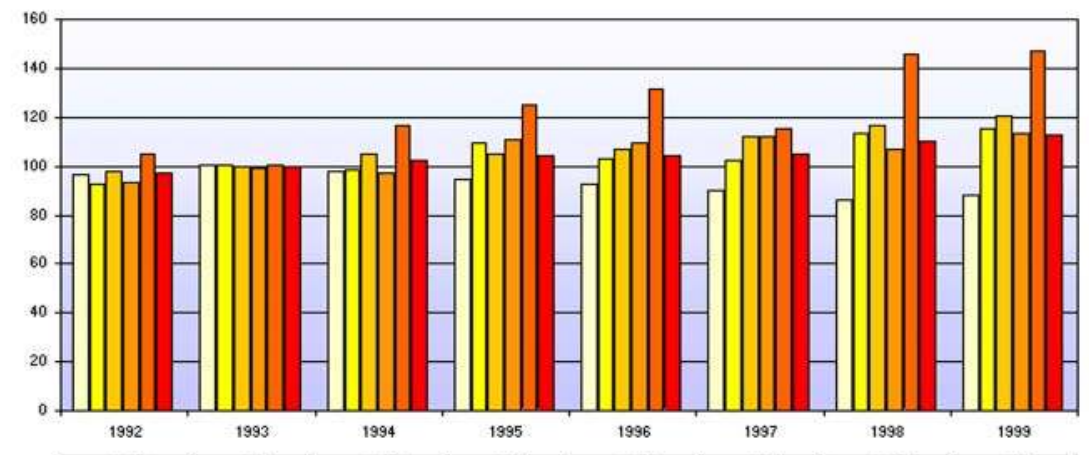

\begin{tabular}{|l|c|c|c|c|c|c|c|c|}
\cline { 2 - 9 } \multicolumn{1}{c|}{} & ott-92 & ott-93 & ott-94 & ott-95 & ott-96 & ott-97 & ott-98 & ott-99 \\
\hline DINDUSTRIA & 96,8 & 100,3 & 97,7 & 94,5 & 92,5 & 89,9 & 86 & 88 \\
\hline DCOMIMERICIO & 92,7 & 100,4 & 98,5 & 109,2 & 102,9 & 102,4 & 113,6 & 115 \\
\hline DSERVIZI & 97,5 & 99,5 & 104,9 & 105 & 107,2 & 111,9 & 116,4 & 120,8 \\
\hline DEDILIZIA CIVILE & 93,3 & 99,1 & 97,3 & 110,7 & 109,3 & 112 & 106,7 & 113,3 \\
\hline DSERVIZI DOMESTICI & 105,2 & 100,2 & 116,9 & 124,7 & 131,2 & 115,6 & 145,5 & 146,8 \\
\hline G TOTALLE & 96,9 & 100 & 102,3 & 104,5 & 104,6 & 105,1 & 109,9 & 112,8 \\
\hline
\end{tabular}




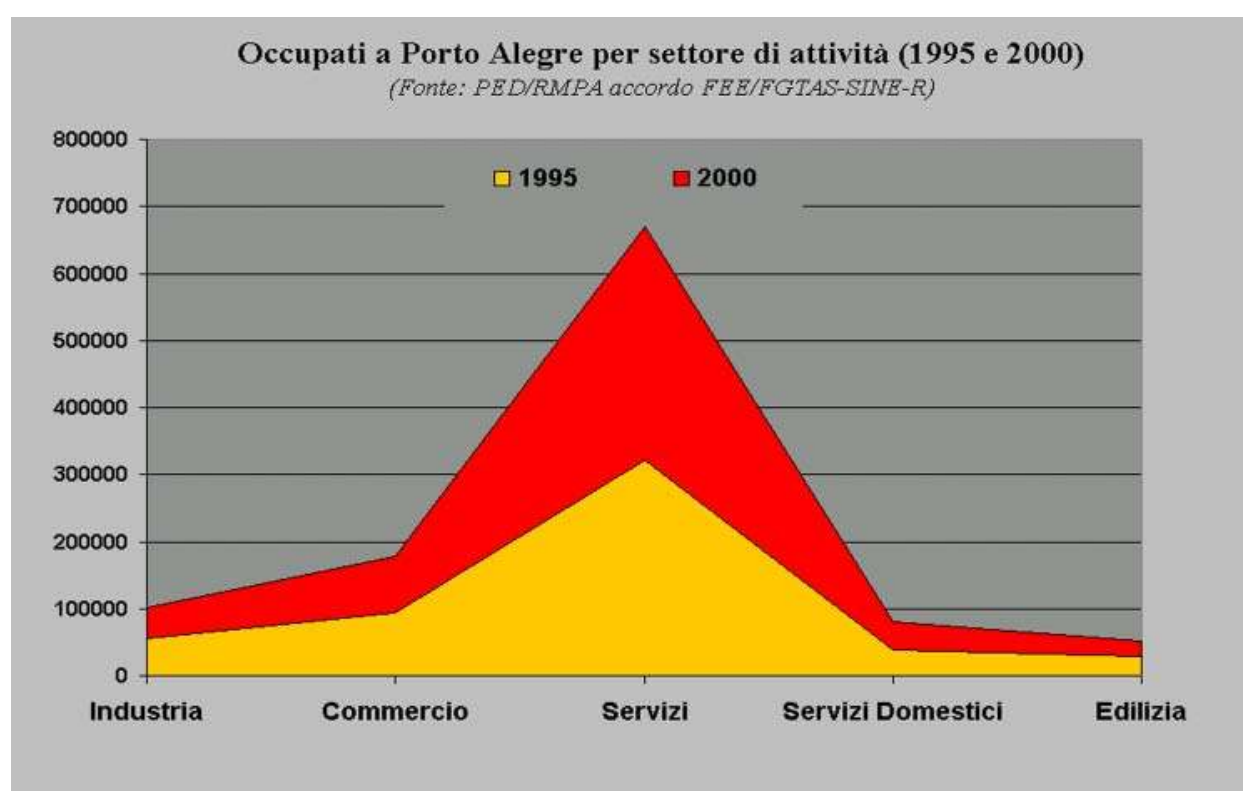

Temi medi di ricerca del lavoro a Porto Alegre (Dati: Accordo FEE/PMPA, 2001)

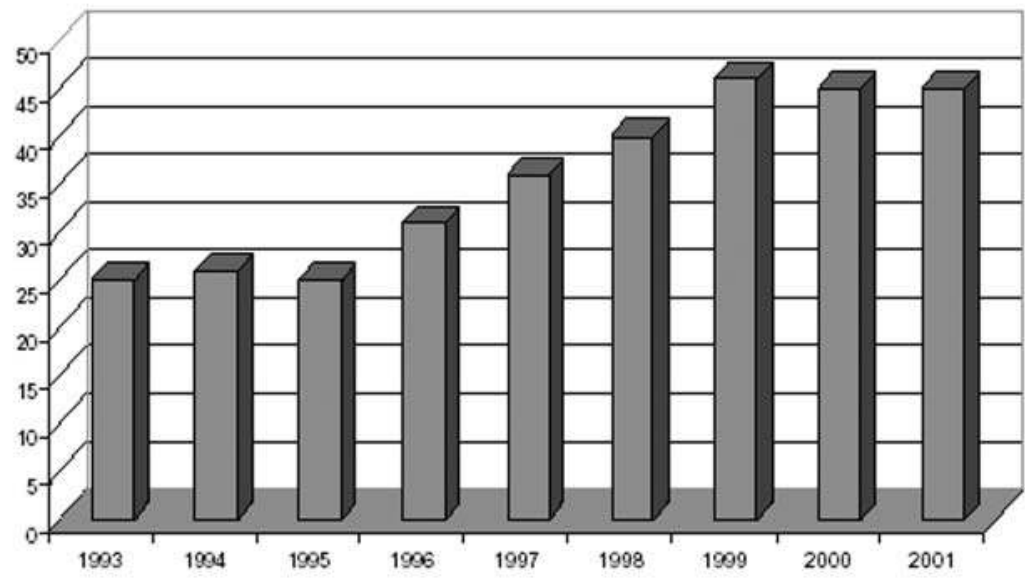

Andamento dell'occupazione a Porto Alegre nell'ultimo biennio (Dati: Accordo FEE/PMPA, 2001)

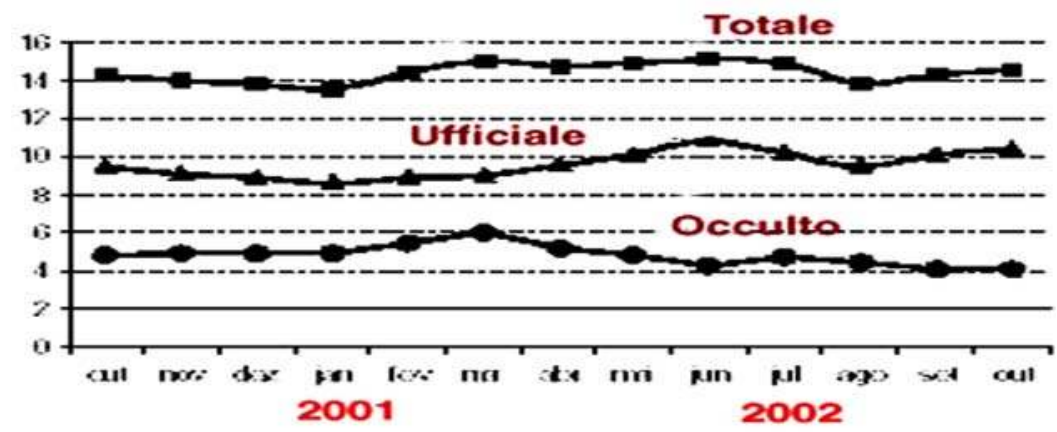

Fig. 6 - Porto Alegre: la situazione occupazionale negli anni recenti 


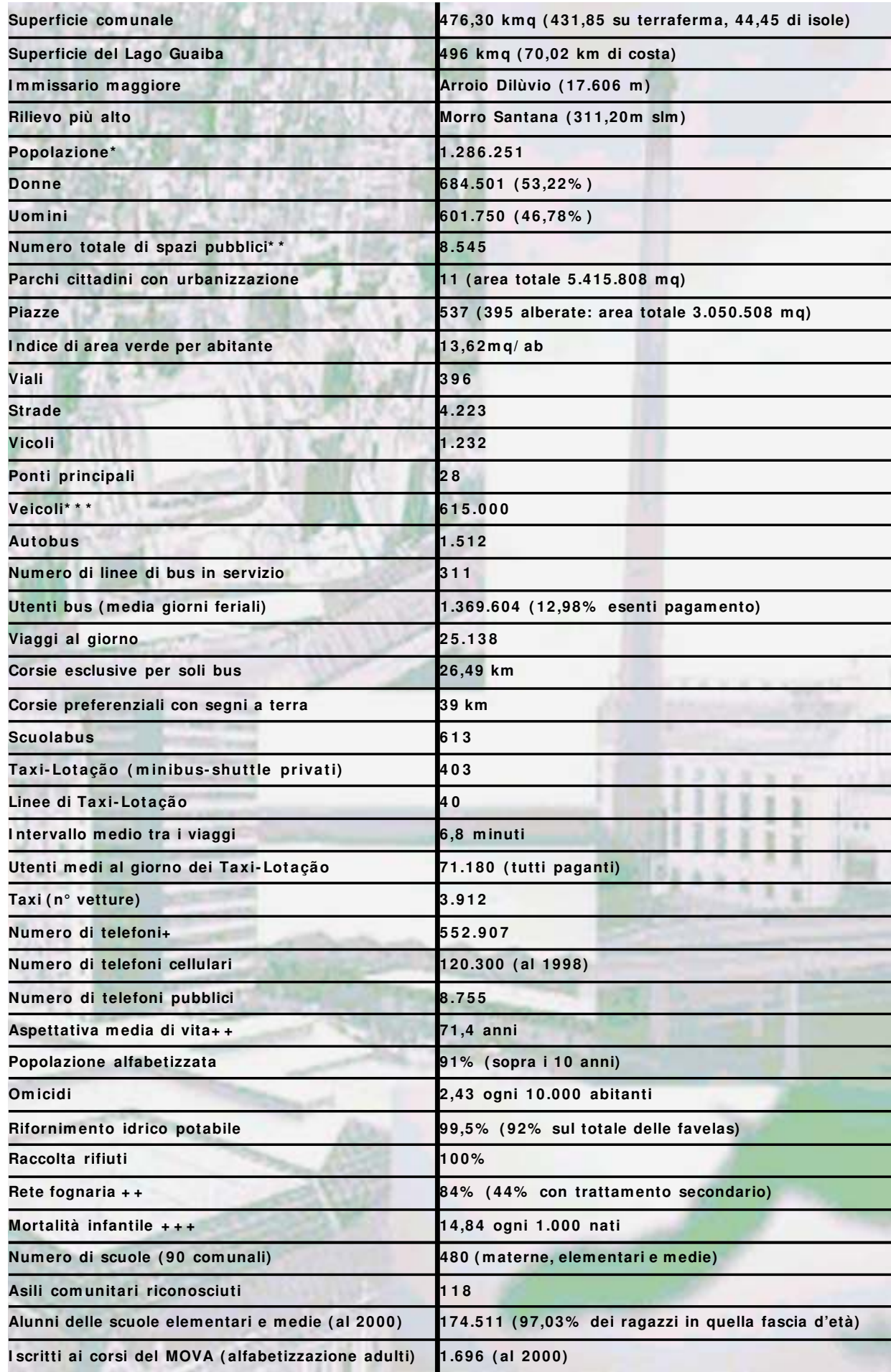

Fig. 7 - Una sintetica autopresentazione dalle pagine web del Comune (www.portoalegre.rs.gov.br) 


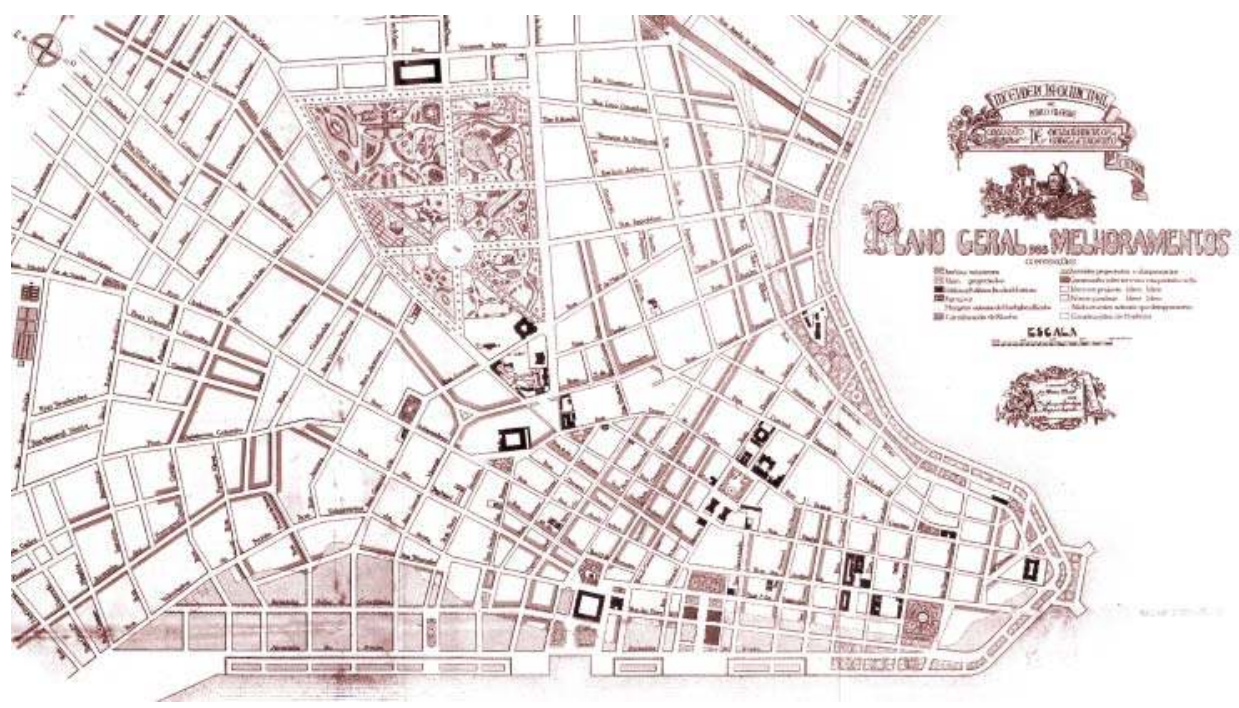

Fig. 8 - Il Plano Geral dos Melhoramentos (1914) è il primo piano positivista brasiliano che si occupa dell'intera città e non solo del centro storico-monumentale
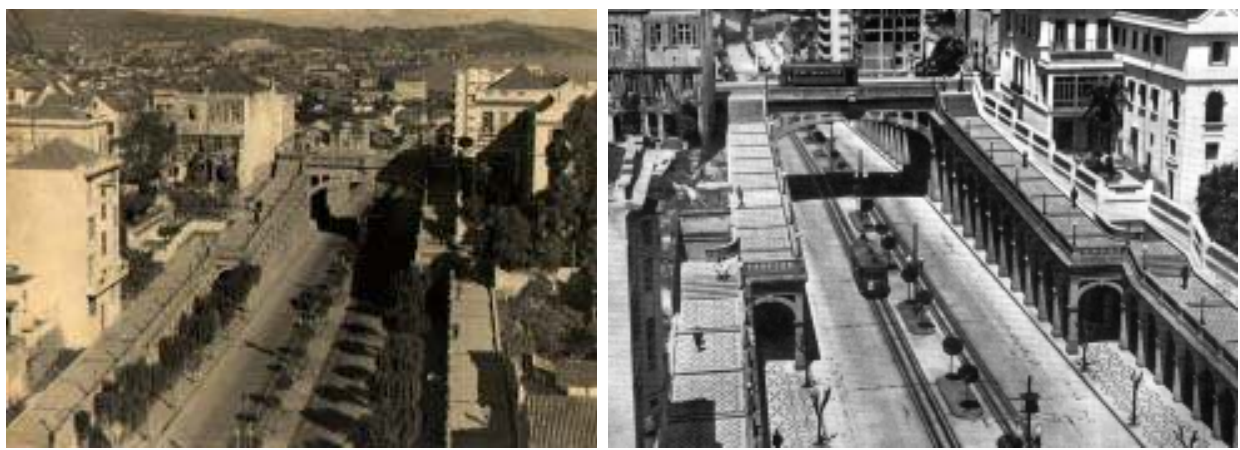

Fig. 9 - Il viadotto Borges de Medeiros (1924) ha costituito il primo grande intervento strategico realizzato nell' ambito della viabilità urbana, sulla base di idee già maturate a metà Ottocento.
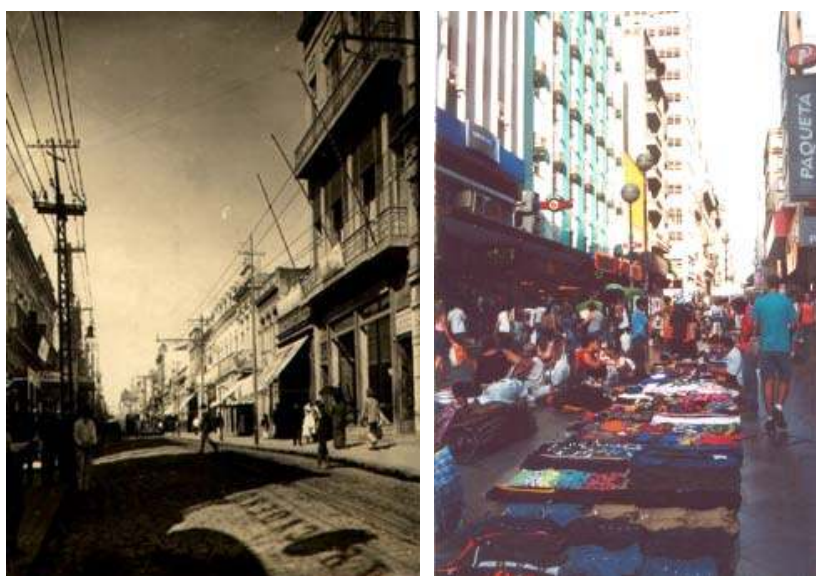

Fig. 10 - La Rua Praia (oggi Rua dos Andradas) nel 1910 (foto di Virgilio Calegari) e oggi. Anticamente la strada affacciava sul lago Guaiba, oggi - in seguito ai successivi riempimenti che hanno triplicato la superficie del centro storico - il ricordo del legame con il lago è affidato solo alla permanenza dell'antico toponimo nell'uso popolare. 


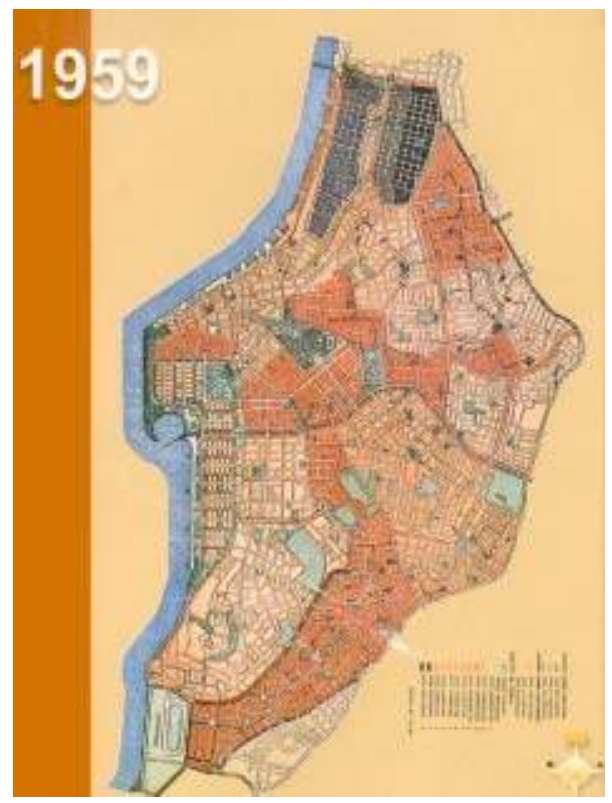

Fig. 11 - Un'immagine del piano funzionalista del 1959, i cui confini di intervento sono stati più volte ampliati negli anni successivi da numerose varianti

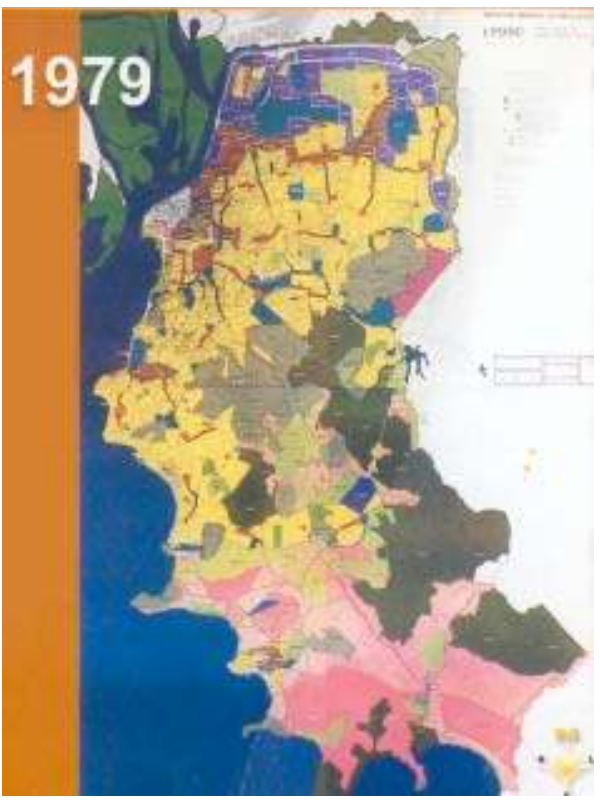

Fig. 12 - Il Piano di Sviluppo Urbano del 1979, stravolto da una variante del 1987.
Fig. 13 - Nell'ultimo secolo, i successivi riempimenti hanno triplicato la superficie del centro storico, mutando il rapporto dell'abitato con il lago (elaborazioni tratte da Menegat, 1998)
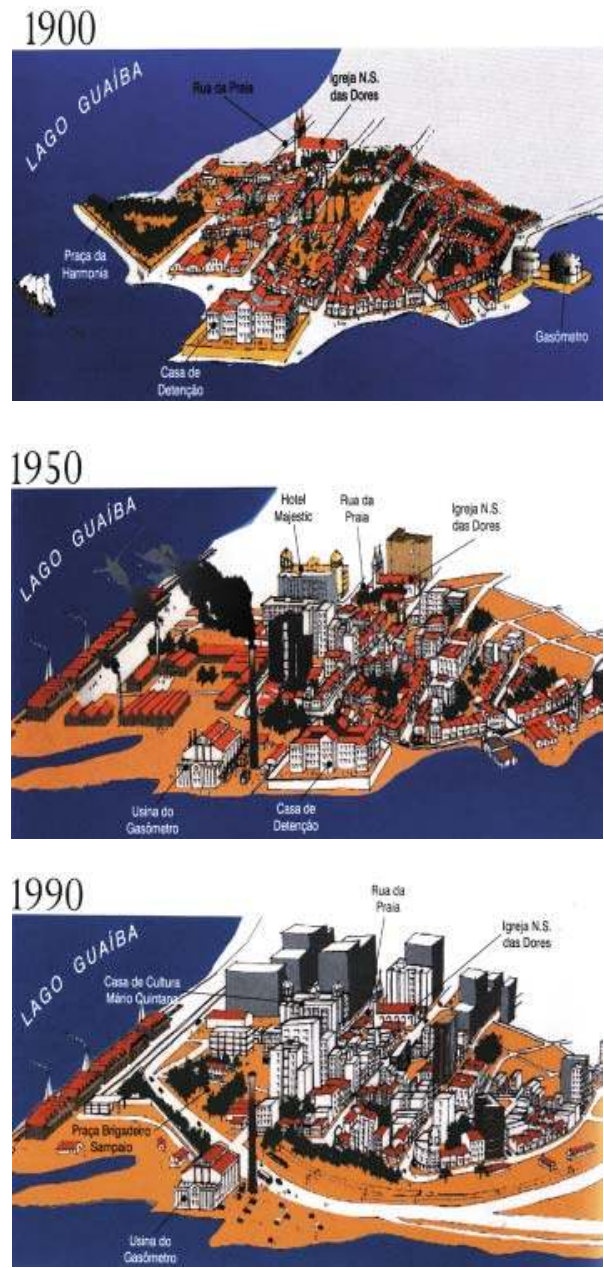

Fig. 13bis - L'area di Vila Iapi nel 1963 (foto di Guerreiro e Flores)

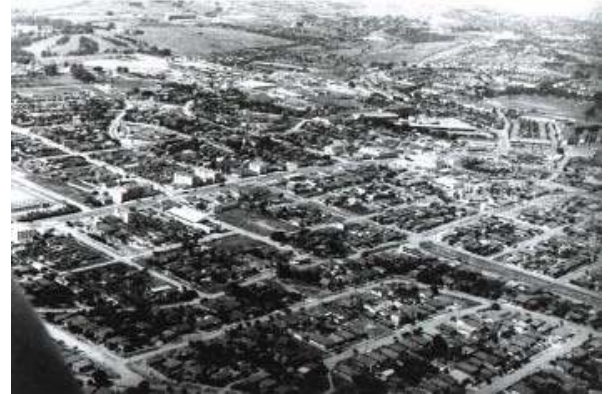




\section{5 \\ Porto Alegre prima del 1989: le politiche dell'alloggio e il patrimonio urbano informale}

\section{1 Due percorsi paralleli artificialmente 'disgiunti'}

La storia delle politiche urbane che hanno interessato Porto Alegre, anteriormente allo 'spartiacque' rappresentato dalle elezioni municipali dell'ottobre 1989, rappresenta nelle sue linee essenziali uno specchio fedele di quanto accadeva contemporaneamente nel resto del Brasile, pur con tutte le cautele che la particolare conformazione del territorio e le vicende politiche e sociali d'inizio secolo inducono a considerare.

Come si è visto, infatti, anche a Porto Alegre il processo di urbanizzazione verificatosi in parallelo a quello di industrializzazione prese forma in modo disordinato, senza che fossero create le pre-condizioni necessarie per accogliere in città l'enorme massa di persone che vi si andava concentrando, e che pertanto è stata spesso costretta a risolvere spontaneamente il problema dell'alloggio attraverso l'organizzazione di insediamenti informali. Inoltre, anche a Porto Alegre la politica della casa e quella urbanistica hanno sempre rappresentato due campi distinti con percorsi paralleli e indipendenti che finivano inevitabilmente per toccarsi, sovrapporsi ed entrare in conflitto. Il loro punto di contatto principale è stato proprio il tema della città informale; il progressivo riconoscimento del suo ampliarsi - divenuto inevitabile specie a partire dagli anni '50 - non poteva, infatti, ammettere che le azioni conseguenti permanessero come programmi isolati e puntuali, ma richiedeva un ripensamento globale della politica cittadina.

Eppure, fu solo verso la metà degli anni ' 70 che il Comune prese realmente in considerazione l'idea di armonizzare le strategie in materia di produzione degli alloggi e quelle di espansione e strutturazione urbanistica; e sembrò farlo - come dimostra il Plano Diretor del '79 - quasi solo perché forzata 'dall'alto', dalla trasformazione delle politiche internazionali e nazionali che si orientavano a leggere il tema della casa sempre meno secondo punti di vista funzionali o 'ideali', ma sulla base di stimoli pragmatici e 'di mercato', tesi a garantire una pax sociale che permettesse alle città un maggiore e più equilibrato sviluppo in termini di crescita economica, attraverso l'offerta ad ogni famiglia di un tetto (quale che fosse!), meglio ancora se autocostruito e quindi 
118 risultate per il potere pubblico in un alleggerimento dei propri impegni.

In Brasile, l'individuazione di 'modi' e 'cause' dei fenomeni di crescita della città informale è avvolta da una simmetrica incertezza: entrambi non sono, infatti, univoci né sempre facilmente documentabili (al massimo estrapolabili da direttrici socio-economiche più generali che possono essere identificate a monte) e, pertanto, le strategie per contrastare la crescita della città autoprodotta hanno sempre mantenuto margini di incertezza notevoli quanto ai risultati, senza contare che hanno dovuto sovente uscire dalle competenze dei singoli municipi. La diminuzione del livello di rendita della popolazione su tutto il territorio nazionale e le migrazioni dalla campagna conseguenti alla recessione e al disimpegno governativo nella politica agraria hanno aggravato negli ultimi decenni il problema della casa. Altre ragioni si aggiunsero durante il periodo militare: ad esempio, nuovi flussi dovuti ai tentativi di sfuggire ai controlli di polizia, più pressanti nelle campagne e più difficili in città. A Porto Alegre - secondo le ipotesi di Bonin (1993) - la crescita esponenziale dei residenti in 'aree di sub-abitazione' fra il 1951 ed il 1965 (parallela ad una generalizzata crescita della popolazione urbana nella città e nel paese) è certo attribuibile alle trasformazioni nel modello agricolo brasiliano; l'ipotesi viene meno tra gli anni ' 70 e gli anni ' $80^{1}$ quando fu piuttosto il calo delle opportunità lavorative e del potere di acquisto della moneta a forzare ad occupazioni irregolari famiglie prima in grado di pagare affitti o, addirittura, di fare piccoli investimenti immobiliari.

Tra il '70 e 1" 80 si riscontra, così, un aumento dal 6 al 9\% del tasso di crescita annua delle sub-abitazioni senza che si legga un parallelo aumento del tasso di crescita della popolazione cittadina; in questo periodo non appare leggibile neppure una correlazione fra il numero dei nuclei 'favelados' e la crescita della popolazione in questi residente, che subisce una significativa 'densificazione' fino al 1987, esaurendo in questo lasso di tempo le possibilità di addensamento e dando così avvio ad una nuova fase di 'invasioni' di terre. È proprio al 1988, tra l'altro, che risale una forte ondata di invasioni, questa volta di quartieri residenziali (cfr. box 3), propiziata da una congiuntura che, a livello nazionale, vide la chiusura della Banca Nazionale dell'Abitazione e, a livello locale, registrò la modifica del Plano Diretor che innescò - con l'aumento degli indici di fabbricabilità - una fase di rimodellamento del mercato immobiliare cittadino e dei fenomeni di segregazione urbana.

Questi fatti portano a ritenere che - a differenza di quanto generalmente sostenuto - la spiegazione del fenomeno della crescita della città informale non vada ridotto solo ad una questione di 'crescita della domanda', quanto piuttosto ad un intersecarsi di questa con una 'riduzione dell'offerta', o almeno con una variazione del target di questa, non più rispondente alla maggioranza delle richieste presentate dalla popolazione. Un attento studio delle trasformazioni delle politiche ufficiali dell'alloggio, della legislazione urbanistica e dei modi della sua applicazione è pertanto fondamentale almeno per 'intuire' le motivazioni di un fenomeno in crescita che - negli anni ' 90 - presentava già caratteri di consolidamento e radicamento nella dimensione dello spazio urbano di Porto Alegre, come di quasi tutte le maggiori città brasiliane.

Del resto, almeno fino al mutamento di orientamenti e politiche maturato negli anni '90, il tema della produzione di alloggi e quello della città informale sono a lungo rimasti compartimentati e separati, seppur uno - nella 
realtà - dipendeva strettamente dall'altro. Quando, nel 1975, l'amministrazione locale finì per intervenire sul secondo, lo fece non tanto per uno specifico interesse per le questioni dell'housing, ma per interessi che si legavano più ai temi della valorizzazione fondiaria e della modernizzazione produttiva. Quella che prese piede dal secondo dopoguerra fu, quindi, 'un'urbanistica capitalista' indissolubilmente legata 'ad un'urbanizzazione capitalista' (Ferretti, 1993) e connessa a politiche dell'uso dei suoli mirate all'elitarizzazione dei profitti e allo scarico dei costi sulla popolazione. Ciò ingenerò un'ondata nuova di espulsione dal centro della popolazione a minor reddito, attraverso meccanismi di mercato che - sostituendosi al ventennio degli sgomberi forzati imposti dal Comune, della magistratura o dei privati dettero avvio a nuovi cicli di segregazione urbana tendenti a favorire l'oligopolizzazione dello spazio cittadino e ad addensare i problemi ai margini del Comune in direzione dei centri vicini della 'grande Porto Alegre'.

Se, per alcuni periodi, questa spirale segregativa frutto di gentrificazione ed espulsioni bianche $e^{2}$ non si innescò, lo si deve anche ad un contemporaneo reindirizzarsi del mercato immobiliare verso segmenti della classe medioalta e alta, in particolare dopo l'estinzione del BNH nel 1986. Questo impedì naturalmente la gentrificazione di alcuni quartieri a basso reddito, portando l'area media delle unità abitative del periodo 1982/1989 da 90,3 mq a 185,21 $\mathrm{mq}{ }^{3}$ in parallelo, molti investimenti di rinnovo urbano furono dirottati su fondi di provenienza estera usati per programmi di infrastrutturazione. Questo non impedì il riprodursi - nella fisionomia urbana - delle due principali caratteristiche dell'economia brasiliana: concentrazione di reddito e miseria.

I paragrafi che seguono cercano di caratterizzare Porto Alegre sotto il profilo della politica settoriale della Casa e sotto quello della crescita progressiva del fenomeno degli insediamenti informali, fino all'avvento dell'Amministrazione Popolare, avvenuto nell'anno in cui nell'area Metropolitana cittadina la MRTROPLAN stimava in circa 128.000 le famiglie costrette a vivere in favelas, metà delle quali prima residenti a Porto Alegre e progressivamente espulse dalle politiche adottate nel tentativo di modernizzare la capitale del Rio Grande do Sul.

\section{Box 3 - 1987/88: le cattedrali nel deser to e l' 'invasione bianca'}

Il cosiddetto fenomeno dell'invasione bianca fu rappresentato da un'ondata massiva di occupazione di quartieri di edilizia economica popolare progettati - nell'ambito dell'ormai fallito Sistema Finanziario dell' Abitazione (SFH) - per abitanti con redditi bassi e medio-bassi, e rimasti incompleti, il più delle volte per fallimento dell'impresa costruttrice o per intercorse lungaggini burocratiche. L'inizio si ebbe nell'aprile 1987, nell' area metropolitana di Porto Alegre, e colpì principalmente aree di lottizzatori privati o 'promotori fondiari'. Fu, quindi, una risposta spontanea di gruppi di cittadini organizzati all'annoso problema del deficit degli alloggi, ma anche una dura protesta contro l'inazione del Potere Pubblico.

Nell'a prile 1988, le unità abitative invase erano circa 20.000, la maggior parte in proprietà pubbliche del DEMHAB di Porto Alegre o della COHAB Statale: circa $47 \%$ erano le unità occupate realizzate dall'iniziativa privata, tutte finanziate attraverso un programma di sovvenzioni chiamato PROÁREAS, responsabile in Brasile di una lunga serie di perversioni (Medvedovski, 1993).

Gran parte dei quartieri occupati si trovava in aree individuate nella zonizzazione urbana come produttive fino agli anni ' 70 , o a copertura vegetale, e - per il frequente fallimento delle imprese costruttrici o degli agenti finanziari coinvolti - erano 
catalogate nell'inventario delle opere fallite. Questi 'tessuti artificiali' occupati (Krafta, 1993) avevano contribuito ad un notevole degrado dell'ambiente dell'area metropolitana portoalegrense, in particolare negli interventi maggiori come i 530 ettari del quartiere Umbú - nel comune di Alvorada - o i 478 ha. di quello Algarve, di cui a lavori interrotti solo meno del $10 \%$ delle unità abitative erano state regolarmente assegnate entro i due anni e mezzo di solito previsti per il completamento delle operazioni. Secondo dati diffusi dal giornale Zero Hora, il 23 aprile dell' ' 87 nella RMPA si trovavano non occupate oltre 14.500 unità abitative, 3000 delle quali a Porto Alegre, 300 a Cachoeirinha e oltre 5000 ad Alvorada. Nel settembre dello stesso anno (ibidem) 10.000 di queste - quelle in condizioni migliori - erano già state occupate, anche approfittando dell' eliminazione dei servizi di vigilanza armata dopo il passaggio delle consegne nella gestione dei fallimenti alla Cassa Economica Federale (CEF) che subentrò nel ruolo della Banca Nazionale dell'Abitazione. Molti dei quartieri erano stati ideati per una fascia di reddito tra i 4,5 e i 5,5 salari minimi, ma i dati rilevati sulla composizione della popolazione che partecipò delle 'invasioni bianche' rivelano che la rendita media si situava per lo più al di sotto dei 3 salari minimi, anche se solo l'1,9\% risultava disoccupato mentre 1 ' $80 \%$ erano impiegati nel settore terziario, e il 55\% degli invasori erano usi ad affittare immobili per residenza. In sostanza, ad invadere non fu una popolazione 'marginale', "ma una porzione significativa della popolazione che si vide tagliata fuori dal mercato delle terre e degli alloggi per la semplice impossibilità di portare a termine il ciclo di realizzazione di quella merce” (Medvedovski, 1993).

All' '89 risalgono i primi accordi fra lo Stato, i Comuni e gli occupanti per regolarizzare la posizione di questi ultimi: il 22 di maggio 1989 fu firmato quello fra gli abitanti irregolari delle 6000 unità del quartiere 'Guajuviras' a Canoas, e in agosto la COHAB cominciò a vendere le 2040 unità del primo quartiere invaso, ribattezzato ' 11 di aprile' in onore della data dell'occupazione. Più difficili furono le procedure di regolarizzazione dei quartieri promossi dall'iniziativa privata: degli 11 casi selezionati dalla METROPLAN ai fini di un rilievo delle condizioni socioeconomiche (tra quelli già conclusi e adatti all'immediata commercializzazione), solo uno - il 'Leopoldina II' - riuscì prima del 1991 ad avviarsi verso la negoziazione. Il problema risiedeva essenzialmente in due fattori:

1) una discrepanza fra le stime di valore del patrimonio fatte da METROPLAN e CEF.

2) la reale disponibilità economica delle famiglie occupanti, più alta solo per le famiglie dei quartieri occupati della capitale $(67,4 \%$ sopra i 4 Salari Minimi contro $14,9 \%$ ad Alvorada, e $10 \%$ a Cachoeirinha).

Ad oggi solo per alcuni di questi quartieri il contratto di regolarizzazione risulta stipulato; per gli altri non vi è certezza legale che saranno realmente le famiglie occupanti le assegnatarie degli appartamenti. Nel quartiere portoalegrense di Rubem Berta - di proprietà della COHAB - solo dopo 10 anni di un processo partecipativo di regolarizzazione urbanistica e fondiaria solo da un anno si è iniziata la cessione degli immobili ai loro attuali occupanti, la gran parte dei quali non sono più quelli dell'invasione del 1987.

Numero di unità abitative occupate nell'invasione bianca del 1987 , per agente realizzatore

\begin{tabular}{|l|r|}
\hline \multicolumn{1}{|c|}{ Promotore della costruzione } & Numero di unità abitative invase \\
\hline COHAB & 8.935 \\
\hline DEMHAB & 109 \\
\hline INDCOOP & 1.408 \\
\hline Imprese Private (finanziamento & 8.982 \\
PROÁREAS) & $\mathbf{1 9 . 4 4 4}$ \\
\hline Totale &
\end{tabular}

Fonte: METROPLAN, riportata su Zero Hora, 23/4/1987 


\subsection{Le Politiche della casa a Porto Alegre nella prima metà del secolo}

L'ascesa al potere del Partito Repubblicano Riograndense (PRR) a Porto Alegre nel 1897, e il lungo periodo di continuità politico-amministrativa che la città conobbe fino al 1937, evidenziarono l'ambiguità del progetto positivista di 'integrazione del proletariato alla società' elaborato dopo le proteste organizzate in tutto il Paese dai ceti operai dal 1891, chiedendo la riduzione degli affitti e stimolando il Senato Federale a discutere un progetto di legge sull'esenzione dalle imposte patrimoniali per le case umili per lavoratori (Bakos, 1988). Nei primi 10 anni di Governo del PRR, quasi nessuna misura reale fu presa per fronteggiare i problemi di alloggio per le famiglie con redditi bassi. Nel 1911, il clamore suscitato dall'articolo 'La situazione del povero a Porto Alegre' (Echo do Povo, 19/8/1911) misurò l'appoggio ormai dato da vasti settori della media borghesia alla richiesta di integrazione del proletariato nella società moderna (Menegat, 1995); del resto, la risoluzione dei problemi igienici delle abitazioni avrebbe avvantaggiato anche la borghesia stessa, migliorando l'immagine complessiva della città. Così, nel 1912, il Consiglio Comunale autorizzò la Giunta a contrarre un prestito per un esperimento-pilota di case operaie, che testasse i costi di nuovi modelli abitativi economici in vista di un'eventuale diffusione su più larga scala grazie a facilitazioni fiscali (tra cui il 50\% di abbattimento sulle imposte edilizie) per le imprese che ne avessero realizzato per i propri operai. L'offerta dei benefici a chi costruisse case operaie da affittare rispettando particolari valori locativi massimi previsti fu reiterata annualmente fino al 1923 (Bakos, 1988) ma non produsse i risultati immaginati. Così, venduto nel 1914 l'inutilizzato terreno del Campo da Redenção per acquistarne altri minori nei quartieri Navegantes, São João e Cristovão Colombo, già nel 1917 e poi nel 1925 il Sindaco di Porto Alegre dette il via ad un autonomo programma pubblico che riempisse il vuoto di iniziativa privata nel settore degli alloggi a basso costo. Il processo innescato ebbe forte impatto politico per tutti i decenni successivi, mirando ad una pax sociale che garantisse la modernizzazione più rapida $\mathrm{e}$ indolore per la città (Bakos, 1986; Pesavento, 1987).

Dal 1918, gli organi ufficiali della categoria professionale degli ingegneri intervennero nel dibattito, reclamando dalle istituzioni misure coercitive contro la costruzione di abitazioni insalubri (previa una riforma del Codice Edilizio del 1903) e nuovi incentivi economici per gli imprenditori che investissero nel campo delle abitazioni popolari, di cui proponevano alcuni modelli-tipo, sintetizzando 'un certo immaginario su cosa dovesse essere considerato socialmente un allog gio popolare igienico e confortevole' (Menegat, 1995). La richiesta non ottenne dal Comune concessioni maggiori di quelle già previste dal 1914. Intanto, però, si iniziava a discutere la possibilità che fosse lo Stato ad occuparsi di alloggi popolari (Garayp, 1980), ipotesi che andrà in porto solo nel 1946 con la Fondazione Nazionale della Casa popolare (FCP).

Nel 1925, il Sindaco di Porto Alegre ottenne di poter dispensare per 5 anni dalle Imposte Patrimoniali 'gruppi di 5 o più abitazioni in muratura o equivalente [...] il cui affitto non eccedesse i 200.000 reis mensili, tasse incluse'. ${ }^{4}$ Più successo ebbe la Legge 325/1936 che - precedendo di 1 anno la Legge Federale per la promozione dei Parchi Proletari - concedeva anche riduzioni delle imposte sui beni immobili a chi aprisse ristoranti del tipo 'cafeteria' nei quartieri proletari (non meglio definiti), per contribuire alla loro vitalità e arricchirli di servizi. 
Alla fine, le poche misure effettivamente adottate non andarono oltre singoli programmi o progetti-pilota isolati e senza seguito, senza tradursi in politiche di portata più ampia o di particolare impegno per l'Amministrazione; restarono nell'ambito di una risposta solo indiretta a pressioni indirette manifestatesi circa questioni di previdenza e assistenza (Pereira, 1980).

Solo alla fine del periodo di Governo del PRR, il tema della casa operaia cominciò a far breccia, a partire dalla costruzione della Vila Operaria das Industrias Renner, uno dei primi esempi nello Stato di realizzazione ad opera di privati, ed uno dei più interessanti progetti realizzati a Porto Alegre dall'Istituto di Previdenza e Assistenza (IAPI) ${ }^{5}$ per i propri dipendenti, e affidato all'ing. Marcos Kruter. Ribattezzato Vila IAPI, esso era un quartiere con 1691 unità abitative (case unifamiliari, blocchi di 4 piani e case gemelle, molte delle quali ampliabili e nel tempo ampliate) su un'area di 66 ha dalla topografia accidentata. Cominciato nell' aprile del ' 42 nell'area est di Porto Alegre - presso il nuovo asse di sviluppo Assis Brasil dove si stavano riubicando le industrie dopo la piena distruttrice del 1941 nell'area 'dos Navegantes' - costituì un caso quasi unico di 'città giardino' realizzata a favore di classi popolari. Dopo la visita di Berry Parker in Brasile negli anni '30 e la realizzazione a São Paulo del quartiere Jardim America si erano, infatti, moltiplicate in tutto il Paese le realizzazioni di bairros jardim, ${ }^{6}$ ma tutti destinati ad un target borghese in aree dove erano evidenti gli interessi e le iniziative del capitale, come accadde per Vila Assunção e Vila Conceição nella zona Sud di Porto Alegre. A Vila IAPI, invece, sia l'alta qualità delle costruzioni, dell'ambiente e del paesaggio, sia la presenza di gerarchie di percorsi organici strutturati e di numerose attrezzature pubbliche, furono promosse attraverso un sistema cooperativo (Souza, 1994) a vantaggio di famiglie della classe lavoratrice.

La costruzione di quest'opera segna un momento importante; quello in cui le specificità assunte dal movimento politico laburista rivelarono la crescente insostenibilità del progetto di egemonia dell'emergente borghesia industriale sviluppato "a partire dalla fabbrica" (Pereira, 1980), rendendo necessario per lo Stato incorporare le politiche sociali rivolte ai lavori salariati della città. La costruzione di Vila IAPI terminò nel 1954, proprio mentre veniva presa una delle poche altre iniziative politiche mirate a risolvere il problema dell'alloggio in ambito comunale, con la Legge 1233/54 che disciplinava più rigorosamente la pratica del parcellamento e della commercializzazione dei suoli urbani (Menegat, 1995). L'unico risultato reale fu, però, opposto a quello dichiarato: si ebbe un'impennata nella crescita del numero dei lotti irregolarmente o clandestinamente edificati, perché la richiesta di servizi alle imprese lottizzatrici alzò il prezzo della terra, allontanando le famiglie a basso reddito dalla possibilità di accedere regolarmente ai suoli urbani (Debiagi, 1978). Così, mentre il rinnovato IAP (ex-IAPI) realizzava altre unità abitative in città per un totale di 3500 fino al 1964 -, l'assenza di rigore nel controllo del rispetto della Legge e la mancanza di scrupoli di molti lottizzatori innescò i primi massivi processi di commercializzazione di lotti irregolari a prezzi più accessibili di quelli offerti sul mercato ufficiale, dando incremento ad un fenomeno che venne a porsi accanto a quello delle invasioni di terre che da anni ormai ${ }^{8}$ rappresentavano l'unica soluzione abitativa per le categorie di reddito che non si potevano permettere di accedere a nessuno dei finanziamenti previsti dal PRR né all'affitto delle poche dimore operaie realizzate. 
Nel 1952 fu creata una nuova 'autarchia' [organo semi-indipendente del Comune] legata all'Esecutivo Municipale, e denominata DMCP - Dipartimento Municipale per l'Alloggio Popolare. ${ }^{9}$ Incaricato di tutte le operazioni finanziarie, amministrative e patrimoniali legate alle politiche del settore, era in parte sovvenzionato dalla Fondazione Statale della Casa Popolare (FCP) $\mathrm{e}$, in parte, da una tassa comunale ad hoc del $3 \%$ sui nuovi edifici in costruzione con area eccedente i $150 \mathrm{mq}$. Ristrutturato in seguito alla creazione del SFH nel 1964, l'anno dopo il DMCP assumerà il nome che ancora porta di DEMHAB-Dipartimento Municipale per l'Abitazione; e dal 1969 costituirà l'agente promotore del $\mathrm{BNH}$ a livello comunale.

Il mutamento non patente di struttura del 1965 consistette soprattutto nella trasformazione della composizione del consiglio di Amministrazione dell'Organismo, a partire dall'eliminazione del rappresentante delle Associazioni Comunitarie e dalla trasformazione del modo con cui veniva scelto il rappresentante dei Sindacati, non più liberamente eletto dalla propria base ma nominato dal potere pubblico (Fruet, 1991). Inoltre, nel 1965, il DEMHAB si trasformò da agenzia multi-servizio in un'istituzione specializzata di supporto tecnico, chiudendo le attività relazionate all'assistenza sanitaria e sociale che aveva portato avanti in passato. Si trasformò, quindi, in un braccio acritico della politica settoriale dell'housing decisa a livello nazionale.

Dal 1965, il Comune creò - con Legge 2903 - il Fondo Municipale dell'Abitazione $(\mathrm{FMH})$ che, per fornire risorse alternative per le politiche del DEMHAB, attingeva soprattutto al 35\% degli introiti della Tassa di Assistenza Sociale: la Giunta mantenne per sé il ruolo di selezionare il personale dell'Ente. In questo periodo la proporzione delle risorse del DEMHAB legate a fondi del SFH crebbe al 50\%, raggiungendo quasi il 90\% nel 1990 (Fruet, 1991); questa incapacità della Municipalità di generare autonomamente risorse per finanziare le politiche abitative si dimostrerà un problema enorme a partire dall'estinzione del $\mathrm{BNH}, \mathrm{e}$ almeno fino alla Riforma Tributaria promossa dal Fronte Popolare nel 1990.

Le realizzazioni del DMCP a favore della popolazione di reddito minore si rivelarono da subito più d'improvvisazione che di pianificazione (Garayp, 1980), più attente all'espansione quantitativa che ai livelli qualitativi, e troppo concentrate sul recupero delle risorse finanziarie investite. Nel breve periodo della sua vita, il DMCP realizzò 2020 unità di abitazione per 31.826 abitanti (Pereira, 1980) delle 2,440 finanziate, e 5,190 lotti (Fruet, 1991).

Come DEMHAB, nei primi 15 anni di vita furono approvati prestiti per realizzare 6047 abitazioni $^{10}$ e 2250 lotti urbanizzati 'Sites-and-Services', finanziati dal programma PROFILURB, ${ }^{11}$ che prevedeva un impegno massimo per le famiglie beneficiarie del $9 \%$ del salario minimo mensile e finanziamenti da 300 mesi al tasso di interesse dell' $1 \%$ annuo. Tra il 1969 e il 1975 - per riallocare parte delle oltre 36.000 persone rimosse dal centro cittadino - fu messa in opera l'acquisizione di 142 ettari nella regione Sud di Porto Alegre, evento che creò forti tensioni fra il DEMHAB e l'Assessorato all'Urbanistica (SPM), quest'ultimo critico sui costi che l'urbanizzazione di un'area così lontana avrebbe comportato per il Comune. Dopo il 1975, le direttrici di azione del DEMHAB subirono alcune modifiche, orientandosi - sulla base delle parallele trasformazioni a livello nazionale - verso la seguente politica dei suoli: 
124 1) comprare terre occupate con rischi di insanabili conflitti tra popolazione e proprietari;

2) comprare terreni adiacenti ad aree attualmente invase per riallocare parte delle famiglie durante eventuali interventi di recupero urbano. Questa direttrice si rivelò difficile per gli interessi speculativi di molti proprietari che intuivano le potenzialità di valorizzazione fondiaria che le regolarizzazioni urbanistiche portavano negli immediati dintorni.

Dal 1975 prese inoltre avvio in città - coordinato dall'Assessorato all'Urbanistica - il Progetto CURA (Comunità Urbana per il Recupero Accelerato), nell'ambito di un programma creato dal BNH nel 1972: i quartieri 'beneficiati' ${ }^{12}$ lambivano una popolazione di 57.000 unità (il 6\% della cittadinanza di Porto Alegre). A livello comunale, proprio nel 1975 fu creato anche il programma PRO-GENTE voluto dal Sindaco Villela per urbanizzare alcune aree irregolari, approfittando dell'apertura del $\mathrm{BNH}$ alla prassi del finanziamento alla regolarizzazione fondiaria suggerita dalla Banca Mondiale attraverso una nota informativa del 1974 (Banco Mundial, 1978). Appena 16 furono - fino al 1979 - le favelas di Porto Alegre che beneficiarono del programma, in particolar modo il nucleo della Restinga Nova creato a 20 $\mathrm{km}$ dalla città per ospitare le famiglie sgomberate da molte aree occupate del centro, passibili di notevole valorizzazione fondiaria.

Dal 1979 si inserirono nei programmi del DEMHAB - fino ad allora impegnato nella realizzazione di lotti urbanizzati, case, appartamenti, opere di infrastrutturazione e costruzione di attrezzature urbane (per cui esisteva un'apposita Divisione al suo interno) - le realizzazioni legate al nuovo programma del BNH: il PROMORAR o Programma di Sradicamento della Sub-abitazio$n e$, che proponeva interventi di reinsediamento in loco dei favelados già pionieristicamente sperimentati proprio dal DEMHAB di Porto Alegre a Vila Santa Rosa nel 1975. Oltre ad alloggi popolari, tra il '51 e il '72 il DMCP/ DEMHAB si occupò anche di 13.000 rimozioni di famiglie residenti in suoli occupati, poi sistemate in aree di sua proprietà (DEMHAB, 1973).

Nel loro complesso, questi numeri sono molto inferiori a quelli presentati dal DEMHAB stesso, il cui direttore (in un'intervista del 15/9/78 al giornale Zero Hora) affermava che l'ente possedeva 'più mutuatari fuori dal sistema del BNH che al suo interno'. Il numero fornito dall'Ente nel 1979 era, infatti, di 17745 unità abitative in fase di sviluppo, con sovrastima certamente di tipo propagandistico. In realtà, infatti, appena 2783 unità erano in costruzione, oltre a 770 lotti urbanizzati e a 1834 appartamenti da realizzare insieme all'INOCOOP tra Vila Nova e il Parque Santa Luzia, destinati però a famiglie dai redditi superiori ai 6 salari minimi per le quali era previsto in teoria il ricorso a sistemi cooperativi e non sovvenzionati (Garayp, 1980). Quest'ultimo accordo, in un certo senso, rifletteva un percorso del DEMHAB simile a quello compiuto dalla COHAB statale all'interno del SFH. $\mathrm{Fu}$ anche grazie a queste nuove politiche suggerite dal BNH e alla grossa disponibilità di risorse finanziarie del periodo di 'boom' del Sistema Finanziario dell'Abitazione (1977/83), che - solo dal 1975 al 1985 - il DEMHAB acquisì 702.6 ha, oltre 35 in più che nei precedenti 22 anni di vita (Fruet, 1991). ${ }^{13}$

$\mathrm{Se}$, ad una prima occhiata, può sembrare che Porto Alegre avesse elaborato, soprattutto durante il periodo del regime militare, dei buoni indirizzi di politica dell'alloggio, va rimarcato che queste politiche - per come furono condotte - rivelarono notevoli limiti visto che: 
1) l'aumento del valore dei suoli conseguente all'infrastrutturazione delle prime 'vilas' regolarizzande favorì le 'espulsioni bianche' di chi non era in grado di sobbarcarsi gli oneri crescenti della costruzione e del mantenimento della casa. 2) lo standard dimensionale dei lotti costrinse ad espellere molte famiglie in ogni intervento.

3) la scelta delle aree su cui intervenire (17 appena su 92 censite in quasi 30 anni) corrispose ad una selezione spesso 'di comodo': priva di criteri oggettivi per l'individuazione dei beneficiari e non ispirata ad una distribuzione spaziale delle azioni su tutta la città (anche a livello numerico è intuitiva la grande sproporzione tra il problema abitativo e le soluzioni individuate).

Una delle critiche più forti mosse al DEMHAB dalla stampa locale e dal Consiglio Comunale in questi anni, fu proprio quella alle politiche di 'favoritismo con fini elettorali' nella distribuzione delle case (Zero Hora, 6/10/78), che in teoria il Comune si era proposto di eliminare nel 1964 riformando l'Ente. Infine, molti degli espropri cosiddetti 'di pubblica utilità' non si rivelarono altro che mascheramenti di massive rimozioni a fini di valorizzazione speculativa. ${ }^{14}$

\subsection{L'ambito statale e i limiti delle politiche della casa}

Anche nel Rio Grande do Sul, il tema dell'abitazione popolare ha avuto un ruolo centrale nella manipolazione politica (Garayp, 1980) e ha svolto - attraverso l'organizzazione del consenso - un forte ruolo nel progetto di egemonia della borghesia urbano-industriale teso a favorire l'accumulazione privata del capitale facendo ricaderne i costi sui lavoratori (Pereira, 1980). Anche nello Stato, durante il periodo populista le politiche dell'alloggio popolare furono portate avanti come funzioni 'distributiviste' del Governo nel settore del benessere sociale, e non tentarono mai di recuperare i capitali investiti nei prestiti immobiliari mangiati dall'inflazione, trasformando " $i$ prestiti per la costruzione della casa propria [...] in vere donazioni”, per di più a beneficio di strati della popolazione ben più benestanti del target per cui erano in teoria previste, e che le ricevano come un privilegio (ibidem). ${ }^{15}$ Alcuni interventi suonarono addirittura come una beffa per il cittadino, così come la creazione e la chiusura continua di Assessorati, Sovrintendenze e Commissioni (come quella per la Terra e l'Abitazione nata dopo l'inondazione di Alegrete del '59 ed estinta due anni dopo), in particolare tra il 1960 ed il 1964, quando si tentò di realizzare un Piano di Emergenza dello Stato del Rio Grande do Sul finanziato dal BID $^{16}$ e che escludeva il Comune di Porto Alegre, poco considerato in virtù della presenza del DEMHAB che gli garantiva già almeno un attivismo 'teorico' nel settore dell'alloggio.

Nel primo periodo della dittatura i cambiamenti furono significativi nella struttura ma non nei risultati. Uno dei primi atti del regime salito al potere nel 1964 fu di eliminare le istituzioni intermedie che non favorivano il processo di concentrazione e centralizzazione, escludendo quelle che cercavano una relazione diretta con gli operai e i lavoratori salariati e potessero svolgere discorsi e pratiche alternative rispetto alle proposte egemoniche del Piano di abitazione Nazionale (Pereira, 1980). Le prime 'Cooperative di Abitazione' (Legge 4380) - appoggiate all'istituto di consulenza e orientamento INOCOOP - stranamente risalgono a questo periodo: anch'esse furono frutto del tentativo centralizzatore di ridurre $i$ sindacati ad organi assistenziali, stornandoli dall'attività principale in 
difesa degli interessi di classe (id.). ${ }^{17}$ Con l'avvento della dittatura e la creazione del BNH, apparentemente si tentò anche di abbassare il livello economico del target scelto per i programmi abitativi statali a finanziamento federale, e nel contempo di trovare fonti nuove di finanziamento che ponessero fine all'inevitabile discontinuità del ritmo di produzione degli alloggi. Ma la maggior parte dei piani non passò lo stadio delle intenzioni (Garayp, 1980), anche se l'indice di inadempienza nel settore degli alloggi popolari calò leggermente dopo il 1975 con la scelta delle $\mathrm{COHAB}$ - il principale agente finanziario del $\mathrm{BNH}$ sul territorio statale ${ }^{18}$ di privilegiare le famiglie con rendita media fra i 3 e i 5 salari minimi e la nascita dei programmi 'risparmiatori' per le fasce ancora più povere (PROMORAR, PROFILURB), che - pur aumentando di intensità in termini assoluti - mantennero una posizione secondaria in termini relativi di investimento (ibidem).

Nel complesso, il cambiamento delle linee di credito del BNH nel 1970 provocò una perdita di dinamismo delle $\mathrm{COHAB}$ oltre che una celere riduzione della qualità delle loro realizzazioni. ${ }^{19}$ Nel Rio Grande do Sul si passò dalle 173.324 unità abitative finanziate tra il 1964 ed il 1969, alle sole 65.633 approvate tra il 1970 ed il $1974^{20}$ e alle 13.074 commercializzate nel 1979, a causa dello slittamento di interesse del BNH per le politiche di sviluppo infrastrutturale urbano, e la sua trasformazione in una 'banca di seconda linea' (Maricato, 1987). Il periodo di declino della COHAB (1975-80) coincise con quello di massimo splendore del DEMHAB; dal 1980 i due organismi seguirono, invece, cicli simili, fino al comune declino dopo il 1985, con l'estinzione del SFH che li sorreggeva (Fruet, 1991).

Nel complesso, la collaborazione tra Stato e Comune è rimasta sempre molto ridotta. A Porto Alegre, si sono avute semmai realizzazioni dovute all'unione di forze dello Stato e della Federazione Nazionale: le prime risalgono al 1942, quando fu promosso dall'ormai ex-IAPI lo studio di massima per realizzare il quartiere Passo da Areia, la cui prima pietra fu collocata il 6 aprile del 1946 (Pereira, 1980). Attraverso il sistema delle Cooperative, invece, l'INOCOOP di Porto Alegre realizzò 12742 unità di abitazione in 17 nuclei residenziali in cui operarono 78 Cooperative diverse ${ }^{21}$ il $66,8 \%$ di queste fu destinato ad alloggi di 'interesse sociale'. Tra lotti e case, fino al tramonto del regime dittatoriale, la $\mathrm{COHAB} / \mathrm{RS}$ aveva previsto la realizzazione di circa 6500 unità d'abitazione e 5000 lotti urbanizzati nella capitale dello Stato; non si sa però esattamente quanti ne abbia veramente realizzati e distribuiti. Con la crisi economica cominciata nel 1983, la posizione della COHAB/RS divenne difficile a causa della bancarotta di una grossa Banca a cui era legata ed il fallimento di molte imprese che stavano lavorando per lei.

Nel 1987 vi erano oltre 3000 unità abitative incomplete nella sola Porto Alegre, che arrivavano a 11.500 nell' area Metropolitana sommandosi alle 2000 bloccate dell'impresa privata. Quasi tutte (cfr. box 3) furono occupate durante quell' anno da un' ondata organizzata di 'invasioni' dimostrative, che toccarono anche quartieri residenziali del DEMHAB, subito venduti agli occupanti e completati. Famiglie con redditi bassi tentavano in tal modo di dare un forte segnale politico (Ghezzi e al., 1987) e di risolvere autonomamente i problemi dell'alloggio a cui le istituzioni non riuscivano a dare risposta, per giunta continuando ad agire con criteri privi di qualsiasi attenzione alle peculiarità territoriali, sia nella strutturazione dei programmi che nella realizzazione dei singoli progetti. Questi, per lo più, contemplarono cattedrali nel 
deserto, nuclei residenziali introversi che venivano ad inserirsi nella città come nuovi 'tessuti artificiali' (Krafta, 1993); senza neppure quelle qualità estetiche delle realizzazioni operaie del primo dopoguerra. In tal senso, 'l'invarianza' sostanziale delle realizzazioni sia della COHAB/RS che del DEMHAB di Porto Alegre negli anni intercorsi tra la loro creazione e il 1989 costituisce un'ulteriore elemento di quella "continuità dei progetti attraverso le amministrazioni, a dispetto del cambiamento dei partiti politici al pote$r e$ " che Fruet (1991) ha principalmente attribuito "all'intreccio del particolare processo costruttivo [lentezza, burocratizzazione, frammentazione in fasi, ecc.] e del processo di finanziamento".

Quest'ultimo elemento si dimostrò determinante soprattutto dopo la chiusura del $\mathrm{BNH}$, quando sia la $\mathrm{COHAB}$ che il DEMHAB persero in poco tempo qualsiasi capacità di finanziamento dei propri programmi, entrando in una sorta di 'limbo' ed incapaci di agire. A Porto Alegre, la situazione non fu molto diversa dalle altre città del Paese. Tra il 1986 e il 1988 il DEMHAB acquisì appena 20 ettari di terra, spesso senza neppure consultare le Divisioni Tecniche e Giuridiche dell'ente, e addirittura senza lasciare chiare tracce degli acquisti sui documenti ufficiali (Fruet, 1991). La produzione di abitazioni calò, invece, dalle 1.924 del 1985 alle 96 del 1986, con una minima ripresa nel 1987 (150 unità abitative).

\subsection{Primi studi e valutazioni sul patrimonio abitativo informale}

Dal secondo dopoguerra al 1989, le risposte date dall'Amministrazione Comunale di Porto Alegre al crescere del numero degli insediamenti per qualche ragione 'irregolari' sul suo territorio sono passate dalla più completa avversione all'accettazione, fino a raggiungere uno stadio di concreto supporto al loro consolidamento, pur - ovviamente - avversando la loro crescita e proliferazione. Sono stati, pertanto, percorsi tutti i gradini che Geoffrey Payne - con riferimento all'ambito dell'intera comunità internazionale - ha sintetizzato con efficacia nel suo testo Informal Housing and Land Subdivisions in Third World Cities: A Review of the Literature (1989), anche se l'approccio settoriale e compartimentato alle politiche dell'alloggio resta una caratteristica che sembra aver pesato - sia sotto il profilo cognitivo che attuativo - un po' su tutta l'azione promossa dal Comune di Porto Alegre per intervenire sul terreno della città informale.

Soprattutto, troppo a lungo la preoccupazione dell'Amministrazione è rimasta ristretta alla soluzione nell'immediato del problema della precarietà abitativa - aspetto più visibile della questione - senza valutazioni a lunga scadenza. Ciò ha impedito a lungo agli amministratori di rendersi conto che "la favela non è un problema, ma una 'soluzione' alla necessità di un riparo, e che la sub-abitazione è appena un indicatore di una situazione più complessa caratterizzata da disoccupazione e sub-impiego" (Oliven, citato in Garayp, 1980), che va quindi affrontata 'a monte', e non limitandosi ad operare su alcuni dei suoi 'effetti', per di più in una prospettiva settoriale.

Questo atteggiamento ha, per certi versi, retroagito sulla stessa conoscenza dei fenomeni legati alla città spontanea, al punto che - pur essendo stati rilevati fin dall'inizio del secolo gravi fenomeni di irregolarità urbana - fu solo in coincidenza con i primi concreti interventi nel settore che ci si decise a studiarli. È, infatti, solo negli anni in cui a livello nazionale già apparivano le 
128 prime proposte di soluzione del problema abitativo attraverso 'donazioni della terra ai favelados' (Garayp, 1980), che risalgono i primi studi esistenti a Porto Alegre sul tema degli insediamenti in aree occupate, cioè gli atti della Commissione della Casa Popolare creata nel 1946 e coordinata dall'industrialefilantropo Renner:22 il Rilievo Economico-Sociale delle Malocas Esistenti a Porto Alegre redatto da una Commissione Speciale designata dal Sindaco (1951), e l'inchiesta Vilas de Malocas realizzata dal sociologo Laurelino Medeiros nello stesso anno, in collaborazione con la Facoltà di Economia. ${ }^{23}$

Il fenomeno della sub-abitazione era senza dubbio molto più vecchio, come dimostra il livello di consolidamento del problema evidenziato sia dalla Commissione del 1946 che da Medeiros, che sottolineò come - pur solendosi convenzionalmente stabilirne al 1945 la data di inizio (Garayp, 1980) ${ }^{24}-d a$ "sempre sono esistite centinaia di baracche e anche loro raggruppamenti", seppur dal 1946-47 il fatto "presentò una nota rivoluzionaria in relazione ai costumi e alle leggi vigenti, ovvero la costruzione in massa in luoghi determinati - terreni vuoti, margini stradali, spazi pubblici - presentò un ritmo accelerato, al punto che apparivano dalla notte al dì vere cittadine, che gli stessi abitanti chiamavano "vilas de malocas" " (Medeiros, 1951). ${ }^{25}$

Un censimento ufficiale, realizzato dall'Assessorato all'Educazione e Cultura con l'aiuto di assistenti sociali dell'Università Cattolica (aspetto che ebbe notevole influenza sull'impostazione del lavoro) fu realizzato in 5 mesi tra il $23 / 7$ e i primi di dicembre de1 1950, e divulgato solo nel 1951. Le conclusioni insistevano sulla necessità di mettere alla portata delle famiglie l'acquisizione del terreno e offrire orientamento alla realizzazione degli alloggi (senza necessità che di questi si occupasse direttamente il Comune), sostenendo che:

[...] Di fatto, la grande maggioranza degli abitanti non sono proprio miserabili, visto che una g ran parte si trova in una situazione economica che gli permetterebbe di spendere cifre ragionevoli per le loro abitazioni. Però, in nessun caso, il g ruppo di famiglie che ha risposto all'inchiesta sarebbe in condizioni di acquisire un terreno, perché, come è risaputo, attualmente i terreni sono supervalorizzati (Secretaria de Educação e Cultura, 1951).

L'idea base che emerge dal testo è che "lo sterminio" delle 'favelas' non è da attuare necessariamente con mezzi violenti, ma ampliando "il piano degli espropri che sta già venendo portato avanti, in modo da ottenere, senza ritardi, grandi aree di terra, in locali appropriati, per l'abitazione popola$r e$ ". Vale a dire - come commenta oggi un testo del DEMHAB (1999) - aree "in regioni periferiche, distanti dal centro, carenti di infrastruttura".

Quello di Medeiros resta, forse, il più interessante e sottovalutato tra i primi documenti esistenti sul tema: pur non essendo rappresentativo dell'atteggiamento 'ufficiale' del potere pubblico di Porto Alegre nei confronti del problema delle favelas (o forse proprio per questo) esso è, infatti, una testimonianza importante di atteggiamenti e pregiudizi diffusi nella società locale nei confronti del tema, ed insieme costituisce il primo tentativo di superarli attraverso la predisposizione ${ }^{26}$ di una metodologia di indagine il più possibile scientifica e di una costante osservazione diretta e ravvicinata. Proprio questo, rappresenta il pregio maggiore della relazione, a tratti viziata da connotazioni e pregiudizi moralisti, ma pronta a sottolineare che le favelas sono (al contrario di quanto si diceva) abitate " $d a$ cittadini ordinari, quasi sempre lavoratori, seppur molte volte con lavoro irrego- 
lare" ${ }^{27}$ Medeiros ha prodotto un palpitante racconto di quotidianità (organizzato in maniera sistematica), a tratti stupito per le inedite scoperte in quanto 'persona' e 'ricercatore', a tratti scientificamente gongolante per le consonanze mostrate dai dati raccolti con quelli di contesti da anni attivi nello studiare il tema della povertà urbana, come anche per le peculiarità di ambito locale riscontrate. Da un punto di vista dei dati numerici, il testo non è di enorme interesse, limitandosi a interpolare la prima indagine della Commissione Comunale del 1949 (12 vilas, 4.558 baracche e circa 15.000 abitanti) con quelli della Commissione della Casa Popolare del settembre 1948 - che aveva stimato i favelados in 20.000 - per pervenire, attraverso alcune considerazioni personali di tipo induttivo e di dubbia validità, a definire in circa 18.000 gli abitanti della città, senza peraltro voler confutare i dati ufficiali in suo possesso. Interessanti risultano, invece, gli aspetti 'qualitativi' emersi da alcuni 'studi di caso' di maggior dettaglio che completano il testo: ad esempio i dati sulla composizione in prevalenza giovane delle 'vilas', definite come luoghi di concentrazione di individui che stanno "cominciando la vita" (66,86\% degli abitanti sotto i 26 anni), quelli sull'alta presenza femminile al loro interno, ${ }^{28}$ sull'alta percentuale di gruppi di origine 'biancoide' $(55 \%$, particolarità tutta caratteristica del Rio Grande do Sul e non confrontabile con altre zone del Brasile), ma anche sulla durata delle unioni ${ }^{29}$ sulla bassa media di figli $^{30}$ e soprattutto sulla composizione delle famiglie (incluse le monoparentali) che vengono valutate - "in mancanza di altre forme di organizzazione sociale", ivi compresi "gruppi ricreativi" - come istituzione fondamentale a partire dalla quale "sono svolte, precariamente e sporadicamente, le varie funzioni comunitarie anche al di fuori delle relazioni di vicinato" (Medeiros, 1951) ${ }^{31}$ Contribuiscono ad un'attenta ricostruzione del fenomeno delle prime consistenti favelas dell'epoca a Porto Alegre anche i dati riguardanti la situazione abitativa in termini di qualità dell'ambiente costruito ${ }^{32} \mathrm{e}$ di caratterizzazione socioeconomica degli abitanti ${ }^{33}$ o quelli di disamina delle dinamiche di aggregazione e costituzione in comunità, ${ }^{34}$ che rivelano una fase particolare di articolazione del problema ancora allo stadio di 'occupazioni spontanee' piuttosto che di invasioni organizzate quali si manifesteranno a partire dagli anni ' $60 .{ }^{35}$ Di grande interesse sono, infine, le riflessioni presentate sulle cause del fenomeno, che evidenziano alcune matrici conservatrici dell'approccio interpretativo di Medeiros. ${ }^{36}$ Ciò è chiaro nella sottovalutazione del tema della speculazione fondiaria (fattore "d'importanza secondaria" che "accade in ogni luogo dove aumenti la densità demografica" $)^{37}$ e della segregazione urbana (indagata come fenomeno sociologico ma separata dalle sue implicazioni politiche), ma anche nell'ipervalutazione del populismo dell'opinione pubblica, rea di aver "difeso l'interesse del maggior numero a qualsiasi prezzo" in nome "di un falso spirito democratico", da definirsi piuttosto come populismo o culto dell'incompeten$z a{ }^{38}$ Le riflessioni di Medeiros restano comunque importanti soprattutto per alcuni cenni metodologici suggeribili alle autorità:

1) la necessità di valutare le favelas come una realtà polimorfa e variegata da studiare con attenzione, possibilmente con l'ausilio di equipe multidisciplinari; 2) la necessità di non di fermarsi alla mera valutazione quantitativa dei fenomeni $^{39}$ ma di pervenire a studi attenti agli aspetti qualitativi del problema dell'informale (inclusi desideri e aspirazioni, che possono riscattare con manifestazioni positive della volontà di cambiamento gli affrettati pre-giudizi a cui può portare la valutazione delle condizioni presenti); ${ }^{40}$ 
130 3) la necessità di ponderare bene ogni analisi prendendo in conto le possibilità di dichiarazioni mendaci dovunque si debba far ricorso ai meccanismi dell'inchiesta e dell'autocertificazione dei dati da parte degli abitanti, per valutare con attenzione i possibili margini di errore;

4) la necessità di elaborare indicatori complessi da usare nell'analisi e nella valutazione dei fenomeni (Medeiros non li chiama così, ma li enumera nel corso del lavoro, parlando di molteplicità dei contatti, di specializzazione, differenziazione, eterogeneità e stratificazione sociale, mobilità, omologazione, cooperativismo e competizione, costruzione di reti di vicinato);

5) la necessità di concentrarsi sullo studio dei modi di aggregazione e interazione fra gli abitanti, che stanno alla base della crescita e del consolidamento degli insediamenti di occupazione ${ }^{41}$ e possono aiutare a non idealizzare né demonizzare singoli fenomeni;

6) la necessità di ricorrere a forme di rappresentazione e restituzione dei dati alternative, come ad esempio racconti di situazioni o vicende particolari (uniche o rappresentative) che possono illuminare su particolari aspetti del problema; 7) un'attenta analisi delle cause che presiedono all'anomalo e massivo moltiplicarsi degli insediamenti irregolari, nella convinzione che

La spiegazione del fenomeno delle "vilas de malocas" non deve essere attribuita ad una causa semplice, ma ad un complesso di cause più o meno numerose [...] Esse sono manifestazione di un fatto sociale strutturale. Sono in particolare un fenomeno di 'vicinanza' e di 'differenziazione sociale' [...] Perciò interpretarle atomisticamente come unità di abitazione è non percepire l'essenza stessa del fenomeno (Medeiros, 1951).

Ciò spiega perché l'autore intendesse il suo lavoro come 'sprone' affinché le elite e i pubblici poteri affrontassero il problema sociale che lì dentro è latente, ma soprattutto come punto di partenza per studi successivi su una questione per risolvere la quale è necessario agire al contempo su molti fattori generatori: non solo, cioè, su quelli di natura economica (mancanza di fondi per le politiche dell'alloggio, trasporti collettivi, organizzazioni che facilitino la costruzione, ecc.) ma anche sugli squilibri di natura educativa, demografica o psicologica, e soprattutto sulle varie carenze interne della pubblica amministrazione.

\subsection{Dal disconoscimento all'accettazione della 'dualità urbana'}

Il messaggio indirizzato dal libro di Medeiros al Comune di Porto Alegre rimase in gran parte inascoltato; tanto è vero che nessuno degli studi successivamente realizzati dal Comune (fino a quello più aperto del 1982) lo cita come fonte, nonostante la ricchezza di dati, e soprattutto l'ampiezza dell'analisi e della metodologia di ricerca. Nei periodi successivi, avvennero infatti - alcuni sommari rilievi sull'allarmante e progressiva crescita dei fenomeni di occupazione abusiva di suoli urbani; ma essi tesero a limitarsi appena ad indagini sulla rilevanza quantitativa degli stessi, precludendosi persino di cogliere la trasformazione qualitativa del fenomeno che - proprio negli anni ' 60 a cui risale la $\mathrm{II}^{\circ}$ analisi conoscitiva ufficiale ${ }^{42}$ - si manifestava con la comparsa delle prime 'invasioni organizzate'.

Nel complesso, fino agli anni ' 80 , il Comune mostrò di tollerare - spesso tappandosi gli occhi - la crescita 'duale' della città: ciò si risolse in un sostan- 
ziale disconoscimento della città informale che andava vertiginosamente crescendo in parallelo alla trasformazione di Porto Alegre come centro industriale (e poi terziario) di grande importanza nel Paese. Il percorso conoscitivo continuò, infatti, invariato: si produssero 'bollettini di dati numerici' realizzati per lo più dall' Assessorato all'Urbanistica (uno nel '64 e uno nel '73), ${ }^{43}$ ma la stringatezza dei dati raccolti e dei criteri di analisi usati evidenzia il disinteresse politico per la risoluzione del problema.

Già dalla ricerca del '64 il Comune andò adottando toni di cautela (DEMHAB, 1999) sullo sradicamento di un fenomeno di crescita irreversibile che al massimo si poteva pensare di frenare, quasi accettando una convivenza con esso seppur con la volontà di circoscriverne l'esistenza dentro un' "area controllabile, all'interno di uno schema ben pianificato o a un Piano Abitativo specifico per il marginale", ${ }^{44}$ svolgendo anche 'un lavoro di ordine educativo' (DMCO, 1964).

Il lento progredire dell'accettazione del problema dell'informalità urbana si nota ancora di più nella ricerca del 1973 dove compaiono nuove espressioni quali promozione sociale, abitazione di interesse sociale e nucleo di suballoggi [sub-moradia] in sostituzione di termini ormai desueti quali agglomerato marginale, cisti sociale o vila; permangono invece in uso vocaboli quali malocas, barracos, casebres, favela (DEMHAB, 1999). Interessante è l'interpretazione che - in una linea di pensiero 'sviluppista' - viene offerta del fenomeno, inteso quale frutto di una fase di transizione da una società rurale ad una urbana che crea inevitabili squilibri tra la concentrazione di persone e le richieste di lavoro, sanità, infrastrutture, servizi e - appunto alloggi. Con questo, si motiva in parte l'accettazione della città spontanea, pur circoscrivendola ad una temporaneità evidente nella soluzione proposta dei trasferimenti da realizzare progressivamente nel tempo ${ }^{45}$ e con l'obiettivo di un de-favelamento a lungo termine (DEMHAB, 1973). Per la prima volta vi è un esplicito riferimento alla problematica dell'irregolarità urbana come questione che si amplia a livello politico nazionale ; e l'intervento dell'Unione è ritenuto indispensabile per assicurare l'equilibrio sociale e la qualità di vita delle popolazioni che vivono "sull'orlo della miseria, al bordo della disperazione" (ibidem). Ma, soprattutto, nello studio vi è uno dei primi riferimenti a livello nazionale all'ipotesi di tentare (accanto a progetti di riallocazione e cittadelle popolari modello) "un'urbanizzazione degli stessi nuclei di baracche", ${ }^{46}$ scegliendo formule differenziate di intervento "per ogni caso e in ogni regione". Nel complesso, nonostante la situazione di emergenza venisse utilitaristicamente 'rispolverata' a più riprese in occasione di massivi sgomberi necessari nell'ottica di una politica che favoriva la valorizzazione dei suoli e la concentrazione di rendita nelle aree più nobili del centro, nel periodo della dittatura non si evidenziò nessuna reale volontà politica di affrontare le cause del fenomeno in crescita della città spontanea. Del resto, il regime non aveva interesse ad evidenziare una sua sconfitta; tant'è che le indagini conoscitive stesse restarono fino agli anni ' 80 dei documenti 'interni' dell'Amministrazione, ben diversamente da quanto avverrà in seguito. Esse non furono neppure integrate da significativi studi svolti da altri livelli istituzionali (le prime indagini del Governo Statale sui quartieri irregolari dell'Area Metropolitana di Porto Alegre risalgono al 1982) ${ }^{47}$ né in ambito scientifico-universitario, dove una tenue produzione di documenti e studi di caso comincia a svilupparsi solo dopo il tramonto del periodo forte del regime militare (Guareschi, 1980; Panizzi, 1981 e 1984; Mascaro, 1983). 
132 Il segno più evidente del 'disconoscimento' del problema della crescita della città informale non è solo visibile nella 'laconocità' (numerica e qualitativa) degli studi conoscitivi compiuti dal Comune di Porto Alegre sul tema; ma soprattutto nel fatto che non sia stata realizzata nessuna indagine conoscitiva specifica sulla città informale in occasione delle due redazioni dei piani regolatori cittadini, né nel '59 né - ed è più grave - nel 1979. È come se si fosse voluto 'scavalcare' tale realtà, passarle sopra con uno strumento interessato solo ad un 'dover essere' astratto ed antistorico, che non teneva conto neppure delle situazioni di occupazione più consolidate. Ciò pare tanto più anomalo se si considera che nei due anni precedenti persino gli orientamenti del $\mathrm{BNH}$ nell'affrontare il tema delle abitazioni autocostruite aveva cominciato a cambiare, portando - proprio nel 1979 - alla creazione delle prime linee di finanziamento per programmi di regolarizzazione fondiaria e recupero urbano (PROMORAR e CURA).

Incrociando i dati di crescita della popolazione e quelli sulle condizioni di subabitazione fra il 1965 e il 1981 è rilevabile il netto scarto pianificatorio (Ferretti, 1984) fra l'astratta definizione delle destinazioni di uso applicate dai Piani del '59 e del '79, le reali condizioni di utilizzo dello stesso e, soprattutto, il sistema complesso di attese create da tali strumenti "specializzati ed ermetici" ${ }^{48}$ Lo stesso Assessorato all'Urbanistica (SPM) ammetteva del resto che:

L'ultimo rapporto informativo più completo sul problema della sub-abitazione a Porto Alegre è del $1973^{49}$ [...]. Il rilievo aerofotogrammetrico si trovava anch'esso non aggiornato, datando l'ultimo al 1956. E fu sull'uso di questa fonte, più informazioni del DEMHAB [...], che si basò il Plano Diretor nella sua valutazione del 1979. In funzione di questo, molti locali dove si trovavano sub-abitazioni furono destina ti a usi non compatibili con la residenza. Allo stesso tempo, cominciarono a sorgere movimenti nelle favelas per il recupero delle stesse e per il conseguente possesso della terra. Sull'altro fronte, il governo accennava a questa possibilità attraverso la riabilitazione di alcuni programmi del BNH fino al momento non impiantati, risorgenti con il nome di Programma di Sradicamento della Sub-abitazione - PROMORAR (Documento della SPM, citato in Ferretti, 1993).

Della settorialità e della superficialità delle valutazioni riguardanti la città informale che questa ammissione rileva (tanto più grave se si guarda al quadro di crescita esponenziale delle favelas dopo il 1965) ci si rese conto non appena approvato il Plano Diretor, a motivo delle nuove direttrici di azione indicate dal $\mathrm{BNH}$, da cui le politiche della casa del DEMHAB dipendevano del tutto. Il Comune tentò maldestramente di porvi rimedio in tempi rapidi già nel 1980, incaricando l'Unità di Studi Socio-Economici (UESE) e il Coordinamento degli Studi Urbani (CEU) della SPM di realizzare uno studio completo sulla subabitazione a Porto Alegre.

Il risultato dell'analisi - sottolineando le difficoltà dell'aggiornamento dei dati per l'incompatibilità esistente tra i principi di classificazione della popolazione a basso reddito previsti nel primo PDDU e la definizione delle aree secondo lo stesso - affermò che la divergenza funzionale trovava origine nel 'misconoscimento' della reale situazione abitativa di segmenti della popolazione in aree allora definite come di preservazione naturale, di relax, ecc. (Ferretti, 1984). L'impostazione data dagli estensori del lavoro denota sia l'ottica persistente di settorializzazione dei problemi, sia la mancanza dell'agognata complementarietà fra gli organismi d'intervento dell'Amministrazione (Ferretti, 1993), sia la pretesa di ingabbiare le diverse situazioni reali via via riscontra- 
te in definizioni tipologiche monolitiche e rigide che rispondessero alla necessità operativa di applicar loro i programmi di recupero o di ri-dislocamento che il DEMHAB voleva mettere in atto utilizzando le categorie del BNH. Del resto, la stessa scheda di rilevamento delle aree irregolari usata era piuttosto 'elementare', e inadatta a rilevare peculiarità delle diverse situazioni che non riducessero ogni ' $v i l a$ ' ad un tutto unico ed omogeneo. ${ }^{50}$

La fase di 'correzione dei dati' vide aggiungere al novero delle aree di subabitazione (concetto non riferito a tutti gli insediamenti che oggi definiremmo 'informali') non solo quelle nate dal 1973 all'approvazione dello strumento urbanistico, ma anche le 8 formatesi dopo l'approvazione dello stesso in difformità dagli usi lì previsti (Ferretti, 1993). Di una certa rilevanza ai fini dell'indagine risultò l'introduzione di categorie di classificazione nuove (corrispondenti alla necessità di valutare il peso e la forma assunta nei processi dai modi di realizzazione delle occupazioni irregolari che portò a definire 102 aree (il 69,9\%) come parcellamenti clandestini originati da 'invasioni' dei suoli (gli unici indicati come oggetto di studio a fini di recupero ${ }^{51}$ minore era la percentuale di 'lottizzazioni clandestine' con posteriore invasione dei suoli). Circa la situazione proprietaria dei suoli irregolarmente occupati lo studio rilevò una sorprendente preponderanza delle aree private su quelle pubbliche $(47,9 \%$, a cui andava aggiunta la voce 'miste' che rappresentava l' $11 \%$, ed una porzione del $6,7 \%$ di situazioni indefinibili), attribuibili al crescente fenomeno delle suddivisioni clandestine e irregolari avvenute con il consenso dei proprietari che miravano a ottenere guadagni diretti o valorizzazione di suoli circonvicini. Importanti anche le rilevazioni sulle dimensioni dei nuclei spontanei $i^{52}$ e sulla loro densità abitativa, ${ }^{53}$ quelle sulle condizioni fisiche dei terreni, ${ }^{54}$ e sulla presenza o meno di forme di urbanizzazione primaria, che rivelarano il rapido diffondersi dei sistemi di 'allacciamento clandestino', $; 5$ fu inoltre rilevato il frequente costituirsi di Associazioni di Residenti - anche nei nuclei minori - usate quali canali di rivendicazione ed attestanti i diversi gradi di organizzazione delle comunità. L'analisi della concentrazione nelle diverse aree fotografò uno stato di avanzata saturazione degli spazi: ad esempio, le aree occupate minori rivelavano un andamento di crescita della popolazione quasi statico (dal 15,1\% del 1965 al 16,4\% del 1980), attribuibile anche alla carenza di spazi fisici in zone spesso ricavate in vuoti urbani del centro o in aree destinate a piazze o servizi dalle previsioni urbanistiche. ${ }^{56}$

Il ricorso a categorie concettuali semplificate - spesso inadatte alla descrizione della complessa realtà indagata - rappresenta il limite maggiore dello studio della SPM del 1982. Cominciarono, comunque, ad essere introdotte nuove distinzioni fra i concetti di 'vila' (zone a maggior concentrazione abitativa che riflettono un certo grado di organizzazione sociale degli abitanti e di lotte per migliori condizioni di vita) e 'nuclei di sub-abitazione' (con minor concentrazione abitativa, minor grado di organizzazione sociale e maggior carattere di provvisorietà). La differenziazione concettuale rifletteva una necessità meno 'conoscitiva' e più 'operativa', quella di segnalare quali insediamenti (le 'vilas') dovessero essere oggetto di maggior attenzione da parte degli organismi pubblici perché il recupero urbanistico garantisse una migliore ottimizzazione dell'investimento finanziario. Per via negativa, si evidenziavano così anche i nuclei che risultava 'conveniente' rimuovere, a dispetto delle chiare priorità espresse dai Movimenti associativi popolari, che già chiedevano ad alta voce la permanenza in loco e l'urbanizzazione delle aree sotto il controllo della popolazione (Ferretti, 1993). 
Nonostante queste debolezze, lo studio del 1982 costituì un passo avanti rispetto al passato, se non altro per l'autodenuncia dei limiti degli interventi compiuti anteriormente sul terreno della città spontanea, e per l'autocritica formulata da livelli tecnici delle istituzioni nei confronti della dirigenza politica di un regime al tramonto, ${ }^{57}$ come risulta da alcuni passaggi delle conclusioni:

L'esistenza di 'vilas' di sub-abitazione a Porto Alegre si colloca come risultato di processi politici ed economici che avevano come obiettivo l'accumulazione del capitale, e che a loro volta ha portato ad un'intensificazione negli ultimi decenni delle disuguaglianze sociali [...] La concentrazione di risorse e decisioni che si è avuta a partire dal 1946 e si è consolidata con la creazione del Sistema Finanziario dell'Abitazione, oltre a rendere possibile l'accumulazione del capitale, serve da motivo e limitazione per non impiantare programmi abitativi alternativi ad opera di Stati e Municipi che non si adeguano alle norme del S.F.H. [...Oggi] l'obiettivo è il recupero nello stesso sito [delle favelas], rendendo possibile l'integrazione di questa popolazione con l'ambiente in cui vive e permettendo lo sfruttamento dell'infrastruttura fisica e sociale già esistente. Questa alternativa è conseguenza dell'esperienza negativa avutasi con il processo di rimozione (Prefeitura Municipal, 1982).

Su questa strada, seppur senza grandi avanzamenti concettuali e (quel che è peggio) senza trarne le dovute conseguenze 'operative', si porrà il nuovo studio sulla città informale realizzato dopo l'elezione di Alceu Collares a sindaco di Porto Alegre nelle prime elezioni municipali libere, nell'imminenza dell'approvazione di una variante al Plano Diretor del 1979. Con l'elezione del Fronte Popolare nell'autunno 1988 saranno realizzati alcuni studi parziali in vista di singoli programmi di intervento su varie 'vilas' cittadine, anche se - come vedremo - si dovranno aspettare gli studi preparatori per il nuovo PRG per avere un nuovo quadro completo dello sviluppo della città informale a livello cittadino. Questi - se non mostreranno in realtà enormi cambiamenti nei modi di esecuzione dei rilievi - potranno però far tesoro dei contatti quotidiani fra tecnici e cittadinanza resi possibili dal processo del Bilancio Partecipativo nell'ambito di un approccio completamente rinnovato alla questione della 'dualità urbana' e del 'doppio regime' dei suoli. E soprattutto non costituiranno più uno strumento 'interno' di conoscenza di cui vergognarsi e pertanto da tenere il più possibile nascosto alla cittadinanza, ma al contrario tenteranno di porsi come mezzo ulteriore di dibattito e scambio di idee tra Amministrazione e cittadini. Al punto che uno dei due testi scelto dal DEMHAB come pubblicazione ufficiale per celebrare il suo cinquantennale è stato La mappa dell'irregolarità fondiaria di Porto Alegre, stampato e distribuito nel luglio del 1999. Un testo che, fin dall'introduzione del neodirettore Carlos Pestana Neto, mette in rilievo l'impossibilità di realizzare un quadro sempre attuale delle trasformazioni in un settore in continua mutazione; ma che si fa un punto d'onore della rappresentazione di una realtà amara da riconoscere, ma utile 'per indicare alternative per minimizzare $i$ problemi sociali causati dalla mancanza di alloggi' e per farlo insieme ai cittadini che le abitano'.

\subsection{Le strategie operative: da 'rimuovere per promuovere' a 'promuove- re per rimuovere'.}

Nel consultare le relazioni dei censimenti realizzati dal Comune nel 1950, 1964, 1973, si nota un'evoluzione nella concezione del fenomeno sociale, genericamente trattato con termini $[. .].[$ che] portano una connotazione di esclusione socioeconomica-cultura- 
le e morale tanto più forte quanto più spinti indietro nel tempo. Il sistema sociale che esclude si incarica di stigmatizzare gli esclusi come se questi non fossero un suo prodotto. Il preconcetto nutrito dalla società formale, regolare, contro il fenomeno sociale informale o irregolare mostra peculiarità in accordo con le epoche (DEMHAB, 1999).

Nel 1947, la creazione della Commissione per lo Sradicamento delle Favelas dette avvio a livello nazionale alla politica degli sgomberi. Porto Alegre vi si adeguò lentamente. È vero, infatti, che già testi del 1951 rilevano la rimozione di alcune aree di sub-abitazione ubicate nel centro cittadino, ${ }^{58}$ ma è altrettanto vero che nel 1948 la Commissione per la Casa Popolare del Consiglio Comunale aveva concluso (con grande anticipo sui tempi teorici di un dibattito che si svolgerà solo dopo 30 anni) che nell'immediato non si possono rimuovere le 'malocas', eccetto che in casi speciali, e che in senso generale pensiamo che [...] vadano conservate dove stanno, servite, però, da acqua, fogne, organizzazione della viabilità, luce ecc.. ${ }^{59}$

Fu semmai l'avvento della dittatura a determinare un aumento nella politica del 'pugno di ferro' su tutto il territorio nazionale, attraverso la fedeltà totale ai programmi centralizzati del BNH (Fruet, 1991). Così, a Porto Alegre, dal 1965 al 1975, con il motto Remover para Promover [Rimuovere per promuovere], il DEMHAB sgomberò oltre 14.400 unità abitative sul territorio comunale, per un totale di 62.800 persone ${ }^{60}$ con punte di grande intensità dal 1969 in poi, come è evidenziato nel grafico a fronte. Di queste, ben 19.255 furono ridislocate in altri comuni dell'area metropolitana (Menegat, 1995).

RIMOZIONI DI UNITA'ABITATIVE EFFETTUATE DAL DEMHAE-1\$5H990

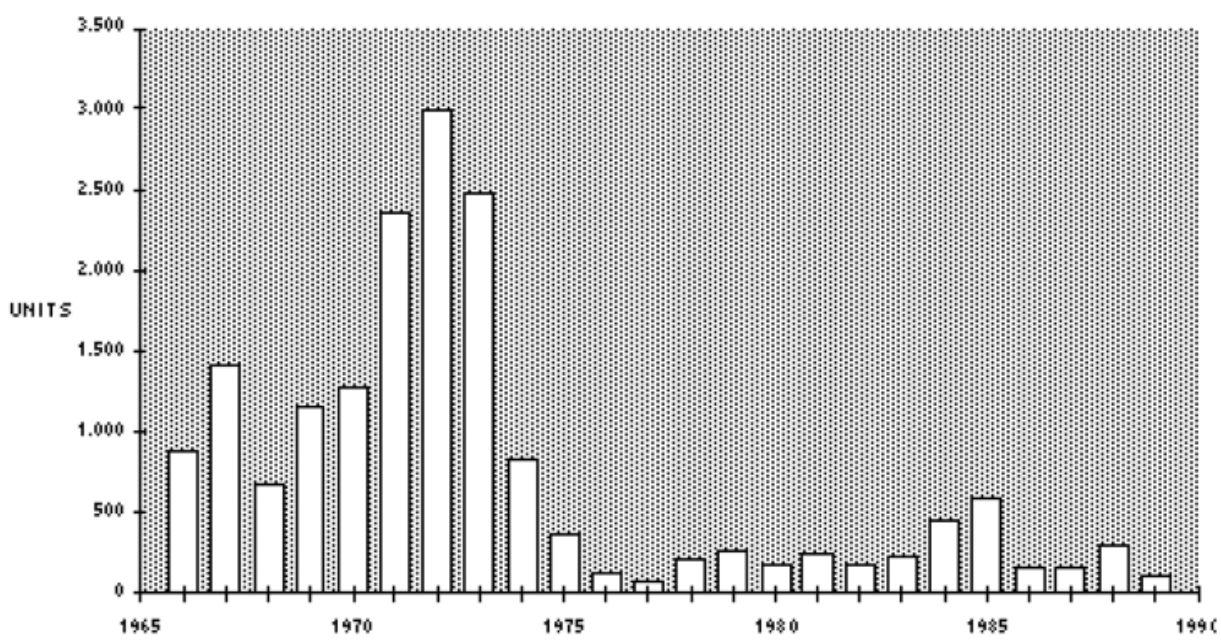

Dati: Fruet (1991)

Il fatto che dei 163 nuclei informali rilevati nel 1981/83, solo 21 appartenessero al gruppo di quelli con oltre 31 anni di età (nati cioè all'inizio degli anni ' 50 , quando il Comune di Porto Alegre aveva rilevato 41 insediamenti di sub-abitazione sul suo territorio) la dice lunga sul numero di rimozioni realizzate prima che entrasse nel linguaggio ufficiale il concetto di regolarizzazione fondiaria (Barcellos, 1986) e che gli sgomberi fossero sostituiti da trattative negoziali di trasferimento per i gruppi residenti in aree insalubri o 'di rischio'. ${ }^{61}$ 
Nonostante i programmi di sradicamento, le concentrazioni di povertà urbana a Porto Alegre continuarono a crescere; così, se nel 1965 gli abitanti delle favelas rappresentavano il $9,8 \%$ del totale dei cittadini portoalegrensi, nel 1972 erano il 10,7\% e nel 1979 erano già saliti al 13,6\% popolando i 128 nuclei definiti di 'subabitazione' (93 di insediamenti clandestini frutto di invasioni, 15 irregolari e 20 in 'aree speciali di re-insediamento' del DEMHAB dotate solo di una minima infrastrutturazione $)^{62}$ che davano asilo a oltre 150.000 famiglie, ${ }^{63}$ di cui era in costante crescita la componente migratoria interna alla stessa Porto Alegre, motivata dalla contrazione del potere d'acquisto della moneta che rendeva i salari più bassi insufficienti a pagare gli affitti.

Nella politica del ventenni, va inquadrata la costruzione del primo insediamento del DEMHAB finanziato dal BNH, il quartiere della Restinga Nuova, concepito nel 1969 per ospitare nei suoi 3.867 appartamenti le famiglie appena sgomberate e il $20 \%$ più benestante di un insediamento contiguo (Restinga Vecchia) fino ad allora usata come 'area di transizione' tra le rimozioni degli anni precedenti e nuove sistemazioni, ma trasformatasi in breve in una favela istituzionalizzata.

Le rimozioni non erano attuate solo attraverso sgomberi affidati alla Polizia, ma anche in modo indiretto e subdolo, attraverso l'aumento dei contributi richiesti agli abitanti o la valorizzazione fondiaria fomentata dalla mancanza di qualsiasi tipo di vigilanza istituzionale sui fenomeni speculativi, strategia che rimarrà viva fino a metà degli anni ' 80 nonostante uno strumento previsto dal Plano Diretor del 1979 (e mai applicato) prevedesse la possibilità di introdurre una tassazione differenziata delle aree vuote, in modo da ampliare l'accesso ai suoli urbani per tutta la popolazione senza rendersi incompatibile con la struttura della proprietà privata (Barcellos, 1986).

Che il disinteresse del Comune per il controllo della speculazione fondiaria fosse grande lo evidenziò nel 1980 uno studio sui vuoti urbani svolto dal $\mathrm{BNH}$ a Porto Alegre, che rivelò che se anche solo le aree vuote esistenti di superficie maggiore di 10 ettari fossero state utilizzate per uso residenziale, si sarebbe potuto costruire un numero di case unifamiliari uguale alla metà dei domicili esistenti (cfr. Fragomeni, 1984). Del resto, ancora nel 1986 oltre 17.000 ettari di terra urbana risultavano ancora 'baldios' [non sfruttati] sommando i 24.438 terreni e le 1.296 glebas inutilizzate, ${ }^{64}$ ovvero il 53,66\% dell'area cittadina, di cui oltre il $21 \%$ risultava in mano allo $0,1 \%$ dei proprietari, ${ }^{65}$ mentre solo lo $0,25 \%$ era costituito da terreni di meno di $300 \mathrm{mq}$ in mano all' $8,8 \%$ dei proprietari (Barcellos, 1986).

Paradossalmente, fu proprio la necessità di trovare una valvola di sfogo per poter continuare la politica delle rimozioni ad hoc necessarie all'ipervalorizzazione fondiaria e all'accumulazione urbana $^{66}$ ad incentivare i primi esperimenti di regolarizzazione, già ventilati come soluzione possibile nel censimento delle malocas del 1973. Agli inizi, l'idea rimase limitata all'ambito urbanistico e ad aree di proprietà del DEMHAB, senza toccare le zone invase di proprietà altrui (Fruet, 1991); ma fu un terreno di prova interessante in vista del prossimo mutare degli orientamenti dello stesso BNH sul tema. Questi si formalizzarono in programmi e linee di finanziamento precise solo nel 1979, e dal 1980 cominciarono ad essere sperimentati a Porto Alegre su un numero crescente di aree, tanto che nel 1983 (cfr. Barcellos, 1986) risultavano iscritte al Programma PROMORAR 28 delle 163 favelas cittadine (equivalenti al 17,2\%), mentre 14 risultavano aver avuto già lo Studio di Fattibilità Urbanistica approvato $(8,6 \%)$. 
Mentre cominciavano ad apparire i primi programmi abitativi centrati sul selfhelp, i 'Sites\&Services' e la regolarizzazione fondiaria, gli sgomberi cominciarono a diminuire enormemente. Già la relazione di attività del DEMHAB del 1979 prevedeva - in sintonia con il nuovo Plano Diretor - solo la rimozione delle 'vilas' situate in aree di inondazione, in aree destinate a parchi pubblici o a protezione naturale, sopra i 100 metri di quota o dovunque gli alti costi dell'infrastrutturazione sconsigliassero 'programmi sociali' a budget contenuto ${ }^{67}$ Progressivamente le categorie per cui era previsto lo 'sgombero' andarono riducendosi di numero, al punto che nella pratica vi rimasero quasi solo le cosiddette aree di rischio e poche di quelle di preservazione naturale, volendo non tener conto delle rimozioni forzose imposte dalla magistratura in aree occupate di proprietà privata, alla fine di lunghi e sofferti processi. Così, nel periodo tra il 1976 ed il 1988 gli sgomberi non superarono le 3.138 unità abitative, contro le 14.408 del decennio precedente. E nel solo quadriennio in cui Alceu Collares fu Sindaco di Porto Alegre, si contano un totale di 5.757 lotti e 280 appartamenti occupati regolarizzati, seppur non in maniera completa, ma alternativamente solo per via urbanistica o giuridica. ${ }^{68}$

$\mathrm{Fu}$ proprio in questo periodo che il processo di decompressione politica (Fruet, 1991) portò ad un cambiamento nella legittimazione del regime autoritario: a partire dalle elezioni del 1974 (in cui lo MDB, unico partito di opposizione, aveva aumentato i suoi rappresentanti alla Camera dal 35 al $49 \%$ e al Senato dal 43 al 59\%) il Governo passò da un processo di legittimazione basato sul successo del modello economico sviluppista, ad un percorso centrato sul supporto elettorale. Questo si risolse in una progressiva apertura politica che finì per lasciar spazio nell'arena ai sindacati, ai gruppi di professionisti, alle associazioni culturali e ai movimenti non-profit. Soprattutto questi ultimi, in rappresentanza tra l'altro del segmento più povero della popolazione urbana, cominciarono a lottare per il conseguimento di servizi nelle aree occupate, in parallelo con il consolidarsi di trasformazioni provenienti dall'esterno che - un po' in tutto il Paese convergevano nella stessa direzione: i casi degli insediamenti occupati di Vila Campo da Tuca e Vila Ramos furono i più eclatanti a Porto Alegre, e finirono per essere inclusi nei primi programmi PROMORAR già dal 1980, l'anno dopo il lancio delle iniziative di regolarizzazione del $\mathrm{BNH}$.

Nel caso di Vila Tronco accadde che nel 1980 una Commissione di Residenti, formatasi indipendentemente dalla locale AM (Associazione di Vicinato legata clientelisticamente all'Esecutivo Municipale) indicesse una riunione per esaminare il progetto di urbanizzazione proposto dal DEMHAB e finanziato dal $\mathrm{BNH}$, e nominasse poi un comitato incaricato di portare avanti un progetto alternativo più aderente agli interessi della comunità (Fruet, 1991); dimensioni dei lotti, larghezza delle strade, grandezza e distribuzione delle aree comuni e destino delle famiglie da rimuovere erano - insieme all'importo mensile stabilito dal DEMHAB a carico dei residenti - i principali punti del contendere ${ }^{69}$ La Commissione organizzò addirittura un plebiscito nel quartiere che - nel settembre del 1981 - vide uscire vincitore il progetto alternativo con il 55\% delle preferenze. L'opposizione strenua opposta dal DEMHAB e sostenuta dal Comune portò nel 1982 alla realizzazione del progetto 'ufficiale', mostrando come la postura prevalente dell'ente pubblico fosse ancora autoritaria e priva di volontà politica per negoziare soluzioni intermedie, e come la comunità - pur libera di esprimere il suo scontento - non fosse dotata di strumenti per incidere sulle politiche di cui era 'beneficiaria' (Fruet, 1991). 
Interessante fu il fenomeno rappresentato dalle 'invasioni bianche' del 1987 (box 3) a cui almeno il DEMHAB di Porto Alegre reagì in modo celere e con una strategia aperta alla negoziazione con gli occupanti. Da questo momento l'approccio del DEMHAB nei confronti della partecipazione popolare comincerà lentamente a cambiare, orientandosi per gradi verso l'accettazione di un 'regime interlocutorio': un significativo gradino di avvicinamento al cambiamento che sarà messo in atto nel 1989 dalla neoeletta Amministrazione Popolare.

\section{Note}

${ }^{1}$ Linchiesta realizzata dal Dipartimento alla Casa di Porto Alegre nel 1965 mostrò una crescita delle famiglie residenti nei 56 nuclei di baracche superiore al $330 \%$ rispetto al 1951 (Garayp, 1980), con un netto incremento delle famiglie originarie della stessa città o dei comuni contermini (30,5\% contro il 27,2 precedente) rispetto all'ancora alta percentuale di quelle provenienti dalla campagna. Quest'ultima tendenza sarà confermata nel 1972 da una nuova inchiesta che stabilirà che il $36,6 \%$ degli abitanti (all' $80 \%$ con reddito medio inferiore ai 2 salari minimi) proveniva dalla città o dai centri vicini. Addirittura il $16 \%$ delle famiglie favelate risulteranno ex-affittuari nella stessa Porto Alegre, e il 63,7\% già abitava precedentemente in favela (Garayp, 1980). Come concluderà l'inchiesta del DEMHAB del 1972: 'maloca alimenta maloca in misura maggiore di qualsiasi altra fonte'.

${ }^{2}$ Bogus (1980) l'ha dipinta con l'allusiva espressione/titolo 'Quando la città arriva alla periferia'.

${ }^{3}$ Da João Rovatti, studio inedito del 1991 citato in Estudos Urbanos, 1993.

${ }^{4}$ Legge 189/1925.

${ }^{5}$ Lo IAPI fu creato con Legge 367 del 1936 e vincolato al Ministero del Lavoro del Governo di Getulio Vargas.

${ }^{6}$ Per Souza (1994) l'influenza diretta di Unwin e Parker in Brasile è sempre stata mediata dalla realizzazioni Statunitensi preoccupate del tema dell'unità di vicinato. Nel caso di Vila IAPI, l'architetto dichiarò di aver inserito molte attrezzature pubbliche per semplice buonsenso; piuttosto furono i libri di Camillo Sitte la sua guida, specie per le problematiche di natura estetica.

Ad esempio il campo da calcio fu ubicato nel fondo di una cavea naturale.

8 Secondo l'inchiesta del DEMHAB del 1973, erano già 41 gli insediamenti su terre occupate nel 1951.

${ }^{9}$ Legge 982 del 18/12/1952.

${ }^{10}$ Tra la sua nascita ed il 1977 il DEMHAB di Porto Alegre realizzò il 26,6\% del totale di alloggi di 'interesse sociale' di Porto Alegre (Pereira, 1980).

${ }^{11}$ Nell'ambito del programma PROFILURB di lotti Sites-and-Services destinati a famiglie con reddito tra 1 e 2 salari minimi, la COHAB/RS finanziò invece 217.713 in tutto lo Stato fino al 1978.

${ }^{12}$ Menino Deus, Azenha, Cidade Baixa, Medianeira e Praia de Belas.

${ }^{13}$ In questo periodo - in cui il numero di dipendenti del DEMHAB rimase stabile intorno alle 200 unità - si verificarono frizioni fra livelli tecnici e dirigenziali all'interno dell'Ente comunale, quest'ultimi accusati di favorire proprietari terrieri e di perseguire interessi personali nella realizzazione delle politiche (Fruet, 1991).

${ }^{14}$ È il caso delle 1500 famiglie della Ilhota che tra il 1975 ed il 1977 (nell'ambito del progetto CURA) furono rimosse e alloggiate - le più benestanti - nella cittadella fuori porta della Restinga Nova e - le più indigenti - nella Restinga Velha, una vera e propria favela istituzionalizzata (Pereira, 1980). I 18 ettari di terreni dove vivevano in origine le famiglie, furono invece riurbanizzati dal Comune e venduti ad altissimo prezzo sul mercato.

${ }^{15}$ Per chi sono le case della COHAB? si chiede Nara De Castilhos Garayp (1980) nell'esaminare i risultati innocui delle proposte di 'soluzione' del deficit abitativo nel Rio Grande do Sul tra il 1964 e il 1980 - Non certo per l'80\% più povero della popolazione brasiliana considerati senza capacità di contrarre debiti, nonostante siano esattamente loro i maggior finanziatori, non solo delle case della COHAB, ma persino delle sontuose e lussuose ville realizzate dal BNH nei quartieri più ricchi e ben attrezzati delle nostre città. ${ }^{16}$ In quell'anno un'inchiesta della Divisione della Casa (all'interno del Piano Triennale per la Casa) stimò l'esistenza nello stato di oltre 37.000 baracche ed un deficit abitativo di 170.000 unità. 
${ }^{17}$ Il fallimento delle realizzazioni cooperative fu tale che dal 1972 l'INOCOOP lascio' le consulenze e l'orientamento per incaricarsi direttamente della costruzione degli alloggi. ${ }^{18}$ Le COHAB [Compagnie di Abitazione] sono costituite come Società per azioni (il nome Companhia deriva infatti da una figura giuridica brasiliana che vuol dire impresa a capitale misto') di cui il potere pubblico ha l'obbligo di detenere almeno il $51 \%$ (Garayp, 1980); nel caso di quelle Statali, una parte del 49\% restante può essere gestito da comuni del territorio dello Stato. Una delle difficoltà maggiori incontrate nello svolgere il loro ruolo di avamposti del BNH sui territori locali è stata (fino alla riforma proautonomia del 1973) legata ai requisiti imposti dal BNH stesso per le costruzioni, a partire dalla proprietà e infrastrutturazione dei terreni.

${ }_{19}$ Andarono, infatti, crescendo formule di intervento sempre meno impegnative come la Casa-embrione (20 mq senza divisori interni, tubi a vista, pavimento in terra battuta e senza controsoffitti), i lotti urbanizzati o anche i progetti integrati che - a dispetto del nome - erano pericolosi acquisti 'a pacchetto' di progetti pronti di imprese private di cui si voleva abbassare il margine di guadagno ma si finì per abbassare la qualità dei risultati prodotti (è di questo genere il quartiere Rubem Berta a Porto Alegre).

${ }^{20}$ Le cifre delle realizzazioni sono poi molto diverse: dal 1964 al 1973 furono realizzate nel Rio Grande do Sul solo 176.600 delle 231.694 unità abitative finanziate (Garayp, 1980)-

${ }^{21}$ Solo la più celebre di esse, la Coop. di Abitazione de gli Operai Bancari di Porto Alegre (nata nel 1966), realizzò 1400 unità abitative fino al 1972 nell'ambito del Piano Nazionale dell'Abitazione; sarà poi assorbita dall'INOCOOP.

${ }^{22}$ La commissione ebbe vita solo per pochi mesi, e nel 1949 fu sostituita dal Servizio di Abitazione vincolato al Comune allora retto da Ildo Meneghetti, e trasformato nel 1952 in Soprintendenza all'alloggio popolare (Garayp, 1980).

${ }^{23}$ Questi lamentò peraltro di non aver potuto realizzare il suo studio in equipe come sarebbe stato opportuno.

${ }^{24}$ Del resto neppure l'IBGE fino al 1940 registrò la presenza di catapecchie permanenti (DEMHAB, 1999).

${ }^{25}$ Medeiros concludeva che il fatto, "universale nelle sue caratteristiche essenziali", a Porto Alegre si presentò "con caratteristiche speciali" ed un aspetto "di impeto epidemico, quasi di calamità pubblica, di rivoluzione in materia di occupazione, di ripari quasi improvvisi, e improvvisati pressoché istantaneamente”.

26 Potremmo anche dire 'creazione', visto che l'autore stesso lamenta l'indefinitezza dello statuto della 'sociologia urbana' e la necessità di fondere insieme criteri di altre branche del sapere per formulare i suoi criteri di analisi.

$2754,25 \%$ è il livello di lavoro fisso riscontrato nell'analisi di approfondimento da Medeiros, mentre 40,42\% sono i capifamiglia con lavoro irregolare e 5,33\% i disoccupati (Medeiros, 1951, pag. 35).

${ }_{28} 56 \%$, dato in netta crescita nelle fasce di età sopra i 15 anni

$2947,61 \%$ non oltre i 6 anni, di cui $28,57 \%$ sotto i 2 anni.

${ }^{30} 2,46$ per nucleo familiare.

${ }^{31}$ Attraverso uno degli studi di caso proposti - la 'vila' denominata Forno do Lixo - le famiglie sono classificate in legali $(50,56 \%$, di cui solo il $13,82 \%$ sposate in chiesa), legalizzabili $(39,32 \%)$ e non legalizzabili $(10,11 \%)$. Quando Medeiros arriva al motivare con esempi e racconti le definizioni, emergono pregiudizi morali sulla realtà descritta, sulla promiscuità e l'estremo grado di vita dissoluta che connota alcune esperienze. Interessante è aquando, nella descrizione della provenienza delle famiglie (45\% delle quali già formate a Porto Alegre) Medeiros osserva la presenza di infelici donnette di servizio o operaie che hanno sbagliato nella vita, e conclude che la città 'ha contribuito maggiormente al gruppo delle famiglie non legalizzate'.

32 Sotto questo profilo, Medeiros propone alcune categorie di analisi riportate ad un giudizio soggettivo del ricercatore sulla qualità intesa come maggiore o minore capacità dell'abitazione nello svolgere le funzioni a cui è destinata: le categorie di giudizio individuate per le case sub-standard esaminate (di cui l'autore annota materiali differenti di composizione indicativi del grado di consolidamento della zona occupata) sono tollerabile, precaria, cattiva, miserabile, innominabile (ovvero ammonticchiamento di cose con intenzione di riparo), che già nei termini mostrano una postura alquanto pregiudiziale dell'autore. In altra parte del testo vengono poi descritte categorie diverse di abitazioni, tra cui le case-barca della Vila Surgida das Aguas, palafitte, e fenomeni di abitazioni realizzate direttamente per la vendita o l'affitto, alcune delle quali (chiamate 
malocas-arranhaceu $=$ baracche-grattacielo) a più piani.

${ }^{33}$ Interessante è soprattutto la descrizione del tipo di professioni dagli abitanti (sottolineando la presenza di molti impiegati pubblici, operai, militari e marinai) e delle forme organizzative dei lavori di riciclaggio della carta nella favela Forno do Lixo, costituentisi come fonte di reddito che si trasforma in centro di interesse e attività per una collettività che non riesce ad oltrepassare lo stadio definito dalla sociologia 'di vicinanza' per arrivare a quello di comunità. Vengono poi descritti i piccoli orti domestici (22,3\% dei casi esaminati e quasi tutti relativi a famiglie originari di aree agricole) e i pollai o porcili domestici ( $11,7 \%$ ridotti progressivamente nel tempo a causa dei molti furti), e di conseguenza il regime alimentare giudicato abominevole per chi poi vive soprattutto di lavori che richiedono sforzi fisici.

${ }^{34}$ In realtà Medeiros non usa il termine comunità, affermando che le favelas di formazione spontanea (per aggregazione e imitazione) che ha esaminato non riescono ad andare oltre lo stadio di collettività con rapporti di 'vicinanza'. sulle dinamiche di costruzione delle 'vilas' si riferisce a fattori pratici (vicinanza al lavoro o a linee di bus importanti, proprietà pubblica dell'area) o psicologici (unione fra parenti o ex-vicini richiamati dall'interno dello Stato da persone conosciute). Per quanto riguarda la provenienza dei maloqueiros, Medeiros espone i risultati di alcuni studi di caso, dove risulta che il $74,7 \%$ di loro sono immigrati dall'interno dello Stato, l'1,7\% sono portoghesi, ed esistono anche alcuni viajeiros, apolidi dallo spirito avventuroso che spesso hanno esplorato situazioni diverse, risiedendo persino all'estero.

${ }^{35}$ In tal senso, si capisce perché Medeiros usi il termine 'invasione' con accezione molto distante da quella che ha oggi, intendendola come penetrazione in città di masse di nuovi venuti, processo di penetrazione progressiva in un'area segregata di un gruppo di popolazione con uno status diverso che va sostituendosi ai primitivi occupanti, o di una funzione istituzionale diversa da quella che anteriormente l'area svolgeva; in tale ottica egli usa il termine anche per significare gentrificazione, visto che riferendola alle aree centrali di subabitazione la inserisce fra le cause dell'aumento dei maloqueiros sostenendo che il processo di centralizzazione ha provocato quello di decentramento (Medeiros, 1951).

${ }^{36}$ Questa postura è evidente dallo spazio che Medeiros dedica a sottolineare come gli abitanti delle 'vilas' siano una popolazione abituata all'accomodamento sociale, carente di abitudine al risparmio e capacità di iniziativa che la spinga ad un miglioramento di condizione, e soprattutto mancante di un ideale definito in materia economico sociale che la colloca in uno stato di conformismo e di inerzia.

${ }^{37}$ Questo nonostante Medeiros rilevi la presenza di ben 1670 terreni vuoti nell'area urbana di Porto Alegre, ed inviti il Comune ad ampliare l'offerta di terreni incorporando nuove zone agli spazi abitabili e facilmente accessibili).

${ }^{38} \mathrm{Nel}$ testo vi sono comunque - accanto allo studio dei fenomeni legati alla crisi economica, alla Guerra Mondiale e all'immigrazione centripeta verso la città - anche critiche più marcatamente politiche; ad esempio al ruolo negativo dell'eccessiva burocrazia (definita febbre dello Stato moderno), alle carenze della modestissima politica degli alloggi, di un efficiente sistema di trasporti collettivi, di percorsi urbani perimetrali che mettano in contatto luoghi di lavoro e di residenza senza attraversare il centro e dell'accesso all'informazione per le categorie sociali meno istruite, oltre che alla mancanza di sufficienti incentivi che cooptino il settore privato e abituino i cittadini più poveri al risparmio, e di un piano regolatore stabile e con linee chiaramente definite.

39 A questo proposito Medeiros sottolinea la poca rilevanza di molti dati generalmente estrapolati, come la densità abitativa o la dimensione media delle baracche, che differiscono molto nelle diverse realtà.

${ }^{40}$ Il discorso è affrontato nell'ambito dell'affresco fatto sulle condizioni culturali ed educative dei 'maloqueiros', ma è ripetuto nel riferimento alla necessità di valutare bene i comportamenti degli abitanti provenienti dalla campagna, non psicologicamente preparati ad affrontare necessità ed attività nuove, relazioni sociali diverse per la velocità, la variazione, l'impersonalità, gli standard culturali diversi che la città impone.

${ }^{41}$ Di tutti i capitoli quello dedicato a questo tema è il più importante, in rapporto agli interessi sociologici dell'autore, che insiste soprattutto sui meccanismi di vendita delle baracche come fonte di reddito per chi le vende (e di minor rischio per chi le compra, dovendo saltare la fase psicologicamente difficile della costruzione in un terreno altrui e ancora vuoto), sui fenomeni di accomodamento relativi ai nuovi venuti ( isolamento maggiore per chi si trova a vivere tra persone più istruite, altezzoso autoisolamento ma maggior accettazione da parte degli altri per chi viene da esperienze migliori), sulle segregazioni che si 
creano con lo stabilirsi di regolamenti ed etiche interne all'insediamento, sulle condizioni di sicurezza psicologica di chi sta da tempo nell'area (e si permette di fare petizioni collettive alle Istituzioni per cacciare nuovi venuti scomodi), sui fenomeni coesistenti di competizione e conflitto fra gruppi (che si limitano all'ambito familiare o individuale ma non raggiungono livelli più estesi) ed infine sui fenomeni di assimilazione o uniformazione sociale e dei costumi fra persone di ambiti e usi differenti che si ritrovano uniti dalla prossimità quotidiana.

${ }^{42}$ Essa fu attuata in corrispondenza della creazione del DEMHAB nel 1965.

${ }^{43}$ La ricerca del 1964 fu attuata in soli 30 giorni dal DMCP ormai in dismissione; pertanto non è certo possibile ritenerla uno studio approfondito. Quella del 1973 occupò invece in 2 mesi di ricerche (dal gennaio al marzo del 1973) oltre 120 studenti del Projeto Rondon sotto la semplice supervisione del Servizio Sociale DEMHAB.

${ }^{4}$ Il termine è il più usato nella relazione; addirittura non si intende la favela come prodotto del marginale, ma viceversa, tanto che esso è descritto con queste parole: possiamo arrivare alla conclusione che $i$ marginali sono individui che vivono in sub-abitazioni [termine qui usato per la prima volta] costituendo agglomerati irregolari senza piani urbanistici, in terreni vuoti, e situandosi, principalmente, nei grandi centri urbani (DMCP, 1964)

${ }^{45}$ Tra gli obiettivi della ricerca vi è, esplicitamente, quello di fornire elementi per lo studio dell'acquisizione di aree per la residenza definitiva, come lotti semi-urbanizzati per lo spostamento di baracche situate in aree necessarie a opere pubbliche di infrastrutturazione o di urbanistica previste nel Plano Diretor (DEMHAB, 1973).

${ }^{46}$ Come già abbiamo avuto modo di osservare, però, solo nel 1980 si avranno interventi in tal senso, a partire da quelli di Vila Santa Rosa e del Nucleo Ramos (DEMHAB, 1999). ${ }^{47}$ Anteriori sono solo alcune indagini sul tema dell'alloggio popolare. Il primo lavoro specifico sul deficit abitativo nel Rio Grande do Sul, ad esempio, risale solo ai tardi anni Settanta, e fu realizzato nell'ambito del PLANHAP I sulla base del censo del '70. Attraverso estrapolazioni e proiezioni non sempre convincenti e di risibile apparente minuziosità, stimava che il deficit dello Stato fosse nel '70 di 141.094 case, nel 1975 di 245664, che nel 1979 avrebbe raggiunto le 318972 unità e nel 1983 le 477984.

${ }^{48}$ Ferretti (1993) comprova la superficialità, le scaramucce fra dipartimenti comunali e le gravi carenze evidenziatesi nella fase di raccolta, analisi e gestione dei dati su cui basare il $1^{\circ}$ PDDU e l'aggiornamento successivo del 1987, in particolare per quanto concerne lo studio della città informale.

${ }^{49}$ Lo studio del 1973 è il primo di tipo urbanistico, interessato cioè al diagnostico evolutivo delle sub-abitazioni e non a semplici rilievi socio-economici.

${ }^{50}$ La scheda di raccolta dei dati usata nella ricerca della SPM del 1982 (coordinata dall'arch. Léo Ferreira da Silva) prevedeva , infatti, in prevalenza dati elementari: oltre a quelli relativi all'esatta localizzazione delle aree e delle varie unità di abitazione, il numero di famiglie residenti, le caratteristiche del terreno e della proprietà del suolo, il tipo di organizzazione spaziale, il tempo di esistenza, la presenza o meno dei vari tipi di reti infrastrutturali, la presenza di rilievi socioeconomici o topografico-catastali, e l'esistenza di attrezzature comunitarie e Associazioni di Quartiere.

${ }^{51} 46$ di queste vennero subito accatastate nel DEMHAB per ricevere i benefici previsti dal programma PROMORAR o PROFILURB che si occupavano di fasce sociali con introiti mensili equivalenti a salari minimi da 1 a 3 (Ferretti, 1993).

${ }^{52}$ Il $71,9 \%$ delle aree di sub-abitazione definite 'misurabili' (meno del 50\% del totale) risultarono in quartieri con più di 100 unità abitative.

${ }^{53}$ La progressione geometrica della crescita nelle aree di addensamento delle fasce a basso reddito risultava essere passata da un tasso del 3,62\% annuo nel 1965 ad uno del $5,72 \%$ nel 1980, a riconferma degli studi condotti dal DEMHAB che rivelavano una crescita demografica più che doppia rispetto a quella complessiva di Porto Alegre.

${ }^{54}$ Esse furono definite 'buone' (a differenza che in altre città) nella maggior parte dei casi; il $31,5 \%$ si trovava in luoghi pianeggianti e asciutti, il 19,2\% in forte declivio, il $15,1 \%$ in declivio debole o moderata, il $15,1 \%$ in zone piane soggette ad allagamenti ed il $4,1 \%$ in luoghi di morfologia irregolare. Solo il $34,3 \%$ degli insediamenti era valutato, nelle conclusioni dello studio, in condizioni sfavorevoli alla residenza.

55 Tutte le 146 aree risultarono prive di fogne, e il 30,8\% di approvvigionamento idrico; il $44,5 \%$ delle abitazioni possedeva un tubo a cui attingere nelle vicinanze, e il 17,2\% possedeva una rete di adduzione idrica; quanto alla luce elettrica, risultò presente nel $93,2 \%$ delle case, pur non esistendo l'illuminazione pubblica nelle aree di studio.

56 Un elemento che ha contribuito nel tempo alla sottostima del fenomeno dell'irregola- 
rità urbana in Brasile è stato dovuto ai dati divulgati dall'IBGE (box 2). Nel caso di Porto Alegre - secondo il calcolo proposto dal DEMHAB (1999) - con questo tipo di definizione si sarebbero avuti annualmente valori di rappresentazione del fenomeno variamente sottostimati (nel 1951, infatti, solo il 15\% degli abitanti viveva in nuclei con oltre 51 domicili irregolari; nel 1964, 3,01\% e nel 1973 4,22\%) dal momento che i nuclei minori sono andati crescendo di numero nel tempo a causa della saturazione del tessuto urbano (nel 1996/98 i nuclei con oltre 51 domicili rappresenteranno però il 4,81\%, una percentuale in crescita a causa della densificazione dei vecchi agglomerati).

${ }^{57}$ Proprio nel 1982 si terranno le prime elezioni di Governatore fuori dal sistema bipartitico obbligatorio del passato.

${ }^{58}$ Medeiros (1951) riferisce di una rimozione di 409 baracche nel 1949, seguita dalla costruzione in loco di alcune case minime ed anche della chiusura di tutti i punti di commercio informale in molte 'vilas'.

${ }^{59}$ Citazione contenuta in Medeiros, 1951.

${ }^{60}$ Fruet (1991) rileva che solo tra il 1969 ed il 1975 le persone rimosse furono il $43 \%$ in più che nei precedenti 6 anni.

${ }_{61}$ "Il passaggio dagli sgomberi con l'aiuto della polizia alle rimozioni di 'vilas' realizzate dai tecnici del DEMHAB è stato per certi versi un evento simile al passaggio che a fine 1998 si è verificato con la sostituzione della Brigata Militare con $i$ vigili urbani per il controllo sul traffico. All'inizio, cioè, non è stato semplice, perché il potere civile non ha la stessa autorità apparente di quello militare. Ma col tempo ha mostrato le sue potenzialità, insite nel rifiuto dell'uso della forza, che ha il vantaggio di non innescare i corrispondenti meccanismi di resistenza strenua da parte degli abitanti" (Saikoski,1999i, in Allegretti, 2000a).

${ }^{62}$ Cfr. Guareschi, 1980.

${ }^{63}$ A questa epoca nacquero quartieri privi di infrastrutture frutto di trasferimenti operati dal potere pubblico, come Vila Mato Sampaio e Fátima-Pinto a est, Maria da Conceição, São Vicente e Restinga a Sud (Guareschi, 1980).

${ }_{64}^{64}$ Per l'Assessorato alle Finanze di Porto Alegre si considera gleba un'area di almeno $10.000 \mathrm{mq}$. ${ }^{65}$ I 15 proprietari maggiori possedevano oltre 432 terreni (cfr. Barcellos, 1986).

${ }^{66}$ Ancora nel 1986 il primo sindaco democraticamente eletto della città pronuncerà questa celebre frase che riporta la città ai primi del '900: I terreni sulla parte alta della collina di Santa Tereza o sulla riva del Guaiba, dove l'edificazione è bloccata dal Piano, hanno finito per essere occupati da 'malocas'. Davanti al promontorio di Santa Tereza, dove carovane di turisti si affacciano ogni giorno, una favela contrasta con la città e offusca il decanta to tramonto degli opuscoli promozionali. I visitatori sono obbligati a cercare un angolo diverso per non fotografare quell'attestato di miseria e mancata capacità previsionale dei pianificatori dello sviluppo della capitale gaúcha (dichiarazione del Sindaco di Porto Alegre Alceu Collares sulla Revista Visão del 5/3/1986).

${ }^{67}$ Con questi criteri si sarebbero dovuti trasferire (con finanziamento PROMORAR) tutti gli abitanti delle 'vilas' do Respeito, Morro da Policia, Beco do Resbalo, Av. Sertorio, Caiu do Ceu, Tio Zeca, Tres fazendas e di altre 11.

${ }^{68}$ Cfr. Zero Hora, 31-12-1988.

${ }^{69}$ Circa le dimensioni dei lotti, il DEMHAB proponeva minimi inferiori a $150 \mathrm{mq}$ e misure differenti, mentre i cittadini proponevano lotti dai $150 \mathrm{mq}$ in su e tutti uguali; per le strade il DEMHAB non voleva ritrattare sulla larghezza minima di $12 \mathrm{~m}$; circa i versamenti mensili il DEMHAB li proponeva al $10 \%$ del salario minimo compresa la costruzione della casa, mentre gli abitanti li volevano al 5\% escludendo i costi della casa; le attrezzature comuni erano proposte dal piano alternativo disperse in zone diverse, mentre il DEMHAB le voleva concentrate in un parco unico. 
Fig. 14 - Il sistema della viabilità, molto vincolato dalla geomorfologia, ha mostrato - nel tempo - un 'struttura resistente': dai '5 caminhos' del 1810 (elaborazione tratta da Riopardense de Macedo, 1998) fino alla costruzione, in corso d'opera, dell'anello della Terza Circonvallazione Perimetrale (Foto: Allegretti, 2002) che rientra nel Sistema di Mobilità previsto dal nuovo Piano di Sviluppo Urbano e Ambientale sintetizzato nello schema qui sotto.
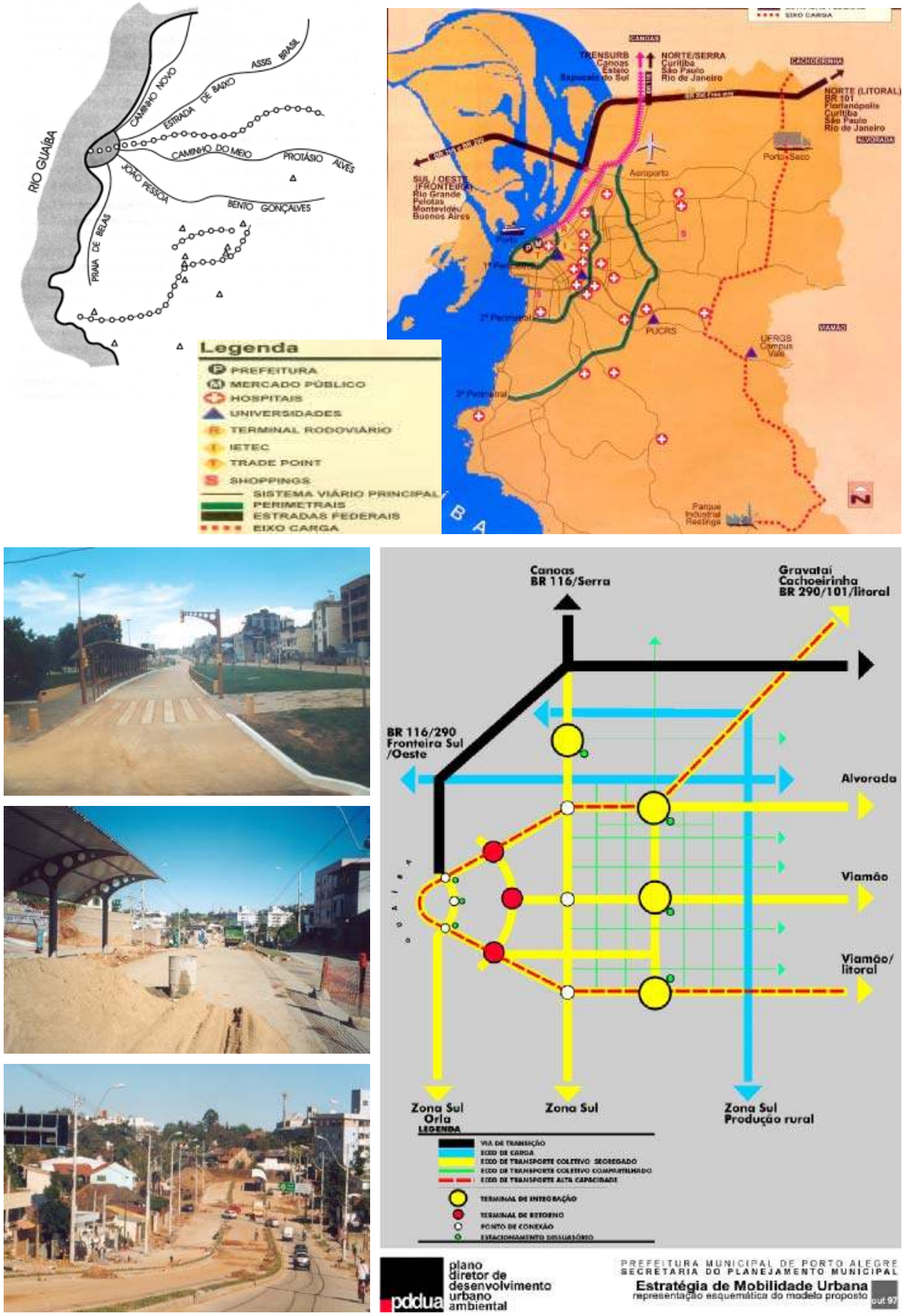


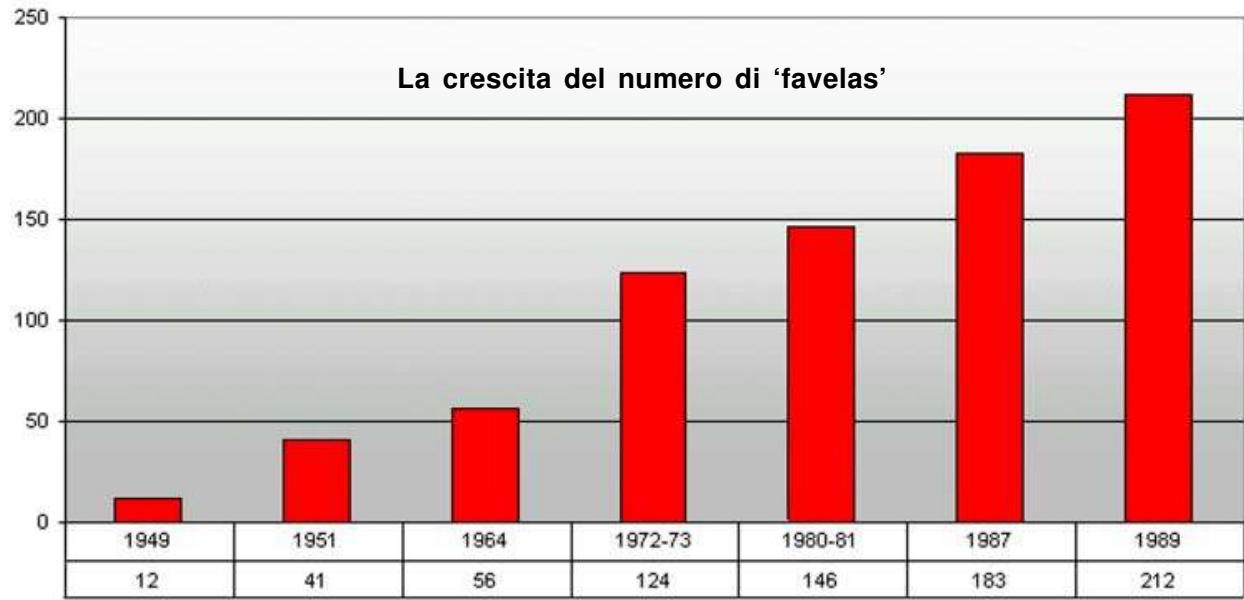

\section{Numero di baracche e numero di famiglie}

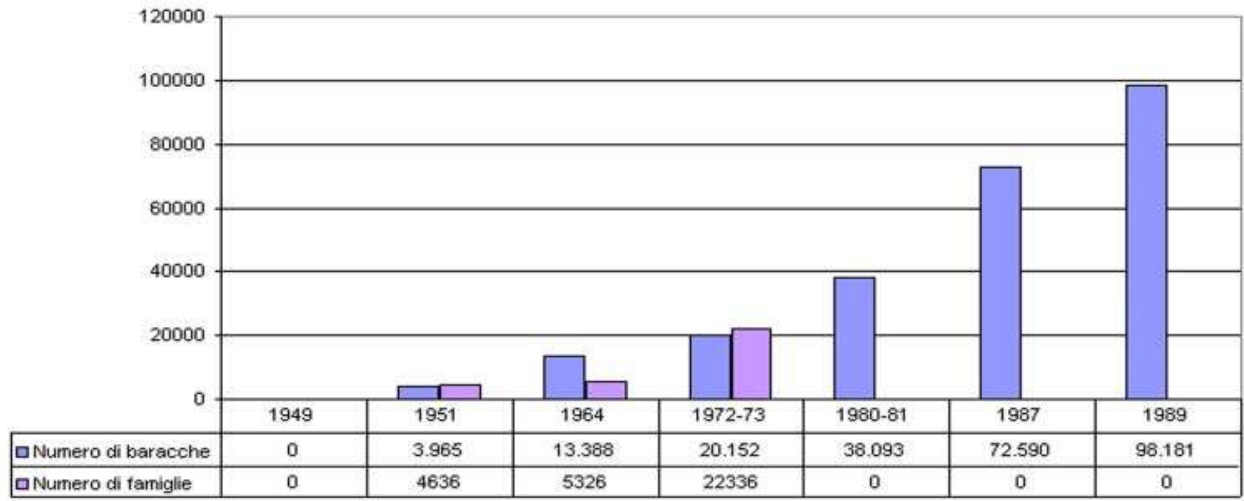

Tassi medi percentuali di crescita annua negli 'insediamenti informali'

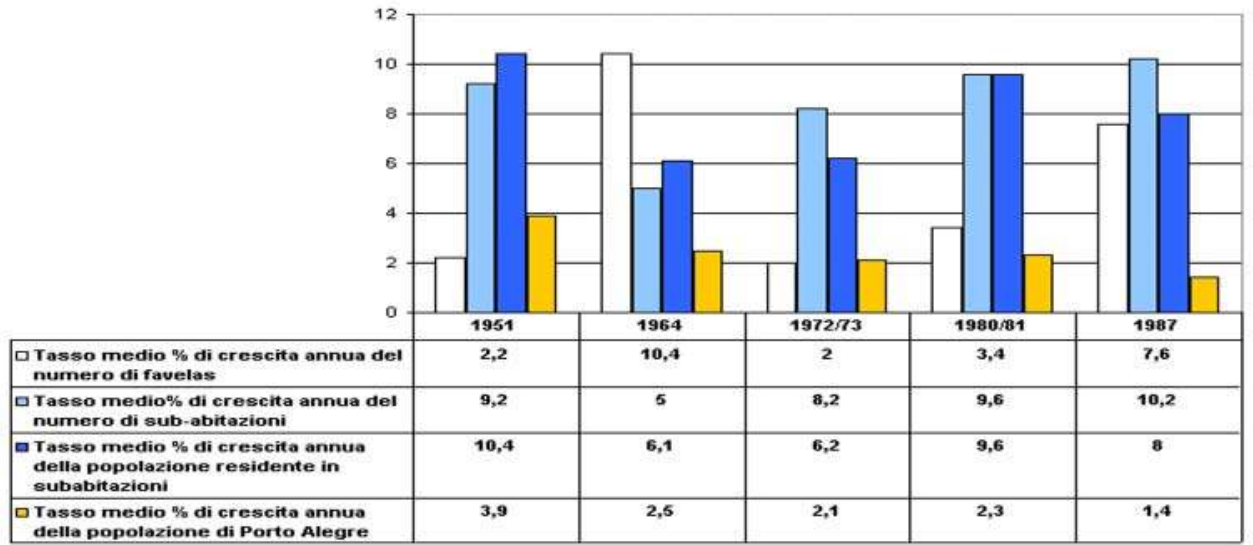

Fig. 15 - L'aumento progressivo degli insediamenti autocostruiti a Porto Alegre dalla $\mathrm{II}^{\circ}$ Guerra Mondiale all'avvento dell'Amministrazione Popolare nel 1989 (Dati: censimenti DEMHAB, SPM, IBGE degli anni citati) 
Fig. 16 - La 'città informale' a Porto Alegre oggi (Dati: DEHMAB, 1999, integrati con dati SPM, 1999)
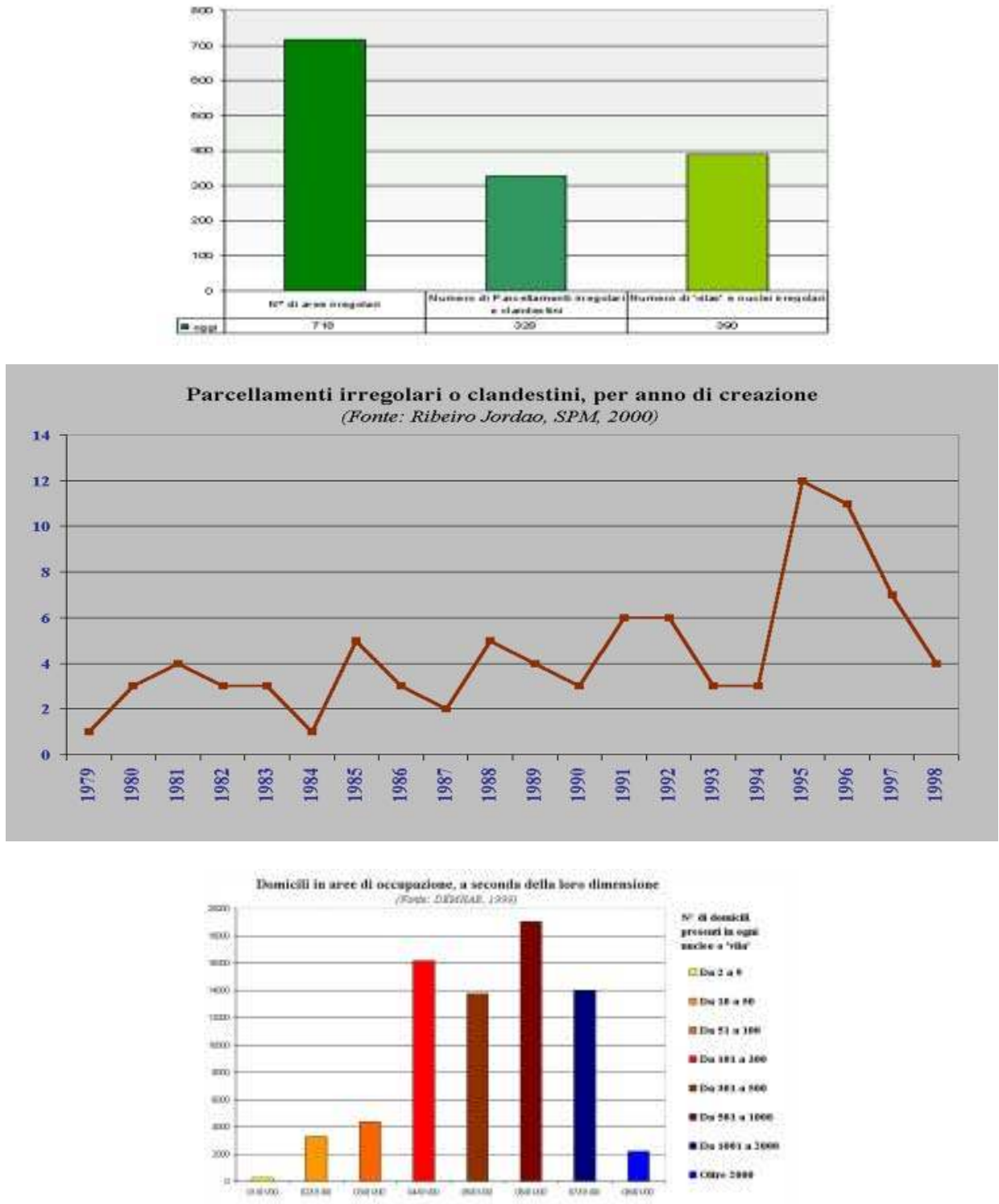

Al progressivo densificarsi della città, corrisponde un aumento dei nuclei irregolari di dimnsioni minori, che vanno a saturare piccole aree interstiziali. La conoscenza di queste aree da parte del Comune è fondamentale, specialmente perché l'IBGE non censisce come 'favelas' le aree con meno di 51 domicili.

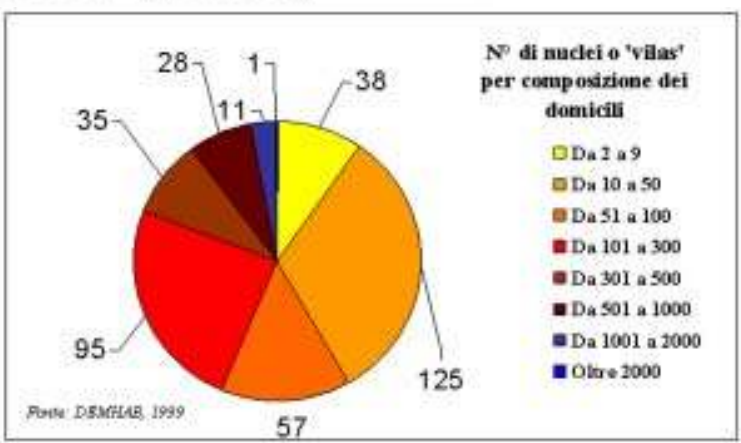




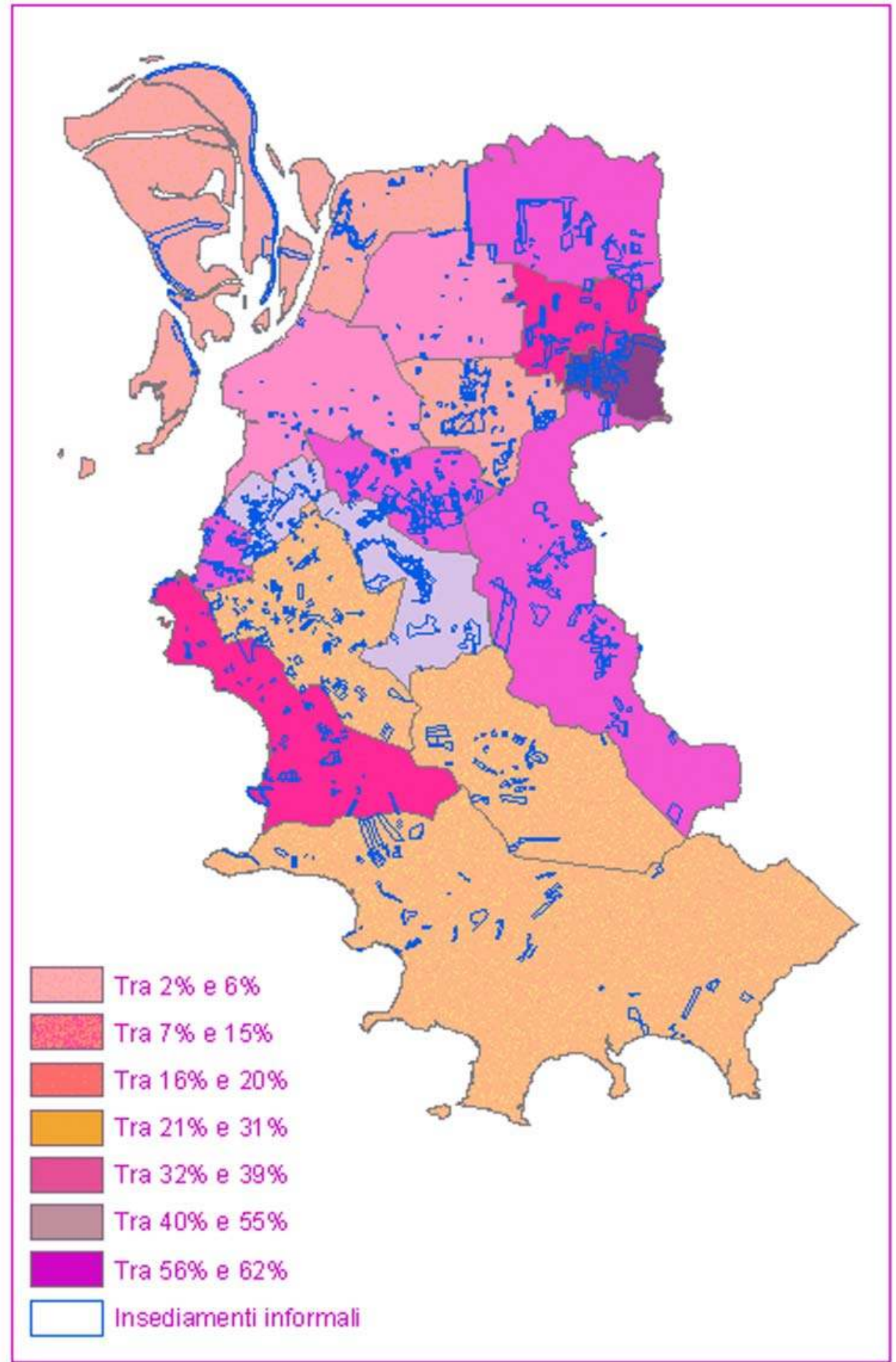

Fig. 17 - Percentuale di cittadini che abitano in domicili irregolari, sul totale della popolazione nelle diverse Regioni cittadine di Porto Alegre (Elaborazione dell'autore su dati: DEHMAB, 2001) 


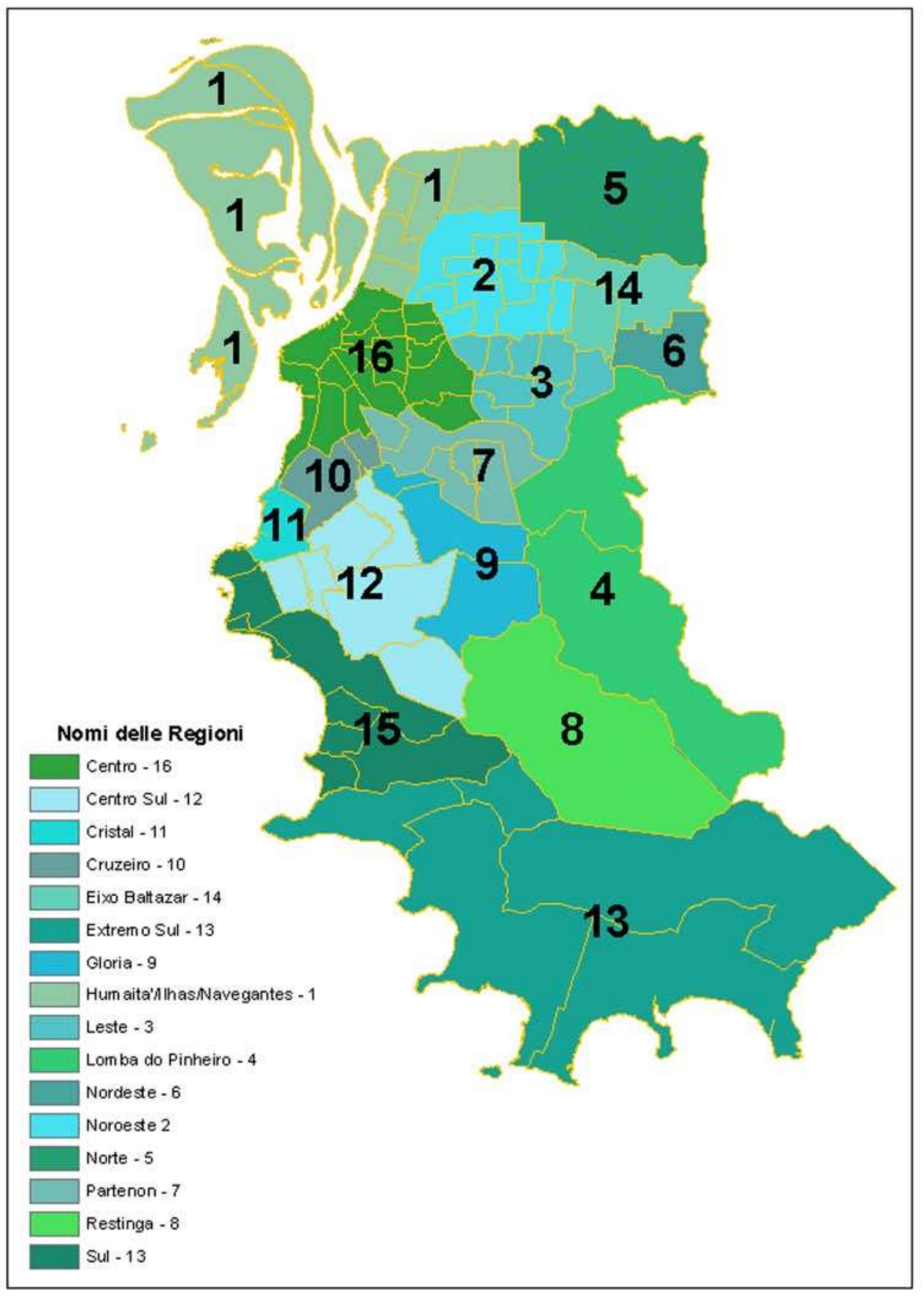

Fig. 18 - La spazializzazione del processo di Bilancio Partecipativo è stato il primo importante momento della costruzione del nuovo processo di gestione partecipativa delle scelte territoriali. Esso ha rispettato le preesistenti articolazioni dei movimenti comunitari e sociali. Così, oggi, 16 Regioni di Bilancio (ROPs) si sovrappongono agli 82 quartieri, contrapponendo ai 'confini bloccati' di questi una mobilità che ha assunto la forma attuale nel 1998, in seguito a numerosi auto-aggiustamenti. 

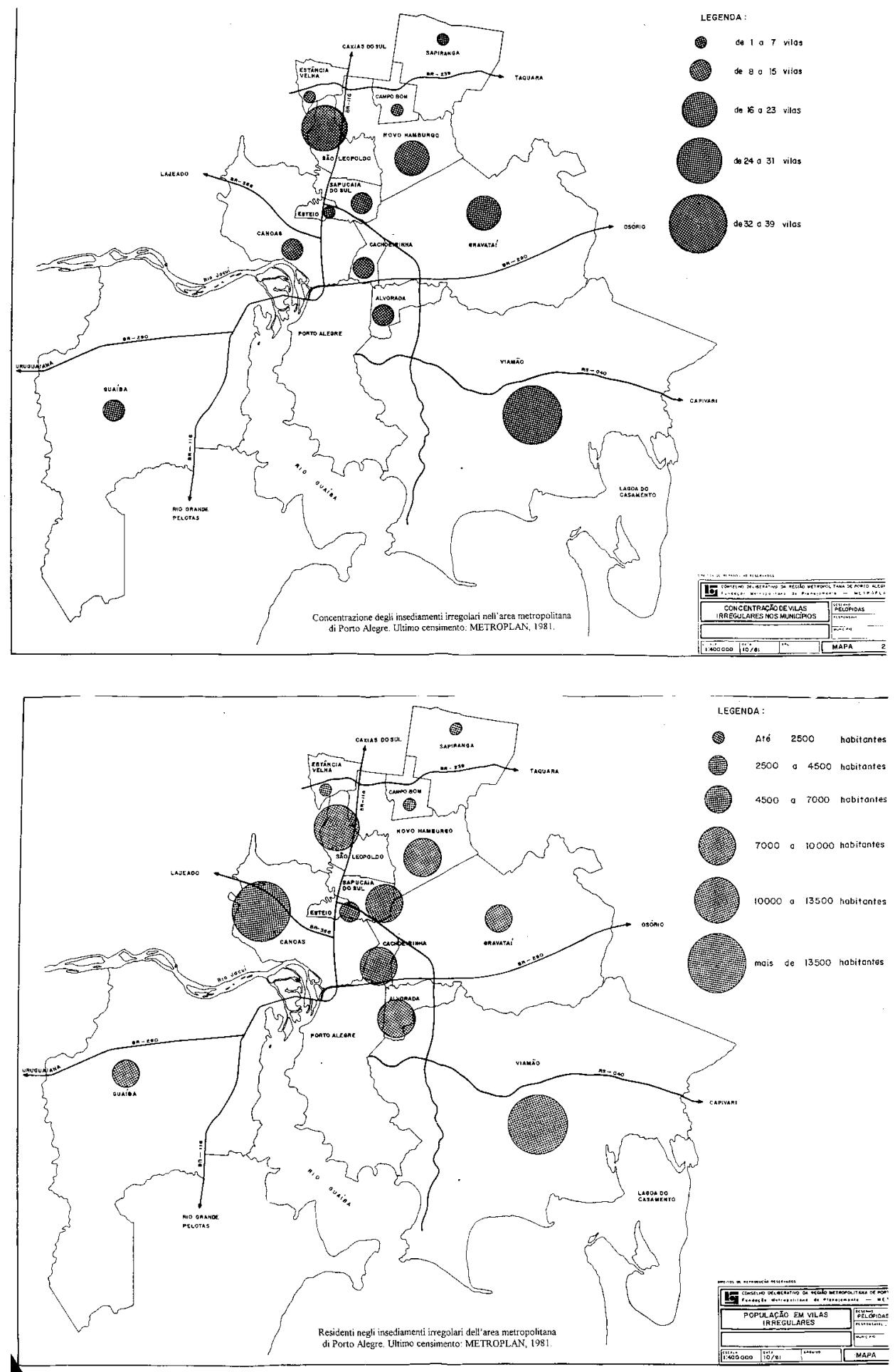

Fig. 19 - Distribuzione dei nuclei abitativi informali nella Regione Metropolitana di Porto Alegre (elaborazioni METROPLAN, 1981) 


\section{6 \\ Porto Alegre prima del 1989: movimenti urbani e apertura delle Istituzioni locali}

Un'analisi dettagliata delle vicende storiche che - a Porto Alegre - hanno visto l'emergere di movimenti popolari impegnati in battaglie di rinnovamento della scena politica e degli obiettivi del governo del territorio, esula evidentemente dalle finalità di questo testo. Per cercare, però, di comprendere le peculiarità del contesto in cui ha posto le sue radici il recente rinnovamento delle politiche urbane, può essere utile evidenziare alcune linee di tendenza che hanno segnato l'ultimo secolo, soffermandoci su alcuni 'momenti' maggiormente significativi.

\subsection{Il nascente protagonismo sociale nella Porto Alegre di fine Ottocento}

[Quella brasiliana] è una società [...] autoritaria in cui la sfera pubblica non arriva mai a costituirsi come pubblica, essendo definita sempre e in modo immediato dalle esigenze dello spazio privato, cosicché la volontà e l'arbitrio vengono a rappresentare i segni distintivi [...] delle istituzioni 'pubbliche' [Chaúí, 1986, pag. 55).

Come ha ben sintetizzato Marilena Chaú, la scena politica brasiliana degli ultimi due secoli si è distinta per le 'relazioni impositive' stabilite da gruppi di elite politica, quasi sempre avversi all'apertura di spazi formali dove i settori popolari potessero manifestare pubblicamente il proprio pensiero e la propria capacità di intervento propositivo nelle scelte per il territorio. In tale ottica, le pratiche clienteliste dei settori oligarchici, le pratiche populiste dei settori progressisti, e persino l'avanguardismo di alcuni gruppi rivoluzionari, non avrebbero rappresentato che "variazioni di uno stesso atteggiamento autoritario che non scorge nella società capacità di formulazione politica” (Pacheco, 2001, pag. 93). Un simile punto di vista - ormai diffuso nella recente storiografia brasiliana spiega perché la partecipazione alla vita pubblica dei settori popolari della società in Brasile abbia teso sempre a passare più per 'gli spazi informali' (come le proteste di piazza) che per i 'processi formali' (come - ad esempio - il meccanismo elettorale), dando corpo ad una 'strategia di resistenza' fatta di pratiche mirate a pervertire le relazioni socio-culturali di taglio autoritario 
150 imposte dai gruppi di potere dominanti. Questa 'strategia resistente' adottata dal "sapere popolare" raramente ha scelto la via dello scontro frontale, preferendo piuttosto quella della 'rielaborazione del discorso dominante', che non mira a superare i meccanismi autoritari proponendone altri radicalmente distinti, ma impegna le sue energie nel cercare di corromperli, nell' agire 'nelle brecce del sistema' per sovvertirne la logica escludente, generando così uno scontro simbolico che appare spesso mirato - in ultima analisi - a conseguire l'ampliamento degli spazi formali di partecipazione per l'allargamento dei diritti e del significato del termine 'cittadinanza'.

A Porto Alegre, questo 'scontro simbolico' si è reso esplicito e visibile negli spazi cittadini, specie a partire dal momento della proclamazione della Repubblica (1889). La ricerca di 'brecce' attraverso cui una vasta porzione della popolazione potesse manifestare i propri interessi davanti ad una visione politica autoritaria, ha innescato - infatti - un processo di costruzione di un'identità di 'cittadino' che ha cercato di definire 'cosa è un'azione politica' per la maggioranza degli abitanti.

Ricardo Pacheco (2001) ha realizzato un'interessante studio comparativo che - approfondendo alcuni eventi dei primi anni della Repubblica a Porto Alegre - ripercorre il progressivo costituirsi di una 'coscienza cittadina' attraverso pratiche informali di intervento nella vita urbana (dalle manifestazioni di strada al costituirsi di entità e organizzazioni di classe) e pratiche formali (come la presentazione di candidati della società civile alle elezioni) messe in atto da segmenti della popolazione tradizionalmente esclusi da ogni forma di discussione e decisione riguardante il territorio. ${ }^{2} \mathrm{Al}$ di là dei singoli episodi affrontati, Pacheco ha mostrato come lo spazio urbano della Porto Alegre di fine Ottocento abbia agito come luogo 'in transizione', in cui il mescolarsi di elementi antichi e moderni materializzava le trasformazioni sociali, economiche, e politiche, dando ai cittadini "la sensazione di stare in un mondo in movimento". ${ }^{3}$ In questo scenario, l'asse portante dello spazio urbano ha teso ad essere la strada, non più mera "estensione del focolare domestico", ma "spazio di vita collettiva, di una vita pubblica che lentamente si distingue dalla vita privata". Nel ricostruire l'incrociarsi di processioni religiose, feste pagane, commemorazioni civiche e manifestazioni politiche nelle strade cittadine divenute spazio di confronto simbolico (e luogo di 'performance' e di legittimazione di rappresentazioni e identità sociali variegate in cerca di un'affermazione sociale), Pacheco ha sottolineato due aspetti importanti di quell'epoca di intensa agitazione sociale:

1) la progressiva sostituzione di manifestazioni popolari 'guidate' da gruppi politici organizzati, con momenti di espressione 'autonoma' delle classi subalterne (spesso misconosciuti nel loro valore dirompente da quelle stesse elite che usavano la nuova libertà repubblicana di esercizio dei diritti di cittadinanza come forma di cooptazione al proprio progetto politico) ${ }^{4}$

2) la forte ispirazione positivista che ha distinto i Repubblicani 'gaúchos' da quelli del resto del Brasile, ${ }^{5}$ lasciando nella città un'impronta indelebile di attenzione agli elementi 'simbolici' che permeano gli spazi urbani. ${ }^{6}$

Questi due elementi - reiteratisi anche successivamente nella vicenda di Porto Alegre - hanno contribuito ad articolare nell'immaginario urbano una serie di rappresentazioni e pratiche sociali importanti per arricchire e ridefinire costantemente il campo del politico e dei 'diritti di cittadinanza' nelle diverse 
fasi storiche della vita urbana, rivelando continuamente la presenza di nuovi individui e/o gruppi interessati ad essere riconosciuti dallo Stato come portatori di diritti politici e di energie attive. ${ }^{7}$

Alle società di mutuo soccorso createsi tra il 1870 e il 1880, si sostituirono rapidamente gruppi di lavoratori organizzati concretamente in forme più visibilmente 'politiche' per la difesa dei propri interessi. Aggregazioni come la Liga Operária, ${ }^{8}$ la Liga Agrícola Industrial, il Centro Operário, ${ }^{9}$ o il Congresso dei Professori attingevano sovente ai principi positivisti a cui si riferiva il PRR, enucleandone però solo gli aspetti ritenuti 'convenienti' per la propria battaglia di classe; operavano, quindi, forme di mediazione simbolica che cercavano di rendere più 'permissive' le prospettive dell'ordine politico in quel momento trionfante.

Il Partito Repubblicano Riograndense, al potere a Porto Alegre nel primo quarantennio del ' 900 , tese sempre a deviare la crescente 'movimentazione sociale' per beneficiare politicamente delle pratiche di resistenza urbana attraverso cui essa prendeva forma ${ }^{10}$ ma al contempo disconosceva il valore politico di ogni azione autonomamente realizzata dai settori popolari. Questo fatto non bloccò il consolidarsi di pratiche sociali segnate dalla volontà di varie categorie ai margini delle decisioni politiche di prendere parte concretamente a dibattiti e scelte sulla conduzione dello Stato, e al contempo di legittimare la richiesta di diritti più ampi per il cittadino repubblicano. Anzi, in qualche modo il PRR ha dovuto riconoscerne la presenza e il ruolo sociale:

\footnotetext{
"Quando i repubblicani chiamano la moltitudine a scendere in strada per farne agente di pressione politica, si costringono a riconoscerne i membri come cittadini e detentori di diritti. Restano forzati a riconoscere la manifestazione di strada come una pratica legittima di esercizio della cittadinanza [...] modalità di interferire nelle questioni politiche. La moltitudine è riconosciuta come personaggio capace di esigere dallo Stato ciò che desidera sia regolamentato come diritto" (Pacheco, 2001, pag. 87)".
}

Questo protagonismo della cittadinanza è così gradualmente riuscito - per slittamenti successivi - ad ottenere che le proprie rivendicazioni di diritti (soprattutto sociali e del lavoro) venissero accettate e legittimate nell'immaginario sociale, anche grazie all'attenzione tributata dalla stampa 'non allineata' a quanto avveniva nello spazio pubblico cittadino. Se il protagonismo della cittadinanza è risultato a lungo 'elettoralmente sconfitto' o 'politicamente subordinato', è rimasto nondimeno 'socialmente proponente' (ibidem), in quanto le rappresentazioni e le pratiche politiche messe in atto hanno saputo dialogare nel tempo con le istituzioni locali, contribuendo sul medio termine a plasmare un'identità sociale peculiare per i cittadini portoalegrensi, dimostratasi di grande importanza come base di stimolo e di appoggio per le recenti trasformazioni delle politiche locali e regionali.

\subsection{Politica formale e protagonismo sociale: le occasioni di 'incontro' fino a metà del ' 900}

Tra il 1914 ed il 1917, la realizzazione dei primi programmi di edilizia popolare in cerca di una pax sociale innescò a Porto Alegre una serie di ulteriori rivendicazioni del proletariato, organizzato intorno alla Federazione Opera- 
152 ia, che aderì alla grande ondata di scioperi proclamati a livello nazionale paralizzando le attività cittadine. Fu durante questo periodo che si creò la Liga de Defesa Popular ${ }^{11}$ che riunì in un'unica piattaforma (e legò ai punti della lotta sindacale relativa agli orari e ai salari lavorativi) una serie di rivendicazioni connesse al miglioramento delle condizioni di vita delle città (come i prezzi dell'acqua e del trasporto collettivo), in un'ottica di divisione di responsabilità per cui alcune richieste venivano indirizzate al settore pubblico e altre direttamente ai privati proprietari delle aziende che impiegavano i lavoratori. L'operazione è interessante in quanto - tra l'altro - denota il nascere parallelo 'di un'identità di classe e di una identità di cittadini' (Menegat, 1995) che prendeva spazio sulla scena pubblica durante l'occupazione di piazze e di strade rappresentative alla ricerca di una soluzione di matrice pubblica per problemi che nella sfera privata non trovavano soluzione (Pacheco, 2001).

Il primo incontro fra la Liga e l'Amministrazione (Stato e Municipio) avvenne il 2 agosto 1917 mentre una grande folla attendeva davanti ai Palazzi della politica, ed ottenne alcuni concreti risultati valutati dall'organo di stampa più vicino agli scioperanti (il Correio do Povo) molto maggiori di quelli ottenuti nelle altre città brasiliane, ${ }^{12}$ seppur non precisamente sui punti che riguardavano i diritti della cittadinanza ad un'equa fruizione dei servizi urbani.

Il dibattito si mantenne acceso negli anni successivi, mobilitando anche importanti categorie professionali come gli Ingegneri. I loro organi rappresentativi inserirono nella discussione un importante punto di vista tecnico (Mello, 1918) ancorché caricato di connotazioni di tipo sociale e morale: corredato dalla presentazione di prototipi di case-tipo realizzabili a basso costo, il loro tentativo di intervento nel settore dell'abitazione popolare finì, infatti, per confondersi con un'azione umanitaria tesa a stabilire un'elevazione morale dei cittadini più poveri mettendo insieme sforzi pubblici (capaci di usare mezzi coercitivi severi) e dell'iniziativa privata.

Negli anni in cui il PRR fu al Governo a Porto Alegre, la politica amministrativa (tesa alla contrazione del debito pubblico, ad integrare il proletariato alla società divisa in classi, e a municipalizzare i servizi pubblici più di ogni altra capitale in Brasile) si orientò in una direzione "più permeabile alle trasformazioni dell'interesse popolare" che offrì alle classi meno fortunate "una possibilità concreta di orientare, in un certo senso, la definizione delle politiche urbane per Porto Alegre" (Menegat, 1995). In tale quadro, le prime organizzazioni popolari "contribuirono ad istituire una macchina amministrativa capace di affrontare, secondo i propri interessi, alcune complessità che la società e lo spazio urbano esigevano, e a consolidare una tradizione di mobilitazione intorno alle questioni urbane" (ibidem), sensibilizzando le istituzioni sulla necessità di creare meccanismi complessi - affinati poi in periodo populista - per farvi fronte.

Fu, però, tra la Costituzione del 1946 e il golpe del ' 64 che le peculiarità alla base dello sviluppo delle esperienze politiche urbane portoalegrensi presero forma. Due risultarono le caratteristiche specifiche 'salienti' del Rio Grande do Sul rispetto al resto del paese: l'enorme appoggio popolare che sostenne la crescita del PTB (il Partito Laburista) in tutto lo Stato, e il bi-polarizzarsi della politica in due blocchi partitici che si alternarono al potere durante tutto il periodo (il PTB-Partido Trabalhista, e il PDS-Partido Social Democrata originato dall'ARENA e appoggiato da quello Liberale, dall'Unione Democratica Nazionale e da nuclei minori). A livello nazionale, infatti, PTB e PDS erano alleati contro l'UDN, mentre a 
Porto Alegre e nel Rio Grande do Sul cominciarono un processo di alternanza, ${ }^{13}$ che vide una progressiva crescita del blocco laburista impegnato nel progetto 'sviluppista' di autonomia industriale proposto dal presidente Vargas, da raggiungersi mediante un patto fra classi popolari e borghesia nazionalista. La seconda particolarità è che il PTB gaúcho aveva una solida base popolare e sindacale e legami con nuclei di 'socialisti umanisti' che riequilibrarono in molte situazioni la presenza di membri dell'oligarchia e della burocrazia dello Stato Novo, entrati grazie ai loro vincoli personali e clientelari con Vargas (Pont, 1985).

L'idea dello sviluppo industriale 'a macchia d'olio' concentrò in quegli anni l'impegno dello Stato nazional-populista sull'asse Rio de Janeiro-São Paulo, centro dinamico sulle cui necessità tendevano a forgiarsi le economie delle altre regioni del paese e dove l'accumulazione del capitale privato subiva grosse accelerazioni. Nel tentativo di affrancare il Rio Grande do Sul dalla sua temporanea esclusione dai centri nevralgici della crescita, il PDS e il PTB si differenziarono per il diverso grado di appoggio dato alle attività tradizionali dell'agricoltura e dell'allevamento, nel primo preponderante (Pesavento, 1990) ed in sottordine nel secondo, che per questo ancora oggi - persino dai suoi detrattori (Pont, 1985) - si vede riconosciuto il contributo dato alla storia delle conquiste ottenute dalle classi popolari.

Esempio di come il PTB riuscì a raccogliere il sostegno popolare è certo Leonel Brizola che - eletto Sindaco di Porto Alegre nel 1955 - tentò di far approvare un Piano di Lavori Pubblici in supporto delle aree più povere della città, e di finanziarlo con l'aumento delle tasse alle fasce di reddito superiori della popolazione. Visto che la proposta di tassazione progressiva era stata fortemente avversata in Consiglio Comunale,${ }^{14}$ Brizola si rivolse ai sindacati per trovare aiuto in una campagna di denuncia "contro $i$ difensori degli interessi delle classi più alte" e organizzò una forte mobilitazione popolare mirata all'approvazione della Riforma Tributaria.

La campagna si concluse con un Manifesto dei Lavoratori e del popolo del Rio Grande do Sul che sancì l'appoggio a Brizola di 5 Federazioni e 16 sindacati e gli garantì un trionfo con 170.000 voti di scarto alle elezioni per Governatore del 1958. Con questa carica, egli portò avanti un programma di interventi nell'economia gaùcha per correggere le 'disparità regionali' con l'appoggio di imprese multinazionali, anche mettendo in atto grossi espropri per ampliare la rete scolastica e contribuire alla Riforma Agraria, per realizzare cioè alcune di quelle 'riforme di base' che il PTB in altri stati non riusciva a concretizzare mancando dell'indispensabile appoggio di ampi settori della società civile e dei nascenti movimenti popolari.

\subsection{La società locale alla conquista di uno spazio sulla scena politico/am- ministrativa}

L'appoggio offerto a Brizola dalle classi popolari nel ' 58 provocò il progressivo sfuggire di alcune azioni dal controllo che il partito pensava di poter esercitare sui propri elettori, come in occasione delle occupazioni di terra realizzate dal MASTER con l'appoggio dei Sindacati e della Unione Studentesca [UEE], che divennero sempre più frequenti nei primi anni '60. Ciò non impedì al PTB di approfondire la tradizione di dialogo tra Stato e richieste popolari iniziata sotto i governi positivisti: essa rese possibili trasformazioni amministrative importanti 
154 come la riscossione delle imposte su base progressiva al fine di realizzare investimenti sociali. La gestione politica che si inaugurò in periodo populista andò così ben oltre quella che di solito è liquidata come "distribuzione di promesse $e$ favori a fini di scambio elettorale" (Menegat, 1995), ovvero una fase in cui le rivendicazioni dei movimenti popolari (considerate solo se legalmente registrate e incamminate per i tradizionali percorsi della burocrazia istituzionale) si limitavano a 'concessioni paternalistiche' di amministratori verso loro protetti (Zaniratti, 2000).

L'istituzione, con lo Statuto Comunale del 1956, di due importanti Consigli Municipali (quello dei Contribuenti per arbitrare questioni tra contribuenti e Fisco, e quello dei Servizi Pubblici, cfr. art. 140) costituì, infatti, uno dei primi segnali di apertura formale dell'apparato amministrativo alla partecipazione della società civile. L'esistenza di un percorso di democratizzazione delle istituzioni locali - se non ottimale comunque superiore a tutte le altre capitali brasiliane - fu sottolineata anche dalla creazione nel 1955 - con Legge 1413/55 - del CMPDDU (Consiglio Municipale del Piano Direttore di Sviluppo Urbano), forum incaricato di collaborare alla stesura, completamento e revisione in progress del Plano Diretor e al pre-progetto di Regolamento Edilizio, che vedranno la luce nel 1959. Esso, all'epoca, riuniva 6 rappresentanti dell'Esecutivo ${ }^{15}$ e 5 di entità pubbliche e di categoria interessate, che all'inizio ${ }^{16}$ annoveravano ad esempio - i Dipartimenti Statali di Statistica e della Sanità, l'Istituto degli Architetti, le Società di Ingegneria e Agronomia ed un rappresentante di Associazioni di Amici del Quartiere, il primo ad essere abolito nel 1964 con il sopraggiungere del regime militare (Fruet, 1991).

Dalle poche ricerche approfondite sulle Associazioni di Quartiere a Porto Alegre (Guareschi, 1980; Ferretti, 1984; Menegat, 1995, Baierle, 1996) emerge il ruolo che queste svolsero nel re-indirizzare - nel corso de gli anni - gli investimenti pubblici verso specifiche aree della città. È al 12 ottobre 1945 che risale la prima Associazione di Quartiere portoalegrense, nata nella zona ex-industriale di Navegantes e chiamata Associação dos Amigos do $4^{\circ}$ Distrito de Porto Alegre. ${ }^{17}$ Molte altre ne seguirono nel 1946 (le prime a Belém Novo, Vila São Borja, Vila Leão e Camaquã) e si legarono negli anni '50 soprattutto ai processi di lotta proinfrastrutturazione dei nuovi insediamenti (quasi tutti abusivi) che sorgevano con rapida progressione in città: ben 94 tra il 1948 ed il 1955, di cui 27 solo nel 1953 (Menegat, 1995).

Nel 1959 il sindaco Loureiro da Silva (PL-PDC) patrocinò - con lo scopo di controllarne la crescita spontanea e di stabilire proficui contatti clientelari con i leader - il " ${ }^{\circ}$ congresso delle Associazioni di Quartiere di Porto Alegre", al termine del quale nacque la FRACAB, Federazione delle Associazioni Comunitarie e di Amici del Quartiere.

$\mathrm{Nel}$ "60 fu invece la volta del " $2^{\circ}$ Congresso", il primo "Metropolitano delle Associazioni di Quartiere". Da esso uscì la "Carta Rivendicativa della Cittâ" in cui si richiedeva ai Comuni attenzione all'infrastrutturazione, ai servizi e alla regolarizzazione delle terre, grande novità per un'epoca che ancora concepiva solo la politica degli sgomberi forzosi. Nell'occasione del $2^{\circ}$ Congresso furono anche chieste sedi proprie per le Associazioni di Quartiere; purtroppo le richieste più interessanti si persero in una pletora di altre accessorie, tra cui persino laghetti di pesca e giardini zoologici (Menegat, 1995).

Nel 1961, il "III Congresso Metropolitano delle Associazioni di Quartiere" si 
pose come obiettivo la discussione con gli amministratori dei problemi generali della città e dei vari nuclei residenziali in particolare. Nel 1962 nacque invece la LIBRA [Bilancia], cioè la Liga Interbairro Reivindicatória e Assessoradora, che - per iniziativa di Associazioni della zona Nord della città - mirava a rafforzare la debole autonomia della Federazione delle Associazioni di Quartiere, attraverso una 'partecipazione umanista, anti-paternalista e di auto-determinazione', ed uno scambio costante con Sindacati, movimenti studenteschi e gruppi di donne. Il "IV Congresso Metropolitano delle Associazioni di Quartiere" del 1966 seguì al golpe militare del 1964 e non ebbe seguito fino ai tardi anni '70. Ovviamente, ebbe carattere molto diverso dagli altri, in quanto le rivendicazioni urbane vennero trattate 'riducendole a questioni tecniche e di pianificazione' (Menegat, 1995) anche se dalle maglie del controllo istituzionale sfuggì un documento che denunciava l'alto costo della vita. Gli elementi più indicativi della volontà di istituzionalizzazione controllata dei movimenti popolari da parte del neonato regime furono la proposta di uno statuto-tipo per tutte le Associazioni e la concessione di un 'Diploma di Lider Comunitario' che riportavano l'autonomia delle varie organizzazioni sotto lo stretto controllo governativo, a somiglianza di quanto - su scala nazionale - il generale Castelo Branco aveva fatto con i partiti di opposizione, sciolti e formalmente riuniti nel MDB dove confluirono soprattutto i membri del PTB e del MTR (Movimento Trabalhista Renovador).

\subsection{Le Associazioni di Vicinato a Porto Alegre verso il tramonto del regi- me militare}

Come accade spesso nei regimi dittatoriali, l'associazionismo su base vicinale (cfr. box. 4) restò pressoché la sola forma di aggregazione 'autonoma' dei cittadini ammessa in Brasile per quasi tutto il ventennio. La garanzia di istituzionalizzazione concessagli dal neonato regime militare (pur minandone l'autonomia) permise almeno il mantenimento di un certo livello di aggregazione popolare attraverso la promozione di incontri, simposi e seminari; nei fatti, garantì - poi - una 'copertura' ad alcuni oppositori del regime, che riuscirono così a sfuggire alle maglie della repressione (Baierle, 1996).

Per lo più, il formarsi di Associazioni di Quartiere 'di opposizione' fu ostacolato dall'ARENA, il partito dei militari al potere dal '64; ma ciò non avvenne tanto - come si potrebbe pensare - attraverso la repressione, piuttosto stimolando il sorgere di entità parallele attraverso cooptazioni e scambi di favori con gli abitanti: a Porto Alegre questo accadde ad esempio a Vila Caiu do Ceu e a Vila Campo da Tuca (cfr. Menegat 1995). Alcune di queste entità parallele stimolate dal regime finirono, però, per cambiare posizione nel momento in cui si accorsero che molte delle promesse dei militari rimanevano irrealizzate dopo il periodo elettorale; a Porto Alegre è il caso di Vila São Vicente Martir, dove fu portata avanti una campagna diffamatoria del candidato che gli abitanti avevano contribuito ad eleggere e si ebbe una rifondazione dell' Associazione a partire dal basso. ${ }^{18}$ In tale quadro, veri e propri processi di delegittimazione politica degli spazi istituzionali cominciarono ad essere condotti all'interno di molte Associazioni di Quartiere - con l'appoggio della stampa locale - soprattutto a partire dall'indebolimento dei militari intorno al 1979, quando tali associazioni vennero a configurarsi come spazi alternativi di risignificazione della politica e dello 
spazio pubblico a partire dal quotidiano (Menegat, 1995).

In parallelo a queste trasformazioni più o meno sotterranee (e comunque spesso limitate all'ambito dei quartieri popolari), la tradizionale struttura bipolare del panorama politico riograndense si riprodusse all'interno dei blocchi politici legali sanciti dal regime militare. E nel contesto di polarizzazione politica, le organizzazioni delle classi popolari apprendevano il cammino verso l'unità, affrontando la necessità di risolvere il rapporto fra le proprie caratteristiche interne di eterogeneità sociale e di pluralismo politico, prima di decidere di dare definitivamente il proprio appoggio al fronte laburista (Menegat, 1995).

Durante il regime militare, nel blocco partitico filo-governativo (ARENA) confluirono in gran parte i membri del Partito Socialdemocratico, mentre nel blocco 'di opposizione' (MDB) confluirono il PTB, il MTR e il PDC; questo divenne un succedaneo del vecchio Blocco laburista e vinse nel Rio Grande do Sul tutte le elezioni statali dal 1966 al 1978 (gli anni della restrizione antipartitica) confermando, con particolare forza a Porto Alegre, la tradizione di opposizione al governo centrale tipica dello Stato gaúcho.

Nel Rio Grande do Sul, infatti, il MDB mantenne un chiaro profilo che dal PTB aveva ereditato soprattutto la capacità di legarsi ad ampi settori popolari strutturando spazi di militanza altrove inesistenti, come il Settore Giovane o il Dipartimento delle Donne a cui si deve la proposta di creazione della 'Tendenza Socialista' che - diffondendosi capillarmente in sezioni sul territorio mantenne il fronte unito nel momento in cui l'apertura del dibattito sulla riarticolazione dei partiti (1978) rischiò di frammentarne la forza. A Porto Alegre, il grande sciopero del 1979 dimostrò l'elevata capacità di articolazione e mobilitazione delle varie organizzazioni che orbitavano intorno alla Tendenza Socialista del MDB, in particolare delle Associazioni di Quartiere di Vila Tamanca (nella Lomba do Pinheiro) e di Vila Fatima (nella zona est di Porto Alegre) a cui appartenevano un alto numero di operai del settore dell'edilizia civile e che organizzarono gruppi di donne e bambini che raccoglievano fondi per sostenere lo sciopero.

Con la riforma partitica successiva, la quasi totalità degli affiliati alla cosiddetta 'Tendenza Socialista' (e molti leader dei nuovi movimenti sociali urbani) migrò nel costituendo PT-Partito dos Trabalhadores, contribuendo in modo determinante a definirne il profilo: esso potè così farsi forza dell'esperienza anticipatrice di legami organici con le classi popolari maturata sotto l'ombrello legale del $M D B$ anche in periodo di regime militare (Menegat, 1995). Il Rio Grande do Sul fu forse l'unico Stato dove un simile percorso prese forma in maniera così evidente, a motivo della lunga e articolata tradizione bipolare maturata nella prima metà del secolo, e della mobilitazione popolare portata avanti anche sotto la repressione attraverso il mascheramento degli spazi di discussione politica con attività culturali, educative e persino religiose (ad esempio all'interno delle CEBs, le comunità di base di evangelizzazione e resistenza) ${ }^{19}$ tese alla formazione di una coscienza anche politica per le classi popolari. Il prevalere di migrazioni interne nello Stato del Rio Grande do Sul - anche durante i grandi flussi migratori e di urbanizzazione degli anni '60 e' 70 - determinò una sostanziale omogeneità nella condivisione delle tradizioni politiche e culturali, e del radicamento in esse delle diverse iniziative di organizzazione popolare; in particolar modo nelle aree più povere. 


\subsection{Dalla protesta alla propositività: il nuovo protagonismo dei movimen- ti cittadini}

È in epoca populista che - attraverso il formarsi delle SABs (cfr. box 4) - andò sostanzialmente profilandosi la nascita di un vero e proprio attore politico nuovo espressamente votato a dibattere le questioni locali, sia attraverso la formulazione collettiva delle richieste che attraverso la negoziazione della loro soddisfazione. ${ }^{20} \mathrm{Si}$ determinò, così, l'apertura di un nuovo spazio pubblico ideale per la negoziazione di rivendicazioni urbane tra i cittadini e l'apparato amministrativo, poi rimodellato in conseguenza dei mutamenti istituzionali fino a generare quelle strutture che ancora oggi si segnalano come spazi ulteriori di esercizio della democrazia diretta. Se del primo periodo di sviluppo delle associazioni di vicinato di Porto Alegre non resta molta documentazione, meglio va per il periodo che parte dalla decadenza del regime militare, quando il crescere del protagonismo popolare trovò rappresentazione e supporto nelle prime ricerche di ambito universitario svolte sui temi dell'abitazione (Pereira, 1980, Garayp, 1980, CAMP, 1987) e dell'organizzazione della popolazione intorno ai problemi dell'habitat.

Il lavorio svolto dalle più significative associazioni di vicinato, principalmente concentrate nei quartieri 'irregolari', verteva - del resto - a quell'epoca principalmente sulla problematica dell'accesso ai suoli e al possesso della terra, sulle carenze di infrastrutture e servizi e sulla richiesta di autonomia delle organizzazioni stesse. Guareschi (1980) ha tentato di ricostruire il tessuto organizzativo dei nuovi movimenti sociali urbani intorno agli anni della rinascita dei partiti (1978-79), evidenziando come in ben 61 delle 128 aree di sub-abitazione all'epoca censite siano rilevabili forme di mobilitazione popolare ed un crescente interesse della stampa locale per quel tipo di rivendicazioni. ${ }^{21}$ Gli studi di Ferretti (1984), Rosa Ribeiro (1985) e Menegat (1995), partendo da una visualizzazione dell'ubicazione delle principali rivendicazioni del periodo 1978/84 in rapporto ai nuclei di sub-abitazione esistenti in città (fig. 13) hanno confermato lo stretto legame esistente tra città informale e 'movimenti resistenti', e la sostanziale continuità di sviluppo delle organizzazioni urbane nello spazio cittadino.

La LIBRA, formatasi nel 1961 facendo riferimento alle antiche esperienze del movimento sindacale, aveva costituito il primo tentativo di rottura con la tradizione di controllo delle Associazioni di Quartiere da parte dei partiti politici e delle Istituzioni; il suo tentativo di introdurre nuovi valori nel quotidiano delle mobilitazioni. Scegliendo esplicitamente di non creare un'entità parallela a quelle già esistenti ma di rifondare le stesse dall'interno, aveva inaugurato una tradizione di risignificazione delle organizzazioni, avversa alla loro moltiplicazione, ma era poi naufragata davanti alla volontà del regime militare di imporre un controllo sull' associazionismo popolare, appunto attraverso la creazione di 'entità parallele' concorrenti alle esistenti, e da esso forgiate. Il tentativo della LIBRA di Porto Alegre non andò però del tutto dimenticato: l'interruzione dovuta alla repressione militare creò sì una discontinuità nella costruzione dei nuovi valori aggregativi, ma non rappresentò una loro scomparsa (Menegat, 1995). Così, a quell'esperienza e ai suoi valori fondativi attinsero alla fine degli anni ' 70 le organizzazioni di quartiere che - approfittando della debolezza del regime - rinacquero sbandierando i vessilli dell'autonomia e dell'indipendenza politica.

A Porto Alegre, le nuove Associazioni di Abitanti (AMs) che cominciarono a 
sorgere in sostituzione delle SABs ormai troppo compromesse con il morente regime, scelsero di ampliare i propri canali di lotta politica, sia recuperando modalità di espressione tipiche della 'cittadinanza informale' di inizio secolo (rese più incisive da picchetti davanti al Comune o barricate nei punti nevralgici della circolazione), sia costruendo alleanze strategiche e mettendo in opera forme di volontariato cooperativo [mutirões o cooperative di aiuto reciproco]. ${ }^{22}$ I canali di comunicazione vennero invece potenziati con denunce sulla stampa ormai 'liberata' e attraverso la divulgazione di 'Lettere aperte' (tra le prime vi furono quella elaborata nei quartieri clandestini di Vila Respeito nel 1979 e di Vila União nel 1982, cfr. Menegat 1995) che tentavano di rovesciare l'immagine di 'marginalità' ormai associata agli abitanti dei quartieri 'irregolari', rivendicando con fierezza lo status di lavoratori regolari di molti di loro, e organizzando la popolazione per far pressioni sulle Istituzioni onde bloccare le azioni di sgombero sulle aree occupate. Quest'ultima lotta ebbe un peso determinante ai fini dell'organizzazione ottimale della rete dei movimenti cittadini, in direzione dell'acquisizione di una forza unitaria a livello urbano e articolata ai diversi livelli del locale. Quando nel marzo del 1979 le ruspe cominciarono ad abbattere 60 abitazioni a Buraco Quente [Buco caldo], uno dei 5 insediamenti della favela denominata Vila Tronco sul panoramico Morro Santa Tereza (da cui si godeva una meravigliosa visuale sul Lago Guaiba), si creò a Porto Alegre un forte movimento di opinione che rese possibile in pochi giorni la rioccupazione dell'area, ribattezzata Buraco Frio. Molte furono le Associazioni di Quartiere formatesi in quei giorni, ed una grande assemblea sul campo da calcio riunì oltre 800 persone in un dibattito sulle ragioni dello sgombero, voluto per dare attuazione al nuovo PRG che - incurante degli usi reali del suolo - aveva previsto quell'area come zona di preservazione ambientale, sperando di togliere ai turisti la pessima impressione causata dalle baracche in quell'area pregiata. Le mobilitazioni a Vila Tronco generarono la diffusa convinzione che quell'esempio di capillare organizzazione resistente potesse essere " $r$ prodotto in un gran numero di quartieri nelle stesse condizioni" (Ferretti, 1984). Gli stessi abitanti di Santa Tereza, minacciati poco dopo da un progetto viario che tagliava in due l'area, sentirono la necessità di dare articolazione stabile al tessuto di lotte da poco sperimentato e fondarono la União de Vilas da Região da Cruzeiro do Sul, un'entità che raggruppava tutti i rappresentanti delle Associazioni di Quartiere della zona chiamata Grande Cruzeiro, un aggregato di circa 40 favelas di diverse dimensioni a sud della città. L'iniziativa fu seguita l'anno seguente da altre regioni cittadine (Lomba do Pinheiro, Gloria, Partenon, Zona Norte) che contenevano le 6 principali macroaree di sub-abitazione dell'intera città, identificate dall' Assessorato all'Urbanistica $[\mathrm{SPM}]$ in base a criteri tecnici che determinavano risultati di delimitazione leggermente diversi da quella datasi autonomamente dagli abitanti a partire dalla storia dell'articolazione territoriale delle loro identità culturali, sociali e politiche (Menegat, 1995).

Le nuove 'Articolazioni Regionali' - riunendo differenti associazioni esistenti entro identificati confini territoriali (CEBs, Chiese Evangeliche, Centri di Umbanda, Squadre di calcio e Club di madri) - riuscirono in breve ad ottenere alcuni interessanti successi. ${ }^{23}$ Rispetto alle semplici Associazioni di Quartiere, queste nuove forme di articolazione della lotta urbana tesero a porsi 
obiettivi via via più ampi a partire dai luoghi del quotidiano, aprendo la strada ad un'ampliarsi del senso e della portata dell'opera rivendicatoria dei movimenti. La nuova nozione di 'Regione' elaborata trascendeva, infatti, i limiti territoriali 'burocratici' dei quartieri, divenendo una sorta di "mappatura interna della città prodotta a partire dalla particolare lettura dello spazio urbano che proposero i nuovi movimenti sociali" (Menegat, 1995). Al desiderio di una maggiore efficienza nell'opera di pressione sulle Istituzioni, l'articolazione in Regioni univa quello di elevare i livelli di organizzazione e politicizzazione popolare in modo da tener presenti trasformazioni sostantive nella relazione tra Stato e cittadini, e anche da veicolare una percezione più globale delle questioni urbane a partire da problemi e progetti comuni.

A cavallo fra gli anni Settanta e Ottanta, la trasformazione delle modalità di lotta delle nuove aggregazioni popolari, coincise anche con una trasformazione dei loro obiettivi rispetto al periodo della Repubblica Vecchia. Tale evoluzione riguardò soprattutto due nodi tematici: il passaggio dalla lotta per affitti a prezzi equi alla rivendicazione della regolarizzazione della terra (che evidenzia il mutamento portato dai programmi di costruzione di case popolari e dall'abitudine all'autocostruzione a concepire la 'casa propria' come il segnale di una raggiunta sicurezza sociale) e il trasferimento dell'iniziativa di mobilitazione popolare dall'ambito sindacale al sistema politico istituzionale.

Intanto, le pressioni dei principali leader dei movimenti urbani - affiliatisi a partire dal 1982 ai rinati partiti politici (PT, PDT, PMDB, PCdB o PCB) contribuirono nel 1982 alla redazione di programmi di partito più o meno accomunati dalla presenza di un nuovo discorso partecipativo (Ferretti, 1984), mentre dal 1983 la lotta comune si spostò sul 'Movimento per l'insegnamento pubblico e gratuito", che a Porto Alegre ottenne cospicui successi nella regione della Grande Santa Rosa (zona Nord) e dimostrò che si andava costruendo una nozione di pluralismo socio-culturale che oltrepassava la politica dei partiti puntando a unificare la pluralità (Silva, 1985) e a costruire nella pratica un'autonomia dei movimenti urbani che più che riferirsi a modelli prestabiliti di democrazia e partecipazione (magari forniti da partiti o istituzioni) facevano leva sugli errori commessi e sulla "memoria collettiva delle esperienze di lotta del passato, da cui estraevano i principi che orientavano il ricorso alle nuove pratiche" (Menegat, 1995).

La difesa delle forme autonome e indipendenti di auto-organizzazione popolare costituirà da quel momento uno degli elementi fondamentali della nuova cultura politica (Sherer-Warren e Krischke, 1987) in alternativa all'autoritarismo caratteristico delle pratiche clientelari e al centralismo di una sinistra che altrove non si faceva scrupolo di usare i movimenti urbani per sostenere strategie pre-tracciate di lotta per il socialismo o il comunismo.

A Porto Alegre, una tale difesa di autonomia si legò strettamente a gesti simbolici (come l'auto-costruzione del Ponte di Vila Campo da Tuca nel luglio 1978) che - oltre a sperimentare la forza dell'azione collettiva - miravano a sottolineare il desiderio dei 'marginalizzati' di rompere il proprio isolamento in maniera autonoma. Proprio approfittando del vicino periodo elettorale, le associazioni mostravano di sapersi auto-organizzare ed unire senza più aspettare dai politici le soluzioni ai propri bisogni. All'epoca il motto più diffuso divenne pertanto: Lavorare per noi stessi e non attendere dallo Stato. ${ }^{24}$ Alle Associazioni di Residenti vennero presto ad affiancarsi le Commissioni 
di Residenti, strutture agili per situazioni di emergenza che richiedevano immediate risposte (come nel caso di sgomberi forzati) per supplire alla mancanza di AMs con status legale, o quando queste erano capeggiate da leader in accordo col Comune e avversi all'interesse degli stessi abitanti.

A partire dal 1982 (in occasione dello sgombero paventato degli abitanti di Vila União) prese il via anche la formazione di "Comitati di Appoggio" alle singole iniziative delle Associazioni di quartiere, formati da consulenti, ONG, gruppi di studenti universitari e rappresentanti di associazioni di categoria con cui si mirava "a sottrarre la lotta urbana al carattere spontaneo e marginale per dargli forza nel confronto col potere pubblico" (Rosa Ribeiro, 1985).

In questi anni, la FRACAB - fino al 1977 finanziata dallo Stato nell' ambito di un programma paternalistico-clientelare e poi abbandonata a se stessa per vendetta politica dopo uno sfavorevole risultato elettorale - seppe risollevarsi, attingendo ai fondi delle singole Associazioni affiliate e divenne (articolandosi in 'dipartimenti tematici') il centro dello scambio di esperienze, della creazione di un linguaggio comune e dell'appoggio tecnico, giuridico e politico per dare impulso - in forma autonoma e indipendente dallo Stato - alle lotte dei movimenti urbani, a partire da quella per sollecitare l'approvazione della Legge Federale 6766/79 sul parcellamento.

A Porto Alegre, il breve periodo 'di riflusso' dell'impegno associazionistico verificatosi nel 1980/1982 (Menegat, 1995) fu riscattato subito dopo da mobilitazioni di ampio significato come lo sciopero generale. Il $1983 \mathrm{fu}$ anche l'anno di costituzione della UAMPA, l'Unione delle AMs di Porto Alegre che inizialmente riunì 51 associazioni (particolare attivismo mostrarono quelle delle aree Nord e Cruzeiro) e svuotò la FRACAB di molti dei suoi compiti, salvo quello di rappresentanza delle Associazioni di Quartiere a livello Statale. ${ }^{25}$ Il $I^{\circ}$ Congresso della UAMPA, realizzato nell'ottobre $1985^{26}$ (alla vigilia delle elezioni municipali), ha costituito l'evento più importante realizzato dai movimenti sociali urbani di Porto Alegre: 300 delegati vi convennero in rappresentanza di 78 Associazioni di Quartiere sostenendo la necessità di subordinare le lotte sviluppate nei luoghi di residenza alle grandi lotte generali, motivo per cui la discussione si svolse a partire dal tema della 'Congiuntura Nazionale', anche nel tentativo di minimizzare i conflitti interni alle diverse componenti politiche ivi rappresentate, almeno in uno dei due livelli su cui il dibattito si svolgeva. Tra i prioritari punti discussi, vi fu la necessità di offrire un contributo all'effettiva democratizzazione del potere esecutivo e legislativo mantenendo un'autonomia dalle istituzioni e l'unità del movimento. Tra le attività da promuovere per prime fu sottolineata la lotta per democratizzare i Consigli Municipali già esistenti, e la promozione della partecipazione attiva delle comunità nell'amministrazione di asili, presidii di sanità e scuole. Si procedette, inoltre, all'elaborazione di una 'Carta di rivendicazioni' della UAMPA e allo studio e "diffusione della conoscenza del bilancio municipa$l e$ " come primo passo per poi pervenire alla creazione di organi popolari con potere deliberativo sullo stesso (Menegat, 1995).

Nel quadro dei provvedimenti mirati all'efficacia dell'azione, vi fu la decisione di articolare le Associazioni per ambiti regionali ${ }^{27}$ ai fini di una lotta comune e dello scambio di esperienze, e quella di scegliere due rappresentanti di ogni Regione che si riunissero almeno una volta al mese con il direttivo della UAMPA per dar corso a lotte e attività di coordinamento. Molte di que- 
ste deliberazioni, in apparenza generiche, già sottendevano lo studio di concrete possibilità di intervento, che in breve guideranno verso la democratizzazione progressiva dei Consigli Municipali che caratterizzò la gestione Collares (del PDT) dopo le prime elezioni libere del 1985. Parimenti, grande peso avranno in seguito le determinazioni sull'articolazione della città in Regioni capaci di stabilire un elenco di priorità di azione sul loro territorio: esse serviranno, infatti, da base organizzativa - sotto la successiva amministrazione Dutra - per il Bilancio Partecipativo.

È proprio in seguito all'elezione del PDT alla guida del Comune di Porto Alegre - dopo le prime elezioni municipali democratiche - che in città presero forma veri e propri dipartimenti municipali concepiti dal sindaco Collares come 'cupole' di organizzazioni popolari di rinnovato contenuto clientelare: addirittura, alcuni leader locali iscritti al PDT furono contrattati dal Dipartimento di Manutenzione Urbana per rappresentare i vari quartieri negli incontri con gli amministratori, annullando i meccanismo rappresentativi adottati nelle varie aree (Menegat, 1995).

La riproposizione di forme di relazioni paternalistico/clientelari tra governo locale e organizzazioni della società civile, percepite come negativo lascito del periodo dittatoriale, ingenerò una sorta di 'contestazione pacifica' all'interno delle AMs, che portò in molti casi ad un ricambio ai vertici delle stesse e ad un riorientamento del loro ruolo in direzione del conseguimento di benefici attraverso le forme della protesta e delle pressioni contro le negoziazioni di tipo personale. Importante ai fini di questa 'riforma dall'interno' è stata l'opera di 'agenti esterni' appartenenti a ONG locali di recente creazione e all'ala progressista della Chiesa Cattolica, le cui 'Pastorali' avevano già rappresentato durante la dittatura una linfa per la formazione dei leader del futuro Movimento Popolare (sia delle sue componenti comunitarie che sindacali, cfr. Gohn, 1985). La struttura rappresentativa, partecipativa e visceralmente avversa alle negoziazioni delle nuove AMs che nascevano per contrapporsi a quelle più smaccatamente compromesse in rapporti clientelari con il Comune, portò a dei 'muro contro muro' con le Istituzioni che permise loro di ricavarsi un forte ruolo nella politica locale (Abers, 1998), diffondendo principi di uguaglianza, diritti umani e partecipazione dal basso che coinvolgevano sempre più residenti (Baierle, 1993).

Il primo atto che servì a chiarire quali meccanismi adottare per gerarchizzare le richieste di ogni organizzazione popolare e mediare con l'Amministrazione, fu la partecipazione della UAMPA - nel 1986 - all'elaborazione del Progetto di Legge per la Democratizzazione dei Consigli Municipali esistenti, valutata criticamente nel $I I^{\circ}$ Congresso dell'Associazione che nel luglio dello stesso anno riunì 220 delegati di 76 associazioni. ${ }^{28} \mathrm{I}$ temi in discussione mostrarono stavolta - fin dall'organizzazione delle giornate dell'evento - uno stretto legame fra il Movimento Comunitario e la congiuntura nazionale e municipale, sottolineando la necessita di valorizzare l'azione dei movimenti urbani nella sfera politica locale senza però chiamarsi fuori da questioni affrontabili solo a scala più vasta. Nel dibattito fu stigmatizzata la necessità di procedere nella democratizzazione delle istituzioni cittadine oltrepassando i timidi tentativi - pur riconosciuti come validi - compiuti dal neosindaco Collares. Ciò andava fatto tenendo conto dei limiti oggettivi imposti dall'assenza di interventi a scala federale sulla Riforma Urbana e su quella Tributaria. Nell'occasione fu rilevato il pericolo che nel rafforzamento del ruolo dei Consigli 
Municipali alcuni leader negoziassero direttamente con la burocrazia comunale, indebolendo così il ruolo del movimento come 'insieme collettivo'. L'aspetto di maggior peso del $\mathrm{II}^{\circ}$ Congresso UAMPA fu però la decisione di concentrare energie - da quel momento in poi - sulla con-discussione del bilancio comunale, ritenuta il punto di svolta necessario ad un rinnovamento delle politiche urbane. $\mathrm{Fu}$ anche lanciata una concreta proposta di creare un Consiglio Municipale di Bilancio (l'unico fino ad allora mancante) che includesse membri dei Consigli Tematici legati agli altri assessorati e dell'UAMPA. L'idea avrebbe presto fatto breccia nel partito del PT alla ricerca di una strategia elettorale vincente.

Il $\mathrm{II}^{\circ}$ Congresso della UAMPA evidenziò che un anno di lavoro dell'Associazione accanto al Comune era servito a maturare e a conoscere meglio la complessità della macchina amministrativa cittadina, portando un 'salto di qualità' anche nelle proposte concrete d'intervento dei suoi partecipanti, sostituitesi alla bandiera generica della 'partecipazione popolare' (Menegat, 1995). Sotto il profilo dell'articolazione interna, nel II $^{\circ}$ Congresso dell'UAMPA nacque il Consiglio Intermedio, organo formato da due rappresentanti di ognuna delle consolidande Articolazioni Regionali, che dovevano darsi una delimitazione fisica su cui il Consiglio Deliberativo avrebbe potuto esprimere pareri in caso di sovrapposizioni.

Il mancato accoglimento delle richieste dell'UAMPA da parte dell'Amministrazione Collares (aggravato - su scala nazionale - dalle mancate promesse del PMDB a livello statale e dalla proroga del mandato di Sarney votata dal parlamento federale) determinò un clima generalizzato di scetticismo e disillusione che segnò negativamente il III Congresso del luglio $1988,{ }^{29}$ tutto ripiegato sulla valutazione del proprio operato e privo delle tematiche di più ampio respiro dell'edizione precedente.

Una valutazione complessiva dei 3 Congressi precedenti all'attivazione del processo di Bilancio Partecipativo da parte dell'Amministrazione Dutra eletta nel 1988, permette di concordare con Menegat (1995) sulla visione lungimirante avuta dall'UAMPA nel concentrarsi sui temi del bilancio come chiave di accesso a tutte le politiche settoriali, e di ridimensionare la critica di Baierle (1992) alle debolezze mostrate nell'affrontare singoli settori di azione concreta. Nello stesso periodo in cui nelle zone orientali di São Paulo le organizzazioni popolari si accontentavano di prendere parte attiva nei Consigli di Sanità, è vero - infatti - che il movimento popolare di Porto Alegre costruiva un'esperienza apparentemente meno integrata alle politiche concrete. Ma, partendo da un processo di articolazione territoriale intorno a singole lotte settoriali, ampliava i suoi orizzonti verso una problematica urbana più generale, costruendo una strategia ben direzionata sui giusti centri di potere (in particolare la discussione del bilancio) e più ampia di quelle mirate a risolvere problemi dei singoli quartieri. Una strategia che alla fine si sarebbe dimostrata vincente, con l'aiuto di istituzioni capaci di cogliere la potenzialità e la forza di quanto in quegli anni di lotta era stato capillarmente costruito.

Una prova efficace della capacità 'articolatrice' del nuovo movimento venne dall'ondata di occupazioni (cfr. box 3) che nel 1988 'invase' nella città un vasto numero di quartieri incompleti di proprietà della COHAB, dell'INOCOOP, dell'HABITASUL, del CEF e del DEMHAB "lasciati imputridire dall'incompetenza amministrativa e dall' irrazionalità degli investimenti” (Ferretti, 1993). 
Questi atti - allo stesso tempo concertati e spontanei - segnarono un mutamento di strategia negli orientamenti del Movimento popolare dalla lunga fase delle richieste di urbanizzazione, servizi e riconoscimento del possesso dei suoli "ad un attacco frontale al diritto di proprietà", che corse anche il rischio di creare divisioni tra gruppi in lotta, visto che il sogno di una casa propria può anche essere letto come il limite utopico dei 'nuovi invasori' (ibidem).

Se nel periodo delle invasioni del 1988 il Comune continuò nella sua politica di privatizzazione del suolo urbano e di appoggio agli investimenti degli oligopoli di costruttori e speculatori immobiliari (in quell'anno venne, infatti, approvato il megaprogetto Praia do Guaíba giustificandolo anche come portatore di fondi da reinvestire nelle aree marginali), lo scontento diffuso permise che poco tempo dopo la stessa Amministrazione lanciasse un nuovo sistema di Partecipazione Popolare al Governo Municipale sottoforma di Consigli Popolari: il loro carattere ancora privo di incidenza sostanziale non servì alla coalizione guidata dal PDT ad evitare la sconfitta nelle elezioni avvenute pochi mesi dopo, che videro uscire trionfatore il Partido dos Trabalhadores.

\subsection{Il Consiglio del Piano Regolatore di Porto Alegre: controllo sociale o apertura progressiva delle istituzioni all'ascolto degli abitanti?}

A Porto Alegre, il lento svilupparsi di un protagonismo sociale interessato a non perdere la propria autonomia organizzativa, non impedì che - dopo la crisi del regime militare - passi significativi fossero portati avanti anche nel dialogo con le istituzioni, inteso al riconoscimento del ruolo propositivo dell'associazionismo civile nei confronti del governo e della trasformazione del territorio. A titolo di esempio, una vicenda che tocca i meccanismi della pianificazione urbanistica può essere indicativa di una tendenza trasformativi in graduale arricchimento.

In occasione della stesura del primo Piano Regolatore di Sviluppo Urbano di Porto Alegre (1979) erano state ridefinite le funzioni ed anche la composizione del Consiglio di Piano Regolatore, divenuto "organo di integrazione del sistema municipale di pianificazione e di coordinamento dello sviluppo urbano" che aggiornava ed emetteva pareri sul Piano e sul Regolamento Edilizio, discuteva delle alterazioni dei modelli urbanistici vigenti ed esaminava il Programma Municipale di Investimento per lo Sviluppo Urbano di Porto Alegre (Oliveira e Barcellos, 1993). Il numero dei membri - 1/3 dei quali rinnovabili biennalmente, scelti dal Sindaco ma sottoposti all'approvazione del Consiglio Comunale - venne portato a 21: 9 rappresentanti del Municipio (tra cui il Direttore del Dipartimento alla Casa), 8 entità di categoria, ${ }^{30}$ e 4 associazioni provenienti dalla 'società civile'. I rappresentanti delle Associazioni di vicinato (un eletto per ognuna delle 4 zone della città previste) restavano in minoranza numerica rispetto alle Associazioni di categoria ed erano comunque discriminati dai meccanismi di scelta in mano al Sindaco.

Nel corso dei tardi anni '80, altre entità che sollecitavano rappresentazione saranno poi affiancate - pur senza diritto di voto - a quelle che già facevano parte del Consiglio; le notevoli pressioni lobbystiche esercitate nel 1989 dal Sindacato dell'Industria della Costruzione Civile per divenire membro ufficiale (seguita nel 1990 dal Sindacato degli Ingegneri del Rio Grande do Sul) furono un riconoscimento della forza reale che quel collegio andava assu- 
mendo in quanto "spazio privilegiato della discussione delle questioni rilevanti rispetto agli interessi” della città (Oliveira e Barcellos, 1993).

Nella sua sostanza, il forum costituito dal Consiglio del Plano Diretor - anche in considerazione dei rapporti numerici fra membri espressione delle differenti componenti sociali - rispecchiava "una composizione simile al gioco di dominazione che si può identificare nello spazio urbano" (Oliveira e Barcellos, 1993); un antagonismo di base che contrapponeva proprietari fondiari e immobiliari e forti categorie economiche ben organizzate per la difesa dei propri interessi, a strati della popolazione spesso disarticolate e in posizione sovente minoritaria. In parallelo, comunque, la partecipazione della comunità veniva - seppur timidamente - presa in considerazione anche nella definizione di varie pratiche urbanistiche, il cui iter iniziò a prevedere la consultazione delle Associazioni di Vicinato: è il caso di tutti quei procedimenti aventi per oggetto l'installazione di attrezzature urbane (piazze, parchi, aree ricreative, supermercati, depositi di auto o gas, garage, cimiteri, terminal e itinerari di trasporto collettivo), l'abbattimento di alberi ed interventi su aree naturali o su divisioni in lotti in zone dotate di AMs o SABs (ibidem).

Entrambi i meccanismi di 'apertura' alla società civile si presentavano però alla fine come 'Giani bifronti', visto che uno dei loro scopi era quello di istituzionalizzare e quindi controllare meglio i rappresentanti dei movimenti popolari, imbrigliandoli nei meccanismi della locale burocrazia di stampo tecnocratico e - ancora - sostanzialmente autoritario.

Ferretti (1993) sembra addirittura ritenere che - attraverso il PDDU del 1979 - il Comune abbia esplicitamente mirato ad "uno svuotamento dell'impeto mobilizzatore ed organizzativo delle associazioni di vicinato e dei movimenti legati all'autodifesa, proprio tramite l'inserimento di un certo grado meramente formale" di partecipazione popolare nel sistema di pianificazione, che interferì con la stessa organizzazione comunitaria. Il Piano (384 articoli assoggettati nel 1980 a ben 257 emendamenti), prevedeva, infatti, la creazione di Associazioni di Residenti - dotate di uno statuto-modello a schema unico, imposto dall'alto - corrispondenti alle diverse Unità Territoriali individuate, $\mathrm{i}$ cui confini risultavano differire da quelli delle Associazioni spontaneamente formatesi in seno al FRACAB. In tal modo, non solo si prevedeva il ricorso ad una rappresentatività che non dava conto delle grandi masse coinvolte dai processi di segregazione urbana, ma si prevedeva anche una 'duplicazione' delle Associazioni mirata ad indebolire le stesse. Questa accese l'opposizione sia della FRACAB che dei Sindacati, i quali ottennero che il provvedimento fosse bocciato nel passaggio del Piano in Consiglio Comunale. Nel 2000 - in seguito all'approvazione del nuovo Piano Regolatore di Sviluppo Urbano e Ambientale - il Consiglio Municipale del Piano sarà nuovamente assoggettato a mutamenti radicali, allo scopo di trasformarlo da semplice 'specchio' delle disparità di peso che i vari settori sociali hanno nella società di mercato, in uno strumento che possa contribuire al loro 'riequilibrio' (cfr. cap. 15). Ciò avverrà parallelamente ad un processo in cui - nel Bilancio Partecipativo - alcune Commissioni miste 8di membri del governo e di cittadini) vedranno cambiare la loro struttura, duplicando il numero dei rappresentanti popolari, rispetto a quelli delle istituzioni.

Questi ultimi episodi appaiono significativi del lento processo di 'riempimento di scatole vuote' che a Porto Alegre i movimenti urbani sono di fatto riusciti a gui- 
dare, dando alle lotte cittadine un carattere paradigmatico nella rappresentazione delle diverse fasi organizzative dell'ambito più vasto del governo locale (Ferretti, 1984) e nella rivendicazione paziente ma inesorabile di diritti spesso formalmente riconosciuti ma concretamente negati. Con tutti i limiti finora sottolineati, la crescita progressiva nel tempo della percentuale di rappresentanti della società civile nel Consiglio del Piano Regolatore, resta - ad esempio - emblematica di una progressiva apertura delle istituzioni alla complessità del dialogo tra attori.

\subsection{Verso il rafforzamento degli istituti partecipativi: il dialogo tra l'Am- ministrazione Collares e i movimenti popolari.}

La tendenza - piuttosto diffusa in Brasile - ad accennare alla partecipazione popolare nella pianificazione (economica, urbanistica, ecc.) "come modo per attingere a obiettivi sociali ampi", ha generato aspettative spesso deluse da un suo mero utilizzo strumentale come fonte per attingere a dati strategici per il governo del territorio (Ferretti, 1984). Ad esso raramente è corrisposta la costruzione di spazi che dessero un ruolo concreto e attivo alla partecipazione nella pratica del governo urbano, almeno in forme non restrittive attraverso cui poter "influire nelle decisioni della politica economica in generale e urbana, in particolare" (ibidem).

Nel caso di Porto Alegre, è difficile dire se - storicamente - a stimolare l'articolarsi dei movimenti sociali (e primi fra tutti quelli a difesa di situazioni urbane precarie fragilmente rappresentate nei canali ufficiali dell'intermediazione politica) sia stata la progressiva creazione di spazi di dibattito e di pianificazione democratica entro cui gestire lo scontro tra pubblico e privato, o piuttosto non siano stati questi ultimi a dare impulso alla creazione di quegli spazi. Il dibattito è a tutt'oggi aperto, anche se è ragionevole pensare che sia stata proprio l'interazione fra queste due componenti che ha portato nel tempo ad una reciproca e progressiva trasformazione per piccoli passi, anche in virtù dello stimolo offerto alla crescita di entrambi dal progredire dei processi di marginalizzazione ed esclusione socio/spaziale, aggravati dal carattere accentratore ed escludente delle politiche di sviluppo economico predominanti in Brasile nell'ultimo trentennio.

Certo è che a Porto Alegre (tra il 1987 e le elezioni del 1988) lo 'scarto' tra enunciazione teorica e prassi operativa sul tema della partecipazione popolare alla costruzione degli indirizzi politici ha ad un certo punto originato una brutale e istantanea presa di coscienza - da parte di molti cittadini - dei propri 'millantati diritti', e ha portato in breve tempo alla progressiva risemantizzazione istituti partecipativi volutamente nati per limitare, attraverso piccoli 'contentini', questa stessa capacità di intervento popolare nell'ambito della politica.

Indubbiamente, la sperimentazione progressiva - ancorché parziale- dei nuovi istituti creati sovente per salvare la 'facciata' di governi sostanzialmente autoritari e dare una risposta immediata (seppur incompleta) alle pressioni dei movimenti popolari, ha offerto un forte contributo al crescere della coscienza di questa 'insoddisfazione', autoalimentatasi in parte proprio delle 'brecce' attraverso cui il ruolo costruttivo della partecipazione popolare aveva potuto mettersi alla prova. Questo pare evidente recuperando la memoria del periodo (1986-88) in cui Porto Alegre è stata governata dall'amministrazio- 
ne di Alceu Collares (guidata dal PDT), che ha rappresentato il momento di transizione dal regime militare alla piena democrazia, ed un periodo importante nella storia urbana, forse eccessivamente trascurato dalla recente storiografia progressista in rapporto ai contributi (almeno indiretti) offerti alla strutturazione di nuove forme di partecipazione dei cittadini nella costruzione delle politiche locali.

Durante la campagna elettorale del 1985, Collares si era accordato con alcuni movimenti sociali urbani per promuovere un progetto di 'partecipazione della popolazione nel governo della città' a partire dalla crescita del potere deliberativo e di controllo nei Consigli Municipali, già dal 1956 previsti come parte della macchina amministrativa cittadina dallo Statuto della città e rafforzati in seguito (Moura, 1989). Durante il $1^{\circ}$ Congresso della UAMPA, anche altri candidati avevano espresso proposte sul tema della democratizzazione della gestione urbana, ma il $46 \%$ dei suffragi raccolto da Collares sembrò premiare la proposta al momento valutata come più realisticamente realizzabile. Ciò segnò una tappa importante nell'evoluzione nella struttura dei Consigli Municipali, che già lo Statuto cittadino del 1971 aveva definito come organi di cooperazione governativa che hanno lo scopo di aiutare l'amministrazione nell'orientamento, pianificazione, interpretazione e valutazione delle materie di sua competenza. ${ }^{31}$

Durante il governo Collares furono, infatti, creati nuovi Consigli nei settori della gestione del personale, dei trasporti, del turismo, della salute e del benessere sociale, che si aggiunsero alla riforma di quelli dei Contribuenti, degli Acquisti e del Piano Regolatore.

Per procedere a queste riforme, già nel gennaio del 1986 l'Esecutivo Municipale riunì - su 'invito' - la UAMPA, alcuni leader di Associazioni di Residenti e Organizzazioni di Madri (M.S. Moura, 1989); essi si mostrarono decisi a non accettare nessuna convocazione in udienze isolate, perché avrebbe minato la forza complessiva del movimento cittadino, rischiando di legittimare una strategia saltuaria di ricerca di consensi da parte del Comune. Fu così stabilita la convocazione di plenarie aperte a tutte le Associazioni regolarmente iscritte nelle 4 Regioni cittadine individuate dal Piano del 1979.

La prima tornata di assemblee cosiddette 'primarie' vide la partecipazione di 50 entità della Zona Nord, 47 della Sud, 46 della Est e 45 della Zona Ovest, cioè della quasi totalità delle Associazioni esistenti, mostratesi interessate a partecipare al processo di riformulazione del ruolo dei Consigli Municipali. Nell'aprile dello stesso anno, un Seminario con l'Amministrazione ed i rappresentanti di 101 entità cittadine (84 delle quali erano Associazioni di Quartiere) propose di mantenere la continuità nominale col passato degli organismi di partecipazione per non confonderli con quei 'Consigli Popolari' che già costituivano organismi autonomi e indipendenti del Movimento popolare. Nella disputa sul nome si celava quella sull'ambito di appartenenza di tali istanze (Fedozzi 2000); se il sindaco voleva inglobarli nella sfera d'influenza amministrativa attribuendogli un nome inesatto per tale ruolo (quel 'Consigli Popolari' che evoca ambiti di autogestione dei movimenti), i movimenti erano più interessati alla creazione di una nuova sfera pubblica autonoma ma riconosciuta nelle sue decisioni dall'ambito istituzionale.

Le organizzazioni cittadine proposero trasformazioni importanti, su cui spesso l'Amministrazione cercò di fare orecchio da mercante. Ad esempio, i 
membri dei Consigli avrebbero dovuto essere elettivi e non di nomina istituzionale, rappresentando per il 60\% il Movimento Comunitario (da eleggersi in regioni da ridefinirsi collettivamente) e per il $30 \%$ le Associazioni di categoria e i Sindacati. ${ }^{32}$ Il mandato dei rappresentanti avrebbe, poi, dovuto essere revocabile da parte di chi li aveva eletti, su basi territoriali che avrebbero dovuto rispecchiare l'autorganizzazione sperimentata attraverso le Articolazioni Regionali di recente costituitesi, piuttosto che i criteri tecnici definiti dal PRG. ${ }^{33}$ Si discusse molto anche sulla concessione di un gettone di presenz $a^{34}$ per i membri dei Consigli e del loro carattere (consultivo o deliberativo?).

La rara prerogativa di Porto Alegre di poter elaborare e mutare il proprio Statuto comunale, permise rapide trasformazioni nel sistema dei Consigli Municipali tematici. La più importante fu quella nella struttura del Consiglio del Plano Diretor che passò da 17 a 21 membri, riconfermando i 4 rappresentanti di entità comunitarie previsti dal PRG del 1979 ma accettandone il principio di 'autonomia' dal potere politico; essi vennero perciò eletti in riunioni plenarie delle Associazioni di Quartiere nelle 4 Regioni cittadine già esistenti. Purtroppo, fu anche riconfermato il carattere meramente consultivo dell'organismo e, con esso, la prevalenza nella sua composizione - dei tecnici dell'Amministrazione.

Questi 'tradimenti' delle attese del movimento popolare organizzato, già nel giugno del 1986 contribuirono a sfaldare il dialogo con le istituzioni: la ragione portante fu il deciso rifiuto di Collares di accettare che fosse la società civile a guidare il processo di riforma e ad imporre articolazioni territoriali che venivano a contrastare con quelle imposte dall'Esecutivo.

Il Progetto di Legge - della cui redazione l'Amministrazione si assunse l'onere già nel settembre 1986 - conteneva varie rivendicazioni della UAMPA, ${ }^{35} \mathrm{ma}$ le tradiva per quanto attiene il nome e l'imposizione di un gettone di retribuzione, oltre a non concedere alle AMs "l'esclusiva" della scelta di candidati della società civile. Esso fu presentato al Consiglio Comunale solo nel novembre del 1987, ma il rischio di venire bocciato, per di più con 6 voti contrari all'interno della maggioranza, lo fece ritirare all'ultimo momento, come suggerito dalla stessa UAMPA.

L'iter di approvazione del Progetto di Legge sui 17 Consigli Popolari ${ }^{36}$ si concluse solo nel dicembre 1988, posteriormente alle nuove elezioni che videro vincitore il Fronte Popolare guidato dal Partito dei Lavoratori (PT). Collares lo controfirmò nell'ultimo giorno del suo mandato come Legge 195/ 88 quasi in forma di 'vendetta postuma' contro i suoi rivali politici, che venivano così ad ereditare l'obbligo di dar forma a strumenti 'ibridi' che traevano origine da un processo di conflitti e di profonde divergenze irrisolte ${ }^{37}$ tra aspirazioni degli attori popolari (rappresentati dalla UAMPA nel dibattito triennale) e carattere autoritario del governo Collares.

\subsection{Quale destino per i neonati Consigli Popolari?}

Il triennio Collares servì a veicolare un'ulteriore apertura dei canali di partecipazione formalmente esistenti nella macchina amministrativa, seppur ipoteticamente con lo scopo autoreferenziale di ampliare la base di appoggio per la Giunta in carica. L'aver deluso le molte attese dei movimenti cittadini di Porto Alegre, costò al sindaco la rielezione; ma è innegabile che il dialogo instaurato con la società civile - almeno limitatamente alla discussione della 
riforma dei Consigli Municipali - ebbe come effetto meritorio la crescita di coscienza delle Associazioni Comunitarie che - pur restando legate alle esperienze sviluppate in proprio nel passato - si trovarono stimolate "a trascendere $i$ limiti delle pratiche già anteriormente sperimentate e ad approfittare di ogni spazio che la nuova congiuntura apriva loro" (Menegat, 1995). Tra l'altro, proprio nel 1988, 56 favelas di Porto Alegre sperimentavano il programma federale FALA FAVELA che tentava - tramite votazioni a scrutinio segreto nei quartieri - di dare una voce ai vileiros [cioè agli abitanti delle aree informali] perché indicassero le priorità di azione governativa da mettere in atto nei loro insediamenti di residenza.

In una simile congiuntura, fu chiaro - fin dall'approvazione della Legge 195 sui Consigli Popolari - che la coalizione appena eletta era totalmente in disaccordo con le misure adottate, pur riconoscendo l'importanza del tema. Tra le critiche formulate ve ne erano anche alcune 'formali' mosse dall'Avvocatura Generale del Municipio, secondo cui l'art. 21 della Legge creava un vincolo artificiale tra l'azione della Giunta e le tempistiche del Consiglio Comunale, ogni qual volta i veti del Sindaco alle scelte dei Consigli non venissero accettati dagli stessi ${ }^{38} \mathrm{Ma}$ la maggior parte delle riserve era di natura sostanziale, e concernevano soprattutto i rischi di frammentazione delle energie popolari attraverso i troppi organismi settoriali, e l'equivoco alla base della fusione di due concetti molto diversi: la democratizzazione dei Consigli Municipali (canali istituzionali di partecipazione alla pubblica amministrazione del comune) e le forme autonome di organizzazione dei movimenti nella sfera della società (Fedozzi, 2000, pag. 52).

Questi temi - oltrettutto - erano già al centro della riflessione della nuova coalizione fin dal maggio 1987 quando, cogliendo l'occasione rappresentata dall'incrinarsi del dialogo tra Collares e i movimenti urbani, il Partido dos Trabalhadores aveva creato il 'Gruppo di politica municipale' che nel settembre dello stesso anno organizzò un Seminario di 3 giorni per elaborare "proposte di mediazione fra la visione utopica di trasformazione sociale che [i militanti] condividevano e la visualizzazione dei passi avanti possibili a livello di istituzioni politiche, attraverso la valorizzazione della partecipazione e degli spazi pubblici conquistati dai nuovi movimenti sociali" (Menegat, 1995). Il Gruppo di lavoro aveva centrato le proprie proposte proprio su una nozione di Consigli Popolari come ipotesi principale di un percorso realistico per concretizzare una reale partecipazione democratica nella gestione istituzionale ${ }^{39}$ che assumesse carattere deliberativo anche nella definizione delle priorità di bilancio (PT/RS, nov. 1987) e si costituisse come 'potere popolare parallelo' ${ }^{40}$ Forse per questo, anche la UAMPA - all'epoca egemonizzata dal PT nei suoi organi dirigenti ${ }^{41}$ - non si era concentrata troppo nel discutere sui contenuti dei Consigli, lasciando che la LC 195/88 presentasse grossi buchi sulle competenze degli stessi.

In ogni caso - davanti alla forte pressione esercitata dal PDT (passato all'opposizione) per inchiodare la nuova giunta alle sue responsabilità sulla Legge appena approvata - il Fronte Popolare dovette scegliere una tattica di dilazione per la traduzione della 195/88 in atti concreti.

Dopo aver riunito i partiti della coalizione e vari militanti del movimento comunitario (Fedozzi, 2000), si scartò l'ipotesi di disconoscere del tutto la legge, preferendo rinviarla all'esame del Potere Giudiziario (sotto sospetto 
di incostituzionalità) e intanto elaborare una proposta alternativa che ne sanasse anacronismi giuridici e distorsioni politiche, a partire dal nome (mutato in 'Commissioni Municipali'), dal numero (accorpando aree amministrative affini) e dal rifiuto della nuova amministrazione di esprimersi sulla scelta dei rappresentanti popolari dentro le stesse, la cui discussione era delegata alla UAMPA come maggior espressione della capacità di organizzazione comunitaria cittadina. Durante il processo di elaborazione di questo pre-progetto alternativo, la giunta dovette modificare la tattica dilatoria scelta, rendendosi conto che l'inesperienza dei suoi interlocutori del movimento comunitario rendeva loro impossibile esercitare la necessaria pressione sul Consiglio Comunale per l'approvazione di nuove regole di strutturazione della partecipazione popolare. Il governo municipale scelse così di continuare la discussione di un'alternativa con i movimenti, ma nel frattempo regolamentò la Legge 195 via Decreto, cercando di potenziarne gli aspetti positivi e minimizzarne i limiti, e si rivolse al tribunale per verificare la presunta incostituzionalità dell'art. 21.

Questo triplice percorso non necessitò di essere messo in atto, visto che l'obbligo di adattare lo Statuto Municipale alla nuova Costituzione Federale del 1988 venne in aiuto alla giunta per superare l'impasse, permettendole di eliminare definitivamente le confuse definizioni che appiattivano l'una sull'altra le forme di partecipazione e il carattere dei Consigli.

Nell'articolo 101 del nuovo Statuto Comunale di Porto Alegre - approvato all'inizio del '90 - saranno così ridefiniti i Consigli Municipali come "organismi di partecipazione diretta della Comunità nella pubblica amministrazione”, composti da un numero dispari di membri (rispettoso della necessità di veder rappresentate le organizzazioni comunitarie di abitanti, le entità di classe e l'amministrazione locale) e finalizzati "a proporre, controllare $e$ deliberare su temi riferiti ad ogni settore dell'amministrazione". Nell'articolo 102 - invece - il Potere Pubblico si obbligherà "a riconoscere l'esistenza di consigli popolari regionali, autonomi, non subordinati" al suo potere, ${ }^{42}$ definendoli come "istanze di discussione e deliberazione di politiche municipali formati a partire dalle organizzazioni rappresentative di tutti i segmenti sociali della regione" a cui appartengono. ${ }^{43}$ Sulla regolamentazione di quanto previsto dall'articolo 101, nell'ottobre del 1990 si instaurerà un dibattito con l'opposizione, intenzionata (con la Proposta Vieira da Cunha, consigliere del PDT) a produrre una nuova "legge artificiale di democratizzazione dello Stato, non espressione di un processo reale di coinvolgimento della cittadinanza e neppure di costruzione di consenso circa la materia" (Fedozzi, 2000, pag. 57)., tanto più dato che le polemiche e i ritardi sull'attuazione delle proposte degli anni precedenti non avevano dato occasione ai movimenti comunitari di Porto Alegre di sperimentare e maturare una pratica reale di collaborazione partecipativa con la giunta. Sulla base di una negoziazione con l'opposizione condotta proprio su tali riflessioni (con la mediazione delle ONG locali 'Fase' e 'Cidade'), nel novembre del 1990 si arriverà ad un Progetto di Legge di sperimentazione per gradi dei Consigli Municipali $\left(\mathrm{n}^{\circ}\right.$ 267/90) che sarà approvato solo a fine legislatura - nel febbraio 1992 - e che manterrà alcune previsioni della 195/88, prevedendo:

a) la tripartizione dei Consigli, con assegnazione della maggioranza dei $21 \mathrm{mem}-$ bri di ognuno ai rappresentanti della comunità e delle organizzazioni di classe 
b) la revocabilità del mandato dei consiglieri

c) il pagamento di un gettone di presenza agli stessi

d) il carattere deliberativo dei Consigli

e) il monopolio della rappresentazione comunitaria da parte delle AMs attraverso la mediazione della UAMPA.

Per certi versi, quindi, il risultato finale del lungo processo di interazione tra forze politiche e movimenti popolari, rinnoverà anche a Porto Alegre " $l a$ tradizione brasiliana di creare leggi artificiali di partecipazione” che riproducono in sé "anacronismi, quando non antagonismi, tra la realtà sociale e il formalismo giuridico-politico". ${ }^{44}$

Nel frattempo, però, proprio sulla base dell'impasse nato intorno alle ambigue formulazioni concettuali sui 'Consigli Popolari', e sulla base delle principali considerazioni critiche formulate alla Legge 195/88, ${ }^{45}$ la nuova Amministrazione andava sperimentando per gradi - prima di proporne qualsiasi formalizzazione burocratica - nuovi organismi di collaborazione con il movimento comunitario. Tra questi, oltre al Bilancio Partecipativo di cui parleremo diffusamente nel seguito, vi era ad esempio la Commissione Interistituzionale Municipale di Sanità (CIMS), suggerita dal processo di municipalizzazione del Sistema Unico della Sanità (SUS), ed esempio ben riuscito della possibilità di procedere a positive sperimentazioni di una reale partecipazione dei cittadini alla co-gestione delle politiche urbane senza venir schiacciati da prassi formaliste e artificialismi legali. Istituita sotto la giunta Collares nel 1987, la CIMS ha rappresentato - con i suoi 78 membri attivi - la ben riuscita "espressione formale di una esperienza sociale di partecipazione consolidata nella pratica della gestione sanitaria pubblica” (Fedozzi, 2000, p. 58), ed è stata trasformata nel maggio 1992 (con LC 277/92) in Consiglio Municipale di Sanità, costituendo una sperimentazione pioniera per dare senso a formulazioni astratte che - solo discusse su base teorica - avevano dimostrato fino ad allora di possedere densità semantica e realismo piuttosto ridotti, e che solo potevano essere riempiti di significati concreti da una concreta interazione (nel quotidiano delle scelte) tra amministrazione pubblica e quei movimenti con cui già dal 1986 era stata avviata una prassi di dialogo per la riforma e l'apertura delle istituzioni locali alla partecipazione attiva dei cittadini nella definizione di politiche e progetti.

Dopo il mutamento elettorale del 1988, il nuovo Statuto Comunale del 1990 ha certo rafforzato e ulteriormente strutturato il quadro dell'integrazione della società all'interno del potere locale che esisteva anteriormente, dandogli operatività ed autonomia dal Governo, ridistribuendo gli equilibri e creando ulteriori canali politici di partecipazione come - ad esempio - il Forum contro la Recessione e la Disoccupazione, il Consiglio dell'Accesso ai suoli, e soprattutto il Bilancio Partecipativo, che ha progressivamente dato un ruolo sempre più attivo alla cittadinanza nella discussione pubblica delle linee di indirizzo del bilancio comunale, ma è soprattutto servito ad invertire i ruoli propositivi e il peso dei diversi strati della popolazione all'interno della macchina decisionale locale. In quest'ottica, le peculiarità dell'evoluzione storica di Porto Alegre che sono emerse da questi primi capitoli hanno certamente giocato come una notevole risorsa a cui attingere per il radicamento di nuovi strumenti per la ricostruzione della città e del rapporto tra cittadini e istituzioni. 
${ }^{1}$ Chauí (1986), pag. 124 e segg.

${ }^{2}$ Cercando di evitare i pregiudizi sia della storiografia democratica liberale (popolo visto positivamente come agente trasformatore della società), sia della storiografia conservatrice (l'agente storico collettivo come perturbatore dell'ordine stabilito), Pacheco utilizza il concetto di 'moltitudine' usato da Gorge Rudé (1991), come 'insieme di individui che si aggregano per manifestare un interesse che in quel dato momento storico è comune' ma non ha una composizione stabile né un'unione basata su precetti universali astratti di carattere permanente'. Pacheco parla di tre forme diverse di cittadinanza attiva coesistenti accanto al cittadino elettore: una cittadinanza informale alla ricerca di 'brecce' dove potersi esprimere; un 'cittadino collettivo' (individuo che partecipa ad azioni politiche collettive, sviluppando una pratica politica corporativa), e un cittadino candidato, che si mescola al processo politico formale, cercando - attraverso di esso - di esprimere le sue opinioni e rivendicare la legittimità dei diritti sociali (pag. 122).

${ }^{3}$ Pacheco, 2001, pag. 40.

${ }^{4}$ Attraverso un'analisi delle descrizioni delle manifestazioni spontanee fatte dall'organo doi stampa del PRR a Porto Alegre, Pacheco riconosce come 'i repubblicani dimostrano di essere interessati a questo appoggio della popolazione urbana ma fanno capire anche che non sono disposti a considerare tutte le manifestazioni della moltitudine come espressioni di cittadini" (pag. 58).

${ }^{5}$ Non va dimenticato che nel tempo vi sono state anche frizioni forti tra il PRR gaúcho ed altri partiti affini del resto del Brasile; il primo caso fu nell'aprile-maggio 1890 , durante il Governo Provvisorio, quando il ministro Rui Barbosa promosse un atto (l'Encilhamento) che permetteva ad alcune banche private di emettere carta-moneta. A Porto Alegre, il PRR promosse - seppur non in prima persona ma attraverso la Liga Agrícola Industrial - varie proteste di piazza davanti alla Banca cittadina autorizzata alla stampa (cfr. Franco, 1996).

"“I Repubblicani gaúchos [...] furono grandi costruttori di frasi ad effetto, nella proclamazione furono produttori di molte immagini simboliche per la Repubblica e, nei primi tempi del regime, eressero monumenti carichi di immagini metaforiche e indottrinatici delle proprie idee" (Pacheco, 2001, pag. 42). Tra gli elementi esemplificativi richiamati nel cap. 4 vi è il frequente cambiamento 'a furor di popolo' dei toponimi degli spazi urbani.

${ }^{7} \mathrm{E}$ il caso dei 'cittadini stranieri', a Porto Alegre molto legati al processo di dinamizzazione dell'economia in cui introducono il proprio bagaglio culturale; nei primi anni della Repubblica molti di essi partecipano alle manifestazioni di piazza, ma riunendosi prima nelle sedi associative proprie, e giungendo in gruppi organizzati e ben identificabili, in modo da sottolineare la propria identità peculiare sulla scena pubblica (Pacheco, pag. 60-61).

${ }^{8}$ La Liga Operária, nata nel 1891, ha avuto la grande particolarità di avanzare proposte politiche piuttosto avanzate, associandole a pratiche religiose profondamente radicate nella popolazione portoalegrense (Pacheco, 2001, pag. 107),

${ }^{9}$ Questo, nato nel settembre 1890 , già nel 1891 presentò alle elezioni statali propri candidati, appoggiando anche alcuni dissidenti del PRR, cacciati (come il celebre Barros Cassal) per essersi rifiutati di appoggiare candidati sgraditi alla presidenza del Brasile. Il 6 settembre 1890 furono realizzate manifestazioni di strada a cui parteciparono intere 'famiglie' (cfr Jornal do Comércio, 9/9/1890), ovvero anche persone prive del diritto di voto che volevano manifestare le proprie affinità elettorali, dando legittimità sociale ai dissidenti a cui era stata tolta ogni legittimità politica, e preparando il terreno all'impegno diretto del neonato Centro Operário nelle elezioni statali. Questo scelse i propri candidati durante un Assemblea Generale, con l'idea che gli interessi degli operai dovessero essere rappresentati 'non da un dottore ma da un loro pari' (Pacheco, 2001, pag. 115). Nel suo operato, il Centro Operário combinò e contaminò dottrine diverse, facendone letture sincretiche: ad esempio, accolse elementi dell' anarchismo - come la necessità di assemblee di classe che articolassero la presenza operaia nella lotta politica come blocco unitario e autogestito - pur negando il suo rifiuto per le organizzazioni partitiche e la partecipazione alle elezioni.

${ }^{10}$ Il PRR (formatosi nel 1882, come visto nel cap. 4, sulle teorie positiviste di Compte) proponeva una sorta di ideale di 'dittatura repubblicana' in mano al partito, che gover- 
nasse sulla base di un 'pensiero scientifico' capace di 'controllare tutte le variabili del movimento sociale in modo da condurlo sulla via del progresso (cf. Trinidade, 1990). L'idea di civismo - come dimostrano molti articoli del suo organo ufficiale di Porto Alegre "A Federação" nei primi anni della Repubblica - coincideva con una questione di 'educazione', o di 'buon comportamento', cioè di 'uso corretto delle prerogative della cittadinanza' (Pacheco, 2001, pag. 96-99). Il 'cittadino educato' per il PRR rappresentava un elettore sottomesso, da mobilitare a proprio piacere per convincerlo 'a votare nel leader tradizionali dell'elite politica della città' (idem, pag. 122). Il partito si percepiva come 'donatore' del diritto al voto nei confronti dell'insieme della società, interpretando il voto non come un 'diritto sostantivo' inerente al cittadino o come la libera manifestazione di una possibilità di libera opzione , ma come un 'dono, una concessione', una sorta di 'formalità' che esclude dalle pratiche riconosciute tutte le manifestazioni di opposizione ai progetti del partito, fatte coincidere con atteggiamenti da 'non-cittadini' (idem); in tal senso, si considerava l'unico legittimo difensore della Repubblica e riteneva il voto popolare e la vittoria qualcosa che gli apparteneva moralmente. Come ha scritto Pacheco (pag. 14): "I repubblicani, che si giudicano proprietari della Repubblica in Porto Alegre, accettano di rinunciare ad essere gli unici eletti, gli unici con il diritto di interferire nella costruzione della legge che regolerà le relazioni sociali. Anche se a tal fine devono ricorrere alla frode elettorale e al misconoscimento dell'esercizio di cittadinanza dei settori popolari".

${ }^{11}$ Essa era formata da due rappresentanti di ogni sindacato aderente alla Federazione Operaia e da una sub-commissione incaricata di discutere le specifiche questioni dei quartieri operai di São João e Navegantes.

${ }^{12}$ Vedi $O$ fim da greve, in Correio do Povo, 3 agosto 1917

${ }^{13} \mathrm{Nel}$ periodo detto 'populista' i governatori del Rio Grande do Sul furono: Walter Jobim (1947, PDS), Ernesto Dornelles (1950, PTB), Ildo Meneghetti (1954, PDS), Leonel Brizola (1958, PTB), Meneghetti di nuovo nel 1962.

${ }^{14} \mathrm{La}$ proposta riprendeva idee di Alberto Bins del 1928

${ }^{15}$ I dirigenti del Dipartimento delle Opere, dell'Acqua e Fogne, delle Finanze; l'ingegnere-capo e altri due scelti dal Sindaco.

${ }^{16}$ Cfr. Atto 1/59 del Consiglio Comunale

${ }^{17}$ Questi dati sono contenuti in un documento manoscritto e senza data dell'archivio FASE-RS che contiene preziosi dati - ricavati da interviste ad antichi dirigenti della FRACAB - dal titolo Levantamento histórico dos movimentos, organizações $e$ reivindicações da população favelada (cfr. Menegat, 1995).

${ }^{18}$ Cfr. Boletim dos Bairros, 1979, in Guareschi, 1980.

${ }^{19}$ L'organizzazione di queste seguì la $\mathrm{II}^{\circ}$ Conferenza Generale del Clero Latino-americano avvenuta a Medellin nel 1968; molti settori della Chiesa Cattolica brasiliana riorientarono la loro azione privilegiando i poveri e gli oppressi nella loro azione pastorale. Le CEBs contribuirono a trasformare molti lavoratori dal basso reddito in soggetti politici attivi capaci di mobilitarsi per migliorare le proprie condizioni di vita nella città attraverso la predicazione di nuovi modi di vivere il Sacro nel quotidiano, rivolti a creare una società più giusta e fraterna. Un interessante approfondimento è contenuto nello studio su alcune CEBs dell' area metropolitana di Porto Alegre in Dvoranovski (1990).

${ }^{20}$ Spesso addirittura attraverso il controllo delle sezioni elettorali distaccate per la verifica del funzionamento dei meccanismi di voto di scambio (Menegat, 1995).

${ }^{21}$ Scelti i 12 nuclei più rappresentativi, Guareschi ha trovato - solo sulla stampa locale ben 485 articoli riferiti a forme di mobilitazione e rivendicazioni delle Associazioni. I nuclei scelti (71.571 persone, cioè il $47 \%$ di coloro che all'epoca abitavano in aree irregolari) sono Caiu do Céu (1000), Conceição (1400), Fatima (2700), Monte cristo (530 abitazioni), Nova Brasília e Respeito (2209 insieme), Restinga Nova e Velha (1800 in tutto), São Vicente Mártir (2400), Tamanca (700),Tronco (2000), Tuca (489).

${ }^{22}$ Le Associazioni di Residenti di Campo da Tuca - zona est di Porto Alegre - sono stati i pionieri in città di questa forma di lavoro sociale cooperativo con cui hanno risolto problemi di carenze infrastrutturali, come il ponte sul fiume autocostruito e inaugurato il 30/7/1978 con lo slogan: "Siamo marginalizzati e non marginali" (Zero Hora, 31/7/78, in Guareschi, 1980). A Vila Tronco (nella Grande Cruzeiro), nel '79, con i mutirões si costruì, invece, un asilo.

${ }^{23}$ La Regione Glória ottenne, ad esempio, una rete di acqua potabile e l'espansione dei servizi di trasporto, la Lomba la riduzione dei costi dei biglietti dell'autobus e la sospen- 
sione dello sgombero di Vila Viçosa, la Regione Nord trionfò nelle richieste di nuove scuole (notizie in Movimentos Sociais em Porto Alegre, archivio FASE).

${ }^{24}$ O Rio Grande, 9/7/1979, citato in Guareschi, 1980. Il verbo 'esperar' vuol dure sia attendere che sperare, ndr.

${ }^{25} \mathrm{Nel}$ settembre 1993 la FRACAB Statale contava 2059 AMs e 57 Uniões de Associações. Di recente, però, alla Conferenza Nazionale della AM brasiliane (CONAM, organismo nato nel 1983) tenutasi a Goiania dal 4 al 6 giugno 1999 - la UAMPA di Porto Alegre e le omologhe associazioni delle altre città del Rio Grande do Sul non sono state rappresentate dalla FRACAB, ma si sono presentate individualmente; lo scopo era mostrare segnali di decentramento, dando voce anche alle Associazioni discordi dalla linea della Federazione Statale.

${ }^{26} \mathrm{Nel}$ ripercorrerne brevemente i contenuti faremo riferimento alla sintesi elaborata da Menegat (1995)

${ }^{27}$ In tal senso, si fece riferimento all'organizzazione di livello superiore dei movimenti urbani che già da un quinquennio si era autonomamente costituita nelle Regioni menzionate a proposito delle rivolte del 1979 e della proliferazione di Uniões de Vilas, favorite da una contiguità spaziale reciproca e da un certo grado di omogeneità sociale. La UAMPA conferì a questo genere di articolazioni un grado maggiore di rigore nella delimitazione delle Regioni, prendendo spunto dal sorgere di una visione più globale della problematica urbana e delle questioni amministrative.

${ }^{28}$ Nel giugno ' 86,150 delle circa 200 Associazioni di Residenti di Porto Alegre risultavano affiatate all'UAMPA, contro le 80 dell'ottobre precedente (Baierle, 1992).

${ }^{29}$ A questa edizione presero parte 400 delegati di 83 Associazioni di Quartiere e 100 osservatori

${ }^{30}$ Dal Regolamento Interno emanato solo nel 1983 si evince che tra questi ultimi gruppi ve ne erano due tradizionalmente progressisti nel Rio Grande do Sul come l'Ordine degli Avvocati e degli Architetti, oltre alla Segreteria Statale per l'Ambiente, alla Fondazione di Economia e Statistica, alla Federazione Statale della Stampa

${ }^{31}$ I Consigli erano già presenti nello Statuto del 1962. Dal 1971 i membri dei Consigli furono nominati dal Sindaco per periodi biennali all'interno di liste presentate dalle organizzazioni, in numero uguale alla metà più uno dei rappresentanti ufficiali dell'Amministrazione in quel settore (LC 3607/71); la composizione era sfavorevole agli organismi di rappresentanza delle classi popolari (Menegat, 1995) ma costituiva comunque un'occasione di apertura graduale di spazi istituzionali a modi ulteriori di rappresentazione della società rispetto a quelli costituiti dai partiti politici.

${ }^{32}$ Il restante $10 \%$ di posti sarebbe spettato a rappresentanti istituzionali.

${ }^{33}$ Per questi eventi i dati sono tratti da Menegat (1995) e Fedozzi (2000).

${ }^{34}$ Per la UAMPA, questo era percepito come un rischio di 'professionalizzazione' dei consiglieri.

${ }^{35}$ L'alto peso dei movimenti nella composizione, il carattere deliberativo dei Consigli e il 'vincolo di mandato' (revocabile) dei suoi membri popolari (Fedozzi, 2000, pag. 50). ${ }^{36}$ I nuovi Consigli erano quelli della cultura, dell'ambiente, dei lavori pubblici, del risanamento, della pianificazione, dell'educazione, dell'alloggio, dello sport, dell'industria, commercio e difesa del consumatore (Moura, 1989). Quelli già esistenti erano trasporti, personale, acquisti, contribuenti, minori, patrimonio artistico e culturale, sanità e PRG.

${ }^{37}$ Fedozzi, 2000, pag. 50

${ }^{38}$ In tal caso, infatti, le decisioni colpite da 'veto' dovevano essere discusse dal Consiglio Comunale (e votate da $2 / 3$ dei presenti), al contempo minando l'autonomia del 'Legislativo' - che diveniva corresponsabile della giunta nella gestione del quotidiano - e paralizzando l'Esecutivo che finiva per dipendere dalle procedure e dai tempi del Consiglio anche per prendere semplici decisioni amministrative (PGM, citato in Fedozzi e Castro Filho, 1989)

${ }^{39}$ Concordando quasi tutte le correnti del PT su questa visione, si instaurò un dibattito per definire ed articolare meglio la nozione di Consigli Popolari, visti in modo vario come embrioni rivoluzionari del contro-potere politico alla borghesia, forum di discussione politica fatti nascere dal basso all'interno del movimento operaio e popolare, agenti di coscientizzazione dei lavoratori, contraltari a que gli apparati burocratici e amministrativi di falsa co-gestione del Comune che erano divenuti i Consigli Municipali. Alla fine del dibattito, la fisionomia assunta dalla nozione di Consiglio Popolare rappresentò "una sintesi politica originata dai discorsi contrari all'autoritarismo e al 
burocratismo" appoggiati sui principi di democrazia di base e autonomia (Menegat, 1995) e su principi riferiti perfino alla tradizione anarchica (sui riferimenti dell'anarchismo cfr. Sherer-Warren, 1984; mentre sul recupero di elementi dei town meetings, delle sections o dei soviet vedi Castoriadis, 1987).

${ }^{40}$ Fedozzi, 2000, pag. 53

${ }^{41}$ Baierle, 1993, pag. 228-29

${ }^{42}$ Oltre che all'art. 102 dello Statuto di Porto Alegre, i Consigli Popolari sono previsti dalla Costituzione del Rio Grande do Sul (art. 19, § 2)

${ }^{43}$ Cfr. Lei Orgânica do Município de Porto Alegre (1990), Corag, Porto Alegre, pag. 31-33.

${ }^{44}$ Fedozzi, 2000, pag. 58.

${ }^{45}$ Esse sono condensate in un passo denso di un rapporto interno del primo periodo di governo del Fronte Popolare: "[La Legge dà] l'impressione che la questione di cui si tratta non risiede nella semplice democratizzazione dell'Amministrazione, confondendo questo con la creazione di organismi autonomi di massa. La non delimitazione delle competenze di tali Consigli segue la stessalinea [...] Di fatto, però, frammentando la partecipazione popolare in un eccesso di Consigli, pregiudica l'ampiezza delle possibilità della sua azione [...] Oltrettutto 'statualizza' le reti di entità rappresentative degli abitanti, delimitando una zonizzazione delle regioni che sotto diversi aspetti è diversa da quanto proposto dai movimenti. Infine, determina che l'elezione dei delegati comunitari avvenga in assemblee di organizzazioni, misconoscendo l'intervento popolare diretto" (Fedozzi; Castro Filho, 1989).

\section{BOX 4 - LeAssociazioni di Quartiere: prime 'finestre di opportunità'per il protagonismo sociale}

Le SABs (Sociedades de Amigos do Bairro = Società di Amici del Quartiere) cominciarono a sorgere nelle maggiori città brasiliane durante il ventennio che precedette il golpe del 1964, sul modello di quelle formatesi a San Paolo già negli anni Trenta in guisa di micro-autorità locali utili a rappresentare un quartiere davanti alle autorità politiche (Zaniratti, 2000). Le SABs si costituivano soprattutto in quartieri informali $\mathrm{o}$ in zone operaie, ed erano per lo più formate da abitanti in condizioni disagiate alla ricerca di un miglioramento dei servizi pubblici per i propri quartieri attraverso una politica di 'buon vicinato' con il potere politico (ibidem): spesso ne facevano parte anche soci non residenti nel quartiere rappresentato, ma che detenevano su di esso qualche forma di influenza economica o politica. Nei primi tempi della loro esistenza le SABs restarono poco note, distinguendosi per livelli mediobassi di partecipazione (Menegat, 1995). Per ottenere i loro scopi, in gran parte scelsero la strada della negoziazione con i politici locali attraverso l'opera di intraprendenti leader di quartiere. La loro crescita di peso nel corso degli anni ' 50 e '60 tese a moltiplicarne il numero soprattutto nelle megalopoli in rapida crescita (Alvarez, 1997). A Por to Alegre, la maggioranza di esse si legò al PTB (Partido Trabalhista Brasileiro), partito di impostazione populista con un deciso programma di accostamento delle organizzazioni cittadine e dei sindacati.

Durante l'Amministrazione Brizola degli anni '50, il processo di moltiplicazione delle Associazioni di Amici del Quartiere fu promosso nell'ambito di uno sforzo istituzionale di articolazione e mobilitazione del blocco politico nazionalsviluppista, con l'intento di prevenirne la formazione autonoma e di proporre il governo locale come motore e protagonista della trasformazione sociale, strumento di lotta contro l'imperialismo straniero e protettore delle classi subalterne (Baierle, 1998). La distribuzione in forme clientelari delle 'chiavi' nei progetti di edilizia popolare (come avvenne a Porto Alegre in Vila dos Industriários) andò perciò di pari passo con il formarsi delle organizzazioni di vicinato. In tal modo, lo Stato puntava a plasmare la società stabilendo a suo insindacabile giudizio i criteri di accesso alla cittadinanza e costruendo legami privilegiati tra settori della politica e settori popolari.

Nel Rio Grande do Sul, ad esempio, è su spinta del PTB che, nel 1959, nacque una rete statale di SABs, la FRACAB (Federazione Riograndense delle Associazioni Comunitarie e di Amici dei Quartieri), che servì da subito per coordinare le relazioni clientelari fra le associazioni ed i leader politici del PTB (Baierle, 1993; Abers, 
1998). Quando quest'ultimo fu cancella to dal colpo di Stato militare, la FRACAB sopravvisse, riciclandosi nel rapporto privilegiato con l'ARENA, il partito dei militari: molte Società aderenti scelsero, però, di mettere in secondo piano qualsiasi richiesta da dirigere al nuovo potere militare.

Il 1964 determinò a suo modo anche i primi germi di rivolta contro il sistema clientelare che il regime stesso si impegnava a diffondere, nella misura in cui alcune associazioni di vicinato divennero rifugio per militanti perseguitati e quindi spazi di affermazione politica alter nativa. L'opposizione al programma massivo di sgomberi e di confino delle popolazioni povere nelle aree più periferiche (Rimuovere per promuovere) generò in molti movimenti popolari un'adesione ai principi d'opposizione al regime che cominciò a trasformare dall'interno il carattere di alcune associazioni, fin da quell'epoca.

Nel 1974, l'indebolirsi del regime offrì una 'finestra di opportunità' allo svilupparsi di rinnovate politiche clientelari, visto che l'ARENA sentì il bisogno di ri-garantirsi l'appoggio popolare. Uno dei sistemi più diffusi usati per tentare una spoliticizzazione delle associazioni di quartiere fu la distribuzione di terre contese ed illegalmente occupate, e contemporaneamente la minaccia dell'evacuazione in caso di 'comportamenti elettorali scorretti' (Fruet, 1991; Baierle, 1998). In entrambi i casi le associazioni di vicinato divennero il cardine della negoziazione con il regime morente: l'unico soggetto legittimato a trattare.

La riapertura della competizione elettorale multipartitica (1979) innestò sulla 'pratica del confronto' (culminata a Porto Alegre nel grande sciopero dei la voratori del '79, cfr. Guareschi, 1980) il riutilizzo delle organizzazioni di quartiere come strumenti 'chiusi' per lo scambio clientelare nelle mani della politica, ma anche forme di cooperazione contro il regime in decadenza.

Le nuove organizzazioni che si formarono in parallelo all'esaurirsi dell'autoritarismo militare, fin dal nome, tentarono di evidenziare il proprio cambiamento qualitativo, abbandonando la dicitura di Associazione di Quartiere (troppo legata a limiti fisici ufficialmente imposti) per assumere quello di Associazioni di Abitanti [AMs o Associações de Moradores], preoccupate di delimitare lo spazio di incontro a partire dalle identità socio-politiche e culturali riconosciute dagli stessi abitanti, elemento fondamentale all'interno di un panorama urbano in rapido mutamento dove si andavano costruendo nuovi spazi di esclusione attraverso fenomeni di valorizzazione dei suoli, sgomberi forzati ed invasioni clandestine.

Se alla fine degli anni '70, a livello nazionale, si era creata la ANAMPOS (Articulação Nacional dos Movimentos Populares e Sindicais), che metteva permanentemente in dialo go leader del Movimento Popolare e di quello Sindacale, nel 1983, a Porto Alegre, la nascita della UAMPA (Unione delle Associazioni di Abitanti di Porto Alegre) si pose come il primo tentativo "di riconciliare" le concezioni "apparentemente antagoniste della mobilitazione popolare" come relazione "monogama" (Baierle, 1998).

Dal dibattito in seno alla nuova unione emersero temi nuovi, come le proposte alternative di politiche pubbliche, la formazione di gruppi di donne e lo sviluppo di imprese cooperative. Molte di queste iniziative, per lungo tempo, ebbero come obiettivo la soppressione del regime militare, ma non si attardarono "a immaginare un oltre"; questo fu spesso lasciato all'immaginazione delle diverse componenti 'formali' del blocco antiautoritario, compreso il centralismo democratico della sinistra partitica con le sue gerarchie di deleghe di stampo sindacale che generò "strutture federative semiartificiali senza reale potere di rappresentanza, agenti più come pompieri che intervengono su incendi e raramente sanno assumere un ruolo-guida come organizzatori o costruttori” (Baierle, 1998).

Così, in tutto il Brasile, i primi due anni di vita delle nuove associazioni di vicinato, delle loro unioni (a livello municipale), federazioni (a livello statale) e Confederazioni (a livello federale), restarono piagati da crisi di identità preoccupanti, che ne dimostrarono la scarsa capacità di costituire una vera 'pratica di confronto' e spesso determinarono la loro morte al venir meno (nel 1985) del legame interno al blocco antimilitare che le aveva sostenute fino ad allora. Si spiega così il buon gioco che il PDT (al governo in molte città tra il 1986 al 1988) ebbe nello strutturare interi dipartimenti delle ammini- 
strazioni locali come vere e proprie 'cupole' di organizzazioni popolari di rinnovato contenuto clientelare, mentre - a livello statale e federale - il PMDB incoraggiò meccanismi di partecipazione popolare, limitandoli al livello di attuazione delle politiche ed evitando ogni coinvolgimento nella fasi di loro formulazione (Baierle, 1998). Durante il periodo del governo Sarney di transizione democratica, i Movimenti Popolari di diverse parti del Brasile tentarono di elaborare una strategia di cooperazione mutua che superasse il fallimento di reti come la CONAM (Confederação Nacional de Associações de Moradores) o la COBRAM (Confederação Brasileira de Associações de Moradores), sua costola dissidente; entrambe originatesi su spinte di origine partitica, esse possedevano, infatti un carattere 'escludente' rispetto alle componenti del Movimento Popolare che non rientravano nel Movimento Comunitario, ovvero nelle Associazioni di Vicinato.

Nel 1985, i militanti di 20 stati, durante $1^{\prime} 8^{\circ}$ Incontro ANAMPOS a Belo Horizonte, cercarono di dar vita a un'organizzazione nazionale con obiettivi simili a quelli che la CUT (la Centrale Unica dei Lavoratori) andava sviluppando per articolare - in piena autonomia - le molteplici componenti del movimento sindacale. Fu anche creata una Commissione Pró-Central do Movimento Popular (CPC) che avrebbe dovuto portare alla creazione di una Central do Movimento Popular; ma essa non divenne mai realtà. Anzi, il processo di 'rafforzamento' dei Movimenti Popolari subì un arresto, a motivo delle argute forme di cooptazione politica messe in atto dal Governo Sarney, anche attraverso il programma 'GENTE LEGAL', che rinforzava l'importanza delle Associazioni di Vicinato, centrandosi sulla loro esistenza legale piuttosto che sulla loro legittimità davanti agli abitanti dei quartieri. Vicende come quella dei coupon per la distribuzione del latte creati da Sarney finiron per dare alle Associazioni di Vicinato un ruolo fondamentale e strettamente 'politico' (Zaniratti, 2000). L'utilizzo improprio del Movimento Comunitario in forma di 'presidio elettorale' sul territorio, fu all'origine di tre diversi indirizzi di trasformazione delle associazioni che lo componevano, quello pessimista, quello pragmatico e quello che tese a sfruttare l'opportunità offerta per una ricostruzione strategica delle lotte urbane.

In breve, l'aumento delle difficoltà della popolazione rese insufficiente l'azione di calmieramento dello scontento che gli scambi clientelari minuti e ad personam avevano fino allora garantito. Questo ingenerò le condizioni per il sorgere di un nuovo tipo di associazioni di quartiere che cominciarono a ripudiare il gioco clientelare, e non solo in nome dei suoi fallimenti concreti ma anche come espressione privilegiata della stortura politica del momento (Abers, 1998). Nella stessa Porto Alegre, la UAMPA tese ad assumere un approccio 'rivoluzionarista' orientato 'all'avvento del socialismo' che funzionò, in realtà, da argine per limitare la ricchezza, l'approfondimento e le prospettive della politica comunitaria (Fedozzi, 2000, pag. 46). Il ricambio ai vertici di molte Associazioni di Abitanti, e il ri-orientamento del loro ruolo verso il conseguimento di benefici attraverso forme di protesta e pressione politica avverse alle negoziazioni di tipo personale, coincisero negli anni '90 con un riorganizzarsi delle politiche locali in molti centri del Brasile, a cui le rinascenti AMs dettero un notevole contributo di idee ed energie. Importante, ai fini di questo duplice rinnovamento, è stata l'opera di 'agenti esterni' appartenenti - ad es. - all'ala progressista della Chiesa Cattolica o a ONG locali di recente creazione (Menegat, 1995). 


\section{7 \\ 1989: la città ad un bivio - il Bilancio Partecipativo (O.P.), emblema del 'nuovo corso'}

\subsection{Verso un concreto coinvolgimento dei cittadini nelle scelte urbane}

Fin dal dialogo instaurato tra l'amministrazione Collares e i Movimenti Popolari di Porto Alegre nel 1986, l'idea dei Consigli Popolari (CPs) è rimasta a lungo l'espressione massima dell'immaginario di democratizzazione urbana possibile (Menegat, 1995), innescando - in seno alle organizzazioni della cittadinanza e alle forze politiche - una serie di vivaci dibattiti sul come mettere in pratica una riformulazione strategica delle strutture decisionali cittadine.

Due - come abbiamo visto - erano i principali orientamenti. Uno interpretava i CPs come organismi autonomi rispetto alle istituzioni, costituiti a partire dai movimenti popolari e in una prospettiva di costruzione dell'egemonia delle classi subalterne; l'altro li interpretava quali nuovi canali istituzionali di partecipazione popolare nella gestione municipale. ${ }^{1}$ Il dialogo tra movimenti e amministrazione comunale, sfociato nella discussa Legge Complementare $195 / 88$, cercò di realizzare un impossibile compromesso tra le due tendenze interpretative, ma come risultato ottenne soprattutto quello di scontentare la società civile organizzata, di produrre un 'provvedimento artificiale e formalista' di incentivo della partecipazione cittadina, e di creare serie difficoltà alla coalizione del Fronte Popolare subentrata al PDT nel gennaio 1989.

Paradossalmente, tra gli effetti indiretti di questo impasse, vi fu l'apertura di un immaginario che pareva ormai 'bloccato' sulla nozione di Consigli Popolari, che propiziò - sia da parte dei movimenti che delle forze politiche - un recupero di ulteriori desiderata e scenari di trasformazione istituzionale ipotizzati negli anni precedenti durante i 3 primi Congressi della UAMPA e in parte ripresi dal Gruppo di politica municipale' creatosi nel maggio '87 dentro il $\mathrm{PT} .{ }^{2}$ In particolare, si tornò a riflettere su una specifica richiesta dei movimenti, che ormai andavano mostrando grande densità organizzativa (Diniz, 1995, p. 385), accumulazione di capitale sociale (Fedozzi, 2000, p. 48) e una crescente cultura civica critica anche nei confronti del proprio tradizionale anti-istituzionalismo. L'idea era coinvolgere attivamente la cittadinanza (attraverso un apposito Consiglio) nella con-discussione del bi- 
178 lancio comunale, ed era stata già ventilata nel $1986^{3}$ come punto di svolta necessario per un reale rinnovamento delle politiche.

Seppur per via di 'reazione', il dibattito sui Consigli Popolari ebbe, quindi, l'effetto di sollecitare nuovi processi di discussione, mirati a configurare le basi di nuovi percorsi decisionali che si ponessero come complementari o paralleli a quelli tradizionalmente attuati, aprendo spazi consistenti di partecipazione anche alle classi subalterne.

Proprio l'imbarazzante situazione determinata dalla Legge 195/88 originò la necessità di accostare alle riflessioni teoriche forme di sperimentazione pratica per gradi di quanto veniva dibattuto; in tal contesto, a Porto Alegre l'azione della neoeletta Amministrazione Popolare cominciò a prendere concretamente corpo "in una dinamica differenziata, di innovazioni e continuità, di iniziative radicate nell'immaginario, permeate da metodi e strutture tradizionali, a volte contraddittori" (Moura, 1993) che però spesso bypassorono o addirittura sopravanzarono le stesse istanze del dibattito teorico parallelamente in corso di svolgimento.

Tra i nuovi strumenti della gestione democratica non codificati dallo Statuto Municipale ma via via sperimentati (doverosamente ancorandoli a nozioni e istituti previsti dallo Statuto, in corso di revisione proprio nel 1989) vi è stato principalmente il Bilancio Partecipativo [Orçamento Partecipativo, o O.P.] cioè la strutturazione di una discussione democratica sulle priorità di bilancio del Comune e sull'articolazione dettagliata del Piano annuale degli Investimenti, che dal primo anno di governo del Fronte Popolare ha preso gradualmente forma, recuperando - in modo spesso implicito - i principi alla base di formule già sperimentate in precedenza - sporadicamente ed in maniera incompleta - in piccoli centri dello Stato del Rio Grande do Sul (ad esempio a Ijuí nel 1966; poi a Pelotas nel 1984) o di altri Stati (come Lages nello stato di Santa Catarina alla fine degli anni '70, ma anche Vila Velha in quello dell'Espirito Santo, o Recife nel Pernambuco, l'unico caso di grande città dove però l'esperimento non è decollato in maniera significativa). ${ }^{4}$

Oggi che la riduzione del ruolo e della forza degli Stati, determinatasi nei processi di globalizzazione economica, ha aumentato l'attenzione nternazionale per le soluzioni di ambito locale, ${ }^{5}$ soprattutto in relazione ai problemi relativi all'urbanizzazione e alla gestione del territorio, il nuovo processo che ha cominciato a prendere forma a Porto Alegre nel 1989, va riscuotendo un crescente e comprensibile interesse, anche per la sua capacità di offrire 'risposte locali efficaci ai nuovi dilemmi urbani, giungendo al nucleo dei problemi della realtà in cui si è trovato ad operare, e proprio a partire dall'ascolto delle percezioni locali, delle motivazioni, della cultura e delle proposte emerse in seno al 'patrimonio sociale' costituito dai Movimenti Popolari operanti sul territorio. È per questo che - come anno di riferimento per rappresentare una 'svolta' importante nella gestione del territorio portoalegrense - abbiamo scelto il 1989, un' annata già simbolicamente importante sia a livello mondiale (per aver segnato l'inizio dell'abbandono della 'Guerra Fredda'), sia nel panorama brasiliano, dato che - insieme alla nuova Costituzione Federale democraticamente disegnata - proprio in quell'anno entrarono in carica in molte zone del Paese nuove amministrazioni locali impegnate a dimostrare come il decentramento - oltre che "un'alternativa conservatrice alla crisi, utile per scaricare il governo centrale di parte delle sue incombenze e, anche, per creare nuove opportunità di investimento del capi- 
tale in questa fase di ristrutturazione del capitalismo su scala mondiale" (Carrion, 1993) può anche rappresentare un elemento chiave per la democratizzazione dello Stato, in grado di creare le 'condizioni virtuali' per l'esercizio democratico di un potere che punti ad un'ampia articolazione della società locale, in vista di una condivisione delle scelte strategiche come di quelle appartenenti alla quotidiana routine amministrativa.

L'ormai vasto panorama di indagini critiche multidisciplinari esistenti sull'esperienza di Porto Alegre, ${ }^{6}$ e quelle sinottiche che la analizzano in rapporto ad altre esperienze consimili, tendono tutte a sottolineare come il Bilancio Partecipativo non sia da leggersi isolatamente, ma come 'motore' di ulteriori trasformazioni innescate sia nelle modalità di utilizzo e rinnovamento di altri strumenti di gestione territoriale, sia nell'evolversi delle diverse politiche urbane che gli hanno fatto da cornice e ne hanno sfruttato le potenzialità negli ultimi 14 anni. Esso, infatti, ha saputo non solo costituirsi come meccanismo di autosperimentazione - che lavora contemporaneamente sul perfezionamento progressivo dei suoi contenuti e dei suoi meccanismi di funzionamento - ma ha sviluppato nel tempo una capacità 'aggregatrice' e di stimolo proiettata al di là di se stesso, divenendo così 'nodo catalizzatore ed articolatore' di politiche rinnovate e 'nodo risolutore' di problematiche e limiti che la sua stessa esistenza ha contribuito ad evidenziare nella gestione del territorio.

La comprensione analitica delle complesse trasformazioni indotte dalla sperimentazione del Bilancio Partecipativo pressoché in ogni settore di intervento dell'amministrazione municipale (e poi statale), e la valutazione delle articolate dinamiche politico/sociali messe in campo in questi anni nella vita cittadina di Porto Alegre, richiederebbero un testo a loro interamente dedicato: non sarà pertanto semplice riassumerne nei paragrafi seguenti neppure $\mathrm{i}$ capisaldi. È però strettamente indispensabile accennarne, per offrire al lettore una chiave di lettura al fitto tessuto di cambiamenti che accompagnano ed inquadrano i temi su cui ci siamo proposti di soffermarci più a lungo. Pertanto, in questo e nei prossimi capitoli saranno offerti alcuni spunti di riflessione sul Bilancio Partecipativo, in riferimento anche alla vasta saggistica che ne ha recentemente esaminato strutturazione, limiti ed esiti. Pur dovendo rimandare a quest'ultima per approfondimenti dettagliati su molti dei temi messi in gioco dalle innumerevoli prospettive di lettura possibili del BP, il presente testo cercherà di soffermarsi su alcuni degli elementi portanti del nuovo percorso partecipativo che si legano strettamente agli ambiti tematici che ci siamo proposti di discutere in maniera più articolata.

La descrizione dell'attuale funzionamento del Bilancio Partecipativo rappresenta una necessaria premessa perché il lettore possa entrare nelle dinamiche della sua articolazione (e nelle terminologie che ne denotano puntualmente fasi e protagonisti); si è così scelto - contrariarmente alle altri parti del testo di premetterla alla ricostruzione temporale dei momenti della sua strutturazione. Questi saranno ripercorsi successivamente, con approccio 'retrospettivo', in modo da comprendere meglio sia la peculiare vicenda evolutiva che ha portato all'arricchirsi del funzionamento del Bilancio Partecipativo e all'ampliamento dei suoi principi fondanti ad altri ambiti delle politiche cittadine, sia gli stretti legami che queste trasformazioni hanno stabilito con le peculiarità storico-culturali di Porto Alegre attraverso una valorizzazione critica delle risorse e delle proposte dei suoi abitanti. 
Il Bilancio Partecipativo è un processo attraverso il quale la popolazione di Porto Alegre prende decisioni, in maniera diretta, sull'utilizzo delle risorse per le opere e i servizi che verranno realizzati dall'Amministrazione Comunale. Il processo si estende durante tutto l'anno (ad eccezione di gennaio e febbraio, che sono i mesi delle vacanze estive), articolandosi in fasi in cui diversi sono gli attori 'preminenti', fermo restando l'importante ruolo di controllo svolto tutto l'anno dai cittadini sull'andamento del processo di discussione e deliberazione. L'adozione del Bilancio Partecipativo ha avuto ed ha lo scopo prioritario di riorganizzare i modi, i luoghi e le responsabilità dell'elaborazione del bilancio pubblico e dei piani annuali e pluriennali di investimento urbano (tradizionalmente messa in opera dall'Esecutivo municipale e da tecnici isolati nei loro gabinetti, cfr. U. De Souza, 2002), ripartendo la fase di diagnosi tecnico/politica su tre direttrici fondamentali: quella della discussione intergovernativa, quella del dibattito pubblico su base geografica e, dal 1994, quella del dibattito su base tematica.

\subsubsection{Ambiti di articolazione del processo}

Oggi, a Porto Alegre, la base geografica cittadina di riferimento per l'organizzazione del Bilancio Partecipativo è costituita da 16 'regioni ${ }^{17}$ (all'interno delle quali è possibile individuare microregioni con peculiari caratteristiche, e - ad un livello inferiore di definizione - quartieri e vilas popolari). Dentro ognuna di esse le comunità di abitanti attuano una diagnosi su base distrettuale delle proprie necessità. In realtà, la popolazione definisce a diversi livelli di discussione assembleare le proprie necessità o le proprie aspirazioni, identificandone 4 prioritarie all'interno di 14 possibili aree tematiche, ${ }^{8}$ al fine poi di gerarchizzare le singole opere e servizi che si vuole siano realizzati per primi dall'Amministrazione nell'anno successivo. Il livello 'regionale' funge da aggregante delle elaborazioni che avvengono su basi geografiche minori (come quelle microregionali, di quartiere o di singole comunità).

In parallelo alle elaborazioni su base geografica, altre ne vengono portate avanti su base tematica; esse consistono attualmente in 6 ambiti diversi di discussione 'a tema' mirati a priorizzare opere strutturali, progetti e direttrici di servizio per la città nelle seguenti aree di intervento: circolazione e trasporti, salute e assistenza sociale, educazione, sport e tempo libero, cultura, sviluppo economico e raccolta delle imposte, organizzazione della città e sviluppo urbano e ambientale. La base di discussione tematica fu introdotta nel 1994 al fine di coinvolgere nel processo di discussione settori sociali fino ad allora non coinvolti, ma anche di dare al BP una dimensione nuova che andasse oltre l'immediatismo delle richieste microlocali, per approfondire invece il dibattito sulla pianificazione urbana complessiva e su alcune politiche di settore, compresi gli ambiti in cui teoricamente il BP non aveva fino ad allora voce.

L'articolazione annuale del processo di Bilancio Partecipativo è scandita da assemblee pubbliche, seminari, incontri di discussione approfondita e sessioni di valutazione e votazione tra loro differenziate. Essendo infatti difficile immaginare migliaia di persone che all'unisono discutono approfonditamente delle singole problematiche urbane, il processo partecipativo si distingue in momenti dibattimentali e decisionali più 'generici' e più 'specifici'; 
questi ultimi sono istanze di approfondimento a cui sono chiamati a partecipare rappresentanti della cittadinanza eletti nei turni di assemblee aperte al contributo attivo di tutti gli abitanti.

Per quanto attiene i livelli della discussione, si potrebbe dire che il discriminante è costituito dalla momentanea preminenza della forma assembleare diretta o di quella rappresentativa indiretta. Pur essendo tutte le assemblee aperte alla cittadinanza, è - infatti - il diritto di voto in ognuna di esse a differenziare i vari livelli di articolazione del dibattito: a seconda cioè che si tratti di Assemblee Plenarie o di Consigli più ristretti formati da rappresentanti eletti nella plenarie, dove anche "le porte chiuse" sono "ugualmente indispensabili per creare le condizioni di confidenza, e offrire la possibilità di 'scoprirsi' vicendevolmente" (Calame e Talmant, p. 142). Così, in alcuni gradi del processo (Assemblee Plenarie e Tematiche, Assemblee di Microregione, di Quartiere o di Comunità) il diritto di voto lo hanno tutti gli abitanti partecipanti di età superiore ai 16 anni. Nel cosiddetto 'Forum dei Delegati', invece, lo hanno solo i Delegati popolari (eletti dalla popolazione dei vari quartieri nelle Assemblee di Quartiere e di Comunità) mentre nel Consiglio del Bilancio Partecipativo (COP), che è la massima istanza decisionale del Bilancio Partecipativo, lo hanno solo i 32 Consiglieri Regionali eletti in ragione di 2 per ogni Regione e i 12 Consiglieri Tematici eletti in ragione di 2 per ognuna delle 6 Assemblee Tematiche (o i loro supplenti, in assenza dei titolari), ma anche i 2 Consiglieri stabili scelti - uno per organizzazione dall'Unione delle Associazioni di Residenti di Porto Alegre (UAMPA) e dal Sindacato degli Impiegati Municipali di Porto Alegre (SIMPA).

\subsubsection{Il ciclo annuale di bilancio: gli spazi 'aperti' per la condivisione delle scelte}

Dal 2002, la discussione annuale dei documenti di Bilancio si articola - per quanto attiene il livello più ampio di dibattito pubblico - in due momenti assembleari principali (cfr. fig. 21):

1) Il processo ha inizio con le cosiddette 'Riunioni Preparatorie' (marzo), nelle quali il Comune presenta il rendiconto dell'esercizio concluso ${ }^{9}$ e il Piano degli Investimenti e dei Servizi (PI) approvato nel ciclo di discussioni precedente per l'anno di esercizio che si sta aprendo. ${ }^{10}$ Vengono anche presentate le eventuali modifiche del Regolamento Interno del BP in vigore, apportate in gennaio dal COP relativamente ai criteri generali di distribuzione dei fondi fra le Regioni, a quelli tecnici, legali e regionali, e alle regole per l'elezione dei rappresentanti popolari nei successivi turni assembleari. Un certo tempo viene anche destinato ad una valutazione critica, da parte dei partecipanti che si iscrivono a parlare, dei conti presentati e delle opere realizzate l'anno prima. Infine, si cerca di propiziare un coordinamento con il Bilancio Partecipativo realizzato a livello Statale, ${ }^{11}$ invitando brevemente un suo rappresentante a spiegame calendario e funzionamento. I diversi organi comunali accompagnano queste riunioni, offrendo chiarimenti su criteri guida e fattibilità delle richieste.

2) Nelle singole comunità, quartieri o (anche) microregioni, si possono svolgere assemblee a base locale dove i cittadini, in autonomia dalle istituzioni, discutono di come organizzarsi per partecipare e supportare le loro scelte durante il processo.

3) Nel Turno Unico, che ha luogo da metà aprile a metà maggio, la popolazione vota le priorità tematiche su cui vuole che il Comune investa in modo 
maggiore nell'anno successivo, e lo fa nelle 16 Assemblee Regionali (che si svolgono in un luogo capiente della Regione interessata) e nelle 6 Assemblee Tematiche (che sono in genere realizzate nella sede della Giunta o del Consiglio Comunale, per aprire ai cittadini spazi istituzionali tradizionalmente elitari). In ognuna delle assemblee dove si votano le priorità, i cittadini eleggono anche direttamente 2 Consiglieri Titolari e 2 supplenti che rappresenteranno ogni Assemblea nel Consiglio di Bilancio Partecipativo (COP). In caso si presentino più squadre ${ }^{12}$ si segue il criterio di proporzionalità rappresentato in fig. 28 per poter dare voci a 'maggioranze' e 'minoranze', purchè adeguatamente sostenute dai cittadini. In totale vengono eletti 32 Consiglieri titolari regionali più 12 tematici (con i rispettivi supplenti) a cui i cittadini che nelle assemblee intermedie hanno già discusso e gerarchizzato le loro priorità - delegano l'elaborazione del Piano dei Lavori per l'anno successivo, una volta definiti gli estremi del bilancio pubblico in collaborazione con l'Amministrazione Comunale. La carica di Consigliere dura un anno, ed è rinnovabile per una sola volta consecutiva. ${ }^{13}$ La revoca del mandato, in caso che il Consigliere non rispetti la volontà espressa dalla popolazione che l'ha eletto nelle Assemblee Intermedie o ecceda in assenze, può essere decisa dal corrispondente Forum dei Delegati Regionale o Tematico, che va appositamente convocato con 15 giomi di anticipo, come previsto dal Regolamento interno del Consiglio di Bilancio (art. 25), e deve esprimere la sua disapprovazione per l'operato del Consigliere con voto favorevole di $2 / 3$ dei presenti.

Nel Turno Unico, la rile vazione delle presenze dei partecipanti delle diverse comunità e quartieri della città - appositamente registratisi all'inizio di ogni assemblea - serve a definire il numero dei Delegati di ogni comunità o quartiere che comporranno i Forum di Delegati Popolari in ognuna delle Regioni e nei gruppi di discussione tematica. Dal 2000, il numero dei delegati corrisponde ad una proporzionalità secca di 1 ogni 10 abitanti presenti della comunità che si impegna a rappresentare (prima aveva dei complicati 'correttivi'.

I componenti dei Forum vengono nominalmente votati in assemblee di Quartiere e di Comunità, dove si presentano in 'chapas' [tandem], ovvero gli abitanti presenti scelgono tra gruppi autoproponentisi di titolare/supplente che li dovranno rappresentare. I Forum che raggruppano per Regione $\mathrm{i}$ Delegati sono responsabili della definizione delle opere e dei servizi che saranno discussi da maggio a luglio, seguendo un ordine di importanza indicato dagli stessi cittadini.

Le Assemblee sono aperte a tutti i cittadini, organizzati ma anche singoli, aspetto - quest'ultimo - che costituisce il grande salto di qualità rispetto alle precedenti forme di partecipazione della società civile alla formulazione delle politiche municipali, riservate solo a rappresentanti di specifiche Associazioni o Entità organizzate che agivano come 'lobby', togliendo al cittadino singolo o disorganizzato ogni ruolo attivo che andasse al di là del diritto di voto e di quello individuale di critica. Come già detto, il diritto di voto nelle assemblee dell'O.P. muta con la loro tipologia. Nelle Regionali lo possiedono, infatti, solo i residenti nella Regione che si registrano all'inizio dell'assemblea, mentre tutti i cittadini lo possiedono nelle tematiche. Nel Forum dei Delegati, lo hanno i soli Delegati.

Per il terzo anno consecutivo, la popolazione impossibilitata o non interessata a prendere parte alle assemblee può seguire le Assemblee via Internet, da 
casa, ed inviare suggerimenti dopo aver completato una procedura di registrazione. Se compatibili con i criteri tecnici che annualmente sono esposti nel Regolamento Interno del Bilancio Partecipativo, questi suggerimenti saranno oggetto di discussione nelle Regioni, ${ }^{14}$ il cui calendario di incontri viene divulgato a febbraio ${ }^{15}$ perché i cittadini possano programmare la loro presenza alle Assemblee.

Nel mese che precede ogni assemblea, il Comune e le Associazioni di Quartiere - in collaborazione - si occupano di pubblicizzarle attraverso i mass media ma anche con un'opera capillare di volantinaggio e di informazione, spesso fatta oralmente attraverso auto con casse acustiche, o 'porta a porta'. Nelle Assemblee Preparatorie e in quelle del Turno Unico il tavolo dei relatori è composto dal Sindaco o dal Vicesindaco, dai responsabili del Gabinetto di Pianificazione (GAPLAN) e del Coordinamento delle Relazioni con la Comunità (CRC), dal Coordinatore Regionale del Bilancio Partecipativo e dai Consiglieri Popolari della Regione o della Plenaria Tematica eletti nel corso dell'anno precedente e in carica fino a luglio.

4) Similmente, tra maggio e luglio, vengono pubblicizzate le assemblee (a tema o su base geografica) che si svolgono nelle micro-regioni, nei quartieri e nelle singole comunità di ognuna delle 16 Regioni. L'organizzazione di queste è direttamente curata dagli abitanti interessati (attraverso la mediazione dei Delegati eletti nell'area), autonomamente dal Comune seppur in coordinamento con i CROPs (i rappresentanti della CRC nelle varie Regioni) e avvertendone i Consiglieri Popolari del Bilancio Partecipativo.

Queste nuove occasioni di incontro hanno lo scopo di fare una diagnosi delle necessità della comunità, di votare ed eleggere i propri Delegati (il cui numero è stato stabilito durante le Assemblee Regionali) e - soprattutto - di arrivare a gerarchizzare opere e servizi nella regione e costituire le Commissioni di accompagnamento dei lavori e le Commissioni di Strada che contribuiscono a disseminare nelle strade e nei quartieri la discussione sull'intervento pubblico nella città formale e, soprattutto, informale.

Nelle assemblee 'locali' di taglio tematico, la cui organizzazione è spesso curata da varie entità della società civile organizzata (ONG, Club di madri, personale di asili, comitati firmatari di petizioni ecc.), l'obiettivo è arrivare a stabilire le direttrici per le politiche settoriali del Comune, priorizzando i servizi e le opere strutturali della città a partire da una discussione più a contatto con ogni singolo 'locale'. In questa sessione i vari organismi di governo invitati al tavolo e impegnati ad essere presenti - forniscono informazioni tecniche generali o specifiche per rendere il dibattito più completo e realistico, e presentano proposte di opere o servizi alle varie Regioni, ai singoli quartieri o ai dibattiti tematici localizzati.

E impossibile descrivere una forma comune di strutturazione per questo tipo di riunioni, fra loro diversissime proprio perché gestite dalle singole comunità locali attraverso l'aiuto dei loro consiglieri e delegati che devono gestirne il calendario e provvedere a chiedere la partecipazione di tecnici comunali secondo il principio della 'partecipazione su convocazione della comunità'. In questo stesso periodo il Forum dei Delegati analizza e delibera sulle 'richieste' pervenute via Internet da ogni comunità e - per meglio discutere sulle gerarchie di priorità presentate dai cittadini di ogni comunità - può decidere di svolgere sopralluoghi in singole aree per cui siano pervenute ri- 
184 chieste di opere e servizi, in modo da usare l'osservazione diretta come strumento per meglio riorientare la gerarchizzazione, risolvendo dubbi o casi di 'parità' tra voti ottenuti dalle singole scelte nei processi di gerarchizzazione. Parallelamente, anche il Consiglio di Bilancio eletto nell'anno precedente è al lavoro, in conclusione del suo mandato: discute, infatti, il progetto di Legge sulle Direttrici di Bilancio (LDO) per l'anno successivo che entro il $1^{\circ}$ giugno deve essere inviato al Consiglio Comunale.

5) A luglio viene realizzata un'Assemblea Municipale unica, dove avviene la solenne consegna al Sindaco delle priorità e delle opere gerarchizzate indicate dai cittadini nelle precedenti fasi del processo. In questa occasione (accompagnata da una festa pubblica) avviene anche l'insediamento dei nuovi Consiglieri eletti nel Turno Unico, e il Comune presenta la previsione delle entrate e della distribuzione delle spese per voce generale (personale, spese correnti e investimenti) riguardante l'anno successivo.

\subsubsection{Il ciclo annuale di bilancio: dalle griglie generali ai Piani di Inve- stimento}

Le Assemblee Plenarie non costituiscono che una piccola parte del lavoro svolto nell'ambito del Bilancio Partecipativo. Le altre tappe che il percorso contempla per giungere fino ad una definizione 'condivisa con i cittadini' dei documenti di bilancio ${ }^{16}$ (e specialmente ad un dettagliamento consensuale dei Piani Annuali di Investimento) chiariscono - fra l'altro - l'infondatezza di molte delle critiche strumentali che accusano il Bilancio Partecipativo di rappresentare un dispositivo per lo scarico di responsabilità da parte dell'Amministrazione sui cittadini, dal momento che sottolineano quale lungo lavoro di analisi, valutazione critica e necessaria ridiscussione con gli abitanti la prima fase del processo di O.P. inneschi per i tecnici e per i più alti livelli politici dell' Amministrazione.

Nella seconda metà dell'anno, infatti, il centro del BP diviene lo stretto rapporto di collaborazione che deve instaurarsi tra l'Amministrazione e i rappresentanti popolari, cosicchè !l'enfasi del processo passa dalla mobilitazione alla negoziazione attraverso un insieme di parametri collettivamente costruiti (CIDADE, 1997b)". A questo scopo iniziano a riunirsi a scadenze regolari le principali istanze decisionali del Bilancio Partecipativo, il Forum dei Delegati (FROP) e, soprattutto, il Consiglio di Bilancio (COP), istanza massima di decisione dell'OP. Poco importa se tutta la discussione con i cittadini avviene prima della formulazione delle previsioni delle entrate e delle uscite per l'anno successivo: quanto discusso resta, infatti, una base imprescindibile per dettagliare successivamente le scelte dell'Amministrazione. Presa di possesso del Consiglio di Bilancio (COP). I 48 Consiglieri (i 32 eletti nelle Plenarie Regionali del Turno Unico, i 12 delle Tematiche, più quello fisso della UAMPA, il rappresentante del SIMPA, e i due coordinatori della CRC e del GAPLAN, che però non hanno diritto di voto e possono perciò essere nominati dal Sindaco $)^{17}$ si insediano e vengono presentati ufficialmente ai cittadini durante una festa pubblica che si svolge nella 'Giornata della Democrazia'.$^{18}$ In questa occasione - tra l'altro - si realizza una Assemblea Municipale in cui si presentano iniziative di importanza cittadina (come i Congressi della Città) e i vecchi Consiglieri Popolari si congedano con l'atto ufficiale di consegna al Sindaco dei 'desiderata' di servizi e opere 
votate dagli abitanti di ogni quartiere e comunità, che sono stati previamente riorganizzate e gerarchizzate per Regione e per Tematica dai diversi Forum di Delegati attraverso discussione e votazione per alzata di mano..$^{19}$ Entro il 15 settembre i nuovi Consiglieri devono decidere il cronogramma delle discussioni e intanto prendono obbligatoriamente parte ad un corso di formazione sul bilancio pubblico organizzato dal Comune. In questo periodo di 'interregno' il COP si articola in Commissioni ed elegge la sua Segreteria Esecutiva $^{20}$ e si realizzano - anche per i delegati tematici e regionali - seminari formativi sul bilancio pubblico.

Il Bilancio Previsionale per l'anno successivo viene presentato a luglio dalla Giunta - per mezzo del GAPLAN e dell'Assessorato alle Finanze (SMF) - ai suoi organi e ai rappresentanti cittadini. Il Bilancio di Previsione è reso pubblico durante la 'Festa della Democrazia' e si basa in genere su una previsione 'cautelativa' forfetaria e di massima, di solito modellata sugli introiti dell'anno precedente, eventualmente arricchiti o depurati di 'fondi finalizzati' ottenuti in stretta connessione con specifici progetti previsti per l'anno successivo. ${ }^{21}$

La Prima Matrice di Bilancio è elaborata dopo che il GAPLAN ha raccolto nel GPR (Sistema Integrato di Gestione dei Progetti) tutte le domande di opere e servizi consegnate dai cittadini alla fine della tornata di assemblee nei quartieri, e delle riunioni dei Forum di Delegati. Attraverso un sistema on line integrato che unisce tutti gli Assessorati e i Dipartimenti, le domande di opere e servizi vengono vagliate sotto il profilo tecnico, legale e finanziario dal GAPLAN. Per procedere alla definizione della Griglia di Bilancio il GAPLAN costruisce 'tre indicatori', analizzando parallelamente le richieste espresse dalla popolazione nelle assemblee regionali e in quelle tematiche, e le necessità rilevate dall'Esecutivo.

Il GAPLAN attribuisce dei punteggi ad ognuna delle quattro priorità espresse da ciascuna Regione (4 alla prima, 3 alla seconda, 2 alla terza, 1 alla quarta $)^{22}$ per ottenere un ranking ponderato (U. De Souza, 1997). Sommando i voti dati alle varie priorità regionali si determina quali saranno le più votate in tutta la città; le prime tre costituiranno le priorità-guida per il Piano di Investimento cittadino, usate come 'primo indicatore' per l'attribuzione dei fondi per lavori e servizi su base regionale.

Il 'secondo indicatore' sono le indicazioni fornite dalle direttrici emerse dalle Plenarie Tematiche. Si parte dalle opere in corso di realizzazione che spesso hanno - per le loro dimensioni - carattere pluriennale e richiedono parziali rifinanziamenti per avere continuità, e si continua verificando le direttrici che presiedono all'indicazione di opere e servizi.

Il 'terzo indicatore' di pianificazione per distribuire le risorse finanziarie tra i diversi Assessorati e Dipartimenti, concerne le necessità dell'Amministrazione per mantenere alti i 'livelli di prestazione di servizio' alla popolazione e valorizzare opere e servizi attivati in precedenza. Oltre a queste 'spese rigide' ${ }^{23}$ che rappresentano un'alta percentuale del bilancio municipale riducibile solo in prospettiva di medio o lungo termine, questo indicatore tiene conto anche delle spese necessarie per opere a carattere emergenziale. Sulla base della stima di entrate prevedibili per l'anno successivo, il GAPLAN può così elaborare la prima griglia di bilancio [matriz orçamentaria] che riporta tutte le previsioni di spesa: personale, materiali, trasferimenti agli As- 
sessorati e alle Autarchie, ${ }^{24}$ servizi a terzi, pubblicità, elaborazione dati, debiti, investimenti, ecc.. Tale matrice è articolata per Assessorato di competenza, e non per distribuzione territoriale delle opere e dei servizi; il 'peso' delle richieste dei cittadini è tenuto in conto grazie ai 3 'indicatori' summenzionati e ad un costo forfetario attribuito (a m, a mq, a mc o simili) ad ogni opera richiesta dagli abitanti. Agli Assessorati competenti sui tre primi temi votati dagli abitanti di Porto Alegre su scala cittadina va - di regola la maggior parte dei fondi per l'anno successivo. La Giunta Finanziaria del Governo e il Coordinamento di Giunta sono i primi ad analizzare la proposta, inviata poi a tutti gli altri organi del Comune che, entro il 15 agosto, elaborano sulla sua base le loro rispettive proposte di bilancio di settore.

Il Govemo discute e delibera sulla Griglia di Bilancio. Alla fine di agosto il GAPLAN mette insieme e tenta di rendere compatibili le priorità espresse dalle Assemblee cittadine con le proposte di bilancio elaborate dai singoli organi comunali, ed elabora una nuova Griglia di Bilancio, stavolta ad 'uso esterno', che fungerà da base alla proposta di gestione per l'anno successivo. La Giunta Finanziaria, il Coordinamento di Governo e il Plenum degli Assessori discutono questa nuova Griglia e dettagliano programmi di servizio e investimenti.

Il COP discute e delibera sulla Griglia di Bilancio. La disamina della proposta del GAPLAN, realizzata nella seconda metà di settembre, è attuata in dettaglio per verificare che rispetti e interpreti bene le priorità regionali e tematiche presentate ai nuovi COPs nelle Assemblee Plenarie di Giugno.

Redazione finale e valutazione della Proposta di Bilancio da parte del Consiglio Comunale. Tenuto conto delle valutazioni ricevute, la nuova redazione è realizzata dal GAPLAN a fine settembre, sulla base della Griglia di Bilancio approvata o modificata dal COP, e consegnata dal Sindaco, dagli Assessori e dal COP al Consiglio Comunale entro il 30 settembre, come inderogabilmente stabilito dallo Statuto Comunale del 1990. Quest'ultimo deve votarla entro il 30 di Novembre. Nel Consiglio Comunale - in un clima in genere teso - si realizza il momento di contatto fra la democrazia diretta e rappresentativa; ${ }^{25}$ di solito i Consiglieri e i Delegati mobilitano le organizzazioni popolari per essere presenti nelle tribune degli uditori per controllare i propri rappresentanti eletti, e magari filmarne o registrarne le prese di posizione. Il Bilancio che verrà approvato dal Consiglio Comunale entrerà in vigore nel corso della gestione annuale seguente, e sarà presentato alla cittadinanza nel corso delle prime Assemblee Plenarie che si svolgono da marzo in poi nel nuovo ciclo dell'Orçamento Participativo.

Elaborazione del Piano degli Investimenti (PI). Costituisce l'atto finale dell'interazione fra Comune e rappresentanti dei cittadini eletti nelle Assemblee Plenarie in vista dell'elaborazione della politica municipale per l'anno successivo. Tra il $1^{\circ}$ ottobre e il 30 dicembre il COP e gli Assessorati, la CRC e il GAPLAN si riuniscono per elaborare il PI per l'anno successivo basandosi sulla Proposta di Bilancio inviata al Consiglio Comunale, sulle richieste priorizzate dalla popolazione e sui criteri generali di distribuzione delle risorse fra regioni. Dal 2002, un forte ruolo è stato attribuito ai vari Forum di Delegati Regionali e Tematici, che tra ottobre e novembre sono chiamati via via ad esprimersi su quanto sta venendo prodotto dal dialogo tra Consiglieri Popolari e Amministrazione. 
La costruzione del PI è una sorta di operazione di 'dettagliamento' di una parte della Proposta di Bilancio, quella appunto riguardante gli investimenti (che nel tempo sono andati rappresentando tra il 3 e il $30 \%$ del bilancio complessivo del Comune, con una maggior frequenza nell'intervallo tra il 13 e il 20\%). ${ }^{26}$ Sull'ammontare di questi, il Bilancio Partecipativo di Porto Alegre ha voce sul $100 \%$ delle risorse previste, a differenza di altre città dove la popolazione può discutere su fette che vanno dall' 80 al $50 \%$ del totale..$^{27}$ Il ruolo principale - nella sua stesura - lo hanno i membri del COP, che si riuniscono anche più volte a settimana per discutere e gerarchizzare le ipotesi di investimento consegnate loro dagli abitanti di Porto Alegre nei mesi precedenti. Ogni seduta viene verbalizzata - e da qualche anno anche registrata - come scelta di trasparenza per tutti i cittadini, che hanno il diritto/ dovere di controllare i propri rappresentanti e possono sfiduciarli qualora nel loro mandato non agiscano in base agli interessi di chi li ha eletti ma sulla spinta di motivazioni personali e/o riesumati meccanismi clientelari.

Il criterio di 'proporzionalità' usato nel distribuire gli investimenti totali del Comune tra le Regioni non è relativo ai Consiglieri per Regione (che sono sempre 2 , proprio per ragioni di equità distributiva), ma è stabilito dall'integrazione di tre criteri generali:

A) popolazione totale della regione;

B) grado di carenza dei servizi o delle infrastrutture richieste;

C) tipo e livello di priorità tematica indicato dai cittadini in ogni Regione

Saranno cioè distribuite più opere e servizi a quella regione che avrà dimostrato di possedere maggior carenza e maggior popolazione, oltre che di aver scelto quella particolare priorità tematica di cui si discute fra le tre principali che hanno ricevuto il punteggio più alto in tutta Porto Alegre. La fig. 29 riporta i tre criteri generali in base a cui realizzare la priorizzazione degli interventi da inserire nel PI, tenendo conto dei fondi comunali e dei fondi speciali disponibili per i vari tipi di investimento. Il peso indica l'importanza relativa di ogni criterio (Augustin, 1994).

Esistono anche dei criteri specifici di valutazione: ad esempio, temi come la Regolarizzazione Fondiaria e l'Urbanizzazione primaria valutano come fattore di peso il numero delle famiglie che verrebbero beneficiate da ogni progetto proposto. Siccome un'opera richiesta va realizzata tutta (dal tetto alle fondamenta) - anche se magari il progetto generale in cui si inserisce si distribuisce su più tappe annuali - questo può erodere fondi ad altre realizzazioni richieste. ${ }^{28}$

A partire dalla quarta priorità in discussione il criterio della 'progressività' si arresta, o almeno si trasforma, dal momento che le richieste priorizzate sono quelle delle Regioni che hanno presentato tali richieste fra le 4 principali priorità tematiche di base, messe tra loro a confronto dai membri del COP che in questo momento devono esercitare sui colleghi tutta la loro capacità di convincimento e trattativa a favore della loro regione, seppur sulla base di alcuni criteri-guida oggettivi.

Esistono alcuni Dipartimenti e Assessorati, come il DMAE, la SMED o la SMS, che hanno - poi - criteri propri per la distribuzione dei fondi (preventivamente discussi e approvati dal COP) a causa del tipo particolare di servizi che forniscono; esiste pertanto una grande varietà di situazioni che richiede ai COPs un impegno e un'attenzione critica notevole per una definizione equa della distribuzione degli investimenti da contemplare nel PI. 
188 Il Piano realizzato in base a questa serie di negazioni tra livelli istituzionali e rappresentanti popolari sarà prima presentato ai Forum dei Delegati (nella Regione Nordest - dotata di Centro Telematico - è in funzione quest'anno una Consulta sperimentale per testare per il futuro opportunità di una maggiore incidenza dei Forum sull'approvazione del PI finale), e poi - una volta approvato - sarà fatto conoscere alla cittadinanza, nel corso delle prime Assemblee Preparatorie che si svolgeranno da marzo in poi nel nuovo ciclo dell'Orçamento Participativo.

Revisione collegiale del Regolamento Interno (RI) del Bilancio Partecipativo: è l'ultimo atto del ciclo annuale dell'OP. Già da novembre/dicembre i Forum dei Delegati sono chiamati ad esprimere al COP il proprio parere sulla necessità di introdurre modifiche migliorative nei criteri generali e tecnici del Regolamento Interno. La discussione termina nel gennaio-febbraio della gestione successiva, quando - sulla base delle suggestioni ricevute e delle autonome valutazioni dei Consiglieri - un'apposita Commissione del COP propone ipotesi di modifica ed emendamenti per alcuni articoli del RI, che vengono votati dal COP in sessione plenaria. Il nuovo RI, in vigore nel ciclo di bilancio successivo, viene pubblicato a spese del Comune e distribuito insieme ai Piani di Investimento che fanno parte del Bilancio di Previsione controfirmato dal Consiglio Comunale.

\subsection{L'organizzazione del dibattito pubblico: alcuni meccanismi puntuali}

Stante l'esistenza di criteri localizzati e annualmente cangianti che presiedono al dibattito e alla discussione tra Amministrazione e cittadini nei diversi quartieri e comunità locali di Porto Alegre, non è facilissimo (e forse neppure significativo) cercare di esporre in modo generalizzato lo svolgersi e lo strutturarsi dei diversi tipi di Assemblea del Bilancio Partecipativo. Esistono però alcuni elementi comuni dell'organizzazione delle assemblee (almeno di quelle Plenarie) che fungono da interfaccia fra il lavoro svolto dalla popolazione e dall'Amministrazione nella definizione di direttrici politiche e di investimenti per la città che vale la pena sottolineare, perché emblematiche del tipo di 'spazio pubblico' che l'O.P. è:

1) In ogni assemblea aperta alla cittadinanza, uno dei momenti fondamentali è quello del 'Credenciamento' o 'Cadastramento' [registrazione], dove ogni quartiere e ogni regione si attribuisce di fatto dei pre-requisiti indispensabili per poter avere maggior voce in capitolo nella distribuzione dei fondi municipali previsti dai Piani di Investimento attraverso l'elezione di un numero più alto di delegati che rappresentano le diverse aree nei Forum dove di fatto si decide come gerarchizzare le domande di opere e servizi presentate dalla comunità. È un momento importante sia perché dà legittimità al processo (permettendo una rilevazione numerica esatta di chi vi partecipa), sia perché determina il numero totale dei Delegati a cui ogni quartiere o comunità della Regione ha diritto, ${ }^{29}$ sia - soprattutto - perché aiuta a capire un elemento portante della struttura aperta e flessibile dell'Orçamento Participativo: il rapporto di reciproca fiducia che si crea fra cittadini e istituzioni. La registrazione delle persone viene, infatti, realizzata in base ad un'autodichiarazione fatta dal cittadino che decide di partecipare all'Assemblea ai volontari che raccolgono nomi e firme degli intervenuti. Non vi è quindi un controllo di 
documenti; ci si affida all'onestà del cittadino, e anche ad una sorta di buon senso sociale (Baierle, 1999i); difficilmente degli infiltrati avranno, infatti, interesse a fingersi di un certo quartiere - contribuendo alla crescita della sua rappresentanza di delegati a detrimento di altre zone della regione - anche se qualche dubbio può restare per quanto concerne l'elezione nominale dei singoli delegati. Il fatto però che ogni partecipante a qualsiasi livello del Bilancio Partecipativo non venga retribuito e faccia opera di volontariato (per giunta assumendosi degli oneri di partecipazione non da poco, e dovendo continuamente fronteggiare il controllo dei propri elettori di riferimento) è ritenuto una sufficiente garanzia atta a minimizzare l'interesse per simili speculazioni. In ogni caso, visto che il maggior numero di partecipanti all'O.P. proviene da aree informali o da vilas e insediamenti irregolari dove l'inesistenza di viabilità, numeri civici e censimenti della popolazione rende problematico anche possedere un documento d'identità; la fiducia all'atto della registrazione dei partecipanti è considerata dall'Amministrazione una garanzia di uguaglianza nell'accesso alla possibilità di discutere del proprio destino attraverso quello dei propri luoghi di vita. ${ }^{30}$ In genere è all'atto del 'credenciamento' che vengono consegnati ai partecipanti materiali vari e opuscoli informativi, compresi - nella prima tornata di assemblee- copia del PI per il nuovo anno e copia del nuovo regolamento interno dell'Orçamento Participativo. Nei casi in cui sia prevista una votazione a scrutinio segreto, l'atto dell'iscrizione consiste con la consegna delle schede di voto; anche in questo caso non si può escludere che qualcuno faccia due volte la fila per ottenerne un seconda, visto che per scelta non vi sono meccanismi più severi di controllo dei partecipanti.

2) Per evitare che il pubblico si stanchi in eventuali attese o ritardi ${ }^{31}$ e magari abbandoni la sala, l'Assessorato alla Cultura (SMC) ormai da anni sperimenta forme diverse di intrattenimento prima dell'inizio delle assemblee. Sempre più frequente va diventando la presentazione di filmati o diapositive ${ }^{32}$ per esporre problemi specifici o informare i presenti di iniziative intraprese; a volte è lo stesso Comune a realizzare piccoli notiziari sull'andamento dei Piani di Investimento dove sono coinvolti anche i leader della Regione in oggetto. Per lo più, la SMC ricorre in genere a piccoli spettacoli teatrali di burattini o composizioni musicali che mirano - in un linguaggio semplice, studiato soprattutto per i bambini che accompagnano i genitori alle riunioni - ad informare la comunità su temi rilevanti per gli abitanti e su questioni sociali relative alla città o alla congiuntura politico/economica che caratterizza il Brasile al momento.

3) In apertura di assemblea vi è in genere una sorta di prolusione affidata ai Consiglieri della regione, o ai moderatori di turno che rappresentano l'Amministrazione al tavolo dei relatori. Molta attenzione viene anche posta nella presentazione dei relatori, e nella divulgazione di messaggi organizzativi, come ad esempio i luoghi dove chi vorrà parlare liberamente potrà iscriversi, e i tempi che ognuno avrà a disposizione (che ogni Regione stabilisce in modo autonomo). ${ }^{33}$ In genere, inoltre, è fatta lettura dell ' 'elenco speciale' dei partecipanti firmato dagli intervenuti alla riunione non appartenenti alla zona dove si realizza l'Assemblea; tcnici o vertici politici dell'Amministrazione, e soprattutto ricercatori e osservatori stranieri che a vario titolo vengono sempre presentati (e generalmente lungamente applauditi dal pubbli- 
190 co), anche a rispetto di una strategia intesa a dimostrare l'esistenza di una costante integrazione fra istituzioni e cittadini, e fra i livelli locali e i livelli globali, cioè fra il 'dentro' e il fuori che osserva questo straordinario processo democratico di cui Porto Alegre e i suoi cittadini dovrebbero continuamente sentire lo stimolo ad essere orgogliosi (F. Luisi, 1998i).

4) Durante ogni Assemblea (in genere verso la fine, per permettere una raccolta e un'elaborazione dei dati delle 'registrazioni' dei partecipanti) vengono anche divulgati $i$ numeri indicativi della partecipazione che l'ha caratterizzata, che costituiscono al contempo un'informazione di tipo tecnico (per valutare più o meno la riuscita dell'Assemblea e il numero dei delegati grossomodo ottenibili) ed un invito a riflettere su un buon risulta to o sulla necessità di migliorare in futuro le strategie di informazione e cooptazione degli abitanti. ${ }^{34}$

5) Come già sottolineato, i rappresentanti delle Istituzioni hanno un importante ruolo di conduzione e di proposta in seno ad ogni assemblea, ma non hanno alcun diritto di voto; questo - in modo visibile - simboleggia il rispetto per l'autonomia dei cittadini all'interno di un nuovo percorso strutturato di incontri tra rappresentanti politici ed abitanti, che vuole porsi come nuova sfera decisionale 'pubblica' ma non 'statale' (Genro, 1997).

\subsection{Tra tecnica e pedagogia: Regolamento Interno e 'criteri' di accogli-} mento delle richieste di investimento pubblico presentate dai cittadini nel BP

La democrazia presuppone che le regole siano chiare per tutti, sennò comporta una divisione di compiti in qualche modo autoritaria (Sant'Ana, 1999i).

Il Regolamento Interno (RI) del Bilancio Partecipativo ha forma autonoma dal 1995, e da allora viene distribuito annualmente in oltre 20.000 esemplari ai partecipanti al processo. ${ }^{35}$ Esso costituisce lo strumento 'flessibile' della 'rigidità normativa' che sta alla base di questo percorso annuale di discussione del bilancio comunale. Vale a dire: esso contiene le norme attraverso cui il processo si struttura in ogni singola gestione annuale, e tali regole risultano 'inderogabili' all'interno di un singolo esercizio (per offrire garanzie di equità ed ugual trattamento ai cittadini partecipanti al processo) ma sono 'rivedibili' entro lassi di tempo predeterminati (attualmente un anno a partire dalla fine di gennaio, in cui viene approvato dal COP il nuovo Regolamento che sarà in vigore in tutto il ciclo annuale successivo). In tal modo, il Bilancio Partecipativo risulta un processo puntualmente strutturato e chiaramente regolamentato, ma evita il rischio di burocratizzarsi, di 'invecchiare' (in quanto 'meccanismo di funzionamento') e di 'congelarsi' mentre i suoi partecipanti evolvono all'interno del percorso che esso disegna. Ma, soprattutto, grazie alla 'normativa leggera' che ne ridisegna annualmente il profilo il BP può denotarsi come percorso 'adattivo' in grado di autocorreggere annualmente (attraverso il concorso di idee e proposte degli abitanti e dei loro rappresentanti nel COP e nei Forum di Delegati) i limiti evidenziatisi nell'anno precedente, oltre che di arricchire e migliorare le proprie capacità di gestire la 'condivisione' delle scelte territoriali e l'attualità del dialogo con le istituzioni.

Il Regolamento Interno comprende un capitolo dedicato alle competenze del COP, dei Consiglieri, dei Delegati e dei loro Forum, ${ }^{36}$ uno (non vincolante 
ma esemplificativo) di suggerimenti sui 'criteri regionali' da adottare per una 'gerarchizzazione più giusta e democratica' delle scelte di investimento locale ${ }^{37}$ ed uno di criteri per la distribuzione dei fondi tra le varie zone della città e i vari 'temi' di riferimento. ${ }^{38}$ Infine, il RI dedica un importante capitolo alla divulgazione presso la cittadinanza dei criteri scelti dai diversi Assessorati, Dipartimenti e Autarchie del Comune di Porto Alegre come discriminante per accettare o meno di finanziare un'opera o un servizio richiesti dalla cittadinanza attraverso le Assemblee Plenarie, le Assemblee di Quartiere e di Comunità, e i Forum di Delegati.

Ormai da anni (precisamente dal 1994) il capitolo è presente nel libretto annualmente rivisto dal COP in collaborazione con il Comune, e divulgato in occasione del primo turno di Assemblee Plenarie. Vi è entrato non solo per una necessità dell' Amministrazione di razionalizzare le discussioni e minimizzare il numero delle richieste in aree difficilmente legalizzabili, ma anche per una specifica richiesta della popolazione (De Souza, 1997) di far 'chiarezza preventiva' sulle modalità con cui gli organismi tecnico-politici del Comune esaminano, approvano o scartano le richieste popolari. Alla fine del 1998, una revisione completa del capitolo sui 'Criteri tecnici' ha cercato di porre rimedio - scegliendo la chiarezza e a tratti anche la durezza come armi di comunicazione - al fatto che in fase di elencazione delle opere richieste dai diversi quartieri e regioni ben raramente se ne è tenuto conto. Ed è quindi toccato all'Amministrazione e ai COPs - durante la costruzione del Piano annuale di Investimento per il 1999 - rileggere tutto il materiale presentato dalla popolazione alla luce dei pre-requisiti sottolineati in precedenza come discriminanti dell'accettazione o meno delle singole richieste.

Quelli contenuti nell'O.P. sembrano criteri rigidissimi, al punto da impedire molti interventi in 'vilas', ma non è così; sono 'ragionevoli'. Un tempo non erano tanti; all'inizio dell' Amministrazione Popolare si erano spazzati via molti di quelli vecchi ritenendoli lacci burocratici. Poi ci si è accorti che per la gente erano una garanzia di la vori svolti con serietà, e che ogni investimento realizzato con questi criteri costituiva in realtà un primo passo verso la seria volontà di regolarizzare situazioni 'infor mali'(Ribeiro Jor dão, in Alleg retti, 2000a).

Potremmo dire che - un po' come è successo in Inghilterra con le Enterprise Zones - l'estrema flessibilizzazione dei parametri costruttivi e urbanistici non sempre ha ottenuto i risultati sperati di attrarre investimenti, potendo essere interpretata come mancanza di garanzie qualitative per gli investitori (Paloscia, 1990). In questo caso - in cui le aree interessate erano soprattutto quelle 'informali', inizialmente poco appetibili per l'impresa privata - è stato lo stesso Comune di Porto Alegre a rendersene progressivamente conto, analizzando dopo qualche anno di 'mano leggera' gli investimenti fatti, e valutando a quali sprechi aveva condotto la mancanza di alcuni prerequisiti minimi, che aveva portato ad investire in aree al centro di contese giudiziarie dove si finiva per valorizzare il terreno di un privato, o a realizzare opere sull'onda delle pressioni popolari avvenute nell'O.P. che poi si rivelavano inutili o perfino 'dannose' (cfr. cap. 10).

Così negli ultimi anni, quello che viene scherzosamente chiamato 'il libretto delle istruzioni per l'uso dell'Orçamento Participativo' (Santos da Silva, 1999i, IN Allegretti, 2000a) si è arricchito progressivamente di cri- 
192 teri tecnici da rispettare prima di formulare le richieste di investimento. Con un doppio valore pedagogico: quello di trasmettere alla popolazione la conoscenza dei percorsi di valutazione tecnica che l'Amministrazione usa nell'analisi degli investimenti da intraprendere, e quello di ribadire quali sono i diritti e i doveri che la popolazione ha nell'interagire con le Istituzioni cittadine.

In realtà oggi la presenza delle AEIS [Aree Speciali di Interesse Sociale] dove si trovano molte 'vilas' - che sono quelle che fanno la maggior richiesta di interventi pubblici - flessibilizza questi criteri, perché spesso si valutano nel complesso gli aggregati; i quartieri più che le singole strade o edificazioni. Le regole ci sono per essere rispettate ma talora anche per costituire una base di discussione non chiusa al dialogo o alla minima deroga. Certo, derogare troppo e visibilmente sarebbe controproducente, un invito ad altri a trasgredire. Ogni eccezione tende a diventare meccanicamente regola se avvallata da un rappresentante dell'Istituzione. È il rischio di uno stretto rapporto, umano più che formale, con i cittadini. Perciò mettiamo una grandissima attenzione nel rispettare dei parametri minimi, che sono una forma di responsabilizzazione della cittadinanza sui doveri a cui deve far fronte in cambio dell'aiuto municipale come sui suoi diritti, visto che è un diritto di ogni cittadino e della città nel suo complesso quello di camminare in strade larghe e sicure, di avere ventilazione o illuminazione. E finché a Porto Alegre ci sarà spazio, è interesse dell' Amministrazione evitare che la città si sviluppi costipata, densa o insalubre, e con infrastrutture di breve durata (Casa Nova, 1999i).

In quest'ottica, già nel Regolamento del BP del 1999 si possono notare alcune novità interessanti, a partire dall'affiancamento ai 'criteri tecnici minimi' di una serie di suggerimenti dati alla popolazione sulle condizioni che sarebbe meglio che un'area presentasse in aggiunta al rispetto delle regole inderogabili, per poter ambire ad ospitare gli investimenti pubblici specificamente richiesti dai cittadini. Un modo di divulgare alcune pillole di furbizia (Santos da Silva, 1999i) per poter avere maggiore ascolto da parte dell' Amministrazione, ma che al contempo costituiscono un contributo alla creazione di 'senso civico', nella misura in cui puntualizzano e spiegano i perché di alcuni componenti della razionalità seguita dal potere pubblico ed illuminano su alcuni criteri che strutturano lo sviluppo e l'organizzazione di una città. Questo doppio binario pratico/pedagogico è sempre presente ad ogni livello della comunicazione col pubblico attuata in questi anni dall'Amministrazione di Porto Alegre.

Anche in questo caso, quindi, dietro i criteri tecnici c'è di più. Tra le righe si spiegano, infatti, le complicità (Real, 1999i) che il Comune non accetta di portare avanti con la popolazione informale, ${ }^{39}$ ma senza mai accennare a termini come 'illegalità' o 'invasione' che potrebbero ferire la gran parte dei lettori a cui il Regolamento Interno si rivolge. Pacatamente - attraverso le regole tecniche fornite dai suoi Assessorati - il Comune espone una filosofia, i suoi irrinunciabili punti di partenza non contrattabili che costituiscono la guida dell'azione puntuale dell'Istituzione locale sul territorio di Porto Alegre.

L'opuscolo è semplice, ed in pochissimi casi ${ }^{40}$ si citano Leggi o Regolamenti a cui adeguarsi, che pure costituiscono la base di molte scelte. Si preferisce piuttosto esporre e spiegare i perché - comprensibili a tutti, se motivati - di certe norme di buon senso che suggeriscono la realizzazione o meno di un'opera, soprattutto delle infrastrutture primarie e delle pavimentazioni. Ad esempio: 
[...] è importantissimo spiegare alla popolazione che una rete di acqua non è considerabile come un oggetto indipendente, ma che essa dipende da opere complementari come le condutture che portano l'acqua dalle stazioni di trattamento, le pompe per il mantenimento della pressione, le casse di raccolta e simili. E va spiegato che ciò che è a monte si finanzia anch'esso con gli stessi soldi che si spartisce l'O.P., per cui ad un'opera richiesta spesso se ne lega un'altra complementare e il luogo da cui prelevare i soldi purtroppo è sempre lo stesso (Real, 1999i, apud Allegretti, 2000a).

È anche a questa 'complessificazione' della visione sulla città che l'O.P. e il suo Regolamento si propongono di contribuire; spiegando tra le righe i percorsi razionali che le concatenazioni di opere seguono ${ }^{41}$ e che devono essere rispettate per non sprecare fondi pubblici che vanno ottimizzati a vantaggio di tutti. Il Comune fa questo prendendosi l'impegno di motivare i dinieghi alla realizzazione di un'opera per mezzo dei suoi tecnici (Passos Cordeiro, 2002i). Dell'opera di coscientizzazione a vasto raggio sulla natura interrelata della crescita di una città fanno parte soprattutto gli incentivi (di punteggi e di priorizzazione) elencati per opere che contribuiscono a migliorare in senso globale la qualità di vita della regione o dell'intera città, non limitandosi ad interventi di miglioramento puntuale; è il caso dei criteri del DMAE e del DEP che premiano richieste di opere che possono contribuire al disinquinamento del bacino idrografico portalegrense.

Le notazioni sulle opere di infrastruttura fuori dal perimetro urbano, e quelle sui programmi di appoggio alle imprese della SMIC, ${ }^{42}$ poi, fanno preciso riferimento alle necessità di legarsi con la pianificazione globale della città, $\mathrm{e}$ con la minimizzazione di diseconomie. Implicitamente, così, l'Amministrazione contribuisce anche a ridirezionare modi e numero delle eventuali occupazioni di terra future, chiarendo quali sono le regole che facilitano le regolarizzazioni sia legali che - soprattutto - urbanistiche, ${ }^{43}$ e sottolineando a più riprese nel testo del Regolamento Interno la necessità dell'impegno alla regolarizzazione da parte di ogni comunità ancora non legalizzata che desideri usufruire di investimenti pubblici sul suo territorio.

Un diritto in cambio di un dovere. Una sorta di quello che i latini chiamerebbero do ut des, un contratto implicito in cui l'Amministrazione offre ai cittadini dei servizi ma chiede in cambio un impegno, l'assolvimento di alcuni doveri. E lo fa ribaltando il punto di partenza rispetto alle tradizioni clientelistiche del passato; l'Amministrazione non offre dei servizi per sdebitarsi con chi l'ha votata, ma li offre come base di partenza che potranno contribuire alla sua rielezione, chiedendo al cittadino di impegnarsi perché sia ottimizzato per tutta la città lo sforzo organizzativo e finanziario fatto dal potere pubblico (Wendler, 1999i).

Va notato - a questo proposito - che nei Piani di Investimento annuali e nei Regolamenti Interni del BP non si parla mai di 'concessione' di qualcosa da parte del Comune, ribadendo il diritto del cittadino a che le sue domande siano ascoltate, seppur a partire da certe regole. A questo scopo l'esposizione di criteri - soprattutto di quelli 'escludenti' - propone delle alternative (non sempre però esplicitate): ${ }^{44}$ se nessuna infrastrutturazione può, infatti, essere realizzata dal DMAE stanti i criteri tecnici stabiliti, la misura che la popolazione di quell'area può richiedere è il re-insediamento altrove, di cui 
194 è responsabile il DEMHAB. La flessibilità scelta dall'Amministrazione Popolare come uno dei criteri d'azione prioritari nell'affrontare i problemi vuol dire, in sostanza, offerta di una gamma molteplice di possibilità da prendere in considerazione; e non una semplice rinuncia ad intervenire nei casi più spinosi che si fa magari scudo di difficoltà tecniche o di finanziamento. In ogni caso - come soprattutto i criteri della SMIC sottolineano - tra le misure suggerite ai cittadini nell'ottica di ottenere risultati migliori e vedere le proprie richieste prese più rapidamente in considerazione, il Comune e il COP suggeriscono alle comunità l'acquisizione di capacità di agglomerazione ed autorganizzazione, a partire dall'autoriflessione comunitaria sulle necessità che si ritengono prioritarie e da risolvere nell'ambito del BP. Tutti questi suggerimenti e insegnamenti vengono veicolati in più occasioni ed in parti diverse del testo, seguendo la strategia della 'ridondanza' ${ }^{45}$

Per tale via è comunque possibile affermare anche che, come ha suggerito Abers (1998b) i criteri tecnici si costituiscono per certi versi come una forma di 'potere tecnico', che nel tempo ha portato a riequilibrare parzialmente il ruolo propositivo dell'Amministrazione (e di alcuni Assessorati o Autarchie al suo interno) nei confronti dei cittadini: questi ultimi, infatti, nei primi anni di sperimentazione del Bilancio Partecipativo avevano sovente assunto un ruolo 'preponderante' all'interno dei processi di decisione sull'allocazione dei fondi, che la Giunta (quasi dominata dal timore del 'rischio elettorale' che comportava mettere in discussione le scelte prese da una mobilitazione così ampia) era stata pavida nel contrastare, e che nel tempo avevano determinato alcune 'derive' non positive nei modi di interferire con alcune regole alla base del funzionamento della macchina amministrativa locale.

\footnotetext{
Note

${ }^{1}$ Cfr. Azevedo, 1988; Gohn, 1989; Moura 1989; Doimo 1990; Silva, 1991; Fedozzi, 2000.

${ }^{2}$ Cfr. PT/RS, nov. 1987

${ }^{3}$ Cfr. Boletim da UAMPA del luglio 1986.

${ }^{4}$ In realtà, non vi è documentazione che attesti se tali esperienze sono state o meno prese in esame nel processo creativo che ha istituito l'O.P. di Porto Alegre.

${ }^{5}$ In Brasile, negli ultimi anni, un alto numero di proposte municipali di intervento e gestione della realtà urbana hanno raggiunto la notorietà internazionale, tanto che ben 55 esperienze figurano fra le good \& best practices inserite nel data-base 1999 delle Nazioni Unite.

${ }^{6}$ Tra gli studi più interessanti meritano di essere citati: Baierle, 1992 e 1998; Pozzobon, 1995; Menegat, 1995; IBASE, 1995; Alfonsin 1998; Abers, 1995, 1996, 1997, 2000a,b, Genro e De Souza, 1997; Fedozzi, 1995, 1996, 1997 e 2000; Cassen, 1998a e 1998b; Gret e Sintomer 2002, Herzberg 2002, De Sousa Santos, 2002). In Italia, è stato tradotto finora solo il testo di Genro e De Souza (2002), e singoli saggi presenti nei Materiali d'Appoggio al Corso di formazione "Indicatori e strumenti di nuova democrazia territoriale: il Bilancio Partecipativo" organizzato a Trento dalla ONG 'Unimondo' (7-11/ 5/2002). Vi sono poi saggi di Allegretti (2000 a,b; 2001 a,b,c; 2002 a,b,c; 2003, a, b). ${ }^{7}$ Il nome 'Regioni' deriva dalle 'articolazioni regionali' dei movimenti urbani. A noi il termine pare deviante (sarebbe meglio tradurlo con 'distretti'), ma lo manterremo per rispettare la terminologia locale.

${ }^{8}$ Le aree tematiche erano originariamente 8 (cfr. De Souza, 1997), poi vennero accorpate e riorganizzate annualmente. Oggi sono: urbanizzazione primaria, politica degli alloggi, assistenza sociale, pavimentazione, scoli pluviali, educazione, illuminazione pub-
} 
blica, sanità, circolazione e trasporti, aree per il tempo libero, sviluppo economico, cultura, risanamento ambientale, sport e tempo libero.

${ }^{9}$ Fondamentale è la pubblica esposizione dei bilanci dell' anno precedente riassunti con l'obbiettivo di essere comprensibili a tutti - sia per voci tematiche (che riflettono le 14 aree di discussione dell'O.P.) che per investimenti puntuali a livello di singoli quartieri.

${ }^{10}$ Ciò significa che il processo di Bilancio Partecipativo 2004 è quello che si sta svolgendo nel corso del 2003 per elaborare le scelte da realizzare nel 2004.

${ }^{11}$ Lo si è fatto finora, ma l'esperienza si è conclusa per la sconfitta elettorale del PT nelle elezioni dell'ottobre 2002

${ }^{12}$ La parola 'chapa' potrebbe tradursi con 'tandem', visto che il Consigliere e il suo vice si candidano insieme.

13 Per statuto, ai Consiglieri dell'Orçamento Participativo (che devono riunirsi almeno 8 volte al mese, art. 26) spetta fra l'altro il compito di riunirsi almeno una volta al mese senza i rappresentanti del Comune (art. 27), per valutare il proprio funzionamento , e almeno una volta al mese coi Delegati e il Movimento Popolare Organizzato della propria regione, per avere aggiornamenti continui e di prima mano sulle problematiche del territorio che essi rappresentano (Art. 24 del Regolamento Interno dell'Orçamento Participativo - 2003).

${ }_{14} \mathrm{Nel}$ caso in cui si tratti di servizi di routine, essi saranno inoltrati al numero telefonico 156. La "partecipazione via Internet" fornisce istruzioni, passo dopo passo, affinché i navigatori siano guidati nella procedura di registrazione, nella scelta della Regione o Tematica, nell'invio di suggerimenti e nell'accompagnamento del loro andamento.

${ }^{15}$ Il calendario degli incontri nei quartieri e nelle comunità è di solito divulgato più avanti nel tempo.

${ }^{16}$ Questi sono essenzialmente (cfr. CIDADE, 1997b):

1) Il Piano Pluriennale, che nel caso di Porto Alegre deve essere reda tto entro il 30 aprile del primo anno di mandato di ogni nuova Amministrazione (da sottoporsi al Consiglio Comunale che deve approvarlo entro il 30 giugno, come previsto dallo Statuto Comunale del 1990, art. 121). Esso entra in vigore dal $1^{\circ}$ gennaio dell'anno seguente e fino al 31 dicembre del primo anno di mandato dell'Amministrazione successiva, anche per dare continuità ai programmi di governo intrapresi a fine mandato di ogni giunta. Deve prevedere le direttrici quadriennali di investimento per il Comune, ed includere (anche tramite aggiunte) tutte le opere la cui esecuzione superi un singolo esercizio finanziario annuale. Si configura, pertanto, come una materializzazione formale del programma del governo che entra in carica.

2) la LDO (Legge delle Direttrici di Bilancio) che definisce mete e priorità dell'anno seguente, basandosi sulle prospettive di investimento e spesa individuate nel Piano Pluriennale, e orienta le politiche tributarie, salariali, del personale e il contenuto della Legge Annuale di Bilancio

3) Il Piano annuale degli Investimenti contiene l'elenco di opere e servizi da attivare ${ }_{17} \mathrm{Cfr}$ art. $3^{\circ}$ del Regolamento Interno, CRC, 2003.

${ }^{18} \mathrm{Nel}$ 2002, la 'festa' è stata tra l'Auditorium Viana e i Magazzini A7 del Porto, il 20/7, dalle 14,30 a notte fonda.

${ }^{19}$ Il documento consegnato dalle Regioni deve contenere esposte le 4 priorità tematiche votate dalla regione in ordine di importanza, scelte fra 14 temi (che possono variare di numero nel tempo) ed inoltre un formulario per ognuna delle 4 aree tematiche contenente la descrizione, l'indirizzo e la posizione gerarchica di ogni opera o servizio richiesto (per opere di pavimentazione e urbanizzazione primaria vanno anche allegati degli schizzi per individuare precisamente il tratto richiesto cfr fig. 30). Per le assemblee tematiche basta, invece, l'esposizione delle direttrici e le priorità delle politiche settoriali di servizi e opere strutturali.

${ }^{20}$ Le Commissioni principali sono: la Tripartita, la Paritaria (che dal 2000 si chiama Coordinamento del COP e ha 4 membri del governo e 8 COPs), quella di Comunicazione. Alla Se greteria Esecutiva del COP - mantenuta dalla CRC che si occupa di Coordinare le Relazioni con la Comunità - compete non solo controllare la frequenza delle riunioni del Consiglio di Bilancio (che per statuto deve riunirsi almeno 2 volte a settimana), ma anche realizzare un registro dei suoi membri e dei delegati regionali e tematici, e soprattutto fornire al COP i bandi pubblici di concorso e appalto, e la data di apertura delle buste con le proposte dell'imprese per dare al COP la possibilità di effettuare controlli della regolarità dei procedimenti.

${ }_{21}$ Cfr. intervento dell'Assessore Sostituto del GAPLAN Roque Werlag fatto il 9/5/2002 
al corso di formazione 'Indicatori e strumenti di nuova democrazia territoriale: il Bilancio Partecipativo" (Trento, 7-11 maggio 2002).

22 Fino al 1996 le priorità da indicare erano solo 4, poi passarono a 5 ed ora sono tornate a 4. ${ }^{23}$ Ad esempio: il materiale di consumo, il salario degli impiegati, il trasferimento di fondi alle cosiddette Autarchie, le cosiddette 'risorse vincolate' (come quelle legate al SUS [il sistema sanitario statale], ai salari del settore educativo, o ad accordi specifici di settore), i 'fondi speciali' (quello per la Cultura, il Patrimonio Storico, l'appoggio all'arte, ai mercati pubblici, all'ambiente, alla sicurezza e agli 'Acquisti collettivi' o FUNCOMPRAS), le spese 'minime' previste dallo Statuto Comunale agli artt. 164 e 183 nei settori della salute ( $13 \%$ della spesa totale) e dell'educazione ( $30 \%$ delle entrate dovute a imposte e trasferimenti dai livelli di governo superiori).

${ }^{24}$ Sono i dipartimenti per molti aspetti autonomi dall'Amministrazione Centralizzata (PMPA), che non sopravvi vrebbero con le entrate proprie (Dipartimento per l'approvvigionamento idrico e le fognature, Dipartimento per gli scoli pluviali, Dipartimento alla Casa, Dipartimento di Pulizia Urbana, Dip. per l'elaborazione dei dati, ecc)

${ }^{25}$ Quando si parla però dell'Orçamento Participativo come fusione di democrazia diretta e rappresentativa non si allude a questo momento (che è forzatamente di contatto fra le due, a causa delle normative federali di ordine superiore), bensì alla sua struttura interna mista.

${ }_{26}$ Nel Pi del 2002, gli investimenti rappresentano il 13,62\% della spesa totale (cfr. PI 2002, pag. 8).

${ }^{27}$ Come vedremo, in realtà la discussione incide anche su fette delle 'spese fisse e di personale' (in quanto propone investimenti che nel futuro pesano su queste voci).

${ }^{28}$ Non è infrequente, pertanto, che - nei casi di realizzazione di case popolari (ad esempio) come seconda priorità, $i$ fondi distribuiti non siano inferiori a quelli dati alla prima priorità: dipende dal tipo di prestazione complessa e costosa che l'intervento edilizio richiede.

${ }^{29}$ Il numero dei Delegati - proporzionale agli abitanti presenti per ogni quartiere o comunità - non è un 'premio' dato alla maggiore partecipazione delle varie aree, ma un diritto conquistato, e non a scapito di altri visto che non avviene una ripartizione di posti su un totale fisso di Delegati, ma il loro numero può crescere infinitamente in ragione di 1 ogni 10 cittadini presenti per singola area.

${ }^{30}$ La cultura scritta della registrazione o della redazione dell'atto è per noi fondamentale per abituare ad una cultura della legalità, ma nel portarla avanti una certa flessibilità è indispensabile, specie se può inibire o imbarazzare i partecipanti (Brunet, 1999i, apud Allegretti, 2000a).

${ }^{31}$ Spesso inevitabili quando i partecipanti da registrare sono più del previsto o i relatori attesi al tavolo tardano a giungere

32 Essi richiedono costi aggiuntivi di realizzazione, ma di recente sono stati gli stessi Consiglieri o Delegati popolari a richiederli (o addirittura a realizzarli, come nel caso della Regione Cristal o Eixo Baltazar) ritenendoli strumenti di forte impatto visivo sui cittadini, utili a far partire una discussione più vivace e basata sulla realtà (Amaral, 2002i).

${ }^{33}$ Interessante sarebbe confrontare i diversi criteri scelti nelle varie regioni per contingentare i tempi dei singoli o dei rappresentanti di quartieri e associazioni che si iscrivono a parlare nel corso delle pubbliche assemblee; di solito il coordinatore al tavolo - per dare ai partecipanti la possibilità di gestire l'andamento di massima del dibattito - propone alcune alternative (tempi più lunghi con tetto al numero di interventi, o esposizioni più concise senza limite al numero di oratori) e invita i presenti a votare la preferita con alzata di mano. In ogni caso "sempre e comunque si è attenti a ribadire che per una discussione ci vogliono delle regole, anche perché riteniamo che sia un modo di educare le persone alla capacità di dibattere in modo maturo. Per questo qualcuno al tavolo si assume sempre l'onere di cronometrare gli interventi dal pubblico perché rientrino nei tempi collettivamente stabiliti come massi$m i$. E anche importante specificare che per parlare è necessaria un'iscrizione, e che per decidere di intervenire si ha a disposizione un tempo limitato di iscrizione; ’̀ l'unico modo per poter programmare con un certo anticipo l'andamento dell'assemblea ed evitare che si arrivi alla fine stanchissimi e in pochi, come è accaduto nel primo anno dell'Orçamento Participativo/RS ancora in rodaggio" (Brunet, 1999i, apud allegretti, 2000a).

${ }^{34}$ Successivamente ad ogni Plenaria viene specificato in base ad un esatto conteggio il numero di delegati ottenuto da ogni quartiere o comunità chiamata a raccolta: farlo 
direttamente in Assemblea sarebbe impossibile, a causa del tempo notevole che richiederebbe la lettura del numero di delegati quartiere per quartiere.

${ }^{35}$ Dati CRC, 1999. A Porto Alegre esiste anche un telefono sempre attivo per informazioni sul Bilancio Partecipativo (il 156) e numerose pagine, ben visibili, esaurienti ed interattive, sul sito del Comune www.portalegre.rs.gov.br

${ }_{36}$ Nella versione 2003 sono 14 pagine e 37 articoli.

${ }^{37}$ I criteri (nel RI 2003 esposti da pag. 15 a 18) sono costruiti sulla falsariga di quelli usati dal GAPLAN per costruire la 'matrice della distribuzione dei fondi' tra le Regioni, e si possono applicare alle discussioni dentro una Regione, come a quelle tra microregioni e singole comunità al suo interno. Veng ono dati suggerimenti anche su come assegnare eventualmente Delegati supplementari alle comunità non rappresentate, premiando quelle 'carenti' e tenendo conto del loro impegno e della loro capacità di coordinamento e articolazione dentro il processo.

${ }^{38}$ Cfr. RI 2003, pag. 19-25.

${ }^{39}$ Chiari in tal senso sono soprattutto i criteri del DMAE (pp.45-47 del RI 2003).

${ }^{40}$ Cfr. i 'Criteri Tecnici' di DEMHAB e SMOV (pp. 26-30 del RI 2003).

${ }^{41}$ Ad esempio nel RI 1999 al paragrafo del DMAE si motivava perché una fognatura non può essere realizzata prima dell'approvvigionamento idrico (questa spiegazione è stata tolta in favore di un assioma nei RI successivi).

${ }_{42}$ Cfr. pp. 49-51 del RI 2003. I criteri SMIC sono esplicitati nel RI solo dal 1998.

${ }^{43} \mathrm{Si}$ potrebbe dire che l'implicito ridirezionamento suggerito va verso il tessuto centrale della città, nella misura in cui tra l'altro viene portata parallelamente avanti dal 1992 una politica di sottolineatura del 'diritto dei poveri al centro' (vedi cap 12).

${ }^{44}$ Ad esempio nei criteri tecnici del DMAE non si accenna alla sostituzione di una rete idrica non realizzata con un'autobotte, come di solito viene fatto a temporanea soluzione del problema sotteso nella richiesta popolare di una 'rete d'acqua', ad esempio in zone occupate non regolarizzabili.

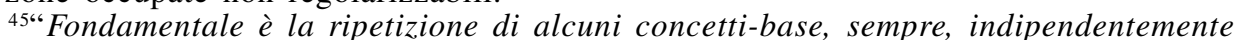
dal tema specifico che si sta trattando, non importa se sia il disinquinamento, la Regolarizzazione Fondiaria o la notizia di un reinsediamento di una comunità altrove. Soprattutto è importante ribattere sui concetti principali su cui il Fronte Popolare basa la sua strategia politica, chiedendo alla cittadinanza di crescere con lei. Esistono dei ritornelli che è importante ripetere: la necessità di partecipare nell'O.P. per avere una voce, la necessità di riunirsi, di creare commissioni e gruppi, la necessità di assumersi sempre dei doveri e delle responsabilità per ogni atto che si porta avanti in collaborazione con il Comune. In fondo è questo il significato ultimo del senso maturo di cittadinanza!” (Carvalho, 1999i, apud Allegretti, 2000a). 
198 Fig 20 - Strumenti di riforma urbana (SRU) e di esercizio della cittadinanza (SEC) previsti dallo Statuto riformato del Municipio di Porto Alegre - 1990 (adattato e tradotto da Nygaard, 1993)

\begin{tabular}{|c|c|c|}
\hline $\begin{array}{l}\text { Tipologia } \\
\text { dello } \\
\text { strumento }\end{array}$ & Strumento specifico & Cenni circa l'uso o il significato \\
\hline SRU & Piano Pluriennale & $\begin{array}{l}\text { Contiene le diretirici, gli obietivi e i limiti temporali } \\
\text { dell'Amministrazione Comunale e viene approvato } \\
\text { (art. 116) con il coneorso dei Consigli delle Regioni }\end{array}$ \\
\hline SRU & Direttive di bilancio & $\begin{array}{l}\text { Contengono limiti di tempo e priorità del Co- } \\
\text { mune; dispongono circa la politica tributaria } \\
\text { c tariffaria per l'esercizio successivo }\end{array}$ \\
\hline SRU & Legge annuale di bilancio & $\begin{array}{l}\text { Contiene investimenti, ricette e spese degli or- } \\
\text { gani dell'Amministrazione diretta e indinetta }\end{array}$ \\
\hline SRU & $\begin{array}{l}\text { Piuno di Sviluppo Economico (agri- } \\
\text { colo, tecnologico, dei servizi, ecc.) }\end{array}$ & Servono alla programmazione dei diversi settori \\
\hline SRU & Plano Dirctor & $\begin{array}{l}\text { Strumento base della politica di gestione, } \\
\text { sviluppo e crescita urbuna }\end{array}$ \\
\hline SRU & Fondo Municipale di Sviluppo Urbano & Serve allarealizavione degli obiettivi principali del Piano \\
\hline SRU & Sistema Cartografico Monicipale & Serve come base per ogni intervento sul territotio fisico \\
\hline SRU & Codici Municipali & $\begin{array}{l}\text { Corrispondono ai noctri Regolamenti (edilizi, } \\
\text { sanitari, ecc,): il principale è il Codlgo de Obmas }\end{array}$ \\
\hline SRU & $\begin{array}{c}\text { Plano Diretor } \\
\text { di Protezione Ambientale }\end{array}$ & $\begin{array}{l}\text { Serve a promuovere pianificavione, protezione. } \\
\text { restauro e controllo dell'Ambiente naturale }\end{array}$ \\
\hline $\mathrm{SRU}$ & Solo Criado & $\begin{array}{l}\text { Regola ke aree dove sono eceeduti } \\
\text { gli indici di sfruttamento }\end{array}$ \\
\hline SRU & Banco da terra & $\begin{array}{l}\text { E destinato a far fronte alle necessità urbane e abita- } \\
\text { tive: è costituito da terneni appartenenti al Comune }\end{array}$ \\
\hline SRU & $\begin{array}{l}\text { Regionalizzazione e decen- } \\
\text { tramento amministrativo }\end{array}$ & $\begin{array}{l}\text { Presenza capillare sul territorio di servizi e } \\
\text { organi decisionali dell Amministrazione }\end{array}$ \\
\hline SRU & Piani e Progetti di inizintiva comunituria & Progetti proposti per iniziativa dei cítladini \\
\hline
\end{tabular}

\begin{tabular}{|c|c|c|}
\hline SEC & Consigli Popolari & $\begin{array}{l}\text { Regionali e indipendenti dall Amministrazione, par- } \\
\text { tecipano alla discussione delle politiche municipali. } \\
\text { Sono alutonomi dallEsecutivo (air.101-102 dello Statuto) }\end{array}$ \\
\hline SEC & Consigli Municipali & $\begin{array}{l}\text { Formati da entità comunitanie di residenti, rappre- } \\
\text { sentanti di categoria e dell'Amministrazione }\end{array}$ \\
\hline SEC & Suffragio Universale & Implica il diritto al voto diretto e segreto \\
\hline SEC & $\begin{array}{l}\text { Consulte Plebiscitarie relative } \\
\text { ad atti dell'esecutivo o Leggi }\end{array}$ & $\begin{array}{c}\text { Convocate dal Sindaco, richiedono } 2 / 3 \text { dei Con- } \\
\text { siglieri Municipali o il } 5 \% \text { degli elettori }\end{array}$ \\
\hline SEC & Tribuna Popolare & $\begin{array}{l}\text { E istituita nelle sessioni del Consiglio Munici- } \\
\text { pale o nel piazzale davanti, ad uso di entitat } \\
\text { sindacali o rappresentanti dei Residenti }\end{array}$ \\
\hline SEC & $\begin{array}{l}\text { Iniziativa popolare } \\
\text { nel processo Legislativo }\end{array}$ & $\begin{array}{l}\text { Presentazione "dal basso" di progetti di legge } \\
\text { o di emendamenti alla Legge Organica }\end{array}$ \\
\hline SEC & $\begin{array}{l}\text { Richiesta di Informazioni } \\
\text { (Pedido) }\end{array}$ & $\begin{array}{l}\text { Diritto ad ottenere informazioni su ogni atto, } \\
\text { contratto, decisione su qualsiasi tema trattato } \\
\text { dal Potere Legislativo o Esecutivo }\end{array}$ \\
\hline SEC & Udienze Pubbliche & $\begin{array}{l}\text { Richieste da entità della società civile, su } \\
\text { progetti, opere ed altri temi trattati } \\
\text { dal Potere Legislativo ed Esecutivo }\end{array}$ \\
\hline
\end{tabular}


Fig 21 - La struttura di funzionamento del Bilancio Partecipativo (O.P.) nel 2002, con il suo percorso tematico e quello ‘territorializzato' nelle 16 Regioni di Bilancio.

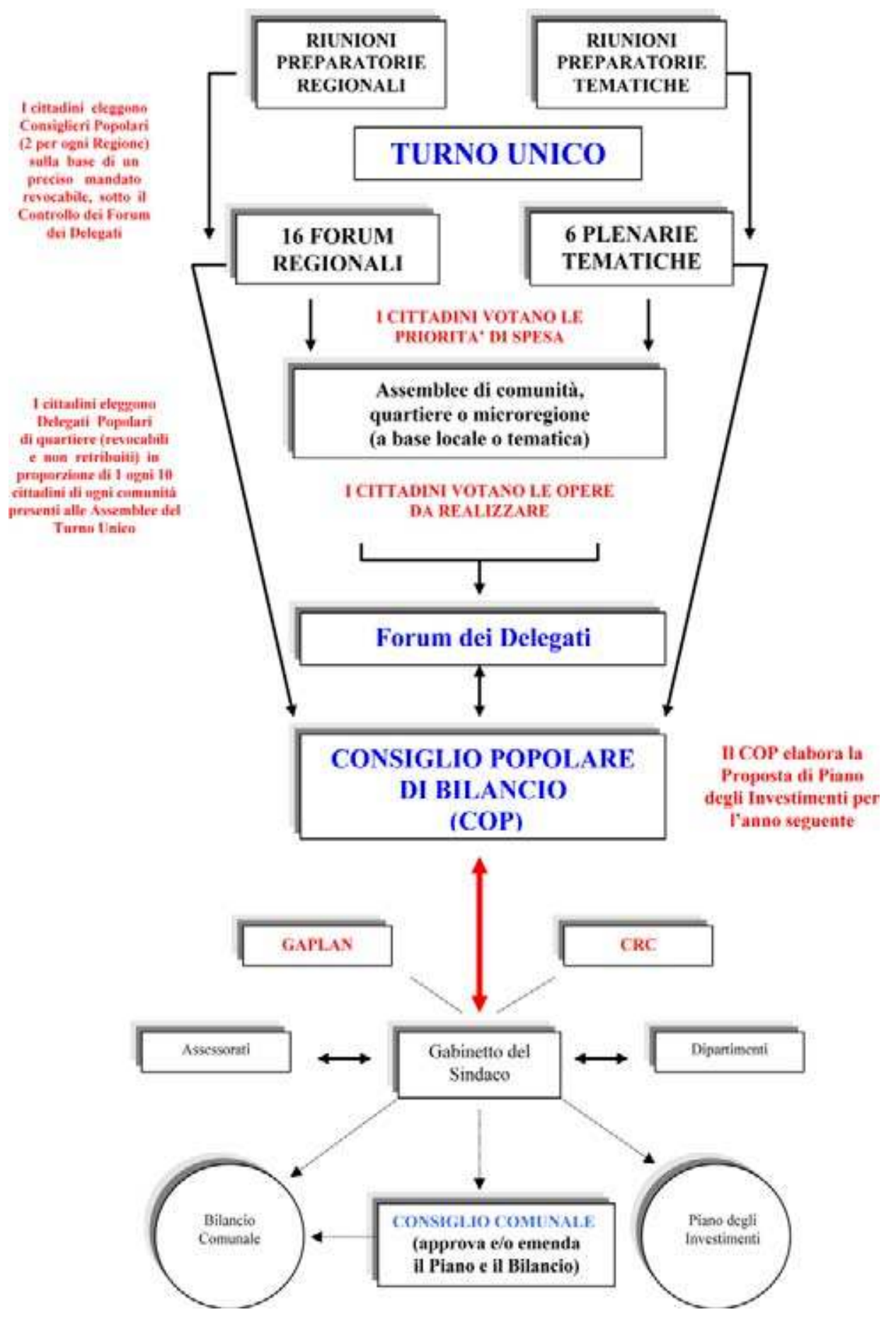


Fig 22 - La struttura di funzionamento del Bilancio Partecipativo (O.P.) nel 1989, durante il primo anno di sperimentazione. Come si può notare da questo schema di funzionamento e da quello esposto nell'immagine successiva, il Bilancio Partecipativo ha visto un consistente trasformarsi della 'macchina di funzionamento' per coinvolgere attivamente i cittadini nella partecipazione alle scelte territoriali. La trasformazione è stata graduale, e il complessificarsi dell 'ingegneria decisionale' ha risposto alle richieste dei cittadini di accrescere il proprio ruolo costruttivo e le garanzie a tutela del pluralismo, ma ha anche seguito una linea politica che ha puntato sul ruolo 'redistributvo' del processo decisionale dell'O.P.

\section{L'AMMINISTRAZIONE COSTRUISCE UN'IPOTESI DI BL ANCTO E GERARCHIZZA LE OPERE DA FARSI PER L'ANNO SUCCESSTVO. POI SOTTOPONE IL TUTTO ALLE ASSEMBLEE POPOLARI PER EMENDAMENTI}
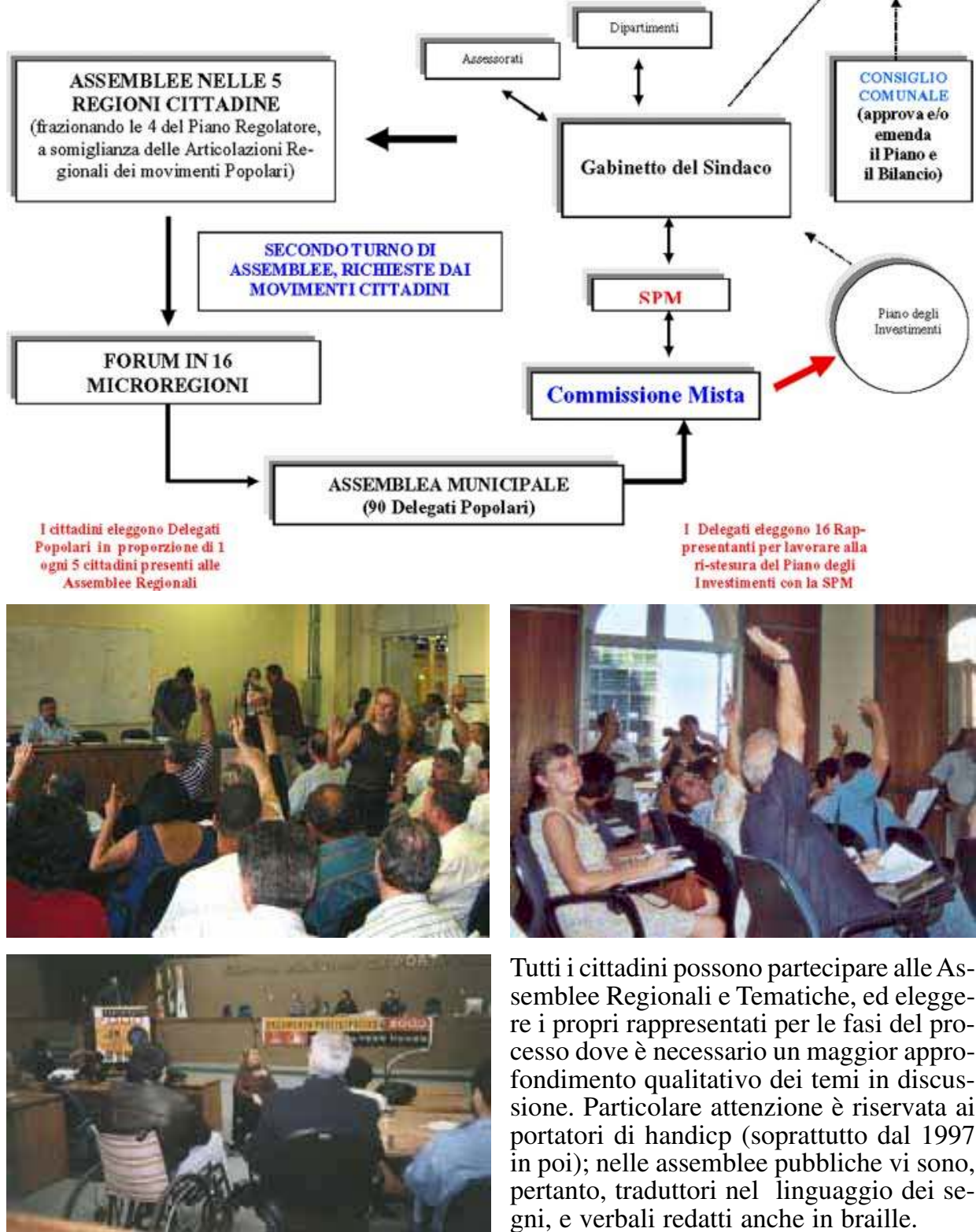

Tutti i cittadini possono partecipare alle Assemblee Regionali e Tematiche, ed eleggere i propri rappresentati per le fasi del processo dove è necessario un maggior approfondimento qualitativo dei temi in discussione. Particolare attenzione è riservata ai portatori di handicp (soprattutto dal 1997 in poi); nelle assemblee pubbliche vi sono, pertanto, traduttori nel linguaggio dei segni, e verbali redatti anche in braille. 
Fig 23 - La struttura di funzionamento del Bilancio Partecipativo (O.P.) tra il 1994 e il 2001 (elaborazione tratta da Abers, 1997), dopo la creazione delle Assemblee Tematiche.
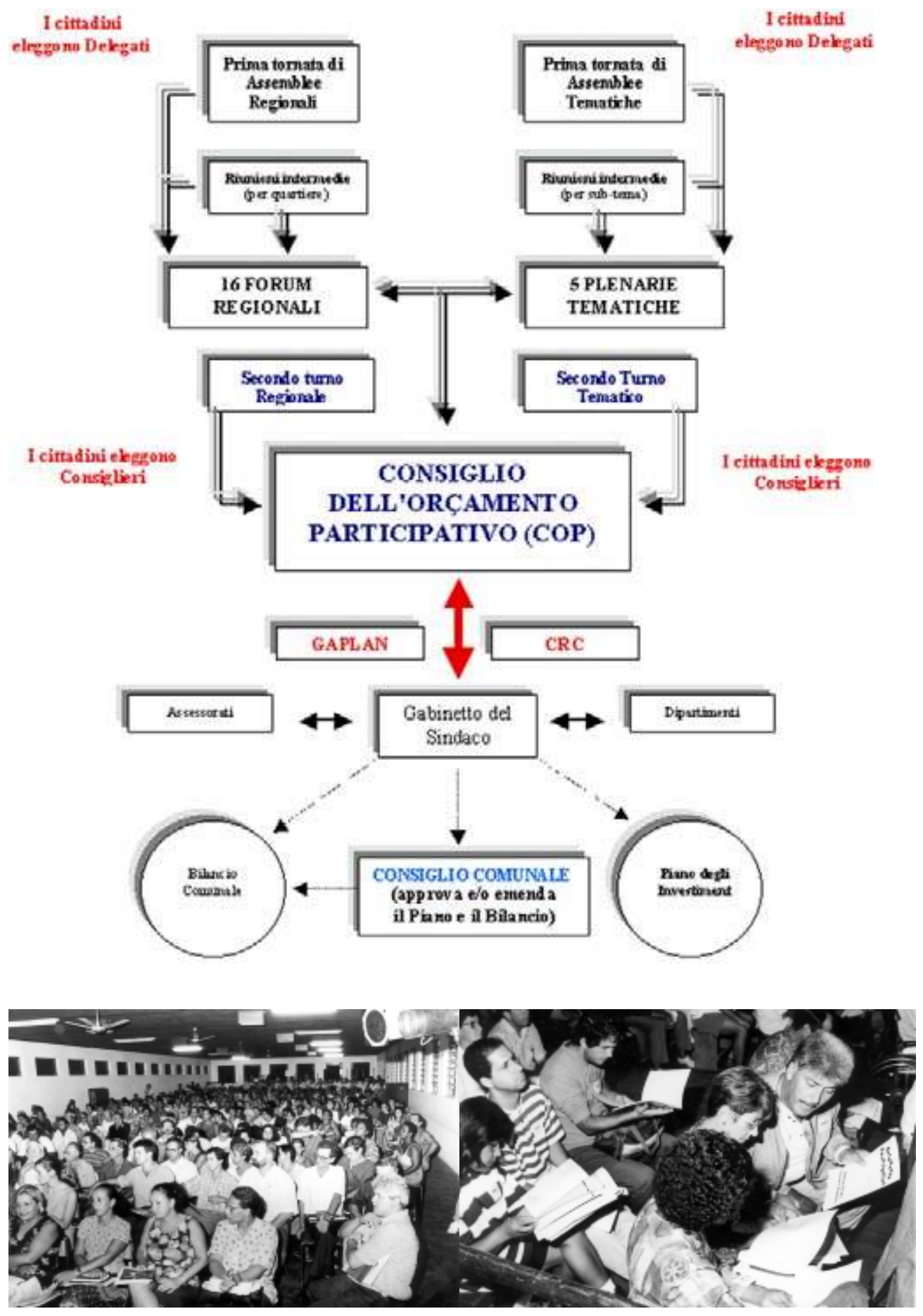

Immagini di assemblee dell'O.P. di Porto Alegre (tratte da Genro e De Souza, 2002). 


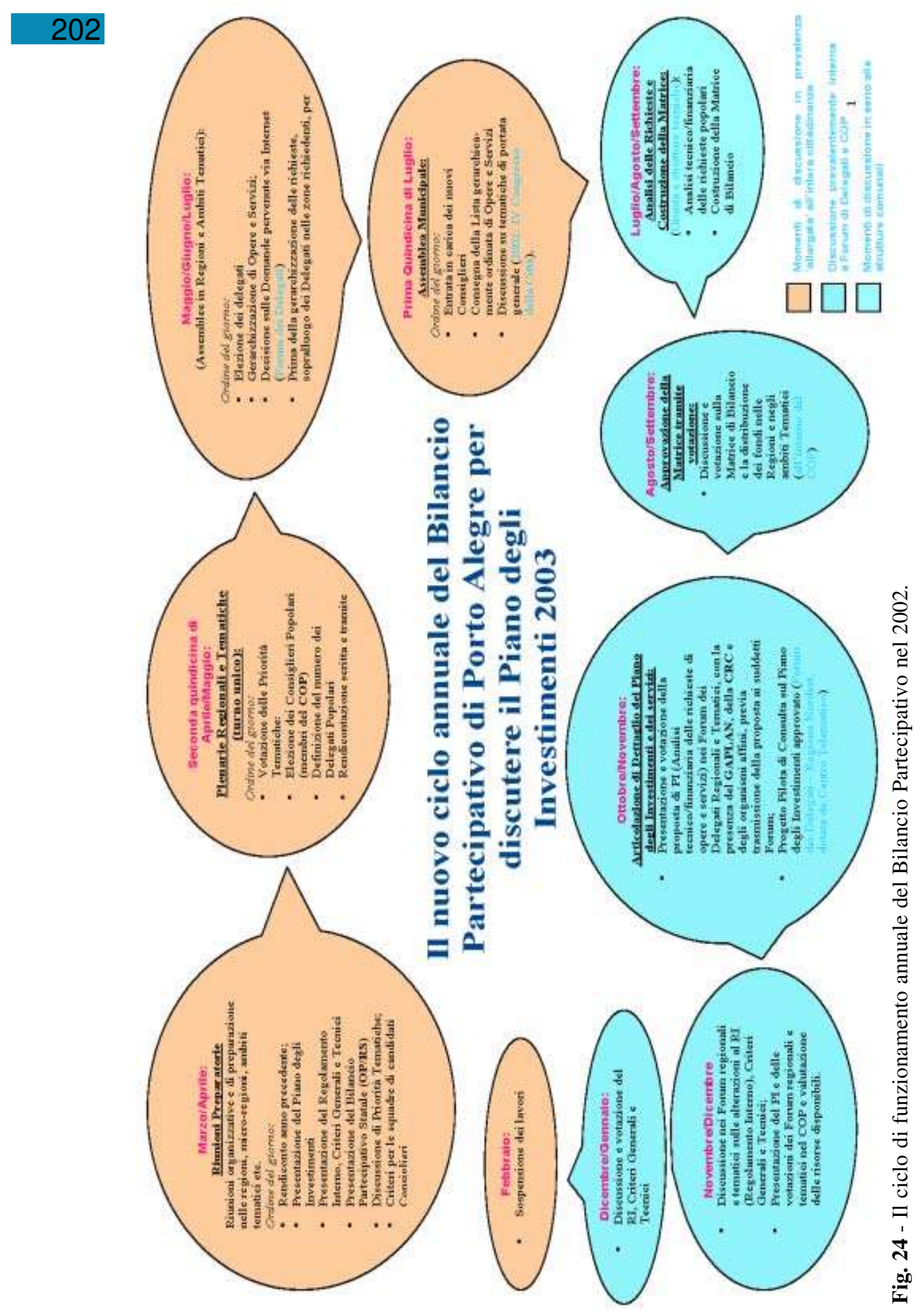




\begin{tabular}{|c|c|c|c|c|}
\hline $\begin{array}{l}1 \\
\frac{1}{\omega}\end{array}$ & 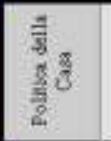 & $\frac{5}{3}$ & $\frac{\mathrm{e}^{2}}{8}$ & 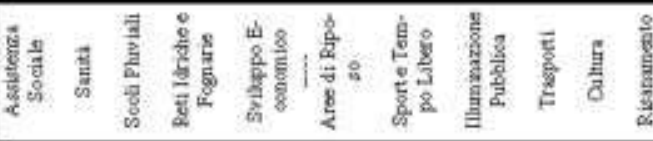 \\
\hline 章 & $\begin{array}{l}\frac{1}{3} \\
\frac{3}{2} \\
\frac{3}{2}\end{array}$ & 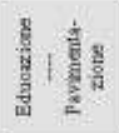 & 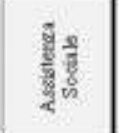 & 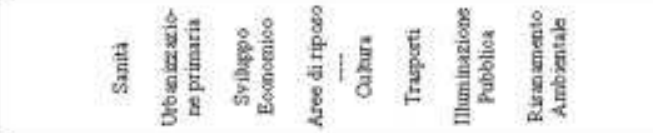 \\
\hline$\frac{4}{\frac{*}{5}}$ & 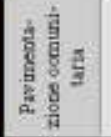 & $\frac{1}{3}$ & 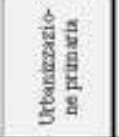 & 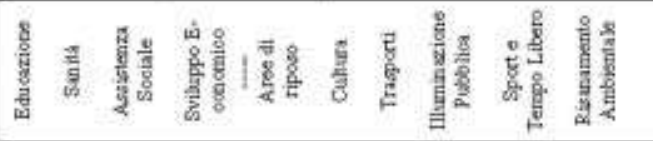 \\
\hline 喜 & $\begin{array}{l}\frac{3}{3} \\
\frac{3}{3} \\
\frac{\pi}{2} \\
\frac{3}{8}\end{array}$ & 青竞 & 蒫 & 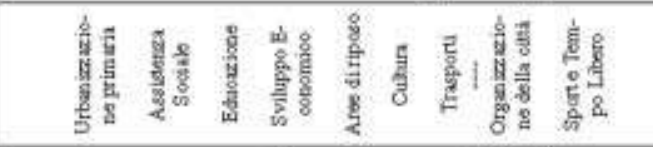 \\
\hline$\frac{1}{\alpha}$ & 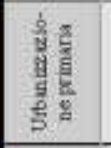 & 章数 & $\begin{array}{l}3 \\
\frac{\pi}{8} \\
\frac{8}{2} \\
\frac{1}{2} \\
\frac{1}{2} \\
\end{array}$ & 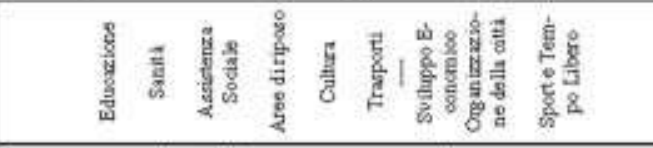 \\
\hline 泰 & 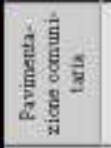 & 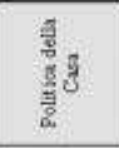 & 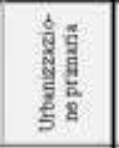 & 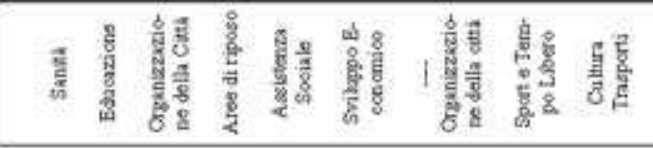 \\
\hline \$ & 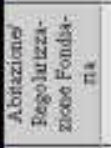 & 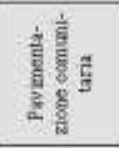 & 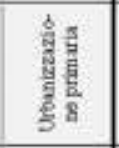 & 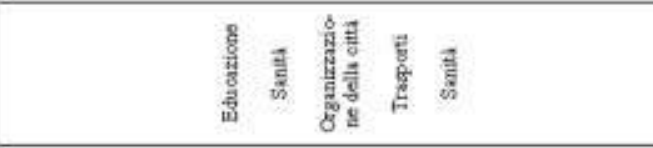 \\
\hline$\stackrel{\circ}{\circ}$ & 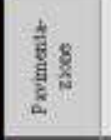 & 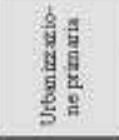 & 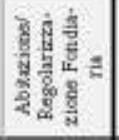 & 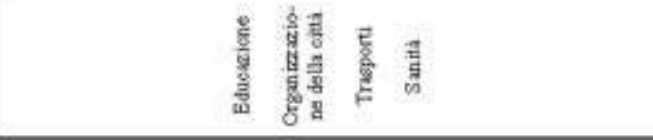 \\
\hline 응 & 音 & 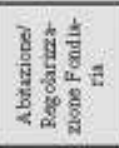 & $\begin{array}{l}\frac{1}{4} \\
\frac{3}{5} \\
\frac{5}{8}\end{array}$ & 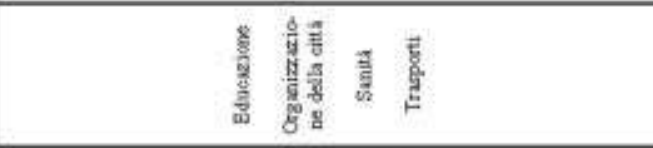 \\
\hline 索 & 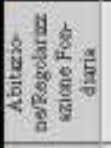 & is & 迹青 & 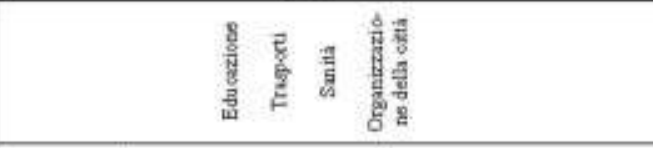 \\
\hline$\frac{\vdots}{2}$ & 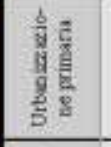 & 竞这 & 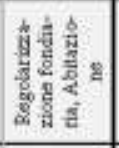 & 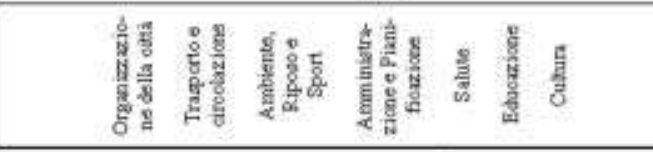 \\
\hline$\underset{\sigma}{*}$ & 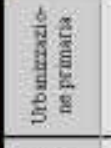 & $\frac{8}{8}$ & $\frac{1}{2}$ & 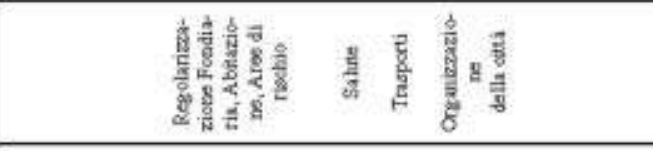 \\
\hline$\stackrel{*}{\Xi}$ & 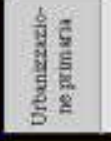 & 部 & 惪 & 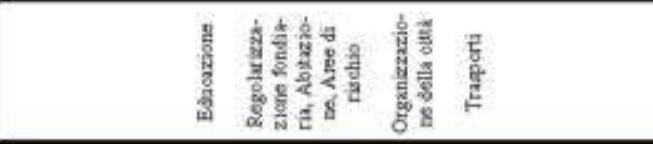 \\
\hline 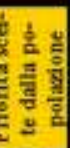 & 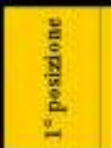 & 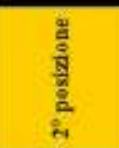 & $\begin{array}{l}\text { हूँ } \\
\text { 产 } \\
\text { 产 } \\
\text { in }\end{array}$ & 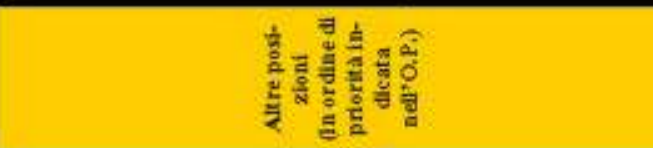 \\
\hline
\end{tabular}

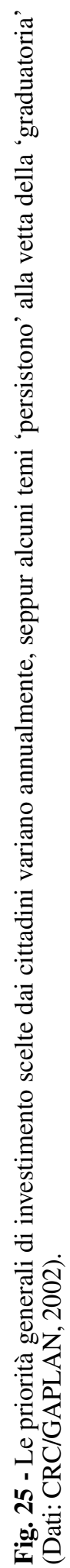




\begin{tabular}{|c|c|c|c|c|c|c|c|c|c|c|c|c|c|c|}
\hline $\begin{array}{l}\text { RISANAMENTO } \\
\text { AMBIENTALE }\end{array}$ & & & & & & & & & & & & & & $\circ$ \\
\hline CULTURA & & & & & & & & & & & & & & 0 \\
\hline $\begin{array}{l}\text { SVILUPPO } \\
\text { ECONOMICO }\end{array}$ & $\sim$ & & & & & - & - & & - & & & & & $\infty$ \\
\hline $\begin{array}{l}\text { ILLUMINAZIONE } \\
\text { PUBBLICA }\end{array}$ & & & & & & & & & & & & & & 0 \\
\hline $\begin{array}{l}\text { SPORTE TEMPO } \\
\text { LIBERO }\end{array}$ & & & & & & & & & & & & & & 0 \\
\hline $\begin{array}{l}\text { AREE } \\
\text { RICREATIVE }\end{array}$ & & & & & & & & & & & & & & 0 \\
\hline CIRCOLAZIONE & & & & & & & & & & & & & & 0 \\
\hline SANITA' & & $\sim$ & - & & & & $\infty$ & - & - & & $\sim-$ & & $\rightarrow$ & $\Rightarrow$ \\
\hline $\begin{array}{l}\text { ASSISTENZA } \\
\text { SOCIALE }\end{array}$ & $m N$ & en & & - & C & & & & $\Rightarrow c$ & & & & $m$ & 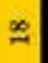 \\
\hline BDECAZIONE & $\rightarrow m$ & & en & $m$ & & & $\rightarrow$ & m & $N \sim$ & $\sim$ & $\infty$ & & $\mu$ & $\$$ \\
\hline $\begin{array}{l}\text { PAVIMENTA. } \\
\text { ZIONE }\end{array}$ & & - & $\vec{\nabla}$ & . & a & $\rightarrow$ & & $\infty$ & & $m$ & $\nabla$ & $\nabla$ & & $\vec{A}$ \\
\hline $\begin{array}{l}\text { POLITICA } \\
\text { DELLA CASA }\end{array}$ & $\nabla+$ & $\rightarrow$ & $\sim$ & 7 & & es & m & $\checkmark$ & $7 \nabla$ & 7 & -7 & $\rightarrow$ & + & $\pi$ \\
\hline $\begin{array}{c}\text { RETI } \\
\text { IDRICHE E } \\
\text { FOGNARIE }\end{array}$ & & & & - & & $\sim$ & & & & & m & $\sim$ & & $\infty$ \\
\hline $\begin{array}{c}\text { SCOLI } \\
\text { PLUVLALI (DEP) }\end{array}$ & - & & & $\sim$ & & & & & & - & $m$ & m & & $\varrho$ \\
\hline 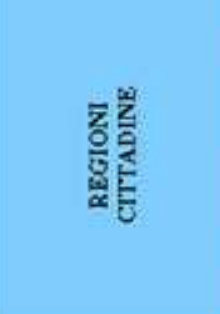 & 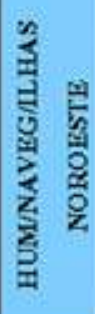 & $\frac{2}{80}$ & 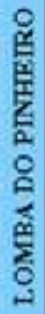 & 불 & & 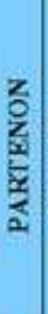 & 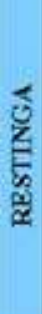 & $\begin{array}{l}\frac{5}{8} \\
\frac{\pi}{0} \\
03\end{array}$ & 总 & 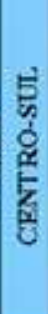 & 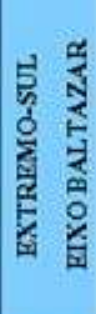 & 茄 & $\frac{8}{3}$ & 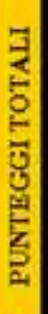 \\
\hline
\end{tabular}




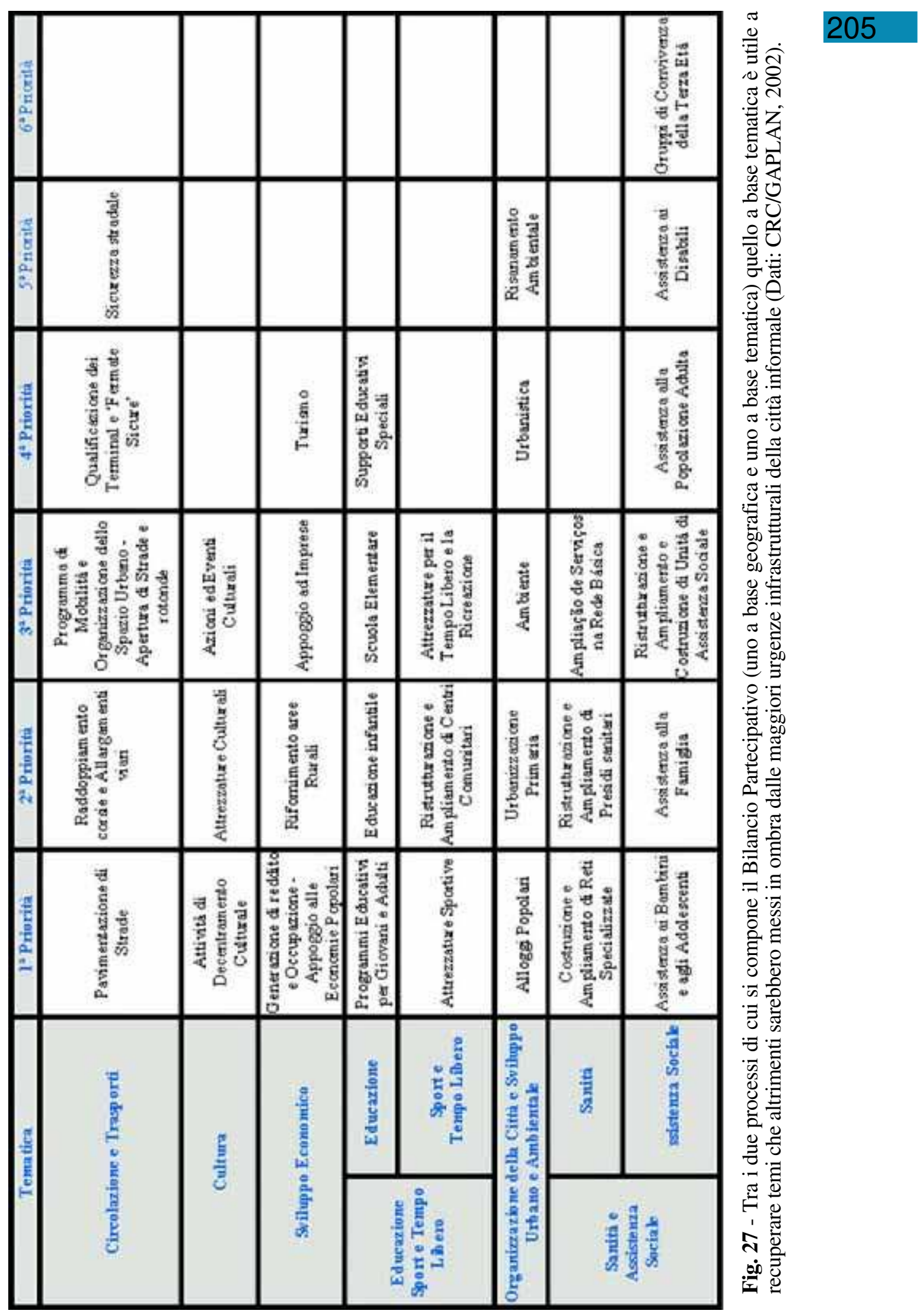


A tutela del pluralismo delle rappresentanze degli abitanti, nel caso ci sia più di una coppia di candidati a Consiglieri (per ogni Assemblea Regionale o Tematica), nell'elezione sarà rispettata la seguente tabella di proporzionalità:

\begin{tabular}{|c|c|c|}
\hline Voti & Titolari & Supplenti \\
\hline $75,1 \%$ dei voti e oltre & $\mathbf{2}$ & $\mathbf{2}$ \\
\hline $62,6 \%$ a $75,0 \%$ dei voti & $\mathbf{2}$ & $\mathbf{1}$ \\
\hline $55,1 \%$ a $62,5 \%$ dei voti & $\mathbf{2}$ & $\mathbf{0}$ \\
\hline $45,0 \%$ a $55,0 \%$ dei voti & $\mathbf{1}$ & $\mathbf{1}$ \\
\hline $37,6 \%$ a $44,9 \%$ dei voti & $\mathbf{0}$ & $\mathbf{2}$ \\
\hline $25,0 \%$ a $37,5 \%$ dei voti & $\mathbf{0}$ & $\mathbf{1}$ \\
\hline $24,9 \%$ meno voti & non eletto & non elett \\
\hline
\end{tabular}

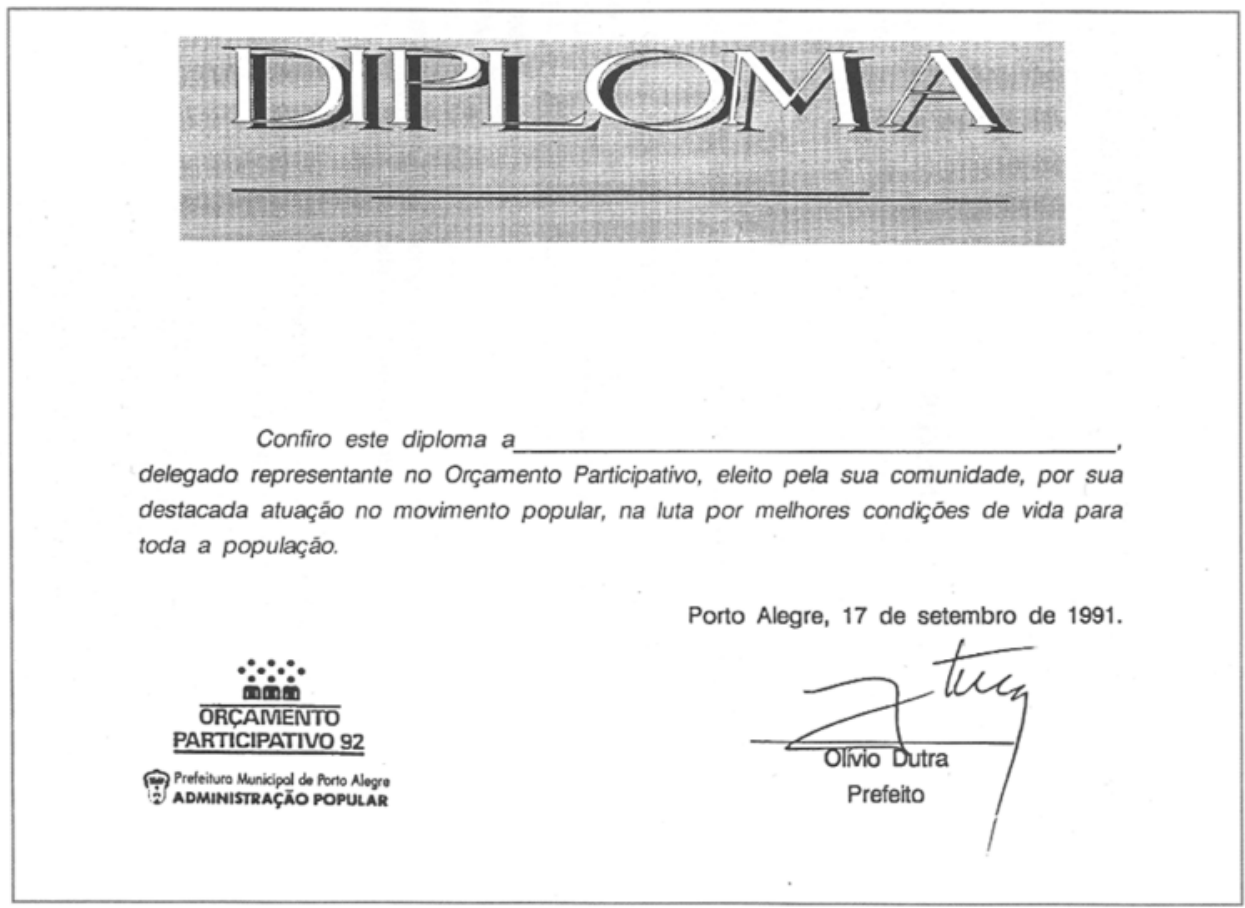

Fig. 28 - L'elezione dei rappresentanti popolari (Delegati e Consiglieri) che prendono parte alla fasi di dettagliamento del Piano degli Investimenti rispetta regole e criteri di traspasrenza. Per garantire 'equo accesso' alla comprensione dei processi, il Comune d Porto Alegre forma i rappresentanti popolari attraverso corsi ad hoc, alla fine dei quali viene rilasciato il diploma sopra illustrato. 


\begin{tabular}{|ll}
\hline \multicolumn{2}{|c}{ Priorità cittadine } \\
Prima priorità & Voto 4 \\
Seconda priorità & Voto 3 \\
Terza priorità & Voto 2 \\
Quarta priorità & Voto 1 \\
\hline
\end{tabular}

\begin{tabular}{|c|}
$\begin{array}{c}\text { Grado di priorizzazione regionale } \\
\text { (Peso relativo 5) }\end{array}$ \\
Quarta priorità.................valore 1 \\
Terza priorità................valore 2 \\
Seconda priorità..............valore 3 \\
Prima priorità...................valore 4
\end{tabular}

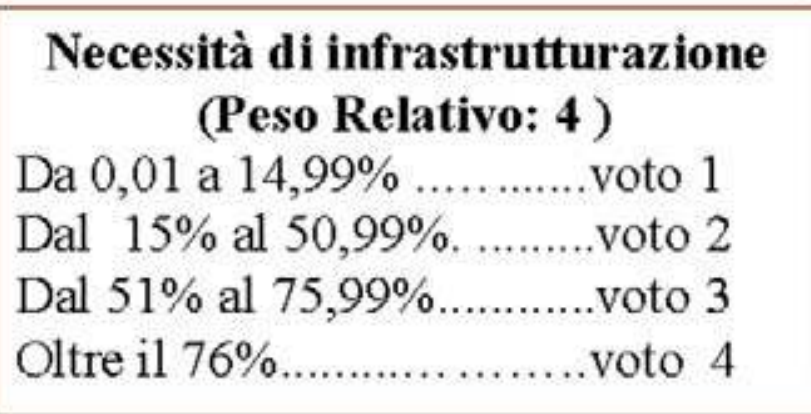

\begin{tabular}{|c|}
\hline $\begin{array}{c}\text { Popolazione della Regione } \\
\text { (Peso Relativo 2) }\end{array}$ \\
Fino a 25.000..............voto 1 \\
Da 25.001 a $45.000 \ldots \ldots$ voto 2 \\
Da 45.001 a $90.000 \ldots \ldots \ldots$ voto 3 \\
Oltre $90.001 \ldots \ldots \ldots \ldots \ldots$ voto 4 \\
\hline
\end{tabular}

Fig. 29 - Il Bilancio Partecipativo necessita di criteri rigorosi e universali per garantire la partecipazione di tutti, il voto delle priorità e l'elezione dei rappresentanti popolari. Vi sono, così, dei criteri di distribuzione per le risorse che, ponderati attraverso opportuni pesi, fanno sì che il bilancio venga ripartito tra le Regioni cittadine anche in rapporto al grado di necessità di attrezzature e servizi che ogni zona ha, e non solo a quanti abitanti ogni comunità è riuscita a mobilitare nelle assemblee. 
Fig. 30 - Le Schede riempite o disegnate dai cittadini nei diversi gradi del processo di Bilancio Partecipativo aiutano l'Amministrazione a gerarchizzare le scelte prioritarie e a costruire un archivio informatizzato delle richieste, che vengono prima presentate sottoforma di 'lista di desideri' e poi priorizzate. Le richieste non soddisfatte in ogni anno, a causa dei limiti di bilancio, di solito vengono riproposte l'anno successivo: pertanto l'archiviazione informatizzata è fondamentale per accelerare di anno in anno l'aggiornmento delle valutazioni di costo di ogni richiesta.

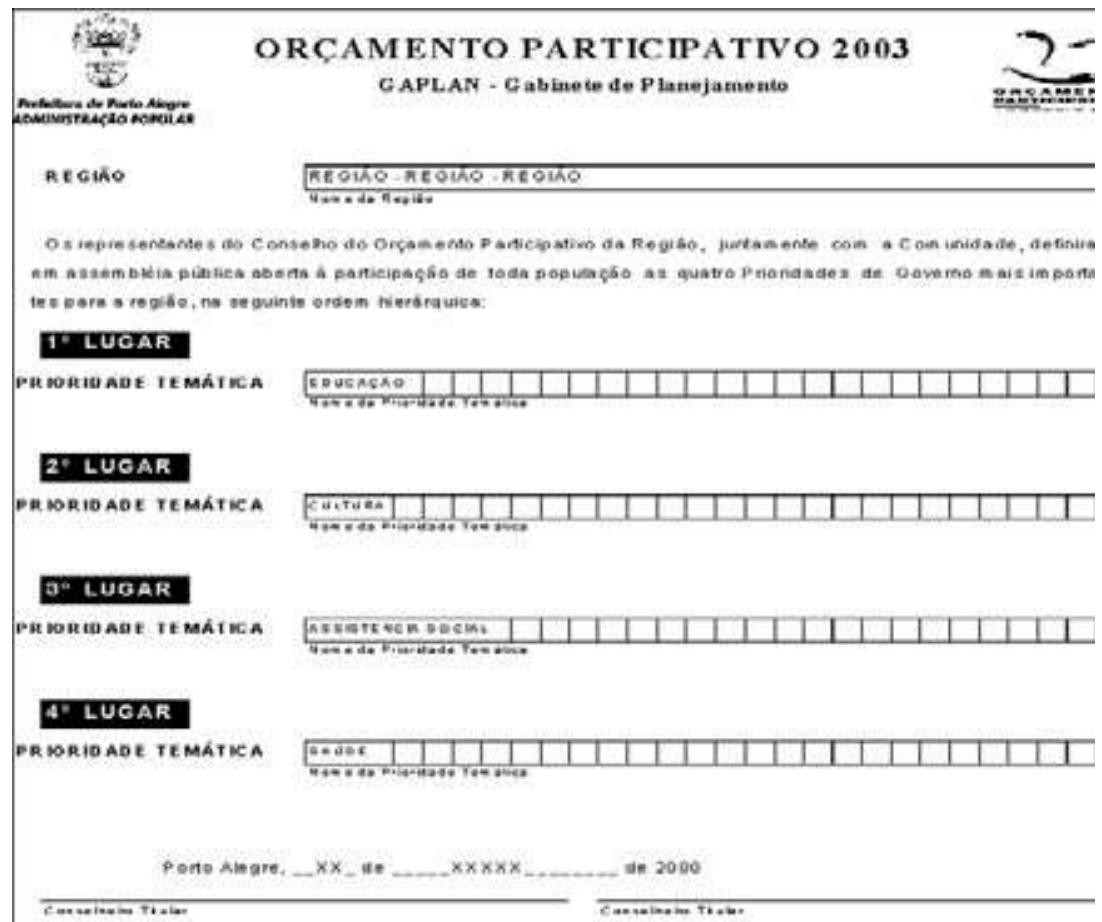

MAPPA DELL'UBICAZIONE DELL'OPERA CHE VIENE RICHIESTA

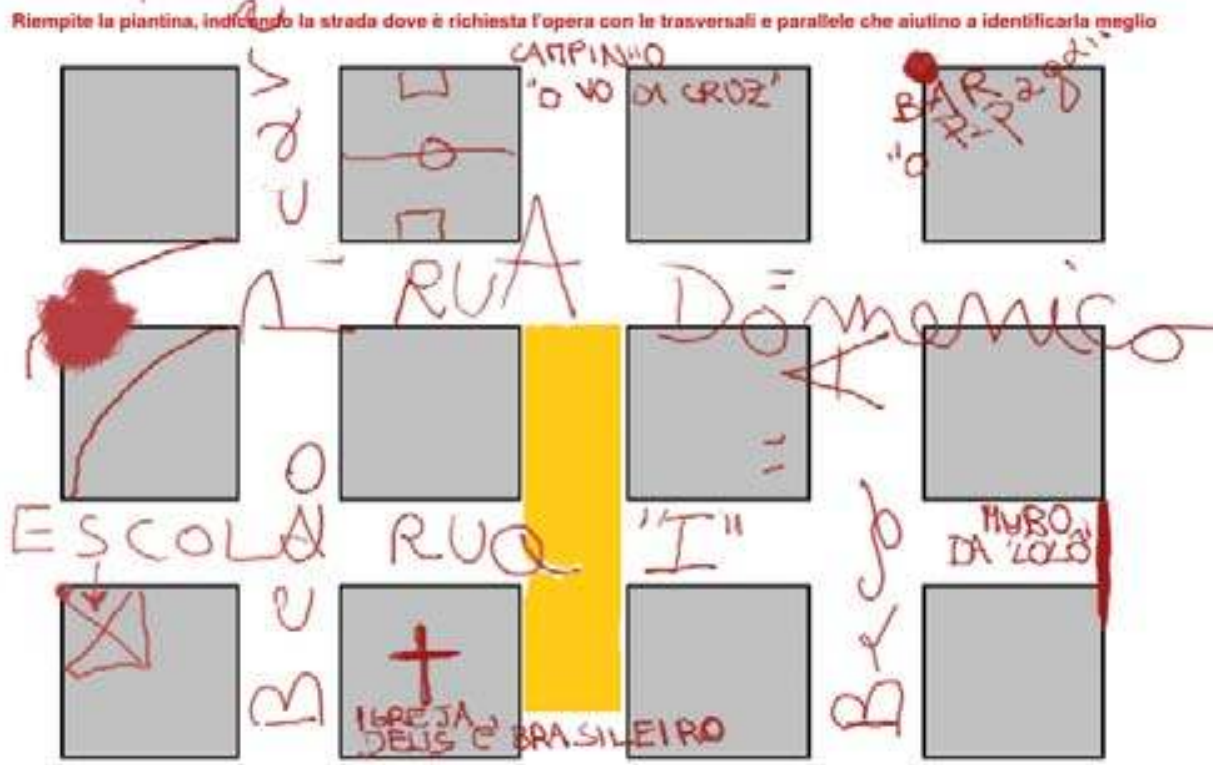




\begin{tabular}{|c|c|}
\hline $\begin{array}{r}\text { Indicatori di pianifica } \\
\text { MATRICE DELL }\end{array}$ & $\begin{array}{l}\text { principali per costruire la } \\
\text { IORITA' CITTADINE }\end{array}$ \\
\hline INDICATORE 1 & ORITA' REGIONALI \\
\hline $\begin{array}{r}\text { II GAPLAN - basandasi sulle, } \\
\text { regioni, calcola } \mathrm{A}\end{array}$ & $\begin{array}{l}\text { natbo priorità tematiche scelle nelle } \\
\text { asi sui seguenti purteggi }\end{array}$ \\
\hline $\begin{array}{l}1^{\mathrm{a}} \text { priorità } \\
2^{\mathrm{a}} \text { priorità } \\
3^{\mathrm{a}} \text { priorità } \\
4^{\mathrm{a}} \text { priorità }\end{array}$ & $\begin{array}{l}\text { punteggio } 4 \\
\text { punteggio } 3 \\
\text { punteggio } 2 \\
\text { punteggio } 1\end{array}$ \\
\hline $\begin{array}{l}\text { - Le tre prime priovità che assor } \\
\text { governo pe }\end{array}$ & $\begin{array}{l}\text { no píi punteggi, saramo le prionità di } \\
\text { regioni cittadine. }\end{array}$ \\
\hline INDICATORE 2 & NARIE TEMATICHE \\
\hline $\begin{array}{l}\text { Dall'analisi delle schede di wo: } \\
\text { servizi e opere isoprathution }\end{array}$ & $\begin{array}{l}\text { plenarie si deducono le diretorici dil } \\
\text { onon priaritari per le Regionali). }\end{array}$ \\
\hline $\begin{array}{r}\text { INDICATC } \\
\text { DELLAMMINISTRAZ } \\
\text { DEL LIVELLO D }\end{array}$ & $\begin{array}{l}\text { - NECESSITA' } \\
\text { PER IL MANTENIMENTO } \\
\text { RVIZI GIA' OFFERTI }\end{array}$ \\
\hline $\begin{array}{r}\text { Spese rigide ofisse, personal } \\
\text { emergenzia }\end{array}$ & $\begin{array}{l}\text { ale di cansumo - Opere a carattere } \\
\text { ssi bancari, ecc. }\end{array}$ \\
\hline $\begin{array}{r}\text { PRIMA MAT } \\
\text { (ordinata pe }\end{array}$ & $\begin{array}{l}\text { E DI BILANCTO } \\
\text { sorati e autarchie) }\end{array}$ \\
\hline
\end{tabular}

\begin{tabular}{|c|c|c|c|c|c|c|c|c|c|c|}
\hline \multirow[b]{2}{*}{ ORGANO } & \multicolumn{2}{|l|}{ PERSONALE } & \multicolumn{2}{|c|}{ COSTIFISSI } & \multicolumn{2}{|c|}{ EVVSTIM.TOTALE } & \multicolumn{2}{|l|}{ TRASFERMENTI } & \multicolumn{2}{|l|}{ TOTALE } \\
\hline & VALOR & 5 & VALOR & 5 & VALOR & 26 & VALORE & 5 & VALORE & 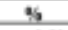 \\
\hline CAMM. & 22.J91.030.000 & 5,41 & $4.378050,00$ & 3,52 & $431,030,00$ & 0,45 & 0,00 & - & $27.600 .000,00$ & 3,50 \\
\hline GAB.PR. & $2331,400,00$ & 0.67 & $1.5314233,00$ & 1,23 & $62.500,60$ & 0,06 & 0,00 & . & $4.427 .603,00$ & 0,56 \\
\hline PGM & $3752.200,60$ & 0.88 & 547.130 .00 & 0,44 & $10.000,60$ & 0.01 & 0,00 & - & 4.239 .659 .00 & 0.54 \\
\hline DEP & $3755,200,60$ & 0.95 & 4.869 .348 .00 & 3,92 & 9.775 .030 .00 & 10,11 & 0,00 & . & $18.419 .543,00$ & 2,34 \\
\hline SECAR & 343200,60 & $0,0 \mathrm{~s}$ & $150.744,60$ & 0,12 & $5,000,00$ & 0,01 & 0,00 & . & $428.044,00$ & 0,06 \\
\hline SME & $3045,500,00$ & 0,72 & 713443,00 & 0,57 & 20000,60 & 0,08 & 0,00 & . & 3.879 .343 .00 & 0,49 \\
\hline GAPLAN & $552.700,60$ & 0.13 & $2 \pi, 24,00$ & 0,2 & $5.000,00$ & 0,01 & 0,00 & . & $839.944,00$ & 0,11 \\
\hline SMC & $5319,600,00$ & 1,26 & 6.501 .924 .00 & 5,23 & 595.030 .00 & 0,62 & 0,00 & . & $12416.524,00$ & 1,58 \\
\hline SGM & $8794.500,00$ & 203 & $2711.974,00$ & 2,18 & $200,030,00$ & 0,21 & 0,00 & . & 11. $706.474,00$ & 1,49 \\
\hline SMA & $6821.100,00$ & 1.62 & 8.55 & 6,28 & $221.010,00$ & 0,23 & 0,00 & . &, 00 & 1,98 \\
\hline SMF & 11.840 .230 .00 & 2.81 & 6.350 .531 .00 & 5.12 & 2.645030 .00 & 3.94 & 0.00 & - & 20344591,00 & 3,41 \\
\hline SMOV & 14 .0. 500,00 & 351 & $9.348 .389,00$ & 7,54 & $60534,00,60$ & 62.61 & 0,00 & - & $84,702.28,000$ & 10,75 \\
\hline SMED & 120290100,60 & 30,60 & 31.205 .722 .00 & 28.50 & 2300.030 .00 & 2,38 & It. $008.974,03$ & 10.35 & $174.343956,00$ & 22.13 \\
\hline SMIC & $3313.100,60$ & 0.91 & $4.433,640,00$ & 3,61 & $2.460 .030,00$ & 2,54 & 0,00 & . & $10.761 .740,00$ & 1,37 \\
\hline SET & $6.606 .610,00$ & 1,57 & & 1,36 & $6.140 .000,00$ & 6.35 & 0,00 & . & $14.438 .165,00$ & 1,83 \\
\hline Sors & $95.828,300,00$ & 22,76 & $6.395 .156,00$ & 5,15 & $358.300,00$ & 0.37 & 0,00 & - & $102.531 .756,00$ & 13,02 \\
\hline SPM & $4.297 .100,00$ & 1,01 & $1.233 .253,00$ & 1,03 & $275.000,00$ & 0,28 & 0,00 & - & $5305.353,00$ & 0,74 \\
\hline SMAM & $11.154 .0000,00$ & 2.65 & $2.463 .637,00$ & 1,98 & 305000,00 & 0,32 & 0,00 & . & $13.922 .637,00$ & $1, \pi$ \\
\hline EGM & $35.538 .783,00$ & 30,31 & $30.197 .54,00$ & 24.30 & $4287.356,60$ & 4.43 & 95. $305.110 .00 \mathrm{~J}$ & 89.65 & $215.419788,00$ & 25.34 \\
\hline $\mathrm{RC}$ & 0,00 & 0,00 & 0,00 & 0,00 & 0,00 & 0,00 & 0,00 & 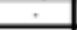 & 39.392 .220 .00 & 5,00 \\
\hline AMP & $\frac{n 54.953,00}{4}$ & 100.00 & $124.272 \mathrm{~min} .00$ & 100,00 & $96.650 .1560 \mathrm{~m}$ & $1000 \mathrm{~m}$ & $106.605014,00$ & 100,100 & 787.54 .404 .01 & 1000 \\
\hline \multicolumn{2}{|c|}{ PERC.DEZ TOTAI } & 53,45 & & 15,77 & & 12.27 & & \begin{tabular}{ll|}
1351 \\
\end{tabular} & & 100,00 \\
\hline
\end{tabular}

Fig. 31 - Il Bilancio Partecipativo si caratterizza per la presenza di regole chiare che presiedono all'elaborazione dei Piani di Investimento, e alla costruzione delle matrici generali di spesa del Comune. 



\section{8 \\ 1989: la città ad un bivio - il Bilancio Partecipativo: introduzione ed evoluzione}

\subsection{Alle origini del Bilancio Partecipativo: il nuovo corso politico}

Nel corso degli ormai 14 anni in cui è stato sperimentato, il Bilancio Partecipativo - il cui attuale funzionamento è descritto nel capitolo precedente - non si è mostrato un semplice 'meccanismo di governo' dall'impostazione statica, ma è andato subendo innumerevoli trasformazioni, con l'obiettivo di aderire all'evolversi delle dinamiche sociali, politiche e culturali che hanno caratterizzato il territorio di Porto Alegre e connotato i suoi cambiamenti.

Per comprendere questo adattamento progressivo, è importante ripercorrere alcuni dei principali riadattamenti strutturali che lo hanno connotato, a partire dal momento in cui - in maniera sperimentale e 'frettolosa' - cominciò a prendere corpo a metà del 1989 , sulla scorta di quanto elaborato nelle occasioni di dialogo stabilitesi negli anni precedenti tra amministrazione, partiti politici e movimenti popolari, e resesi più intense nei primi mesi di governo della neoeletta Amministrazione Popolare.

A Porto Alegre, il tema dei Consigli Popolari era stato molto discusso già durante le 'primarie' del Partito dei Lavoratori (PT) per la scelta dei candidati alle elezioni che - nel IV Congresso Municipale del maggio 1988 - vide trionfare Olivio Dutra e il candidato a Vice-Sindaco Tarso Genro. La piattaforma elettorale elaborata in quell'occasione come documento condiviso da tutto il Fronte Popolare (comprendente anche le formazioni del Partito Comunista Brasiliano, dal Partito Verde e di quello Socialista) ${ }^{1}$ venne a riassumersi con lo slogan "Coragem de Mudar" [coraggio di cambiare], imperniandosi su tre 'punti d'onore':

1) invertire le priorità delle amministrazioni precedenti in favore della cultura, della salute, dell'alloggio e della riduzione del costo della vita;

2) inaugurare solidi spazi di partecipazione e controllo popolare sul Comune, accogliendo le proposte lanciate dai cittadini negli anni precedenti;

3) appoggiare concretamente le lotte della popolazione organizzata per la conquista dei suoi diritti, della sua dignità e della fine dell'autoritarismo.

Eletto sindaco con il 34\% dei voti, Dutra dovette dedicarsi ad un primo peri- 
212 odo 'di aggiustamenti finanziari e di riconoscimento della macchina amministrativa' ai cui meccanismi farraginosi interni il giovane PT non era ancora avvezzo (Menegat, 1995); ${ }^{2}$ parallelamente, però, la Giunta cominciò a strutturare una discussione aperta sui criteri di riforma della macchina amministrativa che doveva far funzionare la neobattezzata Amministrazione Popolare.

Le trasformazioni di questo primo anno non furono per nulla indolori, sia per la resistenza incontrata nei tecnici che per il timore del Partito stesso di perdere il controllo sulle principali decisioni amministrative: moltissimi furono così i conflitti che l'Amministrazione dovette affrontare (sia all'interno della coalizione di governo, sia nel rapporto con i movimenti sociali e le forze produttive) aggravati da una cronica mancanza di fondi dovuta al deficit operativo lasciato dall'Amministrazione Collares, che assommava all' $80 \%$ degli incassi, ${ }^{3}$ e, nel primo anno del nuovo esercizio, costrinse il Comune a destinare il 98\% degli introiti a pagare le spese pregresse e gli aumenti del 236,98\% dei salari degli impiegati comunali decisi dal sindaco uscente.

Per tali ragioni, 1' '89 restò carente di un vero piano d'azione che andasse oltre una gestione delle emergenze improntata ai principi di onestà e rigore nell'utilizzo dei fondi pubblici. Venne, comunque, avviata un'opera di mediazione fra partiti, amministrazione e cittadini nell'ambito del $\mathrm{V}^{\circ}$ Congresso Municipale del PT, a cui parteciparono oltre 400 delegati, in rappresentanza degli oltre 1400 militanti che avevano preso parte alle precedenti discussioni nelle Regioni elettorali (Camargo, 1989). Tra le decisioni prese in questa occasione vi furono quella di istituire un Consiglio Politico, sorta di forum di dibattiti che mediasse fra le varie tendenze interne del PT per mantenerne l'unità e quelle di intraprendere da subito un processo di discussione collettiva del bilancio comunale e di definire la partecipazione dei cittadini alle scelte per il territorio come il progetto strategico dell'Amministrazione popolare che doveva rispecchiare 'nodi tematici' da sempre al centro degli obiettivi del partito stesso.

Quest'ultima decisione fu condivisa da tutte le correnti del Movimento, compresa quella Democratico-Socialista che temeva un diluirsi dell' 'immaginario partitico' e desiderava direttive forti che guidassero i militanti che ora occupavano cariche politiche (Menegat, 1995). Il risultato di questo momento di 'assunzione pubblica di responsabilità' davanti all'elettorato fu l'avvio di quella che Fedozzi (1997, pag. 132) ha definito la 'prima fase' del Bilancio Partecipativo, ${ }^{5}$ caratterizzata “dall'inesperienza dei nuovi dirigenti dell'Esecutivo e dei movimenti comunitari nel promuovere la partecipazione comunitaria, dalla frustrazione degli abitanti in ragione dell'assenza di risultati materiali [...] e dalla conseguente crisi nell'interazione politica tra gli attori comunitari e l'Esecutivo" (ibidem).

\subsection{La 'prima fase' del Bilancio Partecipativo: avvio e difficoltà d'inse- diamento}

Il processo di creazione dell'OP non fu facile e richiese grande volontà politica e pazienza, davanti alle enormi resistenze con cui si confrontò e all'assenza di una precisa strategia a priori:

[...] sapevamo perfettamente quali erano i modelli e le pratiche da rigettare. Sapevamo che cosa non volevamo. Ma c'erano, intanto, grandi difficoltà quando si trattava di definire che cosa volevamo e cosa dovevamo fare nella pratica (Augustin, 1994). 
Una delle basi di riferimento per organizzare il processo che i movimenti urbani e il $\mathrm{V}^{\circ}$ Congresso Municipale del PT avevano caldamente sollecitato, fu la Piattaforma per il Comune di Porto Alegre del Direttorio Metropolitano del PT, approvata nella convenzione che aveva eletto Dutra come candidato a sindaco. In questa, l'idea dei Consigli Popolari era vista come mezzo per riscattare l'eredità storica della classe lavoratrice attraverso:

a) una base territoriale stabilita in accordo con gli abitanti della città, che ripercorresse la geografia delle lotte dei movimenti popolari,

b) la proporzionalità fra mobilitazione popolare e presenza di ogni regione della città nei Consigli stessi,

c) la definizione di un processo 'aperto' che permettesse modifiche nella sua sfera di competenze, in crescita parallelamente al rafforzamento reale dei Consigli,

d) il principio secondo cui i rappresentanti del partito nei Consigli dovevano esprimere un'avanguardia con posizioni avanzate, sottomettendosi però alla maggioranza, anche qualora le decisioni contrariassero le loro posizioni.

Il 24 luglio 1989 un franco incontro fra l'Amministrazione e i leader del Movimento Popolare gettò le basi in direzione della concretizzazione della promessa di studiare forme di partecipazione popolare alla definizione del bilancio comunale. La sfida assunse ben presto un respiro maggiore, nel momento in cui il 'crollo del muro di Berlino' spinse i partiti della coalizione a dar prova di sapersi misurare con il fallimento del "socialismo burocratico, rispondendo in maniera creativa e originale alla principale questione politica della decadenza [...] dell'Est Europeo, la relazione autocratica dello Stato con la società (U. De Souza, 2002). ${ }^{6}$

Fu l'Assessorato all'Urbanistica [SPM], nel luglio stesso, ad iniziare il processo di dialogo con i settori organizzati della popolazione, mirato ad una loro partecipazione nella definizione del bilancio municipale, attraverso riunioni nelle 4 Regioni di Piano Regolatore che dovevano portare a definire le priorità di spesa per il 1990. Fin da subito, l'Amministrazione impose la sua volontà su quella dei movimenti decidendo che la popolazione non dovesse discutere in dettaglio né delle entrate né delle spese correnti (quelle cioè necessarie per la manutenzione di opere già realizzate e per il pagamento dei funzionari che muovono la macchina amministrativa) ma limitarsi a deliberare sulle spese 'di capitale', cioè sui nuovi investimenti in opere pubbliche, acquisti di beni e contrazione di prestiti. Questa presa di posizione preventiva - maturata all'interno soprattutto della SPM, del Consiglio Politico della coalizione e dell'Assessorato alle Finanze - l'Amministrazione poneva in chiaro fin da subito il desiderio di mantenere un equilibrio di poteri e metteva a tacere le divisioni interne dovute alle sue correnti che temevano per una progressiva perdita dei poteri effettivi da parte dell'esecutivo politico.

Sulle forme di gestione del processo di discussione fu convenuto di mantenere temporaneamente in vita l'idea di assemblee informative nelle 4 Regioni del Plano Diretor, (divenute 5 per una suddivisione interna della troppo estesa Zona Sud) e di momenti decisionali che mettessero ad uno stesso tavolo rappresentanti di comunità e tecnici municipali. Il poco tempo per approfondire la discussione e l'inesperienza organizzativa rese caotiche le poche assemblee realizzate tra il 14 e il 18 di Agosto; fu, così, necessario organizzare una seconda tornata di discussione, che per attrarre più attenzione $\mathrm{e}$ 
214 diluire il caos della serie precedente si articolò in 16 micro-regioni $^{7}$ e si svolse tra l'11 e il 16 settembre. La Giunta suggerì che venissero eletti rappresentanti popolari ( 1 per ogni 5 presenti in ogni microregione) e che si riunissero in una Plenaria Municipale dove emendare e approvare il documento di bilancio proposto dal Comune sulla base delle precedenti discussioni con i cittadini, prima di spedirlo al Consiglio Comunale.

In questa fase, l'Amministrazione privilegiò il dialogo con il movimento urbano già organizzato che si era impegnato a co-organizzare le prime 5 Plenarie Regionali; tanto è vero che le Articolazioni Regionali, le Unioni di Vilas e i Consigli Popolari già autonomamente esistenti poterono eleggere in riunioni specifiche i propri rappresentanti.

Le grandi attese che gravavano sul processo, la sua carenza di regole organizzative e la frettolosità del suo concepimento non riuscirono a soddisfare i cittadini, cosicché nella Plenaria Municipale dei 90 Delegati popolari fu deliberato che 16 rappresentanti municipali (uno per microregione) componessero una Commissione mista con i tecnici della SPM per elaborare un Piano dei Lavori [Plano de Obras] che decidesse sul $12,1 \%$ dei fondi di investimento per il Bilancio 1990 (Fedozzi 2000, p. 60) e stabilisse un cronogramma di realizzazione degli investimenti. La Commissione dei Rappresentanti - embrione del futuro 'Consiglio di Bilancio' (COP) - era solo 'informalmente' costituita, quasi 'in prova' in attesa della discussione dello Statuto Comunale attesa per il 1990. Essa lavorò tutto ottobre e novembre con i tecnici dell'urbanistica, alterando la matrice degli investimenti per decentrare nei quartieri periferici la maggior parte dei fondi disponibili, nel timore che si volesse farne beneficiare zone ricche della città. ${ }^{8}$ In realtà furono soprattutto i tecnici ad indicare - in base ai loro criteri politici e tecnici quali richieste popolari soddisfare (Menegat, 1995), lasciando spazio ad una buona dose di discrezionalità nell'esaminare le richieste presentate dai cittadini. Questo non sempre significò rispetto di un formalismo legalista nelle scelte; tanto che la prima strada asfaltata fu una via stretta e tortuosa in una delle più povere favelas sulle colline di Porto Alegre, scelta in base a un valore 'esemplare' per mostrare la preferenza della giunta per progetti non convenzionali (Abers, 1998ab).

$\mathrm{Fu}$ in questa congiuntura, del resto, che si dimostrò che la volontà politica della nuova Amministrazione supportava il nascente processo. Infatti, il sindaco Dutra - alla fine dei lavori della Commissione popolare - inviò un messaggio al Consiglio Comunale, alterando la proposta di Legge di Bilancio già presentata per includere varie nuove richieste dei cittadini. ${ }^{9}$

Alla fine dei 5 mesi di percorso, una lettera inviata al sindaco 1'8 dicembre dai membri della Commissione di Rappresentanti popolari rivelò la sostanziale fiducia instaurata nei movimenti cittadini da un evento che aveva 'piantato $i$ semi della partecipazione, pur non avendo raccolto quai nulla', ${ }^{10} l^{\prime}$ 'insoddisfazione per le barriere burocratiche ereditate da una lunga tradizione di autoritarismo fu chiara nella constatazione che, in fondo, se il processo era stato appena una 'negoziazione del piano degli investimenti' per giunta economicamente e temporalmente limitata, era anche colpa del poco investimento realizzato dal Comune per permettere realmente ai cittadini di appropriarsi dei meccanismi delle procedure di costruzione e approvazione del bilancio, vera e propria 'scatola nera' dell'amministrazione pubblica brasiliana. ${ }^{11}$ 
Il punto è che entrambi gli attori (il movimento popolare ancora in atteggiamento 'rivendicativo' e l'Amministrazione, legata alla concezione del dualismo dei poteri alla base di anni di riflessione sul tema dei Consigli Popolari) mancavano dell'esperienza, di un metodo partecipativo e del linguaggio (Fedozzi, 2000, p. 62) necessari per affrontare la nuova sfida di democratizzazione del bilancio pubblico. Spesso si tese a riprodurre standard di discussione burocratico-contabili e mancò un processo preventivo di divulgazione di dati e conoscenze sulle finanze pubbliche. Non solo: in assenza di un orientamento strategico, le proposte dei singoli Assessorati erano state dibattute settorialmente, pervenendo a un qualcosa che purtroppo "assomigliava ad un piano tradizionale, un piano-libro, con vari volumi. Già eravamo all'ottavo volume e, probabilmente, avremmo avuto bisogno di circa 130 anni per eseguire il Piano proposto [...] e di una lunga dittatura". ${ }^{12}$ Addirittura, Menegat (1995) riferisce dell'esistenza di due Piani di Investimenti: uno elaborato dagli Assessorati (coordinati dalla SPM) e uno elaborato dalla popolazione nell'ambito dell'O.P.; il tentativo di finanziarli entrambi ricorrendo a fondi internazionali non ebbe successo, e il risultato fu che le aspettative ingeneratesi nella cittadinanza circa la realizzazione di alcune opere di prima necessità furono in parte deluse, creando sfiducia nella popolazione che non accolse con l'entusiasmo sperato il secondo anno di attività dell'O.P. L'errore compiuto dall'inesperta Amministrazione era stato quello di seguire l'orientamento pianificatorio tecnocratico e normativo abituale dei funzionari della SPM, che scindeva completamente oggetto e soggetto del Piano, sperando che l'esistenza della neonata Supervisione dello Sviluppo bastasse a risolvere i maggiori problemi insorgenti.

Del resto, oltre a fronteggiare le pressioni di vari settori 'di base' del PT e del Movimento Popolare per una maggiore e più organizzata apertura della macchina amministrativa alla partecipazione dei cittadini, l'Amministrazione doveva lottare contro le pressioni in direzione contraria della maggioranza dei suoi tecnici, che si opponevano al progetto di co-gestione dei bilanci di investimento adducendo la difficoltà di gestire i conflitti tra i vari interessi sociali in gioco e preferendo assestarsi su una concezione normativista del Piano Regolatore come detentore del 'monopolio della buona città'; una posizione priva di fiducia nella società e, anzi, desiderosa di proteggere lo strumento pianificatorio dalle pericolose contraddizioni di quella (Lima, 1993c).

Tra le due tendenze che si contrapposero dentro l'Amministrazione - a partire dalla sperimentazione dei primi processi di apertura della discussione sul bilancio nel secondo semestre dell' '89 - quella della 'pianificazione strategica' portata avanti dalla Segreteria del Sindaco (e rappresentata soprattutto dal vice-Sindaco Tarso Genro) richiese testardaggine e tempo per imporsi. I consulenti del suo 'Assessorato speciale', influenzati dalle tesi pianificatorie strategiche di Mário Testa e dell'ex-ministro cileno Matus (1989), ${ }^{13}$ e dalla 'comunicazione libera' di Habermas (1987a), lamentarono, infatti, a lungo la mancanza di un progetto del Comune che potesse confrontarsi a pari livello con i diversi progetti impliciti di cui erano portatori le imprese, gli speculatori, la popolazione borghese e quella delle aree povere.

La crisi interna determinata dallo scontro fra la loro posizione e quella dei tecnocrati tradizionali portò ad una crisi conclusasi con le dimissioni dell'Assessore all'Urbanistica nei primi mesi del 1990; questo evento diede una 
216 forte scossa ai partiti della coalizione governativa decidendoli alla pubblicazione di un documento chiamato 'L'ora delle Definizioni strategiche' che in parte - veniva a rispondere ad una lettera scritta dalla UAMPA e da vari Delegati Popolari del neonato processo di discussione del bilancio, che - già il 21/9/89 - avevano suggerito vari cambiamenti da apportare per il futuro nel processo, e stabilito alcune precondizioni per appoggiare le riforme tributarie in corso di discussione nel Consiglio Comunale.

'L'ora delle Definizioni strategiche', a partire da una valutazione dell'esistenza - seppur timida - di una linea d'azione distinta dal passato elaborata nei primi 15 mesi di governo del Fronte Popolare, proponeva uno studio delle disuguaglianze sociali e spaziali della città come base per una riflessione sull'organizzazione futura del dialogo con gli abitanti; ed un altro sulla necessità di procedere nell'opera di 'deprivatizzazione' dello Stato che portasse ad una democratizzazione politica prima ancora di quella sociale. Dopo questa presa di posizione comune della coalizione di governo, fu possibile intraprendere la strada di una Riforma Amministrativa, in gran parte elaborata informalmente, visto che una trasformazione istituzionale avrebbe significato un lungo processo e rischi di stravolgimento nel passaggio dal Consiglio Comunale. Il merito di questa trasformazione fu di comprendere la necessità di legarsi ad un ampio processo di modernizzazione tecnica del lavoro, combinata con le trasformazioni politiche e culturali, costituendo "un modello di gestione subordinato al riscatto delle responsabilità dell'azione amministrativa davanti alla città e all'insieme della popolazione" (Buchabui, 1994).

\subsection{La 'seconda fase' del Bilancio Partecipativo: costruendo un'infrastrut- tura adeguata}

Tutti volevano tutto allo stesso tempo. Esigevano che il governo riscattasse le 'promesse' elettorali e iniziasse 'immediatamente' le opere destinate a migliorare la qualità di vita in quelle regioni, storicamente abbandonate dal potere pubblico municipale. Il governo, però, non aveva risorse né progetti. Era necessario, prima, attuare una profonda riforma tributaria, generare dei risparmi locali (per mezzo delle stesse imposte locali) e così dare la possibilità all'amministrazione cittadina di rispondere alle richieste e creare un livello minimo di credibilità (Genro, 1993).

La proposta di Riforma Amministrativa - a cui lavorò tra marzo e agosto 1990 una Commissione integrata di dirigenti comunali - segnò l'inizio di una nuova fase nella vita del neonato Bilancio Partecipativo, marcata dalla comprensione che il potenziamento permanente del ruolo della partecipazione comunitaria necessitasse una struttura politico-amministrativa specificamente concepita. Di tutte le misure annunciate nel Seminario di 3 giorni della Commissione integrata sulla Riforma Amministrativa ${ }^{14}$ solo poche furono realmente realizzate alla fine del 1990, e pochissimo spazio e trattamento superficiale ricevette il tema del decentramento amministrativo, necessità teoricamente coerente con gli sforzi impiegati per potenziare e meglio definire la struttura dell'Orçamento Partecipativo. Questo, del resto, determinò da solo "un tale movimento di tensione positiva da dare l'impressione di un cambiamento molto superiore a qualsiasi riforma amministrativa" (Buchabui, 1994). 
In seguito al cosiddetto 'scandalo della doppia cassa' (cfr. Mengat, 1995), un primo urgente intervento dovette essere realizzato nel settore dei trasporti collettivi, dove per la prima volta il nuovo Governo cittadino mostrò forza e decisione riuscendo a trarre dalla sua parte molti impiegati della Compagnia pubblica Carris, valorizzando le loro proposte e in maniera da creare un sistema di trasporti innovativo che oggi è tra i migliori del paese.

La seconda e più radicale riforma della macchina comunale fu però messa in atto in seno alla SPM, l'Assessorato all'Urbanistica che fino all'Amministrazione Collares aveva svolto un ruolo centrale nella struttura comunale di Porto Alegre, fino a divenirne "il cervello integratore e sistemico" (Lima, 1993a), il plenipotenziario del Sindaco per tutti i processi che comportavano occupazione ed uso del suolo, oltre che per il sistema annuale e pluriennale di programmazione degli investimenti. Se nel gennaio del 1989 erano state create la Supervisione dello Sviluppo ${ }^{15}$ e numerose commissioni, integrate dalla partecipazione di membri dei diversi assessorati, per elaborare il PAG (Programma di azione del Governo), ${ }^{16}$ nel 1990 fu presa la misura che più di tutte corrispondeva esattamente al momento congiunturale e di accumulazione strategica del Governo (Buchabui, 1994). Fu, cioè, creato il Gabinetto di Pianificazione (GAPLAN) che toglieva alla SPM parte del suo strapotere, attribuendo le funzioni di bilancio e di pianificazione globale degli interventi dell'Esecutivo ad un organo legato al Gabinetto del Sindaco, cioè al centro delle decisioni politiche. Il neonato GAPLAN serviva da centro di coordinamento dei vari Assessorati (che fino ad allora agivano come 'municipi separati e autonomi', cfr. Menegat 1995) per evitare la frammentazione delle iniziative e articolare l'elaborazione del bilancio e dei piani di investimento da discutere con la popolazione nell'istituendo processo dell'O.P.: esso venne diviso in due Coordinamenti che lavoravano assieme (quelli del Bilancio e della Pianificazione Strategica). Inoltre la riforma procedette trasformando il già esistente CRC (Coordinamento delle relazioni con la Comunità) da 'balcone del clientelismo' (Menegat, 995) in mediatore fra Amministrazione e società civile, con particolare riferimento all' ambito del Bilancio Partecipativo. Anch'esso venne legato direttamente al Gabinetto del Sindaco, e dal 1991 cominciò a collaborare strettamente con il GAPLAN. L'attività di questi due nuovi organismi - legati da reti di pianificazione orizzontale agli altri organismi comunali - non si esauriva in ambito istituzionale, ma si basava su una relazione diretta con la popolazione, elaborata a partire da un'assidua frequentazione delle riunioni ai vari livelli del nascente meccanismo del Bilancio Partecipativo. Serviva, quindi, anche a chiudere il triangolo delle relazioni fra massimi rappresentanti delle Istituzioni, organi operativi e tecnici dell'amministrazione e cittadinanza, mettendo il primo e l'ultimo in contatto spesso quasi diretto.

Strategica fu - in quel momento - anche la Riforma Tributaria, impostata per portare avanti un risanamento finanziario reso indispensabile non solo dalla scarsezza delle risorse comunali (che rischiavano di non permettere la realizzazione delle molte opere previste nel Bilancio Partecipativo discusso nel 1989), ma anche dalla recente Riforma Costituzionale del 1988 che faceva gravare sui municipi anche "le conseguenze di fatto dello smantellamento progressivo delle politiche sociali a livello del potere centrale"(Carrion, 1993). Per poter recuperare una relazione del potere pubblico con la società 
218 ed agire con indipendenza dai finanziamenti 'vincolanti e incerti' provenienti da altri livelli istituzionali, per l'Amministrazione Popolare di Porto Alegre era imprescindibile risanare 'un Comune praticamente fallito' (Dutra, 1994). L'Assessorato alle Finanze dovette - inizialmente - individuare alcuni mezzi di emergenza e strategie di intervento strutturale per risanare il bilancio, 'moralizzare gli sprechi' e diminuire i costi di tutta la macchina amministrativa dell'Esecutivo comunale. ${ }^{17} \mathrm{Vi}$ era, infatti, la necessità di far fronte all'aumento degli stipendi del personale deciso 'per vendetta' dall'uscente sindaco Collares, senza impugnare un provvedimento che poteva rappresentare una risorsa per conquistare ai programmi del nuovo Esecutivo i dipendenti della municipalità permettendo loro - tra l'altro - di digerire meglio la forte volontà politica di apertura democratica della gestione urbana, mostrata con l'avvio del Bilancio Partecipativo.

A partire da quello che fu denominato 'giorno da cani', in cui il numero di fornitori irati davanti a Comune costrinse la nuova Amministrazione a prendere atto dei debiti accumulati dai suoi predecessori di cui spesso neppure restavano registri a dare testimonianza (Cassel e Verle, 1994), la giunta Dutra si dedicò a tre obiettivi principali:

1) arginare la perdita delle capacità di finanziamento in proprio dell'Amministrazione pubblica, resasi consistente ed inesorabile a partire dagli anni '80. Era necessario poter addirittura invertirla di segno se si voleva intraprendere una politica di 'inversione delle priorità a favore dei più poveri', che certo - almeno all'inizio - avrebbe avuto difficoltà ad essere accettata dai settori benestanti della città e quindi a contare su altre forme di sostegno. ${ }^{18}$ 2) rendere partecipe la popolazione dell'irrazionalità delle passate gestioni politiche per meglio far comprendere le difficoltà del momento, attraverso una comunicazione capillare e semplificata in modo che potesse giungere a tutti gli strati della cittadinanza.

3) recuperare il livello di partecipazione del Comune alla produzione di reddito della città. ${ }^{19}$

Tali obiettivi vennero condensati in una proposta di Riforma Tributaria che, con le modifiche apportate dal Consiglio Comunale, elevò di circa il 25\% le entrate del Municipio. Essa mosse dal principio della giustizia tributaria, abolendo tutte le amnistie e le esenzioni che sempre avevano favorito i grandi debitori e gli speculatori immobiliari; la ISSQN [Imposta sui Sevizi di Qualsiasi Natura] fu adeguata al 5\% di molte altre città brasiliane e particolarmente pubblicizzata presso la cittadinanza fu la campagna "quem tem mais paga mais" ['chi più ha più paga' $]^{20}$ che portò all'approvazione della proporzionalità fra aliquote dell'IPTU (l'imposta sui beni immobili, che salì del 132\%) e redditi dei proprietari (Genro, 1997). ${ }^{22}$ Le misure passarono solo grazie a questa pressione della cittadinanza, ${ }^{23}$ visto che l'Amministrazione Popolare poteva contare teoricamente solo su 9 consiglieri su 33, mancando in Brasile un premio di maggioranza in Consiglio Comunale a favore della coalizione del sindaco eletto con voto diretto.

L'aumento delle entrate municipali durante l'Amministrazione Dutra (in termini reali dell' $82,64 \%$ durante il quadriennio di governo) permise di:

1) triplicare la capacità di intervento in proprio del Municipio (che sotto l'Amministrazione successiva arriverà - nel 1996 - al 51\%); ${ }^{24}$

2) impostare una politica di riaggiustamenti salariali bimestrali degli impie- 
gati dell'Amministrazione, attraverso una delicata ingegneria indispensabile per poter procedere ad una politica di cooptazione del ceto impiegatizio municipale (Horn, 1994) che iniziò di pari passo con una nuova organizzazione delle risorse umane $(\mathrm{RH})$, mirata ad una coerenza con le premesse filosofiche ed i principi politici alla base della nuova Amministrazione;

3) rifinanziare le 191 opere in attesa di realizzazione definite l'anno prima dalla popolazione come priorità del Bilancio Partecipativo; ${ }^{25}$

Questi eventi - di per sé e con la pubblicità che li circondò - ridettero entusiasmo alla popolazione facendo recuperare consensi e credibilità al Comune; ciò servì da stimolo per una ripresa massiva della partecipazione nel processo di discussione del bilancio. ${ }^{26}$

Parallelamente, veniva conclusa la promulgazione del nuovo Statuto Municipale (Legge Organica), che innescò un lento di processo di adattamento della legislazione comunale. Ancora per qualche anno, però, rimasero in vigore gli strumenti pianificatori e regolatori della gestione urbana già in uso all'epoca della riforma costituzionale del 1988; la barriera maggiore all'implementazione della nuova politica di gestione democratica configurata nello Statuto Comunale, anche per Porto Alegre rimase la resistenza al cambiamento di molti tecnici, radicati in una 'dottrina del fare $\mathrm{i}$ piani' saldamente costituitasi in quasi un secolo di pianificazione urbana come 'strumento convinto della capacità di una forte connotazione spaziale di modificare relazioni sociali' (Nygaard, 1993). Il potere di questo sapere tecnico, astratto bene culturale, ebbe a lungo ragione sulle richieste - continue e qualitativamente differenziate - delle comunità interessate; e continuò ad esercitarsi attraverso le categorie del conforme/difforme tramite cui il Plano Diretor del ' 79 di Porto Alegre ebbe spesso ragione di molte delle legittime aspirazioni di quei settori che aveva voluto riconoscere dando loro un ruolo nel Consiglio del Piano Regolatore. ${ }^{27}$

In questo momento, uno degli obiettivi principali dell'Amministrazione nell'ambito delle sue competenze - restò quello di attribuire maggior visibilità all'O.P. sia nella società che all'interno dell'Esecutivo, dandogli forza attraverso la creazione di un 'cordone ombelicale' diretto fra O.P. e Sindaco, supportato a sua volta dalla creazione del Coordinamento di Governo che riuniva intorno a lui il Vicesindaco, l'Assessore alle Finanze, l'Assessore all'Urbanistica, quello all'Amministrazione, il Capo di Gabinetto del Sindaco, 2 rappresentanti del GAPLAN e i Leader dei maggiori Partiti di Governo (cioè PT e PCB). Allo stesso tempo gli errori dell'anno prima "insegnarono [...] che le mete di bilancio dovevano essere realistiche, adeguandosi alle risorse disponibili nello stesso momento in cui si cercava di aumentare queste risorse. Il realismo si presentava addirittura come condizione perché la stessa decisione della popolazione potesse essere rispettata alla lettera (Augustin, 1994). $\mathrm{Nel}$ processo di elaborazione del bilancio del 1991, si realizzarono direttamente 2 turni di dibattito in 16 Regioni cittadine, in conseguenza di una riflessione che l'Amministrazione portò avanti con i rappresentanti popolari circa la creazione di una specifica struttura da dare al processo, a partire dall'ipotesi di una sua spazializzazione che usasse criteri socio-spaziali rispettosi dell'organizzazione territoriale dei movimenti sociali e comunitari di Porto Alegre. Per la prima volta venne anche introdotta una metodologia per la distribuzione delle risorse tra le Regioni cittadine appena identificate, 
220 che assegnava il $70 \%$ dei fondi d'investimento a 5 Regioni 'prioritarie' identificate in base a criteri oggettivi quali:

a) la maggior mobilitazione popolare nel Bilancio Partecipativo

b) la maggior carenza di infrastrutture e servizi

c) la maggior popolazione concentrata in 'aree di carenza massima'

Parallelamente, la Commissione di Rappresentanti fu sostituita da altri due organismi più definiti: il Consiglio del Bilancio e del Piano di Governo (attuale COP) e il Forum dei Delegati, che riuniva i rappresentanti popolari di ogni comunità eletti proporzionalmente alla partecipazione dei loro quartieri alle Assemblee Regionali.

Queste trasformazioni portarono ad elaborare un Piano degli Investimenti in cui la spesa di capitale rappresentava il $20,5 \%$ di quella totale. ${ }^{28}$ Come nell'anno precedente, le priorità fondamentali espresse dalla popolazione furono nel settore dell'urbanizzazione primaria e della pavimentazione. Con qualche ritardo tutte le opere previste furono realizzate, dimostrando il maggiore realismo del PI rispetto a quello 'da fiction' (Fedozzi, 1997, p. 135) del $1990,{ }^{29}$ e così stimolando notevolmente la partecipazione della cittadinanza ai processi futuri. ${ }^{30}$

Se le poche risorse disponibili erano state alla base di una stanchezza e di una sfiducia insinuatasi nei primi mesi del 1990 nei livelli di partecipazione al Bilancio Partecipativo, le realizzazioni 'visibili' (ed 'esibite') messe in cantiere già agli inizi del 1991, risollevarono in tempo - attraverso una sorta di 'effetto emulativo' - le sorti del processo partecipativo iniziato nel marzo del 1991 per discutere il bilancio del 1992. A scanso di equivoci, però, l’Amministrazione si prodigò anche in una campagna informativa per "chiarire alla comunità i limiti del Comune nella realizzazione degli investimenti, limiti questi - associati alle risorse finanziarie e alla capacità operativa realmente disponibile" (Augustin, 1994).

Nel complesso, Fedozzi (1997, p. 138) sottolinea che in questa 'seconda fase' della vita del Bilancio Partecipativo si realizzò un importante mutamento nel suo orientamento politico, giacché fu abbandonata l'idea del 'dualismo dei poteri' (che prevedeva una delega di poteri pubblici ai Consigli Popolari) per costruire dei canali più 'istituzionali' di partecipazione e co-decisione; ciononostante - come sancito nel '90 dal nuovo Statuto - i Consigli Popolari resteranno un'istanza regionale e autonoma riconosciuta, su cui parte del movimento popolare e settori dell'Esecutivo continueranno a riflettere a lungo, e di recente con forza particolare.

\subsection{La 'terza fase' del Bilancio Partecipativo: il consolidamento}

Le bandiere rosse del Partito dei Lavoratori portate in giro da migliaia di persone nelle strade di Porto Alegre, alla vigilia delle elezioni del 1992, più che un preannuncio di vittoria per il secondo mandato dell'Amministrazione Popolare, erano una dimostrazione di approvazione e di adesione alle proposte politiche di questo governo (Pozzobon, 1998)

Gli ultimi due anni di fine mandato dell'Amministrazione Dutra si caratterizzarono per una significativa crescita quantitativa del numero dei partecipanti agli allora tre turni di discussione del Bilancio Partecipativo, propiziata dal- 
l'aumento di 'credibilità' dell'Amministrazione reso possibile dalle celeri realizzazioni del 1991; in particolare crebbero i cittadini partecipanti a titolo personale, visto che le organizzazioni coinvolte del processo, che erano state 250 nel 1989, già dal 1990 si erano assestate a 467 e in seguito crebbero proporzionalmente meno (furono 503 nel 1991 e 572 nel 1992). Molti partecipanti al processo cominciarono ad impegnarsi anche in nuove assise di partecipazione popolare che andarono affiancando il Bilancio Partecipativo, come le Commissioni di controllo e accompagnamento delle opere, mirate a moltiplicare gli effetti benefici dell'OP cercando di rendere più trasparente il rapporto fra imprese e potere pubblico durante la realizzazione delle opere priorizzate dai cittadini, e ad incidere sulla qualità dei servizi prestati dai privati alla comunità, soprattutto nelle aree marginali della città.

Durante il corso del 1992 e del 1993, la struttura e la dinamica processuale del Bilancio Partecipativo andarono facendosi più nitide, in particolare per quanto concerne la distribuzione di risorse ed investimenti sulle diverse zone della città. Venne, infatti, a galla lo scontento delle 11 Regioni cittadine penalizzate dai grandi investimenti compiuti nel 1991 nelle '5 Regioni prioritarie', ed il $\mathrm{COP}^{31}$ propose al Comune di sostituire il criterio della 'concentrazione degli investimenti in aree di carenza massima' con quello della 'distribuzione delle risorse per settore di investimento', ampliando il ricorso ai 'criteri obiettivi' a tutte le Regioni. La nuova metodologia eliminò però due dei criteri forieri di forte penalizzazione di alcune Regioni tradizionalmente abbandonate (importanza della Regione per lo sviluppo urbano, ${ }^{32} \mathrm{e}$ mobilitazione popolare della Regione). ${ }^{33}$ Per distribuire le risorse sul territorio, si cercò quindi di eliminare i rischi di 'soggettivismo implicito' dei criteri adottati (Fedozzi, 1997, p. 140), concentrandosi piuttosto su temi nodali che tenevano conto sia di aspetti 'oggettivi' di carattere 'universalizzante' e 'impersonale' (ibidem) che della volontà politica espressa dalle varie comunità:

a) priorità di investimento scelta dalla Regione

b) popolazione totale della Regione

c) carenza di servizio o infrastruttura (confermato)

d) popolazione residente in aree carenti (confermato).

Nello stesso periodo il Bilancio Partecipativo - precedentemente disertato dai tecnici di molti Assessorati - crebbe di importanza dentro lo stesso Esecutivo attraverso un'opera di formazione, informazione e cooptazione interna, ed il riconoscimento formale del ruolo centrale del COP come istanza di mediazione privilegiata tra abitanti e istituzioni, e come sintesi dell'intero processo partecipativo attivato. Come sottolinea Fedozzi (1997, p. 142) questa progressiva legittimazione del Bilancio Partecipativo nelle stanze della politica locale non diminuì il suo 'carattere conflittuale', intrinseco in quanto luogo di incontro tra interessi molteplici, e spazio di 'disputa' di risorse limitate a disposizione della città; esso continuò inoltre a porsi come elemento di contesa tra la Giunta e il Potere Legislativo Municipale (Consiglio Comunale), che si sentiva defraudato di parte del suo ruolo decisionale.

In questo periodo, attraverso un Progetto di Legge di Iniziativa Popolare presentato nel Consiglio Comunale, il COP cercò di garantirsi una regolamentazione legale che ancora non possedeva, ma la raccolta di firme del 5\% degli elettori del comune non arrivò a concludersi positivamente, anche a motivo dei forti dibattiti sulla 'legalizzazione del processo' che si 
222 sviluppavano nel frattempo dentro il movimento popolare e i partiti della coalizione di governo locale. Nel periodo successivo, infatti, l'Esecutivo mutò posizione rispetto alla 'formalizzazione' e 'regolamentazione legale' del Bilancio Partecipativo, ritirando il suo appoggio al Progetto di Legge Popola$\mathrm{re}^{34}$ che si fermò alla raccolta di 12.000 firme sulle 42.000 richieste, dato che il Movimento Popolare non seppe difendere da solo la posizione difforme di molti sue membri.

I risultati del primo quadriennio di lavoro dell'Amministrazione Popolare sono oggi visibili, sia nella contabilità del Municipio, che nella realtà fisica della città. ${ }^{35}$ Nei 4 anni della Giunta Dutra vi fu una tendenza sostanziale alla crescita degli investimenti sul totale delle spese affrontate dal Comune, in parallelo alla riduzione dei costi di gestione ordinaria e del personale (figg. 40-42).

\subsection{La 'quarta fase' del Bilancio Partecipativo: modifica e ampliamento del processo}

Tra il 1993 e il 1995, alcune modifiche sostanziali nella struttura e nella dinamica dell'O.P. introdussero nuove complessità nel suo funzionamento, ampliandone ed arricchendone obiettivi, esiti e possibilità di attrarre nuovi settori della cittadinanza alla discussione sulle scelte per il territorio di Porto Alegre.

Le sfide principali che la prima Amministrazione Popolare (1989-1992) era stata chiamata ad affrontare - accanto alle riforme 'apripista' intese ad aumentare la partecipazione popolare nell'assunzione di decisioni sugli investimenti pubblici - erano state principalmente quelle di natura economica e amministrativa, anche per dimostrare che l'aumento delle istanze di partecipazione popolare non significava uno scarico di responsabilità da parte dell'Amministrazione, fermamente intenzionata, anzi, a mostrare alla cittadinanza il desiderio di far fronte agli obblighi assunti attraverso uno svolgimento efficiente ed efficace dei suoi compiti. Con queste premesse, il PT capolista alle nuove elezioni di una coalizione che includeva il Partito Progressista Sociale, il Partito Socialista Brasiliano, quello Comunista e quello Verde - riuscì a porre fine ad una tradizione di alternanza che datava dagli anni '40 (dalla fine cioè del lungo 'regno' del PRR), e a far eleggere sindaco al secondo turno l'avvocato Tarso Genro - ex vicesindaco della passata gestione - con il $54,8 \%$ dei voti.

Quanto il 1 gennaio del 1993 entrò in carica l'Amministrazione Genro, l'O.P. a Porto Alegre già andava caratterizzandosi come un nuovo fatto 'politico' di primaria importanza, strutturatore di una nuova relazione delle istituzioni con le comunità degli abitanti, che andavano comprendendo come 'valesse la pena prender parte all'O.P.' e come 'qualcosa di nuovo' nel modo di governare la città stesse effettivamente accadendo (Genro, 1997). Il crearsi di un nuovo 'immaginario sociale' - veicolato anche attraverso un programma Tv curato da uno speciale dipartimento municipale ${ }^{36}$ e le informazioni 'porta a porta' sul Bilancio Partecipativo di cui si incaricavano congiuntamente Comune e Movimento Popolare - contribuì a conferire rapidamente alla neoeletta amministrazione 'quell'identità propria che il sindaco voleva darle, ma senza rompere con la continuità del progetto democratico e popolare' (Pozzobon, 1998). ${ }^{37}$

Fattore centrale di distinzione del quadriennio Genro (1993-96) fu l'importanza strategica assunta dall'impegno sul tema della comunicazione, 
volta a disseminare l'informazione per rendere palesi e giudicabili da tutti in modo semplice gli atti dell'Esecutivo Municipale, e al contempo a mettere a confronto progetti diversi sulla città che mirassero a creare una nuova cultura politica attraverso la trasformazione del modo di guardare alla città come 'un tutto' $\mathrm{e}$ 'per tutti' ${ }^{38}$

La 'costruzione d'immagine' dell' Amministrazione Popolare contribuì a garantire un'interazione fra i diversi settori della municipalità e della stessa coalizione evitando personalizzazioni e puntando soprattutto su esperienze $e$ vissuto della popolazione partecipante ai diversi livelli ed istanze del dialogo con il Comune. L'idea primaria - ancor oggi in vigore - fu quella di far sì che 'la popolazione si percepisse come protagonista' del governo urbano, attraverso la scelta della chiarezza (spesso quasi maggiore nell'esposizione che nelle stesse decisioni strategiche assunte) e della totale trasparenza degli atti governativi, ma anche l'uso di mezzi di comunicazione nuovi per cui vi era stata finora una certa resistenza (Internet e la televisione soprattutto). Nel periodo di governo Genro le spese per la comunicazione e la pubblicità salirono un poco (oscillando fra lo $0,5 \%$ e l' $1 \%$ delle risorse comunali) raggiungendo nel 1996 i 2,7 milioni di R \$ inclusi i bandi di concorso ufficiali. Nonostante gli eventi di rilievo che caratterizzarono il periodo (incluso il vertice Habitat II di Istanbul, dove l'esperienza del Bilancio Partecipativo fu riconosciuta dall'ONU tra le prime 40 'Best Practices' del pianeta) il Comune non poté andare oltre questo livello di spesa, anche per lo stretto controllo esercitato dal Tribunale dei Conti dello Stato (che arrivò addirittura a compiere visite settimanali alla CCS, cfr. Pozzobon 1998) e dal Consiglio Comunale, che annualmente presentò e fece passare emendamenti delle Leggi di Bilancio municipale proprio relativi alla voce 'comunicazione', nel timore che essa si trasformasse in una forma di pubblicità gratuita per la coalizione al governo. Alcuni di questi ostacoli sono stati aggirati parzialmente attraverso l'apertura di un esauriente sito Internet del Comune, e la creazione di una Consiglio Municipale di Comunicazione che non solo è intervenuto nel processo di concessione di radio comunitarie e di consulenza per la moltiplicazione dei giornali di quartiere (che hanno teso poi a proliferare a Porto Alegre come alternativa all'informazione data dalla grande stampa ostile all'operato del Fronte Popolare) ma ha anche preso parte all'elaborazione della legislazione nazionale sulle Tv via cavo, costruita a partire da un Forum Nazionale per la Democrazia della Comunicazione fatto di professionisti, ONG e organizzazioni comunitarie tra cui Porto Alegre costituisce finora l'unico Comune rappresentato. In questo quadro, fu rafforzato il ruolo di uno dei componenti di rilievo dell'organizzazione del Bilancio Partecipativo, il Coordinamento delle Relazioni con la Comunità; ed in particolare fu potenziato il ruolo dei CROP, i Coordinatori Regionali dell'OP, costituiti nel 1991 e a cui Delegati, Consiglieri e comunità delle singole Regioni fanno a tutt'oggi riferimento quale interfaccia dell'Istituzione nell'organizzazione dei processi di discussione pubblica del bilancio.

Queste trasformazioni risultarono premessa necessaria per poter applicare anche al Bilancio Partecipativo il principio della trasformazione nella continuità che assunse la forma delle cosiddette Assemblee Tematiche, create nel 1994 dopo un complesso processo di studio della struttura già operante portato avanti già da oltre un anno dall'equipe Nuñez sui banchi del PT dell'As- 
semblea Legislativa Statale e consolidato con l'istituzione di un Coordinamento Comunale per la critica e la riforma del meccanismo (Brunet, 1999i, apud Allegretti 2000a). Tra i principali limiti rilevati nello svolgersi dell'OP, vi erano prioritariamente:

1) Il fatto che - dopo la cosiddetta 'inversione delle priorità' - la partecipazione apparisse limitata al pubblico costituito da quelli fino ad allora considerati 'esclusi', che peraltro avevano reso possibile, con il loro massiccio interessamento, la legittimazione del processo.

2) Il fatto che - conseguentemente - la discussione tendesse a concentrarsi su alcune specifiche tematiche relative alla città costruita, in primis quelle sull'estensione delle reti infrastrutturali urbane primarie e sull'asfaltatura delle strade nelle aree informali.

3) Il fatto che molte attribuzioni finissero così per restare al di fuori del controllo attento esercitato dalla popolazione sull'operato dell'Amministrazione La riforma, profondamente caldeggiata dal sindaco Genro - autore di vari testi di commento a questo indispensabile salto di qualità (1994, 1997) vide il dibattito incentrarsi su tre binari principali che ne costituirono l'ossatura portante (Brunet, 1999i):

a) La creazione per la popolazione partecipante di una possibilità di controllare nuove questioni relative alla vita e alla gestione urbana, al di fuori dei soli investimenti diretti (che rappresentavano una quota ridotta del totale del bilancio comunale), ${ }^{39}$ già ben controllati;

b) L'approfondimento di singole questioni tematiche, attraverso la costruzione di istanze che ampliassero il contatto tra tecnici e cittadini;

c) L'incentivo all'ampliamento della base di partecipazione del BP, con la cooptazione di nuove componenti della società, ed in particolare con lo sfruttamento del potenziale vivo costituito dai settori già organizzati su basi di differenti interessi o alchimie sia spaziali che tematiche.

$\grave{E}$ in questo contesto che nel 1994 furono istituite le Assemblee Tematiche, andate ad affiancare quelle Regionali dove la natura delle discussioni aveva più una portata di tipo 'areale', svolgendosi su una base organizzativa di tipo geografico.

La riforma del 1994 puntò a coinvolgere in modo organico nuovi settori comunitari, a partire da un pubblico già organizzato, ed iniziando dalla città formale, che in quegli anni aveva espresso il maggior disinteresse per il processo di OP:

Il primo e più disponibile interlocutore che rispondeva a questi requisiti apparve il Sindacato [...]. Per questo ci si concentrò contemporaneamente sui leader sindacali di medici, operai metallurgici, bancari, percorrendo oltre 40 Sindacati per sapere per quali ragioni essi finora avevano disertato la discussione dell'Orçamento Participativo. La risposta-tipo che emerse era 'non sapevamo che fosse nostro compito partecipare'. Ma ve ne fu anche un' altra molto importante per dare uno stimolo costruttivo e un'indicazione di percorso: la differenza della base organizzativa che non era di tipo areale ma tematico (Brunet, 1999i, in Allegretti, 2000a).

La base organizzativa scelta per il nuovo forum che venne prendendo forma fu quindi non più areale, ma tematica. L'idea era che la popolazione partecipante suggerisse all'Amministrazione linee di azione anche in campi non direttamente oggetto di decisioni dell'OP, discutendo di progetti e opere strutturali sulla base di forme di pianificazione democratica anche di taglio 
pluriennale (U. De Souza, 2002); si cercò così di superare il rischio di appiattire il Bilancio Partecipativo su logiche 'immediatiste' non solo in relazione al fattore spazio, ma anche al fattore tempo, discutendo di progetti di ampio respiro da realizzarsi per tappe su tempi medio-lunghi.

I temi intorno a cui strutturare le nuove Assemblee Tematiche (da svolgersi in parallelo a quelle Regionali, con l'elezione di Delegati e Consiglieri secondo criteri simili a ciò che avveniva in quelle) vennero inizialmente selezionati fra quelli che fino ad allora erano rimasti al di fuori degli ambiti di discussione indicati come prioritari dall'OP: 5 furono così le scelte, ${ }^{40}$ notificate ai Sindacati per coinvolgerli attivamente nella predisposizione del nuovo meccanismo partecipati vo cittadino, dando loro nelle Assemblee Tematiche un ruolo equipollente a quello che le Associazioni di Quartiere (AMs) svolgevano nelle Regionali, e per di più affidando loro il compito di monitorare inizialmente tutto il percorso. ${ }^{41}$

In questo cammino creativo l'Amministrazione mirò a ciò che vedeva, ed ottenne ciò che non vedeva (Brunet, 1999i). Infatti, il Comune di Porto Alegre si trovò quasi per caso a scoprire un tessuto ricchissimo di raggruppamenti, anteriori all'entrata in uso della definizione di ONG, da tempo esistenti e operanti in città: una fitta trama di movimenti urbani esterni a quelli formatisi su base 'di prossimità geografica' e ancora non direttamente coinvolti in una discussione aperta a livello cittadino. Da questi l'Amministrazione cercò - con ruolo maieutico mirato ad invertire il principio di frammentazione che le caratterizzava - di tirare fuori proposte costruttive nello stesso modo in cui, per la costruzione delle Assemblee Regionali, aveva attinto alle elaborazioni della UAMPA e dei gruppi di Associazioni di Quartiere, certo meno segmentate e già capaci di raggrupparsi in piramidi o strutture organizzative orizzontali che usassero l'unità d'intenti come forza contrattuale nei confronti del potere pubblico. In tal modo, fu possibile oltrepassare il 'nitido carattere corporativo' (Fedozzi, 199, p. 143) che la proposta originaria delle Assemblee Tematiche possedeva, centrandosi troppo sulla rappresentanza organica dei Sindacati.

Il documento che proponeva la creazione delle Assemblee tematiche fu formalizzato il 25 marzo del 1994, con l'appoggio di 40 dei 130 sindacati cittadini e di molte ONG (Andreatta, 1997). Parallelamente, furono anche introdotte alcune modifiche nella dinamica di elezione dei rappresentanti popolari del Bilancio Partecipativo. Ad esempio

1) alcune organizzazioni (UAMPA e SIMPA) acquistarono 1 Consigliere fisso nel COP;

2) il Forum di Bilancio dei Delegati (una plenaria di Delegati che non aveva avuto un ruolo attivo chiaro) fu sostituita da Forum Regionali e Tematici dei Delegati;

3) l'elezione dei Delegati fu scissa in due momenti: una parte fu eletta nelle Assemblee del Primo Turno, e una nelle Assemblee cosiddette 'Intermedie', ${ }^{42}$ ovvero svolte nei quartieri e nelle comunità tra i due turni di Assemblee Plenarie dell'OP.

I dati rilevati durante 'l'anno di prova', al contrario di quanto si può pensare, non furono ritenuti sconfortanti, sia perché nel corso dell'anno mostrarono una crescita complessiva di interesse per l'iniziativa (l'aumento dei partecipanti nel secondo turno assembleare superò il $40 \%$, senza contare le oltre 30 
assemblee intermedie realizzate e non monitorate nella partecipazione), ${ }^{43}$ sia perché l'aumento di partecipazione si ebbe nonostante che proprio la presenza dei Sindacati fosse calata dal 18,1 all'11,5\% nel corso dell'anno. Il calo dei cittadini non vincolati ad organizzazioni, fu attribuito al sentirsi 'spersi' o in soggezione davanti ad un dibattito fra nuclei già organizzati, e con un alto grado di esigenza critica (Andreatta, 1997).

Il monitoraggio del primo anno di sperimentazione permise di individuare nuove strategie di cooptazione, cosicché già dal secondo anno (che discusse il bilancio per il 1996) le organizzazioni della società civile organizzata presenti nelle nuove Assemblee Tematiche del Bilancio Partecipativo aumentarono notevolmente la loro presenza, adottando una postura critica e combattiva mirata a costruire uno spazio che divenisse meno omologatore alle posizioni del governo e più indipendente (id.). Già da metà del primo anno, esse ottennero che la struttura delle discussioni fosse resa più fluida formando nove sottogruppi per approfondire le discussioni cominciate nella prima tornata assembleare. Se i partiti diminuirono leggermente la loro presenza nel tempo ed i movimenti comunitari crebbero ma senza alterare percentualmente la loro presenza sul totale dei partecipanti, sorprese giunsero dagli impresari (cresciuti dal 4 al 14,3\%) e dalle organizzazioni soprattutto para-governative, riflettendo con chiarezza l'ingresso degli interessi localizzati (Andreatta, $1997)^{44}$ nel plenum delle discussioni del Bilancio Partecipativo.

L'importanza dei suggerimenti e delle correzioni di tiro che i dati del monitoraggio sulle Tematiche resero possibili, offrì lo spunto per realizzare a partire dal '95 - un monitoraggio attento per la costruzione di un 'profilo storico' della partecipazione da estendersi all'intero Bilancio Partecipativo, che fornisse al Comune elementi oggettivi di analisi e interpretazione dei fenomeni partecipativi (Andreatta, 1997); esso è stato portato avanti biennalmente sotto il coordinamento della ONG portoalegrense CIDADE, impegnata fin dagli inizi a seguire ed esaminare lo svolgimento del processo. Seppur mancò la predisposizione di 'un metodo di pianificazione che rendesse possibile compatibilizzare l'incrociarsi delle due dinamiche operative $^{, 45}$ (quella originata dalle Plenarie Tematiche e quella delle Regionali), è indubbio che un'integrazione tra di esse si verificò quasi spontaneamente:

Uno de gli aspetti più interessanti della creazione delle Assemblee Tematiche fu che gettò nuova luce sulle aggregazioni Regionali dell'Orçamento Participativo, aiutandoci ad estrapolare dalle domande locali dei 'temi', e accettando di includere alcune singole Regioni nel dibattito tematico proprio in virtù della forza che specifici temi svolgevano nell'aggregare le domande dei diversi quartieri al loro interno. E allo stesso tempo, attraverso i movimenti interessati alle politiche sociali che cominciavano a mostrare una concezione della città come un tutto, si è attivato un percorso inverso di 'fertilizzazione' (come la chiamava l'allora vicesindaco e [poi] sindaco Raul Pont) nelle Regioni. Le attività pioniere per la captazione sono state quelle della Cultura e dello Sport, dove i gruppi tendevano ad autopresentarsi. Ma chi si è mostrato attivo in questo processo fu per primo e soprattutto il potere pubblico, che ha compiuto questo sforzo di illuminazione del dibattito con forza inventiva quasi superiore a quella mostrata quando fu attivato l'O.P. nel 1989 (Brunet, 1999i, apud Alle gretti, 2002a).

Nel loro complesso, le Assemblee Tematiche si costituirono come uno spazio più 'fluido' delle Regionali, marcate invece da un complesso sistema di 
definizione e gerarchizzazione delle priorità, che sbocca nella definizione delle priorità generali per la città. Le Tematiche non possede vano e ancora non possiedono criteri orientatori del loro lavoro nella discussione delle direttrici (Pozzobon, 1998) e per questo - spesso - non vanno oltre la costruzione di una lista di necessità dei diversi settori coinvolti in queste plenarie, non riuscendo sempre a propiziare una discussione matura delle politiche pubbliche. Eppure, oggi che - proprio grazie alle Tematiche - assessorati come la SMIC riescono ad organizzare la propria 'clientela' in modo più efficace e a canalizzare costruttivamente le pressioni che ricevono dal basso, si può ben riconoscere come l'intervento del potere pubblico sia risultato decisivo in questa fase per quel 'salto di qualità' che caratterizzò il quadriennio dell' Amministrazione Genro, la quale poté da subito giovarsi delle sperimentazioni e delle critiche condotte nel corso della gestione Dutra per caratterizzare l'O.P. come strumento ormai maturo per radicarsi nell'intera città e contraddistinguerne l'immagine stessa ed il messaggio che voleva diffondere al di fuori.

Questo, avvenne tanto più nella misura in cui nel quadriennio 1992-96 furono affiancati all'O.P. molteplici ulteriori canali di partecipazione, come i Consigli Municipali Settoriali (ad es. quello di Accesso alla Terra e all'Abitazione che delibera sulla politica dell'alloggio); questi, pur causando spesso delle sovrapposizioni tra loro e con il lavoro dei rappresentanti eletti nel Bilancio Partecipativo e soprattutto nelle Assemblee Tematiche, sono stati - infatti - ulteriori strumenti di disseminazione del dibattito e di crescita della democrazia a livello cittadino.

Altro punto d'impegno dell'Amministrazione Genro fu la creazione (già nel 1993) del Forum chiamato Cidade Constituinte, a cui vennero invitati a partecipare ulteriori settori della società fino ad allora rimasti estranei al progetto di O.P.: ad esempio l'Università, le imprese ed entità sindacali, professionali e di categoria, oltre alle Associazioni Comunitarie e ai semplici cittadini. Tra workshop, laboratori, convegni, lezioni e seminari (tenuti anche da professionisti esterni) e i due Congressi della Città realizzati nel 1993 e nel 1995, quasi 5000 persone presero parte a questo nuovo processo partecipativo nei suoi 4 anni di vita. Il suo principale obiettivo restò quello di offrire indirizzi alla pianificazione cittadina a medio e lungo termine, di includere la pianificazione partecipata nel rispetto delle territorialità specifiche e dei loro abitanti e di lottare contro la segregazione urbana articolando la città come un polo tecnologico di saperi sparsi sul territorio (Baierle, 1998). Il suo principale risultato fu certo il contributo offerto alla costruzione dell'immagine della città ideale vagheggiata per Porto Alegre dalla sintesi dei desideri dei suoi cittadini (Pozzobon, 1998); il plenum del $\mathrm{I}^{\circ}$ Congresso cittadino ne delineò le direttrici principali nella gestione democratica, decentralizzata, attraente, competitiva e culturalmente ricca e diversificata, mettendo l'accento sulla necessità che Porto Alegre promuovesse al meglio l'integrazione sociale, la qualità della vita e dell'ambiente, le relazioni di partenariato tra pubblico e privato, l'autofinanziamento e i rapporti di integrazione con gli altri centri dell'Area Metropolitana. Inoltre, dal processo denominato Cidade Constituinte emersero le linee guida per la costruzione di due fondamentali strumenti di gestione territoriale: il Piano Regolatore di Sviluppo Urbano e Ambientale [PDDUA] e il Piano di Sviluppo Economico [PDE]. 
228 Per poter meglio rispondere a quanto elaborato all'interno dei diversi processi di partecipazione attivati, l'Amministrazione Genro dovette portare avanti lo sforzo di riformulazione tributaria permanente iniziato nel 1989. All'uopo, fu creata l'Unità Finanziaria Municipal [UFM], incaricata di correggere costantemente il valore delle imposte ${ }^{46}$ mentre il parallelo rafforzamento dei sistemi di controllo incrociato fece sì che l'inadempienza nel pagamento delle imposte sugli immobili, che nel 1993 era del 19\%, cadesse sotto il 15\% già nel 1995, quando la restituzione dei debiti attivi presentò una crescita reale di oltre il 50\% comparato con l'anno precedente (PMPA/GAPLAN, 1996). L'approvazione in Consiglio Comunale di una Legge che istituiva l'IPTU Progressivo nel Tempo permise al Comune di interferire direttamente nel processo speculativo attribuendo funzione sociale ai vuoti urbani (Cfr. cap. 11). ${ }^{47}$ La notevole crescita delle entrate autonome del Municipio durante il quadriennio Genro si tradusse in un riequilibrio finanziario interno che fu basilare per la buona riuscita dei programmi dell'Amministrazione, per la sua indipendenza di azione da fonti di finanziamento vincolanti ${ }^{48}$ e per l'accesso ad ulteriori finanziamenti esterni - concessi solo a municipi finanziariamente sanati (Pozzobon, 1998) - per la realizzazione di opere di grande entità come la $3^{\circ}$ Circonvallazione cittadina (finanziata dal BID) e i miglioramenti del corridoio Nord/Nordest mirati a decongestionare i flussi del trasporto pubblico (fondi BNDES).

Proprio mentre lo Stato e l'Unione lavoravano sulla formula dei tagli al personale (ad esempio con il Programma di Dimissioni Volontarie), il Comune di Porto Alegre si caratterizzò in questi anni per un aumento del personale (soprattutto nei settori del monitoraggio finanziario e territoriale, e in quelli della salute e dell'educazione $)^{49}$ e per il mantenimento della politica salariale di aggiustamenti bimestrali già codificata con Legge 6611/90 e 6855/91. ${ }^{50}$ Se le spese di personale restarono del $40 \%$ al di sotto del tetto posto dal Consiglio Comunale fu anche grazie al risanamento finanziario del Municipio e all'aumento delle entrate. In questi anni, la politica delle risorse umane si impose con negoziati chiari e trasparenti su quella che aveva caratterizzato il difficile quadriennio Dutra (in cui l'Esecutivo aveva dovuto però affrontare i problemi maggiori). La filosofia adottata - in controcorrente nel Paese - fu che 'il Servizio pubblico dovesse essere rinforzato e non dequalificato' (Pozzobon, 1998) anche per valorizzare scelte ed investimenti fatti nel passato. Una democratizzazione delle relazioni di lavoro il Sindaco Genro (avvocato del lavoro) la perseguì anche propiziando la creazione della Commissione Tripartita che funzionerà da quel momento all'interno del COP del Bilancio Partecipativo, unendo rappresentanti dei Sindacati e della popolazione con il compito di deliberare sulla contrattazione di personale nuovo o temporaneo all'interno del Comune di Porto Alegre.

\subsection{La 'quinta fase' del Bilancio Partecipativo: dal consolidamento all'autocritica}

Questa fase - non contemplata da Fedozzi (1997) perché non ancora visibile nella sua autonomia quando egli scriveva - è cominciata, all'incirca, a seguito delle elezioni municipali dell'inverno del 1996, quando il Fronte Popolare, guidato dai candidato scelti nelle 'primarie' del PT (l'ex-vicesindaco Raul 
Pont e José Fortunati) trionfò al primo turno elettorale, riscuotendo una vasta approvazione da parte della cittadinanza.

La nuova Giunta - che fra gennaio e maggio 1999 ha dovuto far fronte alla perdita di molti collaboratori dovuta alla vittoria elettorale del PT a livello Statale $^{51}$ - ha proseguito in una linea di netta continuità con le due precedenti, pur caratterizzandosi individualmente per alcune novità, di cui le principali sono state:

1) l'elaborazione nell'O.P. - per la prima volta - non solo del Piano di Investimento annuale, ma anche del Piano Pluriennale 1997/2000: quello per del 1993 era stato, infatti, presentato dal Governo e semplicemente valutato dal COP. La discussione, svoltasi tra l'8 marzo e il 17 aprile 1997 ha portato 185 emendamenti (1'80\% dei quali accolti) alla proposta dell'Esecutivo, delineando un'ulteriore estensione del processo di pianificazione partecipata;

2) l'adozione del nuovo Piano Regolatore di Sviluppo Urbano e Ambientale, la cui elaborazione 'aperta' era cominciata nel 1993 con il processo Cidade Constituinte;

3 ) la realizzazione di nuovi Congressi della Città per delineare collettivamente le nuove linee generali di sviluppo per le politiche urbane degli anni a venire;

4) la creazione del Sistema Municipale di Istruzione di Porto Alegre (1998) che ha dato origine alla Pianificazione e al Bilancio Partecipativo nella scuola;

5) il potenziamento di nuovi canali di partecipazione, che ha visto l'elevazione del numero dei Consigli Municipali settoriali ${ }^{52}$ e l'apertura di dibattiti sui prestiti bancari;

6) l'interesse per il monitoraggio dei processi partecipativi e soprattutto dell'OP (quest'ultimo portato avanti nel 1998 e nel 2000 dall'ONG CIDADE) ${ }^{53}$ unito a quello per l'analisi e la divulgazione di dati ed indicatori relativi allo sviluppo della città, come le varie Relazioni sugli Indicatori Sociali di Porto Alegre in via di progressivo arricchimento nelle voci come nelle tipologie degli indici utilizzati.

L'Amministrazione Pont ha proseguito con impegno nella linea di 'risanamento finanziario' del Comune,${ }^{54}$ mostratasi indispensabile nel momento difficile che ha dovuto affrontare alla fine del 1998, quando l'Unione ha tagliato oltre 30,19 milioni di $\mathrm{R} \$$ di finanziamenti destinati alla città. ${ }^{55} \mathrm{Ha}$ poi portato avanti il progetto di 'proiezione all'esterno' della città iniziata dalla giunta Genro, specie per quanto attiene al ruolo giocato all'interno della Comunità del Mercosul. Così Porto Alegre, tra le fondatrici nel 1995 della Rete Mercocidades che riunisce 92 dei maggiori centri urbani dei Paesi del Cono Sud dell'America Latina, ${ }^{56}$ ha preso parte sempre più attivamente agli scambi economici e culturali permanenti mirati a difendere gli interessi del potere locale nel Mercosul (Porto Alegre socioeconômica, 1998). Fino al settembre del 1997 Porto Alegre è stata - tra l'altro - la sede della SegreteriaEsecutiva della Rete Mercocidades, e ad essa si deve la creazione di una rete di 'Incubatrici occupazionali' nei Paesi dell'area, ed il lancio del premio 'Scienza e Tecnologia' che proprio l'anno successivo sarà poi vinto da Porto Alegre. ${ }^{57}$ Numerosi sono stati gli eventi organizzati dalla nuova Amministrazione in ambito internazionale (specie nel settore ambientale); fra questi il $I^{\circ}$ Colloquio Latino-Americano sullo Sviluppo Metropolitano e la Sostenibilità in collaborazione con l'UNESCO e la FLACAN (settembre 1998), il Seminario Internazionale sull'Ambiente del maggio 1999, legato alla presentazione di un 
completissimo Atlante Ambientale della città, e il Seminario Internazionale sulla Democrazia Partecipativa della World Bank (novembre 1999).

Particolare è stato l'impegno profuso sui temi ambientali in vari settori delle politiche cittadine, dalla continuazione del programma di disinquinamento del Lago Guaiba vive (con la riapertura alla balneabilità della spiaggia cittadina del Lami) alla realizzazione dell' Aterro Sanitario dell'Extrema (considerato fra $\mathrm{i}$ depositi di rifiuti più moderni del Brasile), dal programma di pulizia del fiume Diluvio finanziato dalla banca FONPLATA alla ricostruzione di molte equipe di educazione ambientale all'interno di Assessorati e Autarchie municipali.

L'Amministrazione Pont ha lanciato, inoltre, nel 1997 - in collaborazione con la Società di Ingegneria ed altre entità professionali e culturali - il Programma di Rivitalizzazione dell'Area Centrale, a partire dal 'recupero visuale' di tutte le attrezzature e gli edifici storici della città: il primo recupero 'simbolico' è stato quello del Mercato Centrale ottocentesco.

Ovviamente, tutte queste proposte hanno dovuto passare al vaglio delle Assemblee del Bilancio Partecipativo, che ha mostrato notevole crescita qualitativa nell'individuare, comprendere e sostenere alcune misure 'globali' di intervento, indispensabili da finanziare a vantaggio dell'intera città, pur a detrimento della disponibilità di risorse per singole Regioni o comunità. Sotto il profilo dell'articolazione e della dinamica del ciclo e dei criteri distributivi delle risorse, il processo di Bilancio Partecipativo non ha registrato nel periodo di governo Pont - trasformazioni significative, fatti salvi il perfezionamento delle procedure di informatizzazione delle richieste popolari, e il dettagliamento nel Regolamento Interno dei 'criteri tecnici' adottati dai vari Assessorati Comunali per il vaglio delle priorità indicate dai cittadini. Nel 1997 sono saliti a 8 i temi in base a cui gerarchizzare le priorità regionali $^{58}$ e si è avuta una modifica dei criteri generali (pesi, voti e fasce) in base a cui distribuire le risorse comunali alle Regioni; ${ }^{59}$ nel 1998, invece, nel Regolamento Interno è stato inserito l'obbligo di prevedere la garanzia di interpreti della Lingua Brasiliana dei Segni (Libras) ad ogni incontro del Bilancio Partecipativo dove sia richiesta. ${ }^{60}$ Dal 2000 il COP ha anche semplificato l'elezione dei Delegati, riducendo a proporzionalità secca (1:10) le fasce di proporzionalità tra abitanti e Delegati prima vigenti, e più volte modificate negli ultimi anni. Inoltre nel Regolamento Interno è stata inclusa la voce: Opere Istituzionali che richiedono risorse di bilancio interne o finanziamento di organi nazionali o internazionali. Da questo momento esse dovranno essere discusse con la comunità prima di ricevere concessioni comunali.

Fino al 2001, peraltro , il ciclo annuale della discussione sul Bilancio (fig. 24) è rimasto articolato in due tornate di Assemblee Plenarie (Tematiche e Regionali) intervallate da una tornata 'intermedia' (di cui non sono mai stati raccolti ufficialmente $\mathrm{i}$ dati sulle presenze), registrando una sostanziale crescita dei partecipanti al dibattito, seppur con un vistoso calo di presenze nella seconda tornata assembleare, quella incaricata essenzialmente della consegna al Sindaco delle priorità di investimento elaborate dai cittadini.

Un significativo percorso di trasformazione della struttura del Bilancio Partecipativo si è semmai avviato nel 2001, quando è entrata in carica la nuova Amministrazione Popolare, guidata per la seconda volta da Tarso Genro e dal vice João Verle (quest'ultimo è poi divenuto sindaco l'8 aprile 2002 in 
seguito alle dimissioni di Genro, necessarie per poter concorrere alla carica di Governatore dello Stato). Il nuovo 'tandem' è stato eletto il 29 ottobre 2000, al secondo turno, con il 59,62\% dei voti, ${ }^{61}$ e tra suoi primi impegni vi è stato quello di porre mano ad una ricognizione critica 'costruttiva' del Bilancio Partecipativo, in grado di evidenziarne esiti positivi e limiti emersi negli ultimi anni di rodaggio dopo il cambiamento strutturale del 1994.

A tale scopo è stata istituito - in seno all'Amministrazione - un Grupo de Trabalho de Modernização do Orçamento Participativo che il 18 aprile 2001 ha prodotto un interessante documento dal titolo 'Rompendo i nostri limiti', ed ha aperto il dibattito sul Bilancio Partecipativo come 'percorso storico perfettibile' a tutti i ricercatori (locali, brasiliani e stranieri) che lo hanno studiato in questi ultimi anni. In quest'ottica, è stato organizzato il seminario "O Orçamento Participativo visto pelos seus investigadores", tenutosi dal 31 maggio al 2 giugno 2001.

Tra i principali 'punti di strangolamento' ${ }^{\prime 62}$ rilevati dal processo di esame critico del Bilancio Partecipativo vi erano, soprattutto, le necessità di:

1) stemperare l'eccessiva visibilità assunta dall'OP in rapporto alle altre istanze partecipative cittadine (Consigli Municipali, Congressi della Città, Forum, Conferenze di Settore, Consigli di Gestione, Consigli Scolastici, Bilancio Partecipativo della Scuola, ecc.) che richiedono una strategia reticolare complessiva di trattamento affinché i conflitti di competenze attuali si traducano in reciproche fertilizzazioni positive;

2) ripensare per il futuro la divisione regionale, nella misura in cui i criteri per la distribuzione dei fondi non bastano a colmare lo 'scarto di equità' dovuto alla presenza di Regioni piccole le cui carenze principali sono già soddisfatte (es: Cristal) e altre grandi segnate da enormi carenze;

3) dare il giusto peso alla ricchezza delle discussioni 'intermedie' che si svolgono nei quartieri e nelle singole comunità ma sono ignorate persino dai grafici di rilevamento delle presenze;

4) controbilanciare la preminenza finora avuta dal Movimento Comunitario nel coinvolgere gli abitanti nel Bilancio Partecipativo, impegnandosi per coinvolgere nel processo nuovi abitanti che possano legittimarlo ancor di più $\mathrm{e}$ arginare le critiche sulla sua 'scarsa rappresentatività';

5) garantire 'un saldo organizzativo' che semplifichi il ciclo annuale del processo e riduca un poco gli obblighi di partecipazione del cittadino, per lasciare spazio anche ad altri processi partecipativi paralleli e complementari, magari di taglio tematico (ad esempio: Plenarie dei Giovani o altre dirette a gruppi specifici di cittadini);

6) qualificare maggiormente la formazione dei cittadini sui temi trattati dal processo (sia dal punto di vista tematico che del metodo pedagogico usato) valorizzando le esperienze ancora frammentarie già provate nei settori ambientale e dei diritti umani;

7) valorizzare i Forum di Delegati in quanto 'spazi di formazione della cittadinanza';

qualificare il lavoro di discussione dentro le Regioni anche ponendo maggior attenzione alla micro-regionalizzazione;

8) rafforzare il senso dell'OP come veicolo di una "cultura della solidarietà", riducendo i rischi di competizione e scontro per le risorse che tendono a crearsi al suo interno, e i "patti di convivenza" a carattere corporativo che si realizzano tra leader popolari all'interno dei Forum di Delegati e rischiano di 
232 bloccare l'entrata nel processo di nuovi gruppi locali;

9) formalizzare e valorizzare i Regolamenti Interni delle singole Regioni e Tematiche, come strumento di arricchimento del dibattito sulle risorse e sull'equità della loro distribuzione;

10) ridurre i rischi di un dibattito 'iniziatico' attraverso un attento lavoro sui linguaggi, perché essi si depurino di sigle e assiomi senza sacrificare i contenuti alla propria 'popolarizzazione';

11) chiarire meglio i rapporti tra COP e Amministrazione (ognuno dei quali è per l'altro 'fuoco di richieste e grande fornitore di dati') per diminuire furbizie, procedure di emergenza e la sostanziale ignoranza del reciproco funzionamento, che porta spesso nell'O.P. temi non di competenza municipale;

12) chiarire meglio i ruoli delle istituzioni e delle organizzazioni della società civile, perché nei momenti di dibattito e/o conflitto non si ingenerino confusioni, specie da parte degli agenti politici originari dei movimenti (CROPs, consulenti di comunità, assessori, ecc.);

13) diminuire la centralità del Comune nell'organizzazione dell'OP e nella proposta di temi, ritmi e regole della sua conduzione; ${ }^{63}$

14) dibattere il ruolo delle organizzazioni autonome della società civile per contrastare lo 'svuotamento' subito da molte a causa della centralità e della pervasività assunta dall' $\mathrm{OP}$;

15) rapportare le questioni discusse nell'OP a temi di portata globale con cui si intrecciano, per evitare di restringere il dibattito dentro le singole Regioni o comunità, seguendo il solco tracciato dall'introduzione delle Assemblee Tematiche e dei Forum di Pianificazione (cfr. cap. 15);

16) articolare meglio i dibattiti con quelli del $\mathrm{BP} /$ statale per evitare sovrapposizioni e duplicazioni che stancano i cittadini;

17) universalizzare e arricchire di più i dibattiti di temi legati alle difficoltà o ai desideri di categorie specifiche di cittadini (disabili, anziani, giovani, minoranze razziali o sessuali) e soprattutto di prendere in carico la sottorappresentazione delle donne nelle istanze rappresentative (Forum di Delegati e COP);

18) semplificare e ridurre le regole complesse di funzionamento del BP, che oggi occupano oltre 60 pagine del Regolamento Interno e rischiano di divenire strumento di 'discriminazione' a vantaggio della 'riproduzione personale' di chi ha più tempo, esperienza del processo e/o cultura per studiarle ed imparare a farne buon uso;

19) pensare ad una soppressione di quei momenti del ciclo (come il Secondo Turno di Assemblee Plenarie) che appaiono stanchi, 'svuotati' ed ormai 'innecessari';

20) prendere in considerazione nuovi mezzi di comunicazione (come Internet) che potrebbero ampliare l'impatto dell'OP sul complesso della cittadinanza; 21) organizzare (come già sottolineato nel Congresso della Città del 2000) una Conferenza Municipale sulla Democrazia e la Gestione dello Stato, perché cittadini e amministrazione riflettano insieme su come riorganizzare la struttura municipale per renderla una 'contropartita' migliore nel rispondere alle sfide poste dallo sviluppasi delle istanze di controllo e decisione popolare.

A questo insieme di 'nodi di senso' del Bilancio Partecipativo, l'Amministrazione Genro ha tentato di rispondere già a metà del 2001, suggerendo ai cittadini di sperimentare alcune trasformazioni del processo di Bilancio Par- 
tecipativo che costituissero un volano per poi affrontare gradualmente nel tempo anche le altre questioni emergenti.

Le modifiche suggerite nella dinamica dell'OP sono state fatte proprie ed approvate dal COP il 29 gennaio 2002, e hanno iniziato ad essere sperimentate nel corso della discussione del bilancio per il 2003. Già nel corso del 2001, però, la discussione del bilancio per il 2002 si era aperta ai navigatori di Internet, prendendo atto della possibilità di mettere le nuove tecnologie " $a$ servizio non dell'alienazione individualista o degli ingranaggi mercantili, ma dell'innalzamento del valore della scena pubblica come il luogo per eccellenza dell'incontro di idee distinte e della democrazia come metodo per incontrare soluzioni giuste per i problemi sociali" (Genro, in PI 2002). Non si permettono 'deliberazioni' fuori dalle sedi dove l'incontro tra i cittadini e con le istituzioni avviene 'faccia a faccia', ma si possono inviare suggerimenti e proposte ai vari Forum di Delegati perché ne tengano conto nella priorizzazione delle opere delle loro Regioni.

Inoltre, il processo di Bilancio Partecipativo (congiuntamente ai 25 Consigli e ai 5 Forum Municipali di settore) del 2001 ha discusso 'a latere' anche le direttrici e gli obiettivi del Piano Pluriennale 2002-2005 - inviato il 30 settembre 2001 al Consiglio Comunale - proponendo 951 emendamenti rispetto alla proposta-base della Giunta, molti dei quali accolti.

Le ulteriori trasformazioni introdotte nel Regolamento Interno del Bilancio Partecipativo per il 2003 hanno dato al processo il funzionamento descritto nel capitolo 7. Esse riguardano essenzialmente 3 questioni principali:

a) la semplificazione del ciclo annuale (con la soppressione del secondo turno di Plenarie, la valorizzazione delle Assemblee di quartiere e comunità, la costituzione di Assemblee Preparatorie per presentare in pubblico la rendicontazione dell'anno precedente e stabilire un coordinamento con l'OP Statale; l'Assemblea Unica Municipale di luglio)

b) l'elezione dei Delegati (condensata durante le assemblee di quartiere e di comunità, anche se il numero viene deciso nelle Assemblee Plenarie del cosiddetto 'Turno Unico')

c) il riavvicinamento del processo di BP alla 'base popolare' attraverso la costruzione di una maggiore 'centralità' per i Forum dei Delegati Regionali e Tematici, chiamati ad esprimere proposte sulla distribuzione delle risorse e a controllare maggiormente il lavoro del COP.

Nel gennaio/febbraio 2001 e 2002, la realizzazione dei due Forum Sociali Mondiali è stata occasione di presentare e discutere limiti e conquiste del Bilancio Partecipativo insieme ad un pubblico internazionale attento e interessato. Rispetto alla dinamica del processo, questo fatto è servito a mettere l'accento sulla necessità di "sintonizzarlo con i dibattiti che vanno ponendo all'ordine del giorno la lotta all'esclusione sociale", ${ }^{64}$ in un quadro internazionale dove "l'economia concentratrice di reddito genera sempre più esclusione" (Genro, in PI, 2002).

\section{Note}

${ }_{1}^{1}$ L'appoggio del PSDB arrivò solo in un secondo tempo.

${ }^{2}$ In una intervista su Teoria e Debate del 1992 (N. 17), Dutra dichiarerà: "Prima stavamo fuori da questa casa, gridando e denunciando. Ma in realtà, non avevamo la conoscen- 
za interna di essa. E la macchina pubblica ha una storia, ha una cultura e inoltre non si orienta per decreto. Essere governo, controllare la macchina [...] non sono cose che si possano realizzare a priori. É qualcosa che si costruisce, che si perfeziona nel corso del processo".

${ }^{3}$ Dutra parlò di un Municipio 'pantagruelico' che prosciugava tutte le risorse che produceva (Andreatta, 1997).

${ }^{4}$ All'interno del PT erano rappresentate tre tendenze principali: quella 'Democratica Socialista' di Raul Pont (eletto sindaco nel 1996), quella detta 'Articulação' di Dutra, e quella detta 'Nova Esquerda' di Tarso Genro. Per una più precisa trattazione delle tesi diverse delle tre correnti nel Congresso cfr. Mene gat (1995).

${ }^{5}$ Fedozzi (1997) distingue quattro fasi essenziali nei primi 8 anni del Bilancio Partecipativo, in base all'evoluzione di 3 criteri tecnico-politici di pianificazione partecipativa: le modifiche nella struttura di funzionamento dell'OP, quelle nella metodologia di distribuzione dei fondi trale Regioni e le variazioni del livello di partecipazione attiva ai vari stadi dell'interazione politica (p. 132)

${ }^{6}$ Va ricordato che il PT è formazione politica socialdemocratica sempre proclamatasi avversa al centralismo della sinistra tradizionale, specialmente dei Partiti Comunisti. Nel centro di questa critica stava il carattere centralizzatore e burocratico del modello, che obiettivamente impediva la libera partecipazione dei lavoratori nella determinazione dei destini dello Stato (Augustin, 1994). In tal senso [...] $i$ contributi universali dell'Orçamento Participativo proiettano i segni dell'utopia che vogliamo conquistare e il modo della democrazia che vogliamo costruire in ogni ambito e istanza del potere (U. De Souza, 1997).

${ }^{7}$ Le microregioni erano: nella ex-Regione 1: Microrregião das Flores, Centro e Navegantes. Nella ex-Regione 2: Zona Norte, Nordeste, Eixo da Baltazar. Nella exRegione 3: Grande Cruzeiro, Grande Gloria e Cristal. Nella ex-Regione 4: Grande Partenon, Lomba do Pinheiro, Zona Leste. Nella ex-Regione 5: Zona Sul, Restinga/ Belém Novo/Lami e Centro-Sul.

${ }^{8}$ Alla fine del processo, il quadro d'insieme che metteva al primo posto 1) la fornitura di dotazioni sanitarie di base, poi 2) la pavimentazione delle aree più disagiate e a seguire 3) la regolarizzazione fondiaria, poi la sanità, l'educazione, l'apertura di strade, l'illuminazione pubblica e per ultimo il trasporto pubblico già interessato parallelamente da un'opera radicale di riforma.

${ }^{9}$ Ad esempio, furono tolti il $70 \%$ dei fondi destinati al nuovo Archivio Comunale e al recupero del Mercato Pubblico, per stornarli sulla costruzione di $42 \mathrm{~km}$ di strade pubbliche in aree povere; $i$ fondi per la palestra Tesourinha furono spostati su 2 scuole comunali per 500 nuovi alunni, e i fondi per la cura dei parchi Marinha do Brasil e Moinhos de Vento (localizzati in aree di valorizzazione immobiliare) furono ritoccati per costruire 32 nuove piazze sportive in periferia (cfr. Porto Alegre Agora $\mathrm{n}^{\circ} 6$ del 6/11/1989).

${ }^{10}$ Cfr. Fedozzi, 2000 (p. 61).

${ }^{11}$ Cfr. Fedozzi, 2000 (p. 62).

${ }^{12}$ Lima (1993b); all'epoca era consigliere dell'Assessore all'Urbanistica

${ }^{13}$ Per Matus, nella pianificazione normativa/tecnocratica obiettivi, attività e risorse sono definiti sovrapponendo regole economico-amministrative sulla realtà, mentre nella pianificazione strategica i soggetti pianificatori stanno dentro la realtà e riconoscono la progettazione 'politica' come sistema che precede la realtà e (cfr. anche Lima, 1993a). ${ }_{14}$ Tra esse, l'estinzione di alcune strutture (come l'EPATUR, l'Impresa di Turismo da aggregarsi alla SMIC, la FESC, il DEP da integrare nel DMAE), la fusione di altre (come l'Assessorato all'Ambiente, il Dip. di Pulizia Urbana e il nuovo DMAE), la trasformazione della SPM in Assessorato alla Pianificazione Urbana a cui legare il Dipartimento alla Casa, la centralizzazione di tutti i progetti sparsi nell'EPO (Ufficio di Progetti e Opere da crearsi nella SMOV) e la sottrazione al controllo diretto del Gabinetto del Sindaco della compagnia di bus pubblici (CARRIS) e del sistema di elaborazione dati (PROCEMPA). Il seminario fu marcato da accesissime polemiche che coinvolsero persino aspetti secondari come la proposta di un 'Comune Mobile' per il servizio ambulante al pubblico e la decisione di piccole opere.

${ }^{15}$ Sorta di organismo 'strategico' il cui scopo era facilitare la comprensione dei criteri e delle linee permanenti di sviluppo a cui il Plano Diretor del 1979 avrebbe dovuto adeguare le sue scelte.

${ }_{16}^{16}$ Esso compreneva il Piano dei Lavori per l'esercizio del 1990 e il Piano Pluriennale del Governo (1990/92) sottomesso al Consiglio Comunale nel settembre 1989. 
${ }^{17}$ Ad esempio, nel 1989 fu ridotto del $26 \%$ il consumo di benzina del parco macchine municipale e del $36 \%$ l'affitto di auto, furono ridotti del $20 \%$ gli stipendi di sindaco e assessori, vennero licenziati tutti i funzionari-fantasma, e garantita la concorrenza fra fornitori di beni e servizi all'Amministrazione assicurando i tempi massimi di pagamento degli stessi (PMPA, 1990).

${ }^{18}$ L'IPTU (l'imposta sugli immobili e i terreni) aveva rappresentato la maggior fonte di entrate per l'Amministrazione negli anni '70, ma nel biennio 1989-90 passò a rappresentare meno del 25\% del valore medio del decennio precedente; nel 1992 - a seguito della Riforma Tributario - risalì al 70\% circa (Verle e Müzell, 1994).

${ }^{19}$ Il termine 'renda da cidade' in questo caso è traducibile come Prodotto Interno Cittadino, ovvero Reddito Cittadino, in analogia al Prodotto Interno Lordo degli Stati. Questo rapporto è perciò vicino alla definizione di 'Coefficiente di spesa pubblica' anche se si limita all'ambito Comunale - sia della produzione che della spesa - e prende considerazione - invece che il bilancio comunale - solo le entrate, cioè non tiene conto della parte del bilancio coperto dal debito pubblico (cfr. UNDP (1996), Lo Sviluppo Umano). L'obiettivo minimo della Riforma era far sì che le entrate annuali dell'Amministrazione, cadute nel 1985 al 3,2\% del valore della produzione cittadina, tornassero almeno al $5,04 \%$ del 1970. In realtà, l'obiettivo fu superato dai risultati ottenuti, visto che nel 1990 si raggiunse il livello percentuale di 4,98\% e a fine mandato di Dutra - nel 1992 le entrate del Comune passarono a rappresentare il 5,95\% della produzione cittadina, superando anche il livello raggiunto in periodo di dittatura (Verle e Müzell, 1994).

20 Simili proposte riproponevano analoghi provvedimenti già presi sotto l'Amministrazione Rocha negli anni '20 e Brizola nel '50.

${ }^{21}$ Cfr. Andreatta, 1997.

${ }^{22}$ Fino ad allora le aliquote IPTU degli immobili residenziali erano appena due: $0,85 \%$ per pochi immobili e 1,2\% per tutti gli altri. Furono introdotte aliquote progressive da $0,2 \%$ a $1,2 \%$, e da $0,6 \%$ a $1,4 \%$ per gli immobili non residenziali (prima gravati da un'aliquota unica dell'1,2\%). Si adottarono anche aliquote progressive sul valore di mercato dei beni immobili, per beneficiare i proprietari dei terreni meno valorizzati. In un'inchiesta del 1996 l'Assessorato alle Finanze, con un'indagine sui giornali cittadini, rilevò che vi era ancora uno sfasamento del $62,28 \%$ fra i valori assunti a base di calcolo dell'IPTU e i valori di mercato (Pozzobon, 1998).

${ }^{23}$ Durante tutto il processo di approvazione dei 14 (su 15) progetti di Legge di natura tributaria proposti dall'Amministrazione, rappresentanti agguerriti della popolazione si presentarono davanti al Consiglio Comunale per fare pressioni sui propri eletti in modo da approvare gli aumenti delle tasse sui rifiuti e sui beni immobili, che dovevano portare Porto Alegre al livello delle altre capitali brasiliane e sostituire i pagamenti a parcelle fisse con rate mensili più facilmente adattabili alle nuove esigenze nel tempo.

${ }^{24}$ Cfr. Genro (1997).

25 Tutto questo lavoro - poteva scrivere l'omai ex-sindaco Dutra nel 1994 - non fu vano, e ci inorgoglisce molto averlo realizzato in condizioni avverse e in un momento storico in cui la società coltivava un profondo discredito per la politica ed i politici in generale. Mostrare, nella pratica, che la politica può essere condotta con una salutare combinazione di trasparenza, probità amministrativa e partecipazione popolare. Crediamo di aver raggiunto questo obiettivo e che oggi la popolazione sappia cosa significa il 'modo petista [del PT, ndt] di governare' (Dutra, 1994).

${ }^{26}$ Addirittura, nella attivissima Zona Nord, il Consiglio Popolare riuscì all'inizio del 1991 a far partecipare i rappresentanti di tutte le comunità con un'operazione capillare di convincimento 'porta a porta' (Menegat, 1995).

${ }^{27} \mathrm{Al}$ consolidamento di questa illusoria dottrina del "discorso competente" (Chauí, 1981) contribuirono nel tempo vari fattori: il taglio autoritario - al contempo progressista e conservatore (Pesavento, 1990) - dell'apparato politico-ideologico positivista, l'influenza del Movimento moderno penetrato a São Paulo nel 1922 nella Settimana dell'Arte Moderna, il miraggio dell'oggettività delle metodologie pianificatorie che rifiutavano ogni giudizio di valore.

${ }^{28}$ Nella realtà essa si dovrà poi limitare a rappresentare una percentuale del $17,51 \%$.

${ }^{29}$ Quello si era mostrato troppo ambizioso, visto che prevedeva spese di capitale per un totale del $13,9 \%$ della spesa totale, mentre non si raggiunse 1'11,2\%. Due miliardi di Crz $\$$ era la cifra che si prevedeva coperta da fondi propri, di cui il $38,63 \%$ per opere di urbanizzazione primaria (fogne e acqua) e 10,9\% per opere di pavimentazione. Alla fine, 
dei $42 \mathrm{~km}$ di pavimentazione comunitaria prevista neppure uno fu portato a termine in quell'anno (Augustin, 1994).

${ }^{30}$ Come osservò un rappresentante della regione 'dos Alpes': Quando la gente vide le macchine, trovò la fede (Augustin, 1994).

${ }^{31}$ In realtà il nome COP è in vigore solo dal 1999; prima aveva un nome più complesso, pur con funzioni analoghe.

${ }^{32}$ Oltre che vago, questo principio dava adito a scelte discrezionali da parte dell'Amministrazione, visto che i voti erano attribuiti dai tecnici del Comune.

${ }^{33}$ Soprattutto quest'ultimo - rifletterono vari Consiglieri - stimolava forme di 'inchaço', ovvero gruppi di pressione che si organizzavano artificialmente per essere presenti in massa alle assemblee dove si valutava la presenza di ogni area, in modo da ottenere - sic e simpliciter - più fondi, disinteressandosi poi del resto del processo.

${ }^{34}$ L'unico membro della Giunta che si dichiarò favorevole alla regolarizzazione fu la CRC, che risultò isolata in un Seminario di Governo realizzato nel 1994 (Fedozzi, 1997, nota 109). 35590 furono le opere da finanziarsi (con 72,43 miliardi di CRz\$) previste nel bilancio per il 1992, di cui 185 nuove opere. Nel PI relativo al 1993 furono, invece, previste 490 azioni tra cui 200 nuove opere (per un investimento di 553 miliardi di Crz $\$$ di cui $46 \%$ dedicato a reti idriche e fognarie, $20,2 \%$ per pavimentazione e $9,1 \%$ per Regolarizzazione Fondiaria). Il PI per il 1994, invece, previde una spesa di 4,8 trilioni di CRz\$ da spendersi prioritariamente in opere di Regolarizzazione Fondiaria, urbanizzazione primaria e pavimentazione. Nel quadriennio Dutra risultarono oltre $150 \mathrm{i} \mathrm{Km}$ di strade asfaltate dopo averle dotate di reti idriche, fognarie e di scolo pluviale (Augustin, 1994). ${ }^{36}$ Già dal 1990, il Coordinamento di Comunicazione Sociale [CSS] aveva assunto quasi uno 'status' di Assessorato (Pozzobon, 1998).

${ }^{37}$ Non per nulla, proprio nel suo ultimo mandato (2001-2002) Genro ha mostrato di aver molto a cuore 1" 'Archivio della Memoria', cioè il riordino e la raccolta dell'archivio ideale composto da tutti i documenti, i manifesti, gli opuscoli informativi al pubblico prodotti in questi anni di Amministrazione Popolare, progetto affidato a Cassia Coutinho, del Coordinamento di Comunicazione Sociale (cfr. Genro, 2001i).

${ }^{38}$ Cfr. Genro, $2001 \mathrm{i}$.

${ }^{39}$ Secondo il Comune l'ordine è dal 15\% al 25\% (Prefeitura de Porto Alegre, 1997); in realtà nei primi 3 anni la cifra è stata di molto inferiore a questo minimo, e solo dopo è riuscita ad avvicinarsi al $23 \%$.

${ }^{40}$ Trasporto e Circolazione; Educazione, Cultura e Tempo Libero; Sanità e Assistenza Sociale; Sviluppo Economico e Politica Tributaria; Organizzazione della Città e Sviluppo Urbano (sottotemi: Ambiente e Risanamento; Urbanistica e Casa).

41 "Io, che entrai in questo momento nel processo, ho avuto la percezione della forza che certi gruppi avevano più di altri. Ad esempio i Sindacati dei Professori e i gruppi legati alle Cooperative di Abitazione in creazione in molti sindacati come organismi 'trasversali," (Brunet, 1999i).

${ }^{42}$ Il nome è stato ufficialmente stabilito nel 1997 (Cfr. Dossier di CIDADE, 2001).

${ }^{43}$ Ciò a dispetto del calo di presenze nelle Assemblee su Circolazione e Trasporti, e Salute e Assistenza Sociale.

${ }^{44}$ In particolare, destò interesse la partecipazione fra gli impresari (categoria in cui era ancora ben lungi dal partecipare la rappresentanza di imprese edili o di gruppi economici forti) di 129 fieranti, artigiani, concessionari di spazi nel Mercato Pubblico e soprattutto di rappresentanti di cooperative agricole, raccoglitori di rifiuti e ambulanti (i cosiddetti 'camelôs'); mentre fra i partecipanti del settore 'organizzazioni governative e non' grande parte fu rappresentata da persone legate alle nascenti Cooperative di Abitazione (dati CRC).

${ }^{45}$ Cfr. Fedozzi, 1997 (p. 144).

${ }^{46}$ Solo tra il 1994 ed il 1995 si passò da 20.000 a 44.000 nuove registrazioni di immobili per il pagamento dell'IPTU, e nel 1995 ben il 56\% dei proprietari scelse la nuova formula di pagamento immediato (PMPA/GAPLAN, 1996).

${ }^{47} \mathrm{Nel}$ primo anno di esistenza del provvedimento, furono individuati 120 beni immobili da sottoporre al provvedimento, per un totale di 301 ettari, il 59\% dei quali in mano ad appena 6 proprietari (PMPA/GAPLAN, 1996).

${ }_{48}$ Per quanto attiene ai fondi di provenienza IPTU, che nel 1988 erano l'equivalente 19,08 milioni di R\$, nel 1995 raggiunsero i 50,7 milioni con una crescita del $156 \%$; l'ISSQN passò, invece, da 48,5 milioni a 85 , con una crescita \% del $75 \%$. La tassa sui rifiuti passò da 6,5 a 17,4 milioni con un aumento del $167 \%$. E mentre il valore corrente 
delle entrate del Comune passò da 167 milioni di R\$ del 1988 a 404 milioni del 1995 con un salto del $142 \%$, le entrate autonome dello stesso ebbero un salto del $110 \%$, da 76,4 milioni del 1989 a 160,7 del 1995 (PMPA/GAPLAN, 1996).

${ }^{49}$ Nel solo settore della salute, i Funzionari con scolarità superiore passarono dai 754 del 1992 ai 783 del 1993, agli 880 del 1994, fino a raggiungere quota 974 nel 1995 (Fonte, annuario statistico 1996).

${ }^{50}$ Una leggera alterazione le due leggi la subirono nel 1994, in occasione del cambio della moneta nazionale.

${ }^{51}$ Un corposo 'rimpasto' è riuscito a porre rimedio al 'fermo temporaneo' imposto al proseguimento di molte politiche municipali, ma notevoli rallentamenti si sono avuti nei tempi di realizzazione di molti impegni presi.

${ }_{52}$ Per l'elenco dei Consigli Municipali, cfr. appendice 3.

${ }_{53}^{53}$ Cfr Quem è o publico do Orçamento Participativo, edizioni 1999 e 2001.

${ }^{54}$ Secondo i dati della SMF, già tra il 1997 e il 1998, le entrate proprie del municipio sono salite gradualmente: l'IPTU è passato da 68,6 a 70,5 milioni di R\$ (nel 1996 era 67,5); l'ISSQN da 120,5 a 127, 2 milioni di R (nel 1996 era 110,5); l'ITBI da 37,2 a 38,9 milioni di R \$ (nel 1996 era 30,9), e la tassa sui rifiuti da 26,5 a 29,0 milioni di R $\$$.

55 11,96 dei fondi PRO-MORADIA e 18,23 dei fondi PRO-SANEAMENTO (Cfr. Porto Alegre agora, dic. 1998).

5629 di queste città sono ancora 'membri richiedenti'mentre 63 sono 'membri a pieno titolo' di questa Rete, mirata a rafforzare il ruolo delle amministrazioni locali come "controparte naturale' del processo di integrazione regionale sudamericano, iniziato negli anni ' 90.

${ }^{57} \mathrm{Il}$ premio è attribuito a equipe di ricerca applicata i cui studi hanno contribuito in modo effettivo a risolvere un problema urbano; nel caso di Porto Alegre è stata una ricerca che ha portato alla creazione di un 'Sistema ibrido di simulazione sulla propagazione degli inquinanti nelle falde superficiali di rifornimento idrico della città'.

${ }^{58}$ Essi diventeranno 13 nel 2001 e ora sono 14.

${ }^{59}$ Carenza del servizio o infrastruttura (peso 4 e 5 voti possibili), popolazione totale della regione (peso 2 e 4 voti possibili) e priorità tematica della regione (peso 4 e 5 voti possibili). Nel 2000 ci sarà un'ulteriore modifica dei criteri generali: carenza del servizio o infrastruttura (peso 4 e 4 voti); priorità della regione (peso 5 e 4 voti).

${ }^{60} \mathrm{Il}$ 'Braille' per i non vedenti sarà introdotto nello svolgimento delle Plenarie dal 2001. ${ }^{61} \mathrm{Al}$ primo turno, Genro (appoggiato dal PT, dal PCB, dal PSB e dal PcdoB) ha raccolto il $48,72 \%$ dei voti.

${ }^{62}$ Cfr. Rompendo nossos limites (2001).

${ }^{63} \mathrm{Si}$ suggerisce in tal senso di guardare al primo anno dell'esperienza di Bilancio Partecipativo Statale, tutto centrato sul ruolo organizzativo dei movimenti popolari (a causa di un provvedimento giudiziario cautelativo che inibiva il Govemo Statale ad investire risorse pubbliche nell'organizzazione).

${ }^{64}$ José Valdir, nel PI 2002, p. 7. 



\section{9: la città ad un bivio - conquiste e difficoltà dell'OP: oltre la mera co-gestione del bilancio}

\subsection{Alcune domande}

Nello scenario politico instabile dell'America Latina, e all'interno della tradizione pianificatoria tecno-burocratica e centralizzatrice che l'ha complessivamente caratterizzata, non c'è dubbio che l'esperienza di Porto Alegre si sia posta come un faro per chi si preoccupa di invertire queste prassi consolidate e restituire "la cosa pubblica alla discussione pubblica" (Baierle, 1996). e "la Polis alla sua vocazione originale di luogo della politica per eccellen$z a$ " (Alfonsin e Allegretti, 2003).

La formale proclamazione della Repubblica in Brasile il 15/11/1989 (dopo 4 anni dall'inizio di quella che fu ufficiosamente definita come 'Nuova Repubblica') non ha portato certo ad una 'repubblica di cittadini' (Baierle, 1998); anzi, per certi versi ha procrastinato -attraverso la logica liberista - l'esclusione delle classi subalterne dal mondo formale della politica, "attraverso un fenomeno di carnevalizzazione e logiche ruffiane e furbesche che nell'immaginario collettivo hanno determinato la convinzione che il cosiddetto spazio pubblico fosse meno pubblico del quartiere, del mercato, della chiesa o del bar, e costituisse invece lo spazio dei colti e dei privilegiati" (ibidem).

Così, se 'taverna' e 'politica' sono rimasti nell'immaginario di molti i due termini di riferimento per significare lo spazio dell'incontro pubblico (il primo) e dell'appropriazione privata (il secondo), parlare di 'religione delle taverne' è un modo per simboleggiare quell'irrazionalità presente nel costituirsi degli spazi urbani brasiliani che ne ha segnato alcuni dei caratteri fondamentali, facendo coincidere ciò che altrove è tradizionalmente letto come 'pubblico' come lo spazio dei soprusi o come 'terra di nessuno' per l'appropriazione individuale.

L'indebolimento di significato subito dalla vita pubblica nei periodi di dittatura ha aggravato questo fenomeno (peraltro comune a gran parte dell'America Latina) direzionando l'attenzione dei cittadini verso lo spazio della vita quotidiana in quanto spazio di de-politicizzazione ma - allo stesso tempo - di potenziale ri-politicizzazione fondata sull'emergere di nuove pratiche sociali a partire dall'interpretazione collettiva degli avvenimenti politici vissuti. 
240 Il tessuto associativo brasiliano - fragile e frammentato - è storicamente cresciuto in una tradizione di clientelismo e autoritarismo decisionale che veicolava, da un lato, la nozione di specializzazione della politica e dall'altro l'idea che i meccanismi formali ed informali di pressione e lobbysmo fossero i più adatti ad ottenere risposte alle richieste della cittadinanza. ${ }^{1} \mathrm{Si}$ può pertanto comprendere come mai i processi partecipativi abbiano posseduto spesso una risonanza limitata sull'insieme della cittadinanza, sia in termini di transito di informazioni che di discussione di problemi e proposte. La maggiore o minore incisività degli stessi è dipesa in gran parte dalla disponibilità e dalla capacità delle entità e dei gruppi-guida di costruire e mantenere vincoli organici con le basi, ma anche dalle iniziative adottate dai singoli governi locali in termini di comunicazione e di procedimenti metodologici tesi a stimolare il coinvolgimento di settori sempre più ampi.

Esaminando il caso di Porto Alegre attraverso la lettura dei cambiamenti apportati alle politiche municipali da 14 anni di sviluppo del Bilancio Partecipativo, che tipo di disponibilità ha mostrato, dal 1989, la macchina politico-amministrativa per rinnovare le sue strutture dando corpo, forza decisionale, visibilità, effettività e - quindi - rappresentatività al suo obiettivo di 'democratizzare la gestione del territorio'? I procedimenti democratici di discussione ed assunzione delle decisioni che abbiamo finora descritto hanno contribuito ad un superamento dei tradizionali approcci autoritari, burocratici e clientelari? È stato condotto un lavoro abituale di socializzazione e apertura delle informazioni, sia in termini di produzione e di trasmissione in un linguaggio e attraverso mezzi accessibili alla maggior parte dei destinatari sia di adeguamento dei ritmi e delle dinamiche dei processi di formulazione e definizione di politiche e programmi a quelli partecipativi? La partecipazione dei cittadini - convogliata nei diversi canali strutturati in questi anni - è servita da strumento di mero appoggio e consenso nei confronti delle politiche 'ufficiali' e alla riproduzione della tradizionale cultura politica finora dominante in Brasile? $\mathrm{O}$ ha prodotto un plusvalore, configurandosi per le istituzioni e per gli abitanti come un mutuo 'apprendistato della democrazia', incidendo sul volto della città, sui modi, sulle procedure e sui contenuti della sua trasformazione? Ha prodotto un mutare dell'immaginario collettivo sulle possibilità di stabilire contatti proficui e permanenti tra cittadini e istituzioni, ricostruendo una fiducia reciproca?

Ormai decine di testi sono stati scritti per esaminare questi temi in rapporto alla messa in opera del Bilancio Partecipativo, letto come processo che ben risponde alla crisi di legittimità degli Stati contemporanei, incorporando la convinzione che i problemi dell'esclusione sociale e della concentrazione degli insediamenti umani nei centri urbani "non possono essere trattati solamente attraverso politiche compensatorie" ma richiedono l'attuazione di "politiche pubbliche che modifichino la distribuzione della rendita e del potere nelle città e negli stati, concretizzando forme di partecipazione diretta nelle gestioni pubbliche" (U. De Souza, 2002).

Ampliando la nostra lettura alle trasformazioni che questa sperimentazione ha innescato nei settori della politica degli alloggi e della pianificazione urbana, in direzione di una maggior condivisione delle scelte tra istituzioni ed abitanti, cercheremo - nel seguito - di suggerire alcune possibili risposte a queste domande, a partire da una rapida disamina delle conquiste del Bilancio Partecipativo, che fa esplicitamente tesoro delle molte ricerche di cui l'esperienza di Porto Alegre è stata oggetto in questi ultimi anni. 


\subsection{Il Bilancio Partecipativo come 'istituzione informale'}

Come era anche inevitabile [l'OP] inciampa nel Potere Giudiziario, che è il potere meglio strutturato del sistema. [...] Il Bilancio Partecipativo è una misura essenzialmente politica. Come arma elettorale funziona sempre, proibito o ammesso. E forse funziona di più da proibito (perché allora passa ad essere un sogno proibito) che non se permesso (quando soffre i guasti inevitabili della realtà). Ossia, sta già al di sopra della legge. Esso è molto somigliante al Movimento dei senza-Terra. L'MST non possiede una base legale, ma possiede una formidabile base morale (Jockymann, 1999).

Quando - nel 1989 - la neonata Amministrazione Popolare ha cominciato a riflettere su come dar forma strutturata all'intervento diretto dei cittadini nella costruzione delle politiche urbane, aveva la possibilità di scegliere fra due strade: la 'riforma' e la 'rottura' rispetto a quelle istanze spesso solo formali di apertura delle Istituzioni locali che abbiamo definito 'le scatole vuote della partecipazione' di Porto Alegre, prima della svolta del 1989.

A suo modo, il Bilancio Partecipativo queste strade le ha scelte entrambe, ponendosi in una 'continuità discontinua' con le precedenti istanze di partecipazione che avevano trovato posto - almeno formalmente - tra gli strumenti di Governo cittadino dell'ultimo trentennio e in maggiore continuità con le elaborazioni dei movimenti urbani. Creando l'OP, infatti, si è dato corpo ad uno strumento 'nuovo' (in tal senso di 'rottura visibile' rispetto alle istanze preesistenti) ma capace di restituire gradualmente 'forma' e 'senso' (cioè risemantizzare) quelle stesse istituzioni, senza distruggerle ma riformandole dall'interno. Fedozzi (2000) rivela che - nelle intenzioni di molti partecipanti alla riflessione condotta all'interno del Fronte Popolare a partire dal 1986 - il Bilancio Partecipativo doveva avere vita breve, servendo appena come appoggio temporaneo per la costruzione dell'utopia socialista. Presto, però, un percorso di realismo politico gli ha conferito 'permanenza' e caratteristiche proprie, rendendolo un 'progetto autonomo' per la gestione urbana, su cui concentrare energie ed interesse. Il meccanismo sviluppatosi a partire dal 1989 non ha preteso di costituire un progetto perfetto, ma - anzi - proprio per la coscienza dei propri limiti rispetta le consegne di stare "in costante trasformazione per rinnovarsi e adattarsi alla crescita stessa della coscienza della cittadinanza" ponendosi come "l'apertura di un cammino per democratizzare radicalmente la democrazia" e recuperare la credibilità dello Stato attraverso un'esperienza di livello locale, mostrando al contempo "che è possibile riformarlo radicalmente [...] collocandolo al servizio degli interessi popolari" attraverso la creazione di istituzioni nuove che permettano "che le decisioni sul futuro siano decisioni sempre compartite" (Genro, 2002). Questo - al contempo - rende conto del perché per il Bilancio Partecipativo si sia scelta una formula organizzativa 'aperta' e 'formalizzata solo in modo leggero' (incentrata sul Regolamento Intemo a cui abbiamo accennato nel cap. 7), ma anche del perché non abbia che potuto privilegiare una collocazione intermedia fra le forme di democrazia rappresentativa e partecipativa, mettendo in contatto due fuochi nodali del potere democratico: uno, originato dal voto; l'altro, originario di istituzioni dirette di partecipazione.

Nei suoi 14 anni di vita, il Bilancio Partecipativo non è stato mai ufficialmente proposto come alternativa alla democrazia rappresentativa come - in mala fede - gli è stato spesso rinfacciato dall'opposizione politica, e non solo 
242 in ambito municipale. Certo, è capitato che - specie all'inizio della prima Amministrazione Popolare - si siano verificati conflitti relativamente seri con il Consiglio Comunale di Porto Alegre; momenti in cui singoli militanti o gruppi politici - a fronte di un Potere Legislativo che diffidava apertamente del Bilancio Partecipativo presentandolo come mero 'spazio di manovra e meccanismo di legittimazione delle proposte dell'Esecutivo' - hanno predicato, in maniera piuttosto pericolosa, 'che il legislativo era "nemico" del popolo' (Alfonsin e Allegretti, 2003). E resta il fatto che ancora oggi la risoluzione dei rapporti dell'OP con le prerogative del Consiglio Comunale è tra le sfide che il processo ha il dovere di affrontare con continuità e in modo nuovo per crescere e migliorare la sua posizione di rilievo tra le principali politiche urbane. ${ }^{2}$

Ciononostante, il Bilancio Partecipativo non si è mai strutturalmente messo in 'competizione' con gli istituti della democrazia rappresentativa. Esso resta una struttura formalmente consultiva, che - certo - nella prassi di governo acquisisce una sostantività ed un peso quasi deliberativo, a motivo della forte legittimazione popolare che smuove, e del 'patto d'onore' verbalmente siglato dall' Amministrazione Popolare con i cittadini di Porto Alegre, che la impegna a rispettare e dare concretezza alle decisioni prese dagli abitanti all'interno del Bilancio Partecipativo come se esso fosse una riconosciuta istanza 'deliberante'. ${ }^{3}$ Formalmente, però, l'OP non usurpa spazi altrui, limitandosi ad agire in un ambito legittimo di spettanza dell'Esecutivo (aiutarlo a formulare una proposta dettagliata di bilancio da presentare in Consiglio Comunale). ${ }^{4} \mathrm{Se}-$ poi - esso concretamente incide sulle votazioni del bilancio realizzate dai Consiglieri Comunali è perché, nei fatti, l'attenzione ed il sostegno popolare che le sue indicazioni si portano dietro sono considerate 'pesanti' dai Consiglieri sotto il profilo politico, anche per l'abitudine che i rappresentanti popolari hanno di seguire i dibattiti del Consiglio con telecamere e registratori, al fine di 'tenere sotto controllo' i propri eletti, preannunciando ritorsioni in sede elettorale per chi cercherà di stravolgere quanto deciso dai cittadini nel corso del processo annuale di OP. Il fatto che - durante la discussione nel Legislativo - l'Orçamento Participativo possa concretamente funzionare da appoggio alle scelte di bilancio presentate dall'Esecutivo (ma solo perché queste hanno dato prova di rispettare sostanzialmente le decisioni alla fine siglate dal COP, non arrogandosi il diritto di introdurre scelte proprie non sottoscritte dai rappresentanti comunitari) deriva dal fatto che il Bilancio Partecipativo mette in gioco una nuova forma di 'etica politica' (Baierle, 1998). Non ha, cioè, potere coercitivo sulle scelte degli eletti - liberi di stravolgerne le linee in una sede in cui hanno il diritto di farlo - ma li pone di fronte alla necessità di assumersi le conseguenze politiche di scelte che sentono il dovere, l'urgenza o (al limite) anche solo la volontà di compiere in controcorrente rispetto alla volontà della parte di cittadinanza che è intervenuta nell'OP. Peraltro, la votazione del bilancio non dovrebbe costituire l'unica né la principale prerogativa del Consiglio Comunale, come ben mostrano di percepire ultimamente gli stessi cittadini di Porto Alegre $;{ }^{5}$ e ridurre lo scontro con l'Esecutivo a questo tema appare sminuente per il Legislativo stesso.

La prerogativa dell'Esecutivo di proporre a suo piacere modi diversi (ed interlocutori differenti dai tradizionali 'attori forti' delle negoziazioni) per la discussione del bilancio, raramente è stata pubblicamente riconosciuta dall'oppo- 
sizione politica interna di Porto Alegre, come ha invece fatto nel settembre del 1996 il consigliere comunale Aiton Ferronato del PMDB. ${ }^{6}$ Ciò non toglie però che tale facoltà permanga, e che l'OP resti al suo interno, affiancandosi al lavoro delle istituzioni elette a suffragio universale appena come "comprensione di esse" che "in un certo senso addirittura le valorizza" (U. De Souza, 2002). ${ }^{7}$

Del resto, il duplice momento rappresentativo/partecipativo che si articola all'interno dello stesso processo di Bilancio Partecipativo, è il miglior modo di creare un 'flusso paritario di rispetto e cooperazione' fra i due sistemi, rendendoli compatibili attraverso la reciproca comprensione, propiziata proprio dal contatto diretto. E per questo è indicato dalla maggior parte degli autori come il suo vero nucleo-base, ${ }^{8}$ che non riproduce né duplica le competenze del Consiglio Comunale, anche nella misura in cui:

[...] la stessa autonomia dei Consiglieri dell'OP è sminuita, visto che essi non possono decidere - a differenza dei politici eletti nel Consiglio Comunale, o nei Parlamenti Federali e Statali - in difformità dalle decisioni delle assemblee pubbliche delle loro comunità di origine. Essi devono rispettare le scelte e le priorità dei collegi di prima istanza, quelli dei Delegati, altrimenti possono essere destituiti come è anche accaduto. In pochissimi casi a dire il vero, io ne ricordo due soli, nella Regione Eixo Baltazar e in quella Centro-Sud, uno dei quali poi non eseguito. Per questo, anche, il loro mandato non è retribuito, ed è limitato ad un anno. Per una forma di 'accerchiamento' alla sua autonomia, visto che è richiesto che la sua rappresentatività sia reale. Il Consigliere rende conto ai Forum di Delegati, che hanno una carica e un incarico molto più a contatto delle Assemblee iniziali, quindi delle realtà locali. Ma per quanto possa essere perfetto il meccanismo di controllo dell'operato dei rappresentanti eletti, la garanzia maggiore resta e vuole restare nella forza delle comunità che stanno loro dietro, nella sana competizione fra loro che quasi obbliga ad un controllo perché [i loro rappresentanti] non abbiano la forza per capovolgere le carte in tavola. Se la avessero, sarebbe una delega pericolosa per la degenerazione dei meccanismi dell'Orçamento Participativo in senso neocorporativo o di un nuovo clientelismo, magari di sinistra ma pur sempre chiuso ed escludente (Brunet, 1999i, apud Allegretti, 2000a).

In tale ottica, è consequenziale che il Bilancio Partecipativo si presenti come un processo articolato in livelli qualitativamente e anche quantitativamente diversi di partecipazione, ${ }^{10}$ guidando verso una complessiva moltiplicazione del dibattito sulle scelte cittadine e la sua articolazione in momenti e spazi distinti esterni allo stesso OP. Così, il Bilancio Partecipativo è da un lato esso stesso moltiplicatore del dibattito in seno alla città, dall'altro si costituisce anche come un creatore di moltiplicatori della discussione, come denunciano i Congressi Costituenti della Città, la creazione o la riforma dei Consigli Municipali e dei Forum dei Servizi ed altre iniziative parallele all'O.P. che specie a partire dal 1994 - hanno arricchito Porto Alegre di luoghi (reali e virtuali) di dibattito. Come ha, infatti, osservato Brunet:

La democrazia ha problemi fisici, di tempo e di spazio. Le grandi assemblee sono sempre più costrette a prendere poche decisioni, quelle fondamentali. [...] Non è perché hai un'assemblea strapiena di persone ad alzare il braccio che hai davvero una democrazia. Semmai in tre mesi di piccole assemblee, locali, puntuali. Questo dato incontrovertibilmente assunto nel tempo, dopo i primi anni di 'assillo da audience' è quello che ci ha aiutato a perseverare, a reggere bene le difficoltà iniziali [verificatesi] nelle Assemblee Tematiche, il poco entusiasmo mostrato per il processo denominato Città Costituente... (Brunet, 1999i, apud Allegretti, 2000a). 
244 In ogni caso, anche al di là di queste considerazioni, resta il fatto che il presunto 'attentato' del Bilancio Partecipativo contro le istituzioni formali della democrazia rappresentativa di origine elettiva non potrebbe consumarsi se non 'ad armi pari'; è quindi attualmente impensabile, visto che - a tutt'oggi - il Bilancio Partecipativo resta un'istanza decisionale priva di una precisa copertura formale che ne dettagli regole, funzionamento, tappe organizzative, cariche, ecc.. Nel Regolamento Interno del 1992 si leggeva: "il Bilancio Partecipativo non è, fino ad ora, legalmente regolamentato. Esistono opinioni divergenti sull'opportunità di una sua regolamentazione attraverso il Consiglio Comunale. Vi è, però, previsione della sua esistenza nello Statuto del Municipio" (art. 10, RI 1992). ${ }^{11}$ Oggi la situazione non è mutata, visto che a tutela dell'esistenza del Bilancio Partecipativo resta valido soprattutto l'art. 116, $\S 1^{\circ}$, dello Statuto Municipale approvato nel 1990, dove si afferma che "resta garantita la partecipazione della comunità, a partire dalle regioni del municipio, nelle tappe di elaborazione, definizione e accompagnamento dell'esecuzione del piano pluriannuale, delle direttrici di bilancio e del bilancio annuale. E non poteva essere altrimenti".

Lo Statuto Comunale di Porto Alegre è stato, del resto, approvato dopo la creazione del Bilancio Partecipativo, ed avrebbe costituito un atto di forte ingenuità politica da parte dell'Amministrazione Popolare non prevedere una formalizzazione - seppur minima e per via indiretta - del processo, nell'ambito degli strumenti di gestione della politica cittadina.

Così, vari tentativi dell'opposizione di contrastare l'O.P. come misura illegittima hanno dimostrato che - sotto questo punto di vista - il processo è difficilmente attaccabile. Eppure, l'art. 116 resta pressoché l'unico dello Statuto Comunale in cui si fa cenno a qualcosa che assomigli all'O.P. La strada scelta dall'Amministrazione Popolare è stata, infatti, quella della 'minima copertura' e 'formalizzazione' dello strumento che - come emerso dal dialogo del 1989 con i movimenti urbani della città - doveva restare essenzialmente autoregolamentato.

Il processo di costruzione dell'Orçamento Participativo dimostrò che la democrazia diretta esige necessariamente un grande dinamismo, senza imprigionarsi in soluzioni preconcepite. La propria popolazione organizzata orienta trasformazioni in direzione del perfezionamento delle regole di funzionamento, cercando sempre una partecipazione maggiore. [...] la regolamentazione implicherebbe rigidezza nelle definizioni. Oltre a ciò, la struttura giuridica esistente nel nostro Paese tenderebbe ad essere usata non per garantire l'O.P., ma per mettere in dubbio la sua legalità e, pertanto, il suo funzionamento. L'idea è che la garanzia di continuità e di ampliamento dell'esperienza si fonda nella forza del movimento popolare che la sostiene (Augustin, 1994).

Per queste ragioni la regolamentazione dell'Orçamento Participativo non avviene tramite legge comunale, ma è revisionata annualmente dalla stessa società, in maniera autonoma. "L'O.P. non è un'opera rifinita, perfetta e indiscutibile. Né lo potrebbe essere, perché la definizione unilaterale della perfezione sarebbe espressione di autoritarismo e negazione del processo dialettico, di costante trasformazione e superamento del nuovo sul vecchio che caratterizza i processi sociali" (U. De Souza, 2002).

A questo cosiddetto 'riadattamento annuale' partecipa il Consiglio di Bilancio: seppur l'opera più appariscente dei Consiglieri popolari è quella di definizione delle priorità da inserire nel Piano di Investimento dell'anno successivo, in real- 
tà la loro vera impronta resta in questa auto-regolamentazione, che sopravvive il tempo di una nuova stagione. Se nella definizione delle priorità, infatti, $\mathrm{i}$ Consiglieri sono vincolati dal loro mandato a rispettare l'ordine delle priorità presentato loro dai cittadini attraverso i Forum dei Delegati, nel potere di autoregolamentazione del Bilancio Partecipativo essi possono teoricamente esercitare il loro spirito critico anche ad un livello più personale, giovandosi della propria esperienza, trasmessa in parte ai loro successori sotto forma di trasformazioni apportate ai meccanismi della discussione pubblica ai suoi vari livelli. Questo aspetto di 'informalità' costituisce un lato inedito e forse non ancora sufficientemente indagato dell'Orçamento Participativo di Porto Alegre, che deve annualmente scontrarsi con le pretese di 'regolamentazione' avanzate da consiglieri comunali - che si sentono spesso minacciati nei loro margini di potere - e non solo all'interno dell'opposizione politica. Nel 1992, è stato, infatti, un consigliere comunale del PT - Clòvis Ilgenfritz - a cercare di mettere una 'camicia di forza' all'O.P. tramite una Legge Complementare (Baierle, 1999i, apud Allegretti, 2000a); nel marzo del 1996, invece, è stato il consigliere del PDT Nereu d'Avila a tentare di 'imbrigliare' l'O.P. (e indirettamente l'esecutivo) con una Legge che avrebbe dovuto obbligare alla conclusione delle opere previste entro l'anno solare in cui erano registrate nei PI, a destinare una quota di investimenti alle opere infrastrutturali di grande portata e a permettere ai consiglieri comunali un ruolo decisivo dentro il processo. Entrambe le proposte suscitarono una vera e propria sollevazione popolare e del COP, e furono accantonate. ${ }^{12}$

L'informalità del Bilancio Partecipativo quale meccanismo di funzionamento pur legalmente previsto nell'ambito degli strumenti di gestione municipale, costituisce in realtà un'arma a doppio taglio. Se da un lato, infatti, essa apre la possibilità di un continuo perfezionarsi dei contenuti democratici dell'OP e garantisce la sua 'non-stagnazione' (U. de Souza, 2002), dall'altra lo rende soggetto alla volontà politica del momento, non garantendolo in linea teorica contro l'eventuale decisione di un futuro Esecutivo Municipale di spazzarlo via dalla scena pubblica portoalegrense. Questa ambiguità è molto sentita sia all'interno dell'Amministrazione che del COP, ma finora non ha mai prevalso il desiderio di istituzionalizzare il Bilancio Partecipativo, percepito anzi come un'inevitabile 'inizio della fine' per un processo per cui l'apertura è ritenuta garanzia di non invecchiamento e di salvezza dal 'congelamento burocratico'. L'ultimo esempio della predilezione espressa dalla società nei confronti dell'opzione 'flessibilità' dell'OP (rispetto a quella 'certezza del diritto') lo si è avuto in occasione della Proposta di Legge Municipale $n^{\circ}$ 030/99 Prot. 1181 del 9/4/1999 presentata dal consigliere Isaac Ainhorn, rappresentante del PDT, al momento alleato di governo dell' Amministrazione Popolare. La Legge, affossata anche questa volta dalle manifestazioni di protesta organizzate dal COP (seppur non sempre molto partecipate $)^{13}$ prevedeva un'inversione dei ruoli fra Consiglio Comunale ed Esecutivo nell'elaborazione dei Piani annuali di Investimento, la riduzione al $50 \%$ delle voci di spesa discutibili dalla popolazione, l'elezione dei delegati proporzionale agli abitanti delle varie Regioni, la presenza di delegati di diritto come i presidenti delle Associazioni Comunitarie, e - infine - la soppressione dell'autoregolamentazione del processo in favore di una struttura da mutarsi anche annualmente, ma prevista in una Legge da votarsi ogni volta in Consi- 
glio Comunale. Soprattutto, l'unificazione proposta dei metodi di discussione e deliberazione su scala cittadina "annullava uno degli aspetti più positivi dell'O.P., cioè la sua capacità di adattarsi in modo diverso ai vari territori locali della città, che oggi fa sì che in alcune aree siano le plenarie il luogo del conflitto, $e$ altrove - come nella zona Nord - siano più forti le intermediarie, a seconda delle opzioni scelte dagli abitanti" (Cúnico, 1999i, apud Allegretti, 2000a).

La proposta volutamente ignorava che "il dinamismo del processo si esprime anche nell'ampliamento graduale delle questioni che effettivamente stanno sotto la sua sfera di influenza" (Augustin, 1994), e che alcune delle maggiori conquiste dell'Orçamento Participativo di questi anni sono proprio frutto del processo annuale di 'riadattamento critico' delle proprie competenze e del proprio funzionamento realizzato dal COP, che ha avuto un acme nel 1994 con la creazione dei 'Criteri Tecnici e Legali' e delle Plenarie Tematiche (cfr. capp. 7 e 8). Per questo, per alcuni autori l'autoregolamentazione sarebbe elencabile tra gli elementi che 'trascendono il processo di gestione pubblica e di pianificazione democratica' (U. de Souza, 2002), appartenendo a quelli che contribuiscono prioritariamente a generare coscienza e senso di cittadinanza, cioè alla sfera delle proprietà 'educative' e 'formative' del Bilancio Partecipativo che favoriscono l'approfondirsi delle capacità di ampliamento degli orizzonti al di fuori dell'immediatismo politico, di autocoscienza e di riflessione critica dei partecipanti, e il desiderio di correggere le distorsioni in un processo di perfezionamento e di crescita per tappe. Oggi, la necessità riprendere in mano la discussione sull'opportunità di una maggior 'copertura formale' del Bilancio Partecipativo nella legislazione locale (seppur 'flessibile' e 'leggera' per non sminuirne le possibilità di autoregolamentazione e $\mathrm{i}$ benefici sperimentati in 14 anni di 'minima copertura') è ritorna di attualità, particolarmente con l'approvazione della Legge Federale 10.257/01 sullo 'Statuto delle città', che sottolinea come le sperimentazioni realizzate nell'ultimo decennio in ambito politico/amministrativo municipale possano - anzi 'abbiano il dovere' - (Alfonsin, 2002) di 'contribuire ad un rinnovamento progressista del quadro normativo brasiliano, accettando di iniziare leggere il diritto non solo come uno strumento di prevaricazione - come è stato spesso usato in passato - ma anche come un mezzo di progresso democratico' (ibidem). Quella della maggior formalizzazione dei processi di Bilancio Partecipativo è quindi oggi una posizione che guadagna appoggio anche tra i giuristi e gli amministratori progressisti, come emerso nel "II ${ }^{\circ}$ Congresso Brasiliano di Diritto Urbanistico", tenutosi proprio a Porto Alegre per valutare apporti e sfide della nuova Legge sullo 'Statuto delle Città' (14/16 luglio 2002). ${ }^{14}$ Ma che - soprattutto - potrà guadagnare spazio tra i cittadini se, come ormai pare certo, l'esperienza di 4 anni di Bilancio Partecipativo Statale nel Rio Grande do Sul non troverà continuità dopo la recente sconfitta dell'Amministrazione Popolare nelle elezioni dell'ottobre 2002; e se 'l'appiglio' che renderà possibile questa prematura morte della sua sperimentazione sarà proprio la 'non esistenza' formale del processo.

Sul dibattito pesano però forti elementi di volontà politica, che non ne rendono serene le posizioni. Secondo alcuni critici, cittadini e militanti dello stesso PT (cfr. Allegretti 2000a), infatti, la difesa ad oltranza che l'Amministrazione Popolare ha fatto in questi anni dell'informalizzazione del Bilancio Partecipativo potrebbe spiegarsi anche con l'aggiunta di una considerazione 
di natura utilitaristica, cioè la necessità della coalizione di legarsi a doppio filo con il suo fiore all'occhiello ${ }^{15}$ per garantirsi contro un eventuale cambio di maggioranza che mettesse a rischio un processo molto amato ma da questa 'informalità' reso fragile. Del resto non è una novità che:

Non aprirsi del tutto, tenere qualcosa per sé, è caratteristica di ogni spazio politico, che così salvaguarda la sua fetta di possibilità di portare avanti - unico fra gli altri - un certo tipo di intervento significativo (Elizete Menegat, 1999i, apud Allegretti, 2000a).

\subsection{Quale spazio per il Bilancio Partecipativo sui mezzi di informazione?}

La mitizzazione del Bilancio Partecipativo - trasformarlo in una specie di icona di una città esotica "dove la sinistra ha dato buoni risultati" - è un modo di ridurne l'importanza. E, al tempo stesso, di isolarlo come una "merce", che può essere consumata solo da una singola città [...] Esso è la "testata d'angolo" di un sistema complesso di controllo pubblico dello Stato, fondato su numerosi consigli e strutture decisionali, formali o informali. [...] Ciò che rappresenta innovazione e "progresso democratico" nell'esperienza dell'OP è che sperimenta, in forma embrionale, un altro contratto politico. E lo fa senza rendere nullo l'attuale, mantenendone e valorizzandone la rappresentatività. In verità, esso si propone solo di dare opportunità a tutti di parlare, senza discriminazione sociale o economica: offre, alle persone e ai gruppi sociali con poca influenza sulle decisioni pubbliche, l'opportunità di dar se guito alle proprie richieste e ai propri interessi più elementari. L'OP, in particolare, organizza i conflitti senza direzione della democrazia puramente formale, molte volte manipolati dal potere economico e dai media, rendendoli conflitti aperti, mediati da regole autonome [...]. Il regolamento interno dell'OP proviene direttamente dalla società (autonomia) e dalla Costituzione (eteronomia) e bilancia i limiti della democrazia diretta ed anche il suo grado di ampiezza. [...] Essendo un antidoto alla malattia sociale della passività, che mantiene sempre tutto come sta e rafforza $\mathrm{i}$ privilegi, é naturale che i conservatori lo attacchino. La critica "da sinistra" dell'OP sa anch'essa bene dove mira. Siccome l'OP si fonda su un contratto politico innovatore, tra il governo della democrazia rappresentativa e le comunità organizzate, é difficile che sia dominato dalle micro-organizzazioni che ancora si fanno una copertura del messianismo proletario. Lo stesso che ha liquidato il volto democratico dell'esperienza sovietica e l'ha fatta scadere nel totalitarismo, oggi sostituito dal potere delle mafie nel capitalismo russo (Genro, 2001).

L'appassionata difesa-spiegazione sul Bilancio Partecipativo proposta dall'allora sindaco Tarso Genro sulle pagine del quotidiano 'Zero Hora' del 20 giugno 2001, non costituisce solo una sintesi interessante di questioni e prospettive di lettura attraverso cui il processo viene di solito esaminato, ma rappresenta anche uno dei rari spazi che la stampa locale di Porto Alegre ha accettato di dedicare in questi 14 anni a quello che pure ha rappresentato, fin dal primo mandato dell'Amministrazione Popolare, il principale strumento di governo urbano, specie per quanto attiene la realizzazione degli investimenti, cioè di quanto sulla scena urbana appare più 'visibile' e 'vendibile' dai mezzi di informazione.

La mancanza di stimoli e accettazione piena da parte della stampa locale nei confronti del Bilancio Partecipativo di Porto Alegre, è stata sempre interpretata dal Fronte Popolare come forma di disapprovazione ed ostracismo politico, ${ }^{16}$ dato che i due maggiori quotidiani cittadini ${ }^{17}$ e la rete televisiva locale RBS appartengono allo stesso gruppo editoriale, legato ad ambienti economici un tempo molto influenti nella gestione delle risorse pubbliche locali, e vicino a formazioni politiche apertamente ostili all'Amministrazione Popo- 
248 lare. Che tale esegesi sia legittima è dimostrato anche da analisi puntuali sulla stampa locale ${ }^{18}$ che evidenziano il contrapporsi di due fasi successive: 1) la prima, segnata da una 'strategia del silenzio', identificata come quella più idonea a non far decollare un meccanismo fondato sulla partecipazione $\mathrm{e}$ quindi sulla conoscenza dell'esistenza del processo da parte della popolazione (Genro, 1997); ${ }^{19}$

2) la seconda, fondata su una strategia 'riduzionista' e 'minimizzante' che presenta l'OP come un mero 'incubatore di piccole opere' senza la minima importanza per il futuro urbano (ibidem).

La variazione di strategia è risultata indifferibile nel momento in cui il Bilancio Partecipativo ha acquisito una dimensione internazionalmente apprezzata, e - dopo il riconoscimento tributatogli dal programma 'Best Practices' dell'ONU al vertice di Istanbul - la strategia 'omissiva' è divenuta 'imbarazzante' (Genro, 2002), essendo rilevata da organi di stampa stranieri come 'Le Monde Diplomatique' (1998) o da celebri 'firme' come Raul Moreau e Affonso Ritter. ${ }^{20}$ La nuova attitudine 'minimizzante' della stampa locale non è mutata neppure con l'affermarsi dell'OP come il policy-maker di riferimento per il compimento di scelte strategiche per il territorio di Porto Alegre, cioè quando - attraverso di esso - gli abitanti hanno deciso opere di grande impatto come il restauro del Mercato Centrale, la Centrale di Trattamento Liquami del ricco quartiere di Ipanema, o la costruzione di 5 grandi arterie di traffico, tra cui la $3^{\circ}$ Perimetrale, l'anello di circonvallazione che percorre la città da Nord a Sud.

Né l'esplosione del Bilancio Partecipativo in ambito statale né il ruolo di 'riferimento ideale' assunto dal processo portoalegrense per i numerosi studi di ricercatori di provenienza diversa e l'estendersi di sperimentazioni in molte città brasiliane e straniere, e neppure la 'centralità' assunta dall'OP sui media internazionali in occasione dei Forum Sociali Mondiali del 2001 e del 2002, sembrano aver smosso l'atteggiamento assunto dagli organi di informazione locale di Porto Alegre. Questo ovviamente ing enera due ordini di conseguenze negative:

a) la prima sulla stessa stampa portoalegrense che (tanto più in un contesto territoriale segnato dall'alto livello di politicizzazione della cittadinanza) dimostra una visione sociale semplificata e nihilista ${ }^{21}$ ottusità e provincialismo oltre che, ignorando volutamente un fatto 'centrale' non solo sotto il profilo politico e culturale, ma anche sotto quello strettamente giornalistico, ${ }^{22}$

b) la seconda sulla città, costretta ad 'investire' maggiori fondi sulla pubblicizzazione di un processo che potrebbe essere reso noto senza aggravi di spesa per le casse del Municipio e soprattutto privata di un dibattito onesto che permetta all'O.P. di maturare a partire anche dalle osservazioni dei suoi avversari (Genro, 2002).

In questi anni, l'Amministrazione cittadina ha, così, dovuto acquisire spazi di natura pubblicitaria sui vari media 'avversi' (come la programmazione quotidiana del canale RBS può facilmente rivelare) ed investire su massicce e diversificate campagne di coscientizzazione e informazione degli abitanti sul Bilancio Partecipativo, in particolare nei periodi di svolgimento delle Assemblee Plenarie (marzo-maggio). ${ }^{23}$ Con tutte le difficoltà 'di routine' finora sottolineate, ovvero lo stretto controllo esercitato dal Tribunale dei Conti dello Stato e dal Consiglio Comunale, che spesso e volentieri - almeno su queste voci di spesa - ha potuto 'emendare' le proposte di Bilancio approvate dai cittadini dentro l'OP. 
Per certi versi, queste prevedibili difficoltà possono leggersi oggi come una 'risorsa' offerta e fatta propria dal Bilancio Partecipativo, nella misura in cui hanno stimolato l'Esecutivo alla costruzione di strategie alternative di comunicazione con i cittadini, e la costruzione di rapporti organici di interazione con i movimenti popolari mirati a condensare energie diffuse su un ambito (quello comunicativo/informativo) assolutamente strategico per ogni processo partecipativo che ambisca ad un ruolo 'nodale' nella gestione territoriale, cosi come è stato riconosciuto di recente anche da misure giudiziarie 'cautelative' come il 'liminar'. ${ }^{24}$

L'interesse preminente mostrato in questi 14 anni dall'Amministrazione Popolare per il potenziamento non solo del mero ruolo di meccanismo di gestione e di 'decisore urbano' dell'O.P., ma di quello di 'moltiplicatore pedagogico e culturale' dedicato alla formazione della coscienza cittadina, ha reso centrale la predisposizione di materiale di supporto per la discussione che - in ogni istanza di partecipazione interna o collegata all'OP. - risultasse 'adeguato' ai differenti livelli culturali e alle possibilità di ricezione completa dell'informazione da parte dei cittadini. La filosofia della 'trasparenza' e del 'coinvolgimento attivo' ha teso così ad impostare politiche 'informative' configuratisi piuttosto come 'strategie comunicative' a doppio senso (andata e ritorno) articolate su alcuni pilastri fondamentali su cui oggi vigilano la Commissione della Comunicazione in seno al COP del Bilancio Partecipativo ed il Consiglio Municipale di Comunicazione:

1) perseguire in modo visibile la 'democratizzazione della comunicazione', adottando un approccio 'adattivo', 'graduale', 'dialogico' e 'sperimentale' nell'impostare, valutare e ri-orientare ogni politica informativo-comunicativa destinata ai cittadini;

2) favorire una differenziazione dei target comunicativi e una razionalizzazione delle poche risorse che è possibile destinare alla pubblicizzazione delle iniziative di partecipazione e all'informazione capillare del pubblico, utilizzando strumenti differenziati ${ }^{25}$ di comunicazione ed informazione su regole, fasi e contenuti tematici dei processi partecipativi (in primis del Bilancio Partecipativo), puntando nel contempo a modernizzare e razionalizzare le capacità comunicative ed informatiche del Comune, ${ }^{26}$

3 ) curare l'uso di linguaggi e formule espressive "attente a non ferire l'orgoglio e i diritti delle fasce meno fortunate della popolazione, che per anni ha subito una segregazione economica e spaziale (e in parte ancora la subisce) e che si ha il dovere di reintegrare nella cittadinanza di diritto ad ogni livello, evitando di farle subire anche l'umiliazione di essere discriminata a livello di linguaggio e rappresentazione" (Anton, 1999i, apud Allegretti, 2000a);

4) mettere in atto e rendere visibile l'ascolto paziente della popolazione nell'ambito dei processi decisionali dialogici attivati, quale elemento indispensabile per individuare i linguaggi da usare e $\mathrm{i}$ tempi più adatti in cui procedere a trasformazioni qualitative dei contenuti delle discussioni ${ }^{27}$ evitando però di articolare 'contenuti differenziati' ${ }^{28}$ per 'pubblici differenziati';

5) curare la verbalizzazione di quanto discusso e deciso in ogni occasione di pubblico incontro tra Comune e cittadini, in modo da diminuire la sfiducia e le incomprensioni generate dalla mera comunicazione orale, e offrire appoggio ad una evoluzione lineare dei processi dialogici, minimizzando il rischio 
di dover continuamente riaffrontare questioni su cui si erano già raggiunti accordi o letture condivise;

6) favorire la riscoperta e la valorizzazione delle peculiarità culturali dei cittadini (specie edelle minoranze) anche in seno alla gestione 'tecnica' della città - e non solo limitatamente all'ambito settoriale delle politiche culturali, per rendere la comunicazione più incisiva, ma anche stimolare l'azione pubblica ad arricchire i suoi esiti, riacquistando gradualmente 'la complessità dei suoi sistemi culturali di base' (Genro, 1999i, apud Allegretti, 2000a); ${ }^{29}$

7) qualificare ed ampliare la politica delle risorse umane, per favorire un' 'umanizzazione' del processo comunicativo (Genro, 2002), attraverso reti di 'agenti di intermediazione'; ${ }^{30}$

8) lasciare documentazione scritta del rapporto biunivoco di comunicazione tra Amministrazione e cittadini, costituendo il Progetto Memoria dell'Amministrazione Popolare, avviato nel 1993 (seppur in fase operativa solo a partire dal 1998$)^{31}$ per offrire un panorama di tutto quanto negli anni è stato prodotto dal Comune e 'controprodotto' dalla popolazione in termini di informazione e interazione, dentro ai processi partecipativi attivati ${ }^{32}$

9) non sacrificare totalmente la valorizzazione della tradizionale 'cultura orale' brasiliana, ${ }^{33}$ riscoprendo le cerimonie di 'festa' o 'le inaugurazioni' ${ }^{34}$ di opere richieste dai cittadini come occasioni per trasmettere informazioni e rafforzare l'interesse per una partecipazione attiva alla costruzione delle scelte urbane; 10) sostenere lo sviluppo di mezzi di comunicazione alternativa, ${ }^{35}$ come le radio comunitarie ${ }^{36}$ e gli oltre 40 giornali di quartiere o di entità regionali (da ormai un decennio in forte crescita numerica ma - soprattutto - qualitativa) che oggi tributano all'O.P., e alle priorità al suo intemo definite, lo spazio non riconosciutogli dai grandi mezzi di comunicazione cittadina, nella misura in cui esso rappresenta la cornice entro cui risulta inserita ogni relazione fra cittadini e Istituzione, fra una periferia che per molti aspetti non è più tale, e un 'centro' che, per tappe, riesce a porsi sempre più vicino alla popolazione;

11) costruire 'sinergie' con la società civile e le sue strutture organizzative per la realizzazione di ricerche ed indagini conoscitive, ma anche per costruire messaggi più incisivi e con un grado di semplificazione dei problemi adattato alle reali possibilità dei futuri lettori; cioè, 'magari, anche superiori a quelle che autonomamente l'Amministrazione immaginerebbe' (Baierle, 1999i, apud Allegretti, 2000a).

In questi anni, una delle locali ONG più coinvolte nella collaborazione con il Comune, è stata la storica CIDADE, che ha tra i propri obiettivi "contribuire all'autonomia dei movimenti sociali, e tra $i$ suoi motti 'Se le persone non accolgono se non sfide per cui già sono preparate, è fondamentale aiutarle a prepararsi a nuove sfide" (CIDADE, 1997a, p. 1). Oltre ad occuparsi di accogliere e orientare $\mathrm{i}$ numerosi ricercatori stranieri che si recano a Porto Alegre a studiare l'O.P., CIDADE ha realizzato una serie di inchieste approfondite per costruire ed aggiornare nel tempo il profilo dei partecipanti al Bilancio Partecipativo, anche con l'aiuto della ricercatrice americana Rebecca Abers (cfr. cap. 10). Sulla base di queste analisi ha poi prodotto - con il Comune o indipendentemente - opuscoli e manuali-guida su temi importanti relativi alla gestione pubblica, indispensabili a formare tecnicamente i cittadini partecipanti al processo di O.P. Ad esempio, ne "Il ciclo dell'Orçamento Partecipativo" (agosto 1997) - più incisivo e chiaro di quelli fino ad allora 
realizzati in proprio dall'Amministrazione - una schematizzazione per punti e una strutturazione per domande ricorrenti (tipo FAQ) ${ }^{37}$ e risposte costruite collettivamente, spiegano il funzionamento e la possibilità di intervenire attivamente nell'OP, ma anche attori, livelli, regole, incompatibilità e responsabilità interne al processo, oltre che i suoi modi di interagire con la democrazia elettiva. Interessantissimo anche "Desdobrando o Orçamemento de Porto Alegre" (1997), dove un linguaggio semplice - che evita impoverimenti e riduzionismi - illustra come funziona un bilancio pubblico, con particolare riferimento a quello comunale, ${ }^{38}$ e paragona le fonti di entrate e uscite per il Comune con l'economia familiare, oltre a chiarire interrelazioni e vincoli tra $\mathrm{i}$ vari strumenti ${ }^{39}$ per offrire ai partecipanti "una visione complessa e realistica dei procedimenti di gestione dei beni pubblici” (Baierle, 1999i, apud Allegretti, 2000a).

\section{Come descrivere entrate e uscite di un bilancio pubblico (CIDADE, 1997b)}

\begin{tabular}{|c|c|c|}
\hline Entrate Correnti & Bilancio pubblico & Bilancio domestico \\
\hline Entrate tributarie proprie & $\begin{array}{l}\text { Imposte e tasse municipali } \\
\text { (IPTU, ISSQN, ITBI) }\end{array}$ & Stipendio \\
\hline Trasferimenti & $\begin{array}{c}\text { Imposte statali e dell'Unione, } \\
\text { Salario per l'Educazione, } \\
\text { Accordi } \\
\end{array}$ & $\begin{array}{l}\text { Donazioni ricevute da amici o } \\
\text { parenti, assegni mensili }\end{array}$ \\
\hline Patrimoniali & Affitti, dividendi & $\begin{array}{l}\text { Affitto ad altri di una casa } \\
\text { propria, dividendi }\end{array}$ \\
\hline Di capitale & $\begin{array}{c}\text { Operazioni di credito } \\
\text { (PIMES, BIRD, BID, BNDS) }\end{array}$ & $\begin{array}{c}\text { "pappagallo in banca" } \\
\text { [prestito bancario a breve } \\
\text { termine e bassi interessi, } \\
\text { anche con intermediazione di } \\
\text { terzi] }\end{array}$ \\
\hline Uscite correnti & Bilancio pubblico & Bilancio domestico \\
\hline Costi di gestione & $\begin{array}{c}\text { Pagamento del personale, } \\
\text { materiale di consumo, servizi } \\
\text { a terzi }\end{array}$ & $\begin{array}{l}\text { Acquisti, alimenti, vestiti, } \\
\text { trasporto, affitto, ecc. }\end{array}$ \\
\hline Trasferimenti & $\begin{array}{l}\text { Pagamenti a personale } \\
\text { inattivo, interessi, } \\
\text { trasferimenti per la } \\
\text { manutenzione di } \\
\text { autarchie/imprese } \\
\end{array}$ & $\begin{array}{l}\text { Donazioni realizzate a favore } \\
\text { di amici o parenti }\end{array}$ \\
\hline Spesa di capitale & Bilancio pubblico & Bilancio domestico \\
\hline Investimenti & $\begin{array}{l}\text { Progetti e opere, acquisto di } \\
\text { materiale permanente e } \\
\text { attrezzature }\end{array}$ & $\begin{array}{l}\text { Acquisto di un frigo, della } \\
\text { cucina o della Tv }\end{array}$ \\
\hline Investimenti finanziari & $\begin{array}{c}\text { Acquisto di Titoli, di } \\
\text { Immobili, partecipazione } \\
\text { all'aumento di capitale di } \\
\text { un'impresa }\end{array}$ & Mettere a risparmio \\
\hline
\end{tabular}

Attraverso esempi pratici, il libello invita anche il lettore a rilevare la necessità di prevedere una certa flessibilità per i margini di errore nel calcolo e nella previsione di ogni voce di spesa, prima di procedere alla valutazione degli investimenti realizzabili sia con le risorse normali che con quelle straordinarie, oggi in costante crescita per compensare il calo massivo dei regolari trasferimenti da altri livelli istituzionali (specie da quello federale). ${ }^{40}$ In 
chiusura, sotto forma di semplici domande da porsi in corso di discussione ai diversi livelli di dibattito pubblico, vengono dati suggerimenti per iniziative di controllo popolare' realizzabili sul Comune attraverso il Bilancio Partecipativo ed altri meccanismi interrelati; CIDADE mira così esplicitamente a rendere più incisivo e fattivo l'intervento della popolazione e dei suoi rappresentanti nell'OP, anche al di fuori delle tradizionali competenze di questo ma in direzione di "un'incidenza maggiore anche nella determinazione di quale quota percentuale di investimenti prevedere sul totale del bilancio" (Brunet, 1999i, apud Allegretti, 2000a). L'ottica che presiede all'elaborazione di questo strumento di informazione - che è al contempo di lavoro e formazione per i cittadini - è esplicitamente dichiarata nel testo: "l'affermazione del diritto di cittadinanza ed il consolidamento della democrazia dipenderà dalla mobilitazione e dall'organizzazione [dei cittadini] per qualificare il proprio intervento" (CIDADE, 1997).

Essa non dà solo la misura del rispetto dell'autonomia con cui si sviluppa il dialogo tra Comune e movimenti popolari nella costruzione delle strategie informativo/comunicative, ma ben illustra anche il binario prioritario seguito dal Comune di Porto Alegre (con particolare impegno a partire dall'Amministrazione Genro, cfr. Pozzobon, 1998); quello cioè della qualificazione dei cittadini e, con essa, dell'ampliamento di orizzonti e dell'arricchimento costante del dibattito sulla città, a partire dalla partecipazione istituzionalizza ta nell'O.P. .

\subsection{Il forte impegno degli attori istituzionali}

Meglio lo Stato è costituito, e più nell' animo dei cittadini gli affari pubblici prevalgono su quelli privati.[...] In uno Stato ben governato tutti vanno di corsa alle assemblee; sotto un cattivo governo nessuno vuol fare un passo per recarvisi. Perché nessuno si interessa a ciò che vi si fa, o perché si prevede che la volontà generale non vi prevarrà, o perché infine le cure domestiche assorbono completamente [...] Non appena qualcuno dica degli affari di Stato: che me ne importa?, si può essere sicuri che lo Stato è perduto (Rousseau, Cap. XV, pag. 801)

Uno degli scopi apparentemente centrali del Bilancio Partecipativo parrebbe quello di trasferire le decisioni sull'allocazione degli investimenti municipali in infrastrutture e servizi alle assemblee di cittadini, coinvolgendo gli abitanti in scelte difficili e sfruttando le tensioni che si sviluppano nel momento delle decisioni per generare una 'pacificazione' e un'accettazione condivisa una volta che queste sono state assunte. A ben guardare, però, questo non è l'unico né il più importante obiettivo del Bilancio Partecipativo, specie se si guarda in prospettiva allo snodarsi dei dibattiti interni alla coalizione che ne ha promosso l'attivazione. In quanto sfera pubblica non statale in cui la società può co-gestire la città e controllare lo Stato, e in quanto processo di formazione di una nuova 'coscienza di cittadino' (Genro, U. De Souza, 2002) il Bilancio Partecipativo è stato pensato come qualcosa di più di un meccanismo di gestione urbana. ${ }^{41}$ Via via che veniva sperimentato, è andato caricandosi di significati maggiori, in quanto strumento per dimostrare la convivenza possibile tra democrazia diretta e democrazia rappresentativa, e mezzo per stimolare una ricostruzione etica della politica (Baierle, 1994). È per questo che i suoi estensori rifiutano decisamente il riduzionismo spesso implicito nella diffusione mediatica che - soprattutto in ambito internazionale - veicola dell'OP soprattutto l'immagine di 'strumento innovativo di gestione urbana'. ${ }^{42}$ Per chi ne 
ha vissuto e ne va vivendo le trasformazioni e le conquiste, il Bilancio Partecipativo resta innanzitutto un processo di crescita parallela e contemporanea, per tappe, dei cittadini e delle istituzioni, inteso a favorire una ricostruzione del loro rapporto di mutua fiducia, da tempo incrinato.

Una delle originalità del processo strutturatosi a Porto Alegre è che il Comune non si è limitato a far leva sulle strutture e le articolazioni del Movimento Comunitario già esistenti, ma - oltrepassando il ruolo 'indiretto' che in genere il Potere Pubblico si riserva all'interno dei processi di riorganizzazione democratica - è divenuto promotore esso stesso, 'agente esterno-interno' del movimento di rafforzamento delle strutture della società civile (che in passato le varie amministrazioni si erano al massimo impegnate a 'cooptare' piegandole ai propri scopi). Il Comune non si è, quindi, limitato alla creazione di un ambiente propizio alla promozione della crescita dei movimenti popolari, ma ha offerto un supporto logistico e una volontà di dialogo che ha pochi precedenti, ${ }^{43}$ ottenendo risultati positivi ed in crescita grazie a:

a) la forte centralità data - fin da subito - alle decisioni assunte nel Bilancio Partecipativo, strumento al contempo di grande concretezza e valore simbolico (in quanto dà ai cittadini l'opportunità di discutere del denaro proveniente dalle loro tasse) oltre che dotato di uno scadenzamento dei tempi e di un'obbligatorietà di elaborazione dei documenti che ne costituiscono annualmente il 'prodotto'. questi tendono a favorire il trasformarsi 'in progetto' delle tensioni che vengono a contrapporsi al suo interno. In virtù di tali caratteristiche l'OP apparve fin dal suo primo anno come lo spazio ideale su cui concentrarsi per farne il fulcro e il 'motore scatenante' di una riforma di democratizzazione delle istituzioni ben più ampia;

b) l'orientamento - garbato ma deciso - dato anche a domande puntuali fatte al di fuori del Bilancio Partecipativo, per reintegrarle e riassorbirle lentamente in esso (Moura, 1993);

c) l'impegno dell'Amministrazione alla costante comunicazione ed informazione della cittadinanza, diretto alla trasparenza, ma anche alla chiarezza ${ }^{44}$

d) una strategia di azione incentrata sul rapido concretizzarsi di molte delle opere discusse nell'O.P., indispensabile (specie all'avvio del processo) per vincere alcune resistenze implicite nella facile disposizione a perdersi d'animo del 'cittadino comune' e per scatenare un 'effetto dimostrazione' rivelatosi fondamentale per il coinvolgimento di cittadini e gruppi ancora 'scettici' sulla reale volontà di dialogo dell'amministrazione, ${ }^{45}$

e) la valorizzazione del cittadino partecipante in quanto 'abitante' del proprio territorio e non in quanto portatore di 'diritti formali' ${ }^{46}$ (contribuente, residente, elettore, ecc.);

f) la creazione di nuove figure amministrative che fungessero da agenti facilitatori del processo di discussione del bilancio e da articolatori delle azioni di govemo nelle microregioni: ad esempio, i CROPs legati alla CRC e agli 8 Centri Amministrativi Regionali ${ }^{47}$ o gli Agenti Comunitari dei singoli Assessorati (cfr. cap. 12);

g) la perseveranza nel mantenere il Bilancio Partecipativo un processo 'mancentred' [centrato sull'uomo], in tutti i suoi diversi gradi espressivi; ${ }^{48}$

h) l'impegno costante a fare dell'OP non un semplice strumento di 'distribuzione condivisa di risorse', ma di 'redistribuzione di reddito', attraverso una continua attenzione ai cittadini più deboli (partecipanti o meno all'interno di 
un processo che è comunque volontario) ${ }^{49}$

i) l'impegno dei rappresentanti dei più alti livelli politici cittadini ad essere presenti con frequenza assidua alle riunioni dell'OP e a garantire la presenza dei propri tecnici, per mantenere un contatto diretto con gli abitanti.

L'impegno profuso dall'Amministrazione nel dare coerenza e continuità a queste linee d'azione prova come "lontano da una partecipazione destinata a 'ridurre la presenza del governo', la politica del Bilancio Partecipativo deriva da un impegno profondo e durevole di attori centrali che, direttamente ed indirettamente, influenzano l'organizzazione della società civile" (Abers, 1998b). Tale impegno - come si è già detto - ha puntato a dare al processo un chiaro ruolo pedagogico, coerente con una forte tradizione brasiliana di attenzione a questo tema ${ }^{50}$ che (come sottolineano numerosi studi concentrati su questa prospettiva di lettura $)^{51}$ ha ottenuto alcuni importanti risultati nei confronti dei gruppi e degli individui partecipanti ai vari gradi di discussione e deliberazione del Bilancio Partecipativo, e principalmente:

1) ha determinato un moto di trasformazione delle caratteristiche dei leader comunitari, dal momento che l'assunzione di decisioni in assemblee aperte ha richiesto capacità di mobilitazione e di convincimento dei partecipanti, e doti maggiori di oratoria di quanto non fosse necessario in passato. A fianco ai casi $d i$ adattamento alle nuove regole mirati al mantenimento del prestigio già acquisito, si sono sviluppate strutture organizzative parallele (sovente in primo tempo informali) per mettere in discussione i vecchi leader, o stimolare l'emergere di nuovi; 2 ) ha funzionato come "apprendistato alla democrazia" (Abers, 1998b) ${ }^{52}$ nei confronti di gruppi ed individui, luogo in cui "persone ordinarie acquisiscono l'attitudine organizzativa che potranno utilizzare e diffondere in altri spazi e contesti" (ibidem). Ciò è stato possibile diffondendo sia tecniche $\mathrm{e}$ norme di buon senso per l'organizzazione di riunioni democratiche e trasparenti nei loro iter decisionali (formulare ordini del giorno e votazioni chiare, iscriversi a parlare, attendere il proprio turno, non prevaricare gli altri parlandogli sopra, rispettare il tempo dato per ogni intervento e per l'assemblea nel suo complesso, quindi anche sapere 'rinunciare' a parlare) sia permettendo a intere comunità di appropriarsi di un bagaglio critico e metodologico fondamentale (acquisire la capacità di ascoltare gli altri, di argomentare e convincere, di saper discutere su 'parti' senza perdere di vista il tutto, di accorgersi dell'esistenza dei ragioni e problematiche che negano la tendenza di ognuno a porsi come 'ombelico del mondo');

3 ) si è posto come 'maestro di negoziazione' anche su temi specifici che non di rado mettono in crisi persino tecnici con esperienza ed accesso all'informazione superiore a quella dei 'cittadini comuni', ${ }^{53}$ divenendo strumento di formazione di un sapere locale critico contestualizzato;

4) ha saputo incoraggiare l'assunzione di potere derivante dalla partecipazione, senza necessariamente esacerbare le disuguaglianze fra chi possiede forza e potenziali aggregativi differenti per pervenirvi;

5) ha contribuito alla 'de-idiotizzazione' (Schimidt, 1993) del sentimento di cittadinanza, stimolando un impegno attivo che va oltre il controllo dell'operato istituzionale per farsi 'partner' del trasformarsi del territorio attraverso la valorizzazione delle energie progettuali diffuse tra chi 'abita', 'vive', 'produce' e al contempo 'consuma' (culturalmente ed economicamente) il territorio; 
6) ha veicolato la costruzione di una 'solidarietà negoziata' (Abers, 1998b), invitando le comunità locali a seguire una logica di reciprocità attraverso cui gli stessi poveri compiono sacrifici a protezione di coloro che versano in condizioni ancor più disagiate;

7) ha reso chiari e comprensibili alcuni nessi logici tra trasformazioni 'globali' e 'locali', e contribuito a comprendere i 'limiti d'azione' delle istituzioni di livello diverso, permettendo ai cittadini di recedere da alcuni pregiudizi circa l'onnipotenza del ruolo dell'amministrazione comunale, e facendo loro comprendere che la sua vicinanza al cittadino non giustifica che la si usi come il 'capro espiatorio' di qualsiasi malfunzionamento e stortura rilevabile sul territorio.

Questi esiti - pur agognati - non potevano certo essere programmati all'inizio della sperimentazione del Bilancio Partecipativo, tanto più che esso è venuto sviluppandosi in modo 'adattivo' e 'incrementale' e non sulla base di un'idea preconfezionata o 'bloccata'. Sono stati mete, punti di impegno, ma per nessuno di essi era possibile immaginare con certezza una realizzazione; e spesso raggiungerli ha comportato accese tensioni e profusione di impegno aggiuntivo da parte del Comune. Ad esempio, quello del raggiungimento di una 'cooperazione solidale' fra quartieri e Regioni non è stato un percorso agevole; ha, infatti, richiesto che l'Amministrazione lottasse vari anni per far accettare alle Regioni e al COP l'approvazione di norme 'equitative' di distribuzione dei fondi, oltre che una buona dose di umiltà da parte di molti partecipanti per accettare di scoprire gradualmente i limiti del proprio operato e della propria situazione ritenuta 'estrema', attraverso un confronto con situazioni peggiori (cfr. Abers, 1998b). Ma è riuscito lo stesso a prendere gradualmente piede, sebbene quello della crescita delle 'scelte solidali' resti ancora un obiettivo perfettibile, come sottolineato nel documento finale del Grupo de Trabalho de Modemização do Orçamento Partecipativo dell'aprile 2001. Ugualmente, come hanno rilevato molti ricercatori e osservatori che a Porto Alegre hanno potuto confrontare assemblee popolari in epoche diverse, anche la trasformazione della capacità organizzativa dei movimenti popolari incaricati di dar forma e gestire le Assemblee Regionali o di quartiere ha comportato una lenta trasformazione (seppur progressiva, alla fine netta) per passare dal caos primigenio degli inizi agli attuali incontri ordinatamente strutturati. ${ }^{54}$

In questo processo di stimolo al crescere e allo strutturarsi della società civile, per poter partecipare come 'pari' e come 'partner cosciente' delle istituzioni alla gestione e progettazione delle scelte politiche per il territorio, non vi sono state solo lentezza e gradualità, ma anche imprevisti e sorprese positive importanti.

Ad esempio, la ricercatrice statunitense Rebecca Abers (1998a)- focalizzando un suo studio di caso sul Bilancio Partecipativo in una regione (l'Extremo Sul) che prima dell'istituzione dell'O.P. non aveva conosciuto esperienze di partecipazione ampia alla vita pubblica né di organizzazione comunitaria ha rilevato la capacità del nuovo meccanismo istituzionale di scoraggiare da subito il ricorso alle abituali prassi di stampo clientelistico e promuovere azioni di lotta collettiva mirate non solo ad ottenere investimenti per il proprio quartiere, ma anche a lavorare in cooperazione con gruppi di altri quartieri in una cooperazione territoriale più ampia. Abers ha anche dimostrato come la preesistenza di forme di associazionismo combattivo sia stata condizione non solo 'non sufficiente', ma addirittura 'non necessaria' per la possi- 
bilità di radicamento del nuovo sistema di coinvolgimento decisionale, specie tenuto conto del carattere chiuso e non partecipativo di una gran parte dell'associazionismo comunitario preesistente all'OP. Non è pertanto un caso se - a Porto Alegre - spesso la mobilitazione nel Bilancio Partecipativo dei quartieri più poveri, e fino al 1989 privi di qualsiasi esperienza di azione collettiva, sia spesso risultata alla fine superiore a quella delle zone storicamente combattive. ${ }^{55}$ Anche in queste ultime si sono, comunque, verificati altri interessanti fenomeni di trasformazione qualitativa e dei modi della discussione.

Una scelta importante è stata quella di porre al centro del processo gli 'individui' e non i gruppi, adottando persino il motto 'una testa un voto' che contraddistingue le modalità di assunzione delle decisioni nell' OP. Se, all'inizio della discussione sui Consigli Popolari (1987-1988), dentro lo stesso Fronte Popolare si riteneva che le forme di partecipazione individuale avrebbero condotto ad un indebolimento delle AMs, oltre che rappresentare una concezione borghese della cittadinanza, si capì poi che esse potevano, invece, rappresentare una sorta di 'ossigenazione' del processo (Fedozzi, 2000, pag. 55), rappresentando fasce di interessi più ampie di quelle che si poteva immaginare, e permettendo l'universalizzazione dell'espressione di entità sociali tra loro diverse. Tale scelta si è mostrata in grado di 'non ridurre l'individuo a rappresentante di una classe sociale' (ibidem) e di evitare la burocratizzazione e il formalismo della 'rappresentanza via organizzazioni' così come di ridurre le pratiche clientelari e personalistiche dei dirigenti comunitari, costretti (senza garanzie a-priori di poter rappresentare i propri cittadini) ad attivarsi e mobilitarsi costantemente a vantaggio della comunità più che di se stessi.

Le caratteristiche di strutturazione dell'esperienza partecipativa cominciata a Porto Alegre con la creazione del Bilancio Partecipativo, sono - in sostanza - riuscite a spezzare quel circolo vizioso (Putnam, 1993) di non-organizzazione, discordia e isolamento individuale tipico di molto associazionismo comunitario tradizionale, proprio massimizzando il sistema di informazioni orizzontali centrate sull'interscambio di 'esempi concreti di realizzazioni ottenute da altri', che ha fornito ad ogni raggruppamento locale elementi di conoscenza del comportamento e delle strategie degli altri, al fine di ristabilire - anche al di fuori del circolo della famiglia (Abers, 1998a) - la 'fiducia reciproca' e quella nell'operato dell'Amministrazione. Il ricrearsi di una fiducia nelle istituzioni - al contempo esito e fautrice di nuovi rapporti di collaborazione diretta tra Stato e Società civile - ha rappresentato un ulteriore duro colpo alle possibilità di riproduzione di relazioni populistico/clienteliste, proprio nella misura in cui ha reso sempre più difficile l'appiattimento della popolazione a 'cliente' del mondo politico, riscattandone la componente attiva di cittadinanza in arene decisionali aperte, dove le tensioni che presiedono al costruirsi del territorio possono svilupparsi alla luce del sole per cercare di 'produrre risultato'.

In tale ottica, il Bilancio Partecipativo ha funzionato come 'strumento scatenante' di un nuovo tipo di contratto sociale capace di generare uno spazio di co-amministrazione (Pozzobon, 1995) dove ristabilire il rispetto per una volontà popolare collettivamente espressa tramite la ricostruzione di un ruolo dell'istituzione su terreni chiaramente distinti dalla tradizione autoritaria che ha caratterizzato storicamente la presenza dello Stato nella società brasiliana. Va infine sottolineato che, oltre ad essere soggetto 'promotore' e 'strutturatore' di un processo formatore di una concezione 'attiva' e 'propositiva' della cit- 
tadinanza, l'Amministrazione di Porto Alegre - all'intemo dell'OP - è risultata anch'essa oggetto di un percorso di trasformazione, che l'ha 'civilizzata' (Genro, 1994, p. 120), l'ha stimolata (e talora 'costretta') a rendersi trasparente, a riformulare la sua conoscenza di se stessa e del territorio che amministra, ma anche a riorganizzare il suo sapere interno e a eliminare ambiguità ed incertezze e - in misura minore - inefficienze e mancanza di coordinamento tra le parti che la compongono. ${ }^{56}$

Così, nonostante sovente i criteri tecnici del Comune abbiano finito (specie nei primi anni) per prevalere sulle ragioni degli abitanti, l'Amministrazione si è trovata obbligata a concentrarsi - anche nelle proposte - solo sui progetti che poteva e può giustificare davanti ad un'opinione pubblica ormai 'allenata a fare pressioni' per avere informazioni e chiarimenti (Abers, 199b).

Al contempo, l'O.P. si è rivelato in questi anni anche uno strumento insostituibile di 'ricostruzione etica della Politica', tramite l'incorporazione politica di nuovi attori e la loro partecipazione attiva nella discussione e formulazione delle politiche pubbliche (Baierle, 1998).

L'esperienza della partecipazione come duplice apprendistato (per i cittadini e per le Istituzioni locali) ${ }^{57}$ sembra, in sostanza, aver generato un meccanismo per cui la cittadinanza ha acquisito capacità di discutere anche nel dettaglio questioni complesse. Ed il Potere Pubblico è stato forzato ad acquisire la capacità di fornire in modo semplice e comprensibile - seppur non semplificato - dati ed informazioni complesse alla popolazione; sconfiggendo così il dubbio che la partecipazione sia possibile solo di fronte alla risoluzione di problemi elementari.

A questo ha, certo, contribuito la caratteristica progressivamente assunta nel tempo dal Bilancio Partecipativo di 'moltiplicatore' su più livelli del dibattito in corso di svolgimento all'interno della città, di cui sono prova il sorgere prima delle Assemblee Tematiche, poi delle Commissioni di Accompagnamento e controllo dei lavori e dei Forum di Servizio (che si occupano delle richieste di manutenzione che non competono all'O.P.), infine del processo Cidade Constituinte, ma soprattutto il moltiplicarsi spontaneo delle Associazioni di Residenti e delle Commissioni informali di Strada (senza statuto approvato ufficialmente), di isolato o di quartiere.

Un interessante ruolo nel progressivo 'slittamento' degli orizzonti dell'O.P. lo hanno svolto, soprattutto, i numerosi Consigli Municipali, accresciuti di numero, riformati e restituiti ad una genuina partecipazione popolare dopo decenni in cui questa era stata ridotta a residuo facciatista, peraltro utile a che il Potere Pubblico esercitasse un controllo sui movimenti urbani.

Queste strutture, moltiplicatesi in questi ultimi anni, sono servite, infatti, a compiere un percorso 'a ritroso' per ricominciare a discutere pubblicamente di politiche settoriali dopo aver restituito alla cittadinanza una voce autorevole sulla gestione dei fondi a disposizione dell'Amministrazione. E - seppur alcune di queste istanze partecipative "hanno forme particolari e diverse di elezione o di indicazione per la composizione" e sono, pertanto, viste da alcuni critici come pericolose per la frammentazione ulteriore che introducono nei movimenti popolari (De Olho no Orçamento, n. 7/98) - esse non cessano di avere un aspetto positivo, stimolando un indispensabile arricchimento dei contenuti, della qualità e dell'ampiezza di visione degli spazi e dei momenti di interazione tra abitanti e istituzioni. 
Quanto finora rilevato, denota - nel complesso - un quadro di impegno coerente e costante dell'Amministrazione Popolare nell'investire risorse ed energie organizzative in un processo ritenuto 'strategico' per far sì che la partecipazione popolare ai meccanismi di gestione della città (su cui la coalizione al govemo a Porto Alegre ha puntato fin dal 1989) possa gradualmente estendersi in altri ambiti, ed arrivare a offrire un contributo propositivo ed in continua crescita qualitativa a tutti i livelli di sviluppo delle politiche urbana.

È vero che - in un contesto in cui gli enti pubblici funzionano di solito su una routine (e l'apprendimento non è per loro un fatto naturale) - il Comune di Porto Alegre ha contribuito non poco a decostruire routine di comportamenti consolidati, impegnandosi in tutte le fasi di sviluppo del Bilancio Partecipativo per dargli forza, visibilità e centralità, oltre che per sostenerlo nei momenti in cui è stato attaccato e minacciato da critiche pregiudiziali. È altresì vero che l'impegno dell'Amministrazione di Porto Alegre è stato innegabilmente profuso con continuità, per tenere desta l'attenzione della città sull'O.P. dando concreta realizzazione a tutte le richieste priorizzate dai cittadini, per potenziarne il ruolo di moltiplicatore del dialogo e di strumento capace di indirizzare le politiche, per correggerne i limiti con l'aiuto del COP e della popolazione in modo da raggiungere maggiore 'solidarietà' ed 'equità distributiva' a vantaggio dei più deboli, e - soprattutto - per connetterlo con alcune riforme della macchina amministrativa per dargli più efficacia e credibilità. Sarebbe però un errore seguire quelle letture del percorso evolutivo dell'OP troppo incentrate sull'azione di 'empowerment della cittadinanza' svolto dall'Amministrazione Popolare in questi anni. ${ }^{58}$ In fondo - come ha ben dimostrato Menegat (1995) - "i movimenti sociali urbani di Porto Alegre proponevano la democratizzazione della discussione sul bilancio del municipio molto prima del 1989" (Alfonsin e Allegretti, 2003) e la loro pressione aveva iniziato a produrre effetti di 'apertura' alla partecipazione popolare già a partire dall'amministrazione Municipale di Alceu Collares.

In ogni caso, sottolineare la distanza tra esegesi inconciliabili, oggi vuol dire solo gonfiare artificialmente uno scontro sul 'diritto d'autore' del Bilancio Partecipativo, che in realtà non c'è mai stato, né tra attori protagonisti del processo $^{59}$ né tra ricercatori, ${ }^{60}$ visto che da ogni parte è sempre stato riconosciuto come 'processo collettivo' non solo nel suo funzionamento, ma anche nelle tappe della strutturazione. Anzi, va forse sottolineato che è proprio negli scritti e nei discorsi degli stessi rappresentanti politici portoalegrensi - senza eccezioni - che l'OP è sempre volutamente presentato come una creazione collettiva - addirittura una 'creatura collettiva' (Genro, 2001i) - dei cittadini di Porto Alegre, senza distinguere il loro ruolo di tecnici, di politici o di membri dei movimenti comunitari che essi avevano o hanno. A volte, si ha addirittura la sensazione che - proponendo (reiteratamente e in forme estremamente comunicative) un recupero narrativo di aspetti pregnanti e fasi dell'esperienza di crescita temporale dell'OP - si cerchi esplicitamente di contribuire alla creazione quasi di un 'mito collettivo' che deve molto ai movimenti popolari, pur avendo nel suo centro "l'individuo come soggetto storico" (Andreatta, 1997).

Si potrebbe dire che, per molti versi, la proposta del Bilancio Partecipativo ha due coautori - il Fronte Popolare e i movimenti urbani - e che la pressione 
anteriormente esercitata da quest'ultimo ha avuto un peso determinante nell'implementazione di un progetto che, per questo, va oggi letto come una "politica pubblica contestualizzata [...] situata storicamente, e fortemente segnata dalle condizioni sociali e storiche specifiche" (Alfonsin e Allegretti, 2003) del percorso seguito nel territorio portoalegrense dai movimenti sociali urbani (cfr. cap. 6).

Come ha scritto Baierle (1998), l'esperienza di governo del Fronte Popolare a Porto Alegre ha innescato un "fondamentale processo di apprendimento mиtuo", non occorso perché lo Stato ha imposto una particolare visione della partecipazione democratica sulla società, ma piuttosto perché le istituzioni hanno aperto lo spazio pubblico in cui settori organizzati della popolazione hanno potuto appropriarsi della politica locale, rivelando che il processo di appropriazione poteva essere messo in atto da soggetti molteplici (piuttosto che unitari) rappresentativi di una vasta gamma di forze politiche e sociali. All'interno di questa dinamica, se non vi è dubbio che l'Amministrazione comunale ha giocato un ruolo attivo nel costituire questo soggetto molteplice, va riconosciuto che le azioni del Potere Pubblico erano esse stesse modellate dagli 'interessi' autonomamente costituiti dei settori popolari, ora articolati nei loro spazi specifici di azione civica.

In tal senso, l'OP di Porto Alegre rappresenta un momento di incontro 'a metà strada' (o un 'punto di equilibrio', come definito da Genro, 2002) fra due approcci diversi e consonanti di democratizzazione, uno top-down e uno bottom$u p$, che nel 'radicamento nel locale' vanno cercando una durabilità che non costituisca mera sopravvivenza, ma opportunità di crescita continua e parallela del meccanismo partecipativo e della popolazione che vi partecipa.

\subsection{L'incontro dell'OP con le diverse anime della città: un esempio di 'au- toprogettualità'}

Ogni volta che si guadagna in coerenza, in unità si perde in creatività, in adattamento alla diversità dei contesti e degli attori (P. Calame, A. Talmant, 2001, p. 139)

Il Bilancio Partecipativo di Porto Alegre ha avuto il merito riconosciuto di giungere per gradi ad una proposta metodologica comune di lavoro tra istituzioni e società civile, che ha stimolato quest'ultima a non contare su proposte belle e pronte dell'Amministrazione, ma a guadagnarsi il diritto alla partecipazione (Menegat, 1995) attraverso uno sforzo immaginativo e di comprensione della complessità di una gestione amministrativa globale. Se - all'inizio del processo - i canali di informazione usati dal Comune si mostrarono insufficienti a raggiungere la gran parte dei cittadini, è soprattutto sui militanti della società civile già organizzata (ed in particolare sui leader delle associazioni di quartiere) che ricadde un consistente lavoro di cooptazione e coinvolgimento della popolazione alle assemblee. Ma tra i principali contributi autonomi offerti alla strutturazione e al consolidamento del Bilancio Partecipativo dall'impegno diretto dei movimenti popolari nella sua costruzione, resta soprattutto quello saggiamente affidato loro dall' Amministrazione già nel primo anno di sperimentazione dell'OP, ovvero la sua 'spazializzazione' nel territorio cittadino.

Nel cap. 8 abbiamo visto come il primo tentativo di costruire una base 'territorializzata' di riferimento per il processo di OP ripercorse sostanzial- 
mente l'organizzazione fisica delle 'Articolazioni Regionali' attraverso cui il movimento comunitario cittadino era andato organizzandosi a metà degli anni '80. Il secondo passo compiuto dall' Amministrazione - non appena verificati i problemi organizzativi dovuti all'eccessiva ampiezza degli ambiti fisici a queste corrispondenti - fu di chiedere ai movimenti popolari di proporre una scomposizione delle Articolazioni in micro-regioni che facilitassero l'organizzazione di dibattiti ed assemblee sul territorio. Ciò fu fatto sia tenendo conto dei legami di cooperazione preesistenti tra singole comunità ed organizzazioni popolari, sia lavorando sulla rilevazione del senso di appartenenza e delle caratteristiche identitarie delle varie zone della città anche in rapporto alle difficoltà fisiche di comunicazione tra singoli quartieri e nuclei abitati in rapporto alla complessità territoriale e alle peculiarità geomorfologiche e di sviluppo storico di Porto Alegre (Menegat, 1995). Già durante il corso del 1990, ai 15 ambiti originariamente individuati se ne aggiunse uno nuovo, per la scissione della micro-regione Restinga/Belém Novo/Lami in Microregione Extremo Sul e Restinga. E - fin dalla predisposizione della discussione sul bilancio per 1991 - le micro-regioni individuate dal movimento cittadino vennero elevate a Regioni di articolazione del processo di Bilancio Partecipativo. Tra di esse, i Consiglieri Popolari ne scelsero poi alcune a cui - in base ai differenti criteri esaminati nel cap. 8 - sarebbe toccato spartirsi il $70 \%$ delle risorse 'di capitale' per i nuovi investimenti. Il numero di Regioni - 16 - si è mantenuto invariato fino ad oggi, ma le variazioni nelle delimitazioni fisiche delle varie Regioni hanno richiesto più tempo per l'auto-assestamento. Così, è possibile rintracciare variazioni consistenti nella 'spazializzazione' dell'OP fino al 1995, quando il COP decise di assemblare la Regione autonoma delle isole del lago Guaiba (lhas) a quella Humaitá/ Navegantes, mentre parallelamente la Regione Eixo Baltazar fu smembrata in due per difficoltà di dialogo tra le comunità che ne componevano alcune sue parti, dando vita alla regione Noroeste. Piccoli auto-aggiustamenti di confine, protrattisi sino al 1998, hanno determinato in quell'anno un assestamento sostanziale delle Regioni, che il COP - su proposta dell'Amministrazione - ha accettato di aggregare a due a due, in modo da individuare 8 Macro-Regioni di Pianificazione (poi registrate nel Piano Regolatore entrato in vigore nel marzo 2000) a cui far corrispondere anche 8 Centri Amministrativi Regionali (CAR), ovvero strutture di decentramento di alcune pratiche amministrative in cui trovano sede anche i CROPs delle due Regioni di riferimento (cfr. cap. 12), che curano - insieme ai movimenti comunitari e ai Consiglieri popolari da esse eletti - 1'organizzazione dei cicli di dibattiti dell'OP all'interno di quegli ambiti fisici. Sulla base delle Regioni si sono inoltre articolati i Consigli Municipali di Assistenza Sociale ed altre strutture riconosciute dal Comune per favorire la partecipazione degli abitanti all'orientamento delle diverse politiche pubbliche sul territorio.

Questo 'addensarsi' di strutture organizzative sugli stessi ambiti di riferimento, potrà forse avere un effetto 'bloccante' nel tempo sulla loro eventuale riarticolazione (specie perché sancito negli annessi di una Legge Municipale approvata, come è quella che istituisce il nuovo Piano Regolatore di Sviluppo Urbano e Ambientale): non esiste però nessun ostacolo 'formale' al fatto che in futuro le Regioni cittadine possano autonomamente proporre e votare una riorganizzazione dei propri limiti. Inoltre, esse restano libere di suddivi- 
dersi in micro-regioni e consorzi di comunità e quartieri, per facilitare l'organizzazione dei processi partecipativi.

La spazializzazione del Bilancio Partecipativo è stata, quindi, autonomamente realizzata dai cittadini e dai loro movimenti organizzati, privilegiando una lettura dell'articolazione del territorio urbano in termini socioculturali rispetto alla codifica dei suoi 'segni fisici': e attualmente resta legata agli stessi principi strutturanti che hanno permesso di superare le preesistenti divisioni dei 'bairros' e delle 'Unità di Parcellamento' consacrate dal vecchio Piano Regolatore anche nel tentativo di frammentare le energie sociali autorganizzato attraverso lo 'scavalcamento' delle loro articolazioni operato ricorrendo a limiti fisici elaborati dai tecnici del Comune. La scelta fatta dall'Amministrazione Popolare fin dal suo esordio alla guida della città è stata quindi quella di designare la 'spazializzazione' dei processi partecipativi come ambito di autonomia organizzativa della società civile, valorizzando per tale via le sue energie e capacità aggregative, nel riconoscimento del fatto che le frontiere tra ambiti di organizzazione dei processi non sono neutre (M. de Souza, 2002), in quanto: a) possono arricchire o indebolire singoli gruppi sociali dentro ogni area ${ }^{61}$ influenzando le dinamiche di distribuzione del reddito;

b) possono influire sugli equilibri e le dinamiche sociopolitiche e identitarie sia aggregando insieme spazi disomogenei (in grado o meno di cooperare tra loro) sia rompendo o mutilando reti di solidarietà informale e 'luoghi' omogenei (o complementari) sotto il profilo del senso di appartenenza e della percezione identitaria.

Di conseguenza, se ogni divisione 'difettosa' del territorio messa in atto (sia involontariamente, per forza di inerzia tecnocratica, sia deliberatamente) ${ }^{62}$ può rischiare di generare ingiustizie, tensioni, frustrazioni, risentimenti e conflitti inutili dentro la società civile ${ }^{63}$ e tra essa e il potere istituito, demandare alla società civile di indicare una possibile articolazione territoriale e gestire la fase di ricerca per identificarne le caratteristiche ${ }^{64}$ parve all'Amministrazione Popolare il modo migliore per neutralizzare o almeno diminuire tali rischi. A distanza di 14 anni, la linea del Comune di Porto Alegre non pare cambiata se come concordemente riconosciuto da tutti i critici - non sono mai stati rilevati interventi istituzionali mirati a forzare le autonome decisioni della popolazione e del COP in questo settore, o a 'proporre con forza' diverse formulazioni della questione. Semmai, per evitare che si creassero blocchi 'centripeti' chiusi nell'immediatismo e nel localismo delle loro discussioni interne, il Comune ha stimolato la costruzione di istanze e consigli a partecipazione 'aperta' (come i Consigli Municipali e le Assemblee Tematiche) che avessero come traguardo la cooperazione tra territori diversi, ed il "progressivo affrancamento della discussione dal localismo trito" a favore della capacità di "pensare la città come un insie$m e$ ", traguardi già indicati come necessari dal documento di valutazione scritto dai rappresentanti popolari a conclusione del primo anno di sperimentazione dell'OP (Representantes das Microrregiões de Porto Alegre, 1989).

In ogni caso, è certo che un simile modo di procedere ha favorito che - in un territorio morfologicamente e socialmente così articolato come Porto Alegre - l'impatto multiforme di un processo innovatore come il Bilancio Partecipativo (per di più interessato ad innestare un dialogo sui conflitti esistenti fra le diverse anime della cittadinanza) assumesse forme diverse, rispettose delle diverse dinamiche con cui era stato accolto e andava radicandosi nelle diverse zone della città. 
Come collettore e compositore di conflitti, infatti, l'O.P. si scontrò in molte aree con le preesistenti strutture di organizzazione della popolazione, arrestandosi temporaneamente o riorganizzando il loro modo di articolarsi nell'ottica degli obiettivi concreti ma anche pedagogici che i suoi vari estensori si erano prefissi nel promuoverlo. In molti casi, la capacità di interazione specifica mostrata nel suo 'incontro con i diversi locali' ha portato l'O.P. (almeno inizialmente) ad un'organizzazione diversificata nelle varie aree di Porto Alegre, che la sua struttura flessibile e aperta ed il suo ruolo di 'moltiplicatore' inevitabilmente hanno propiziato, anche come forma di auto-sopravvivenza. In questi casi, è risultato come la preoccupazione ideale di ricercare 'modelli di partecipazione' funzionanti e replicabili, abbia avuto la pazienza di cedere il ruolo-guida ad un percorso fattivo centrato sullo 'svilupparsi di processi con base in politiche e programmi concreti e non preventivamente istituzionalizzati' (Moura, 1993), in un percorso di lento e progressivo avvicinamento alle previsioni dell'immaginario teorico, senza che un rilevante ruolo venisse svolto dall'aspetto 'codificatore' e 'normativo' dell' Istituzione; piuttosto dal suo braccio 'pratico' (spesso rappresentato da membri politicizzati del movimento comunitario), attento alla concretezza degli atti di gestione del territorio e delle finanze.

Ad esempio, in zone con alti livelli di attrito (interni o nei confronti del Potere Pubblico), i conflitti sociali sono riusciti nel tempo a comporsi, perché l'OP ha permesso di ricorrere a quelle che Andreatta (1997) ha definito 'vie traverse', ossia prima attraverso l'opera concreta che non il lavoro di coscientizzazione e cooptazione dei cittadini. In tali casi, la microregionalizzazione autonomamente cominciata in alcune aree, e oggi suggerita dal COP anche all'interno del Regolamento Interno del Bilancio Partecipativo, ha rappresentato un'importante risorsa per la riorganizzazione ed il consolidamento del processo su nuove basi territoriali.

\subsubsection{Alcuni esempi}

Il caso della Grande Cruzeiro (un'area stretta fra rilievi collinari che conta oltre 40 favelas) è emblematico di come, per affermarsi, l'O.P. necessitò talora di una preventiva e autonoma risoluzione da parte della comunità dei problemi interni di mobilitazione che la affliggevano. Come abbiamo accennato nel cap. 6, dal 1980 esisteva nella regione una Unione di Favelas (União de Vilas) creata dagli abitanti per aver più forza contro la minaccia costante degli sgomberi, sempre attuale in una zona interessante per la posizione nel panorama cittadino che offriva la possibilità di proficui lucri immobiliari. Se l'adesione all'O.P. avrebbe potuto apparire automatica nel tentativo di trasformare le istituzioni locali da nemici in partner, così non fu; o almeno non in maniera lineare e meccanica. Il conflitto storicamente forte e quasi pregiudiziale contro il Potere Pubblico generò, infatti, una seconda entità aggregatrice delle Associazioni di Quartiere (il Consiglio Popolare del Morro Santa Tereza) e la duplicità del comando rese necessaria un'armonizzazione dei leader. Per far questo, nel 1994, l'Amministrazione decise di 'localizzare la sua azione' (Andreatta, 1997), dando vita ad un'ulteriore struttura, il Forum Speciale per la discussione delle questioni pubbliche, che tentava di superare - mettendoli a confronto su questioni di importanza sovralocale - i due blocchi di potere autogeneratisi nell' area, nessuno dei quali era disposto a 
rinunciare alla sua fetta di dominio. Questo sembra aver rotto la visione egemonica centrata sulla singola 'vila', e solo così l'O.P. ha potuto riprendere il suo cammino in questa Regione, diventando il centro di dibattito anche per le questioni locali. In parallelo, l'acquisizione e l'urbanizzazione dell'area detta 'Ipê Barracão' è servita, e ancora serve, da valvola di sfogo dove collocare - in luoghi non lontani dal loro ambito tradizionale di vita - le famiglie che è necessario spostare durante le operazioni di regolarizzazione fondiaria e urbanistica di alcune aree della regione.

Così - attraverso la costruzione di opere di interesse comune, come la viabilità percorsa dai mezzi pubblici, o quella che lega tra loro diverse 'vilas' - il $\mathrm{BP}$ è stato in grado di 'approfondire e massificare le lotte condotte già da tempo dai movimenti urbani' (Andreatta, 1997) superando le liti di vicinato (il cosiddetto 'bairrismo'), cioè lottando contro la frammentazione degli orizzonti, al contempo fisici e sociali.

Sforzi diversi ed intensi ha richiesto, invece (e ancor oggi richiede), il distretto delle Isole della Laguna, assemblatosi alla regione Humaitá/Navegantes nel 1995. In quest'area dai forti contrasti ('vilas' poverissime e ricche case di vacanza decadute) la protezione ambientale del cosiddetto 'Delta del Guaiba' ha costituito un grande impedimento allo sviluppo delle popolazioni locali, almeno a partire dal Decreto $28.436 / 79$ che ha istituito il PLANDEL, il Piano Base del Parco Statale del Delta del Jacuí, che vincola ogni minima realizzazione all'assenso della Fondazione Zoobotânica Statale. La misura era certo necessaria per arginare il forte degrado della zona, ma è risultata poco comprensibile agli oltre 5000 abitanti delle 4 isole ${ }^{65}$ in prevalenza raccoglitori di rifiuti [lixeiros], robivecchi e allevatori di maiali, ma soprattutto persone che vivono di lavori saltuari. A differenza che nelle altre parti della città, nelle isole il discorso della 'democrazia sostantiva' non dava stimolo all'O.P., nella misura in cui il PLANDEL frustrava ogni richiesta presentata dalla popolazione per infrastrutturare l'area, anche solo con i servizi essenziali. Tra il 1992 e il 1993 l'Amministrazione tentò piccoli interventi informali, pavimentazione e conservazione delle strade esistenti, una rete fognaria e una di approvvigionamento idrico, e una scuola affidata ai Padri Maristi, a cui apparteneva tra l'altro Padre Antonio Cechin, organizzatore di molte cooperative di riciclaggio e nominato dal Sindaco Dutra 'subprefeito' [una sorta di sindaco aggiunto] delle Isole. Nell'area, 16 erano all'epoca le Associazioni ufficialmente registrate, tra cui club sportivi, centri di 'Umbanda', associazioni ricreative e Club di madri. Per cooptarle nell'O.P., il Comune studiò un'organizzazione alternativa dello stesso, stabilendo una riunione Plenaria in ogni isola e indicendo poi una Plenaria congiunta. Ma, già nel 1993, la frustrazione per la mancanza di possibilità di concreto intervento (in particolare per la costruzione di un muro contro le piene) depressero i leader comunitari, molti dei quali rinunciarono al loro incarico. La partecipazione all'O.P. - sempre poco convinta ebbe un calo notevole, tanto che nel 1994 il movimento popolare nelle isole dovette riorganizzarsi ripartendo da zero e ricomporre la credibilità dell'OP divenne una sfida maggiore dell'anno prima (Andreatta, 1997).

La rinascita della partecipazione cominciò ad aversi con la scelta di organizzare commissioni tematiche di area: cultura, ambiente, difesa civile, educazione per giovani e per adulti, e un comitato contro la fame e la miseria. I nuovi delegati dell'anno successivo presentarono al Plenum una richiesta 
264 atipica di investimento per il Comune: "uno studio sulle limitazioni giuridiche dell'area di preservazione e su come aggirarle" (ibidem). Così, con l'adesione delle richieste alle specificità locali dell'area, il processo di discussione fra popolazione e istituzioni riuscì a ripartire nel 1995, scegliendo per di più di aggregarsi alla regione Humaità/Navegantes (che si trova dall'altro lato del ponte che dà accesso alle isole) e rinunciando alla sua autonomia decisionale in cambio del sentirsi maggiormente inserita nella città. La vittoria del Fronte Popolare nelle elezioni Statali del 1998 ha dato avvio ad un processo di dialogo con il nuovo Governo sulla riducibilità del vincolo ambientale nell'area ormai abitata: esso ancora non ha prodotto risultati visibili, ma si spera possa produrli in breve tempo, se la nuova amministrazione che uscirà dalle elezioni dell'ottobre 2002 non interromperà le negoziazioni cominciate con il Comune di Porto Alegre.

Interessante anche la particolare strutturazione che il Bilancio Partecipativo ha dovuto assumere, poi, nella regione centrale della città, punto di convergenza del sistema stradale e commerciale e della rete metropolitana dei trasporti, ma soprattutto sede privilegiata delle attività culturali, formative e amministrative. Queste attività non hanno scarificato quelle residenziali, visto che a tutt'oggi la Regione conta circa 300.000 abitanti, 8000 dei quali residenti in favelas irregolari che fanno da contraltare alla massiccia presenza della classe media e medio-bassa. Fino al 1989 la tradizione dei movimenti comunitari nell'area era piuttosto arretrata e articolata in modo frammentario per attività isolate, nonostante qui fosse nata la rivendicazione del 1954 per le linee di bus notturni da cui aveva avuto origine la FRACAB, la Federazione delle Associazioni di Amici del Quartiere (cfr. cap. 6). La mancanza di strutture di discussione preesistenti e la diffidenza dei leader delle 20 associazioni esistenti nei confronti dell'Amministrazione Popolare fu un ostacolo all'installazione del Bilancio Partecipativo nella regione, almeno finché - nel 1991 - non sorsero nuovi leader, formatisi soprattutto all'interno della classe media. Queste condizioni specifiche della regione Centro dettero origine ad una struttura atipica delle riunioni dell'OP, spesso aperte a conferenzieri invitati da fuori e articolatesi intorno alla discussione del ruolo di ogni persona nella sua comunità (Andreatta, 1997) - quindi secondo una concezione molto diversa da quella collettivistica che caratterizzava altre aree della città. I risultati concreti ottenuti alla fine di questo ciclo di iniziative, grazie alla credibilità ottenuta dal processo, portarono netti benefici soprattutto in alcuni dei quartieri più polemici, e fino ad allora dimenticati, come il quartiere ebraico di Bom Fim (pericoloso soprattutto di notte e beneficiato con illuminazione notturna e rafforzamento della sicurezza) e quello omosessuale di Olaria nella Cidade Baixa; entrambi sono attualmente centri vitali della vita culturale e notturna dell'élite portoalegrense, ma senza aver snaturato i caratteri distintivi che ancora possedevano all'inizio degli anni '90. In questa regione ebbe inizio, tra l'altro, uno degli atti più meritori attribuibili all'Amministrazione Popolare in questi anni; la politica di rivendicazione del 'diritto dei poveri al centro' iniziata nel 1992 con la trasformazione della favela Vila Planetario (vedi cap. 13), senza rimuovere dal luogo gli abitanti, come la logica della valorizzazione fondiaria avrebbe suggerito.

Altro esempio significativo delle diverse strategie con cui l'O.P. si organizzò nei diversi territori che compongono Porto Alegre, è rappresentato dalla re- 
gione della Restinga, vera città nella città (anche se fuori dall'agglomerato urbano più compatto) nata negli anni '70 come ghetto popolare composto di persone fatte sgomberare dal Potere Pubblico da varie aree della città e che oggi conta circa 45.000 abitanti. La sua peculiare evoluzione l'aveva resa un luogo di scambi clientelari con i poteri istituzionali, che passavano soprattutto per la sede decentrata del Dipartimento alla Casa, lì localizzata. La strategia scelta dall'Amministrazione Popolare nel 1989 per favorire l'attecchimento del Bilancio Partecipativo fu di impiantare un CAR [Centro Amministrativo Regionale] ponendo particolare attenzione al fatto che incarnasse i principi del nuovo Esecutivo, e che si costituisse come vero e proprio mediatore fra le Istituzioni, le necessità e le rivendicazioni comunitarie, coordinando, eseguendo e controllando soprattutto le richieste di servizi, di conservazione e manutenzione. Migliorare i servizi nel quartiere (a partire dalla sostituzione della linea di bus Belém Novo con la Tinga, un pool di imprese efficienti, fino all'ampliamento dell'Unità Sanitaria e del Pronto Soccorso Parque Belém) fu visto come il modo per conquistarsi la popolazione, a dispetto dei pochi fondi insufficienti a venire incontro alle sue maggiori richieste. L'O.P. in questo caso, impegnato soprattutto a far emergere nuovi leader comunitari, venne incontro all'impeto di democratizzazione di una fetta della comunità e riuscì a "rompere la spina dorsale del movimento comunitario tutelato, che viveva intorno ed in funzione dello Stat"o abituando la popolazione locale "al nuovo vocabolario delle negoziazioni - quando la parola No passò a sostituire, molte volte, le tradizionali FORSE, o L'ANNO PROSSIMO ${ }^{66}$ per sollecitazioni multiple che potevano andare fino alla copertura del patio di casa" (Andreatta, 1997). Con il recupero della sua capacità finanziaria, il Comune fu in grado di realizzare opere fondamentali da tempo in discussione, come la pavimentazione della strada Barro Vermelho ('fango rosso'), e il Viale 7.109 per cui passavano i bus. Attualmente, la trasformazione in 'Distretto Industriale' - con la costruzione del Parco Tecnologico - ha innestato un'interessante battaglia della popolazione contro qualsiasi tipo di industria inquinante, da cui si sono poi originate altre lotte come quella (che data 1993) per il recupero ambientale del Morro São Pedro, snaturato dalle cave per costruire i terrapieni del quartiere. Attualmente la Regione della Restinga - area popolare non soggetta a forme di gentrificazione anche a causa del suo isolamento - non solo costituisce uno dei 'centri culturali' della città (con oltre 80 Associazioni ricreativo/culturali), ma ha messo in atto una serie di iniziative imprenditoriali autorganizzate che hanno stimolato il Comune a creare programmi di appoggio alle microimprese in aree marginali, e le cosiddetti 'incubatrici di impresa' proprio qui sperimentate per la prima volta e ora replicate in altre città sudamericane della Rete Mercocidades.

\subsection{L'obiettivo della 'equità distributiva'}

Non basta essere un g ovemo 'promotore', visto che i propri investimenti possono dividere ancor di più la società e a aumentare le sue differenze sociali. Il giusto sarebbe chiedere: promotore di che? Di chi? Di che progetto di società? (Genro, 2002)

È possibile, plausibilmente, ipotizzare che una delle ragioni per cui il Bilancio Partecipativo è riuscito ad imporsi all'attenzione pubblica e ad acquisire in breve tempo visibilità e legittimazione agli occhi dei cittadini, dell'Esecutivo e - in ultima analisi - anche del Consiglio Comunale, ${ }^{67}$ sia il fatto che 
esso non è stato usato come 'strumento neutro', ma inserito dentro un progetto politico che, già dal 1989, faceva perno principalmente sulla inversione delle priorità' a favore delle fasce di popolazione tradizionalmente dimenticata dagli investimenti urbani, e comunque fino ad allor a mai coinvolta in nessuna forma di negoziazione delle scelte per il territorio se non all'interno di meccanismi di stampo clientelare-paternalista.

Il Bilancio Partecipativo - fin dalla sua creazione - ha deliberatamente puntato al coinvolgimento di questa ampia parcella di cittadinanza, come dimostrano le molte ricerche che ne hanno esaminato i primi anni di sperimentazione $^{68}$ sottolineando l'impegno di risorse umane e finanziarie diretto dall'Amministrazione Popolare proprio verso gli strati più disagiati della popolazione. Essi, anzi, hanno costituito l'indispensabile "massa di manovra per far decollare il processo nell'immaginario cittadino, anche sfruttando il passaparola e l'effetto emulazione determinato dai primi concreti investimenti decisi da coloro che avevano inizialmente scommesso sul nuovo processo decisionale facendosi forza per superare il legittimo disincanto che ogni nuova azione istituzionale non poteva che suscitare dopo tanti anni di deliberata esclusione da parte del Potere Pubblico di chi già era un 'escluso' per il mercato e per la società” (Cúnico, 1999i, apud Allegretti, 2000a).

In tale ottica, si può dire che il costituirsi dell'O.P. come nuovo centro decisionale cittadino, fu 'la prima politica' messa in atto dalla neoeletta Amministrazione Popolare nel 1989 con l'intento di dare inizio ad una democratizzazione effettiva dell'azione politica che "integrasse $i$ cittadini comuni in un "nuovo spazio pubblico', istigandoli ad essere più esigenti e più critici” (Genro, 2002); e per come essa fu messa in atto, in un certo senso costituì una sorta di "politica sociale'. Se, infatti, la creazione del Bilancio Partecipativo creava - in linea teorica - solo un nuovo spazio dibattimentale che sarebbe anche potuto divenire luogo di attrazione per le classi sociali già tradizionalmente incluse nei processi di negoziazione urbana, il modo con cui il progetto fu condotto nei primi anni della sua sperimentazione denota la volontà di propiziare

[...] un'inversione delle priorità di azione dell' amministrazione in grado di generare una distribuzione del reddito e contribuire alla socializzazione della politica. Far l'una cosa senza l'altra sarebbe stato poco; avrebbe creato un paternalismo nocivo all'affermazione dell' autonomia dell'individuo e delle organizzazioni di base della società, o - al contrario - avrebbe reso inefficace la lotta politica promovendo la 'ritirata' delle persone verso un ambito sempre più privato della loro esistenza. La democrazia, infatti, non può essere separata dalla libertà, e la libertà non può essere isolata da un'uguaglianza minima di opportunità [...] uguaglianza per influire e per decidere sulla propria disuguaglianza sociale (Genro, 2002)

L'impegno verso il coinvolgimento delle classi più deboli nell'OP fu così finalizzato a generare concrete opportunità di inversione dell'allocazione degli investimenti a loro vantaggio, ma contestualmente alla ricostruzione del 'senso di cittadinanza' attraverso un'azione concreta di promozione dei loro diritti e di restituzione di una 'voce' che avesse un peso sulle scelte operate dalle politiche pubbliche. In tale quadro di significati, si può capire perché - nel tempo - l'O.P. abbia finito per conformarsi come un percorso di 'riequilibrio' di alcune distorsioni della 'società di mercato', centrandosi sul ruolo attivo delle comunità emarginate. Se ci si chiede se 
questo è stato solo 'uno degli esiti possibili' (se l'OP avrebbe potuto essere uno strumento in mano ad altri segmenti della cittadinanza) la risposta è che indubbiamente tale esito non è stato casuale, ma - leggendo tra gli investimenti dei primi anni di sperimentazione - esso appare chiaramente 'guidato' da una volontà politica forte, concentratasi dapprima a fare del Bilancio Partecipativo lo strumento essenziale per dare una voce ai cittadini tradizionalmente esclusi da ogni decisione sulle risorse pubbliche, e poi (specialmente dal 1994) a trasformarlo in un luogo 'includente' di incontro per tutta la cittadinanza, pur senza rinunciare a sottolineare costantemente la necessità di salvaguardarne i meccanismi di promozione della solidarietà verso i cittadini più poveri.

In quanto 'politica' (che ha comportato un sostanziale 'investimento in democrazia' da parte dell'Amministrazione che l'ha promossa), il Bilancio Partecipativo ha - quindi - potuto affermarsi e consolidarsi a Porto Alegre facendo centro sulla necessità di 'sbilanciare' temporaneamente il governo del territorio a favore dei gruppi più deboli della società come forma di discriminazione positiva dei più deboli ${ }^{69}$ per poter ambire alla costruzione di una maggiore 'giustizia distributiva' e recuperare nel tempo un forte dinamismo territoriale, che servisse " $a$ ricostruire un 'patto a vasto spettro' tra categorie diverse di cittadini, incluse varie inizialmente scettiche su scelte non compiute in loro favore" (ibidem).

Questi obiettivi sono stati raggiunti gradualmente, ma perseguirli non è stato meccanico né pacificante; ha comportato, anzi, momenti di forte tensione ed il superamento di ostacoli di cui va riconosciuto pieno merito all'Amministrazione Popolare che (sovente anche a costo di contrasti interni alla stessa maggioranza) ha dovuto più volte opporsi con coraggio al rischio plebiscitario montante (e sfidare gli incerti elettorali connessi con questo contrasto) nelle grandi assemblee frequentate prioritariamente dagli abitanti delle favelas cittadine, che a gran voce lottavano per imporre le loro priorità, col rischio - da un lato - di far crescere scontento ed avversione negli strati della popolazione che abitavano in prevalenza la città formale, ma anche - dall'altro - di consolidare scelte escludenti per chi, tra le categorie sociali più deboli, non partecipava comunque ai momenti decisionali nel Bilancio Partecipativo e nelle altre arene deliberative cittadine via via attivate.

Riguardo a quest'ultimo pericolo, va sottolineato che l'influenza esercitata dai gruppi più organizzati dentro il Bilancio Partecipativo non si fa solo notare direttamente al momento del voto sulle priorità di bilancio, ma incide anche sui criteri utilizzati dai diversi livelli assembleari per effettuare la ripartizione dei fondi e l'accoglimento stesso delle priorità, visto che sono i rappresentanti eletti dai cittadinia decidere ed approvare ogni variazione del Regolamento Interno dell'O.P..

Come abbiamo già accennato, quando 1' 'effetto dimostrazione' ha evidenziato la sua insufficienza a garantire agli abitanti più deboli una voce nell'O.P., tanto più dato il sistema di elezione proporzionale dei Delegati che ha spesso finito per incentivare "una rotazione significativa delle associazioni di quartiere nelle posizioni dominanti del processo" (Abers, 1998b), è stata l'Amministrazione a dover intervenire in alcuni casi a garanzia dei cittadini più deboli (perché dotati di minor capacità di mobilitazione e organizzazione dei 
268 propri gruppi); e non sempre è stato facile raggiungere lo scopo. La maggior parte dei militanti partecipanti al Bilancio Partecipativo, infatti, si è spesso dimostrata inflessibile sulla concessione di benefici a chi non partecipa direttamente all'O.P. (o vi partecipa senza mobilitare le proprie comunità di riferimento), lungi dal voler accettare anche solo di comprendere le 'condizioni al contorno' e i 'costi partecipativi' che spesso bloccano i più poveri dalla partecipazione. Una sorta di 'etica del lavoro' legata al concetto di 'diritti e doveri della cittadinanza' (che in questo caso pare ritorcersi contro la classe politica che ha lottato per diffonderne la comprensione) ha sovente reso difficile il dialogo in favore dei più poveri. ${ }^{70}$

Nel tempo si sono certo evidenziati casi di appoggio dato da quartieri meno bisognosi ad altri in condizioni di maggiore difficoltà; ma per lo più si è trattato di casi di cooperazione in vista di ragioni strategiche e di alleanze produttive lette a partire da una nuova ed interessante forma di valutazione sui 'tempi lunghi' che costituisce uno dei frutti dell'apprendistato alla democrazia rappresentato dall'OP. Prendendo spunto da questi casi, l'impegno dell'Amministrazione si è concentrato sulla costruzione di una 'solidarietà negoziata' (Abers, 1998b) che - attingendo alla capacità descrittiva di singoli 'rappresentanti solitari' di aree molto bisognose e poco mobilitate, e dal contatto 'vis-a-vis' che offre il lavoro in comune nelle assemblee $^{71}$ - fosse in grado di incidere sugli egoismi corporativi degli altri leader comunitari al momento della definizione delle priorità di bilancio. Ma, soprattutto, il lavoro dell'Amministrazione Popolare si è appuntato sulla costruzione di criteri definiti e chiari, capaci di garantire una giustizia distributiva anche contro il rifiuto della maggioranza dei partecipanti organizzati. In tal senso alcuni criteri 'formali' di valutazione più realistica ed oggettiva (cfr. cap. 7) sono stati inseriti all'intemo della struttura 'informale' dell'Orçamento Participativo, anche se a costo di grandi battaglie: essi non appaiono come criteri puramente 'tecnici' visto che l'indice di 'peso' dei diversi criteri sul giudizio complessivo è deciso dalla popolazione, e che la variabile 'priorità principali della Regione' incorpora le scelte democraticamente definite dai cittadini.

In sostanza, la scelta fatta dall'Amministrazione con l'inserimento di questi criteri è stata essenzialmente di natura pedagogica: forzare gli stessi partecipanti a dibattere annualmente di criteri di giustizia distributiva, lasciando quindi nelle loro mani le decisioni finali. Che vi siano ancora grosse resistente popolari al superamento dei limiti di disuguaglianza di accesso all'O.P. è rivelato dall'opposizione mossa dai Forum Regionali all'accettazione dell'estensione di criteri di giustizia distributiva alle decisioni interne ad ogni Regione, che il COP ha tentato di introdurre nel 1995; al momento, 13 delle 16 Regioni semplicemente ignorarono la decisione ritenendola assurda per il suo paternalismo implicito (Abers, 1998b). Solo a distanza di 7 anni quasi tutti gli ambiti Regionali hanno ormai accettato di mescolare criteri di misurazione 'semi-oggettiva' dei bisogni con quelli di negoziazione politica diretta, utili a risolvere le discussioni in momenti di 'impasse' o di 'pareggio' dei punteggi attribuiti alle diverse priorità. Ma è stato frutto di un duro impegno dell'Amministrazione per far capire a tutti la necessità che le regole di distribuzione dei fondi garantiscano l'integrazione progressiva dei più poveri nella 'città di diritto'

I risultati ottenuti in questi anni sembrano comunque aver sostanzialmente 
centrato alcuni dei principali obiettivi che l'Amministrazione perseguiva nei suoi sforzi per connotare il Bilancio Partecipativo come propiziatore di 'giustizia ed equità distributiva' in seno al complesso delle politiche municipali che ha contribuito ad indirizzare in questi 14 anni. Lo dimostrano alcuni studi indipendenti, come quello realizzato da Marquetti (2001) in collaborazione con la Fondazione Ford.

Analizzando il rapporto tra alcuni indicatori territoriali di povertà ${ }^{72}$ e gli investimenti pro-capite compiuti dal 1992 ad oggi nelle 16 Regioni di Bilancio di Porto Alegre - così come formulati nei Piani di Investimento elaborati in seno al Bilancio Partecipativo - Marquetti (2002) ha, infatti, documentato come "l'OP ha avuto un effetto redistributivo negli investimenti"; lo stesso è emerso rapportando il numero di opere e servizi attivati in ogni Regione agli stessi indicatori di povertà tra il 1989 e il 2000. Nei due casi, le curve di distribuzione degli investimenti risultano molto vicine a quelle di maggior concentrazione delle situazioni di disagio (fig. 35) al punto che l'autore ha concluso la sua ricerca affermando che il Bilancio Partecipativo ha finora funzionato come "un potente strumento di distribuzione del reddito" e dimostrando quale peso hanno avuto nel raggiungimento di questi risultati i diversi criteri di 'rilevazione oggettiva del bisogno' che nel tempo sono stati inseriti nel Regolamento Interno dell'OP proprio allo scopo di evitare che i benefici della distribuzione delle risorse pubbliche risultassero proporzionali esclusivamente al peso e alla capacità decisionale degli attori più abili, assidui ed organizzati che partecipano del processo. In particolare, Marquetti si è fermato ad analizzare uno dei nuovi criteri che (nel 1992) la popolazione ha suggerito di inserire in sostituzione di quello che favoriva una distribuzione delle risorse pubbliche concentrata direttamente a vantaggio delle Regioni con più residenti in 'aree di carenza massima': ovvero il criterio della 'popolazione totale della Regione'. Marquetti ha verificato che questo criterio, pur avendo permesso di introdurre una nozione di 'distribuzione delle risorse per settore di investimento' non eccessivamente penalizzante per le Regioni meno povere, non ha alterato la sostanziale equità distributiva del Bilancio Partecipativo.

Marquetti - pur sapendo di riferirsi a valori medi sui redditi e gli investimenti pro-capite - ha dimostrato come fino ad oggi, nella situazione specifica di Porto Alegre, vi sia stata sostanzialmente una relazione di proporzionalità inversa tra numero di abitanti delle 16 Regioni auto-definite dai movimenti urbani, e loro popolosità. Il 'peso secondario' attribuito ai criteri della popolosità delle Regioni per la distribuzione delle risorse (in rapporto a quello dei fattori 'carenza di infrastrutture e servizi' e 'priorità tematiche scelte dalla Regione') ha creato problemi solo alle poche Regioni al contempo povere e popolose come il Partenon; negli altri casi (fig. 35) si può rilevare un rispetto della stessa 'equità distributiva' rilevata nelle ulteriori analisi sul rapporto di proporzionalità diretta tra investimenti pubblici e grado di necessità e povertà del territorio. Il che - ancora una volta - sottolinea come a Porto Alegre l'interazione tra Amministrazione Popolare e cittadini abbia elaborato e corretto in questi anni regole congruenti con i bisogni del proprio territorio, la cui validità di funzionamento non è assoluta e acriticamente replicabile in altre situazioni, ma va esaminata in rapporto alle peculiarità locali e agli obiettivi che le politiche di distribuzione del reddito intendono proporsi. 
Fig. 32 - Chi partecipa al Bilancio Partecipativo e come si relazione ad istanze autorganizzate di agregazione della società civile?. I dati dell'inchiesta CIDADE/PMPA del 2000 (2002) mostrano, tra le altre cose, che tipo di legame esiste tra organizzazioni della società civile e partecipazione nell'O.P., ma anche quali sono le occupazioni medie prevalenti degli abitanti che intervengono nelle pubbliche assemblee.

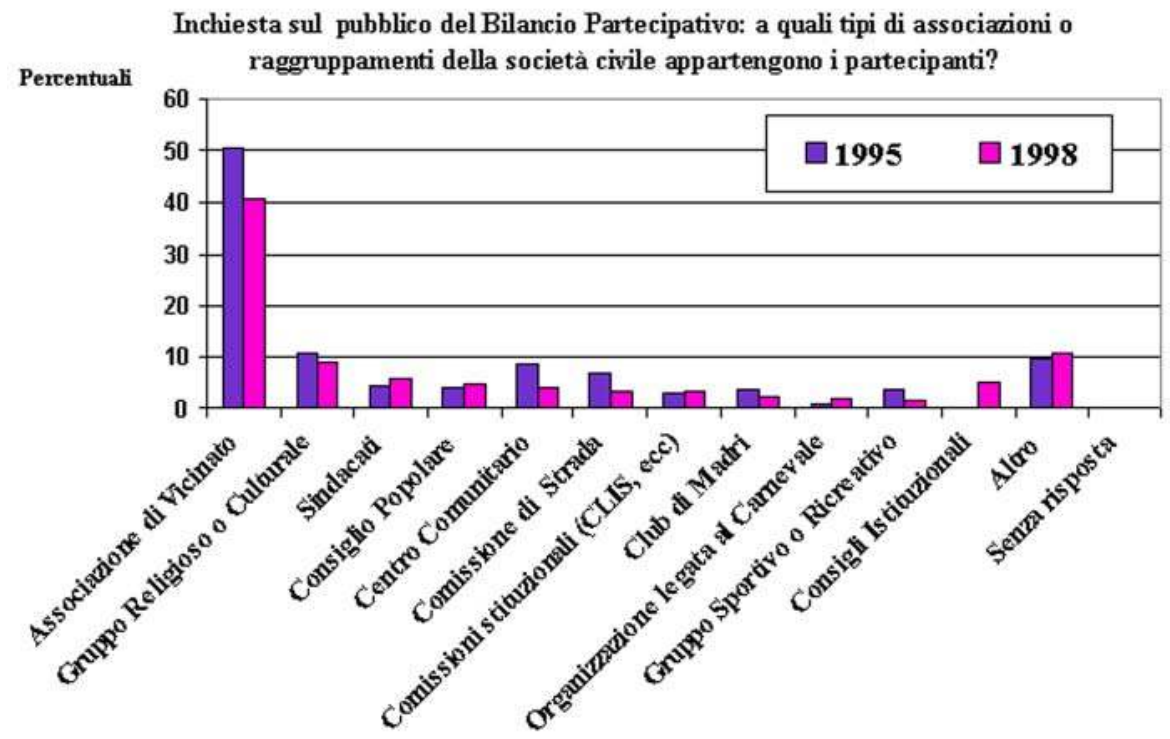

Che tipo di lavoro svolgono, in media, i partecipanti alle assemblee pubbliche del Bilancio Partecipativo?

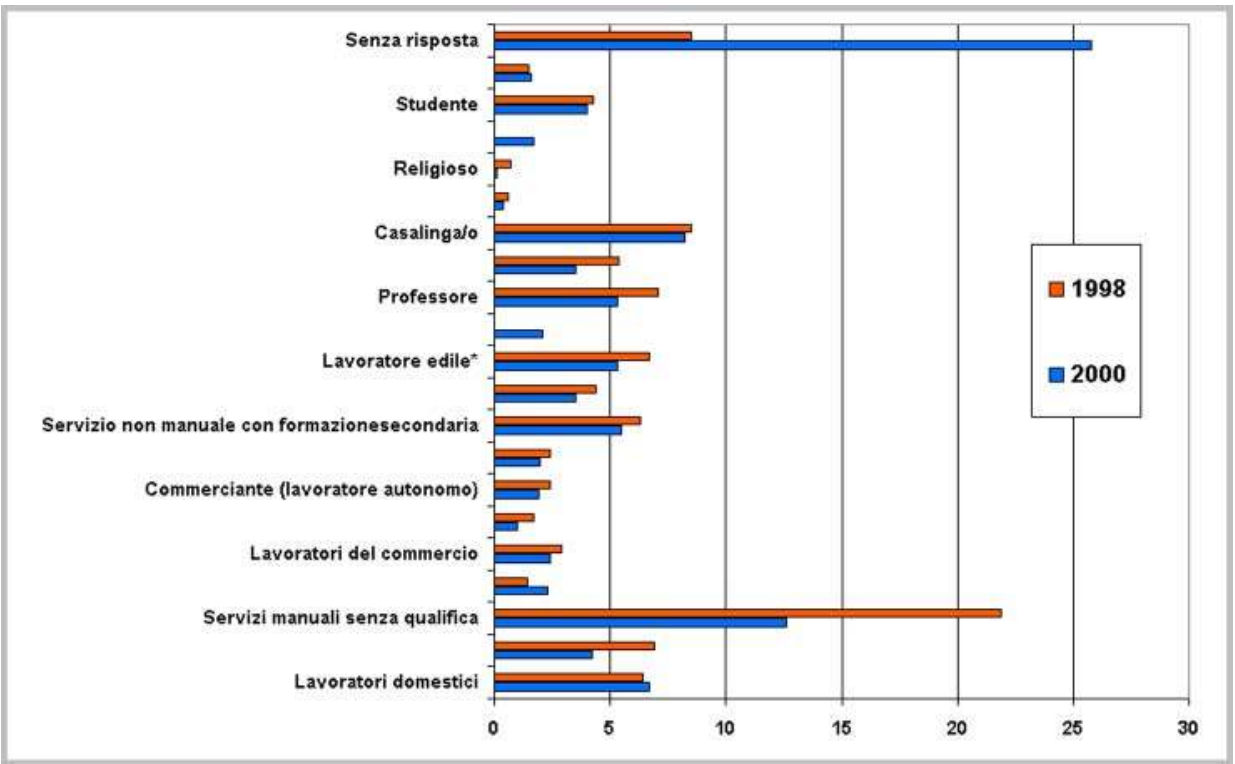


Fig. 33 - Per una buona riuscita del processo di O.P. è basilare che i vertici dell' Amministrazione mantengano un contatto diretto con i cittadini, impegnandosi nel presenziare alle assemblee pubbliche (nella foto sotto, da sinistra, l'ex-sindaco di Porto Alegre Tarso Genro, l'attuale sindaco Joao Verle, l'attuale governatore del Rio Grande Sul, Germano Rigotto, e il suo predecessore, Olivio Dutra, attuale Ministro delle Città e primo sindaco di Porto Alegre nel quindicennio di governo dell'Amministrazione Popolare). Si è poi dimostrato fondamentale anche costruire una rete di 'agenti intermedi' che supportino il processo partecipativo, inserendo ruoli simili anche in ogni assessorato, per lo sviluppo partecipativo delle politiche di settore. Il grafico (Dati SMA, 2001) rappresenta come la politica del personale, in questi ultimi anni, ha curato l'aumento dei funzionari, specie nei settori del welfare. Lo schema, invece, si riferisce al tipo di azione che dovrebbero sviluppare gli Agenti Comunitari nel far interagire gli abitanti e la struttura tecnica durante l'elaborazione dei progetti per il territorio.
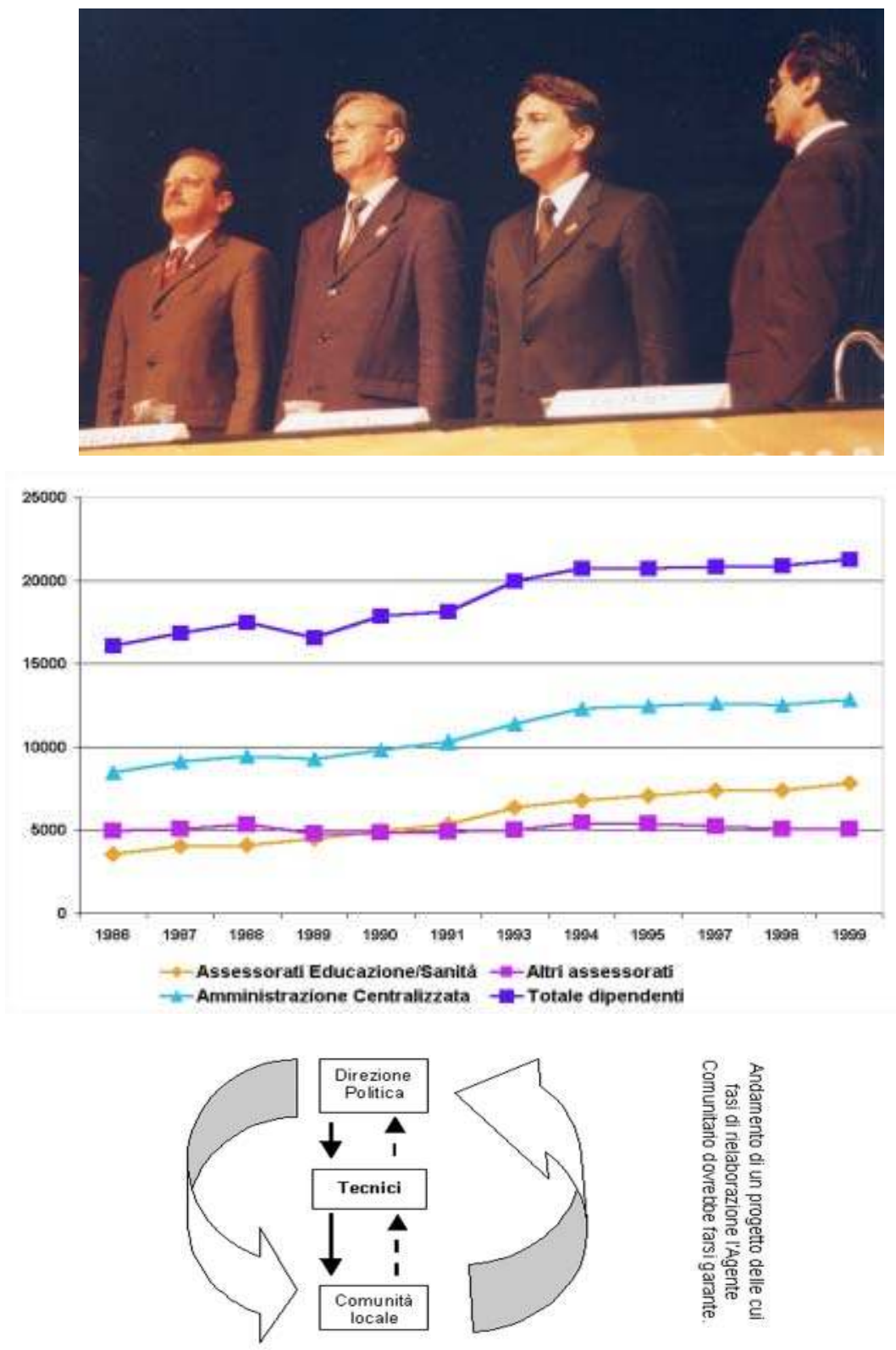


\begin{tabular}{|c|c|c|c|c|c|}
\hline & $\begin{array}{c}\text { GAPLAN - } \\
\text { Gabinetto di } \\
\text { Pianificazione }\end{array}$ & $\begin{array}{l}\text { CRC - Coor } \\
\text { dinamento } \\
\text { delle Relazioni } \\
\text { Comunitarie }\end{array}$ & $\begin{array}{l}\text { FASCOM - } \\
\text { Forum dei } \\
\text { Consiglieri } \\
\text { Comunitari }\end{array}$ & \begin{tabular}{c|} 
CROPs - \\
Coordinatori \\
Regionali dell'O.P.
\end{tabular} & $\begin{array}{c}\text { CTs - Coordinatori } \\
\text { Tematici }\end{array}$ \\
\hline $\begin{array}{c}\text { Data di } \\
\text { creazione }\end{array}$ & $\begin{array}{c}1990 \text { (informale) } \\
1994 \text { (formalizzato) }\end{array}$ & $\begin{array}{c}\text { 1981. Dal } 1989 \text { vin- } \\
\text { colato al Gabinetto } \\
\text { del Sindaco }\end{array}$ & 1990 & 1992 & 1994 \\
\hline Partecipanti & $\begin{array}{l}\text { Consulenti e funzio- } \\
\text { nari del Comune }\end{array}$ & $\begin{array}{l}\text { Consiglierie } \\
\text { funzionari } \\
\text { del Comune }\end{array}$ & $\begin{array}{l}\text { Consiglieri com. } \\
\text { di Assessorati } \\
\text { e altri organi }\end{array}$ & $\begin{array}{c}\text { Consulenticom. della CRC } \\
\text { e degli Assessorati (oggi solo } \\
\text { legatiai CAR-Centri Amm.- } \\
\text { nistrativi Regionali) }\end{array}$ & $\begin{array}{l}\text { Consulenti della CRC } \\
\text { e/o di Assessorati }\end{array}$ \\
\hline Compiti & $\begin{array}{l}\text { Coondinamento della } \\
\text { Pianificazione Strate- } \\
\text { gica. Gestione ed ese- } \\
\text { cuzione del PI. Elahora } \\
\text { lapresentizione delle } \\
\text { spese di ogni gestione } \\
\text { annuale. Coordina } \\
\text { l'elaborazione della } \\
\text { procedura di bilancio } \\
\text { per l'esercizio annuale }\end{array}$ & $\begin{array}{l}\text { Articola la relacio- } \\
\text { ne con la comunità } \\
\text { attrinerso i CROP. } \\
\text { Coordina le riunio- } \\
\text { ni della I e II tomat } \\
\text { ta di Plenarie del- } \\
\text { lOP. Coordina le } \\
\text { riunioni del COP }\end{array}$ & $\begin{array}{l}\text { Discute e propone } \\
\text { politiche di paate- } \\
\text { cipevione popolare } \\
\text { auticolando per } \\
\text { quanto possibile } \\
\text { il lavoro dei vari } \\
\text { Assessorati }\end{array}$ & $\begin{array}{l}\text { Ve ne è uno responsabile per } \\
\text { ognuna delle } 16 \text { Regioni, } \\
\text { che segue tutto il processo } \\
\text { dell'O.P. presenziando } \\
\text { specialmente alle } \\
\text { Assembloe Intermedie }\end{array}$ & $\begin{array}{c}\text { Ognuna delle } 5 \text { tematiche } \\
\text { ha un CT che accompagna } \\
\text { il processo di discussione } \\
\text { nelle Plenarie }\end{array}$ \\
\hline $\begin{array}{c}\text { Periodicità } \\
\text { dell'intervento }\end{array}$ & Permanente & Permanente & Settimanale & Permanente & Permanente \\
\hline Coordinamento & $\begin{array}{l}\text { Su indicazione } \\
\text { del Sindaco }\end{array}$ & $\begin{array}{c}\text { Su indicazione } \\
\text { del Sindaco }\end{array}$ & $\begin{array}{l}\text { Su indicazione } \\
\text { degli Assesso- } \\
\text { rati Comunali }\end{array}$ & $\begin{array}{l}\text { Su indicazione } \\
\text { della CRC }\end{array}$ & $\begin{array}{l}\text { Su indicazione } \\
\text { della CRC }\end{array}$ \\
\hline
\end{tabular}

Settori della Società Civile coinvolti nell'organizzazione dell'O.P.

(tradotto e aggiornato da Andreatta, 1997)

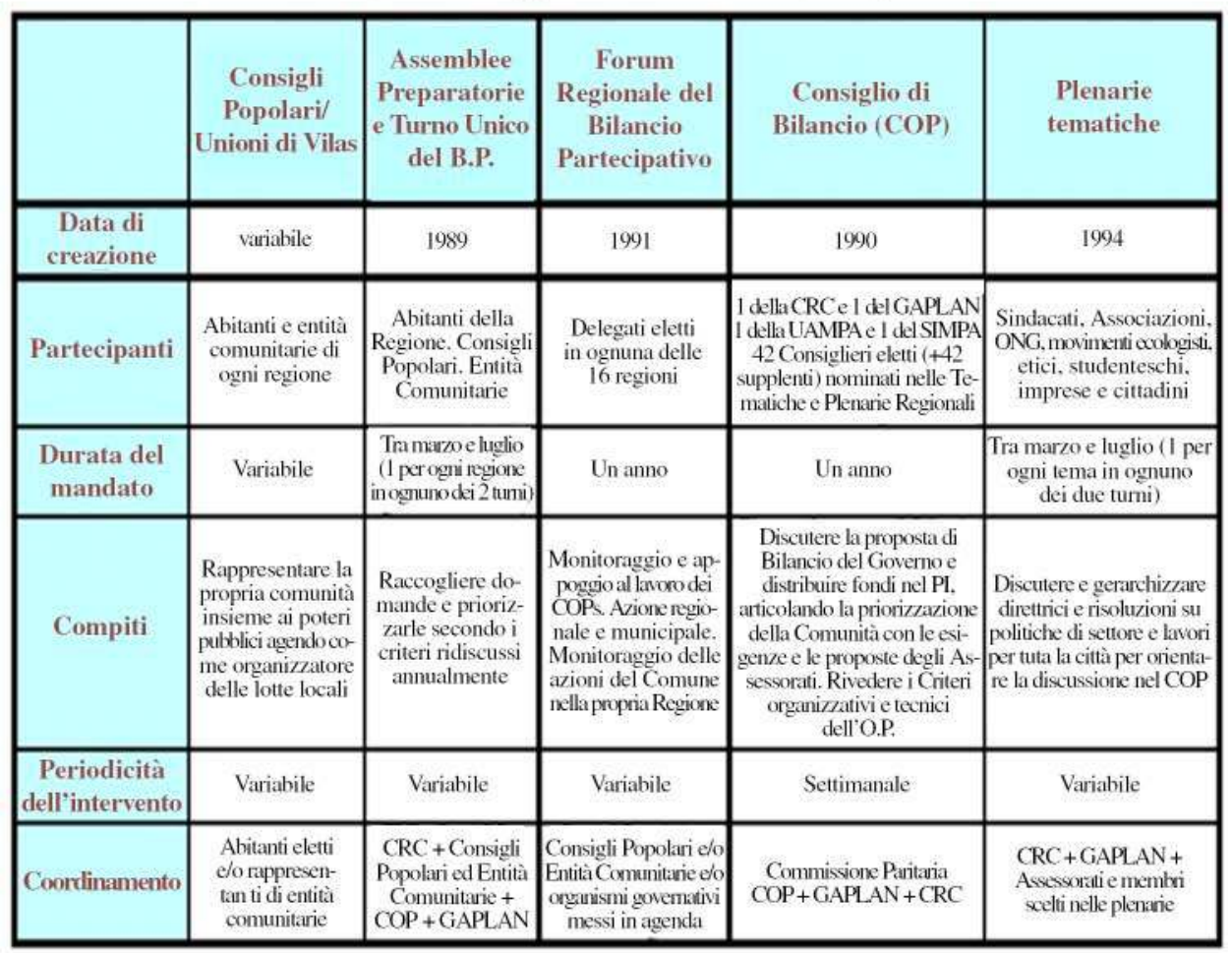


${ }^{1}$ Singer (1989) ha rilevato che una delle difficoltà iniziali maggiori dei sistemi decisionali partecipativi risiede nella tendenza degli agenti chiamati a partecipare a porsi più come gruppi di pressione su chi detiene il potere che come partecipanti a un Forum che può prendere decisioni, oltrepassando le stesse richiesta a cui risponde

2 "I confini reali fra "l'avversione" popolare al potere legislativo e una proposta dittatoriale di soppressione del potere legislativo possono essere infatti piuttosto labili; è pertanto necessario affrontare solidamente la questione anche perché la mancata mediazione potrebbe perfino caratterizzare [l'Amministrazione] come neopopulista". (Alfonsin e Allegretti, 2003).

${ }^{3}$ Nell'inchiesta CIDADE-PMPA 2002 (p. 58), il 29,4\% dei partecipanti alle Assemblee del 2000 intervistati ritiene che l'OP abbia SEMPRE un potere decisorio sulle politiche pubbliche, per il 34\% lo ha QUASI SEMPRE.

${ }_{4}^{4}$ A riconoscimento di questo, il Tribunale di Giustizia dello Stato ha annullato nel marzo del 1998 una legge comunale che proponeva l'O.P. nella città di Canoas - nell'area metropolitana di Porto Alegre - perché proposta da un consigliere dell'opposizione e non dal Sindaco in carica. La Costituzione Federale Brasiliana e quella Statale del Rio Grande do Sul (art. 149) prevedono, infatti, che la discussione sul bilancio pubblico sia di competenza dell'Esecutivo Municipale ma votata ed emendata alla fine dal Consiglio Comunale; con l'istituzione dell'O.P., pertanto, l'Amministrazione Popolare ha fatto una scelta che era nei suoi poteri per arricchire il rapporto tra istituzioni e cittadini attraverso una forma di contratto sociale in cui la volontà politica dei governanti resta fondamentale - in particolare all'attivazione del processo - perché esso sia efficiente e fertile (U. De Souza, 2002).

${ }^{5}$ L'inchiesta CIDADE-PMPA 2002 (pp. 60-61) rivela che il 34,9\% dei partecipanti all'OP ritiene che il principale compito del Consiglio Comunale sia 'proporre e votare leggi' di interesse locale, mentre solo il $10,3 \%$ pensa che il suo compito prioritario sia discutere e votare il bilancio. Una certa confusione sul suo ruolo resta, però, visto che il 19,3\% degli intervistati non sa spiegare quale esso dovrebbe essere; vi è poi un $18,5 \%$ di persone che ritengono che il Consiglio Comunale debba 'esaudire richieste di cittadini'. Vi è inoltre un $24,4 \%$ dei partecipanti all' $O P$ che ritiene che esso non interferisca in nulla con il lavoro del Consiglio Comunale.

6 "Non credo che l'O.P. limiti il Consiglio Comunale, al contrario, lo aiuta; per il Consiglio fa poca differenza se furono consultati tecnici o consiglieri popolari [...] La parola finale è il potere effettivo del voto del Consiglio" (cfr. Zero Hora, 18/9/1996).

${ }^{7}$ L'inchiesta CIDADE-PMPA 2002 (p. 61) tra i partecipanti alle Assemblee dell'OP ha rilevato che ben il 45,9\% ritiene che il l'O.P. favorisca i compiti del Consiglio Comunale, e solo il 2,2\% ritiene che ne pregiudichi il ruolo. Ovviamente questo dato esprime solo una percezione che i cittadini hanno del processo, che può essere stata veicolata dall'influenza del lavoro portato avanti nello stesso, e quindi non avere carattere di oggettività di giudizio.

${ }^{8}$ Genro (2002) ha sottolineato che è la sperimentazione di questa stessa combinazione fra decisione individuale (voler partecipare) e partecipazione collettiva (che genera decisione pubbliche) a permettere all'O.P. di tessere 'non la negazione ma la critica pratica della libertà meramente formale mediante cui il cittadino vota e torna a casa'. ${ }^{9}$ Come ha osservato in un'intervista un Consigliere del Bilancio Partecipativo che vivendo in una favela davanti all'Ippodromo - ha dovuto suo malgrado appassionarsi ai diversi giochi che coinvolg ono cavalli: non creare vincoli di mandato e revocabilità per i rappresentanti popolari nell'OP "sarebbe come dare ad un COP la forza di contrattazione libera di un fantino al Palio di Siena, cosa che è un po' pericolosa in un meccanismo che non è un gioco, ma decide delle sorti di una città e della sua gente” (M.A. Dilly, 1999i II, in Allegretti 2000a).

${ }^{10}$ Nell'inchiesta CIDADE-PMPA 2002 (p. 59) risulta che - secondo la percezione dei partecipanti all'OP - i rappresentanti rispettano le richieste della comunità SEMPRE (37,2\% contro il 43,2\% del 1998 e il 50,7\% del 1995), QUASI SEMPRE (27,9\% contro il $19,6 \%$ del 1998 e il $18,8 \%$ del 1995), A VOLTE (9,4\%, contro il $16 \%$ del 1998 e il $10,6 \%$ del 1995), MAI (1,6\% contro il 3,9\% del 1998 e l'1,1\% del 1995). Le variazioni indicano il rischio del crearsi nel tempo di forme di 'neoclientelismo' che diminuiscono la totale fiducia delle comunità nei propri rappresentanti. Anche per questo, il Gruppo di 
Lavoro sulla Modernizzazione dell' OP del 2001 ha fatto pressione per ridare maggior potere di controllo e decisione ai Forum dei Delegati, più prossimo agli abitanti.

${ }_{11}^{11}$ Tra gli articoli scomparsi dal RI, era scritto anche: Le decisioni del COP, dentro la loro sfera di competenza, devono essere necessariamente seguite dal Comune (art. 12) e I rappresentanti e $i$ delegati accompagnano effettivamente la votazione del Bilancio $e$ dei progetti di natura tributaria in Consiglio Comunale (Art. 13).

${ }^{12}$ Come visto nel cap. 8, precedentemente l'Amministrazione aveva tolto il suo appoggio ad una raccolta di firme per una Legge di Iniziativa Popolare mirata a regolamentare il Bilancio Partecipativo.

${ }^{13}$ Tra l'altro, la UAMPA, in questa battaglia, non ha accettato di farsi portavoce dei movimenti popolari (mostratisi divisi sulla questione) contro il provvedimento, come affermato dal Presidente nella riunione preparatoria della CONAM '99, del 30/4/1999. La giustificazione è stata che i 25 del direttivo non conoscono bene il progetto, e che lo stesso estensore non ne è convinto, ma lo porta avanti "per avere una tribuna da cui parlare al suo elettorato, che è la classe media cittadina" (Dias, incontro UAMPA del 30/4/99).

${ }^{14}$ Come motivato in Alfonsin e Allegretti (2002), i casi complementari di Santo André (SP) e Vila Velha (PR) illustrano come 'la mera volontà politica dei movimenti popolari urbani può non essere sufficiente a garantire il mantenimento del processo che coinvolge la partecipazione popolare'; nel secondo caso l'istituzionalizzazione dell'OP in legge, ha permesso l'avvio di una azione legale presso la Giustizia che ha garantito la continuità amministrativa della politica pubblica del Bilancio Partecipativo in un momento di assenza di volontà politica. .Del resto, in Brasile durante il processo costituente del 1988, ' $i$ movimenti popolari hanno già discusso - e deciso positivamente - sulla convenienza di cercare di includere nella legislazione strumenti giuridici di garanzia per $i$ diritti sociali, politici e di cittadinanza. Sembra un problema superato che insiste a riproporsi sotto forma di una sfiducia (nuovamente) nel Potere Legislativo e nel Diritto. Da parte nostra, crediamo - senza riduzionismi ingenui - che il marchio legale del Diritto possa avere un ruolo da svolgere nello stimolo della costruzione di città più giuste, solidali e sostenibili'.

${ }^{15}$ Menina dos olhos o laranja de amostra com'è chiamato l'O.P. a Porto Alegre

16 "Si può dire perfino che [l'OP] sia stato ignorato dai principali mezzi di comunicazione della città, non solo per essere identificato come 'cosa del PT' (il che evidentemente darebbe prestigio al partito in modo 'eccessivo'), ma anche per il fatto che il processo socializza l'influenza sullo Stato e, soprattutto, sottrae lo Stato all'influenza esclusiva dei costruttori di opinione e dei gruppi economici. Ossia, l'influenza sullo Stato passa ad essere esercitata dal basso in alto, e i privilegiati sono quelli che si mettono a disposizione per partecipare, non più quelli che hanno influenza insieme ai media, o agli individui che compongono la stessa amministrazione pubblica" (Genro, 2002).

17 'Zero Hora' e la sua versione economica ridotta. Gli altri organi di stampa cittadini sono di poco interesse, visto che lo storico 'Correio do Povo' è oggi un mero sommario di notizie, il 'Jornal di Commercio' veicola poche notizie di ambito politico locale, e il 'Diario Gaucho' ha un'impostazione scandalistica centrata su cronaca nera e rosa.

${ }^{18}$ Cfr. Allegretti 2000a, § 7.7.

${ }^{19}$ In Allegretti (2000a § 7.7) una consultazione dell'indice per parole chiave del ben organizza to archivio elettronico del quotidiano 'Zero Hora' rivela solo 5 articoli che hanno fatto riferimento all'O.P. (uno scritto dal vicesindaco Genro, perciò di doverosa pubblicazione) nel quadriennio 1989/1992 Essi hanno raggiunto quota 39 fino al 1994. ${ }^{20}$ I riferimenti al BP su 'Zero Hora' sono saliti a 207 tra il 1995 ed il 1997, e a 224 nel biennio successivo, ma per configurare - qualitativamente - attacchi e critiche unilaterali o semplici 'atti dovuti' (difficilmente non pubblicabili) verso testi vergati dal Sindaco o notizie su presentazioni internazionali o premi ricevuti dalla città. Nel periodo tra il 1998 e il 1999, l'aumento degli articoli sull'O.P. è, invece, dovuto al raddoppiamento del processo con la creazione dell'Orçamento Participativo/RS, e alle vicende che hanno minacciato l'integrità dei due processi: la proposta di Legge Isaach Ainhom per quello comunale, e la successiva duplice interruzione - voluta dalla giustizia - dell'O.P./ RS, in seguito alle denunce dell'ex-governatore Alceu Collares. In ogni caso, durante la ricerca nell'archivio non sono stati identificati articoli che 'informino' sull'O.P., sullo svolgersi delle riunioni o dei meccanismi organizzativi dello stesso (Allegretti, 2000a). ${ }^{21}$ Osorio (in Genro, 2002).

${ }^{22}$ Per il giornalista Pedro Luiz da Silveira Osório, ex-coordinatore della CCS di Porto Alegre visto che la stampa locale non viene meno in linea generale al suo interesse per 
aspetti come la prossimità dei fatti ed il loro essere inediti o pittoreschi, il suo tentativo di "adeguamento alla cultura del lettore", può ignorare "il potenziale rivoluzionario e trasformatore contenuto nel Bilancio Partecipativo", ma non oscurare "quale straordinario fatto giornalistico esso rappresenti". Sia perché parla del quotidiano di migliaia di portalegrensi (giustificando, se fosse necessario, il suo inserimento nei notiziari locali) sia perché possiede "scene singolarmente pittoresche, istantaneamente rivelatrici, ad uno sguardo professionale, di possibilità immense e straordinarie di ordini del giorno, materiali, reportage e foto" che potrebbero costituire "punti di partenza per notizie e materiali sull'Amministrazione Comunale - visto che là stanno esposte le sue debolezze e i suoi eventuali meriti - e per reportage sulla città e la sua gente (in Genro, 2002).

${ }^{23}$ La situazione è migliorata nel '99 quando - con la vittoria del Fronte Popolare nelle elezioni Statali - il Comune di Porto Alegre ha acquisito accesso più semplice alla TV Educativa Statale.

${ }^{24}$ I 'liminar' sono misure giudiziarie cautelative intese a prevenire la degenerazione di un processo, intervenendo con un blocco immediato su tutti i suoi meccanismi organizzativi per evitare l'irrimediabilità del danno. Nelle azioni contro la pubblica amministrazione è particolarmente usato per evitare sprechi presunti del patrimonio pubblico in attesa del pronunciamento in merito alla questione contestata (ad esempio: blocco immediato di lavori pubblici, ecc.). Ad esempio, nel primo anno di sperimentazione del Bilancio Partecipativo dello Stato del Rio Grande do Sul, il tentativo dell'ex-governatore Collares di contrastare l'esistenza dell'OP mettendone in dubbio la legittimità formale (poi fallito) ha colpito con un 'liminar' (maggio 1999) tutte le spese di pubblicizzazione e organizzazione dell' O.P.

${ }^{25}$ Esistono "forme di comunicazione differenziata. Ad esempio, per gli opuscoli si privilegiano gli strati della popolazione con istruzione medio-bassa e $i$ bambini, sfruttando la loro curiosità. Per tutti sono fatti i manifesti per le strade o negli Uffici. Infine, per la classe media - dato il boom attuale - c'è Internet dove il Comune non fa una presentazione di facciata, ma svolge un vero servizio: ci sono moduli di richiesta on-line, canali per segnalare disfunzioni in tempo reale, [...] mappe sempre aggiornate dei lavori stradali, percorsi e orari di tutte le linee di autobus della città"(Carvalho, 1999i, apud Allegretti, 2000a). Altri strumenti convenzionali generalisti adottano approcci 'analitici' (come il Diario Oficial da Prefeitura de Porto Alegre che pubblica tutti gli atti amministrativi, i concorsi e simili) o 'sintetici' (è il caso delle 8 pagine del mensile Porto Alegre agora il cui nome significa Porto Alegre ora, ma anche La piazza di Ponto Alegre, in riferimento al termine greco agorà.

${ }^{26}$ Il nuovo sito del Comune costituisce un'importante sforzo di investimento in questo senso. Articolato e completo ma semplice da usare anche per utenti inesperti, esso ha ricevuto nel luglio 1999 il primo premio 'Cittadinanza su Internet' della CONIP (http://www.conip99.com.br); il Forum brasiliano di presentazione delle novità nella modernizzazione del servizio pubblico e della gestione amministrativa e finanziaria pubblica) nelle categorie Miglior Sito Municipale e in quello Circolazione e Trasporti, per via del 'Sistema di bus Monitorato Automaticamente'.

${ }^{27}$ Opuscoli e testi informativi contenuti nell' Archivio Memoria evidenziano significativi e progressivi passi avanti compiuti in direzione di un approfondimento di qualità e contenuti dell'informazione negli ultimi 7 anni, in particolare sui temi della regolarizzazione fondiaria, della riscossione dei tributi e della salvaguardia dell'ambiente.

28 "Il materiale è uguale per tutti, e proprio per questo costa un notevole sforzo di chiarezza. Non sarebbe possibile trasmettere un'informazione in due versioni: una per la classe media e una per la popolazione meno istruita. Sarebbe un'incoerenza, un'ammissione di sconfitta dell'Amministrazione Popolare, vorrebbe dire mentire ad uno dei due, cercare di 'indorare la pillola' ai ricchi per accettare investimenti a favore dei più bisognosi o viceversa. Vorrebbe dire, in conclusione, riconoscere e perpetuare l'esistenza di due città, quando poi in ogni sede sosteniamo che c'è una sola popolazione, che tutti sono uguali, che non ha senso distinguere tra una città di diritto e una informale. Questa necessità di coprire con uno stesso prodotto le esigenze di una vasta gamma di lettori costa uno sforzo aggiuntivo al Comune, [...] per raggiungere allo stesso tempo diversi gradi di complessità. Così la squadra di creativi della CCS gioca moltissimo sull'abbinamento di disegni chiarificatori ai testi" come fumetti, vignette e simili (Carvalho, 1999i, a pud Allegretti, 2000a)

${ }_{29}$ Grazie all'attenzione alle specificità culturali propiziata da queste linee di indirizzo, 
"sono stati organizzati dei corsi di formazione per gli operatori ecologici del DMLU per insegnare loro come comportarsi davanti ai residui delle cerimonie afro di cui spesso sono piene le strade e che finivano per accumularsi come sporco comune perché nessuno degli spazzini era disposto a toccarli, per credo, per superstizione o per semplice ignoranza di come relazionarvicisi” (Brunet, 1999i, apud Allegretti, 2000a).

${ }^{30}$ Nell'ambito dell'OP questi agenti sono stati i CROP delle varie regioni (cfr. cap. 12). ${ }^{31}$ La responsabilità dell'organizzazione del Progetto è stata affidata alla Central de Distribuição del settore della Comunicazione Sociale, e purtroppo deve contare solo su tre persone, una sola delle quali fissa. Si tratta della stessa ideatrice del Progetto, che ha lottato per oltre 4 anni per poterlo realizzare, Cassia Vasconcelos Coutinho.

32 Della 'contro-informazione' si occupa il settore Rádio e TV Escuta, incaricato di segnalare errori, malintesi e proteste ai vari assessorati e sollecitare rapide risposte nelle sedi competenti (soprattutto giomali, Consigli Municipali e O.P.), ed archiviare su CD e cassette (per mezzo di stagisti) i testi di radio e Tv riguardanti l'Amministrazione.

33 " L'altro momento educativo-informativo, quello orale [...] viene realizzato sia attraverso la trasmissione dei nodi e delle conclusioni dei vari dibattiti che $i$ partecipanti all'O.P. - ed in particolare $i$ COP, $i$ delegati e le Associazioni di Quartiere -sono invitati a fare ai cittadini non partecipanti, che nel momento della festa. Certo, scrivere $e$ pubblicare è una garanzia di chiarezza" ma è altrettanto importante anche valorizzare i modi tradizionali della comunicazione informale[...] "Non ammettere l'esistenza della città informale come futura prospettiva di diritto, non vuol dire non accettarla realisticamente nel presente come realtà di fatto, e quindi non adeguarsi alle sue forme di articolazione. Se nel quotidiano le riunioni e la presenza del 'corpo a corpo' dei tecnici sul territorio, specie negli ambiti più bisognosi, sono la garanzia per l'Amministrazione di raggiungere la popolazione 'attiva', la capillare informazione demandata ai movimenti popolari e il momento della festa sono le strategie per raggiungere anche una parte di quella non diciamo 'passiva', ma certo 'non ancora attiva' (Carvalho, 1999i, apud Allegretti, 2000a)".

${ }^{34}$ Esse costituiscono anche un ulteriore momento di una politica coerente e continuativa - non quindi sviluppata per punti con qualche fugace apparizione dei vertici dell'Amministrazione nei territori periferici - di avvicinamento della politica ai cittadini, per rafforzarne il dialogo che trova il suo principale momento di istituzionalizzazione nell'OP. "L'inaugurazione non è mera promozione di quanto realizzato, e momento di orgoglio dell'Amministrazione; è un momento di unione fra i politici e la gente, ed anche di cementificazione del rapporto tra noi tecnici e la gente con cui abbiamo collaborato per mesi [...] Quasi tutte le Amministrazioni del mondo fanno le inaugurazioni a fine lavori, ormai anche nelle favelas [...] Quello in cui forse Porto Alegre differisce è la sistematicità e la capillarità [...] Ogni tratto di strada è una vittoria, una conquista per la popolazione che l'ha ottenuto attraverso l'O.P.. E la festa deve essere festa, non può essere funestata; a meno che non si inauguri forse una caserma, è raro vedere forze di polizia presenti a controllare un'inaugurazione in una 'vila', anche se ci sono il Sindaco, 10 assessori e dei deputati federali. Se ci sono pericoli piuttosto aspettiamo [...] Anche la festa è momento di crescita, quindi, che l'Amministrazione Popolare se vogliamo 'usa', ma con parsimonia, però; senza renderla una lunga e noiosa cerimonia ufficiale come finiscono per essere quelle nella città formale. Ad esempio, io mi arrabbio quando leggo 'inaugurazione' su un comunicato stampa o un volantino di avviso per la popolazione, e magari è l'arrivo dello scolo pluviale in una strada già da tempo asfaltata e inaugurata. Ritengo si debba essere precisi e rigorosi La popolazione sta attenta, è critica; non deve sentirsi usata come se fosse per fare campagna elettorale, sennò l'Amministrazione perde credibilità, si ridicolizza" (Casa Nova, 1999i - XII, apud Allegretti, 2000a).

${ }^{35}$ Dal 1999, Porto Alegre supporta - ospitandone gli incontri mondiali - il Progetto 'Software libero' per la promozione dell'autonomia e della libertà tecnologica e comunicativa sui nuovi media.

${ }^{36}$ Solo dal dicembre 2000 il Brasile ha una Legge che regola ufficialmente il settore, e per giunta in modo penalizzante per i mezzi di comunicazione indipendenti.

${ }^{37}$ FAQ $=$ Frequed Asked Question (Domanda abituale)

${ }^{38}$ Le norme di elaborazione di questo sono definite nella Legge Federale 4320, e rispondono alle competenze descritte negli articoli 165 e 166 della Costituzione Federale ${ }^{39}$ Ciò è basilare, visto che a partire dalla III $^{\circ}$ Amministrazione Popolare guidata da Raul 
Pont anche il Piano Poliennale che direziona gli investimenti per un quadriennio viene discusso con la cittadinanza attraverso l'O.P.

${ }^{40}$ Proprio tra il 1996 e il 1997 le Entrate Straordinarie hanno avuto una crescita dallo 0,9\% all' $8,7 \%$ del totale generale delle entrate del Comune di Porto Alegre (CIDADE, 1997).

${ }^{41} \mathrm{Nel} 1994$ Genro osservava che questa nuova sfera pubblica dovrà avere come motivazione di fondo le pressioni settoriali, operando per sottomettere lo Stato e portarlo, dalla sua posizione di struttura 'sopra la Società', ad un'inversione che non sia statalizzante della società, ma civilizzatrice dello Stato, sottomettendo il suo movimento al vaglio permanente della Società civile.

42 Basti pensare alla descrizione fattane nel Database delle 'Best Practices' ONU del 1996 (scheda $\mathrm{n}^{\circ}$ 75), dal titolo Partecipazione burocratica e popolare in campo pubblico. L'enfasi attribuita al fattore finanziario - elemento 'omologante' che agisce nell'ombra dietro all'interesse per le singole esperienze del programma dell'UNCHS - riconferma il principale vizio occulto dell'operazione 'Best Practices', racchiuso nella sua maggiore ambizione, la replicabilità, che espone i progetti ai rischi connessi ad una pretesa di universalità, svuotandone la storicità concreta.

${ }^{43}$ Tra questi, l'esperienza di Birmingham, Alabama, citata in Haeberle (1989) e in Abers (1998b).

${ }^{44}$ Lo si verifica anche per via negativa, dato che ogni qual volta una politica non è risultata chiara nelle sue linee, la partecipazione dei cittadini non ha raggiunto livelli elevati: è il caso del processo Cidade Constituinte.

${ }^{45} \mathrm{Il}$ peso di questo fattore è emerso anche per via negativa, quando (dal 1993) l'O.P. è entrato in una fase più legalista. Ad esempio, il rifiuto opposto per un certo tempo ad intervenire sulle 'lottizzazioni clandestine' prive di infrastrutture (per non avallare spese costose in aree semidisabitate, non incoraggiare i lottizzatori a continuare la loro opera e non beneficiare gli speculatori alzando il valore dei loro terreni) ha frenato la partecipazione degli abitanti di queste, finché non è stato chiaro che un impegno solenne a copartecipare con diritti e doveri all'attivazione dei processi di regolarizzazione fondiaria poteva renderli partecipi della distribuzione dei fondi municipali nell'OP.

${ }_{46}$ Nel cap. 7 abbiamo sottolineato come l'iscrizione alle assemblee non richieda la presentazione di documenti, ma è sufficiente l'interesse per la discussione ed un'autodichiarazione dell'abitante per poter partecipare.

${ }^{47}$ I CAR sono strutture decentrate di informazione e svolgimento di alcune pratiche amministrative.

48 Accanto alla scelta - sempre riconfermata - di dare più centralità al singolo cittadino che ai gruppi nella partecipazione, vi è stato il rifiuto a burocratizzare e localizzare il processo, creando 'sedi' per le Regioni. In fondo, le Regioni (così come i quartieri) sono essenzialmente rappresentate dai loro Consiglieri, che accettano di divulgare i propri recapiti privati (e spesso perfino i cellulari) in tutti i documenti informativi prodotti dal Comune.

${ }^{49}$ I criteri 'oggettivi' esposti nel cap. 7 costituiscono uno degli elementi principali di questa 'attenzione' tesa a garantire una voce sulla distribuzione delle risorse anche a comunità che non vi prendono parte, ma presentano necessità oggettive da risolvere, con alto grado di necessità e carenza.

${ }^{50} \mathrm{Si}$ pensi a Paulo Freire, o alle EWTO o WEM - Experimental Workshop on Theory of Organization - create dal sociologo Clodomir Santos de Morais alla fine degli anni ' 50 ed oggi espansesi in molti paesi, specie in Africa.

${ }^{51}$ Schmidt (1993).

52 "Il valore principe dell'Orçamento Participativo, [è] quello di scuola di democrazia. Perché democrazia è anche essere minoranza e potersi esprimere, poter avere una voce per convincere altri, anche se il più delle volte devi levare forte la voce per non ottenere nulla. Ti fa crescere come cittadino e come persona ogni volta che ti mette alla prova per dimostrare la capacità di coerenza del tuo discorso" (Dos Santos Duarte, ex-Consigliere dell'O.P., 1999i).

${ }_{53}$ Come hanno dichiarato alcuni tecnici nelle interviste da me realizzate, sovente $\mathrm{i}$ cittadini mostrano un'inattesa conoscenza di quanto realizzato in altre parti della città e zittiscono con l'arma del confronto motivazioni tecniche sovente capziose e poco solide con cui l'Amministrazione tenta di giustificare alcune sue scelte.

${ }^{54}$ Addirittura, il fatto che dopo la discussione e i conflitti sui temi in discussione il quorum calasse fortemente proprio al momento delle votazioni, è indizio di come tra le ragioni del calo di partecipazione pubblica alle riunioni dell'O.P. verificatosi nel 1991 
vi fosse anche l'ancora non raggiunta capacità organizzativa delle stesse, il caos che scoraggiava molti di coloro che ancora non erano riusciti a mettere ben a fuoco il funzionamento del meccanismo.

${ }^{55}$ Abers $(1995,1998)$ ha rilevato, ad esempio, che se nel 1989 il $60 \%$ di coloro che prendevano parte alle riunioni dell'OP. vivevano nelle sei regioni della città che vantavano già un passato di mobilitazione collettiva, nel 1995 l'andamento toccò un punto di flesso, e il $62 \%$ dei partecipanti già risultava composto da persone provenienti da regioni fino allora ritenute a debole mobilitazione. Un'inchiesta promossa nel giugno 1995 da alcune ONG di Porto Alegre e dal Coordinamento delle Relazioni Comunitarie del Municipio su un campione del $10 \%$ dei partecipanti delle 16 assemblee regionali e delle 5 tematiche, ha anche dimostrato che se il $33 \%$ dei partecipanti all'OP era completamente nuovo a qualsiasi esperienza di organizzazione della società civile, circa il $60 \%$ di coloro che erano già attivi in associazioni prima dell'istituzione dell'O.P. avevano notevolmente aumentato il loro impegno.

${ }^{56}$ In occasione della creazione del sistema informatico, l'Amministrazione dovette apprendere a controllare meglio le spese eliminando gli 'storni' in passato possibili grazie a voci vaghe e ambigue.

${ }^{57}$ Questo aspetto di apprendistato simmetrico e biunivoco appare praticamente inconfutabile, come dimostra l'unanimità di consensi attribuitagli da tutti gli intervistati (anche quelli più critici) in Allegretti 2000a.

${ }^{58}$ A parte alcune letture 'di partito' che poco ci interessano, vi sono letture simili soprattutto in ambito nordamericano; gli stessi Abers (2000) e Goldfrank (2002) a volte calcano troppo l'accento solo sul ruolo svolto dal Comune di Porto Alegre e dal PT nell'implementazione del processo.

${ }_{59}$ Colpisce molto che - nonostante i riferimenti che si trovano in vari testi circa 'autori politici' (Gramsci, Habermas, Castoriadis, De Sousa Santos) le cui teorizzazioni (e in qualche caso recente, persino la presenza a Porto Alegre nei primi anni del Bilancio Partecipativo) hanno molto pesato sulla 'concezione' del Bilancio Partecipativo - in tutti gli scritti redatti da protagonisti 'di punta' delle varie fasi di strutturazione del processo (dai tre sindaci di Porto Alegre Genro, Dutra e Pont a 'teste pensanti' del primo periodo dell' OP come il sociologo Luciano Fedozzi, Gilson Lima, Iria Charão ecc.) vi sia una grande attenzione a non identificare 'padri putativi' del processo, lasciando che sia percepito come un 'processo di creazione collettiva'.

${ }^{60}$ Ad esempio, è vero che se Menegat (1995) ha documentato con una serie di interessanti interviste il lavoro volontario di 'alfabetizzazione' della popolazione realizzato da molti leader locali (affiliati al PT o no) attraverso piccoli depliant esplicativi delle terminologie relative al bilancio, Abers ha documentato in più occasioni processi di 'alfabetizzazione' da parte di agenti politici. In ogni caso, le due attrici non polemizzano mai tra loro, hanno al massimo differenze di accento ed interessi diversi nell'esaminare il ruolo dei diversi attori.

${ }^{61} \mathrm{Nel}$ caso dell'OP di Porto Alegre, Souza (coordinatore di una ricerca comparativa tra il percorso della capitale gaúcha e quelli di Belo Horizonte e Recife) cita come prova i criteri di distribuzione interni ad ogni Regione, che possono penalizzare o meno una comunità povera a seconda del numero totale (alto o basso) di altre comunità in condizioni simili esistenti nella stessa Regione.

${ }^{62}$ Souza (2002) parla di 'gerrymandering' come fenomeno di deliberata frammentazione delle energie sociali attraverso la sovrapposizione di proiezioni geografiche artificiali su di esse.

${ }^{63}$ Dimensioni troppo grandi impediscono ai più poveri di muoversi e far sentire la loro voce nei processi decisionali; Regioni che mescolano comunità eterogenee o 'rivali' generano conflitti e frammentazione del 'senso di luogo',ecc.

${ }^{64}$ Purtroppo ancora non esistono studi specifici che registrino passo per passo come tale processo è stato condotto.

${ }_{65}^{65}$ Isola del Pavone, Isola della Pintada, Isola Grande dei Marinai e Isola dei Fiori

${ }^{66}$ In maiuscolo sono state rappresentate le parole in corsivo nel testo citato, essendo questo tutto in corsivo.

${ }^{67}$ Se molti membri del Consiglio Comunale, a parole, recalcitrano ancora nel riconoscere apertamente una legittimità allo strumento decisionale dell' $O P$, il fatto che in 14 anni siano stati apportate pochi emendamenti ai bilanci discussi con i cittadini (e sempre su voci di importanza non strutturale) significa che - nella pratica - gli riconoscono una 
legittimità 'di sostanza' dovuta all'impegno di un numero tale di rappresentanti della cittadinanza sufficiente ad attribuirgli capacità reale di pesare incisivamente sulle scelte per il territorio portandosi dietro una forte fetta dell'opinione pubblica e un numero di difensori agguerriti da poter essere considerati 'rischiosi' per la rielezione.

${ }^{68}$ Cfr. Abers, 1996, 1998; Menegat, 1995; Fedozzi, 1997 e 2000

${ }^{69}$ Cfr Allegretti 2002b, p. 75-77.

${ }^{70}$ Il termine 'carona' (autostop) è stato spesso usato spregiativamente per negare a chi non partecipa all'O.P. almeno con qualche rappresentante per quartiere il diritto di 'andare a traino' dei benefici procurati dai più impegnati.

${ }^{71}$ Oggi, questo è arr9icchito dalle 'carovane', gruppi organizzati di Delegati popolari che vanno a visitare le diverse comunità per rendersi conto 'de visu' dei loro problemi.

${ }^{72}$ In particolare, Marquetti ha considerato il reddito nominale medio dei capifamiglia, la percentuale di madri con sola licenza elementare, il numero di domicili e nuclei irregolari, e la presenza di abitanti sotto i 15 anni. 



\section{0 \\ 1989: la città ad un bivio - alcuni mumeri dell'OP: superando la sterile contrapposizione tra qualità e quantità}

Il fondamentale, in questo processo, è che, al di là della mobilitazione di rappresentanze collettive organizzate della società, il cittadino, in quanto individuo, può essere protagonista e sentirsi responsabile nei confronti di questo partenariato governo/società, cosa che finisce per diventar parte della sua identità personale in quanto abitante della città, $\mathrm{e}$ per ripercuotersi sull'identità urbana (Resoluções III ${ }^{\circ}$ Congresso da Cidade, 2000, p. 7-8).

Come abbiamo visto nei capitoli precedenti, il Bilancio Partecipativo si è imposto gradualmente alla città come strumento di partecipazione, centrato sul ruolo del cittadino-abitante (piuttosto che del cittadino-elettore, già portatore di diritti formali) inteso quale individuo che agisce all'interno di una collettività territoriale. In questo, l'OP è andato differenziandosi dai preesistenti istituiti tradizionali di concertazione, non tanto per la forma negoziale (presente anche in quelli), quanto piuttosto per il carattere pubblico e aperto dei suoi momenti dibattimentali e per il fatto che le rappresentanze popolari che guidano i suoi momenti decisionali non preesistono al processo, ma sono annualmente elette al suo interno. E sono legate ai cittadini che le hanno elette da vincoli di mandato che le rendono revocabili (almeno per quanto riguarda i Consiglieri che compongono il massimo organo decisionale dell'OP). Questo capitolo si propone di analizzare alcuni dati numerici che si riferiscono al processo, e mostrare come essi diano interessanti informazioni sul livello di 'qualità' (in costante crescita) che ne connota sia l'organizzazione che l'impatto sulla città, in termini di capacità di attrazione dei cittadini come di articolata capacità di previsione di opere e servizi. Questo è ovviamente un elemento fondamentale visto che, da ormai 14 anni, l'O.P. rappresenta il principale 'snodo decisionale' delle politiche cittadine.

A tale proposito, vale la pena ricordare che il Regolamento Interno dell'Orçamento Participativo - distribuito annualmente in oltre 20.000 esemplari ai partecipanti al processo - dedica un interessante capitolo alla divulgazione presso la cittadinanza dei criteri scelti dai diversi assessorati e autarchie del Comune di Porto Alegre come discriminante per accettare o meno di finanziare un'opera o un servizio richiesti dalla cittadinanza attraverso i diversi gradi di assemblee dell'O.P. Ormai da alcuni anni, il capitolo è presente nel 
libretto (annualmente rivisto dal COP in collaborazione con il Comune) che viene divulgato già in occasione delle Assemblee Preparatorie. Questo strumento per ordinare e pre-selezionare alcune richieste della cittadinanza ha contribuito fortemente (come parte dell'impianto pedagogico che governa l'interazione vis-a-vis tra abitanti, amministratori e tecnici) a costruire un argine alle derive populistiche o corporativistiche teoricamente immaginabile dentro un processo ad alta partecipazione, in cui tuttavia esistono già - come abbiamo visto - altri meccanismi 'riequilibratori' delle semplici maggioranze decisionali, per garantire che a decidere delle politiche e dei progetti per l'intera città non sia appena la legge del più forte (o del più presente) ma modalità di scelta che contemperino i punti di vista dell'Amministrazione, quelli dei partecipanti ed anche quelli di chi - pur non partecipando - ha diritto a che vengano presi in carico dalla comunità almeno i propri bisogni più urgenti.

\subsection{Quale pubblico per il Bilancio Partecipativo?}

C'è un invalso sentimento comune che l'OP sia per "la gente delle favelas" e che "la gente delle favelas" vuole prioritariamente opere di infrastrutturazione urbana. Ovvero, vi è un brutale preconcetto che ancora richiede un lungo e paziente lavoro per essere superato. La priorizzazione di coloro che hanno maggiori carenze (e si sottolinei che "chi è più carente" ha un sesso, un'età, un'etnia, ecc.) non deve significare l'esclusione dei più, ma esattamente ciò che è, ossia, 'priorizzazione'. Questa questione può anche essere esaminata da un punto di vista della classe (o del reddito). L'avvicinamento con i settori delle classe medie urbane è molto importante per la diversificazione del pubblico dell'OP. Non è sempre stato facile, ed esattamente per le ragioni sopra esposte (Rompendo nossos limites, 2001).

Quanto osservato a proposito degli obiettivi politici e del 'target' in base ai quali a Porto Alegre si è puntato fino ad oggi ad orientare azioni efficaci di promozione e arricchimento del Bilancio Partecipativo, sottolinea come un elemento qualificante in ogni processo a partecipazione libera e volontaria debba necessariamente essere il costante e attento monitoraggio dei partecipanti, per elaborare sempre nuove strategie di coinvolgimento degli abitanti, e comprendere motivazioni, interessi e limiti di chi partecipa ai processi e per contro - anche di chi sceglie di non prendervi parte.

Evoluzione della partecipazione popolare diretta nelle principali fasi assembleari del Bilancio Partecipativo di Por to Alegre (1989-2002)

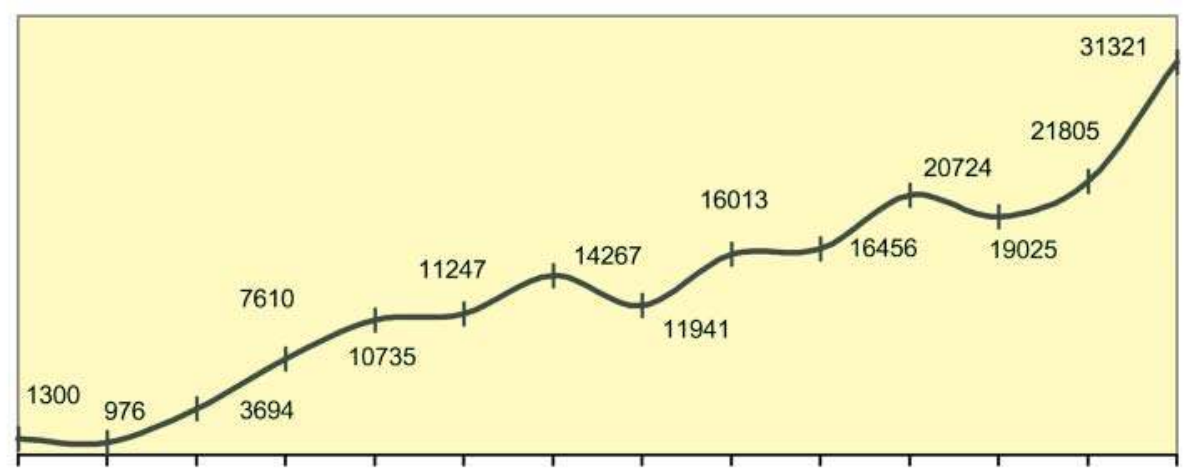

19891990199119921993199419951996199719981999200020012002

(Fonte: Coordinamento Relazioni con la Comunità del Comune di Porto Alegre, 2002) 
Di questo a Porto Alegre ci si è cominciati a rendere conto soprattutto a partire dalla seconda gestione dell'Amministrazione Popolare (1993-1996), e con particolar forza a partire dal momento in cui si è cominciato a mettere in piedi la sperimentazione delle nuove Assemblee Tematiche. Proprio nel 1994, un'indagine dell'Istituto di ricerca META rivelava che già l'8,4\% della popolazione adulta di Porto Alegre aveva preso parte almeno 1 volta alle Assemblee Plenarie del Bilancio Partecipativo, ${ }^{1}$ mentre a fine ' 97 la percentuale è stata stimata intorno al 25\% (cfr. PI 1998). Tali dati, sommandosi a quelli di analisi delle dinamiche della partecipazione nelle principali tornate assembleari, sono serviti a riflettere - nel tempo - non solo su come la capacità di radicamento nel territorio portoalegrense mostrata dal Bilancio Partecipativo, permetta oggi di pensarlo come un'esperienza 'difficilmente reversibile' (Abers, 1998b), ma anche sulla 'turnazione' che si verifica tra i partecipanti al suo interno. Ovvero, se anche le oltre 40.000 persone che annualmente prendono parte al Bilancio Partecipativo ${ }^{2}$ sono ben lontane dal rappresentare una maggioranza sul totale degli abitanti di Porto Alegre, ${ }^{3}$ esse hanno però una rappresentatività superiore alla loro reale consistenza. Non solo perché le ripetute riconferme elettorali dell'appoggio di cui l'Amministrazione gode costituiscono una modalità indiretta di approvazione dell'OP come principale strumento e 'nodo articolatore' delle politiche municipali, ma anche e soprattutto perché - nel distendersi del tempo il totale dei cittadini che hanno preso parte al processo di Bilancio Partecipativo è certo maggiore di quello che i dati quantitativi annuali rivelano. Intrecciando, infatti, questi ultimi con le analisi qualitative sulla partecipazione al processo e con le due indagine succitate, si rileva un fenomeno di 'turnazione' (per soddisfazione o per disapprovazione) che in questi anni ha visto spesso non riprestarsi al processo molti dei cittadini meno motivati che non hanno ottenuto in tempi rapidi ciò che speravano, $\mathrm{o}$ che hanno già visto soddisfatte le richieste prioritarie della propria comunità. ${ }^{4} \mathrm{~A}$ compensare le loro assenze, nel ciclo successivo, l' 'effetto dimostrazione' e il passaparola messo in moto da chi ha verificato la 'sostantività' del Bilancio Partecipativo ${ }^{5}$ (cioè la sua possibilità di portare reali benefici a chi si impegna al suo interno) hanno in genere portato nuove presenze che, nonostante nel tempo si siano sempre registrati anche 'gruppi stabili' di partecipanti (come una parte di quelli legati al ruolo mobilitatore del movimento comunitario cittadino) contribuiscono al rapido rinnovo del pubblico e alla diffusione della conoscenza del processo. Non è un caso che ben il 43,5\% degli intervistati in una ricerca statistica del 2000 (cfr. CIDADEPMPA, 2002, p. 15) sia risultata prendere parte al processo per la prima volta in vita sua, mentre il $38,9 \%$ ha tra 1 e 4 anni di esperienza (il 14,3\% tra l'altro è già stato eletto almeno una volta Delegato o Consigliere). Se nel 1995 la percentuale di chi partecipava da oltre 6 anni era del 10,6\%, ed era salita al $15,7 \%$ nel 1998, oggi è scesa al 4,7\% dando prova di quel fenomeno cospicuo di 'ricambio del pubblico' a cui si accennava.

$\mathrm{Su}$ questi fenomeni, ha cominciato a riflettere nel 1995 un'inchiesta delle ONG CIDADE e FASE/RS realizzata in collaborazione con la CRC, ${ }^{6}$ per rilevare le ricorrenze di alcuni fenomeni 'qualitativi' che aiutassero a conoscere meglio il pubblico dell'OP. Oltre a costruire una sorta di 'profilo socioculturale' del partecipante medio alle Assemblee Regionali del Bilancio Partecipativo (in genere persone appartenenti a quella fascia sociale che il Comune mirava prioritariamente a coinvolgere), essa rivelò il peso di esperienze associazio- 
284 nistiche già maturate nel generare impegno alla partecipazione; oltre il 76\% degli intervistati risultarono, infatti, membri di associazioni e movimenti urbani - nel 62\% dei casi Associazioni di Quartiere - e 14\% di altre Associazioni a base locale come Commissioni di Strada informali, Centri Comunitari, Club di Madri e simili (Abers, 1998b). In seguito, il reiterarsi biennale di simili analisi di monitoraggio dei partecipanti al Bilancio Partecipativo ha rilevato una crescita 'per emulazione' delle aggregazioni di abitanti in aree prima poco 'fertili' per i movimenti urbani, in parallelo ad una perdita di importanza delle Associazioni popolari di tradizione clientelista ed autocentrata ${ }^{7}$ caratterizzate da gracili livelli di democrazia interna e da forte rappresentatività all'esterno (in genere presidenti 'a vita' o addirittura con trasmissione ereditaria delle cariche, caratterizzati dal ruolo di 'agenti elettorali sul campo' di politici locali). Parallelamente, la creazione delle Assemblee Tematiche e di altri forum deliberativi aperti alla cittadinanza - e soprattutto alle sue associazioni - ha ampliato la partecipazione al costruirsi condiviso delle politiche cittadine a soggetti provenienti da ambiti socioculturali ed esperienze di aggregazione differenti da quelle che connotavano il profilo medio dei tradizionali partecipanti (esperienze in sindacati, associazioni ricreativo-culturali o sportive, consigli scolastici, ecc.).

\subsection{1 "Prevalenze" di pubblici}

Oggi, le ultime indagini tese a restituire i diversi profili del variegato pubblico del Bilancio Partecipativo (CIDADE-PMPA, 2002), ${ }^{8}$ rilevano una sostanziale continuità con gli obiettivi che in passato l'Amministrazione Popolare ha perseguito nell'investire sul coinvolgimento dei cittadini nella democratizzazione della struttura amministrativa e progettuale di Porto Alegre. Ed anche con le dinamiche interne all'organizzazione comunitaria spontanea.

Ad esempio, è interessante che - oggi - la maggior fetta dei partecipanti al Bilancio Partecipativo dichiari di non avere 'preferenze partitiche' $(40,7 \%)^{9}$ e che il dato sia in crescita rispetto al $34 \%$ registrato nel $1996 .{ }^{10}$ Nonostante nel frattempo la città abbia per ben due volte rieletto con entusiasmo il Fronte Popolare alla sua guida, le preferenze espresse dai partecipanti all'OP a favore di una identificazione con le idee e la piattaforma del PT si fermano a 38,9\%. ${ }^{11}$ È poi un dato significativo che - secondo l'inchiesta di CIDADE-PMPA - il $60,9 \%$ dei partecipanti all'OP partecipi in parallelo a forme diverse di aggregazione sociale ( $47 \%$ di una sola, $19,8 \%$ di due o tre, $3,4 \%$ di oltre 3 contemporaneamente), secondo una ripartizione ben evidenziata dalla fig. 32 .

Anche se la percentuale di partecipanti non impegnati in nessun'altra attività aggregativa è cresciuta nel tempo (era 24,1\% nel 1995, 30,1\% nel 1998, e $39,1 \%$ oggi), resta il fatto che la maggioranza dei cittadini che partecipano all'OP tende ad essere già precedentemente 'attivo' e 'mobilitato'. Tra chi si preorganizza - per prendere parte al Bilancio Partecipativo ed acquisire forza al suo interno - la maggioranza lo fa sulla base degli spazi della propria vita quotidiana: il 30,5\% vi si reca, infatti, con la propria Associazione di Abitanti (AMs), ${ }^{12}$ il 9,6\% con altri gruppi aggregati intorno al vicinato, $1^{\prime} 8,4 \%$ con un movimento di rivendicazione per la costruzione di asili nido autogestiti. Solo lo $0,6 \%$ degli intervistati dichiara di partecipare solo a titolo personale, mentre crescono rispetto al passato le mobilitazioni di nuovi gruppi aggregati intorno a rivendicazioni specifiche, come quelli del Movimento per l'Alfa- 
betizzazione (MOVA, 1,2\%). Del resto, il 30\% dei partecipanti dichiara oggi di partecipare all'OP per aiutare la sua comunità (ed è ben il 58,3\% tra le donne contro il 50,3\% di due anni fa), o per esercitare i diritti di cittadinanza $(23,3 \%)$, mentre il $17,8 \%$ già si appaga della democraticità del meccanismo decisionale (questo gruppo sale a poco oltre il $31 \%$ tra coloro che affermano di conoscere almeno alcune regole del processo, e a $29 \%$ tra chi ne conosce la maggioranza). ${ }^{13}$ Del 2,2\% che ha segnalato ragioni di impegno diverse da queste e dall'ipotesi 'presentare richieste al Comune', il 35\% ha ammesso di non sapere per quali reali ragioni partecipa alle Assemblee. ${ }^{14}$

Che la presenza nell'OP sia legata a battaglie pregresse o parallele portate avanti dai movimenti comunitari, lo si nota anche da alcune forme di 'delega' che si riproducono nei momenti dei dibattiti e delle dichiarazioni di voto sulle varie questioni: ad esempio, il $37,7 \%$ dei partecipanti non parla mai nelle assemblee (indipendentemente dalla fascia di età e dal fatto di essere uomo o donna), delegando allo scopo persone con cui si accompagna e leader di comunità; va però riconosciuta una graduale 'crescita' nella distribuzione delle responsabilità di impegno, visto che nel 1998 erano ben il $62 \%$ coloro che non intervenivano. Pochi restano comunque i giovani $(5,7 \%)$ che prendono la parola con frequenza sia nelle Assemblee Tematiche $(0,3 \%)$ che nelle Regionali $(0,4 \%)$; in genere lo spazio della parola è soprattutto occupato dagli ultracinquantenni. Un aspetto indicativo, è che i partecipanti che in genere prendono la parola, in maggioranza $(39,5 \%)$ tendono a farlo durante le Assemblee di Quartiere o di Comunità, in luoghi cioè dove si sentono più 'protetti' da un ambiente familiare, conosciuto e meno dispersivo; si spiega anche così (oltre che per il numero di partecipanti) l'insistenza mostrata dal Gruppo di Lavoro sulla Modernizzazione del Bilancio Partecipativo attivato nel 2001, nel sottolineare la necessità di valorizzare gli spazi di democrazia rappresentati da questo tipo di riunioni.

Sotto il profilo della composizione sociale, oggi si nota una crescita dei partecipanti analfabeti $(4,7 \%$ contro il $3 \%$ del 1998), ma un calo di coloro che non hanno terminato le elementari 34,3 contro il $46 \%$ del 1998 e il $37 \%$ del $1995)$ ed una crescita di quelli che hanno studi secondari e oltre $(20,1 \%$ contro il $16,1 \%$ del 1998 e il $14,2 \%$ del 1995), categoria in cui le donne superano gli uomini di 2,8 punti percentuali. Tra i rappresentanti popolari eletti nell'OP, la percentuale di persone prive di istruzione scolastica scende al $2,7 \%$, (ma vi si sommano $0,9 \%$ di persone appena alfabetizzate), ma ben il $24 \%$ non ha completato le elementari e il $12,4 \%$ ha frequentato le scuole medie senza terminarle; segno che il Bilancio Partecipativo riesce a coinvolgere attivamente nei ruoli più impegnativi anche persone con preparazione scolastica medio-bassa, attraverso un accurato lavoro di semplificazione e traduzione dei temi trattati al suo interno. ${ }^{15} \mathrm{Nel}$ complesso, tali dati rispecchiano il fatto che Porto Alegre risulta la capitale brasiliana con il grado più basso di analfabetismo del paese ${ }^{16} \mathrm{e}$ moltissimi progressi sono stati compiuti nell'alfabetizzazione nell'ultimo decennio; si rileva quindi, anche tra i partecipanti dell'OP, una complessiva seppur discreta - tendenza alla crescita del livello di scolarizzazione.

Interessante è notare come - per quanto concerne il reddito familiare - la maggioranza dei partecipanti si situi nella fascia tra i 2 e i 4 Salari Minimi (29,3\% con una leggera prevalenza femminile), o al di sotto dei 2 Salari Minimi (24,9\% con una prevalenza delle donne di quasi 13 punti percentua- 
286 li) mentre solo il $13,1 \%$ dei partecipanti supera la soglia dei 12 Salari Minimi. Nel 1998 erano solo il 12,2\% i partecipanti che percepivano redditi maggiori di 12 Salari Minimi, ma ben il 30,9\% non arrivavano alla soglia dei 2 . $\mathrm{Nel}$ complesso, se le prime tre fasce di reddito (fino a 8 Salari Minimi) includevano nel 1998 il 78,1\% dei partecipanti, oggi ne comprendono il 76,9\%. Da rilevare è che permane una certa differenza di composizione - oltre che di interessi - tra i partecipanti alle Assemblee Regionali e quelli delle Tematiche. Ad esempio, tra chi prende parte normalmente solo alle Assemblee Tematiche ${ }^{17}$ gli appartenenti alla fascia di reddito oltre i 12 Salari Minimi sale al $28,1 \%$ (mentre scende al 6,5\% tra i partecipanti alle sole Regionali) che scendono al $20,3 \%$ tra chi si impegna in entrambi i tipi di istanze. Parallelamente, i partecipanti con reddito sotto i 4 Salari Minimi rappresentano il $62,7 \%$ tra chi partecipa alle sole Regionali, mentre scendono al 30,9\% tra chi partecipa alle sole Tematiche (e 44,5\% tra chi partecipa ad entrambe le istanze). Tra i Delegati e i Consiglieri, invece, prevalgono persone che percepiscono redditi tra i 2 e i 4 Salari Minimi (23,2\% contro il $21,2 \%$ del 1998) e tra 4 e $8(20 \%$ contro il 28,2\% del 1998). ${ }^{18}$ I fenomeni di gentrificazione di questi ruoli non sono conclamati, ma si possono notare dalle variazioni avvenute nelle fasce estreme; coloro che percepiscono redditi inferiori ai 2 Salari Minimi scendono dal $24,1 \%$ del 1998 al $14,2 \%$ di oggi, mentre coloro che percepiscono oltre 12 Salari Minimi passano dall'11,2\% del 1998 al 15,1\% attuale. ${ }^{19}$

La fig. 32 offre, inoltre, un quadro delle attività professionali prevalenti, rilevando un calo dei lavoratori generici (dal 21,9\% al 12,6\%) un'invarianza dei lavori casalinghi o a domicilio $(14,9 \%$ con una prevalenza non schiacciante della rappresentanza femminile - il $18,2 \%$ ) ed un lieve aumento dei lavoratori del mercato informale (2,3\% contro l' $1,4 \%$ del 1998). Considerando le sole Assemblee Tematiche, si rileva una maggiore incidenza dei servizi qualificati non manuali $(10,1 \%)$ e dei professori $(9,3 \%)$, mentre i lavori non qualificati scendono al 9\%, I disoccupati rappresentano il 15,9\% del pubblico (con una lieve prevalenza delle donne), mentre i lavoratori autonomi sono il $18,9 \%$ (scendendo al $12,8 \%$ tra le donne) e gli impiegati pubblici rappresentano il $12,1 \%$ dei partecipanti dell'OP.

La distribuzione dei partecipanti per fasce di età appare equilibrata e con poche variazioni rispetto al passato: si ha una leggera prevalenza di ultracinquantenni $(25,9 \%$, una fascia però più ampia delle altre), mentre i cittadini nella fascia $16 / 25$ si attestano al $17,6 \%$, quelli tra $26 / 33$ al $16,4 \%$, quelli tra $34 / 41$ al $20,4 \%$ e quelli tra 42 e 49 al $18,6 \% \cdot{ }^{20}$ Lo stato civile vede invece una prevalenza di persone sposate $(45,5 \%)$, un poco in calo rispetto al 1998 (erano il 51,9\% ma i divorziati erano il 7,9\% contro il 9,6\% attuale). Tra gli eletti (Delegati e Consiglieri), vi è una prevalenza di ultracinquantenni $(36,2 \%)$ e di persone tra i 42 e i 49 anni (29\%), mentre i ragazzi tra i 16 e i 25 anni non superano 1 ' $8,8 \%$. In compenso, tra chi partecipa per la prima volta alle Assemblee, è crescente nel tempo, sia nelle Tematiche $(5,7 \%$, in particolare se si discute di Sport e Tempo Libero) che nelle Regionali (6\%).

La composizione dei partecipanti - relativamente all'origine etnica - riproduce sostanzialmente la composizione che si rileva nelle città del sud del Brasile: il 20,9\% si definisce appartenente ai gruppi 'afroamericani', mentre il 62,3\% è rappresentato da persone di origine europea. Le proporzioni non variano tra gli eletti in seno al Bilancio Partecipativo: il 60,9\% di essi è bianco e il 20,4 di colore. 


\subsubsection{Questioni di genere}

Un'altra ragione per cui il Bilancio Partecipativo ha catturato le donne è che il governo ha mostrato da subito che un bilancio municipale può essere così semplice come un bilancio domestico. Che non è esoterico, che è qualcosa che appartiene al quotidiano delle donne (E. Marxbackes, apud Solidariedade, 2003).

Un'ultima necessaria considerazione riguarda la presenza nel Bilancio Partecipativo delle donne, che tradizionalmente - al suo interno - hanno avuto occasione di mostrare una densa nozione di organizzazione a partire dal quotidiano. In generale, la presenza femminile nel Bilancio Partecipativo risulta in graduale crescita: oggi, infatti, le donne rappresentano il 58\% dei partecipanti, contro il 51,5\% del 1998 e il 47,2\% del 1995 (rispetto ad allora si è avuta una crescita di quasi 11 punti percentuali), anche se la presenza nelle Tematiche pare calata del 3,5\% rispetto all'ultima analisi, specialmente nei settori della Cultura, dei Trasporti, dello Sviluppo Economico e della Politica Fiscale. ${ }^{21}$ Deve però constatarsi anche un fenomeno di maschilizzazione man mano che si passa ad analizzare i ruoli 'rappresentativi' dell'Orçamento Partecipativo, ovvero i Consiglieri e i Delegati. Ad esempio, quest'anno, sul totale degli 88 Consiglieri popolari eletti (titolari e supplenti, regionali e tematici) del Bilancio Partecipativo, le donne rappresentano il 39,8\% del totale $(38,6 \%$ sui titolari), ${ }^{22}$ senza contare che i Consiglieri di diritto (UAMPA e SIMPA) sono tutti maschi, e tra i 4 rappresentanti del Comune (titolari e supplenti) vi è una sola donna. Inoltre, i dati sulle rappresentanze femminili nei Forum di Delegati e nel COP - letti nella sequenza temporale dal 1989 ad oggi - indicano perfino un leggero decremento (CIDADE-PMPA, 2002, p. 34).

A che cosa il fenomeno sia esattamente dovuto, richiederebbe analisi specifiche più attente; è però intuibile che nella disparità contino sia ragioni storico-culturali che mancate attenzioni di natura pratico-organizzativa. Se, infatti, nelle Assemblee Plenarie, il Comune di Porto Alegre ha sempre predisposto spettacoli di intrattenimento e servizi di babysitter per permettere anche alle famiglie con bambini piccoli di prendere parte con più agio alle riunioni (e molte comunità locali fanno lo stesso in occasione delle assemblee di quartiere o di microregione), lo stesso sarebbe difficile da garantire nelle centinaia di riunioni annuali dei Forum dei Delegati e del COP, che già di per sé richiedono impegno assiduo da parte dei rappresentanti popolari eletti.

Empiricamente, in questi anni, si è constatato da più parti che il ruolo delle donne è mutato in positivo dentro il Bilancio Partecipativo; esse prendono sempre più spesso la parola, lottano per le proprie comunità ed intervengono a fare proposte di carattere 'progettuale' che sovente sono meglio articolate di quelle dei partecipanti uomini, ed ottengono perciò più ascolto e posizioni prioritarie tra le richieste gerarchizzate in sede di costruzione dei Piani di Investimento. ${ }^{23}$ Ma questo ovviamente non basta.

Di recente, lo stesso Gruppo di Lavoro del Comune di Porto Alegre sulla Modernizzazione del Bilancio Partecipativo, ha rilevato la necessità di porre rimedio a questa tendenza 'escludente', rafforzando (anche attraverso politiche attente alle questioni 'di genere') l'universalizzazione del Bilancio Partecipativo e della sua rappresentatività sociale; al contempo, ha però rilevato come ancora oggi, tra i partecipanti, 'solo poche donne ritengono che l'OP debba essere pensato in modo da favorire l'uguaglianza di genere, sebbene 
288 molte cominciano già a porsi almeno la domanda', mentre 'al tempo della ricerca condotta da Rebecca Abers (94/95), secondo l'autrice, questi temi neppure venivano posti tra i partecipanti al Bilancio Partecipativo. ${ }^{24}$ Lo stesso Gruppo di Lavoro ha, del resto, dovuto ammettere che varie delle iniziative prese in questi anni dal Comune a favore delle donne "non sono passate per il Bilancio Partecipativo'; escludendo quindi dai benefici lo strumento principale di governo locale del territorio, si è finito spesso per ridurre gli interventi a 'politiche di settore' incentrate sulla discriminazione positiva, ma non dando alle azioni una collocazione trasversale e sufficientemente centrale. E siccome:

Tali conflitti poggiano su rapporti di potere. Ignorare tali rapporti significa rafforzare l'oppressione. In questo modo, le politiche pubbliche implementate apparentemente senza una particolare attenzione ai conflitti tra i sessi hanno l'effetto di rafforzare i rapporti di dominazione, ingiustizia ed esclusione nei riguardi delle donne. Volenti o nolenti, le politiche pubbliche incidono sempre su questi rapporti, trasformandoli e facendoli diventare più ugualitari, oppure consacrando le ingiustizie. Sotto questo aspetto, il processo di Porto Alegre sembra meritare una critica. Introdurre meccanismi di capacitazione e di ascensione al potere delle donne è un imperativo della stessa Democrazia. [...] E' necessario dare voce alle donne in maniera esplicita affinché i rapporti tra i sessi diventino più ugualitari (Alfonsin, 2002).

\subsection{Le tendenze al di là dei da ti: l'O.P. e la distribuzione dei finanziamenti}

Nel capitolo precdeente abbiamo visto come il Bilancio Partecipativo abbia efficacemente conseguito obiettivi di 'equità distributiva' nei confronti dei settori più deboli della cittadinanza, sovente anche a prescindere da una loro attiva partecipazione al processo (Marquetti, 2001).

Sarebbe forse inutile chiedersi se vi sia un modo inequivocabile per fugare il legittimo dubbio che un'arena deliberativa connotata dal tipo di partecipazione media finora rilevata (seppur tendente ad una progressiva diversificazione) possa non tener conto della complessità delle esigenze di un territorio articolato come quello di Porto Alegre. Una risposta certa che lo fughi forse non esiste, ma è possibile attenuare un tale dubbio - senza perdersi nel mero confronto di concezioni teoriche sulle virtù della democrazia rappresentativa e di quella diretta - attraverso due approcci diversi e complementari: l'analisi delle richieste insoddisfatte (domanda insoluta) e l'eventuale permanenza di corpose critiche sull'operato a cui le scelte compiute nel Bilancio Partecipativo hanno guidato, unita alla disamina delle richieste progressivamente accolte nel tempo per verificare quale articolazione e complessità esse denotino.

Il primo tipo di analisi è estremamente complesso, e produce risultati troppo discrezionalmente interpretabili, esigendo di processare una mole cospicua di dati (non sempre conservati nel tempo, e comunque irrealistici in quanto 'proiezione di un desiderio' concretamente non esaudibile in toto né dalle finanze, né dalle competenze, né dalla capacità progettuale e gestionale di un Comune) e di discernere tra critiche fondate e contrapposizioni di natura corporativa, politico-ideologica o forme di rivalsa o vendetta in mala fede. Il secondo metodo appare un po' più semplice e forse più obiettivo, dovendosi concentrare essenzialmente sulla valutazione relativa tra tipi diversi di opere e servizi attivati, rapportandoli intuitivamente ad un quadro interpretativo dei diversi settori di intervento in cui sarà necessario operare simultaneamente in una città delle caratteristiche di Porto Alegre. 
Per questo, abbiamo preferito riferirci ad un approccio del secondo tipo per muovere alcune considerazioni d'insieme, appoggiandoci a due circostanziate analisi diacroniche dei Piani di Investimento del Bilancio Partecipativo dal '91 ad oggi contenute in Allegretti 2000a (pp 222-245) e Isasa de Mello, 2002 (pp. 27-73), e di cui vorremmo riproporre - aggiornandole alcune considerazioni. Tale analisi di dettaglio avrà inevitabilmente un'impostazione attenta soprattutto agli aspetti qualitativi del trasformarsi delle richieste popolari presentate nell'OP (e delle loro tipologie aggregative); pertanto non può prescindere da una breve costruzione del quadro 'quantitativo' in cui esse si collocano, che lasciamo volentieri all'esame delle figg. 40 e 43. Queste cercano di offrire una cornice per comprendere come il Bilancio Partecipativo (durante i suoi 14 anni di sperimentazione) abbia visto variare nel tempo il quadro delle risorse di cui i Piani di Investimento (PI) sono andati a dettagliare la distribuzione, giovandosi dell'attivo concorso degli abitanti partecipanti al processo. La ricostruzione di questo scenario in mutamente è risultata particolarmente complessa per almeno 3 ragioni:

1) dal '91 il Brasile ha cambiato più volte moneta ${ }^{25} \mathrm{ma}$ i dati dell'Amministrazione di Porto Alegre non sono stati sempre convertiti nell'ultima (il Real) per renderli comparabili; ${ }^{26}$

2) la redazione dei Piani di Investimento presentati dal 1991 ad oggi in sede di O.P. è molto variata ed è spesso difficile omologare i dati per un confronto rapido e significativo;

3) i criteri interni dell'Orçamento Participativo, il numero e la tipologia delle assemblee, e la valutazioni delle priorità su scala cittadina e regionale si sono estremamente trasformate in questi 11 anni in virtù dei continui adeguamenti che la struttura flessibile del processo subisce;

4) i dati contenuti nell'Annuario Statistico del Comune (l'ultimo pubblicato risale al 2000), nel Relatorio de Atividades e nel Relatorio dos Indicadores Sociais (ultime edizioni 2001) appaiono estremamente analitici, e vanno pertanto sfrondati estrapolandone alcuni (o sommando tra loro i valori parziali di cui in taluni casi non appaiono totali) in modo da chiarirne la funzione di supporto ad alcune osservazioni;

5) consultando lo schedario del Comune di Porto Alegre delle opere realizzate o in corso di realizzazione è difficile ${ }^{27}$ riuscire a identificare i tempi di conclusione di ogni opera prevista dai vari PI o le ragioni dei suoi persistenti ritardi, seppur è possibile condurre delle valutazioni sul grado di complessiva 'solvenza' delle domande finanziate (figg. 37 e 38 ).

A dispetto del fatto che questa concomitanza di ragioni non ha reso agevole né omogenea l'analisi di molti dati né l'apprezzamento di alcuni fenomeni che pure sarebbe stato interessante indagare, ${ }^{28}$ una lettura incrociata di una simile analisi e della formulazione dei 'criteri tecnici' per l'ammissibilità delle richieste popolari aiuta a comprendere come l'OP - pur rivolgendosi in linea prioritaria ad un pubblico di 'emarginati', che per lo più si organizzano per presentare richieste basilari per la propria sopravvivenza - vada lentamente subendo una trasformazione qualitativa in direzione di un'adesione più articolata a tutti i bisogni della città, come attestato dalla stessa comparsa (nel 1999) di criteri tecnici per il vaglio di richieste ad assessorati prima non presenti nel Regolamento Interno (come quelli alla Cultura e all'Industria e Commercio) ed il comples- 
sificarsi nell'ultimo triennio delle specifiche per il finanziamento proposte dal Comune nelle aree dell'Educazione, della Salute, dell'Assistenza Sociale e dello Sport e Tempo Libero.

Da questa disamina incrociata emerge un quadro di graduale articolazione della capacità del Bilancio Partecipativo di 'comprendere' in sé scelte che rispondono ad istanze più ampie di quelle che si potrebbero ritenere congruenti con i soli deficit che connotano le aree di residenza della maggioranza dei partecipanti al processo. Ciò significa che i 'criteri riequilibratori' che ne segnano la struttura e le regole, uniti alle potenzialità pedagogiche che si attivano nel corso dei pubblici dibattiti, fanno sì che l'OP risulti 'sbilanciato' sul lato della città informale più nella composizione del suo pubblico che nella sua azione propositiva, in particolare a partire dal 1994, quando la creazione delle Plenarie Tematiche ha arricchito il dibattito, facendolo uscire da quel parziale 'settarismo' in cui la necessità di inversione delle priorità a favore degli strati più bisognosi della popolazione poteva tendere a relegarlo nei primi 5 anni di vita.

\subsection{Esame comparato dei Piani di Investimento (1990-2002): la crescita dello sguardo sulla città nel suo complesso.}

\subsubsection{La fase dell'avvio}

I primi due anni di vita del Bilancio Partecipativo sono stati fondamentali per quella necessaria inversione delle priorità di investimento che era stata alla base della campagna elettorale del Fronte Popolare nel 1988. In tal senso, durante il 1989, le linee di governo dell'Amministrazione Dutra circa l'investimento di fondi pubblici sulla città e le priorità espresse dai primi nuclei di popolazione che cominciava a partecipare delle assemblee pubbliche trovarono un punto di unione profonda nella scelta di destinare i pochissimi fondi che l'Amministrazione aveva a disposizione (cfr. cap. 8) per opere ritenute urgenti ed improcrastinabili (come reti di approvvigionamento idrico e fognario e pavimentazione delle strade) in alcuni dei nuclei più poveri e periferici della città. In realtà, prima della Riforma Tributaria dell'agosto 1990 , pochissime delle opere prese in carico dal Comune poterono essere realizzate; addirittura nessuno dei $42 \mathrm{~km}$ di pavimentazione comunitaria richiesti nel 1989 fu messo in cantiere (Augustin, 1994), e ben 191 delle opere 'in attesa', definite l'anno prima dalla popolazione come priorità, dovette essere rifinanziata e reintrodotta nel Piano degli Investimenti del 1991. Durante questi due primi anni, le 2 priorità tematiche indicate dalla popolazione come principali restarono invariate, anche a motivo della sovrapposizione che si determinò fra i due PI del $1990^{29}$ e del 1991 per via delle irrealistiche previsioni di bilancio formulate dall'Assessorato alle Finanze nel 1989. Gli investimenti in questi settori andarono a beneficiare quasi esclusivamente nuclei poveri della città informale, ignorati dall'Amministrazione Collares al punto che lo stesso misero investimento che l'Amministrazione Popolare poté realizzare coi pochi fondi del 1989 per garantire ad un maggior numero di quartieri acqua, fogne, reti di scolo pluviale e raccolta dei rifiuti risultò percentualmente superiore a quanto investito nello stesso settore dal governo precedente. 


\begin{tabular}{|c|c|c|c|c|c|c|}
\hline Anno & $\begin{array}{c}1986 \\
\text { (Ammini- } \\
\text { strazione } \\
\text { Collares) }\end{array}$ & $\begin{array}{c}1987 \\
\text { (Ammini- } \\
\text { strazione } \\
\text { Collares) }\end{array}$ & $\begin{array}{c}1988 \\
\text { (Ammini- } \\
\text { strazione } \\
\text { Collares) }\end{array}$ & $\begin{array}{c}1989 \\
\text { (Ammini- } \\
\text { strazione } \\
\text { Popolare) }\end{array}$ & $\begin{array}{c}1990 \\
\text { (Ammini- } \\
\text { strazione } \\
\text { Popolare) }\end{array}$ & $\begin{array}{c}1991 \\
\text { (Ammini- } \\
\text { strazione } \\
\text { Popolare) }\end{array}$ \\
\hline \hline $\begin{array}{c}\text { Investimen- } \\
\text { ti in US\$ } \\
\text { nel settore } \\
\text { del } \\
\text { 'Saneamen- } \\
\text { to basico' }\end{array}$ & 4.064 .887 & 7.889 .189 & 9.440 .321 & 5.339 .592 & 17.131 .853 & 23.026 .910 \\
\hline
\end{tabular}

Dati tratti dal PI di Porto Alegre, 1992

Evoluzione degli investimenti complessivi del Comune di Porto Alegre (1986-1991)

\begin{tabular}{||c|c|c|c|c|c|c|}
\hline Anno & $\begin{array}{c}1986 \\
\text { (Ammini- } \\
\text { strazione } \\
\text { Collares) }\end{array}$ & $\begin{array}{c}1987 \\
\text { (Ammini- } \\
\text { strazione } \\
\text { Collares) }\end{array}$ & $\begin{array}{c}1988 \\
\text { (Ammini- } \\
\text { strazione } \\
\text { Collares) }\end{array}$ & $\begin{array}{c}1989 \\
\text { (Ammini- } \\
\text { strazione } \\
\text { Popolare) }\end{array}$ & $\begin{array}{c}1990 \\
\text { (Ammini- } \\
\text { strazione } \\
\text { Popolare) }\end{array}$ & $\begin{array}{c}1991 \\
\text { (Ammini- } \\
\text { strazione } \\
\text { Popolare) }\end{array}$ \\
\hline \hline $\begin{array}{c}\text { Investimen- } \\
\text { ti } \\
\text { complessivi } \\
\text { in USS }\end{array}$ & 9.367 .418 & 14.276 .896 & 27.155 .429 & 7.831 .395 & 29.246 .371 & 42.310 .218 \\
\hline
\end{tabular}

Dati tratti dal PI di Porto Alegre, 1992

I grafici allegati al PI del '92 per chiarire alla popolazione l'impegno dell'Amministrazione Popolare a seguire le indicazioni fornite dalle Assemblee dell'O.P., pur con tutte le ristrettezze finanziarie del momento (e senza azzerare l'intervento del Comune negli altri campi), sono evidenti di questa prima fase di furore pavimentatorio e fognario indiscriminato (Mallmann,apud Allegretti 2000a) che caratterizzò gli esordi dell'Amministrazione Popolare e del Bilancio Partecipativo, al punto che le curve degli investimenti totali e degli investimenti in urbanizzazione primaria si assomigliavano notevolmente (fig. 42).

Nei primi due Piani di Investimento annuale redatti attraverso il Bilancio Partecipativo colpisce la mancata apparizione dei temi legati alla casa, sparita dall'orizzonte della politica municipale con il fallimento del $\mathrm{BNH}$ e non ancora massivamente ricomparsa sotto le forme alternative della 'regolarizzazione fondiaria', del 'trasferimento in alloggi per gli abitanti delle aree di rischio', delle Cooperative d'Abitazione e dei mutirões. Nel 1991, dei pochi interventi accolti, 2 prevedevano 'urbanizzazione di lotti' ed altri la pavimentazione di marciapiedi gestita attraverso mutirões, strumento già sperimentato durante l'Amministrazione Collares (cfr. cap. 12).

Il Piano del '91 - inizio di quella seconda fase dell'OP che Fedozzi (2000, p. 15) denota come "la svolta" - presenta una veste grafica un po' dimessa; la sua prima parte non è un documento finanziario burocratico, bensì un 'giornale' che informa la cittadinanza su temi come l'organizzazione del Forum contro la Recessione e la Disoccupazione (a cui è legata una proposta di semplificazione delle concessioni edilizie), i vantaggi della Riforma Tributa- 
ria Comunale appena approvata e i programmi dell'Assessorato all'Industria e Commercio (SMIC) per fronteggiare la crisi economica, come la ' $\mathrm{Ce}$ sta basica' per la famiglia, le fiere-modello, i Punti di Offerta e il 'Santo della Casa', programma di sostegno alla commercializzazione in negozio di prodotti dell'economia informale di ambito domestico attraverso uno show-room gestito dalla SMIC. Questa sorta di 'giornale' pare un modo per divulgare alcuni progetti per la città e recuperare il ruolo propositivo dell'Amministrazione davanti alla popolazione, la cui posizione era stata preponderante fino ad allora nella costruzione delle priorità di spesa del denaro pubblico.

In tal senso, è significativa soprattutto la comparsa - a livello di proposta - di uno dei primi 'progetti integrati' dell' Amministrazione, il 'Centro di Bairro' (centro di quartiere), mirato a creare piccoli centri commerciali di valorizzazione di microimprese e commercio informale, per l'animazione dei quartieri dove già esistesse una tensione che, seppure periferica, presentasse somiglianze con quanto in passato era avvenuto nel centro di Porto Alegre. L'operazione - mirata a trasformare l'occupazione spontanea in una convivenza armonica - è presentata dal PI del 1991 come un ampliamento che dà continuità al già avviato Progetto Centro, da discutere in una speciale commissione del Forum contro la Disoccupazione: è quindi letta come un marchio distintivo per la città tutta, non limitato a benefici da circoscrivere ai singoli quartieri. Nel complesso il 38,63\% dell'investimento previsto dal PI del 1991 è destinato ad opere di urbanizzazione primaria, il 10,9\% alla pavimentazione, il $9,8 \%$ alla sanità, il $15,5 \%$ ad interventi infrastrutturali diversi destinati a 'tutta la città'

L'anno dopo, concludendo nella presentazione del $\underline{\mathbf{P I}} \mathbf{9 2}$ che "più che la conquista della pavimentazione, della rete fognaria, della scuola e dell'acqua in tubi, l'O.P. stimola l'esercizio del diritto di cittadinanza e che lottando per rivendicazioni storiche della propria comunità il cittadino comune passa a conoscere $i$ problemi di altri quartieri, le carenze di altre 'vilas' $\mathrm{e}$ pertanto apprende a conoscere la città come un tutto e a capire la disputa per la rendita", il Sindaco Dutra si apprestava a dare inizio alle 590 attività (tra cui 185 nuove opere più quelle dell'anno prima da completare) richieste per il 1992 dalla popolazione. E sottolineava il tentativo dell'Amministrazione di rafforzare le entrate proprie (giungendo stavolta al $12 \%$ della spesa totale) 'cercando risorse là dove il reddito si concentra', anche per non dover dipendere da altre fonti vincolanti nel miglioramento 'delle condizioni di vita di migliaia di cittadini’ (PI, 1992). Interessante è che le opere dotate di finanziamento straordinario non compaiono più in un capitolo a parte come avveniva ancora nel PI del 1991, dove una piccola introduzione spiegava i programmi PROSEGE, PROBASE e PRONURB finanziati dal Ministero dell'Azione Sociale e cosa era il FUNDOPIMES (Programma integrato di miglioramenti Sociali) che gestendo fondi della World Bank e dello Stato del Rio Grande do Sul - finanziava progetti nelle aree dello sviluppo istituzionale ma anche della pavimentazione, del drenaggio, e della raccolta dei rifiuti.

Sebbene anche in questa gestione il COP destinò oltre il $50 \%$ dei fondi da investire al settore dell'urbanizzazione primaria, ${ }^{30}$ della pavimentazione $(34,6$ i km previsti nelle 74 strade indicate dalla popolazione) e della costruzione di nuove scuole (per un totale di 4650 nuovi posti), una serie di novità cominciano a fare capolino nel piano.

La prima è la comparsa (fig. 25) di 5 nuove categorie tematiche alle spalle 
delle tre prime priorità, in modo da organizzare gli investimenti per tipologie invece che solo per dipartimenti o assessorati di riferimento. In secondo luogo, visto che nel 1991 le sole 5 regioni più povere (Norte, Cruzeiro, Partenon, Lomba do Pinheiro e Leste) avevano fatto incetta di oltre il $70 \%$ dei fondi cittadini destinati all'investimento (contro il $30 \%$ delle altre 11), si ebbe il primo 'auto-riadattamento critico' dei criteri si selezione delle opere più urgenti da finanziare, ai fini di una più equa distribuzione delle risorse pubbliche fra le regioni (Andreatta, 1997) .In terzo luogo, in virtù della creazione del Programma di Regolarizzazione Fondiaria vennero anche previsti i fondi a beneficio di 8809 famiglie. A fronte dell' accoglimento della richiesta di ricostruzione in loco di Vila Planetario (cfr. cap. 14), altre favelas del centro non ottennero fondi per andare oltre un generico esame da parte della squadra di avvocati dell'equipe comunale.

Infine, il PI '92 segna la comparsa - nell'elenco delle priorità - di alcune opere considerate patrimonio dell'intera città, tra cui la costruzione del centro-studi sulle malattie animali Zoonoses, il restauro di 5 edifici del patrimonio storico, la conclusione del tetto del Mercato Pubblico e l'Albergo Municipale per le donne vittima di violenza carnale, il condizionamento dell'aria nel Museo di Porto Alegre, l'inizio dei lavori per il Distretto Industriale della Restinga, e le Stazioni di Trattamento Fognario nelle zone Sud e Nord e nel quartiere-città di Rubem Berta. Vennero finanziati anche i primi passi del nuovo programma Pró-Guaiba per il disinquinamento del lago e l'estensione ad altri 6 quartieri del servizio di 'raccolta differenziata' dei rifiuti casa per casa, legata ad alcuni progetti nell'ambito del riciclaggio realizzati insieme ai Padri Maristi.

Rispetto al PI precedente, quello del' 92 rivela quindi una notevole complessificazione del dibattito sulla città interno all'O.P.. Seppur si continua a valutare le aree verdi di quartiere come beneficio locale e non per la città tutta, almeno gli edifici monumentali da recuperare non appaiono confinati nella distribuzione dei fondi alla voce 'micro-regione Centro' che poteva correre il rischio di vedersi accollare ad libitum i restauri di ogni porzione del tessuto storico. Il loro restauro è incluso in una voce 'Tutta la città' (già presente nel '91 ma solo per piccole opere, o per recupero e ampliamento di edifici ad uso del Comune) la quale contempla anche una serie di programmi diffusi dei vari assessorati, come il piano di illuminazione Vilas e strade e Una piazza al mese (entrambi della SMOV), le reti di telecomunicazione e il recupero delle aree intorno a edifici di valore culturale (l'Officina del Gasometro, poi divenuta simbolo culturale della città, e lo storico Parco Farroupilha).

Nonostante questa evoluzione, il PI del 1992 resta ancora limitato ad interventi di natura prevalentemente 'fisica' sulla città, restando il processo di O.P. il vero punto di contatto con la sua riorganizzazione dal punto di vista sociale, fatta eccezione per i settori della scuola e della salute investiti da interventi maggiormente 'integrati' fra i due livelli di azione essendo essi vincolati per Statuto a dei parametri di investimento minimo inderogabile. ${ }^{31}$

\subsubsection{La fase del consolidamento e dell'ampliamento del Bilancio Parteci- pativo}

Il PI del 1993 - la cui realizzazione coincide con l'entrata in carica della nuova giunta - costituisce un ulteriore passo avanti nel recupero della capacità propositiva dell'Amministrazione, a partire dalla prefazione del nuovo 
sindaco che reclama l'urgenza del passaggio "dal particolare, dall'opera necessaria ad una comunità, al globale, che interessa tutta Porto Alegre" ribadendo che il Bilancio Partecipativo "ha l'obbligo di pensare il futuro della città e già cammina in tale direzione" (Genro, in PI '93).

$\mathrm{Da}$ un punto di vista dell'ammontare dell'investimento in proprio dell' Amministrazione (44 milioni di US\$), il PI '93 presenta una piccola diminuzione in rapporto al precedente; questa è esplicitamente motivata nell'introduzione, spiegandola con l'aumento di spese fisse, specie nei settori dell'educazione e della sanità, conseguenti ad investimenti decisi negli anni precedenti (e in parte - come gli stipendi del nuovo personale - costituenti vincoli distribuiti su tempi lunghi) e alla necessità di mantenere in buono stato di conservazione l'alto volume di opere e servizi forniti nei tre anni precedenti. Ancora una volta il Piano - che segna il passaggio a quella terza fase della storia dell'O.P. che Fedozzi (2000, p. 15) chiama 'la costruzione di un nuovo metodo di pianificazione partecipativa', si propone come spazio pedagogico di comprensione delle complessità di interdipendenze che regola l'organizzazione dell'ente locale, invitando i cittadini a pensare nel tempo e a concepire ogni opera come un continuum la cui realizzazione finisce per influire sulle voci di spesa degli anni successivi accumulandosi nel tempo con tutte le altre via via realizzate, e inevitabilmente contribuendo alla diminuzione del volume di risorse utilizzabili per investimenti diretti. Come sempre da questo momento in poi, nessun meccanismo dell'amministrazione urbana è lasciato al caso o all'intuizione del cittadino; ogni passo viene motivato nelle sempre più analitiche introduzioni ai PI, in modo da contribuire all'arricchimento del livello di comprensione dei meccanismi che presiedono alla costruzione della città anche per i cittadini meno istruiti che prendono parte agli incontri dell'O.P. Il linguaggio sarà spesso semplificato - specie nei riassunti generali dei dati - col ricorso a termini come 'spese obbligatorie' per motivare voci anomale o percentuali di spesa che l'Amministrazione vuole tener fuori dalle 'spese fisse' perché legate ad investimenti passati.

Per il '93, degli interventi indicati come prioritari dalla popolazione riunita nell'anno precedente, vengono messe in cantiere 410 'azioni', 200 delle quali sono destinate ad opere nuove. Una notevole chiarificazione del modo di esporre il Piano ed una complessificazione dei criteri di indicazione delle aree 'tematiche' prioritarie su cui convogliare i finanziamenti (frutto della revisione autoregolata del Regolamento Interno svolta dal COP) permettono di cominciare un confronto di dati con le gestioni che seguiranno. Le priorità del PI '93 - caratterizzate ancora dalla presenza ai primi posti dell'urbanizzazione primaria e della pavimentazione ${ }^{32}$ (fig. 25) - articolano in sottotemi la nuova categoria tematica 'organizzazione della città' arricchendone il significato. La collocazione come terza priorità dà per la prima volta vigore al tentativo di ricostruzione della politica dell'alloggio attraverso un ventaglio di molteplici possibilità: 26 favelas (8172 lotti) vengono beneficiate dal Programma di Regolarizzazione Fondiaria e 300 embrioni abitativi (nucleo servizi più una stanza) vengono messi in cantiere dentro il progetto di recupero infrastrutturale Humaitá-Navegantes. Prosegue la realizzazione di 1189 unità abitative finanziate dalla Caixa Economica Federal e l'urbanizzazione di tre 'vilas'. ${ }^{33}$ Un ruolo preponderante sul totale degli investimenti (giustificato da un finanziamento esterno del BID) cominciano ad avere dal 1993 alcune opere di 
interesse cittadino come il risanamento del Lago Guaiba e del suo sistema di immissari, e quelle di animazione delle rive dello stesso (Programma 'Guaiba vive'), ma anche il nuovo PRG del settore fognario e del trattamento delle acque ad essi interrelati. È interessante che queste opere 'per tutta la città' appaiono legarsi nel contempo alle singole regioni, integrando fra loro aree tematiche prima compartimentate; ad esempio il programma di disinquinamento lacustre prevede la costruzione di abitazioni per reinsediare le famiglie delle favelas Vila Cai-Cai e Recanto do Chimarrão che scaricavano i propri liquami neri nelle acque del Guaiba. Il restauro del Museo di Arte della città e di altri 4 edifici storici, la creazione di un ortomercato, i progetti 'Memoria culturale dei quartieri' e l'installazione del Sistema di Bus Monitorato Automaticamente sono le altre maggiori opere di interesse cittadino che rompono la logica del 'quartierismo' e del 'regionalismo'; $; 4$ nella stessa categoria compaiono i progetti di sviluppo economico della SMIC presentati nel '91, tra cui il 'Santo di Casa' e l'ampliamento a 10.000 beneficiari del programma di 'Acquisti Collettivi'.

Il Piano del 1994 - che si apre sotto l'egida dell'affermazione che ogni opera è uno strumento di resistenza alla crisi ed alla disoccupazione (Genro, in PI 1994) - segna un ritorno ad investimenti maggiori dell'ordine del $22,67 \%(85,8$ milioni di US\$). ${ }^{35}$ Nell'introduzione, la prima sottolineatura è sulla crescita rappresentata dalle spese per l'educazione e la sanità e sulla continuità data a molte opere non terminate nel ' 93 che occuperanno quindi anche i tecnici e gli operai nel nuovo anno: il problema - si prevede - si riprodurrà anche con le opere qui finanziate, seppur - si spera - con minore intensità. Inspiegabilmente non vengono elencate esplicitamente le tre prime priorità tematiche di investimento indicate dalla cittadinanza, ai primi posti delle quali si trovano la pavimentazione e l'urbanizzazione primaria e (dopo i primi risultati 'visibili' ottenuti negli anni precedenti, a partire dalla ricostruzione di Vila Planetario) il tema della regolarizzazione fondiaria/abitazione/aree di rischio. ${ }^{36} \mathrm{Al}$ complesso delle tre è dedicato il $75 \%$ delle risorse. Manca però una tabella riassuntiva generale della distribuzione dei fondi per aree tematiche. In compenso, nell'ambito della sezione 'pavimentazione' appare la voce totale di metri pavimentati nella regione, importante in un'ottica di trasparenza ma significativa anche nel quadro di una competizione ormai innescatasi fra regioni e quartieri.

Nella sezione delle opere per 'Tutta la città' compare per la prima volta un alto numero di lavori di spettanza del Dipartimento alla Casa (DEMHAB), per lo più legate al recupero di aree di rischio idrogeologico, mentre i fondi PIMES finanziano l'infrastrutturazione di 300 lotti tipo 'Site \& Service' e la continuazione di programmi di Regolarizzazione Fondiaria.

Negli altri settori di investimento spicca la costruzione di un nuovo Centro Amministrativo Regionale (CAR), la continuazione del miglioramento del sistema trasportistico pubblico (busvie e riforma dei terminal centrali), le due 'scuole comunali aperte' del Distretto Centrale e del nuovo 'reassentamento' Wenceslau Fontoura, lavori alla sede del Consiglio Comunale, all'Officina del Gasometro trasformata in centro culturale e al Mercato Pubblico, ma soprattutto all'Ospedale di Pronto Soccorso. Accanto alla continuazione del programma 'Guaiba vive' (che prevede la creazione di sentieri e aree di gioco nell' area recuperata da cui era stata rimossa Vila Cai-Cai) e di quello 'Centro di Quartiere' della SMIC, si istituiscono i primi finanziamenti per il 'Porto Secco', nodo 
del traffico pesante su gomma. Molte di queste opere vengono disperse all'interno della voce poco chiara e apparentemente onnicomprensiva 'organizzazione della città', divise per Assessorato o Dipartimento di spettanza.

Il Piano del 1995 si apre in modo anomalo, con due pagine aggiunte di errata corrige che, a contrariis, mostrano da parte dell'Amministrazione la volontà di rispettare le scadenze fissate per l'esposizione al pubblico, necessaria per rendere il Bilancio Partecipativo un 'percorso determinato' in una giusta miscela di regolamentazione e apertura capace di creare 'una cultura ed una psicologia nelle quali i leader hanno bisogno di conoscere le regole del processo' (Genro, 1997) e in cui i due contraenti del patto di co-gestione (Comune e cittadinanza) hanno 'regole del gioco' chiare che costituiscono un impegno in direzione della trasparenza e del rispetto reciproco. Il Piano esce all'indomani di grandi trasformazioni sottolineate nella prefazione dal Sindaco: ad esempio il Piano monetario 'Real' che costringe le Istituzioni a 'limitazioni, ritardi, problemi e [...] rescissioni di contratti con le imprese' e rende difficoltoso valutare la reale incidenza sul PI del grande cambiamento interno al Bilancio Partecipativo avvenuto con la creazione nel '94 delle Assemblee Tematiche. L'importanza di queste non è leggibile a fondo nel PI, anche perché esse sembrano svolgere la loro azione principale soprattutto sull'ampliamento della discussione dai soli investimenti ad altre voci della spesa pubblica come i costi fissi e il personale ${ }^{37}$ che non sono oggetto di trattamento da parte di un piano che appositamente cambia titolo in "Piano di Investimento (opere)". ${ }^{38}$ Le condizioni difficili dell'economia si leggono nella riduzione degli investimenti propri da parte del Municipio (Amministrazione Diretta + Autarchie) a 58 milioni di US\$. Nonostante la crisi economica e la diminuzione delle entrate proprie del Comune, si rileva una notevole riduzione dei costi di personale $(38,4 \%)$ ed un passaggio degli investimenti al 30,7\%. ${ }^{39}$

Il Piano del ' 95 si presenta con una struttura semplice, che sarà replicata da quelli successivi in modo da permettere un rapido confronto dei dati. Per la prima volta viene abolita l'elencazione di alcune opere non finanziate, ma ritenute importanti dalle comunità regionali al punto da averle volute inserire con valore di 'rivendicazione politica' nei piani precedenti, sebbene con l'annotazione 'finanziamento zero' accanto. La struttura è però bipartita, denunciando come la creazione delle Tematiche non mostri di aver ancora trovato un punto di fusione con la tradizionale struttura dell'Orçamento Participativo per regioni, permanendo quasi come un 'compartimento stagno' addirittura nell'elencazione delle opere da eseguire. La categoria tematica 'organizzazione della città' - che già appariva pluricomprensiva - subisce così un'ulteriore moltiplicazione, mentre le opere per 'Tutta la città' si trovano disperse tra le Regionali e le Tematiche includendo voci nuove come l'acquisto di opere d'arte, contributi per l'installazione del Parco 'Morro do Osso', opere di paesaggismo a lato del corso d'acqua Diluvio e piste ciclabili. La seconda parte del PI riunisce però le richieste di investimento accolte solo per regioni (+ la categoria 'Tutta la città') e così l'apparente complessificazione della lettura finisce per costituire un'ulteriore garanzia di trasparenza, evidenziando chiaramente dove le decisioni locali e strutturali per la città sono state prese. Nel settore dell'Abitazione sono complessivamente 6,98 milioni i R $\$$ trasferiti all'Autarchia DEMHAB, tra cui il progetto-pilota della 'Banca dei materiali', che prevede kit di materiali da costruzione da distribuire per realizzare moduli 
sanitari. Ma gli interventi più interessanti previsti paiono quelli decisi nell'ambito delle nuove Assemblee Tematiche. Ad esempio, i programmi di ausilio agli asili comunitari autorganizzati e la contrattazione di 64 nuovi professori per corsi di alfabetizzazione per adulti (SEJA) o la riorganizzazione dell'Archivio Storico. Nell'ambito dello sviluppo economico vengono destinati nuovi fondi al Porto Secco (da aggiungersi a quelli dell'anno prima non ancora utilizzati), alla commercializzazione di lotti del Parco Industriale della Restinga, a nuovi programmi di formazione e generazione di reddito per la popolazione più povera, ma anche ad un'opera anomala come il 'Corridoio Culturale'. Complessivamente appare una continuità notevole con le previsioni degli anni precedenti, pur in una maggiore organicità ed interrelazione delle scelte. Ad esempio un grosso contributo è dato ai progetti integrati di animazione dei 'Centri di Quartiere' per completare i pochi fondi elargiti nel 1994 e non utilizzati, mentre grande impulso subiscono il programma di disinquinamento Pró-Guaiba (con fondi BID) e il PIMES di miglioramento sociale (finanziato dalla World Bank e dal BANRISUL). Per la realizzazione per tratti della circonvallazione detta Terza Perimetrale, di collegamento esterno fra i quartieri intorno alla città, il Piano non stanzia fondi ma registra la volontà popolare di premere su organismi federali ed internazionali per ottenere il finanziamento. Un fatto - questo della registrazione di un 'non-finanziamento' nel PI, piuttosto raro, ma indicativo della necessità che il piano non sia solo uno strumento burocratico, ma di dialogo e chiarimento con la popolazione.

Da questo stesso punto di vista parte anche il PI del 1996, che nel saggio introduttivo 'La radicalizzazione della democrazia' commenta i passi avanti che l'O.P. ha mostrato nel corso dell'anno appena concluso verso una 'maggior responsabilizzazione dei cittadini e verso l'autocostruzione di una più ampia comprensione' dell'interconnessione dei problemi che il Potere Pubblico deve affrontare quotidianamente a vari livelli. Il punto di partenza della riflessione è principalmente il tentativo fatto dal Comune di Porto Alegre di chiedere allo Stato il versamento di contributi per compensare i servizi ospedalieri svolti a favore di moltissimi pazienti dell'interno del Rio Grande do Sul; una proposta che aveva avuto il veto governativo in un tipico scontro fra poteri retti da maggioranze politiche diverse, ma che - attendendosi nel periodo di pubblicazione del PI '96 il voto finale dell'Assemblea Legislativa Statale - richiedeva un forte supporto e le pressioni della cittadinanza per poter passare e tradursi in un beneficio a vantaggio del sistema sanitario cittadino.

A parte questa, poche appaiono le novità di rilievo rispetto al PI precedente, di cui vengono portati avanti molti programmi già avviati. Laddove novità sono presenti, esse vengono sommariamente descritte, almeno nel caso delle iniziative proposte all'interno delle Assemblee Tematiche. È il caso dell'istituzione dei Fondi per il Decentramento della Cultura (FUNCULTURA, FUMPHAC e FUMPROARTE) appena creati per offrire uguali opportunità di accesso alla popolazione sul territorio e promuovere le attività nei quartieri e (è detto espressamente) nelle 'favelas', incentivando la creazione di commissioni e gruppi culturali locali. Viene offerta spiegazione anche del FUNCOMPRAS, fondo gestito dalla SMIC per promuovere centri di distribuzione per generi primari alle popolazioni più povere, a cui sono destinati anche 10 capannoni per attività comunitarie gestite in collettività come panifici, lavanderie comunitarie, associazioni di sarte e simili. Nel settore del- 
l'Abitazione vengono elargiti fondi ('Per tutta la città') per costruire 316 lotti urbanizzati in varie zone della città.

L'investimento maggiore resta la contropartita comunale per i fondi PróMoradia del Piano del 1995, che costituiscono una 'spesa vincolata' al Piano precedentemente approvato. Vengono stanziati i primi fondi per il progetto della circonvallazione 'Terza Perimetrale' in attesa di finanziamento già nel Piano precedente; e si proseguono i progetti 'Guaiba vive' e 'Centro di Quartiere'. Più cospicui del solito appaiono i fondi destinati alla qualificazione dei servizi di Pulizia Urbana, specie nel settore dello smaltimento e della raccolta differenziata. Alla SMAM sono destinati i fondi per case di emergenza in legno da dare a famiglie in aree di rischio geotecnico, mentre viene introdotto anche un piccolo fondo PRO-AMBIENTE ed il progetto 'Vai-apiedi' per migliorare passeggiate pubbliche dove abbiano la precedenza i pedoni. Compare, infine, anche un progetto 'fermata sicura' per facilitare gli handicappati nell'uso dei trasporti pubblici, e un progetto-pilota di piattaforme idrauliche per carrozzelle, interessanti indizi di un innalzamento qualitativo del livello della discussione in svolgimento all'interno dell'O.P.

Il PI 1997 inizia con alcune novità, visto che invita a formulare attraverso la discussione nell'O.P. non solo la Proposta di Bilancio, ma anche il Piano Pluriennale di medio termine della Giunta neoeletta al momento del suo avvio un evento importante nella misura in cui deve contenere le linee strategiche su cui articolare nel quadriennio successivo la politica del nuovo Esecutivo Municipale. Il testo è accompagnato da uno scritto del sindaco uscente che riflette sulla necessità di moltiplicare l'esperienza del Bilancio Partecipativo per il Paese, dal momento che dimostra come "interessi collettivi, seppur difesi da gruppi sociali in momenti localizzati, non perdono la natura e la portata della loro universalizzazione"(Genro, in PI 97).

L'investimento previsto dal PI 97 è di 140.167.309,89 R \$, il 20,32\% delle uscite totali. ${ }^{40}$ In esso colpisce l'arrivo al primo posto del tema ribattezzato Politica Abitativa, in sostituzione del vecchio Regolarizzazione Fondiaria che non faceva risaltare a sufficienza la varietà di strategie che il DEMHAB mette in atto (cfr. cap. 12) per tentare di dare una soluzione alle maggiori emergenze nel settore dell'alloggio; anzi, i diversi tipi di soluzioni e i corrispondenti tipi di finanziamento sono elencati dal PI in calce alla voce.

Tra le previsioni per 'tutta la città' vi sono 93 lotti urbanizzati e 139 unità abitative nel quartiere-città della Restinga, per accogliere famiglie in aree di rischio provenienti da varie zone, oltre a 159 lotti urbanizzati (ma senza moduli sanitari) destinati a Cooperative di Abitazione, ma anche espropri obbligati dovuti a sentenze sfavorevoli al Comune e alcuni acquisti di aree. Si riconosce una maggiore articolazione delle voci di spesa e dei programmi dei Fondi Speciali per la Cultura (tra cui la Settimana di Porto Alegre e l'avvio del progetto di scambio culturale nell'ambito delle Mercocidades) e di quelli gestiti dalla SMIC per lo sviluppo economico. Una novità è il fondo per la modernizzazione amministrativa finanziato dal BID, che pone l'accento su una delle principali sfide postesi poi dall'Amministrazione Pont. Proseguono, a ranghi ridotti, i programmi 'Guaiba vive' (progetto di riscatto della convivenza col lago), 'Progetto Centro', 'Banca dei Materiali', PIMES, PROSANEAR, 'Centro di Quartiere', il 'Pró-Guaiba', il 'Progetto GAIA' e il Fondo Pró-Ambiente, ormai segnali forti dell'Amministrazione realizzati per 
tappe, seppur in seconda battuta rispetto alle decisioni autonome della popolazione per opere puntuali. Le Assemblee Tematiche paiono aver garantito la sopravvivenza per queste iniziative prima non comprese dalla popolazione, che ora comincia a rispettarle e a concedere loro annualmente un 'rinnovo della fiducia'.

Inizia a prendere forma il progetto strategico della nuova viabilità con 9 milioni di $\mathrm{R} \$$ distribuiti per la creazione del corridoio Nord/Nordest e finanziati dalla Banca Nazionale dello Sviluppo (BNDES), e un primo tratto della Terza Perimetrale. Viene previdentemente istituito (su invito del Comune fatto proprio dal COP) un fondo per pagare future contropartite in progetti di viabilità strutturale finanziati dall'esterno, mentre comincia ad avere un peso lo stanziamento per ricostruire vie urbane deteriorate. Arrivano quasi a conclusione i progetti di restauro del Parque Farroupilha, del Teatro de Camâra e delle piste sportive nel Parco Marinha do Brasil, l'unico dotato di una lunga pista ciclabile sul lungolago. Ricompaiono gli acquisti per opere d'arte, mentre non hanno seguito i programmi-pilota per disabili previsti nel 1996.

Il PI del 1997 è redatto in modo più leggibile dei precedenti, con le opere ordinate in ogni regione in base all'elencazione locale delle priorità. Di grande interesse appare una tabella che fa la sua comparsa per la prima volta, riassumendo la posizione delle priorità per regione e rivelando alcune singolarità delle richieste avanzate dalla popolazione.

Analoga chiarezza e ricchezza di tabelle e dati mostra il PI del 1998, il primo elaborato nella terza Amministrazione Popolare. Nella Prefazione, il Sindaco descrive il processo di discussione popolare del Piano Pluriennale 1997/ 2000 svoltosi tra l'8 marzo e il 17 aprile 1997, che ha portato a 185 emendamenti, l'80\% dei quali accolti (148 articoli), delineando un'ulteriore estensione del processo di pianificazione partecipata. Il testo puntualizza alcuni segni di cambiamento nella gerarchizzazione delle priorità, citando l'importanza del fatto che la popolazione abbia contribuito a far mantenere al Comune una situazione finanziaria equilibrata a dispetto della crisi vissuta nel paese e dai municipi in generale ed approvato nel tempo investimenti in aree essenziali per la cittadinanza come il Programma di Salute della Famiglia (PSF), i NASF (Nuclei di Appoggio Socio-familiare nell'area dell' Assistenza Sociale) o il MOVA (Movimento di Alfabetizzazione), oltre ad opere di natura più 'fisica e infrastrutturale'.

Per quanto riguarda la distribuzione per Dipartimento e Assessorato dei finanziamenti, a seconda delle priorità indicate dalla popolazione nelle Assemblee Regionali in ordine di importanza, essa risulta un po' più articolata che in passato, essendo le priorità divenute 10 (3 a pari merito) e contemplando praticamente tutti i dipartimenti e quelle che fino al 1997 erano sotto-priorità tematiche, ma che venivano indicate con precisione dai quartieri, facendo sorgere la necessità di rispecchiare meglio i diversi temi (in tutto divenuti 12).

Molti, ancora una volta, sono i programmi già avviati e portati avanti per il '98. Tra le novità se ne rilevano alcune interessanti nell' area della Salute e dell'Assistenza Sociale, e il Programma 'Segnale Verde' per il progressivo allontanamento dei bambini bisognosi dai semafori. Nell' area della Politica della Casa viene portato avanti un ventaglio di iniziative diverse di autoaiuto tra cui il finanziamento di mutirões nella favela Chacara da Fumaça, da 
tempo fermi, oltre alle ceste di materiali da distribuire ai futuri abitanti dei Loteamentos Timbauva, Fontoura e Mario Quintana. Nell'area della Cultura viene istituito un programma di incentivo per i cortometraggi e continuato l'appoggio al Decentramento Culturale. In quella dei Trasporti è co-finanziato (insieme alla FINEP) lo studio del Piano della Circolazione, le busvie del corridoio di decongestionamento Nord-Nordest e la contropartita per i finanziamenti BID per la Terza Perimetrale, per legare la zona settentrionale dell'aeroporto (davanti a cui viene anche finanziata una passerella di sovrappasso) alla zona Sud della città senza attraversare il Centro. Nell'ambito dei fondi gestiti dalla SMIC ottiene il via libera la riforma del Mercato di Bom Fim e il Condominio di Imprese REPOTs (Regione di Potenziale Tecnologico) mirato allo sviluppo economico-tecnologico della città, in una prima fase-pilota limitato al quartiere Navegantes che ha un'alta concentrazione di imprese di elettronica e informatica. Vengono poi portati avanti programmi per la creazione di reddito, il Porto Secco e l'Incubatrice di Imprese della Restinga, oltre a mantenere i Fondi FUNCOMPRAS e FUNMERCADO.

Per la prima volta appare finanziata come voce autonoma una Conferenza, quella sullo Sviluppo Economico, oltre al 'Progetto Centro 24 ore' di animazione serale del centro storico, e parte di una Centrale di Commercializzazione dei Rifiuti riciclati. Dal Fondo Municipale di Sviluppo è tratta la contropartita per il Finanziamento FONPLATA per il disinquinamento del corso d'acqua Diluvio; un'operazione 'integrata' importante perché con fondi di recupero ambientale il DEMHAB riesce a finanziare un quartiere per trasferirvi gli abitanti della favela Vila da Fonte che proprio nel ruscello gettava i suoi scarichi. Anche l'Assessorato all'Ambiente e il DEP gestiranno una parte dei fondi (in parte per programmi di Educazione ambientale), mentre continuano i programmi 'Pró-Guaiba' e 'Guaiba vive', PIMES e PROSANEAMENTO, con la sostituzione delle reti del quartiere 'nobile' di Ipanema la cui spiaggia viene liberata dai bar abusivi e trasformata in una passeggiata costellata di opere di artisti locali. Un'opera finanziata e ritenuta importante è il Piano Regolatore del Drenaggio urbano. Complessivamente deve registrarsi un aumento dei programmi di recupero e protezione ambientale e la loro dimensione di integrazione maggiore con altri interventi di settore.

Il Piano degli Investimenti per il '99 comincia con una prefazione più lunga del solito dedicata al continuo ampliarsi di canali e spazi nuovi di dibattito cittadino anche al di fuori del Bilancio Partecipativo, come le Commissioni di Accompagnamento dei lavori, i Forum di Servizio Regionali e Tematici (per decidere della manutenzione e della conservazione) e le Conferenze settoriali. L'ulteriore moltiplicazione di questi luoghi di dialogo è dichiarata come uno dei principali scopi dell'Amministrazione Popolare, a partire dalla realizzazione della Terza Conferenza sulla Città, dove tentare di gettare le basi della pianificazione di Porto Alegre per il 2000. In questo quadro, una parte non secondaria della Prefazione è destinata a sostenere il Progetto di ampliamento del Bilancio Partecipativo a livello statale, quale opportunità per risolvere problemi comuni, integrando politiche pubbliche di livello diverso. Tale processo era in realtà già iniziato prima dell'insediamento del nuovo Esecutivo attraverso la discussione condotta nell'ambito dell'O.P. di Porto Alegre, per suggerire direttrici per il Piano Pluriennale dello Stato.

L'investimento previsto per il 1999 è valutato al 21,05\% del totale delle usci- 
te del Comune e, in apertura, vengono indicate le fonti di credito per i maggiori progetti non finanziati da fondi propri. ${ }^{41}$ Con chiarezza maggiore del solito, vengono individuati i diversi programmi già avviati e portati avanti per il '99, specificando la presenza di eventuali finanziamenti esterni e le contropartite di spettanza del Comune: la continuità mirata al mantenimento e al potenziamento degli investimenti compiuti negli anni precedenti tende a caratterizzarsi come un elemento-base della strategia di governo dell'Amministrazione Popolare, puntando a comunicare (attraverso la ripetizione di alcune informazioni-chiave) il concetto del 'tempo' come par6te integrante fondamentale dei progetti e delle politiche messe in campo.

Ognuno dei programmi e delle voci di spesa è inoltre brevemente descritto sotto il titolo e i costi, e questo non avviene (come in passato) solo per i programmi o i progetti nuovi: vi è quindi un crescente sforzo per trasformare - come era stato sempre ambizione dell'Amministrazione Popolare - il PI in un articolato 'manuale di consultazione' per la cittadinanza.

Sono riconfermati tutti i nuovi programmi di Educazione, Sanità e Assistenza Sociale ${ }^{42}$ ed anche nel settore della cultura. I Fondi gestiti dalla SMIC vengono invece meglio articolati per subaree: Rifornimento (tra cui opere in favore dei pescatori delle isole), Economia Popolare (con gruppi di lavoro, programmi di formazione e riforma di alcuni capannoni per la raccolta differenziata), Scienza e Tecnologia (il Condominio di imprese REPOT's) e Appoggio all'Impresariato (che gestisce alcuni Fondi speciali).

Una voce nuova appare a vantaggio dell'Assessorato alle Finanze e di quello al Personale (SMA), dotati di fondi del BID per la modernizzazione fiscale. Il DEMHAB (già beneficiato - come nel 1998 - dai Fondi FONPLATA per il disinquinamento del torrente Diluvio) entra nel PI con fondi ulteriori elargiti dalla Tematica di Organizzazione della Città per finanziare infrastruttura in aree di Cooperative di Abitazione, e con un piccolo contributo al Progetto 'More Melhor' che mira a promuovere la partecipazione popolare per la regolarizzazione di aree di proprietà del DEMHAB stesso (lottizzazioni e unità abitative di cooperative).

I programmi principali di protezione ambientale si ricavano le loro nicchie di finanziamento, giovandosi anche dei fondi che il Dipartimento di Nettezza Urbana (DMLU) riceve per la copertura di alcune discariche.

Circa 30 milioni di US\$ vengono finanziati dal BID per il raddoppiamento delle vie (gli espropri necessari vengono autofinanziati a parte) che costituiranno l'anello della Terza Perimetrale, i cui lavori avrebbero dovuto già iniziare a fine 1998 ma hanno subito dei ritardi. Altissimo il numero dei progetti (oltre 40) finanziati al DMAE per la sostituzione di reti fognarie e di adduzione idrica in varie parti della città, sia 'nobili' che 'informali'.

\subsubsection{Verso una raggiunta maturità del Bilancio Partecipativo}

Il PI del 2000 si apre con tre considerazioni interrelate: una sull'importanza del processo in corso con il III Congresso della Città (incaricato di stabilire gli obiettivi di strutturazione delle politiche urbane per il decennio successivo), una sulla sperimentazione del primo anno di integrazione tra il Bilancio Partecipativo municipale e l'analogo processo attivato a livello statale dal nuovo Governo guidato da Olivio Dutra, e la terza sul forte ritmo che è stato impresso nell'ultimo anno alla realizzazione delle opere finanziate dai PI precedenti, anche grazie al controllo e alla pressione attiva esercitata dalle Commissioni popolari di Accom- 
302 pagnamento dei Lavori in varie zone della città. Il collegare insieme le tre riflessioni è un modo di illustrare una strategia articolata che punta contestualmente ad operare su due livelli: quello della realizzazione di opere vicine al cittadino e quello della programmazione di interventi e strategie di governo articolate su tempi medio-lunghi e capaci di interagire con le scelte di altri livelli politico-decisionali. Il Sindaco Pont, in una nota finale, commenta con amarezza gli attacchi giudiziari in corso contro il Bilancio Partecipativo, ma si dice ottimista sia per il ruolo di prima linea che i cittadini si stanno riservando nella difesa di questo strumento di democrazia, sia per i crescenti riconoscimenti internazionali ottenuti dall'O.P., non ultimo quello tributato a Porto Alegre con l'organizzazione del Seminario Internazionale sulla Democrazia Partecipativa supportato dal World Bank Institute tra il 10 e il 13 novembre 1999.

In apertura viene messa in risalto la novità di questo piano degli investimenti, che per la prima volta vede il tema della salute entrare tra le prime tre priorità tematiche cittadine, e le richieste per programmi di assistenza sociale collocarsi al 5 posto della graduatoria stilata dai voti dei cittadini che hanno partecipato al ciclo annuale di dibattiti svoltosi nel 1999. L'osservazione è utilizzata dall'assessore al Bilancio Partecipativo (coordinatore della CRC) per sottolineare come questa novità sia una riprova di come il deficit infrastrutturale accumulato dalla città cominci a colmarsi, ma al contempo della necessità di rivedere le priorità di livello locale per far fronte alla necessità di continuare a lottare contro l'esclusione sociale a fronte dello smantellamento in corso delle politiche di welfare di ambito nazionale. In tale quadro, viene fatto risaltare come - coerentemente - le spese che il municipio prevede per il 2000 nel settore dell'Educazione rappresentino il 32,89\% delle entrate derivanti da tasse e trasferimenti, una cifra ben superiore al $25 \%$ richiesto dalla Costituzione Federale e allo stesso 30\% previsto dallo Statuto comunale; parallelamente anche le spese per la Salute $(90.227 .754$ R \$ che diventano 335.227.754 calcolando i contributi statali del Sistema Unico della Salute) sono superiori (seppur solo dello 0,63\%) al 13\% delle uscite totali dell'Amministrazione diretta, previste dallo statuto comunale.

Coerentemente con i nuovi e più articolati criteri tecnici per l'accoglimento delle singole domande di finanziamento, nella distribuzione dei fondi per tema e per regione cittadina, vengono spesso sottolineate le 'condizioni' a cui l'avvio di un'opera è sottoposta, ribadendo - in molti casi - la necessità che le comunità locali (specie nella città informale) non adottino un atteggiamento attendista, ma procedano all'autoeliminazione di quegli ostacoli che non potranno che ritardare l'inizio dei lavori di costruzione delle opere finanziate. Particolare risalto è dato anche alle voci 'continuità con opere degli anni precedenti' e all'elencazione chiara delle contropartite che il Comune deve fornire per potersi giovare di finanziamenti esterni (come quelli 'ProMoradia' per la prima priorità, rappresentata dalla Politica della Casa). L'elencazione 'a parte' delle opere finanziate attraverso le decisioni prese nelle Assemblee Tematiche, evidenzia ancora una volta come queste costituiscano la 'garanzia' di continuità per i programmi di sviluppo economico, modernizzazione fiscale, politica culturale e ricreativa, come anche per quelli di protezione ambientale (come il Guaiba Vive e i programmi di miglioramento dei parchi con costruzione di piste per eventi) e di promozione dell'abitare cooperativo autogestito. Una voce isolata e fondamentale appare 
quella degli espropri (8.000.000 $\mathrm{R} \$$ ) per procedere con la realizzazione della III Circonvallazione perimetrale.

Nel PI 2001 l'apertura del libretto - ad opera del sindaco uscente Pont e del nuovo Genro - appare molto centrata sul contributo positivo che l'integrazione tra l'O.P., i Consigli Municipali e di Sviluppo Settoriale ed i processi di bilancio partecipativo tematico (come quelli nel settore della scuola aperti agli studenti della rete scolastica comunale) va garantendo alla città, nell'arricchire la qualità ed il coordinamento degli interventi, e nel favorire la crescita degli apporti del controllo e della progettualità dei cittadini sull'apparato municipale pubblico. Il documento rappresenta al contempo un bilancio del quadriennio appena trascorso ed una presentazione delle sfide che si aprono con la nuova gestione pubblica. In particolare, il sindaco uscente sottolinea i miglioramenti apportati nella valorizzazione del capitale sociale (attraverso programmi di formazione e alfabetizzazione che hanno permesso a Porto Alegre di collocarsi al primo posto tra le città più alfabetizzate del paese, e spesso sono stati realizzati finanziando accordi di appoggio a progetti già avviati da comunità locali) e in alcuni settori forse meno visibili ma strategici per uno sviluppo equilibrato della città ed un miglioramento generalizzato della città: ad esempio le opere di macrodrenaggio, trattamento delle acque nere, valorizzazione attiva di 150 ettari di aree pubbliche a verde, e municipalizzazione di strutture sanitarie come l'Ospedale Presidente Vargas. Il punto di incontro delle presentazioni dei due amministratori è rappresentato dall'organizzazione del $1^{\circ}$ Forum Sociale Mondiale, letto come opportunità di far conoscere al mondo le opportunità e le peculiarità dello sviluppo democratico di Porto Alegre, ma anche come occasione di crescita per i cittadini e per la loro capacità di rafforzare "una nuova visione politica e un nuovo stile di vita, che abbiano all'ordine del giorno la nozione che la lotta per la città va al di là dei limiti della strada e del quartiere" e che si devono contrastare con tutte le forze i progetti "di decostruzione della società" centrati sulla lettura "dell'egoismo come virtù, a detrimento del sentimento di comunità" e sulla sovrapposizione dei valori economici ai valori umani (Genro, in PI 2001, p.3).

In quest'ottica il PI 2001 - di cui viene ribadito il ruolo di "contratto di impegno" per l'amministrazione nei confronti dei suoi cittadini - cerca di evidenziare un percorso di "approfondimento dello sviluppo cittadino fortemente radicato nella solidarietà" e nell'estensione dell'inclusione sociale e del diritto alla città per tutti (ibidem). E perciò muove da alcuni commenti sulle conclusioni del III Congresso della Città elaborate - a fine processo - tra il 26 e il 28 maggio 2000 ed indirizzate a costruire per il 2001 una Conferenza Municipale sulla Democrazia e la Gestione dello Stato che possa estendere il dibattito ad altri livelli di governo e permetta di elaborare a livello locale alcuni dei temi al centro del $\mathrm{I}^{\circ}$ Forum Sociale Mondiale.

Nel piano può colpire l'assenza di una voce riferita al contributo offerto dall'amministrazione comunale per l'organizzazione del Forum Sociale Mondiale (in passato previsto per altri eventi): il punto è e che esso consisterà principalmente in un ruolo attivo di coordinamento dei contributi volontari e di mediazione con gli sponsor privati, e le sue 'spese vive' (così come accadrà nel 2002) saranno coperte principalmente attraverso residui di cassa e spese di pubblicità legate alle voci per lo sviluppo del turismo, ossia non attraverso 
304 fondi da prevedersi nel Piano delle Opere dettagliato attraverso l'OP. ${ }^{43}$ L'avvici- $^{2}$ narsi dell'evento pare comunque farsi sentire nel PI, se è vero che - tra le voci di spesa riguardanti l'intera città - ne compaiono alcune nuove nei settori della Cultura e dello Sviluppo Economico, che alludono ad interventi di valorizzazione dei percorsi turistici e rivelano particolare attenzione alla valorizzazione del ruolo di alcune minoranze etnico-culturali indie o afrobrasiliane.

Per il resto, le opere più significative previste per il 2001 riguardano le priorità della Pavimentazione Comunitaria (che conta su 9.000.000 di RIII\$ di fondi del BID) e della Politica della Casa, e servono soprattutto a dare continuità ai progetti della Terza Circonvallazione, al rafforzamento di alcune altre vie strutturali della periferia cittadina, ${ }^{44}$ alla costruzione di corsie preferenziali per autobus e ai programmi alloggiativi del progetto Pró-Moradia (con fondi PIMES).

Poche variazioni parrebbero connotare - ad uno sguardo disattento - il Piano degli Investimenti del 2002: tra le maggiori voci di spesa, permangono infatti - le prosecuzioni del restauro delle sedi principali del Comune, dei progetti del Pró-Moradia, del CEITEC (Centro di Eccellenza Iberoamericano di Elettronica Avanzata), degli assi viari strutturali e della III Circonvallazione Perimetrale, a cui si aggiungono il Progetto Integrato per la Zona Nord 'Habitar Brasil' ed un programma di pavimentazione di lottizzazioni irregolari e clandestine ormai legalizzate, entrambi finanziati dalla Banca Interamericana di Sviluppo con una contropartita municipale vicina al $50 \%$ dei costi complessivi.

A ben guardare, però, il Piano è molto diverso dai precedenti, a partire dalla sua veste grafica, più attenta che in passato alla temporalizzazione ed alla spazializzazione del Bilancio Partecipativo: tanto da essere il primo a graficizzare uno schema del ciclo annuale e una carta della città con indicate le 16 Regioni, riprodotte poi nei diversi capitoli che lo compongono per collegare i singoli investimenti ai luoghi dove si radicheranno. Il Piano soprattutto - rappresenta un notevole salto di qualità nel dettagliamento delle voci di investi,mento; accanto al tradizionale riassunto delle 'opere principali' approvate e dei progetti selezionati all'interno delle Assemblee Tematiche, vi sono - infatti - delle spiegazioni sulle loro implicazioni in rapporto al tipo di politica dentro cui si collocano. Ad esempio, tra i programmi di Assistenza Sociale chiamati "Salute della Famiglia" si spiega che - al di là dei progetti localizzati - saranno attivate 10 equipe itineranti di "municipalizzazione solidale' che opereranno nelle aree non ancora coperti da centri sanitari, ma in regioni che avevano messo all'ordine del giorno la salute durante il processo di Bilancio Partecipativo Statale, a cui l'OP di Porto Alegre cerca di coordinarsi in maniera più costruttiva che in passato. Inoltre, viene registrato nel PI l'avvio di accordi di collaborazione con ONG per progetti di formazione e capacitazione per giovani e adolescenti che dovranno in seguito mantenersi con le proprie gambe; e si comincia a specificare in dettaglio quali Consigli Municipali tematici hanno sottoscritto l'approvazione di opere e servizi che operano in maniera integrata. Interessante è anche la comparsa di voci di investimento nuove, come il cospicuo investimento in 'attrezzature di monitoraggio ambientale' cofinanziato dal BID, che offre la misura dei benefici dell'attivazione di nuovi progetti integrati ed intersettoriali che sempre più ricercano (e si giovano di) finanziamenti inter- 
nazionali, per sopperire ai tagli di molti programmi federali determinati da un periodo di crisi economico-monetaria che ha colpito il Brasile dal gennaio 1999. Tra le voci di investimento destinate al complesso cittadino, ve ne sono alcune che paiono una diretta filiazione dei dibattiti attivati in città dal $1^{\circ}$ Forum Sociale Mondiale: una su tutte, il finanziamento ai programmi di commercializzazione di prodotti 'equi e solidali' (che - parallelamente entrano anche nelle priorità del Bilancio Partecipativo Statale, che nel 2002 ha previsto $77.000 \mathrm{R} \$$ a questo scopo, cfr. PIS-OP/RS 2002) e la ripresa dei finanziamenti agli 'acquisti collettivi'.

Questi 'slittamenti' di significato rispetto ai PI precedenti si collocano in un quadro di trasformazioni che altera la collocazione delle maggiori priorità tematiche indicate dai cittadini, e si ricollega all'ampio dibattito svoltosi in occasione della discussione del Piano Pluriennale della nuova giunta, inviato al Consiglio Comunale il 30 aprile 2001 e trasformato rispetto alla proposta iniziale da ben 951 emendamenti proposti dai cittadini attraverso il consiglio stesso, il COP e 8 dei principali Consigli Municipali tematici. L'articolarsi di questo Piano quadriennale intorno all'asse centrale delle politiche sociali e della lotta all'esclusione "provocata dal capitalismo e dalla politica neoliberale" (Assis Brasil Olegário Filho, in PI 2002, p. 6) tende a retroagire sulle priorità del Bilancio Partecipativo, facendo sì che molti dei progetti finanziati tendano ad essere progetti integrati, la cui principale finalità pare quella di rispondere a richieste legate alle politiche sociali. Così, al secondo posto delle priorità cittadi-

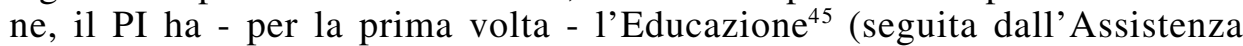
Sociale e dalla Salute) e le politiche sanitarie vengono finanziate con un 16,9\% dei fondi dell'Amministrazione Diretta (contro il 13\% di minima previsto dallo Statuto Comunale), quasi a dimostrazione del fatto che "il Bilancio Partecipativo ha la capacità di prendere decisioni formulate sulla base di un dibattito più ampio che non la sola congiuntura cittadina o nazionale, mediando le richieste locali con gli interessi generali e dei settori più esclusi della società" (José Valdir, in PI 2002, p. 7).

Per il modo con cui è articolato, il documento di programmazione pare più di un mero gesto "di trasparenza amministrativa", cercando di trasformarsi in uno "strumento di convivenza democratica e di controllo della società sullo Stato, senza cui la democrazia tende a svuotarsi in mezzo alla freddezza dei riti e delle formalità sconnesse dalla vita e dalla realtà" (ibidem). Tanto più che - a differenza dei precedenti - esso non uno strumento isolato, ma viene affiancato da un ampliamento delle potenzialità democratiche del Bilancio Partecipativo che - per la prima volta - utilizza Internet sia per controllare in tempo reale lo stato di esecuzione di ogni opera prevista nei piani di investimento annuali, sia per proporre idee di opere e servizi ${ }^{46}$ - nonostante che l'unica istanza legittima per assumere decisioni restino i momenti di contatto vis-a-vis nelle assemblee e nei forum del Bilancio Partecipativo. Questa opportunità - la prima delle grandi trasformazioni organizzative che la struttura del ciclo dell'OP di Porto Alegre subirà a cavallo tra il 2001 e il 2002 - intende anche dimostrare che "le nuove tecnologie possono essere messe a servizio [...] dell'elevazione del valore della scena pubblica come il luogo per eccellenza per l'incontro tra idee diverse" (Genro, in PI 2002, p. 5), piuttosto che "dell'alienazione individua- 
306 lista" (ibidem) e "dell'auto-isolamento" (Valdir, in PI 2002, p. 7).

Quest'insieme di elementi, rafforza l'azione formativa e di indirizzo che ogni PI cerca di svolgere nei confronti della discussione dei finanziamenti da distribuire nell'anno successivo: non va dimenticato, infatti, che il Piano 2002 ha accompagnato per tutto l'anno (venendo letto e consultato dai cittadini) la discussione del bilancio preventivo per il 2003, il primo realizzato all'interno della nuova strutturazione del ciclo di Bilancio Partecipativo entrata in vigore a fine gennaio 2002.

Al momento dell'uscita di questo libro, il Piano per il 2003 non è ancora disponibile in visione, ma nell'Assemblea Municipale cittadina tenutasi il 20 luglio 2002 per la 'consegna delle priorità per il 2003' al Comune, sono state ampiamente divulgate (attraverso un apposito depliant scritto in maniera semplice e circostanziata) le previsioni di entrate sui cui esso si dovrà fondare. Questo nuovo momento pubblico di 'presa di coscienza' delle possibilità di finanziamento delle politiche municipali, costituisce un momento importante e abbastanza nuovo per il Bilancio Partecipativo, nella misura in sostituisce un momento di informazione di solito realizzato tramite la distribuzione di materiale informativo con un incontro pubblico dove vengono esposti ai cittadini i dati economico-finanziari che sostanzieranno le previsioni di spesa su cui si baseranno gli investimenti nell'anno successivo; non a caso, per rendere questo momento più attraente ed incisivo, esso è stato riassorbito dentro un'intera giornata di festa cittadina, un momento simbolico in cui si susseguono la consegna delle priorità e la festa popolare per l'entrata ufficiale in carica dei nuovi Consiglieri Popolari del COP, eletti nelle Assemblee del Turno unico. Nel documento estimativo sulle entrate per il 2003 si ipotizza una prosecuzione della recente tendenza all'esigua crescita delle finanze comunali, e si cerca di offrirne una spiegazione comprensibile a tutti, motivandola con 4 eventi essenziali dello scenario politico-economico con cui le scelte di Porto Alegre devono fare i conti:

1) la riduzione progressiva dei finanziamenti agli enti locali (fig. 43), attraverso la ricentralizzazione promossa da alcune Leggi Federali (Lei Kandir e Fondo per la Stabilizzazione Fiscale);

2) la tendenza nazionale ad un ritmo di crescita dell'economia che tocca direttamente gli ambiti da cui di solito provengono le risorse comunali (settore immobiliare, prestazioni di servizio);

3) i limiti posti dalla vigente legislazione comunale all'aggiornamento automatico dei valori catastali (che resta indietro rispetto ai ritmi di valorizzazione degli immobili);

4) la riduzione di molte linee nazionali di credito conseguente alle politiche di contenimento del debito. Essa impedisce la concessione di prestiti (specie nei settori della casa e dell'urbanizzazione primaria già immobilizzati dal 1998), a prescindere dalla situazione finanziaria di ogni ente.

A questa stagnazione delle entrate (cfr. tab. seguente) andrà aggiunta la crescita delle spese dovuta - come spiega il documento - sia all'opera di 'sostituzione' che il Comune deve svolgere nei settori del benessere sociale (in un quadro di sussidiarietà asimmetrica che decentra responsabilità ma non risorse per affrontarle), sia all'aumento di costi di manutenzione e di personale che gli elevati ritmi di investimento degli anni precedenti generano. 


\begin{tabular}{|c|c|c|c|}
\hline \multicolumn{4}{|c|}{ ENTRATE PREVISTE } \\
\hline \multicolumn{2}{|c|}{ Entrate totali del Sistema Unico di Salute } & \multirow[b]{3}{*}{$10,84 \%$} & $352.000 .000 \mathrm{R} \$$ \\
\hline \multirow{2}{*}{$\begin{array}{l}\text { Entrate totali previste per } \\
\text { Amministrazione Diretta } \\
(92,50 \%) \text {, FASC }(0,01 \%) \text {, } \\
\text { DEMHAB }(3,69 \%) \text {, } \\
\text { DMLU }(3,80 \%)\end{array}$} & Entrate correnti previste & & \multirow[b]{2}{*}{$1.051 .268 .325 \mathrm{R} \$$} \\
\hline & $\begin{array}{l}\text { Entrate di cap itale previste } \\
\text { (operazioni di credito) }\end{array}$ & & \\
\hline \multirow{2}{*}{ Entrate totali del DMAE } & Entrate correnti previste & $94,40 \%$ & \multirow{2}{*}{$201.267 .800 \mathrm{R} \$$} \\
\hline & Entrate di capitale previste & $5,60 \%$ & \\
\hline \multicolumn{4}{|c|}{ USCITE PREVISTE } \\
\hline \multirow{4}{*}{$\begin{array}{c}\text { Uscite stimate per } \\
\text { Amm inistrazione Diretta, } \\
\text { FASC, DEMHAB, DMLU }\end{array}$} & Personale & $59,80 \%$ & \multirow{4}{*}{$\begin{array}{c}1.066 .768 .325,40 \\
\mathrm{R} \$\end{array}$} \\
\hline & Spesa corrente & $21,11 \%$ & \\
\hline & Investimenti & $12,71 \%$ & \\
\hline & $\begin{array}{l}\text { Riserva di contingenza (circa 5,8\% } \\
\text { delle entrate correnti liquide) }\end{array}$ & $6,38 \%$ & \\
\hline \multirow{4}{*}{$\begin{array}{c}\text { Uscite previste del DMAE } \\
\text { (nella spesa sono esclusi } \\
\text { 15.500.000 R } \$ \text { previsti per } \\
\text { il Fondo Municipale di } \\
\text { Previdenza) }\end{array}$} & Personale & $26,93 \%$ & \multirow{4}{*}{$185.767 .800 \mathrm{R} \$$} \\
\hline & Spesa corrente & $41,59 \%$ & \\
\hline & Investimenti & $25,58 \%$ & \\
\hline & $\begin{array}{l}\text { Riserva di contingenza (circa 5,8\% } \\
\text { delle entrate correnti liquide) }\end{array}$ & $5,90 \%$ & \\
\hline \multicolumn{2}{|c|}{ Uscite previste del Sistema Unico di Salute } & & $352.000 .000 \mathrm{RS}$ \\
\hline
\end{tabular}

(Comune di Porto Alegre, dati: OP-Assembleia Municipal, luglio 2002)

In tale quadro - spiega il documento ai cittadini - è necessario comprendere che tanto maggiore sarà l'investimento, tanto crescerà la necessità di fondi per la manutenzione ed il personale;

[...] il momento attuale esige decisioni importanti, di natura ancora più profonda che la scelta di priorità o le nuove opere e servizi. Esige che pensiamo ad alternative che aumentino le entrate, per evitare un'accentuata riduzione degli investimenti, rendere possibile la manutenzione e la messa in funzione degli investimenti già fatti [...] ed incrementare le risorse per azioni che combattano l'impoverimento, senza destabilizzare le finanze municipali [...]. Questo è il punto centrale che dobbiamo risolvere nella discussione del bilancio 2003, perché Porto Alegre possa continuare a crescere in maniera sicura e responsabile, democratica e sostenibile, cosciente e solida (OP-Assembleia Municipal, luglio 2002, p. 3). 
La panoramica qui sopra integrata dalla disamina puntuale dei PI dal 1989 ad oggi, rileva alcune tendenze macroscopiche difficili da contestare nonostante in questi anni le previsioni di investimento siano talora risultate leggermente superiori alle spese reali valutabili in chiusura di gestione. Tra di esse, ve ne sono alcune più significative, come ad esempio:

1) l'organizzazione dell'O.P. pare riflettersi in quella dei dati. L'evoluzione della strutturazione dei Piani di Investimento come guide agevoli per la consultazione va di pari passo con una complessificazione del dibattito interno all'O.P. e dei criteri interni che presiedono alla valutazione delle priorità e delle scelte da finanziare. In non poche occasioni la loro composizione addirittura trascende lo stesso O.P. e tratta di altre questioni urbane, con l'obiettivo di diffondere la moltiplicazione della democrazia partecipativa ad altre istanze che siano in gradi di co-gestire con l'Amministrazione le politiche urbane al di fuori delle mere indicazioni relative alla gestione delle voci 'spese di capitale' del bilancio. La stessa esposizione dei dati tende progressivamente ad una maggiore leggibilità via via che la struttura delle 'aree tematiche' si fa più complessa e completa. La massima chiarezza si ha a partire dal PI del 1999 dove numerose tabelle riassumono persino i dati delle richieste regionali per permettere un confronto tra annate e località diverse. L'obiettivo non pare essere solo la crescita di trasparenza della gestione municipale (anche a pro delle categorie meno istruite di partecipanti), ma anche una possibilità di comparazione fra dati e scelte diverse, che è l'essenza delle battaglie fra quartieri e regioni nell'indicazione delle priorità di investimento ed una garanzia di pluralismo. Il mutare dei modi di esposizione dei dati fino al 1995 rende infatti disagevole la comparazione fra gestioni diverse del Municipio, per la mancanza di uniformità degli stessi dati; l'uniformazione espositiva sopravvenuta nel 1996 agevola, quindi, un confronto che in passato sembrava essere stato incentivato solo per far risaltare i meriti dell'Amministrazione Popolare in rapporto alla gestione Collares (fig. 42). La maggiore chiarezza, oggi, rende inoltre più comprensibile la natura di alcune incoerenze nella distribuzione dei fondi dovute sia alla natura di certi investimenti il cui impegno a volte rende impossibili conteggi puntigliosamente proporzionali alla posizione ottenuta dal tema nella scala delle priorità, sia al fatto che la 'negoziazione' fra cittadini e istituzioni ha molteplici livelli e tempi diversi di svolgimento $;^{47}$

2) da una comparazione fra le aree tematiche di investimento prioritario indicate dalla popolazione nei diversi anni (fig. 25) emerge un progressivo complessificarsi della lettura della città da parte della cittadinanza e l'evoluzione del rapporto tra i due partner dell'Orçamento Participativo (Amministrazione e cittadini) alla ricerca di un punto di equilibrio fra i propri ruoli decisionali e le proprie esigenze.

A riprova del forte deficit accumulato da una città che ha per decenni ignorato il crescere tumultuoso della città informale (che oggi chiede a gran voce di essere parificata a quella 'formale') vi è una sostanziale continuità nel tempo delle aree prioritarie di intervento collocatesi alle prime 3 posizioni della graduatoria delle 'urgenze': la cosiddetta 'triade consolidata'48 composta da richieste di interventi di urbanizzazione primaria, pavimentazione e - in un secondo tempo - politica della casa, stimolata dall'attivazione del Programmi di Regolarizzazione Fondiaria nel 1990. Il loro alternarsi può 
essere messo in relazione con due fenomeni: "quello del 'confronto', che è un momento basilare dell'OP - che trasmette con lentezza esempi agli altri e fa loro desiderare di ottenere lo stesso" e quello "della creazione di immaginario collettivo che la città formale inevitabilmente veicola” (Brunet, apud Allegretti 2000a). Il profilo secondario mantenuto nei primi anni dalla Politica della Casa può attribuirsi anche alla politica del 'tutto e subito' (Genro, 1997) che sconsigliava la priorizzazione ai primi posti di un settore ancora lento, burocratizzato e bisognoso di riorganizzarsi come quello gestito dal DEMHAB.

Del resto, la definizione delle priorità non è una variabile 'indipendente', o comunque dipendente solo dalle necessità dei cittadini, ma spesso subisce oscillazioni a seguito della verifica dell'efficienza e dell'efficacia con cui il Comune sa dare risposta a certi bisogni espressi sotto forma di priorità. E spesso - ancora oggi - sono i disservizi verificati l'anno prima ad incidere sull'ordine delle priorità. Come si registrava in un fondo dal titolo Cittadinanza inquieta:

[...] La priorizzazione è il momento più importante dell'O.P. [...] Nel 1998, le comunità popolari stanno indicando chiaramente che ancora non hanno risolto le loro necessità urbane fondamentali (fognatura e pavimentazione). Peraltro, passando l'alloggio al terzo posto, dopo tre anni nelle prime due posizioni, forse sta dimostrando anche la sua insoddisfazione con il ritmo di risposta alle richieste nell'area del Dipartimento alla Casa [... ] Nel Seminario di Formazione della Regione Leste, realizzato il 15.08.98, uno dei partecipanti ha addirittura proposto il ritiro del tema della Regolarizzazione fondiaria dalla lista delle priorità possibili finché il DEMHAB non sia in grado di farsi carico delle richieste dei Piani di Investimento anteriori ('De olho no Orçamento' n. 7, 1998).

In tal senso, sarebbe un'opzione pragmatica da parte della popolazione dirigersi verso aree (come il binomio urbanizzazione-pavimentazione) dove " $i l$ controllo sulle richieste da parte dei forum regionali è molto più efficace e coinvolge molte meno zone di incertezza (ibidem) senza implicare in maniera determinante il potere giudiziario coi suoi tempi preistorici e il suo orientamento spesso conservatore” (B. Alfonsin, apud Allegretti 2000a). Non sono - del resto - pochi i finanziamenti 'virtuali' che - pur ottenuti in un PI - restano a lungo inutilizzati; da una rapida analisi della finestra di 'monitoraggio delle realizzazioni' del Sito del Comune di Porto Alegre ne appaiono ancora alcuni stanziati vari anni fa a cui (per ragioni diverse) è affiancata la suggestiva scritta "opera paralizzata". E - come si nota nelle figg. 37/39 - in alcuni settori i rallentamenti appaiono maggiori e più frequenti.

Questo, ovviamente, non è sufficiente a spiegare tutte le variazioni che intervengono nell'oscillazione delle richieste di priorità, agendo piuttosto come 'una' delle concause. Ad esempio, per quanto riguarda settori come la Salute e la Scuola - che solo dal PI 2000 hanno fatto la loro comparsa tra le prime tre priorità cittadine - va tenuta in conto anche l' 'insolvibilità tecnica' di parte delle richieste ipotizzate. Se i cospicui fondi stanziati fino al 1992 hanno permesso di risolvere alcune emergenze relative alla carenza di strutture, in seguito il fenomeno delle richieste in questi settori si è localizzato solo in singole regioni, mentre sul complesso cittadino esse sono arretrate di posizione. Due le spiegazioni principali: la bocciatura di molte richieste per servizi dipendenti dallo Stato e che evadibili dal Municipio, e il fatto che:

[...] Il Com une ha preso l'abitudine di sottolineare nei Piani di Investimento che per lo Statuto Comunale e la Legge brasiliana esistono dei livelli di spesa minimi obbligatori 
in questo settore e quindi le persone in qualche modo si sono sentite già tutelate. E tanto più oggi, con la creazione del SUS [il Sistema Unico di Sanità che mette in collaborazione più livelli istituzionali, $n d a$ ]. Ancora oggi spesso nelle Assemblee Plenarie qualcuno al tavolo dei rela tori ricorda che l'O.P. discute solo interventi di sua competenza, anche se nei settori delle scuole superiori, degli Istituti Tecnici e di alcuni Servizi Ospedalieri esso può e deve assumersi il compito di fare da portavoce dei suoi cittadini ai livelli istituzionali superiori. Il che significa che non è inutile rilevare carenze in tali settori durante le pubbliche Assemblee o anche farli inserire nelle priorità regionali come gesto dimostrativo (Borges, apud Allegretti, 2000a).

Come abbiamo visto, fino al 1994 apparivano, del resto, nei PI anche alcune richieste di finanziamento non accolte ma registrate dalla popolazione come importanti. Uno dei casi più eclatanti è quello del 1992, quando - accanto al finanziamento per la ricostruzione di Vila Planetario - sono riportate tutte le richieste non accolte di altre 'vilas' centrali, quasi a sottolineare l'appoggio che tali richieste costituivano a quella difficile realizzazione intrapresa: dall'anno successivo gli studi di fattibilità per un ampliamento del programma di sostegno al 'diritto dei poveri al centro' figureranno nei PI non direttamente finanziati ma approvati nell'ambito degli studi da condurre sotto la voce 'costi di gestione', affidati al personale interno dell' Amministrazione.

Talora, la ridotta presenza di specifici 'settori di domanda' tra le principali priorità è per contro dovuta ad una risposta pubblica mostratasi efficace: è il caso del settore della circolazione e dei trasporti, slittati tra le ultime priorità (eccetto casi sporadici di riemersione) dopo il massiccio intervento nel settore compiuto nel primo biennio dell'Amministrazione Dutra.

L'aspetto più interessante che la tabella comparativa di fig. 25 sottolinea è comunque l'arricchimento progressivo di articolazione delle voci di spesa, in particolare a partire dal 1998, quando il COP inserisce nel Regolamento Interno 12 priorità, dando autonomia ad alcuni temi come lo Sport, la Cultura, le Aree di svago, lo Sviluppo Economico e l'Assistenza Sociale, che i cittadini avevano lamentato essere penalizzate dall'aggregazione ad altre voci di spesa.

Guardando analiticamente le voci di investimento finanziate a partire dal PI 1995 (cioè dopo la creazione delle Assemblee Tematiche) ci si rende conto di uno 'scarto' nell'articolazione delle previsioni di spesa, che non pare - a breve termine - provocare modifiche sostanziali nella gerarchia delle priorità tematiche, pur contribuendo a diversificare molto gli ambiti di investimento pubblico. Tale evento - più sostenuto dal potere pubblico che dai partecipanti all'O.P. - segna l'approdo ad un 'punto di equilibrio' fra il ruolo dell'Amministrazione e della partecipazione cittadina nell'O.P., finora parzialmente sbilanciato sulla seconda almeno per quanto attiene alle decisioni sul merito degli investimenti; e dà l'avvio ad un modo più complesso di ripartire $\mathrm{i}$ fondi di investimento fra le diverse aree tematiche, recuperandone soprattutto alcune rimaste 'neglette'. Ciò che non è facile esaminare è però il modificarsi della quota di spesa riservata alle 'scelte strutturali' discusse nelle Assemblee Tematiche, che - secondo alcuni analisti - avrebbe in qualche modo favorito una restituzione di potere agli Assessorati, tanto più coniugandosi con gli espliciti criteri tecnici per selezionare le indicazioni popolari (Abers, 1998b). Se anche necessiterebbe uno studio apposito per cogliere la misura di questa parziale 'resistituzionalizzazione' di poteri decisionali, pare certo che ciò sia avvenuto in virtù del fatto che solamente le tre prime priorità cittadine sono trattate pienamente "secondo i criteri di carenza, popola- 
zione e priorizzazione", talché "il margine di arbitrio degli Assessorati [...] finisce per essere preponderante" per le altre voci, nonostante che detti organismi costituiscano strutture proprie di partecipazione intorno a loro, come alcuni Consigli Popolari (De olho no Orçamento, n. 7/98).

Questa particolare 'congiuntura' si riflette bene nel vigore assunto - ad esempio - dalle spese per la cultura, ma anche nel moltiplicarsi di programmi complessivi per la città, che dal 1995 sembrano soppiantare la logica degli investimenti frammentati e localizzati, a vantaggio di progetti di maggior coerenza e portata globale, per lo più inseriti nella categoria a beneficio di 'tutta la città' che da quel momento si accrescerà notevolmente di dimensioni e peso percentuale.

Per certi versi, quindi, la complessificazione portata dalla creazione delle Assemblee Tematiche è un fenomeno positivamente ambiguo, se è vero che si è fatto importante veicolo di moltiplicazione del dialogo e di coinvolgimento di nuove persone, recuperando anche un ruolo propositivo e decisionale più ampio per l'Amministrazione, attraverso un contatto nei seminari tematici che innesta nuovi processi di co-maturazione del pubblico e della struttura stessa del processo di Bilancio Partecipativo.

Ciò ha determinato mutamenti non solo nell'aumento del numero complessivo delle priorità tematiche regionali da 7 a 12 , ma proprio nella gestione fattane. La popolazione - con il maturare della sua lettura delle necessità e dei desideri - è sembrata, ad esempio, capire sempre di più l'importanza di voci fino ad allora sottovalutate dall'urgenza di risolvere problemi a cui nel frattempo è stato offerto un duro colpo attraverso anni di interventi mirati a reintegrare la città informale in quella di diritto. È così che si spiega l'accettazione - da parte della popolazione e dei suoi rappresentanti - di voci di bilancio necessarie "per dare continuità a progetti avviati nel passato e che è necessario portare avanti per elevare la qualità globale di vita agendo contemporaneamente su più aspetti della vita cittadina" (Baierle, apud Allegretti 2000a), dove acquisiscono spazio gli ambiti della cultura, dell'assistenza sociale alle famiglie o della protezione dell'ambiente. Un interessante indicatore di questa maturazione lo offrono, ad esempio, $\mathrm{i}$ progetti maturati negli ultimi due anni a favore di portatori di handicap (come i giochi per bambini disabili inaugurati nell'aprile 1999 nel Parco Moinhos de Vento), dove si riflette la massiccia partecipazione in alcune Assemblee Tematiche di gruppi organizzati di non vedenti e di non udenti, che hanno rappresentanti propri eletti persino nel Consiglio di Bilancio e vengono tutelati dallo stesso Regolamento Interno che garantisce loro assistenza di operatori e traduttori specializzati durante il processo.

Ciò che - a partire dal 1999 - si evidenzierà nell'Orçamento Participativo Statale si può leggere oggi anche nell'articolarsi delle richieste di investimento a livello comunale: al di là delle opere fisiche, tra i cittadini di Porto Alegre si va facendo strada una diffusa convinzione della necessità di ampliare i livelli di istruzione, ${ }^{49}$ di ottenere programmi 'professionalizzanti', corsi di formazione e qualificazione degli asili autogestiti, in modo che essi divengano luoghi di 'pre-formazione' e non semplici depositi (Dilly, 1999i-II in Allegretti 2000a). Ed è per tale via che nei PI oggi si moltiplicano fondi per il sostegno alle cooperative, l'appoggio al mantenimento dell'integrità dell'istituto della famiglia o alla microimprenditoria, specie se proveniente dal settore informale e da gruppi di donne che tentano "di dare concretezza al diritto 
312 alla parità tramite iniziative nel settore della creazione di reddito" (ibidem). E' in tale quadro che l'educazione riacquista un suo posto tra le prime posizioni della gerarchia di priorità tematiche, mentre assumono individualità propria aree come lo 'Sviluppo economico' e la creazione di piazze, da vivere come luoghi per la convivialità e lo svago.

Nei PI successivi al 2000, l'evolvere lento ma progressivo di queste tendenze è ormai un esito palese della maturazione del Bilancio Partecipativo (per il 2003, l'Educazione appare addirittura come la $2^{\circ}$ priorità cittadina). Ciò che rallenta il processo di trasformazione è, forse, la mancanza di una discussione maggiore su alcuni temi (come lo Sviluppo Economico) nelle 16 regioni, e la difficoltà reale di generalizzare alternative concrete di carattere solidale, che lascia la discussione molto ristretta alle Tematiche, dove la partecipazione popolare - ed in particolare quella degli strati più poveri della popolazione - non è ancora consolidata (De olho no Orçamento, $\mathrm{n}^{\circ} 7$ ). Lo dimostrano il caso della discussione sul Piano Pluriennale e sul PRG, e quella sul contratto da firmare col BID per il finanziamento della Terza Perimetrale, risultate per il pubblico dell'Orçamento Participativo come 'questioni più teoriche che pratiche' (ibidem). In tal senso, sia l'Amministrazione che i nuovi COPs hanno la responsabilità di affinare strategie per discutere di 'politiche' e tradurre certi temi nel quotidiano, lavoro senza cui è forse prematuro modificare i criteri che attualmente vincolano solo le prime tre priorità ad essere analizzate appieno secondo gli indicatori di carenza, popolazione e priorizzazione.

\subsection{Alcune trasformazioni qualitative nel meccanismo of ferta-domanda}

La tirannide che ci spaventa davvero è [...] la dittatura del sondaggio, [...] la dittatura del populismo non mediato e arginato dalla fatica razionale della politica [...] la rinuncia delle classi dirigenti [...] a svolgere il compito di mediazione e di intelligenza tra le pulsioni collettive e l'opera di governo. In breve, la rinuncia ad educare e la scelta di essere soltanto gli esecutori di ordini ricevuti. La dittatura delle emozioni è tanto feroce e assoluta quanto la dittatura dei comitati centrali, dei comandi supremi, dei sovrani, dei tiranni autoreferenti, ma è infinitamente più preoccupante perché riproducibile in ogni altra "democrazia" diretta (V. Zucconi, 2001, pg. 15)

Le tendenze ancora timide riscontrabili dall'osservazione delle priorità d'investimento in ambito cittadino emergono con più chiarezza alla scala delle 16 regioni e delle micro-regioni che dal 1995 cominciano a prendere forma al loro interno. Non è qui possibile passare in rassegna le migliaia di richieste di intervento puntuale accolte in questi 11 anni dall'Amministrazione, e soprattutto quelle presentate ma non accolte; tuttavia vale la pena ricordare (appoggiandoci sulla lettura comparata tentata in Allegretti 2000a che - soprattutto dal $1997^{50}$ - tendono ad evidenziarsi una serie di 'singolarità emergenti' che rafforzano e guidano, a partire dall'ambito regionale, il diffondersi di queste tendenze all'articolazione e alla differenziazione delle richieste 'per temi'. In particolar modo per quanto attiene Regioni segnate da forti peculiarità storiche o morfologiche come la Ilhas/Humaità/Navegantes ${ }^{51}$ la Restinga ${ }^{52}$ la Noroeste ${ }^{53}$ la Nordeste ${ }^{54}$ e - soprattutto - la Regione Centro. ${ }^{55}$ Parlare di priorità di investimento così come indicate su scala cittadina o solo regionale dai partecipanti al Bilancio Partecipativo ha un po' il sapore di discutere di una classifica; ed in realtà un po' lo è, dal momento che il confronto fra 
posizioni è una delle componenti fondamentali dell'O.P., sia per l'ottenimento di risultati 'concreti' in sede di finanziamento dei progetti che per la crescita delle persone che partecipano del processo. È però indispensabile ricordare che una simile prassi non è una sterile elencazione, ma corrisponde a delle trasformazioni qualitative delle stesse opere realizzate, discusse sovente nei dettagli nelle Assemblee Intermedie, nei Forum tematici e nei Consigli Municipali, che rappresentano oggi il luogo del passaggio da una gestione consensuale del bilancio e delle sue priorità all'impostazione partecipativa delle diverse politiche di settore. Questi aspetti 'qualitativi' non emergono apertamente da una semplice lettura dei documenti di programmazione economica prodotti in sede di O.P.; piuttosto sono rintracciabili nel campo della trasformazione delle politiche municipali di cui i progetti approvati dal COP sono la punta dell'iceberg.

Un esempio lo si può avere esaminando il settore tematico della 'pavimentazione', tradizionalmente tra quelli indicati entro le prime tre priorità cittadine a partire dal Governo Dutra del 1989, quando nel primo anno furono promessi alla popolazione $42 \mathrm{~km}$. di strade asfaltate, rimandati poi al '91 vista la sovrastima del progetto rispetto ai fondi disponibili (Augustin, 1994).

'Pavimentazione' è un termine generico, che a Porto Alegre per lo più vuol (o almeno voleva) dire 'asfalto'; una sovrapposizione quasi istintiva nelle teste dei cittadini, perché l'asfalto - così come il garage - "è uno dei più basilari miti della città formale, un'aspirazione che spesso porta con sé l'idea di auto, di velocità, di pulizia, di mancanza della famosa terra rossa che caratterizza la città informale di gran parte del Brasile. Ma che dovrebbe poter essere associato anche all'idea di crepe, di spreco, di allagamenti, di pericoli per $i$ bambini e di cani e gatti investiti, se concepito da solo, slegato dalle canalizzazioni, dall'equa distribuzione fra strade e vicoli, dalla presenza di adeguati marciapiedi e di illuminazione. Che l'asfalto preso isolatamente sia un mito legato al mondo della città di diritto solo og gi sta diventando abbastanza chiaro anche nelle teste dei tecnici comunali" (Baierle, apud Allegretti, 2000a).

Questo sta avvenendo con ritardo, "e chi deve fare 'mea culpa' siamo anche noi dei movimenti popolari e delle ONG, specie noi ingegneri che $i$ pericoli dell'uso indiscriminato dell'asfalto e soprattutto della sua funzione impermeabilizzante dovremmo conoscerli, e che ci siamo lasciati troppo a lungo accecare da altro" (Pozzobon, 1999i - I, apud Allegretti, 2000a). Del resto, in altre città il percorso non è stato dissimile. Ancora nel novembre del 1997, l'allegato del giornale ' $O$ Dia' di Rio de Janeiro, dedicato al recupero del quartiere Caju nell'ambito del Programma Favela-Bairro, esibiva un titolo cubitale di questo genere: La dignità arriva con l'asfalto.

A Porto Alegre, il 'furore pavimentatorio' (che si potrebbe parafrasare anche come 'asfaltatorio') iniziò concretamente nel '91 - quando furono realizzati i 42 km di strade previsti due anni prima - e continuò nel '92 con ritmi analoghi (34,6 $\mathrm{km}$ ), scendendo a $21 \mathrm{~km}$ nel 1993, e poi assestandosi su una media oscillante fra i 20 e i 30 annui. Dal ' 94 una voce descrittiva nuova nei PI permette di valutare i metri di strade realizzati in ogni regione della città annualmente, più o meno con distribuzione equilibrata in tutto il territorio cittadino, fatta eccezione per la regione Centro, già abbastanza dotata.

I dati quantitativi sotto riassunti, permettono però di rilevare un fenomeno di progressiva differenziazione delle politiche di costruzione delle strade pubbliche, che si accompagna ad una crescita delle realizzazioni nel settore dell'illumi- 
nazione pubblica, ad un'intensificazione dei controlli e delle multe (dal '92 specie per mancata o cattiva realizzazione dei marciapiedi da parte dei proprietari prospicienti la strada realizzata, come previsto dalla Legge) e alla costruzione di percorsi pedonali adiacenti alla viabilità carrabile. E se un 'punto di flesso' si ha nel '94, quando è inaugurata una politica più decisa di demolizione e ricostruzione dei marciapiedi mal eseguiti dai privati, il momento maggiore di svolta qualitativa è segnato dal '96, quando un'indagine attenta della SMOV - a seguito delle sempre più pressanti richieste presentate dalla cittadinanza dentro e fuori dell'O.P. - dà la misura dei rischi che la politica di asfaltatura fino ad allora usata (già da epoche precedenti al Fronte Popolare) rivela. L'indagine mette, infatti, in luce le necessità di grosse spese manutentive rivelatesi necessarie in molti ambiti territoriali già a pochi anni di distanza dalla pavimentazione delle strade. Del resto, dal 1996, le ri-pavimentazioni stradali aumentano di oltre il $1000 \%$ a Porto Alegre, facendo avvertire la necessità di una trasformazione nelle modalità costruttive fíno ad allora utilizzate. Si registra, così, un aumento delle forme di pavimentazione alternativa, come quella in blocchi di pietra irregolari (già percepibile dal 1997 con l'aumento del 77,71\% nell'uso) che - permettendo una maggiore traspirazione del manto stradale - minimizza problemi di dissesto dovuti ad agenti atmosferici, pur dimostrandosi inadatta in aree di grossa pendenza a causa dell'effetto di trascinamento delle piogge, come constatato di recente in varie 'vilas' di Porto Alegre.

Questa progressiva 'qualificazione' o - almeno - 'diversificazione' degli interventi di pavimentazione (evidenziata in modo sintetico nella tabella qui sotto) tende ad assumere le fattezze di un ventaglio ampio di modalità costruttive associato ad un maggior coordinamento della SMOV con altri dipartimenti nella realizzazione contemporanea di reti infrastrutturali per minimizzare le diseconomie dovute alla continua sostituzione di marciapiedi e manti stradali in occasione di realizzazioni disgiunte (Real, apud Allegretti, 2000a). ${ }^{56}$

Modalità costruttive della viabilità pubblica a Porto Alegre (1992-1997)

\begin{tabular}{|l|c|c|c|c|c|}
\hline Anno & \multicolumn{5}{|c|}{ Costruzione di vie pubbliche (mq) } \\
\hline & Asfalto & $\begin{array}{l}\text { Blocchi } \\
\text { rettangolari }\end{array}$ & $\begin{array}{l}\text { Pietrame a } \\
\text { pezzatura } \\
\text { irregolare }\end{array}$ & $\begin{array}{l}\text { Blocchetti di } \\
\text { cemento } \\
\text { sagomati }\end{array}$ & $\begin{array}{l}\text { Costruzione } \\
\text { parallela di reti } \\
\text { infrastrutturali }\end{array}$ \\
\hline 1992 & 252.370 & 0 & 535 & 771 & 0 \\
\hline 1993 & 165.561 & 2.590 & 0 & 0 & 0 \\
\hline 1994 & 121.807 & 6.344 & 2.170 & 0 & 1.820 \\
\hline 1995 & 292.379 & 1.450 & 4.305 & 9.960 & 0 \\
\hline 1996 & 145.888 & 1.715 & 8.092 & 5.565 & 11.200 \\
\hline 1997 & 142.091 & 615 & 6.750 & 14.121 & 0 \\
\hline 1998 & 64.381 & 0 & 0 & 0 & 1.964 \\
\hline 1999 & 166.988 & 0 & 0 & 2.620 & 602 \\
\hline 2000 & 294.171 & 504 & 2.606 & 2.902 & 0 \\
\hline
\end{tabular}

Dati: SMOV 1992/2000 
Più interessanti degli indubbi risultati di ottimizzazione delle risorse sono, comunque, le modifiche che la nuova strategia ha apportato in sede di Bilancio Partecipativo nel rapporto tra tecnici del Comune e cittadini, favorendo una qualificazione della discussione e delle proposte presentate in vista delle scelte sui futuri investimenti pubblici. In particolare tra il ' 98 e il ' 99 ha preso corpo una vera e propria 'campagna' dell'Amministrazione per 'correggere il tiro' di una prassi (l'asfaltatura acritica di ogni percorso pubblico da riorganizzare) rivelatasi inefficace.

La tendenza dell'O.P. nei primi suoi anni di vita è stata di dare ciò che le persone chiedevano. E spesso queste non chiedevano 'pavimentazione' ma asfalto. C'era un difetto loro, forse di ignoranza, forse di semplificazione indotta dal mito dell' asfalto che la città informale indubbiamente veicola; ma c'era soprattutto un difetto dell' Amministrazione e dei suoi tecnici, che non volevano rendersi conto che non si poteva prendere come una specifica tecnica il frutto di una discussione semplificata che non andava oltre l'elencazione di priorità tematiche o localizzative (Baierle, apud Alle gretti 2000a).

Questo problema, apparentemente da risolvere in ambito 'tecnico', è stato alla base di un interessante mutamento di prospettiva all'interno dell'O.P., rendendo necessario un dialogo più stretto fra tecnici e cittadini, una riorganizzazione dei compiti di alcuni livelli di rappresentanza al suo interno (in particolare i delegati, che hanno un maggiore contatto quotidiano in loco con gli abitanti dei quartieri) e - soprattutto - favorendo uno slittamento di interesse verso la disamina delle priorità di intervento nei loro aspetti tecnici anche puntuali e nel loro peso economico sul medio e non più solo sul breve termine. A questi importanti 'slittamenti' di significato e di portata del dibattito in corso ai vari livelli dell'O.P., se ne è aggiunto uno in direzione della varietà e del pluralismo delle scelte. La discussione serrata con i tecnici sui temi della pavimentazione ha - infatti - guidato all'emergere di posizioni diverse all'interno della cittadinanza. Così - ad esempio - nel marzo del 1999 un gruppo di cittadini del quartiere-giardino alto-borghese Vila Assunção (fino ad allora poco attivi nelle riunioni dell'O.P.) si sono riuniti per fondare ufficialmente un'Associazione di Quartiere e difendere la pavimentazione 'storica' di blocchetti di pietra nelle loro strade minacciata da alcuni lavori di infrastrutturazione. Nelle intenzioni poco ragionate del Comune, infatti, ai lavori doveva seguire un'asfaltatura delle vie; dell'altra modalità costruttiva, però, gli abitanti non solo hanno sottolineato l'importanza storica per un quartiere-modello degli anni '40, ma anche il valore ai fini della diminuzione del traffico e della velocità, e quindi dell'aumento della sicurezza e del silenzio.

La 'qualificazione' sul tema della pavimentazione si colloca oggi in un quadro di trasformazioni parallele più vasto: ad esempio, all'interno dei finanziamenti per la costruzione della circonvallazione detta 'Terza Perimetrale' esiste una clausola del BID - organo finanziatore - che impegna il Comune ad una contropartita in 'pavimentazione comunitaria' da distribuire tra le aree che meglio si organizzeranno per sfruttare l'occasione. Tra i criteri imposti dal BID per la scelta delle iniziative da finanziare ve ne sono alcuni in linea con quelli in base a cui sono selezionate le priorità dell' OP (ad esempio la proporzionalità dei fondi con il numero di persone che le varie opere beneficeranno) e altre che invitano all'integrazione delle 'vilas' nella città 
privilegiando le strade che leghino singoli luoghi di residenza ad attrezzature comunitarie esistenti. Vi sono però anche clausole che costituiscono un passo indietro, come quelle tese a privilegiare gli interventi meno complessi e di più ampio respiro (ad esempio strade di larghezza 10 metri per bus e con ampio marciapiede), senza impedimenti in mezzo di via o muri di contenimento da ritoccare. Attraverso queste clausole -descritte dai tecnici alla popolazione nelle varie occasioni di contatto diretto, in forma di costruzione del quadro di riferimento in cui l'Amministrazione deve operare le sue scelte - il denaro tende ad essere distribuito attraverso criteri di 'comodo' riguardanti una facile operatività per i lavori, mentre vengono lasciate le opere più complesse ad altre formule di finanziamento che il Comune dovrà procacciarsi autonomamente. Nel complesso, però, il finanziamento del BID è annoverabile tra quelle intese 'propositive' di nuove forme di collaborazione tra il Comune e enti finanziatori esterni; di quegli accordi che reinterpretano il termine di 'comunitario' (in questo caso 'pavimentazione comunitaria') come 'beneficiante grossi numeri di persone' piuttosto che come 'fatto in comunità', ma che comunque tentano di leggere la città come un luogo di aggregazione di più centri, strutturazione di un tessuto che non accetta di essere frammentato per monadi non comunicanti.

Allo stesso modo, nell'ambito del lavoro del DMAE per la fornitura di reti idriche e fognarie, le progressive discussioni con la popolazione hanno chiarito l'opportunità di realizzare particolari sistemi 'combinati' piuttosto che lavorare due volte sulla stessa area con sprechi finanziari e di tempi; il Comune è riuscito così a portare avanti un programma scaglionato e graduale (cfr. Allegretti, 2000a) che attualmente ha portato la fornitura d'acqua a raggiungere - con mezzi diversi - il $99 \%$ della popolazione cittadina, ${ }^{57}$ aumentando progressivamente la rete fognaria trattata e coordinando il proprio lavoro con quello di altri Dipartimenti e Assessorati che operano sul territorio, seppur nei limiti della volontà popolare di risolvere innanzitutto le emergenze più urgenti, anche a costo di qualche irrazionalità operativa.

Per favorire tali trasformazioni del livello qualitativo della discussione dell'O.P. (che ha riguardato anche settori differenti come le attività produttivo/commerciali o la produzione di beni 'immateriali' come le attività culturali) il Comune ha svolto un ruolo 'trainante' e 'di guida' sulla cittadinanza (Abers, 1998b) innescando una graduale trasformazione della domanda presentata dai cittadini nel corso dei vari livelli di confronto fuori e dentro l'O.P. ed i Consigli Municipali. La progressiva stabilizzazione e complessificazione della relazione tra società politica e società civile nell'approntamento di linee strategiche e politiche cittadine a Porto Alegre, è stato certo favorito dalla struttura flessibile dei criteri tecnico/organizzativi del Bilancio Partecipativo. Come ha osservato un Consigliere popolare dell'OP:

Non è che i problemi della popolazione più povera di Porto Alegre siano maggioritariamente risolti, perché purtroppo va registrato un alto numero di vilas in condizioni di grande povertà e l'apparirne di nuove. Direi piuttosto che il dato più significativo del mutare lento ma progressivo dei volti dei Piani di Investimento di questi anni è l'acquisizione di una 'pazienza' da parte degli strati più poveri della popolazione. Non una rinuncia a lottare, perché anzi la lotta e le critiche all' Amministrazione si sono forse inasprite in questi anni; ma un'accettazione ragionata di un meccanismo che si riconosce non discriminatorio ma neppure facile da gestire perché richiede un impegno, l'attesa, la capacità di condurre una lotta democratica di 
persuasione e alleanza reciproca fra quartieri e regioni. Mi sembra di poter dire che nella crescita delle opere per tutta la città e nello spuntare timido di qualche opera 'concessa' dai più poveri e battaglieri ai più benestanti e pigri, si legga la maturazione della città e dell'OP con essa. Un complicarsi e un arricchirsi della lettura della città da parte dei suoi abitanti (Dilly, 1999i - I, apud Alle gretti, 2000a).

Un'affermazione che aiuta bene a comprendere perché " $i$ risultati del Bilancio Partecipativo non possono e non devono essere misurati attraverso numeri e percentuali, sebbene questo sia fondamentale per provare che la partecipazione, la trasparenza e la democrazia rendono la spesa pubblica più efficiente" (Prefeitura de Porto Alegre, 1997).

\section{Note}

${ }^{1}$ Secondo la ricerca realizzata dall'Istituto Ethos (sempre nel 1994 e su un campione di 1200 cittadini di Porto Alegre di vari strati sociali), invece, ancora solo il 46,3\% aveva sentito parlare dell'OP, e di questi solo il 17,9\% vi avevano preso parte almeno una volta (1'8,3\% sul totale complessivo del campione) in almeno una delle sue fasi.

${ }^{2}$ La stima, che tiene conto anche delle assemblee che si svolgono nei singoli quartieri e comunità, è contenuta nel documento 'Rompendo nossos limites' del Gruppo di Lavoro sulla Riforma e Modernizzazione dell'OP, aprile 2001.

${ }^{3}$ I 31.321 partecipanti ufficialmente registratisi nel solo Turno Unico della primavera 2002, rappresentano poco meno del $2,5 \%$ dell'intera popolazione cittadina valutata secondo le proiezioni IBGE per il 2002).

${ }^{4}$ La non-partecipazione nell'immediato del secondo tipo di cittadini si manifesta in genere come approvazione del processo (seppur tradotta in un temporaneo disinteresse) e quindi può prevedere un futuro ritorno in prima persona.

${ }^{5}$ Secondo la ricerca CIDADE-RMPA 2002 (p. 57) i partecipanti all'OP che ritengono di essere già stati beneficiati dall'impegno dentro il processo sono il $60,1 \%$, contro il $58,5 \%$ del 1998 e il 56,6\% del 1995 , segno che vi è una lieve crescita nel numero di coloro che 'ritornano a partecipare' (le ragioni possono essere di varia natura; anche la crisi economica che negli ultimi anni va rendendo più difficile soddisfare per intero certe richieste in breve tempo).

${ }^{6}$ L'inchiesta fu realizzata sul $10 \%$ circa (662 persone) dei partecipanti alla seconda tornata di Assemblee Plenarie, alla ricerca di dati socioeconomici degli stessi e di esperienze di partecipazione in altri settori della vita cittadina.

${ }^{7}$ Interessanti trattazioni del clientelismo in Brasile sono in Graziano(1976),Diniz (1982),Blamck (1986), Gay (1990).

${ }^{8}$ La ricerca (26 chiuse e 9 aperte per ogni intervistato) ha mantenuto l'impostazione delle edizioni precedenti nel tentativo di assicurare il confronto dei dati almeno per le domande legate alle variabili socioeconomiche, alle modalità e alle motivazioni dell'impegno e alla percezione che il pubblico partecipante ha del BP. Sono state tuttavia aggiunte nuove domande con l'obiettivo di ampliare l'analisi, considerando la partecipazione all'OP dello Stato, l'esistenza o no di preferenze partitiche e la percezione sul ruolo del Consiglio Comunale e la sua relazione con il Bilancio Partecipativo. Essa è stata strutturata in 4 nuclei: 1) Profilo del partecipante all'OP (insieme a quale gruppo partecipa alle riunioni: sesso, gruppo etnico, età, stato civile, livello di istruzione, professione, occupazione, ore di lavoro e reddito familiare); 2) Partecipazione all'OP (perché partecipa alle riunioni, partecipazione in anni passati, anni in cui ha partecipato, partecipazione alla regioni e/o tematica, come è stato informato sulle riunioni, se è già stato eletto delegato e/o consigliere, quante volte è stato eletto, come sono eletti i delegati, se usualmente prende la parola durante le riunioni, se conosce le regole di funzionamento dell' $\mathrm{OP}$, la differenza fra le plenarie regionali e tematiche e se partecipa all'OP dello Stato - quest'ultima domanda rivela che il 78,3\% degli intervistati non vi partecipa, ma all'epoca dell'intervista si era solo nel $1^{\circ}$ anno della sperimentazione ); 3) Livello di partecipazione a organizzazioni della società civile e alle strutture dell'OP (se fa parte di una o più organizzazioni, a quale partecipa con maggiore assiduità, se ricopre incarichi direttivi in un'organizzazione, frequenza della partecipazione, se ha preferenze per un partito politico e per quale partito), 4) Percezione dell'OP (se ha avuto 
beneficio dall' $O P$, quanto potere decisionale reale ha, se i rappresentanti popolari rispettano le decisioni prese nell'OP, se i rappresentanti dell'amministrazione informano in maniera soddisfacente, il ruolo del Consiglio Comunale e la ripercussione dell'OP sul suo operato). Essa è stata realizzata col concorso della NRM Consultoria Estatistica Ltd, su un campione casuale semplice per ogni Tematica e per ognuna delle 16 Regioni. Con riferimento al numero di partecipanti alle riunioni (il cui proxy è stato il valore più elevato fra i cinque anni 1995/99 si è stabilito un 'intervallo di confidenza' di 0,9 per le tematiche e per le regioni prese singolarmente e di 0,95 per i dati generali. L'errore massimo delle stime è stato fissato in 0,075 punti percentuali per ogni tematica e per ogni regione e in 0,05 punti percentuali per i dati generali. Su questa base sono state realizzate 388 interviste nelle tematiche $(14 \%$ in più rispetto a quanto richiesto) e di 1.189 nelle regioni $(8,68 \%$ in più rispetto a quanto richiesto), che hanno rappresentato il $10,95 \%$ dei partecipanti ai principali turni assembleari dell'OP nel 2000.

${ }^{9}$ I 'senza preferenza' scendono al $25 \%$ tra i Consiglieri, al $28,3 \%$ tra i Delegati e al $35,5 \%$ tra i dirigenti delle AMs; parallelamente le preferenze espresse a favore del PT (il partito leader del Fronte Popolare) salgono a 50\% tra i Consiglieri, al 47,6\% trai Delegati e al $43 \%$ tra i dirigenti di AMs.

${ }^{10}$ Il dato (ricerca $J B$-Vox Populi) è in Dias, Marcia (2000): allora il $46 \%$ dei cittadini indicava preferenze per il PT.

${ }_{11}$ Questo dato è confermato anche un rilevamento 'informale' citato in Solidariedade (2003). 12 Nelle Assemblee Tematiche il dato disaggregato cala all'11,6\%, mentre nelle Regionali rappresenta il $36,7 \%$. Va notato che il $42,9 \%$ degli intervistati dichiara ancora di essere venuto a conoscenza delle riunioni dall' AM stessa (dato simile al 1998 e solo un po' più basso del al 1995, quando rappresentava il 48,2\%). In secondo luogo, l'informazione proviene dagli amici, vicini e parenti (18,9\% contro il 14,4 del 1998), da Delegati e Consiglieri dell'OP (11,4\% contro il 9,7 del 1998), da Radio e TV (10\% contro l'1,6 del 1995 e il 7,8 del 1998), da rappresentanti del Comune (9,4\% contro 1'8,6 del 1998 e il 6,5 del 1995), da auto con altoparlanti (9,4, contro il 6,5\% del 1995) o da altri mezzi di informazione del Comune $(8,4 \%)$ o indipendenti $(4,1 \%$ in crescita rispetto al passato). Riguardo al livello di soddisfazione delle informazioni sull'OP fornite direttamente dal Comune, per il 28,9\% dei partecipanti è SEMPRE soddisfacente, per il 34,9\% QUASI SEMPRE, per il 16,1\% A VOLTE, per il 2,2\% MAI (complessivamente, rispetto alle risposte di '95 e '98 si nota una sorta di disimpegno informativo dell' Amministrazione). ${ }^{13}$ Una conferma di questa percezione di 'democraticità' dell'OP viene dal fatto che solo il $10 \%$ ritiene che Delegati e Consiglieri siano eletti 'per indicazione preventiva' (e in tal caso, il 51,3\% per indicazione dell'AM locale, il 28,5\% per riconferma di leader comunitari doi varia naturale e solo 1'1,3\% indica il 'governo' come mandante dei nominativi presentati); il 36,7 riconosce carattere 'aperto' alle assemblee dove presentano le candidature.

${ }^{14}$ Questa sorta di 'fiducia' (o di 'ignoranza fiduciosa') di molti circa il processo a cui partecipano è rivelata da molti dati; ad esempio il 44,2\% degli intervistati non sa spiegare quale differenza esiste tra Assemblee Tematiche e Regionali, ma continua a parteciparvi; per lo più la coscienza specifica sembra essere 'intuitiva' visto che sulle Tematiche tende a convogliarsi quasi spontaneamente un tipo di pubblico più istruito e con maggior potere acquisitivo.

${ }_{15}$ Anche questo rende possibile il fatto che oltre il 56,9\% dei partecipanti dica di conoscere la maggioranza dei regolamenti interni dell'OP, e solo il $4 \%$ attualmente non le conosce.

$165,06 \%$ sopra i 10 anni secondo il Censimento IBGE 1991

${ }^{17}$ Il 44,3\% degli intervistati afferma di partecipare solo alle Regionali, mentre il 18,5\% ad entrambe

${ }^{18}$ Un dato qualitativo indicativo della forte presenza dei rappresentanti 'diretti' delle favelas portalegrensi a tutti i livelli dell'OP, è il fatto che ad esempio quello che mostra che dei Consiglieri di Bilancio (Titolari e Supplenti) eletti dalla popolazione nel 1998, stando agli indirizzi riportati annualmente sul Piano degli Investimenti, ben il 54\% hanno voluto specificare nel loro indirizzo di riferimento per la popolazione la 'Vila' di appartenenza. Certo, non è un dato scientifico, sia perché i criteri di descrizione degli indirizzi non sono unitari, sia perché l'indirizzo segnalato è una sorta di 'autodenuncia' del consigliere stesso, e quindi soggetta all'influenza di fattori psicologici non infrequenti da rilevare quando si parla con questi militanti: cioè l'orgoglio per la propria appartenenza ad un gruppo di emarginati in forma di 'rivendicazione', o al contrario la 
vergogna (reazione che appare più rara) di chi attraverso l'O.P. cerca di acquisire un ruolo semi-ufficiale e approfitta di una via da poco dotata di nome e inserita sullo stradario per vantare la sua appartenenza ad un quartiere della 'città formale'. Seppur non scientificamente rappresentativo, il dato può ugualmente essere considerato indicativo, anche nella misura in cui i COPs non sono - come i Delegati - semplici rappresentanti dell'unità di vicinato che li ha eletti, ma rappresentano l'intera regione, e vengono scelti dall'insieme maggioritario dei partecipanti di ognuna delle 16 macrozone che fondono città informale e città formale. ${ }^{19}$ In realtà, le rilevazioni sul reddito devono tenere in conto che coloro che si sono rifiutati di rispondere alla domanda sono passati dal 2,4\% del 1998 al $12 \%$ attuale.

${ }^{20}$ Secondo i dati IBGE il 55,5\% degli abitanti di Porto Alegre ha tra i 15 e i 49 anni, mentre il $20 \%$ ha oltre 50 anni. Nell'OP, la fascia $16-49$ rappresenta il $73 \%$ circa e gli ultracinquantenni il 25,9\%; in realtà i minori di 16 anni, non avendo diritto al voto, a Porto Alegre non partecipano - a differenza che in altre città dove esistono assise specifiche per queste fasce di età (un esempio è l'OP Mirim per i bambini di Barra Mansa, vicino a Rio de Janeiro).

${ }^{21}$ Le donne paiono rappresentare una parcella consistente soprattutto tra le persone non coniugate $(38,9 \%$ contro il 36,9 degli uomini), vedove $(9,6 \%$ contro il $2,8 \%$ degli uomini) e separate o divorziate (11,6\% contro il $7 \%$ degli uomini); il 60,4\% si situa all'interno di categorie di reddito familiare inferiore ai 4 Salari Minimi (con 14,8 punti percentuali in più rispetto agli uomini nella stessa fascia) e all'interno dei gruppi etnici di origine africana, le donne rappresentano il 63,6\% dei presenti alle Assemblee.

${ }^{22}$ Usiamo qui i dati fornitici da CIDADE (35 donne su 88, di cui 17 titolari). In realtà, la CRC ci ha fornito un dato totale leggermente diverso (38). Abbiamo difficoltà a verificare quello esatto (pur avendo l'elenco completo dei nomi dei Consiglieri), visto che almeno di 20 nomi di origine e trascrizione anomala non riusciamo a identificare il sesso.

${ }_{23}$ Sarebbe interessante realizzare uno studio sulle 'proposte' e le 'richieste' accolte o bocciate nell' OP per capire quale ruolo attivo e propositivo le donne giocano nel processo: le considerazioni intuitive di chi ha partecipato a lungo all'OP lasciano intravedere risultati molto interessanti...

${ }^{24}$ Cfr. Rompendo nossos limites, 2001

${ }^{25}$ Dal Decreto Legge 2283/1986 l'unità di misura era il CRUZADO (Cz\$); equivalente 1 millesimo del vecchio CRUZEIRO (Cr\$) in vigore negli anni '70 e '80. Dal 16/1/1989 entra in vig ore il CRUZADO NOVO (NCz\$) per la Risoluzione 1565/89; dal 18/3/90 torna invece in vigore il vecchio CRUZEIRO (Cr\$) con la Risoluzione 1689/90; dal 1/8/ 93 entra provvisoriamente in vigore il CRUZEIRO REAL (CR\$) con Risoluzione 2010/ 93 del Consiglio dei Ministri; dal 1/7/1994 - invece - con Legge 8880/1994 entra in vigore il REAL $(\mathrm{R} \$)$, che vige tuttora.

${ }^{26}$ Per la difficoltà e il tempo che richiedono le conversioni multiple abbiamo dovuto minimizzare l'uso di tabelle contenenti dati monetari, anche tenendo conto del fatto che la conversioni in dollari (US\$) non sempre sarebbero univocamente espressive a causa delle forti oscillazioni subite da questo nel tempo. In base ai valori delle varie monete rispetto a quelle precedenti (contenuti nei Decreti Legge di trasformazione della valuta), abbiamo calcolato - impostando delle equazioni multiple - i coefficienti di conversione per arrivare ad un'uniformazione dei dati posseduti nell'ultima moneta, il Real. Essi risultano così definiti: $1 \mathrm{R} \$=2,750 \times 1000 \mathrm{CR} \$ ; 1 \mathrm{R} \$=2,750 \times 1000000 \mathrm{Cr} \$ ; 1 \mathrm{R} \$=$ $2,750 \times 1000000 \mathrm{NCz} \$ ; 1 \mathrm{R} \$=2,750 \times 1000000000$ e $1 \mathrm{R} \$=2,750 \times 1000000000000$. ${ }^{27}$ A meno di non imbarcarsi in un'analisi titanica sulle singole realizzazioni, regione per regione.

${ }^{28}$ La congiuntura - intesa come convergenza di situazioni e fenomeni socioeconomici e politici nello stesso momento - rende difficile una valutazione complessiva dell'incidenza di alcuni mutamenti interni sulle tipologie e la distribuzione degli investimenti. Ad esempio, nel 1994 la creazione delle Assemblee Tematiche mutò completamente il profilo della distribuzione degli investimenti su scala cittadina, mentre la creazione della Commissione Tripartita del COP fece sì che l'O.P. cominciasse ad indirizzare la politica dell'Amministrazione Popolare anche relativamente alla gestione delle spese correnti e di personale, e non solo a quelle di capitale. L'incidenza di queste trasformazioni sul mutare delle voci di spesa del 1995 e degli anni immediatamente successivi non è facile da valutare, nella misura in cui nel 1994 il Plano Real di conversione monetaria impose notevoli restrizioni alla spesa pubblica, sommando i suoi effetti a quelli che avrebbero eventualmente potuto generare le trasformazioni interne alla struttura dell'OP.

${ }^{29}$ Il PI del 1990 prevedeva come priorità tematiche (in ordine di importanza): dotazioni sanitarie di base, pavimentazione delle aree più disagiate, regolarizzazione fondiaria, sanità, 
educazione, apertura di strade, illuminazione pubblica e per ultimo il trasporto pubblico.

${ }^{30}$ Lo scopo era servire 15 nuove vilas di acqua e sostituire le reti in 5 quartieri, creando 14 nuove reti fognarie.

${ }^{31}$ Come già detto altrove, lo Statuto Comunale prevede una spesa minima per il settore dell'educazione (30\% delle entrate dovute a imposte e trasferimenti dai livelli di governo superiori) più alto del minimo del $25 \%$ previsto dalla Costituzione Federale; nel 1994 si arriva al 31,98\%, cioè quasi $/ \%$ sopra il minimo previsto a livello nazionale.

${ }^{32}$ La SMOV, a cui nel 1992 erano andati il 35,4\% dei fondi destinati essenzialmente alla pavimentazione, si riconferma come l'Assessorato strategico del primo quinquennio di O.P., ottenendo il $43,9 \%$ dei fondi totali per opere di vario genere, fra cui $21 \mathrm{Km}$ di nuove pavimentazioni distribuiti su 51 strade. Inseriti nel novero delle opere di urbanizzazione primaria sono 17 nuove reti fognarie e nuovi terrapieni di copertura di discariche di rifiuti (fondi PIMES).

${ }^{33}$ Vila Fatima, Vila $1^{\circ}$ de Maio e Vila Tronco

${ }^{34}$ Resta stranamente confinata in questa logica, invece, la commercializzazione del primo isolato del Distretto Industriale della Restinga, messo in carico alle opere a beneficio della regione.

${ }^{35}$ Sul totale delle uscite il costo di personale arriva al 48,41 e i costi fissi al 28,92.

${ }^{36}$ L'ordine non è esplicitato ma sembrerebbe essere quello qui seguito, se si guarda alle percentuali di investimento totali dei vari Assessorati e Autarchie.

${ }^{37} \mathrm{Su}$ quest'ultimo si esprime anche la neonata Commissione Tripartita del COP.

${ }^{38}$ L'opposizione è con i 'servizi', in parte esposti nei PI precedenti, almeno se comportavano investimenti in opere.

${ }^{39}$ Il fatto può essere attribuito ad una serie di concause; l'aumento dei finanziamenti dovuti a trasferimenti di risorse e Fondi esterni conquistati a seguito dell'approvazione del Piano Real di stabilizzazione monetaria, in gran parte vincolati a progetti specifici di investimento (e non utilizzabili per coprire le voci costi fissi e personale, che sul totale finiscono per apparire ridimensionate sul complesso delle spese) e l'operazione di vigilanza e controllo dei cittadini sulle diverse voci di spesa del Comune svolta attraverso le Assemblee Tematiche e la Commissione Tripartita del COP.

${ }^{40}$ Queste uscite sono stimate sommando quelle di Amministrazione Diretta, DMLU, DEMHAB, FESC e DMAE, ma escludendo l'impresa di bus CARRIS, l'impresa di turismo EPATUR e la PROCEMPA per il processamento dei dati.

${ }^{41}$ Il BID per la Pavimentazione Comunitaria, la Terza Perimetrale, la Modemizzazione Amministrativa e il Piano di Macrodrenaggio; il BNDES per il Corridoio Norte/Nordeste; il FONPLATA per il disinquinamento del torrente Diluvio e l'ampliamento del Centro Sanitario HPS; la Cassa Economica Federale per i programmi Pró-Moradia, PróSaneamento; e la FINEP.

${ }_{42}^{4}$ Tra questi il Progetto SEJA, i NASF, il Progetto 'Segnale verde' e l'aiuto ai Consigli Tutelari presenti in 8 microregioni, ognuno con 5 consiglieri, ed il MOVA che dovrebbe passare da 3100 a 6350 alunni.

${ }^{43}$ Lo stesso accade per le voci di finanziamento del WSF da parte dello Stato del Rio Grande do Sul (il cui contributo è stato decisamente più consistente); esse non figurano né nel 2001 né nel 2002 nell'elenco dei progetti del Bilancio Partecipativo Statale, non essendo legate alla costruzione o alla manutenzione di 'opere', ma essendo voci di costo della gestione ordinaria.

${ }^{44}$ Ad esempio, il progetto Severo Dullius, finanziato dalla Banca Nazionale per lo Sviluppo (BNDES).

${ }^{45}$ La posizione è a pari merito con quella della Pavimentazione Comunitaria. Le differenze di budget previste per due priorità in pareggio è motivabile con il maggiore costo 'vivo' sugli investimenti delle opere di pavimentazione (rispetto alle altre, in cui una parte dei progetti grava sulle spese di personale) e con il loro essere vincolate ad una contropartita di fondi esterni del BID.

${ }^{46} \mathrm{Nel} 2001$, sono stati 5516 i contatti con la pagina web del Comune destinata ad accogliere suggerimenti e proposte di opere e servizi, di cui ne sono stati formalizzati 380 (cfr. Genro in PI 2002, p. 5).

${ }^{47}$ Ad esempio in Consiglio Comunale (dove la Proposta di Bilancio presentata dall'Esecutivo e dal COP viene 'riaggiustata' a fine iter nel confronto con le opposizioni politiche) si richiede talora una risoluzione 'nell'immediato' di problemi di priorizzazione delle azioni, gestita dai COPs e non in grado di tornare per consultazione alle Assemblee 
Plenarie con tutta la cittadinanza.

${ }^{48} \mathrm{La}$ 'triade' corrisponde ai primi ambiti di intervento della tabella in cui lo studioso britannico Alan Norton (1994) ha riassunto le 16 funzioni che ricorrono con regolarità tra i compiti dei governi locali dei Paesi europei (pp 64-66).

${ }^{49}$ Non è un caso la reiterazione di domande per la collocazione di istituti superiori anche nelle periferie, come incentivo a non abbandonare gli studi per i giovani meno abbienti.

${ }^{50}$ Nel PI del '97 compaiono tabelle di raffronto che rilevano anche le gerarchie di priorità votate a scala regionale.

${ }^{51}$ Questa nel '97 si distingue per essere l'unica Regione ad indicare la voce 'attrezzature sportive' fra le 4 priorità principali, e nel '99 è l'unica ad avere tra le prime 5 lo 'sviluppo economico' e ad ottenere l'attivazione di un deposito frigorifero di pesce a favore dei pescatori dell'isola della Pintada, la più attiva e dinamica del piccolo arcipelago fino ad allora penalizzato in ogni richiesta dalla presenza dei vincoli del Parco Naturale Statale. ${ }_{52}$ La tematica dello Sviluppo Economico è stata (fin dal 1991) al centro delle sue richieste, ottenendo il primo contributo diretto della SMIC ad una regione (se si escludono quello per la riorganizzazione degli ambulanti nel centro ed uno piccolo alla regione Lomba do Pinheiro per il Centro Dimostrativo di Agricoltura Alternativa); la ragione risiede originariamente nella realizzazione del progetto lungamente accarezzato di costruzione di un Distretto Industriale e di un Parco Tecnologico, che con la sua approvazione innescherà un'interessante serie di meccanismi di autorganizzazione economica e impresariale, oltre alla nascita delle prime lotte ambientaliste di matrice popolare contro la ventilata installazione di industrie inquinanti. Vera città nella città (anzi, fuori dalla città), la Restinga ha condotto prima una lotta per essere integrata nel sistema trasportistico cittadino, e - ottenuti parzialmente tra l' '89 e il '90 i risultati voluti - dal '91 ha priorizzare altri temi, evidenziando una forte capacità organizzativa che ha reso le priorità distribuite nel tempo 'per blocchi tematici', con forte impegno in alcuni ambiti e capacità di proseguire autonomamente l'organizzazione una volta ottenuto l'innesco dei primi benefici richiesti, per passare poi a sollecitare interventi in altri campi. Nel settore dell'abitazione è stata una delle poche regioni a non insistere con il DEMHAB per la costruzione di alloggi o la regolarizzazione fondiaria. Situata in un'area con disponibilità di terreni da acquistare, e abituata ad una lunga tradizione di pianificazione tecnocratica in blocchi condominiali anonimi sul modello $\mathrm{BNH}$, la Restinga ha scelto la via del 'poco e subito', e quella dell'autorganizzazione degli spazi abitativi. Sfruttando l'ampio ventaglio di possibilità diverse in cui dal 1989 si andava riorganizzando la Politica della Casa, nel 1991 e nel 1992 si è fatta finanziare 'embrioni' e 'lotti urbanizzati' tipo Sites-and-Services (a cui se ne sono aggiunti 200 nuovi nel 1995, 93 nel 1997 e poi altri nel 1998), riorganizzando gran parte della distesa di baracche di Vila Esperança senza attendere i tempi lunghissimi e penalizzanti che le poche forze del DEMHAB hanno richiesto altrove per l'organizzazione di nuovi insediamenti o la regolarizzazione fondiaria di quelli esistenti. Dal '94, quindi, la Regolarizzazione Fondiaria non ha costituito più sistematicamente una delle grandi priorità della regione, che è andata riorganizzandosi intorno ai due poli della Restinga Vecchia e del Nuovo Distretto Industriale (di cui oggi sono in vendita i primi lotti del Parco Tecnologico), richiedendo la costruzione di scuole e la pavimentazione graduale del tessuto viario alla base della nuova strutturazione, e la sua messa in sicurezza per i pedoni nei tratti a traffico più intenso (nel 1996). Dal 1997 - passati i temi del Distretto Industriale al vaglio delle Tematiche dello Sviluppo Economico e finanziate nella categorie di opere a beneficio di 'tutta la città' - l'agglomerato si è organizzato per l'espansione richiamata dalle nuove potenzialità economiche. La pavimentazione e l'illuminazione dei nuovi percorsi strutturanti è apparsa prioritaria (1362 i metri di pavimentazione finanziati nel 1997, 1335 nel 1998 e 1080 nel 1999), mentre si è iniziata la regolarizzazione di nuclei stabilitisi in modo informale. Dalle assemblee di preparazione per il PI 2000 è emersa anche una nuova serie di richieste nei settori dell'educazione e della cultura (94 erano già nel 1991 le Associazioni culturali, assistenziali e sportive della regione, riunite nel Consiglio di Sviluppo Comunitario della Restinga) e soprattutto per finanziamenti mirati ad appoggiare microimprese e incubatrici autorganizzatesi a partire dalla propositività di alcuni abitanti della regione. Lo spazio dedicato alla Restinga sul totale degli interventi 'regionali' annualmente finanziati dal Comune è piuttosto ristretto; il che (visto che nonostante la partecipazione altalenante nell'O.P. la Restinga è rappresentata da un alto numero di delegati) è un segno indiscutibile sia di capacità dei suoi rappresentanti 
dell'OP di portare avanti gli interessi dei loro corregionali ricorrendo a fondi diversi, sia di maturità e solidarietà al momento di confrontarsi con le altre regioni nel decidere i finanziamenti più urgenti da approvare

${ }^{53}$ La Regione Noroeste è nata nel 1995 da una costola dell'Eixo Baltazar, a causa di dissapori tra l'area nordovest abitata da classe media e medio-bassa e le zone più povere della Regione. In tale ottica si spiegano le particolari priorità proposte dai suoi abitanti come principali, spesso lontane da quelle ritenute più 'urgenti' dalla popolazione più povera. Nel 1997 (anno consacrato da quasi tutte le regioni alla pavimentazione stradale), la popolazione della neonata regione ha identificato come seconda priorità la riorganizzazione di 4 piazze con installazione di attrezzature per lo sport e il gioco che potessero trasformarle in veri spazi urbani. Nel 2000, la Regione ha priorizzate al secondo poste la Salute (e al $5^{\circ}$ le aree per il tempo libero), così come nel 2001 (quando al $3^{\circ}$ posto è passato lo Sviluppo Economico), mentre nel 2002 le Aree per il Tempo libero sono balzate nuovamente al $2^{\circ}$ posto.

${ }^{54} \mathrm{Nel} \mathrm{1997,} \mathrm{la} \mathrm{Nordeste} \mathrm{ha} \mathrm{messo} \mathrm{messo} \mathrm{al} \mathrm{primo} \mathrm{posto} \mathrm{l'educazione,} \mathrm{ottenendo} \mathrm{la}$ costruzione di una grande scuola completa dal $1^{\circ}$ all' $8^{\circ}$ grado per tentare di minimizzare l'abbandono scolastico che di solito consegue alla frammentazione spaziale dei blocchi di classi (dalla $1^{\circ}$ alla $5^{\circ}$ e dalla $6^{\circ}$ all' $8^{\circ}$ ) nell'estesa favela Chacara da Fumaça. Del resto, la stessa regione sarà l'unica nel 1998 (anno in cui si riscontra una crescita dei servizi educativi e sanitari un po' in tutta la città) a richiedere come terza priorità il miglioramento dei servizi di Assistenza sociale della FESC (così come nel 2001) e di quelli sanitari nel settore della famiglia, in particolare per il quartiere 'disastrato' di Vila Safira. Nel 2002 la richiesta di Servizi Educativi si ripresenta al $2^{\circ}$ posto.

${ }^{55}$ Nella regione, abitata in prevalenza da classe media, l'ordine delle priorità rispetto alla media cittadina è sempre risultato 'fuori dal coro', così come la stessa organizzazione delle prime assemblee del Bilancio Partecipativo realizzate sul tema del 'ruolo dell'individuo nella storia' (cfr. Andreatta, 1997), che hanno condotto solo in secondo tempo alla nascita di nuovi leader comunitari e ad una forma di aggregazione solidale che ha permesso la ricostruzione in loco delle favelas Vila Planetario, Vila Renascença, Vila das Placas, Vila Lupicinio e - prossimamente - Vila Zero Hora. La Regione Centro ha seguito un percorso opposto a molte altre. Anche tenendo conto del fatto che la ricostruzione di edifici storici ed emergenze monumentali era prevista nella categoria sovraregionale 'tutta la città' e fino all'organizzarsi al suo interno delle comunità più povere, essa ha privilegiato priorità poco valutate in periferia come 'l' organizzazione della città', i trasporti e la cultura, proponendo miglioramenti soprattutto nei modi di usufruire del centro cittadino. Ne sono esempi la riorganizzazione degli ambulanti, il Progetto Convivio, l'illuminazione e le linee di autobus notturne, il recupero ambientale di una piccola via popolare della Cidade Baixa nel 1991 (la Travessa dos Venezianos). Progressivamente, molti interventi e programmi di rivitalizzazione e animazione del nucleo storico urbano sono migrati - specie grazie alle Assemblee Tematiche - verso la categoria sovraregionale tutta la città, permettendo a questa regione di distinguersi nel novero della città per la priorizzazione in controtendenza di alcuni temi, come quello culturale, indicato al secondo posto nel 1997, al quarto nel '98 e '99 (in quest'ultimo con riferimento al decentramento culturale) e al $3^{\circ}$ nel 2000. O come lo Sviluppo Economico, nel 98 al terzo posto con la riforma del mercato di Bom Fim e dei punti di vendita coperti di altre piazze, ancora $3^{\circ}$ nel 2000 nel 2001 e $5^{\circ}$ nel 2002. Il Centro è stata anche l'unica regione - nel ' 97 - a presentare come quarta priorità l'Assistenza Sociale (facendo da apripista a molte altre), riconfermata nel 1999 con particolare attenzione ai Gruppi di assistenza per la famiglia.

56 "Il rapido trasformarsi (a cavallo del 1996) di alcune opere di manutenzione in vere e proprie ricostruzioni ex-novo, ha richiesto ai tecnici della SMOV e dei Dipartimenti che agivano di concerto con essa di correre rapidamente ai ripari. In primo luogo, questo ha reso necessario ridirezionare le stesse richieste di pavimentazione fatte dalla popolazione nel Bilancio Partecipativo, spiegando perché l'asfalto sulla lunga durata non in tutti i casi era da consigliarsi, seppur apparentemente costava meno e quindi rendeva possibile evadere subito un numero maggiore di richieste di intervento" (Real, 1999i, in Allegretti 2000a).

${ }^{57}$ Cfr. Relatorio dos Indicadores Sociais de Porto Alegre, 2001. 
Fig. 35 - Come mostrano gli studi di Marquetti (in Avritzer e Navarro, 2003), il Bilancio Partecipativo di Porto Alegre si è dimostrato, in questi anni, un importante strumento di giustizia distributiva. La presenza di criteri di allocazione delle risorse che tutelano i più deboli, pur dando forte valore alle scelte dei cittadini realizzate nelle assemblee pubbliche, ha fatto sì che la maggioranza degli investimenti sia stata compiuta nelle regioni cittadine più povere.

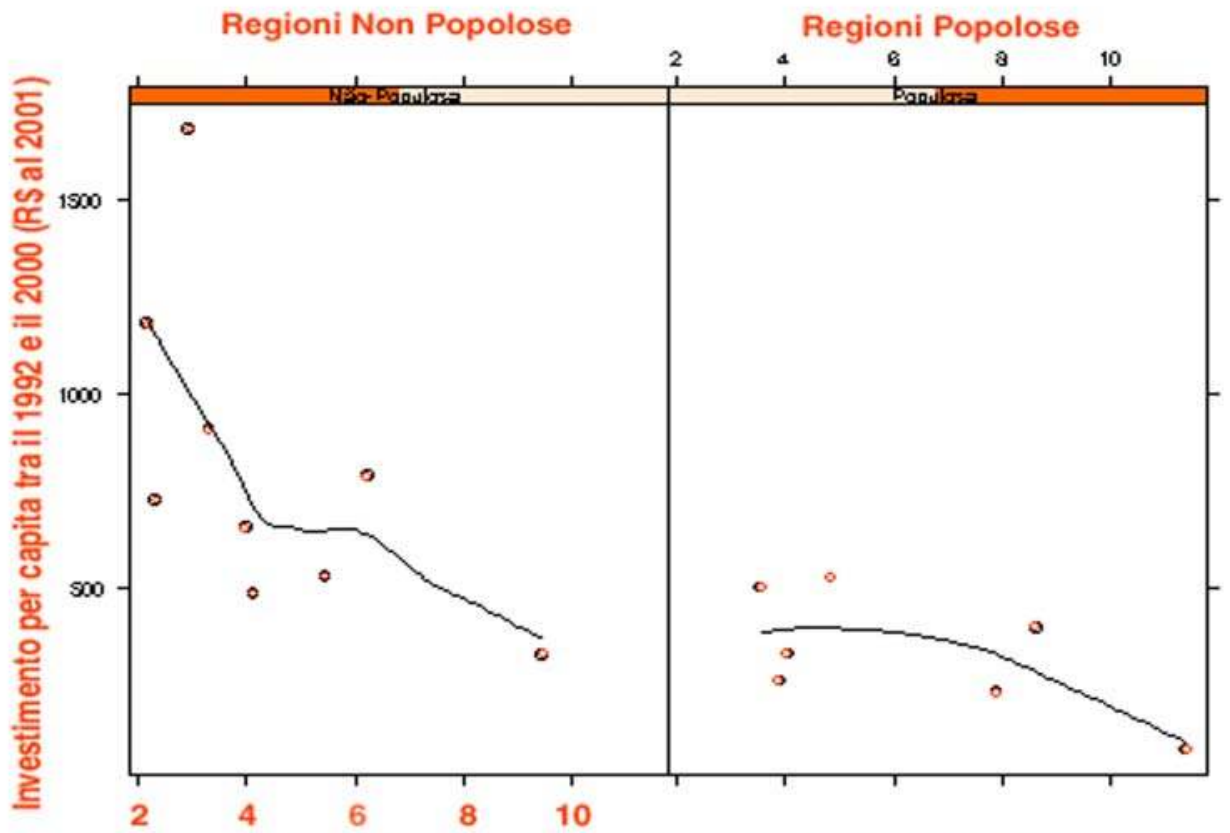

Rendimento nominale medio del capofamiglia (in Salari Minimi)

I grafici evidenziano come le curve degli investimenti seguano da vicino la distribuzione delle aree cittadine abitate da una popolazione tradizionalmente più svantaggiata, mentre la proporzionalità con le aree più popolose (se considerate indipendentemente dalla situazione sociale media degli abitanti) risulta 'attenuata'.
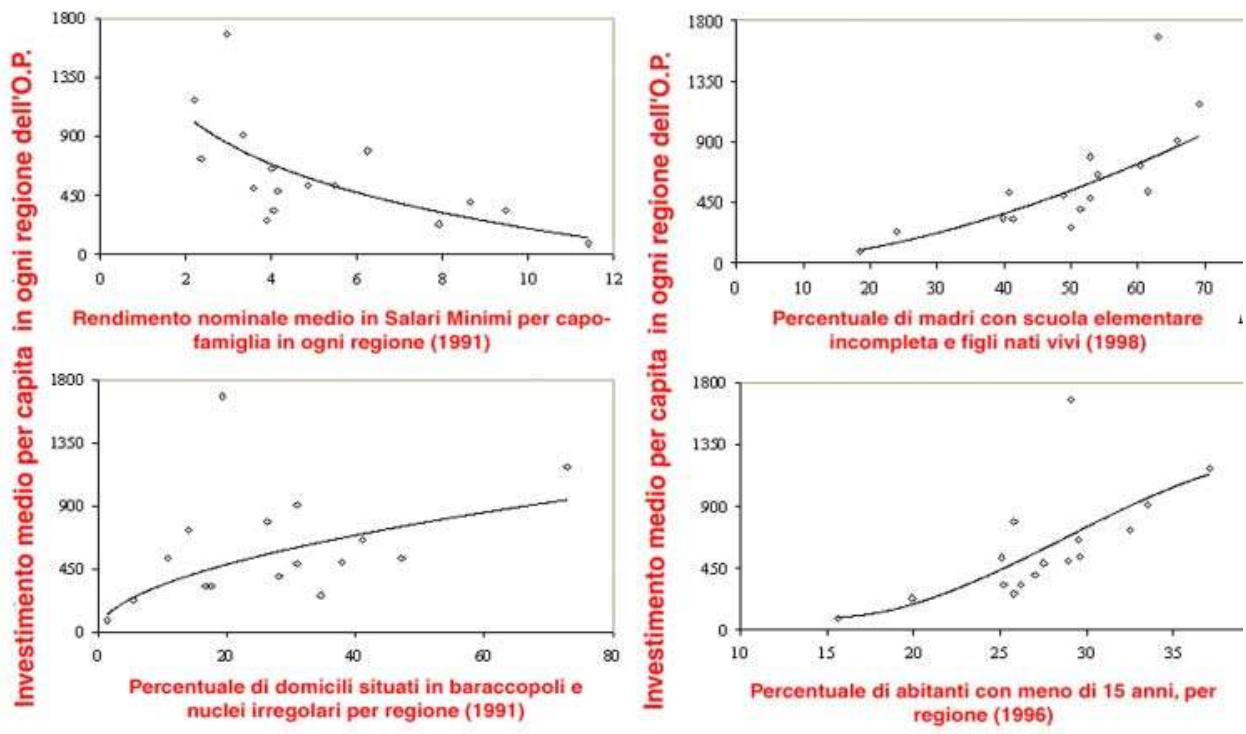
Fig. 36 - Dal 2001 è possibile intervenire nel processo di Bilancio Partecipativo anche via Internet, con dei suggerimenti. La partecipazione ai momenti deliberativi è però riservata a chi si fa presente nelle assemblee.

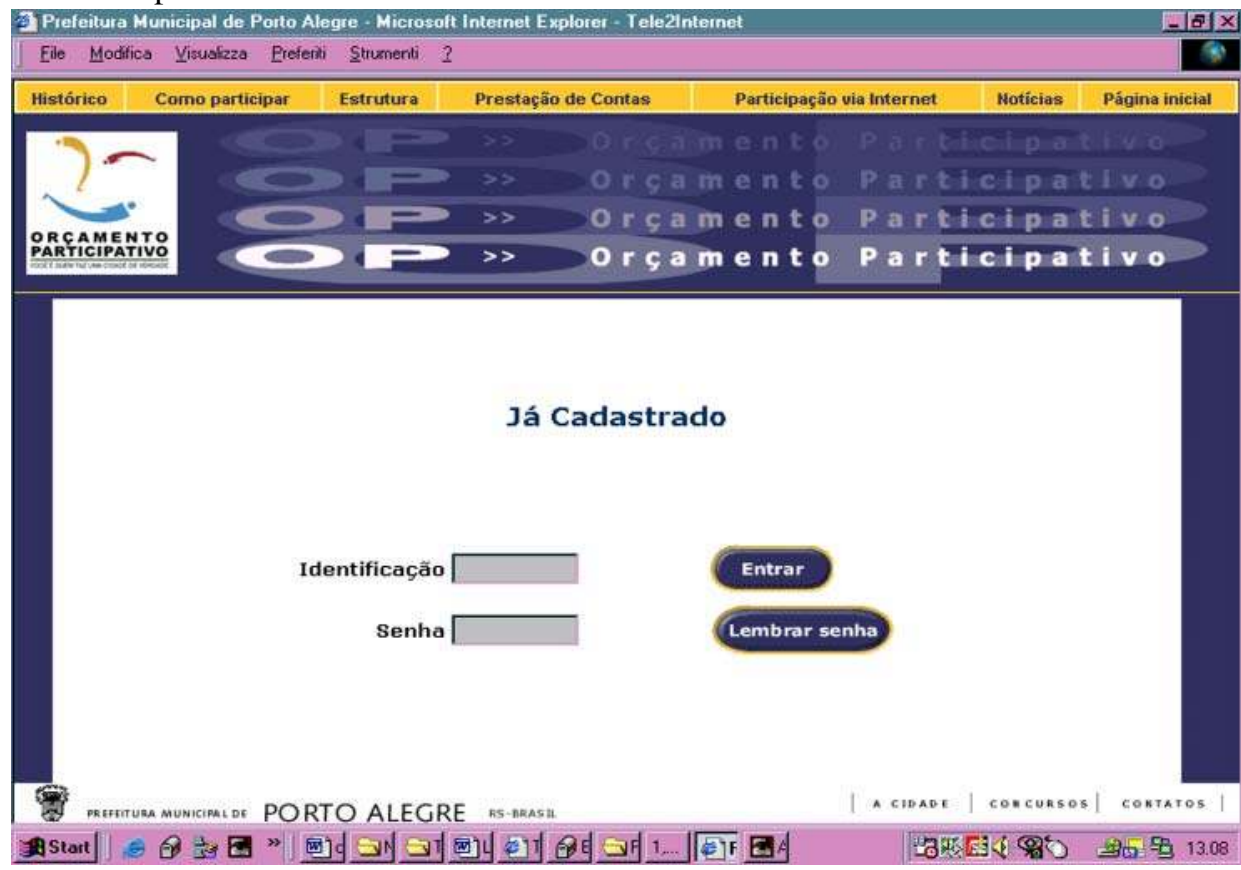

Inoltre, a Internet è demandato un ruolo centrale nel controllo dell'esecuzione delle opere decise attraverso il Bilancio Partecipativo. In particolare, attraverso varie chiavi di ricerca (per zona, per tema, per data, per assessorato di competenza, ecc.) è possibile controllare quasi in tempo reale tutte le opere previste dai Piani di Investimento del Comune dal 1990 ad oggi, e il loro stato di realizzazione.

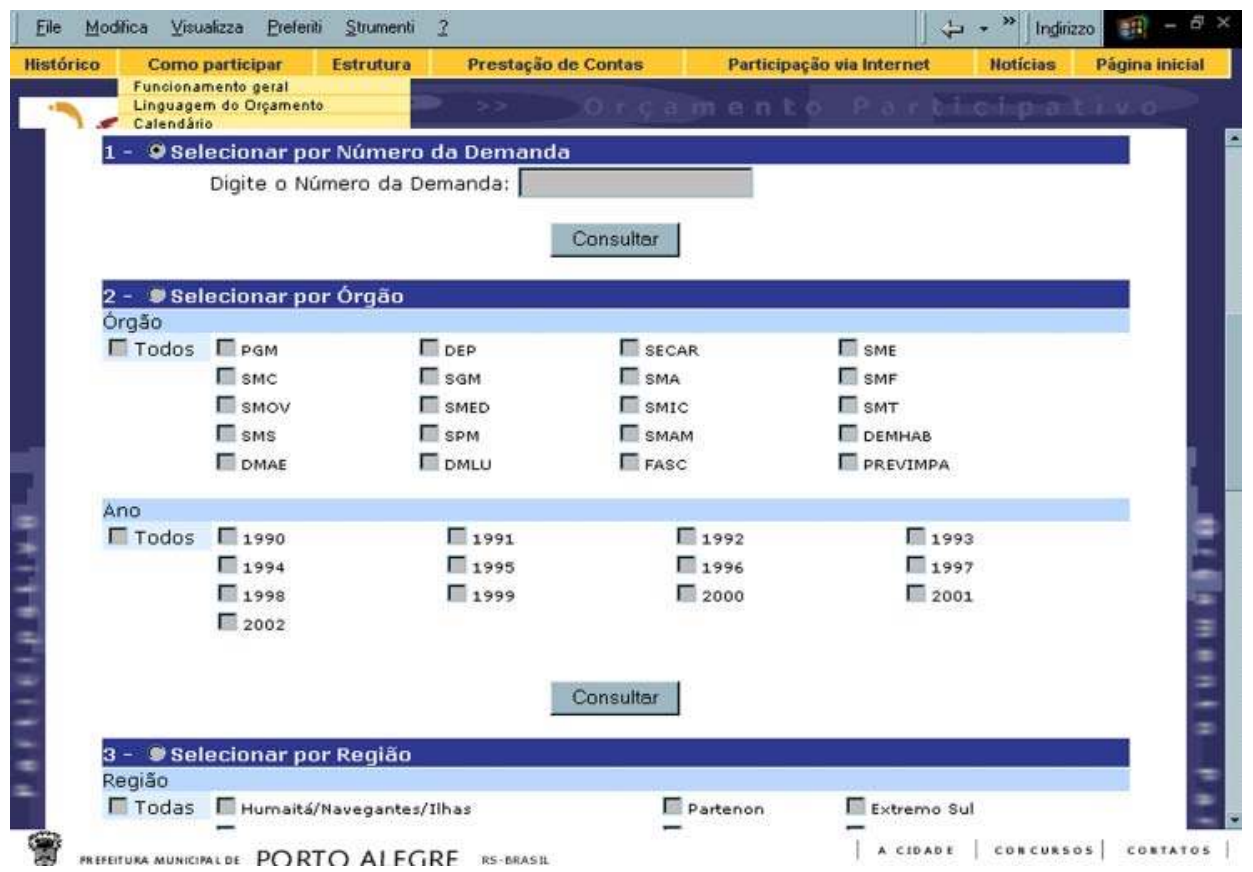


Fig. 37 - Esempio di una ricerca via Internet sullo stato di esecuzione delle opere previste dal Piano degli Investimenti 2002.

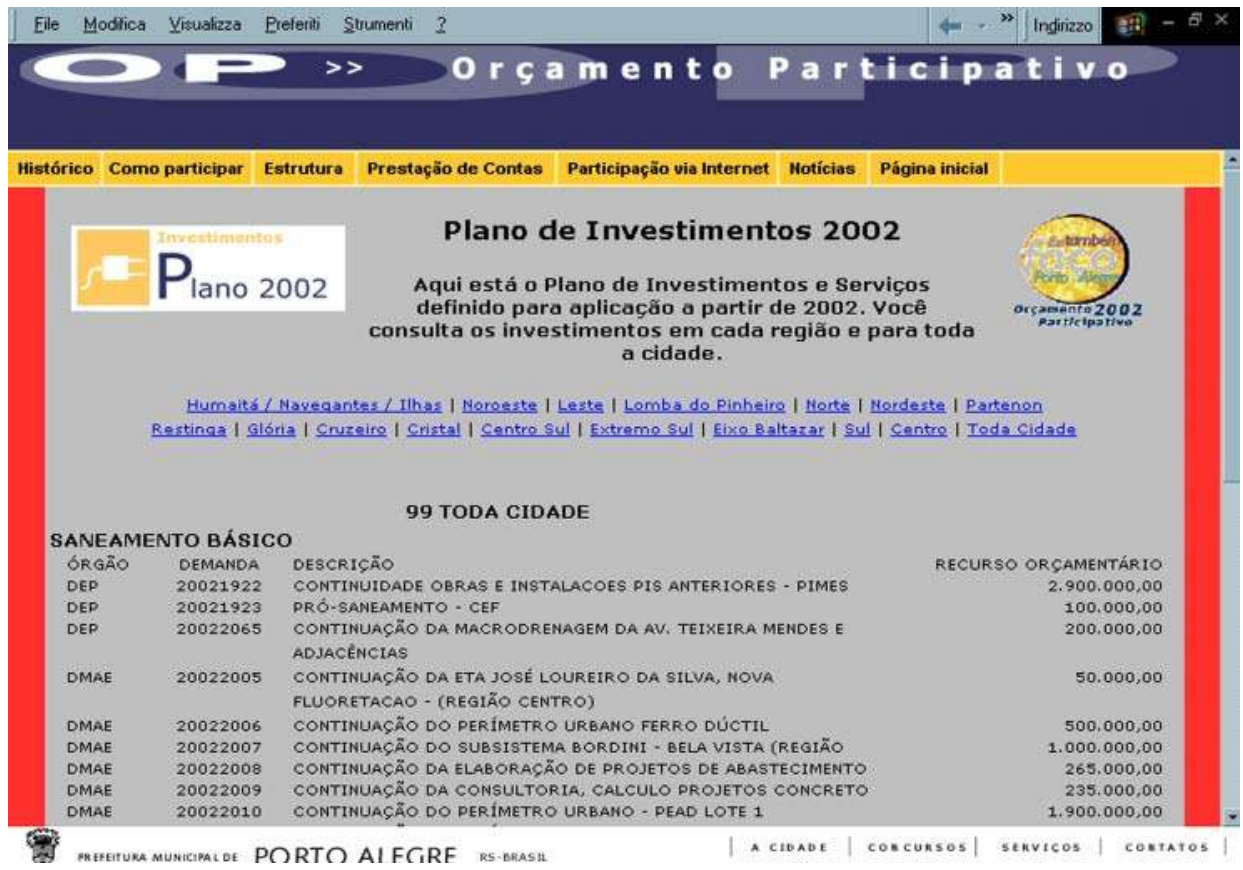

Il grafico sottostante rileva lo stato di avanzamento delle opere approvate nei Piani di Investimento (Assemblee Regionali + Tematiche) dal 1990 ad oggi, divise per assessorato di competenza (al 31/12/2002).

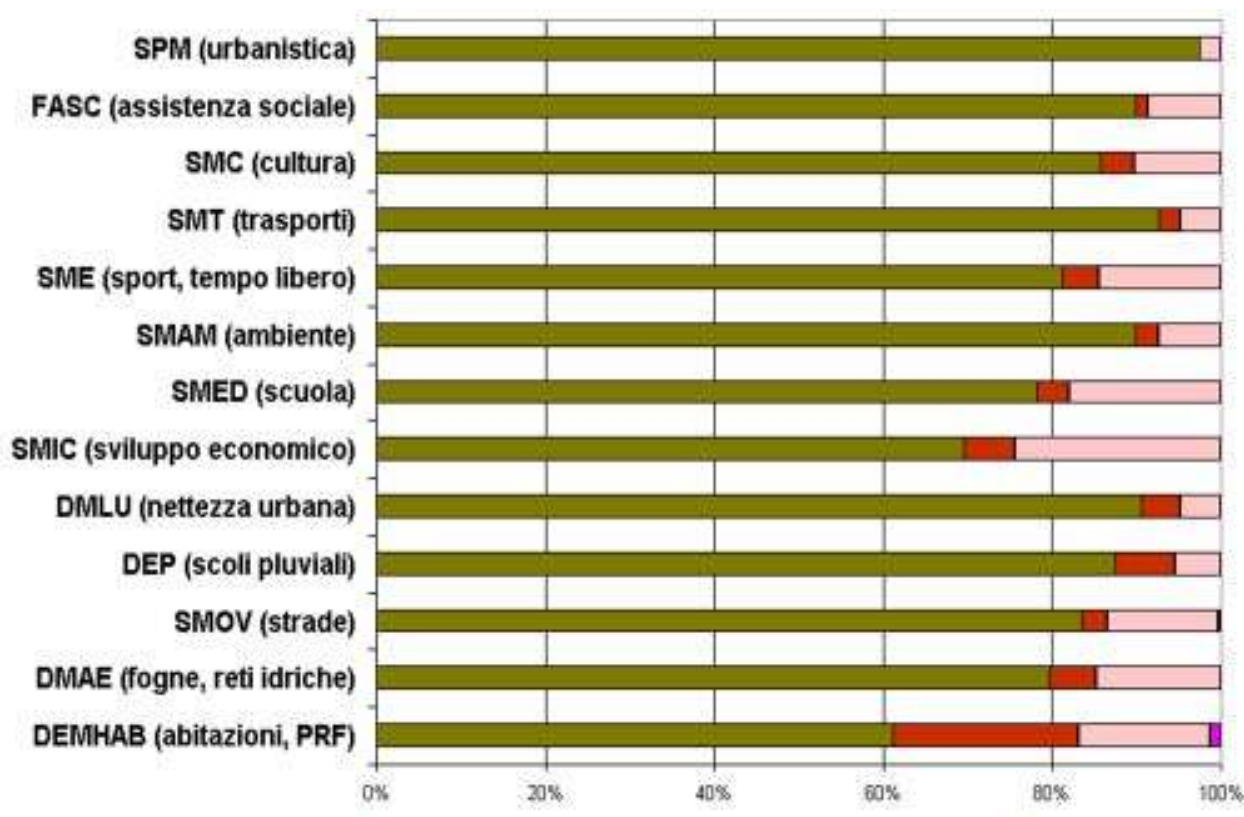


Fig. 38 - Il grafico sottostante evidenzia i diversi stati di avanzamento delle opere approvate nei Piani di Investimento dal 1990 ad oggi per tutte quante le Assemblee Tematiche del Bilancio Partecipativo (al 31/12/2002).

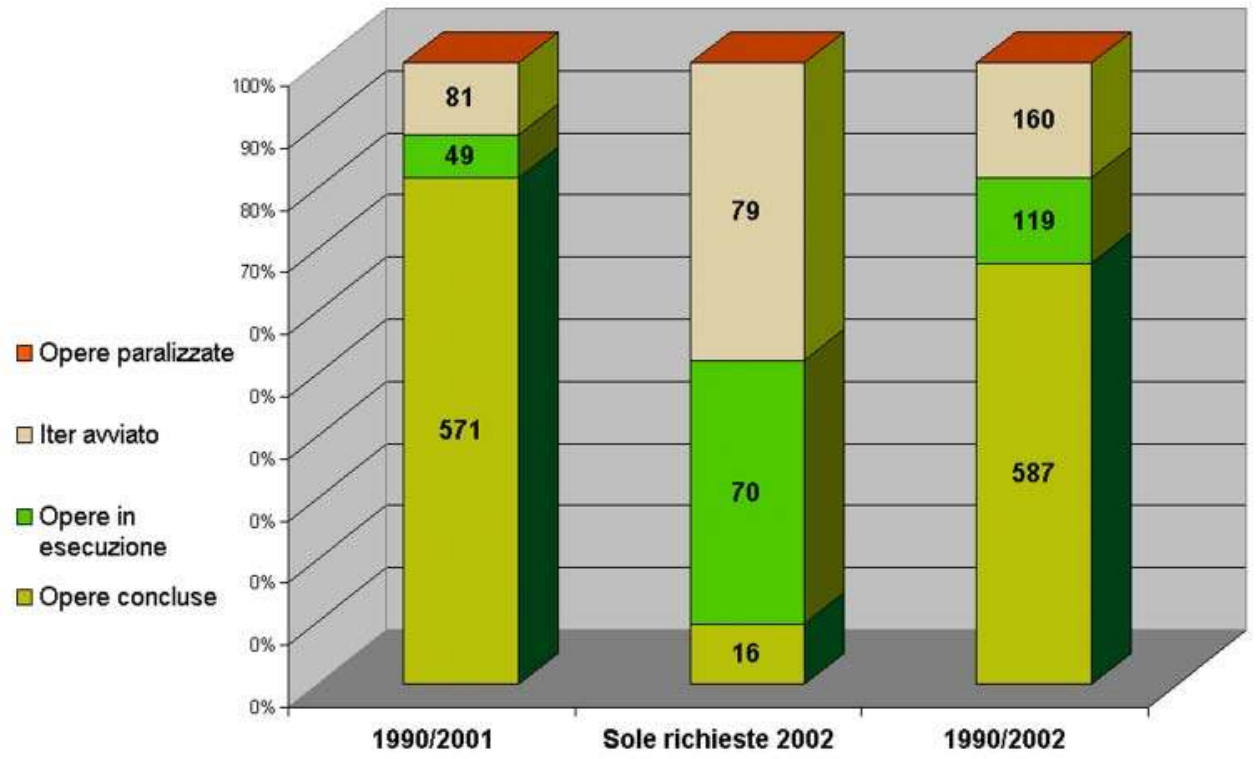

Fig. 39 - Il grafico sottostante evidenzia i diversi stati di avanzamento delle opere approvate nei Piani di Investimento dal 1990 ad oggi per tutte quante le Regioni cittadine del Bilancio Partecipativo (al 31/12/2002).

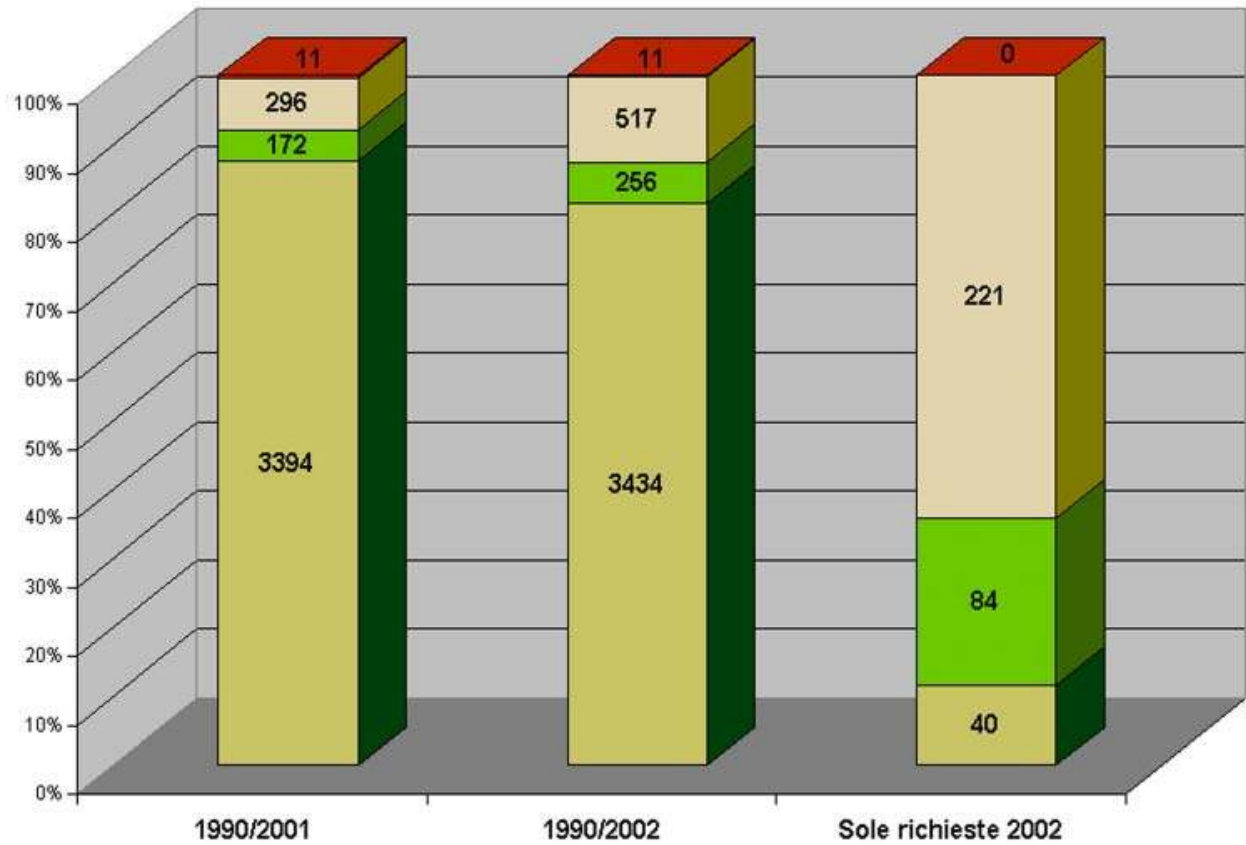


Fig. 40 - Variazione nel tempo delle percentuali degli investimenti sul totale delle spese comunali

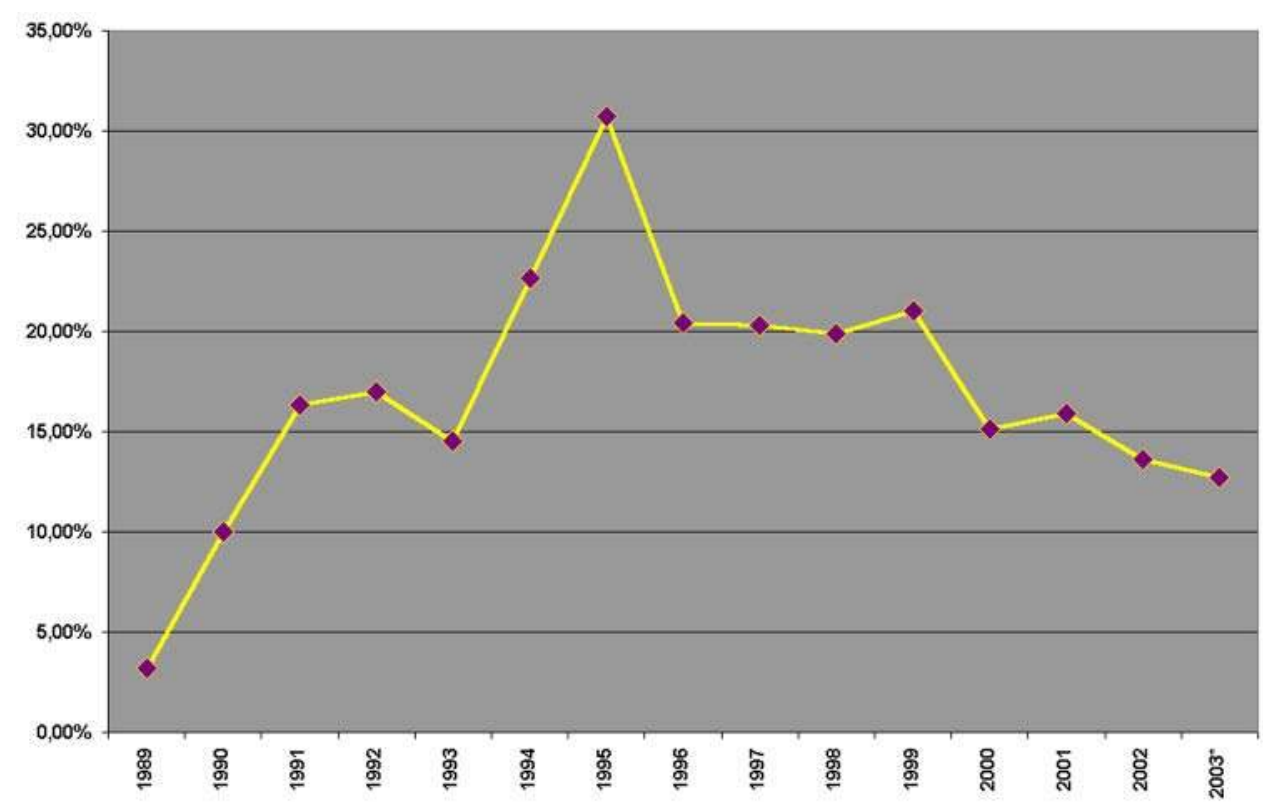

Dati: PI 1989-2002

* Stima GAPLAN, in OP-Assembleia Municipal 2002 (1/7/02)

Fig. 41 - Variazione degli investimenti per unità ammministrative di riferimento (Valori indicizzati al 31-12-2000)

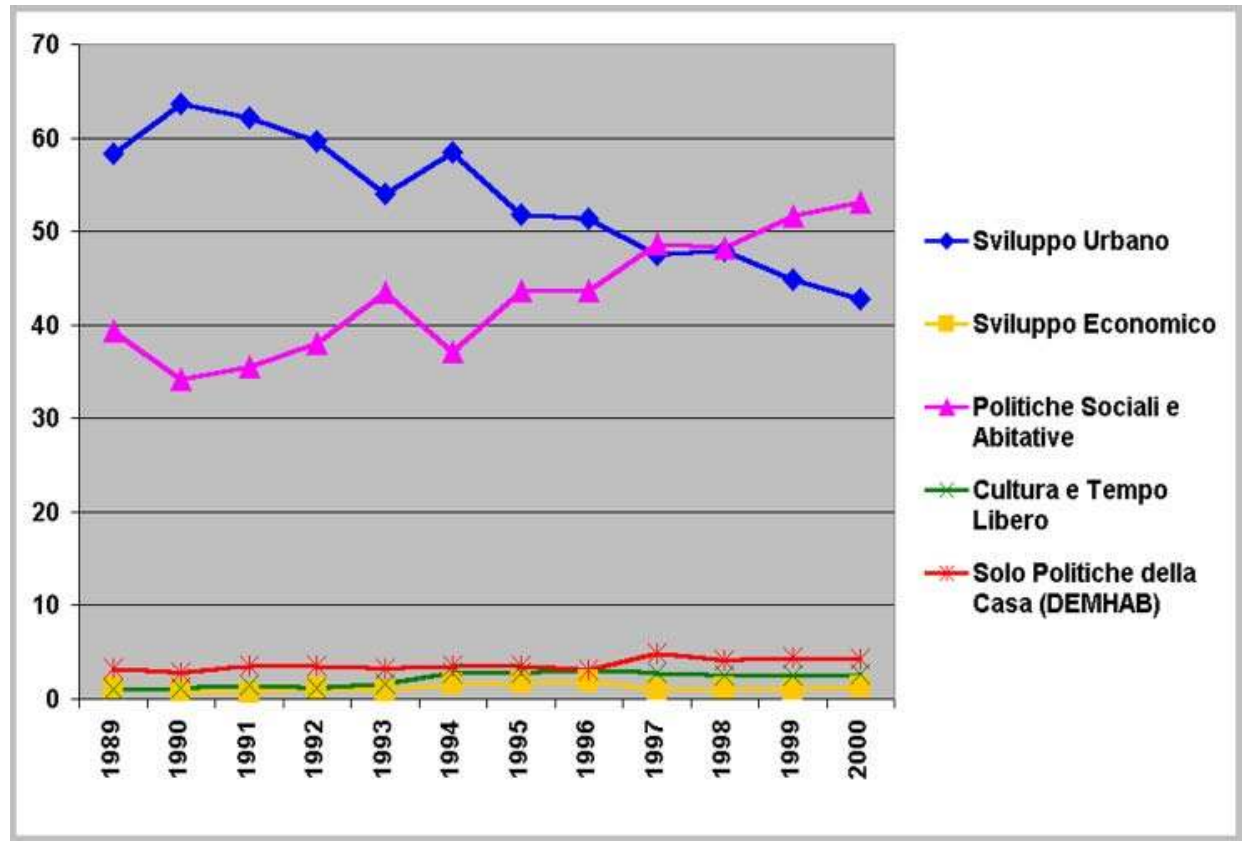


Fig. 42 - Aumento degli investimenti nel solo settore dell'urbanizzazione primaria nel primo biennio di governo dell'Amministrazione Popolare di Porto Alegre (Dati: Plano de Investimentos, 1992)

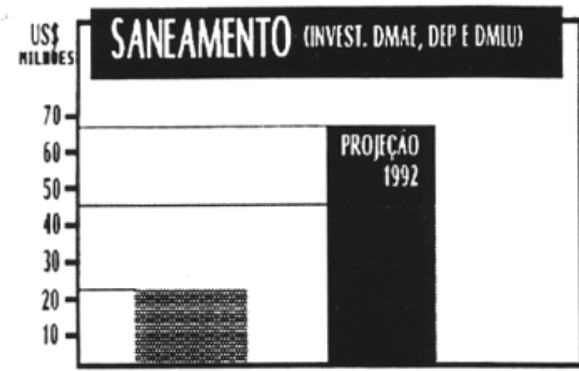

Adn. Anterior (86-88) Adm. Popular (1989-91)

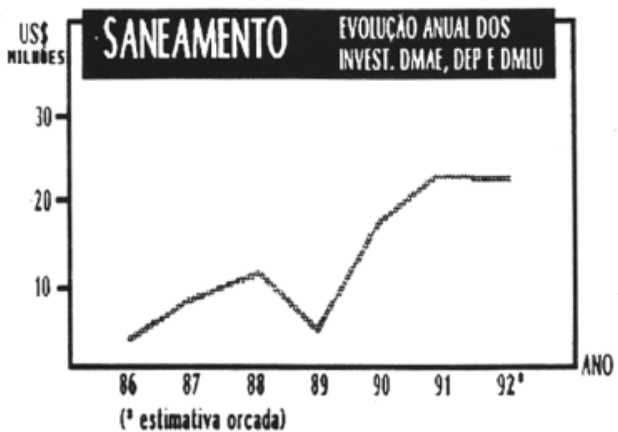

Fig. 43- Dato il progressivo calo delle risorse destinate ai Comuni in Brasile (evidente dal primo grafico), il Bilancio Partecipativo, per nutrirsi, necessita di un costante impegno delle Amministrazioni per mantenere un livello costante ed elevato di risorse da destinare agli investimenti (spese in conto capitale). Nel secondo grafico è rappresentata la costante crescita (in valori indicizzati al 1/7/2001) delle entrate a Porto Alegre, evidenziando la componente dovuta ad entrate proprie, ovvero non frutto di trasferimenti da enti di livello superiore.
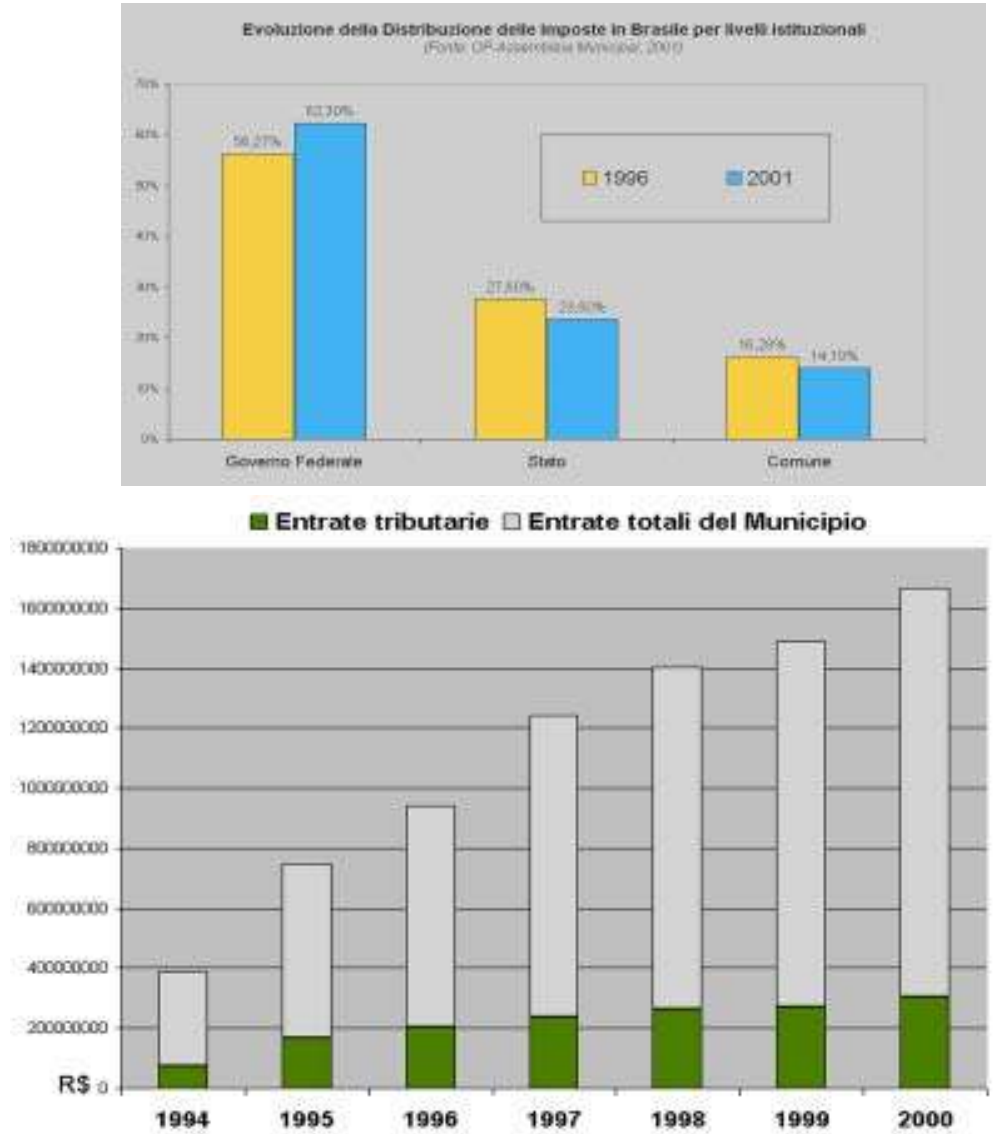

Dati: SMF, Comune di Porto Alegre, 2001 
Sezione Terza

\section{I dialogo tra città formale e città spontanea}





\section{1 \\ Città autocostruita e istituzioni verso il riconoscimento reciproco}

\subsection{La Porto Alegre informale oggi; dalla conoscenza al riconoscimento}

Come accennato nel cap.5, neppure a Porto Alegre la Banca Nazionale dell'Abitazione, nei suoi 22 anni di vita, ottenne effetti significativi sulla riduzione del deficit abitativo. Essa svolse, però, un ruolo decisivo nell'incidere sull'immaginario collettivo, accreditando la concezione della 'casa propria' come l'unica possibile soluzione al problema dell'abitare, visto che su questa opzione tese a concentrarsi tutta l'azione istituzionale, anche attraverso l'elargizione di sussidi che facilitassero le condizioni di finanziamento.

Quest'immaginario indotto offrì, in tutto il Brasile, un cospicuo contributo all'aumento dello spontaneismo e dell'informalità abitativa, sommandosi agli aumenti di costi dei suoli urbani determinati dal trasformarsi degli orientamenti del Sistema Finanziario dell'Abitazione (SFH) in direzione di una stretta collaborazione col settore privato e agli effetti della Legge Federale 6766/79 sul Parcellamento dei suoli. Essa - prevedendo forti sanzioni per chi violasse norme, standard e procedure - ebbe l'effetto ${ }^{1}$ di ridurre per un certo periodo (almeno finché ci si rese conto che non sarebbe mai stata applicata) l'attività dei promotori di suddivisioni irregolari di lotti, ottenendo come risultato la diminuzione dell'offerta di terreni urbani e quindi l'istaurarsi di nuovi meccanismi di valorizzazione fondiaria e di contemporaneo aggravamento della 'segregazione urbana', accompagnato dall'esplosione del fenomeno delle occupazioni collettive di terreni, soprattutto pubblici. La situazione fu aggravata in ambito locale dalle leggi comunali ${ }^{2}$ che - negli stessi anni - istituirono in varie città Piani Regolatori con standard di infrastrutturazione urbana così alti che associati agli alti costi dei terreni determinati dalla congiuntura nazionale bloccarono in pratica tutta la produzione privata di lotti per la popolazione a basso reddito, arenando persino quella promossa dagli stessi Comuni.

Porto Alegre non fa eccezione a questo quadro. Lo 'stallo' generatosi dopo l'approvazione del Piano Regolatore del 1979 - culminato nella grande ondata di invasioni bianche del 1987 (cfr. box 3) - obbligò l'amministrazione Collares - eletta nelle prime elezioni libere del 1985 - a varare in poco tempo 
332 una cospicua riforma dello strumento urbanistico e a promuovere la creazione di uno stock di lotti urbanizzati per popolazione con basso reddito attraverso lo strumento della Banca delle Terre (cfr. § 14.4.2). Gli effetti ottenuti sulla riduzione del disagio abitativo furono comunque poco visibili, anche perché la variante urbanistica adottata si impiantò su censimenti vecchi e sottostimati, e su un'ottica di approccio alla città informale altamente deficitaria, rivelatasi poco interessata alla precisa conoscenza in termini 'qualitativi' della situazione reale in cui versava la popolazione delle numerose aree cittadine autocostruite.

Con questa situazione si trovò a fare i conti nel 1989 l'Amministrazione Popolare, alla sua entrata in carica alla guida del Comune. Le prime valutazioni parziali condotte sul tema della segregazione urbana, all'inizio degli anni '90, rivelarono una situazione dove i 100 maggiori proprietari terrieri (rappresentanti appena lo 0,69\% del totale) detenevano quasi il 50\% dei terreni non occupati, un terzo dei quali nelle mani di imprese immobiliari (Pozzobon, 1998, p. 8). Nel 1989, l'Assessorato all'Urbanistica valutò che il $18,65 \%$ dell'area propriamente urbana (3.766 ettari) era ancora costituita da vuoti sparsi, che gli interventi di ampliamento dei servizi pubblici rischiavano di valorizzare a vantaggio dei privati e a detrimento della collettività, specie di quei segmenti in difficoltà costretti - per giunta - ad affrontare $\mathrm{i}$ disagi determinati dall'aumento delle distanze e in molti casi a pagare direttamente i costi della valorizzazione di quegli investimenti privati.

In parallelo a queste indagini quantitative, si cominciarono a studiare con maggiore profondità - grazie anche alla collaborazione della Fondazione di Economia e Statistica (FEE) e di alcune Università cittadine - gli effetti segregativi conseguenti alla neutralità apparente (PMPA/SPM, 1996) ${ }^{3}$ della legislazione urbanistica di ambito locale e il loro contributo alla creazione di sub-cittadinanze in aree informali e alla diffusione di un modello di occupazione residenziale basato "sulla periferizzazione (gerarchicamente ordinata per grado minore di informalità), sulla polarizzazione e sulla femminilizzazione delle povertà" (Alfonsin, 2001i-I). Mentre, infatti, le classi medie e alte non avevano avuto problemi insormontabili a pagare i costi richiesti dalla normativa urbanistica per il 'miglioramento della qualità di vita', le altre categorie si erano dovute rivolgere alla cosiddetta 'produzione sociale' delle abitazioni, in un processo inarrestabile di frammentazione anarchica dell'espansione urbana e di espulsione degli 'insediamenti autoprodotti' (così come a Porto Alegre sono chiamati dal Piano Regolatore vigente) e dei parcellamenti irregolari verso i limiti comunali e l'area metropolitana. In particolare, nelle prime indagini svolte dall'Amministrazione Popolare, si cercò di valutare le conseguenze sull'ambiente costruito e naturale di un'occupazione predatoria che costituiva la naturale contropartita (dominata dal lavorio sotterraneo di piccoli e medi 'incorporatori' e dall'occupazione spontanea) del mercato restrittivo dell'abitazione e dei suoli (Pozzobon, 1998).

Il Comune di Porto Alegre arrivò così a disegnare una situazione in cui si stimava che circa il $32 \%$ della popolazione con reddito mensile familiare fino a 5 salari minimi era costretta a restare esclusa dal mercato formale dell'alloggio, e in cui nell'ultimo quindicennio i cosiddetti 'insediamenti autoprodotti' erano giunti a 215 , dando accoglienza a 50.911 abitazioni e a oltre 196.000 abitanti (il 15,5\% della popolazione cittadina), senza contare 
le altre numerose forme di abitazione irregolare esistenti in città (PMPA/SPM, 1995). Parimenti fu rilevato che 92 aree verdi previste nel PRG del ' 79 risultavano occupate, e che quasi 5.000 famiglie vivevano in area di rischio (Pozzobon, 1998). L'aspetto più preoccupante che emerse dai primi studi fu che, paragonando i tassi di crescita annuale di Porto Alegre con quelli degli insediamenti autocostruiti, i secondi continuavano a restare doppi dei primi, seppur in calo rispetto agli interregni fra le precedenti ricerche sviluppate, come la tabella qui sotto evidenzia.

\section{Confronto fra i tassi di crescita della popolazione di Porto Alegre e quelli delle sue aree informali (Dati PMPA-SPM, 1995)}

\begin{tabular}{|c|c|c|}
\hline \multirow{2}{*}{ Lasso di tempo } & \multicolumn{2}{|c|}{ Tasso geometrico di crescita della popolazione (\%) } \\
\cline { 2 - 3 } & Porto Alegre & Insediamenti autoprodotti \\
\hline $\mathbf{1 9 6 5 / 7 2}$ & 3,4 & 7,1 \\
\hline $\mathbf{1 9 7 2 / 8 1}$ & 1,9 & 5,5 \\
\hline $\mathbf{1 9 8 1 / 9 5}$ & 1,06 & 2,1 \\
\hline
\end{tabular}

Fino al $1995,{ }^{4}$ le statistiche portate avanti sull'irregolarità nell'occupazione dei suoli restarono comunque disperse e incomplete, e si caratterizzarono per una frammentarietà dei dati e l'adozione di metodologie continuamente variate nella loro elaborazione, al punto da impedire qualsiasi comparazione significativa (Pozzobon, 1998, p. 10). Ad esempio, nell'inchiesta del 1981 gli insediamenti informali (che rappresentavano il 15,2\% del totale, di cui $69,9 \%$ parcellamenti clandestini per invasione, e $30,1 \%$ parcellamenti irregolari e clandestini) erano messi in rapporto alla zona di ubicazione: così $87,9 \%$ venivano a trovarsi in zona urbana intensiva, $2 \%$ in zona urbana estensiva e 3,3\% in area rurale, e $4,7 \%$ a metà fra le prime due. Nel 1995 furono invece usati criteri più articolati di definizione identificati in base ai promotori delle varie tipologie irregolari di costruzione della città (non solo parcellamenti ma anche condomini, quartieri occupati, viabilità e accessi clandestini) interpretando l'irregolarità come un concetto generale decorrente dall'esistenza di contrarietà al regolamento urbanistico legale nelle sue diverse manifestazioni. Pertanto, molti dati non risultarono confrontabili con ciò che era stato rilevato in passato, pur mantenendo in assoluto una loro espressività nel denunciare - ad esempio - l'esistenza di 246 parcellamenti irregolari prodotti dall'iniziativa privata, 215 'vilas' [insediamenti autoprodotti sulla base di occupazioni], ${ }^{5} 45$ lottizzazioni e condomini di promozione pubblica, cioè prioritariamente in aree del DEMHAB (PMPA/SPM, 1995).

Lo studio della SPM del 1995 ha costituito comunque una base di dati interessante per una migliore conoscenza del fenomeno dell'irregolarità urbana a Porto Alegre. Ad essa ha attinto anche la riformulazione del nuovo Piano Regolatore di Sviluppo Urbano e Ambientale approvato nel '99 (cfr. cap. 15), per la prima volta impiantato su una base di dati di recente elaborazione e quindi su una situazione molto più vicina del solito alla realtà in rapida 
334 trasformazione, nonostante il ricorso ad una cartografia non recentissima (Ribeiro Jordão, 1999i - I, apud Allegretti, 2000a).

A partire da quel documento, l'interesse dell'Amministrazione Popolare per la città informale è apparso in costante crescita, stimolato anche dal contatto quotidiano dei suoi livelli tecnici e politici con gli aspetti 'qualitativi' dell'universo della segregazione urbana: una prassi propiziata dai processi di discussione pubblica delle problematiche del territorio come il Bilancio Partecipativo. Per questo, dal 1996 il DEMHAB - che più di tutti gli altri organismi municipali lavora a contatto con i segmenti più poveri della popolazione (anzi, ormai quasi solo con loro) - ha commissionato alla propria Equipe di Ricerca Sociale un lavoro di aggiornamento dei dati sugli insediamenti autoprodotti, che non si limitasse a reperire dati 'tecnici', come il numero di abitazioni informali e la loro localizzazione, ma comprendesse anche alcuni aspetti storico-evolutivi dell'area. La ricerca si è poi trasformata in uno dei libri pubblicati dal Comune (con il nome di 'Mappa dell'irregolarità fondiaria di Porto Alegre') per avviare le celebrazioni dei 50 anni di vita del Dipartimento alla Casa (DEMHAB, 1999).

A dire il vero, la ricerca - realizzata da un'equipe di appena due sociologi e conclusa nel 1998 - lascia ancora scoperti molti aspetti relativi all'irregolarità urbana; ad esempio, il censimento socio-economico delle famiglie, la loro provenienza, la mobilità, il livello di consolidamento degli insediamenti restano dati solo saltuariamente posseduti dal DEMHAB e solo relativamente ad alcune delle aree dove ha attualmente in corso interventi pubblici di regolarizzazione fondiaria e urbanistica. ${ }^{6}$ Neppure il documento successivo sul tema, reso pubblico dal Consiglio Municipale per l'Accesso alla Terra e all'Abitazione in occasione della $\mathrm{II}^{\circ}$ Conferenza Municipale sulla Casa (luglio $2001),{ }^{7}$ costituisce in realtà una correzione di rotta, essendo piuttosto una riarticolazione per regioni del documento precedente del DEMHAB.

Riflessioni analoghe possono farsi sulla ricerca commissionata dall'Assessorato all'Urbanistica - nello stesso periodo - all'architetto Kelly Ribeiro Jordão, con l'obiettivo di produrre una mappa digitale che raccogliesse tutti i dati sull'irregolarità fondiaria a Porto Alegre, compresi i parcellamenti, non presi in considerazione dal DEMHAB (Ribeiro Jordão et al., 1999). Nello studio della Jordão sono state identificate 583 aree irregolari di cui 328 'parcellamenti irregolari' o 'clandestini' e 255 'vilas' di oltre 10 famiglie; è stato cioè incluso tutto l'universo dell'irregolarità (eccetto i nuclei con meno di 10 famiglie), comprese le aree legalizzande ma le cui pratiche non sono state ancora espletate in toto dal DEMHAB o dai propri abitanti. Nell'ottobre del 1998 l'Equipe dei sociologi del DEMHAB - usando gli stessi criteri di ricerca ma concentrandosi solo sulle 'vilas' - ne ha stimato 390, ovvero (anche senza voler contare i 38 nuclei con meno di 10 abitanti non presi in considerazione dalla Jordão) 97 in più di quante indicate 9 mesi prima dalla Ribeiro Jordão. Ad indicare non solo che il problema della crescita della città illegale non riesce ad essere fermato neppure dall'attivissima politica degli alloggi condotta dall'Amministrazione Popolare in questi 11 anni, ma anche che neppure una conoscenza esatta ed immutabile del fenomeno è concretamente praticabile, se non per chi ha giornalmente sotto mano il lavoro con gli abitanti di queste aree.

Del resto, le numerosissime invasioni che hanno colpito l'area metropolitana 
Fig. 44 Quadro sintetico dell'irregolarità fondiaria a Porto Alegre oggi

\begin{tabular}{|c|c|c|c|c|c|c|c|}
\hline $\begin{array}{c}\text { Popola- } \\
\text { zione di } \\
\text { Porto } \\
\text { Alegre }\end{array}$ & $\begin{array}{l}N^{\circ} \mathrm{di} \\
\text { aree ir- } \\
\text { regola- } \\
\text { ri****}\end{array}$ & $\begin{array}{c}\text { Numero } \\
\text { di Par- } \\
\text { cella- } \\
\text { menti } \\
\text { irrego- } \\
\text { lari e } \\
\text { clande- } \\
\text { stini* }\end{array}$ & $\begin{array}{l}\text { Numero } \\
\text { di 'vilas' } \\
\text { e nuclei } \\
\text { irrego- } \\
\text { lari (con } \\
\text { meno di } \\
10 \text { do- } \\
\text { micili)** }\end{array}$ & $\begin{array}{c}\text { Numero } \\
\text { di domi- } \\
\text { cili in } \\
\text { nuclei e } \\
\text { 'vilas'k* }\end{array}$ & $\begin{array}{c}\% \text { di } \\
\text { domicili } \\
\text { in nuclei } \\
\mathrm{e}^{\mathrm{e} \text { 'vilas' }} \\
\text { sul tota- } \\
\text { le dei } \\
\text { domici- } \\
\mathrm{li}^{* *}\end{array}$ & $\begin{array}{c}\mathrm{N}^{\circ} \text { di } \\
\text { abitanti } \\
\text { in nuclei } \\
\text { e 'vilas' } \\
* * *\end{array}$ & $\begin{array}{l}\text { Percen- } \\
\text { tuale di } \\
\text { abitanti } \\
\text { in nuclei } \\
\text { e 'vilas' } \\
\text { sul tota- } \\
\text { le della } \\
\text { popola- } \\
\text { zione*** }\end{array}$ \\
\hline 1.288 .879 & 718 & 328 & 390 & 73.057 & $17,60 \%$ & 284.922 & $22,11 \%$ \\
\hline
\end{tabular}

* Il dato è tratto da Ribeiro Jordão, 1999

** Il dato è tratto da DEMHAB (1999);

*** Dato ottenuto per estrapolazione (DEMHAB, 1999)

**** Valore ottenuto sommando i dati più aggiornati del DEMHAB con quelli sui 'parcellamenti' di Ribeiro Jordão

Aspetti evolutivi delle 'vilas' di Porto Alegre confrontabili nei vari censimenti ufficiali del DEMHAB (Fonte: DEMHAB, 1999)

\begin{tabular}{|c|c|c|c|c|c|}
\hline \multirow{2}{*}{ Ambito tematico } & \multirow{2}{*}{$\begin{array}{c}\text { Specificazione } \\
\text { dell'ambito } \\
\text { tematico }\end{array}$} & \multicolumn{4}{|c|}{ Censimenti per campione } \\
\hline & & 1950 & 1964 & 1973 & $1997 / 98$ \\
\hline Mq di costruzione & & 17,32 & 17,51 & - & - \\
\hline$N^{\circ}$ di vani & & 2 & - & - & 3,51 \\
\hline \multirow{5}{*}{ Tipo di costruzione } & Muratura & 0,18 & - & - & 44,07 \\
\hline & Legno & 98,99 & 82,36 & - & 35,16 \\
\hline & Mista* & 0,83 & 0,69 & - & 16,23 \\
\hline & Restanti & - & - & - & 4,54 \\
\hline & Danneggiate & - & 16,95 & - & - \\
\hline \multirow[b]{2}{*}{ Acqua $(\%)$} & $\begin{array}{c}\text { Rubinetto col- } \\
\text { lettivo }\end{array}$ & 73,10 & - & - & - \\
\hline & $\begin{array}{l}\text { Altre formule } \\
\text { (autobotte, poz- } \\
\text { zi, corsi } \\
\text { d'acqua, allac- } \\
\text { ciamenti clan- } \\
\text { destini) }\end{array}$ & - & - & - & 91,45 \\
\hline \multirow{3}{*}{ Luce (\%) } & Lampioni & 92,20 & - & - & \multirow{3}{*}{90,89} \\
\hline & Elettricità & 2,44 & - & - & \\
\hline & Altre formule & 5,36 & - & - & \\
\hline Fognature (\%) & & nessuno & - & - & 48,32 \\
\hline
\end{tabular}

Dove c'è il segno (-) è da intendersi come 'dati non rilevati'.

* Legna + latta; legno + fango; legno + teloni; teloni + latta 
336 di Porto Alegre a partire dalla crisi del dollaro del gennaio 1999 (17 solo tra la metà di marzo e quella di aprile, cfr. Zero Hora 13/4/1999) sono il segno di una recrudescenza del problema abitativo che oltretutto - finché continuerà ad essere represso altrove con la forza, come è stato fatto in questi mesi da alcune delle Amministrazioni limitrofe - correrà il rischio di tendere a spostarsi verso Porto Alegre, anche a motivo del diverso trattamento riservato dalla locale amministrazione al problema degli alloggi.

Nonostante queste precisazioni, le indagini fin qui citate - a cui sostanzialmente attingono anche gli Annuari Statistici e le Relazioni sugli Indicatori Sociali di Porto Alegre annualmente pubblicate dal Comune - fanno emergere alcuni dati interessanti. Ad esse abbiamo attinto per costruire i grafici e le tabelle riassuntive esposte in figg. 7, 15/16, e per costruire una lettura spazializzata di alcuni fenomeni di distribuzione dell'informalità su scala cittadina (figg. 17/18), sull'esempio delle mappe digitali dell'esclusione realizzate di recente dalle città di Santo André e di San Paolo come strumento di appoggio offerto ai cittadini nella discussione e nella selezione delle priorità nei locali processi di Bilancio Partecipativo. Tali elaborazioni:

a) rivelano la tendenza dei nuclei più recenti a divenire sempre più piccoli $\mathrm{e}$ ad incunearsi [se-encravar] in interstizi e vuoti urbani defilati ma non troppo lontani dalle principali vie di comunicazione e dai nuclei più strutturati della città. ${ }^{8}$ Il dato è interessante soprattutto perché fa giustizia di quel $4,81 \%$ di domicili $(41,79 \%$ delle prime tre fasce dimensionali) che erano stati ignorati nel 1991 dal censimento dell'IBGE in quanto con meno di 51 famiglie insediate. E sottolinea quindi la necessità di un esame attento dei contesti locali, per cogliere le peculiarità e le reali tendenze evolutive di ognuno su un tema delicato come quello dell'informalità urbana.

b) Per quanto riguarda i parcellamenti irregolari e clandestini, il dato più significativo riguarda, invece, il fatto che a Porto Alegre parrebbero esistere solo 3 aree che - a conoscenza dell'Amministrazione - siano state opera di un'azione di suddivisione clandestina in lotti da parte di grileiros, ovvero di non proprietari dell'area che hanno sfruttato a loro vantaggio terreni altrui e sono poi scomparsi. Tutte e tre sono di origine privata (terreni al centro di contese ereditarie), segno di un controllo costante che il Comune è riuscito in quest'ultimo ventennio ad esercitare perlomeno sulle sue proprietà per evitare la speculazione fondiaria a proprio danno (Ribeiro Jordão, 1999i). ${ }^{9}$ La distribuzione nel tempo della creazione irregolare di lotti, dopo il 1979 (anno in cui fu emessa la Legge 6766 sui Parcellamenti) evidenzia una leggera tendenza al calo dei parcellamenti irregolari negli ultimi anni, ma suggerisce anche come ancora oggi i processi di democratizzazione dei suoli non siano stati sostanzialmente sufficienti a rallentare la crescita di alcuni meccanismi di costruzione della città informale, in parte attribuibile anche alla mancanza di una riforma amministrativa che semplifichi un'edificazione rapida dei suoli almeno per quanto concerne l'abitazione di interesse sociale (come vedremo, però, al § 15.2.2, il nuovo Piano Regolatore propone la sperimentazione di una misura innovativa per invertire questa tendenza). L'aspetto più interessante delle due ultime ricerche sopra citate non sta comunque nei dati quantitativi offerti, ma è forse soprattutto di ordine metodologico. Per la prima volta, infatti, sono state elaborate delle definizione chiare e dei criteri di ricerca sostanzialmente coincidenti all'interno di due studi 
eseguiti con finalità diverse da due Dipartimenti o Assessorati differenti, ${ }^{10}$ a testimoniare una innovativa volontà di coordinamento nella conoscenza $\mathrm{e}$ nel monitoraggio di alcuni fenomeni importanti che segnano il territorio cittadino. Ma anche - come la pubblicazione del DEMHAB (1999) evidenzia fin dalle sue premesse e dall'approccio anche discorsivo al tema ${ }^{11}$ - il desiderio di rinnovare l'ottica con cui si è in passato guardato, anche solo sotto il profilo conoscitivo e rappresentativo, alla città informale. ${ }^{12}$

\subsubsection{Alcune definizioni per differenziare gli insediamenti autoprodotti}

Al fine di chiarire alcuni concetti fondamentali che nel seguito ricorreranno frequentemente, può essere utile riportare alcune delle definizioni codificate dai due censimenti appena citati, intersecandole con quelle date dal vigente Piano di Sviluppo Urbano e Ambientale di Porto Alegre:

A) Loteamento [parcellamento] è la suddivisione di un bene immobile in lotti destinati all'edificazione, con apertura di nuove vie di circolazione, di spazi pubblici o prolungamento, modifica o ampliamento delle vie esistenti ${ }^{13}$ (art. 143 del Piano Regolatore di Porto Alegre approvato con Legge Complementare 434/99). Esso è considerato:

- Regolarizzato o Legale quando sottomesso all'approvazione del potere esecutivo municipale e conseguentemente rispetta gli standard urbanistici stabiliti dal Piano. L'approvazione è valida 180 giorni, periodo in cui il lottizzatore dovrà registrare il progetto al Catasto degli Immobili, pena scadenza dell'approvazione. Una volta registrato, il parcellamento potrà essere licenziato [licenciado], cioè potranno cominciare le opere di urbanizzazione. Da questo momento strade, piazze ed altre attrezzature pubbliche entrano a far parte dei beni comunali.

- Irregolare - se è stato approvato ma non registrato al Catasto, o anche registrato ma non impiantato in accordo con il progetto approvato; in tal senso i lotti risultano solo commercializzati attraverso Contratti Privati di Promessa di Compravendita o simili, ma senza valore ai fini della registrazione catastale, perché verificando la situazione del parcellamento, l'Ufficiale non lo troverà $o$ lo incontrerà con una pianta differente, e potrà in ambo i casi impugnarne la validità.

Clandestino, se il parcellamento non è stato approvato dal Potere Pubblico Municipale, ma vi è stata lo stesso una suddivisione fisica in lotti destinati alla costruzione, commercializzati dal proprietario del terreno o da un suo rappresentante - attraverso un'agenzia immobiliare o meno - con Contratti Privati di Promessa di Compravendita o simili e perfino Scritture Pubbliche che non permetteranno però all'acquirente di accatastare il suo lotto al Catasto Immobiliare perché non esisterà alcuna matricola della parcella. ${ }^{14}$

Si definiscono invece insediamenti autoprodotti ${ }^{15}$ oppure occupazioni, nuclei o 'vilas' irregolari i quartieri informali che insistono su aree pubbliche o private senza il consenso esplicito dei loro proprietari e, a seguire, presentano altre numerose irregolarità giuridiche, urbanistiche, amministrative e/o finanziarie. Se essi costituiscono un tutto unico ${ }^{16}$ sono considerati irregolari anche se solo una parte delle costruzioni al loro interno lo è. ${ }^{17} \mathrm{Si}$ considerano nuclei quelli con meno di 51 abitazioni non presi in considerazione nei censimenti dell'IBGE o - ambiguamente - anche quelli privi di una struttura organizzativa che li caratterizzi come 'vilas'. È interessante che la ricerca del 
338 DEMHAB utilizza il termine 'qualitativo' di 'nucleo-vila' per denominare ambiti piccoli ma i cui abitanti si riconoscono organizzativamente come vila, e restituisce a molti quartieri la denominazione scelta dai loro abitanti, a cui nel passato l'Amministrazione ne aveva sovrapposto altre in modo perentorio, senza neppure che essi ne fossero a conoscenza. Complessivamente, il grado di irregolarità di nuclei e 'vilas' è in partenza sempre piuttosto alto, a differenza di quello dei diversi tipi di parcellamenti che possono anche violare una sola regola per volta e che talora godono in gran parte del benessere urbano completo, seppure ve ne sono alcuni in cui l'unica differenza da una 'vila' è che i proprietari dei lotti possiedono qualche credenziale di titolarità fondiaria, seppur precaria (DEMHAB, 1999).

Le modalità di costituzione di un 'insediamento autoprodotto' possono essere trsa loro diversissime; nel cap. 13 ne evidenzieremo alcune, che ovviamente non possono esaurire le casistiche reali che si presentano nei diversi contesti.

\subsection{Da baraccopoli a quartieri: nuovi strumenti per reintegrare la città spontanea}

Non vi è più modo di ignorare che legalità ed illegalità sono due volti dello stesso processo sociale di produzione dello spazio urbano [...] É necessario che giuristi, urbanisti e amministratori urbani comprendano che esiste una relazione diretta tra l'illegalità urbana e la natura dell'ordinamento giuridico vigente (Fernandes E., 2002)

Le enormi disuguaglianze di ricchezza, riprodotte sui territori di un Paese dove oggi l'82\% della popolazione vive in ambito urbano, hanno - spesso accompagnato la concentrazione delle infrastrutture e delle attrezzature nei quartieri medio-alti, mentre le aree dove risiede la popolazione a basso reddito si sono viste sempre più condannate all'assoluta mancanza di investimenti pubblici. Privati della possibilità di inserirsi nella città attraverso un'occupazione formale del territorio urbano, gli esclusi dal mercato formale della terra e dell'abitazione hanno avuto come unica opzione quella di occupare terreni inutilizzati, pubblici e privati, per poter esercitare uno dei diritti fondamentali dell'essere umano: quello alla casa (Alfonsin B, 1997). Da questa dinamica hanno preso avvio numerose tipologie di insediamenti più o meno spontanei, caratterizzati da un'occupazione disordinata dei terreni, dalla precarietà delle abitazioni e delle infrastrutture, e dalla coesistenza di forme di irregolarità urbanistica e giuridica: una situazione fotografata dall'uso del termine posse [possesso], che suole far riferimento proprio a questa situazione, in cui all'occupazione de facto di un'area non corrisponde nessun titolo di proprietà [propriedade] o di concessione d'uso.

Sebbene questo sia un problema nazionale - nella misura in cui coinvolge l'esplosiva questione della proprietà privata della terra e della sua funzione sociale - la ricerca di soluzioni in materia è stata spesso demandata ai governi locali, come se il tema, effettivamente, trattasse appena della morfologia della città, dell'altezza degli edifici, della struttura di strade e luoghi pubblici (Pessoa, 1982). Il risultato di questo 'scarico di responsabilità' - disgiunto da una parallela politica di decentramento delle risorse - neppure a livello locale ha permesso di arginare il progredire dell'esclusione sociale e della segregazione spaziale dei più poveri, e di elaborare una politica adeguata ad 
affrontare il problema. Già prima della formale chiusura del BNH (creato per risolvere il problema dell'abitazione e trasformatosi spesso in una complicazione per la soddisfazione di quel diritto, cfr. Alfonsin B., 1997), gli strati più poveri della popolazione avevano comunque già individuato nell'autocostruzione una possibile e più rapida soluzione ai propri problemi, risolvendo la questione dell'accesso ai suoli urbani con la ripresa massiccia delle occupazioni di terreni vuoti che avevano subito un rallentamento - seppur non un arresto - nel periodo della dittatura. Generazioni intere di cittadini hanno così accettato di chiamarsi fuori dai regolari processi di urbanizzazione delle città, convivendo con la paura degli sgomberi sollecitati dai proprietari delle terre irregolarmente occupate, ma soprattutto con l'assenza di infrastrutture, di servizi e di reali diritti di cittadinanza.

È con questa storia pregressa che si sono trovate a fare i conti negli anni ' 80 le prime amministrazioni locali che (come quelle di Recife e di Belo Horizonte $)^{18}$ hanno intravisto l'unica concreta possibilità di cominciare a risolvere il problema dell'alloggio nell'intraprendere un autonomo cammino decisionale adeguato alle necessità del loro territorio locale. Lo stesso è toccato poco dopo a tutte quelle altre municipalità trovatesi d'improvviso (nonostante da tempo la 'morte annunciata' del BNH suggerisse di sperimentare nuovi percorsi organizzativi) a dover fare i conti da sole con uno dei maggiori problemi del Paese, scaricato praticamente in toto sulle loro spalle dal Governo Centrale e, in parte, anche da quelli statali. È a quest'epoca che - davanti al bisogno di fare di necessità virtù e di analizzare per la prima volta in modo serio il patrimonio informale sorto e sviluppatosi nelle città per quasi un quarantennio - molti comuni si sono resi conto di come lo sviluppo autonomo ed incontrollato di interi quartieri avesse reso il deficit abitativo meno numerico che qualitativo. La constatazione di questo fatto apparentemente banale - che la definizione ormai accettata nei dibattiti accademici e nei movimenti per la riforma urbana sintetizza con le parole deficit di abitabilità (Maricato, 1996) - ha condotto ad alcune interessanti conseguenze.

La prima è stata la riflessione sul potenziale che un patrimonio già costruito (seppur in modo precario) poteva offrire in termini di risposta ad un problema che nel suo stesso porsi presentava già delle indicazioni di percorso per una sua - almeno parziale - soluzione. La seconda è stata la constatazione sul rischio crescente di non poter attingere a questo 'patrimonio' se non si agiva in fretta. Esso tende, infatti, a degradarsi nel tempo nella misura in cui il "deficit di abitabilità" è rinforzato "dalla mancanza di sicurezza nell'esercizio del diritto alla casa" (Alfonsin B., 1997), visto che nessuno ha interesse a investire in beni che non si ha la sicurezza di poter mantenere. ${ }^{19}$

Le due riflessioni congiunte hanno portato ad un concreto risultato: quello di dare avvio su larga scala a quei Programmi di Regolarizzazione Urbanistica $e$ Fondiaria già da tempo ventilati a livello teorico nel Paese (e con timidi tentativi-pilota che si ispiravano anche a sperimentazioni degli anni '50) e messi in opera solo in seguito alla diffusione dell'approccio di 'minimo intervento' internazionalmente, propagandato dalla Banca Mondiale come unica soluzione concretamente possibile al problema delle carenze abitative.

La trasformazione ha stimolato approcci multiscalari al tema, rendendo necessari (parallelamente all'avvio delle prime sperimentazioni) lo studio e la 
340 riorganizzazione, a livelli diversi, degli strumenti normativi e finanziari necessari per portare avanti i nuovi processi di intervento sul territorio, che hanno trovato un momento opportuno di rielaborazione nell'ambito della Riforma Costituzionale del 1988. Da quel momento, la politica di regolarizzazione fondiaria è pertanto divenuta (affiancata all'altra soluzione proposta parallelamente anche dal 'twin approach' della Banca Mondiale) la componente essenziale di una politica abitativa di tipo nuovo, che - pur costituendosi come una riduzione dell'impegno istituzionale sul campo - ha avuto l'indubbio vantaggio di poter restituire la cittadinanza, negata dalla perversa logica di accumulazione della terra e della ricchezza (Alfonsin B., 1997) alle popolazioni delle aree finora non riconosciute dalla 'città formale'. Il concetto di Regolarizzazione fondiaria, dal '79 (quando fu inglobato nei primi programmi-pilota del $\mathrm{BNH}$ ) ad oggi, ha subito indubbiamente modifiche ed interpretazioni diverse nel dibattito ai vari livelli di organizzazione amministrativa e perfino nei diversi luoghi, finendo per riflettere ottiche e modi locali di occuparsi della questione e favorendo persino l'uso di strumenti d'intervento non sempre uniformati a livello nazionale Così, in senso ampio, essa oggi non pare potersi riferire solo agli strumenti normativi esistenti e già utilizzati dai comuni, ma tende ad assumere una valenza generale di "processo di intervento pubblico, sotto gli aspetti giuridici, fisici e sociali, che ha l'obiettivo di legalizzare la permanenza delle popolazioni che abitano nelle aree urbane occupate in difformità dalla legge, il quale implica come componenti accessorie miglioramenti nell'ambiente urbano dell'insediamento, nel riscatto dei diritti di cittadinanza e della qualità della vita della popolazione beneficiaria"(Alfonsin B., 1997). ${ }^{20}$

La definizione - aperta ma chiarissima nei suoi presupposti - contiene l'indicazione che un simile processo non può fermarsi al primo atto di riconoscimento formale della proprietà dei suoli, senza risultare incompleto e senza rischiare di non ottenere risultati durevoli nel medio e lungo termine. In tal senso, diviene fondamentale cercare il più possibile di garantire la permanenza degli abitanti nella stessa area dove hanno fissato la residenza, e di promuoverne il miglioramento della qualità di vita a partire da una preselezione delle aree, che escluda quelle di rischio, come quelle in cui risulti impossibile (se non a prezzo di costi insostenibili) introdurre graduali migliorie dell' ambiente costruito: in tale impossibilità viene introdotta la nozione di 'ridislocazione' [relocalização o reassentamento].

Una definizione ampia come quella sopra esposta costituisce un'implicita negazione della validità di quelle interpretazioni limitative che si fermano alla regolarizzazione giuridica dei lotti, o - per contro - non teng ono in conto l'imprescindibilità di questa, concentrandosi invece solo su operazioni di mera regolarizzazione urbanistica o di recupero urbano, cioè su regolarizzazioni parziali, pur utili a migliorare la qualità della vita degli abitanti ma che possono generare - in assenza dell'assegnazione di titoli di proprietà o concessione d'uso dei terreni (cosa che avviene spesso quando i Comuni devono intervenire su aree di loro proprietà) - sprechi di denaro pubblico, o problemi di sgomberi forzosi di seconda generazione al mutare degli equilibri politici su cui si regge ogni amministrazione, tanto più se l'area non è stata inserita nei piani urbanistici come 'area speciale di interesse sociale a fini di abitazione' (AEIS). 
Con tali premesse, la Regolarizzazione fondiaria comporta "un'implicazione etica" (B. Alfonsin, in Allegretti 2000a) raramente esplicitata nella sua definizione, ma evidente se la si mette in relazione con i modi con cui avvengono le diverse occupazioni dei suoli. Potendo, infatti, consacrare e perpetuare ingiustizie di vario genere, essa richiede una volontà politica forte mirata a conoscere ed intervenire "caso per caso, adattando il senso di giustizia che permea gli strumenti legali di intervento alle diverse e peculiari situazioni che connotano nella realtà il territorio"(ibidem).

Proprio ad esaminare in dettaglio questi due poli della questione (strumenti giuridici e finanziari di intervento e situazioni di adattamento differenziato degli stessi alle concrete azioni sul territorio) dedicheremo questo ed i prossimi capitoli, attraverso esempi e racconti di 'luoghi'.

Chiaramente, lo faremo in riferimento all'esperienza di Porto Alegre, dove da oltre un decennio - il Comune sta cercando di mettere in pratica contemporaneamente livelli di intervento differenziati e complementari sul terreno del reinglobamento della città informale nella 'città di diritto', partendo dal postulato che la regolarizzazione fondiaria riesca ad ottenere risultati migliori e duraturi solo laddove non sia conseguenza di provvedimenti settoriali o 'tampone', ma venga strettamente integrata sia ad un costante impegno verso la regolarizzazione urbanistica delle aree illegalmente occupate, sia ad azioni mirate al reinserimento economico, sociale e politico dei loro abitanti, il cui coinvolg imento attivo costituisce condizione indispensabile per il successo stesso degli interventi. ${ }^{21}$

\subsection{Strumenti giuridici per la Regolarizzazione fondiaria: un panorama in trasformazione}

[L'occupazione per necessità] semplicemente sta lì, sfidando tipi, modelli, sigle e concetti giuridici [...] Essa, ad un'efficacia giuridica 'erga omnes' di un vuoto titolo di proprietà, oppone un'efficacia 'de facto' di un possesso non formalmente riconosciuto attraverso titoli ma pieno, e pieno di un diritto legato in modo elementare alla vita, come quello di nutrirsi o di avere una casa [..]È in questa zona che l'ordinamento giuridico vigente necessita di nuova luce ermeneutica, anche sui suoi riconosciuti limiti (B. Alfonsin, 1997).

Ha scritto Edesio Fernandes (2002) che in Brasile parrebbero esservi diversi "gradi di illegalità urbana", se è vero che alcune pratiche "sono più tollerate ed anche maggiormente giustificate di altre", per lo più in maniera direttamente proporzionale "all'esistenza di documenti formali - per quanto giuridicamente precari essi siano - che per lo meno suggeriscano un tentativo di continuità nella catena di trasmissione delle proprietà". ${ }^{22}$ Simili pratiche di illegalità nelle forme di accesso ai suoli e all'abitazione non sono, tra l'altro, limitate agli strati più poveri della popolazione; anzi, moltissime di esse - di solito quelle che godono di un maggior livello di impunità - si verificano proprio all'interno dei gruppi sociali privilegiati, e vanno dalla frequente violazione delle norme urbanistiche ai cosiddetti "condominios fechados" [condomini chiusi] che, "tra gli altri effetti negativi, impediscono la libera circolazione di tutti nelle strade e il libero accesso agli arenili - che sono beni di uso comune di tutti" (ibidem). 
342 In questo testo, a noi interessa occuparci di un solo tipo di illegalità urbana: quella conseguente ai processi di esclusione sociale e segregazione spaziale che hanno caratterizzato la crescita intensiva delle città del Brasile come di tutti i paesi in via di sviluppo. In particolare, ci interessa leggerla a partire dal punto di vista degli interventi complessi tentati con l'obiettivo di un suo 'reinserimento' nel corpo cittadino, ovvero di ciò che ruota intorno a quel concetto di Regolarizzazione Fondiaria che pare ormai collocarsi contemporaneamente sullo spinoso terreno pubblico-privato del diritto urbanistico e di quello costituzionale, postulando la necessità di trovare un modello di disciplina fondiaria che sia capace di inquadrare la legalizzazione dell'informale in maniera nuova.

La questione dell'esistere del diritto alla correzione e all'adeguamento dello spazio abitabile (in senso fisico e giuridico) per una popolazione che vive in aree non regolarmente acquisite né edificate, non è - infatti - un problema semplice e risolvibile a partire da un solo punto di lettura. In relazione all'idea del possesso necessario, essa pare però seguire una via che la indica come indispensabile, dal momento che "essendo in gioco il diritto ad abitare, viene quindi implicato indiscutibilmente il diritto a vivere" (Bobbio N., 1992), e a vivere in un contesto ordinato dove "altre libertà e altre vite devono essere rispettate" (Alfonsin B., 1997). Del resto, misconoscere la regolarizzazione come un diritto equivarrebbe, sotto il profilo della disuguaglianza economica, a mettere in ombra quanto affermato dall'articolo 3 della Costituzione Federale, quello sugli obiettivi della Repubblica Brasiliana tra i quali è elencato lo sradicamento della povertà.

È seguendo con convinzione questa linea di pensiero che negli ultimi dieci anni il Movimento per la Riforma Urbana in Brasile ha trovato la forza di lottare per una regolamentazione dell'incompiuto capitolo costituzionale sulla Riforma Urbana che articolasse le sue previsioni e i suoi strumenti di riferimento intorno ai diritti fondamentali previsti nella Carta Costituzionale e al principio della funzione sociale della proprietà e della città (art. 5, art. 30, inc. VIII, e art $182, \S 2^{\circ}$ della Costituzione Federale). Quest'ultimo - principio fondante del Diritto Urbanistico e del Diritto Ambientale - era già stato ripetutamente inserito in tutte le Costituzioni brasiliane succedutesi dal 1934, senza però essere debitamente reso operativo attraverso la creazione di meccanismi e strumenti costituzionali e legali che permettessero e garantissero il suo compimento, ma soprattutto senza essere chiaramente definito in termini concettuali. Almeno fino al 1988, quando la nuova Costituzione gli ha dato "una formulazione concettuale solida, che può essere così sintetizzata: il Diritto alla proprietà immobiliare urbana é assicurato nella misura in cui essa compia la propria funzione sociale, che la sua volta é quella determinata dalla legislazione urbanistica, soprattutto in ambito municipale. Spetta al governo municipale esercitare il controllo giuridico sui processi di sviluppo urbano per mezzo della formulazione di politiche di ordinamento territoriale, nelle quali gli interessi individuali dei proprietari coesistano necessariamente con interessi di natura sociale, culturale e ambientale di altri gruppi e della città nel suo insieme" (Fernandes, 2002). ${ }^{23}$

Oggi il Brasile si interroga sul grande cambiamento di paradigma che, proprio imperniandosi su questo principio, va riarticolando il panorama legislativo federale. Sono stati necessari più di 10 anni di discussioni, emendamenti 
e provvedimenti sostitutivi di ogni genere affinché il progetto di legge $\mathrm{n}^{\circ}$ 5.788 fosse finalmente approvato, dando forma alla Legge Federale $\mathrm{n}^{\circ} 10.257$ del 10 luglio 2001 detta "Statuto della Città". Il suo testo porta in sé tutte le difficoltà del complesso processo di negoziazione e scambio tra i diversi interessi in gioco nell'ambito della questione del controllo giuridico dello sviluppo urbano, ma resta sicuramente un'enorme conquista. Infatti, nell'enfatizzare l'importanza dei processi e dei meccanismi di gestione democratica delle città e di democratizzazione delle modalità di accesso ai suoli urbani e all'alloggio, lo "Statuto della Città" propone anche "le basi per una trasformazione della qualità politica del processo di costruzione di un ordinamento giuridico-urbanistico" (ibidem), disponendo che "il decentramento e la democratizzazione camminino insieme per garantire la piena legittimità sociale dei processi di pianificazione urbana, di quelli di formulazione delle politiche pubbliche, di approvazione delle leggi urbanistiche e di gestione delle cittă'. La variazione di prospettiva che il nuovo strumento porta con sé agisce all'interno del dibattito sulla gestione urbana soprattutto lungo quattro direttrici:

ampliando lo spazio delle competenze giuridiche e dell'azione municipale nella formulazione degli indirizzi di pianificazione e gestione democratica del territorio urbano, attraverso l'esplicitazione di un 'Progetto di Città' che permei di sé la legislazione urbanistica comunale;

consolidando la nozione di funzione sociale e ambientale della proprietà e della città, che diventa il perno dell'intero Diritto Urbanistico e rompe con la tradizione civilista e con la concezione individualista del diritto di proprietà immobiliare, che ha orientato gran parte della dottrina giuridica durante $i$ decenni dell'urbanizzazione intensiva del Brasile;

regolamentando e creando tutta una serie di strumenti urbanistici per la costruzione di un ordine urbano socialmente giusto e inclusivo;

proponendo specificamente una serie di strumenti giuridici per la regolarizzazione degli insediamenti informali in area urbana.

In tale ottica, lo "Statuto della Città" conferma e rafforza i fondamenti del progetto politico-giuridico di riforma urbana che vari municipi brasiliani ${ }^{24}$ e tra essi Porto Alegre - sono andati mettendo in atto già dalla fine degli anni '80, a dispetto di un contesto giuridico nazionale che appariva "restrittivo e spesso perfino ostile" (Fernandes, 2002). Al loro coraggio di sperimentare, certo la nuova Legge Federale deve molto: nella pratica, essi hanno - infatti - costruito l'agenda politica che si è oggi trasformata nel principale riferimento per tutti gli altri comuni brasiliani ed ha favorito il crearsi di quel clima politico che ha consentito di approvare lo "Statuto della Città" con una larghissima maggioranza parlamentare, a dispetto della 'radicalità progressista' di molti dei suoi contenuti.

\subsection{La sperimentazione di nuovi strumenti giuridici nell'esperienza di Porto Alegre}

Anche a Porto Alegre, le sperimentazioni che - con azione integrata e multiscalare - sono state portate avanti tra il 1989 e il 2001 nell'ambito dei programmi di reinglobamento della città formale nella 'città di diritto' non hanno potuto godere del supporto basilare che oggi offre "lo Statuto della Città" per favorire e regolamentare il coordinamento tra strumenti regolatori 
344 tradizionali della pianificazione urbana (zonizzazione, lottizzazione/frazionamento, indici costruttivi, modelli insediativi, coefficienti di sfruttamento, profili e rapporti dimensionali standardizzati, allineamenti e arretramenti, ecc.) e nuovi strumenti di regolarizzazione (come la Concessione del Diritto Reale di Uso del suolo, l'usucapione collettiva, ecc.) o semplicemente "induttori", ${ }^{25}$ come l'edificazione, il parcellamento e l'utilizzazione obbligatoria; l'applicazione extrafiscale della tassa sui beni immobili (IPTU) progressiva nel tempo; l'imposizione dell'esproprio-sanzione con pagamento in titoli del debito pubblico; il dettagliamento del Diritto di superficie; il ricorso al 'Diritto di prelazione' per i comuni; la concessione onerosa del Diritto di costruzione ai privati, ecc.. Come accaduto a molte altre amministrazioni progressiste negli stessi anni, Porto Alegre ha svolto semmai un ruolo di 'apripista' (sovente coraggioso), contribuendo a sperimentare ed interpretare in maniera progressista - cioè 'retro-illuminandoli' con un continuo riferimento ad alcuni nodi fondanti del dettato costituzionale - tutta una serie di strumenti normativi di azione puntuale già presenti nell'ordinamento normativo brasiliano, messi in relazione con le azioni e gli obiettivi perseguiti dalla linea politica scelta dalla città per relazionarsi con una realtà fisica e umana cangiante come quella che caratterizza gli spazi urbani carenti di regolarizzazione (Alfonsin B., 1997).

Trattare dettagliatamente di questi strumenti - e del quadro normativo 'a monte' di essi - sarebbe ovviamente impossibile in queste pagine; rimandando, pertanto, alle tabelle riassuntive di figg. 20 e 46 (che tentano di offrire un riassunto dell'ordinamento giuridico in cui molte amministrazioni hanno operato fino al 2001), ci soffermeremo a descrivere appena alcuni strumenti fondamentali sperimentati in questi anni, accennando brevemente all'uso che ne è stato fatto nello specifico caso di Porto Alegre.

\subsubsection{Strumenti giuridici a predominante urbanistica: ${ }^{26}$}

\section{1) Plano Diretor [Piano Regolatore]}

È il principale strumento di organizzazione dello spazio urbano, "complesso di norme legali e di direttive tecniche per lo sviluppo globale e costante del municipio, sotto gli aspetti fisico, sociale, economico e amministrativo, desiderato dalla comunità locale", ${ }^{27}$ dotato però anche di obiettivi specifici nel momento in cui tra $\mathrm{i}$ suoi fini vi è quello di orchestrare una strategia di trasformazione in direzione dell'ottenimento di un miglioramento della qualità di vita della comunità locale (Silva, 1995), cosa che può essere fatta solo a patto di prevedere azioni mirate e puntuali sul territorio. La Costituzione Federale del 1988 gli attribuisce il ruolo di strumento per verificare e dare compimento alla funzione sociale della proprietà in rapporto alle esigenze fondamentali di organizzazione della città (art. 182, § 2). Nel caso di Porto Alegre, il PRG vigente risale al dicembre 1999 (cap. 15).

2) ZEIS o AEIS [Aree o Zone Speciali di Interesse Sociale]

Se - in senso ampio - la zonizzazione è una ripartizione del territorio municipale a seconda della destinazione della terra, dell'uso del suolo o delle caratteristiche architettoniche (Silva, 1995), la regolarizzazione fondiaria comporta due letture. Una ammette solo la destinazione d'uso prevista dal Piano Regolatore, spesso pressato a disciplinare la zonizzazione a partire da equilibri fra interessi economici e politici in favore del 'libero' mercato; un'altra tende a rispettare il contesto imposto da necessità sociali che hanno condotto 
una determinata parte della popolazione ad installarsi in uno spazio cittadino che la comunità stessa ha zonizzato, eleggendolo - ad esempio - per la propria residenza, spinta da insopprimibili condizioni di necessità, e generando un conflitto fra città legale e città reale. Le AEIS $^{28}$ sono mirate - all'interno del contesto pianificatorio e di zonizzazione generale - a dare riconoscimento legale a questa seconda forma di occupazione del suolo urbano, regolarizzandola poi come appropriata al luogo attraverso norme specifiche talora eccezionali rispetto agli standard urbanistici ed edilizi generali. Al Potere Municipale resta la possibilità - attraverso il Piano Regolatore - di prevedere AEIS anche prima che si renda necessaria una correzione a posteriori delle previsioni urbanistiche, così spezzando "l'automatismo, normalmente inerente al diritto di proprietà immobiliare, tra la semplice esistenza di quel diritto e il potere che esso conferisce al proprietario di usare il bene a qualunque scopo", nel tentativo di rendere compatibile "la funzione sociale della proprietà con la funzione sociale della città" (Alfonsin De Moraes, 1997). I Tribunali brasiliani hanno ammesso che "una volta fissate le norme ed $i$ criteri di zonizzazione per legge", l'individuazione delle AEIS sul PRG possa esser fatta con decreto del Sindaco anche in tempi successivi. A Porto Alegre le AEIS sono state istituite con L.C. 338/95, dando evoluzione alle AFRUs (Aree Funzionali di Recupero Urbano) già previste dagli artt. 37, 44 e 49 del Piano Regolatore del '79 per 15 aree ${ }^{29}$ ma rimaste inapplicate. Già nel 1993 un Progetto di Legge nel Consiglio Comunale aveva definito 4 tipi di AEIS (intese come aree destinate alla produzione e manutenzione di alloggi di interesse sociale, con destinazione specifica e norme proprie di uso e occupazione del suolo) che sono state poi confermate dalla Legge successiva:

AEIS $1=$ aree pubbliche occupate a fini residenziali

AEIS $2=$ aree private occupate a fini residenziali ${ }^{30}$

AEIS 3 = suddivisioni in lotti clandestine o irregolari

AEIS 4 = Vuoti urbani da destinarsi a programmi abitativi popolari

Facendo un regesto di tutti gli insediamenti precedentemente zonizzati per legge o decreto, il nuovo Piano di Sviluppo Urbano e Ambientale di Porto Alegre del dicembre '99 contiene 102 AEIS demarcate: tutte aree in cui da tempo il Comune stava già svolgendo interventi di regolarizzazione fondiaria e/o urbanistica, ${ }^{31}$ individuate all'interno del processo Cidade Constituinte per la costruzione del nuovo PRG (cfr. cap. 15). Per molte altre è in corso una procedura di individuazione, aggiornata via via che nuove richieste di regolarizzazione si fanno presenti nel Bilancio Partecipativo e in altre sedi. Dal 1995 la SPM ha portato avanti un'interessante discussione tra tecnici di vari Dipartimenti e Assessorati e con la società civile per definire metodologie, criteri e standard flessibili di urbanizzazione e regolarizzazione per le AEIS, predisponendo un apposito Gruppo di Gestione delle AEIS (GGA), che nel settembre ' 97 ha ipotizzato in un interessante documento alcuni standard qualitativi minimi per la predisposizione dell'infrastruttura nelle varie AEIS I e II, attraverso uno studio di criteri utilizzati in altre città del Paese ed una verifica in loco dei risultati ottenuti dall'Amministrazione Popolare in insediamenti di Porto Alegre già da anni oggetto di interventi di regolarizzazione urbanistica. Tra gli scopi dichiarati vi è, infatti, creare un nuovo metodo di lavoro, di tipo "matriciale", sulla base del quale ogni AEIS assuma la forma di un vero patto di intervento per ogni nucleo (GGA-SPM, 1997) in grado di 
346 semplificare e agilizzare le procedure posteriori, ma riconoscendo "l'eterogeneità e la peculiarità degli insediamenti popolari che esigono trattamento legale ed urbanistico specifico" (ibidem). Il documento del GGA rileva che "gli standard di qualità dell'habitat considerati come i minimi accettabili dalla legislazione vigente non corrispondono agli standard di qualità possibile, determinati dalla carenza di fondi privati di buona parte della popolazione e dalla carenza di fondi pubblici destinabili all'habitat urbano" e, pertanto, sottolinea come norme 'ideali' e uguali per tutta la città non ottengono lo scopo voluto di garantire eguali standard di abitazione a tutta la popolazione ma accentuano l'esclusione di gran parte di essa dalla legalità urbanistica e giuridica. Per questo, il GGA sollecita il Comune ad "un riciclaggio della visione tecnica quanto a concetti, obiettivi e procedimenti”, e ad agire secondo una nuova forma mentis che garantisca a tutti uguale accesso ai suoli urbani senza imporrei modi uguali di vivere, in ciò collocandosi appieno nello spirito delle nuove procedure amministrative e di gestione della produzione dell'alloggio. Nel testo del GGA si stabiliscono anche alcuni criteri per identificare situazioni più adatte ad essere gestite con strumenti diversi o complementari rispetto alle AEIS, come le Operazioni Concertate, da usarsi nei casi in cui gli alti costi di regolarizzazione rendano impossibile al Potere Pubblico l'assunzione totale dei costi dell'operazione, o rendano necessario agire di concerto con organismi di livello istituzionale differente. I parametri urbanistici minimi vengono individuati soprattutto in riferimento alle "vilas" di occupazione, "perché i parcellamenti, tendendo ad imitare il formale in sottotono, finiscono per avere raramente bisogno di criteri di sicurezza o salubrità" (Ribeiro Jordão, 1999i). La flessibilità dei parametri urbanistici minimi ammessi nelle singole aree (circa viabilità, attrezzature,criteri di altezza e densità dei lotti) non intacca la necessità di rispettare alcuni limiti massimi che caratterizzano l'area come passibile di regolarizzazione, come le dimensioni dei lotti, che non potranno superare $\mathrm{i}$ $150 \mathrm{mq}$ su terreni pubblici e i 250 in terreni privati. ${ }^{32}$ L'indicazione di dimensioni minime di progetto e di dimensioni minime ammissibili serve a definire un campo a cui ricondurre l'ampiezza di strade e marciapiedi delle singole aree regolarizzande, accompagnate da raccomandazioni generali per ogni tipologia viaria anche in rapporto al rispetto del profilo del terreno, alla disposizione di infrastrutture e alla possibilità di animazione e vitalità d'uso delle stesse, che nella loro formulazione danno la misura di un palese rispetto esistente per le caratteristiche e le potenzialità della città informale. ${ }^{33}$

È interessante notare la lista di 'eccezioni alle eccezioni' che il testo del GGA propone, ad esempio per casi di lotti con doppia testata su strada che potranno essere minori di quelli minimi assoluti (o di lotti 'ingabbiati' interni e 'a chiodo' con testata ammissibile di $2 \mathrm{~m}$.); essa tende all'accettazione di una grande varietà di casistiche da valutare nelle diverse situazioni singolarmente, e alla distinzione fra condizioni ottimali suggerite e condizioni di necessità malvolentieri accettate (fig 47).

3) Parcellamento, edificazione ed utilizzazione obbligate

Il paragrafo $4^{\circ}$ dell'art. 182 della Costituzione Federale afferma che al Potere Pubblico municipale è data facoltà - mediante una Legge specifica per aree indicate nel Piano Regolatore - di esigere dal proprietario del suolo urbano non edificato, subutilizzato o non utilizzato, che promuova un suo 
adeguato sfruttamento. In caso che questi non ottemperi alla richiesta il Comune può provvedere a:

a) parcellamento o edificazione obbligata del terreno

b) imposizione di un'imposta progressiva nel tempo sulla proprietà edificabile e territoriale urbana

c) espropriazione con pagamento mediante titoli del debito pubblico (l'emissione dei quali deve essere preventivamente approvata dal Senato Federale), con termine di riscatto fino a 10 anni, per un valore uguale a quello reale dell'indennizzo e comprensivo degli interessi legali.

Lo strumento (rispetto al passato) amplia i poteri conferiti ai Comuni per disciplinare le proprietà private situate in suo territorio, attraverso misure sanzionatorie contro coloro che - lasciando sottoutilizzati certi spazi - dimostrano di rinunciare all'esercizio di un diritto e nel contempo a sviluppare la funzione sociale che ad esso inerisce. Prima dell'approvazione dello "Statuto della Città", risultava assente la Legge prevista dalla Costituzione per stabilire i criteri e $i$ procedimenti generali di applicazione di queste misure; molte realtà locali le hanno però ugualmente sperimentate sostenendo che è ai Piani Regolatori e a Leggi Municipali specifiche che spetta il compito di stabilire i criteri specifici e i tempi entro cui i proprietari devono adempiere agli obblighi per il compimento della funzione sociale della proprietà; sulla questione nessun dubbio di incostituzionalità è stato sollevato. A Porto Alegre, il Consiglio Comunale già dal 1995 cominciò ad applicare l'IPTU (l'imposta sugli immobili) progressiva nel tempo che - sostenuta da una forte pressione popolare sui consiglieri comunali - ha permesso al Comune di interferire direttamente nel processo speculativo attribuendo funzione sociale ai vuoti urbani, così "configurandosi come un importante strumento di riordino, di sviluppo" e di continuità per il territorio (Pozzobon, 1998, p. 22). La Legge Complementare 312/93 ha, infatti, stabilito la costituzione di alcune Aree di Urbanizzazione e Occupazione Prioritaria (AUOPs) dentro le quali i terreni inutilizzati maggiori di $3000 \mathrm{mq}^{34}$ vengono assoggettati nel tempo a tasse sempre più alte nella misura in cui i proprietari non si attengono alle esigenze legate alla funzione sociale della proprietà, intesa quale "diritto di accesso di ogni cittadino alle condizioni basilari di vita" (L.C. 312/93, art. $1, \S 1^{\circ}$ ). Ai proprietari dei terreni inutilizzati o subutilizzati che rispondono alle specifiche della legge e si trovano dentro le 5 AUOPs demarcate successivamente con L.C. 333/1994 - sono stati dati tra i 9 e gli 11 mesi di tempo per presentare progetti di parcellamento dei suoli o costruzione (e 24 mesi per completare l'edificazione a decorrere dall'approvazione dei progetti), prima di essere assoggettati a tasse sul valore degli stessi beni in crescita del $20 \%$ annuo $^{35} \mathrm{o}$ - eventualmente - di essere espropriati in vista della messa in opera di progetti specifici di pubblico interesse: in caso di vendita, non vi è slittamento della decorrenza dei termini rispetto al momento della notifica ${ }^{36}$ e la penalità grava come una sorta di 'ipoteca' sul bene (Kern, 2002i). Al 1998, quando è stato ultimato dal Comune di Porto Alegre un aggiornamento del censimento dei vuoti urbani, 49 sono risultati quelli nuovi inseriti (per un totale di 228,54 ettari) dentro i confini di Aree Urbane di Occupazione Prioritaria (AUOPs). Il profilo dei 120 beni immobili individuati - tutti in aree dove il Comune sta realizzando investimenti che possono valorizzare $\mathrm{i}$ beni e quindi tornare a vantaggio degli stessi 65 proprietari 
348 costretti a valorizzarli - è quello individuato in fig. 45: 35 hanno superficie superiore a $10.000 \mathrm{mq}$ e 6 oltrepassano i 100.000 (CCS/PMPA, 1999). ${ }^{37} \mathrm{La}$ misura, adottata alla vigilia dell'approvazione del nuovo Piano Regolatore, è certo di particolare importanza se la si relaziona all'impegno su vari fronti che l'Amministrazione Popolare sta portando avanti per cercare nuove opportunità di integrazione sociale e riequilibrare alcune disparità provocate dagli incontrollati fenomeni della rendita urbana. Vale la pena osservare che - nel caso di Porto Alegre - la definizione delle AUOPs, seppur riassorbibile dentro gli obiettivi e il programma politico governativo di lotta all'esclusione sociale, ha un' origine diversa da quella più strutturata che assume entro gli obiettivi con cui l'IPTU Progressivo nel Tempo è stato inserito nel 2001 dentro lo "Statuto della Città". A Porto Alegre, infatti, lo stimolo iniziale alla definizione delle AUOPs è venuto dalla necessità di govemare il problema dei vuoti urbani e delle diseconomie che generavano nella gestione del territorio; ed è per giunta nato con analisi e individuazioni puntuali, ma " $a l d i$ fuori di un progetto complessivo, cosicché si rischia che - se non si aggiorna la legge istitutiva e non se ne rivede l'ottica - l'istituzione delle AUOPs finisca per ridursi alla copertura di un gioco mirato ad aumentare sotto mentite spoglie gli introiti fiscali del Comune attraverso una 'cattura' del plusvalore fondiario di certi terreni” (Kern, 2002i). Del resto, ad oggi, l'alto numero di aree individuate a Porto Alegre non pare poter essere assorbito dal mercato, e vanno moltiplicandosi i ricorsi che già paralizzavano il completamento dell'operazione di razionalizzazione territoriale e fiscale. In conseguenza di queste incoerenze, oggi vi sono in corso ben 206 pratiche su lotti che spesso non si riesce esattamente a sapere se rientrino in toto, parzialmente o per nulla dentro i confini delle 5 AUOPs ${ }^{38}$ moltissime pratiche risultano "sospese" per incertezze sulla loro appartenenza o per contenziosi giudiziari, mentre delle 69 non bloccate, 16 sono in corso e 53 (cioè il 76,6\%) hanno già cominciato i processi di tassazione progressiva dei proprietari che non hanno potuto o voluto venire incontro alle richieste dell'Amministrazione (dati Kern, SPM, 22 luglio 2002). In questo quadro, è ovvio che è necessario stabilire delle priorità di azione, perché per far funzionare fruttuosamente delle misure di questo genere non paiono sufficienti delle "semplici macchie di colore su una carta, ma è necessario che il Comune costruisca dei consorzi per l'infrastrutturazione delle aree con i proprietari intenzionati a sfruttare $i$ propri beni immobili, visto che il costo delle infrastrutture richieste ai privati, al momento risulta proibitivo" (Kern, 2002i); forse una soluzione potrà aversi con l'entrata in vigore della Legge Comunale in corso di approvazione sugli "urbanizzatori sociali" (cfr. § 15.2.2), che dovrebbe facilitare l'azione dei privati intenzionati a contribuire alla politica sociale del Comune realizzando insediamenti abitativi di interesse sociale. Un'altra osservazione interessante riguarda, infine, il fatto che i lassi temporali e i valori $\%$ di progressione delle imposte previsti a Porto Alegre dovranno essere rivisti perché 'eccedono' (in grado di penalizzazione dei proprietari privati) quelli ammessi dai compromessi politici che hanno portato all'approvazione dello "Statuto della Città" (cfr. Guimaraens, 2002; Kern, 2002i).

4) Solo Criado_[suolo creato]

È uno strumento giuridico che muove dal principio che il diritto di proprietà (ius proprietatis) non include necessariamente il diritto per il proprietario di 
agire sul proprio bene senza limitazioni conformemente alla sua volontà o al suo interesse: ${ }^{39}$ la sua base costituzionale può essere identificata - fra le altre disposizioni - nell'art. 30 (inciso VIII) della Costituzione. Si considera solo criado l'area costruita che "oltrepassa un certo valore, fissato in ragione delle esigenze globali di uso del suolo, in una data regione" cittadina (Souza J.V., 1991), cioè tutto ciò che viene costruito al livello del suolo, in eccesso a quanto previsto dal coefficiente di sfruttamento dei terreni (Grau, 1983). Nel caso si volesse costruire oltre i livelli permessi dal coefficiente unico, si deve acquisire il diritto di costruire in altri terreni (privati o pubblici) e realizzare una permuta: ad esempio, si destineranno i nuovi terreni a preservazione del patrimonio naturale, artistico o storico, alla creazione di aree di gioco e svago e simili, e la loro capacità edificatoria (non utilizzata a vantaggio del privato) sarà 'trasportata' sui terreni a cui si vuole applicare il solo criado. Non esistono impedimenti a che $\mathrm{i}$ fondi ottenuti dal Comune in rapporto all'utilizzo dei terreni sul suolo comunale vengano convogliati su un Fondo di Sviluppo Urbano destinato alla politica della casa. È quanto viene fatto a Porto Alegre, dove il Solo criado diviene strumento per la costituzione di programmi abitativi di interesse sociale, divenendo misuratore della capacità delle diverse componenti della città di procedere di pari passo senza accrescere le disparità fra fasce della popolazione, ma contribuendo attivamente al complessivo miglioramento della città. ${ }^{40}$ Nella capitale del Rio Grande do Sul, tale strumento è risultato più efficace delle AUOPs perché offre immediati ritorni alle finanze comunali nel momento stesso in cui i progetti di permuta vengono presentati dai privati. Oggi ha un 'forte concorrente interno' (Kern, 2002i) che non permette di monitorare esattamente l'andamento del suo apporto economico alla crescita del Fondo di Sviluppo Urbano. Infatti - durante l'apertura della $\mathrm{III}^{\circ}$ Circonvallazione Perimetrale, l'ente finanziatore internazionale aveva proposto di coprire i costi delle numerose espropriazioni necessarie, ma il Comune di Porto Alegre ha preferito procedere - dovunque possibile - per via di accordi con i proprietari, con l'obiettivo di non smentire la sua linea politica improntata al 'dialogo' col territorio. Il risultato di questa 'operazione di coerenza' è stato che il meccanismo degli incentivi comunali alle 'permute' ha alzato molto il potere contrattuale dei privati proprietari e la loro capacità di negoziazione, e al contempo - per 4/5 anni (cioè finché non saranno esauriti i lavori, o almeno lo stock dei terreni comunali per le permute) sta rendendo impossibile valutare quante 'permute di indici' e quali apporti economici reali può produrre il 'Solo criado' sull'economia cittadina.

5) Trasferimento dello ius aedificandi

La differenza con il solo criado, a cui appare molto simile, sta in questo: un proprietario che volesse costruire al di sopra del coefficiente unico di sfruttamento dei suoli stabilito nei PRG (dove la zonizzazione lo permette), invece di ottenere questo diritto dal Potere Pubblico, lo acquisirà da un privato. In tal senso esso è strumento destinato a compensare i proprietari di immobili interessati da vincoli di conservazione o ad impiantare programmi sociali, qualora si debba negoziare il consolidamento del possesso di persone in condizioni di bisogno che occupino un immobile assoggettabile a questa pratica (Saule, 1997).

6) Riurbanizzazione Consorziata

Le diverse legislazioni municipali e la dottrina giuridica non appaiono dare un'interpretazione uniforme di questo strumento. Il suo utilizzo dipende da 
350 una preventiva dichiarazione di interesse sociale - a fini di esproprio - che deve essere fatta dal Comune relativamente ad un'area di riurbanizzazione. Gli autori che preferiscono definire questa forma indiretta di regolarizzazione fondiaria (presa in senso ampio) come consórcio imobiliário, la ritengono uno "strumento di cooperazione fra il potere pubblico e l'iniziativa privata" attraverso cui il primo realizza opere di urbanizzazione nelle aree carenti di infrastrutture e servizi, e "il proprietario dell'area riceve una quantità di lotti urbanizzati corrispondenti al valore totale che le aree avevano prima di ricevere quei benefici. I lotti in avanzo restano al Potere pubblico, che potrà farne commercio con la popolazione biso gnosa di abitazione" (Saule, 1997). ${ }^{41}$

7) Operazione interrelata

Ogni proprietario, per mezzo di questo strumento giuridico, può richiedere al Comune la modifica degli indici e delle caratteristiche d'uso e occupazione del suolo del proprio terreno oggetto di occupazione abusiva, o di altri di sua proprietà, impegnandosi a costruire e a donare alla Municipalità abitazioni di interesse sociale per la popolazione stessa dell'insediamento irregolare (Silva, 1995). Tali indici - a compensazione - potranno essere sfruttati altrove dallo stesso proprietario. Come sottolinea la Alfonsin (1997), senza le attenzioni indispensabili ai fini di tale attività pubblico-privata, l'operazione può risolversi in una pura e semplice rimozione degli abitanti verso altre aree intitolate allo stesso proprietario. Per questo genere di operazioni (fortemente dipendenti dalla volontà politica dell'Amministrazione) è imprescindibile pertanto l'inserimento in un programma di azioni coerente che contempli principi quali quelli del minimo spostamento e tenga come guida principale l'idea della funzione sociale della proprietà, faro per un'azione illuminata. Nel caso di Porto Alegre, negli ultimi anni si sono dati diversi esempi di 'operazioni concertate' dei cui obiettivi diamo qualche indicazione al § 13.4.2.

\subsubsection{Strumenti giuridici a predominanza amministrativa}

\section{1)Concessione del Diritto Reale d'Uso (CDRU)}

Il Decreto-Legge 271/1967 ha aperto le possibilità di estensione di questo diritto reale già contemplato nel Codice Civile (artt. 742/745), ma fino ad allora limitato all'ambito privato familiare. Ha quindi permesso la destinazione di terreni pubblici o privati all'insediamento di fasce di popolazione a basso reddito, o alla legalizzazione della permanenza in aree già occupate. La concessione è a tempo determinato, rinnovabile, gratuita o onerosa seconda l'orientamento dell'Ente Pubblico, e deve specificare la destinazione d'uso e l'area per cui è concessa (Ribeiro, 1997); contravvenendo i concessionari ai termini, essa può essere revocata dall'Amministrazione. In caso di regolarizzazione fondiaria la destinazione permessa è abitativa, pur non essendo sempre chiaro se attività commerciali o artigianali svolte in ambito domestico possono essere ammesse. Non si sono mai verificate critiche di incostituzionalità alle numerose leggi di ambito locale che recepiscono questo strumento, che sembra del resto possedere solidissime basi costituzionali: è, infatti, previsto dal $\S 1$ dell'art. 183 , che adotta persino una prospettiva esplicita di genere sottolineando che le concessioni possono essere conferite all'uomo, alla donna, o a entrambi, indipendentemente dallo stato civile. ${ }^{42}$ La versione licenziata dal Parlamento dello "Statuto della Città" proponeva di regolamentare una Concessione d'Uso Speciale a fini Residenziali, che ha 
avuto il veto totale del Presidente della Repubblica. Nonostante ciò, data soprattutto la mobilitazione del Forum Nazionale per la Riforma Urbana, ${ }^{43}$ il 4 settembre 2001 lo stesso Presidente ha sottoscritto il Provvedimento Transitorio $\mathrm{n}^{\circ} 2.220$, che, in determinate condizioni, riconosce il Diritto soggettivo (e non più solo la prerogativa delle pubbliche amministrazioni) degli occupanti di immobili di proprietà pubblica - anche comunale - alla Concessione d'Uso Speciale a fini Residenziali (Fernandes, 2002). Il Provvedimento Transitorio stabilisce anche in quali condizioni il potere pubblico municipale può portare avanti la rimozione degli occupanti di aree pubbliche verso altre aree più adeguate.

A Porto Alegre, la CDRU è stata regolata dalla LC 242/91 (modificata dalla LC 251/91) che prevede che le famiglie da beneficiare abbiano utilizzato lotti non maggiori di $150 \mathrm{mq}$ e solo a fini residenziali: per chi risiede in aree di preservazione naturale permanente, con caratteristiche geo-morfologiche inadatte all'uso residenziale, o interessate da investimenti pubblici il cui beneficio per la collettività venga meno a causa dell'occupazione a fini abitativi, è oggi sancito il diritto al trasferimento altrove, in terreni appartenenti al Banco delle Terre. Misure sanzionatorie e rescissorie del contratto di CDRU sono stabilite per chi affitti o venda informalmente a terzi o compri un immobile altrove, mentre si stabilisce specificamente la necessità di far partecipare le comunità locali di residenti ad ogni tappa della regolarizzazione. Due importanti innovazioni riguardano la titolarità attribuita ad entrambi i membri di ogni coppia (in caso di separazione la CDRU sarà riconosciuta a chi avrà l'effettiva tutela dei figli) e il riconoscimento degli usi misti capaci di ingenerare impiego e reddito per i residenti dell'Abitazione/laboratorio o abitazione/negozio. La concessione è stabilita a titolo oneroso (in una percentuale del $7,5 \%$ del reddito familiare) per responsabilizzare gli abitanti e recuperare parzialmente i costi. La LC 445/2000 ha - di recente - introdotto un'importante modifica che viene incontro alle richieste di molti abitanti: all'art. 9 viene- infatti - ammesso il riscatto dell'abitazione (seppur non del lotto, che resta in mano pubblica) da parte del beneficiario, e la possibilità di vendere l'alloggio a terzi, purché non proprietari di altri immobili e capaci di dimostrare la loro appartenenza a fasce sociali di basso reddito. Secondo gli ultimi dati aggregati disponibili, nel 2001 il DEMHAB ha siglato 1439 nuovi contratti di CDRU (Relatório de Atividades, 2001)

2) Catasto delle Terre Pubbliche/Banca delle terre

A rigore, il Catasto delle terre pubbliche (che funge da registro fondiario per una consultazione rapida di tutti i beni immobili titolati come beni municipali) è condizione primaria per interventi di regolarizzazione di beni demaniali (o, più raramente, di beni pubblici di uso speciale o di terreni di uso comune della popolazione) che avvengono attraverso la legge che li 'naturalizza', come avvenuto a Porto Alegre nel caso di Vila Planetario, favela nata in parte sull'area destinata ad una piazza dal PrG. Il Banco de Terras è una sorta di separazione amministrativa fatta nei pubblici registri del Comune degli spazi urbani attualmente o potenzialmente passibili di nuovi insediamenti, destinati ad implementare la politica della casa o utili per il re-insediamento di famiglie povere sgomberate da altre zone o residenti in aree di rischio (sotto i fili dell'alta tensione, sopra condotti sotterranei di combustibile, in zone a rischio di piena o di crolli). È quindi uno strumento per politiche comple- 
352 mentari a quelle mirate alla regolarizzazione dei suoli. A Porto Alegre, nel 2002, il DEMHAB ha speso 1.1000.0000 $\mathrm{R} \$$ in espropri ed acquisizioni per consolidare la sua 'Banca delle terre'.

\section{3) Requisizione Urbanistica}

Per quanto si configuri come requisizione di un immobile di proprietà privata per soddisfare un interesse pubblico, non attinge alla disciplina sugli espropri. Lo chiarisce la definizione elaborata da Cretella (1989), che la definisce come atto unilaterale di gestione pubblica, per cui lo Stato esige da una persona una prestazione d'attività, una fornitura di beni mobili, l'abbandono temporaneo del godimento di immobili o di un'impresa, per usarli in maniera conforme all'interesse generale per un determinato scopo. Essa è giustificata in caso di imminente pericolo pubblico e prevede che sia assicurato al proprietario un indennizzo ulteriore in caso vi siano danni (art. 5, inc. XXV, della Costituzione Federale). Non è raro che un Comune sia costretto a sistemare temporaneamente persone residenti in aree di rischio e che il trascorrere di tempo per cercare soluzioni alternative possa rivelarsi fatale; in quei casi la requisizione urbanistica può essere una soluzione temporanea utile. Nell'ambito delle operazioni di regolarizzazione fondiaria, essa è strumento complementare e temporaneo (non necessita pertanto di essere previsto dalle normative comunali), che serve a tamponare situazioni di emergenza.

4) Diritto di prelazione

Dopo molte accuse di incostituzionalità, è stato recentemente disciplinato dallo "Statuto della Cittă" (artt. 25-26). Attraverso questa prerogativa il Comune ha, infatti, la precedenza nell'acquisizione di beni immobili urbani oggetto di possibile alienazione, togliendo così al suolo urbano la sua caratteristica di pura e semplice merce soggetta, soltanto, alle convenienze del libero mercato e del proprietario (Alfonsin B., 1997). Anch'esso è strumento indiretto e complementare (perché relativo a provvedimenti senza diretto rapporto con occupazioni già in atto nella stessa area) di regolarizzazione fondiaria. Non può essere applicato all'intera città ma solo ad aree previste da specifiche Leggi comunali, meglio se individuate anche all'interno del Plano Diretor (ibidem).

5) Esproprio con pagamento in Titoli del Debito

È la forma più visibile e radicale di intervento pubblico sulla proprietà e lo spazio urbano. La Costituzione Federale ha introdotto novità importanti a riguardo, come il permesso ad indennizzare i proprietari con titoli del debito pubblico, cosa che prima avveniva solo in ambito rurale. In tal modo si evita di dover attuare gli espropri con diretto coinvolgimento delle casse municipali e quindi facendola precedere da lunghe valutazioni di opportunità.

6) Sdemanializzazione [desafetação]

È la manifestazione di volontà solenne del Potere Pubblico che un bene di dominio pubblico sia sottratto alla demanialità pubblica per essere incorporato nel dominio privato dello Stato o del privato; il processo può essere espresso o tacito, come nel caso di disuso immemorabile di un bene pubblico da parte dell'amministrazione competente (Cretella, 1989), e si dimostra di particolare rilevanza per le regolarizzazione di aree pubbliche in origine destinate a uso comune ma da lungo tempo occupate, e che si vorrebbero trasferire alle popolazioni ivi residenti. Molti Statuti Comunali hanno riconosciuto questa forza normativa fattuale. Ad esempio l'articolo $1^{\circ}$ delle Disposizioni transitorie di quella di Porto Alegre afferma che: 
Agli occupanti di aree di proprietà del Comune, di sue Autarchie, imprese pubbliche e società a capitale misto, non urbanizzate o edificate anteriormente all'occupazione, che ivi abbiano stabilito la loro dimora entro il 31 gennaio 1989 e che non siano proprietari di altri immobili, sarà concesso il diritto reale di uso come regolamentato nella legge complementare che dovrà essere votata entro 60 giorni $[\ldots]$.

$\S 1^{\circ}-E^{\prime}$ vietato il trasferimento a terzi del diritto reale d'uso

$\S 2^{\circ}$ - Nel termine di 180 giorni dalla promulgazione della Legge Organica, l'Esecutivo, insieme con l'Unione delle Associazioni di Residenti di Porto Alegre, procederà al rilevamento [...] di dette aree, dopo aver dato avvio alla Camera Municipale ad un progetto di legge che regolamenti la concessione del Diritto Reale d'Uso.

\section{7) Regolarizzazione di parcellamento}

Nel tener conto delle conquiste legali e giurisprudenziali riconosciute agli acquirenti degli immobili già prima della sua promulgazione, la Legge 6766/ 1979 si occupò di regolare le promesse di compravendita dei beni immobili urbani, premurandosi di disciplinare lo spazio urbano che costituisce l'intorno delle lottizzazioni in modo da preservarlo da possibili distorsioni ambientali e paesaggistiche generatrici di inconvenienti urbanistici. In questo contesto, l'art. 38 prevede come strumento di azione e garanzia la regolarizzazione delle lottizzazioni e delle loro suddivisioni clandestine e irregolari. ) A Porto Alegre, per portare avanti questi interventi sulla base della LC 140/86 (che riguarda solo divisioni di lotti anteriori al 1979) è nata informalmente dentro la Unità di Parcellamento dei Suoli della SPM un'Equipe di Coordinamento delle Regolarizzazioni Fondiarie in forma di routine amministrativa di identificazione, apertura di procedimenti, avviamento dell'iter di regolarizzazione di loteamentos senza alcuna priorità (B. Alfonsin, 1997). Nel nucleo di Regolarizzazione dei Parcellamenti del DEMHAB si sono iscritti 40 nuclei entro il termine stabilito dal Decreto del Sindaco 11637 del 4/12/96 (alterato con decreto 11806 del24/9/97), con il vincolo di essere abitati da persone con salari inferiori ai 12 minimi familiari, e di dimostrare che hanno diritto a chiedere la dichiarazione di AEIS perché il $50 \%+1$ degli abitanti ha reddito basso. Per aversi regolarizzazione, "in teoria, all'approvazione della 'licença de operação' che è l'abitabilità dei lotti, le case non ci dovrebbero essere. Ma in genere ci sono già tutte (Almeida, 1999i). La Comunità deve contrattare un tecnico per fare il progetto urbanistico ed un memoriale descrittivo dei lotti; la scelta può avvenire in apposite liste di professionisti autorizzati all'abbattimento fino al $40 \%$ delle tariffe professionali in aree povere, concordate con il Sindacato degli Architetti. Le case sui lotti registrati al Catasto saranno tutte regolarizzate; il 'nuovo' e le 'demolizioni con ricostruzione' sono considerate fuori dal congelamento che la regolarizzazione apporta allo stato di fatto e devono passare per le regolari procedure previste dal PRG. Inoltre, questo dovrebbe valere solo per le attività residenziali, anche se oggi si tollerano attività miste svolte in casa. I processi sono lenti, per le difficoltà della comunità di riunirsi e contrattare tecnici; molti "hanno l'idea che sia il Municipio a doverlo fare per loro. Solo oggi che l'O.P. è diventato più rigoroso nel chiedere accordi di impegno alla regolarizzazione fondiaria da parte delle comunità, queste vanno organizzandosi ed abituandosi ad una cultura della 'carta'(Almeida, 1999i). Così, dei 358 parcellamenti che a fine 1995 erano stati monitorati come rientranti nelle possibilità di regolarizzazione 
354 offerte dalla Legge 140/86, nel 1997 solo 181 avevano sollecitato la regolarizzazione amministrativa e 2 soli l'avevano ottenuta, beneficiando meno di 500 persone. Al gennaio del 1999, però, già 85 risultavano i parcellamenti con procedimenti in corso d'opera (Alibio, 1999i). ${ }^{44}$ All'inizio del '97 il COMATHAB [Consiglio Municipale della Terra e dell'Abitazione] ha affrontato il problema, chiedendo al Sindaco la creazione di una struttura di regolarizzazione specifica per i parcellamenti irregolari. La competenza è stata trasferita nuovamente al DEMHAB dove è stata creata unapie Unità di crisi detta NRL [Nucleo para Regularização de Loteamentos] per il trattamento di questo tipo di regolarizzazioni, una conquista ulteriore della pressione popolare esercitata nei diversi canali di partecipazione presenti a Porto Alegre per far comunicare in modo trasparente cittadini e Amministrazione. Così, negli ultimi anni, alcuni criteri per occuparsi di questo genere di regolarizzazioni sono mutati anche nel Regolamento Interno dell'O.P., richiedendo però sempre la dimostrazione del basso reddito, un formale impegno delle varie comunità alla regolarizzazione, ed una compartecipazione cospicua alle spese della legalizzazione. ${ }^{45}$

\subsubsection{Strumenti giuridici a predominanza tributaria}

\section{1) IPTU Progressivo}

In senso ampio, è anch'essa una misura indiretta integrativa (in questo caso preventiva) nelle procedure di regolarizzazione fondiaria. Per riassumere le caratteristiche di questo strumento (di cui abbiamo già accennato nel paragrafo su "Parcellamento, edificazione ed utilizzazione obbligate"), va sottolineato che l'Imposta Urbana sugli Edifici e i Terreni Progressiva nel Tempo, è una forma di sanzione imposta ai proprietari di suoli dall'art. $182, \S 4$, della Costituzione Federale. Essa è proporzionale ai beni posseduti e al grado di inazione rispetto a quello che richiede l'esercizio del suo diritto in rapporto alla funzione sociale che gli è propria (B. Alfonsin, 1997). Purtroppo non esistono ancora ricerche e dati che indichino gli effetti sortiti da questa Imposta sanzionatoria sull'uso del territorio. Certo è che una misura consimile prevista nello Statuto della Terra - l'Imposta Territoriale Rurale (IPTR) - non ha prodotto nel tempo i benefici sperati ai fini della Riforma Agraria, anche a causa della latitanza dei meccanismi di controllo che hanno determinato alti gradi di impunità (id.). La finalità di questa misura è extrafiscale, dal momento che non mira ad arricchire le Finanze Municipali, anche se - come visto nel caso di Porto Alegre - può tendere a ridursi a ciò se non inserita in un piano coordinato di azioni mirate a sviluppare la sua ratio.

2) Contributo di miglioramento (Contribuição de Melhoria)

È un'altra forma indiretta (con valore preventivo) di aiuto ai processi di regolarizzazione. Consiste in un tributo mirato a restituire al Potere Pubblico l'equivalente in denaro della valorizzazione ottenuta da un privato, in immobili di sua proprietà, come risultato di investimenti pubblici. È, cioè, una sorta di compensazione per gli investimenti fatti dall'Amministrazione. L'utilità del contributo interviene anche nella misura in cui nessun Ente Pubblico che ha il potere di esproprio è mai riuscito ad ottenere - nel portare avanti un'azione di esproprio - alcuna riduzione al valore dell'indennizzo dovuto agli aumenti di valore apportati da interventi pubblici (Alfonsin De Moraes, 1997). 


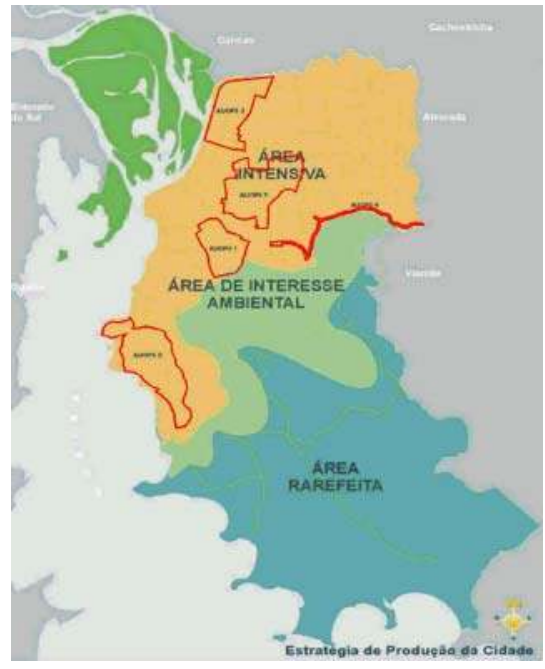

Fig. 45 - Le AUOPs (Aree Urba-

Ipotesi sul numero di beni immobili da notificare all'interno delle AUOPs (in funzione del valore delle aree, in RS, al 1/7/2002)

Fonte: M.E. Guimaraens, M.E. 2002

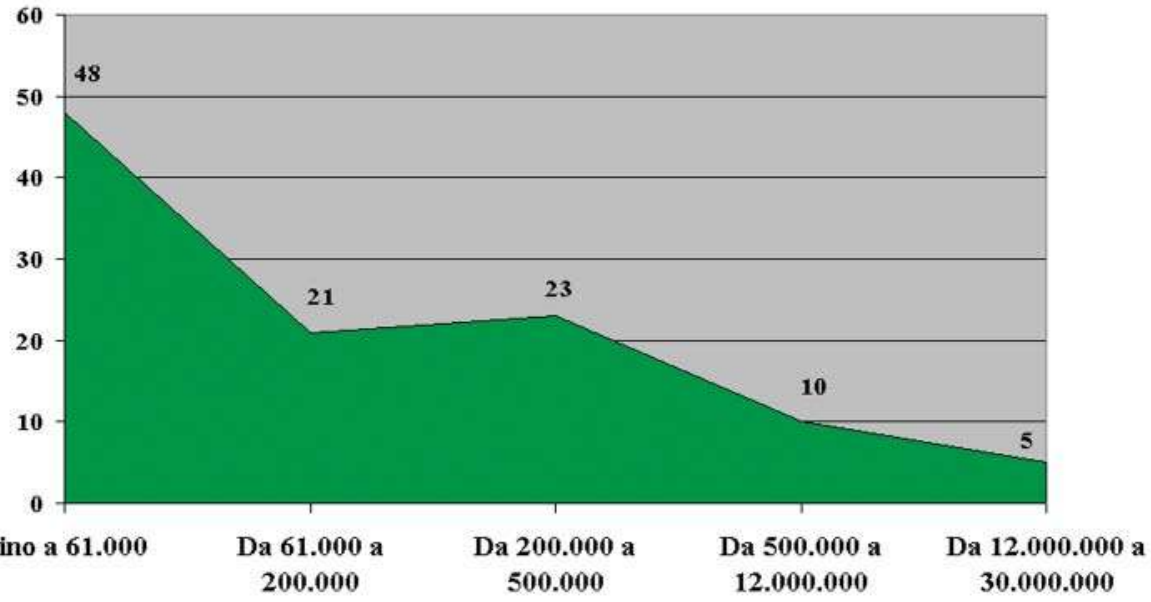

Ipotesi sul numero di beni immobili da notificare all'interno delle AUOPs

(in funzione delle dimensioni delle aree)

Fonte: M.E. Guimaraens, M.E. 2002

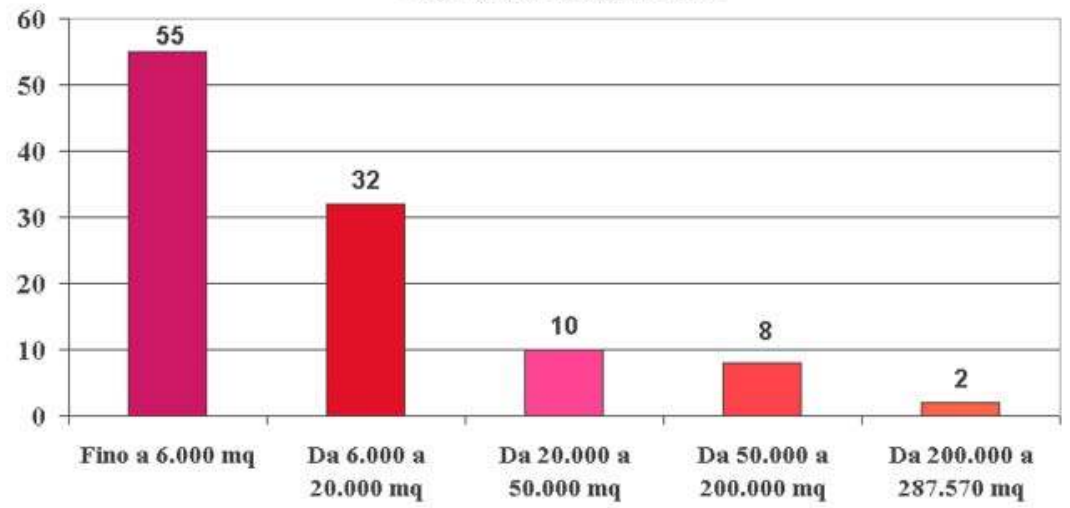




\section{11.4.4 Strumenti giuridici originati dal diritto privato}

\section{1) Usucapione urbana}

Tale istituto interessa soprattutto laddove $\mathrm{i}$ fenomeni di occupazione riguardino terreni privati. Essa, infatti, rappresenta una delle forme di acquisizione della proprietà, come diritto reale maturato nell'esercizio del possesso su un bene immobile, con spirito di proprietario e per un lasso di tempo determinato dalla Legge. L'art. 183 della Costituzione Federale ha messo insieme numerose proposte di iniziativa popolare elaborate in fase pre-costituente, prevedendo la possibilità dell'usucapione entro un termine di 5 anni per beni immobili di area non eccedente $250 \mathrm{mq}$ utilizzati per abitazione propria o della propria famiglia, e qualora il possessore non sia proprietario di altro immobile e non vi siano state contestazioni dei legittimi proprietari in tempo utile. La giurisprudenza brasiliana non ha mostrato uniformità di vedute sull'applicabilità immediata di questo strumento oggi previsto dall' art. 9 dello "Statuto della Città": in particolare - nelle azioni collettive (oggi disciplinate dall'art. 10 della stessa legge) gli occupanti appellantisi a questo strumento sono usciti sconfitti dal giudizio dei tribunali. ${ }^{46}$ Solo a Recife (attraverso l'acquisizione di dominio utile su terreni costieri oggetto di enfiteusi) condizioni locali speciali hanno reso possibile un procedimento altrove impossibile finché non precisamente disciplinato da una Legge specifica, che ora però c'è.

A Porto Alegre, il lavoro istruttorio per le 'azioni di Usucapione' è realizzato dall'Unità di Regolarizzazione e Titolazione legata al DEMHAB. Solo a fine processo entra in gioco l'Avvocatura del Comune (PGM) attraverso il servizio gratuito di Assistenza Giuridica Municipale per iniziare l'iter legale in tribunale in vista della sentenza. Nel 1997 (data dell'ultima indagine sul tema, cfr. Alfonsin, 1997) le 'vilas' interessate dal procedimento erano già 47, insediate su aree private, con oltre 17.500 lotti da regolarizzare $;{ }^{47}$ in nessuna sono stati conclusi il lavori, e i ritardi e i cambi nelle equipe tecniche hanno già fatto desistere molti abitanti. Del resto, le tappe previste a Porto Alegre richiedono tempi di attesa molti più lunghi della semplice regolarizzazione fondiaria in aree pubbliche (dai 4 anni in su) per via dell'intervento della magistratura nella parte conclusiva del processo, e rischiano così di rendere inattuali i rilievi topografici a causa della mobilità nell'area. Per questo, per accelerare i tempi, oggi sono priorizzate le aree per cui già esista denaro in bilancio (ovvero ottenuto dagli abitanti nel Bilancio Partecipativo ) per dare continuità alla regolarizzazione tramite l'urbanizzazione immediata parallela al processo di legalizzazione giuridica.

2) Diritto di Superficie

È un contratto - diverso pertanto dalla concessione - per cui un proprietario [superficiente], mediante atto pubblico riportato sul Registro degli Immobili, "concede ad un altro [superficiario] il diritto di erigere sulla superficie del suo terreno, per un tempo determinato o indeterminato, a titolo gratuito o oneroso, qualunque costruzione il dominio sulla quale spetterà al superficiario per tutta la permanenza in vigore del contratto" (Silva, 1995). Come accade per il Solo Criado e con altri strumenti giuridici che sembrano sminuire la pienezza del godimento del diritto di proprietà, sovente lo strumento del Diritto di Superficie è stato accusato di incostituzionalità, tanto più che - benché di antica tradizione - non è neppure stato incorporato nel Codice Civile. 


\subsection{Alcune riflessioni}

Come evidente dall'excursus del paragrafo precedente, gli interventi di Regolarizzazione Fondiaria richiedono il coordinamento di tipologie diverse di strumenti giuridici strictu sensu ${ }^{48}$ con altri collaboranti, necessari - ad esempio - ad individuare le fonti di finanziamento per dette politiche o ad inquadrare alcune procedure amministrative collegate alle fasi precedenti o successive ai processi stessi. L'uso di tali strumenti differisce - spesso anche notevolmente - nelle varie realtà di applicazione: ad esempio, nell'uso degli strumenti 'a predominanza amministrativa' e 'originari del diritto privato' in molti ambiti locali si riscontrano modalità prevalentemente mirate alla legalizzazione della posizione individuale delle famiglie irregolarmente insediate sul territorio piuttosto che delle varie comunità informali nel loro complesso. Del resto, la difficoltà di 'attecchimento' dei mezzi di regolarizzazione collettiva dei terreni occupati ha a che fare con "una mentalità che non risparmia le classi più povere" identificando "la libertà con misure che si legano sempre di più alla sfera dei diritti di proprietà individuali" (Moraes, apud Allegretti 2000a):

Coloro che vanno in controtendenza sono pochi, sono piccole comunità fortemente politicizzate. Ma per lo più i singoli non mostrano alcun interesse per le regolarizzazioni collettive dei terreni. Alle difficoltà giuridiche si aggiunge quindi il mancato supporto alla volontà politica; ciò che interessa ai 'posseiros' è vedersi garantito a fine processo un titolo di usufrutto - o meglio di proprietà - individuale. In questo senso solo poche città oggi tentano programmi più vasti di diffusione di una coscienza di gruppo. Porto Alegre è fra queste - seppur anche lì l'usucapione collettiva non è riuscita ad attecchire - le altre si limitano a quel poco di coscienza del costruire in collettività che dà il mutirão, misura importante ma non sufficiente a cambiare una mentalità (Moraes,1999i, a pud Allegretti, 2000a).

Gli strumenti giuridici di regolarizzazione fondiaria presenti nell'ordinamento brasiliano hanno, quindi, possibilità di 'presa' e 'attecchimento' differenti. Accanto a quelli 'reali' di maggior uso, che Alfonsin (1997) definisce necessari ma non sufficienti, ne esistono così altri - che si potrebbero definire 'virtuali' o 'in potenza' - che risultano sottoutilizzati più o meno in tutti $\mathrm{i}$ contesti. Il Banco de Terras, l'usucapione collettiva (cioè rilasciata a nome di gruppi di persone associate, con proprietà indivisa) e la requisizione urbanistica sono tra quelli ovunque più sottoutilizzati; altri tendono a divenire 'virtuali' nei singoli contesti a seconda degli orientamenti congiunti dell' Amministrazione e della popolazione. E ciò pare vero soprattutto per gli strumenti giuridici che sembrano maggiormente sminuire la pienezza del godimento del diritto di proprietà, come il Diritto di Superficie, il Solo Criado, l'IPTU progressivo, l'Espropriazione con Titoli del Debito ed il Contributo al Miglioramento: essi rappresentano le forme più visibili e radicali di intervento pubblico sulla proprietà e lo spazio urbano in direzione del soddisfacimento del dovere alla funzione sociale della città e della proprietà più volte richiamato dalla Costituzione, ma - stante l'impopolarità di cui godono presso i 'poteri forti' cittadini - finiscono per restare strumenti poco sfruttati, in attesa che lo "Statuto delle Città" - sancendone con più forza la necessità di utilizzo - ne sviluppi le grosse potenzialità attraverso uno stimo- 
358 lo alla trasformazione del contesto politico-giuridico in cui sono stati fino ad ora interpretati ed usati.

Notevoli differenze di impostazione tra contesti connotano anche le politiche e le strategie operative di legalizzazione della città 'informale' nell'ambito delle quali i diversi strumenti sono utilizzati per lo più con l'obiettivo della regolarizzazione giuridica degli insediamenti, che risulta però di solito esito più difficile da raggiungere persino di quelli di 'inclusione sociale' portati avanti in parallelo. Non sono poche, oggi, le Amministrazioni che vanno ampliando le forme del coinvolgimento diretto ${ }^{49}$ almeno della popolazione beneficiaria dei vari progetti nella discussione degli stessi, a livelli differenti di organizzazione, partenariato, corresponsabilizzazione e impegno fattivo e determinante. Raramente, però, si va oltre i beneficiari diretti ${ }^{50}$ per coinvolgere - come nel caso di Porto Alegre - la popolazione urbana nel suo complesso, affinché si esprima su scelte 'di punta' e su politiche fondamentali dell'amministrazione.

L'idea di ricorrere proficuamente ad equipe di lavoro multidisciplinari (piuttosto che al lavoro di singole categorie professionali, foss'anche in parallelo) inizia invece a diffondersi notevolmente, dopo ormai 10 anni di sperimentazioni internazionali sul tema della regolarizzazione fondiaria, e va conducendo a risultati migliori, e in ogni caso più 'risolutivi' (ci si perdoni il gioco di parole) perché più duraturi e ricchi di interdipendenze. In quest'ottica molte amministrazioni brasiliane possiedano ormai una Soprintendenza che coordina le operazioni partendo dall'assimilazione dell'idea che la politica abitativa è molto più che la semplice produzione di abitazioni, ma implica anche $\mathrm{i}$ concetti di sicurezza giuridica, sanitaria e di riconoscimento politico davanti all'Amministrazione, con le loro implicazioni sociali, psicologiche ed economiche. Le fattive rivoluzioni oggi in atto all'interno delle strutture amministrative tradizionali, sono il segnale di una maturazione notevole della politica amministrativa brasiliana in parallelo col mutare della coscienza internazionale su questi temi. Così come lo è lo sforzo compiuto dalla maggior parte delle Amministrazioni per evitare gli sgomberi forzosi nei propri territori, per limitarne il numero o almeno attuarli con preparazione psicologica e tentativi di convincimento preventivo della popolazione attraverso l'indispensabile prestazione d'opera di assistenti sociali ed intermediari di vario genere (dai sacerdoti delle varie fedi, alle ONG locali, fino alla pubblicità sui media).

Sebbene il ruolo di intermediatrici svolto dalle Amministrazioni assuma rilevanza sempre maggiore nei confronti dei conflitti anche fra privati proprietari e occupanti, la pratica della negoziazione è ancora lontana dall'essere istituzionalizzata come strumento di intervento sulla città informale; in città come Rio essa è addirittura lontana dall'essere utilizzata nella pratica. Altrove, come a Porto Alegre, la negoziazione si affianca, invece, in maniera assidua alla regolarizzazione fondiaria, cercando di dar corpo ad una politica abitativa di tipo nuovo che "rafforzi la sfera pubblica non-statale" introducendo "specificità" ed istanze locali nella discussione sul problema dell'accesso ai suoli e della casa (B. Alfonsin, 1997).

Nel complesso, però, si percepisce ancora una diffusa difficoltà a portare avanti contemporaneamente interventi di regolarizzazione nei diversi tipi di aree (pubbliche, private) e di suddivisioni di lotti (irregolari, clandestine, occupate). La tendenza di molte Amministrazioni a "specializzarsi" nel ri- 
spondere ad alcune situazioni (ibidem) può però andare sia a detrimento delle comunità che occupano aree con caratteristiche diverse, sia della crescita uniforme ed equilibrata delle città. A Rio la priorità è, ad esempio, di regolarizzare i parcellamenti irregolari di suolo [loteamentos], mentre a Porto Alegre, almeno fino a 2-3 anni fa, in quel settore non esistevano interventi numericamente significativi e ci si concentrava soprattutto sulla Concessione del Diritto Reale d'Uso in aree pubbliche occupate da 'favelas' . Ciò non toglie, però, che vi possano essere anche situazioni che necessitano un urgente intervento negli ambiti poco presi in considerazione. Al superamento di questa 'settorializzazione' delle modalità di intervento non contribuiscono certo strutture municipali spesso vecchie, burocratizzate nei flussi decisionali ed incapaci di esprimere la volontà politica necessaria per favorire l'integrazione fra i diversi organismi (e fra i diversi livelli) della Pubblica Amministrazione; così come non aiuta l'eccessiva rigidezza della legislazione sui Catasti e i Pubblici Registri, che spesso si manifesta nella pratica come resistenza degli ufficiali di registro a nuove forme di organizzazione dei dati e alla flessibilizzazione con nuovi strumenti per l'attribuzione dei titoli di proprietà (ibidem).

Ciò determina spesso una grande precarietà delle registrazioni degli interventi condotti "in un mondo dove la cultura orale è la regola" (B. Alfonsin, 1997) che non solo lascia nell'insicurezza gli abitanti delle aree solo parzialmente regolarizzate (in quanto non sono state terminate le procedure di registrazione catastale), ma crea anche perdita di informazioni e contenuti, rende difficoltose le valutazioni di costi e benefici anche al fine di una replicabilità o di un miglioramento dei programmi. $\mathrm{E}$ a volte può pregiudicare persino il risultato dei progetti: ad esempio quando, in mancanza di documentazione cartacea o elettronica, la sostituzione di un tecnico coincide con la perdita della storia del progetto e di molti dei dati e conoscenze ad esso relativi.

Questo accade molto spesso a motivo della mancanza di continuità politica a livello municipale ${ }^{51}$ e si traduce spesso in discontinuità degli interventi di regolarizzazione, creando continue aspettative e frustrazioni e scaricando sui cittadini le disfunzioni conseguenti ai meccanismi democratici dell'alternanza. E non è un caso che gli esperimenti con risultati migliori emergano sempre nelle rare città (come appunto Porto Alegre) caratterizzate da una solida continuità politica.

E' forse troppo sperare che "Lo Statuto della Cittä" possa - da solo - dar vita ad una nuova cultura che permetta di dare rapida soluzione a tutti questi ostacoli. È certo, però, che almeno su un tema è fondamentale concentrare nei prossimi anni la riflessione: la relazione dei processi di regolarizzazione fondiaria con il mercato formale delle terre nelle città brasiliane. Vi è, infatti, un rischio reale che i programmi di legalizzazione degli insediamenti generino effetti perversi non voluti, reinserendo d'improvviso nel mercato dei suoli una popolazione con bassi redditi storicamente esclusane. Il rischio di 'assedio' (B. Alfonsin, 1999i) da parte della speculazione fondiaria nei confronti di questi nuovi proprietari - per giunta spesso inesperti dei meccanismi del mercato e facilmente allettabili ed anche raggirabili - è ormai da lungo tempo al centro delle preoccupazioni del Potere Pubblico, anche nella misura in cui rischia di esporre le esperienze compiute ad un fallimento dei loro obiettivi primari, quelli cioè di garantire una casa alle popolazioni a basso reddito e di regolarizzare vaste porzioni di città informale cercando di minimizzare le 
360 ingiustizie e di pervenire rapidamente a situazioni di equilibrio legalizzato. ${ }^{52}$ In tale ottica, sono già stati sperimentati in questi anni meccanismi giuridici 'autovaccinati' contro questo problema per proteggere il residente del terreno regolarizzato dall'espulsione, almeno da quella 'bianca' che avviene attraverso il mercato formale (visto che spesso è difficile agire su quello informale). Le ZEIS e le AEIS, per esempio, conferiscono alle aree su cui si sviluppano un preminente interesse sociale, cioè precisano che la loro destinazione è esclusivamente mirata ad abitazioni di interesse sociale, riducendo così il valore del terreno e conseguentemente l'interesse degli eventuali speculatori. Stabilendo parametri urbanistici restrittivi - a partire da quelli sulle dimensioni dei lotti, dei coefficienti di sfruttamento e dei rapporti dimensionali [gabaritos] - le ZEIS costituiscono meccanismi automatici di riduzione dell'interesse del mercato immobiliario per quelle aree; ma, al contempo, 'marchiano' le aree impedendo loro una completa integrazione nel territorio dove si collocano. Questa integrazione andrà quindi conseguita con azioni parallele, come programmi sociali e particolare cura delle 'interfacce' tra quartieri di origine e prevalenza sociale diversa, lavorando - ad esempio - sul valore simbolicoaggregativo degli spazi pubblici e sugli 'eventi' (fiere, sagre, tornei sportivi) che possano garantire una certa continuità di animazione e di fusione sociale. Un tema su cui, da ormai quasi 10 anni, va lavorando il Programma di Rio de Janeiro Favela-Bairro (pur con i suoi numerosi limiti cfr. Allegretti, 2000a e 2001a), ma anche molte città che cercano di propiziare l'integrazione sociale attraverso il lavoro con i bambini e con le scuole e lo sport quali strumenti di 'ricostruzione dal basso' della coesione urbana.

Ciò che va messo in discussione è quindi un quadro di azioni e politiche molto più vasto di quello che concerne semplicemente l'esegesi e l'uso dei nuovi strumenti normativi che lo "Statuto della Cittă" sistematizza e chiarifica. Vuol dire, forse, ripartire dall'ingegno locale e dalle sperimentazioni contraddittorie ma entusiasmanti di contesti tra loro diversi, per cercare modi di ridurre i limiti e le distorsioni ancora evidenti nei processi di reinserimento della città formale in quella 'di diritto'.

È in quest'ottica che nei prossimi capitoli esamineremo alcune politiche messe in atto nell'ultimo decennio a Porto Alegre nel tentativo di non far navigare isolatamente nel mare delle politiche urbane gli strumenti giuridici necessari per reintegrare la città irregolare, connettendone l'uso sistematico con nuovi canali di partecipazione popolare e di divisione delle responsabilità dello sviluppo urbano fra 'società politica' e 'società civile'

\section{Note}

${ }^{1}$ Anche se solo dopo alcuni anni, a motivo degli stock accumulati di lotti suddivisi e registrati in passato con riferimento ad altre normative.

${ }^{2}$ In Brasile i Consigli Comunali hanno un potere legislativo, esercitato attraverso Leggi Complementari (L.C.)

${ }^{3}$ Norme di promozione dello sviluppo basate su regole generali ed uguali per tutti inevitabilmente finiscono per accentuare le disuguaglianze già esistenti sul territorio.

${ }^{4}$ Il Censimento di quell'anno rientra negli impegni presi dal Comune all'art. 230-IV dello Statuto Municipale, di promuovere quinquennalmente un censimento della popolazione con basso reddito, il primo dei quali dovrà essere divulgato entro il 30 dicembre 1996. ${ }^{5}$ Il nome è usato quasi solo a Porto Alegre. Di per sé sarebbe un termine neutro, che originariamente designava un concetto molto vicino alla traduzione del vocabolo in- 
glese alley (una stradina semi-privata su cui prospettano piccole case allineate), ed è oggi passato ad indicare per antonomasia i quartieri poveri autocostruiti in seguito ad un'occupazione di terra collettiva o spontanea (Anton, 1999i; DEMHAB, 1999). La traslazione di significato del termine è avvenuta tramite la definizione di vila de malocas, a seguito della perdita della seconda parte del binomio. Questa progressiva 'contrazione del nesso logico' con successiva modifica del significato di un vocabolo che altrove ancora conserva il suo significato originale di alley (a São Paulo ad esempio, oltre che in tutti i toponimi storici anche di quartieri alto-borghesi della metà del secolo) è stata resa possibile dal forte ruolo politico svolto nell'ultimo ventennio dai movimenti urbani di Porto Alegre e di altre città del Brasile meridionale, unita all'uso di un termine che nella sua originaria connotazione si caratterizzava più per la forza puramente descrittiva dell'immagine che evocava, che non per una stigmatizzazione negativa del fenomeno che mirava a descrivere. Oggi, pertanto, il termine vila (talora vila popular) costituisce a Porto Alegre e dintorni il sostituto privilegiato - e suppostamene 'neutrale' quanto a connotazioni dispregiative o laudative - di vocaboli quali invasão o occupação, non più tollerati a causa della loro connotazione polemica non solo dagli abitanti, ma anche da istituzioni pubbliche che ritengono fondamentale impostare su nuove basi (anche 'terminologiche') un dialogo produttivo con gli abitanti dei quartieri autocostruiti, che eviti il più possibile ogni fattore di tensione, polemica e fraintendimento fra il potere pubblico e i cittadini a cui si rivolge.

${ }^{6}$ Tra il 1997 e il 1998 il DEMHAB ha realizzato 14 censimenti socioeconomici su 1920 abitazioni e 7481 abitanti da cui ha dedotto la media di 3,90 abitanti per vano nei nuclei irregolari (DEMHAB, 1999).

${ }^{7}$ Conselho Municipal de Accesso a Terra e Habitação (2001); O diagnóstico da situação habitacional de Porto Alegre, Pref eitura de Porto Alegre, Porto Alegre

${ }^{8}$ Il $56,41 \%$ dei nuclei hanno meno di 100 domicili, ma sul totale delle abitazioni non superano il $10,77 \%$. La fascia di maggior rappresentatività resta comunque quella delle favelas di dimensione 'media' (tra 101 e 500 abitazioni) che costituiscono il $41,16 \%$ del totale (DEMHAB, 1999).

${ }_{9}^{9}$ Nell'agosto del 1989 tre grileiros furono cacciati dalla polizia dal Morro da Polìcia su segnalazione degli abitanti di alcune favelas della Regione Gloria; lo stesso giorno l'area di protezione ambientale che essi avevano cominciato a suddividere in lotti fu riforestata (cfr. Zero Hora, 23/8/89).

${ }^{10}$ Nella ricerca della Jordão, addirittura tra i collaboratori viene citato il Sociologo del DEMHAB Aldovan De Oliveira Moraes, che ha compiuto gli studi per la ricerca parallela.

${ }^{11} \mathrm{Nel} \S 1$ del censimento, I redattori affermano di voler riportare l'Unità di Ricerca (UPE) ad andar oltre il semplice censimento socio-economico di emergenza per sussidiare, invece, la politica della casa del DEMHAB. Pur essendo il censimento solo di tipo quantitativo, i dati e le notizie raccolte per alcune regioni e quartieri nello svolgimento del testo, anche prendendo coscienza della difficoltà di dare un quadro completo distendendo la ricerca su 2 anni (dal 17/7/96 al 29/6/98) con diverse interruzioni forzose.

12 In tal senso, i due testi sono interessanti anche per l'attenta cura del linguaggio, realizzata (nel caso di quello del DEMHAB) anche ai fini della pubblicazione e della distribuzione gratuita alle Associazioni di Quartiere. Ad esempio, il termine occupazione è usato solo in due casi: per riferirsi a nuclei già costruiti e poi invasi, e per indicare costruzioni di baracche a lato di spazi pubblici prive di un centro di gravitazione che non sia l'affaccio stesso su di essi. Inoltre, nell'esaminare le singole aree di autoproduzione abitativa, vengono accolti vocaboli di uso popolare e nominativi auto-attribuiti dagli abitanti finora mai codificati, mostrando un senso di realtà ed un rispetto per l'ambito tematico/problematico descritto.

${ }^{13}$ Nella versione del Piano 'commentata' in linguaggio comune è scritto: "Parcellamento é una forma de divisione del suolo in cui avvenga necessariamente l'apertura di nuove vie. 'Parcellizzare' significa dividere un'area in riquadri costituiti da parti di terreno minori, separate da strade e con spazi destinati a piazze o ad una scuola".

${ }^{14} \mathrm{Da}$ Silva (1995) definisce l'insediamento non-conforme come quello in cui l'edificazione non rispetta le restrizioni, insieme o isolatamente, concernenti il dimensionamento, gli allineamenti, l'occupazione e gli standard dimensionali stabiliti per il lotto. Basterebbe aggiungere a tali restrizioni la proprietà (titolo) della terra per incontrarvi un ritratto dell'oggetto-spazio caratteristico delle operazioni di regolarizzazione (B. Alfonsin, 1997). 'parcellamenti irregolari' e 'clandestini' sono sanzionati dalla Legge 6766/ 
79 (specialmente negli articoli 38 e 50/52), sulla carta dotata di molta forza per punire (civilmente e penalmente) il lottizzatore, ma in tal senso rimasta lettera morta, per la mancanza di organizzazione e volontà politica di molti comuni di portare avanti controlli circostanziati, che si rivelerebbero utili di fronte alle grandi difficoltà che la regolarizzazione di simili lotti anomali generano, costringendo a ricorrere contemporaneamente all'ausilio di molti strumenti giuridici. L'inesistenza dei numeri di classificazione delle particelle - nel caso delle lottizzazioni clandestine - ingenera l'impossibilità di agevole negoziazione e compravendita dei lotti stessi da parte dell'Amministrazione interessata a portare avanti il processo. La Legge 6766/79 ha in tal caso un grosso peso per le conseguenze fisiche, giuridiche, amministrative, procedurali e di accatastamento dei lotti nei processi di regolarizzazione, intervenendo a tutela dei compratori in fase di acquisto per la regolarizzazione dei lotti.

${ }_{15}$ Come nella Legge Comunale 338/95 sulle Areee Speciali di Interesse Sociale e nel PDDUA del' 99 .

${ }^{16}$ E il caso di 6 delle 'vilas' inserite nel programma 'More Melhor' del DEMHAB, irregolari anche se una parte dei loro lotti ha con il DEMHAB (proprietario delle aree) dei Contratti Privati di Promessa di Compravendita o Carta di Impegno.

${ }^{17}$ Il documento del COMATHAB (2001) che sono considerate irregolari anche quei nuclei e quelle 'vilas' localizzate in aree di proprietà del DEMHAB in cui meno dell' $85 \%$ dei lotti hanno qualche tipo di contratto.

${ }^{18}$ È a Belo Horizonte che, nel 1983, fu emanata la Legge che ha reso possibile il ProFavela, un provvedimento pioniere nel proporre un programma sociale di regolarizzazione delle favelas, avendo introdotto una formula originale: la combinazione tra l'identificazione e la demarcazione delle favelas come aree residenziali a fini di abitazione sociale - inizialmente denominate "settori speciali" - nel contesto della zonizzazione municipale; la definizione di norme urbanistiche specifiche di uso, parcellamento e occupazione del suolo in tali aree; e la creazione di meccanismi politico-istituzionali di gestione partecipativa dei programmi di regolarizzazione.

${ }_{19}$ Sul tema - internazionalmente noto come "security of tenure", dal 1999 sta venendo portata avanti dall'agenzia Habitat dell'ONU la Campagna Globale sulla 'Garanzia del possesso' (cfr. il sito UNCHS-United Nations Centre for Human Settlements (Habitat) www.unchs.org/tenure).

${ }^{20}$ Il Seminario Internazionale di Città del Messico (24-26/2/1993) ha così definito la regolarizzazione fondiaria: "Regolarizzare un insediamento umano è dare un contenuto specifico al diritto ad un alloggio adeguato, attraverso un processo che coinvolga il miglioramento dei metodi per riconoscere l'occupazione e legittimare l'accesso al credito, ai servizi (urbani) e alle opportunità" ( in Ribeiro Jordão et al., 1999).

${ }^{21} \mathrm{La}$ conclusione parrebbe quasi intuitiva, ma non sempre ha ispirato molti degli esperimenti compiuti in Brasile nei primi anni '90. Lo dimostrano sia la ricerca Questão Urbana, desigualidades sociais e Políticas Públicas: Avaliação do Programa Nacional de Reforma Urbana (1994) che quella svolta dalla giovane avvocatessa Betânia Alfonsin De Moraes nell'ambito dell' Osservatorio delle Politiche Urbane e Gestione Municipale (1997). Quest'ultima ricerca assume un'interessante e dichiarata 'ottica di genere' come tentativo di adesione critica ad una realtà dove sempre più spesso è la donna a svolgere ruoli (anche formalmente riconosciuti) di guida familiare; il punto di vista adottato pare tradursi nel testo in uno sguardo più umano che osserva - con attenzione al loro ruolo di soggetti sociali attivi - sia le donne che gli uomini all'interno di processi non letti mai come meri atti burocratici, semmai come contesti creativi nei quali è possibile inserire un'azione propositiva per riparare al continuo riprodursi di disuguaglianze.

${ }^{22}$ Per una trattazione di questo aspetto cfr. Fernandes (1997).

${ }^{23}$ Per una discussione del principio della funzione sociale della proprietà nel contesto della Costituzione Federale del 1988, cfr. Fernandes (1995; 1998) e Saule Jr. (1997).

${ }^{24}$ Tra gli altri Diadema, Santo André, Belo Horizonte, Recife, Belém, e - di recente - San Paolo, Barra Mansa ecc..

${ }^{25}$ Cfr. Fernandes (2002); Medauar e Menezes (2002).

${ }^{26}$ Qui il termine urbanistico è da intendersi in senso restrittivo, come indicante giuridicamente il campo dei PRG e delle norme di governo del territorio fisico.

${ }^{27}$ Meirelles, 1990, apud Alfonsin, 1997.

${ }^{28}$ Ad esse fa riferimento il Provvedimento 39/95 della Corregedoria Geral de Justiça 
${ }^{29}$ Cfr. Menegassi, 1999i in Allegretti, 2000a.

${ }^{30} \mathrm{Nel}$ Nuovo Piano Regola tore - in realtà - le AEIS 1 e 2 sono unite in una stessa categoria.

3156 sono legate al Programma di Regolarizzazione fondiaria e 46 a specifici interventi del DEMHAB su terreni di sua proprietà (Alfonsin, 1997). Il Consiglio per l'Accesso alla Terra e all'Abitazione (COMATHAB) rappresenterà il garante della partecipazione popolare nell'adozione concreta dello strumento, potendo esso per legge proporre AEIS; il Forum della Regolarizzazione Fondiaria dovrà discutere e accompagnare la regolarizzazione giuridica e urbanistica di tutte le aree beneficiate.

32 "Il discorso sulla qualità di vita non dovrà impedire la regolarizzazione e distribuzione della terra urbana, visto che questo è un tema fondamentale nella stessa definizione della qualità di vita. [...] La pratica ha dimostrato che una strada, seguendo il nostro esempio, deve avere la larghezza della funzione che deve compiere, permettendo anche la manutenzione delle relazioni quotidiane presenti nell'andare a piedi, nei giochi dei bambini, negli incontri" (Atti del Seminario del Governo sulla Politica Urbana e Abitativa, 1993).

${ }^{33}$ L'istituto della negoziazione appare fondamentale per riadattare i lotti di misura inferiore a quelli minimi previsti tramite contrattazioni con i vicini, per permettere ventilazione, illuminazione e sgocciolamento delle acque dai tetti che non danneggi nessuno e per 'consorziare' la disposizione degli arretramenti finitimi in modo tale da creare più ampi spazi aperti a beneficio di tutti invece che piccoli vuoti bui e senza accesso lontani fra loro in ciascun lotto.

${ }^{34}$ In realtà l'art. $2^{\circ}$ differenzia le dimensioni minime in base alla zona censuaria (per la $1^{\circ}$ fascia sono $3000 \mathrm{mq}$, per la $2^{\circ} 4000 \mathrm{mq}$ e per la $3^{\circ}$ il minimo è $5000 \mathrm{mq}$ ).

${ }^{35}$ Le percentuali sono più precisamente specificate agli artt. 12 e 14 della L.C. 312/93 ${ }^{36}$ Art. 15, L.C. $312 / 93$

37 è del 1999 anche la LC 8443 a cui è annessa la mappa che indica i limiti fisici delle AUOPs.

${ }^{38}$ Il problema maggiore sono i cosiddetti 'filhotes' (letteralmente 'cuccioli') ovvero subalterni frutto di parcellamenti mal registrati al catasto. Ma ne esistono altri dovuti al cattivo disegno delle aree: addiriitura il 'Morro do Osso' è stato eliminato dall'assoggettamento ad AUOPs in quanto occupato da area naturale protetta.

${ }^{39}$ Le limitazioni allo ius aedificandi o al diritto a godere del bene non provengono, del resto, solo dalle regole e dai criteri di zonizzazione stabiliti nel PRG o dal coefficiente di sfruttamento e dal tasso di occupazione del suolo previsti per ogni diverso sito nella legislazione comunale le cui variazioni implicano una crescita della richiesta di servizi da parte della comunità che occuperà $i$ locali (Grau, 1983).

${ }^{40}$ In tal senso, il Solo Criado costituisce uno strumento di contrattazione urbanistica in mano al potere pubblico.

${ }^{41}$ Sulla stessa linea si colloca Silva (1995) per cui il proprietario consegna all'amministrazione il suo immobile, ricevendo come pagamento beni immobili debitamente urbanizzati corrispondenti al valore del suo immobile prima delle opere di urbanizzazione realizzate con fondi pubblici.

${ }^{42}$ La particolarità è sottolineata in Alfonsin, 1997, pag. 78.

${ }^{43}$ Vedi: www.direitoacidade.org.br .

${ }^{44} \mathrm{Di}$ questi 15 avevano presentato la documentazione, 12 avevano avuto rilievo e sopralluoghi, 4 erano in analisi al DMAE, 15 in analisi urbanistica alla SPM, 16 in fase di analisi giuridica alla PGM, 9 in fase di di negoziazione e correzione urbanistica, 7 in fase di elaborazione dell'EVU, i 2 già regolarizzati, 1 aopprovato come condominio al Registro dei Parcellamenti (caso raro, perché in genere le fasce a reddito basso non prediligono la forma condominiale), 1 non ha più ufficializzato l'iscrizione e 3 casi sono stati archiviati (dati NRL del DEMHAB, maggio 1999). Il Beco dos Garcias, uno dei Parcellamenti più controversi - la cui regolarizzazione fondiaria è stata osteggiata in giudizio dallo stesso lottizzatore abusivo con una strategia definita 'suicida' dalla SPM - ha avuto l'EVU approvato all'inizio del dicembre 1999 grazie alla tenacia della comunità locale, appoggiatasi ad un professionista privato combattivo e supportata da alcuni tecnici convinti che fosse necessario porsi come riferimento ed incentivo attraverso l'esempio di una tenacia premiata e soprattutto coordinarci fra noi supplendo alla mancanza di coordinamento che rende insormontabili a volte per la comunità semplici incomunicabilità fra Assessorati (Mallmann, 1999i).

${ }^{45}$ Il documento GGA-SPM (1997) raccomanda che nei 'loteamentos' si esiga l'infra- 
struttura minima o la firma di un termine di impegno nella PGM da parte del lottizzatore o degli abitanti.

${ }^{46}$ Il più delle volte in considerazione dell'impossibilità che la norma costituzionale vada contro i diritti acquisiti dei singoli proprietari. Oggi l'art. 10 prevede che le usucapioni riconosciute collettivamente attribuiscano frazioni ideali di terreno ad ogni membro della comunità; ma il bene resta indivisibile e il condominio non è estinguibile. ${ }^{47}$ Le prime 8 vilas che già nel 1996 avevano processi in fase conclusiva - avviati cioè al Giudice - sono: Vila São Martinho, Vila Nossa Senhora de Lourdes, Vila Orfanotrofio, Vila São Vicente Martir, Vila Chacara Sperb, Vila Alto Embratel, Vila Primeiro de Maio, Vila Coronel Massot.

${ }^{48}$ Strictu sensu, sono strumenti specifici della Regolarizzazione fondiaria solo le ZEIS (o $A E I S$ ), la CDRU, la Regolarizzazione dei Loteamentos e l'Usucapione Urbana.

${ }^{49}$ Il termine 'incorporare' usato da Alfonsin (1997) è più ricco di sottintesi e indicativo di possibili distorsioni in atto

${ }_{50}$ Questi vengono coinvolti non foss'altro che al fine di rendere efficienti le politiche di regolarizzazione già pre-individuate come la migliore e più celere soluzione a molti problemi della città reale. Spesso il coinvolgimento socio-organizzativo è risultato nodale per il successo di operazioni che sarebbero risultate fallimentari se elaborate in un Gabinetto di Pianificazione; senza contare che molti enti finanziatori richiedono espressamente partenariati e partecipazione alle scelte.

${ }^{51}$ A lungo vi è stata l'impossibilità giuridica di eleggere un Sindaco o un Governatore per due volte consecutive; così, nei casi migliori la continuità era garantita da un vicesindaco nominato poi primo cittadino.

${ }^{52}$ L'esposizione maggiore delle famiglie al mercato si ha con il riconoscimento da parte del potere Giudiziario dell'Usucapione a fini abitativi, che dà al residente la proprietà sull'area occupata e la libertà di godimento del terreno. La combinazione dello strumento dell'usucapione con quello dell'AEIS (o con analoghe previsioni urbanistiche con forza specificate dai piani) potrebbe affiancare allo strumento giuridico di regolarizzazione offerto alle famiglie uno di destinazione speciale dell'area capace di neutralizzare i rischi dovuti al mercato immobiliare. 


\section{2 \\ 'Diritto alla città' e 'città dei diritti': alcune politiche fondamentali}

\subsection{Il diritto alla città come "umbrella-right"}

[...] L'inizio del XXI secolo mette in gioco la necessità che sia consolidato un ramo del diritto specifico, che disciplini l'ordine giuridico delle città fondato su principi e valori universali e internazionali. [...] L'esperienza brasiliana di costruzione del ramo del diritto alla città, oriunda del processo di democratizzazione dello Stato brasiliano iniziato nell' Assemblea Nazionale Costituente, può perfettamente servire come esempio delle difficoltà che necessitano di essere superate (Saule, 1997).

In un testo 'impegnato' e 'distante da ogni pretesa neutralità' ${ }^{1}$ il giurista Nelson Saule Jr (1997) ripercorre alcune tappe del lavoro dell' Assemblea Costituente che ha scritto la Costituzione Federale del 1988 riguardanti il capitolo della Riforma Urbana, e si sofferma a discutere sul concetto di Diritto alla Città, che ha preso forma attraverso un Emendamento Popolare sottoscritto da 131.000 elettori e presentato da un gruppo coeso e multiforme di entità e organizzazioni di categoria, ONG e movimenti urbani, che colsero l'opportunità di intervenire direttamente nel processo di riformulazione costituzionale attivato dopo la dittatura. ${ }^{2}$ L'Emendamento Popolare (alla base del quale sta lo stesso gruppo che ha sostenuto di recente la legge sullo "Statuto della Città") ha costituito un momento centrale del processo costituente, così come quello sulla Gestione Democratica dello Stato di Diritto. ${ }^{3}$ Esso ha contribuito al riconoscimento e all'istituzionalizzazione dei diritti delle persone che vivono nella città, fornendo orientamenti per promuovere politiche pubbliche che dessero loro concretezza in forma coerente ed unitaria. Tra i temi in cui l'Emendamento si articolava vi era quello del 'Diritto alla Città' ${ }^{4}$ poi mutuato dall'Amministrazione Popolare di Porto Alegre - già in fase di campagna elettorale - come punto di partenza del programma portato avanti dal 1989 in poi.

Il Diritto alla Città comprende i diritti inerenti alle persone che vivono nelle città ad aver condizioni degne di vita, di esercitare pienamente la cittadinanza, di ampliare i diritti fondamentali (individuali, economici, sociali, politici e ambientali), di par- 
tecipare della gestione della città, di vivere in un ambiente ecologicamente equilibrato e sostenibile. [...] L'effettiva a ttuazione di questo diritto comprende l'integrazione nello sviluppo economico dei segmenti sociali esclusi e marginalizzati della nostra società, in modo che possano ottenere e usufruire dei benefici e della ricchezza generata da questo processo (Saule, 1997).

Per dar corpo ad una simile articolata ipotesi interpretativa del 'Diritto alla città' (che presupporrebbe 'a monte' l'esistenza di un 'diritto alla scelta' sul vivere o meno in città) l'Emendamento Popolare introduceva la necessità di 5 principali azioni:

1) Assicurare e ampliare i diritti fondamentali delle persone che vivono nella città promovendo una giusta distribuzione dei beni e dei servizi urbani e la preservazione dell'ambiente;

2) Stabilire il regime della proprietà urbana e del diritto di costruire su di essa, condizionandoli all'esercizio della funzione sociale della proprietà e mettendoli in relazione con il principio dello stato sociale di necessità;

3) Adottare a questo scopo strumenti efficaci come l'esproprio ai fini della Riforma Urbana

4) Conferire al Comune le competenze e il dovere di applicare, in accordo con la realtà locale, gli strumenti di volta in volta più adeguati ad ogni situazione concreta;

5) Stabilire gli strumenti più efficaci di partecipazione popolare, per assicurare la gestione democratica della città come mezzo per esercitare il diritto di cittadinanza.

Sulla base di questa schematizzazione, è possibile riscontrare la diretta 'filiazione', dal processo di approvazione costituzionale, di molti dei documenti di programma del Fronte Popolare di Porto Alegre relativi alla gestione della città, in particolar modo a partire dalla dura autocritica compiuta nel 1990 con la redazione del documento interno del PT L'ora delle definizioni strategiche, dove - accanto alla necessità di una 'sterzata' per correggere difetti, debolezze ed incertezze fino a quel momento mostrate nel governare la città - si ridelineavano orientamenti e criteri su cui far leva nel prosieguo del quadriennio per "restituire il diritto alla città agli oltre 500 mila abitanti che non godono di una condizione di cittadinanza”.

A questo scopo, il testo di autocritica del 1990 sottolineava la necessità di rafforzare la politica di temporanea 'inversione delle priorità' mirata a rendere il 'Diritto alla Città' effettivo per tutti quei cittadini che ne erano finora rimasti esclusi; e definiva una linea di azione denominata "Priorità Popolare" avente come contenuto principale il miglioramento della qualità di vita degli strati più poveri della popolazione. Questo doveva essere raggiunto mirando prioritariamente a: 1) beneficiare la popolazione delle 'vilas' e dei quartieri popolari; 2) integrare in modo stretto il lavoro di assessorati e organismi comunali; 3 ) chiamare la popolazione non solo a discutere le proposte di intervento ma anche a partecipare al monitoraggio dell'esecuzione e della valutazione delle attività realizzate; 4) fare corrispondere a queste politiche una capacità operativa reale in grado di renderle "fattibili".

Questo è un processo di significato pedagogico e umanizzatore, in cui gli individui saranno stimolati a riconoscere e ad esigere il compimento dei propri diritti e, anche, a rispettare, a conservare e a valorizzare il patrimonio pubblico, l'infra- 
struttura urbana, la pulizia pubblica, l'ambiente e gli altri cittadini. Obiettivi politici di questa importanza non vengono raggiunti semplicemente con mezzi amministrativi, o con la mera concessione di benefici, distribuiti in forma paternalista o meno. È necessario far esplodere un processo con una dimensione politica e culturale senza precedenti in città. È necessario fare in modo che gli abitanti si sentano cittadini di Porto Alegre [...], si appassionino alle possibilità che saranno aperte dall' Amministrazione Popolare per questa città e per la convivenza che in essa può realizzarsi (PT, 1990).

La concretizzazione di questi orientamenti - che altrimenti sarebbero rimasti confinati nell'ambito di uno slogan politico - cominciò a prendere forma proprio nel 1990 attraverso il perfezionamento del processo di Bilancio Partecipativo e l'avvio di alcune importanti politiche-guida dell'Amministrazione Popolare, prima fra tutte quella della Regolarizzazione fondiaria che l'anno dopo darà corpo (con la trasformazione della favela Vila Planetario in Jardim Planetario, cfr. $\S 14.5$ ) all'importante linea strategica di affermazione del 'diritto dei poveri al centro', inteso come uno dei volti del 'Diritto di tutti alla città'. L'O.P. è stato considerato dall'Amministrazione Popolare, fin da subito, come uno strumento-quadro di raggiungimento del 'Diritto alla città', proprio nella misura in cui questo è stato interpretato come un diritto quadro (o umbrella-right, come l'abbiamo definito nel titolo), cioè come "un diritto ad altri diritti urbani", nella misura in cui li contempera e li riassorbe in sé, richiedendo anche, talora, la rimozione di barriere legali per permettere la partecipazione alla vita pubblica di gruppi "socialmente marginalizzati, tanto nell'identificazione di necessità e priorità locali, quanto nella formulazione di politiche, piani e progetti" (Saule, 1997).

La previsione del Piano Regolatore attraverso una norma costituzionale provoca una distinzione profonda [...] in cui il Piano smette di essere uno strumento basilarmente tecnico e si trasforma [...] in una missione costituzionale per i Municipi $[. .$.$] La finalità del Piano Regolatore di assicurare il diritto alla città presuppone$ la piena osservanza del principio di sovranità popolare come fonte della sua legittimità e efficacia giuridica, che significa la sua istituzione e applicazione con partecipazione popolare (Saule Junior, 1997).

In questo senso l'O.P. non poteva essere certo letto, neppure ai suoi esordi, come uno strumento da lasciare 'isolato'. Esso poteva acquisire un significato solo in relazione a politiche puntuali - di settore ed integrate - che ne concretizzassero le direttrici di orientamento, e all'elaborazione di uno strumento di gestione territoriale che rinnovasse dall'interno l'importanza attribuita dalla Costituzione al Piano Regolatore. Il rinnovo dei Consigli Municipali come guida all'implementazione delle politiche locali, e - in seguito l'attivazione del processo Cidade Constituinte per riformare democraticamente il Piano Regolatore (cfr. cap. 15), furono i primi modi individuati per estendere lo 'spirito democratizzatore' dell'O.P. oltre se stesso.

La solitudine del Bilancio Partecipativo, anche nei primi anni, fu - comunque - solo apparente. Esso fu, infatti, accompagnato da un solido quadro di sviluppo di politiche sociali mirate a "rompere con l'assistenzialismo, cercando, invece, l'inclusione sociale, il rispetto dei diritti e della condizione umana" come "premessa di una politica seria e impegnata a favore dei più", capace di "costruire una città per tutti" anche "mettendo come priorità pro- 
getti di cittadinanza" (PMPA/CCS, 1996). Trasferire risorse economiche dai settori 'tradizionali' all'area sociale (fig. 41) - che portò a quadruplicare il numero delle scuole municipali tra il 1986 ed il 1995 e portò le spese per l'Educazione dal 13\% delle uscite comunali del 1985 al 36\% del 1995 (Pozzobon, 1998) - fu il modo scelto per dare sostegno effettivo al mutamento di indirizzi politici che l'O.P. incamava.

In tal senso il Bilancio Partecipativo si affermò come strumento prioritario (nel senso di anteriore, non di unico) per la costruzione del 'Diritto di Cittadinanza'. Accogliendo in seno alla discussione sull'allocazione delle risorse cittadine tutti gli abitanti di Porto Alegre, indipendentemente dalle divisioni fra 'città formale' e 'città informale', l'O.P. si è costituito come luogo di conferimento di una 'cittadinanza de facto', transitoria, che permette di operare per il graduale raggiungimento di una 'cittadinanza di diritto' estesa a tutti gli abitanti della città reale. Così, ha dato corpo a quell'ampia politica di "superamento dei diritti formali" e allo "sblocco delle relazioni con la società" che il documento di re-indirizzo strategico del PT studiato nel 1990 riteneva necessario per far sì che ogni azione del Governo fosse "permeata dai principi di costruzione della democrazia e della partecipazione popolare" (PT, 1990).

La costruzione in progress del Diritto alla Città come nozione complessa e articolata - quale appariva nell'Emendamento Popolare del 1988 e quale è sempre stata registrata nello Statuto Comunale di Porto Alegre del 1990 - è pertanto stata identificata con un processo di "democratizzazione sostantiva, attraverso un crescente ampliamento del numero di abitanti beneficiati dall'infrastruttura urbana e dai servizi pubblici municipali. Cioè, un movimento di 'deprivatizzazione' del Comune, mirando a che non si particolarizzino $i$ benefici dell'azione dello Stato" e a scardinare "una macchina amministrativa pesante e poco produttiva che si muove per una logica propria fatta di particolarismi e forme esacerbate di corporativismo" (PT, 1990).

In questo senso, l'accezione privilegiata dall'Amministrazione Popolare ha sottolineato molto i caratteri di 'diritto collettivo' del 'Diritto alla Città', come diritto anche 'della Città' ${ }^{5}$ senza però cessare di considerarlo anche come "una sommatoria di diritti individuali primari come il diritto alla casa, all'istruzione o anche all'assistenza sociale, che si riassumono nel diritto ad una migliore qualità della vita in ogni suo momento, dalla famiglia, al lavoro fino al riposo" (J. Alfonsin, 1998i, a pud Allegretti, 2000a). Pertanto, le politiche messe in atto con l'obiettivo di raggiungere progressivamente la pienezza del 'Diritto alla Città' per tutti, hanno coperto questioni di natura diversa, come per esempio:

1) la democratizzazione culturale (già sancita agli artt. 193/199 dello Statuto Comunale, oltre che all'art. 200 dove si stabilisce l'impegno alla difesa della cultura indigena), intesa come processo che "renda possibile l'emergere e l'arricchimento della cultura e di nuovi valori attraverso la diversità delle sue manifestazioni" (PT, 1990);

2) il diritto alla libera scelta tra opzioni differenti (e non per forza uniche o omologate), per troppo tempo riservato solo a pochi di quelli che potevano dirsi 'cittadini' a pieno titolo;

3) il diritto a contribuire al progresso della città proponendo opzioni nuove e punti di vista differenti, rimasto a lungo precluso a causa di un'organiz- 
zazione del patrimonio pubblico e della sua gestione istituzionale "rivolta principalmente al controllo, allo sviluppo e alla manutenzione della 'città formale' e alla subordinazione delle contraddizioni della 'città informale'alle norme omogeneizzanti basate sui criteri di sviluppo della 'città formale"'(PT, 1990);

4) la garanzia per tutti di poter progressivamente acquisire "una voce, il tempo e le energie" (elementi che danno corpo all'astratto diritto alla libertà di espressione) per esprimere i propri giudizi sulla gestione della città senza essere costretti a limitarsi a lottare per la propria sopravvivenza;

5) la garanzia per tutti di poter essere accettati e ascoltati in luoghi prima preclusi a molti, "venendo trattati con un linguaggio rispettoso e che non rifletta l'esistenza di discriminazioni" (Pestana, 1998i, apud Allegretti, 2000a); 6) la riscoperta del significato dello 'spazio pubblico' attraverso la sua 'deprivatizzazione' ottenuta nell'ambito di una politica che per lungo tempo ha puntato sull'inversione delle priorità istituzionali come modo "per offrire d'impeto un'opportunità di entrare nella scena della città dei diritti a chi non la aveva mai avuta" (Marques, 1999i, apud Allegretti, 2000a);

7) l'uso dello spazio pubblico e dei luoghi aperti come ambiti simbolici e visibili di un cambio di prospettiva: ad es. l'apertura dei 'palazzi del potere' (Consiglio Comunale, sala Giunta, ecc.) a varie riunioni dell'O.P., la creazione dell' 'angolo democratico' per la libera espressione del pensiero (tipo Hyde Park Corner) nel principale incrocio del centro storico, l'organizzazione di piazze tematiche come la 'giornata dei conti pubblici' in una tensostruttura contenente pannelli con i conti pubblichi che richiama i passanti davanti al municipio, 'portando l'informazione al cittadino' nello spazio pubblico invece che lasciare che se la cerchi da solo, ecc..

Oggi, con l'abitudine creata dall'O.P., gli spazi pubblici non sono più spazi vietati. Qualsiasi comunità arriva in un Ufficio ed è ricevuta, persino dal Sindaco, che comunque si muove molto per percorrere i territori locali nel quotidiano, senza limitarsi come nel passa to ai periodi pre-elettorali. L'O.P. è stato un traino per dare 'esempio' di come operare ad altri livelli della gestione quotidiana della cosa pubblica. Un esempio che si dirige alla comunità come ai membri della stessa istituzione, e non solo di quella municipale, visto che abitua i cittadini ad 'esigere' anche in altri ambiti istituzionali. In un certo senso la logica delle cose è stata invertita. Prima vengono gli esclusi, i più poveri, poi gli impresari che cominciarono a percepire la trasformazione di questi spazi, dove erano gli unici a transitare finora. [...] Per sopravvivere economicamente, molti settori della città formale hanno dovuto imparare ad accettare un dialogo con cittadini prima ignorati perché non considerati come tali, ed ora divenuti - anche in forza del loro attivismo - interlocutori privilegiati delle Istituzioni (Helmann, apud Allegretti, 2000a).

In questo quadro, nei prossimi paragrafi analizzeremo tre delle principali politiche che in questi anni hanno orientato il lavoro dell'Amministrazione Popolare di Porto Alegre, e che - nel campo dell'impegno al reinserimento della 'città informale' nella 'città dei diritti' - rappresentano a loro modo tesi, antitesi e sintesi di un unico progetto coerente. La prima sarà la Politica della casa, che nei prossimi capitoli avrà una trattazione più puntuale attraverso l'ottica di alcune concrete realizzazioni; la seconda quella di regolarizzazione del commercio informale, che costituisce un punto di osservazione atipico dell'universo dell'informalità cittadina; la terza sarà la 
cosiddetta 'Politica delle risorse umane', che costituisce un punto di incontro e di snodo di altre politiche, nella misura in cui costruisce nel quotidiano gli strumenti della mediazione fra cittadini e istituzione nell'ambito degli interventi sul territorio.

\subsection{Le molteplici strade della Politica della Casa}

Il DEMHAB non è nato per risolvere i problemi strutturali di mancanza di abitazioni delle popolazioni impoverite ma, bensì, per costituire un elemento attivo e importante nell'appropriazione degli spazi sociali urbani per mezzo della speculazione immobiliare (PMPA/DEMHAB, 1993).

Così, all'inizio della gestione Genro, nel documento Elementi per una politica della casa a Porto Alegre, il DEMHAB valutava criticamente le proprie origini e il proprio ruolo per almeno 25 anni della storia cittadina, nell'ottica rinnovata adottata dall'Amministrazione Popolare per ribaltare il motto-guida 'Rimuovere per promuovere', filiazione diretta di quel Programma di Sradicamento della Sub-abitazione che il SFH aveva promosso negli anni Sessanta e che anche a Porto Alegre aveva trovato un posto d'onore nell'ambito dell'organigramma del Dipartimento alla Casa.

Il trasferimento del Programma di Regolarizzazione Fondiaria dalla SPM al DEMHAB, avvenuto nel 1993, ebbe proprio il senso di rafforzare il ruolo di quest'ultimo come organo definitore ed esecutore della politica abitativa del Municipio, riscattandone un'immagine di serietà ed onestà (Pozzobon, 1998) compromessa dall'aver svolto per anni il compito di "principale balcone di clientelismo” dell'Amministrazione (Menegat, 1995).

A dispetto di queste trasformazioni, va riconosciuto con Pozzobon (1998) che - nell'ambito delle solide politiche sociali promosse dall'Amministrazione Popolare - la delicata questione della Politica dell'Alloggio non ha costituito - nei primi anni - un campo di particolare impegno. Lo rivela anche il fatto che, nel periodo tra il ' 92 e il ' 96 (in cui pure singoli interventi innovatori vennero configurandosi come 'fiori all'occhiello' della Giunta, come l'intervento integrato che portò al trasferimento della Vila Cai-Cai nell'ambito del disinquinamento del Lago Guaiba), l'indice medio di spesa di bilancio nel settore dell'alloggio popolare restò oscillante intorno al 3,5\%. Persino nel 1994 - quando la Regolarizzazione fondiaria fu scelta nel Bilancio Partecipativo come principale priorità della città - non superò il $3,62 \%$ dell'impegno finanziario comunale. E in media, tra il 1989 ed il 1995, la produzione di alloggi per le fasce della cittadinanza con redditi mensili fino a 5 salari minimi (lotti infrastrutturati e abitazioni) è stata di 800 unità per anno, ovvero "molto al di qua di quello che sarebbe necessario per rispondere alla crescita vegetativa delle famiglie totalmente escluse dal mercato formale, stimato in 1200 per anno" (Pozzobon, 1998). Teoricamente, quindi, il municipio ha continuato ad accumulare un deficit di 400 unità abitative all'anno: 3200, circa, fino al 1996, non considerando le necessità create da un aumento dell'immigrazione in città dalle aree circonvicine. In realtà, il deficit reale risulta ancor maggiore, se si considera che il Comune si è concentrato nel reinsediare abitanti già sistemati informalmente, seppur in situazioni di alto rischio o in nuclei da deconge- 
stionare nel corso di processi di regolarizzazione fondiaria.

Solo nel 1997 si avrà un cospicuo aumento dell'impegno finanziario profuso nel settore, dopo la rielezione del tema a priorità fondamentale indicata dai cittadini. Questa porterà oltre il 15\% l'incidenza delle spese per le Politiche della Casa sul totale degli investimenti cittadini, cioè oltre i 20 milioni di R\$ (Pozzobon, 1998). Come ha ammesso il Sindaco Genro in un'intervista:

Durante il nostro governo, abbiamo avuto modo di affrontare, in termini di politica dell'alloggio, solo il trattamento di aree ad alto rischio [...], primo, per un' assenza di visione strategica circa questa questione nella città, che ha fatto sì che il Governo fosse mosso dalla necessità, premuto dalla responsabilità immediata. La seconda ragione è la difficoltà nel trattamento della questione fondiaria. Una visione equivocata ha generato, internamente ed esternamente al Governo, una valutazione superlativa di cosa è la regolarizzazione fondiaria, della sua semplicità di esecuzione, trasmettendo una grande illusione alla comunità, e, all'inizio, al corpo tecnico [...]. In verità la regolarizzazione fondiaria è una cosa molto complessa [...] Oggi i Comuni sono considerati organi politicamente responsabili per la Politica dell'Alloggio per un'assenza totale del Governo Federale. Pertanto, il municipio deve avere una politica diretta, variata, agile, una politica alternativa, anche per i segmenti sociali di reddito più basso (Genro, intervista apud Pozzobon, 1998).

Ed è proprio dal 1997, infatti, che il ventaglio di possibilità offerte dal Comune di Porto Alegre nel tentativo di dare una soluzione massiccia al problema della casa tenderà ad ampliarsi, non tanto numericamente quanto qualitativamente, mettendo maggiore accento su programmi 'alternativi' (e più 'agili' da finanziare) rispetto alla Regolarizzazione Fondiaria, che dal 1990 aveva costituito l'ossatura portante dell'intervento municipale nel settore (Pestana, 1998i, apud Allegretti 2000a). Un'ossatura dimostratasi però debole, a motivo dei molti fattori esterni influenti su di essa: primi fra tutti le lentezze della giustizia e del sistema catastale.

Tra l'altro, già dal '94 erano scomparsi molti aiuti Federali (come il Programma FICAM, ${ }^{6}$ a Porto Alegre sopravvissuto fino al FICAM V, o PROHAP, che nel '92/'93 finanziò 500 unità abitative nella Zona Sud), mentre nel '95 entrò in liquidazione la $\mathrm{COHAB}$ Statale.

A questo nuovo ri-orientamento degli indirizzi del DEMHAB ha, indubbiamente, contribuito il COMATHAB (Consiglio Municipale della Terra e dell'Abitazione), organo di partecipazione diretta della comunità alla definizione e al monitoraggio della Politica della Casa. Questo fu creato nel 1994, sulla base di una Proposta di Legge dei movimenti urbani già presentata nel 1990, proprio come aiuto al Comune per una più corretta elaborazione di nuovi indirizzi a vantaggio delle fasce sociali di minor reddito, nel momento in cui esse indicavano nell'O.P. il tema dell'alloggio come priorità fondamentale. Sulla base delle idee dibattute con il COMATHAB, nel 1997 si è tenuta la $1^{\circ}$ Conferenza Comunale sulla Casa (la $\mathrm{II}^{\circ}$ ha avuto luogo nel dicembre 2001), che ha visto la partecipazione di tutti i dipendenti del DEMHAB, di vari segmenti della comunità, ONG e Sindacati, ed ha portato alla scelta del 1998 come 'anno della Regolarizzazione Fondiaria'. Per questo, il bilancio discusso all'interno dell'O.P. alla fine del 1997 (orientato a considerare il problema della casa come prioritario), ha previsto che oltre 30 milioni di $\mathrm{R} \$$ venissero destinati dal Comune di Porto Alegre ai programmi 
di Regolarizzazione Fondiaria e di reinsediamento di famiglie a basso reddito allontanate da aree occupate rischiose o destinate ad attrezzature comuni.

La politica abitativa è cara, anche per piccole opere, e la capacità di lavoro è associata ai fondi molto più di altre politiche - come quelle della SMIC - per quanta creatività possa possedere. I sindaci Olivio e Tarso ri-allogg iarono circa 700 famiglie in 8 anni lavorando su 5 'vilas'; dal 1997 il ritmo è cresciuto anche su esplicita richiesta della popolazione e sono state finora circa 4500 le famiglie rialloggiate, in $18 \mathrm{nu}$ clei. Questa forma di moltiplicazione non può che passare per l'autorganizzazione, le cooperative, i mutirões. La gente lo ha capito, e per fare prima spesso chiede i lotti urbanizzati da autocostruire.[...]. I nostri tecnici sono sempre sotto pressione; perdere un termine di scadenza è perdere un finanziamento. L'unica cosa che possiamo fare è creare questo clima umano gioioso fra colleghi che stempera la tensione. Ora stiamo pensando ad una riorganizzazione del personale del DEMHAB, ma non possiamo fermarci per farla (Pestana, 1999i, apud Alle gretti, 2000a).

\subsubsection{Un ventaglio di programmi differenti}

Le figg. 48/54 evidenziano con chiarezza il progressivo cambiamento della tipologia degli interventi nel settore dell'alloggio avvenuta dall'inizio del 1989 ad oggi (e soprattutto a partire dal 1993) in rapporto alla maggiore omogeneità che caratterizzava ancora il Governo Collares, sostenuto dagli ultimi bagliori del Sistema Finanziario dell'Abitazione. Soprattutto, sottolineano il progressivo equilibrarsi delle differenti opzioni di intervento nel settore della casa a partire dal 1997; un cambiamento che si riflette anche nell'arricchirsi progressivo delle voci dei 'criteri tecnici' del Bilancio Partecipativo per le richieste nel settore dell'alloggio, che tendono a scomporre temporalmente le diverse fasi in cui si articola il completamento di ogni opera. ${ }^{7}$ Le diminuzioni progressive osservabili nell'offerta di unità abitative pronte e complete (in genere riservate ai programmi di trasferimento di famiglie residenti in aree di maggior rischio) corrispondono, infatti, non a un disimpegno generalizzato ma

[...] ad una riduzione di impegno dovuta ad un'emergenza finanziaria crescente e che è andata di pari passo a quella abitativa, così da richiedere l'accrescimento numerico dei programmi di impegno relativo minore per poter soddisfare un numero maggiore di famiglie in assenza di aumenti di fondi e di 'gambe' all'interno del DEMHAB, ovvero di tecnici in numero sufficiente da poter seguire un alto numero di progetti complessi e definiti fino ai particolari. Una politica che i cittadini hanno complessivamente capito, e a cui molte regioni (ad esempio la Restinga) si sono adeguate (Pestana, 1999i, apud Allegretti 2000a).

Attualmente si può riscontrare soprattutto una notevole crescita dei programmi intesi a re-insediare altrove (di concerto con la SMAM ed altri assessorati) famiglie residenti in aree di rischio per la salute e l'incolumità fisica, ${ }^{8}$ seppur con grossi rallentamenti nell'esecuzione delle opere richieste e finanziate attraverso l'O.P., dovuti ai tagli dei finanziamenti promessi da altri livelli istituzionali su cui il Comune aveva fatto conto nell'approvare il Bilancio e il Piano di Investimenti per il 1999. Per quanto concerne il 'bilanciamento' delle diverse 'opzioni' offerte dal DEMHAB ai cittadini con minore reddito, si può oggi riscontrare una fase di adeguamento rispetto allo 'sbilanciamen- 
to' che anni fa pendeva decisamente a favore dei Programmi di Regolarizzazione Fondiaria. Continuano però a sussistere ritardi legati ad alcune forme di consegna dei prodotti finiti o intermedi che fanno sì che - nonostante tutto - la regolarizzazione fondiaria resti la formula di intervento in grado di soddisfare (in virtù degli 'interventi di minima vivibilità' che si propone) un maggior numero di famiglie, in tempi più rapidi. Anche di questi temi ha discusso di recente la $2^{\circ}$ Conferenza Comunale sulla Casa che ha avuto luogo tra il 7 e il 9 dicembre 2001 (con 435 partecipanti registrati) ed ha dato l'avvallo ad alcuni grandi progetti integrati; ma soprattutto ha segnato l'avvio dell'elaborazione del Piano Municipale dell'Abitazione (nominando il comitato misto che elaborerà la prima bozza da sottoporre ai cittadini) e alla costruzione di un 'diagnostico partecipativo' nelle 8 Regioni di Pianificazione (cfr. cap. 15), che dovrà differenziare dati, indicatori di disagio e richieste dei cittadini nelle diverse parti del territorio, facendoli convergere in Pani Regionali. Circa 1000 persone hanno preso parte nel 2001 alle pre-conferenze, eleggendo 200 delegati per la prima stesura di 8 Piani (Relatório de Atividades, 2001).

Nel prossimo capitolo - in riferimento ad alcune concrete realizzazioni - esamineremo da un punto di vista 'qualitativo' il ventaglio di strategie 'aperte e flessibili' che attualmente l'Amministrazione Popolare offre per tentare di far fronte all'alta richiesta di soluzioni abitative che proviene delle fasce più povere della popolazione. Qui vale, però, la pena accennare ad alcuni dei principali programmi portati avanti dal DEMHAB di Porto Alegre nell'ambito della Politica della Casa, che - come si può notare - non fanno riferimento esplicito a recupero di strutture edilizie preesistenti:

\section{1) Il Programma di Regolarizzazione Fondiaria}

E' un processo che mira a promuovere il miglioramento delle condizioni ambientali e residenziali di uno spazio di terra occupato e già edificato al di fuori del puntuale controllo istituzionale, integrandolo al tessuto urbano a partire da operazioni di regolarizzazione legale ed amministrativa della proprietà dei suoli, associate ad altre di natura più strettamente urbanistica: dal consolidamento alla regolarizzazione dei tracciati viari, dalla dotazione di reti infrastrutturali a quella di attrezzature e servizi pubblici fondamentali. In genere non opera sulle dimore private, salvo quando è prevista qualche demolizione con ricostruzione.

Se la regolarizzazione fondiaria è passo indispensabile ai fini della garanzia di irreversibilità delle trasformazioni fisiche, a sua volta l'urbanizzazione e la regolarizzazione fisica - segno tangibile della trasformazione dello spazio urbano - costituiscono importante incentivo a procedere alla regolarizzazione fondiaria, che costituisce la parte più lunga del processo. E ovvio che - laddove i terreni risultino già occupati - l'urbanizzazione non può intendersi come adozione o soddisfacimento degli standard urbanistici legali vigenti, ma opera definendo 'standard minimi' per facilitare l'impianto di infrastrutture, definire i lotti utilizzabili a fini abitativi, garantire la circolazione e le migliori condizioni possibili di insolazione ed aerazione. La mediazione tra interessi individuali e della collettività è parte essenziale di questo processo, che richiede il coinvolgimento - nella definizione delle soluzioni generali e di dettaglio - della comunità. Essa è, infatti, 
374 l'unica in grado di chiarire le necessità della popolazione occupante e orientare su quali benefici possono portare le diverse soluzioni tecniche in virtù 'di una comprensione più sociale dei problemi urbani nella comunità' (Bonin, 1993). A seconda della proprietà dei terreni occupati, si adoprano sistemi di legalizzazione diversa e gradi di intervento differenziati. Per esempio, si minimizzano le spese pubbliche nei terreni privati finché si è in attesa del verdetto del giudice sull'ammissibilità dell'usucapione, anche per evitare che il proprietario possa obbligare il Comune ha comprare l'area su cui è arbitrariamente intervenuto, facendosi pagare indennità di esproprio maggiori in virtù del valore accresciuto per via dei lavori fatti dalla stessa amministrazione.

Per gli abitanti, la sicurezza patrimoniale costituisce un'indispensabile forma di sicurezza (per la vecchiaia e nei confronti dei figli), dato che la regolarizzazione offre la certezza di una trasmissibilità per via ereditaria. Allo scopo di impedire che la legalizzazione inneschi arbitrari processi di 'gentrificazione' e 'de-caratterizzazione' delle aree, l'Amministrazione Popolare mette in atto espedienti diversi almeno sui terreni pubblici (su quelli privati poco può fare a parte dichiarare lo stato di AEIS), come la concessione agli abitanti dei terreni, con forme diverse di usufrutto e contratti che danno solo la disponibilità dei manufatti e non dei suoli (CRDU, PRU), in modo da mantenere il controllo sull'area nelle mani del Potere Pubblico. Per l'istituzione, la regolarizzazione fondiaria genera un aumento della domanda di servizi urbani, dal momento che porta ad essere inclusi nei registri ufficiali strade, reti e servizi prima gestiti informalmente dagli abitanti; costituisce quindi un onere non indifferente, sia per gli investimenti iniziali sia per la successiva manutenzione. A fronte di questo impegno, si può sperare in un aumento dei contributi d'imposta relativi ai valori fondiari acquisiti alla 'normalità urbana' (che generano l'apparizione di contribuenti prima sconosciuti, che domandavano servizi pubblici ma non pagavano imposte in contraccambio). Questo però non è sempre sicuro né facilmente ottenibile; in particolare non lo è con quella 'regolarità' richiesta dalle necessità programmatorie dell'Istituzione. Le figg. 57-58 evidenziano - per ogni regione cittadina - il quantitativo di abitazioni irregolari che stanno attualmente beneficiando del Programma di Regolarizzazione Fondiaria a Porto Alegre. Nel 2001 vi sono state 1470 nuove pratiche di regolarizzazione di lotti inviate dal DEMHAB alla SPM, in aggiunta alle 2266 già in corso di esame (Relatório de Atividades, 2001). Fino ad oggi il PRF ha beneficiato oltre 132600 persone e 34000 alloggi (De Oliveira Moraes, 2002).

\section{2) Il Programma 'MORE MELHOR PARTICIPANDO'}

Nella sostanza è una costola del precedente, creato dal DEMHAB per intervenire solo in parcellamenti e 'vilas' situati in aree di sua proprietà. Attraverso la commercializzazione dei lotti, si crea un Fondo Comunitario che ha un valore pratico e pedagogico di stimolo per la popolazione a saldare i propri debiti con il Comune, sotto il controllo della comunità tutta. Infatti, il contenuto del Fondo ritorna agli insediamenti in forma di miglioramenti progressivi all'infrastruttura. Le formule per la permanenza degli abitanti in loco sono diverse: ad esempio, a Vila Vargas è utilizzato un Documento di Impegno [Carta Compromisso], mentre a Vila Mapa II si utilizza il PRU [Permesso remunerato d'uso]. Per l'Unità di Ricerca del DEMHAB, sono a tutt'oggi da 
considerarsi illegali le aree in cui meno dell' $85 \%$ dei lotti sia stato commercializzato; in senso strettamente legale, lo restano ancora tutte (compresa Vila Leopoldina III, di cui sono già stati commercializzati tutti i lotti) "finché i documenti non saranno registrati al Catasto, cosa che il DEMHAB non pare aver fretta di fare, visto che tanto si tratta di aree di sua proprietà" (Almeida, apud Allegretti, 2000a).

Nel 2002, il DEMHAB ha anche effettuato l'aggiornamento e la verifica di tutti i nuclei familiari che, fino al 1980, si sono iscritti nelle sue liste, al fine di coinvolgerli nel Programa de Arrendamento Residencial (PAR) istituito dalla Caixa Econômica Federal - in convenzione con il Comune - per facilitare l'acquisto di alloggi a famiglie con reddito fino a 6 Salari Minimi. Nell'agosto 2002 è stato anche lanciato il Programa de Quitação Antecipada, per incentivare gli acquirenti di immobili finanziati con fondi propri del DEMHAB (attualmente circa 1.500) a saldare le loro prestazioni, usufruendo di un abbattimento del 50\% sull'attuale valore dei debiti contratti.

\section{3) I 'reassentamentos' [rialloggiamenti o reinsediamenti]}

Attraverso il Programma 'Mudando para Melhor' [cambiando in meglio], essi rappresentano oggi una cospicua fetta degli interventi del DEMHAB. Letteralmente, il nome indica un programma di 're-insediamenti' o ' $r$ iallocazioni', ma tradurlo 'trasferimento' (con vocabolo meno cacofonico) è impreciso, visto che oggi sempre più spesso si parla di 'reassentamentos no local' [reinsediamenti in loco] in unità abitative ricostruite dal Comune sugli spazi occupati. Riguardano intere comunità che si trovano in 'aree di rischio', o in aree dove le previsioni urbanistiche prevedono spazi pubblici o viabilità importante e la cui realizzazione non è differibile. Singoli spostamenti concernono, poi, famiglie le cui abitazioni si trovano in mezzo ad ampliamenti stradali $\mathrm{o}$ ad aree attrezzate previste dagli EVU [studi di fattibilità urbanistica] dei Progetti di Regolarizzazione Fondiaria. L'impegno più volte ribadito a spostare le persone verso luoghi 'il più possibile prossimi' all'area originaria di residenza è quello che finora ha presentato maggiori difficoltà ad essere messo in pratica, a motivo dei costi della terra (che vincola il Comune anche in sede di espropri), del progressivo saturarsi dell'area urbana, e della lentezza di ogni azione che preveda l'intervento della magistratura. Il trasferimento avviene sempre verso aree sicure e dotate di infrastrutturazione essenziale, che siano di proprietà dell'Amministrazione. Talora - se necessario - smembrando i residenti in aree possibilmente vicine ai loro luoghi di lavoro o ben collegate dai servizi pubblici di trasporto almeno con il centro, previa consultazione ripetuta degli stessi.

Tutte le operazioni di questo genere (anche attuate in aree private) sono sotto il controllo diretto del DEMHAB e il costante monitoraggio della popolazione attraverso il COMATHAB. Nel marzo del 1998 è capitato che l'area di Timbaúva - dove era pronto a partire un progetto di re-insediamento per 400 famiglie provenienti da altre aree di rischio sgomberate - venisse occupata, (su pressione di forze vicine all'opposizione politica) ${ }^{9}$ costringendo il DEMHAB a chiedere al tribunale l'inizio di un'azione di reintegrazione di possesso per poter procedere con i lavori già finanziati. E' stata comunque condotta un'operazione di negoziazione con gli occupanti, e riconosciuto il loro 'stato di necessità sociale' (Pestana, 1998i) da ridiscutere all'interno 
dell'O.P.. Per rispetto alle decisioni di questa formula democratica di discussione, il DEMHAB si è comunque mostrato inflessibile sulla necessità dello sgombero, chiedendo al Comune di negoziare con lo Stato un'area per il reinsediamento delle nuove famiglie occupanti. Le notizie di casi conflittuali di questo genere vengono in genere date anche ufficialmente dalla Municipalità attraverso il proprio bollettino Porto Alegre agora e opuscoli chiamati Informe Direto, nel tentativo di portare ogni operazione al pubblico dibattito in modo diretto e rapido, evitando le illazioni e le strumentalizzazioni dei maggiori organi di stampa locali, quasi tutti nelle mani dell'opposizione. L'interesse dell' Amministrazione Popolare è anche mostrare alla popolazione "la necessità di rispettare, a costo di usare la durezza pur senza mancare di comprensione per $i$ grandi problemi che affliggono $i$ più poveri, gli impegni reciproci assunti dalla società civile e dalle istituzioni politiche in quella forma di patto territoriale che è il Bilancio Partecipativo" (Pestana, in Allegretti, 2000a).

4) Il Programma di 'ajuda-mutua' o 'mutirão' [Programma di aiuto reciprocol

E annoverabile tra gli impegni di minor onere economico per il DEMHAB, che - già all'epoca di Collares - aveva sostenuto alcune migliaia di famiglie nel dar soluzione al problema abitativo, sfruttando sistemi di autorganizzazione che dagli anni '70 alcune comunità portoalegrensi più organizzate avevano adottato per migliorare il loro habitat. In sostanza, il Programa de Ajuda Mutua è un partenariato sviluppato in regime di co-gestione, tra una comunità - che dedica parte del suo tempo all'auto-costruzione dei propri alloggi (specie nel fine settimana) - e DEMHAB, che si occupa di gestione, consulenza tecnica e finanziamento. Il programma mira a 'coinvolgere' $\mathrm{e}$ 'coscientizzare' gli abitanti che scelgono questa forma di costruzione tramite un'operazione di lenta appropriazione dell'alloggio e il lavoro diretto alla sua realizzazione, veicolo anche per la diffusione di saperi tecnici e per una forma di 'educazione ambientale" ${ }^{10}$ che finora ha dimostrato di riuscire a minimizzare il fenomeno della 'vendita delle chiavi' a case concluse $(5 \%$ contro una media del $30 \%$ nelle altre tipologie di fornitura d'alloggio; dati DEMHAB, 2002). Il Mutirão coinvolge solo su base di adesione volontaria e a seguito di attente selezioni per individuare $\mathrm{i}$ soggetti ritenuti più adatti a non desistere rapidamente - famiglie che devono per vari motivi essere reinsediate in luoghi diversi da quelli dove abitano (o nello stesso, ma in condizioni di maggiore vivibilità) ma non hanno un'immediata urgenza di farlo, o accettano di vivere temporaneamente in 'case di passaggio' (capannoni o dimore singole) come accaduto nei quartieri Cavalhada, Chacara da Fumaça e Maria Da Conceição (raro esempio di 'riallocazione sul posto' tramite mutirão). Esistono anche forme di mutirão mirate alla costruzione collettiva di infrastrutture o marciapiedi, come è avvenuto nei quartieri di Vila Santa Rosa e João Batista; peraltro, a distanza di anni, i risultati si sono sovente dimostrati così poco durevoli rispetto a quelli raggiunti nell'approntamento di residenze private, da sconsigliare essi stessi il ricorso a questa prassi.

A Porto Alegre, il ricorso ai mutirões è stato avversato con forza anche in sede istituzionale, ad esempio dalla prima direttrice dell'era PT del DEMHAB, che si è opposta ad una loro istituzionalizzazione ${ }^{11}$ anche mentre essi veni- 
vano utilizzati su vasta scala in molte città del Brasile, suscitando spesso accesi dibattiti. ${ }^{12}$ Solo nel '93 il Programma di Ajuda Mutua [o Mutirão] venne inserito nel ventaglio delle Politiche della Casa del DEMHAB. L'idea era che potesse contribuire "allo stabilirsi di relazioni creative, partenariati che mettano in gioco la divisione del potere e delle responsabilità nella gestione dei fondi pubblici" ma soprattutto "alla valorizzazione dell'individuo sotto l'aspetto sociale, culturale, di creazione di reddito e soprattutto in relazione all'accesso ai benefici della città legale" (DEMHAB, 1998a). In realtà, il Programma fu attivato soprattutto per poter usufruire di un finanziamento PIMES del BANRISUL disponibile sul tema (De Paula Pereira, 2002i). Il progetto-pilota del Programma sono state 16 abitazioni unifamiliari a due piani [sobrados] costruite nella Vila Ipê Barracão: l'inaugurazione di queste casette - oggi molto cambiate sul retro per i numerosi ampliamenti autocostruiti - è avvenuta dopo 2 anni e 10 mesi di lavoro, nell'ottobre del 1996 con una festa pubblica. Ma nel secondo lotto l'estrazione delle chiavi per attribuire ai 'mutirantes' i diversi alloggi è avvenuta solo dopo 6 anni, anche a causa di ben 13 defezioni su 25 nel giro dei primi 5 anni del percorso costruttivo (Mayer, apud Allegretti 2000a) L'idea originaria era quella di prevedere "la partecipazione della popolazione a tutti i livelli - dal progetto architettonico alle forme di convivenza posteriori, passando per la costruzione delle abitazioni"; difficoltà di varia natura nel percorso di sviluppo del Programma hanno, poi, obbligato a ridimensionare alcuni degli obiettivi originari. Ciò si deve, in parte, anche alla formula di adattamento scelta nel mutuare l'esperienza da situazioni molto diverse, come quelle che caratterizzavano le città di Fortaleza o São Paulo. Queste ultime facevano, infatti, riferimento a mutirões autogestiti, finanziati da linee di credito che prevedevano fondi amministrati direttamente dalle Associazioni di Quartiere e dalle loro strutture di consulenza. A Porto Alegre, invece, il Comune ha deciso di tenere per sé le redini del processo, ed in assenza di linee di finanziamento fornito direttamente alla popolazione, il Programma si sviluppa in regime di cogestione; inoltre la scelta dei beneficiari del Programma non è stata originata da un'autoselezione degli stessi in base al principio di 'libera adesione', ma è stata piuttosto 'suggerita' ogniqualvolta potesse sembrare utile in vista di 'reassentamentos' non urgentissimi. La lunghezza delle operazioni di completamento degli alloggi e alcuni piccoli fallimenti del passato hanno costretto ad alcune modifiche nelle modalità di intervento adottate (ad esempio, oggi il Comune si incarica di realizzare le fondamenta e le parti 'meno visibili' e più tecnicamente delicate dell'opera, al fine di motivare il cittadino dandogli il senso di un progredire rapido dell'opera). ${ }^{13}$ Essi spiegano anche perché il Pogramma attualmente sviluppi progetti per poche famiglie beneficiarie, anche se stanno venendo terminate le selezioni per altre realizzazioni da portare avanti con criteri diversi. Al luglio 2002 solo 172 delle 300 case in mutirão originariamente previste erano state realizzate (il $37 \%$ circa sono rimaste inconcluse e hanno dovuto essere terminate ricorrendo a imprese edili), e il numero degli insediamenti interessati da nuove realizzazioni è sceso a due (Loteamento Cavalhada e Vila Maria da Conceição, 17 unità in ognuna; dati DEMHAB, 2002).

Anche per questo, il DEMHAB ha deciso di chiudere con il vecchio Programma, senza però disperderne gli insegnamenti e gli aspetti positivi. Così 
dal 2003 ripartirà, su basi di 'autogestione' e non più di 'co-gestione', fondendosi con il Programma di Appoggio alle Cooperative e puntando su una migliore organizzazione delle 'comunità mutirantes' (non più solo 'prestatrici d'opera'), e su una miglior articolazione dei finanziamenti. Che dovrà separare (anche ai fini delle richieste in sede di Bilancio Partecipativo) la costruzione delle infrastrutture di base dei nuovi quartieri dai materiali e dalle altre spese per la realizzazione degli alloggi.

\section{5) Le Cooperative di Abitazione $(\mathrm{CH})$}

La promozione di Cooperative d'abitazione su modello uruguaiano ha avuto una forte impennata alla fine della prima Amministrazione Genro, come forma di risposta a domande variegate di settori diversi della società, delle cui richieste il DEMHAB non avrebbe modo di occuparsi direttamente. Esistono attualmente due tipi di Cooperative autogestite che si appoggiano al DEMHAB (col vincolo che i soci guadagnino meno di 12 Salari Minimi) ed in tal modo usufruiscono di una serie di incentivi fiscali oltre ad appoggio tecnico: quelle per la costruzione di alloggi ex-novo su aree di proprietà collettivamente acquisite, e quelle cosiddette di occupazione, che gestiscono in proprio la regolarizzazione fondiaria di un'area occupata, appoggiandosi però al DEMHAB per aiuti tecnici, amministrativi e fiscali.

In questi anni le Cooperative d'Abitazione si sono accresciute di numero nello Stato (oltre 70 fuori da Porto Alegre), soprattutto a seguito di un corso di post-laurea in Cooperativismo gestito dal DEMHAB con la UNISINOS, l'Università di São Leopoldo, e di una forma di promozione messa in atto dallo Stato del Rio Grande do Sul nel 2000 attraverso una Legge apposita (che ha regolamentato a livello locale quella nazionale 5764/71 sui finanziamenti alle cooperative) ed un accordo con la Caixa Economica Federal che prevede una contropartita di $1 / 3$ dei cooperanti, entro tempi stabiliti. Il DEMHAB ha elaborato un libretto a fumetti con la storia del Cooperativismo mondiale e locale, ed ha immaginato uno statuto-tipo che sottopone all'approvazione delle nuove Cooperative, dove vi è la clausola-obiettivo di contribuire "alla cultura, all'ideale e alla pratica cooperativista popolare autogestita". Attraverso queste proposte, si cerca - soprattutto - "far capire che il grande potenziale della Cooperativa ̀̀ di non fermarsi alla costruzione, ma [...] estendersi alla gestione dell'insediamento, dal recupero dei rifiuti alla vita in comunità" e anche di sensibilizzare sul fatto che sarebbe bene "non giungere allo smembramento della Cooperativa una volta costruite le case; che la registrazione al Catasto va fatta collettivamente per non piegarsi all'ideologia individualista che oggi prevale anche tra $i$ vileiros" (Benfatto, 1999i, in Allegretti, 2000a).

Già dal 1991 sono state oltre 1200 le famiglie riunitesi in cooperative per evitare sgomberi forzati, aiutate dal Comune attraverso l'opera di incentivo e consulenza tecnico/legale del DEMHAB, che finanzia parte delle opere di infrastruttura dietro rimborso in prestazioni, ed organizza anche fondi di risparmio collettivo per l'acquisizione delle aree e la realizzazione di progetti e lavori.Nel 1999, a Porto Alegre, le Cooperative autogestite per la costruzione o la regolarizzazione di alloggi a basso costo erano 55 (operanti su un totale di oltre 100 ettari e a beneficio di oltre 4000 famiglie), delle quali 39 avevano già acquisito le aree dove costruire per un totale di oltre 130 ettari 
di terra. ${ }^{14}$ Esistono anche forme miste fra Cooperative e mutirões, come la ABEMEVIC, che ha realizzato i suoi 38 alloggi in regime di mutirão.

Al luglio 2002, l'equipe di 4 persone del DEMHAB ha registrato collaborazioni con 63 Cooperative di Costruzione e Risparmio Preventivo, delle quali 33 autogestite, 28 di occupazione e 2 miste (dati DEMHAB, 2002). Esse sono concentrate in 7 diverse Regioni dell'O.P., specie nella zona Sud e NordEst in ragione dei prezzi delle aree. Qualche problema sta venendo da Cooperative che acquisiscono aree in zona agricola, urbanizzandole proditoriamente, probabilmente sarà risolto a breve con l'espulsione delle stesse dal registro del DEMHAB, come la SMAM sollecita da tempo (nel Partenon è già accaduto che, per un'urbanizzazione non autorizzata, la Coop. Abbia chiesto di trasformarsi in Cooperativa di Occupazione per facilitare le pratiche di Regolarizzazione Fondiaria). Attualmente sono però ancora poche quelle che hanno in fase realizzativa gli edifici: le prime opere concluse sono stati gli 80 'sobrados' consegnati nel 1996 in São Jorge e São Alfredo alle Cooperative dei Vigilantes e degli abitanti di Belém Novo, e - di recente - alcuni blocchi di alloggi dell'Aldeia dos Sonhos e delle Cooperative dei Giornalisti e dei Giudici del Lavoro. Oltre alle prime 95 unitàpilota della Coop. Renaçer (l'ultima finanziatasi con il Fondo Pró-Moradia), a cui verrà poi aggiunto un secondo piano. Molto più indietro sono le Cooperative di Occupazione, che navigano nella difficoltà di motivare i loro aderenti a causa delle enormi lentezze dei problemi a cui devono far fronte: solo 3 hanno finito di pagare l'area e 1 sola ha già un progetto di regolarizzazione in corso di valutazione.

La Cooperativa dei Metallurgici COOMETAL, nell'area nord di Porto Alegre sta mettendo in piedi il primo condominio a 5 piani $^{15}$ previsto sui 14 ettari acquistati dai suoi 500 soci nel 1993: l'obiettivo è realizzare una piccola comunità solidale di autosostentamento e autoconsumo radicata in un'area naturale dove sorgeranno teatri di verzura, orti comunitari, una lavanderia pubblica e diversi progetti per la creazione di reddito appoggiati al lavoro della SMIC. Anche per questo, il finanziamento per la parte di infrastruttura del progetto è stato ottenuto dal Comune attraverso la tematica di 'Organizzazione della città e sviluppo urbano' dell'O.P.: rappresenta - caso molto raro nella storia dell'O.P. - un prestito restituibile in 6 mesi $^{16}$ come premio ad un'iniziativa originale che tenta di far compiere un 'salto di qualità' all'ambito della costruzione di case per la popolazione a basso reddito, e come incentivo alla costituzione di Cooperative di Abitazione di cui l'Amministrazione Popolare tende ad incentivare la diffusione nonostante le grandi difficoltà che i loro componenti devono incontrare nell'inserirsi nel mercato formale dell'abitazione e nei meccanismi pianificatori del Comune.

Per quanto concerne i progetti degli insediamenti - almeno di quelli destinati a persone fra i 3 e i 5 salari minimi - il DEMHAB cerca di fare da coordinatore ed elemento di contatto fra abitanti e accademia, di mettere in contatto le Cooperative con l'Università, ma ha difficoltà a trovare professori disposti a firmare i progetti fatti dai loro alunni senza compensi. Il programma universitario della Pontificia Università Cattolica "RONDON" (di interscambio fra Stati) ha recentemente accettato di lavorare sul recupero cooperativo di un'area informale. Gli isolati 149 e 158 della Chacara da Fumaça sono stati, invece, riprogettati in collaborazione con la UFRGS, ma alla fine dell'eserci- 
tazione studentesca su diverse ipotesi di EVU possibili, il professore ha chiesto al DEMHAB un compenso per il lavoro fatto e - non ricevendolo - non ha consegnato gli elaborati. ${ }^{17}$

Per quel poco che si può vedere dai non molti progetti realizzati, approvati o in corso di realizzazione nell'ambito delle Cooperative di Abitazione di Porto Alegre, per ora le tipologie insediative e i modelli spaziali utilizzati nella progettazione appaiono estremamente convenzionali e non certo frutto di un ampio dibattito comunitario inteso a dar corpo ad un immaginario spaziale direttamente legato all'ideologia solidale del cooperativismo. ${ }^{18}$

La prevista fusione con l'equipe dei 'mutirões' e alcuni accordi per scambi formativi con la Ffederazione Uruguayana delle Cooperative (FUCVAM) fanno sperare in un cambio di direzione; soprattutto, si potrebbe puntare ad invertire la prevalenza delle forme di proprietà individuale che - per ora sembra l'obiettivo finale di ogni progetto presentato.

\subsubsection{Risorse finanziarie di appoggio alla Politica della Casa}

La Riforma Tributaria del 1990 costituì uno degli impegni prioritari della nuova Amministrazione di Porto Alegre, per poter recuperare una relazione di fiducia con la società civile ed agire con indipendenza dai finanziamenti 'vincolanti e incerti' provenienti da altri livelli istituzionali. La Riforma, movendo dal principio della giustizia tributaria, non solo abolì tutte le amnistie e le esenzioni che sempre avevano favorito i grandi debitori del Potere Pubblico e gli speculatori immobiliari, ma puntò soprattutto ad affinare e adeguare ai principi-guida dell'Amministrazione Popolare alcuni strumenti tributari nelle competenze municipali, rivelatisi di particolare importanza soprattutto ai fini dell'attivazione e del progressivo ampliamento del Programma di Regolarizzazione fondiaria creato nello stesso anno. È a questo periodo che risale - dunque -l'adeguamento al 5\% della ISSQN [Imposta sui Sevizi di Qualsiasi Natura], ma soprattutto la riorganizzazione in senso progressivo delle aliquote dell'IPTU [l'Imposta Edificatoria e Territoriale Urbana] fino ad allora in numero di appena due, ed estese in una fascia compresa tra lo $0,2 \%$ e $1 ' 1,2 \%$ per gli immobili residenziali, e da $0,6 \%$ a $1,4 \%$ per gli immobili non residenziali. Si adottarono anche aliquote progressive sul valore di mercato dei beni immobili, per beneficiare i proprietari dei terreni meno valorizzati. In parallelo, il nuovo Statuto del Comune ridefinì alcuni strumenti di intervento in ambito finanziario ed urbanistico, che contribuiranno nel tempo a trovare fondi per molte delle 'opere fisiche' incautamente finanziate l'anno prima - allora senza reali risorse disponibili da sfruttare - nell'ambito dell'O.P.

Al miglioramento delle condizioni finanziarie 'autonome' del Comune di Porto Alegre, portò un suo contributo anche la Giunta eletta nel 1992, che si impegnò ad un'opera permanente di riformulazione tributaria, creando l'Unità Finanziaria Municipal [UFM, incaricata di correggere costantemente il valore delle imposte], ed eliminando alcune 'distorsioni' sopravvissute alla prima Amministrazione Popolare, come le esenzioni fiscali a pro di alcuni servizi del sistema finanziario e delle opere realizzate per il settore pubblico. Inoltre, rafforzando i sistemi di controllo tributario incrociati lottò contro l'inadempienza tributaria di molti cittadini, portando la restituzione dei debiti attivi ad una crescita reale di oltre il 50\%, già nel 1995. Ma, soprattutto, fu 
varata la Legge che istituiva l'IPTU Progressivo nel Tempo (cfr. cap. 11) per penalizzare la 'speculazione d'attesa'. L'equilibrio finanziario raggiunto in questa epoca - e consolidato attraverso una messa in efficienza dei servizi tributari durante il quadriennio guidato da Raul Pont - si rivelò basilare, sia per la buona riuscita dei programmi dell'Amministrazione, sia per la sua indipendenza di azione da fonti di finanziamento vincolanti. Tra l'altro, favorì il Comune nell'accesso ad ulteriori finanziamenti esterni - concessi solo a municipi finanziariamente sanati (Pozzobon, 1998) - per la realizzazione di opere di grande entità in aggiunta alla politica dei piccoli passi portata avanti dall'Amministrazione Popolare. ${ }^{19}$

Nonostante non tutti gli strumenti di incentivo e sanzione previsti dalla Legislazione Federale e contemplati agli artt. 206/207 dello Statuto Municipale di Porto Alegre ${ }^{20}$ siano stati usati con la stessa frequenza, l'Amministrazione Popolare ha predisposto un variegato e coerente panorama di possibilità a cui fare riferimento per i diversi interventi urbani di reinserimento della città informale in quella 'di diritto' ${ }^{21}$ Soprattutto il Solo criado si è configurato come strumento utile per la costituzione di programmi abitativi di interesse sociale ${ }^{22}$ divenendo misuratore della capacità delle diverse componenti della città di procedere di pari passo senza accrescere le disparità fra fasce della popolazione, e legandosi ad altri strumenti come il Banco de Terras (creato con LC 268/92 ma non molto sfruttato per mancanza di iniziativa), attraverso la predisposizione del Fondo Municipale di Sviluppo Urbano [FMDU o FMD] previsto all'art. 234 dello Statuto.

Il Fondo ${ }^{23}$ - destinato all'esecuzione di programmi abitativi il cui finanziamento è curato quasi in toto dalla SECAR, l'Assessorato Straordinario alla Ricerca di Fondi ${ }^{24}$ - è costituito non solo dai proventi del Solo Criado, ma anche dalle risorse provenienti dalla vendita degli indici costruttivi, da quella di terreni inadatti alla residenza popolare ${ }^{25}$ dall'imposta di concessione prevista dalla LC 7592, dai pagamenti della CDRU, da donazioni e fondi nazionali e statali e da fondi specificamente destinatigli dal Comune allo scopo di mantenere una continuità e una progressività nella realizzazione dei vari interventi nel tempo (Dantas Machado, 1999i, apud Allegretti, 2000a). Oggi, però, i maggiori proventi della Politica Abitativa di Porto Alegre vengono soprattutto dall' IPTU progressivo nel tempo (che ha tardato ad affermarsi a causa della lentezza della giustizia) e da prestiti di varia natura, fra cui attualmente i più importanti sono:

$\S$ il FUNDOPIMES [Fondo del Programma Integrato di Miglioramenti Sociali] del governo del Rio Grande do Sul integrato da fondi della Banca Mondiale e del BID;

$\S$ i Fondi FGTS provenienti da programmi della Caixa Economica Federal (come il PROMORADIA, tagliato per oltre l' $80 \%$ nel '99, ma che nel giugno '96 aveva offerto finanziamenti con contropartita municipale per oltre $7 \mathrm{mi}$ lioni di $\mathrm{R} \$$ per beneficiare oltre 10.000 persone);

$\S$ il fondo FONPLATA [Fondo Finanziario per lo Sviluppo del Bacino del Plata] con sede in Bolivia e partecipazione di Argentina e Paraguai, destinato fondamentalmente ad opere infrastrutturali, di disinquinamento fluviale e azioni complementari;

$\S$ il fondo PROTECH del Governo Federale per la creazione specifica della Vila Tecnologica. 
Parlare del FMD a Porto Alegre come supporto principale alla Politica della Casa è un po' prematuro, visto che esattamente il Fondo non è stato ancora implementato, perché - seppur obbligatorio - vi è nella realtà una resistenza alla centralizzazione delle risorse, e soprattutto ai vincoli di destinazione d'uso come sarebbe destinarlo all'abitazione popolare. E questa è una falla non da poco anche dell' Amministrazione Popolare che però dipende anche dal forte peso delle opposizioni in Consiglio Comunale e dall'esperienza fallimentare fatta nel SFH con la centralizzazione dei fondi. Il rigore ha aspetti pericolosi, e forse alla fine è meglio questa sorta di inf ormalità nell'uso del FMD (Dantas Machado, apud Allegretti, 2000a-II).

Per quanto riguarda specificamente il Programma di Regolarizzazione fondiaria del Comune di Porto Alegre (che non è il solo ad attingere al FMDU), “esso ha teso negli ultimi tempi a pescare un po' dovunque per poter proseguire dopo i pesanti tagli ai finanziamenti federali, ottenendo inattese vittorie con finanziamenti insperati per azioni puntuali ma anche per interventi complementari di trasferimento di famiglie che cera necessario rimuovere dai luoghi dove vivevano" (Fernandez, 1999i, apud Allegretti, 2000a). Di questa categoria fanno parte non solo i fondi FONPLATA per la pulizia del fiume Diluvio, che hanno permesso il re-insediasmento dell'intera favela Vila da Fonte - 125 famiglie che finora scaricavano nel fiume le loro acque nere - nel Loteamento Santa Paula nella Regione Lomba do Pinheiro, ma anche quelli in corso di erogazione per la risistemazione dell'ingresso in città da nord (cap. 16). Vi sono poi le cosiddette Azioni Concertate, ovvero negoziazioni con l'iniziativa privata che secondariamente possono servire a risolvere problemi abitativi. È quanto avvenuto per la costruzione dello Shopping Center BIG del Cristal, che ha permesso il trasferimento- per tappe graduali - di tutte le famiglie residenti nell'omonima favela a spese dell'impresa che ha acquisito il terreno; ed è quanto avverrà probabilmente per la Vila Zero Hora ubicata nel centro della città se la trattativa verrà conclusa dal Comune. Fondi da usare per la regolarizzazione fondiaria sono attesi a breve termine anche dall'approvazione del provvedimento chiamato 'Urbanizzatore Sociale' ( $\$ 15.2 .2$ ) contenuto nel nuovo PRG; infine, vi è il cosiddetto Autofinanziamento, previsto nei casi in cui il Comune offre appoggio solo logistico e a livello di consulenze tecnico-legali a lavoratori con basso reddito organizzatisi per comprare, urbanizzare e costruire (o talora solo regolarizzare) in aree urbane attraverso Cooperative di Abitazione e mutirões. Costituisce un indubbio 'fanalino di coda' l'autofinanziamento, inteso come recupero dei costi sostenuti dal DEMHAB attraverso i contratti di CDRU o gli affitti di abitazioni costruite per popolazione con redditi bassi. "Al massimo copre i prestiti contratti con la Caixa Economica Federal o il Banco do Brasil, senza che resti nulla per altro anche all'interno di un sistema di pagamenti che non si prefigge di stabilire priorità fra $i$ creditori se non di tempo" (Dantas Machado, 1999i, apud Allegretti, 2000a-I). Come sottolinea, infatti, il Soprintendente Finanziario del DEMHAB:

Esistono due ordini di problemi. Il primo è il mancato e difficoltoso adeguamento tariffario dei contratti, che solo la recente computerizzazione su vasta scala renderà possibile; il secondo è certamente l'altissimo livello di inadempienza che risiede in due ragioni, una di natura economica (il livello basso e i redditi incostanti di molte famiglie) e l'altra di natura più psicologica, legata ad una visione tradizionale che una parte della popolazione ha ancora del Potere Pubblico come di un suo debitore, 
che non vale la pena pagare una volta ottenuto il beneficio di una casa, perché era suo dovere dartela. Il nostro insistere tramite l'O.P. e le visite di campo dei tecnici è a volte un grido disperato, specie in aree dove l'inadempienza dell'uno contagia l'altro che non vuole sentirsi più stupido del proprio vicino. Il DEMHAB è un grande acquirente di terreni in città; oggi l'Esecutivo Municipale - che già paga tutti gli stipendi del nostro personale - deve coprire anche una gran parte del debito immobiliare che cresce di $500.000 \mathrm{R} \$$ al mese, perché il DEMHAB non riesce a pagare a causa delle inadempienze che raggiungono il 39,8\% del totale dei contratti, pur con livelli di ritardo o gravità diversa. Oggi per cercare di porre un argine a questo 'tragico iato' instauratosi con la fine del SFH, stiamo cercando di rivedere 12.000 contratti dei 33.494 stipulati, $^{2}$ per prestazioni da 1 a $400 \mathrm{R} \${ }^{28}$ che è il prezzo più alto che viene pagato al DEMHAB da un usufruttuario, nel caso quelli di una parte dei 1032 appartamenti del Jardim Leopoldina e dei 64 dell'Humaità/ Navegantes comprati nel 1995 dopo il fallimento della ditta Guerino, i cui immobili erano stati invasi nel 1987. Non so quante speranze abbiamo, anche perché il DEMHAB ha sempre abbattuto i valori di locazione e Permesso d'Uso Remunerato [PUR] ogni volta che ha regolarizzato aree altrui occupate; quasi per un effetto educativo, ma mantenendo un minimo contributo per lo stesso motivo. Eppure continuiamo a insistere e a rinegoziare i debiti rateizzandoli fino a 40 soluzioni, quasi più come forma pedagogica e simbolica di approccio al problema del senso di cittadinanza che non con la speranza di rientrare minimamente nei costi dei nostri interventi, che finiscono sempre per essere 'a fondo perduto' anche se non lo sono purtroppo i finanziamenti che hanno alle spalle, come quelli PROMORADIA. Dopo il terzo mese di ritardo nei pagamenti mandiamo un 'avviso di riscossione' del debito; molti neppure si fanno vedere e perciò passiamo le pratiche al Coordinamento Giuridico che negozia e solo in ultimissima analisi dà ordine di sgombero. [...] Se ci si impegna per creare un rapporto di onestà reciproca coi cittadini e si viene traditi, prima o poi si dovrà reagire. Ma, d'altro canto, credi che serva mettere in una strada così tante famiglie con redditi per lo più da 1 a 3 salari minimi? Non ritorneranno ad occupare terreni e rientreranno così dalla finestra nel giro dei problemi che il DEMHAB dovrà prima o poi risolvere? Non siamo dei privati cittadini, siamo quelle istituzioni che sempre dovranno occuparsi del problema. Altri enti si sono messi a fare la voce grossa, come la COHAB Statale che (essendo in liquidazione) ha necessità di chiudere la gestione nel migliore dei modi, e forse non ha neppure interesse a mantenere un buon rapporto con la sua utenza, a differenza del DEMHAB. Noi, invece, proseguiamo sulla via del dialogo e della negoziazione paziente, consci che anche per gradi e piccoli passi qualcosa va migliorando. In genere ci vogliono 7 mesi di tempo-tecnico per arrivare ad un'azione in Tribunale; approfittiamo di queste lentezze per essere flessibili. Cioè facciamo di necessità virtù. (Fernandez, apud Alle gretti, 2000a).

\subsection{La regolarizzazione per tappe del commercio autorganizzato; un punto di vista alternativo sull'informale}

Nonostante i suoi indubbi meriti [...] la politica dell'alloggio che viene portata a vanti a Porto Alegre ha ancora un punto di vista 'in negativo' sulla città informale. Pur essendo giunta a fare ciò da cui altre città sono lontanissime - riconoscere gli apporti positivi dei suoi abitanti - tende però a continuare a leggere lo spazio della città autocostruita soprattutto per sottrazione come regno del 'non' (il non salutare, il non regolare, il non regolamentare, il non ordinato, il non organico); per ciò che le manca, quindi, più per ciò che in positivo può offrire alla città nel suo complesso in termini magari anche estetici, di spazi simbolici o di relazione (Sant'Ana, 1999i, apud Alle gretti 2000a). 
zione, ma è sostanzialmente veridica; del resto, al punto del percorso urbano di Porto Alegre in cui si situa oggi l'operato dell'Amministrazione Popolare sarebbe impossibile aver già oltrepassato un approccio 'per sottrazione', se tutti i giorni il Comune deve fare i conti - dentro e fuori l'O.P. - con i disagi e i problemi che un patrimonio informale ereditato da decenni di disinteresse istituzionale per gli strati più poveri della popolazione provoca a coloro che vi abitano, alla funzionalità e all'equilibrio territoriale e ambientale del corpo urbano nel suo complesso.

Nelle politiche dell'Amministrazione di Porto Alegre vi è però anche un punto di vista 'alternativo' e tutto sommato 'riequilibrante' rispetto all' approccio mostrato dalla Politica della Casa ai territori abitati autoprodotti che segnano il volto cittadino: ovvero la politica compiuta dall' Assessorato all'Industria e al Commercio (SMIC) nei confronti della regolarizzazione del commercio informale e della promozione delle iniziative imprenditoriali autonome che nascono sul terreno della città spontanea. Essa rappresenta il miglior esempio di quel capovolgimento di ottica riguardo alla città informale auspicato dall'Amministrazione Popolare al momento del suo insediamento e mirato a ribaltare il vecchio motto-guida 'Rimuovere per promuovere' nel suo opposto 'Promuovere per rimuovere', riferito appunto alle sacche urbane di esclusione socioeconomica.

Anche in questo settore, il panorama di Porto Alegre ha subito un notevole cambiamento con l'elezione della prima Giunta Municipale del PT, che ha inciso sulle stesse trasformazioni urbane di una buona parte della città, specie per quanto tocca l'animazione del centro cittadino. Alla fine del suo mandato (nel 1983) il Sindaco del PDS João Antonio Dib redasse l'ambizioso progetto chiamato Un centro più umano, ${ }^{29}$ che si proponeva il trasferimento dei terminal dei bus fuori dal centro, la rimozione del commercio ambulante (da sistemare in locali sotterranei legati alla stazione dei treni), la costruzione di garage sotterranei e di una grande esplanade. Lo scopo dichiarato era recuperare un'area 'malata' eliminando i flussi disordinati e la fusione di attività informali accostate "alla sporcizia e ai borseggi come minaccia per la salute del grande organismo vivo della città” (Borba, 1993). Il progetto a cui stranamente non fu chiamata a collaborare la SPM - suscitò un vespaio di polemiche, trovando appoggio solo nelle banche, nei Sindacati dei Costruttori e nella grande distribuzione. Si schierarono contro le associazioni dei piccoli commercianti e gli ambulanti informali ${ }^{30}$ (che vivevano tutti proprio dei clienti degli autobus)", la federazione dei garagisti e la sede locale dell'Istituto degli Architetti Brasiliani. Questi ultimi, dubitando della necessità di tante "opere ex-novo (affrontate per giunta con semplificazione)" che mettevano a rischio edifici di valore storico e danneggiavano il paesaggio urbano, sottolinearono che il centro dovrebbe sempre permanere come "luogo dove il popolo conosce se stesso, nella sua diversità". Il progetto di Dib non solo rompeva la multiformità esistente nell'area, e minacciava tanto le strutture fisiche quanto le dinamiche esistenti, ma soprattutto serviva gli interessi forti ed accelerava la "chiusura del centro alle classi popolari" (Borba, 1993), alterando la piazza XV, una delle ultime aree sottratte alla specializzazione funzionale, "ultima possibilità per quelle classi di usufruire di quello che è l'essenza della vita urbana: il contatto sociale, l'esperienza che illustra, l'aggiornamento culturale, l'espressione” (IAB/RS, 1983). Queste 
posizioni della comunità cittadina trovarono un'autorevole appoggio nel Consiglio Comunale (dominato dalle opposizioni: PMDB, PT, PDT), che si contrappose al potere Esecutivo a partire da una critica ai supporti economici all'operazione, ed elaborò un Progetto di Legge per proibire demolizioni o costruzioni nel Centro che non passassero per la sua approvazione.

In un periodo in cui nel Paese si gettavano le basi per la ridemocratizzazione delle Istituzioni, risultava impossibile, "anche per un Sindaco 'competente', imporre soluzioni nate nei circoli tecnocratici" (Borba, 1993); di questi nuovi orizzonti il Consiglio si fece carico, costituendo una Commissione Speciale per lo studio dei problemi del centro che divenne canale aperto alle richieste popolari. Borba (1993) ipotizza che questo evento - apparentemente localizzato in un 'caso specifico' - possa aver fatto sorgere le prime idee di una consulta plebiscitaria, di un foro di dibattiti permanente di cui anche l'IAB sottolineava la necessità, rimarcando come fosse necessario "ricercare altre forme per ampliare la partecipazione della comunità alle scelte”.

Viste le posizioni che sosteneva e le professionalità che raccoglieva, l'IAB fu indicato come l'organismo più adatto a produrre, in modo democratico, un progetto alternativo per l'area; a rimarcarlo fu soprattutto il Movimento Cidade-Viva che voleva fare della discussione sul centro un paletto iniziale di un nuovo modo di decidere sulle questioni urbane. Se questo non si realizzò fu in parte per l'immaturità dei tempi (il processo di democratizzazione brasiliana procedeva, infatti, per gradi) e in parte perché l'Esecutivo di Porto Alegre 'congelò' il progetto portando alla dissoluzione del Movimento, che non riuscì a sopravvivere alla mancanza del nemico che ne aveva coagulato le forze. ${ }^{31}$ Degli eventi che connotarono questa pacata 'rivolta' non tutto andò però perduto; alcuni germi maturarono a distanza di qualche anno, ma non certo durante l'Amministrazione del successore di Dib, Alceu Collares, che promosse per il centro il progetto Quadra Um e l'espansione dello stesso sulla riva del lago, verso sud, attraverso il Progetto Praia do Guaiba, 244,67 ettari da urbanizzare di cui 11,25 ettari da privatizzare. Anch'egli - infatti - affrontò subito il commercio ambulante in modo duro, attivando una stretta vigilanza per reprimere gli 'illegali' al fine di 'pulire', 'ordinare' e 'umanizzare' il Centro. Dopo le prime rivolte, egli mutò però di tattica abbandonando la 'foga ordinatrice' e tentò di risolvere la crisi dell'area centrale nel suo complesso, estendendone i confini e diluendone i problemi con un'operazione imposta dall'alto.

Dai due interventi sopradescritti si distacca quindi il Progetto Centro promosso dal primo sindaco del Fronte Popolare, che cercò di ravvivare il centro e di adattarlo ai nuovi tempi: non tanto intervenendo sugli spazi fisici, ma agendo sulle relazioni sociali in modo 'sensibile', evitando cioè l'espulsione (di attività e persone) diretta o come conseguenza della valorizzazione immobiliare e della gentrificazione da essa generata. I primi 200 ettari su cui il Progetto Centro operò videro una serie di piccole modifiche progressive ispirate all'idea di far vivere di giorno e di notte il centro di una città votata in gran parte al terziario e al turismo, senza opere faraoniche. Le realizzazioni furono accompagnate (nei primi anni in cui prendeva piede l'O.P. ) da un Forum permanente di Dibattiti sull'Area Centrale, che riuniva 32 entità professionali e comunitarie e diversi Assessorati, mentre per la risoluzione del problema del 'commercio informale' il sindaco organizzò una struttura di 
dialogo fra la SMIC, i negozianti dell'area e gli ambulanti, per arrivare a delle soluzioni di 'patto sociale' incentrate sulla redistribuzione degli spazi e sulla vigilanza 'per attività' e non 'per singolo venditore', in modo da contrastare solo la vendita di contrabbando. L'istituzione del Forum contro la Recessione e la Disoccupazione suggerì al Sindaco una posizione di tolleranza nei confronti della rapida crescita del commercio informale data la situazione di recessione economica. ${ }^{32}$ Parallelamente, furono riorganizzate in un nuovo padiglione di $500 \mathrm{mq}$ le bancarelle ortofrutticole, ritenute 'essenziali al rifornimento dell'area centrale'. Dutra riprese anche alcuni suggerimenti emersi dalla lotta portata avanti dal Movimento Cidade-Viva nel 1983, confermando la vocazione culturale di Praça XV, rinnovata nel suo arredo urbano in parallelo ad una campagna di coscientizzazione su come usarlo. ${ }^{33}$ In tal modo, l'Amministrazione Popolare tentò una valorizzazione simbolico/economica di un centro 'inespressivo e praticamente vuoto nei fine settimana' (Borba, 1993). In direzione dell'accoglimento delle istanze esplicitamente o implicitamente proposte dal settore 'informale' della popolazione, il cambiamento non fu repentino, ma procedette per passi.

Nel frattempo, proprio a cavallo fra gli anni '80 e i '90, Porto Alegre stava subendo un'altra interessante trasformazione, con l'esplosione dei primi grandi Shopping Center che hanno indotto un interessante passaggio di scala nella dinamica commerciale cittadina, rompendo gli schemi strettamente locali e i concetti tradizionali di vicino e lontano, introducendo nuovi parametri per la valorizzazione dello spazio, e creando comportamenti diversi nel consumatore. Al contrario di quanto si può pensare, questo fenomeno ha toccato notevolmente anche la città informale, seppur spesso come riflesso di una riorganizzazione dei settori medio e altoborghese della popolazione. In uno studio sulla trasformazione del commercio a Porto Alegre nell'ultimo ventennio, Schäffer (1993) ha sottolineato la creazione dei grandi Shopping Center come momento di rottura importante da segnalare nell'ambito della storia urbanistica della città per almeno 4 ordini di motivi:

1) per le trasformazioni direttamente indotte nella maglia urbana o sui sistemi di traffico, ${ }^{34}$ ma anche nel rapporto fra cittadini, nuove attrezzature e amministrazione, attraverso un gioco di pressioni e concessioni che garantisco la corretta produzione del nuovo spazio. Anche a Porto Alegre le diverse Amministrazioni hanno finito per adeguarsi a quanto richiesto dalle tendenze 'globali' (compreso il Fronte Popolare che - per un contratto pregresso - per la costruzione dello Shopping Praia de Belas nel 1991 ha dovuto sborsare 2 milioni di dollari per investimenti pubblici nell'immediato intorno) o - nel migliore dei casi - ad ottenere vantaggi per la città con meccanismi di scambio (cfr. 13.4.2).

2) per le trasformazioni indotte nelle geografie dei desideri ${ }^{35}$ ponendosi non solo come luoghi di approvvigionamento, ma anche di relax, di riunione, di circolazione anonima, di contatto con la modernità, di osservazione del comportamento dell'altro, luoghi il cui schema di sicurezza esclude la presenza della povertà (il mendicante per strada, la visuale sulle favelas arrampicate su ogni possibile altura circostante). ${ }^{36}$ Queste considerazioni anche a Porto Alegre hanno attribuito in questi ultimi anni ai centri commerciali cittadini il ruolo di luogo della modernità, per il consumatore, e garanzia - per la città dell'inserimento nel modello mondiale di approvvigionamento (Schäffer, 
1993), ${ }^{37}$ tanto che oggi si può notare il peso notevole avuto da alcuni di essi sia sulle trasformazioni del rapporto del cittadino con gli spazi della vita pubblica, sia sulla valorizzazione di molte aree circostanti (è il caso soprattutto dell'Iguatemí nella zona Nordest).

3) per le trasformazioni indotte nelle pratiche quotidiane del rifornimento che formalizzano il tempo locale e il tempo globale di ogni famiglia, accentuando - ad esempio - la differenza fra chi possiede il frigo e chi non lo possiede (differenza che in altri paesi perde ogni rilevanza), fra chi possiede un'auto e chi - in zone di marginalità urbana - non ha l'opzione della scelta del luogo dove fare le proprie spese, fra le famiglie 'integrate' e quelle dove la donna - estromessa per diverse ragioni dal mercato lavorativo - ha modo di occuparsi quotidianamente dell' approvvigionamento familiare. ${ }^{38}$

4) per le trasformazioni indotte in direzione di una forzata riorganizzazione stessa degli altri livelli di commercio, che hanno progressivamente subito sia una ridislocazione e uno slittamento geografico all'interno del corpo urbano, sia fenomeni di riassetto interno e del rapporto col consumatore. ${ }^{39}$ In questo processo si sono ingenerati anche a Porto Alegre fenomeni nuovi, come la nascita dei negozi domenicali nelle aree povere (gestiti nei giorni di riposo dai lavoratori e dove acquistano coloro che nei giorni feriali preferiscono servirsi vicino ai luoghi di lavoro), la trasformazione dei modi di presentazione al pubblico e degli orari di vendita delle bancarelle (che si impongono come i luoghi del minor spreco di frutta e verdura, come provato dalle classifiche della rivista $\mathrm{AGAS})^{40}$ o la completa riorganizzazione del settore della distribuzione all'ingrosso che ha perso in questi anni la sua molteplicità di forme per concentrarsi nella CEASA localizzata nella periferia di Porto Alegre.

Soprattutto queste ultime due osservazioni sono importanti per comprendere una situazione diversa da quella che caratterizza, ad esempio, l'ambito europeo, dove la grande distribuzione minaccia da tempo con forza qualsiasi altra forma di organizzazione entrandovi in concorrenza diretta. La presenza di ambiti di vita urbana informale e di aree che (nonostante l'impegno dell'Amministrazione Popolare) restano in parte segnate da una sostanziale segregazione nella città e da condizioni di marginalità economica, ha permesso, infatti, a Porto Alegre la sopravvivenza di forme di commercio minuto accanto al rafforzarsi della grande distribuzione. Ciò spiega perché a Porto Alegre - che aggiunge al suo essere città di un Paese periferico le specificità di uno sviluppo urbano reso complesso e mal articolato dalla sua stessa localizzazione - non si escludano geografie diverse e compresenti del commercio, come quella del tempo lento locale del magazzino all'angolo e quella della velocità globale del centro commerciale (Schäffer, 1993).

È proprio prendendo atto del doppio binario che il quadro sopra richiamato individua con chiarezza, che la SMIC ha portato avanti, fin dai primi anni del Governo Dutra, una riflessione sulle potenzialità delle attività commerciali e produttive informali, che hanno progressivamente trasformato le sue politiche di intervento nel settore, anche grazie all'appoggio del Forum popolare contro la Disoccupazione e la Recessione e del Bilancio Partecipativo. Dietro alle linee direttrici e ai criteri tecnici elencati nell'O.P. vi è, infatti, una prospettiva particolare di cui la SMIC si è fatta portatrice, e che ha dovuto contemperare nel tempo con le ottiche e le esigenze degli altri attori. 
Il problema del commercio spontaneo nelle aree informali, è un tema allo stesso tempo semplice e complesso. Il nostro Assessorato lavor a nella linea dello sviluppo economico, in armonia col contesto e dentro limitazioni imposte da altri organismi responsabili. Alla fine di una serie di discussioni collegiali siamo pervenuti a decidere che noi possiamo intervenire nella regolarizzazione del commercio in aree informali solo al termine di un lavoro svolto da altri Assessorati, e non solo perché l'occupazione irregolare urbana che si consolida ha difficili questioni legali dietro, da risolvere in prima istanza. È che noi abbiamo requisiti minori di cui chiedere il rispetto, in relazione ad altri organismi, come ad esempio l'Assessorato alla Sanità che deve valutare i locali dove il commercio - specie se alimentare - si svolge. Ma soprattutto il nostro interesse è per lo sviluppo economico, quindi - se arrivassimo per primi - tenderemmo ad avallare con più facilità ogni attività che produce reddito, a causa della deformazione che la nostra logica ci impone, considerando che in fondo tutto nell'informale è sviluppo. La nostra relazione è con l'individuo, non con la collettività. Qui sta l'atipicità del nostro sguardo, come SMIC. $\mathrm{Ma}$, a ben vedere, ci rendiamo conto che per certe cose l'ottica dell'informale limitata all'ambito economico è appiattente e distorta, perché non coglie gli aspetti 'sofferti' dell'informale per chi ci vive dentro, oltre che lo scacco che rappresenta per la città e la società nel suo complesso. Così, la prima valutazione per ogni regolarizzazione commerciale è fatta dalla SPM e dal DEMHAB. Verificato il rispetto di altre condizioni, noi riceviamo il fascicolo di un procedimento ed emettiamo rapidamente (dopo alcuni controlli) una licenza di esercizio temporanea [alvarà]. Se un esercizio viene chiuso per qualche motivo, le persone vengono subito da noi, che teniamo i rapporti con gli individui. Ma al $99 \%$ non è stato per causa nostra e dobbiamo responsabilizzarlo mandandolo alla SMOV o alla SPM, senza la cui liberatoria non possiamo operare, anche se talora vorremmo. La cosa interessante è che gli 'informali' ci sentono come degli amici, molto di più di quanto non accada con i commercianti formali, che ci vedono come burocrati vincolanti. Allo stesso tempo ci temono, perché abbiamo l'ultima parola, il potere della revoca e della chiusura. Comunque chiudiamo molte più attività nelle aree formali che in quelle ir regolari (Barbosa, 1999i, apud Allegretti 2000a).

In genere le licenze commerciali temporanee emesse in aree informali hanno validità annuale, passive di rinnovo previa verifica del mantenimento delle condizioni di irregolarità e di quelle sanitarie per certi tipi di commercio. A parte specifiche attività, non vi è neppure la richiesta di sicurezza contro gli incendi, almeno se l'attività è svolta insieme al domicilio. La strada seguita per regolarizzare il commercio e l'artigianato, in aree informali, è quella della formalizzazione per gradi, a partire da un tipo di licenza diversa da quella 'illimitata' data nella città formale.

Noi usiamo mezzi duali che implicitamente riconoscono l'esistenza di due città diverse, ma che tendono verso una città unica. Nelle aree informali abbiamo una linea direttrice: agire solo in base a reclami, aspettare che siano i commercianti e gli abitanti ad organizzarsi con i loro tempi. Certo, se ci viene detto che in una 'vila' uno commercia tenendo 15 bombole di gas in casa dobbiamo intervenire. Il sistema delle licenze temporanee è una sorta di 'premio allo sviluppo' nella battaglia contro la precarietà socioeconomica delle famiglie più povere, che però ha delle regole del gioco chiare e semplici. Un'attività di grosse dimensioni - come un supermercato in una 'vila' - che si svincola dalla precarietà economica del luogo dovrà seguire - a nostra scelta - i modelli della città formale. La gentrificazione è, cioè, riconosciuta, ma fino al punto in cui può divenire 'sfruttamento' di un'opportunità come quella costituita dalle licenze temporanee, che sono un atto di fiducia ma vincolata ad un attento monitoraggio da parte nostra del permanere delle condizioni in cui sono 
erogate. La rinnovabilità della licenza è il nostro strumento di controllo che nei casi dubbi associamo a sopralluoghi. Bisogna, infatti, stare attenti - soprattutto nelle aree informali soggette ad usucapione e quindi a completa privatizzazione una volta regolarizzate - ad evitare la presa di possesso di tutta l'area da parte di grosse società commerciali. Il marchio di 'AEIS' e i nostri rinnovi sono un punto di osservazione e protezione dalle speculazioni in mano al potere pubblico. Anche lavorare per GT areali è utile, se però non si limitano a strumenti di emergenza e poi muoiono o si indeboliscono troppo dopo l'approvazione del progetto principale a cui lavorano, come sta succedendo un po' a quello di Rubem Berta a cui io stesso ho preso parte (...) o quello nato per il trasferimento di Vila Cai-Cai. Tante emergenze fanno sì che alla consegna della prima grande conquista invece che trovare lo spirito per andare avanti il gruppo si disgrega, non arrivando neppure a valutare e a gestire quello che ha fatto. Sarebbe necessario che altri subentrassero, come la World Bank sug gerisce, magari Università o ONG. Molti (o tutti) i programmi di intervento, soprattutto nella città informale, andrebbero concepiti come terreno di un operare integrato fra Dipartimenti seppur non concepiti o ufficialmente definiti come 'integrati'. I GT avrebbero dovuto lanciare una mentalità più che esaurirsi in se stessi (Barbosa, 1999i, apud Allegretti 2000a).

All'interno del sistema dei GT integrati, che riguardano soprattutto i 'reassentamentos' di famiglie o intere comunità in locali diversi di residenza, la SMIC ha un posto importante al tavolo delle contrattazioni e deve sovente lottare per imporre sulla visione d'ordine degli altri assessorati il suo realismo economico, secondo cui la mancanza di previsioni cospicue di attività commerciali nei nuovi quartieri può solo originare un disordine posteriore di tipo spontaneistico o un rapido degradarsi delle condizioni dei manufatti per la mancanza di risorse che le famiglie possano destinare alla manutenzione dopo il re-insediamento. In passato - soprattutto prima della Nuova Repubblica - si creavano senza scrupoli interi quartieri-dormitorio lontanissimi dai centri vitali della città senza o con pochissimi spazi commerciali 'minimi' (è il caso della Restinga o di Rubem Berta, cfr. $\$$ 14.3), e sempre nella logica del 'servizio agli abitanti' e non della 'promozione economica'. Poi si è osservato che le attività commerciali si autoproducono comunque, e tanto più quanto il luogo è decentrato. Oggi la tendenza in crescita è a inglobare questa osservazione e prevedere la possibilità di attività miste nei quartieri popolari, come sollecita lo Statuto Municipale. L'errore è forse

appiattirsi troppo sulla riproduzione di ciò che accadeva in origine nella 'vila rimossa' senza adottare un'ottica di promozione sociale ed economica ulteriore in parallelo ai doveri e ai costi che la nuova situazione residenziale certo comporta. Bisognerebbe avere il coraggio di pensare, anche noi tecnici, nella logica della sussistenza di chi deve viverci. Esiste ancora un forte 'iato' fra la progettazione e la realtà. Le case prodotte dal DEMHAB o da imprese private nell' ambito di 'operazioni interrelate' non sono preparate per il commercio ma ci viene richiesto di dare il permesso per il commercio (Barbosa, 1999i, apud Alle gretti 2000a).

Per colmare questo 'iato', che non pare esserci volontà politica e, soprattutto, risorse economiche per risolvere (il DEMHAB non costruisce altro che alloggi, e in unione con altri Assessorati servizi di base collettivi come scuole o centri di salute), è stata creata una nuova figura nel sistema delle licenze commerciali, chiamata 'licenza vincolata all'abitazione' che riconosce l'impossibilità di dividere monoliticamente residenza e lavoro e "nella logica 
dell'impatto ipoteticamente non disturba il vicinato"; 41 esso serve anche "ad evitare che persone non appartenenti ai quartieri inseriti nelle AEIS $S^{42}$ o reinsediati piombino come sciacalli per sfruttare economicamente $i$ residenti, e promuovere invece l'autopromozione economica degli abitanti nei luoghi di vita" (ibidem).

Un difetto è che ancora non organizziamo corsi di formazione per aprire un commercio nelle aree informali; del resto le loro licenze non producono un gettito significativo per noi. Ora però stiamo cambiando linea, a seguito di richieste ricevute nell'O.P. Già abbiamo attivato nell'Assessorato programmi di formazione con corsi e borse. Ma è ampliato a tutti, non specifico per le 'vilas', perché le direttrici sono di mescolarli, di evitare di perpetuare la divisione tra formale ed informale che poteva accettarsi solo transitoriamente per pervenire ad una città e ad una cittadinanza unica con gli stessi diritti. Ciò accade soprattutto nelle Prestazioni di Servizio o nelle attività artigianali, quelle a scala piccola e senza uso di macchinari, dove non avrebbe senso distinguere formali ed informali. Questo vale anche per le concessioni crediti, come nel Programma Portosol (ibidem).

Il tema della 'transitorietà' attiene soprattutto ad alcuni Programmi-pilota di sviluppo economico dell'Amministrazione Popolare, come quelli dei 'capannoni di smistamento dei rifiuti riciclabili' [galpões]. A Porto Alegre ve ne sono 8 gestiti dal Comune che danno lavoro a circa 500 persone (Relatorio de Atividadeds, 2001), ${ }^{43}$ alcuni all'interno di 'reassentamentos' ma non solo, come nel caso delle Isole e della Restinga. Spesso questi - realizzati in collaborazione con il DMLU e varie associazioni di quartiere - sono un sistema per aiutare abitanti di aree informali che lavorano nella città informale come i cosiddetti 'operatori ecologici' prima detti 'raccoglitori di rifiuti' [catadores de lixo] e prima ancora dispregiativa mente lixeiros [pressappoco il nostro 'monnezzari']. In questo caso la prospettiva volutamente 'transitoria' nel concepimento, non ha funzionato come tale. Nati, infatti, per dare temporaneamente lavoro a persone non qualificate, creando delle specie di 'incubatrici di lavoro' per favorire la manutenzione delle case e aiutare ad aprire altre attività, i Galpões sono diventati strutture di occupazione permanente.

Questo perché spesso la miseria o l'ignoranza restano nere, o semplicemente perché ci scontriamo con pigrizia e comodismi, o semplice mancanza di capacità imprenditoriali. Per questo oggi la SMIC ha creato corsi di formazione per gli 'operatori del riciclaggio', per accelerarne l'uscita ed il ricambio progressivo. Tu vivi in un mondo che ha aspettative di crescita, stimoli alla differenziazione; molte di queste persone, però, purtroppo non progrediscono e non possiamo certo allontanarli dalle loro reti e dai luoghi di lavoro. Forse dovremmo fare dei contratti a tempo determinato non rinnovabili, per responsabilizzare fin da subito sulla necessità di crescere, ma chi ne ha il coraggio? Quelle commerciali sono - per esperienza - iniziative che anche nel mondo informale non partono solo dalla necessità nera, ma da individui che hanno già una forza imprenditoriale e accumulano lentamente a beneficio di casa, famiglia e lavoro stesso, in cicli continui di miglioramento. C'è poi un altro segmento di persone che non sanno organizzarsi, ma dipendono comunque dal reddito, sono vincolati a povertà e disinformazione. Perciò lavoriamo con loro su un doppio binario di crescita concreta e teorica (ibidem).

Nel 2001 ha anche aperto un'Officina di Riciclaggio di Materiali Plastici (prodotti PET), che la SMIC e la Federazione dei Riciclatori hanno voluto 
per diminuire i troppi passaggi intermedi e l'incertezza che i materiali raccolti venissero realmente riutilizzati. La collaborazione con la Federazione dei Riciclatori è stata basilare per finanziare i programmi, dato che è lei che ha garantito la mobilitazione dei suoi aderenti nel Bilancio Partecipativo.

Anche i Programmi di Generazione di Reddito e i Programmi di Educazione al Lavoro e alla Cittadinanza - ora in ampliamento numerico notevole per via della crescita di richieste nell'O.P. - danno borse di formazione nella linea del sussidio all'autorganizzazione, ma si concentrano (come alcune linee di microcredito Portosol) sulla stimolazione soprattutto di 'lavori svolti in collettività', e non distinguono necessariamente tra città formale ed informale, così come non lo fanno le 8 Fiere Ecologiche e le 25 Fiere Modello di strada organizzate da 4 gruppi di 100 'fieranti' nell'ambito dei rifornimenti primari alla città, con l'obiettivo non solo di animare i quartieri e restituire temporaneamente al cittadino l'uso 'antico' delle strade, ma anche di indurre una regolazione ed un calmieramento anche nei mercati e i prezzi privati, attraverso un importante impegno diretto del Comune in specifici ambiti del mercato (cfr. Allegretti, 2002a). La SMIC lavora, infatti, con due logiche parallele: aumentare il reddito aumentando i salari e diminuendo i prezzi. Perciò esistono dal '91 delle 'fiere regolatrici', di cui la più utile è certo quella dei 'materiali scolastici', ma ce ne sono tante nel settore alimentare: ed esse sono oggi accompagnate da lezioni per le scuole, divenendo uno spazio educativo su temi di economia e mercato. Parallelamente, è stato attivato il Programma di 'acquisti collettivi' (con 47 'punti di offerta') che abbassa i prezzi per le 'vilas' irregolari; il Municipio crea una Centrale di acquisti e rivende a prezzi bassi a gruppi organizzati per ridurre $\mathrm{i}$ costi di vita e premiare il piccolo commercio di vicinato, soprattutto nelle periferie. Per questo c'è un fondo speciale del Comune (FUNCOMPRAS). I prezzi vengono fissati dopo essere stati discussi con la cittadinanza (in genere sono fra il 20 e il $25 \%$ al di sotto di quelli di mercato, cfr. Relatório de Atividades, 2001) "ma, pur senza che il Comune vi lucri sopra, si è scelta la via di non fare donazioni o distribuzioni per evitare di creare richieste assistenziali e in modo da responsabilizzare tutti i cittadini" (Barbosa, 1999i). Per quanto riguarda, invece, le 'incubatrici di impresa' (come quella chiamata IETINGA nel quartiere della Restinga, del 1999), esse costituiscono un incentivo a mettere in cantiere piccole produzioni casalinghe di mobili, artigianato, tessuti, e sono generalmente strutturate come 'isole formali' in vicinanza di aree informali o con sacche di informalità, in forma di capannoni di circa $900 \mathrm{mq}$ che ospitano 16 piccole imprese in spazi di $50 \mathrm{mq} .{ }^{44}$ offrendo un'infrastruttura (da un locale sicuro ai telefoni, fino alle consulenze tecniche e gestionali) per dar loro un avvio alla professione, temporaneamente supportato dai mezzi del Potere Pubblico.

La SMIC porta oggi avanti 27 tipi di Progetti facenti parte del PDE [Piano di Sviluppo Economico], mirati a favorire 'una cittadinanza creativa e non alienata' attraverso 'la democratizzazione dell'informazione e delle conoscenze strategiche e la qualificazione dei processi lavorativi'(Relatório de Atividades, 2001). Tra questi progetti, esiste un Centro di Educazione al Lavoro impegnato a sviluppare in collaborazione con altre entità (l'ILEM, il Centro Vida della FGTAS) una Rete Municipale di Educazione Professionale, attivo soprattutto nella Zona Nord della città. Vi è poi un settore detto Supervisione di 
Economia Popolare incaricato di lavorare nella quotidianità con attività autogestite e piccole imprese nate in aree a basso reddito, con piccoli finanziamenti e fornitura di materiali oltre che consulenze mirate ad una 'qualificazione' che renda le iniziative indipendenti e autosostenibili in tempi rapidi. Da poco, nell'area informale del Morro da Cruz è nata una griffe che porta questo stesso nome, realizzata da un gruppo di piccole sarte locali con materiali riciclati, ed oggi divenuta di moda nelle elite cittadine. L'Assessorato ha poi un settore chiamato di Azioni Collettive, che sostiene iniziative di economia solidale sviluppate con spirito collettivistico, che mira ad una "nuova forma di relazione nel lavoro e nella gestione" (Relatório de Atividades, 2001): finora ha seguito 30 gruppi (circa 500 persone) interessati, e attraverso di essa sta venendo ora attivata nella zona Nord della città una Incubatrice Popolare. ${ }^{45}$

La difficoltà maggiore di tutte queste iniziative resta il taglio del cordone ombelicale, che spesso - come è accaduto per i 'papeleiros' [raccoglitori di carta] di Vila Planetario - costituisce la morte del segmento organizzato. Nell' area dei cosiddetti 'pescatori artigianiali' dell'are a Navegantes/Isole, ad esempio, ci sono grosse difficoltà per mancanza di locali dove conservare il pesce tra la pesca e l'arrivo al consumatore. Attraverso l'O.P. ci sono stati richiesti e li abbiamo creati in forma di containerfrigorifero, ma è subito nato un grosso problema su chi li amministra. Noi vogliamo che siano i pescatori autorganizzati a farlo. Non per tirarci ind ietro da una nuova responsabilità ma anche per spirito pedagogico; come si può pretendere di incentivare uno spirito imprenditoriale con forme assistite? Ed è un dubbio che resta, ancora in corso, come molti altri su un ambito che a noi ancora sfugge, e forse sfugge anche dalle mani di chi di queste attività vive (Barbosa, 1999i, a pud Alleg retti 2000a).

\subsection{La politica delle risorse umane}

Le burocrazie di tutto il mondo sono note per la mediocrità. Le loro caratteristiche non includono l'immaginazione, la creatività, l'innovazione. Seguono soluzioni trite e sono chinati per seguire percorsi stereotipati. Generalmente vogliono mantenere lo status quo. I funzionari governativi sono in genere avversi ai rischi. Non hanno coraggio di fronteggiare l'opposizione dei gruppi ben ammanicati (Siddiqui e Khan, 1987).

Storicamente, è stata prassi dei governi conservatori e populisti mettere la popolazione contro gli impiegati pubblici, dando a credere che l'aumento dei salari dei funzionari sarebbe possibile solo a partire dal maggior impoverimento della popolazione lavoratrice. Questa formulazione di una particolare disputa per il reddito e la ricchezza (...) si risolveva appena in una perdita di qualità del servizio pubblico (Campello, 1994).

Abbiamo legislazione e mezzi per fare molte cose, oggi. Ma i tecnici non amano lavorare con le sfide. Il vizio del personale 'pallido' è un retaggio della dittatura che dava importanza e visibilità ai tecnici, ma nessuno spazio politico di azione (Mene gassi, 1999i, apud Alle gretti 2000).

Come abbiamo avuto modo di accennare, il mutare di atteggiamenti del Dipartimento alla Casa [DEMHAB] nei confronti di alcuni temi legati alla politica degli alloggi ebbe un importante salto qualitativo in coincidenza con l'entrata in carica dell'Amministrazione Popolare, anche per una trasforma- 
zione significativa impressa alla sua organizzazione in termini di personale. Questa si inserì in un quadro più vasto di rinnovamento della politica delle risorse umane del nuovo Esecutivo, che costituì al contempo una scelta 'obbligata' e una strategia operativa 'cosciente'.

L'Amministrazione Dutra, infatti, davanti alla necessità di destinare il 98\% delle risorse municipali per pagare le spese del personale, a cui negli ultimi mesi il Sindaco uscente aveva aumentato notevolmente gli stipendi, scelse di fare di necessità virtù. E - pur avendo bisogno di procedere rapidamente a risanare un Comune praticamente fallito (Dutra, 1994) - scelse di non impugnare il provvedimento dell' Amministrazione precedente, intuendo che lasciare gli stipendi al livello a cui erano stati portati poteva costituire al momento un problema, ma a medio termine una risorsa per conquistare ai programmi del nuovo Esecutivo i dipendenti. La Riforma Tributaria dell'anno successivo battè, pertanto, altre strade per il risanamento delle casse del Comune (cfr. cap. 8) pervenendo a rendere possibile in breve una politica di riaggiustamenti salariali bimestrali degli impiegati dell' Amministrazione, ottenuta attraverso una 'delicata ingegneria' indispensabile per poter procedere ad una strategia di cooptazione del ceto impiegatizio municipale (Horn, 1994) ${ }^{46}$

La reazione iniziale dei nuovi governanti all'immobilismo della burocrazia costituita con cui si scontrarono fu (...) la stessa con cui, di solito, i funzionari pubblici si sono presentati ad ogni cambio di governo: spavento, sfiducia e tentativo immediato di prescindere dal quadro funzionale (Pessin e Mainieri Paulon, 1994).

Questo si rivelò vero al punto che furono prese in considerazioni anche opzioni come la terziarizzazione selvaggia in attesa della creazione di programmi di formazione o la sburocratizzazione istantanea e violenta, che avrebbe però solo mostrato la mancanza di accumulo teorico e metodologico da parte dei nuovi governanti, cioè una sostanziale debolezza. Nell'autocritica condotta nel 1994 circa l'inizio della Politica delle Risorse Umane del primo periodo Dutra, Pessin e Mainieri Paulon ammettono che il primo approccio della nuova amministrazione fu carico di preconcetti e contraddittorio, e se le misure radicali immaginate non si attuarono vanno ringraziati anche " $i$ meccanismi di impedimento di un utilizzo riprovevole delle persone, che impediscono, anche, che si disprezzi la storia che le ha costruite". Questi impedimenti costrinsero l'Amministrazione Popolare a fermarsi a riflettere sulla necessità di essere coerenti anche in questo campo con le premesse filosofiche e i principi politici del Fronte Popolare. E così che, a partire da un 'taglio trasversale' nella struttura piramidale degli impiegati del Comune, si formarono dei gruppi di discussione con i vari livelli di funzionari per poter realizzare uno 'Studio di Esplorazione' capace di restituire un'immagine dello stato delle cose che l'Amministrazione Popolare si trovava davanti, e di aprire uno spazio interlocutorio che permettesse al nuovo Esecutivo di spiegare le sue ragioni e i suoi intendimenti e trovare il modo migliore per poter attuare le sue linee politiche.

Fu così verificato che 'oliare la macchina' non era sufficiente, visto che era la stessa sua 'logica' a dover essere invertita, cominciando a mettere in dubbio questioni che i due contendenti (funzionari e nuovi politici) 
avevano sempre ritenuto 'naturali'. Per questa via si mirò a pervenire non a 'trasformazioni per decreto' ma piuttosto a modifiche negoziate scelte fra possibili alternative (ibidem). Uno degli aspetti più interessanti di questo tentativo di 'dialogo' avviato dall'Esecutivo nell'ottica di meglio comprendere la macchina amministrativa con cui si trovava contatto, " $f u$ la riflessione permanente iniziata sul ruolo che la tecnica e $i$ tecnici dovevano occupare nell'orizzonte di lavoro dell'Amministrazione Popolare e su come bisognava avvicinarsi e rapportarsi al mostro burocratico” (Alfonsin B. apud Allegretti 2000a). ${ }^{47}$

Per portare al successo la costruzione di un Piano delle Risorse Umane (RH) che facesse da 'snodo' al rinnovamento delle diverse politiche di settore, fu scelta "la relativizzazione della linearità potere-sapere tanto cristallizzata in questo tipo di istituzione", che alla fine si risolse in una "vera guerra contro la tecnocrazia" la cui "deistituzionalizzazione" coincise con "l'istituzionalizzazione di nuove forme di organizzazione" mirate ad uno "smontaggio progressivo, nel quotidiano", delle vecchie prassi (Pessin e Mainieri Paulon, 1994).

Questa trasformazione si imperniò sull'idea che è nel quotidiano, nelle routine e nei procedimenti più semplici del giorno per giorno che si distrugge la cultura burocratica, visto che è con lo stesso procedimento che essa mette radici. La strategia scelta in questa lotta dall'Amministrazione Popolare fu quella di lavorare 'per corridoi' (De Lima, 1999i, apud Allegretti 2000a), cioè di penetrare nel vecchio valorizzando quei tecnici "che meglio sembravano prestarsi a veicolare con l'esempio le nuove idee" (ibidem), ma con lo scopo - che in questo la differenzia da altre Amministrazioni che raggiunsero risultati apparentemente analoghi - di muovere (sotto l'apparente guerra) una pacifica "proposta di negoziazione tra il suo "sapere-governante" e il "sapere-istituito-da-chi-fa-funzionare” (Pessin e Mainieri Paulon, 1994).

Un aspetto che colpì i partecipanti alle diverse tappe di questo dialogo, puntualmente documentate secondo la tradizione pedagogica brasiliana (dagli atti degli incontri ai corsi di formazione e qualificazione per tecnici dei vari livelli), fu non incontrare nessuna documentazione simile che motivasse le scelte e le trasformazioni apportate nel settore delle Risorse Umane dai governi precedenti. Un aspetto forse prevedibile, ma che dette la certezza all'Amministrazione Popolare di seguire una strada corretta per abbandonare le vecchie prassi del passato e aprire un dialogo con le Amministrazioni future a partire dal chiarimento metodologico del percorso intrapreso verso una sburocratizzazione ancora oggi lungi dall'essere raggiunta.

La particolare congiuntura non aiutò la Giunta Dutra nella cooptazione dei suoi funzionari, che determinò all'interno dell'Esecutivo una certa 'impazienza' nei confronti del cambiamento. Gli eventuali errori o - perlomeno le 'forzature di mano' riscontrabili nel quadriennio Dutra ${ }^{48}$ si devono leggere nell'ottica di questa 'urgenza' di dotarsi subito di "professionisti in grado di mettere le proprie capacità a servizio di ciò che è pubblico, ridando significato allo spazio pubblico in una costruzione permanente di un nuovo senso di cittadinanza, in quanto lavoratori, e degli utenti che giustificano l'esistenza di questo lavoro" (Pessin e Mainieri Paulon, 1994). E se non si poteva aspettare i tempi lunghi necessari per trasformare "individui privati e privatizzatori dei beni pubblici (resi più forti dall'essen- 
za del privatismo attraverso il corporativismo) [...] in professionisti del senso di cittadinanza altrui" (ibidem) apparve più facile sostituirli, o meglio - non potendosi licenziare i funzionari di quadro già assunti - assumerne altri scelti attraverso il metodo degli 'incarichi di fiducia' (CC), che potessero sostituirne alcune mansioni-chiave dando maggior garanzia di adesione alle linee politiche dell'Amministrazione. In parallelo, l'evolversi rapido dell'OP rivelò la necessità di creare nuovi ruoli di intermediari fra lo Stato e la popolazione, o di istituzionalizzare - dando loro un ruolo 'ufficiale' nei ranghi dei diversi assessorati - presenze che bene o male anche alcune Amministrazioni passate avevano avuto, caratterizzandole per una nuova trasparenza e nuove responsabilità.

Maggiori risultati ebbero i Sindaci successivi, Tarso Genro e Raul Pont, che operarono su vari fronti, escluso - forse - quello del problema dei linguaggi diversi, tutt'ora una ferita aperta. ${ }^{49}$ Essi - entrati incarica "con un accordo salariale realizzato, che garantiva una maggior stabilità nelle relazioni con l'insieme dei funzionari" (Pozzobon, 1998) - mantennero viva la politica di aggiustamenti bimestrali delle buste paga codificata con Legge 6611/90 e 6855/91 e successive integrazioni (PMPA/GAPLAN, 1996), pur restando del $40 \%$ al di sotto del tetto per le spese di personale posto dal Consiglio Comunale proprio grazie al risanamento finanziario del Municipio e all'aumento delle entrate proprie. ${ }^{50}$ In tal modo, - mentre lo Stato e l'Unione lavorano da tempo sulla formula dei tagli al personale - il Comune di Porto Alegre si è caratterizzato in questi anni addirittura per un aumento del personale, mirato a far funzionare l'Amministrazione in modo migliore nella prestazione di servizi alla popolazione e - soprattutto - conservare in efficienza le opere di infrastruttura precedentemente realizzare. Come si può vedere dalla fig. 39, un notevole aumento nel numero dei funzionari riguardò, soprattutto, i settori dell'Assistenza Sociale e Sanitaria ${ }^{51}$ e dell'Educazione tra il 1993 ed il 1996, anche attraverso una redistribuzione del personale tra i vari organismi comunali. ${ }^{52}$ Per quanto concerne le Autarchie, i Dipartimenti cioè da cui dipendono i tipi di intervento rimasti in questi 11 anni nelle prime tre posizioni dell'elenco di priorità tematiche indicato dalla popolazione attraverso l'O.P., il saldo positivo (fig. 19) mostra che nel corso dei primi tre Governi dell'Amministrazione Popolare si sono assunti nuovi dipendenti (ancorché non tecnici di quadro), limitatamente però ad alcuni settori strategici, di cui - ad esempio - non sembra far parte il Dipartimento alla CASA, che fra i dipendenti attivi ha visto una riduzione del 38,91\% nel corso dei primi 9 anni di Governo del Fronte Popolare. ${ }^{53}$ A partire dal Governo Genro, un importante ruolo fu affidato invece agli incarichi di monitoraggio finanziario e territoriale, mirati ad un'ulteriore ottimizzazione dei risultati della politica. A questi, ha offerto un contributo notevole anche l'informatizzazione finanziata con fondi del BID e portata avanti con decisione dall'Amministrazione Pont. Non si riuscì invece a mettere in piedi - come desiderato - una politica di qualificazione del personale soprattutto dei tecnici dei vari Assessorati - attraverso un nuovo Piano delle carriere (Pestana, 1999i, apud Allegretti 2002).$^{54}$ Esso fu, infatti, messo in cantiere affidandone l'ideazione ad una Società esterna, ma la sua realizzazione dovette essere interrotta perché 
[...] c'era alla base della riforma un movimento conflittuale; il corpo politico voleva facilitare la maturazione di quello tecnico, ma i lavoratori volevano sfruttare l'occasione soprattutto per degli aumenti salariali, comprensibili ma impossibili per le smunte casse comunali. Fu lo scontro fra queste due esigenze che determinò lo svuotamento del progetto (Genro, 1999i, in Allegretti 2000a).

Nel complesso, comunque, Genro - da sindaco - mise in piedi una strategia di confronto coi suoi funzionari che risultò di maggior successo rispetto a quella che aveva 'lasciato accadere' quando era vicesindaco, una strategia di cooptazione (realizzata soprattutto all'interno del processo di revisione del PRG chiamato Cidade Constituinte) centrata sull'ostentazione della volontà

[...] di incorporare nelle decisioni politiche i pensieri dei tecnici, e il loro accumulo. Nel mio governo io ci tenevo a riunire personalmente i tecnici, influendo sulle relazioni anche personali con loro. Valorizzando il loro sapere, fermo nello spiegare il perché del nuovo agire politico. Forse per questo - a quanto mi dicono - ho lasciato un buon ricordo in molti quadri tecnici (Genro, apud Alle gretti 2000b).

$\mathrm{Fu}$ proprio in questo quadriennio di Governo che l'Amministrazione Popolare inferse coscientemente anche un altro colpo fondamentale alla lotta contro la burocratizzazione che aveva costituito la base del Piano delle Risorse Umane del Governo Dutra. Attraverso la creazione dei GT, dei Nuclei interdisciplinari, dei progetti 'Centri di Quartiere' e delle Assemblee Tematiche, infatti, si accerchiò su due fronti lo 'spauracchio burocratico', attraverso l'istituzionalizzazione delle logiche del coordinamento, dello scambio di 'feed-back' tra squadre di lavoro e quella dell'agglomerazione. Entrambe erano viste come logiche contrastanti con quelle dell'isolamento monadico e della separazione delle funzioni caratteristiche della burocrazia (Pessin e Mainieri Paulon, 1994). In tal modo, seppur all'inizio del suo mandato Raul Pont doveva amaramente constatare che "lo stesso successo ottenuto nella relazione con la comunità nel suo coinvolgimento e partecipazione, ancora non è stato raggiunto con l'apparato di funzionari del Comune”, oltre 25.000 dei quali ereditati da "decenni di politica clientelista e da lunghi periodi di autoritarismo" (Prefeitura de Porto Alegre, 1997), ${ }^{55}$ l'esperienza compiuta alla guida della città gli ha consentito, poi, un maggiore ottimismo:

Oggi abbiamo ottenuto un compromesso ragionevole all'impegno dei tecnici nelle nostre linee politiche. Credo che la trasformazione dei ritmi di lavoro, più stancanti ma più 'umani' (nel senso di 'orientati all'uomo') e fuori da gli schemi convenzionali e dal mito dell'immutabile 'orario di ufficio', abbia favorito ciò in maniera determinante, attirando la collaborazione - seppur indotta - di molti funzionari, almeno di quelli che partivano da una base di sensibilità personale al problema dell'altro. Tutti qui nell'Amministrazione - politici e tecnici - abbiamo poche vacanze e poche nottate libere, pieni come siamo di 'incontri corpo a corpo' con la popolazione, specie con la più povera. Ma ne vale la pena. E certo ci aiuta; anche solo i lunghi viaggi in auto verso la periferia, e il cameratismo che generano, sono un fattore collante fra quadri tecnici e dirigenti politici, e fra questi e la gente Pont, 1999i, apud Alle gretti, 2000b)

$\grave{E}$ in tal senso che la nuova organizzazione delle risorse umane $(\mathrm{RH})$ ha evidenziato nel tempo la possibilità di interessanti progressi di tipo 'qualitativo' nel portare avanti con sostanziale coerenza le premesse filosofiche della po- 
litica della nuova Amministrazione, ponendosi entro un quadro in controcorrente nel Paese (Pozzobon, 1998), centrato sulla democratizzazione delle relazioni di lavoro, già sancita negli artt. 23/24 dello Statuto Comunale ${ }^{56}$ e rafforzata attraverso la creazione nel 1994 della Commissione Tripartita che oggi - insieme ai rappresentanti dei Sindacati e della Popolazione all'interno del COP del Bilancio Partecipativo - delibera sulla contrattazione di personale nuovo o temporaneo, in rapporto alle esigenze di investimento e di gestione del Comune e della popolazione, ma anche in rapporto al trasformarsi della congiuntura economica e delle politiche dei livelli superiori di governo, statale e federale.

\subsubsection{Riorganizzazione funzionale come redistribuzione di poteri: un esempio}

La gerarchizzazione verticale del potere e, pertanto, del sapere, reprime la possibilità di riconoscimento delle alternative che provengono dai più diversi segmenti organizzativi, congelando le strutture dentro la loro propria logica (Pessin e Mainieri Paulon, 1994).

La Politica delle Risorse Umane messa in atto a Porto Alegre a partire dal 1989 non è stata una semplice strategia di gestione del personale, ma un anello di una vera e propria 'redistribuzione di poteri', non limitata ai singoli gruppi di tecnici ma estesa al rapporto tra istituzioni e società. Essa si è articolata per tappe nel tempo, in modo da pervenire gradualmente ad una maggiore efficacia dell'intervento istituzionale sull'organizzazione della città e delle politiche di settore, evolvendo in parallelo alla maturazione del processo di Bilancio Partecipativo e delle altre istanze ad esso collegate. Per avere un esempio di queste trasformazioni, si può osservare il caso del DEMHAB. La crisi del Sistema Finanziario dell'Abitazione che prese piede nel 1986, portò (già sotto il sindaco Collares) ad una modifica sostanziale del ruolo del Dipartimento alla Casa nell'ambito delle Politiche dell'alloggio, ma non ne modificò significativamente le strutture interne (Fruet, 1991), che subirono una riorganizzazione sostanziale "adattata alla nuova situazione di emergenza e di volontà di darvi una risposta" soprattutto a partire dal 1989, quando "fu necessario chiudere $i$ nuclei e $i$ coordinamenti che si occupavano di costruzioni condominiali e di attrezzature comunitarie divenuti inutili pesi davanti ad una situazione finanziaria stagnante che non poteva permettersi di lasciare dei validi tecnici inattivi, ad occuparsi formalmente di temi che non si aveva più risorse per trattare" (Marques, 1999i apud Allegretti, 2000a). Sotto la direzione di Lires Marques (1989-1992) il DEMHAB divenne sede di rapidi cambiamenti e redistribuzioni di incarichi e di personale, nell'ambito di quella riorganizzazione delle competenze riguardanti le politiche urbanistiche e della casa e che penalizzò soprattutto la SPM, divenuta "roccaforte dei maggiori malumori e delle resistenze più assidue all'implementazione dei metodi e delle strategie scelte dal nuovo Esecutivo" (B. Alfonsin, apud Allegretti, 2000a).

Proprio mentre in quest'ultimo assessorato veniva creata l'equipe multidisciplinare ed inter-assessorati per dare avvio al Programma di Regolarizzazione Fondiaria, al DEMHAB cominciavano ad essere cooptati i primi tecnici per i nuovi lavori sulle 'vilas' richiesti nell'ambito dell'O.P.: 
[...] compiti ritenuti 'sporchi' per cui fu chiesto il consenso dei singoli tecnici, e fummo in pochi a dire sì, anzi solo in due inizialmente, provenienti da un settore, quello degli 'edifici comunitari' che è stato un controsenso sopprimere proprio mentre l'Amministrazione parlava di senso di comunità e di cittadinanza. Per 9 anni, fino alla pensione nel 1998, sono rimasta come architetto incaricato di EVU di favelas, e non è stato facile come per quelli arrivati dopo, che già sapevano all'atto dell' assunzione su che temi avrebbero dovuto impegnarsi (Tetê, 1999i, apud Alle gretti, 2000a).

La distribuzione dell'organico del Dipartimento subì un notevole cambiamento. Confrontando l'organigramma del personale stabilito con Ordine di Servizio 2/1983 e quello stabilito con Ordine di Servizio 14/89, e modificato fino all' Istruzione 4/93, si nota che nel primo i 'flussi decisionali e di responsabilità' hanno un impianto centrato sulla Direzione Generale intesa quale autorità integrale (a cui fanno capo in posizione sottomessa solo 2 organi ausiliari chiamati Sub-diretorias, quella Generale Amministrativo/Finanziaria e quella di Ingegneria); vi sono, inoltre, due soli organismi consultivi di supporto all'azione del Direttore Generale, tra cui l'Ufficio Sradicamento della Subabitazione Popolare-PROMORAR: un filo diretto con i programmi centralizzati del SFH, che perciò ricompare come Unità a sé all'interno di ogni singola equipe tematica. Il contatto con la popolazione appare in questo organigramma ridotto alla presenza del Servizio Sociale, alle dirette dipendenze del 'centro decisionale principale' come del resto il Servizio Giuridico.

Ben diversa è la suddivisione dei flussi di responsabilità nel 1989/94, dove anche nella terminologia - le Divisioni sono sostituite da Coordinamenti fra decisori diversi, e al lavoro della Direzione Generale, intesa come autorità deliberativa, si affiancano numerose Commissioni settoriali (Infortunistica, Informatica, ecc.), il Consiglio di Sviluppo Politico-Istituzionale, una Commissione Sindacale e altri organi di consulenza che danno la misura di un'assunzione delle scelte più collegiale, o perlomeno più articolata e complessa. Tre sono le Soprintendenze, intese come organi di integrazione incaricati di seguire le pratiche amministrative, finanziario/commerciali o tecniche; ad esse si affiancano 2 Coordinamenti dotati di autonomia, quello giuridico (con 3 incaricati di 'vilas'), e quello Sociale, che non è più un semplice 'Servizio' di assistenza, ma ha un'Unità di Relazioni Comunitarie con 25 agenti scelti su 'incarico confidenziale' (CC) e un'Unità di Studio e Ricerca Sociale mirata all'approfondimento della conoscenza generale sulle realtà nuove in cui il DEMHAB opera. La stessa Soprintendenza Tecnica si articola in 2 unità semi-autonome (Unità di Informazioni e Ricerca Tecnologica e Unità di Cartografia) e in 3 Coordinamenti (quello con funzione strategica della Pianificazione, quello di Lavori con 3 unità di controllo, e quello di Urbanizzazione e Regolarizzazione Fondiaria, con 10 incaricati di 'vilas' nell'unità di 'Operazioni'). Scompare l'Unità incaricata della manutenzione, passata come routine ad altri assessorati.

Quest'ultimo organigramma trova un'evoluzione e una semplificazione interessante in quello approvato con Decreto 11855/97 che chiarisce il ruolo di alcuni organi collegiali di supporto al lavoro 'di vertice', e sottopone la Direzione Generale al monitoraggio e ai suggerimenti di istanze di controllo e accompagnamento come il COMATHAB (formato anche da cittadini), of- 
frendole la consulenza di un collegio che riunisce Consiglieri e Agenti Comunitari. Al centro del quadro vi è stavolta non più la Supervisione Finanziaria, ma la nuova Sovrintendenza di Azione Comunitaria e Regolarizzazione Fondiaria, da cui dipendono i Coordinamenti di Urbanizzazione e Regolarizzazione Fondiaria [CUR], quello di Coordinamento Comunitario (che include Servizi Sociali, Equipe Ambientali e Agenti Comunitari), un'Unità di Ricerca Sociale e - su un piano di autonomia maggiore - i Programmi di Appoggio alle Cooperative di Abitazione e ai Mutirões. La Sovrintendenza per le Questioni Giuridiche si relaziona con una Commissione Permanente di Inchiesta e con la Commissione di Negoziazione, incaricata delle situazioni più difficili che si presentano all'ente da risolvere in termini di contenziosi, soprattutto con famiglie insolventi nei confronti del DEMHAB, o fra occupanti e proprietari legittimi di beni immobili. Un aspetto interessante è l'indicazione - accanto ad ogni organo operativo o deliberativo - della possibilità di far riferimento a consulenze esterne senza appesantire la struttura interna, la quale sembra votarsi alla ricerca di vie molteplici e autonome di soluzione dei problemi dell'alloggio che facciano riferimento ad un ventaglio di interventi che ormai colloca nel suo centro i programmi di Regolarizzazione Fondiaria di parcellamenti irregolari (NRL) ma soprattutto di 'vilas' populares' (PRF). Di recente è stata anche creata la Equipe sui Materiali (in corrispondenza della $\mathrm{I}^{\circ}$ Fiera delle Tecnologie Costruttive per Alloggi Popolari, del dicembre 2001) e rafforzata la sezione Finanziaria-Commerciale, per una miglior gestione dei contratti con i residenti nei 110 insediamenti del DEMHAB: dal giugno 2000 va funzionando con regolarità un Programma di Controllo delle Inadempienze Contrattuali, che nel 2001 ha rinegoziato 952 pratiche di famiglie insolventi. ${ }^{57}$

Questo rapido confronto mostra, indubbiamente, una progressiva 'orizzontalizzazione dei poteri' realizzata attraverso strutture di coordinamento, che poi confluiscono (attraverso i GT, i Nuclei Operativi tematici o e le Commissioni 'Intersecretarias') in altre strutture di dialogo fra tecnici di aree differenti che lavorano su oggetti in comune, ma con punti di vista e obiettivi diversi o complementari. Evidenzia, inoltre, la creazione ed il progressivo rafforzamento di un ruolo 'ufficiale' attribuito agli Agenti Comunitari, e "l'implicito irrompere della cittadinanza in varie fasi dei processi decisionali a lato dei tecnici, perlomeno sotto forma di presenza incombente sul loro lavoro se non direttamente implicata in esso" (Pestana, 1999i, apud Allegretti, 2000a). E questo senza che l'organigramma del DEMHAB faccia alcun riferimento diretto al Bilancio Partecipativo.

In un certo senso, è come se - progressivamente nel tempo - la cementazione del rapporto fra cittadini e Amministrazione propiziata dal Bilancio Partecipativo avesse determinato ricadute organizzative soprattutto a livello dei settori di intervento maggiormente implicati nella risoluzione dei problemi emergenti, indicati dalla popolazione come prioritari nell'O.P. (come è appunto la casa). Tanto è vero che un percorso analogo a quello del DEMHAB lo hanno compiuto altri enti - come il DMAE o il DEP - arricchitisi (a dispetto del loro carattere 'tecnico') di istanze di trattamento dei rapporti diretti con le comunità interessate dai progetti. Questo mutamento non ha comportato un esautoramento degli organismi municipali dal loro ruolo, semmai una complessificazione ed un arricchimento delle 'interfacce' fra cittadini e Isti- 
400 tuzioni locali, cosa che è leggibile anche in uno slittamento di orientamento delle pratiche quotidiane del lavoro svolto dai funzionari del corpo tecnico dell'Amministrazione ai diversi livelli.

Quella avviata dall'O.P. è stata una trasformazione a due direzioni convergenti, dalla parte del governo (tecnici e politici) e dalla parte dei cittadini, entrambi 'allevati' all'interno del Bilancio Partecipativo, tramite cui crescono in una cultura del dialogo franco e della responsabilizzazione reciproca mirata ad eliminare i residui di paternalismo e di clientelismo ancora presenti come retaggio di anni di pratiche politiche impostate su basi differenti dalle attuali, e segnate soprattutto da una grande distanza fra chi apparteneva alle istituzioni e chi ne stava fuori. Non c'è perciò da stupirsi che il dialogo abbia richiamato ulteriore dialogo. E non ne sono testimoni solo i Consigli Popolari che hanno cambiato il volto delle strutture Sanitarie o Educative, o i Consigli Municipali come il COMATHAB che influisce sui nostri indirizzi operativi qui al DEMHAB; ma soprattutto le pratiche del contatto quotidiano, quello che noi chiamiamo il 'corpo a corpo' indispensabile fra chiunque svolga un lavoro diretto a un gruppo di cittadini e gli stessi che - essendone beneficiari - hanno il diritto, ma direi anche il dovere, di intervenire a renderlo 'il migliore possibile' seppur all'interno dei vincoli tecnici, temporali o finanziari che lo caratterizzano, e di cui comunque le persone spesso già messe a conoscenza attraverso lo stesso O.P. o gli altri forum di partecipazione (Pestana, 1999i apud Allegretti 2000a).

Oggi - oltre al 'corpo a corpo' più o meno formalizzato dei tecnici comunali con la popolazione delle aree dove il DEMHAB o altri dipartimenti e assessorati lavorano - esistono dei 'funzionari di tipo nuovo' incaricati di mettere in relazione le richieste provenienti dai diversi territori locali di Porto Alegre con le esigenze tecniche, finanziarie e di gestione amministrativa dell'Esecutivo Municipale. I principali agenti di mediazione dell'Amministrazione - che devono interfacciarsi con i mediatori della cittadinanza (soprattutto Delegati e Consiglieri dell'O.P. e leader comunitari ${ }^{58}$ dei vari quartieri) - sono indubbiamente:

\section{1) I CROPs e $i$ CTs (Coordinatori Regionali o Tematici dell'Orçamento}

\section{Participativo)}

Direttamente legati al processo di Bilancio Partecipativo, sono dei 'centri amministrativi ambulanti' 59 che hanno preceduto la creazione delle strutture dei CAR, i Centri Amministrativi Regionali a cui oggi sono legati. Essi sono quadri politici del governo vincolati al Coordinamento delle Relazioni con la Comunità (CRC) che dal 1991 hanno tre compiti base:

1) Guidare, in ciascuna Regione del Bilancio Partecipativo, il processo di discussione del bilancio, senza interferire direttamente nelle decisioni, ma garantendo il dibattito democratico e fornendo chiarimenti sui criteri che guidano la definizione degli investimenti. Sono anche una delle fonti di informazione sulla realizzazione del Piano degli Investimenti, e stimolano la creazione di commissioni di accompagnamento dei lavori.

2) Globalizzare le azioni di governo nella regione, operando così contro la frammentazione della struttura amministrativa. Il CROP aiuta a programmare il contatto della popolazione con il governo, per mezzo delle riunioni come dei forum dei servizi, che si occupano di conservazione e di manutenzione [...].

3) Preservare e diffondere determinati valori. Il Bilancio Partecipativo esige che si 
resti fermi nell'intenzione di costruire processi cooperativi e di solidarietà; nel caso contrario si stabilisce la logica della competizione e dello 'strappare vantaggi', del guadagno a qualsiasi prezzo, generando così processi di esclusione. Pertanto, le negoziazioni ispirate ad una pratica solidaristica devono essere una costante nell'azione pedagogica che il CROP esercita insieme alla cittadinanza (testimonianza di Eunice De Andrade Araùjo apud Genro, De Sousa 2002).

In queste azioni rientra anche presenziare a tutte le riunioni dell'OP nelle singole comunità e quartieri, ovvero ai momenti in cui la pressione della presenza istituzionale è di per sé estremamente allentata perché rappresentano la fase di maggior libertà decisionale per gli ambiti locali. Fondamentale per ogni CROP - 'interfaccia' del Comune più prossima alla popolazione - è saper interloquire con tutti i settori della società per dirimere eventuali controversie, oltre che conoscere il funzionamento della macchina amministrativa e del gioco politico, che deve servirgli ad ausiliare i leader comunitari nel costruire le relazioni tra potere pubblico e popolazione 'costruendo scorciatoie' (ibidem). Di solito assunti su incarichi di fiducia (CC), e in mancanza di una formazione ad hoc, essi corrono rischi non indifferenti. Oltre a quello dell'impreparazione o dell'inadeguatezza al dialogo e alla mediazione, quello di portare avanti con spirito paternalistico compiti che spetterebbero alla comunità, instaurando relazioni 'di tutela' (generatrici di subordinazione e dipendenza) che sono ancora presenti nella cultura politica brasiliana. Oppure, il rischio di assumere atteggiamenti parziali in conseguenza di storie di militanza anteriore nell'area, venendo meno all'imparzialità che il ruolo richiederebbe. Per minimizzare questi rischi, i CROP non vengono scelti mai fra chi è residente o ha risieduto nell' area. ${ }^{60}$

\section{2) Gli Agenti o Consiglieri Comunitari (ACs)}

Questa figura professionale, in fondo, è sempre esistita, seppur con nomi diversi, come ad esempio "Fiscal de vilas". I meriti dell'Amministrazione Popolare sono "averla 'ufficializzata' dandole una dignità istituzionale, ed averla resa - appunto - professionale, cioè sottratta al subdolo ruolo di mediatore del clientelismo" (Helmann, 1999i, apud Allegretti, 2000a). Gli Agenti Comunitari appaiono nei vari assessorati dopo il 1990, a seguito della nascita della CRC: rappresentano incarichi di fiducia (CC), di solito scelti tra ex attivisti del movimento popolare, e sono in numero proporzionale alle necessità e alle possibilità economiche di ogni organismo municipale. Non è loro richiesta una specifica formazione (come accade invece per gli Assistenti Sociali), proprio perché la loro funzione è di mediazione ed interlocuzione essenzialmente politica fra l'organismo municipale per cui lavorano e la comunità. E, teoricamente, non necessitano di specifiche 'tecniche' per farlo: ${ }^{61}$ almeno il loro coordinatore è però un tecnico laureato. Solo il DEMHAB ne ha 16 , uno cioè per ogni regione dell'O.P.: la scelta è stata presa nel 1994, a causa del tema delicato su cui il Dipartimento alla Casa interviene. Le altre autarchie o assessorati (DEP, DMAE, SMOV, Assessorato alla Sanità $)^{62}$ ne hanno meno, e affidano loro la responsabilità di macroregioni, ad esempio le 8 di Pianificazione. Costituiscono collaboratori essenziali dei tecnici, sollevandoli dal dovere di discutere con la popolazione locale sulle politiche del Dipartimento a cui afferiscono, e permettendo loro di concentrarsi sui programmi e le azioni tecnicamente definite in cui 
402 questi si concretizzano. Lo sforzo che essi compiono deve essere a due sensi: comprendere la proposta tecnica perché arrivi alla comunità e portare la visione di questa a costituire elemento-guida fondamentale dell'elaborazione dei tecnici. In termini ideali, il ruolo degli ACs dovrebbe garantirei flussi di comunicazione e feed-back rappresentati nello schema di fig. 39, al fine del concepimento e della correzione dei progetti da impiantare sul territorio. Nella realtà accade spesso, invece, che questa doppia interazione non si realizzi; ma - a differenza di quanto si potrebbe credere - "è più difficile che l'AC serva a facilitare l'imposizione di un progetto preconcepito ad una comunità che non ad imporre almeno la visione (se non le richieste precise) della comunită" (Helmann, ibidem). Sovente i rapporti che si stabiliscono tra Agenti Comunitari (che hanno natura di mediazione politica) e i tecnici di quadro del Comune ${ }^{63}$ non sono semplici; l'altissima mobilità degli $\mathrm{ACs}^{64}$ finisce per aumentare la loro precarietà e diminuire la loro utilità, nella misura in cui la conoscenza sedimentata dei vari territori locali dovrebbe costituire un elemento prioritario per lo svolgimento del loro ruolo. Dal 1990 a Porto Alegre esiste il FASCOM, un Forum che riunisce insieme settimanalmente tutti gli ACs dei vari organismi municipali, per scambi di opinioni e per proporre al Comune modifiche nei modi con cui avviene il coinvolgimento dei cittadini nelle diverse politiche e progetti.

Il Bilancio Partecipativo svolge, indubbiamente, un ruolo nodale per dare ordine e coerenza a mediazioni di questo genere e propiziare una trasformazione non solo dei rapporti tra cittadini e governo locale, ma anche tra tecnici e tecnici, "con lo scopo di farla proseguire in altre sedi, di espanderla dal bimestrale al mensile, fino al quotidiano" (Casa Nova, 1999i - II apud Allegretti, 2000a). L'apertura e la flessibilità dello stesso modello organizzativo dell'O.P., e la sua capacità di valorizzare le persone nella loro umanità, costituisce un valido antidoto ai pericoli maggiori della burocratizzazione il cui universo è impersonale e obbedisce ad una razionalità che "va da sé e proviene da una sola mano, quella della logica del sistema", in cui il momento dell'assunzione delle decisioni è "diluito e oscuro" 65 e che raramente è interessata "al ritorno a scopo valutativo del prodotto del lavoro" (Pessin e Mainieri Paulon, 1994).

Una considerazione importante riguarda comunque la lucidità che deve essere mantenuta nei rapporti tra tecnici e comunità, da improntarsi sempre ad un connubio di "fiducia" e contestuale "cautela" nell'opera di mediazione che, dal lato degli abitanti, viene portata avanti dai diversi leader comunitari: i quali tra l'altro - talora possono presentare deficit di rappresentatività in rapporto alle stesse comunità che si autopropongono di rappresentare. Infatti:

Spesso può capitare che alcuni leader finiscano per rappresentare solo se stessi e non le comunità di cui sono fatti portavoce. Magari perché sono buoni oratori o abili creatori di reti di relazioni sul loro territorio di dominio riescono ad emergere, ma progressivamente mostrano un interesse precipuo concentrato su singoli temi o interventi. Per questo noi - tecnici, assistenti sociali, agenti comunitari - dobbiamo stare molto attenti quando ci rapportiamo con loro. Soprattutto dobbiamo osservare, ascoltare criticamente. Dobbiamo saper cogliere l'enorme potenziale positivo che comunque c'è nell'interagire con i beneficiari degli interventi pubblici su cui stai lavorando, ma sapendo che coloro con cui parli possono rapportarsi a te in modo 
'deformato', ad esempio acconsentendo con te se rappresenti un potere che sentono superiore o anche fingendo di capire ciò che dici per non apparire ignoranti. La cosa migliore è stare molto sul territorio e sentire punti di vista diversi. Per questo, da qualche anno, gli orientamenti del Comune e dei singoli assessorati e autarchie non disdegnano anche di prendere in considerazione leader di movimenti di opinione informali, voci-contro. E magari li stimoliamo ad emergere anche formalmente creando nuove entità rappresentative di orientamenti diversi. Questa comunque è una questione delicata, perché rischia di creare divisioni locali inutili o addirittura dannose, e di portare la popolazione a leggere l'Amministrazione come un nemico che cerca di dividerla e smussarne la forza. Per cui quello che noi suggeriamo di solito e di disputare democraticamente la presidenza di un' Associazione tra voci diverse, di continuare a riunirsi, se necessario di revocare mandati ai rappresentanti, se agiscono per conto proprio. Quello coi leader comunitari è nel complesso un rapporto articolato e difficile da ricondurre a dei binari unici, perché la sua forza è variare con il tempo e i luoghi, cosa che richiede a noi rappresentanti del Potere Pubblico impegno notevole, apertur a e flessibilità (Frare, 1999i-II apud Allegretti, 2000a).

Se le forme diverse del 'corpo a corpo' messe in atto da assessorati e dipartimenti comunali raramente di per sé costituiscono - per i modi in cui si svolgono - una garanzia nei confronti delle deviazioni dei leader a contatto con le strutture del potere, o con le loro 'piccole fette di potere', un ruolo più solidamente positivo svolge invece il Bilancio Partecipativo, che si pone come un loro complemento 'riequilibratore'. Per come è congegnato, infatti, esso contribuisce alla trasformazione dei leader comunitari e delle loro attitudini 'politiche', nella misura in cui esso non solo "cozza con la ristrettezza e le limitazioni della democrazia rappresentativa”, ma si differenzia anche "dal 'consiglismo puro', quel processo non regolato in cui i più abili e attivi traggono vantaggio" e dal . "populismo tradizionale, meramente consultivo, in cui la partecipazione popolare è un semplice elemento di conoscenza, perché l'Esecutivo prenda le decisioni che gli paiono più convenienti" (Genro, De Sousa, 2002). Nel Bilancio Partecipativo, ciò che fa la differenza sono la combinazione di "regolamentazione e apertura" del processo, e l'esistenza di un 'percorso determinato' che "crea una cultura ed una psicologia nelle quali $i$ leader hanno bisogno di conoscere le regole del processo" (ibidem), devono rispettarle e anche attivare la partecipazione, che è al contempo la garanzia per loro di ottenere dei risultati visibili (con pochi partecipanti si hanno pochi delegati, e quindi poche possibilità di 'neutralizzare' la forza gli altri quartieri), ma è anche un elemento costante di controllo sul proprio operato.

A ben guardare, il Fronte Popolare di Porto Alegre pare aver prestato molta attenzione ai rischi che possono derivare dal rimettere troppo potere 'unilaterale' nelle mani dei leader comunitari. Ha quindi operato per esaltarne il ruolo rappresentativo, limitandone al contempo quello fattivo. Memori di ciò che era avvenuto all'epoca del Presidente Sarney e poi di Collor con la distribuzione dei ticket del latte affidati discrezionalmente alle Associazioni di Vicinato per la distribuzione, si sono così evitate 'distorsioni' pericolose che - altrove - hanno minato i risultati attesi da coalizioni simili a quella che governa Porto Alegre. È il caso della São Paulo dell'epoca Erundina (cfr. Taschner, 1997) dove è accaduto che l'eccessivo peso dato alle Associações de Moradores come interlocutori principali dell'Amministrazione e co-gestori delle politiche nelle favelas, le abbia trasformate in "plenipotenziarie 
404 dell'informalità', cioè in sorta di 'Catasti' (ibidem) attraverso cui gli abitanti della favela eseguivano le transazioni ed ottenevano il benestare per ampliare una casa o invadere un terreno, venendo i favori dei leader di comunità remunerati con percentuali del valore della transazione compiuta. In un tale quadro, le AMs e i loro leader, per via del controllo delle vendite e dei permessi di ampliamento e ristrutturazione, hanno finito per trovarsi "coinvolti in un complesso gioco di interessi ed esposti alla corruzione, molte volte deturpandosi in quanto legittimi rappresentanti degli strati popolari" (Guimarães, 1992) e minando dalle basi il sistema di 'fiducia reciproca' costruito dal PT e dai suoi alleati. A Porto Alegre una simile degenerazione non sembra essere avvenuta negli ultimi anni, né pare possibile. Esistono, infatti, reti di controllo originate dal sovrapporsi di livelli di monitoraggio reciproco, con una serie di veti alle rielezioni successive di alcuni di questi (come i Consiglieri dell'O.P.) che esprimono un desiderio dell'Amministrazioni di cautelarsi proprio da simili 'distorsioni', svolgendo un ruolo educativo e trasparente che disabitui dai tradizionali meccanismi clientelari da cui non necessariamente sono immuni per definizione le amministrazioni progressiste.

\section{Note}

${ }^{1}$ La definizione è tratta dall'introduzione,dell'avvocato Jaques Tavora Alfonsin.

${ }^{2}$ L'emendamento fu presentato dall'ANSUR [Articolazione Nazionale del Suolo Urbano], dall' MDF [ Movimento di Difesa del Favelado], dall'FNA [Federazione Nazionale degli Architetti], FNE [Federazione Nazionale degli Ingegneri], dall'IAB [Istituto degli Architetti del Brasile] e dal Coordinamento Nazionale dei Mutuatari e Inquilini.

${ }^{3}$ Quest'ultimo fu sottoscritto da 336.047 elettori e presentato dalla Commissione Brasiliana Giustizia e Pace, dall'Associazione Brasiliana della stampa [ABI], e dall'ABAP [Associazione Brasiliana di Appoggio alla Partecipazione Popolare nella Costituente]. ${ }^{4}$ Gli altri erano la proprietà immobiliare urbana, la politica dell'alloggio, dei trasporti e dei servizi pubblici e la gestione democratica della città.

${ }^{5}$ Interessante, ad esempio, nel testo elaborato sulle AEIS, l'affermazione che esse servono fondamentalmente a rendere compatibili standard minimi accettabili per i singoli ma che garantiscano gli interessi più generali della città, con gli standard specifici della struttura esistente che riflettono gli interessi locali, e di assicurare meccanismi inibitori della speculazione immobiliare, senza congelare la città e riconoscendo stadi differenziati di evoluzione dei nuclei (GGA-SPM, 1997).

${ }^{6}$ La sigla voleva dire Finanziamento per Costruzione, Ampliamento o Miglioramento di Abitazioni di Interesse Sociale; dal 1980 il Programma era diretto a unità isolate, e solo dal 1984 finanziò condomini, suscitando in Porto Alegre un grande interesse che in 3 mesi vide oltre 1000 famiglie mettersi in lista per utilizzarlo (Atti del Seminario di Governo sulla Politica Urbana e della Casa, 1993).

${ }^{7}$ Il Regolamento Interno del 2003 prevede la possibilità di finanziare 8 tipi di richieste: per Regolarizzazione Fondiaria e Urbanistica (Rilievo topografico e catastale, urbanizzazione di vilas, costruzione di unità abitative), per 'reinsediamenti' (acquisto dell'area, produzione di lotti urbanizzati con modulo sanitario, costruzione di unità abitative); Mutirão e appoggio a Cooperative di Abitazione.

8 "Quando usiamo il tema dell'area di rischio non siamo sempre in buona fede; sappiamo che se fossero ville potrebbero occupare magari quello stesso terreno, ma siccome sono baracche sono esse stesse 'il rischio'. Rischio sono le case, più che le aree" (Eliane Menegat, 1999i, apud Allegretti, 2000a).

9 “ Fu un'occupazione 'sporca', politica nel peggior senso della parola perché organizzata dai neoliberali di Britto per mettere alla prova il PT ad una vigilia elettorale importante. E per fortuna il PT ha risposto bene, grazie anche alla UAMPA che ha avuto un ruolo decisivo e si è fermamente opposta allo sgombero in prima istanza nei corridoi di palazzo perché la cosa non arrivasse all'orecchio della stampa. [...] le 
menti del PMDB pensarono che quindi era buono spingere ad occupare lì perché il $P T$ avrebbe dovuto usare il pugno di ferro per non perdere $i$ finanziamenti uscendo fuori tempo con la realizzazione, e cosi avrebbe offuscato l'immagine dell'intero partito che qualche mese dopo avrebbe dovuto concorrere alle elezioni statali. L'occupazione crebbe attraverso il tam-tam dei media fino ad arrivare a 3000 famiglie in 3 mesi, che minacciavano il progetto di quasi 1 milione di $R \$$ finanziato dalla Caixa Economica Federal, e rendevano indispensabile la 'reintegrazione di proprietà'; eppure sgomberare con la polizia poteva essere un suicidio davanti a persone che erano state formate per resistere e lottare. Se non ci fosse stata una negoziazione politica a rete, a cui partecipò l'Assemblea Legislativa attraverso le Consigliere Comunali Vieira da Cunha e Jussara Cony [...], e la stessa UAMPA a fare da intermediario, sarebbe potuto accadere ciò che la destra voleva e che il PT forse non aveva letto in tutta la sua pericolosità. Del resto il Sindaco e il DEMHAB sembravano aver assunto una posizione di chiusura per proteggere dei fondi destinati dall'Orçamento Participativo $e$ quindi sacri e intoccabili.[...]. Fu alla fine un test importante per l'Amministrazione, ed un test vinto, che non diede alla TV e a Britto il risultato sperato. L'elezione prima era stata vinta da Britto proprio in TV e proprio sul tema delle occupazioni in zona Sud, questa è stata vinta da Olivio [Dutra] sul campo. Proprio la sera prima dello sgombero previsto gli occupanti ottennero $543.000 \mathrm{R} \$$ per un'altra area lungo la Protasio Alves, pur vuota e non infrastrutturata ma non peggiore di quella occupata, dove oggi si è insediata una cooperativa di manodopera, un asilo, una buona Associazione di Quartiere, un Club di Madri e persino un corso di alfabetizzazione per adulti. Oggi quella è una piccola area-modello di autorganizzazione con 700 famiglie, quando avrebbe potuto essere una bomba in negativo; e con un progetto 'batiti boop', cioè rapidissimo. I conservatori di solito legano le occupazioni al PT, ma come si può vedere anche dal numero di occupazioni che hanno piagato l'era PT a Porto Alegre, esse possono essere anche armi nelle mani della destra" (Dias, presidente UAMPA, 1999i, apud Allegretti 2000a).

${ }^{10}$ Una gestione partecipativa presuppone la necessità di un processo educativo di formazione e informazione nel corso dell'implementazione dei programmi (DEMHAB, 1998a).

11 "[Sono] una forma disonesta di gestione dei fondi pubblici, che sfruttano un lavoro quasi-nero mentre fingono di moltiplicare gli interventi a favore dei più deboli. Per questo andrebbero cancellati del tutto, anche se va ammesso che le formule attualmente più usate di mutirões, quelli per la produzione di case, non sono più disoneste di qualsiasi altro intervento che affida le case private all'autocostruzione, con la differenza che almeno il potere pubblico fa uno sforzo di 'educazione professionale' dei mutirantes" (Marques, 1999i, apud Allegretti, 2000a).

12 I dibattiti maggiori si ebbero a São Paulo nell'epoca Eundina. Ai critici dei programmi di 'ajuda mutua' autorganizzati che parlavano di sfruttamento della manodopera, i difensori ribattevano:

a) che l'auto-costruzione, bene o male, è contenuta nel salario del lavoratore, visto che l'andamento e il bilancio seguono il ritmo degli investimenti che l'utente si può permettere (ciò non è valido per i mutirões del tipo adottato a Porto Alegre)

b) che la periferia urbana brasiliana è nata per autocostruzione e ed è meglio istituzionalizzare un processo che tanto andrebbe avanti, garantendo assistenza tecnica e miglioramento della qualità del prodotto

c) che di fronte alla scala del problema è impossibile pensare solo in termini di unità pronte e finite

d) che il progetto di unità realizzato nel mutirão è di solito più flessibile e più adeguato alla famiglia che vi abiterà di quanto non lo siano le piante dei blocchi residenziali.

${ }_{13}$ Nell'agosto 1996 il DEMHAB ha promosso un Seminario tra tutti i partecipanti al Programma di Ajuda Mutua per favorire un'autovalutazione di problemi e soluzioni applicabili allo stesso da parte dei mutirantes. A seguito di questo (nel corso del quale architetti di altre città hanno mostrato esempi differenti di costruzione collettiva e solidale), sono state messe in opera alcune variazioni di indirizzo suggerite dalla popolazione.

${ }^{14}$ Le aree erano così distribuite: 7 nella Lomba do Pinheiro, 6 nella Restinga, 6 nella Chacara da Fumaça, 4 nel quartiere Orfanotrofio, 3 a Ponta Grossa/Belém Novo, 5 a Vila Nova, 1 a Espiritu Santo, 1 a Campo Novo, 1 nel Partenon, 2 nel Morro da Cruz.

${ }^{15}$ Gli edifici hanno una struttura metallica semplificata ma dedotta da quella applicata dalla ditta Archel nel 'reassentamento' della Favela Vila Cristal nel Loteamento Vila Nova. 
${ }^{16}$ Il Comune non investe, infatti, soldi pubblici in aree private, come è quella acquistata dalla Cooperativa dei Metallurgici. Le richieste delle Cooperative possono essere presentate solo nelle Assemblee tematiche (a cui dal 1994 partecipano attivamente molti soci) per non mettersi in concorrenza con situazioni di bisogno più elevate. Le Cooperative indicano inoltre i loro rappresentanti nel COMATHAB.

${ }^{17}$ Davanti a un ricatto simile il DEMHAB non ha potuto fare nulla, perché all'interno degli accordi con l'Università nessun tecnico pubblico può firmare i progetti.

${ }^{18}$ In ogni caso, da una lettura degli statuti delle diverse Cooperative - depositati al DEMHAB - la parte di progettazione dell'insediamento non è mai esplicitamente inserita (eccettuato il caso della COOMETAL) tra i compiti da discutere comunitariamente, restando pertanto nel campo delle ipotesi minoritarie di progetti che sembrano porsi prioritariamente altri obiettivi (cfr. Allegretti, 2000a).

${ }^{19}$ Tra gli esempi, la $3^{\circ}$ Circonvallazione cittadina (finanziata dal BID) e i miglioramenti del corridoio Nord/Nordest mirati a decongestionare i flussi del trasporto pubblico (con fondi BNDES).

${ }^{20}$ Espropriazione ai fini di integrazione delle aree nelle funzioni sociali della città, parcellamento ed edificazione obbligatoria, operazioni interrelate o riurbanizzazione consorziata, diritto di prelazione, sdemanializzazione, ecc..

21 “ $E$ importante, comunque, avere codificato nelle Leggi locali l'uso di questi strumenti variati di azione; essi restano come delle riserve, un potenziale che è già approvato $e$ che non è fallito. È solo giacente, andrà sperimentato e potrà dare magari risposte positive" (Dantas Machado, 1999i, apud Allegretti, 2000).

22 "In realtà appare oggi utile creare una Commissione che si occupi più specificamente di questo Robin Hood che toglie ai ricchi per dare ai poveri, per controllare $e$ direzionare meglio l'uso dei suoi fondi ai fini della creazione di abitazioni popolari" (Ribeiro Jordão, 1999i, in Allegretti, 2000a).

${ }^{23}$ Il Decreto $11.503 / 96$ e la LC $7592 / 95$ ne disciplinano il funzionamento.

${ }^{24}$ Il DEMHAB, pur essendo un'Autarchia, non ha una politica estera autonoma; la SECAR rappresenta in tal senso una forma di ricentralizzazione della cooperazione (Dantas Machado, 1999i, apud Allegretti, 2000a).

${ }^{25}$ L'espressione, usata nel prontuario dell'Unità di Regolarizzazione dei Parcellamenti del DEMHAB (1998), è certo ambigua, perché sembra suggerire l'idea di un'esclusione dei poveri dalle aree nobili; i numerosi programmi improntati al 'diritto dei poveri al centro' realizzati nell'ultimo decennio evidenziano però come questa lettura non sia nell'animo dell'Amministrazione Popolare.

${ }^{26} \mathrm{Nel} 1993$ - come è scritto negli atti del Seminario del Governo sulla Politica Urbana e Abitativa - erano $30 \%$.

${ }^{27}$ Di questi 13.992 sono quelli attualmente attivi, secondo i dati forniti dal DEMHAB del 2/9/1999.

${ }_{28}$ Secondo Fernandez il valore medio dei pagamenti non aggiornati è intorno agli 11,61 R\$.

${ }^{29}$ Il progetto fu reclamizzato su alcune pagine comprate sul quotidiano locale Zero Hora in modo apocrifo, e solo riconosciuto più tardi come proposta ufficiale dell'esecutivo (Borba, 1993).

${ }^{30}$ Questi usarono i media per manifestare il loro sdegno, non possedendo organizzazioni formalmente riconosciute.

${ }^{31}$ Il Movimento (che riuniva il 'Grupo Cidadela' ed altri di matrice culturale, politica ed ecologica) promosse l'occupazione della Piazza XV nel novembre 1983, realizzandovi attività culturali con l'appoggio di molti artisti locali ed una tribuna per tutti i cittadini che volessero esprimere le loro opinioni. Lo scopo - che ottenne per il Movimento molto spazio sui media - era dimostrare le grandi potenzialità - culturali e politiche - già possedute dal centro, che rendevano superflui grandi e costose trasformazioni (Borba, 1993).

${ }^{32} \mathrm{La}$ valorizzazione del potenziale del commercio informale attivo nel centro cittadino si orientò nella stessa direzione del programma abitativo di Dutra, convinto dell'indispensabilità e della vitalità per un centro storico della funzione abitativa che meglio garantisce il valore patrimoniale e storico degli spazi (Santos, 1986), ma anche del fatto che il centro è uno 'spazio integrato' che appartiene e deve appartenere anche ai cosiddetti 'marginalizzati', a quel popolo per cui anni prima lo IAB/RS ed il Movimento Cidade-Viva avevano lottato; e che solo discutendo con loro i progetti che lo riguardano si possono ottenere i risultati migliori, quelli che solo emergono dalla $\mathrm{mi}$ glior forma di gestione, cioè da quel dibattito democratico a cui in nessun caso è 
desiderabile rinunciare, tanto più [...] nel governo della città (Borba, 1993).

${ }^{33}$ Il restauro delle pavimentazioni storiche e del Mercato e il riutilizzo dell'Usina del Gasômetro e dell'ex-hotel Majestic (1990) come Centri Culturali furono invece alcuni degli sforzi compiuti in direzione della preservazione del carattere storicamente pregevole di alcune aree sottoutilizzate del centro. Interessanti - seppur difficili da portare avanti per la presenza di aree a giurisdizione federale e statale - i progetti di risanamento delle acque del Lago Guaiba (oggi in via di realizzazione), il ripristino di alcuni tragitti di passeggio in barca verso il delta dello Jacuí e gli interventi sul Porto e sul muro che lo circonda (il muro di Mauá costruito nel 1947), di cui si tentò di minimizzare il ruolo negativo di ostacolo visuale attraverso una serie di passerelle; tutti fondati sull'ideaguida che il riscatto del legame fra la città e l'acqua si può ottenere solo (contrariamente a quanto fatto da Collares) deprivatizzando gli spazi ed accentuando il loro uso pubblico (Borba, 1993) nel rispetto della memoria e della vocazione di Porto Alegre.

${ }^{34}$ Si pensi che lo Shopping Center Rua da Praia, costruito nel 1990 in pieno centro, e quello Masson (1991) non possiedono spazi propri di parcheggio e hanno richiesto alle Amministrazioni (quella appena subentata del petista Dutra) rivoluzioni vere e proprie nei piani del traffico. Gli spazi di parcheggio sono oggi assunti a indicatore della capacità della completezza di risposta alle richieste di servizio, e quindi del valore intrinseco dei diversi luoghi di smercio differenziato.

${ }^{35}$ Il marketing distorcente dei supermercati e degli Shopping centers incorpora in tal senso le tendenze prodotte su vasta scala; ad esempio introducendo il marketing verde che riprende i temi della protezione ambientale e della salute. Del pari il fare le compere - reso con l'altisonante e ormai abusato termine inglese di fare 'shopping' - è promosso come piacere, come ricreazione, e non come un impegno o una necessità; il carattere ludico serve a mascherare i problemi dati dalla spesa familiare in una società soggetta alle severe politiche dell'aggiustamento strutturale, e lo stesso vagare di intere famiglie per la città alla ricerca delle offerte migliori (circolazione che ha dei costi spesso dimenticati nei bilanci familiari) assume un carattere di passeggiata che mette in secondo piano il carattere di necessità dell'atto dell'a pprovvigionamento (Schäffer, 1993). Come rivela un altro studio della Schäffer su Porto Alegre (1991), l'influenza della presenza di un supermercato gioca un ruolo così forte sull'immaginario collettivo e le aspettative comunitarie che in molte inchieste, anche fatte in zone depresse e con gravi problemi sanitari o di mancanza di servizi, su quali azioni erano ritenute necessarie per il miglioramento del tenore di vita, il supermercato è risultato sempre il fattore più sottolineato come portatore di miglioramento a livello urbano locale.

${ }^{36}$ Secondo Frugoli (1990) l'aumento degli Shopping center resterà a lungo una tendenza consolidata, visto che - del resto - essi rappresentano una alternativa alle deficienze nell'infrastruttura dei servizi urbani. Là i frequentatori immaginano di incontrare un luogo al riparo dalle statistiche della violenza, dalle intemperie climatiche, dai grovigli del traffico, dai disordini della geografia urbana. Del resto si è verificata la minima incidenza di lamentale e richieste di sconti in questi spazi dove la figura del proprietario è sostituito da funzionari senza potere decisionale sui prezzi (Schäffer, 1993), ed una diluizione del rapporto di amore/odio nel movimento della città che si deve affrontare per raggiungerli; quasi che questi centri fossero i luoghi di concentrazione dei vantaggi (e assumessero in tal senso una carica ideale per il proprio pubblico), lasciando sempre di più in eredità alla città il ruolo di concentrazione dei difetti.

${ }^{37}$ Secondo Gaeta (1991), l'espansione degli Shopping Center fu una risposta ad importanti trasformazioni del capitalismo brasiliano, che mutarono il profilo del pubblico consumatore ma anche [...] una pedina nella strategia dell'espansione dell'industria civile delle costruzioni (e dei gruppi finanziari legati al settore), che per molti anni beneficiò della politica dello Stato, per mezzo delle risorse del Fondo di Garanzia per Tempo di Servizio (FGTS) e dei libretti di risparmio. Non a caso, l'espansione avvenne quando la strategia di costruzione di opere pubbliche e case popolari si fermò a causa della crisi finanziaria del Paese; e la concorrenza per la miglior localizzazione urbana ha favorito anche gli speculatori, grazie all'aumento del valore dei suoli.

${ }^{38}$ E' più a livello di possibilità concrete che non di desideri che si evidenziano le due diverse e parallele geografie del commercio, visto che (a differenza del frigo o dell'auto privata che incidono sulle reali possibilità di acquisto nei grossi centri della distribuzione) la televisione è diffusa anche negli ambiti più poveri, dove contribuisce a creare un immaginario collettivo colonizzato dalla pubblicità anche nell'ambito delle scelte alimentari. 
${ }^{39}$ Se di paradosso vive l'urbano, il cui vivere ammette due tempi [...] il supermercato distrugge, modella, ricrea la bottega all'angolo (Schäffer, 1993). Nella periferia, infatti, i piccoli negozi permangono come luoghi dove la presenza del proprietario offre la possibilità di una relazione più intima e vicina, ma l'aspetto fisico tende a omologarsi a quello dei supermercati (idem) rendendoli dei mini-mercati dove scompaiono le bilance che permettevano il controllo diretto dell'acquirente, aumentano le dimensioni e i colori delle merci in vendita per colpire la fantasia di chi compra, ormai aduso a metodi di auto-selezione della merce, per la frequentazione di luoghi dove egli è anche il vendito$r e$, ed esige imballaggi pianificati per attirare l'attenzione che favoriscano il 'guardi $e$ venda da sè a se stesso (Schäffer, 1993).

${ }^{40} \mathrm{E}$ ', questo, uno dei risultati più positivi della riorganizzazione (che riduce le rese da minimi dell' $8,6 \%$ a massimi del $17,6 \%$ contro il $18,5-24,8 \%$ dei supermercati) di un settore che in passato rappresentava il $20 \%$ dell'approvvigionamento urbano e negli anni '90 si e' ridotto al 5\% (Schäffer, 1993).

${ }^{41}$ Ipoteticamente, visto che lo stesso Consigliere della SMIC mi cita alcuni casi nel quartiere di Rubem Berta dove si sono avute lamentele forti per bar e simili.

${ }^{42}$ La dichiarazione di AEIS non tocca la SMIC nella flessibilizzazione dei parametri, che riguarda solo altri Assessorati. Come osservano alla SMIC l'indicazione su una cartina non è significativa; è l'imprenditore che è protagonista del commercio. Una zona indicata dalla zonizzazione come commerciale non significa solo commercio e non residenza (Barbosa, 1999i, apud Allegretti 2000a).

${ }^{43}$ Nel 1999 erano 250 (cfr. SMIC, 1999).

${ }^{44}$ In 4 moduli vengono svolti corsi di formazione e accompagnamento dell'impresa; vi è poi una infrastruttura fisico-amministrativa 'condominiale' di $1000 \mathrm{mq}$. (SMIC, 1999). ${ }^{45}$ Finora il Programma ha lavorato su 3 fronti: la raccolta selettiva dei rifiuti (in cui rientrano gli 8 capannoni succitati), appoggio a 7 gruppi organizzati (le 20 sarte della Regione Cruzeiro, le 30 partecipanti della Commissione Municipale di Donne e creazione di Reddito, i 30 partecipanti al programma Santo da Casa, 20 artigiani associati per la produzione domestica, 20 lavoratori del settore acquisti collettivi e giardinaggio, 25 della UNIVENS e le sarte del Morro da Cruz), l'Incubatrice popolare della Zona Nord. Per il 1999/2000 si prepara un programma di 7 moduli di formazione per 50 persone (SMIC, 1999).

${ }^{46} \mathrm{La}$ risoluzione della crisi finanziaria offrì - tra l'altro - la possibilità di 1155 nuove assunzioni, oltre tre quarti delle quali nel settore dell'educazione e della sanità.

${ }^{47}$ Nella conclusione della loro analisi svolta per l'Assessorato all'Amministrazione di Porto Alegre, Pessin e Mainieri Paulon (1994) rilevarono che la forma caricaturale con cui molti tecnici (intoccabili difensori di trincea dell'immobilismo organizzativo che fanno leva sull'autorità burocratica dell' "incarico" e sulla facciata cognitiva della "formazione") sentivano l'esigenza "di definirsi 'apolitici' davanti ai colleghi di corporazione prima di emettere qualsiasi opinione personale sui loro lavori”, si dimostrava quasi come "un'autorizzazione che si richiedono tra loro per esporre la propria soggettività protetta sotto la falsa muraglia del conoscimento 'puro'” e - a contrariis finiva per dimostrare la verità delle affermazioni foucaultiane secondo cui ogni sapere è politico perché ha la sua genesi in relazioni di potere. Lo scontro della nuova Amministrazione con i suoi tecnici finiva pertanto per essere spesso uno scontro politico anche quando si trovava di fronte a impiegati della sua stessa area politica, e pertanto non si annunciava facile già in partenza trasformare in un dialogo il cozzare di due corporazioni.

${ }^{48}$ si prenda il caso del depauperamento del ruolo della SPM o della vicenda della ricostruzione della favela 'Vila Planetario', cfr. cap. 14.

49 "Nell'O.P. esiste un problema che io ritengo importante, ed è quello dei linguaggi. In una delle mie tematiche c'è ad esempio C....; ̀̀ maleducato, interrompe, grida, usa terminologie crude. Come lui altrove ci sono altri leader popolari così. Non molti, ma quelli così si fanno notare. Molti tecnici che vengono a parlarci si lasciano prendere dal panico davanti a simili forme di espressione, si irritano o si deprimono. Per me è una cosa normale, neppure la noterei più; è uno dei tanti modi di esprimersi, né più né meno. Ma perché ho un'esperienza, un'abitudine. Chi non ce l'ha spesso non regge, e poi non vuole tornare" (Brunet, 1999i, apud Allegretti, 2000a). Come ci diceva un'architetto della SPM: "Non è una popolazione uguale alla gente che frequenti nel quotidiano. Spesso sono poveri o poverissimi, gente con cui tu - tecnico avvocato, architetto o ingegnere con la tua vita borghese - forse altrove non avresti mai a che fare. Forse 
dovrebbero formarci a questi incontri, per capire che quello che ci spaventa è solo un modo di esprimersi legittimo come gli altri: che noi siamo lì per risolvere quei problemi. Penso ci vorrebbe una formazione permanente all'O.P., per noi e per il pubblico, per abituare all'interfaccia, e migliorare i risultati" (Ribeiro Jordão, 1999i I, apud Allegretti 2000a).

${ }^{50}$ Fino al '98, la politica delle risorse umane si impose con negoziati chiari e trasparenti su quella che aveva caratterizzato il difficile quadriennio Dutra in cui l'Esecutivo aveva dovuto affrontare i problemi maggiori; vi fu, tra l'altro, un solo sciopero, in occasione dell'alterazione dell'indice di aggiustamento salariale nel 1995, ma con bassa adesione di categoria (Pozzobon, 1998).

${ }^{51}$ In quest'ultimo, i funzionari passarono dai 754 del 1992 ai 783 del 1993, agli 880 del 1994, per divenire 974 nel 1995 (Pozzobon, 1998).

${ }^{52}$ Un'ottimizzazione dell'efficienza, fu ottenuta in questo periodo anche attraverso misure come il blocco assunzioni degli autisti e l'aumento dei servizi in affidamento a terzi. Parallelamente alla crescita di alcune specifiche richieste presentate nell'O.P. si redistribuì il personale tra la SMED e la SMA.

${ }^{53} \mathrm{La}$ riduzione è attribuibile a quella su scala nazionale delle possibilità di intervenire sulla Politica degli Alloggi, se non con interventi minimali. Colpisce un poco anche la leggera diminuzione dei tecnici del Sistema di Elaborazione Dati del Comune di Porto Alegre (PROCEMPA); va però osservato che la politica della 'modernizzazione amministrativa e dei sistemi informatici' è stata avviata proprio nel 1997 dal Sindaco Raul Pont, ed inoltre i dati non rilevano l'impegno alla qualificazione del personale già in attività attraverso una crescita dei programmi annuali di formazione in quest'ultima decade (dai 32 partecipanti del 1990 si è passati ai 2322 del 1997 come mostra l'Annuario statistico di Porto Alegre).

${ }^{54}$ Dal Governo Genro furono solo concesse alcune gratifiche - ai Procuratori Legali, al personale di controllo e monitoraggio dell'Assessorato alle Finanze e ai Tecnici Scientifici - che (come abbiamo già detto) suscitarono un po' di scontento in altre categorie di impiego, ma servirono ad evitare quelle 'fughe di cervelli' verificatesi, invece, nel gennaio 1999 verso l'Amministrazione Statale, seppur per ragioni diverse.

${ }^{55}$ I problemi dell'Amministrazione di Porto Alegre - scrive Pont - non sono molto diversi dai problemi diagnosticati nel governo federale e statale, nonostante possiedano una relazione sindacale meno in attrito e con alcune esperienze partecipative e elettive già rodate e con risultati positivi. Ma questo è insufficiente. Le richieste continuano e il semplice aumento del numero di funzionari non risolverà il problema [...] Abbiamo bisogno di attaccare l'arcaica e oltrepassata struttura amministrativa, $i$ cui metodi consumano, nella stima realizzata, oltre il 50\% del tempo speso con procedimenti in transito e non in lavoro effettivo (Pref eitura de Porto Alegre, 1997).

${ }_{56}$ Questi prevedono censimenti periodici annuali del personale esposti al pubblico ogni mese di marzo, la presenza di un rappresentante eletto dagli impiegati nei Comitati Direttivi di ogni Autarchia, e di un rappresentante sindacali degli stessi in ogni istituzione pubblica. ${ }^{57}$ Le prevalenze delle rinegoziazioni sono in insediamenti della $\mathrm{IV}^{\circ}$ Unità della Restinga (54), Wenceslau Fontoura (89), Guapuruvu (113); Campo do Cristal (105)

${ }_{58}$ Per leader comunitario si intende ogni persona che ricopre una carica di responsabilità all'interno di associazioni ed entità locali di vario genere, quartieri, microregioni e regioni; esso costituisce pertanto parte attiva dei processi di partecipazione dei cittadini comuni alla politica. Certo, un grado minimo di istituzionalizzazione a rigore esiste per questi personaggi, che provengono dalla Società Civile e appartengono a entità radicate sui diversi territori locali. Essi sono, infatti, a capo di Associazioni di Abitanti di un quartiere, di un Asilo autogestito, di un Club di Madri, di una società sportiva, di una particolare parrocchia, di un'Associazione di Commercianti o Artigiani; ma possono anche essere le guide di un movimento di opinione che partecipa attivamente alle pubbliche discussioni sulle scelte da compiere per la città, purché sia riconosciuto, abbia una sede sociale, un luogo di riunione - pur mutante -, che produca del pensiero, della critica e possibilmente degli atti di ciò che professa (Brunet, 1999i, apud Allegretti 2000a).

${ }^{59}$ Testimonianza di Eunice De Andrade Araùjo apud Genro, De Sousa (2002), p.38.

${ }^{60}$ Annullare questi rischi pare però impossibile: essi "In un certo senso, l'Amministrazione si affida all'onestà dei suoi collaboratori [...] implicitamente sollecitando l'autodenuncia di qualsiasi situazione personale che possa configurare un'incompatibilità con questo incarico" (Borges, 1999i, apud Allegretti, 2000a). 
61 "Questo può sovente creare problemi, nella misura in cui talora arrivano in un ente credendosi innovatori con chiave per risolvere problemi, e si intromettono con leggerezza in processi che magari vanno avanti da anni, impegnandosi con la comunità a far cose che il DEMHAB o chi per lui non può fare"(Frare, 1999i, apud Allegretti, 2000a). ${ }^{62}$ L'Assessorato delle Finanze non ne ha, non avendo un'interfaccia permanente con la comunità.

${ }_{63}$ "Chi ne esce meglio sono sempre i tecnici CC, cioè assunti con un incarico politico di fiducia. Il loro affiatamento con gli Agenti Comunitari è in genere migliore, sia per gli interessi politici che almeno evitano loro di parlare agli abitanti di questioni tecniche in geroglifici, sia perché non hanno in genere quell'aria di sufficienza tipica delle 'caste' nei confronti di chi non ha una formazione tecnica. [...] La relazione di potere che mette tensione fra architetti e ingegneri e Agenti Comunitari si esplica da parte dei primi come disprezzo per una presunta ignoranza culturale. Ed è pericoloso perché, mentre un AC non ha strumenti per vincere, il tecnico ha dalla sua l'ipotesi in seconda di portare avanti il dialogo da solo prescindendo dall'esistenza dell'altro" (Helmann, 1999i, apud Allegretti, 2000a).

${ }^{64}$ È da ritenersi abbastanza grave che dalla fine del 1997 ad oggi siano cambiati già 3 coordinatori degli AC nel solo DEMHAB, e ben 9 Agenti su 16 siano mutati all'inizio del 1999; nel complesso, poi, solo 4 dei 16 attuali hanno iniziato prima del 1997 il loro lavoro. ${ }_{65}$ "Il potere resta generalmente centrato nelle mani di un gruppo tecnico che nel suo interno fa il possibile perché non si riesca ad identificare chi, come persona, si responsabilizza per una determinata azione" (Pessin e Mainieri Paulon, 1994). i rischi dovuti al mercato immobiliare. 
Fig. 46 - Quadro riassuntivo dell'uso dei principali strumenti di regolarizzazione fondiaria a

Porto Alegre nei primi 10 anni di Amministrazione Popolare (tradotto da Alfonsin De Moraes, 1997, e aggiornato al dicembre 1999 con l'aiuto di K. Ribeiro Jordão)

\begin{tabular}{|c|c|c|c|c|c|c|c|}
\hline & $\begin{array}{c}\text { Struttura } \\
\text { ammini- } \\
\text { strativa } \\
\text { utilizzata }\end{array}$ & $\begin{array}{l}\mathrm{N}^{\circ} \text { di } \\
\text { insedia- } \\
\text { menti di } \\
\text { cui ci si } \\
\text { occupa }\end{array}$ & $\begin{array}{c}\mathrm{N}^{\circ} \text { di } \\
\text { famiglie } \\
\text { beneficia- } \\
\text { te }\end{array}$ & $\begin{array}{l}\mathrm{N}^{\circ} \text { di lotti } \\
\text { effetti- } \\
\text { vamente } \\
\text { regola- } \\
\text { rizati }\end{array}$ & $\begin{array}{c}\text { Tempo } \\
\text { medio } \\
\text { impiega- } \\
\text { to per } \\
\text { l'inter- } \\
\text { vento }\end{array}$ & $\begin{array}{l}\text { Presenza } \\
\text { di mec- } \\
\text { canismi } \\
\text { di parte- } \\
\text { cipazione } \\
\text { popolare }\end{array}$ & $\begin{array}{l}\text { Presenza } \\
\text { di politi- } \\
\text { che pub- } \\
\text { bliche 'di } \\
\text { genere' }\end{array}$ \\
\hline AEIS/ ZEIS & SPM & $\begin{array}{c}102-12 \\
\text { nuovi }\end{array}$ & . & . & $\begin{array}{c}\text { Ancora } \\
\text { non inizia- } \\
\text { to }\end{array}$ & $\begin{array}{c}\text { Durante la } \\
\text { scelta delle } \\
\text { aree, la } \\
\text { pianifica- } \\
\text { zione e la } \\
\text { discussio- } \\
\text { ne dei } \\
\text { criteri }\end{array}$ & $\begin{array}{c}\text { Non pre- } \\
\text { senti }\end{array}$ \\
\hline $\begin{array}{l}\text { USUCA- } \\
\text { PIONE }\end{array}$ & $\begin{array}{c}\text { DEM - } \\
\text { Coordi- } \\
\text { namento di } \\
\text { Urbaniz- } \\
\text { zazione e } \\
\text { Regolarizz } \\
\text { azione } \\
\text { (CUR) }\end{array}$ & 47 & 17.500 & $\begin{array}{c}225 \text { azioni } \\
\text { presentate } \\
\text { in Tribuna- } \\
\text { le }\end{array}$ & 4 anni & \multirow{2}{*}{$\begin{array}{c}\text { Indicazio- } \\
\text { ne dell'area } \\
\text { attraverso } \\
\text { l'O.P.. } \\
\text { Assemblee } \\
\text { nelle 'vilas' } \\
\text { per l'ap- } \\
\text { provazione } \\
\text { dell'EVU. } \\
\text { Forum } \\
\text { della Re- } \\
\text { golarizza- } \\
\text { zione fon- } \\
\text { diaria }\end{array}$} & $\begin{array}{c}\text { Le azioni } \\
\text { sono inte- } \\
\text { state a } \\
\text { nome di } \\
\text { entrambi i } \\
\text { conviventi }\end{array}$ \\
\hline CDRU & $\begin{array}{l}\text { DEMHAB } \\
\text { - CUR }\end{array}$ & 18 & 2.886 & 380 & 3 anni & & $\begin{array}{c}\text { I contratti } \\
\text { sono asse- } \\
\text { gnati a } \\
\text { entrambi i } \\
\text { conviventi }\end{array}$ \\
\hline $\begin{array}{c}\text { REGOLA- } \\
\text { RIZZAZIO- } \\
\text { NE DI } \\
\text { PARCEL- } \\
\text { LAMENTO }\end{array}$ & $\begin{array}{c}\text { DEMHAB } \\
\text { - SPM }\end{array}$ & $\begin{array}{c}181 \text { ( } 2 \text { soli } \\
\text { anteriori al } \\
1979)\end{array}$ & $\begin{array}{c}\text { Manca } \\
\text { stima }\end{array}$ & $\begin{array}{l}500 \text { (rego- } \\
\text { larizzazio- } \\
\text { ne ammi- } \\
\text { nistrativa) }\end{array}$ & 4 anni & $\begin{array}{l}\text { Non codi- } \\
\text { ficata }\end{array}$ & $\begin{array}{l}\text { Non pre- } \\
\text { senti }\end{array}$ \\
\hline
\end{tabular}

Schema riassuntivo dei principali strumenti giuridici comunemente usati in Brasile nella Re golarizzazione fondiaria (Tradotto e adattato da B. Alfonsin De Moraes, 1997).

\begin{tabular}{|c|c|c|}
\hline $\begin{array}{l}\text { STRUMENTO UTI- } \\
\text { LIZZATO }\end{array}$ & OGGETTO & CONCETTI BASE \\
\hline $\begin{array}{c}\text { AEIS = Aree (o zone) } \\
\text { Speciali di Interesse So- } \\
\text { ciale }\end{array}$ & $\begin{array}{l}\text { Insediamenti abitativi sorti } \\
\text { spontaneamente caratteriz- } \\
\text { zati da irregolarità giuridi- } \\
\text { che o urbanistiche } \\
\text { nell'occupazione del suolo } \\
\text { urbano }\end{array}$ & $\begin{array}{l}\text { Flessibilizzazione dei parametri urbanistici } \\
\text { sull'uso, occupazione e parcellizzazione dei } \\
\text { suoli, a partire dal riconoscimento delle partico- } \\
\text { larità locali, in modo da facilitare la regolariz- } \\
\text { zazione fondiaria degli insediamenti }\end{array}$ \\
\hline $\begin{array}{l}\text { Concessão do Direito } \\
\text { Real de Uso (Concessio- } \\
\text { ne del Diritto Reale di } \\
\text { Uso) }\end{array}$ & $\begin{array}{l}\text { Occupazione di terreni pub- } \\
\text { blici }\end{array}$ & $\begin{array}{l}\text { Contratto siglato dal Comune con gli abitanti } \\
\text { appartenenti a questa persona giuridica, per } \\
\text { l'uso degli stessi a fini abitativi, per un periodo } \\
\text { determinato }\end{array}$ \\
\hline $\begin{array}{l}\text { Apoio à Usucapião Ur- } \\
\text { bana (Leggi di Appoggio } \\
\text { all'Usucapione Urbana) } \\
\text { a specificazione } \\
\text { dell'articolo } 183 \text { della } \\
\text { Costituzione. }\end{array}$ & $\begin{array}{l}\text { Occupazione di terreni pri- } \\
\text { vati }\end{array}$ & $\begin{array}{c}\text { Acquisizione del diritto reale (proprietà o enfiteusi) } \\
\text { in relazione all'area privata occupata di fatto per } 5 \\
\text { anni continuativi a fini abitativi, in lotti non superiori } \\
\text { a } 250 \mathrm{mq} \text {. }\end{array}$ \\
\hline $\begin{array}{l}\text { Legge Federale } 6.766 / 79 \\
\text { e Leggi Municipali per } \\
\text { la Regolarizzazione dei } \\
\text { Lotti }\end{array}$ & $\begin{array}{l}\text { Parcellizzazione dei suoli in } \\
\text { lotti irregolari o clandestini }\end{array}$ & $\begin{array}{l}\text { Regolarizzazione delle divisioni in lotti e suc- } \\
\text { cessiva attribuzione dei titoli degli stessi, accet- } \\
\text { tati dall'Amministrazione, ferma restando la } \\
\text { possibilità di un'azione di regresso per risarci- } \\
\text { mento danni contro il lottizzatore }\end{array}$ \\
\hline
\end{tabular}




\begin{tabular}{|c|c|c|}
\hline Circa le direttrici urbanistiche & $\begin{array}{c}\text { Circa il dimensionamento delle aree } \\
\text { pubbliche }\end{array}$ & Circa le arce private \\
\hline $\begin{array}{l}\text { Plano Diretor: } \\
\text { 1) Sistema viario strutturante } \\
\text { 2) Sistema viario integratore } \\
\text { 3) Attrezzature urbane e comunitarie } \\
\text { (accessibilità ai servizi e rete di } \\
\text { infrastruttura) } \\
\text { Condizionamenti ambientali (corsi } \\
\text { d'acqua e pendenze) }\end{array}$ & $\begin{array}{l}\text { 1) Valutazione del progetto viario } \\
\text { con l'obiettivo di promuovere gli } \\
\text { adattamenti possibili } \\
\text { 2) Stabilimento di classificazione, } \\
\text { concetto e funzione delle vie } \\
\text { locali; definizione di parametri } \\
\text { 3) (specie rapporti dimensionali } \\
\text { minimi) } \\
\text { 4) Reti: dimensionamento minimo } \\
\text { in funzione del tracciato viario. } \\
\text { Per gli spazi: considerare le } \\
\text { attrezzatre esistenti nelle } \\
\text { vicinanze, e la possibilita di } \\
\text { accoglimento delle richieste } \\
\text { attraverso le attrezzature } \\
\text { dell'intorno } \\
\text { 5) Fasce di protezione e pendenze } \\
\text { da analizzare caso per caso }\end{array}$ & $\begin{array}{l}\text { 1) Dimensione dei lotti } \\
\text { 2) Arretramento della costruzione } \\
\text { (fronte e retro) } \\
\text { 3) Altezza massima } \\
\text { 4) Uso predominantemente } \\
\text { residenziale/commercio unito } \\
\text { all'abitazione }\end{array}$ \\
\hline $\begin{array}{l}\text { Aree di rischio: } \\
\text { Identificazione delle occupazioni in } \\
\text { situazione di rischio (totale o parziale) }\end{array}$ & $\begin{array}{l}\text { Soggette ad analisi speciale } \\
\text { Necessità di elaborazione di un } \\
\text { parere tecnico }\end{array}$ & \\
\hline
\end{tabular}

Schema-guida riassuntivo delle caratteristiche richieste alla viabilità nelle AEIS (tradotto e adattato da GGA-SPM, 1997).

\begin{tabular}{|c|c|c|c|c|}
\hline TIPO & FUNZIONE & \multicolumn{2}{|c|}{$\begin{array}{l}\text { DIMENSIONE MINIMA } \\
\text { Progettata } \\
\text { Ammissibile }\end{array}$} & RACCOMANDAZIONI \\
\hline Principale & \begin{tabular}{|c|} 
- Legame tra il \\
sistema viario delle \\
AEIS e le strade \\
dell'immediato \\
intomo \\
-Accesso per le reti \\
di infrastrutturazione \\
urbana
\end{tabular} & $\begin{array}{c}9,00 \mathrm{~m} \\
(1,50 / 6,00 / 1,50)\end{array}$ & $\begin{array}{c}7,20 \mathrm{~m} \\
(1,10 / 5,00 / 1,10)\end{array}$ & $\begin{array}{l}\text { Le reti di infrastruttura } \\
\text { saranno impiantate in } \\
\text { caso l'intomo non } \\
\text { possieda il sistema che } \\
\text { possa rifomire detta area }\end{array}$ \\
\hline Secondaria & $\begin{array}{l}\text { Legame fra le strade } \\
\text { con funzione di via di } \\
\text { accesso settoriale }\end{array}$ & $\begin{array}{c}\text { Con palificazione } \\
\text { elettrica } 5,20 \mathrm{~m} \\
(1,10 / 3,00 / 1,10) \\
\text { Senza palificazione } \\
\text { elettrica } 5,00 \mathrm{~m} \\
(1,00 / 3,00 / 1,00) \\
\end{array}$ & $\begin{array}{c}\text { Con palificazione } \\
\text { elettrica e } \\
\text { marciapiede } \\
\text { pubblico almeno da } \\
\text { uno dei due lati } \\
4,10 \mathrm{~m} \\
(1,10 / 3,00)\end{array}$ & \\
\hline Secondaria speciale & $\begin{array}{l}\text { Accesso ad un corso } \\
\text { d'acqua canalizzato } \\
\text { per pulizia anche del } \\
\text { fondale. Potrà } \\
\text { costituirsi come via di } \\
\text { accesso settoriale }\end{array}$ & $\begin{array}{l}\text { Con palificazione } \\
\text { elettrica su uno dei } \\
\text { due lati } 7,10 \mathrm{~m} \\
(1,00 / 5,00 / 1,10)\end{array}$ & $\begin{array}{l}\text { Definita in base a } \\
\text { valutazione tecnica } \\
\text { in loco }\end{array}$ & $\begin{array}{l}\text { Possono essere usate } \\
\text { come aree di riposo } \\
\text { II livello della via deve } \\
\text { essere lo stesso dei } \\
\text { percorsi laterali pubblici }\end{array}$ \\
\hline Pedonale & $\begin{array}{l}\text { - Legame tra le vie } \\
\text { secondarie } \\
\text { - Accesso alla } \\
\text { maggior parte delle } \\
\text { case }\end{array}$ & $\begin{array}{c}\text { Con o senza pali della } \\
\text { luce } \\
3,00 \mathrm{~m}\end{array}$ & $\begin{array}{l}\text { Senza pali della luce } \\
2,00 \mathrm{~m}\end{array}$ & \\
\hline
\end{tabular}


Fig. 48 Reinsediamenti recenti di famiglie nel "Programma de Reassentamento"

\begin{tabular}{|c|c|c|}
\hline Anno & $\begin{array}{c}\text { Numero di famiglie } \\
\text { riallocate }\end{array}$ & $\begin{array}{c}\mathbf{N}^{\circ} \text { di insediamenti } \\
\text { dove è avvenuto il } \\
\text { 'reassentamento' }\end{array}$ \\
\hline 2000 & 1683 & 13 \\
\hline 2001 & 484 & 10 \\
\hline
\end{tabular}

Trasferimenti di famiglie nell'ambito del Programma 'Aree di rischio'

(Fonte: SMAM - Assessorato all'Ambiente, Annuario Statistico 2000)

\begin{tabular}{|c|c|c|}
\hline Anno & $\begin{array}{c}\text { Numero di famiglie } \\
\text { reinsediate }\end{array}$ & $\begin{array}{c}\mathbf{N}^{\circ} \text { di abitazioni oggetto } \\
\text { di sopralluogo }\end{array}$ \\
\hline 1994 & 379 & - \\
\hline 1995 & 331 & 780 \\
\hline 1996 & 99 & 140 \\
\hline 1997 & 119 & 1.420 \\
\hline 1998 & 63 & 90 \\
\hline 1999 & 762 & 128 \\
\hline 2000 & 342 & 154 \\
\hline
\end{tabular}

Tipologie diverse di progetti costruttivi realizzati dal DEMHAB tra il 1990 e il 2000

(Fonte: DEMHAB, Annuario Statistico 2000)

\begin{tabular}{|c|c|c|c|c|c|c|c|c|c|}
\hline Anno & $\begin{array}{l}\text { Unità } \\
\text { di abi- } \\
\text { tazione }\end{array}$ & $\begin{array}{l}\text { co- } \\
\text { struite } \\
\text { ex- } \\
\text { novo }\end{array}$ & & & $\begin{array}{l}\text { Rimo- } \\
\text { zioni }\end{array}$ & Case & & $\begin{array}{l}\text { demo- } \\
\text { lizioni }\end{array}$ & Totale \\
\hline & $\begin{array}{c}\text { Case } \\
\text { di } \\
\text { legno }\end{array}$ & $\begin{array}{l}\text { Case } \\
\text { in mu- } \\
\text { ratura }\end{array}$ & $\begin{array}{l}\text { Moduli } \\
\text { sanita- } \\
\text { ri }\end{array}$ & $\begin{array}{l}\text { Recinti } \\
\text { (metri) }\end{array}$ & & $\begin{array}{l}\text { Case } \\
\text { di e- } \\
\text { mer- } \\
\text { genza }\end{array}$ & $\begin{array}{l}\text { Re- } \\
\text { staura- } \\
\text { te }\end{array}$ & & $\begin{array}{c}\text { Perso- } \\
\text { ne be- } \\
\text { nefi- } \\
\text { ciate } \\
\text { dai } \\
\text { vari } \\
\text { interve } \\
\text { nti }\end{array}$ \\
\hline 1990 & 40 & 26 & 15 & 2.105 & 130 & 28 & 40 & 19 & 2.525 \\
\hline 1991 & 87 & 20 & 35 & 3.457 & 126 & 51 & 55 & 63 & 33.653 \\
\hline 1992 & 103 & 6 & 40 & 5.063 & 400 & 47 & 81 & 316 & 40.155 \\
\hline 1993 & 152 & 5 & 29 & 3.319 & 330 & 142 & 86 & 151 & 32.300 \\
\hline 1994 & 109 & 4 & 35 & 13.405 & 482 & 79 & 133 & 66 & 28.500 \\
\hline 1995 & 122 & 7 & 24 & 546 & 643 & 110 & 125 & 168 & 18.475 \\
\hline 1996 & 126 & 1 & 14 & 495 & 313 & 114 & 117 & 281 & 11.800 \\
\hline 1997 & 147 & 10 & 18 & 3.203 & 345 & 149 & 110 & 140 & 10.550 \\
\hline 1998 & 139 & 16 & 18 & 600 & - & 160 & 104 & 720 & 18.910 \\
\hline 1999 & 38 & 3 & - & 1.546 & 193 & 137 & 78 & - & 13.870 \\
\hline 2000 & 195 & 2 & 44 & 1.230 & 346 & 224 & 85 & 152 & 14.895 \\
\hline
\end{tabular}


Fig. 49 - Distribuzione dei Parcellamenti Irregolari su terreni del Dipartimento alla Casa di Porto Alegre, e grafico che evidenzia l'andamento della costruzione di Unità di Abitazione dello stesso DEMHAB negli ultimi anni (elaborazion: DEMHAB, 2001)

\section{LOTEAMENTOS IRREGULARES}

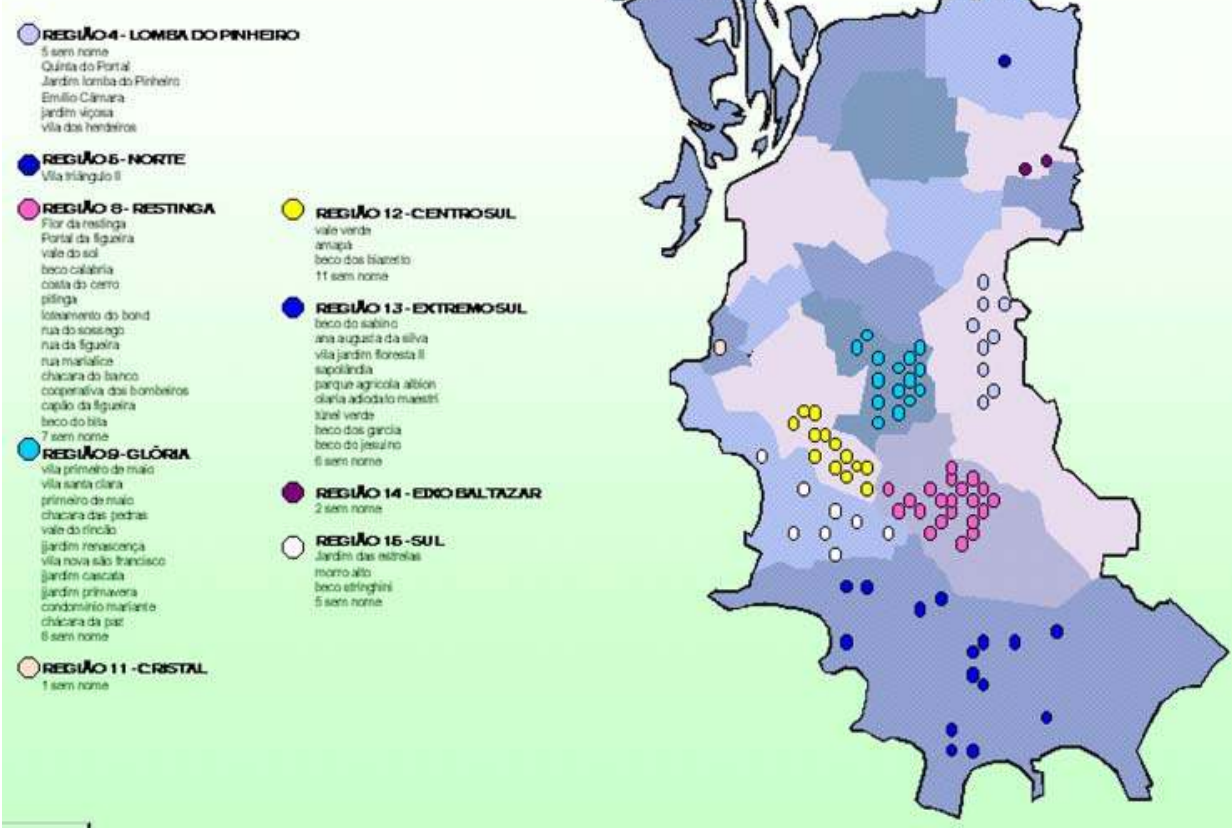

Unità di abitazione realizzate dal DEMHAB su aree di sua proprietà

(Fonte: DEMHAB, 2001)

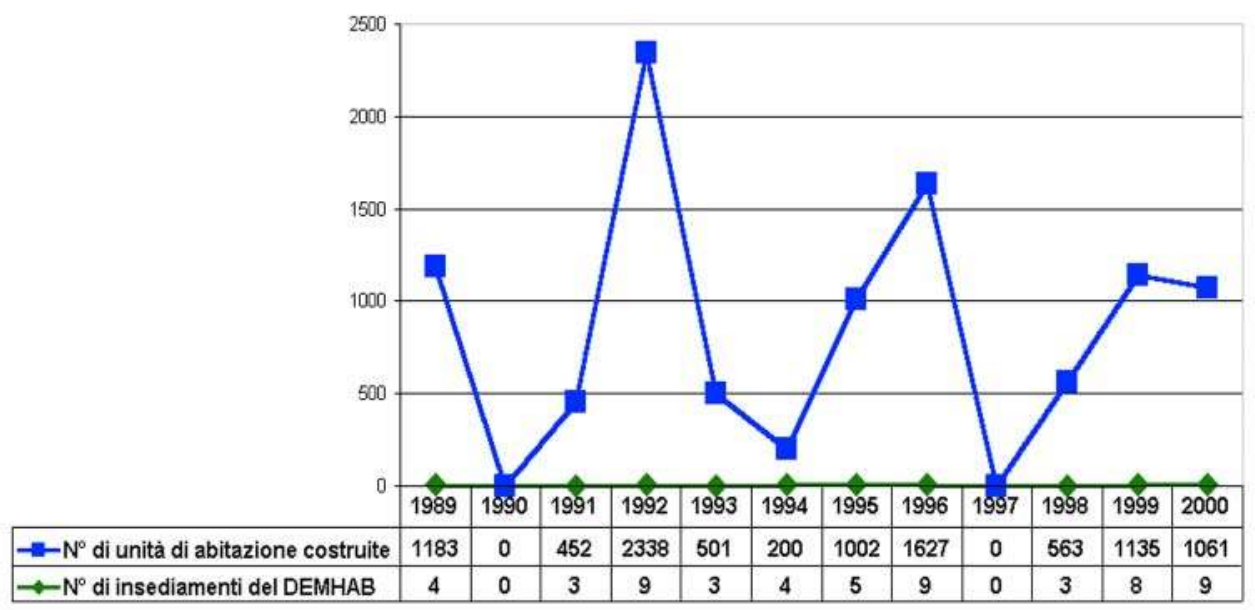


Fig. 50 - Distribuzione delle Cooperative di Abitazione a Porto Alegre e plastico dell'insediamento della cooperativa 'Renascer' (immagini: DEMHAB, 2001)

\section{cooperchivismo Habiliacional}

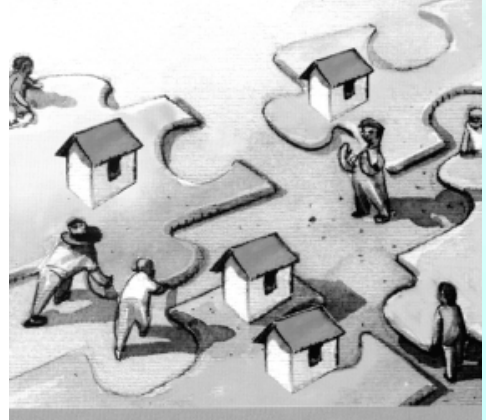

\section{A UNIÃ○ É PEÇA F U N D A M N TAL para sua casa}
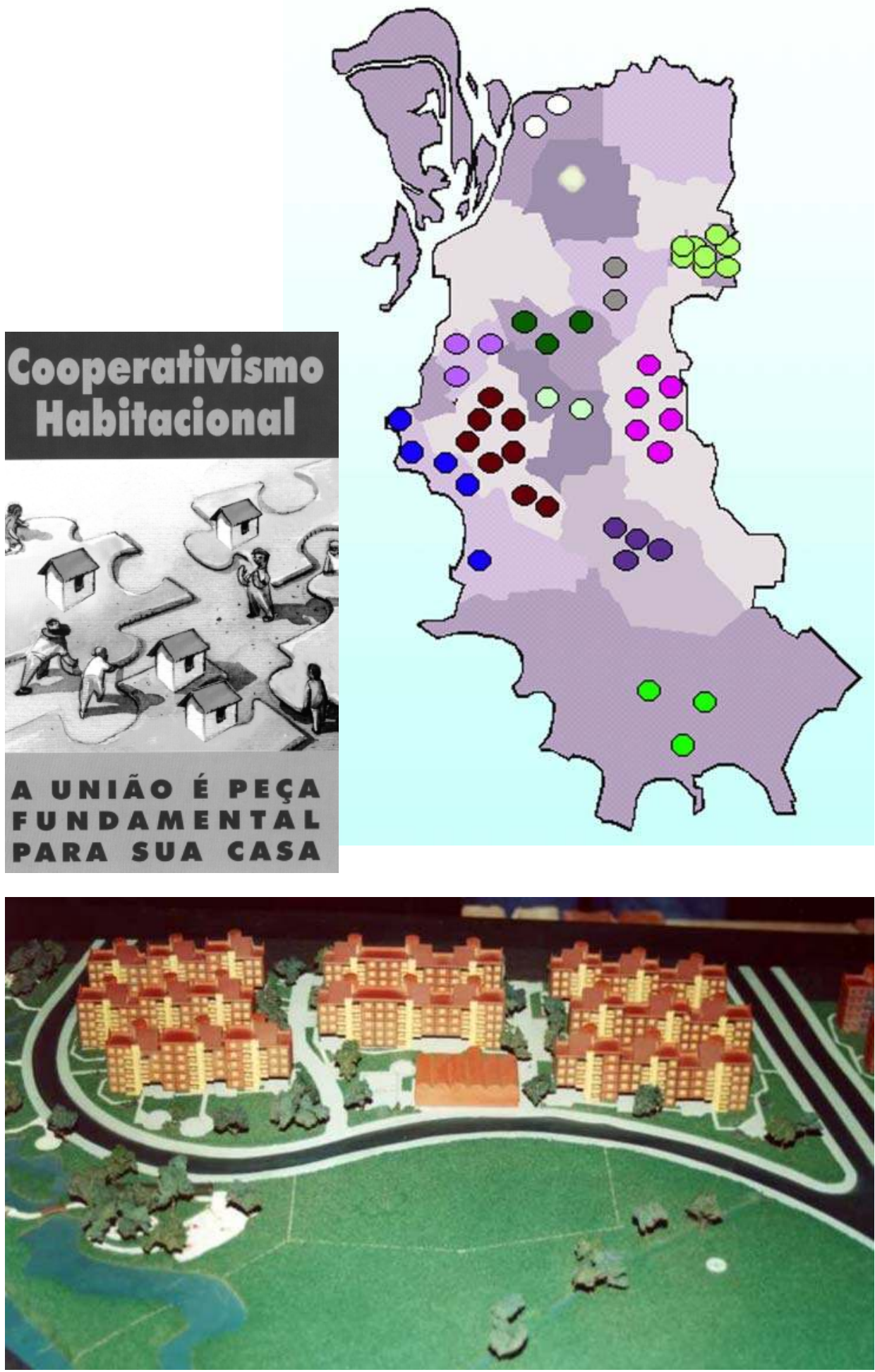
Fig. 51 - I Mutiroes sono una forma di cooperativismo non molto utilizzata a Porto Alegre. Nell'immagine la distribuzione degli insediamenti costruiti con questa formula e alcune immagini degli stessi durante le varie fasi di esecuzione che impegnano il lavoro delle famiglie che li abiteranno (dati: DEMHAB, 2001)

\section{Programa AJuda Mútua}

ABEMEVIC Situaçäo concluida
Número de UHs: 38

Chácara da Fumaça Situaçáo concluida
Número de UHs: 27

Cavalhada

Situaçẩo: Em andanento

Número de UHs: 17

Ipè I, II, III

Situaçấo concluída Núnero de UHs: 46

- Maria da Conceiçăo Stuaç̧ẫo: Em andamento Número de UHs: 17

Lomba do pinheiro Situaçảo: concluida Número de UHs: 28
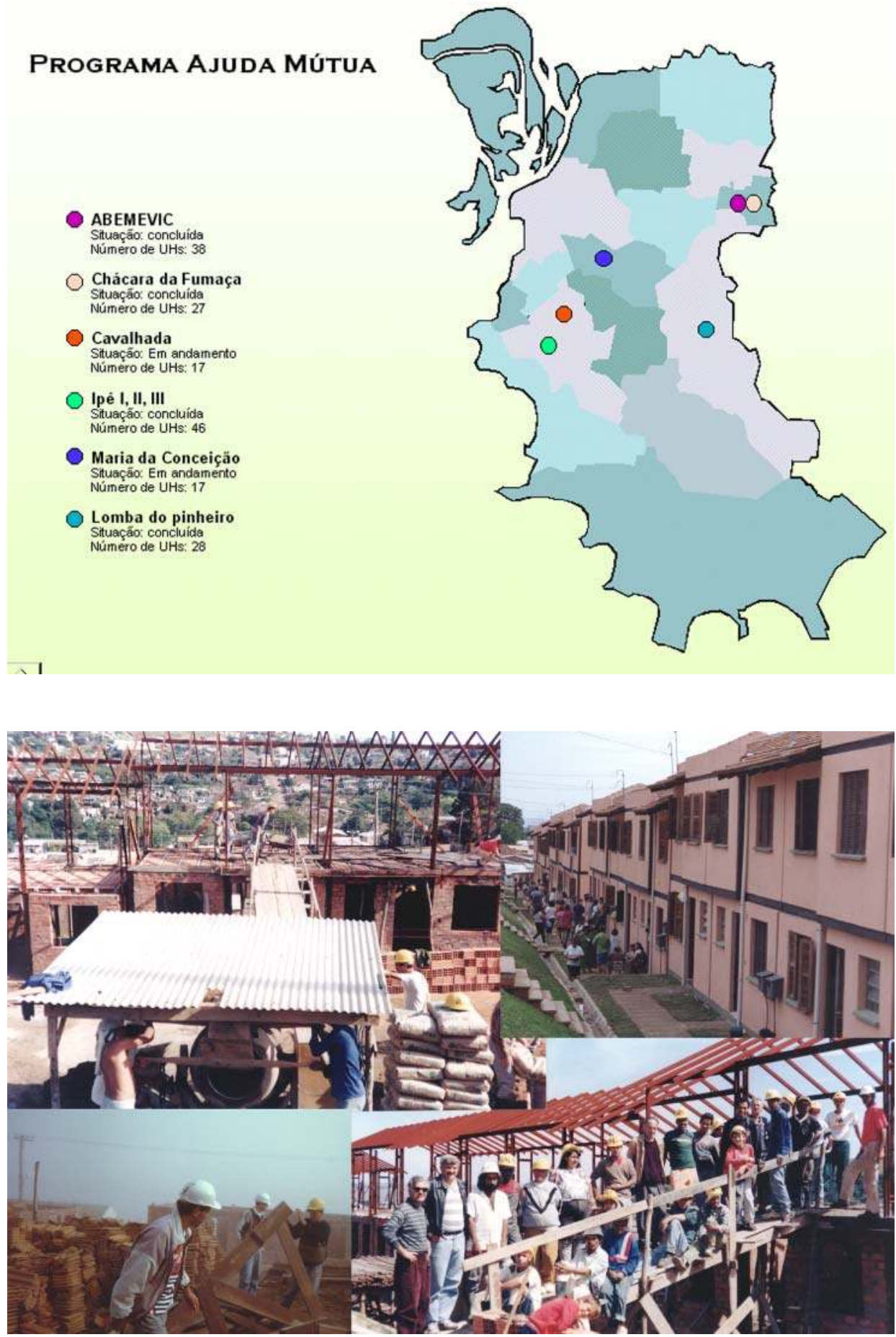
Fig. 52 - Immagini di alcune fasi di costruzione di un'opera in Mutirao, che si conclude con l'estrazione delle chiavi che attribuirà una casa ad ogni famiglia che ha lavorato alla costruzione.
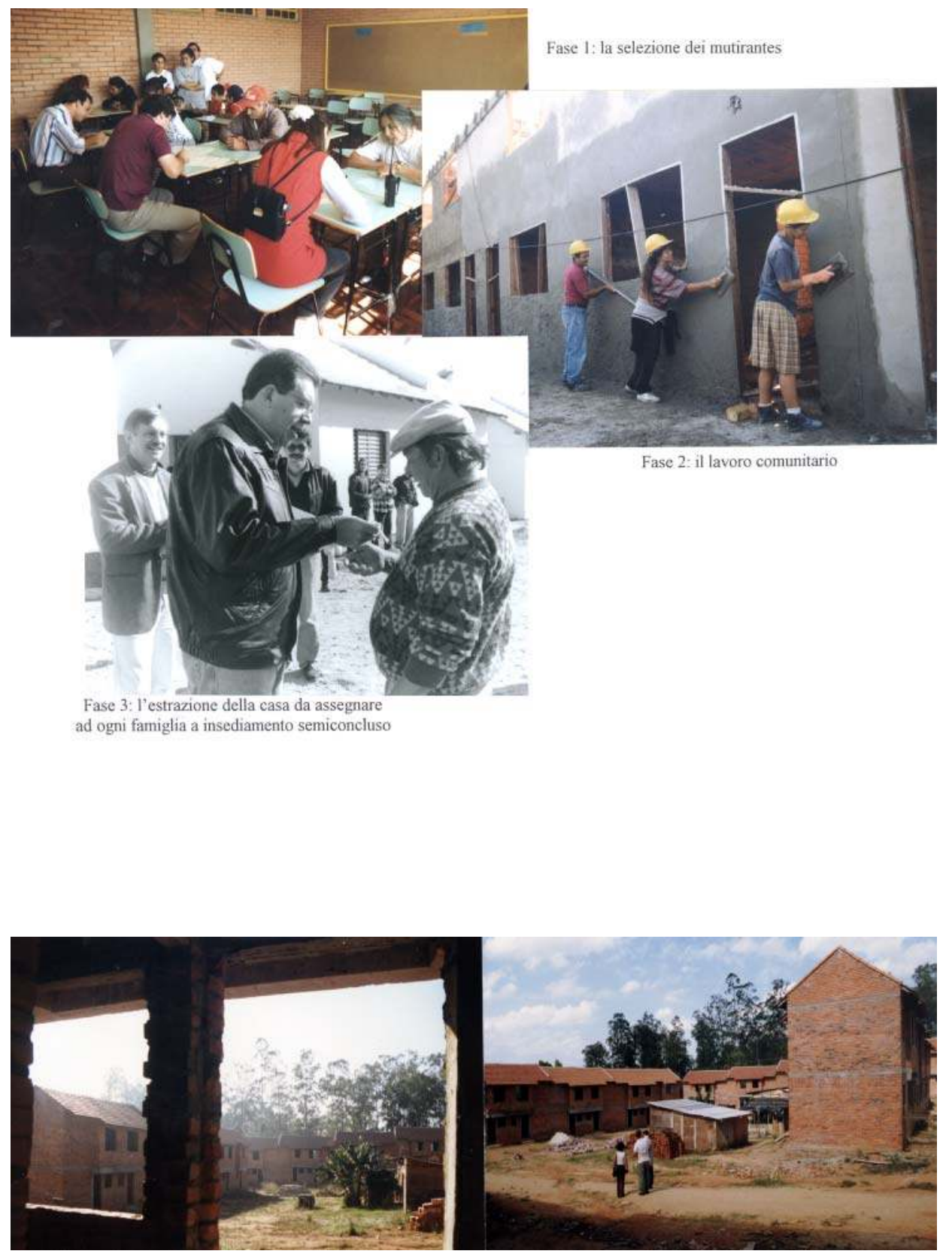

Fig. 53 - Le due foto rappresentano un quartiere nella Chacara da Fumaça di Porto Alegre, dove la formula costruttiva del Mutirao è stata adottata da una Cooperativa di Abitazione (ABEMEVIC). 
Fig. 54 - Foto del quartiere realizzato in Mutirao per rialloggiare gli abitanti della favela Maria Degolada. Il modello costruttivo è una variazione in corso d'opera di tipologie usate in passato dal DEMHAB, rinnovate grazie al contributo degli abitanti. Pianta e alzato sono stati, di recente, riproposti nel Mutirao del Loteamento Cavalhada II.

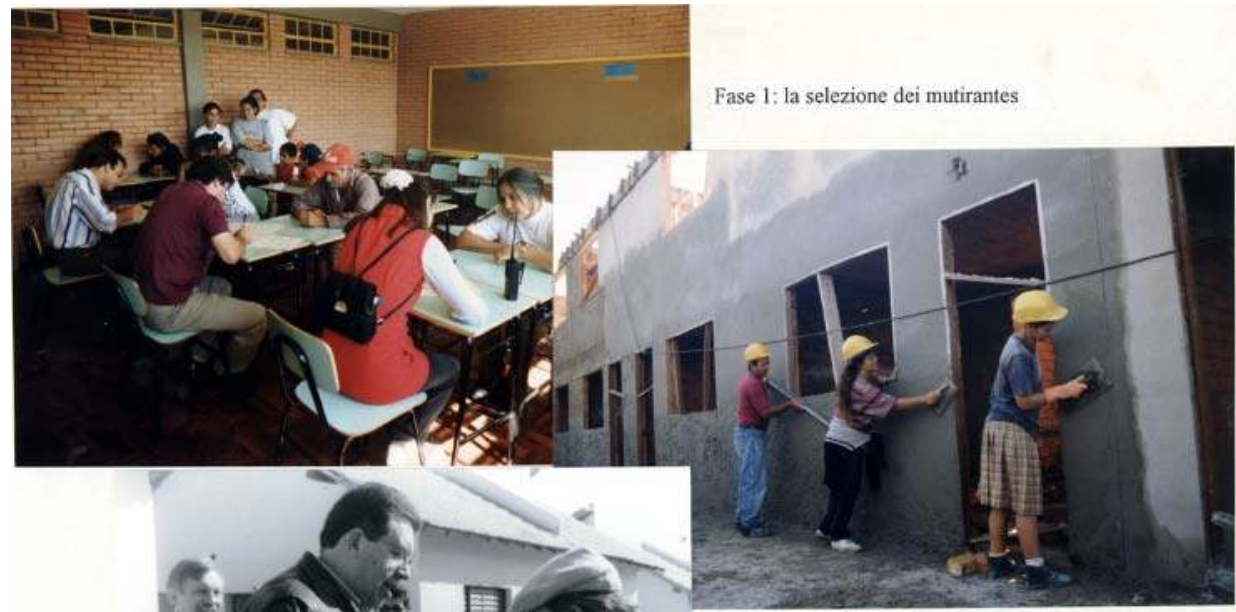

Fase 2: il lavoro comunitario

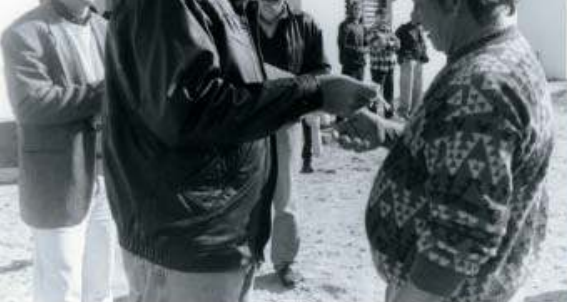

Fase 3: l'estrazione della casa da assegnare ad ogni famiglia a insediamento semiconcluso

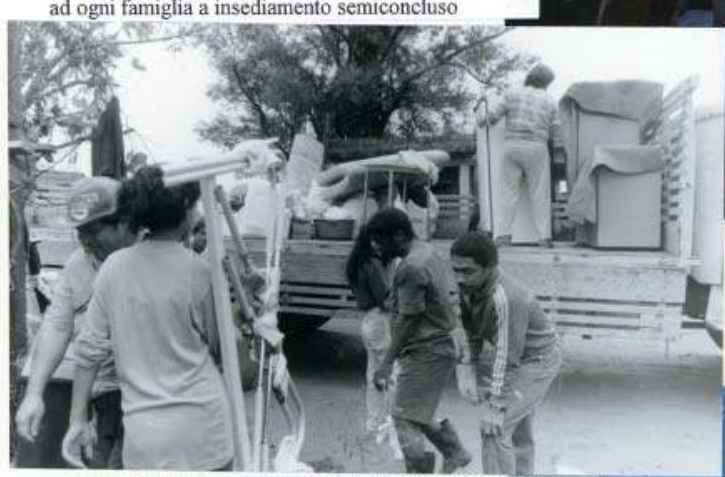

Fase 5 ; il trasloco dalle aree di rischio o da zone di ingombro in progetti di regolarizzazione
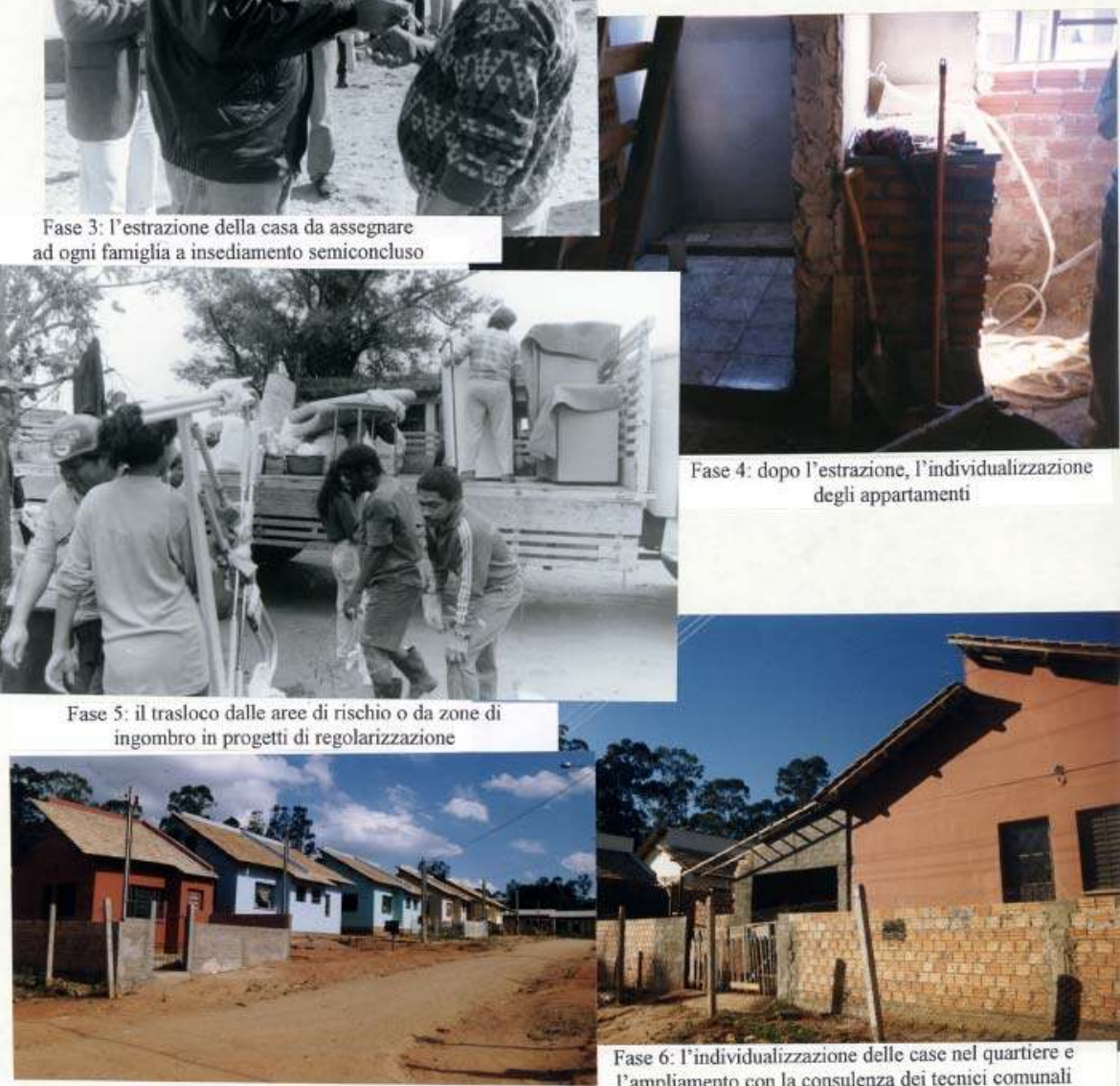

Fase 4: dopo l'estrazione, l'individualizzazione degli appartamenti

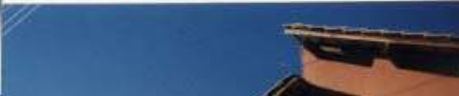


Fig. 55 - Distribuzione cittadina delle aree inserite nel Piano di Regolarizzazione Fondiaria che presentano conflitti in corso circa la proprietà dei terreni (immagini: DEMHAB, 2001)

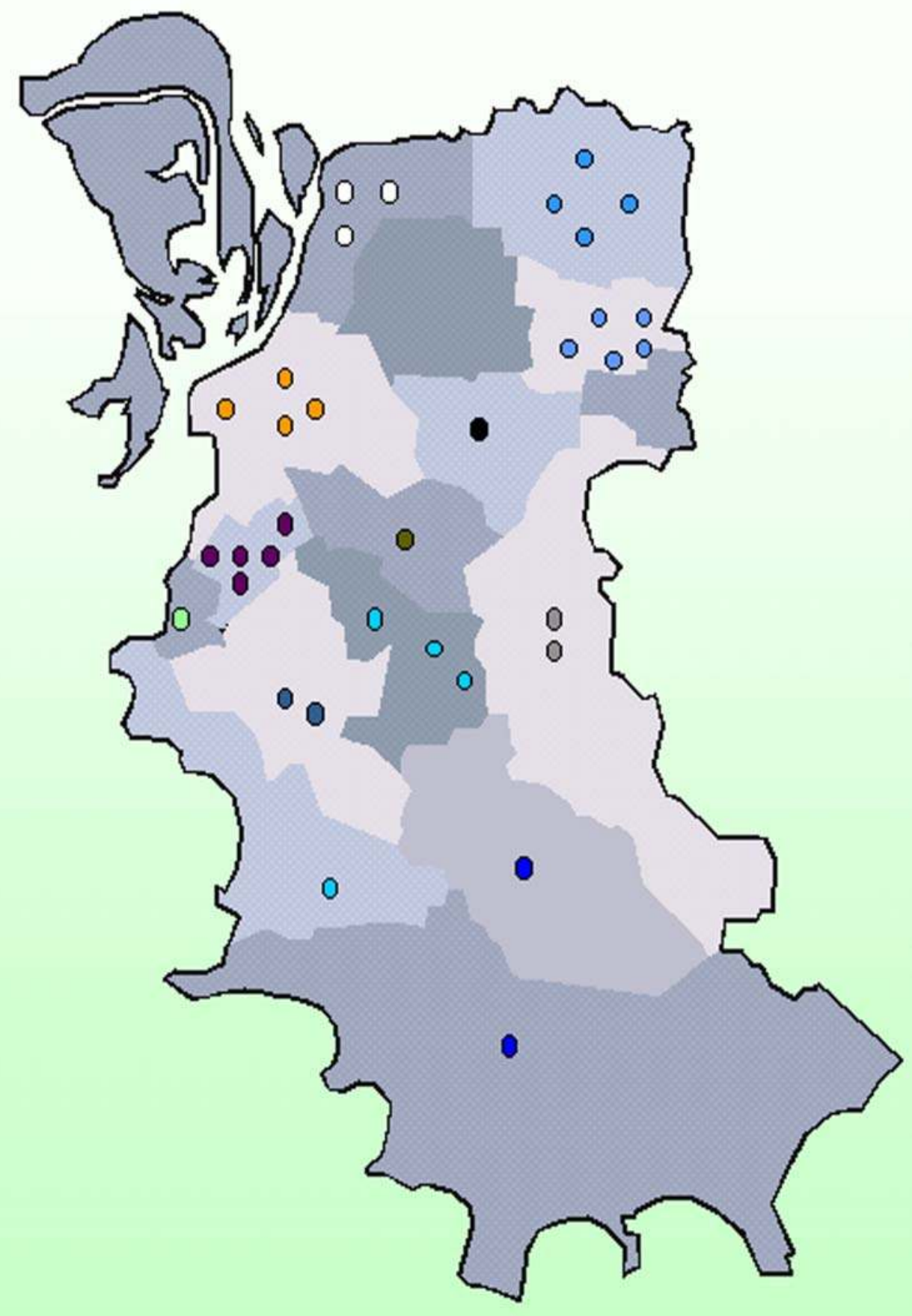


Plano de Desenvolvimento Econômico

\section{Crescimento em todos os sentidos}

Fig. 56 - Il Piano di Sviluppo Economico di Porto Alegre, partecipativamente costruito nel 1993, mette a frutto numerose idee creative provenienti dall' ambito dell'economia informale. Nella foto al centro una bottega 'volante' allestita sotto la pensilina di una fermata del bus durante la festa patronale dos Navegantes.
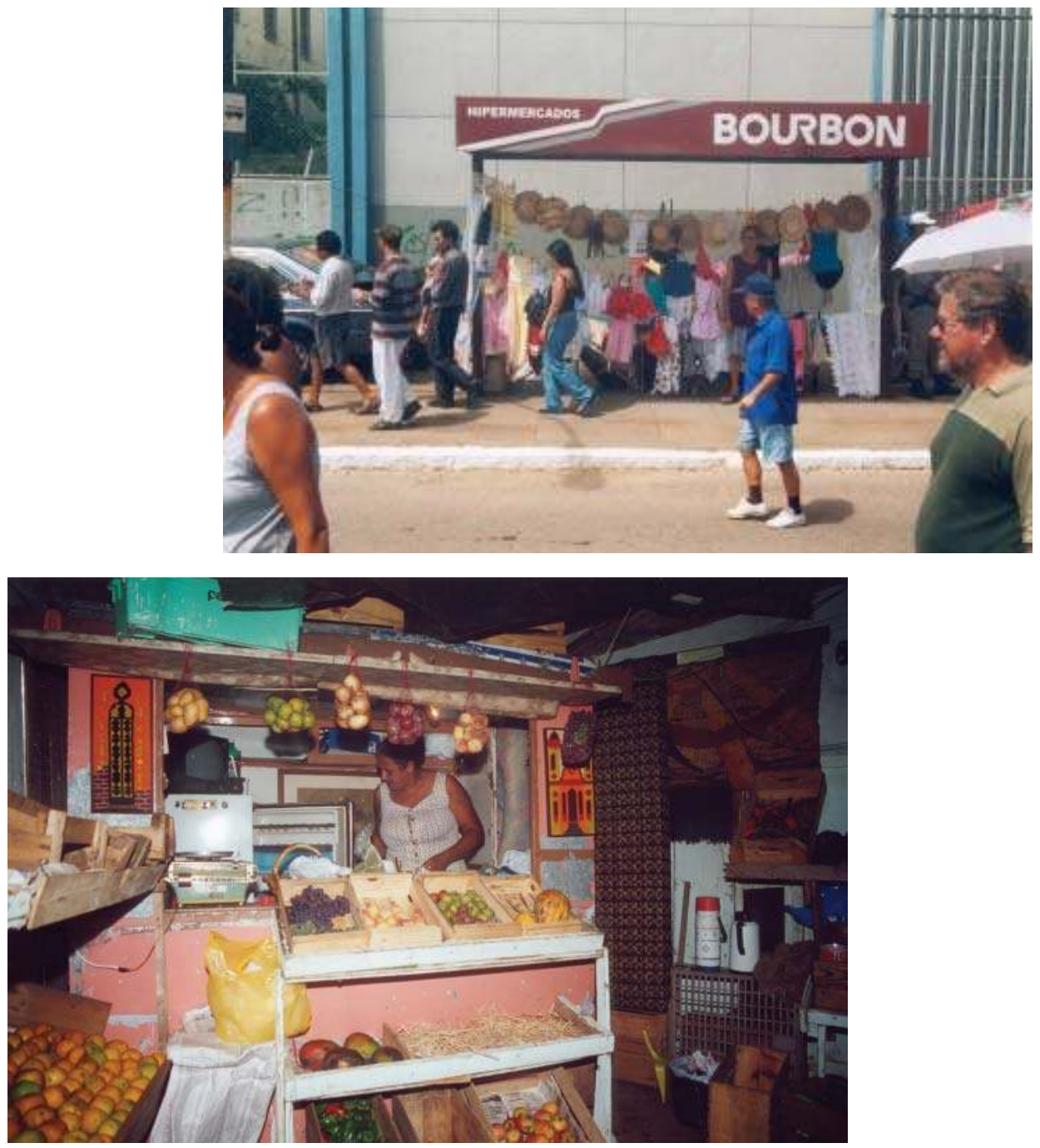
Sezione Quarta

Politiche viste da progetti 



\section{3 \\ Da "favelas" a "bairros": strategie a confronto}

\subsection{Il Programma di Regolarizzazione Fondiaria: verso un'azione integrata?}

La regolarizzazione fondiaria si fa, non si discute. Non discutiamo con l'Assessorato all'Ambiente se si può regolarizzare l'area di vegetazione nativa; semmai discutiamo su come farlo, in certi casi. Essa non è un progetto, è un processo aperto; il tempo della regolarizzazione è lontano, nel futuro, non è un termine prevedibile. È aperto al dialogo. Ecco perché è importante cominciarlo subito nel maggior numero di 'vilas' (Menegassi, 1999i, apud Alle gretti, 2000a).

A Porto Alegre, l'obiettivo dell'inversione delle priorità di investimento in struttura urbana ha trovato traduzione concreta nell'istituzione del Bilancio Partecipativo e dello specifico Programma di Regolarizzazione Fondiaria [PRF], avvenuta contestualmente alla stesura del nuovo Statuto Municipale, nel 1990. Il PRF originariamente non fu legato al DEMHAB - che storicamente si era occupato di problemi abitativi dando molta enfasi al tema della produzione di alloggi e non occupandosi molto degli insediamenti irregolari - bensì all'Assessorato all'Urbanistica (SPM), le cui attribuzioni erano più ampie e riguardavano l'intero corpo cittadino. Qui, l'equipe multidisciplinare creata nel '90 incentrò il lavoro su: 1) l'esame della domanda reale delle comunità ai fini della regolarizzazione fondiaria e la conoscenza delle diverse realtà locali e delle loro peculiarità;

2) lo studio di nuovi strumenti di riforma e sviluppo urbano, che vennero poi adottati nel nuovo Statuto Comunale in funzione delle pressioni ricevute dai gruppi organizzati di residenti in aree irregolari e dai movimenti per la riforma urbana;

3) la predisposizione di un processo di pianificazione strategica in collaborazione con funzionari di tutti gli organismi comunali interessati dal problema della regolarizzazione (il DEMHAB, gli Assessorati ai Lavori Pubblici, alle Finanze e all'Urbanistica, l'Ufficio Legale del Municipio).

Dopo l'esautoramento della SPM da molte funzioni, la responsabilità del Programma fu trasferita al DEMHAB, che oggi gestisce il PRF attraverso il Coordinamento di Urbanizzazione e Regolarizzazione (CUR). ${ }^{1}$ Questa rifocalizzazione può forse spiegare perché il terzo impegno non fu condotto a 
424 termine e (seppur la sua priorizzazione lasciò tracce nella perseveranza di alcuni tecnici, riflettendosi in alcuni significativi interventi di valore 'esemplare' - e quindi strategico - portati avanti nei primi 4 anni di governo dell'Amministrazione Popolare). Solo alla fine del 2001, l'obiettivo è stato ripreso in mano in maniera coordinata, sull'esempio del processo attivato dal Sistema di Gestione della Pianificazione previsto dal nuovo Piano Regolatore del '99 (cfr. cap. 15) e in conseguenza delle linee d'azione suggerite dalla $\mathrm{II}^{\circ}$ Conferenza Comunale sulla Casa del dicembre 2001.

Oggi, il CUR del DEMHAB lavora su terreni pubblici e privati con diverse competenze nei due casi (nel secondo dà solo appoggio logistico e consulenza tecnico-legale nelle azioni per ottenere l'usucapione), seguendo un processo che prende avvio dalle richieste d'intervento presentate nel Bilancio Partecipativo dalle comunità interessate alla regolarizzazione fondiaria. Alle stesse comunità spetta ottenere i fondi per sopralluoghi e rilievi topografici, e partecipare poi alle varie fasi che portano all'approvazione dell'EVU [Studio di Fattibilità Urbanistica] proposto dai tecnici e a cui solo i beneficiari possono dare il loro assenso definitivo prima che venga portato avanti l'iter che porterà per gradi (a seconda dei fondi via via stanziati, nuovamente attraverso l'O.P.) alla regolarizzazione giuridica ed urbanistica (fig. 60).

In parallelo, comunque, il CUR non tralascia di analizzare anche zone della città non particolarmente attive nel Bilancio Partecipativo, ma non per questo meno bisognose di soluzione di gravi problemi legati all'alloggio e all'esclusione sociale. Sta, poi, agli Agenti Comunitari stimolare le comunità a farsi presenti nell'O.P., ma anche ai Consiglieri del Bilancio Partecipativo prendersi in carico le necessità delle comunità più bisognose. Per 'indurre' questi meccanismi di solidarietà tra territori e decisori urbani, spesso le stesse istituzioni incentivano visite guidate di Delegati e Consiglieri del Bilancio Partecipativo nelle comunità più disagiate, affinché prendano contatto diretto con situazioni non sempre note a tutti nella loro gravità, e che il Comune ha presenti a motivo della necessità di mantenere una conoscenza aggiornata dell'intero territorio.

Quest'attenzione speciale vale soprattutto per le 'vilas', visto che sia la SPM che il Nucleo di Regolarizzazione dei Parcellamenti [NRL] che ha sede nel DEMHAB dal $1996^{2}$ tendono a comportarsi diversamente con i parcellamenti irregolari e clandestini, "attendendo che le comunità o i lottizzatori - le cui condizioni di vita sono molto migliori che nelle 'vilas' - si presentino a chiedere le migliorie necessarie e la legalizzazione dell'area dove vivono" (Alibio, 1999i, apud Allegretti, 2000a).

Per tutti i quartieri che via via entrano a far parte del Programma di Regolarizzazione Fondiaria, esiste oggi anche un'istanza chiamata Forum della Regolarizzazione Fondiaria, che riunisce bimestralmente due rappresentanti eletti di ogni 'vila' beneficiata, e dove il Comune fa i rendiconti dell'andamento dei processi in ogni area, e discute di problemi comuni. Attualmente, sono nate anche appendici regionali del Forum, per localizzare meglio la discussione nel territorio cittadino, e scambiare informazioni ed esperienze.

Dal marzo '93 è, inoltre, attiva presso il DEMHAB una Commissione di Negoziazione che fa da intermediaria in tutti i casi che oppongono occupanti di aree private e loro legittimi proprietari. L'obiettivo è di evitare sgomberi affrettati dovuti ad azioni giudiziarie; e di palesare "la volontà politica del- 
l'Amministrazione Popolare di promuovere, ogni qual volta sia possibile, la negoziazione e l'intermediazione fra le parti coinvolte" (DEMHAB, 1996). Nel 1994, la Legge LC 7433/94 ha anche creato l'Assistenza Giuridica Municipale gratuita presso l'Ufficio Legale del Comune [PGM] "per intervenire in difesa dei cittadini e degli organismi municipali necessitati su questioni relative alla regolarizzazione fondiaria di terreni urbani" (B. Alfonsin, 1997): alla PGM, già lo Statuto comunale attribuisce anche il compito di promuovere extra-giudiziariamente la conciliazione delle parti in conflitto di interessi, in appoggio ai Programmi di Regolarizzazione fondiaria (art. 4, II) di cui l'equipe ad hoc deve seguire tutte le fasi istruttorie per giungere alla regolarizzazione giuridica e solo posteriormente a quella urbanistica.

Dal 1994 - all'interno del PRF - è attivo anche un nuovo strumento integrato di risoluzione dei problemi abitativi, legato a specifiche aree di occupazione, il cosiddetto GT [Grupo de Trabalho] composto da membri di assessorati e dipartimenti diversi interessati alla Regolarizzazione di aree particolarmente problematiche, per le quali la soluzione non può solo ravvisarsi nel ricorso ad interventi settoriali diversi e contestuali. I GTs, che si moltiplicano per la gestione ordinaria e straordinaria di singoli processi localizzati di intervento, prevedono anche la partecipazione di rappresentanti di associazioni attive nella comunità, ed una rotazione del ruolo di coordinamento tra gli esponenti dei diversi organismi rappresentati.

\subsection{Il 'corpo a corpo' tra tecnici e abitanti: uno strumento indispensabile}

Il trasmigrare del PRF verso azioni progressivamente più articolate e coordinate con altri organismi comunali necessiterebbe anche di un arricchimento della conoscenza della realtà informale, che a Porto Alegre mostra ancora uno scarto fra l'anelito quantitativo e quello qualitativo. Come abbiamo visto, infatti, il tipo di indagini finora realizzate dall'Amministrazione su scala cittadina, non sembrano soddisfare la necessità di conoscenza 'locale' del pluriverso delle favelas, anche se evitano l'errore compiuto in passato (e ancor oggi ripetuto in altre città) di arrestarsi davanti alla definizione di 'vila' come qualcosa di per sé univoco e qualitativamente omogeneo. L'apparente resa di fronte alla carenza di mezzi e alla scarsezza di tempo che impediscono all'Amministrazione di realizzare 'in prima persona' un lavoro che certo sarebbe più proficuo realizzare 'in partenariato' (ad esempio con le AMs, ONG o istituti universitari) è però controbilanciato dai diversi modi in cui l'Amministrazione è riuscita a costruire mezzi molteplici per un costante contatto fra istituzioni e cittadini: il Bilancio Partecipativo in primo luogo, poi gli altri Forum aperti alla compartecipazione popolare (Consigli Popolari, Consigli Municipali, GT, Commissioni di Accompagnamento dei Lavori, Forum di Servizi, ecc.), e - soprattutto - il 'corpo a corpo' quotidiano dei tecnici dei vari organismi municipali con gli abitanti.

Quest'insieme di occasioni e di istanze dialogiche a diverso raggio di azione contribuiscono certo a far sì che l'Amministrazione possieda costanti aggiornamenti sulla realtà della città autocostruita, e nello stesso tempo segnano i limiti di un sapere inevitabilmente reso 'non sistematizzato' dalla mancanza di una 'centrale di convergenza' delle informazioni via via apprese ,che sovente restano, purtroppo, 'giacenti' (e quindi assopite e soggette a 
rapido invecchiamento) in singoli organismi municipali o - peggio ancora sui tavoli di lavoro di singoli tecnici.

Nella misura in cui "la mobilità estrema del mondo informale costituisce un blocco notevole a mettere in atto un sistema di conoscenze più sistemiche che rischiano di invecchiare nel momento stesso in cui le rilevi" e di "congelare realtà instabili illudendo di una conoscenza che già sfugge mentre credi di possederla" (Anton, 1999i, apud Allegretti, 2000a), i Dipartimenti - come il DEMHAB - che necessitano di un maggior contatto quotidiano con le aree informali, si affidano in modo progressivamente più intenso proprio alle pratiche del 'corpo a corpo' fra tecnici e popolazione.

Queste tendono a costruirsi però come un processo di conoscenza 'periferico' o 'terminale', ovvero a concentrarsi su ambiti già pre-selezionati attraverso precedenti istanze partecipative: questo è considerato il metodo più realistico per appropriarsi di conoscenze di tipo qualitativo sui diversi ambiti locali senza " $d i$ sperdere le poche energie che il Potere Pubblico ha” (Pestana, 1999i, apud Allegretti, 2000a) in approfondimenti che in molti casi solo tre mesi dopo sarebbero superati se l'inizio di lavori concreti non segnasse un necessario 'congelamento' della situazione della 'vila', ormai esplicitamente accettato dagli abitanti.

Questa limitazione non è né assoluta né così rigida, dal momento che talora sono lo stesso DEMHAB, la SMAM o la SPM a cominciare degli studi su singole aree (magari nell'ambito di Programmi o progetti specifici come il PRF, l'Areas de risco o il Centro de Bairro) e poi a proporre alla popolazione ipotesi di regolarizzazione fondiaria o 'reassentamento' da conquistarsi nell'O.P.. Ma nel complesso è una proposizione valida.

In ogni caso, si può considerare la prassi del ricorso costante al 'corpo a corpo' come un fattore importante, sia in senso 'riequilibrante' della mancanza di indagini sistematiche sulle diverse aree-quartiere che compongono la realtà informale portoalegrense, sia in direzione dell'approfondimento della conoscenza 'verticale' dei territori locali. Il tipo di conoscenza che ne emerge è, però, purtroppo, di tipo 'informale', ovvero anch'essa non trova sistematizzazione, specialmente per quanto attiene a tematiche quali l'analisi morfologica degli insediamenti spontanei o quella tipologica dei modi dell'abitare della città autocostruita. Si potrebbe, anzi, dire con Rigatti che "non esiste formalmente nessuna analisi propriamente detta, ma solo un insieme di osservazioni affiancate che al massimo si compongono nella testa dei tecnici ma non trovano traduzione su carte o documenti; tutt'al più affiorano in qualche scheda di natura socioeconomica sulla composizione dei residenti come semplici 'annotazioni ai margini' su alcuni aspetti peculiari che caratterizzano il loro modo di vivere" (1999i, apud Allegretti, 2000a). Ciò tende ad influire notevolmente sui progetti di riorganizzazione e ricostruzione in aree informali, specialmente perché essi sovente si trascinano nel tempo a partire da un originario EVU che serve da base per interventi graduali finanziati per tappe attraverso l'O.P., e seguiti da tecnici diversi nel corso del tempo sulla base di considerazioni il più delle volte 'estemporanee'. In questi casi, nella mancanza di elaborati prodotti nell'ambito di studi di dettaglio di aspetti morfologico/costruttivi delle singole 'vilas', il 'corpo a corpo' reiterato con la popolazione interviene come indispensabile strumento di sussidio al rispetto della specifica 'cultura locale' ma anche come una forma di 'mediazione fra desideri': sia di quelli che i cittadini proiettano sull'opera 
in realizzazione, sia di quelli che l'Amministrazione vorrebbe veder realizzati nella favela, per giunta minimizzando e ottimizzando i suoi sforzi. Molto incisive sono - a questo proposito - le osservazioni dei tecnici impegnati nel PRF, relativamente al peso che il 'corpo a corpo' svolge nel loro lavoro. $\mathrm{Ne}$ abbiamo scelto 6, tratte dallo studio di campo di Allegretti (2000a):

Il corpo a corpo è un processo informale, che non sta scritto né previsto in nessun luogo, ed è supportato dal corpo tecnico e sociale in virtù del lavorare a lungo con persone bisognose $[\ldots]$. E' ciò che qualifica il lavoro [...] dà nozioni concrete di cittadinanza alle persone che hanno l'opportunità di dialogare ed esprimere richieste su ciò che più le tocca nel quotidiano. A noi tecnici cambia la percezione di termini e concetti astratti, al contatto col loro peso reale sulla vita altrui [...] Per questo non possiamo più affermare con sicurezza che il significato del termine 'sgombero' sia 'un ordine da eseguire ad ogni costo' (Saicoski, assistente sociale, 1999i).

Tutto è empirico. Nessuno ci for ma a lavor are in favelas. Le diverse gerarchie stradali, la labilità del confine fra il dentro e il fuori, fra ciò che si fa nella baracca e ciò che si presume si faccia fuori casa, sono cose che abbiamo imparato da soli lavorando accanto agli abitanti. Io prima lavoravo per il PT nell'organizzazione degli spazi adibiti ad 'eventi', poi ho lavorato in altre città, ad esempio alla costruzione di un ospedale. La realtà delle 'vilas' la conoscevo per la mia militanza nel partito ma non l'avevo esaminata con l'occhio di architetto; non avevo fatto due più due. Mi mancavano delle riflessioni sullo spazio e i modi di vivere. Non mi ero mai immaginata che c'è chi il bagno lo concepisce solo 'fuori' mentre per me è una parte intima dell'interno della casa. Il bagno fuori non è solo una permanenza atavica di funzioni non svolgibili vicino all'abitare, ma è l'idea di un servizio che può servire più case $o$ più persone in una comunità. Così diventa forzatamente un luogo da separare dall'ambito intimo. Allora ti accorgi con timore che per portare persone non abituate a vivere in una casa con bagno devi cambiare i loro modi di vivere la quotidianità domestica. E che i tuoi strumenti di architetto non bastano, avresti bisogno di appoggio anche per una cosa così intuitiva in apparenza, seppur oggi la Tv può essere un aiuto a veicolare certe immagini e certi modi di vita, un supporto inatteso anche per noi. Ma è soprattutto la possibilità di instaurare un dialogo con le persone che abitano dove tu interverrai che ti dà sollievo nel lavoro. [...] Resta il fatto che spesso ti devi anche guardare le spalle dagli effetti del 'corpo a corpo': può rischiare di intontirti, di deviarti da vincoli che l'ente pubblico che tu rappresenti ha e che tu devi spiegare alla gente per arginare alcune loro richieste. (Casa Nova, architetto e coordina trice del PRF, 1999i-VIII).

[...] Se dai loro una mano, spesso ti prendono la spalla. Non è per malafede. È per entusiasmo, per attaccarsi ad un intervento che finalmente vedono prendere corpo, e magari è il primo. Per questo è importante che nel relazionarci con gli abitanti noi restiamo saldamente ancorati alla realtà, e facciamo un'opera di mediazione; è giusto capire i loro punti di vista, è giusto far capire i nostri (Frare, assistente sociale, 1999i-II).

Tutto è più doloroso, difficile e sterile senza un contatto diretto con gli abitanti. Per me è un obbligo morale mostrare e alterare il progetto in base ai loro suggerimenti; solo così mi riempio di suggestioni tecniche che seguono la realtà concreta dei problemi. [...] Una grande resistenza, certo, è l'uso che al DEMHAB si fa della casa standardizzata. Una vila vive di case costruite su misura, anche se vincolate dalle risorse. Di case 'mobili', anche...Una casa standardizzata non la sentono come loro. Mi sono resa conto con l'esperienza che $20 \mathrm{mq}$ in un progetto tecnico sembrano molto più piccoli che in una 'maloca'; è una questione di colori, di rapporti dimensionali, di freddezza contro calore (Sonia M. da Silva, architetto, 1999i). 
A volte facciamo anche delle scoperte di 'reinserimento sociale' tramite il lavoro. A Santa Paula c'è un matto che dice di avere 'le viti in testa' che lavora al mutirão associato ad una famiglia; è praticamente rinato alla vita perché per la prima volta ha un ruolo utile e qualcuno che gli affida una responsabilità. Il 'corpo a corpo' è il luogo di contatto anche con questi aspetti che vanno oltre la mera realizzazione fisica (Mayer, architetto, 1999i).

Con l'O.P. e le diverse politiche sociali dell'Amministrazione Popolare, in fondo esiste già un quadro di interventi 'a monte' per reintegrare i cittadini delle 'vilas' nella città, e per un programma centrato sugli esseri umani come quello dell' Amministrazione Popolare è questo ciò che importa di più. Lo spazio con i suoi attributi specifici ha un ruolo minore che altrove, sia sotto il profilo simbolico che sotto quello della lotta alla marginalità e all'esclusione. Credo che costituirà un passo importante per il futuro quello di attribuire a noi tecnici un ruolo più creativo nel trattamento del costruito, e questo potrà avvenire solo con l'allentarsi della pressione e dell'urgen$\mathrm{za}$, che per ora l'O.P. sembra stimolare attraverso la competizione che gli esempi creano tra i quartieri. Che poi è uno stimolo positivo per gli abitanti ad alzare la voce per conquistarsi il benessere e i propri diritti (Guimarães, architetto, 1999i) .

A fronte della 'scoperta' che la pratica del 'corpo a corpo' ancora rappresenta per molti tecnici dell' Amministrazione Comunale più impegnati nel lavoro quotidiano svolto a fianco della popolazione emarginata (soprattutto in rapporto a posizioni ancora ostili, o perlomeno indifferenti, della maggior parte dei loro colleghi), essa è spesso letta dai cittadini interessati come qualcosa di 'naturale', come se l'abitudine al dialogo fra base e vertice del sistema politico creata dall'O.P. avesse aperto 'naturalmente' le porte ad ulteriori livelli di interazione, progressivamente più legata a tematiche specifiche dell'intervento sulla città informale. Come osservato dalla Delegata locale dell'O.P. subito dopo un incendio accaduto nella Vila Zero Hora (apud Allegretti, 2000a):

Appena c'è stato l'incendio mi sono recata al DEMHAB e ho 'pressionato' per ore finché non ho trascinato qui il Direttore in persona... Se chi lavora per noi non ci sta accanto in ogni momento, come può rispondere bene alle nostre necessità? I tecnici comunali hanno il dovere di venire qui da noi a vedere, ed è compito di noi leader comunitari far sì che ciò avvenga.

In tale ottica, il 'corpo a corpo' - su cui non esistono a Porto Alegre teorizzazioni scritte, neppure a margine di documenti legati alle diverse politiche di settore - appare come una pratica 'implicita', una sorta di incontro informale a mezza strada fra le esigenze della popolazione e la volontà politica dell'Amministrazione, un componente insostituibile di quella negoziazione continua che è parte integrante del programma di governo dell'Amministrazione Popolare:

Bisogna avere il coraggio di andare in una 'vila' con qualsiasi tempo per capirne le condizioni e i problemi reali. Spesso gli abitanti stessi ci invitano, per vedere le scale che senza drenaggio diventano cascate, o le poche strade asfaltate che si riversano come fiumi sulle zone accanto. A dire il vero raramente ci andiamo, specie da quando il Comune ha sostituito le sue auto con una 'flotta' in affitto; gli autisti si lamentano a muoversi in certe condizioni con le loro auto. Magari ci andiamo appena smesso di piovere, ma è importante che accettiamo di farlo, per poter contribuire a sensibilizzare negli ambiti giusti per una soluzione rapida, e mostrare alla popolazione una vicinanza continuativa e non episodica (Frare, 1999i, apud Allegretti, 2000a - II) 
La discorsività è fondamentale anche nel lavoro del tecnico, perché lo apre, lo rende modificabile. Il tecnico viene continuamente testato dalla comunità per vedere se si merita la sua fiducia, per guadagnarsi sul campo il suo diritto ad essere un referente. Una volta in un vicolo mi hanno aggredita a colpi di mattoni dicendomi che mi sarei svegliata con le formiche in bocca. Ogni volta che iniziavo i lavori di allargamento del 'beco' [vicolo stretto, nda] trovavo un cumulo di terra davanti. Un giorno sparì; la comunità aveva accettato questa donna testarda come referente. Quel momento ha segnato la vittoria del nostro metodo dialogico, e ora io sono un carro blindato per l'entrata di chiunque altro nella Vila da Tuca. Da quel momento ho vinto molte battaglie; ad esempio una volta i residenti si rifiutavano di allargare e aprire un 'beco' dicendo che tutti sarebbero passati di lì per prendere il bus nel quartiere accanto. Abbiamo negoziato una via intermedia: avrei aperto il vicolo solo quando la linea del bus sarebbe stata allungata fin dentro la vila, e coșì ho dovuto fare pressione sulla SMT perché lo scambio negoziato potesse aver luogo. [...] Altrove apprendi che solo la strate gia dell'attesa e del soffocamento è vincente: nelle aree più pericolose aggredisci dall'intorno, aspettando che l'esempio delle zone vicine risvegli l'interesse al cambiamento. Altrove ancora non puoi aspettare, devi importi. Nelle aree in pendenza, ad esempio, le priorità sono geografiche e non quelle magari indicate dagli abitanti; devi iniziare dall'alto per evitare che i dilavamenti senza scoli distruggano l'asfalto in basso. Poi c'è il discorso di come aggirare la 'borghesia delle vilas' che sta sulle strade migliori o vicino ai bus e spesso tenta di imporsi con necessità meno impellenti. Insomma, col dialogo scopri che ad ogni luogo devi adattare una strategia diversa per conformare alla realtà il tuo progetto. Inoltre umanizzi il tuo lavoro, impari a capire le cose, le risposte e i rifiuti incomprensibili. Ad esempio, mi è capitata una signora che non voleva essere trasferita lì vicino in una casa costruita dal DEMHAB; solo dopo molti contatti ho capito che era così povera da non poter si permettere una cucina, e accendeva per terra il fuoco per cucinare. Temeva di non poterlo fare in una casa rifinita col pavimento. Un'altra volta ho scoperto la storia di Madame Miami Beach, come la chiamano, che lavorava in un consolato ma era decaduta e si era creata muri di bugie e usciva nel fango coi tacchi alti per non ammettere dove viveva; l'interno della sua casa era da classe media ma fuori era una baracca, e lei viveva chiusa nel suo dramma. Abbiamo scelto di usare il suo terreno per un ampliamento e abbiamo potuto trasferirla in una casetta più piccola ma fatta dal DEMHAB ai margini della 'vila', così che poteva sembrare del quartiere vicino. A nessuno è costa to nulla essere umani (Casa Nova, apud Alle gretti, 2000a).

La costruzione di questo e del prossimo capitolo muoverà proprio dalla constatazione dell'esistenza di una comunicazione e di un contatto diretto tra tecnici e abitanti, continuativi ma finora non codificati in una strategia di azione ufficialmente definita e, quindi, - in linea teorica - garantiti solo dal fragile equilibrio fra la volontà politica del momento, l'abnegazione dei singoli tecnici e la capacità di rivendicazione dei propri diritti e delle proprie necessità da parte della popolazione. Abbiamo scelto di raccontare in forma 'narrativa' alcune 'storie' e alcuni 'luoghi in trasformazione' di Porto Alegre, per cercare di evidenziare le trasformazioni che le interazioni fra tecnici e cittadini hanno apportato o via via apportano ai modi di intervento dell'Amministrazione Popolare sulle diverse parti di città informale di Porto Alegre. Tenteremo quindi di leggere alcune politiche (più attinenti alla formazione professionale dell'autore di questo libro) a partire da alcuni progetti realizzati o in corso di realizzazione, per cogliere la capacità di radicamento nel territorio degli interventi, e per tentare di leggere fino a che punto quel 'riconoscimento reciproco' fra cittadini e istituzioni, che i diversi livelli di interazione certo stimolano, possa definirsi comprensione, o resti una semplice 'accettazione a distanza'. 


\title{
13.3 Strategia della necessità e contro-strategie istituzionali: la regola- rizzazione fondiaria da terreno di confronto a terreno d'incontro
}

\begin{abstract}
Invece di cancellare gli slums, i nostri urbanisti dovrebbero metteme in evidenza la bellezza, offrire loro opportunità di riscatto e miglioramento. Questo è quanto hanno fatto i veneziani o gli abitanti di Assisi. Le loro prime abitazioni non erano altro che misere baracche. Ma, via via che prosperavano, non si sono comportati come noi oggi, [...] faremmo: abbandonando cioè i tuguri che, per quanto miserabili, erano pur sempre le loro case. Hanno cominciato invece ad abbellirli (Kohr, 1976).
\end{abstract}

Come abbiamo visto in precedenza, in tutto il mondo in via di sviluppo i Programmi di Regolarizzazione Fondiaria hanno teso a divenire negli ultimi 15 anni il terreno privilegiato di intervento dei poteri locali, anche in conseguenza di un ridirezionamento delle risorse stanziate da diverse istituzioni finanziarie internazionali per le politiche urbane e abitative.

Anche a Porto Alegre (cfr. cap. 12), la regolarizzazione fondiaria va rappresentando la modalità di intervento quantitativamente maggioritaria nell'ambito delle Politiche della Casa: essa è, infatti, capace di valorizzare investimenti degli abitanti autonomamente realizzati, circoscrivendo il più possibile l'intervento pubblico al recupero degli spazi comuni e di mobilità, e favorendo il consolidarsi dei lavori dei privati sulle abitazioni soprattutto attraverso la regolarizzazione dei lotti e la garanzia della permanenza duratura in loco, ma minimizzando gli investimenti diretti della collettività.

In tal senso, la regolarizzazione fondiaria - in quanto agisce sulla città autocostruita (che non necessariamente coincide con la città spontanea) - è il terreno dove meglio si può leggere la problematicità dell'incontro fra l'universo della città formale e quello della città informale. In particolar modo nelle aree frutto di occupazioni organizzate o spontanee, visto che i 'parcellamenti irregolari o clandestini' (che pure sarebbero un ambito di grande interesse da esaminare, anche a motivo della crescita numerica che hanno subito di recente più o meno in tutti i paesi in via di sviluppo) presentano gradi di ibridazione maggiore con i modi di strutturazione della città formale, ed inoltre costituiscono un ambito decisamente secondario dell'intervento pubblico a Porto Alegre, a motivo del grado minore di problematicità che presentano mediamente le condizioni di vita e di alloggio dei loro abitanti.

Proprio perché terreno di confronto tra 'strategie locali' di sopravvivenza degli abitanti e strategie di intervento dell'Amministrazione, non sarebbe corretto voler indicare precise 'regole' sulla base delle quali esso si struttura. Ma - esaminando occorrenze e progetti concretamente messi in atto - è certo possibile leggere delle 'ricorrenze' significative che strutturano questo 'confronto' di strategie di cui l'Amministrazione Popolare vorrebbe propiziare un costruttivo 'incontro' proprio all'interno del Programma di Regolarizzazione Fondiaria.

\subsubsection{La 'strategia della necessità' nelle occupazioni di terreni inedificati}

Il favelado sa che il solaio è l'aspettativa del futuro. Per questo priorizza risorse per la sua costruzione; su di esso si può fare un ampliamento [...] La favela storicamente si costituisce in quattro tappe. Nella prima, c'è lo zinco come tetto, e il legno come parte; poi la muratura a vista e il solaio; più tardi il rivestimento e la tintura; per quarto stadio, si può prevedere la sua integrazione alla città e la sua trasformazione in un quartiere di classe media (Casé, 1996). 
La nascita di una 'vila' per occupazione di un terreno inedificato può avvenire sia in maniera programmata che per invasione graduale e spontanea. Le prime, sovente si pongono contemporaneamente come un esito di una 'strategia della necessità' (Alfonsin, 1998i, apud Allegretti, 2000a) ma anche come un gesto di lotta politica (Osorio; Dias, 1999i, ibidem) che segna il territorio in modo visibile, procedendo per fasi:

1) La 'pre-organizzazione' comprende la scelta dell'area da occupare e della data più opportuna per farlo, e la predisposizione degli strumenti necessari a segnare il territorio, dal semplice acquisto dei materiali (assi di legno, paletti, fili di rame, cartoni e tavole di plastica ecc.) alla preparazione degli strumenti per poter resistere sul posto (cibo, acqua, fornelli, candele). Nel caso delle occupazioni organizzate, in questa fase si ha la costituzione di comitati ristretti addetti ad una selezione oculata di un ventaglio delle aree migliori da occupare (per lo più in base a contatti con membri interni agli Enti Pubblici mirati a minimizzare i rischi di sgombero), all'organizzazione delle persone e al coordinamento delle prime fasi dell'invasione. La scelta del luogo esatto e dell'ora dell'azione è bene restino incerti e riservati fino all'ultimo, per evitare azioni preventive della polizia. ${ }^{4}$ I terreni da occupare corrispondono di solito alle proprietà meno propizie all'edificazione, sovente a quelle dove i codici legali proibiscono l'edificazione (sponda di corso d'acqua, pendio ripido, aree donate dal proprietario del lotto per area verde o destinata ad attrezzature pubbliche) mentre ormai gli occupanti organizzati tendono ad evitare le aree private (a meno che non siano aree contese tra eredi o abbandonate da tempo), e la mescolanza su aree a proprietà mista. La proprietà dei suoli segna spesso, infatti, il destino di un insediamento in relazione all'interesse del Comune per la sua regolarizzazione o ai rischi di essere fatti sgomberare da provvedimenti giudiziari. ${ }^{5}$ Accade però spesso che il diffondersi rapido della notizia dell'occupazione porti tutto intorno altre famiglie che si aggiungono al gruppo singolarmente, occupando aree non previste in un primo tempo e con proprietà diversa dall'occupazione iniziale. Nella scelta di aree con instabilità idrogeologica (pendii, zone di esondazione o erosione, ecc) vi è una sorta di 'saggezza' (istintiva o calcolata) degli occupanti, dal momento che queste aree - seppur di rischio per chi vi va ad abitare - sono quelle per cui sarà più lento (se vi sarà) il processo di rivendicazione legale della proprietà, mancando il fattivo motore del deprezzamento dei terreni sul mercato immobiliare che l'occupazione ingenera; anzi, vi è persino la possibilità di ottenere dai proprietari un fattivo appoggio alle richieste successive di urbanizzazione se queste possono valorizzare terreni migliori adiacenti. ${ }^{6}$ Il canale principale di informazione sulle terre da occupare è sempre quello informale, come rilevava una ricerca FIPE del 1993/94 (Prefeitura de São Paulo, 1995). ${ }^{7}$ 2) La fase dell'occupazione vera e propria comprende la demarcazione almeno sommaria del territorio (lotti, aree comuni) e la costruzione delle baracche di materiali provvisori fino all'ambito tetto, che per legge costituisce la prima garanzia di non poter essere immediatamente fatti sgomberare senza un'istruttoria giudiziaria. Di solito, l'occupazione avviene nel fine settimana (per lo più la notte del venerdì) per permette di contare su organici di polizia ridotti, su minori controlli amministrativi da parte del Comune, e sull'aiuto materiale di parenti ed amici che lavorano. In questa fase, vengono organizzate cucine da campo, asili comunitari e turni di lavoro per dare for- 
432 ma più compiuta all'accampamento e per vigilare sull'arrivo delle forze dell'ordine o su altre forme di 'attacco' agli occupanti. Si cominciano a formare le prime reti di solidarietà interna e quelle per lo scambio di saperi e competenze per realizzare eventuali allacciamenti clandestini alle reti idriche ed elettriche. La demarcazione più attenta dei lotti avviene in genere in un secondo tempo, sulla base di progetti di massima schizzati da studenti o tecnici che appoggiano più o meno apertamente l'occupazione, o dagli stessi abitanti. Negli ultimi 20 anni (Panizzi, 1984) vi è stata anche nell'area metropolitana di Porto Alegre la tendenza ad un'organizzazione dello spazio molto vicina a quella della città formale (strade larghe, lotti ariosi di misure standard, arretramenti delle case dal filo di strada, previsione di aree per servizi comunitari) in modo da rendere più agevoli nel seguito eventuali pratiche di regolarizzazione fondiaria. In alcune zone vengono addirittura prolungati i tracciati viari, al punto che sovente, una volta consolidate, è difficile riconoscere le aree occupate dal tessuto circostante. In sostanza, il cambiamento provocato dalla prassi diffusa della Regolarizzazione Fondiaria nelle nuove occupazioni si legge soprattutto nella regolarità viaria; "le strade sembrano sempre meno essere concepite come 'mangiamento' della proprietà privata, come spazio residuale o male necessario, ma come un elemento progettuale indispensabile" (Alibio, apud Allegretti, 2000a).

3) Prima, durante o immediatamente dopo questi eventi inizia la fase della 'negoziazione'. Il primo atto è l'arrivo della polizia o delle autorità comunali (se il terreno è municipale), l'identificazione degli abitanti e dei loro leader. In genere è a questo punto che la comunità si organizza per identificare i propri rappresentanti per condurre trattative con i proprietari e/o le autorità pubbliche. Nelle occupazioni organizzate, in questa fase, i leader restano per lo più quelli del Comitato che ha promosso l'occupazione; se però essi non vi partecipano direttamente, si fanno affiancare o sostituire da persone di polso che si evidenziano nella comunità, per poter gestire 'senza traumi' la transizione verso l'autogestione da parte degli occupanti. Quando non vi è alle spalle una rete di solidarietà con gli occupanti già predisposta (con istituzioni religiose o caritative, ONG e 'padrini' politici), è in questo momento che la comunità si organizza per cercare un appoggio logistico ed uno "politico' alla propria iniziativa (includendo in questo un avvocato e un 'protettore' politico o sindacale). Ambivalenti restano di solito i rapporti con la stam$\mathrm{pa}$, specie in aree come Porto Alegre dove essa è schierata prevalentemente a fianco della grande borghesia. Se, spesso, i media sfruttano il 'caso umano' rappresentato dalle storie personali degli occupanti, essi non garantiscono un'attenzione desta in difesa del loro gesto 'politico', ma tendono a rimestare nel torbido degli aspetti violenti o al massimo pittoreschi dell'occupazione. In questa fase è generalmente ben desta 'l'organizzazione resistente' degli occupanti, con diversi gradi di motivazione alla lotta per permanere sul posto e veder riconosciuti i loro diritti all'accesso alla terra e a un'abitazione. 4) Il consolidamento dell'occupazione parte in genere solo quando si intravedono spiragli di un esito possibile per le negoziazioni con la proprietà e/o le Istituzioni; può non manifestarsi laddove l'insicurezza ceda il posto ad atti inequivocabili che fanno prevedere lo sgombero. Esso avvia un processo naturale per la gran parte delle 'vilas', che tende con il tempo a trasformarle da luoghi dell'abitare (apparentemente) provvisorio in veri e propri quartie- 
ri della città dal carattere solido e permanente, a partire da una sorta di 'inviluppo' in muratura che avvolge gradualmente le strutture provvisorie con materiali diversi e più duraturi. Il primo segnale del consolidamento spesso è costituito dalla scelta di un nome, sia per la vila sia per le singole strade, sovente accompagnata da un'autonumerazione delle case: in città come Curitiba, addirittura, alcune 'vilas' neonate facevano in passato a gara per assumere il nome del sindaco in carica, per scongiurare lo sgombero attraverso un 'ricatto mediatico' ${ }^{8}$ Tutte le forme successive di appropriazione del territorio e degli spazi abitativi (consolidamento murario, ampliamento del metraggio quadrato, costruzione di servizi igienici, di patii, di orti, piantumazione, rifinitura e tinteggiatura delle case) sono indicatori di un fenomeno progressivo ed inarrestabile, il cui grado dipende principalmente dal livello economico degli occupanti e dalla loro capacità di sfruttare la nuova condizione abitativa come stimolo per innestarvi possibilità di creazione di reddito e occupazione. Di solito, in questa fase vengono identificati anche gli 'spazi simbolici' intorno a cui la comunità si aggrega. Per lo più, essi sono rappresentati da campi di calcio, asili gestiti in comunità, sedi delle Associazioni di Quartiere, bar e chiese; più raramente centri comunitari o aree verdi di particolare pregio. Accanto al processo di conferimento di una forma a questi spazi vi è quello della loro difesa comunitaria da occupazioni esterne o interne: in questo secondo caso, però, la convinzione messa nella lotta è talora minore (almeno nel caso di centri comunitari e sedi di AMs) come vari casi a Porto Alegre dimostrano. Solo per i campi da calcio sembrano non essere ammesse eccezioni: il caso della comunità di Vila Chacara das Pedras a Porto Alegre (che ha lottato nel 1988 per veder trasformato in piazza il Campo della squadra amatoriale del Vila América Futebol Clube) è un esempio pressoché unico. ${ }^{9}$ Nei vari casi, questa fase può corrispondere a gradi diversi di rafforzamento o sfilacciamento dello spirito comunitario e aggregativo. Di solito, la maggior rottura dei vincoli solidaristici è proporzionale alla rapidità e all'entità delle concessioni ottenute dal proprietario e dalle autorità pubbliche attraverso la negoziazione: la resistenza dei legami fra occupanti non è comunque deterministicamente proporzionale (in senso inverso) alla durezza dello scontro con gli 'avversari', ma è legata anche ai vincoli stabiliti tra di essi prima o durante i 'giorni caldi' dell'occupazione. Ci sono comunità completamente polverizzate, comunità pertanto così definibili solo per il vincolo di prossimità che lega le famiglie, ed altre solide che organizzano da subito 'cooperative informali' per l'acquisto di materiali o la costruzione di servizi e attrezzature (comuni ma anche individuali) in mutirão. Laddove si arrivi alla costruzione di case in comunità (specie nelle occupazioni organizzate da settori della chiesa progressista o leader della sinistra politica) di solito viene scelto il sistema dell'estrazione dell'alloggio a fine realizzazione, per favorire una cementazione del senso comunitario ed evitare discriminazioni e rallentamenti a svantaggio dei membri più deboli della popolazione occupante. È in questa fase (specie nelle occupazioni spontanee) che si evidenziano i cosiddetti 'picaretas', ovvero coloro che tradiscono lo spirito dell'occupazione, ad esempio mettendo in vendita la casa e tornando alla loro abitazione originaria (o ad occupare nuovamente), o addirittura imbrogliando nuovi venuti tramite illusioni di una 'baracca propria', magari venduta a 2 o 3 famiglie allo stesso tempo per poi scomparire. Soprattutto nelle occupazioni 
434 organizzate vi è un controllo comunitario su simili episodi proprio per garantire che non se ne verifichino troppi. Nel corso del consolidamento delle case e della 'vila', vi sono comunque sempre anche processi 'naturali' di vendita informale delle abitazioni abitate per un certo periodo, oltre che fenomeni di appropriazione dello spazio a danno dei vicini, seguendo formule di 'diritto interno' diverse da favela a favela. Tra queste, la più diffusa è - di solito -quella del cosiddetto 'diritto di prelazione' a favore di coloro che si sono stabiliti per primi nell'area o che hanno cominciato un ampliamento o il consolidamento dei confini dei lotti. Non è infrequente neppure che alcuni lascino l'occupazione e affittino la casa: in questo caso, purtroppo, gli affittuari non tendono in genere ad investire sul consolidamento delle abitazioni e queste si affiancano per mancanza di alterazioni a quelle delle persone più povere, frenando il processo di trasformazione della favela in quartiere.

5) La riorganizzazione della comunità intorno a specifiche richieste (servizi di trasporto, infrastrutture, attrezzature scolastiche e sanitarie) su cui lottare con il potere pubblico, di solito costituisce un nuovo momento di 'slancio positivo'. Nel caso di Porto Alegre e di molti comuni dell'area metropolitana un momento fondamentale è l'elezione democratica di rappresentanti comunitari, e la mobilitazione per partecipare al Bilancio Partecipativo dove presentare le proprie richieste. Questo non necessariamente si verifica in proporzione diretta al grado di organizzazione preventiva delle comunità, come Abers (1995, 1996, 1997) ha dimostrato nella Regione Extremo Sul di Porto Alegre. Spesso il grado di benessere già raggiunto dalla comunità e la mancanza di urgenza riconosciuta delle rivendicazioni, possono costituire limiti alla capacità di aggregazione delle persone intorno a nuove lotte. Oggi, per lo più, accanto all'urbanizzazione primaria, le comunità spontanee portoalegrensi fanno richiesta di regolarizzazione fondiaria dell'area, sapendo che un impegno comunitario in una direzione legalista faciliterà l'accoglimento di ulteriori rivendicazioni. La fase che precede i lavori di regolarizzazione fondiaria (specie se essi contemplano 'reassentamentos' anche parziali) è di solito critica, perché si hanno rapide impennate nella densità della popolazione residente che spera di ottenere benefici dall'Amministrazione. In tal senso, oggi le comunità locali eseguono spesso forme di vigilanza interna, mentre il Comune usa il censimento fisico/sociale per 'congelare' la situazione abitativa ad una certa data e non concedere nulla a chi è arrivato nell'area successivamente.

6) La regolarizzazione fondiaria costituisce un processo a sé, articolato in tappe diverse, e con gradi di maggiore o minore completezza (urbanistica, legale, ecc.) a seconda di numerosi fattori dipendenti dalle condizioni proprietarie dell'area, dalla sua ubicazione, dalla disponibilità finanziaria del Comune o di eventuali aiuti esterni, dalla partecipazione della comunità al processo e dalla predisposizione dell'insediamento e dei suoi residenti a soddisfare alcune necessità imprescindibili per mettere in atto l'intervento (pendenze, possibilità di allargamento di strade, accettazione di rimozioni parziali ecc.). Non ultima, sarà importante per il 'modo' in cui realizzarla la sintonia fra abitanti, loro leader e tecnici del Comune che prenderà forma nei processi di 'corpo a corpo', attraverso strategie di informazione costante e di minima interferenza con la vita domestica. La fase che accompagna e segue la regolarizzazione fondiaria è solitamente critica perché può indurre all'intensificarsi di fenomeni di vendita irregolare degli appartamenti, con rischi di 
'gentrificazione' dell'area. In alcuni casi, la regolarizzazione fondiaria potrà non essere realizzabile per tutte (o alcune) delle abitazioni, per l'esistenza di 'zone di rischio' o di eccessiva densità. Si dovrà quindi procedere a 'reinsediamenti' parziali o totali a spesedell'Amministrazione (o di finanziatori privati, nei casi delle 'operazioni concertate'). La regolarizzazione (urbanistica e fondiaria) si associa spesso a fasi di 'chiusura' della 'vila' verso il suo centro, con securizzazione delle abitazioni, e tendenza a rapporti difficili con eventuali occupanti dell'ultim'ora, o comunità finitime ancora in condizioni di precarietà conclamata. Questa fase può diventare problematica, innescando massicci fenomeni di vendita (più o meno formale) di alloggi e lotti, e di conseguente 'gentrificazione'.

Spesso - come di recente a Vila Pascoa - succede che alcune persone ci mettano le case in vendita dietro le spalle addirittura mentre simulano di voler firmare la regolarizzazione fondiaria con il DEMHAB. Lo scopo è di poter esporre l'ambito cartello 'casa in vendita con censimento realizzato' o 'casa in vendita con impegno firmato di regolarizzazione' e simili. I venditori sanno che la vendita di una chiave automaticamente annulla la validità del contratto regolarizzato o regolarizzando, ma ci provano, facendo leva sull'ignoranza di molti acquirenti. Spesso abbiamo il sospetto che forse non vi sia ingenuità da nessuna delle due parti, ma una strategia astuta che punta sull'effetto 'cose fatte'. Ovvero tutti sanno dell'irregolarità e della nullità teorica della compravendita, ma sperano in un meccanismo diffuso, cioè la solidarietà di solito prestata al nuovo arrivato dai vicini, che impediscono in genere al DEMHAB di assumere misure drastiche di espulsione dei nuovi arrivati. Essi appaiono, infatti, come casi umani ipoteticamente imbrogliati e 'precari'; cioè privati del loro denaro e col rischio di perdere tutto a favore di qualcuno che fugge magari per occupare altrove a Por to Alegre o nell' area metropolitana e ricominciare un cic lo di guadagni basati sul meccanismo della rendita differenziale ottenuta dalla vendita del bene-casa (Casa Nova, 1999i, apud Allegretti, 2000a-III).

\subsubsection{Le contro-strategie puntuali del Potere Pubblico}

'Tem que aprender' [deve imparare, ndt] è il lemma che i tecnici tendenzialmente usano dovunque per giustificare la rigidità di applicazione di certe leggi o la durezza di pur rare e casuali punizioni nei confronti di occupanti. Pochi hanno capito che lungi dall'insegnare, l'intransigenza imposta dall'alto genera un muro contro muro, uno scontro di monadi, e che invece è la negoziazione, la concessione in cambio di qualcosa a generare la crescita del cittadino anche in direzione dei suoi doveri (Moraes, 1999i, apud Allegretti, 2000a).

In confronto ai vileiros, noi del Comune siamo sempre disarmati, visto quanto poco sono sempre durati divieti e proibizioni. Per non esserlo dovremmo, forse, usare astuzie simmetric he alle loro. A volte lo facciamo anche, ma è difficile che loro non trovino uno stratagemma per renderle inutili in poco tempo. Pertanto, la politica migliore (e appositamente non dico la 'tattica') è lavorare insieme, puntare su una collaborazione continuata tra istituzioni e cittadini che metta in gioco il loro orgoglio e il loro senso di cittadinanza. L'Amministrazione Popolare crede per esperienza che questo sia possibile (Casa Nova, 1999i, apud Alle gretti, 2000a).

Se la 'tolleranza' ha rappresentato, dal 1979, il criterio comportamentale adottato prioritariamente in gran parte delle città brasiliane, a Porto Alegre questa scelta è stata particolarmente evidente a partire dal 1989. A parte, 
436 infatti, gli sgomberi ordinati dalla magistratura a danno di occupazioni in aree private ${ }^{10}{ }^{2}$ sono state poche le risposte 'dure' messe in atto dall'Amministrazione Popolare fino ad oggi. Vi è stato nel dicembre 1989 un interdetto proibitorio contro gli occupanti di un'area prevista per il 'reassentamento' di famiglie costrette a spostarsi dalle opere di urbanizzazione primaria a Vila Tronco, lo sgombero imposto il 9/11/1990 a 36 famiglie che avevano occupato un'altra area di 'reassentamento' nella Chacara da Fumaça, ${ }^{11}$ la rimozione (il 5/12/1990 ) di 46 famiglie che avevano invaso la piazza del Jardim Vila Nova, quella di famiglie che (nel 1997) per meno di 12 ore si erano installate nell'area dell'Ipê Barracão destinate ai mutirões, e, infine, l'allontanamento di un gruppo cospicuo di persone che aveva occupato l'area di 'reassentamento' prevista a Timbauva poco prima delle elezioni statali del 1998. In tutti i casi la presenza della Brigada Militar è stata solo di supporto ad operazioni di 'allontanamento negoziato', portate avanti dal Comune insieme ad altri organismi; e le ragioni del gesto erano appoggiate dalla cittadinanza nella misura in cui le occupazioni interferivano direttamente - e a scadenza ravvicinata - con decisioni prese democraticamente nell'ambito dell'O.P. e quindi ritenute 'indiscutibili' da gran parte della popolazione (Dias, 1999i, apud Allegretti, 2000a). Negli altri casi, il Comune ha privilegiato la via della soluzione negoziata (e per lo più della permanenza in loco degli occupanti), come nelle soluzioni raggiunte in extremis alla fine del 1993 per il quartiere dell'impresa Guerino Jardim Leopoldina II, occupato dal 1987, ${ }^{12}$ o dell'ex-Motel Coqueiros; anzi, in questi caso l'intermediazione del Comune ha impedito lo sgombero violento che i privati avevano ottenuto dalla magistratura e che la polizia avrebbe dovuto eseguire.

Nella maggior parte dei casi, l'Amministrazione Popolare ha scelto la via della legalizzazione e dell'urbanizzazione delle favelas, affrontando fattivamente (con provvedimenti normativi ad hoc e con un patto di cogestione costruito attraverso l'O.P.) le osservazioni dei critici che appuntano le loro accuse sul fatto che la certezza della permanenza incentiva nuove invasioni e l'addensamento delle vecchie e porta nel terreno occupato un simulacro del mercato immobiliare formale, sia in relazione alla terra che agli immobili.

La possibile gentrificazione (o 'espulsione bianca') innescata dalle operazioni di recupero urbanistico delle aree favelate, è - in teoria - una possibilità legittima dal momento che le politiche pubbliche urbane e dell'alloggio non interferiscono nel processo di distribuzione del reddito e di inserimento della popolazione nell'economia in modo diretto, ma di riflesso lo fanno con processi che indubbiamente fanno scegliere ad alcuni di approfittare, per sopravvivere, della rendita differenziale attraverso la vendita dei loro beni. ${ }^{13}$ A Porto Alegre, il potere pubblico ha deciso di operare in modo da minimizzare il ricorso a tali scelte (ad esempio dando i terreni in semplice concessione di uso, attraverso una legislazione adeguata di zonizzazione e regolamentazione delle AEIS, e con norme che impediscono la verticalizzazione, la densificazione e il cambiamenti di uso a favore di altri strati sociali) ma non ha scelto di impedire tassativamente questa opzione. ${ }^{14}$ Così, la LC 445/ 2000 ha reso possibile nelle CDRU (rispettando particolari condizioni) la vendita del 'bene-casa' costruito su lotti il cui controllo resta però nelle mani del Comune. ${ }^{15}$ Questo per permettere ad entrambi un margine di libertà maggiore nel portare avanti i propri interessi minimizzando il ricorso di ne- 
cessità a pratiche informali come la 'vendita delle chiavi' (i cosiddetti contratti freddi) ${ }^{16}$ per esercitare la propria libertà a fruire appieno di un bene che costa alle singole famiglie notevoli investimenti nel corso della loro vita.

A partire da queste considerazioni globali, l'Amministrazione Popolare - in questi 14 anni di governo - sembra aver cercato di fronteggiare alcuni punti della strategia della necessità che ha guidato molte occupazioni, ricorrendo ad una "contro-strategia soft" nel relazionarsi con la popolazione ad occupazione ormai venuta. Questa è fondata sulla continua negoziazione - a partire dalla fase di occupazione dei terreni fino alla messa in atto della gestione post-legalizzazione degli insediamenti - e sul dialogo continuativo. L'obiettivo è quello di pervenire ad una comprensione reciproca fra esigenze dei cittadini più emarginati e delle istituzioni, a cui la "regolarizzazione fondiaria dia concretezza fisica" costituendosi "come beneficio per la città e per la collettività intera e non solo per singole fasce sociali astratte da un contesto più vasto" (Menegassi, 1999i, apud Allegretti, 2000a).

$\mathrm{Se}$, pertanto, la regolarizzazione fondiaria è da leggersi come l'esito dell'incontro fra le due strategie (degli occupanti per necessità e dell'Amministrazione), ciò non toglie che i tecnici adottino e ripropongano in versione via via adattata alle risposte che incontrano, delle singole contro-strategie dissuasorie durante alcuni passaggi 'critici' del consolidamento delle occupazioni. Questo si mostra necessario nella misura in cui - anche all'interno del dialogo che si instaura attraverso l'O.P., il 'corpo a corpo' e le altre istanze di negoziazione può esserci sempre "la tendenza a tirare la corda dalla propria parte", ed "è necessario che il Comune si cauteli" (Casa Nova, 1999i, apud Allegretti, 2000a). Tra le cautele necessarie come risposta alla scorrettezza in rapporti stabiliti come rispettosi - e che dovrebbero comportare diritti e doveri simmetricamente distribuiti fra contraenti - alcune meritano una rapida citazione:

1) La strategia dell'abbandono dell'impresa:

A volte l'interesse anche solo classificatorio per un' area, diciamo 'il sondaggio' dei suoi problemi, innesca strategie di alterazione persino dei dati. Un esempio: c'è una favela che noi del DEMHAB oggi chiamiamo 'la vila dei separati', Dona Teodora, che è un caso interessante. Avevamo deciso che potevamo studiarla, censirne gli abitanti, ma quando ci abbiamo messo piede le coppie hanno iniziato a fingere di separarsi, per costituire più nuclei familiari, immaginando che se avessimo proposto delle soluzioni abitative nuove ogni famiglia avrebbe potuto guadagnare due case, magari da vendere o da affittare. Per fortuna una 'spiata' di qualche zelante ci ha messo in allerta e abbiamo per il momento abbandonato la partita (Casa Nova, 1999i, apud Alle gretti, 2000a).

Questa strategia di abbandono vale anche per singole fasi dell'impresa che si rivelano inutili o sovradimensionate, seppur in linea generale previste come tappe regolamentari di un intervento. E il caso dei rilievi topografici dell'esistente in aree occupate troppo dense e che si prevede di rimuovere, che risulterebbero passaggi antieconomici, "a vantaggio solo della pura conoscenza ma senza un esito pratico" (Guimarães, 1999i, apud Allegretti, 2000a).

2) La strategia del congelamento

E' messa, invece, in atto quando la comunità locale ha già presentato richiesta di regolarizzazione fondiaria nell'O.P. ed ha ottenuto il finanziamento per realizzarne la prima tappa, ovvero il rilievo topografico/catastale. Que- 
sto si configura come "un atto crudele ma necessario", una sorta di "magnanimo atto di ingiustizia" (Mallmann, 1999i, apud Allegretti, 2000a-VIII) in cui - purtroppo - talora vengono bloccate possibilità di crescita o ratificate ingiustizie. Ogni rilievo sociale o catastale è "un atto di inizio e un atto di conclusione. Chiude ciò̀ il processo spontaneo, o almeno di affluenza numerica, nella favela e apre come atto necessario il processo di regolarizzazione, $i$ cui benefici saranno estesi solo a chi è stato censito nell'occasione come già residente nella favela. É il documento fondamentale delle persone fisiche, spesso - per i molti privi di documenti - anche il primo atto di esistenza ufficiale. Ed è anche il primo documento di registrazione delle proprietà, delle forme dei lotti, quello a cui si ricorre nelle contestazioni fra vicini. In questo senso fissa le ingiustizie, perché spesso certifica la legge del più forte, chi ha saputo guadagnarsi nell'occupazione lotti maggiori" (Mallmann, 1999i, apud Allegretti, 2000a-VII). In questo frangente viene spiegato alla popolazione che solo chi è inserito nel censimento delle persone che accompagna il rilievo topografico potrà beneficiare delle opere successive ed essere inserito nei criteri della minima modifica che sono alla base della riorganizzazione dell'insediamento affidata all'EVU, redatto dai tecnici del Comune e poi approvato dalla popolazione. Analogamente, in seguito a questa approvazione, viene fatto firmare un impegno alla Comunità e ai singoli occupanti dei lotti rimodellati dall'EVU (che funge da congelamento ulteriore di una situazione di fatto) al rispetto di quanto ivi previsto, in modo da evitare il frequente fenomeno degli ampliamenti e degli spostamenti dei confini a danno dei lotti finitimi. Questa strategia cautelativa teoricamente presume il mantenimento di un 'polso duro' da parte dell'Amministrazione per potersi garantire in futuro il rispetto delle decisioni prese. Purtroppo, spesso, la mancanza di controlli fa sì che questo non si avveri. ${ }^{17}$

3) La strategia della spesa bloccata

Rilievi topografici, geologici e geotecnici e opere di urbanizzazione costituiscono $\mathrm{i}$ 'costi visibili' di ogni intervento (facilmente quantificabili in quanto legati a pubblici appalti) visto che per lo più i progetti sono eseguiti da tecnici dell'Amministrazione e le spese correnti del personale e funzionamento pubblico coprono le azioni di preparazione sociale, sviluppo ed educazione comunitaria, assunti dalla metodologia di azione come essenziale strumento della realizzazione stessa. A Porto Alegre, i leader comunitari coinvolti non ricevono rimborsi di alcun tipo per scelta politica di non professionalizzarli nel loro ruolo, pur correndosi così il rischio che questo a volte determini una riduzione dell'impegno - comprensibile - da parte degli stessi. ${ }^{18}$ La fermezza mostrata dal Comune nel non derogare agli investimenti previsti nell'O.P. (necessità imposta dalle stesse ristrettezze finanziarie complessive), è al contempo una strategia per responsabilizzare i residenti su ciò che viene realizzato sul loro territorio di residenza, nella certezza indiscutibile che nessuna spesa ulteriore potrà essere fatta in caso di cattiva realizzazione o manomissione delle opere previste; e che - in caso di rallentamenti ingiustificati ed eccessivi - si dovrà procedere al rilievo della mutata situazione da rifinanziarsi ex-novo.

4) Il principio della continua responsabilizzazione degli abitanti

E posto in correlazione con quello della spesa bloccata e mira a creare un sistema di controllo allargato che minimizzi diversi problemi dovuti alla violazione di accordi espliciti ed impliciti tra gli attori in gioco nella regolarizza- 
zione fondiaria, a cui porre un rimedio ex-post (nei termini 'legalisti' del rispetto dei patti sottoscritti) risulta complicato e talora antieconomico. "Eseguire un'opera di costruzione è come fare un viaggio. Si sa la destinazione e il modo per arrivare, ma non si ha mai la certezza che non ci saranno problemi", scriveva Johan Van Lengen nel suo Manuale dell'Architetto Scalzo; e questo sembra particolarmente adatto ai lavori svolti nelle aree informali. Quella della continua responsabilizzazione dei beneficiari sull'opera collettiva è pertanto una strategia preventiva che si articolata nella trasformazione degli abitanti in 'occhi e orecchi' dell' Amministrazione, sia a livello individuale che collettivo. Questo non significa puntare sulla 'delazione' - che nell'etica della favela (Leeds, 1998) è spesso considerata un'azione fra le più abominevoli; piuttosto puntare su una co-gestione che affida ai beneficiari degli interventi di Regolarizzazione e ai loro rappresentanti un ruolo attivo nelle varie fase dei lavori. Ciò include sia l'autocontrollo che il controllo nei confronti di terzi, ad esempio le Imprese..$^{19}$ Attraverso Commissioni di Accompagnamento e Monitoraggio dei Lavori la popolazione deve vigilare sull'integrità del cantiere e sull'operato di chi spesso si mostra irrispettoso di alcune delle norme contenute e più volte ripetute nei capitolati di appalto. ${ }^{20}$ Il Comune deve assicurarsi che le Commissioni siano ben assortite con la partecipazione di rappresentanti delle varie strade interessate; non è raro, infatti, che "molti se ne disinteressino appena finiti i lavori davanti alle loro case" (Casa Nova, 1999i, apud Allegretti, 2000a).

5) La strategia dell'occupazione preventiva

Riguarda tutti i casi in cui vi sia la necessità di rimuovere qualche casa da aree occupate, o addirittura l'intero insediamento. In questi casi è fondamentale - contemporaneamente al trasferimento delle persone - mettere mano alla demolizione immediata delle baracche e ai lavori di rioccupazione dell'area sgomberata con altre attività, ${ }^{21} \mathrm{o}$ affidarla con precisi accordi alla popolazione intorno perché la salvaguardi. L'occupazione preventiva ha anche un suo peso in ogni singola ricostruzione, dove tende ad applicarsi alla creazione di spazi vuoti, patii, arretramenti di fronti dal filo di strada. La tendenza acquisita con l'esperienza dai tecnici del Comune è, infatti, quella di dare a questi spazi le dimensioni minime concesse dalle AEIS e di occuparli con ostacoli fisici di diverso genere, per minimizzare ogni rischio di occupazione impropria soprattutto delle aree comuni con ampliamenti [i cosiddetti puxadinhos $=$ spintine in avanti] che $\mathrm{i}$ regolamenti in molti casi proibirebbero ma che la mobilità familiare rende necessari ai residenti. Del resto la semplice destinazione pubblica o comunitaria si è mostrata insufficiente a sottrarre gli spazi all'appropriazione individuale visto che "il pubblico, anche a causa della tradizione politica che il Brasile ha alle spalle, è spesso legittimamente letto dai più poveri come terra di nessuno, piuttosto che come luogo di tutti" (Helmann, 1999i, apud Allegretti, 2000a). ${ }^{22}$

6) La strategia dell'accerchiamento dei poteri paralleli ${ }^{23}$

Spesso la topografia della favela, la sua forma di occupazione con vicoli [becos] sinuosi e invisibili anche nelle foto aeree, la rendono 'conveniente' per l'attività illegale, tanto più per le comunità stabili e consolidate dove si creano "coesione sociale e senso comunitario legati ad un sentimento di lealtà e identità con una determinata comunità e anche alla condizione di 'favelado'” (Leeds, 1998). Questo può essere 'la rovina' per la maggior par- 
440 te degli abitanti degli ambiti peggiori, destinati a non poter usufruire di interventi pubblici che restano sgraditi ai pochi interessati al permanere delle condizioni ottimali per i loro traffici. La legge di ordine e protezione interna [lei do morro o lei do fumo] che vige soprattutto nelle favelas sede di traffico di stupefacenti - avversa come massimo crimine alla delazione - è accettata, in fondo, più o meno da tutti, anche nelle sue componenti di cooperazione forzata, per via della poca simpatia di cui godono le forze dell'ordine. Essa genera a lungo termine l'accettazione a vari gradi di sistemi alternativi di sicurezza e previdenza (quest'ultimo riguarda però solo pochi eletti) che indicano quali forme di violenza sono permesse e a chi. E seppure nel fondo la cosiddetta 'narcocrazia' non è altro che un insieme "di commercianti che usano lo spazio fisico della favela o del quartiere popolare come palco delle operazioni per un'attività altamente lucrativa del settore informale" (Leeds, 1998), è unendosi alle inadempienze e all'assenza dei diversi poteri istituzionali sul terreno della città informale, che essa in Brasile si traduce in un fenomeno ben più diffuso, radicato e pericoloso anche per chi cerca di recuperare questi ambiti fisici allo spazio cittadino. Non è escluso (come accaduto in alcune favelas centrali a Porto Alegre) che per non duplicare i conflitti di potere all'interno dell'area, alcuni leader del narcotraffico si facciano eleggere come rappresentanti legittimi della comunità, facendo coincidere potere reale e potere formale in un' unica figura. Altrove essi accettano, per comodismo, astuzia o desiderio di non sovresporsi, la mediazione di 'fantocci'; in ogni caso dimostrano l'esistenza di un fragile equilibrio fra la rudimentale organizzazione democratica della comunità e le forze autoritarie locali con potenziale di sottomettere i leader legittimi (ibidem) che anche a Porto Alegre non di rado ha portato all'eliminazione fisica di qualche leader popolari che ha osato porsi in contrasto duro con $\mathrm{i}$ detentori del potere economico e delle armi del proprio quartiere. A Porto Alegre - oltre all'impegno messo dal Comune nel trasformare l'O.P. in uno strumento di 'riforma' dall'interno (seppur senza garanzie di riuscita 'a priori') delle comunità di vileiros - vengono messe in atto altre strategie. Ad esempio, l'Amministrazione Popolare è molto attenta a non far associare la sua immagine a quella della forza pubblica, che non gode di particolari simpatie fra le popolazioni più povere. Mai nelle feste di inaugurazione di lavori nelle 'vilas' è presente la polizia, così come nelle 'rimozioni concordate' e dentro e fuori le riunioni dell'O.P., dove i poliziotti o i militari che vi partecipano lo fanno per lo più a livello individuale come cittadini. In tal modo, il potere politico tende a porsi come campo della mediazione degli interessi, come 'potere amico' che nelle favelas si sottrae alla morsa dello scontro fra due forze armate che in molte città del Brasile appaiono pericolose in modo simmetrico e in grado di disintegrare con regimi di paura il senso della collettività e la partecipazione popolare alla democratizzazione delle politiche cittadine. Queste precauzioni, sommandosi alla chiarificazione e al miglioramento dell'organizzazione spaziale e agli incentivi dati a feste, mercati ed eventi culturali nel cuore delle 'vilas' e nei loro dintorni, contribuiscono ad innescare fenomeni di salvataggio delle stesse, e ad incentivare l'abbandono da parte dei maggiori trafficanti attraverso una strategia di 'accerchiamento' di alcuni poteri occulti che si oppongono al recupero della città informale e alla democratizzazione delle decisioni. ${ }^{24}$ Molte altre 'tecniche puntuali' vengono adottate dai tecnici dell' Amministrazione nei singoli casi; ad alcune, importanti e più strutturate ma ancora in 
sperimentazione (come l'educazione ambientale) accenneremo nel cap. 16. Ciò che colpisce, è che la strategia della vigilanza e del controllo da parte dell'Amministrazione su quanto realizzato - che certo verrebbe da indicare istintivamente come la prima da mettere in atto - resta alla fine la meno attuata, essenzialmente per 3 ragioni: la necessità di molte persone addette al controllo che comporterebbe, la frammentazione delle competenze interne all'Amministrazione (con un forte ruolo per la SMOV) e la sostanziale 'informalità' in cui molte regolarizzazioni solo parziali restano confinate, cosa che rende difficile una coerente applicazione di misure sanzionatorie. A questo si aggiunge un'ulteriore mancanza di coordinamento che contribuisce ad una forma piuttosto difficile da combattere di disuguaglianza di trattamento fra i 'vileiros' di Porto Alegre, e riguarda i controlli incrociati per la verifica di eventuali proprietà possedute dagli occupanti censiti in città, specie se provenienti da altri comuni. Ciò fa sì che continuino ad operare indisturbati molti di coloro che usano le occupazioni come strumento di guadagno, mettendo in vendita case costruite in tempi rapidi sui lotti occupati. ${ }^{25}$ Non è inopportuno ricordare che a Porto Alegre, per il raggiungimento di un risultato concreto, queste strategie si appoggiano su un processo costante e graduale di discussione delle diverse tappe dei programmi di Regolarizzazione fondiaria con la popolazione residente sul posto; questo attualmente sta avvenendo in 138 'vilas' cittadine inserite a diversi livelli di avanzamento dei lavori nel PRF coordinato dal DEMHAB.

\subsubsection{Una sintesi problematica}

Alloggiate nell'informalità del sistema, queste "città informali" hanno sviluppato ingranaggi complessi, dinamiche sociali particolari, linguaggi spaziali peculiari e meccanismi propri di economia, potere e dominazione (Duarte, 1996).

L'assenza delle norme urbanistiche predeterminate che reggono il resto della città si esprime nelle favelas attraverso l'esistenza della diversità e della differenza (Equipe 112, in Duarte et al., 1996). Se la favela è differente dal resto della città, ogni favela è di solito anche diversa dalle altre. Ciò non significa affermare che nulla esiste in comune tra diverse favelas, ma appena avere coscienza del fatto che "gli elementi comuni sono di poco valore per elaborare progetti urbanistici che ricercano l'integrazione delle stesse con il tessuto urbano" (ibidem). In una città territorialmente complessa e frammentata come Porto Alegre - e per di più marcata dalla prevalenza di favelas di dimensione medio/piccola questa considerazione appare particolarmente pertinente, e il contatto diretto che l'O.P. propizia fra abitanti e rappresentanti delle istituzioni da anni ormai non fa che sottolinearlo, costringendo questi ultimi ad una continua e reiterata presa in carico delle differenze di organizzazione locale.

Queste differenze organizzative locali hanno un loro peso evidente sulle modalità di articolazione dello spazio costruito nelle diverse aree informali talora persino 'macroscopiche', cioè leggibili anche a prescindere dalla presa d'atto delle grandi differenze morfotipologiche 'locali' che caratterizzano le singole favelas. Ad esempio- in termini generali - appare evidente la differenza di densificazione del costruito nei lotti tra le occupazioni di terreni e $\mathrm{i}$ parcellamenti clandestine o irregolari [loteamentos]. Se nelle prime, infatti, il timore di ulteriori occupazioni ed il disordine dell'occupazione generano 
442 per lo più agglomerati densi e talora claustrofobici, nei secondi la razionalità originaria dell'organizzazione dello spazio immaginata dal 'loteador' porta già impresso un marchio di 'apparentamento' con la città formale. Inoltre, nel secondo caso, il metodo di spartizione e occupazione dei terreni offre maggiori garanzie di difesa del diritto di 'possesso' dei lotti (se non reale, almeno 'apparente', cioè agente sulla psicologia dei residenti) che ingenerano una maggiore predisposizione degli abitanti a riservare spazi aperti soprattutto sul fronte, ad immaginare preventivamente la costruzione di garage, aree coperte per il barbecue [churrasqueras] e simili. Uno dei massimi esempi in questo senso è Vila Pascoa, nel 1994 soggetto e oggetto di interventi di mutirão per la costruzione di marciapiedi e reti fognarie e di scolo pluviale: essa è - infatti - caratterizzata da strade regolari su cui si affacciano lotti di dimensione quasi standard, dove ogni casa è preceduta da un patio di dimensioni medio-grandi, e circondata da alte grate che servono a proteggere i proprietari "da coloro a cui - già per la nostra condizione di abitanti di 'loteamentos' - sembriamo ricchi”, come osservato da un'abitante del quartiere, a conferma della diffusa percezione dell'esistenza di gradi diversi di povertà visibili e riconosciuti nell'ambito della stessa città informale.

Anche solo considerando le 138 'vilas' attualmente inserite nel PRF, si evidenziano con immediatezza differenze di tipo più microscopico e localizzato, riferibili ad esempio a prevalenze tipologiche o morfologiche marcate come nel caso delle costruzioni 'a veranda' di Vila Asa Branca, dei giardini di Vila SS. Trinidade (costituita da una comunità di ascendenza tedesca riunita intorno ad una centrale di selezione dei rifiuti) o dei grandi orti organizzati di Vila Alto Erechim ${ }^{26}$ o di Vila Malvina nella regione Cruzeiro. ${ }^{27}$ Quest'ultima, costituita da famiglie originarie di zone rurali contigue del Rio Grande do Sul, è stata fondata ed è tuttora abitata da una comunità piuttosto unita sia a livello di organizzazione sociale che di consonanza in termini di costruzione dello spazio; si distingue perciò da altre 'vilas' della stessa Regione per l'autorganizzazione di vari spazi pubblici di incontro come il vasto slargo stradale che è stato scenario della festa per la conclusione dei lavori di regolarizzazione fondiaria. A Vila Malvina vi è addirittura stata l'elezione a simbolo di quartiere di un grande albero ucciso da un fulmine, intorno al quale i residenti hanno realizzato una sorta di basamento/sedile circolare durante le operazioni di regolarizzazione fondiaria concluse nel maggio del 1999.

Il fatto che l'intervento pubblico avvenga su aree già strutturate, e benefici popolazioni già radicate sui diversi territori locali, segna l'incontro fra due strategie fondate sul concetto-guida della 'necessità', che per la popolazione si traduce nell'immediatezza della relazione strada/abitazione e nell'unione casa/lavoro (i due principali paradigmi organizzatori dello spazio dell'informale) e per l'Amministrazione è alla base del bisogno di rispettare gli investimenti anteriori degli abitanti ed incentivare quelli futuri, minimizzando ed ottimizzando l'impiego delle proprie risorse. Entrambe le strategie di organizzazione e trasformazione dello spazio appaiono non precisamente strutturate; hanno cioè alle spalle dei saperi 'informalmente' desunti da esperienze di lavoro sul campo, ma non metodologicamente sistematizzati. In questo quadro, il 'corpo a corpo' fra tecnici comunali e abitanti dell'insediamento viene a costituirsi come il luogo di una 'negoziazione', che deve fare i conti con una serie di ambiti 
problematici di discussione che la Dichiarazione di Salvador Bahia ${ }^{28}$ del 3 dicembre 1993 sul recupero della città informale ${ }^{29}$ definiva sinteticamente con la sottolineatura che "riconoscere gli abitanti è riconoscere una storia" (quella del quartiere), ${ }^{30}$ che "abitare nello stesso quartiere non significa necessariamente partecipare dello stesso destino", per cui "riconoscere gli abitanti è riconoscere le loro differenze ${ }^{31}[\ldots] \mathrm{e}$ il loro lavoro e [...] il valore professionale degli sforzi fatti per la strutturazione sociale del quartiere" ${ }^{32}$ A Porto Alegre - come è evidente dai capitoli precedenti - l'Amministrazione Popolare ha programmaticamente portato avanti in questi 14 anni una politica di riconoscimento e valorizzazione degli abitanti delle aree urbane informali e delle loro differenze, all'interno delle molteplici istanze decisionali partecipative che compongono la vita politica e culturale della città. Maggiori difficoltà ed ambivalenze ha, invece, evidenziato nel mettere in atto un percorso di valorizzazione dei saperi e delle professionalità specifiche che hanno presieduto alla crescita della città informale intesa - secondo il principio 1.9. della Dichiarazione di Salvador - non come il frutto di modalità di organizzazione spontanea dello spazio abitato, ma semmai come il risultato visibile di un apprendistato culturale che ha portato alle diverse specificità morfologiche e ai modelli insediativi caratteristici di molte favelas cittadine. $\mathrm{Si}$ potrebbe, anzi, dire che il processo in questa seconda direzione è ancora agli esordi, seppur evidenzia costanti progressi: il suo ambito di svolgimento resta comunque quello della Politica della Casa, specie per quanto attiene la Regolarizzazione Fondiaria. Questa deve quotidianamente fare i conti con una serie di nodi problematici che restano ancora largamente irrisolti i principali dei quali - senza pretendere di essere esaustivi - sono:

\section{1) I referenti sconosciuti}

$\mathrm{Nel} \mathrm{dialogo}$ fra tecnici e cittadini vi è una sostanziale ignoranza reciproca tra cittadini e che i primi hanno delle caratteristiche dei secondi. La Mappa dell'Irregolarità Fondiaria di Porto Alegre costituisce solo una 'base minima' di conoscenza che nulla dice sugli aspetti sociali, lavorativi, culturali, di provenienza e di composizione familiare degli abitanti delle oltre 390 'vilas' di Porto Alegre (senza contare altre forme di irregolarità). È evidente che un'operazione 'a tappeto' di censimento è impensabile, sia per i costi sia per la mobilità che caratterizza le aree informali e che significherebbe rapido invecchiamento dei dati. La creazione però di un archivio-catasto unico delle favelas tipo quello esistente a São Paulo dove far via via convergere notizie, dati e aggiornamenti raccolti da tutti gli assessorati (Pasternak-Taschner, 1997) potrebbe costituire un valido supporto per i tecnici che intervengono sulle stesse, anche per comprendere i gradi di progressiva integrazione con i quartieri circostanti, il mutare delle categorie di reddito ${ }^{33}$ e l'esistenza di abitazioni in affitto, che può essere un utile indicatore degli investimenti futuri che la Regolarizzazione fondiaria potrà 'scatenare'. Se il 'corpo a corpo' adottato a Porto Alegre può costituirsi come un 'supplente' per la raccolta in via informale di simili dati al momento di ogni intervento, e per il sondaggio delle necessità dei desideri e della popolazione locale, limitarsi ad esso ha però delle controindicazioni, visto che costringe gli architetti a concentrarsi su indagini devianti dalle loro specificità professionali, e - soprattutto - sovente interviene in ritardo, quando miti e pregiudizi si sono già formati nelle teste di molti tecnici a riguardo del luogo di cui dovranno occuparsi e dei loro interlocutori. 
Da questa precarietà urbana, risultato della povertà dei suoi abitanti e del disinteresse del potere pubblico, sorsero le immagini che fecero della favela il luogo della carenza, della mancanza, del vuoto da riempire con i sentimenti umanitari, del pericolo da sradicare con le strategie politiche che fecero del 'favelado' un capro espiatorio dei problemi della città, l' "altro", distinto dall'abitante civilizzato [...] Luogo del fango e del fiore che dentro ad esso nasce, luogo delle visuali più belle e del maggior cumulo di sporcizia, luogo della finezza e dell'eleganza di tanti sambisti, da sempre, e della violenza dei più famosi banditi che la città ha conosciuto ultimamente, la favela sempre ispirò e ispira tanto l'immaginario pieno di preconcetti di chi da essa vuole distinguersi, quanto i tanti poeti e scrittori che cantarono le sue varie forme di se gnare la vita urbana (Zaluar e Alvito, 1998).

Il tema della dualità della favela, intesa come specchio invertito per la costruzione di un'identità urbana ha ingenerato miti diversi che hanno reso difficile il 'dialogo tra sordi' tra i suoi abitanti e quelli della 'città formale', che l'ignoranza di dati ed analisi precise nutre costantemente, sommandosi sovente ad una 'malafede' che impedisce la ricezione di questi anche quando sono presenti. Del resto, la stessa ricerca ha spesso contribuito ad alimentare pregiudizi contrapponendo troppo nettamente le due città: talora addirittura con eccessiva idealizzazione del mondo delle favelas, perpetrata soprattutto ad opera di politici progressisti, accademici o tecnici della cooperazione stranie$\mathrm{ra}^{34}$ che ne hanno 'mitizzato' le origini ed offuscato la possibilità di cogliere la veridicità degli elementi di cooperazione solidale e spirito comunitario, sovente attribuiti ad ambiti che - invece - spesso "privilegiano l'individualismo, rendendo difficile la definizione degli spazi di uso pubblico, comune - strade, vicoli, piazze, slarghi - e anche la loro manutenzione” (Bueno, 1995). Accanto a questi miti, esistono poi quelli in direzione inversa, che si diffondono tra i vileiros circa la 'città legale': ad esempio credenze relative alla conformazione di precisi ambiti fisici e tipologie costruttive che costituiscono un nemico ostico per i tecnici che lavorano al PRF e sono costretti a lottare duramente per "far capire loro che la tesi che sostengono è sbagliata. Tanto che a volte ci viene da pensare che nella realtà sappiano di mentire ma tentino ugualmente di appoggiare i loro desideri ad esempi 'forti' tratti dal mondo della città formale, che secondo loro dovrebbero far colpo su di noi e convincerci in maniera definitiva a venir loro incontro" (Mallmann, 1999i, apud Allegretti, 2000a). Tra gli ambiti problematici più diffusi:

1) l'idea che non esistano nella città formale le 'case appaiate', un modello che molti abitanti di 'vilas' in via di rimozione e 'reassentamento' tentano di rigettare, come se costituisse un artificio studiato per i poveri, una forzatura da abitazioni popolari che procurano solo litigi con i vicini e insicurezza circa la proprietà totale del proprio alloggio, una parte del quale (seppur solo un muro) risulta condiviso con altre persone;

2) 2) l'idea che nella città formale ogni abitazione abbia per forza un garage privato. Questo accade anche negli edifici multipiano occupati, dove i 'posseiros' spesso vorrebbero costruire box singoli per auto saturando tutta l'area di pertinenza del condominio, adducendo ad esempio non i palazzi, bensì le case monofamiliari della città formale, con un evidente scarto semantico fra i termini del confronto;

3) l'idea che la pavimentazione stradale sia necessariamente l'asfalto (che 
assurge mitologicamente a simbolo della città formale) e che i marciapiedi vengano realizzati dal Comune e non dai residenti le cui abitazioni prospettano sulla via in questione (come, invece, è).

Ciò genera spesso lunghe e infruttuose discussioni con i tecnici comunali incaricati di opere della regolarizzazione fondiaria di favelas, costretti a difendere la realtà dei fatti davanti ad una posizione piuttosto naturale dei vileiros, che desidererebbe che i miglioramenti delle proprie condizioni di vita - quando devono avvenire - fossero definitivi e completi, ovvero il più possibile ricalcati sui modelli della città formale, che essi però (più o meno volontariamente) tendono a distorcere o idealizzare. ${ }^{35}$

\section{3) Il ruolo del tecnico}

Nell'ambito della città spontanea, la sequenza con cui avviene la presa di possesso dello spazio (OCCUPAZIONE ® COSTRUZIONE ® INFRASTRUTTURA ( PARCELLAMENTO) è antinomica rispetto all'ordine che caratterizza la città formale, o almeno ne inverte alcuni termini, come nel caso dei 'loteamentos' irregolari o clandestini. Ciò colloca molti tecnici "nella scomoda posizione di finale del processo" e dando "il ruolo di pianificatori dello spazio a questa popolazione, che con sforzi e investimenti individuali va dando forma ai suoi insediamenti" (Equipe 121, apud Duarte et al., 1996). In questo 'riconoscimento implicito' di una capacità di 'costruttori dello spazio' che processi come la regolarizzazione fondiaria avallano, risiede gran parte dell'ostilità diffusa che i tecnici di molte amministrazioni continuano ancor oggi a manifestare nei confronti di quelle che Magalhães (1997) ha definito come 'interventi di tipo non convenzionale nel campo della produzione di alloggi', ovvero politiche 'al di là dell'enfasi nella produzione di abitazioni', a cui anche il Comune di Porto Alegre da almeno un decennio ricorre in modo sistematico. Oggi questo atteggiamento di ostilità si è mediamente piuttosto modificato rispetto al 1990, sia perché oggi i tecnici del PRF scelgono volontariamente di lavorare sul tema, sia perché a volte vengono già assunti sapendo di quali tipi di progetti dovranno occuparsi. Dentro il PRF, si va quindi notando una maggiore apertura di molti architetti ed ingegneri nei confronti dello svolgimento di compiti di 'architetto sociale', sottintesi dalle pratiche di 'corpo a corpo'. Seppur l'Amministrazione Popolare non abbia attivato strumenti di formazione specifica per questo nuovo genere di professionisti, il radicarsi dell'O.P. ha reso molte categorie di dipendenti comunali - e gli stessi cittadini - più preparati all'interazione dialogica anche su questioni tecniche. Nello stesso tempo, l'articolarsi delle figure di mediatori, sia nell'ambito del corpo tecnico-politico municipale (Assistenti Sociali, Agenti Comunitari, Commissione di Negoziazione) che dei movimenti popolari, ha restituito ai tecnici una loro specificità di ruoli che nei primi anni di Governo Popolare avevano temuto di essere sul punto di perdere a favore di un'ibrida posizione di mediatori politici, che a molti architetti e ingegneri appariva estranea alla propria professionalità. Per molti tecnici più direttamente coinvolti nel 'progetto politico' dell'Amministrazione Popolare (i cosiddetti CCs) si è evidenziato un ulteriore passaggio, caratterizzato dalla vera e propria 'scoperta' delle nuove prospettive offerte alla professione dal 'corpo a corpo' con i cittadini delle 'vilas' e della funzione 'educativa' e 'formativa' svolgibile nel contatto con gli abitanti delle aree di intervento. Dal punto di vista della popolazione, è invece evidente l'esisten- 
446 za di gradi differenziati di percezione della capacità di reintegrazione nella sociètà formale che i progetti del PRF offrono: e ciò, spesso, differenzia il contributo attivo di progettualità immesso dalle comunità locali nei lavori di regolarizzazione (Tramontina, 1999i, apud Allegretti, 2000a) ${ }^{36}$ Anche in seguito alla regolarizzazione fondiaria, infatti, una 'Vila' continua ad essere percepita come tale dai suoi abitanti (sin dal nome), essenzialmente perché in questa il processo di urbanizzazione non è completo (cioè non copre dall'infrastrutturazione alla costruzione delle case) ed essa resta inserita in un contesto di autorganizzazione che in Porto Alegre neppure una volta ha ancora fatto i conti con una legalizzazione completa e definitiva delle proprietà dei suoli. La questione si fa più complessa nei 'reassentamentos', visto che essi avvengono secondo modalità fra loro molto diverse. Nel caso di quelli in loco (come nella Vila Planetario e nella Vila das Placas, cfr. $\S 14.5$ e 14.6) è palese la sensazione di 'riscatto' dalla condizione di 'vileiros' che i residenti mettono in risalto (a partire dal cambio di nome dell'insediamento) anche a motivo della partecipazione intensa degli stessi alle varie fasi di progettazione. Per gli altri, la questione è più variegata. ${ }^{37} \mathrm{Nel}$ caso dei 'lotti urbanizzati' tipo 'Site \& Service' (con o senza case di emergenza o moduli sanitari) in genere gli abitanti tendono a sentirsi ancora 'vileiros', seppur con un grado di informalità minore che nella situazione abitativa precedente, ma con la coscienza di restare 'altro' dalla città formale.

4) I modelli abitativi

A Porto Alegre, anche nei casi di 'reassentamento', l'adozione della verticalizzazione non ha preso piede, e i modelli abitativi proposti sono rigorosamente monofamiliari. Stante la disponibilità di terreni vuoti in ambito cittadino (seppur con prezzi abbordabili per il Comune ormai solo in periferia), l'Amministrazione Popolare ha compiuto la precisa scelta di non snaturare i tradizionali modi di vita dei vileiros con cui si sono negoziate le rimozioni, non superando i 2 piani delle abitazioni, e prediligendo le tipologie unifamiliari. I motivi essenziali della scelta, fra loro interrelati, sono stati l'opposizione alla verticalizzazione da parte degli stessi cittadini e l'ottimizzazione degli investimenti in direzione della soddisfazione dei beneficiari degli interventi, che - ricevendo sovente alloggi non molto spaziosi (a causa dei limitati finanziamenti disponibili) - abitando al piano terra hanno almeno la possibilità di ampliare il loro spazio abitativo, qualora le condizioni dell'insediamento lo permettano. Per questo anche in 'reassentamentos' in aree centrali dense il Comune ha finora cercato di offrire ad ogni famiglia almeno una stanza a piano terra. Per quanto attiene strettamente alle regolarizzazioni fondiarie, il caso della ricostruzione ex-novo di abitazioni tocca solo singoli interventi puntuali dove sia necessario riallocare famiglie la cui ubicazione attuale sia di intralcio alla messa in opera del progetto. In tutti i casi i modelli abitativi sono dedotti da un abaco di alloggi-tipo raramente aggiornato, che viene presentato e discusso con la popolazione ma che sostanzialmente non varia molto a causa delle necessità burocratiche legate ai pre-finanziamenti delle opere. In questo senso in nessun progetto si può parlare a ragione di progettazione partecipata degli insediamenti (almeno per quel che attiene le unità d'abitazione) ma al massimo di progettazione accompagnata (Casa Nova, 1999i, apud Allegretti, 2000a-III) nelle sue varie fasi dalla popolazione, a cui comunque resta l'ultima parola sugli EVU, cioè sui piani di fattibilità urbanistica di 'reassentamentos' e regolarizzazioni 
fondiarie. In queste ultime, vi sarebbe la possibilità di un contatto proficuo con le tipologie abitative autocostruite, che però finora pare aver prodotto ben pochi risultati sull'aggiornamento dell'abaco di alloggi-tipo. Non si registrano del resto studi condotti da tecnici dell'Amministrazione relativamente all'organizzazione delle abitazioni spontanee a Porto Alegre.

Due soli sono stati gli elementi dedotti dall'osservazione delle abitazioni autocostruite ed introdotti per la pressione degli abitanti (neppure frequentemente) in alcune tipologie abitative destinate ad ospitare 'reassentamentos': il vano unico lasciato da suddividere liberamente ai residenti con divisori di varia natura, ed un piccolo patio sul retro dell'alloggio. Il patio ${ }^{38}$ è del resto tra gli elementi funzionali e simbolici quasi irrinunciabili nella costruzione dello spazio dell'alloggio; esso è inteso quale capitale, perché può essere indispensabile per molti lavori (compreso il 'selezionatore' di rifiuti), per hobby, per necessità domestiche (orti, allevamenti) o per l'ampliamento futuro dell'abitazione, ma è anche- per la sua 'apertura' - luogo simbolo della trasformazione. Esso rappresenta, in tal senso, una "possibilità virtuale di riaccomodamento $e$ ricomposizione di un'esperienza di appartenenza familiare" (Sant'Ana, 1997). Spesso, anzi, il termine patio è utilizzato come sineddoche per indicare la casa nelle favelas di Porto Alegre, il luogo centripeto e armonioso (ibidem) dell'unità domestica, del legame con le radici culturali o della tradizione agricola familiare (magari di 2 o 3 generazioni anteriori), che segnala frontiere simboliche e perciò assume forme particolari come nella Vila Asa Branca, dove si collegano le tradizioni delle aree di immigrazione veneta alle abitazioni del nordest brasiliano, ovvero le due matrici culturali che hanno dato origine alla Vila (Casa Nova, 1999i, a pud Allegretti, 2000a-IV). In tal senso, il patio può costituire un principio di territorializzazione per le stesse reti sociali dentro la favela, che riassorbe in un "continuum spaziale le discontinuità temporali ed intercetta una disposizione errante e nomade" (Sant'Ana, 1997). Addirittura, negli ambiti religiosi evangelici assume la connotazione di luogo "santificato dalla presenza di Gesù che ci illumina" (ibidem) in quanto ambito del territorio familiare dove si radicano valori religiosi e morali della famiglia e del gruppo, e in quanto unico luogo anche di 'contemplazione' della casa; mentre nei riti dell'umbanda è il luogo dove sono sistemate le casette dei santi, quelle che gli inesperti potrebbero scambiare per cucce di cani.

Per questo, patii di piccole dimensioni sono stati introdotti, fin dalla ricostruzione di Vila Planetario nel $1992^{39}$ - nella pianta di abitazioni di taglio piccolo-borghese che (a parte le critiche di solito mosse dai futuri abitanti alle dimensioni ridotte) sono state finora ben accolte, nella misura in cui paiono ben rappresentare - nell'immaginario colonizzato di molti favelados - l'emblema ideale del "riscatto sociale" a cui aspirano. ${ }^{40}$

5) Organizzazione spaziale e luoghi d'incontro

Organizzazione spaziale e luoghi di incontro nelle aree informali sono nodi cruciali per comprendere il reale interesse dell'Amministrazione Popolare al "riconoscimento e alla valorizzazione materiale del lavoro effettuato" dagli abitanti sui territori autoprodotti e "del valore professionale degli sforzi fatti per la strutturazione sociale del quartiere", ${ }^{41}$ ma anche per cogliere la volontà di radicamento dell'intervento che ci si avvia a realizzare. Il modo in cui i due temi sono stati finora trattati durante gli interventi di regolarizzazione fondiaria a Porto Alegre non permette conclusioni univoche, dipendendo 
448 da fattori diversi quali l'apertura e l'interesse dei singoli professionisti incaricati ad accettare stimoli progettuali provenienti dall'ambito di intervento, la capacità di interazione con i residenti, il grado di strutturazione e consolidamento della favela, ecc.. Finora, il principio del 'minimo intervento', che costituisce la linea portante del PRF, si è complessivamente dimostrata una garanzia per la conservazione dei caratteri principali dell'organizzazione spaziale autoprodotta, e al contempo un limite nel trattamento dell'interfaccia con i quartieri circonvicini, verso cui raramente sono stati aperti in questi anni spazi mirati al contatto e alla fusione di percorsi e funzioni, strutturati sull'esempio di quelli che hanno caratterizzato le fasi-pilota del Programma Favela-Bairro di Rio de Janeiro (Allegretti, 2001b). Raramente - nel contatto con i tecnici dell'Amministrazione - si rileva un precipuo interesse per lo studio attento dei modi di articolazione dello spazio delle varie favelas e dei loro valori morfologici, ${ }^{42}$ funzionali e simbolici. Globalmente, il 'limite' dell'intervento istituzionale sono state considerazioni di ordine economico/funzionale riferite a classi di esigenzetipo (sicurezza e illuminazione, passaggio di mezzi di emergenza e di pulizia, separazione di alcune funzioni con primato di quella abitativa, riequilibrio di quella che Casé ha definito come l'ingiustizia della quota), ${ }^{43}$ tutt'al più integrate nei singoli casi dal soddisfacimento di singole richieste presentate dai cittadini o da una sensibilità personale riversata nella strutturazione degli spazi e di alcuni particolari costruttivi. ${ }^{44}$ A questa sensibilità del progettista e alla sua capacità di cogliere, in modo rapido e sintetico, alcune caratteristiche distintive degli spazi autoprodotti dove interviene, sono in genere demandati gli aspetti aggiuntivi del progetto che non possono essere immediatamente ricondotti alle linee guida degli interventi di regolarizzazione fondiaria: scarsità dei finanziamenti, urgenza della realizzazione, senso di realtà.

Il tema degli spazi pubblici e comunitari resta, oggi, uno dei principali punti critici del discorso sull'approccio alle forme e alle funzioni nei quartieri autocostruiti, ed evidenzia -tra l'altro - una sostanziale ignoranza dei tecnici comunali di Porto Alegre sul tema, ${ }^{45}$ che si esplica spesso in un desiderio semplicistico di imporre canoni e schemi interpretativi propri della città formale a cui la condizione di AEIS permetterebbe anche di derogare. L' 'assenza' di dibattito e approfondimento sistematico su un tema importante come quello degli spazi pubblici e dell'articolazione dei percorsi e dei limiti delle favelas, si lega a un metodo progettuale 'per isole' (Di Lima, 1999i, apud Allegretti, 2000a), che continua a diffondere la percezione di molte aree di uso comunitario progettate nelle vilas riurbanizzate come esclusive della comunità, e non come nuovi luoghi della città. Questo modo di procedere per certi versi rafforza le tendenze all'isolamento che caratterizzano la vita di molti quartieri - specie in una città complessa come Porto Alegre -, puntando sulle piazze e i vuoti da inserire nei progetti di regolarizzazione fondiaria non come 'interfacce' con i quartieri vicini della città formale, ma come 'centri gravitazionali' della favela stessa. Nei progetti del DEMHAB, del resto, quella che Casé (1996) ha definito la necessità di ricerca 'empirica' del centro delle favelas (attraverso l'esame delle inter-relazioni comunitarie stimolate da funzioni e attività amministrative, religiose e socio-sportive, che nelle aree informali rappresentano le funzioni nobili) sembra in vari casi essere sostituita dalla 'costruzione di nuovi centri' - o almeno dalla ricerca di uno spostamento del baricentro - che prescinde dal riconoscimento dei 'gangli' inevitabil- 
mente già connotati in aree di occupazione consolidata come le 'vilas' regolarizzande sono, quali ad esempio i campetti sportivi autodelimitati o strutture di ritrovo quali gli asili comunitari o gli esercizi commerciali informali a cui Maria Ruth Amaral de Sampaio ${ }^{46}$ ha applicato la sua definizione di religione del baretto [a religião do botequim]. Ultimamente però - come testimoniano i casi di comunità quali Vila Malvina o Vila Alto Erechim - alcuni progettisti del DEMHAB hanno mostrato un'attenzione crescente a questi temi, ed il nuovo clima si è riflesso anche nella relazione finale del Gruppo di Gestione delle AEIS (GGA-SPM, 1997) dove viene presa in considerazione l'idea che la strada (soprattutto quelle definite di $\mathrm{II}^{\circ}, \mathrm{III}^{\circ}$ e $\mathrm{IV}^{\circ}$ tipo) possa tornare a svolgere nelle 'vilas' regolarizzate molteplici funzioni comunitarie di incontro e relax, specie dove non sia agevole ricavare aree ad hoc:

Tentare di sintonizzarmi con la tecnica di demarcazione dei lotti dei vileiros mi ha garantito la possibilità di alloggiare più famiglie nella stessa area, garantendo a tutte parità di accesso dalla strada; e così ho recuperato spazio per un'attrezzatura comune. Ho scoperto una razionalità interessante nel loro modo di costruire le strade; la curva permette non solo di superare un dislivello in modo meno brusco, ma anche di far sì che ancora più lotti affaccino su strada. Credo che in futuro avrò difficoltà a riprogettare con la solita scacchiera, che al potere pubblico sembra un modo di controllare meglio l'urbanizzazione ma finisce spesso per essere più dispersiva e irrazionale nello sfruttamento del terreno [...]. Il prossimo passo sarà forse capire come devo ubicare un'attrezzatura comune per garantirle un valore simbolico all'interno dell'insediamento, per renderla struttura collettiva anche a livello di percezione simbolica; finora nel dialogo con gli abitanti questo aspetto non è emerso a li vello cosciente (Casa Nova, 1999i, a pud Allegretti, 2000a - XII).

Nel complesso, comunque, la strada da percorrere sembra ancora molta prima di arrivare ad una comprensione della strutturazione spaziale dell'informale da usarsi anche come concreto stimolo ad una progettazione più 'creativa' nell'ambito delle regolarizzazioni fondiarie, che eviti l'attuale 'semplificazione' e la tendenza a ridurre l'urbanistica a mera urbanizzazione (Rigatti, 1999i, apud Allegretti, 2000a). ${ }^{47}$ In tale ottica, per ora, il 'corpo a corpo' nelle diverse tappe della ri-progettazione dei luoghi si ripresenta - per ora - come l'unico possibile luogo dell'apprendimento, oltre che della mediazione alla piccola scala anche fra esigenze puntuali - e persino fra specifiche progettuali di cui i residenti non di rado fanno richiesta al tecnico - e le concezioni spaziali di cui questo si fa portatore, tentando di spiegarle o talora anche di imporle ai cittadini, ma sempre attraverso la necessità di un dialogo e di una convinzione. Altri strumenti però iniziano a profilarsi: l'avvio dei primi Piani di Azione Regionale del nuovo PRG e il recente processo di regionalizzazione per costruire il Piano dell'Abitazione Popolare di Porto Alegre, potrebbero essere i luoghi per recuperare questa capacità di approfondimento della spazialità degli interventi. Molto, però, dipenderà ancora dalla capacità dei tecnici coinvolti di svolgere un ruolo 'maieutico' nei confronti degli abitanti, stimolandoli a superare richieste e stereotipi diffusi da un immaginario culturale omologato che - a prima vista - sembra non poter scampare ai modelli abitativi imperanti.

A volte nel dialogo la Comunità ci insegna e ci dà forza per vincere gli stessi timori che noi tecnici mostriamo davanti a un campo di cui non siamo padroni, anzi dove 
ci sentiamo ospiti e non sempre ben tollerati. È capitato, ad esempio, che sia stato il Presidente di una AM ad affermare per primo la necessità di demolire delle case, con più coraggio di un politico tradizionale demagogicamente contrario per principio a queste operazioni. Ci siamo chiesti all'inizio perché lo facesse, se per ingraziarsi noi, per eliminare dei nemici; poi abbiamo capito che la visione del bene collettivo che aveva un rappresentante locale era meno 'timida' delle nostre proposte (Casa Nova, 1999i, a pud Allegretti, 2000a - IV).

\section{6) L'appropriazione dell'insediamento}

Quello dell'appropriazione degli spazi all'indomani degli interventi di recupero è un nodo problematico che inizialmente veniva trattato solo in riferimento alle 'strategie dirette', mirate a minimizzare i rischi di gentrificazione dei quartieri informali regolarizzati. L'osservazione 'informale' (in mancanza di analisi scientifiche di settore) dei fenomeni differenti di appropriazione dello spazio costruito, sostituito - nei casi di 'reassentamento' - o riformato - nelle regolarizzazioni fondiarie - da parte degli abitanti, ha condotto in questi ultimi anni alla rivalutazione delle 'forme indirette' di riduzione dei rischi di espulsione bianca, mirate a favorire una graduale presa di possesso e la costruzione di legami affettivi con i luoghi di vita e con l'alloggio.

Le riflessioni sulla possibilità di successo di strategie mirate a rinsaldare il senso di appartenenza delle persone ai luoghi vengono dall'osservazione quotidiana diretta di ciò che accade soprattutto nei 'reassentamentos' ed in particolare nei mutirões, dove le persone faticano per costruirsi la propria abitazione e raramente poi l'abbandonano. Non è detto che favorire l'appropriazione delle abitazioni da parte degli abitanti sia facile. Specie per i 'reassentamentos' periferici non lo è. Ma resta un modo per favorire almeno nel tempo di permanenza la cura dei luoghi. E comunque, da parte del Comune, è un segno di rispetto per gli abitanti farli partecipare in qualche modo alle diverse tappe del progetto e lasciar loro delle scelte che li facciano sentire dei complici nella costruzione delle loro case (May er, 1999i, apud Alleg retti, 2000a-II).

Simili riflessioni hanno condotto in questi ultimi tempi il Comune di Porto Alegre a lasciare alcuni 'margini di scelta aperti' per i residenti nella ricostruzione (totale o parziale) degli spazi abitativi toccati dalle regolarizzazioni fondiarie, ed anche in alcuni spazi collettivi. Per certi versi sono state semplicemente 'rese legittime' le forme di ampliamento frontale, e soprattutto tergale, delle unità abitative - sempre messe in atto anche a dispetto dei divieti - riconducendole così almeno ad una breve discussione in grado di far propri consigli suggeriti dai tecnici comunali. Così, in molti lotti regolarizzati è stato lasciato apposito spazio per i cosiddetti puxadinhos [ampliamenti di piccoli vani], mentre a Vila Planetario il Regolamento ha dato libertà agli abitanti di aprire delle finestre al $2^{\circ}$ piano (dietro presentazione di uno schema di progetto al Comune), e nel Loteamento Costa e Silva, la "Cartilha do Usuario" presenta - sperimentalmente - 5 schemi grafici che riguardano suggerimenti agli abitanti su come ampliare le abitazioni del DEMHAB minimizzando la riduzione dei problemi che di solito creano le estensioni improvvisate (violazione della privacy dei vicini, riduzione della luce e della ventilazione trasversale, rottura di tubi, ecc.). Se la costruzione di solai sotto i tetti delle abitazioni, per favorire l'ingrandimento in verticale degli alloggi, o la consegna allo stato grezzo delle pavimentazioni si sono coniugate strettamente a forme di risparmio per l'Amministrazione, altri aspetti hanno solo 
mirato ad un coinvolgimento diretto degli abitanti almeno in alcune delle scelte visibili riguardanti le loro case, da compiere in comunità. È il caso della scelta e della disposizione della copertura vegetale, che la SMAM ormai sovente concorda con gli abitanti (Eliane Menegat, 1999i, apud Allegretti, 2000a) per sollecitare quelle relazioni di 'cura' che l'osservazione di orti e giardini in molte aree informali indica come possibili, ${ }^{48}$ a patto che non vengano imposte da fuori "come è accaduto nel 'reassentamento' di Vila Nova, dove a distanza di un anno le condizioni della vegetazione ripiantata sono disastrose proprio a causa del mancato coinvolgimento degli abitanti e soprattutto della scuola locale - nel lavoro di piantumazioni" (ibidem) Un altro caso è quello della scelta dei colori e della tinteggiatura delle abitazioni, sia nei 'reassentamentos' che in singole unità abitative singole ricostruite durante lavori di regolarizzazione fondiaria. ${ }^{49}$

"Io faccio sempre scegliere i colori preferiti per le case ai mutirantes che lavorano con me. Il DEMHAB faceva sempre colori tutti uguali per risparmiare. E le persone ridipingevano le case. Una volta una signora mi ha spiegato che era necessario per quando il marito tornava a casa ubriaco, senno' cercava di entrare dai vicini, con quelle case uguali tutte in fila. Allo stesso tempo, quindi, è segno di una necessità pratica (non sempre, però) e dell'acquisizione di una preoccupazione estetica. Più volte le persone si lamentano con noi di avere case tutte pronte, perché vogliono mettere piastrelle o carta da parati. Su questo abbiamo trovato un'intesa a metà strada; lasciare pavimenti e muri interni non finiti su richiesta; noi risparmiamo e i cittadini possono individualizzare il loro habitat. Questa è ciò che si chiama 'sinergia' Un'interazione che fa contenti entrambi e può ottimizzare un risultato. Come vedi lavorare è un apprendistato dai due lati, anche per noi tecnici; è imparare a soddisfare un'utenza che prima il Potere Pubblico non considerava degna di permettersi di fare delle richieste specifiche (Mayer, 1999i, apud Allegretti, 2000a-III).

Quindi, nell'ottica dell'appropriazione e risemantizzazione ${ }^{51}$ degli spazi regolarizzati da parte degli abitanti, i tecnici del Comune di Porto Alegre sono giunti con l'esperienza a recuperare elementi delle costruzioni prima ritenuti in assoluto secondari. A volte, infatti, il 'secondario' può rivelarsi necessario a rendere visibile il miglioramento della propria condizione ambientale di vita quotidiana, come nel caso dei numeri civici delle abitazioni che per i residenti regolarizzati sono l'emblema più significativo della loro nuova condizione di cittadini. Lo stesso può valere anche per ciò che ad un occhio esterno appare a prima vista 'superfluo'. È il caso dei cellulari - teoricamente un 'di più' in gran parte della società formale, ma di cui oggi molte favelas a Porto Alegre pullulano, perché sono il solo modo di ottenere un diritto alla comunicazione che le 'vilas' per decenni non sono riuscite ad avere, mentre i satelliti hanno annullato in parte la differenza fra città formale ed informale nel settore della telefonia. Nel particolare ambito territoriale di Porto Alegre è il caso soprattutto delle churrasqueiras, i caminetti esterni tradizionali di tutto il Rio Grande do Sul che servono a cucinare la carne arrostita allo spiedo, piatto tipico, e quasi irrinunciabile, dei fine-settimana in tutti gli strati sociali dello Stato. Durante l'incendio di una parte di Vila Zero Hora a fine aprile 1999, il panorama desolato delle macerie lasciava emergere solo i caminetti per l'arrosto, l'unico elemento in muratura sopravvissuto delle baracche di legno e cartone andate a fuoco. Una vanità superflua, in apparenza, o forse un modo per sopravvivere sentendosi più uguali, più cit- 
452 tadini, come notava - per nulla sorpreso da quella visione - l'Agente Comunitario della Regione Centro appena arrivato sulla scena dell'incendio.

La possibilità di scelta negoziata dei 'gruppi di vicinato' è oggi un'esigenza considerata importante dai tecnici comunali, anche per favorire la permanenza sul posto degli abitanti dopo le regolarizzazioni fondiarie e - soprattutto - i 'reassentamentos'. Questa nuova disponibilità al negoziato è riflesso di una ferma volontà espressa dalla popolazione durante anni di 'corpo a corpo' e compresa tardivamente dal Comune come un aspetto non secondario in grado di favorire l'appropriazione degli ambiti di residenza. Oggi, pertanto, prima di lavori di regolarizzazione fondiaria che comportino rimozioni parziali o totali delle famiglie residenti, vengono fatte riunioni apposite in piccoli gruppi per vagliare le preferenze nei rapporti di vicinato (cfr. Allegretti, 2000a), a parziale risarcimento del blocco che la legalizzazione delle proprietà dei terreni pone alla mobilità interna di natura volontaristica che caratterizza in genere gli ambiti di vita informale (Sant'Ana, 1997).

Ai fini di favorire la manutenzione degli ambiti territoriali regolarizzati da parte degli abitanti, si cerca, invece, di prevedere negli interventi "forme costruttive e organizzative semplici" (Casé, 1996) e modalità di educazione ambientale in grado di suscitare interesse verso la manutenzione dell'ambiente costruito, ad opera delle Equipe di Educazione Ambientale possedute ormai all'interno di ogni organismo comunale.

\subsection{Gli 'interventi complementari' alla Regolarizzazione fondiaria}

Cooperative, mutirões e reassentamentos sono considerate strategie complementari a quella della Regolarizzazione fondiaria, a cui più o meno dovunque ormai si sono ridotte le Politiche della Casa. Ma paradossalmente sono 'più politiche della casa' della regolarizzazione fondiaria. Se questa, infatti, beneficia un luogo e regolarizza la sua proprietà al fine di invitare gli abitanti ad aprire le tasche agli autoinvestimenti migliorativi, le altre strategie hanno la costruzione di case come oggetto diretto degli interventi, e non più solo indiretto. Così, però, l'aspetto urbanistico è spesso messo in secondo piano, quasi come conseguenza del fatto che il problema della proprietà dei terreni deve essere risolto in partenza per attivare questi programmi complementari, e si finisce per avere aree vuote da urbanizzare in maniera ordinata su cui non c'è stimolo a esercitare la fantasia. In sostanza questi nuovi insediamenti vengono spesso concepiti come una "città formale di secondo ordine" sviluppata per parti sconnesse. [...] E raramente essi si lamentano, purché però sia soddisfatta la condizione di un reale miglioramento della loro condizione abitativa. In fondo il loro immaginario spaziale e il loro sogno abitativo coincidono con quelli piccolo-borghesi che vedono tutti i giorni in Tv; ed assecondarli acriticamente appare la strada più semplice anche per il Potere Pubblico (Mayer, 1999i, apud Allegretti, 2000a).

I cosiddetti 'programmi complementari’ alla Regolarizzazione Fondiaria costituiscono oggi - almeno a Porto Alegre - una fetta cospicua dell'impegno dell'Amministrazione locale, indispensabile ad un'azione a tutto campo sulla città informale. Mirati, soprattutto, a dare soluzioni migliori di vita a chi abita in 'aree di rischio' e a facilitare la diminuzione della densità abitativa in alcune 'vilas' legalizzande, essi paiono qualcosa di più di una delle due metà dell' 'approccio combinato' preconizzato dalla Banca Mondiale.

A Porto Alegre, infatti, i 'programmi complementari' appaiono dei termini di transizione tra la politica abitativa tradizionale del SFH e il nuovo orizzonte 
del 'disimpegno' istituzionale (o del minimo impegno) rappresentato dalla Regolarizzazione Fondiaria. E, quindi, sono a pieno titolo delle componenti della Politica della Casa promossa dall'Amministrazione Popolare, legate ad Unità e Coordinamenti specifici del DEMHAB, e che hanno per oggetto interventi architettonici ed urbanistici generalmente completi, seppur in stallo quantitativo rispetto alle necessità a causa dei recenti 'tagli' finanziari compiuti dal Governo dell'Unione, che tramite il Programma PRO-MORADIA e i prestiti FUNDO-PIMES aveva finanziato fino al 2000 questo genere di interventi. Come ogni intervento pubblico a Porto Alegre, anche 'reassentamentos', mutirões, lotti urbanizzati e Cooperative di Abitazione devono fare richiesta di finanziamento attraverso l'O.P., evidenziando la volontà fattiva delle comunità coinvolte di vedere risolti i loro problemi collaborando con l'Amministrazione a soluzioni negoziate, e vagliando alternative differenti in rapporto a tempi e urgenza dei problemi. La situazione è un po' diversa per le nuove frontiere dei progetti urbani come le 'operazioni consorziate', che (nate per permettere la realizzazione di grandi investimenti commerciali) sono state talora usate dal Comune come occasione per risolvere situazioni di estremo disagio abitativo come 'contropartita' della concessione edilizia; pur venendo inserite nel Piano degli Investimenti ed essendo ampiamente discusse con la popolazione beneficiaria, esse propiziano - comunque - dei finanziamenti privati 'speciali', aggiuntivi rispetto alla gestione finanziaria ordinaria del Comune. Possono quindi servire a beneficiare (attraverso 'reassentamentos') comunità necessitate, anche se non attivissime nell'O.P..

\subsubsection{I 'reassentamentos': l'altra metà dell'approccio combinato?}

Inseriti all'interno di una politica che fa del dialogo con i cittadini il suo principale strumento di negoziazione dei conflitti, essi non si configurano oggi più come semplici 'rimozioni', ma come interventi che cercano di rendere compatibili le richieste istituzionali e quelle della comunità, offrendo un'alternativa residenziale a famiglie che vivono in aree 'improprie' per ragioni differenti. ${ }^{52}$ Costituiscono, pertanto, una scelta secondaria in condizioni di inevitabilità rispetto alla regolarizzazione fondiaria. Non sono mai attuati per mantenere la stessa funzione - quella residenziale - a vantaggio di classi sociali diverse da chi vi abita: se, cioè, l'area è adatta a risiedervi e non lo è l'ambiente costruito, al massimo si realizza un 'reassentamento no local' sullo stesso sito, ma non si promuove una rimozione.

I 'reassentamentos' presentano ventagli di soluzioni differenti per la riorganizzazione sul territorio delle famiglie da trasferire o da reinsediare in loco, che vanno dalla cessione di unità di abitazione in usufrutto alla collocazione in condomini ${ }^{53}$ fino alla distribuzione in lotti di proprietà pubblica tipo Sitesand-Services (con o senza moduli sanitari o embrioni abitativi) su cui è concessa l'autocostruzione. Talora si verificano anche le diverse soluzioni insieme, con smembramento della popolazione verso luoghi diversi, qualora vi sia difficoltà a mantenere unita l'intera comunità in una stessa area, il più vicino possibile a quella di origine. In tal caso, le consultazioni preventive degli abitanti servono a sondare le loro diverse preferenze in termini di dislocazione sul territorio e di tipologia di soluzione abitativa, cercando di predisporre ventagli equilibrati di opzioni (ad es: a sistemazioni più lontane dal luogo di origine corrispondono lotti o case di maggior dimensione). Come 
accennato al $\S 12.2 .1$, nei casi di 'reassentamento' non urgente, il Comune ricorre talora a 'mutirões' e cooperative d'abitazione.

La principale caratteristica comune che lega le diverse forme di 'reassentamento' è il passaggio da una situazione irregolare di regime proprietario dei suoli a situazioni regolari (terreni di proprietà dell'Amministrazione, gestiti dal DEMHAB); il che non significa regolarità assoluta dei fattori legati alla costruzione degli alloggi, almeno laddove sia permessa l'autocostruzione o l'ampliamento delle unità abitative minime predisposte dal Potere Pubblico. Tanto è vero che non solo in considerazione del permanere di condizioni socioeconomiche difficili per la popolazione, ma anche a motivo di una 'informalità' diffusa nell' organizzazione dei nuovi insediamenti, sul totale dei 110 insediamenti di Porto Alegre di proprietà del DEMHAB (Relatório de Atividades, 2001) molti sono quelli definiti come 'vilas'dalla stessa popolazione. Un altro aspetto in comune è che dopo ogni trasferimento di una comunità, le abitazioni precedenti vengono immediatamente distrutte, e ai vari Assessorati è affidato il controllo e lo sviluppo in tempi rapidi di progetti alternativi che evitino la rioccupazione del locale (DEMHAB, 1997b).

I gradi diversi di democraticità che è possibile leggere nei diversi processi di 'trasferimento' hanno un livello minimo garantito dal fatto che le richieste e le priorità di 'reassentamento' sono definite attraverso l'O.P. dalla mobilitazione sociale delle stesse comunità. Rispetto alle esperienze-pilota che descriveremo nel prossimo capitolo, i 'reassentamentos' hanno in genere periodi di preparazione minore, “un po' per l'esperienza formata negli interventi-pilota, un po', va ammesso, per disinteresse, a causa della differente 'visibilità' dei vari progetti" (Frare, 1999i, in Allegretti, 2000a).

I modi con cui sono condotti i censimenti delle 'vilas' da reinsediare raramente mettono in rilievo aspetti 'qualitativi' significativi per minimizzare i problemi derivanti dall'affiancamento su territori contigui di ex-vileiros di aree tra loro rivali, magari per la presenza di gang o trafficanti in competizione. I problemi originatisi nella Cavalhada dopo il 'reassentamento' di gang ostili a quelle della ex-Vila Cai-Cai, o nella Chacara da Fumaça in seguito al recentissimo trasferimento degli abitanti di una 'vila' ad alta densità di spaccio come la Mirim sono certo dovuti "a questa mancanza di tatto e di approfondimento delle relazioni di potere e rivalità esistenti sul territorio" (ibidem). Anche la progettazione urbanistica delle aree suscita dubbi:

La progettazione urbanistica che portiamo avanti al DEMHAB non appare a noi stessi molto creativa. Riguarda solo i 'reassentamentos', ovvero le aree vuote che li ospiteranno [...] L'inserimento del disegno delle aree di cui il DEMHAB si cura nella città è sottoposto ad un'enorme burocrazia, quella della Commissione di Parcellamento del Suolo, che però si mostra interessata soprattutto all'inserimento delle attrezzature standard previste dalla Legge. Alla fine noi urbanisti del DEMHAB siamo dei 'parcellatori di terreni a norma di legge', e il disegno lo curiamo solo delle aree comunitarie. Lasciamo 'galleggiare' dei fondi nel mezzo della città. Ovvero, se l'equipe di Regolarizzazione Fondiaria del CUR si occupa del disegno interno delle aree occupate intese quasi come isole, noi dobbiamo esaminare il raggio intorno di aree ancora vuote e far rispettare $\mathrm{i}$ condizionamenti ambientali inseriti nelle direttrici del Piano Ambientale della SMAM del 1998. [...] In sostanza noi lavoriamo su una città formale, con regole, criteri, condizionanti che la caratterizzano. Il problema è però che queste aree ospiteranno persone non abituate all'ordine spaziale della città formale, verso cui mostrano difficoltà di accettazione. [....] Per ora di evidenzia uno ‘scarto' ambiguo: è come se si concepisse la 
parte urbanistica dei 'reassentamentos' come una maglia rigida, pur sapendo per esperienza che l'architettura al suo interno sarà mobile (Carpenedo, 1999i apud Allegretti, 2000a).

Per quanto attiene al progetto architettonico, nei casi in cui esso ancora è previsto (e non sostituito da semplici lotti Sites-and-Services per autocostruzione), raramente i dati rilevati nel censimento o il dialogo con gli abitanti (al di là delle mere indicazioni quantitative) rivestono un particolare peso nella sua costruzione, che per lo più avviene nelle grandi aree del DEMHAB (come Timbauva e la Chacara da Fumaça) per sommatoria di lotti, aggiunti via via che si rende possibile avere risorse economiche per riempirli. Se talora - nell'incertezza della copertura finanziaria che arriverà - non si discutono dettagliatamente i progetti con gli abitanti è per "non creare enormi aspettative e poi magari non essere finanziati [...] Al limite in fase successiva si può rivedere qualche aspetto insieme alla popolazione che dovrà abitarvi, ma non è certo una forma di progettazione partecipata" (Saicoski, 1999i, apud Allegretti 2000a).

Dopo il 'trasloco', è importante verificare la coesione dei nuovi abitanti e la capacità di intervento delle Associazioni di Quartiere nel nuovo insediamento, e - se necessario - l'ente pubblico deve cercare di fomentarne il rafforzamento. Dal momento del trasloco, infatti, il loro referente non è più il DEMHAB con il suo ruolo di coordinatore degli interventi complementari, ma si spezzetta in molteplici interlocutori, ovvero i singoli assessorati e organismi municipali e/o statali a cui la comunità dovrà rivolgere le richieste di futuri miglioramenti dell'insediamento. Nei primi tempi appare utile in quanto 'sostituto unico e molteplice' il ruolo svolto dai CAR, i nuovi Centri Amministrativi Regionali che dovrebbero rappresentare il Comune nelle 8 Macroregioni di Pianificazione, ma che ancora non paiono essere percepiti dalla popolazione nel loro potenziale decisionale, ritenuto secondario rispetto al potere 'centrale' che si rende loro ben visibile nell'O.P. In teoria, dopo 6 mesi dal 'reassentamento' il DEMHAB (a parte la riscossione degli affitti) ritiene concluso il suo compito con quelli che ormai considera 'cittadini di un quartiere di Porto Alegre'; "anche se in realtà per molti aspetti sono ben lungi dall'esserlo concretamente" (Frare, 1999i, ibidem) sarebbe pericoloso prolungare il periodo di 'tutela' perché "genererebbe acquiescenza e dipendenza, come è accaduto nella Restinga, dove vi era una grande abitudine al paternalismo delle gestioni politiche precedenti. Noi dobbiamo spingerli a capire che il DEMHAB fa parte del Comune ma non è il Comune, e che ritenere ciò è semplificare la propria visione della città e dei propri problemi" (Frare, 1999i, in Allegretti, 2000a).

Resta il fatto che, spesso, allo scadere di questa 'tutela' temporanea, si avviano processi di favelizzazione istituzionalizzata (ibidem), tanto più oggi che la cancellazione dei fondi federali Pró-Moradia non permette più di finanziare le 'Ceste di materiali' per le famiglie a cui è stato assegnato solamente un lotto regolare. Al massimo, in casi rari di situazioni urgenti, si riescono a finanziare sui 'fondi di emergenza' del Comune le ormai celebri 'case di emergenza in pino' dipinte di rosa $(2,70 \times 5,40 \mathrm{~m} \text {. })^{54}$ e alcuni moduli sanitari, gli stessi che di solito sono riservati a tamponare i problemi determinati da incendi o altre emergenze improvvise, e che vengono rapidamente conglobati e fatti scomparire alla vista (o talora rivenduti) da ampliamenti e consolidamenti murari realizzati progressivamente a proprie spese dalle famiglie insediate. 
Le operazioni concertate o interrelate costituiscono una conquista recente di Porto Alegre, anche se in città come San Paolo erano usate già dall'inizio del decennio: gli esempi avutisi finora permettono di dire che si tratta essenzialmente di operazioni di scambio fra Potere Pubblico e operatori privati, in cui i secondi si impegnano a garantire a loro spese particolari opere che possano dare benefici alla collettività, ad esempio un 'reassentamento' di famiglie con basso reddito residenti nell' area interessata dalla compravendita, da eseguire sotto il controllo e la supervisione del DEMHAB. In un documento preparatorio al $1^{\circ}$ Seminario Municipale sulla Casa, il DEMHAB aveva inserito tali operazioni nel Progetto 'Parceria' [Partenariato] consistente " $\mathrm{nel}$ rendere compatibili gli interessi tanto dell'iniziativa privata quanto del settore pubblico, attraverso un partenariato in cui le imprese lottizzatrici sviluppano progetti di parcellamenti popolari in aree proprie o di terzi (partenariato tra privati)" e il potere pubblico li mette sul mercato, divulgando il programma, compiendo la selezione delle famiglie e sviluppando la gestione finanziaria della realizzazione "con lo scopo di incentivare la diminuzione della speculazione immobiliare, attraver so la semplice offerta sistematica di nuovi insiemi di lotti, ridurre le liste di attesa delle famiglie con reddito fino a 12 salari minimi, regolare il mercato immobiliare e progredire nel controllo di forme di autofinanziamento" (DEMHAB, 1997b).

A Porto Alegre, la prima grande operazione interrelata dell'era PT, che ha direttamente inciso sulle Politiche della Casa, è del 1998, e riguarda la vendita di un'ampia area nella Regione Cristal, destinata ad ospitare il supermercato BIG ed un Centro Commerciale per una superficie di $52.000 \mathrm{mq}$. In cambio della concessione, l'impresa Multiplan si è impegnata a costruire in un'area di sua proprietà nel quartiere Vila Nova (lontano alcuni chilometri da quella originaria) tutte le famiglie della favela Vila Campos do Cristal ubicata nell'area della realizzazione prevista. Il trasferimento è stato a lungo negoziato con le famiglie, che - nei mesi precedenti - si recavano ciclicamente (ogni sabato) con un pullmann fornito dal Comune a visitare lo stato dei lavori, per fare in modo che la comunità non si sentisse estromessa dalle trattative, ma anche per superare gradualmente il 'trauma' del trasferimento, che spesso costituisce la fase più critica dei 'reassentamentos'.

Il re-insediamento è stato realizzato in tre fasi, corrispondenti a tre settori del nuovo quartiere realizzato a Vila Nova: nella prima sono state trasferite 277 famiglie, di cui 265 già occupavano le loro abitazioni da metà novembre 1998 (essendo i lavori di costruzione degli alloggi iniziati a giugno dello stesso anno); nella seconda, conclusa nel dicembre 1998, sono state trasferite le restanti 716 famiglie, comprese 300 provenienti da altre 'aree di rischio' della città che la Multiplan, nel patto con l'Amministrazione Popolare, si era impegnata a riallocare. Attualmente - dopo il trasferimento nel 'reassentamento' di Campo Novo (all'inizio del 2002) delle ultime famiglie censite - restano in un' area finitima 39 famiglie all'epoca non censite (Solidariedade, 2003) per cui il DEMHAB sta cercando un terreno adatto nella Lomba do Pinheiro (cfr. cap. 15).

Il 1 giugno 1998 era stato completato il $1^{\circ}$ schema delle opere; in 5 mesi sono state realizzate le case a due piani - tutte quante di $48 \mathrm{mq}$ senza considerazione per le tipologie familiari differenti ${ }^{55}$ - con una struttura metallica ideata dalla ditta Archel, ${ }^{56}$ una delle più grosse di Porto Alegre ed una delle 
poche ad aggiudicarsi un'enorme fetta degli appalti delle realizzazioni del DEMHAB grazie all'esperienza e ai ribassi che può praticare. L'asfalto nelle strade del nuovo insediamento (dotato anche di una scuola, aperta dal 25 ottobre 1998 per i dibattiti elettorali) è stato sistemato dalla Multiplan, pur non essendo parte del contratto stipulato con il Comune. È stato anche fatto un tentativo di sistemazione paesaggistica intorno ad un corso d'acqua (coperto in pochi mesi di immondezza dai nuovi abitanti), mirando a legare ed integrare le varie parti del progetto. Nell'area di preservazione naturale presente ai lati del ruscello sono state ripiantate 2000 piante in accordo con la SMAM, sebbene i futuri abitanti si fossero dichiarati contrari a questo accorgimento.

Nel dialogo con la comunità, precedente al progetto di 'reassentamento', alcune proposte della Multiplan sono state riviste. Ad esempio, prima non era prevista la dotazione della cucina negli alloggi, poi realizzata. Non si è, invece, tenuto conto di alcuni aspetti messi in rilievo dalla Commissione di Negoziazione creata dagli abitanti di Vila Campos do Cristal, ovvero della necessità di differenziare le tipologie abitative a seconda della composizione familiare, e di chiarire per tempo il divieto a fare ampliamenti in un terreno che in realtà è concesso solo in CDRU ai suoi nuovi abitanti. A dispetto di queste raccomandazioni, l'impresa ed il DEMHAB hanno concesso agli abitanti di portarsi dietro a Vila Nova il materiale della demolizione delle loro or iginarie baracche. Così, già 15 giorni dopo i primi trasferimenti, il quartiere di Vila Nova era un cantiere, pieno di recinti, tettoie, pollai, canili e veri e propri piccoli ampliamenti delle abitazioni [puxadinhos]. Ironia della sorte, essendosi il dialogo fra proprietari e nuovi abitanti affidato in gran parte a opuscoli informativi su come usare le nuove abitazioni, essi sono stati stampati e distribuiti in ritardo, con l'ingenuo divieto - a lettere cubitali - di costruire strutture provvisorie o definitive nei giardinetti ubicati davanti e dietro le abitazioni.

L'apparenza fisica delle persone muta spesso dopo il trasloco, a partire dall'esistenza del bagno in casa. Ho avuto molte occasioni di notarlo. L'educazione ambientale fa anche questo lavoro di insegnamento di come usare le case. E stai certo che un libretto non è sufficiente. A Vila Nova i re-insediati di Vila Cristal hanno ricevuto degli opuscoli dall'impresa, un modo di comunicare impersonale che non può far presa sui vileiros; è un pezzo di burocrazia rigettata se non accompagnata da un lavoro personale di educazione ambientale. Questo senza contare che c'è ancora chi non sa leggere. Il fatto è che in quel periodo c'è stato un buco di continuità e al DEMHAB mancava un'equipe ambientale. Nessuno ha neppure pensato di chiederla a prestito da altri assessorati. Risultato? Dopo qualche giorno davanti c'erano tazze dei bagni divelte, che alcuni non sapevano a cosa servissero (Frare, 1999i, in Allegretti 2000a).

Un altro aspetto di cui l'impresa che ha progettato Vila Nova non ha tenuto conto - a maggior ragione vista la distanza del 'reassentamento' dal luogo originario di vita delle famiglie - è stata la necessità per molti abitanti di reinstallare attività di sostentamento economico. Così - pur senza permessi ed in strutture tutte uguali che non presentano differenziazioni fra residenze, né spazi pensati per il commercio - gli abitanti si sono organizzati, e pochi giorni dopo l'insediamento già fiorivano numerosi i negozietti, bar ed officine. Nel maggio 1999, erano già stati costruiti sulla strada principale veri e propri negozi e officine di autoricambi in muratura, senza che la SMOV esercitasse alcun controllo sulla proliferazione. Questo evidenzia un difetto strutturale di approccio settoriale del DEMHAB e dell'Amministrazione Popola- 
458 re al problema della casa, ritenuta talora elemento salvifico sufficiente a migliorare le condizioni di una famiglia, senza rendersi conto che forse è vero il contrario. Cioè, quanto il Forum del Riciclaggio e alcune ONG da anni predicano a Porto Alegre: che il più delle volte è l'abitazione che può essere mantenuta solo a patto dell'attivazione di programmi di creazione di reddito. Questo appare tanto più vero in casi come questo, in cui il 'gioco al risparmio' dell'impresa, e i tempi e i modi della realizzazione, già a distanza di un anno dal trasferimento della Vila Campos Cristal lasciavano immaginare in quali condizioni si ridurranno presto le abitazioni se non saranno messi in opera programmi di creazione di reddito, di formazione professionale ed educazione ambientale che rendano possibile il buon uso e l'appropriata manutenzione delle strutture. Per coloro che non hanno accettato tutte le condizioni previste dal trasferimento della favela del Cristal, la ditta proprietaria del supermercato BIG ha garantito un piccolo ventaglio di alternative. La prima era trasferirsi vicino alla nuova Cooperativa di Abitazione Chapeu do Sol, dove sono state innalzate case più grandi di legno in lotti 10x20 (il terreno era più ampio e più caro, ma si risparmiava sulle case, offrendo maggior spazio per le famiglie più numerose o con animali). Altri abitanti "accettarono un'altra delle opzioni offerte dall'impresa che si era aggiudicata la realizzazione dello Shopping Center, ovvero l'indennizzo per la demolizione della casa, un'opzione che c'era solo perché si trattava di una ditta privata, e che il Comune non può offrire, oltre che ritenerlo immorale perché non è vero che lascia $i$ beneficiari come cittadini liberi di scegliere, ma non permette spesso di ottimizzare i risultati, e magari viene sprecato in futilità e la famiglia torna a rioccupare altrove" (Frare, 1999i, in Allegretti 2000a).

In altre città brasiliane 'operazioni interrelate' del genere sono state attaccate per il loro valore di 'deroga' alla condotta urbanistica legittima, ovvero come mero modo di 'farsi burla' delle restrizioni all'occupazione dei suoli e alle leggi sulla zonizzazione per accrescere il guadagno immobiliare (Pasternak Taschner, 1997). A Porto Alegre, nonostante i dubbi che la politica di moltiplicazione dei Centri Commerciali può legittimamente sollevare, l'operazione condotta al Cristal ha avuto critiche minori, perché la rimozione degli abitanti della 'vila' del Cristal è stata salutata come un atto necessario atteso da tempo, ed inserito con coerenza nella Politica della Casa del Comune, per di più senza scavalcare le richieste fatte dalle comunità nel Bilancio Partecipativo. All'interno del corpo tecnico, però, molti aspetti delle soluzioni tecnico/architettoniche degli edifici di Vila Nova hanno suscitato accese critiche, così come le modalità del trasloco e la mancanza di corsi di educazione ambientale per abitanti, che avevano provenienza e caratteristiche lavorative non molto dissimili da quelle dei residenti nella ex-Vila Cai-Cai per il cui trasferimento nella Cavalhada ( $\$ 14.4)$ si erano usate ben maggiori cautele ed era stata messa in piedi una struttura di coordinamento fra vari assessorati.

Maggiori perplessità ha suscitato un'altra rimozione, quella della Vila Mirim, ubicata nell'area nordest di Porto Alegre proprio sulla sede di una grossa arteria viaria (il Viale Nilo Peçanha) prevista davanti all'area di grande valorizzazione fondiaria a lato del Centro Commerciale Iguatemí. Anche in questo caso, sul finale della negoziazione con le 200 famiglie di residenti per il 'reassentamento' (finanziato con Fondi PRO-MORADIA 1995 e contropartita comunale del 20\%) c'è stato un partenariato del Comune con l'impresa che doveva realizzare la 
nuova strada e gli edifici circostanti. Ciò ha contribuito a diminuire i costi del Municipio per la costruzione della viabilità, permettendogli di concentrare gli investimenti sul re-insediamento degli abitanti della favela nella Chacara da Fumaça. Con questo accordo, "che rientra nella costruzione di un patto sociale allargato interno alla città" (Pestana, 1999i, in Allegretti 2000a), il Comune ha potuto costruire alloggi completi per gli ex-vileiros, invece che limitarsi a lotti tipo Sites-and-Services di 6x18 m., con moduli sanitari di 3,30 mq., come previsto in un primo tempo. Il trasloco, terminato nel febbraio del 1999, ha lasciato però il dubbio che lo spostamento della Vila abbia mantenuto degli aspetti oscuri legati alla valorizzazione fondiaria dell'area, anche se l'evento si inserisce bene nella Politica della Casa dell'Amministrazione Popolare, visto che accanto alla strada di progetto scorre il ruscello Arroio da Areia, intorno a cui si stringeva un insediamento in condizioni precarie e insane.

In seguito, con l'approvazione del Decreto Municipale n. ${ }^{\circ} 11.978 / 98$,il Comune di Porto Alegre è andato consolidando la sua esperienza in relazione alle 'misure di compensazione' da richiedere ai grandi stabilimenti commerciali, anche studiando normative straniere, come l'aggiornamento del 1996 della Legge francese Royer. Ad esempio, la concessione della licenza concessa nel novembre 1999 all'Ipermercato Carrefour del quartiere 'di transito' Passo da Areia, non si è limitata a richiedere opere viarie e di urbanizzazione a beneficio della collettività, ma ha previsto alcune misure di compensazione attente anche agli aspetti di sviluppo locale, in seguito ad uno Studio di Impatto Economico realizzato dalla SMIC e poi discusso insieme alla comunità locale (che il proprietario aveva, tra l'altro, contattato con varie promesse perché appoggiasse la realizzazione dello stabilimento) e particolarmente attento all'area di influenza diretta dell'opera da realizzare (ADIR = con raggio di $1000 \mathrm{~m}$.). Ad esempio, la Carrefour ha dovuto costruire un asilo per 60 bambini della comunità locale, contrattare almeno il 10\% dei dipendenti tra persone della zona con oltre 30 anni, destinare i propri residui solidi e un corrispettivo annuale in denaro ai Programmi di Appoggio all'Economia Locale e di Riciclaggio della SMIC, ospitare 40 esercizi dei dintorni nei suoi spazi, e promuovere il marchio di vendita "Sapore Locale" dei piccoli produttori rurali della zona.

\section{Note}

${ }^{1}$ Il CUR è composto da 2 avvocati, 2 ingegneri, 7 architetti, 1 economista, 1 disegnatore e 6 stagisti; sociologi e assistenti sociali sono vincolati ad altre unità nel DEMHAB, ma spesso collaborano con il CUR. Ogni intervento è documentato attraverso un iter amministrativo e faldoni documentari.

${ }^{2}$ Istituito con Portaria ${ }^{\circ} 156$ dell'11/10/1996 sulla base del provvedimento 'More Legal' di semplificazione delle pratiche amministrative in tema

3 “'Un Consigliere Comunale aveva promesso agli abitanti del 'beco'la luce elettrica; mi ci sono agganciata portando il 'vereador' sul luogo e chiedendogli come pensava di mettere i pali in un vicolo dove non c'era spazio per passare. Giorni dopo mi ha telefonato ringraziandomi del richiamo alla realtà" (Casa Nova, 19999-VIII, apud Allegretti2000a).

4 "Scegliamo solo le prime persone, perché sappiamo che l'idea di un'occupazione è una nuvola di polvere che si espande rapidamente di persona in persona. Li incontriamo in gruppi massimo di 15 per volta, per non destare sospetti con riunioni di centinaia di persone. Magari approfittiamo di una cena, di una partitella di calcio, di una messa, di una manifestazione politica per parlare loro" (Osorio, 1999i, in Allegretti, 2000a).

${ }^{5}$ Generalmente sono i movimenti di origine 'organizzata' a svolgere analisi più attente per individuare gli oggetti e i luoghi più adatti ad una futura occupazione. Le occupazioni ‘spontanee' per piccoli 
nuclei familiari mossi da impellenti necessità corrono di solito maggiori rischi di avvenire in aree pericolose (sotto linee elettriche aree, in cima a tubi o casse di acqua e reti fognarie), nella doppia accezione del rischio che l'ubicazione può causare a loro stessi e all'intera comunità impedendo la corretta manutenzione e l'utilizzo ottimale di reti e servizi per la collettività, e del concreto pericolo di essere facilmente costretti dalla forza pubblica (ancorché con operazioni di convincimento piuttosto che di sgombero forzato) ad allontanarsi dall' area. Parlando di aree 'adatte' o 'inadatte' ad un' occupazione, va chiarito che il concetto non è tanto riferito alla maggiore o minore salubrità del luogo ma nel senso in cui gli stessi occupanti adottano i termini viavel o inadequado per indicare la minore o maggiore probabilità di essere costretti ad abbandonare il luogo in tempi rapidi senza possibilità di stabilirvi una dimora duratura. "Spesso lo stesso pericolo corso con l'occupazione di un'area 'inadatta' vale la partita; e non tanto perchè il rischio faccia parte del gioco, quanto perché dalla nostra (specialmente in città amministrate da partiti 'amici' come accade in gran parte del Rio Grande do Sul) abbiamo le nuove politiche della negoziazione ad ogni costo. E quindi occupare un'area pericolosa' ed entrare nell'occhio del ciclone della stampa o del dibattito politico può avere un suo esito positivo; che ci venga data in cambio un'altra area. L'occupazione da lungo tempo è un atto politico, ma prima non era possibile - o almeno non era automaticamente verificato nei suoi presupposti logici - questo ragionamento. Un tempo dovevi scegliere meglio dove occupare. Oggi quando occupi devi occupare oculatamente se vuoi restare in loco; sennò puoi permetterti più leg gerezza o addirittura scegliere la via dello scontro aper to e della massima pubblicità, anche se resta sempre buona regola evitare i terreni dei privati, che chiudono un occhio sui propri interessi molto meno del potere pubblico" (Osorio, 1999i, ibidem).

${ }^{6}$ Nella misura in cui l'esistenza nel tessuto urbano dellafavela ha effetto anche sul deprezzamento dei terreni circostanti a quello occupato (per ragioni di inquinamento della falda, di rumore, di degrado dei terreni sotto il profilo igienico e soprattutto di paventata pericolosità sociale oltre che di probabilità di espansione dell'occupazione) non si può però escludere che interventi rapidi di rimozione da parte del potere pubblico siano sollecitati dai proprietari dei fondi finitimi. Minor presa nel sollecitare azioni concrete di intervento rapido sulle occupazioni ha invece la constatazione del degrado portato da ogni nuova favela all'ambiente urbano nel suo complesso, attraverso l'interferenza nei sistemi idrici, fognari, di raccolta dei rifiuti e di drenaggio, che forse costituisce il suo maggiore pericolo a lungo termine per chi vi abita ma anche per la cittadinanza tutta, ma non possiede un 'richiamo immediato' nei confronti dell' intervento istituzionale (Comune, Stato, Polizia, magistratura) che in generale cede prioritariamente alle denunce dei singoli proprietari direttamente toccati dall'invasione. ${ }_{7}^{7}$ Purtroppo non esistono dati di questo tipo per la realtà specifica di Porto Alegre.

${ }^{8}$ A Porto Alegre stratagemmi del genere non sembrano aver funzionato. Ad esempio, Vila Cabo Rocha si è ribattezzata Vila Zer o Hora in onore della sede del quotidiano locale che la sovrasta, ma in nessuno dei 3 incendi che l'hanno devastata ha mai ricevuto un aiuto dal giornale.

${ }^{9}$ Cfr. Zero Hora, 3 ottobre 1988.

${ }^{10}$ Ad esempio le 2400 famiglie che nel marzo del 1991 occuparono un' area privata presso il Porto Secco nella Zona Nord di Porto Alegre, o le 120 che occuparono il 29 settembre del 1990 un' area a Vila Ingà.

${ }^{11}$ Cfr. Zero Hora, 9-10-12/11/1990.

${ }^{12}$ In questo caso sono state obbligate ad andarsene solo le famiglie giunte dopo il 29 ottobre 1993, data dell'ultimo censimento 'congelatore' della situazione.

${ }^{13}$ In alcuni quartieri oggetto negli anni '80 dei programmi di recupero e 'Sradicamento della subabitazione' PROMORAR (ad esempio Campo da Tuca, Nova Brasília, São Vicente, Nova Restinga, Monte Cristo) sono stati gli stessi abitanti a richiedere al Comune l'emanazione di regole che impedissero ulteriori segregazioni operate dal mercato in tempi successivi, e quindi processi di 'gentrificazione' su insediamenti riallocati o bonificati con l'intervento del potere pubblico.

${ }^{14}$ In ogni caso è la stessa politica dell'urbanizzazione delle 'vilas' con mantenimento di caratteristiche eforma urbis prevalenti a contenere in sè un antidoto a questo problema. Perchè, pur anche avvenendo qualche isolata 'espulsione bianca', se "la favela urbanizzata mantiene le sue caratteristiche urbanistiche peculiari - vie e lotti minori e irregolari - sarà oggetto di interesse solo per gli strati della popolazione di minor reddito della città, e - almeno in linea generale - è possibile che la politica di urbanizzazione della favela [...] continui a dare assistenza a questo target, e non accada ciò che sta succedendo nei quartieri residenziali del decennio '70, che oggi sono ogni giorno di più l'alternativa per gli strati della classe media e medio-bassa” (Bueno, 1995).

${ }^{15}$ Attualmente solo nelle aree occupa te prima del 1989 si può vendere casa (non terreno), cioè non in quelle disciplinate dalla Legge 242 sulla CDRU.

${ }^{16}$ Nei loteamentos il pezzo di carta che il lottizzatore abusivo dà all' acquirente instaura una mappa delle differenze fra situazioni psicologiche dei cittadini informali (Anton, 1999i). 
17 "La regolarizzazione smaschera la malafede. Una volta demarcati i lotti, $i$ cittadini possono anche comportarsi come prima e agire informalmente ma sanno che ne dovranno rispondere di persona; e soprattutto che non hanno più alibi per espandersi a spese dei vicini. Nonostante questo, non è raro che gli abitanti contin uino a comportarsi come prima, ag endo nell'informalità assoluta. Per leg ge non posso aprire finestre? Io le a pro, e se il vicino me la chiude mi arrabbio perché io l'ho fatto per primo, e nella legge della favela avrei più diritto. Solo che in teoria quella legge non dovrebbe valere più" (Frare, 1999i, apud Allegretti, 2000a).

${ }^{18}$ È evidente che i costi delle azioni inerenti al potere pubblico non possono essere confusi con quelli di realizzazione delle opere, sennò andrebbero diluiti in anni o decenni di realizzazione di queste politiche e programmi(Bueno, 1995).

${ }^{19}$ L'inizia tiva privata, si è più volte consta tato c he tenta "spesso di ridurre gli standard di livello tecnico di qualità (specie nei casi di rilievi planialtimetrici e catastali e di esecuzione di opere sotterranee) o di attribuire in modo sistematico il cattivo funzionamento delle reti all'uso indebito $e$ non all'esecuzione pressappochista. Questa posizione (oltre alle distorsioni sviluppantesi in Brasile nelle opere appaltate da organi pubblici) decorre dal preconcetto del cittadino medio sulla favela, intesa ancora folcloricamente come antro di banditi e per sone sprezzanti della legge, che non meritano ciò che il Comune sta facendo" (Bueno, 1995).

${ }^{20}$ Ad esempio, nel Capitola to-Tipo di Porto Alegre è detto che: Indipendentemente dallo stato di conservazione e dallo standard di costruzione delle abitazioni toccate, l'intervento realizzato sarà, necessariamente, nell'ambito della perfetta regola d'arte di ingegneria e in modo da garantire la sicurezza della costruzione, avendo come modello di finitura minimo quello preesistente, e massimo quello delle unità di abitazione da costruirsi nella vila. Le parti in muratura dovranno avere perfetto ancoraggio con il resto. Dovrà essere realizzato l'adeguamento del tetto alla nuova configurazione delle abitazioni dopo i tagli previsti. Inoltre nelle Raccomandazioni generaliè specificato sempre: Considerando che gli interventi qui descritti avverranno in area di occupazione irregolare e disorganizzata, è fondamentale che durante l'esecuzione dei servizi si faccia molta attenzione nel trattare con la comunità coinvolta, perché il successo dell'opera dipende basicamente dalla collaborazione di queste persone. Al momento dell'esecuzione dei lavori, indicheremo i rappresentanti della vila con cui, insieme con il personale di vigilanza dei lavori, andrà risolto qualunque problema che per caso dovesse presentarsi.

${ }^{21}$ Sui colli noi non abbiamo una politica dei belvedere per arrivare prima degli occupanti, e ce ne pentiamo. Se li valorizzassimo forse risolveremmo tanti problemi. Invece la nostra tradizione ha abituato la gente a privatizzare la visione, il panorama, e ora sono i poveri a rivendicare questo diritto privativo, a salire sui morros o a 'cogliere erba Marcela' come dicono loro (Eliana Menegat, 1999i). ${ }_{22}$ Molte associazioni e sing oli cittadini ci chiedono con urgenza loro stessi di strutturare gli spazi vuoti ancora esistenti, pavimentarli, dar loro un nolo simbolico o un significato pratico per la comunità, per paura che diventino spazi di nessuno, e quindi sog getti all'appropriazione da parte di singoli individui(Campos, 1999i).

${ }_{23}$ Nello sforzo per "proteggere la società" contro le due minacce rappresentate dai criminali comuni e dai militanti politici di sinistra, lo Stato brasiliano creò inavvertitamente la forma di crimine organizzato contro la quale oggi si vede obbligato a proteggere la società (Leeds, 1998), dove 'protettori di livello locale' giocano un ruolo di plenipotenziari proprio nelle "comunità non protette", cioè le favelas. Poi lo Stato brasiliano ha usato la presenza di gruppi di trafficanti come pretesto per tattiche repressive che, in questo periodo di ridemocratizzazione, hanno legittimità solo quando certe attività sono definite come aberranti, anti-sociali e passibili di coercizione. Paradossalmente, tale processo ha creato una situazione in cui, per le favelas, è preferibile l'omissione dello Stato quando questo si fa rappresentare dalla polizia e dalle forze di sicurezza (id., 1998). La Leeds sembra quasi suggerire l'idea di un senso di colpa della politica di oggi che accetta piccoli vincoli della criminalità, in nome di un percorso di maturazione parallela che i criminali comuni e i prigionieri politici hanno fatto, quando - perseguitati e incarcerati negli stessi luoghi dal regime militare - questi ultimi importarono nelle prigioni la struttura organizzativa e l'ideologia del 'collettivo' antigovernativa, usata in prima istanza per difendere i propri diritti di prigionieri e poi utilizzata come struttura autonoma di forza nel seguito. I prigionieri ereditarono un poco del discorso radicale della sinistra [...] buona parte del sistema di valori della società contemporanea e molte delle pratiche dei politici tradizionali, costituendo un conservatorismo di base che oggi tende ancora a dominare le relazioni fra gruppi di trafficanti e favelas (Leeds, 1998). Il codice di condotta interna stabilito da questi nuovi leader andò espandendosi proprio nella misura in cui le autorità carcerarie tentavano di diluirlo mescolandoli ai prigionieri comuni: e così che nacquero i celebri poteri forti come la Falange Vermelha o il Comando Vermelho che hanno sfomato eroi popolari in tutto il Brasile (l'accostamento popolare dei loro leader con Lampião, il più celebre Robin Hood del Brasile, è indicativo del credito di cui essi 
godono presso molte comunità locali.) e approfittato delle nuove opportunità offerte negli anni ' 70 dall'avvento della cocaina per creare isole di 'autosufficienza' affiancato dai sequestri di persona che sostituirono le rapine degli anni precedenti.

${ }^{24}$ Nella Vila Maria da Conceição il Comune ha ceduto al piccolo ricatto di un trafficante, costruendogli una casa che dava le spalle (senza finestre) al nuovo insediamento realizzato in 'mutirão'. La deroga all'impiento dell'insediamento era indispensabile, perché i lavori non restassero bloccati del tutto. Del resto anche nella Vila da Tuca per poter allargare e illuminare un vicolo buio, l' architetto del DEMHAB ha dovuto trattare con alcuni poteri occulti locali, convincendoli della necessita di preservare le donne dalle violenze sessuali, un tema che ha fatto presa sull'etica interna che vige nel 'mondo parallelo' del narcotraffico (Casa Nova, 1999i-IX). Accerchiamento o temporaneo cedimento sono in realtà due tattiche complementari, dove la radicalizzazione dell'esperienza cede alla mediazione quando questa va a vantaggio di un vasto gruppo di persone e della stessa città nel suo complesso.

${ }^{25}$ Una simile valutazione (in mancanza di dati del tutto informale) è corroborata dall'osservazione del discreto numero di baracche disabitate con sopra cartelli che ne annunciano la vendita, anche in occupazioni recenti.

${ }^{26}$ Per lo più è proprio nell' origine della popolazione che si rintracciano i germi del carattere unitario di alcune aree informali, o di loro settori. Alto Erec him è una vila arocca ta su un 'mor ro' verde e formata da immigrati dell' interno dello Stato che - a differenza del solito - hanno mantenuto intatta la fitta vegetazione come elemento di connotazione dell'area. Nell'intervenirvi, gli architetti del DEMHAB hanno puntato - pur con estrema semplicità - a valorizzare l'elemento di scoperta del paesaggio e del panorama che caratterizza i percorsi autorganizzati dagli occupanti, l'umanità del rapporto con la vegetazione che ne fa una delle poche isole ancora verdi tra le favelas di Porto Alegre. Cfr. Allegretti 2000a (Box 10).

${ }^{27}$ Addirittura a Vila Floresta (nella Zona Nord di Porto Alegre) dal 1993 funziona un orto comunitario per 64 famiglie.

${ }^{28}$ La Dichiarazione può considerarsi una sorta di follow-up di quella prodotta nella Conferenza di Caracas di 2 anni prima.

${ }^{29}$ Questa costituisce ancor og gi un riferimento importante per il Comune di Porto Alegre, specie nei punti riguardanti le politiche pubbliche redistributive, la partecipazione alle scelte decisive per la città, il riconoscimento del diritto a costruire la parola dei poveri e a fare in modo che sia udita (principio 1.6.) e a ricostruire la fiducia in se stessi degli abitanti dei quartieri popolari rendendoli interlocutori paritari (principio 1.11).

${ }^{30}$ Principi 1.2 e 1.3.

${ }_{31}^{31}$ Principio 1.5 .

${ }^{32}$ Principio 1.4.

${ }^{33}$ Secondo Machado da Silva (1967) c'è nelle favelas una borghesia favellata che monopolizza l'accesso, il controllo e la manipolazione delle risorse economiche e delle decisioni politiche, e fa sì che gli strati inferiori delle favelas non esercitino alcun controllo sugli accordi che gli strati superiori fanno con i gruppi politici sovralocali, fatto che contribuisce in modo decisivo al dominio dei gruppi e politici sovralocali sullo stesso strato sociale superiore della favela.

34 "Come cooperante devo ammettere di essermi scontrato con molti miti nel mio lavoro sulle aree informali: ad esempio circa la facilità della co-gestione e dell'autogestione, o sul ruolo delle ONG e del Terzo settore che al mio arrivo qui in Brasile ho trovato praticamente assente, e semmai sostituito da movimenti urbani, ma ancora allo stadio rivendicatorio e poco costruttivo. Anche il lavoro di appog gio alla questione di genere - che oggi qui comincia molto timidamente a prendere piede, e forse solo perché può appoggiarsi a finanziamenti internazionali - è stato uno scoglio non da poco che ho trovato. Ma grazie a queste 'comate' ho imparato che è importante adattarsi a lavorare nel luogo, ad agire senza fretta e su tempi lunghi per contribuire a cambiare insieme delle mentalità, o semplicemente ad accettarne le differenze guardando alla realtà come è piuttosto che come vorremmo che fosse" (Lange, 1999i).

${ }^{35}$ A Porto Alegre, oggi, alcuni tecnici realizzano piccoli book fotografici di casi della città formale che smentivano le credenze espresse ripetutamente e difese con veemenza dagli abitanti dell' area da regolarizzare.

${ }^{36}$ La condizione di costruttore, associata alla sua capacità di lav orare e di appropriarsi di nuovi spazi è rivestita, quindi, di un senso ulteriore rispetto ad una logica di sopravvivenza e capitalizzazione. Essa si inscrive nelle possibilità di agire e, così, territorializzarsi [...] il mezzo urbano è visto come un campo aperto per 'compiere ricerca' e da riciclare', in un movimento di risemantizzazione di materiali passibili di essere ricodificati e lavorati e con i quali si progetta la propria abitazione, cioè, essa è fatta con questi materiali, ma è anche pensa ta in questa logica di riciclaggio, di ristrutturazione, da cui risulta la costruzione e ricostruzione delle case, le demolizioni, gli ampliamenti, lo scambio, la vendita, i rinterri [...] La comprensione del- 
l'ambiente urbano come uno spazio riciclabile [...] riporta ad una forma di temporalizzare e mettere in atto la propria relazione con lo spazio abitativo della 'vila' (Sant'Ana, 1997).

${ }^{37}$ Tra i primi risultati dell'inchiesta in corso di realizzazione nella scuola del 'reassentamento' Cavalhada questo aspetto emerge abbastanza chiaro, mostrando come il grado di progettualità spaziale immesso nella conformazione degli spazi dell' abitazione costituisca un discriminante nei confronti della percezione di 'legalità' del proprio modo di abitare. A fronte di un parere piuttosto univoco espresso dalle fasce di età più giovani circa la differenza tra il 'reassentamento' e la favela di origine, molti adulti sembrano ritenere che 'anche la Cavalhada è una Vila, solo organizzata in modo diverso' (cfr. Tramontina, 1999i, apud Allegretti2000a); e paiono farlo in ra pporto a considerazioni che si legano alla mancanza di un riscatto di natura economica e sociale. Su questo punto, un approfondimento degli studi potrebbe rivelare elementi interessanti e consigli, e certo la conclusione dell'inchiesta in corso di realizzazione potrà già offrire conclusioni significativi.

38 "Il pa tio, fatta eccezione per le 'vilas' dense del centro cittadino, è un uso diffuso, più ancora nei parcellamenti ir regolari che nelle occupazioni. [....] Spesso, se i vileiros occupano tutto lo spazio è per necessità o paura che altri riempiano $i$ vuoti. Dove si hanno lotti legalizzati difendibili col ricorso alla giustizia è certo che uno spazio vuoto sarà lasciato. Per questo le regolarizzazioni devono ambire a riproporlo anche in spazi che prima non lo a vevano, chiaramente dopo aver consultato gli abitanti. L'unico rischio è che - se lo spazio è grande - sia occupato da ampliamenti dell'alloggio" (Guimarães, 1999i, apud Allegretti, 2000a-I).

${ }^{39}$ Il documento della SPM/PRF (1992) realizzato in occasione della regolarizzazione fondiaria di Vila Planetario, suggeriva anche la creazione di piccoli spazi semipubblici davanti alle case, proprio in base all'osservazione di molte 'vilas' di Porto Alegre.

${ }^{40}$ Del resto Nélson Ferreira dos Santos (1980), già 20 anni fa osservava che a Rio de Janeiro - nel celebre esperimento-pilota di progettazione partecipata condotto a Bràs de Pina dai giovani architetti della Compagnia di Sviluppo delle Comunità su concessione del governatore Negrão De Lima - oltre il $40 \%$ delle scelte ricadeva sui modelli più simili agli appartamenti della classe media di Rio, perché tali appartamenti erano "costr uiti da uomini abitanti nella favela e mantenuti dalle loro donne", ma anche a dimostrazione del fatto che "gli abitanti della favela non hanno nessuna cultura isolata" (Burgos, 1998).

${ }^{41}$ Dichiarazione di Salvador, principio 1.4.

42 "Affermare il valore estetico di una favela potrebbe essere considerata dai più un'eresia; mentre per me capire i perché di questo valore che a volte intuisco resta un miraggio, e mi sento intimidita anche solo ad accennarne davanti a colleghi che provano evidente repulsione per la forma delle strade, i materiali e persino i colori accesi di una vila" (Cas a Nova, 1999i, apud Allegretti, 2000a - II).

${ }^{43}$ L'ingiustizia della quota si manifesta nella constatazione che "più in alto è l'abitazione, mag giori sono gli sforzi del residente, indipendentemente dall'età, nel frequente e inevitabile tragitto di salita e discesa" (Casé, 1996). Per questo si manifesta sovente la necessità di poli di convivenza e servizi per accudire la popolazione residente all'intorno (id.), magari non specificamente richiesti dalla distanza in linea d'aria, ma richiesti "dall'allungamento prog ressivo c he va riconosciuto alla distanza ogni qual volta si superano i venti metri di dislivello" (De Lima, 1999i), a riprova del fatto che "non si può mai lavorare astrattamente su delle mappe per aree di influenza delle attrezzature e servizi senza valutare le condizioni reali dei singoli luoghi" (id.). L'inverso dell'ingiustizia della quota alta è l'ingiustizia della quota bassa: in queste ultime aree si concentrano i rifiuti, le fogne e l'acqua stagnante proveniente dalle aree più alte.

${ }^{44}$ È quest' ultimo soprattutto il caso dei progetti di EVU redatti (seppur spesso continuati e integrati da altri) dalla cosiddetta Tia Tetê,l'architetto decano del PRF del DEMHAB, da un anno in pensione. I suoi luoghi di intervento sono ancor oggi leggibili per la fluidità delle forme dei percorsi e la grazia di alcuni tocchi costruttivi, che segnano ad esempio le regolarizzazioni di Vila Malvina, Vila Alto Erechim (cfr. BOX 10 in Materiali) o Vila Dona Teodora.

${ }^{45}$ Il testo del 1980 di Nelson Ferreira dos Santos Quando a rua vira casa [Quando la strada si trasforma in casa] costituisce un riferimento quasi obbligato per i progettisti del Programma FavelaBairro di Rio de Janeiro, mentre è scarsamente conosciuto a Porto Alegre.

${ }^{46} \mathrm{Nel}$ suo studio sulla favela paulistana di Heliópolis

${ }^{47}$ Difficilmente noi tecnici abbiamo modo di mettere in gioco doti di creatività, un po' perché siamo pochi e pieni di lavoro, un po'perché forse si tende a delegare ciò che è meno strettamente tecnico ai cittadini stessi. Allora - se si vuole incidere un po' di più su aspetti più variati, inclusi quelli estetici - bisogna impegnarsi in prima persona 'fuori orario', come amici, dando consigli. A me è capitato che comunità con cui avevo lavorato venissero a cercarmi per chiedermi 'tu che sei un'esperta dacci dei consigli per costruire il nostro asilo'. Mi sono quasi sentita spaventata da questa fiducia, non mi sentivo all'altezza. Quasi quasi mi sembrava di averla ormai scampata...Poi ho capito che era una 
sfida da affrontare, per ninno vare i rapporti tra noi e loro, ma anche per capinli meglio su temi in cui durante il la voro di regolarizzazione fondiaria non mi ero applicata perché erano collaterali. Oggi direi che un po' a molti di noi manca la possibilità di immettere nelle favelas una dimensione creativa del nostro lavoro, fuori dalle impellenze (Casa Nova, 1999i - VI, apud allegretti, 2000a).

${ }^{48}$ I motivi sono i più svariati: dall'utilità pratica ad abitudine dovute alla provenienza, diletto estetico, o persino religioso-superstizioso (come accade con essenze usate per 'cacciare i mali' come il comigoninguém-pode, l'arruda, la espada de São Jorge).

${ }^{49}$ Il Condominio Coqueiros sul Morro Santa Tereza è oggi un re-insediamento popolare in un exmotel espropriato, o meglio ritornato in possesso dell' amministrazione a motivo dell'inadempienza del proprietario su pagamenti dovuti all'Amministrazione. Inizialmente monocromatico color cotto, per scelta dell'Amministrazione, è oggi divenuto un' area multicolore dato che la monocromia era intesa dai nuovi abitanti - abituati alla varietà di molte "vilas" come monotonia e rischio di indistinguibilità degli appartamenti (Carvalho, 1999i).

${ }^{50} \mathrm{Nel}$ progetto di mutirão per l'Ipê Barracão, i tecnici avevano progettato un balcone al secondo piano ipotizzando che potesse essere vetrato o in parte trasformato in bagno; quest'ultima scelta è stata subito fatta propria da tutti fino a convincere il DEMHAB a modificare direttamente il progetto per il futuro.

${ }^{51}$ L'idea diriappropriazione risemantizza trice tipica delle favelas "è messa in atto nella pratica del bricolage e di produzione di piccoli manufatti utili o decorativi delle proprie case, fatti con og getti abbandonati nella strada o ricevuti dai vicini, protettori, abitanti 'borghesi' dei quartieri adiacenti" (Sant'Ana, 1997).

${ }^{52}$ Queste possono andare dal trovarsi in 'aree di rischio' censite come tali dalla SMAM, all'abitare in aree insalubri, di preservazione naturale o destinate al passaggio di un'importante arteria viaria, fino all'ubicazione in aree previste di uso pubblico o di allargamento viario nell' ambito di interventi di regolarizzazione fondiaria.

${ }^{53}$ Un caso particolare è quello del Motel Coqueiros, nel Mor ro Santa Teresa; il propr ietario Raul Piccoli per molto tempo non pagò le tasse e dal 1993 il Comune lo acquisì al suo patrimonio per ospitare 70 famiglie di senza tetto, circa 350 persone che lo avevano occupato, con un accordo di locazione fimato in extremis il giorno prima dello sgombero previsto, il 19/6/1993 (cfr. Zero Hora del 20/6/1993).

${ }^{54}$ Questo tipo di costruzioni lignee, per cui vengono ripetutamente stanziati fondi nell'O.P., servono al DEMHAB come scorta per imprevisti (come incendi o crolli) che portano alcune famiglie a perdere la propria casa, o per isolare portatori di malattie infettive contagiose, come recitano (al punto 5.9.) gli atti sintetici del $1^{\circ}$ Seminario sulla Casa di Porto Alegre del 1997. Pertanto si affiancano alle altre Politiche emergenziali (soprattutto al Programma di Assistenza Continuata per il reinserimento sociale di famiglie seguite dalla FESC, dall'SMS e dai Consigli Tutelani, tramite la fornitura di lotti urbanizzati) di un Comune peraltro costretto costantemente "ad agire in un'ottica emergenziale anche se non si limita a questa e la reinserisce nell'obiettivo più generale di creazione di una democrazia sostantiva" (Pestana, 1999i, in Allegretti, 2000a).

${ }_{55}^{5} \mathrm{La}$ stanza da letto è unica, lasciando libertà di divisioni interne ai residenti.

${ }^{56} \mathrm{La}$ costruzione è in muratura su intelaiatura metallica, con l'introduzione di kit completi elettrico/ idraulici incassati nel muro. Prima sono state realizzate le pareti e poi sono stati fatti i buchi nel muro per gli allacciamenti. Ogni casa costa $10.000 \mathrm{R} \$$ a causa della struttura tradizionale che costringe a contrattare le ditte a pezzi. Un fatto che l'ing. Hoffmeister ha teso a sottolineare durante la visita guidata del Consiglio Integrato del Piano Regolatore a cui ho preso parte nel novembre 1998 è stato che tutte le ditte chiamate in causa erano gauche. L'Archel è la stessa che ha realizzato il Jardim Planetario. 
Fig. 57 - A Porto Alegre la Politica della Casa, di recente, è spesso riconfermata tra le prime 3 priorità cittadine. In figura, sono evidenziati - nei diversi distretti cittadini - gli investimenti destinati alla Politica dell'Alloggio Popolare tra il 1995 e il 2001 (Dati DEHMAB, 2001)

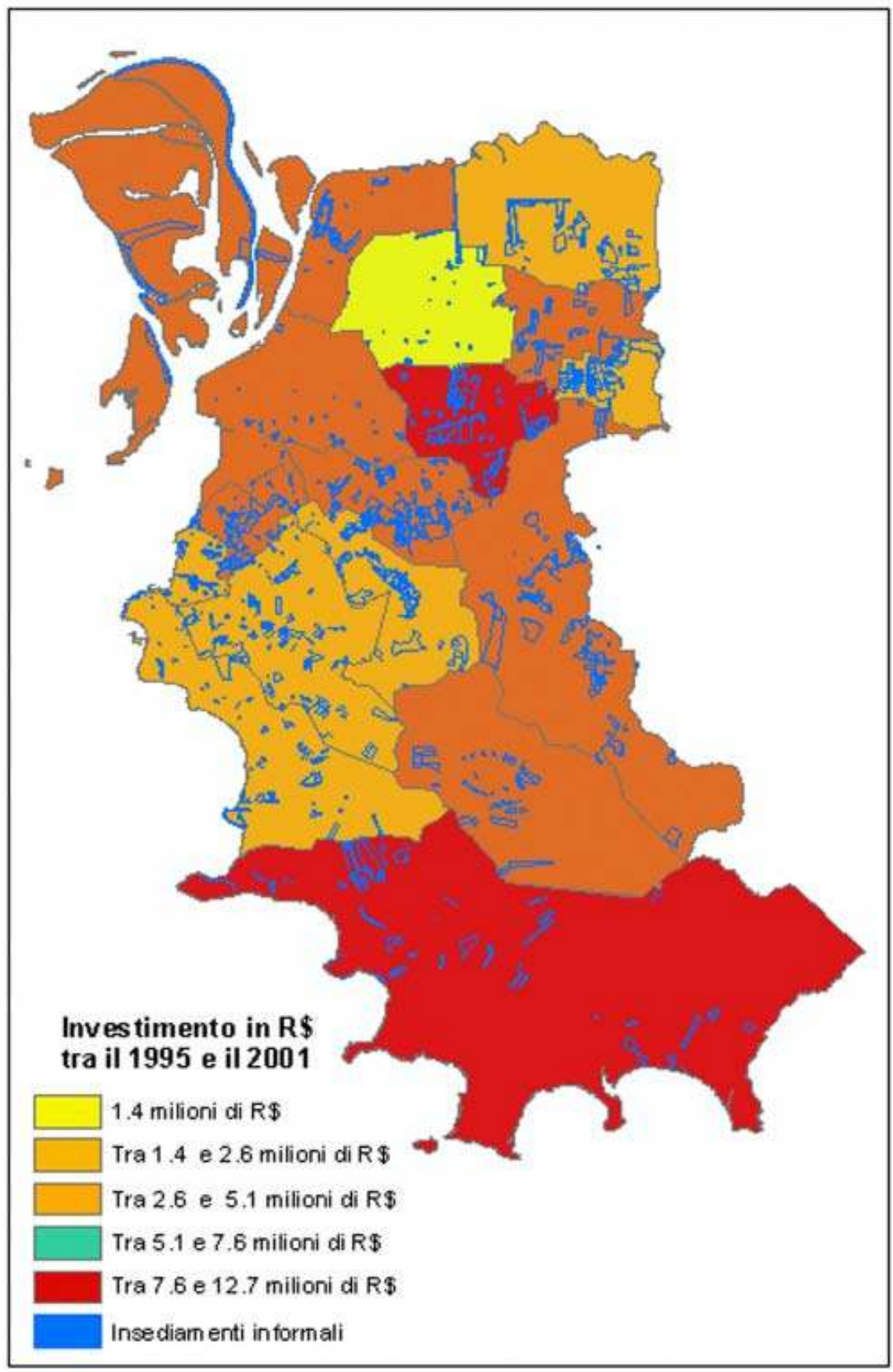




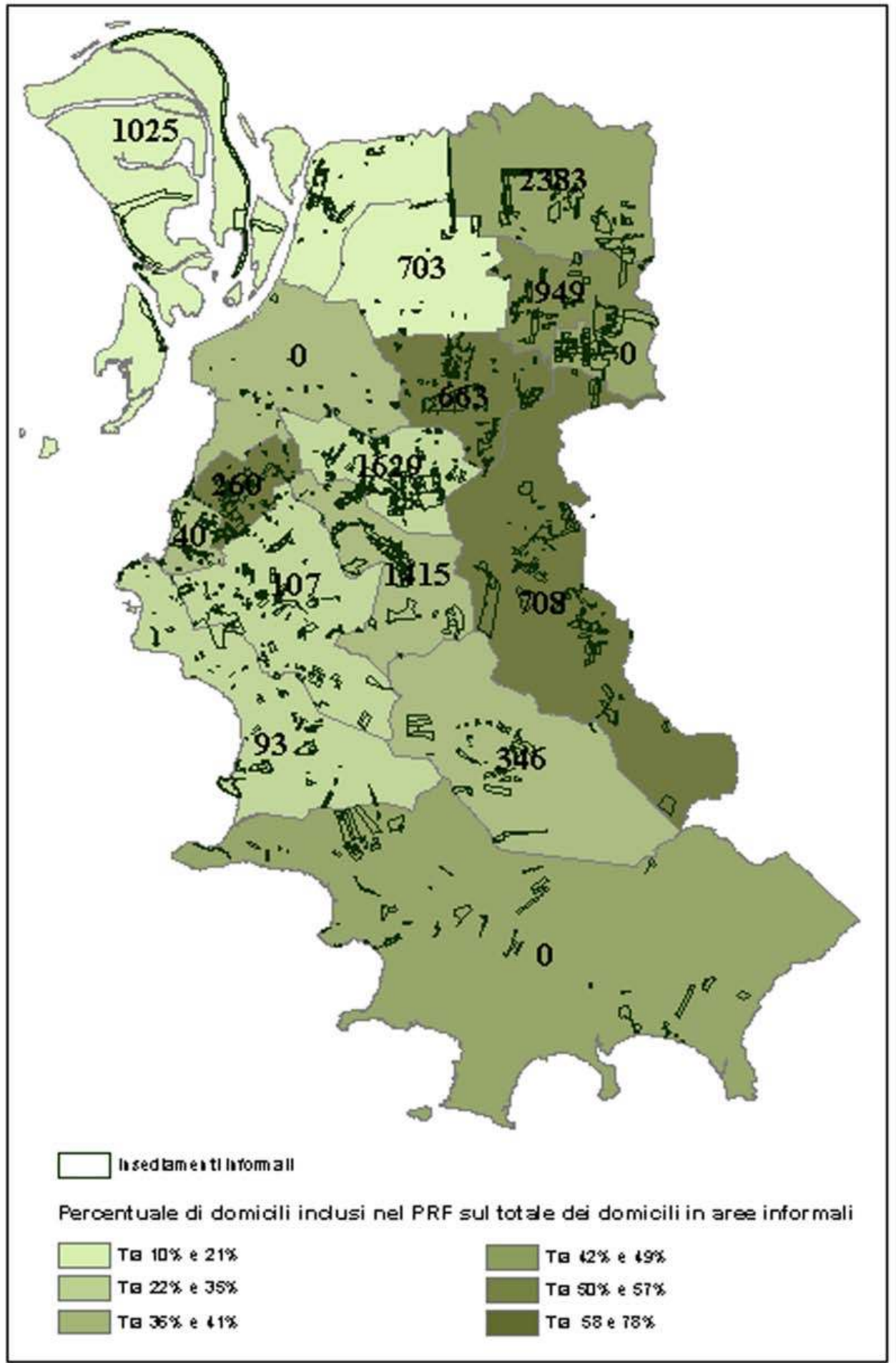

Fig. 58 - Percentuale di domicili attualmente sottoposti al Programma di Regolarizzazione Fondiaria a Porto Alegre, con indicato il numero di alloggi che si trovano in 'area di rischio', regione per regione (Dati DEMHAB, 2001). 
Fig. 59 - Un esempio del PRF a livello regionale: aree informali sottoposte al programma di Regolarizzazione Fondiaria nella zona 'Est' della città (Dati DEMHAB, 2001).

\section{PROGRAMA DE REGULARIZAÇÃo FUNDIÁRIA - PRF}
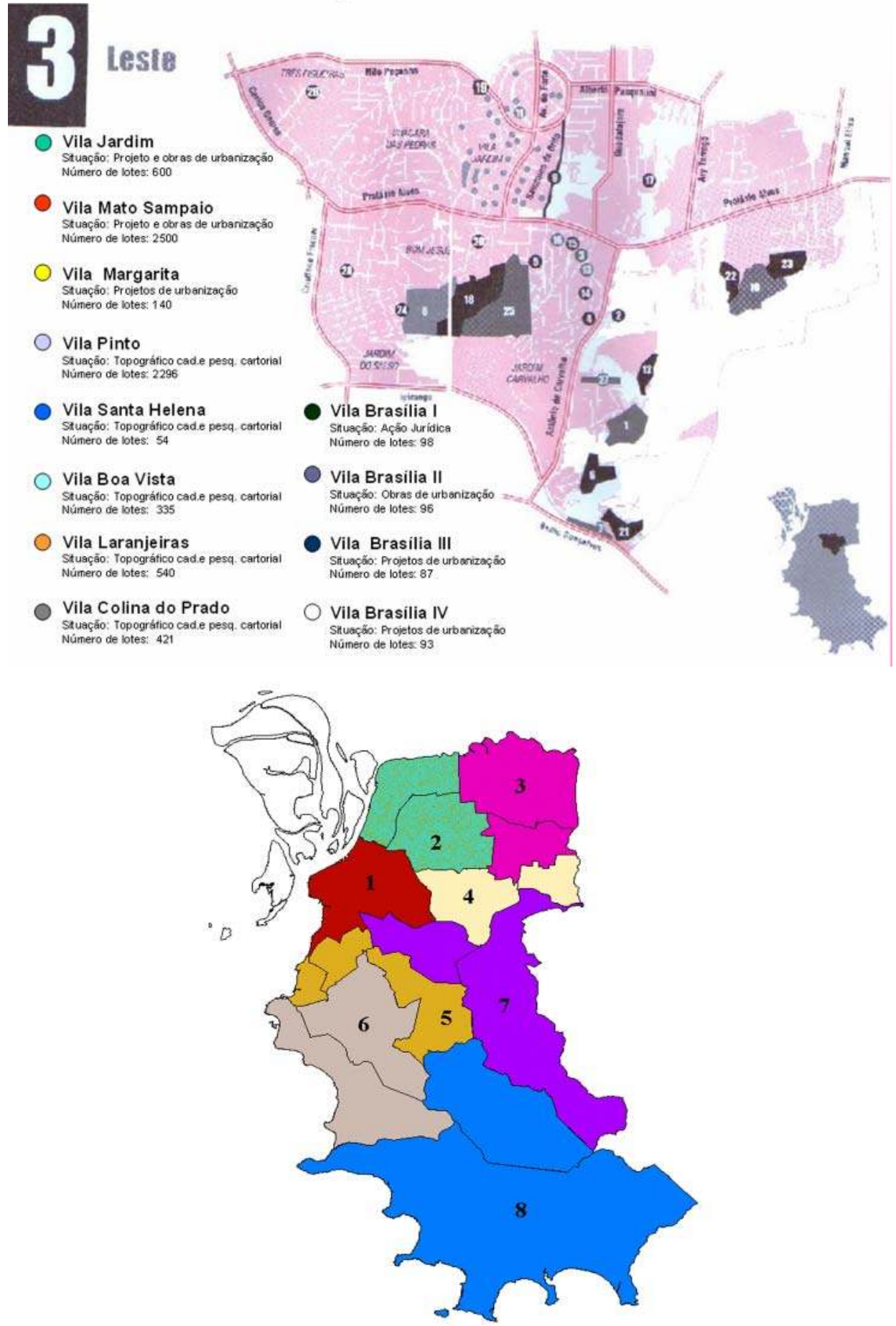

Fig. 60 - Le 8 Regioni di Pianificazione come codificate nel Piano di Sviluppo Urbano e Ambientale (PDDUA) in vigore a Porto Alegre dal marzo 2000. 
Fig. 61 - Organigramma di funzionamento del Programma di Regolarizzazione Fondiaria a Porto Alegre (2001).

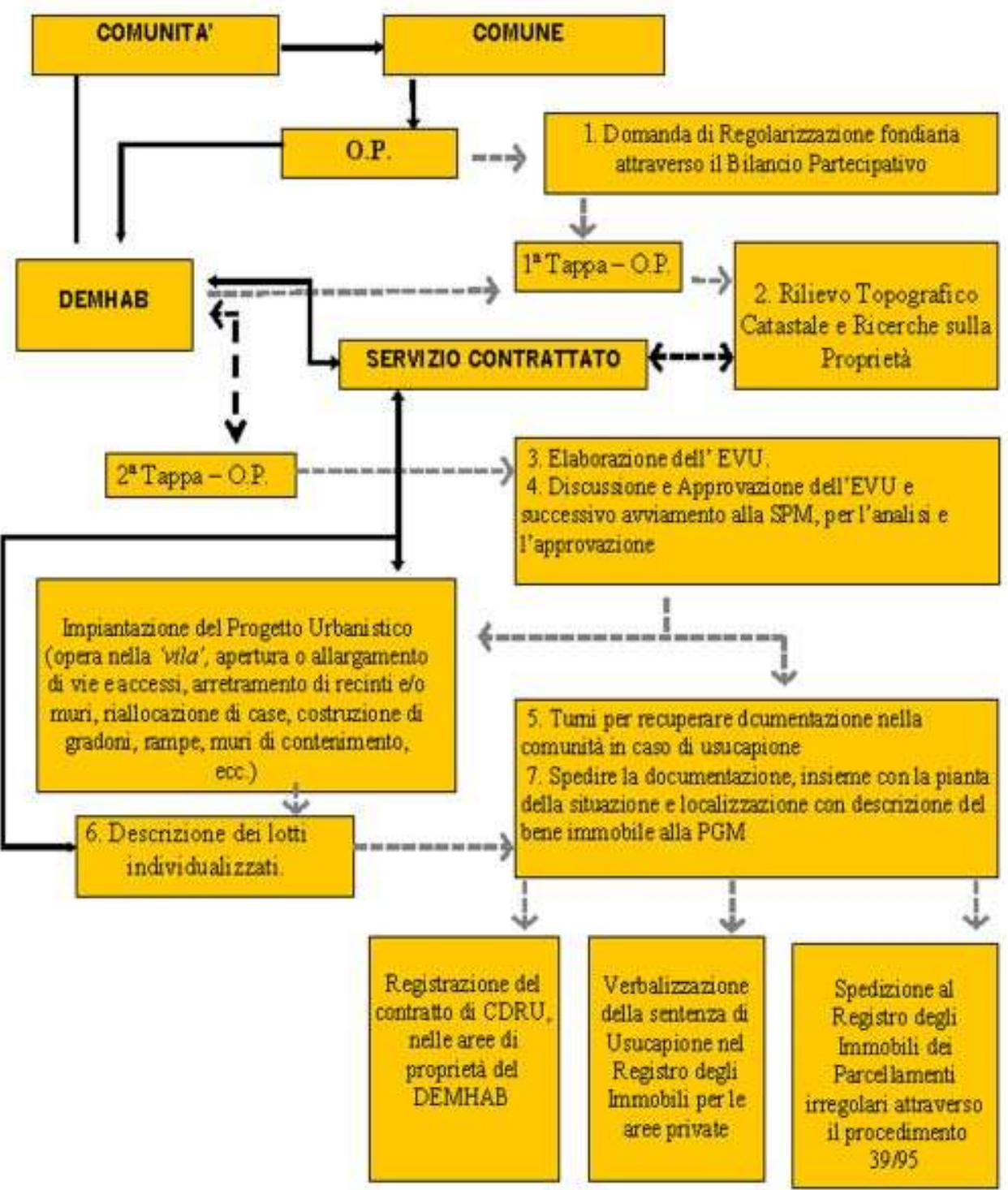


Fig. 62

\section{'Corpo a corpo'e aslattamento creativo deiprogetti}

Conversando con un sacerdote in una favela a Porto Alegre

"Il "corpo a corpo" tra popolarione e Istiturioni intomo ad un progetto reso necessario da una situarione di necessitã e finanziato nell' O.P. ẽ un po" come quando io organizzo le mie processioni in una favela intomo ad un cavallo o ad una mucca, che fungono da massa, da punto di aggregazione della processione che sennō (specie per quanto riguarda $i$ bam bini) tende a disperdersi. Io mi adatto al loro modo di vita anarchico, girovago e già adattivo. Coci nei progetti che escono da un "corpo a corpo"; almeno quelli a cui ho assistito. C"ẽ una necessitả, poi una proposta comunale ed una strategia adattiva, che genera una controproposta che non puō fare a meno di radicarsi nel modello presentato dai tecnici, e che ha una forte componente razionale. È lo stesso nelle mie pocessioni: ê chiaro che poi accade che quella mucca coi mantelli colorati e ricoperta di fíchi d'india per omamento diventa un segnale distintivo e crea imitazioni successive consolidandoci come merzo esprescivo. Ma resta il fatto che l'inizio del processo era l'adattamento ad una necessitã che ha preso un volto, ssi ẽ fissata nell "immaginario collettivo un po" come gli scenari di un film se lo vedi e solo dopo leggi il libro da cui ẽ tratto. Guarda, te lo disegno [e mi schiza con un bastoncino sul terreno Q̨uesto schema]
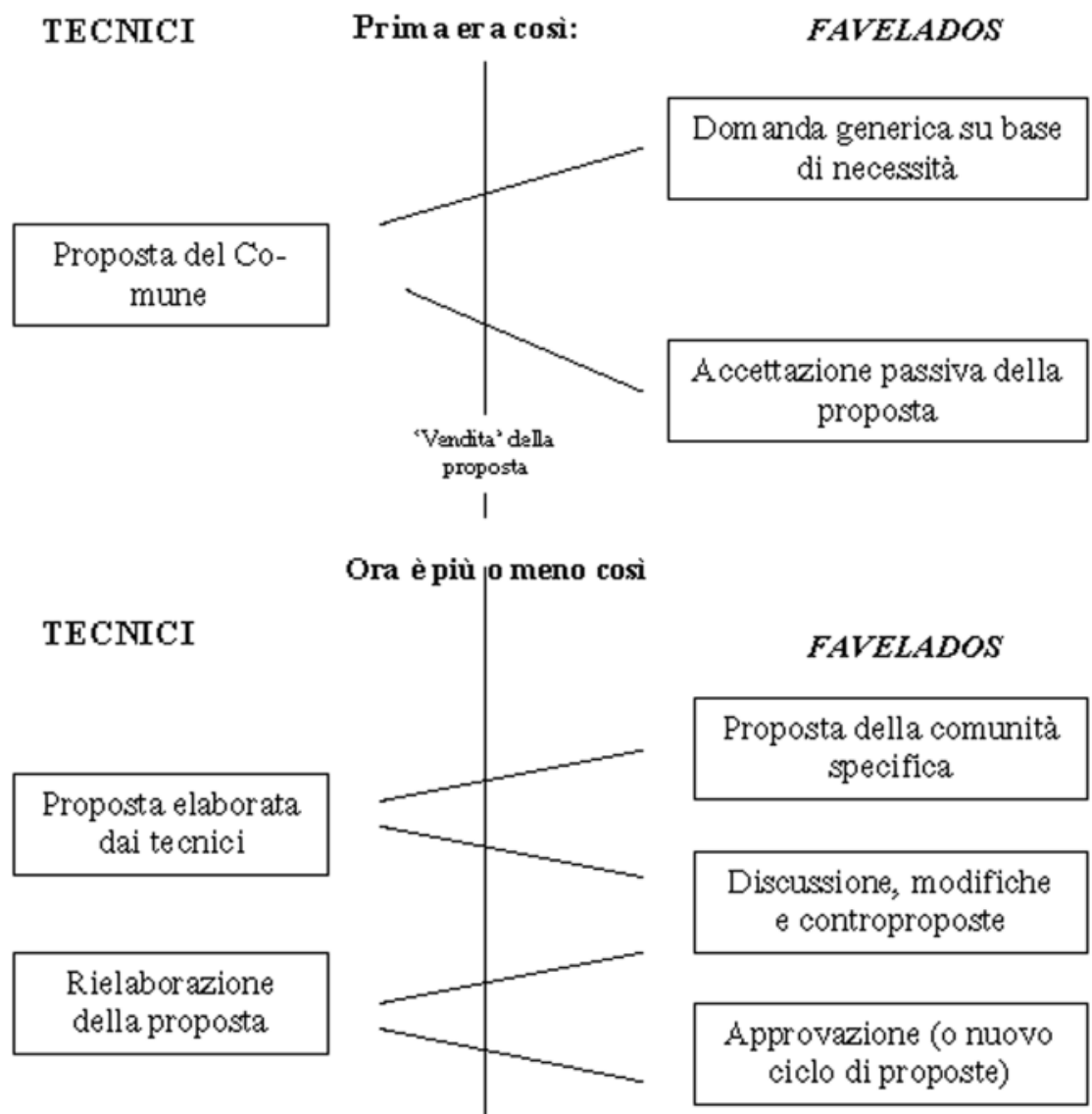

Entrambi i processi avrebbero in realtả una 'post-fazione; il processo di adattamento creativo di quanto realizzato alle nuove necessità via via insorgenti della popolazione; nel vecchio metodo questo momento diventava anarchia, oggi è spesso di minor impatto perchè anch 'esso discusso-magari in via informale - con i tecnici. In un certo senso si puō dire che l'Istituzione oggi studia 'informalmente' le formule adattive della gente e cerca di venire incontro alle necessita che celano, ma senza assumere regole físse o modelli di intervento, che creerebbero solo controreazioni. Da entrambe le parti si accelera un forte processo creativo che stimula produttivitāo e per una vol ta tende all"ordine piuttosto che al caos. Il metodo ê azione, reazione e controazione; una reciproca strategia adattiva che si traduce in un metodo di intervento, ma mai urico". 



\section{4 \\ Reintegrando la città 'ecentrica': 5 storie di luoghi in trasformazione}

\subsection{Porto Alegre letta dal mutare di alcuni luoghi}

Uno sguardo attento alla concretezza e alla materialità del territorio può costituire un duro banco di prova anche per le politiche che appaiono più innovative $\mathrm{e}$ coerenti, se giudicate sotto il profilo dell'impostazione teorica e metodologica. Leggere l'esperienza condotta a Porto Alegre negli ultimi 14 anni, attraverso il trasformarsi di alcuni suoi 'luoghi', non altera sostanzialmente il giudizio sul funzionamento e la validità concettuale del Bilancio Partecipativo o delle diverse riforme politiche che esso è andato diffondendo in altri settori della gestione cittadina; semmai ne mette in luce alcune 'fragilità' e alcune debolezze su cui è possibile lavorare ad un miglioramento.

Per questo, il presente capitolo si struttura diversamente dai precedenti, assumendo una natura più narrativa, che punta a ricostruire le vicende di alcuni spazi cittadini 'eccentrici' che in questi anni si sono trasformati in nuove 'centralità di significato' con modalità che illuminano sulle potenzialità ma anche su alcuni limiti del percorso di gestione del territorio intrapreso dall'Amministrazione Popolare di Porto Alegre in questi anni. In riferimento agli esiti di alcuni studi sul campo contenuti in Allegretti (2000a, pp. 346-359 e 405-442), racconteremo alcuni percorsi di trasformazione riconducibili all'ambito delle 'Politiche della Casa'. Seppur - in parte - si è trattato di interventi 'integrati', questo è, infatti, il settore di impegno prevalente, e perciò si è configurato un ruolo centrale per organismi comunali quali il DEMHAB e la SPM.

Non stupisca che talora abbiamo scelto degli esempi 'incompiuti' o 'incompleti', che sembrerebbero - quindi - non fare giustizia dei numerosi interventi pur felicemente portati a compimento a Porto Alegre in questi ultimi anni. La scelta non è stata, infatti, compiuta in base alla loro rappresentatività, ma piuttosto in base all'unicità dei casi. Questi sono, infatti, metodologicamente interessanti nell'arricchire gli spunti riflessivi che abbiamo cercato di stimolare in questo testo, e al contempo hanno un valore paradigmatico perché evidenziano alcuni limiti di approccio a luoghi e situazioni peculiari, che - 
472 come evidenzieranno i prossimi capitoli - alcune nuove direttrici delle politiche territoriali di Porto Alegre stanno cercando di affrontare.

\subsection{Vila Campo da Tuca: cooperazione e non-finito}

Vila Campo da Tuca si trova nella Regione Partenon del Bilancio Partecipativo, a $6 \mathrm{~km}$. a sud del centro storico di Porto Alegre: in un'area dove il PRG del '79 prevede densità residenziali tra 175 e $200 \mathrm{ab} / \mathrm{ettaro}$, ne presenta una di circa $296 \mathrm{ab} / \mathrm{ha}$. È il maggior centro pulsante della zona, ubicatosi in area collinare su terreni metà privati e metà di organi pubblici diversi (DEMHAB, Istituto pensionistico Federale) in seguito a un'occupazione avvenuta per tappe a partire dal 1966. L'ultimo censimento realizzato (METROPLAN/ GTZ, 1997), ha rilevato 3877 abitanti e 924 nuclei familiari, con una media di 4,2 membri per famiglia. Il $67 \%$ degli abitanti è originario di Porto Alegre, ed il $65 \%$ risiede in loco da oltre 5 anni, con un buon numero di famiglie che già da 40 anni vivono nell'occupazione; la partecipazione delle donne alle attività comuni è nell'ordine del $56 \%$, mentre quella maschile è del $43 \%{ }^{1}$ Fin dal nome, la favela porta il segno forte della sua storia. Inizialmente si chiamava, infatti, Vila da Tuca, in omaggio a una sarta (Tuca, che lavorava per una caserma dell'esercito sita in zona, gestendo di notte una celebre casa di appuntamenti) che ebbe un ruolo importantissimo nell'organizzazione della resistenza comunitaria e nella mediazione con la polizia durante vari tentativi di sgombero. Fin dall'inizio, la comunità si organizzò spazialmente per lasciar spazio a un campo da calcio, progressivamente divenuto il centro aggregatore. Così, il nome ibrido che la comunità si è data fonde i due poli identitari senza privilegiarne uno a detrimento dell'altro.

Da sempre piuttosto organizzata a fronte della necessità di lottare unita contro la continua minaccia di sgombero (specie a partire dalla fondazione dell'AM, nell'agosto 1978), la comunità già nel 1980 ottenne l'energia elettrica (estesa insieme all'acqua a tutta la vila tra il 1984 e il 1985) e la possibilità di costruire un asilo autogestito. La sede della AM fu costruita in mutirão, mentre dal 1982 furono organizzati un Gruppo di Giovani che faceva teatro e il Gruppo delle Donne, che cominciò una campagna per ottenere un Centro di Promozione del Minore (CPM). Nel 1985 la comunità aprì una strada (la 'Rua D') con l'aiuto di 17 agricoltori del movimento Sem Terra, rimuovendo tre case, e nel 1986 furono costruiti in mutirão un ponte e il CPM, mentre il Comune iniziò la raccolta dei rifiuti casa per casa. Dal 1989 la comunità ha cominciato a evidenziarsi all'interno dell'O.P., ottenendo l'illuminazione notturna, la rete intorno al campetto, e nel ' 93 le risorse per procedere al rilievo topografico-catastale dell'area occupata, che ha reso possibile al DEMHAB lo studio dell'EVU per procedere alla regolarizzazione fondiaria. Oggi vi è anche in atto l'organizzazione di una Cooperativa di Occupazione che cerca di negoziare l'acquisto di un'area privata di 3 medici che hanno inoltrato al tribunale una richiesta di 'reintegrazione di proprietà' contro gli occupanti.

Intanto, dal 1990, un accordo tra la METROPLAN [la Fondazione di Pianificazione Metropolitano e Regionale], il Comune di Porto Alegre e la GTZ [la Società Tedesca di Cooperazione Tecnica] aveva portato alla costituzione di 'officine di lavoro' con la comunità, orientate da una equipe tecnica, al fine di discutere ed elaborare l'EVU parallelamente alla costituzione di un Comi- 
tato di Sviluppo del Campo da Tuca, concepito come organo di aggregazione di tutte le entità comunitarie esistenti (l'AM, gli organismi religiosi, i club di donne, e la squadra calcistica del Flamenguinho). All'epoca, nell' area vi erano 4393 abitanti e 1046 case su 12,3 ettari. Non sempre le scelte approvate nelle 'officine' furono ben accolte dai residenti, a dimostrazione della concreta eventualità che i leader di quartiere possano non essere del tutto rappresentativi o che non instaurino un dialogo corretto con la comunità durante i lavori. Addirittura, per esprimere il dissenso dai loro rappresentanti su alcune scelte, fu promossa una raccolta di firme.

L'intento di questo 'pool' di intervento era di portare avanti un approccio complesso e multidisciplinare alla Regolarizzazione fondiaria, per minimizzare danni e controindicazioni di un approccio solo fisico. Al suo interno, al DEMHAB (entrato solo nel 1995) sono toccati alcuni dei lavori più puntuali di riassetto fisico, mentre il Programma PRORENDA portato avanti da GTZ e METROPLAN si è maggiormente focalizzato sull'aspetto sociale, con un Progetto di Riscatto che non escludeva però anche alcuni interventi più concreti come la costruzione di una sala di riunioni, 3 unità abitative e alcune opere di urbanizzazione e allargamento di strade e vicoli, come la celebre 'Rua I' ${ }^{2}$ che fatto strano in una vila - non ha ancora un nome, neppure dato informalmente dalla popolazione come segno di appropriazione del territorio.

A rigore - anche negli innegabili momenti di scoordinamento e contrasto avutisi tra i partner di questa operazione - è sempre rimasto almeno un approccio comune, centrato su un avvicinamento all'informale inteso quale cultura dell' interlocuzione. A volte si potrà ritenere questo approccio asistemico perché non è traducibile in un decalogo di azioni puntuali, ma esso ha una forte coerenza di fondo basata sull'ascolto del luogo e delle persone (Casa Nova, 1999i-V, a pud Allegretti, 2000a).

I fondi per concretizzare le opere di regolarizzazione fondiaria previste nell'EVU furono conquistati dalla popolazione nell'O.P. e registrate nei Piani di Investimento del 1994 e del 1995, come fondi di provenienza PróMoradia (a contropartita del 20\%) a beneficio di 570 famiglie (2.280 persone). Alcuni ritardi dovuti a problemi sulla natura e la proprietà dei suoli hanno permesso di eseguire le opere solo tra l'aprile del 1997 ed il giugno del 1998. Sulla lentezza hanno influito anche varie difficoltà nei rapporti del DEMHAB con le imprese vincitrici per l'appalto. Ben due hanno dovuto essere sostituite durante i lavori a causa della cattiva realizzazione delle opere, che ha portato alla rescissione del contratto e al rallentamento dei lavori per via della lunghezza delle procedure di subentro.

Oggi, alcune delle unità abitative di 'reassentamento' terminate per conto del DEMHAB già presentano evidenti segni di degrado fisico, dovuto alle ripetute interruzioni dei lavori. Le opere principali realizzate in questi anni si sono dovute purtroppo limitare (per problemi giuridici e di finanziamento) solo ad alcune parti della Vila. Un'ampia porzione in area di rischio, sulle ripidi pendici di un corso d'acqua trasformato in fogna, attende di conquistare il 'reassentamento' nell'O.P., mentre sull'altra riva si trova un altro insediamento chiamato Condor che insiste su un'area Federale in attesa di sdemanializzazione. Pertanto, i lavori nel Campo da Tuca per ora hanno riguardato:

1) L'allargamento della cosiddetta 'strada comunitaria', che ha richiesto la ricostruzione ex-novo di 2 alloggi e la riforma di altri 2, la creazione di un marciapie- 
474 de pubblico e l'arretramento di recinti, reti e muretti di delimitazione dei lotti. 2) La creazione di muri di contenimento del terreno nella strada in forte pendenza detta 'Rua I' e ancora priva di un nome, con realizzazione del marciapiede e arretramento di muri e recenti e costruzione di rampe di accesso ai lotti prospicienti.

3) L'allargamento della Rua Campo da Tuca, strada di accesso che ha richiesto la ricostruzione ex-novo di 3 alloggi e la riforma di altri 4, la pavimentazione di un vicolo, la creazione di due moduli sanitari e l'arretramento di recinti, reti e muretti di delimitazione dei lotti.

4) La pavimentazione della Rua Largo do Campo e di una traversa laterale, con arretramento di recinzioni e ricostruzione di 7 residenze.

5) Lavori singoli in altre vie minori

Non tutte le opere richieste dalla popolazione nell'O.P. sono state poi realizzate, dal momento che i lavori portati avanti dalla METROPLAN nella 'Rua I' hanno creato due aree di rischio a strapiombo che hanno richiesto di ricavare dai fondi già stanziati le risorse per costruire muri di contenimento. Attualmente, la comunità è pertanto mobilitata per ottenere dallo Stato e nell'O.P. comunale nuovi fondi integrativi, nonostante la conclusione in 15 mesi di opere previste come realizzabili in 4 mesi abbia provocato "una smobilitazione e discredito agli occhi dei residenti che ha coinvolto persino i leader comunitari, ottenendo come conseguenza uno scarso coinvolgimento della Commissione di accompagnamento dei Lavori, il disimpegno della comunità con le Imprese nei casi di furti di materiali, arrivandosi fino a fare minacce di morte ai funzionari della stessa [sic]" (DEMHAB, 1998c).

Vila Campo da Tuca è un luogo di forti fermenti comunitari (quasi tutti con leadership femminile) e lo era già prima del lavoro di rafforzamento dei legami solidaristici e di coordinamento fra le varie espressioni dell'unione fra abitanti, messo in atto dal Programma PRORENDA. Attualmente sono in realizzazione alcune opere intese a potenziare il lavoro sociale autorganizzato nell'area, strette intorno ai principali simboli della comunità, come il Campo del Flamenguinho, squadra di cui è in costruzione una sede sociale e da cui è partirà un programma di 'Sport e Cittadinanza' mirato al recupero di bambini di strada [laranjas $=$ arancini] coinvolti nel traffico di stupefacenti, fortemente remunerativo a motivo dell'alta competizione fra bande. Un caso raro, esemplare dello spirito di comunità della 'vila', è stata l'adesione convinta di vari membri ad una permuta di lotti per ri-alloggiare alcune famiglie costrette a spostarsi per i lavori di allargamento stradale (Casa Nova, 1999i, apud Allegretti, 2000a-VIII).

Per altri versi, però, Vila Campo da Tuca è un quartiere dove regnano violenza e individualismo. Della violenza i suoi abitanti parlano e si lamentano molto, anche se "non ammettono che altri vi facciano riferimento" (Frare, 1999i, apud Allegretti, 2000a); più volte è capitato agli architetti del DEMHAB, o ad imprese che avevano vinto appalti per lavori da realizzare nell'area, di essere salutati da scariche intimidatorie di armi da fuoco.

Per quanto concerne l'individualismo, la 'Rua I' già presenta varie abitazioni che hanno occupato lo spazio del marciapiede appena costruito, con scale, garage e persino ampliamenti delle unità di abitazione; addirittura i muri e le massicciate a gradoni di contenimento del terreno sono state usate come pericolose fondazioni per nuove costruzioni, a dispetto della raccomandazione del Comune a non costruirvi sopra. Del resto, in mancanza di controlli 
e demolizioni da parte della SMOV, che si rifiuta di intervenire su aree ancora ben lungi dall'essere legalizzate, i cittadini di questa zona esercitano il loro desiderio di possesso e appropriazione dello spazio. E non solo a detrimento degli spazi pubblici, ma anche di quelli privati dei propri vicini. ${ }^{3}$ Questo furore edificatorio avviene ai margini che separano Vila Campo da Tuca dalle aree di parcellamenti circostanti più o meno regolari, in una zona decentrata dove vivono $i$ cittadini meno integ rati alle attività comunitarie del quartiere (Frare, 1999i, apud Allegretti, 2000a), e con modi che sembrano una pericolosa imitazione della città formale contigua ma fuori da qualsiasi regola formale, come mostrano muri di $5 \mathrm{~cm}$. di spessore che reggono improvvisate residenze di 2 piani. La parte di lottizzazione 'formale' si trasforma così in pochi metri in una 'vila' di occupazione informale, recidiva ad ogni regolarizzazione.

Per le parti della 'vila' affacciate intorno ai centri focali (il campetto da calcio, l'asilo, la sala riunioni) quello dell'appropriazione dello spazio si è rivelato come un aspetto positivo, manifestatosi dopo i lavori. Vicino alla Rua Comunitaria un grosso albero è stato eletto a simbolo urbano significativo dopo che una donna ha fatto un voto a un Santo ed ogni anno deve organizzarvi intorno una festa per i bambini, ed oggi è sempre coperto di banderuole, striscioni e 'feticci' legati a feste religiose, mentre alcuni muretti sono stati riempiti da murales. Lo stesso capannone di riciclaggio del DMLU (che rientra nel programma della SMIC descritto al cap. 12) è nella Tuca molto più caratterizzato che in altre 'vilas'; affacciando su una via e non emergendo in modo visibile da uno spiazzo libero o da un angolo, è stato trasformato in un'emergenza distintiva dandogli una forma simile a quella del retro dei camion dei rifiuti, che ha anche l'utilità pratica di facilitare lo scarico e lo stoccaggio dei materiali (Frare, 1999i, apud Allegretti, 2000a-I). Tre delle casette ricostruite dal DEMHAB per ospitare famiglie che si trovavano in mezzo a strade previste dall'EVU approvato, sono state ribattezzate dai cittadini "Le tre Marie" dalla costellazione che ricorda la loro disposizione: come gli altri elementi puntuali immessi nell'area dal procedimento di recupero urbanistico sono stati trasformati per qualche via (in questo caso attraverso il linguaggio, applicato alla toponomastica che caratterizza il muoversi dei residenti nel loro habitat) in simboli ed emergenze del quartiere legalizzando. C'è anche una famiglia che non ha gradito l'ampliamento di una delle vie e ha spostato di $90^{\circ}$ il fronte principale della casa. Nel complesso, comunque, già dopo un anno dalla fine dei lavori del DEMHAB, era possibile verificare i meccanismi di autopromozione innescati dai primi lavori previsti dalla regolarizzazione fondiaria; sebbene la regolarizzazione del possesso dei lotti sia ancora lontana, gli abitanti ormai si sentono sicuri del loro diritto a rimanere sul posto, rassicurati dai lavori stradali svolti e dal 'corpo a corpo' costante con i loro referenti nel DEMHAB (tecnici e assistenti sociali). Così l'impressione che si ha visitando la Tuca è quella di lavori che fervono, con molte case in via di consolidamento in cui attorno alle strutture in legno sta venendo creato un involucro di muratura che ingloba il precedente, ma anche la chiesa cattolica senza più fedeli divenuta un garage, ed altre rapide e anomale trasformazioni d'uso.

Eppure, se gli abitnti lavorano, ufficialmente, da 2 anni, a Vila Campo da Tuca è tutto fermo: c'è un vecchio EVU in riapprovazione alla SPM (ripresentato perché gli EVU scadono ciclicamente, in mancanza di un progetto urbanistico definitivo) e gli abitanti quasi non intervengono alle riunio- 
476 ni del Bilancio Partecipativo, "quasi che un progetto di trasformazione non gli interessasse più e si accontentassero degli spazi di vita che si sono costruiti ormai nel tempo"(Casa Nova, 2002i-II). La mancanza di coordinamento fra organismi pubblici intervenuti nell'area ha creato dei piccoli 'simboli della superficialità e della disorganizzazione dei vari livelli pubblici' su cui gli abitanti della via ironizzano: ad esempio un'auto da tre anni ferma in bilico in mezzo a un pendio perché quando fu costruito il muro a retta e allargata la strada ci si dimenticò prima di farla scendere, oppure i pali della luce messi dalla CEEE statale nei 'becos' allargati dal DEMHAB non sono stati ancora spostati e si trovano nel mezzo delle strade create al loro posto, rendendone difficile l'uso ai veicoli. Molte strade non sono pavimentate per la necessità che intervenga la SMOV a seguito di una richiesta specifica dell'O.P., di cui in questo caso appare l'aspetto di 'frammentazione dei processi' che talora (dove passi molto tempo fra un intervento e l'altro sullo stesso sito) può pregiudicare parzialmente le opere, innescando processi di degrado, e non contribuendo certo a razionalizzare i lavori.

Il caso della Tuca rappresenta, però, soprattutto l'esempio di una collaborazione mancata con il Programma PRORENDA URBANO ${ }^{4}$ dotato di un'ottica convergente rispetto a quella del Comune di Porto Alegre, ispirandosi al principio dell'aiuto all'autoaiuto in aree informali urbane e in aree agricole povere. A Porto Alegre, il PRORENDA ha preso avvio nel ' 90 in 5 aree contemporaneamente, ${ }^{5}$ occupandosi di una popolazione di 46.073 abitanti. Oggi, sotto un profilo formale, la cooperazione tecnica con Porto Alegre si è chiusa, ma restano ancora numerosi i contatti, e l'appoggio offerto informalmente ai gruppi di alcune sotto-aree dove il PRORENDA è intervenuto, che si configurano come "relazioni di fiducia o affetto interpersonale createsi durante $i$ 5 anni di collaborazione" (Di Lima, 1999i, apud Allegretti, 2000a).

La forma di cooperazione messa in piedi assegnava alla GTZ un lavoro di consulenza all'entità statale, i cui tecnici consigliavano quelli municipali, in un meccanismo 'a pioggia'. Nel caso di Porto Alegre vi fu una particolarità rispetto alla prassi ora abituale; il Comune non contribuì con alcun supporto finanziario (in quel momento impensabile, non essendo stata ancora varata la riforma tributaria) e la GTZ e lo Stato si divisero al 50\% i costi dell'intervento. Pur essendo il responsabile dell'amministrazione dei 5 spazi fisici dove il programma si svolgeva, cioè, il Comune restò in secondo piano senza un'attiva partecipazione ai lavori, cosa che ha ritardato il processo di realizzazione degli stessi, costringendo i tecnici-partner dell'accordo a lavorare per 'corridoi' (fra interessati all'implementazione del programma) ma senza reale collaborazione istituzionale.

La collaborazione fattiva del DEMHAB (come istituzione) iniziò solo a partire dal $1993^{6}$ e non per garantire una continuità agli interventi nell'area, ma per gestire i finanziamenti conseguiti nel Bilancio Partecipativo dalla comunità locale. Da questa non-collaborazione ne è uscito sconfitto soprattutto il Progetto di Sviluppo Locale Integrato che era composto da un Piano Urbanistico (discusso e approvato dalla popolazione nel '92) e da uno di Sviluppo Sociale (concluso nel 1994) con uno stretto raggio di azione 'orizzontale', ma un forte radicamento 'verticale' nel territorio per orientare le azioni comunitarie autogestite. I due strumenti, il cui scopo era supportare un lavoro mirato "all'esercizio dell'autogestione e del diritto di cittadinanza" 
(METROPLAN/GTZ, 1997), cercavano di coniugare "sapere scientifico $e$ sapere popolare" attraverso lo strumento delle officine di lavoro (in particolare di quella denominata ZOPP5) ispirate al testo tedesco di Jungk e Mullert 'Officine del futuro' del 1973, che proponeva un metodo di pianificazione democratica basata sull'apprendere facendo e suddivisa in fase critica, fase utopica, fase della realizzazione e fase post-officinale. Ciò che nel Programma PRORENDA appariva una novità, rispetto alle azioni che nello stesso periodo l'Amministrazione Popolare di Porto Alegre metteva in atto per proprio conto con analoghi obiettivi, era:

1) l'attenzione prestata al contesto fisico in parallelo a quello sociale. Se si confrontano i progetti del neonato PRF con quello PRORENDA, l'approccio dei primi agli aspetti spaziali e territoriali appare semplificato, sacrificato in rapporto alle urgenze di natura sociale.

2) l'adozione di un metodo di lavoro partecipativo scientificamente fondato e diffuso a vari tecnici del Comune (SPM e DEMHAB) in forma di seminari formativi organizzati dalla GTZ, che lavora con metodi analoghi in vari paesi.

In consonanza con l'approccio più 'intuitivo' usato dal Comune di Porto Alegre, l'idea di partecipazione nei processi di trasformazione urbanistica non era ridotta a semplice 'pacificazione' dei processi decisionali ma intesa come "percorso educativo di coscientizzazione, molto più ampio, che richiede la reintegrazione, nell'essere umano, dei concetti di "diritti" e "responsabilità", perduti o soppressi in "altri anni” (METROPLAN/GTZ, 1997). Ma, nel PRORENDA, ogni atto e verbale di assemblea veniva registrato; si cercava di formalizzare ogni scambio di opinioni in un accordo. In questo, il tipo di partecipazione messa in atto nei progetti portava - soprattutto nel 1990 - il segno di una tradizione partecipativa europea più formalmente ingabbiata da ruoli stabili e da documenti scritti di pronunciamento delle opinioni, mirati ad eliminare ogni dubbio in caso di incomprensioni o contese. Fu anche installato un 'collegio', istanza decisionale massima dei progetti anche sotto il profilo economico, che riuniva rappresentanti dei vari partner e metteva ogni scelta in dettaglio su carta, distribuendo poi il materiale a tutti.

I due piani di lavoro, nell'approccio del PRORENDA, tendevano ad intersecarsi e arricchirsi a vicenda: parallelamente al lavoro propedeutico di creazione di Comitati locali di residenti, gli stagisti operanti all'interno del Progetto condussero, infatti, una serie di analisi fisiche, e di rilievi dei materiali e dei percorsi più usati mirati a rilevare il grado di consolidamento di ogni 'vila', le aree più problematiche e di 'minor investimento', come anche $\mathrm{i}$ percorsi e l'articolazione dei centri vitali del quartiere: in una parola la distribuzione della mobilità (anche abitativa) "che costituisce il tratto distintivo della città informale rispetto a quella formale" (Di Lima, 1999i, apud Allegretti, 2000a). Parallelamente al processo di costruzione dell'EVU urbanistico (che durò 6 mesi e fu alterato per esigenze del DEMHAB relative alle larghezze stradali), la comunità chiese di promuovere una richiesta per essere considerata AEIS, un concetto che nel 1993 era ancora da discutere e chiarire, ma che accese le speranze di un trattamento 'facilitato' rispetto al resto della città. Proprio considerando questa eventualità, i tecnici della METROPLAN/GTZ si concentrarono a studiare le relazioni del quartiere con l'intorno, e il raggio di influenza possibile dei servizi interni ed esterni alla Vila, per verificare la necessità o meno di accogliere tutte le richieste presen- 
478 tate in seno alla comunità e apparentemente mirate a conquistare l'autosufficienza (e quasi l'autarchia) del loro quartiere. In particolare lo rese necessario l'osservazione che molti 'vileiros' intendevano la formalizzazione come duplicazione piuttosto che come integrazione delle strutture di uso comune.

Dal costante contatto con la popolazione ci sorse il dubbio che vi fosse in atto un processo di autoesclusione dalla città simmetrico a quello di esclusione che per decenni la città aveva messo in atto contro le 'vilas'. Ovvero, arrivando ad un rapporto con le Istituzioni più equilibrato e armonico, scattava nei 'vileiros' quasi un desiderio di appropriazione della città. Come se volessero portarne tutti i benefici 'dentro' i loro ambiti di vita. Questo a noi sembrava pericoloso. Perché creare una nuova scuola se basta parlare con la direttrice di quella del quartiere vicino e aumentare il numero di posti? Per questo realizzammo alcune tavole da esporre alla popolazione dove mostravamo l'ubicazione dei servizi esterni (Centri di Salute, scuole, supermercati, uffici pubblici), e con dei cerchi rappresentavamo il raggio di influenza previsto ufficialmente per certe attrezzature, considerando più $\mathrm{o}$ meno anche $\mathrm{i}$ caratteri dell'area che ha una grande pendenza che certo è un fattore squilibrante per l'accesso ai servizi esterni di chi vive più lontano dalla parte formale di città. Mi resi conto che nei primi anni l'O.P. aveva questo difetto: le persone chiedevano e - dopo la discussione - l'O.P. dava ad alcuni quanto richiesto. Le richieste si orientavano così verso servizi utili, ma forse innecessari per quell'area, ridondanti. Ci chiedemmo se era pigrizia. Alla fine capimmo che c'era ancora una 'bar riera invisibile' che separava città formale informale e non permetteva ai vileiros di compartire con gli altri certi servizi, e viceversa. Questo ci ha indurito nel non concedere realizzazioni che ritenevamo inutili, e ci ha fatto capire che col dialogo dovevamo invertire la situazione (Di Lima, 1999i, apud Allegretti, 2000a).

Il lavoro realizzato nell'ambito del Programma PRORENDA avrebbe potuto rappresentare un interessante punto di partenza per i nuovi interventi finanziati dall'O.P. che il DEMHAB doveva realizzare dal 1994. Soprattutto avrebbe potuto essere una buona guida metodologica.

Invece, i diversi progetti dispersero il loro 'potenziale integrativo' in sequenze di lavoro frammentate temporalmente e sostanzialmente disinteressate l'una al lavoro dell'altro. Solo oggi, l'approccio metodologico del PRORENDA pare far breccia in alcuni organismi del Comune di Porto Alegre, filtrando però attraverso singoli 'tecnici', nonostante per 5 anni l'Amministrazione Popolare abbia avuto un potenziale collaboratore a lavorare sul suo territorio con obiettivi e modalità analoghe: un caso di collaborazione mancata e di scoordinamento istituzionale che può soprattutto attribuirsi alla rivalità tra Stato e Comune, guidati da maggioranze politiche antagoniste, "come in altri ambiti dove la GTZ opera" (Lange, ibidem).

\subsection{Rubem Berta: tra eterostrutturazione ed autoproduzione degli spazi abitati}

Il nome di Rubem Berta (fondatore della compagnia aerea Varig) designa oggi due aree cittadine di dimensione molto diversa, la più grande delle quali ha preso il nome dalla minore, secondo un processo di 'traslazione di scala' non raro nel territorio di frangia. Storicamente, infatti, il primo insediamento chiamato Rubem Berta - situato nella zona nord di Porto Alegre - è stato quello più piccolo: un enorme condominio popolare ${ }^{7}$ detto ${ }^{\prime} \mathrm{COHAB}$ Rubem Berta' perché pianificato all'inizio degli anni ' 80 sulla base di un 
progetto-tipo dei burocrati della Banca Nazionale dell'Abitazione di cui la Compagnia Statale di Abitazione del Rio Grande do Sul (COHAB) rappresentava un esecutore periferico.

Costruito su un terreno della COHAB/RS di $563.689 \mathrm{mq}$, il quartiere-dormitorio doveva dare alloggio a oltre 20.000 persone in 4992 appartamenti distribuiti in 39 nuclei da 128 famiglie (detti ' le palle'), ognuno dei quali costituito da una torre di 4 blocchi di edifici in linea di 4 piani con 32 appartamenti senza ascensore. Segnato da un'iperdotazione di strade, il megacondominio prevedeva anche alcuni servizi minimi assolutamente sottostimati: una scuola, un centro comunitario, un posto di polizia e un centro medico, aree verdi e sportive, piccoli parcheggi, alcuni centri culturali nelle unità di vicinato e 5 piccoli nuclei di negozi, pensati come 'sfogo al commercio' piuttosto che come 'servizio al cittadino' o 'fonte di sussistenza' per le famiglie insediate. All'epoca, tra l'altro, l'area circostante (anticamente occupata da ampie aziende agricole) era un grande deserto circondato da vuoti urbani lasciati a lungo a 'dormire' per fini speculativi. Così, non potendo attingere alla strutturazione dei tessuti circostanti, la forma scelta dall'architetto Nadruz per l'impianto urbanistico si rifece ad alcuni quartieri-giardino degli anni ' 40 posti a sudovest di Rubem Berta: per stemperare la rigidità degli schemi abitativi, un'intellettualistica forma 'organica' riprodusse il modello del Grosssiedlung Britz berlinese ${ }^{8}$ con un grande anello stradale a ferro di cavallo in pendenza, ai lati del quale si attestavano 39 nuclei di alloggi annegati in un 15\% di area da sistemare a verde, inclusa una piazza con una piccola laguna. Attorno, nacque poco dopo un altro quartiere popolare - destinato a categorie di reddito un po' più alte - chiamato Jardim Leopoldina: una rigida scacchiera di isolati e strade rettilinee in forma di controcanto visivo di Rubem Berta. Negli anni '90 sorgeranno altri due quartieri disordinati di edilizia semispontanea (Wenceslau Fontoura e Timbauva) su tracciati urbanistici regolari per lotti tipo Sites \& Services.

L'evoluzione storica degli insediamenti intorno al COHAB Rubem Berta spiega perché il suo nome passò presto a designare anche la 'Grande Rubem Berta', ovvero tutto il vasto quartiere al suo intorno che conta oggi oltre 79.000 abitanti, si estende su oltre $8,82 \mathrm{Kmq}$ - a circa $18 \mathrm{Km}$ dal centro storico di Porto Alegre. Attualmente, però, il nome di Grande Rubem Berta non è sostanzialmente riconosciuto dalle varie comunità che abitano il suo territorio, e resta una sorta di 'astrazione geografica', di fatto inesistente al di fuori della cartografia ufficiale del Comune.

Rubem Berta si ubica nella Regione 'Eixo Baltazar' del Bilancio Partecipativo che ha assunto gli attuali confini solo nel 1995, in seguito alla scissione della ex-regione 'Noroeste'. Esso unisce aspetti di estrema rappresentatività della situazione di altri quartieri ad altri di unicità; e - soprattutto - intreccia insieme un percorso di degrado urbano progressivo e accelerato ed uno di riscatto di tipo 'virtuoso' che oggi pare essersi dotato degli strumenti necessari per riuscire a prendere il sopravvento sul primo, seppur con rallentamenti e contraddizioni. Concepito come progetto integrato nell'ultima fase di vita della Banca Nazionale dell'Abitazione (in cui si compravano 'a pacchetto' da imprese private interi quartieri, per ridurre al contempo i costi per l'ente pubblico e i guadagni per l'impresa) l'insediamento COHAB venne a trovarsi in una situazione simile a quelle che nell'est europeo sono icasticamente definite 'bombe a orologeria', quartieri dove la manutenzione finiva per legarsi a doppio 
480 filo con le imprese che ne avevano prodotto i componenti costruttivi e - alla scomparsa di queste - rischiava di subire solo forme inarrestabili di degrado. Sorta di mostruoso modellino in scala naturale (Rigatti, 1997), ${ }^{9}$ il quartiere è nato in un quadro di interventi del tutto disinteressato ad aspetti qualitativi, morfologici e di rispetto delle specificità degli ambiti locali. La realizzazione fu inoltre segnata dalla difficoltà di mantenere i ritmi impartiti ai lavori, interrotti più volte da vari impasse, soprattutto in coincidenza con il fallimento della Banca Nazionale dell'Abitazione e il passaggio di gestione alla Compagnia Statale. Così, nel novembre 1985 appena 10 dei suoi nuclei (1280 appartamenti), isolati da una strada nella zona nord, erano terminati, e dovettero essere commercializzati in tutta fretta, sotto la minaccia di occupazione da parte di molti dei 12.916 iscritti nelle liste di attesa. Non poterono però essere registrati al catasto, essendo il condominio un forma giuridica che non ammetteva suddivisioni di lotti ma solo la regolarizzazione dell'intero nucleo, ancora ben lontano dalla conclusione visto che la costruzione dei 3712 appartamenti restanti restava paralizzata dal 1984.

Gli altri 29 nuclei (ancora inconclusi, a causa delle richieste di aggiustamenti economici da parte dell'impresa realizzatrice e del ritiro della Caixa Econômica Federal dal coinvolgimento nell'opera) vennero occupati il 21 aprile 1987, nell'ambito di una grossa ondata di occupazioni dimostrative che toccò l'intera area metropolitana di Porto Alegre (cfr. box 3).

La divisione ineguale degli spazi e l'eccesso di aree libere non strutturate grosso errore strategico per un'area a destinazione popolare - innescò complessi processi di appropriazione privata. In assenza di chiari confini fisici, gli stessi spazi previsti come 'condominiali' nei 39 nuclei furono progressivamente colonizzati, e si ebbe un consistente aumento della popolazione, stimabile oggi in circa 35.000 persone. A loro volta, i materiali di costruzione (blocchi di cemento espanso) fecero sì che le alterazioni a strutture venissero spesso portate avanti a pregiudizio della sicurezza statica; mentre l'eccesso di assorbimento del calore costrinse molti residenti a rivestire esternamente le strutture. Il progetto iniziale ha così inglobato molte modifiche spaziali apportate dagli abitanti, la cui posizione si è cercato poi di regolarizzare negoziando specifici doveri contrattuali per le famiglie residenti in cambio della conclusione dei lavori. Oggi, Rubem Berta - con la sua mescolanza di aree formali e informali in un unico quartiere occupato - costituisce un esempio 'virtuoso'ma 'imperfetto' di Regolarizzazione Fondiaria. La vicenda delle sue trasformazioni recenti si impernia, infatti, su scoordinamenti, inefficienze e diatribe fra enti pubblici oltre che su una popolazione sostanzialmente addormentata ${ }^{10}$ e restia ad abbandonare le antiche pratiche clientelari sperimentate nel lungo rapporto diretto soprattutto con l'Amministrazione Statale. Al contempo è però il racconto di un lento 'risveglio' parallelo delle istituzioni e dei cittadini che ha trovato nel Bilancio Partecipativo lo stimolo ad un nuovo rapporto fra i due, incentrato su una maggiore complessità degli scambi. La storia di Rubem Berta illumina, quindi, di speranza sulla possibilità di capovolgere in positivo (anche sotto il profilo del controllo dello spazio) processi che paiono inarrestabili, trasformando in 'luogo centrale' una periferia cittadina che sembra 'lasciarsi accadere'. Inoltre, illustra la possibilità di una sinergia tra forze diverse e di una 'convergenza operativa' fra amministratori e tecnici, in un tentativo di intervenire sulla città informale non solo a partire da operazioni puntuali, ma 
muovendo da un progetto globale e coerente a cui ancorare le specifiche conquiste ottenute dalla popolazione attraverso il Bilancio Partecipativo.

Della lunga vicenda di battaglie degli occupanti del quartiere per ottenere il diritto ai servizi urbani e alla regolarizzazione (oggetto di una circostanziata ricostruzione in Allegretti, 2002c), ci interessa in realtà un passaggio particolare, che è successivo alle prime singole conquiste ottenute dagli abitanti, prima per mano dello Stato del Rio Grande do Sul (proprietario dell'area e degli edifici popolari) e poi del Comune di Porto Alegre, ma precede le prime 'conquiste' di fondi nel Bilancio Partecipativo. Queste arriveranno solo nel '96, dopo 5 anni di crescente partecipazione alle assemblee da parte della popolazione locale, e dopo aver formalmente ottenuto dall' Assessorato all'Urbanistica del Comune un programma coerente in cui reinserire le diverse richieste puntuali, a partire dall'impegno alla regolarizzazione urbanistica e amministrativa del complesso e a una sua ridefinizione come 'lottizzazione', che permettesse perlomeno di pervenire ad un'attribuzione delle responsabilità pubbliche e private sull'area.

Il 'cambio di paradigma' nelle modalità di trasformazione del vecchio megacondominio data al 1993, e si lega ad un progetto urbanistico pilota di grande respiro: il Progetto 'Centro de Bairro' nell'area Jardim Leopoldina, con cui il Comune mirava a scoprire e valorizzare nuove centralità all'interno del corpo urbano, stimolando soprattutto la riqualificazione degli spazi ad uso pubblico e la legalizzazione di aree informali. Il programma della SPM aveva un triplo obiettivo strategico: 1) dare avvio al rimodellamento di alcuni quartieri a partire da progetti strutturati, aggregando ad essi le domande puntuali presentate dalla popolazione nel Bilancio Partecipativo; 2) costruire un'interfaccia tra Assessorati e all'interno della stessa SPM, 15 dei cui funzionari partecipavano a delle 'Oficinas' per definire proposte di valore politico da discutere con la cittadinanza interessata; 3) creare per i tecnici un'occasione di rapporto più stretto con la società civile e di crescita professionale, attraverso convegni e seminari.

Il Laboratorio Jardim Leopoldina, dedicandosi alla costruzione delle interfacce con i quartieri contigui, finì per deviare la sua attenzione sull' area invasa di Rubem Berta, ridirezionando il suo fuoco "proprio a partire dalle situazioni di maggior urgenza e indeterminatezza [...] e dalle questioni di morfologia legate alla relazione ancora sfilacciata con il resto della città" (Turkienicz, 1999i, apud Allegretti 2000a). Essendo la struttura di Rubem Berta una sorta di 'oasi' nella maglia urbana, fu messo in discussione come ricostruirne il tessuto per integrarlo con le altre 'città artificiali' dalle forme più regolari, al punto che le 'Oficinas' realizzate con la popolazione finirono per incentrarsi sulla riorganizzazione della maglia stradale e del sistema del commercio informale che intanto era andato 'esplodendo', per garantire agli abitanti sia dei servizi proporzionati al loro numero che delle fonti di sopravvivenza economica.

Mentre cercavamo una soluzione al problema degli ambulanti, divenne evidente che uno degli aspetti maggiormente benefici dell'occupazione era stato proprio il fiorire - pur disordinato - del commercio-fonte di sopravvivenza, contro la logica del progetto originario di commercio-servizio minimo concentrato in 5 piccole aree di risulta. In fondo il commercio, attestandosi sui margini stradali e in qualsiasi luogo costituisse un angolo o una emergenza, inserì una logica di continuità spaziale tipica delle occupazioni spontanee in un'area rarefatta (oltre che non conclusa) 
abbastanza caratteristica della logica modernista. Per certi versi anche l'occupazione spontanea mostrava dei margini qualitativi - in certi momenti maggiori del progetto della $\mathrm{COHAB}$ - consistenti nella logica più 'umana' che introduceva nel quartiere, mettendo in relazione commercio e servizi (come gli asili comunitari) con le linee di tensione create dai tragitti pedonali e dei pochi veicoli lungo i percorsi casa/scuola/fermate dei bus (Mallmann, in Alle gretti, 2000).

Il progetto di regolarizzazione fondiaria che andò ad affiancarsi al Centro de Bairro cercò di proiettare sul quartiere una razionalità ordinatrice ma non impositiva che riconfigurasse gli spazi senza abbandonare la logica organizzativa interna alla mercè degli utenti, né ridurre il recupero urbanistico al consolidamento dei tracciati informali, dimenticando di armonizzarlo con le necessità di ordine pubblico (raccolta dei rifiuti, scoli pluviali, passaggio ambulanze, possibilità di manovra per le auto e recupero di spazi comuni, a parte il campo da calcio già salvaguardato come spazio libero dagli abitanti del quartiere). Quello che si avviò fu un processo di Regolarizzazione fondiaria raro nel panorama portoalegrense, sia perché il progetto prese avvio 'dall'alto' - seppur sulla base di pressioni popolari (solo raramente convogliate nella sede dell'O.P.) - sia perché nacque come parte di un progetto strutturato a più vasto raggio (e non 'puntuale') di forte valenza urbanistica. Anche per queste caratteristiche, fu uno dei pochissimi progetti di regolarizzazione fondiaria di Porto Alegre non affidato al DEMHAB ma alla SPM.

La collaborazione con l'Università Federale del Rio Grande do Sul ha dato al progetto di regolarizzazione fondiaria di Rubem Berta un carattere più 'sistematico' di altri sotto il profilo dello sviluppo metodologico, per certi versi più simile a quelli del PRORENDA che non a quelli direttamente operati dal solo Comune di Porto Alegre. Vennero così realizzate mappe percettive, mappe di analisi dei flussi quotidiani pedonali e veicolari per capirne e rispettarne le logiche, e studi sul livello di consolidamento delle aree pubbliche e condominiali occupate da costruzioni irregolari attraverso gli 'indicatori' costituiti dai materiali costruttivi. Ciò che - forse - si perse per strada, fu soprattutto la possibilità di valorizzare e coordinarsi con i vari studi comparati di 'percezione ambientale' (Reis, 1997) o 'sintassi urbana' (Rigatti, 1997) che singoli docenti universitari andavano conducendo - per conto proprio - su Rubem Berta, ormai divenuto quartiere-laboratorio per l'interessante campionario di interventi spontanei di colonizzazione dello spazio innestatisi su una base 'razionalmente programmata', secondo modalità individuali-emulative (cfr. § 13.6 in Allegretti, 2000a). Gli studi realizzati nella fase di pre-indagine evidenziarono la possibilità di ovviare alla mancanza di segnali urbani riconoscibili, intervenendo sull'uso dei colori delle costruzioni e su alcuni spazi non occupati per ridiscutere la stessa desolante logica di indifferenza spaziale alla base dell'originario progetto, ricostruendo le interfacce e le comunicazioni tra i diversi nuclei abitati collocatisi nell'area verso la fine degli anni '80, fino ad allora solo in guisa di "insieme di parti giustapposte che necessitano di una serie di azioni mirate alla loro integrazione (SPM, 1993, op. cit.). Attraverso il censimento delle 47 associazioni comunitarie e dell' "ipertrofia delle reti commerciali di rifornimento di base tipica della periferia" (ibidem), il 'Centro de bairro' cercò di individuare i referenti con cui dialogare, di definire il grado di 'animazione' delle diverse aree e di individuare i deficit sentiti dai residenti in termini di attrezzature, servizi, razionalizzazione della mobilità. 
Un gruppo informale di regolarizzazione fondiaria che riuniva DEMHAB, COHAB e SPM si formalizzò nel 1994 nel Gruppo di Lavoro interdisciplinare 'GT Rubem Berta' per rispondere alle richieste degli abitanti con un interventi integrati che operassero al contempo sui temi dell'alloggio, del lavoro, del commercio, dei servizi e dell'assistenza sociale. Fu fatto un censimento puntuale delle 1.984 costruzioni irregolari nate a seguito dell'occupazione ad oggi, accresciutesi almeno del $10 \%$ nonostante il rilievo dovesse 'congelare' la situazione in vista della regolarizzazione fondiaria ${ }^{11}$ - e, soprattutto, furono censiti alcuni aggregati di baracche sorti sulle aree libere di dimensioni maggiori, spesso ubicate in area di rischio (come Vila Recanto da Lagoa, costruita su palafitte nell'area del laghetto ricreativo previsto dal progetto originario) Sulla base del censimento la SPM e l'Università elaborarono una bozza di Direttrice per il Parcellamento del Suolo in un'Officina di lavoro montata negli ultimi mesi del 1994, approfittando di un accordo tra Comune e Stato siglato per risolvere - su forte pressione degli abitanti - il contenzioso di competenze sull'area che per quasi 7 anni aveva bloccato ogni intervento a Rubem Berta. Nell'accordo, la comunità assunse un ruolo preponderante e decisivo, tanto che accanto alla firma del Sindaco di Porto Alegre e del liquidatore della $\mathrm{COHAB}$ (che nel frattempo si era avviata alla chiusura) appaiono ben 11 firme di rappresentanti comunitari (cfr. Allegretti, 2002a). Nel 1995, la bozza fu ridiscussa e trasformata insieme alla popolazione nell'ambito di un processo mirato ad una 'pianificazione partecipata', in 57 Oficinas de Trabalho organizzate nella scuola Grande Oriente ${ }^{12}$ per far sì che la comunità riconoscesse e capisse la necessità di una pianificazione globale, e "il Comune con il suo "Bilancio Partecipativo" non accogliesse più sollecitazioni di azioni puntuali ma solo rivendicazioni in accordo con le priorità elencate nel Progetto Urbanistico" (GT Rubem Berta/PMPA, 1999). Furono proprio i rappresentanti popolari dell'epoca a dirsi convinti della necessità di 'svegliare le coscienze' a partire da proposte di rottura che suscitassero la discussione. In realtà - per motivazioni di fattibilità economica - alla fine fu scelto un 'basso profilo', seppur accresciuto in prospettiva da alcune proposte più audaci della cui difficoltà di finanziamento gli stessi tecnici ebbero fin da subito coscienza.

Attraverso modellini 3D, kit di simulazione in scala 1:200 sui singoli blocchi costruiti e il semplice linguaggio del giornaletto Rubem Berta informativo, $\mathrm{i}$ tecnici del GT evidenziarono quali edifici 'irregolari' erano nati sulle reti di urbanizzazione e potevano costituire un pericolo per la salute degli abitanti, e riuscirono a far capire progressivamente agli intervenuti la necessità di approvare rapidamente un progetto globale di regolarizzazione fondiaria e recupero urbanistico che desse a tutti 'sicurezza' sui propri diritti. Nel corso dei laboratori, furono gli stessi abitanti a 'segnare il tempo' del dibattito, decidendo quando era opportuno porre fine alla discussione con i modellini e passare alla 'carta', un supporto bidimensionale più difficile da leggere ma legato - nell'immaginario comune - al percorso burocratico 'reale' di ogni progetto.

Il processo dialogico fece emergere spunti progettuali e gestionali importanti, spiegando - attraverso le voci degli abitanti - alcuni processi spontanei di costruzione dello spazio susseguenti all'occupazione, ed evidenziando una serie di tensioni sociali che - se non tenute in giusto conto - avrebbero potuto inficiare il progetto urbanistico allo studio. A distanza di anni, i giudizi dei rappresentanti della comunità di Rubem Berta (inclusi quelli che professano 
484 pubblicamente fedi politiche opposte all'amministrazione in carica) è pressoché unanime circa la democraticità del processo di 'progettazione partecipata' messo in atto, così come sull'utilità dello strumento del Bilancio Partecipativo come stimolo ad una maggior coesione della comunità.

Va però notato che, sotto il profilo metodologico, né il Comune nello Stato si mostrarono interessati a mettere alla prova particolari saperi specifici sul tema dei 'progetti partecipati'; fu pertanto solo casuale se sia l'architetto Mallmann della SPM che l'architetto Turkienicz dell'Università (UFRGS) avessero una precedente formazione in materia di partecipazione dei beneficiari ai progetti.

Il Progetto di fattibilità urbanistica (EVU) - approvato dal Comune il 16/10/ 98 poco dopo l'individuazione ufficiale del quartiere COHAB Rubem Berta come AEIS ${ }^{13}$ - fu ridiscusso - nucleo per nucleo - tra marzo e agosto ' $99,{ }^{14}$ con una popolazione in larga parte diversa da quella originariamente ascoltata, anche a motivo della rapidissima turnazione che caratterizza gli abitanti di un complesso edilizio troppo rigido e disastrato per soddisfare facilmente le esigenze di famiglie in rapida espansione e in costante mobilità sociale. Il risultato, diversissimo da quello concepito all'inizio degli anni ' 80 , ha preso spunto proprio dalle indicazioni che l'autorganizzazione degli occupanti ha fornito nel tempo, con rapide trasformazioni dell'organismo territoriale che nel '96 hanno reso necessario agli abitanti lottare in sede di Bilancio Partecipativo per ottenere un finanziamento destinato ad un contratto di prestazione di servizio per realizzare un nuovo rilievo topografico/catastale. Alla fine, il $58,10 \%$ dell'area è stata destinata agli edifici condominiali e loro pertinenze (ridotte di dimensione per facilitarne la manutenzione e l'appropriazione da parte dei residenti), un 14,57\% per piazze e attrezzature comuni e scolastiche, e un 27,33\% alla viabilità. Si sono anche previsti 11 nuovi edifici per ospitare gli attuali occupanti delle 11 aree di piazza che il progetto mira a recuperare almeno parzialmente secondo un sistema distribuito di piccoli playg round, e 26 aree ad uso commerciale che ottimizzino gli usi del suolo consolidatisi a seguito dell'occupazione, riconfermando le attrezzature già esistenti e prevedendo 'scambi di terreni' per ogni abitazione e negozio censito nel 1994 che dovesse essere demolito per favorire l'urbanizzazione primaria e la fluidità dei percorsi (non però per i garage, valutati come appropriazione indebita e superflua).

In parallelo all'approvazione del piano, il gruppo misto per Rubem Berta ha stabilito:

1) di non regolarizzare nessuna costruzione abusiva ostruente reti idrico/ fognarie, aree di allargamento viario e accessi esistenti o progettati con l'assenso popolare attraverso le Oficinas.

2) di dare alla comunità la responsabilità di comunicare al Comune ogni nuova edificazione creata dopo il rilievo del ' 97 e di definire tutte le costruzioni eccedenti gli edifici originali e passibili di essere regolarizzate sul posto nelle aree di pertinenza condominiale

3) di attribuire alla comunità la responsabilità di contrattare professionisti privati per presentare piante firmate da un tecnico, con il rilievo delle costruzioni da mantenere e demolire

4) di attribuire alla comunità la responsabilità di negoziare per ogni condominio l'occupazione delle aree comuni, registrando gli esiti delle riunioni condominiali e appoggiandosi all'Associazione di Vicinato locale (AMORB). Il fulcro degli orientamenti condivisi tra gli attori operanti per la riqualifica- 
zione del quartiere fu di sovvertire l'indifferenziazione dello spazio pubblico ereditata dal progetto originario, valorizzando alcuni processi di 'appropriazione-socializzata $^{\prime 15}$ verificatisi dopo l'occupazione del 1987, e concentrandosi sul chiarimento delle responsabilità sui diversi tipi di spazi, pubblici e privati, ad esempio attribuendo ai diversi condomini (coincidenti non più con $\mathrm{i}$ 39 nuclei, ma con i singoli blocchi di appartamenti) delle 'aree a beneficio comune', ad esempio aree su strada da affittare per commercio o garage di cui reinvestire i proventi nella manutenzione dello stesso condominio.

A partire da quest'idea di garantire la 'sostenibilità' dello spazio condominiale attraverso l'autoproduzione e l'autogestione delle rendite - tra le novità più interessanti del progetto approvato del ' 98 - il processo decisionale per la reintegrazione di Rubem Berta nella Porto Alegre formale fu studiato in chiave 'dinamica', come processo di costruzione progressiva di alternative d'azione, ma anche di quello che - nell'ambito delle tecniche di partecipazione alle decisioni - viene definito re-framing, cioè di apprendimento e ristrutturazione cognitiva sia per i tecnici che per i cittadini, basata sull'incontro di differenze e su un'interazione in più tappe mirata a non 'fermare' eccessivamente il progetto risultante e ad affinarlo per gradi.

L'ultima versione del progetto, consegnata dall'arch. Mallmann della SPM a seguito della ridiscussione con gli abitanti, avvenuta nei singoli nuclei tra marzo e luglio 1999, presenta così differenze significative rispetto alla versione sottoscritta dal Sindaco Pont a fine '98. Il processo è servito ad affinare i risultati per i suoi beneficiari e a facilitare la messa in opera del progetto da parte del Comune, ponendosi anche come forma di ulteriore democratizzazione del rapporto tra cittadini e Istituzioni sul piano dell'intervento puntuale e non solo delle politiche. Avendo cioè già raggiunto un obiettivo, su questo ha innestato un ampliamento del grado di partecipazione alla riformulazione del progetto da parte dei nuovi abitanti o di quelli non mostratisi in passato interessati alla discussione, 'decentralizzando' la stessa nei singoli luoghi di vita.In tale ottica, l'approvazione del progetto di fattibilità della regolarizzazione nell'ottobre 1998 ha segnato l'inizio di un'esperienza in perfezionamento progressivo, aprendo la fase forse più delicata della vita di Rubem Berta, marcata dalla necessità di dare concretezza e seguito alla prima grande vittoria ottenuta dagli abitanti, attraverso una forte mobilitazione di energie partecipative nell'O.P., che permettesse loro di vedersi finanziare annualmente porzioni consistenti delle opere previste.

$\mathrm{Nel}$ corso del tempo, Rubem Berta ha elaborato strategie proprie di partecipazione al Bilancio Partecipativo unendo furbizia e pigrizia. Durante i primi anni dell'OP, le richieste non evase dal comune - anche a causa della difficile situazione legale del quartiere - avevano frustrato una partecipazione che andava sull'ordine dei 300-500 abitanti ad assemblea regionale.

Se non si è innescato un circolo vizioso di frustrazione e disinteresse crescente per il quartiere, (dato che - divenendo l'OP l'unico spazio di assunzione delle decisioni per gli investimenti da fare nella città - non prendervi parte attiva poteva generare un'ulteriore stasi per la riprogettazione dell'area) lo si deve in parte al progetto 'Centro de Bairro', attraverso cui l'Amministrazione ha mostrato di interessarsi al quartiere, stimolando l'autoprogettualità degli abitanti e spingendoli - attraverso un'opera quotidiana di 'corpo a corpo' con i propri tecnici - ad interessarsi al Bilancio Partecipativo quale 
486 'unico reale centro decisionale' dove poter contribuire attivamente al passaggio dei progetti dalla carta alla concretizzazione.

Il lavoro attento sul territorio ha prodotto come risultato la ricostruzione di una sostanziale fiducia tra istituzioni e cittadini; e - con l'approvazione del progetto discusso nelle Oficinas del 1995 - si è stabilito un 'punto di svolta', attraverso un segnale concreto che ha portato un'impennata nella partecipazione dei cittadini di Rubem Berta al Bilancio Partecipativo e una rapida partenza dei primi lavori di regolarizzazione urbanistica a partire dal 1998. L'analisi di Allegretti (2002c) analizza la dinamica con cui il finanziamento, la realizzazione e alcuni stalli nei lavori di esecuzione degli interventi finanziati nell'O.P. hanno interagito con l'alternarsi di interesse, fiducia e poi disinteresse dei cittadini di Rubem Berta per il Bilancio Partecipativo, retroinfluendo anche sull'interessamento per il nuovo Bilancio Partecipativo Statale attivato nel 1999. Accanto ad un 'affinarsi' delle richieste comunitarie e della loro coerenza con i criteri del Piano di Regolarizzazione Fondiaria e Urbanistica approvato nel '98, è così possibile leggere, negli ultimi anni, un'impennata di fiduciosa partecipazione all'O.P. seguita da una recente caduta di interesse (fig. 87), che confermano una delle caratteristiche più evidenti di questo processo: ovvero la sua stretta interdipendenza rispetto alla volontà politica di tener conto delle elaborazioni dei cittadini, trasformandole rapidamente in azioni concrete e visibili, e così motivando i partecipanti di un processo 'volontario' che certo si essiccherebbe laddove non producesse risultati effettivi.

Nel caso di Rubem Berta, del resto, il calo consistente di partecipanti alle assemblee nel 2002 riflette un diffuso sentimento di disillusione maturato di recente in conseguenza di un rallentarsi del processo di concretizzazione del Piano di regolarizzazione e di alcune disattenzioni di cui sono risultati parimenti colpevoli l'Amministrazione Statale, quella Comunale e il GT-Rubem Berta, arenatosi in una fase di discussione sulla regolarizzazione degli esercizi commerciali informali, anche a causa di un coordinamento poco incisivo nel periodo di 'rotazione' toccato al Dipartimento Municipale dell'Abitazione (DEMHAB).

Ad esempio: a Rubem Berta - sotto la guida dell'Associazione di Vicinato che da vari anni costituisce la 'testa di ponte' per gestire i rapporti tra i residenti e l'Amministrazione - si era deciso che i lavori di pavimentazione e piantumazione dei 39 nuclei regolarizzandi dovesse rispettare rigorosamente la proporzionalità con le presenze di ognuno di essi nelle assemblee di decisione dell'O.P.. Questo aveva determinato strategie di mobilitazione diversificate, premiando le sub-aree più coese nel presenziare alle varie fasi del processo, a cui sono andate 25 delle 30 opere finanziate fino al 2002 dal Bilancio Partecipativo (5 erano di interesse dell'intero quartiere). Ma, in fase di realizzazione delle opere, alcuni dei nuclei più mobilitati (come il 15 e il 38, dove risiedevano presidente e ex presidente dell'AMORB) non sono stati asfaltati nell'ordine previsto dall' autorganizzazione dei cittadini, avendo il Comune addotto la necessità di un macrodrenaggio che superava il valore dei finanziamenti ricevuti, e preferendo priorizzare diversamente le opere di pavimentazione. Il vedere scavalcati i criteri stabiliti dagli abitanti, ha portato ad un'immediata perdita di credibilità sia del processo di Bilancio Partecipativo che dell'Amministrazione e dell'Associazione di Vicinato.

Inoltre, le interpretazioni di natura 'politica' - inevitabilmente date a questo 
'scavalcamento' della volontà popolare - si sono sommate all'osservazione di un'accelerazione 'sospetta' (perché troppo vicina alla data delle elezioni comunali dell'ottobre 2000) nella concessione delle prime registrazioni catastali dei contratti regolarizzati di proprietà degli immobili, riscattati dagli abitanti dopo oltre 13 anni dall'occupazione del 1987. L'arrestarsi di questa distribuzione di certificati catastali subito dopo il voto ha portato nuovi elementi di sfiducia e delusione per l'operato delle forze politiche. ${ }^{16}$ Un dubbio diffusosi rapidamente tra gli abitanti - dato che la registrazione catastale di chi vive in AEIS come Rubem Berta costa 1/10 di quanto paga di solito un privato cittadino - era quello di essere soggetti a processi di regolarizzazione rallentata in quanto 'cittadini di serie $\mathrm{B}$ ' ${ }^{17}$ L'incapacità delle due amministrazioni interessate di 'ascoltare' questi segnali di scontento e reagire prontamente ha dato all'interpretazione popolare una patina di legittimità, ora difficile da contrastare. La situazione è stata peggiorata dal confronto di queste 'concessioni' con la linea di fermezza adottata dalla liquidatrice della $\mathrm{COHAB}$, che negli ultimi anni non aveva esitato a far eseguire espulsioni di famiglie insolventi dalle abitazioni in via di regolarizzazione per recuperare la maggior parte possibile dei crediti dell'ente liquidando, a costo di contraddire le stese battaglie intraprese nel 1987, quando era stata tra le promotrici dell'occupazione degli edifici inconclusi. Infine, i 4 anni di permanenza in carica di un Governo Statale dello stesso colore politico di quello municipale non hanno portato al quartiere i benefici in cui aveva sperato, e per cui gli abitanti si erano fortemente mobilitati anche in seno al Bilancio Partecipativo di livello Statale. La valutazione data a posteriori - è stata di una paralisi reciproca fra due poteri affini non più stimolati dalla 'sana competizione' tra coalizioni politiche di segno opposto che in passato - nonostante la sua anomala vicenda proprietaria -aveva persino beneficiato Rubem Berta, almeno in periodo pre-elettorale. Questa 'paralisi' si è tradotta nello spazio fisico nella presenza di 'scatole vuote' visibili, come la costruzione nel 1999 di una sede del Programma di Salute Familiare per 1200 famiglie, mai entrato in funzione, o nel blocco (terminato nel luglio 2002) dei lavori di costruzione di una strada di progetto che taglia da nordest a sudovest Rubem Berta, mettendo a servizio di tutti l'asse delle attrezzature sportive e religiose, e accorciando i tempi di percorrenza all'interno del quartiere.

Indubbiamente, vi è poi stata una gestione quotidiana dei lavori poco incisiva, e incapace (specie in vicinanza delle campagne elettorali dell'ottobre 2000 e 2002) di adottare quel rigore che gli stessi abitanti avevano invocato contro chi nella comunità - si opponesse, per egoismi personali, alle demolizioni e agli espropri indispensabili all'intera comunità per apportare le migliorie previste dal piano di regolarizzazione partecipativamente costruito in precedenza.

La giustificata durezza con cui di solito a Porto Alegre si sta attenti a far rispettare le decisioni comunitarie prese in sede di Bilancio Partecipativo, ha ceduto il posto a un modo di fare centrato su quello che i brasiliani chiamano 'jeitinho', ovvero 'l'aggiustatina', la capacità di cedere a richieste individuali a detrimento di decisioni già collettivamente assunte, ${ }^{18}$ rivedendo (e smentendo) per via informale e poco trasparente il rigore di un processo che con difficoltà - ma con successo - si era portato avanti negli anni precedenti in maniera limpida e partecipativa. Agli occhi di molti non sono risultate più chiare neppure la gerarchia e la concatenazione logica tra le opere, apparse alterate da considerazioni sul potere 'mobilitatore' di certe opere più visibili, 
488 a discapito di altre più utili ma meno 'spendibili' a fini elettorali.

Finché ad orientare la regolarizzazione del quartiere erano stati i criteri tecnici, anche le scelte più dure per i cittadini-abitanti erano passate al vaglio della comunità, motivate e giustificate agli occhi di tutti da un bene collettivo, ma i nuovi eventi per molti non trovavano spiegazioni logiche al di fuori della dietrologia politica. Quest'insieme di fatti ha evidenziato un conflitto latente tra 'politica' e 'territorio' che - agli occhi dei cittadini - si è tradotto in una paralisi degli interventi di regolarizzazione urbanistica e fondiaria, andata non solo a discapito degli abitanti, ma anche della certezza delle regole che li avevano fino ad allora orientati: e che ha provocato un discredito diffuso sia del meccanismo del Bilancio Partecipativo che della coalizione alla guida del Comune e dello Stato, come ben evidenzia il contributo elettorale dato da Rubem Berta nella 'svolta a destra' del governo statale il 27 ottobre 2002.

L'irruzione (visibile e predominante) di un ingombrante elemento 'politico' all'interno di un bilanciato rapporto di ricostruzione della credibilità e della fiducia nelle istituzioni che nel tempo era stato costruito soprattutto tra 'tecnici' e 'abitanti' (cioè tra saperi tecnici e sapienze territoriali), si è rivelato estremamente squilibrante. Forse, gli abitanti di Rubem Berta avrebbero anche accettato il blocco temporaneo dei loro sogni (abituati ad anni di lentezze burocratiche) ma chiedevano spiegazioni esaurenti sulle ragioni dei ritardi e delle variazioni di programma, e non ricevendone di sufficientemente credibili, hanno tratto le loro conclusioni, riponendo le loro speranze in una nuova coalizione. Si potrebbe dire che hanno sempre retto a lungo alle difficoltà, ma non hanno sopportato la disillusione dopo un periodo di ottimismo e euforia nelle possibilità di riscattare il loro territorio.

In parallelo, l'Associazione di Abitanti AMORB (colpita di riflesso dalla sfiducia dei concittadini, pur senza proprie colpe) ha dovuto elaborare delle strategie di sopravvivenza per non perdere la capacità di realizzare il contatto e la mediazione con il proprio territorio di riferimento. Per anni aveva combattuto per il miglioramento del quartiere, collaborando in modo proficuo anche con un'amministrazione comunale di idee politiche diverse da chi la dirige ormai da tre mandati consecutivi, anche grazie all'importante 'mediazione' che il Bilancio Partecipativo rappresenta. In quest'ottica, per anni, l'AMORB ha agito sue due piani: quello della mediazione con i poteri istituzionali e quello dell'autorganizzazione, mirata a realizzare e finanziare autonomamente azioni 'stimolanti' per la comunità. Ad esempio, nel mag gio '99 l'Associazione di Vicinato (che oggi organizza maratone sportive e feste, ma soprattutto gestisce uno dei 5 asili comunitari del quartiere, corsi per anziani, un giornalino dell'insediamento, corsi di computer per ragazzi, un nucleo di avvocati e commercialisti che prestano consulenze gratuite agli amministratori di 112 dei condomini presenti nei 39 nuclei) ${ }^{19}$ ha concluso con una clinica della zona e un'assicurazione privata un accordo di 'convenzione' a basso costo per le famiglie locali. Soprattutto - senza fondi pubblici - è stata portata a conclusione nei primi mesi del '99 la riforma completa del capannone che ospita le varie attività. Alla base dell'intervento - completato da creazione di una lunga rampa per disabili davanti alla sede - vi è stata l'esigenza di far sì che il centro comunitario diventasse "più che una mera riunione di persone, ovvero una convergenza di idee, di lotte, di forze sociali [...] affermazione di solidarietà nella conquista di obiettivi comuni”, come 
recita l'opuscolo creato per propagandare l'iniziativa della riforma e una mostra fotografica che il Museo del Lavoro di Porto Alegre ha dedicato alla stessa dal 1 al 30 maggio '99. A questo scopo fu chiamata Maria Tomaselli, un'artista nota in città per aver realizzato i centri comunitari di alcuni quartieri popolari sul Morro da Cruz e Maria da Conceição, come 'inneschi' per un rinnovamento dei quartieri, esempi per discutere una riforma visuale dell'intera area. Insieme allo scultore Caé Braga e con l'aiuto di vari sponsor privati, l'artista riformò il capannone dell'Associazione, adottando un antagonismo armonico dei colori, vivi e forti, che attraverso il richiamo all'arte popolare la sottolineasse come "luogo centrale, simbolo visibile per un quartiere ancora sfilacciato e privo di centri" (cfr. Malmann, 1999i, apud Allegretti 2000a?). Questa operazione ha, per certi aspetti, recuperato alla discussione di quartiere anche istanze di natura estetico/morfologica fino ad allora messe da parte, dimostrando che anch'esse meritavano considerazione in quanto significative sotto l'aspetto della percezione sociale e identitaria dei luoghi, e come contributo alla qualità della vita quotidiana (non è un caso, che alla ricostruzione dell'AMORB sia seguita l'autorganizzazione della verniciatura dei 39 blocchi in colori diversi, ed interessanti operazioni autogestite di piantumazione nei condomini). Oggi, però, l'AMORB pare aver assunto una posizione di più spinta politicizzazione, per reagire davanti alla crisi di fiducia nelle istituzioni che va rinascendo a Rubem Berta, a segnalare un disagio che le ultime elezioni statali hanno mostrato diffuso in tutta Porto Alegre, fotografando lo scontento per una percepita e progressiva stanchezza e burocratizzazione del rapporto dialogico costruito con la cittadinanza. In questo nuovo quadro, l'AMORB ha iniziato a organizzare marce di protesta contro il degrado del territorio locale (ad esempio, nell'ottobre 2001 ne è stata indetta una contro la chiusura della stazione di polizia in coincidenza con un aumento dell'insicurezza e dei reati contro gli abitanti), a mobilitare la stampa locale, a filmare e fotografare le opere incompiute e i luoghi degradati per poi chiedere un'inchiesta al Consiglio Comunale e divulgare il suo punto di vista nell'Esquina Democratica, un incrocio nel centro storico di Porto Alegre dove ogni cittadino ha diritto di esporre lamentele e farsi ascoltare. Per certi versi, l'AMORB ha dovuto ricominciare a far politica (in un modo che ricorda modalità di legame clientelare contro cui l'O.P. si era proposto di ribaltare), forse soprattutto nella speranza che il nuovo Governatore Statale possa ricordarsi di Rubem Berta una volta eletto.

I suoi dirigenti - nonostante posizioni politiche antitetiche a quelle dell'Amministrazione Popolare - hanno sempre però mostrato rispetto e fiducia nell'OP, e continuano a credervi, al di là della difettosa attuazione delle sue scelte degli ultimi 2 anni. Ma al momento attuale non pare semplicissimo recuperare l'entusiasmo degli abitanti per il processo, dove l'insediamento resta ben lontano dal raggiungere quella forza contrattuale che i suoi quasi 30.000 abitanti gli potrebbero dare se anche solo una percentuale superiore al 5\% di essi prendesse parte attiva alle riunioni dell'OP (attualmente siamo a meno dell' $1 \%$ in ogni assemblea e del 3\% sul totale annuo).

Oggi, comunque, quella di Rubem Berta non è una vicenda conclusa, e pare ancora possibile 'raddrizzare il tiro' per recuperare quel margine di valore aggiunto che l'autoprogettualità dei residenti e di alcune associazioni comunitarie ha prodotto in questi anni, nell'interazione positiva con un fronte istituzionale che - seppur con alti e bassi - ha cercato di superare le divisioni tra 
livelli governativi e di coagulare energie diverse (comunità, università, Comune, Stato) intorno ad un 'progetto' costruito con i cittadini, non solo nelle sue scelte strategiche ma anche in molti dei suoi elementi di dettaglio.

Per questo - pur riconoscendo limiti ed imperfezioni del processo che l'ha riguardato - Rubem Berta va guardato con l'interesse che merita: quello per un luogo di intreccio di differenti volontà di riscatto, dove però l'interessante processo trasformativo non è stato voluto e stimolato direttamente dall'Amministrazione Popolare (almeno non nei modi in cui si è sviluppato), ma è risultato come il valore aggiunto di un'autoprogettualità all'opera per merito della forza interna di alcune organizzazioni degli abitanti e della positiva interazione con alcune individualità operanti negli apparati tecnici delle amministrazioni, prima tra tutti l'architetto Mallmann della SPM, che ha spesso portato avanti la meritoria opera contro il parere dei suoi diretti superiori, conducendo una battaglia personale per evitare che si ripetesse la tradizionale prassi dei 'progetti interrotti', che Porto Alegre ha ben conosciuto anche negli ultimi anni, e persino in molti casi di 'progetti pilota' pressoché abbandonati a sé stessi (una volta terminati i lavori di costruzione) per concentrarsi su altre urgenze. ${ }^{20}$

In quest'ottica, va tributato interesse al lavoro di modificazione continuata delle linee di progetto urbanistico svolto a Rubem Berta, che ha precorso la sperimentazione coerente dei principi della pianificazione 'esperienziale' e permanente che strutturano il nuovo Sistema di Gestione della Pianificazione immaginato dal Piano Regolatore di Sviluppo Urbano e Ambientale recentemente entrato in vigore a Porto Alegre (cfr. cap. 15 e Allegretti, 2002d); tanto più perché ha puntato "non solo su una trasformazione fisica di quell'isola urbana che Rubem Berta era, semmai sulla trasformazione dei rapporti di responsabilità tra gli abitanti e il territorio" (De Oliveira, 1999i, apud Allegretti, 2000a). ${ }^{21}$

In fondo, pare ancora possibile recuperare una volontà politica finora mostratasi sostanzialmente incompleta (Santos da Silva, 1999i, apud Allegretti $2000 a)^{22}$ per fare di Rubem Berta un 'progetto-pilota', e dargli la visibilità che meriterebbe la naturale saldatura che si è creata tra autoprogettualità degli abitanti e progettualità istituzionale, altrove raramente giunta a risultati potenzialmente così interessanti, oltre che congruenti con lo spirito che anima le riforme politiche in senso partecipativo avviate a Porto Alegre, a partire dal 'nodo' del Bilancio Partecipativo.

\subsection{Il Loteamento Cavalhada: un progetto-pilota per l'integrazione de- gli interventi}

Il primo grande 'reassentamento' avvenuto a Porto Alegre è stato - all'epoca dell' Amministrazione Dutra - quello di Vila Tripa, un insediamento nato spontaneamente nel 1985, a partire dall'invasione di una famiglia proveniente da Bagé; l'ubicazione nei pressi dell'aeroporto e di una strada a scorrimento veloce (l'Av. Sertorio) aveva causato incidenti tra gli abitanti della favela, ma soprattutto (secondo i quotidiani del marzo '91) aveva ridotto la parte finale delle piste aeree ad un immondezzaio, a detrimento della sicurezza di decolli e atterraggi. Così, il 1 aprile 1992 la direttrice del DEMHAB firmò il passaggio all'Amministrazione - attraverso esproprio amiche vole - di un terreno di 19,75 ettari nella zona Nord della città, destinato ad ospitare 1200 
famiglie provenienti da aree di rischio, comprese le 120 di Vila Tripa; i suoi 700 abitanti furono trasferiti tra il 29 settembre e il 27 novembre di quello stesso anno nel nuovo insediamento chiamato Wenceslau Fontoura, ${ }^{23}$ senza che fino al 1996 venisse presa alcuna misura per risistemare l'area 'disoccupata', visto che la pista ciclabile ipotizzata in un primo momento fu poi ritenuta inutile. Furono loro offerti lotti urbanizzati con casette-embrione di 14,5 mq. al costo simbolico di $7 \mathrm{R} \$$ al mese, escluse le bollette dell'acqua e della luce da saldare individualmente. Un errore commesso dall'Amministrazione fu di non garantire con immediatezza alcune delle condizioni al contorno che avevano reso possibile a Vila Tripa la sopravvivenza economica di molte famiglie, legate alla raccolta e al riciclaggio dei rifiuti. Nell'area di Wenceslau Fontoura, infatti, solo con ritardo fu attivato il capannone di selezione e riciclaggio dei rifiuti attualmente ancora in attività, e non grazie alla solerzia dell'Amministrazione Popolare, ma semmai a quella di Padre Antonio Cechin, un esponente della Chiesa Cattolica progressista molto noto a Porto Alegre per le battaglie a difesa dei 'papeleiros' [raccoglitori di carta], e per essere stato sub-sindaco della regione delle Isole durante la gestione di Olivio Dutra. Il risultato di questo ritardo fu che molte famiglie in breve tempo vendettero irregolarmente le chiavi delle nuove residenze costruite per loro dal Comune, per poter tornare ad abitare in zone dove la raccolta dei rifiuti fosse più proficua e permettesse la sopravvivenza economica; così oggi

[...] a mia conoscenza è rimasta una sola persona di quel gruppo originario di 'selezionatori di rifiuti' nel nuovo 'reassentamento', a causa di una politica abitativa chiusa nella sua settorialità ed incapace di prendere in considerazione insieme le diverse componenti che permettono la sopravvivenza di un qualsiasi essere umano, a cui certo una casa non può bastare, e tanto più in un'area così fuori dal mondo come quella dove le famiglie di Vila Tripa furono sistemate. E il Comune questo for se neppure lo sa, visto che i controlli sugli abitanti dei 'reassentamentos' non si possono proprio dire efficaci e frequenti, ed in genere sono limitati ai 'si dice' che informalmente gli agenti comunitari raccolgono (Cechin, 1999i, apud Allegretti, 2000a).

Un calcolo compiuto dalla stessa Associazione di Quartiere (cfr. Zero Hora, 21/4/95) valutò che già a tre anni di distanza solo 30 famiglie delle 146 trasferite lì nel 1992 erano rimaste; le altre avevano venduto le chiavi degli 'embrioni' ormai ampliati, a prezzi oscillanti tra i 2000 e i $4000 \mathrm{R} \$$ e si erano trasferiti in zone più vicine a imprese che acquistavano carta e cartone usati, ad esempio nell' Isola della Pintada.

Negli anni, la metodologia dell'Amministrazione Popolare nel portare avanti i 'reassentamentos' si è in parte perfezionata. Dopo il trasferimento in aree pubbliche di 7.576 famiglie provenienti da 49 'vilas' in varie aree della città (solo tra il 1993 e il 1995), si è così giunti, alla fine del 1995, all' 'interventopilota integrato' condotto da vari assessorati in occasione della rimozione della Vila Cai-Cai, una favela situata tra le rive del Lago Guaiba e l'Av. Beira Rio nella zona Sud della città, la cui eliminazione si rendeva necessaria sia a motivo delle condizioni igieniche e di sicurezza allarmanti in cui vivevano $\mathrm{i}$ suoi abitanti, ${ }^{24}$ sia ai fini del proseguimento del Programma Pro-Guaiba di disinquinamento del bacino idrografico portoalegrense. Il programma di rimozione - come è prassi dell'Amministrazione Popolare sui 'reassentamentos' - tentò di individuare una soluzione localizzativa per il nuovo insediamento 
492 il più possibile vicina al luogo originario di residenza delle famiglie. L'area fu così individuata nella Cavalhada, una zona di crescita 'nobile' della città ad alcuni chilometri dalla Vila Cai-Cai; il Comune non trovò, infatti, un'altra area di oltre 5 ettari a costi accessibili in tempi che permettessero di evadere rapidamente la richiesta di costruzione di 228 alloggi presentata dagli abitanti della Vila già nel Bilancio Partecipativo del $1993^{25}$ in seguito ad un referendum interno in cui il $75 \%$ degli abitanti votanti risultò favorevole al trasferimento, il $18 \%$ contrario e il $7 \%$ dubbioso. ${ }^{26}$

Trasferirsi è stata alla fine una scelta della popolazione che ne ha fatto richiesta nell'O.P., anche se convinta a ciò dal continuo dialogo con noi tecnici. La scelta dell' area è stata, invece, a carico dell' Amministrazione, che ha dovuto alla fine compiere una scelta per certi versi coraggiosa in un' area naturalisticamente interessante e che la presenza di Vila Isabel accanto stava sempre più valorizzando come luogo di vita di fasce di red dito elevate della cittadinanza (Saicoski, 1999i, apud Allegretti, 2000a).

Sulla stampa del periodo sono registrate le numerose polemiche che accompagnarono l'acquisto dell'area di 40 ettari ceduta dall'Arcidiocesi di Porto Alegre; esse strumentalizzarono (servendosi anche di gruppi ecologisti) i vincoli naturalistici esistenti in una parte della collina prescelta, per dar corpo alla paura che i nuovi abitanti potessero contribuire a deprezzare l'area, sostenendo che come è abitudine nelle favelas - essi avrebbero distrutto la vegetazione della zona - l'attuale Parco del Morro do Osso - per farne legna da ardere o costruzioni provvisorie [puxadinhos] per ampliare le unità abitative. Nell'ambito di questa battaglia, l'Assessore all'Ambiente Gregol, ecologista dal piglio radicale, fu sostituito con il leader sindacale Almeida, dotato di un maggiore tatto politico.

Proprio per mostrare l'infondatezza di queste proteste strumentali e discriminatorie, il DEMHAB ha organizzato puntualmente tutta una serie di iniziative di contorno al trasferimento della Vila Cai-Cai, dalla costruzione di una separazione fisica con le aree di vegetazione nativa ai corsi di educazione ambientale. E alla fine, le casette ad un piano raddoppiabile del DEMHAB sono risultate ben meno dannose per il paesaggio degli alti edifici residenziali che stanno venendo realizzati davanti. Se osservi alcune colline cosiddette 'nobili' qui accanto ti accorgerai che sembrano favelas per ricchi tanto è il disordine che le connota (Frare, 1999i, apud Allegretti, 2000a).

In realtà è accaduto che fossero i bambini del 'reassentamento' a raccogliere lattine e rifiuti buttate dalle ville miliardarie dei condominios fechados nella zona da preservare (Mayer, 1999i, ibidem).

Tra le prime misure messe in atto dal DEMHAB vi fu il 'congelamento della vila', controllata da una roulotte di vigilantes per evitare nuovi arrivi rispetto agli abitanti censiti dal DEMHAB. Poi si discusse con gli abitanti di Vila CaiCai un Regolamento di condotta: tra le misure indicate 'a maggioranza' dalla popolazione - che pure possedeva moltissimi allevamenti informali - vi fu quella di non permettere animali nel nuovo insediamento. Per garantire libertà di scelta, il Comune lasciò aperta, a chi non volesse separarsi dai propri animali, l'opportunità di accettare una sistemazione di ripiego in lotti urbanizzati nel Loteamento Timbauva, dal lato opposto della città. Un gruppo (tra cui una signora con 15 gatti) scelse questa soluzione, e ancora oggi mucche e pecore pascolano nella zona dove le famiglie sono state re-insediate. 
Il regolamento a suo modo è stato un'imposizione della città formale, difficile da capire per i vileiros così come l'idea dell'affitto per le case e le bollette per servizi che prima avevano gratis tramite collegamenti clandestini; e tanto più appariva strana e foriera di equivoci e litigi l'idea delle bollette dell'acqua a 'responsabilità collettiva' invece che individuale. Eppure l'elaborazione di quello strumento è stato un momento di crescita cittadina per tutti. Non si poteva però non tener conto che seppur decise a maggioranza - le clausole in esso contenute non fossero ritenute vincolanti da alcuni (Frare, 1999i, apud Allegretti, 2000a).

La resistenza al trasferimento, quando si manifesta, non è un capriccio. È il modo di manifestare la necessità di mantenere in vita le proprie 'reti di sopravvivenza' che spesso si instaurano nelle unità di vicinato. Ed è un punto che va preso seriamente in considerazione dal potere pubblico. Certo, per noi è difficile da capire subito questa resistenza perché siamo adusi alla 'mobilità' senza limiti. Ma per i poveri non è così. Non dimenticherò mai una bambina che piangeva per il trasferimento, perché a Natale al semaforo vicino alla Cai-Cai aveva guadagnato 19 bambole, mentre altre famiglie vivevano dei donativi e dei resti delle feste di compleanno dei ricchi del quartiere Cristal. Per questo bisogno di inserire l'umanità e le condizioni specifiche di ogni situazione nelle politiche, abbiamo scelto di offrire ventagli flessibili di opzioni a chi viene rimosso (Saicoski, 1999i, apud Allegretti, 2000a).

Il trasferimento delle 211 famiglie ( $\mathrm{su} 228$ ) che accettarono e sottoscrissero il regolamento di convivenza, fu completato il 19 dicembre 1995, dopo 2 anni di preparazione attenta dei lavori; la sede dell'antica favela fu immediatamente occupata da un parco fluviale attrezzato, nell'ambito del Programma Guaiba Vive, e dalla continuazione di una pista ciclabile che percorre parte delle rive cittadine del Lago, attraversando il Parco pubblico Marinha do Brasil e costeggiando quello privato appartenente alla squadra di calcio dell'Internacional. Per le nuove abitazioni, il Comune seguì la sua linea maestra; "non alterare d'imperio $i$ modi di abitazione tradizionali dei 'vileiros' realizzando un insediamento esteso di alloggi bassi, che a Porto Alegre costituisce ancora oggi la regola di ogni 'reassentamento' per evitare le distorsioni verificate in città come San Paolo, dove la densità urbana obbliga alla verticalizzazione delle favelas e altera $i$ modi di vivere gli spazi pubblici e privati dei loro abitanti" (Pestana, 1998i, ibidem). Furono realizzate unità abitative di 30 mq (ampliabili di un piano dai residenti, come oggi è puntualmente accaduto) in lotti di 4x16 $\mathrm{m}$., concesse in CDRU agli abitanti dietro pagamento di una cifra non superiore al $10 \%$ dello stipendio familiare mensile. Il risultato oggi visibile è quello di un insediamento molto convenzionale, composto di file parallele di piccole casette a schiera di colori-base omogenei, spesso alterati dall'appropriazione individuale manifestatasi in questi anni sia attraverso la ritinteggiatura degli alloggi che attraverso l'ampliamento in verticale e in orizzontale degli stessi. ${ }^{27}$ Anche in questo caso fu offerta un'opzione di scelta a chi viveva in case di dimensioni maggiori; partecipare di un mutirão nello stesso insediamento, accettando di vivere temporaneamente nelle casette realizzate dal DEMHAB.

Per quanto attiene ai servizi, già mesi prima del trasferimento la prima richiesta presentata dalle donne di Vila Cai-Cai riguardò scuole, centri di salute e trasporti. Se in altri 'reassentamentos' (come Timbauva o Wenceslau Fontoura) ${ }^{28}$ i servizi dovettero essere guadagnati dalla popolazione in due anni di lotta nell'O.P., (appoggiandosi alle realizzazioni dei Padri Maristi o ai quartieri vicini nell'attesa dei servizi comunali), qui la coesione del gruppo ottenne fin da subito un autobus che portasse alle scuole del quartiere Cristal i bambini dopo 
494 il trasloco delle residenze, in attesa di una scuola interna all'insediamento. Il processo di costruzione dell'insediamento 'Cavalhada I' fu più rapido di altri, a motivo della cura che il Comune mise nel pianificare l'intervento in maniera coordinata e multidisciplinare. I primi assessorati ad intervenire furono la FASC e quello alla Salute. Vila Cai-Cai, infatti - pur elencata dalla SMS come una delle 10 'vilas' della fame di Porto Alegre -, non aveva in atto politiche di assistenza sociale. Pertanto, la stessa composizione dei suoi abitanti era ignota all'Amministrazione, che necessitava di una conoscenza approfondita per poter pianificare l'intervento. Le Assistenti Sociali entrarono a fine '93 nella vila sul lago, in parallelo ad un'antropologa [Helena Sant'Ana] che stava svolgendo una ricerca post-laurea sulla rappresentazione dello spazio e le forme di appropriazione di esso in una favela in via rimozione. Purtroppo, pur lavorando fianco a fianco, tra la Sant'Ana e i tecnici del Comune vi fu poco scambio; anche per questo - forse - il progetto di 'reassentamento' risultò spazialmente povero e banale oltre che discutibile e la tesi, ricca di spunti (cfr. box 13, Allegretti 2000a) restò lettera morta, spingendo la sua redattrice ad una posizione molto dura sul lavoro del DEMHAB; posizione che solo a quasi 4 anni di distanza l'autrice ha attenuato valutandola 'forse ingiustificatamente acrimoniosa dal momento che non faceva $i$ conti con le emergenze e $i$ vincoli con cui il Comune era costretto a lavorare" (Sant'Ana, 1999i, apud Allegretti, 2000a). $\mathrm{Si}$ dovette lavorare sulle malattie trasmesse dagli animali, come la Leptospirosi; un veterinario fece delle lezioni sul rapporto di igiene da intrattenere con gli animali, e una settimana prima del trasloco fu fatta una festa in cui un carro della Facoltà di Veterinaria portò via - fra i pianti dei bambini - tutti gli animali che non potevano essere tenuti. Quando il Comune si rese conto della particolarità e delle difficoltà della relazione con la comunità di Vila Cai-Cai, fu formato un Gruppo di Lavoro (GT) che integrava il lavoro di tutti gli assessorati ${ }^{29}$ che andavano coinvolti in un 'reassentamento', che non poteva limitarsi ad essere il risultato di una Politica della Casa settoriale. La necessità di questo organismo fu sentita in modo particolare perché questa Vila non era abitata da persone battagliere all'interno dell'O.P. e di altri forum cittadi$\mathrm{ni}$, anche a causa del tasso di analfabetismo e degrado socioeconomico. La creazione del GT coordinato dal DEMHAB non fu indolore; molti assessorati, infatti, in un Seminario sul tema, chiesero di affidarne la gestione al CAR Norte essendo il DEMHAB malvisto "proprio per il suo lavoro 'sporco e con gli sporchi"” (Saicoski, 1999i, apud Allegretti, 2000a). Attraverso il GT (misura non nuova in città, ma diffusa soprattutto nelle Regolarizzazioni Fondiarie) il Comune riuscì ad installare in tempi rapidi nella Cavalhada una scuola (completata solo nel dicembre '96 e che dal 1998 ospita dalla $1^{\circ}$ all' $8^{\circ}$ serie) e un'unità di riciclaggio, mirando ad affrontare nel contempo le questioni del rispetto dell'ambiente e della creazione di reddito. La prima questione fu affrontata contestualmente dalle equipe ambientali del DEMHAB, del DMAE, del DMLU e della SMAM, che realizzarono un interessante lavoro di documentazione e formazione il cui materiale di supporto sembra inspiegabilmente andato perso con il cambio dei tecnici dell'Amministrazione nel 1997. Le quattro tappe di svolgimento furono:

1) riunioni con la comunità per piccoli nuclei divisi per età e per accessi stradali, al fine di discutere sul 'reassentamento' letto dalle diverse soggettività;

2) riunioni generali con l'intera comunità; 
3) visite organizzate al Morro do Osso con adulti e bambini;

4) Registro fotografico fatto dalle varie famiglie come ricordo della Vila CaiCai, per documentare gli aspetti più amati che si voleva tentare di emulare nella nuova area; gli alberi, il rapporto con l'acqua, ci fu anche una signora che voleva fotografare il vento e Luisa, la coordinatrice dell'equipe, alla fine riuscì a ideare una foto dall'alto sulle pietre che reggevano i tetti di lamiera e amianto delle baracche come modo per rappresentarlo (Saicoski, 1999i, apud Allegretti, 2000a).

Il tema della creazione di occupazione fu gestito insieme dalla SMIC, dal DMLU (che rifornisce il capannone di smistamento dei rifiuti) e dal DEMHAB (che offrì l'area); un rilievo sul potenziale economico della Cavalhada si arrestò per mancanza di fondi, limitandosi a coloro che maggiormente erano stati pregiudicati dal trasferimento cioè $i$ 'papeleiros' che afferivano ai due depositi dei 'boss' di Vila Cai-Cai: Alemão [il Tedesco] e Marino, che costringevano chi lavorava per ognuno di loro a servirsi nei loro negozi in un rapporto di semi-schiavitù. Fu la discussione con le 39 famiglie che nelle loro baracche selezionavano i rifiuti distribuiti dai due $\operatorname{boss}^{30}$ a far nascere l'idea di una Centrale di Riciclaggio rifornita dai camion del DMLU. Quella realizzata nella Cavalhada - inaugurata il 7/8/96 - fu la $7^{\circ}$ creata a Porto Alegre (la centrale-pilota era stata nella Restinga); avrebbe capacità per 55 persone ma ne occupa 35 per garantire loro uno stipendio maggiore, ed è gestita da una Cooperativa co-finanziata dal DMLU e diretta da Celoir (una giovane donna che sta costruendo la sua casa nuova in mutirão nell'insediamento): oggi funge da Centro di Educazione Ambientale per l'area vicina, dando la misura di come si possa "produrre reddito con il rispetto dell'ambiente e la raccolta differenziata e senza essere necessariamente sfruttati da 'protettori' come avveniva a noi papeleiros quando abitavamo nella Vila Cai-Cai" (Celoir Saraiva, 1999i, apud Allegretti, 2000a). ${ }^{31}$

Dal dicembre del 1996 funziona un'Unità di Salute Familiare, con un medico, un infermiere, ausiliari e 2 agenti di salute che segue anche gli abitanti della vicina Cidade de Deus. È stata una progressiva conquista dell'insediamento, un po' come il Modulo di Assistenza Sociale della FESC costruito nel settembre '98. La scuola (dopo un'analisi sul basso livello di stima imperante nella popolazione) funziona oggi per cicli secondo una nuova proposta pedagogica che non prevede bocciature e lavora sull'autostima. Facendo ruotare molte discussioni intorno al tema del 're-insediamento', rappresenta oggi il centro pulsante del quartiere e l'unica struttura che cerca di mettere in atto a distanza di tempo forme di valutazione circa i benefici e gli eventuali problemi apportati agli abitanti dalle modalità del 'reassentamento' (Tramontina, 1999i, apud Allegretti, 2000a). ${ }^{32}$ Teoricamente, infatti - come prevede il manuale d'azione di cui si sono dotate le Assistenti Sociali del DEMHAB - sarebbe previsto che per almeno 6 mesi dopo ogni 'reassentamento' l'organismo responsabile controllasse e seguisse le trasformazioni e il consolidamento della popolazione nell'area anche 'al fine di cogliere elementi utili a non commettere eventuali errori e leggerezze in futuro' (Frare, 1999i, apud Allegretti, 2000a). Nella realtà però questo non accade, perché il DEMHAB subito concentra le sue poche forze su nuovi progetti e non pare aver tempo e volontà politica neppure per siglare accordi con altre strutture (ad esempio ONG o l'Università) per delegare il monitoraggio delle sue realizzazioni. Così è av- 
496 venuto anche alla Cavalhada, dove il contatto successivo con il 'reassentamento' è stato ripreso solo a motivo della costruzione dei nuovi insediamenti chiamati Cavalhada II e III, che includono anche le costruzioni in mutirão.

Purtroppo, con i primi mesi dopo il trasloco degli abitanti della Vila Cai-Cai, la struttura del GT cominciò ad indebolirsi fino quasi a spegnersi. Se l'Unità di Riciclaggio decollò grazie al lavoro di formazione della Cooperativa svolto dalla SMIC, altre iniziative prima molto curate persero continuità. L'allentarsi del controllo sulle condizioni abitative si è tradotto in un proliferare di piccoli ampliamenti che sovente accecano e soffocano gli alloggi vicini saturando i lotti; gli animali hanno preso a proliferare come nelle altre 'vilas', ${ }^{33}$ al punto che si sono avuti problemi con l'Ente Poste dopo che un postino è stato morso da un cane. Seppur in mancanza di nuove valutazioni ufficiali fatte dal Comune a medio termine, la formula della 'Gestione integrata' si è però rivelata positiva ed è stata replicata in seguito in altri 'reassentamentos', come quelli della Restinga, di Belém Novo (dove attraverso il programma Guaiba vive il Comune lavora ad un riscatto dell'autostima e del senso di utilità sociale dei pescatori), del Loteamento Santa Paula (dove la SMAM lavora sulla questione ambientale in collaborazione con il DEP nell'ambito del programma 'Un ruscello non è una fogna'). Alla fine del quadriennio Genro, la SGM ha messo in piedi un Forum che anticola le politiche sociali all'intermo di ogni 'reassentamento', anche quelli privi di GT; e il DEMHAB e la SMED da allora lavorano insieme ad un programma di incentivo alla scolarità, mirato ad evitare ogni interruzione di continuità nella formazione dei nuovi abitanti dei vari insediamenti.

Si sono cioè create delle 'gestioni ampliate silenti' in cui solo un Assessorato in quel momento puntualmente richiesto lavora, funzionando con minore o maggiore impeto in rapporto al livello di necessità delle famiglie. Spesso è il Gabinetto del Sindaco a svolgere un ruolo fondamentale, così come è nel caso dell'operazione interrelata che ha portato al 'reassentamento' della Vila Cristal, e come sta avvenendo per le 5 favelas che occupano l'area dove è previsto l'ampliamento dell'aeroporto, o sul tracciato della Terza Circonvallazione: in tutti questi casi il DEMHAB ha avuto ed ha un piccolo ruolo (Saicoski, 1999i, apud Allegretti, 2000a).

In questa ottica, l'esperienza della Cavalhada I presenta il rischio implicito di molte delle politiche portoalegrensi: "non riuscire a mantenere le rivoluzioni" (Rigatti, 1999i-II, apud Allegretti 2000a) ovvero a 'gestire la continuità' così come il Comune si è impegnato a fare in questi anni con la cura degli investimenti destinati alla città formale, che minimizzano le spese di manutenzione e rendono possibile l'aumento annuale del volume degli investimenti. Ciò nondimeno, essa ha rappresentato un punto di incontro - sul terreno della riorganizzazione fisica della città - di molte politiche convergenti mirate al capovolgimento dell'esclusione e dell'emarginazione, e al riscatto del senso di cittadinanza di persona a lungo rimaste nell'ignoranza dei loro diritti e doveri. In tal senso - pur con il difetto di non essere stato sede di un processo duraturo di valutazione dei risultati ottenuti dall'impegno profuso dall'Amministrazione - resta un momento importante per l'evoluzione delle Politiche della Casa a Porto Alegre. Anche se, oggi, la sua esemplarità sta venendo messa a rischio dal trasferimento in quell'area di comunità diverse (e spesso 'rivali') per cui nell'ultimo anno va rilevandosi una forte crescita della violenza interna, che si traduce anche in progressivo degrado delle strutture fisiche e dei servizi. 
14.5 Vila Planetario: atto pioniere per affermare il 'diritto dei poveri al centro'

Nel capitolo 'Da baracche a cartolina', Andreatta (1997) descrive un po' edulcoratamene (almeno se considerato dal punto di vista del risultato fisicospaziale) il processo che nel '92 portò alla ricostruzione della Vila Planetario, un'antica baraccopoli che oggi porta il nome di Jardim Planetario ed è costituito da 90 casette di mattoni di $25 \mathrm{mq}$ di pianta (tra cui 73 casette accoppiate di 51 e $58 \mathrm{mq}$ ) dove vivono oltre 475 persone, la maggioranza delle quali è integrata al mercato del lavoro. Questa realizzazione, pur dai numeri così esigui, rappresenta - letta oggi - uno dei momenti più rappresentativi del rinnovamento delle politiche cittadine adottate dall'Amministrazione Popolare di Porto Alegre, dal momento che fu lo strumento dell'affermazione del 'diritto dei poveri al centro' e intervenne con coraggio a mettere in discussione un trentennio di politiche urbane fondate sulla speculazione edilizia e appoggiate dalle giunte precedenti a quella eletta nel 1988.

Circondata da abitazioni di classe media, Vila Planetario (situata accanto al Planetario cittadino) era dal 1960 una delle 18 sacche di povertà nascoste nelle maglie del centro di Porto Alegre, ${ }^{34}$ una baraccopoli con fogne a cielo aperto e solo 3 latrine pubbliche, abitata in prevalenza da disoccupati, ambulanti e soprattutto riciclatori di rifiuti, 60 dei quali (nell'agosto 1988) si erano riuniti nella prima Cooperativa Mista di questo genere che la città abbia avuto, mirata a migliorare il potere acquisitivo degli associati e a "trasformare l'immagine del papeleiro davanti alla società con l'introduzione di uniformi e cartellini distintivi". ${ }^{35}$ Non avendo potuto realizzare il previsto magazzino, essi continuavano a depositare nelle baracche il materiale riciclabile da rivendere, ingenerando proteste da parte dei vicini e problemi di salute soprattutto fra i bambini. Con l'avvento dell'Amministrazione Popolare, la situazione fu messa allo studio già nel '91 dal neonato PRF coordinato da Gilson Lima, mentre parallelamente la comunità residente - che già con l'idea della Cooperativa Mista aveva mostrato capacità di aggregazione - si organizzava per ottenere la legalizzazione dell'insediamento nel Bilancio Partecipativo.

La favela non si trovava su un'area prevista a verde dal PRG né su un'area privata lasciata vuota in attesa di valorizzazione fondiaria (entrambi situazioni frequenti fra le 'vilas' del centro della città), bensì su un terreno donato alla Fundação Rio-Grandense de Atendimento ao Excepcional per costruirvi una scuola per portatori di handicap; mai sfruttato e perciò reincorporato al patrimonio comunale. La richiesta degli abitanti - approvata nel PI 1992 dell'O.P. - fu affidata al Programma di Regolarizzazione Fondiaria che ne fece il progetto-pilota di applicazione dello strumento della Concessione di Diritto Reale di Uso del Suolo, di recente inserito nello Statuto Comunale. La questione della CDRU fu uno scoglio duro che il Comune dovette superare nei rapporti con la Comunità, che avrebbe preferito la cessione delle proprietà alle famiglie. Facendo leva sul fatto che quella soluzione era stata la prima richiesta degli abitanti all'inizio delle negoziazioni, il Comune tenne duro, con l'obiettivo di mantenere il controllo sui terreni ed evitare sconsiderati fenomeni di 'gentrificazione' piuttosto probabili data la localizzazione centrale del terreno. Il valore da corrispondere mensilmente per 30 anni rinnovabili (e mai aggiornato) fu adattato al salario minimo, secondo una quota del 7,5\% . 
Era importante - soprattutto essendo un esperimento-pilota - che i cittadini si responsabilizzassero sul fatto che un'occupazione è comunque un atto non legale, seppur comprensibile in condizioni di necessità, e che la regolarizzazione è giusto se gua vie diverse da quella della cessione della proprietà. [...] Alcuni di noi erano convinti che l'insicurezza (seppur minima) che si ha in una casa non di proprietà, potesse stimolare alla cura dell'ambiente costruito secondo le aspettative del Comune. E forse in questo sbagliammo, peccando di ottimismo e idealizzazione; mancando incentivi ad investire su un bene che lasciava un margine di insicurezza, seppur trasmissibile per via di eredità ai figli, alcuni abitanti misero in secondo piano la manutenzione degli immobili. (B. Alfonsin, 1999i apud Alle gretti, 2000a- IV).

L'operazione condotta a Vila Planetario fu essenzialmente un atto politico, mirato a 3 obiettivi essenziali:

1) offrire un 'segnale' di forte volontà politica alla cittadinanza tutta, circa la necessità di non ritenere il centro urbano come luogo 'intoccabile' (nelle mani della speculazione edilizia e dei poteri forti dell'economia cittadina) attraverso la dimostrazione dell'autonomia decisionale del Potere Pubblico almeno sulle sue proprietà;

2) mostrare la ferma volontà dell'Amministrazione Popolare di favorire l'eterogeneità sociale sul territorio urbano e imporre l'inversione delle priorità promessa dal 1989 attraverso la sperimentazione di nuovi strumenti legali in grado di mettere concretamente in atto i principi costituzionali della funzione sociale della città e della proprietà privata;

3) dare uno 'scossone interno' (ibidem) a molti settori della stessa Amministrazione, mostrando loro come - volendolo - il livello politico era capace di imporsi sulla tecno-burocrazia convinta di aver trionfato ancora una volta sui buoni propositi della nuova Amministrazione.

L'imminenza delle elezioni comunali previste per l'ottobre del 1992 costituì un elemento fondamentale per la riuscita del progetto di Vila Planetario, che si trovò a scavalcare d'imperio (per volontà dello stesso Sindaco) le resistenze interne opposte dalla direttrice del DEMHAB - scippato di un progetto abitativo in cui tra l'altro non credeva, e che riteneva eccessivo per i suoi costi (Marques, 1999i, apud Allegretti, 2000a) - e quelle dello stesso Assessorato all'Urbanistica, incaricato della redazione del progetto urbanistico e architettonico. Persino il Consiglio del Piano Regolatore innescò una dura polemica ritenendosi 'scavalcato' su una questione di sua competenza (la variazione del regime urbanistico di un'area prevista di scuola e ora usata per residenza), e neppure formalmente interpellato sul da farsi. All'interno del fronte progressista, la polemica riguardò soprattutto i modi in cui il progetto fu esposto dalla SPM e rapidamente portato a conclusione (tanto da dover costringere il Sindaco a pubbliche scuse davanti al Consiglio del Piano Regolatore). L'equipe del PRF e il Sindaco, che lo vollero fortemente, furono, infatti, accusati di una carenza di democraticità nel dibattito interno alla stessa Amministrazione (tanto da essere ribattezzati 'la banda dei 9 sciiti', ibidem), ${ }^{36}$ cosa che non poteva dirsi rispetto all'intero corpo cittadino, dove l'O.P. - in cui il progetto fu deciso e accettato dalla popolazione - era teoricamente aperto al dibattito per tutti.

Qualche difficoltà il Comune dovette affrontarla, comunque, anche nei rapporti con la comunità insediata nella favela. Ad esempio quando la Legge sulla CDRU impose di accettare che 13 famiglie (arrivate dopo l'approvazione dello Statuto Comunale) non potessero prendere parte - per un vincolo lega- 
le - a questo primo progetto di 'reassentamento' in loco, cioè di reinsediamento delle famiglie nella stessa area dove vivevano ma in abitazioni più salubri. Esse dovettero essere trasferite in altre 'vilas' adiacenti come Vila Pinto ${ }^{37}$ Risolto questo problema con le armi del dialogo e della motivazione ragionata, la comunità si strinse con unità intorno al progetto; il 20 giugno del '92 uscì il primo numero del giornale realizzato dalle 102 famiglie del quartiere con l'appoggio di 8 alunni del corso di Comunicazione Comunitaria della Facoltà di Giornalismo della UNISINOS (Zero Hora, 22/6/1992).

Per quanto attiene, invece, alle proteste degli abitanti dei quartieri borghesi circostanti, esse non furono incanalate nell'O.P. - dal Comune considerato l'istanza principale dove dibattere queste questioni - ma affidate alla propria rappresentanza politica in Consiglio Comunale, la quale (non riuscendo a portare avanti un'azione politica incisiva) usò la carta della giustizia. L'inizio dei lavori non costituì, pertanto, l'avvio della conclusione della vicenda: un' urgente misura giudiziaria cautelare chiamata 'liminar' e sollecitata dall'ex sindaco Dib, bloccò il 7 luglio l'impresa Archel che aveva vinto l'appalto per le opere (essendosi presentata come unica interessata) ${ }^{38}$ e aveva iniziato la demolizione di Vila Planetario il 26 giugno, dopo il trasferimento delle prime famiglie nelle abitazioni provvisorie di legno costruite nella prospiciente via Olinto, appositamente chiusa al traffico.

La reazione fu "un panico generale. Le case erano state distrutte e la gente sentì che il tappeto veniva tolto da sotto i piedi di tutti [...]. Ma passato l'impatto, gli abitanti si riorganizzarono, portando i figli davanti al Consiglio Comunale. L'agitazione andò a buon fine: le macchine tornarono a funzionare”. (D. Silva, presidente AM, apud Andreatta, 1997). Il pericolo innescò forti reazioni di solidarietà con gli abitanti, persino dalla stampa avversa al progetto e da alcuni settori della classe media del vicinato, ${ }^{39}$ il 9 luglio fu organizzata una marcia di protesta con striscioni che recitavano "Planetario unido jamàs serà vencido", il seppellimento simbolico di un fantoccio rappresentante 'la povertà', e l'impiccagione di un altro rappresentante il Consigliere Dib. Il 20 luglio, il Tribunale di Giustizia sospese il liminar, ma il 4 agosto Dib si rivolse nuovamente alla giustizia, ottenendo un secondo blocco temporaneo dei lavori per un altro presunto 'vizio di forma' che la PGM del Comune dimostrò inconsistente.

La polemica di cui l'ex-sindaco Dib si fece portavoce lo oppose al Comune in un dialogo fra sordi, in cui la sua idea di vendere il terreno per comprarne di maggiori in periferia ed ospitare così più persone ${ }^{40}$ era smascherata dall'Amministrazione Popolare come un modo politicamente corretto di sostenere "l'indecenza dell'atto di concedere ai poveri terreni di valore nel centro cittadino" (B. Alfonsin, 1999i-III, apud Allegretti, 2000a). In questa idea, Dib si vide appoggiato anche da noti architetti e urbanisti cittadini che attraverso l'ampio spazio dedicato loro dai media locali avversi all'operazione - dichiararono che l'intervento del Jardim Planetario legittimava un processo di "appropriazione di un bene pubblico senza concorrenza" e accreditava un'interpretazione degli articoli dello Statuto Comunale relativi alla CDRU come congelamento dell'eccezione a detrimento della creazione di una regola di intervento nell'ambito della città informale. Dib trovò inattesi e numerosi alleati all'interno dell'Amministrazione: la lunga lista di pareri dati dalla SPM sul pre-progetto del Jardim Planetario costituisce un capolavoro delle strategie messe in atto dalla burocrazia per snervare e far capitolare il Sindaco. 
500 Se, pertanto, alla fine l'opera fu realizzata, lo si deve all'alto livello di convinzione che animava l'equipe del PRF (che lavorava con organico ridotto a beneficio di oltre 2600 famiglie), supportato da un uso strumentale del rispetto delle gerarchie istituzionali a cui l'Amministrazione Popolare ricorse, per non restare impantanata in una polemica che avrebbe potuto indebolire la sua linea politica. Le prime nove case in muratura furono consegnate il 28 settembre dello stesso anno, e le altre dopo le elezioni; il capannone usato come 'casa di passaggio' - donato al DEMHAB dall'impresa Archel - fu, invece, abilmente 'riciclato' e ricostruito con funzione di scuola nel Loteamento Wenceslau Fontoura. La modalità di demolizione con ricostruzione (scelta a motivo delle condizioni estreme della 'vila' ma, forse, anche per minimizzare l'impatto estetico dell'insediamento sull' area centrale, venendo così parzialmente incontro ad alcune preoccupazioni dei vicini) suscitò dubbi e malumori anche internamente allo stesso fronte progressista favorevole all'opera, venendo associata ad una nuova forma di manifestazione dell'antico discorso igienista (fin troppo ricorrente nella storia della città) il cui fantasma fu ambiguamente ventilato anche dall'opposizione politica, convinta che "non si estirpano i fuochi della miseria truccando le favelas", ${ }^{41}$ cosa che l'insieme coerente delle Politiche messe contestualmente in campo dall'Amministrazione Popolare decisamente non lascia pensare che si stesse facendo. Oggi, il rinnovato Jardim Planetario è stato cancellato dalla Mappa dell'Irregolarità Fondiaria redatta dal DEMHAB, pur non essendo in realtà ancora terminato il processo di legalizzazione dell'area con la registrazione della CDRU al Catasto. Per questo, nell'analoga carta redatta dalla SPM - il cui approccio è ben più legalista di quello del Dipartimento alla Casa - il Planetario figura ancora come 'area irregolare'; e così è considerato purtroppo anche da alcuni suoi abitanti, e soprattutto dalle favelas vicine (inclusi i delegati dell'O.P.), che continuano significativamente ad includerlo nel novero delle 'vilas'. Sono, invece, notevolmente migliorati i rapporti dell'insediamento con il vicinato, come dimostrano fatti fino al ' 92 impensabili: la cattura di un ladro d'auto favorita dalla collaborazione degli abitanti, il fatto che quotidianamente molti dei 219 alunni e dei 40 impiegati dell'istituto per sordomuti accanto, usano il Jardim Planetario in guisa di 'scorciatoia' per recarsi dalla fermata dell'autobus alla scuola, e il fatto che l'asilo a gestione comunitaria che si trova in un canto dell'insediamento ospita alunni provenienti dalle aree circostanti e non più solo dall'interno della ex-favela.

A distanza di tempo, il vincolo temporale che costrinse i progettisti dell'opera ad agire in tempi ristretti (a motivo delle vicine elezioni comunali a cui il PT voleva presentarsi con il nuovo 'biglietto da visita') è stato forse il maggior responsabile di alcuni limiti che oggi si possono attribuire all'esperimento. Ad esempio, si è dovuta fare una concessione ad un'occupante ${ }^{42}$ che da 17 anni abitava in una casa in muratura di 88 metri quadri e aveva intrapreso un'azione legale contro il Comune per non doverla sostituire con un'abitazione più piccola di 30 mq; sebbene l'azione fosse senza speranze di essere accolta, sarebbe stata sufficiente a posporre di alcuni mesi i lavori, e così il Comune dovette cedere al ricatto. Ma, soprattutto, non si è potuto approfondire lo studio architettonico-urbanistico dell'insediamento, e - soprattutto - non lo si è potuto fare con sufficiente tempo per poter cogliere al meglio suggerimenti e necessità degli abitanti. Aguiar (1998) ha portato avanti un'analisi del progetto basata sul metodo di Hillier e Hanson detto della 'sintassi urbana', arrivando a concludere che - 
per il modo in cui fu realizzato - il Jardim Planetario non pareva mirare "all'obiettivo messianico di tradursi in integrazione comunitaria" rispetto al quartiere circostante, ma semmai ad un "contrasto voluto" per creare "un segnale", qualcosa di provocatorio che "invece di apparentarsi all'estetica della città esistente", da quella avesse voluto "differire radicalmente". Con questa conclusione (che in realtà nel testo costituisce una premessa), tutta l'analisi puntuale svolta da Aguiar non appare che una posizione politica avversa a quella dell'Amministrazione, spacciata per una serena e oggettiva analisi scientifica. E se, forse, la critica sull'introversione urbanistica del Planetario sarebbe stata anche legittima se espressa con onestà intellettuale, mascherata dietro questa apparente oggettività extra-giurisdizionale, essa appare dubbia. Non si può negare che il Planetario abbia voluto essere un 'marchio', ma non di pura polemica, bensì di un costruttivo tentativo di capovolgere l'acritico sottostare ad una tradizione di distribuzione della rendita urbana che Aguiar descrive come "tendenza naturale". Va anche detto che un modo di vita non dissimile da quello piccolo-borghese di molte zone della città formale è il modello stesso di immaginario a cui i 'vileiros' atting ono quasi sempre quando interpellati sui loro desiderata relativi all'alloggio. Pertanto è il modo che essi - in qualità di abitanti - ritenevano più giusto per sentirsi integrati nell'intorno (come la nuova denominazione 'Jardim Planetario' attesta), l'obiettivo che Aguiar nega sia stato raggiunto con la provocatoria realizzazione.

L'esito di tali critiche, purtroppo, ha solo il risultato di riconfermare l'incomunicabilità fra architettura e politica che a Porto Alegre in questi anni si è spesso rivelato come incolmabile 'scarto' fra mondo accademico e mondo dell'azione concreta. Ė indiscutibile, però, che il disegno sia urbanistico che architettonico del Jardim Planetario non rappresenti particolare innovazione o creatività. Ciò si spiega con la mancanza di esperienza del Comune in questo ambito di intervento e con i limiti spaziali, temporali e finanziari con cui la ricostruzione ha dovuto fare i conti. Il nuovo 'Jardim Planetario' (90 lotti di 44 e 49 mq: 15 occupati da case monopiano, 52 di case a due piani con due stanze e 27 di tre stanze) si è così distinto per una struttura bloccata, concepita per non permettere adeguamenti individuali dello spazio nel corso del tempo ed incapace di venire incontro all'abitudine alla mobilità interna delle famiglie che è tipica delle aree informali. Molte 'limitazioni' furono in realtà discusse con gli abitanti, e da essi accettate, anche nel timore che un eccesso di richieste potesse mettere a rischio il recupero dell'area.

Seppur in un lasso di tempo molto breve, infatti, vi fu però uno stretto contatto fra istituzioni e cittadini, che ha in parte determinato le caratteristiche funzionali ed estetiche dell'opera così come è oggi. In base a questa interazione fu confermata la proposta del Comune di dare ad ogni abitazione un accesso a piano terra (SPM/PRF, 1992), scartare le ipotesi alternative di progetto che prevedevano edifici più alti e maggior spazio per le attività comunitarie ${ }^{43}$ la circolazione ed anche (in una delle 5 ipotesi) eventuali parcheggi. ${ }^{44}$ La mancanza di spazi di circolazione carrabile fu una scelta degli abitanti per "minimizzare $i$ pericoli per $i$ bambini" ma anche motivata dall'indigenza delle famiglie, come spiegato con durezza nella Nota del progettista sul Parere 464 emesso dalla SPM. Tuttavia, oggi - approfittando della mancanza di controllo da parte dei vigili urbani - non è insolito vedere auto all'interno dell'isolato accanto ai carretti da 'papeleiros' (anch'essi vietati). È stata addirittura costruita una piccola rampa abusiva all'in- 
502 gresso ovest (quello più nascosto) per superare i gradini appositamente costruiti dalla SPM proprio per evitare l'ingresso delle auto nell'insediamento. Durante la fase di progetto, altre due scelte importanti furono messe in discussione; se ammettere nell'insediamento anche persone provenienti da altre 'vilas' o da aree di rischio (eventualità avversata dall'equipe del PRF e bocciata subito dai residenti) e se conservare o distruggere le 9 abitazioni in muratura già esistenti ( 3 in buono stato e 6 in condizioni accettabili), che potevano essere inserite in lotti di progetto senza demolirle. La comunità alla fine votò quasi compatta per la demolizione, nell'idea di ottenere un insediamento più omogeneo ed ordinato, cioè per le stesse ragioni portate dal Comune, per cui lavorare su un'area vuota sarebbe stato più semplice e rapido. La seconda discussione - non assembleare ma per commissioni rappresentative - fu sulle dimensioni dei patii di servizio sul retro dei lotti. I rappresentanti della comunità li sollecitarono piccoli per evitare che qualcuno costruisse stanze da affittare, fornendo ai tecnici del Comune - che ancora si dicono segnati da quella esperienza di 'corpo a corpo' con gli abitanti- preziose indicazioni sui comportamenti e i dettagli progettuali da evitare per minimizzare i successivi problemi di gestione, anche in termini di sicurezza. ${ }^{45}$

Il terzo punto di discussione comunitaria fu relativo alla conservazione di alcune attrezzature comuni come il forno comunitario, l'atelier di cucito o le attrezzature religiose cattoliche ed evangeliche, che non erano facilmente giustificabili per la legge sulla CDRU, in quanto attività non residenziali. Gli abitanti dissero che molte di quelle attrezzature erano in disuso e che preferivano più spazio per loro. La mediazione non fu facile, perché le suore facevano pressioni sul Comune per restare; alla fine, per non fare ingiustizie, fu soppresso anche il piccolo centro comunitario previsto in un angolo rimasto vuoto, ma rimase una piazzetta, pressoché imposta dal coordinatore del PRF, Gilson Lima, ai residenti che "temevano rubasse spazio a loro e venisse occupata da altri disperati" (Guimarães, 1999i-I, in Allegretti, 2000a). Inserendosi il 'reassentamento' in un'area centrale e ricca di molteplici attività differenziate, non furono previsti esercizi commerciali: oggi ve ne sono due 'informali' in funzione, peraltro ricavati al piano terra delle abitazioni dei loro proprietari e 'tollerati' dal Comune. Le strutture comuni oggi visibili furono 'recuperate in extremis': il Catasto, infatti, descriveva solo per scritto (senza piante) i confini del lotto dove era installata la 'vila', facendo riferimento al fiume Diluvio di cui nel frattempo era stato rettificato il corso. Per questo motivo, i tecnici del Comune proseguirono nelle operazioni di ridisegno graduale dei lotti immaginando di lasciare libero lo spazio conteso. Verificata l'assenza di proteste e rivendicazioni, 'informalmente' ne attribuirono al Comune la titolarità, disegnando un centro Comunitario che venne realizzato senza aumenti di spesa dall'impresa, che aveva avuto l'appalto per un numero superiore di case (94 invece di 90), alcune delle quali poi soppresse dal trasferimento altrove di alcune famiglie che si scoprì erano arrivate dopo l' '89. La chiave fu affidata al presidente dell'AM, che 6 mesi dopo litigò con la moglie e lo occupò. Oggi l'AM è una semplice saletta; il Comune non ne volle più sapere nulla e chiuse gli occhi su quanto accadde dopo la consegna (Guimarães, 1999i-II). Lo stesso è accaduto con il Club delle madri, dove oggi vive la nipote di un'abitante del luogo che doveva starci qualche giorno in attesa di un trasloco. Peraltro, oggi va anche segnalato un notevole rifiorire delle attività lavorative domestiche e di quelle legate al 
riciclaggio dei rifiuti, che cominciano a riempire i patii di tutte quelle famiglie oggi maggiormente colpite dalla recrudescenza della crisi economica brasiliana. Quest'ultima ha probabilmente dato il suo contributo ad un peggioramento nelle condizioni di manutenzione dell'edilizia residenziale, ed in particolar modo degli spazi comuni, concepiti in forma di uno spazio centrale di sosta e di aree pedonali con vialetti di 3 e 2 metri di larghezza (uno solo è di 4 metri, per l'eventuale passaggio di mezzi di emergenza) fronteggiati da piccoli spazi semipubblici che migliorano la percezione dell'ambiente e - contribuendo ad accrescere la distanza fra alloggi prospicienti - anche l'illuminazione e la ventilazione delle abitazioni. La piazzetta verde, versa oggi in condizioni di totale incuria: il Comune si è, infatti, affidato troppo ad un intervento di cura aut organizzata dei residenti che non è mai arrivato. ${ }^{46} \mathrm{~A}$ posteriori:

\footnotetext{
"Non si può dire che al Planetario vi fu una vera progettazione partecipata, nella misura in cui la responsabilità maggiore della progettazione è rimasta su noi tecnici. Non avremmo neppure potuto metterci lì a chiedere alle persone cosa e come lo volevano, perché vi era il rischio di creare attese troppo grandi e perdere molto tempo, e d'altro canto c'erano fondi limitati e tempi stretti [...]. Abbiamo però discusso passo passo le varie ipotesi che presentavo via via alla comunità della Vila [...] All'inizio avevo fatto un modellino con i mattoncini Lego, poi ho visto che imparavano anche a leggere le piante. Andando avanti, abbiamo ottenuto delle piccole vittorie di cui siamo fieri; e dei momenti di crescita comune importanti, come la ri-locazione di una coppia gay nell'angolo sudest [...]. Solo 3 famiglie su 100 che parteciparono alla prima discussione sulle piante degli alloggi non concordarono [...] La grande soddisfazione è stata per me ricevere una lettera di gratitudine alla fine della realizzazione." (Guimarães, 1999i-I, in Allegretti 2000a).
}

Verso la conclusione di questo pur rapido processo di interazione progettuale con gli abitanti, fu messa in discussione la destinazione di alcuni fondi avanzati dal finanziamento previsto. Qui, l'eccessiva fretta e l'incapacità dei tecnici di imporre la propria visione a 'lungo termine' sull'immediatismo dei cittadini, non ha dato risultati particolarmente avanguardistici. Nell'opzione se acquistare controsoffittature da mettere sotto il tetto a falde o serbatoi d'acqua, gli abitanti scelsero i secondi, facendo risparmiare il Comune, ma commettendo un errore a discapito del proprio interresse; perché i cassoni dell'acqua erano più economici e richiedevano meno manodopera, e avrebbero potuto metterli da soli posteriormente. Il risultato è che pochissime famiglie oggi hanno potuto dotarsi di un controsoffitto che le protegga dagli sbalzi termici, e devono ricorrere ad impianti di condizionamento e riscaldamento.

Una battaglia personale vinta dall'architetto che progettò il Jardim Planetario fu la scelta delle tegole in laterizio, con miglior resa estetica e termica, nonostante un costo leggermente superiore al fibrocemento. "Era un risparmio piccolo, che non valeva la pena, ma non fu semplice convincere le persone e anche $i$ sovrintendenti del Comune a pensare su tempi lunghi, in cui le tegole mostrano vantaggi economici, perché ne puoi sostituire alcune e non devi cambiare tutto il tetto o metà di esso. Mi alleai con i rappresentanti popolari più colti, e, quando la gente capì, il loro appoggio servì a far pressione sui miei superio$r i$ " (Guimarães, 1999i-I, apud Allegretti, 2000a). Un'altra vittoria riguardò le scale interne, che il DEMHAB voleva di $60 \mathrm{~cm}$.; il progettista convinse gli abitanti che $70 \mathrm{~cm}$ potevano facilitare il trasporto dei mobili e la scelta passò.

La partecipazione innescò, così, sia meccanismi di interazione tra saperi 
504 'scientifici' e saperi 'laici', sia forme di collaborazione inter-istituzionale, e moltiplicò il dialogo in sedi diverse dal Bilancio Partecipativo, andando oltre la discussione di 'priorità' per attestarsi sul dettagliamento di scelte tecniche. Nonostante i limiti e le costrizioni a cui fu soggetto, il progetto di trasformazione di Vila Planetario si è, quindi, rivelato un successo, sia per avere innescato un effetto domino che attrasse altre migliorie nelle aree circostanti (il restauro del Planetario a lato, il recupero della piazzetta verde oblunga sul lungofiume Ipiranga), sia per aver generato un effetto trascinamento nei confronti di operazioni consimili meglio studiate (nello stesso centro storico). Ma, soprattutto, per aver raggiunto i suoi principali obiettivi, contribuendo alla ricostruzione dell'autostima e del senso di cittadinanza degli abitanti, e liberando energie individuali e collettive per un miglioramento della situazione socioeconomica degli stessi. Del resto, lo stesso quotidiano Zero Hora (di fede politica avversa al fronte Popolare) il 13/4/1993 (4 mesi dopo la conclusione dei lavori) elencava i benefici ottenuti dal nuovo insediamento sui suoi abitanti: un aumento superiore al 50\% del numero degli impieghi stabili fra i suoi residenti (il 50\% nell'ambito di concorsi pubblici presso il DMLU, gli altri nell'edilizia, nell'assistenza meccanica e nel commercio), diminuzione dell'alcoolismo e delle malattie infantili, scomparsa di topi e scarafaggi. E questo, nonostante la drastica decisione del Comune di non costruire nessun deposito di materiali di riciclaggio per favorire i papeleiros già all'opera nella Vila, dovuta a motivi di spazio, troppo ristretto per riospitare una convivenza quotidiana con i rifiuti.

Oggi, comunque, non tutto si è mantenuto secondo le previsioni. Il Regolamento di Condotta ha previsto regole ${ }^{47}$ che avrebbero dovuto garantire al Comune (amministratore del condominio in co-gestione con un residente eletto annualmente) un certo livello di manutenzione e di ordine dell'insediamento, ma esse sono state sostanzialmente ignorate: una signora ha persino unito due case sfondando un muro interno, anche se ad oggi non si contano molti 'puxadinhos', ovvero ampliamenti di vani a detrimento dei minuscoli patii tergali o degli spazi semipubblici sul fronte principale delle abitazioni. Si vanno, però, diffondendo varie forme di 'appropriazione dello spazio' da parte dei residenti, visibili dall'esterno (all'interno le situazioni sono così multiformi da essere difficilmente descrivibili per sommi capi), quali il cambio degli infissi, la disposizione di tettoie o grate alte intorno al patio di accesso, colorazioni diverse date ai manufatti, il cambiamento delle aiuole e delle piastrelle delle verandine all'ingresso, il taglio delle grate di sicurezza delle finestre del secondo piano, ritenute un elemento di sicurezza per i più ma per altri un ostacolo a stendere i panni o a disporre fiori su mini-balconcini sospesi.

L'errore maggiore è stato abbandonare la popolazione un po' a se stessa dopo la costruzione del Jardim Planetario, senza farle sentire né il controllo pubblico sui loro comportamenti né, soprattutto, la voglia di aiutarli a crescere. Ad esempio, era previsto un programma di educazione ambientale ed è stato abbandonato. Come ci rimproverò sorella Udila, la suora che seguiva le attività di creazione di reddito nella Vila prima che i suoi atelier fossero estromessi dal nuovo progetto, non basta dare un habitat nuovo; è necessario dare accompagnamento e assistenza. Non si può pretendere che il senso di cittadinanza nasca da un giorno all'altro, spontaneamente. Va colti vato (Guimarães, 1999i-I, a pud Allegretti, 2000a).

Ai limiti di concezione dello spazio fisico e di gestione delle prime fasi, la vicenda del Planetario ha aggiunto un sostanziale disinteresse per il monitoraggio e la 
valutazione 'a posteriori' degli esiti raggiunti, in rapporto agli obiettivi con cui era stato motivato il progetto. In realtà, l'architetto Guimarães (incaricato della progettazione generale ed esecutiva) presentò un documento iniziale piuttosto ricco sotto il profilo della metodologia di intervento da portare avanti; esso venne però sostanzialmente disatteso, per certi versi anche in direzione migliorativa (come nel settore della partecipazione popolare alle discussioni, che nella realtà risultò ampliata). Così, il Comune di Porto Alegre ha perso l'occasione per valutare dettagliatamente non solo l'integrazione sociale ottenuta, ma anche gli esiti dello strumento della CDRU, che ad oggi segna il maggior successo di Vila Planetario. Come ha, infatti, recentemente verificato una ricerca comparativa coordinata da un'università inglese (Fernandes, 2001), dopo 10 anni solo 1 famiglia delle 90 reinsediate ha tentato di vendere la chiave dell'appartamento dato dal Comune e andare altrove, ed è stata peraltro costretta dallo stesso a fare marcia indietro; una percentuale bassissima, se si pensa al fallimentare intervento di CDRU promosso nel 'reassentamento' di Vila Tripa nel Loteamento Wenceslau Fontoura, dove solo il $70 \%$ delle famiglie originarie ha 'venduto la chiave', essendogli state tolte tutte le reti lavorative-amicali senza dotarle, tempestivamente, di opportunità e politiche integrate mirate alla creazione di reddito nel nuovo insediamento. Questo elemento che connota il successo del Planetario, in quanto progetto basato sulla 'valorizzazione delle reti sociali e lavorative già tessute dalla popolazione insediata', stranamente non è mai stato divulgato con enfasi dall'Amministrazione, soprattutto a motivo del fatto che non è mai stato ufficialmente valutato (solo qualche tecnico ne ha 'informalmente' preso atto); il che appare grave per un'area che doveva essere il terreno-volano della prima sperimentazione relativa allo strumento giuridico della CDRU in aree informali centrali.

È stato così completamente disatteso l'invito che lo stesso progettista del Jardim Planetario aveva rivolto nell'ottobre del 1992 all'Amministrazione, ${ }^{48}$ attraverso un'articolata proposta di una equipe minima che portasse avanti un'attività di Valutazione di Impatto, per sistematizzare - ricomendo ad una metodologia aperta e da ridefinirsi parzialmente in corso d'opera - il "contributo di orientamento" che un progetto sperimentale (e con pochi esempi simili a cui attingere nel contesto latino-americano) poteva offrire al perfezionamento dell'approccio di alcune politiche abitative legate all'ambito della città informale.

[...] Purtroppo, le autorità, in generale, hanno mostrato resistenza a valutazioni sistematiche delle proprie realizzazioni, fatto che rende difficile lo sviluppo di strate gie non convenzionali. Un lavoro di convincimento deve essere portato a vanti anche sotto questo aspetto (Guimarães, 1998).

\subsection{Da Vila das Placas al Condominio dos Anjos: il sogno di essere 'normali'}

Dopo l'esperienza di 'reassentamento no local' di Vila Planetario, altre baraccopoli del centro cittadino hanno stretto alleanze per farsi finanziare dal Bilancio Partecipativo studi di fattibilità per un reinsediamento sui siti ormai occupati, spesso riuscendoci già nel 1992. Alcune, in seguito a questi studi, non sono riuscite a garantirsi la permanenza in loco: è il caso di Vila Zero Hora e del Beco dos Servidores (uno stretto vicolo che parte da un cancello su strada e penetra in un'impressionante 'vila' senza altri sbocchi, abitata quasi completamente da impiegati del DMLU), che insieme contano 202 abitazioni (DEMHAB, 1999). Nel 1994 fu ipotizzata la ricostruzione di 
506 questi due aggregati di abitazioni all'interno del Programma 'Centro de Bairro' del quartiere Azenha, chiarendo che la situazione proprietaria dell'area (già interessata da parziali sgomberi ordinati dall'autorità giudiziaria) richiedeva il trasferimento in un'area vicina acquistata dal Comune. ${ }^{49}$ Ma la comunità si dimostrò disunita, senza contare che il presidente dell'Associazione di Vicinato pareva poco interessato a modificare la struttura della 'vila', adatta a proteggere dalla polizia alcune gang del traffico di stupefacenti: e così - visti i principi con cui tutto si muove a Porto Alegre - nulla di quanto più volte ipotizzato dal Comune è mai accaduto, mancando la collaborazione dei cittadini nell'O.P. Solo nel 2000, gli abitanti hanno trovato coesione, ottenendo nel Bilancio Partecipativo il finanziamento del primo nucleo di 23 alloggi, oggi in corso d'opera, per cominciare a risolvere i problemi di disagio abitativo.

Altre 'vilas' sono, invece, riuscite ad ottenere il 're-insediamento in loco' sul modello del Jardim Planetario. Tra esse, Vila Lupicinio Rodrigues, una baraccopoli nata nel 1959 su un terreno pubblico municipale ai margini di un corso d'acqua (il Diluvio) di cui fu poi regolarizzato il corso. Formata da 71 baracche che ospitavano 82 famiglie (300 persone, il 50\% delle quali minori di 19 anni) con condizioni economiche e di alfabetizzazione estremamente disagiate.

Nel 1993, il PRF eseguì uno studio di fattibilità finanziato attraverso la voce 'spese di gestione' del bilancio (e quindi esterno all'O.P.), e tra il '96 e il '97 gli abitanti ottennero nel Bilancio Partecipativo 7700.000 R\$ di fondi PróMoradia (con contropartita del 32,21\% del Comune) per la realizzazione delle unità abitative necessarie alla ricostruzione. Il progetto, concepito in un solo mese di tempo per non perdere il finanziamento, è stato solo 'accompagnato' dai beneficiari, ma l'interazione tra l'architetto del DEMHAB incaricato e gli abitanti ha introdotto notevoli variazioni sugli studi precedentemente condotti dal PRF (cfr. Allegretti, 2000a), abbassando da 4 a 2 piani le stecche di alloggi, aumentandone a 4 le diverse tipologie (monolocali e appartamenti ad 1, 2 e 3 stanze) ed introducendo piccoli patii, un asilo comunitario e un muro di separazione visuale dall'intorno sul lato tergale (Campos, 2001i). Ma, soprattutto, con un intenso lavoro di formazione comunitaria, i lati su strada dei blocchi dei nuovi appartamenti (terminati nel 2000) ${ }^{50}$ sono stati istoriati con dei mosaici ceramici realizzati nel 2001 dagli 'ex-vileiros', ispirandosi alla vita del musicista che dà il nome al Condominio nel quale ora abitano.

Nelle adiacenze, anche Vila Renascença - 47 domicili aggregati da oltre 40 anni intorno ad un fronte principale che dà sul lungofiume detto Ipiranga (DEMHAB. 1999) - ha ottenuto una forma particolare di 'reinsediamento in loco'. Diversamente da altre favelas di Porto Alegre, la Renascença era abitata da un 10\% di anziani ultrasessantenni e da una popolazione con reti lavorative 'stabili' ${ }^{51}$ Grazie alla buona organizzazione dei suoi abitanti, stretti intorno all'Associazione dei Residenti $[\mathrm{AM}]$ e alla Delegata nell'O.P., la Renascença I per due volte è stata contemplata all'interno dell'O.P. per l'urbanizzazione e la legalizzazione dell'area. Il tipo di 'reassentamento' ottenuto è anomalo, perché parziale, realizzato in più tappe e per interventi puntuali; un ibrido tra la regolarizzazione fondiaria $\mathrm{e}$ il 'reassentamento' di stampo 'igienista' (Rigatti, 1998i, in Allegretti 2000a) che di solito viene scelto per il centro cittadino. La via trasversale aperta nel 1996 per decongestionarne la densità è oggi un luogo affascinante, fiancheggiata dai murales coloratissimi realizzati dai bambini della comunità per raccontarne la storia di riscatto.Uno degli aspetti più interessanti di questo esempio è come 
ha funzionato il meccanismo dell'innesco di miglioramenti autoprodotti che l'Amministrazione ha sempre tentato di promuovere, fin dall'approvazione della Legge sulla CDRU, applicata in quest'area. Oggi, ben 19 delle famiglie residenti nella Renascença I hanno scelto di riformare la casa per conto proprio, rispettando i criteri urbanistici e architettonici decisi d'accordo con il DEMHAB (da Silva S. M., 1999i, apud Allegretti, 2000a).

La più interessante tra le esperienze di 'reassentamento no local' successive all'esempio di Vila Planetario è, però, quella del Condominio dos Anjos, costruito grazie ai fondi Pró-Moradia ottenuti nel 1997 nel Bilancio Partecipativo dalle 61 famiglie $(255 \text { persone })^{52}$ di Vila das Placas. Nel PI del 1992 (anno in cui fu finanziato il rilievo necessario ad essere inclusa nel PRF) e poi del '98, l'area figura col nome di 'Condominio La Plata'. Un grosso errore, vista la rivalità (o almeno la carenza di dialogo) esistente fra Vila La Plata e Vila das Placas, in realtà due parti di un isolato unico che il PRG prevedeva come piazza e che fu occupato nel $1960 .{ }^{53} \mathrm{Nel}$ suo complesso, l'area affacciava su due strade opposte (via La Plata e il lungofiume Ipiranga) ed era composta di due raggruppamenti di case separate da un alto muro.

Già dal 1992 l'architetto Guimarães (lo stesso del Planetario) aveva cominciato a studiare qualche ipotesi organizzativa, ma con la destrutturazione dell'equipe gli studi andarono perduti. Successivamente- discutendo con i tecnici del Comune, proprietario dell'area - gli abitanti si sono resi conto che la redistribuzione dei lotti sarebbe stata equitativa; perciò la maggioranza degli abitanti della parte chiamata La Plata hanno deciso di desistere dalla richiesta, visto che i grandi lotti di cui si erano appropriati sarebbero stati penalizzati. Solo 9 famiglie hanno cercato di aggregarsi alla regolarizzazione fondiaria, restando però in minoranza all'interno della propria Associazione di Quartiere. ${ }^{54} \mathrm{~A}$ dispetto dell'opposizione del Comune per questa divisione, solo gli abitanti di Vila das Placas hanno portato avanti la richiesta nell'O.P., nel 1997 ottenendo 871.280 R \$ (con contropartita comunale del 51,80\%) per la regolarizzazione dell'insediamento. Gli altri abitanti hanno continuato a cercare di negoziare singolarmente la vendita dei terreni.

Vila das Placas ${ }^{55}$ - anche grazie alla sua posizione privilegiata - era abitata da una comunità ben servita di mezzi di trasporto ed attrezzature collettive per lo sport, il tempo libero e la salute; restava però precaria l'infrastruttura (reti di acqua, luce e fogne), cosa che la differenziava dalle condizioni migliori in cui si attestavano le 20 abitazioni della 'rivale' Vila La Plata, i cui occupanti hanno lavorato in proprio per costruire allacciamenti (persino quelli alle reti di Tv via cavo). Accanto a Vila das Placas vi era un deposito del DEP ed un'area ricreativa per i suoi dipendenti, oltre alle sedi di due scuole di Samba molto note in città: la Società Ricreativa Culturale Embaixadores do Ritmo, e la Sociedade Recreativa Cultural e Beneficiente Garotos da Orgia. All'epoca dell'indagine socioeconomica, la densità abitativa appariva piuttosto elevata, con una media di 4,4 persone per abitazione e un reddito medio di 1,64 salari minimi per famiglia, con 1'89,90\% della popolazione che non superava i 3 (UPE/DEMHAB, 1999). ${ }^{56}$

Vila das Placas aveva un carattere molto particolare, in quanto piuttosto omogenea nella composizione; gran parte dei suoi abitanti venivano dalla stessa località rurale - São Gabriel - e vi era una forte unità di intenti e posizioni che l'hanno trasformata da una delle favelas più violente di Porto Alegre in una delle più pacifiche e organizzate (UPE/DEMHAB, 1999). Alla fine del 1987 l'AM - 
508 prima informale - fu registrata nel Diario Oficial do Estado, in tempo per partecipare alla distribuzione clientelare dei ticket del latte. Scomparsa ufficialmente tra il 1994 e il 1995, dopo i fallimenti delle prime richieste di regolarizzazione fondiaria nell'O.P., rinacque nel 1996. Negli ultimi anni, la comunità si è mostrata molto attiva in vari forum dell'O.P., nella Conferenza di Assistenza Sociale e nel COMATHAB, nei Comitati del Consiglio tutelare e dal 1997 nei programmi di alfabetizzazione per adulti del MOVA, costruendo una rete di scambi con altri quartieri che le ha permesso di ottenere nel COP il progetto di riurbanizzazione. Il progetto di 'reassentamento no local' aveva già un nome (ed uno Statuto di Convivenza redatto collegialmente dagli abitanti) ${ }^{57}$ prima che - nel maggio 1999 - fosse conclusa la demolizione della baraccopoli: la denominazione Condominio degli Angeli nacque per suggerimento della stessa popolazione che non voleva più alcun legame con il suo passato, nonostante come ultimo atto prima dei lavori gli alunni del corso di alfabetizzazione per adulti abbiano redatto un documento di ricostruzione storica dell'identità e delle vicende del quartiere.

Il progetto è stato firmato dall'architetto Sonia Maria da Silva del DEMHAB (che lo rilevò nel 1993 dall'agonizzante equipe riunita intorno alla PGM nell' ambito del progetto AEIS), la quale - fin da subito - si è proposta di riformularlo insieme ai beneficiari.

Una regolarizzazione o un'urbanizzazione di una Vila non è come una normale costruzione civile che consegni a degli utenti. Devi stare insieme con le persone, perché ti intrufoli nella loro vita. Devi dedicare tempo a dialogare, a spiegare, a chiarirti le idee. Però è soddisfacente. Tutto è più doloroso, difficile e sterile senza un contatto diretto con gli abitanti. Per me è un obbligo morale mostrare e alterare il progetto in base ai loro suggerimenti; solo così mi riempio di suggestioni tecniche che seguono la realtà concreta dei problemi [...] Una grande resistenza, certo, è l'uso che al DEMHAB si fa della casa standardizzata. Una vila vive di case costruite su misura, anche se vincolate dalle risorse [...] Così per la riprogettazione de Las Placas ho cercato di cambiare registro; ho studiato i problemi individualmente, cosa che in un 'reassentamento' è più facile che in una semplice regolarizzazione fondiaria. C'era una polemica sugli scapoli che abbiamo cercato di risolvere con miniappartamenti per non creare ingiustizie con alloggi unici per tutti come nella Cavalhada (da Silva S. M., 1999i, apud Alle gretti, 2000a).

Non appena ottenuti nell'O.P. i fondi per la ricostruzione, e prima che il DEMHAB potesse fare il censimento, a Vila das Placas sono arrivati nuovi aspiranti residenti, addensandola. Così, si è dovuto optare per una verticalizzazione, progettando edifici di 2 piani e mezzo, e reinsediando anche i negozi esistenti nella 'vila'(che differiscono in alzato ma non in pianta dalle abitazioni) rivolgendoli - per migliorare i loro affari - verso l'Ipiranga; questo atto è stato necessario "per salvaguardare le condizioni di vita degli abitanti, che è uno degli scopi del 'reassentamento no local" (da Silva, 2002i). Le negoziazioni (svolte all'esterno del processo dell'O.P., che non si occupa di questi aspetti di dettaglio) sono risultate tutt'altro che semplici, e l'architetto ha contribuito notevolmente alla loro riuscita, ottenendo persino un' area appartenente alla Scuola di Samba, che ormai pareva invischiata in un 'muro contro muro' col presidente dell'AM locale. In tal modo, l'area di costruzione ha potuto aumentare, rendendo possibile la realizzazione di 2 unità in più in un'area del DEP e di 5 a lato della Scuola di Samba. Conclusa questa fase, gli abitanti sono stati chiamati ad affrontare il tema della tipologia residenziale preferita per il 'reassentamento'. Il risultato ha sorpreso il DEMHAB, convin- 
to che la presenza del vincolo di AEIS sull'area avrebbe semplificato la ricostruzione, in deroga ad alcuni parametri urbanistici convenzionali (circa la larghezza della viabilità interna, i parcheggi, le dimensioni dei lotti e delle case). Invece è accaduto che la maggioranza dei residenti abbia rifiutato il ricorso ai vantaggi dell'AEIS in nome di un desiderio di riscatto sociale completo.

Una delle prime cose che mi fu chiesto era di progettare delle abitazioni da approvarsi come regolari case private, senza i vantaggi delle AEIS. Gli abitanti volevano rientrare a pieno diritto nella città formale, eliminare quello stigma negativo e compromissorio che Vila Planetario ancora mantiene. Per questo erano disposti a penare e ad aspettare. Il progetto è per questo risultato complesso. Ho dovuto giocare con i centimetri. Ad esempio accrescendo le scale ho avuto enormi problemi col Regolamento edilizio. Ho dovuto persino ricavare dei parcheggi, i cassoni per i rifiuti ed il posto per il portiere. A parte queste difficoltà credo che alla fine il risultato se ne sia giovato (Silva, Sonia Maria da, 1999i, a pud Allegretti, 2000a).

Il Condominio è stato realizzato in più tappe (a partire dall'agosto 1999 fino al primo semestre 2001), anche sui richiesta degli abitanti, che preferivano minimizzare il traumatico periodo nelle 'case di passaggio' adottando una formula solidale di 'mutuo scambio' di ospitalità tra i membri della comunità. Il progetto realizzato consiste in un grande corpo ad U arretrato di 4 metri dal marciapiede e disposto intorno ad un centro semantico su cui si affacciano i patii, che dà le spalle al muro che lo separa da Vila La Plata e si apre verso la Scuola di Samba, ancora da molti avvertita come il centro pulsante del quartiere. Ognuno dei 12 blocchi che lo compongono ha appartamenti di 24, 36 e 49 mq., più un terzo piano di due stanze ed una lavanderia. Nel complesso, una tipologia di organizzazione spaziale in apparenza lontana dalle formule abitative dell'insediamento spontaneo, ma approvata dalla popolazione "che vuole sentirsi dentro lo stesso rigorismo della citta formale ed ha promesso di assumersi l'incarico di una vigilanza reciproca sulle regole di comportamento" (Silva, Sonia Maria da, 1999i, apud Allegretti, 2000a).

L'unità e l'accordo fra gli abitanti si è dimostrato fondamentale nel 1998, quando un docente universitario della UFRGS presentò in pubblico - con prospettive colorate e immagini di corredo attraenti - un progetto polemico da contrapporre a questo, che prendeva come campo d'azione tutta l'area pubblica intorno, compreso il deposito del DEP e parte del Viale Ipiranga; un'idea pertanto irrealizzabile e che pareva solo mirata a creare aspettativa e fomentare le polemiche interne al DEMHAB, già esistenti circa il progetto approvato dalla popolazione di Vila das Placas. Per l'Università e i dirigenti del DEMHAB, che avevano passato a questa dati errati (forse sperando di contribuire a far denigrare il progetto della Da Silva) il risultato dell'episodio fu un boomerang. Non solo, infatti, gli abitanti criticarono duramente il nuovo progetto (che tra l'altro prevedeva 200 alloggi e quindi l'affluenza di nuovi abitanti non accettati dai residenti), ma - sentendosi presi nel mezzo in una lotta interna fra dipendenti del Potere Pubblico - fecero ancor di più quadrato intorno a quello da loro già discusso col DEMHAB, leggendo nella nuova proposta il desiderio di una speculazione edilizia. Tra l'altro, durante questa vicenda gli abitanti - molto impegnati in un tentativo di rinascita - si mostrarono anche molto urtati dalle scritte sotto le tavole universitarie, che riportavano sempre la dicitura "Vila das Placas", ignorando il desiderio dei residenti di ricostruire la propria identità attraverso il riferimento ad una leggenda popolare di 
510 un angelo a cui doveva riferirsi il nuovo nome scelto per il condominio. Oggi, a progetto concluso, i risultati paiono molto interessanti: il nuovo condominio popolare, traendo le conseguenze dall'esperienza-pilota di Vila Planetario e dai suoi limiti, è riuscito ad imporsi come un segnale urbano per il quartiere, grazie anche ai suoi colori vivaci, alle sue forme inconsuete e al buono stato di manutenzione garantitogli dagli abitanti. Al punto che, senza neppure attendere che fosse concluso, i riottosi vicini di Vila La Plata si sono organizzati in sede di Bilancio Partecipativo per ottenere anch'essi un reinsediamento simile. E - già nel Piano degli Investimenti del 2002 - hanno ottenuto i fondi per un censimento topografico-catastale che segna la loro entrata tra gli insediamenti del Programma di Regolarizzazione Fondiaria.

\section{Note}

${ }^{1}$ Il $16 \%$ della popolazione è composta da impiegati nel ramo dei servizi, $10 \%$ del settore secondario, 5\% dell'area commerciale: il $61 \%$ della popolazione attiva è disoccupato. Il $35 \%$ delle famiglie non arriva a 1 Salario Minimo mensile, il $34 \%$ tra 1 e 2 , il $15 \%$ tra 2 e $3,9 \%$ tra i 3 e i 4 e $4 \%$ sopra i 5 Salari Minimi; il $92 \%$ di chi ha lavoro formale o informale lo esercita nell' ambito dell'area metropolitana. Il grado di analfabetismo tra gli adulti è del 6\%, un po' superiore alla media cittadina (METROPLAN/GTZ, 1997).

${ }^{2}$ Di questa il DEMHAB ha curato la realizzazione di un marciapiede, la Metroplan l'altro.

${ }^{3} \mathrm{Ci}$ sono case che ampliandosi a sbalzo sopra le abitazioni contigue vi hanno piantato nel mezzo pali e pilastri.

${ }^{4}$ L'iniziativa dello Stato del Rio Grande do Sul (all'epoca di matrice politica diversa dal fronte Popolare) e della Società di Cooperazione Tedesca [GTZ] è parte di un programma cooperativo più vasto fra la $\mathrm{ABC}$ [Agenzia di Cooperazione Tedesca] e la BMZ [Ministero Tedesco della Cooperazione Economica] aperto a ONG e Enti Locali.

${ }_{5}^{5}$ Oltre alla Tuca vi erano Vila Mato Sampaio/Vila Fatima, Maria da Conceição, Medianera/Tronco e Resting a Velha.

${ }^{6}$ Il DEMHAB cominciò a lavorare tardi con 2 tecnici, poi con uno, e lasciando un interregno di oltre 3 mesi prima che nel luglio 1997 vi cominciasse a lavorare l'arch. Casa Nova, che contattò il suo predecessore personalmente per cercare di dare continuità ad un lavoro già molto sacrificato.

7 "Contro tutto e tutti si scelse di approvare il progetto come una sorta di condominio; un parcellamento avrebbe, infatti, richiesto di lasciare un $35 \%$ area verde, e così in qualche modo si scavalcavano alcuni vincoli. Il condominio avrebbe potuto essere registrato subito, entro 180 giorni dall'approvazione del progetto, ma non lo fu; quindi per certi versi è nato irregolare" (Franceschelli, apud in Allegretti, 2000a).

${ }^{8}$ Di Taut e Wagner (1925-27).

${ }^{9}$ Rigatti, 1997, op. cit..

${ }^{10}$ Cfr. intervista a Camargo (1999i, apud Allegretti 2000a).

${ }^{11}$ L'Unità di ricerca del DEMHAB nel 1998 ha, però, sottolineato l'esistenza di ben 538 costruzioni clandestine ad uso abitativo sui terreni previsti per aree pubbliche o condominiali (DEMHAB, 1999), circa il 27,12 \% del totale.

12 Proprio la realizzazione delle Oficinas in una scuola aiutò ad identificare il processo meglio nei suoi valori pedagogici; altrove avrebbe avuto più il sapore di una discussione politica (De Oliveira, 1999i, a pud Allegretti, 2000a).

${ }^{13}$ Con Decreto ${ }^{\circ} 11.892$ del 19.01.98 Rubem Berta è divenuta AEIS di tipo I, cioè in area pubblica.

14 "A lavoro finito ci accorgemmo che vari aggiustamenti finali sarebbero stati necessari. Ma lo sapevamo, per questo lavorammo ad un progetto 'strategico', che potesse essere approvato quanto prima nelle sue linee principali, e poi aggiustato in secondo tempo. Nelle condizioni iniziali era difficile fare di più, ma abbiamo voluto lasciare una porta aperta al cambiamento, contando sul fatto che l'approvazione di un progetto è per una comunità un momento forte e può aggregare alla discussione nuove forze [...] Se vuoi, abbiamo lavorato come fa l'O.P., per esempi e tappe successive di perfezionamento delle decisioni" (Mallmann, 1999i, apud Allegretti 2000a). 
${ }^{15}$ Per certi versi, nel Rubem Berta post-occupazione è possibile rintracciare quel genere di spazi che Castex e Panerai hanno chiamato privato-collettivo (1971), che obbediscono ad un accordo più o meno formalizzato tra persone che difendono interessi che in parte sono propri e in parte sono divisi con i propri vicini (Keller, 1979), a differenza di quanto avviene in aree della città più autosufficienti dove le necessità di scambio sociale appaiono sensibilmente ridotte e si sviluppano in spazi neutri ad hoc costruiti, piuttosto che sullo stesso territorio dell'abitare.

${ }^{16}$ Oggi poco più di $1 / 4$ dei certificati è stato rilasciato. E molti consegnati (nei nuclei 26, 33 e 37) sono sbagliati.

${ }_{17}$ Intervista a Santos Da Silva, 2002i, apud Allegretti, 2002a.

18 "Perche' demolire un garage privato se la strada condominiale puo' essere postata piu' in la? Perche' spostare un negozio abusivo se l'accesso all'edificio antistante si puo' fare dal retro? Le esigenze del singolo elettore sembrano prender piede su quelle della comunita' insediata. Poco al poco molti dettagli del piano urbanistico faticosamente elaborati dagli abitanti vengono bypassati, stravolti, aggiustati: al fine di non scontentare nessuno si scontentano molti. Un lungo e serio lavoro di progettazione viene indebolito dalla pressione elettorale" (cfr. Allegretti e Smeriglio, in Carta, 24 febbraio 2002).

19 Attraverso dei corsi e un'iscrizione all'AMORB si punta a dare una credibilità maggiore a questi amministratori, perché sia loro più facile esigere dai residenti i pagamenti delle quote necessarie a gestire i servizi collettivi.

${ }^{20}$ L'isolamento in cui l'architetto Mallmann è stata lasciata in questi anni (specie per quanto attiene gli aspetti di interazione politica e sociale con i cittadini, dove le è mancato il supporto di agenti comunitari e assistenti sociali impegnati sul posto) è piuttosto eloquente in tal senso.

${ }_{21}$ De Oliveira, 1999i, in Allegretti 2000.

${ }_{22}$ Cfr. Santos da Silva, in Allegretti 2000.

${ }^{23} \mathrm{Al}$ momento del trasferimento le famiglie erano diventate 146 (cfr. Zero Hora, 21/4/ 1995) per un fenomeno tipico di 'densificazione' che precede i trasferimenti.

${ }^{24}$ Il Consigliere Comunale del PDT Ervino Besson, nel visitarla il 9 maggio del 1989 l'ave va definita un mini Biafra (cfr. Zero Hora 10/5/89). Nel censimento del 1993 il DEMHAB dichiarava in condizioni precarie l'82\% delle abitazioni (Sant'Ana, 1997).

${ }^{25}$ Già dal luglio di questo anno iniziò però il censimento delle famiglie residenti (cfr. Zero Hora, 8/7/93).

${ }^{26}$ I dati riferiti dal DEMHAB sono contestati dall'Associazione di Quartiere che riferiva di un 60\% di favorevoli e di $40 \%$ di contrari (Sant'Ana, 1997).

${ }^{27}$ I solai predisposti dal Comune per un secondo piano "costituiscono una porta aperta ed un invito alla crescita per le famiglie" (Sonia Maria da Silva, 1999i, apud Allegretti, 2000a).

${ }^{28}$ Nel Wenceslau Fontoura dal 1992 al 1994 fu utilizzata la scuola del vicino quartiere COHAB Rubem Berta; poi fu costruita scuola provvisoria oggi recuperata per abitazioni, e solo dal 1997 è stata costruita la scuola nuova.

${ }^{29}$ Il Sindaco, per questo, emise una 'Portaria' [Decreto] nominando singoli membri responsabili in ogni organismo.

${ }^{30}$ I 'papeleiros' veri e propri erano, invece, pochissimi.

${ }^{31}$ Celoir gode di un'enorme considerazione fra le 9 Assistenti Sociali del DEMHAB (ognuna con permanenza media di 3-5 anni), perché rappresenta "il 'riscatto realizzato', la semplice 'abitante dei rifiuti' divenuta leader comunitario, che guida gruppi alla maturazione, parla in TV, è delegata dell'O.P."(Saicoski, 1999i, apud Allegretti, 2000a).

32 Attualmente è in atto, nella scuola, un'interessante ricerca sull'Organizzazione Sociale e Comunitaria del Loteamento Cavalhada realizzata con la collaborazione degli alunni e dei loro genitori. Emerge un giudizio ambivalente su un'area dove si fanno difficili i rapporti tra vicini (anche a causa dei materiali costruttivi usati che non creano barriere acustiche tra gli alloggi), i problemi della sicurezza a causa della mescolanza di gruppi provenienti da favelas diverse, alcuni problemi tecnici (come gli allagamenti) e i problemi del lavoro. Molto sentita è la lontananza dei vecchi benefattori che quassù rende più difficile guadagnarsi la vita. Le case dai più sono ritenute confortevoli, ma rumorose e troppo piccole: non in pochi abitanti sottolineano che in fondo anche questa è una Vila, seppur le case sono ordinate in maniera diversa, e il fatto di non poter vendere o fare scambio di case per riorganizzarsi nell'insediamento (seppur qualcuno lo fa a suo rischio) da' una sensazione di prigionia. I bambini sottolineano la mancanza di aree di gioco e lamentano la mancanza del 
512 lago, e l'inacessibilità dell'area di protezione naturale. Ma gli aspetti più sentiti sono le leggende metropolitane su un fantomatico cimitero indigeno in zona.

${ }_{33}$ Nel Loteamento Fontoura sono visibili vari rottweiler - probabilmente per gare e scommesse clandestine - chiusi in piccoli recinti poco sicuri.

${ }_{34}$ Cfr. Moradores recebem casa novas, su Zero Hora del 28/9/1992.

${ }^{35} \mathrm{Cfr}$. articolo Papeleiros fundam sua prima cooperativa, in Zero Hora 15/8/1988.

36 "L'opposizione non voleva capire la nostra ottica, che il diritto dei poveri al centro è parte del suo diritto alla cittadinanza. Loro erano, e sono, preoccupati dei valori della speculazione immobiliare, secondo cui la terra è una merce [...] Anche alcuni tecnici dell'area urbanistica danno importanza ai valori speculativi e privilegiano il paesaggio a detrimento dell'uomo" (Dutra, 1999i, apud Allegretti, 2000b).

${ }^{37}$ Cfr. Zero Hora, 13 aprile 1993.

${ }^{38}$ Cfr. l'articolo Sò uma empresa interessada no projeto de reurbanização, su Zero Hora del $1 / 5 / 1992$.

${ }_{39}$ In questo frangente spiccò Neusa Amoretti, architetto e scultrice che abitava in un palazzo prospiciente, poi diventata personaggio attivo nella storia della partecipazione popolare a Porto Alegre in difesa dei 'vileiros'.

40 Analoghe le conclusioni del Presidente del Sindacato delle Industrie della Costruzione Civile (Sinduscon) Gianfranco Cimenti, su Zero Hora del 16-8-92, a cui sullo stesso numero del quotidiano il coordinatore del GAPLAN Lima risponde che i sondaggi eseguiti dal Comune non avevano indicato nessun acquirente interessato all'area.

${ }^{41}$ Cfr. intervista a L. C. da Cunha, urbanista della Commissione per Porto Alegre 2000, su Zero Hora, 16/8/1992.

${ }_{42}$ Cfr. intervista a Maria Olinda de Carvalho, in Zero Hora 27/6/1992, pag. 26.

${ }_{43}$ "L'esistenza di aree comuni sarebbe un fattore di novità per la popolazione, che dovrebbe occuparsi della loro manutenzione" e rischierebbero di essere oggetto "di depredazione, vandalismo, atti marginali” (SPM/PRF, 1992).

${ }^{44}$ Nel programma SPM/PRF (1992), molte delle scelte compiute sono giustificate anche attraverso tabelle di confronto con realizzazioni della World Bank o di Municipi brasiliani, e con riferimento ad una piccola bibliografia.

${ }^{45}$ Su consiglio di un 'trafficante' (oggi pastore in un chiesa evangelica di S. Paolo, e allora presidente dell'Associazione Amigos da Vila) fu suggerito di "smussare gli angoli retti nei vari isolati perché $i$ rapinatori non potessero aspettare le vittime indisturbati dietro gli angoli". "A me per certi versi quella vicenda ha cambiato alcuni modi di pensare, aprendomi delle finestre sconosciute. Nel progetto successivo per la Vila Triangolo Caí ho addirittura consultato il direttore della Pianificazione della Polizia Militare e gli ho chiesto consigli e suggerimenti su aspetti della sicurezza dopo avergli mostrato una bozza di progetto. Lui fu molto colpito da questa inusuale apertura. Mi portò una lista di raccomandazioni che tuttora uso" (Guimarães, 1999i, in Allegretti, 2000a).

46 "[Volevo] lasciare la piazza libera ed osservare come gli abitanti davanti se ne appropriavano e poi decidere che fame. Ma non c'era tempo né i fondi necessari per il monitoraggio prima di fare il progetto, e il Comune ne voleva fare il centro dell'inaugurazione. Così mi parve più saggio soprassedere e progettai una cosa semplice con degli alberi, delle aiuole e delle panchine. Molte di queste ultime sono state divelte; del resto il Comune le ha messe di ferro e al sole, ti immagini che ustioni; ecco perché ci hanno messo quella coperta sopra... E una delle poche in legno sostituite - vedi - è le gata da una catena ad un palo da uno degli abitanti. Degli alberi aveva promesso si sarebbe occupato un signore che abita davanti, con la passione delle piante, ma vatti a fidare. Oggi è veramente malridotta; persino $i$ giochi per i bambini del mini play-ground stanno scomparendo e queste reti di ferro tutte intorno sono luogo di appropriazione privata dei vicini. Non so in cosa ho sbagliato, forse nella fiducia data agli abitanti, che crede vo l'avrebbero accolta come il centro del loro mondo e l'avrebbero curata. Ora mi rendo conto che non averla concessa a loro fa sì che essi scarichino le responsabilità sul Comune" (Guimarães, 1999i-II, apud Allegretti, 2000a).

${ }_{47}$ Ad es., la ritinteggiatura massimo ogni 10 anni e la possibilità di disporre cancellate di massimo 1 metro di altezza sul fronte, e grate di massimo 2,20 metri sul retro; divisori interni e finestre sul retro ai piani superiori saranno realizzabili solo dietro preventiva richiesta al Comune.

${ }_{48}$ Cfr. documento interno di Guimarães (SPM) Para à avaliação de impacto a ser conduzida na Vila Planetario (1992), dove sono suggeriti alcuni indicatori da utilizzare 
per la valutazione ex-ante e per quella ex-post e relativi non solo a indicatori numerici: tra essi l'impatto della CDRU e delle bollette dei servizi infrastrutturali sulla rendita familiare, l'andamento della scolarità e dei rapporti di lavoro, la percezione ambientale e la soddisfazione per gli appartamenti, le migliorie apportate agli spazi fisici, le trasformazioni nei rapporti con i vicini.

${ }^{49}$ In forma di appartamenti a tre piani che dovevano ospitare anche le 20 del Terminal Princesa Isabel e le 35 ubicate sul terreno dove era previsto il prolungamento della via Florianópolis.

${ }^{50}$ Sono stati 9 i mesi di permanenza degli abitanti in 'case di passaggio' simili a quelle usate nella Cavalhada, ma riprogettate per adattarle al luogo: 5 padiglioni di compensato con pavimenti lignei rialzati dal suolo e col tetto in fibrocemento, ognuno diviso in 16 aree di $15 \mathrm{mq}$. (la media dimensionale delle baracche della 'vila'). Due i moduli di bagni e docce comuni, ubicati nella strada Settembrino de Carvalho chiusa al traffico. Per quel periodo, è stato redatto un 'Regolamento di convivenza' concordato dal Comune con la popolazione. Il materiale delle demolizioni è stato donato dagli abitanti a quelli della Vila Zero Hora colpita nel maggio 1999 da un incendio (cfr. Allegretti, 2000a).

${ }^{51}$ Il $67,5 \%$ ha terminato la Terza Media; il 37,5\% degli abitanti ha un impiego 'formale', anche se il reddito medio per famiglia non supera i 2,05 salari minimi al mese, cfr. UPE/DEMHAB, 1999c.

${ }^{52}$ Cfr. UPE/DEMHAB, 1999.

${ }^{53}$ Cfr. Ribeiro Jordão, 1999.

54 "In 9 non possiamo neppure fare una Cooperativa a norma di legge - sosteneva Daniel, uno dei 9 contestatari de La Plata - dobbiamo accontentarci di una cooperazione informale. [...] Il PT non ci ha mai aiutato, per questo non lottiamo nell'O.P. Sai, forse sbaglio, ma la politica non si parla, si vive, come la religione” (in Allegretti, 2002a).

55 Il nome è nato nel 1982, quando furono posti davanti alla Vila alcuni grandi cartelloni pubblicitari (in brasiliano Placas), come riportato nella storia autodocumentata dagli alunni del MOVA locale nel 1998.

${ }^{56}$ Il rilievo eseguito dall'Unità di Ricerca del DEMHAB mostrava che nessuno dei 255 abitanti era in affitto; la media del tempo di permanenza era di almeno 10 anni (una mobilità più bassa che altrove, ma non rara nelle ambite occupazioni del centro cittadino). Solo 3 domicili ospitavano commercio: due bar e un alimentari. Il 69,49\% delle abitazioni era in stato normale o precario secondo i canoni del DEMHAB, poche in stato buono o pessimo. La maggioranza era in muratura o mista mattoni/legno ormai dal 1993; vi erano anche 8 case di materiali di recupero. Il numero delle stanze variava da 2 a 5 con gruppi familiari mediamente da 3 a 6 componenti. Molto alta era l'incidenza dei giovani: il $71,09 \%$ nella fascia 0/19 anni. Non vi era neppure un residente con oltre 60 anni (che nella media cittadina rappresentano il 6\%). Il livello di scolarità era piuttosto basso (il $50,91 \%$ degli abitanti non aveva superato la $5^{\circ}$ elementare), mentre l'analfabetismo si attestava al 4,05\% (la media cittadina è 5\%). Il 23\% della popolazione attiva (a Porto Alegre valutata tra i 10 e i 64 anni) aveva un lavoro formale, mentre il 10,29 informale. ${ }^{57}$ Nello Statuto del Condominio citato nel documento storico del MOVA sono registrati 140 adulti, 70 bambini, 45 adolescenti, 19 gatti e 12 cani vaccinati dal 1997 . democrazia sostantiva” (Pestana, 1999i, in Allegretti, 2000a). 
514 Fig. 63 - Vila Campo da Tuca: una Regolarizzazione Fondiaria completata 'a metà', nonostante l'opportunità di una positiva interazione con l'Ente Metropolitano di Pianificazione

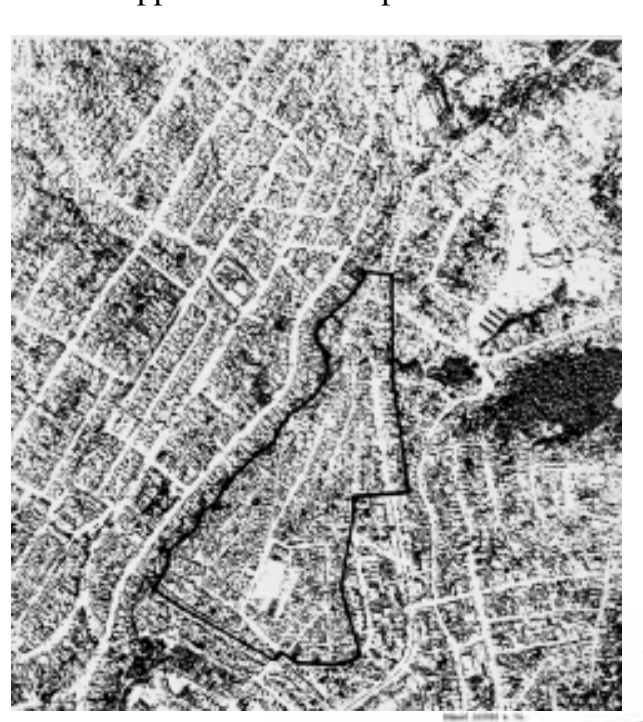
(METROPLAN) e l'Agenzia di Cooperazione Tedesca (GTZ), che sull'area gestivano il Programma Prorenda Urbano/RS

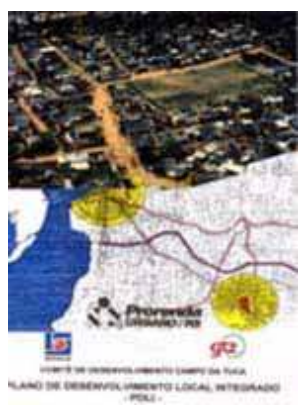

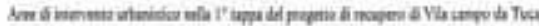
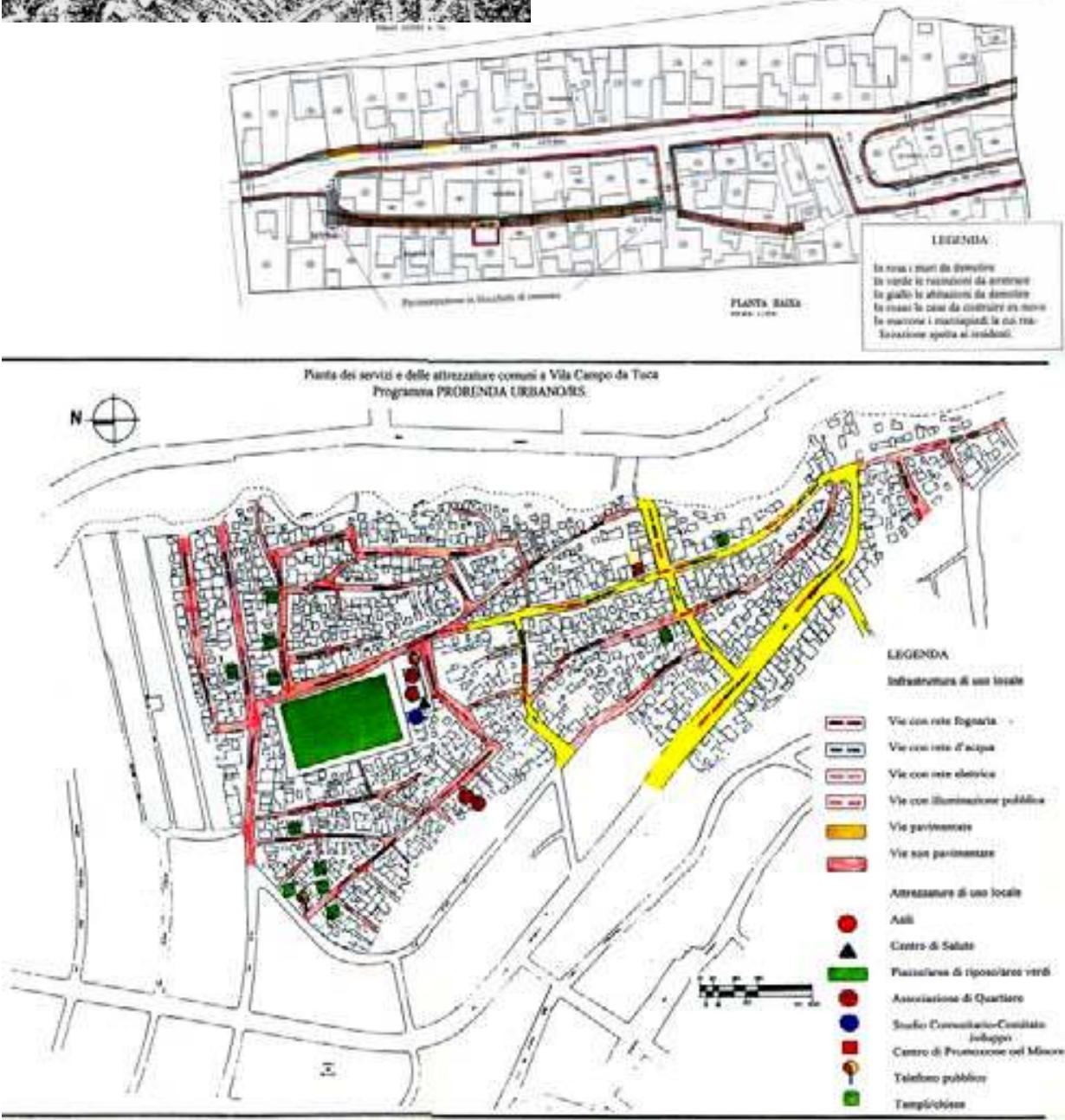
Fig. 64 - Vila Campo da Tuca: alcune immagini di cambiamenti portati dalla Regolarizzazione Fondiaria

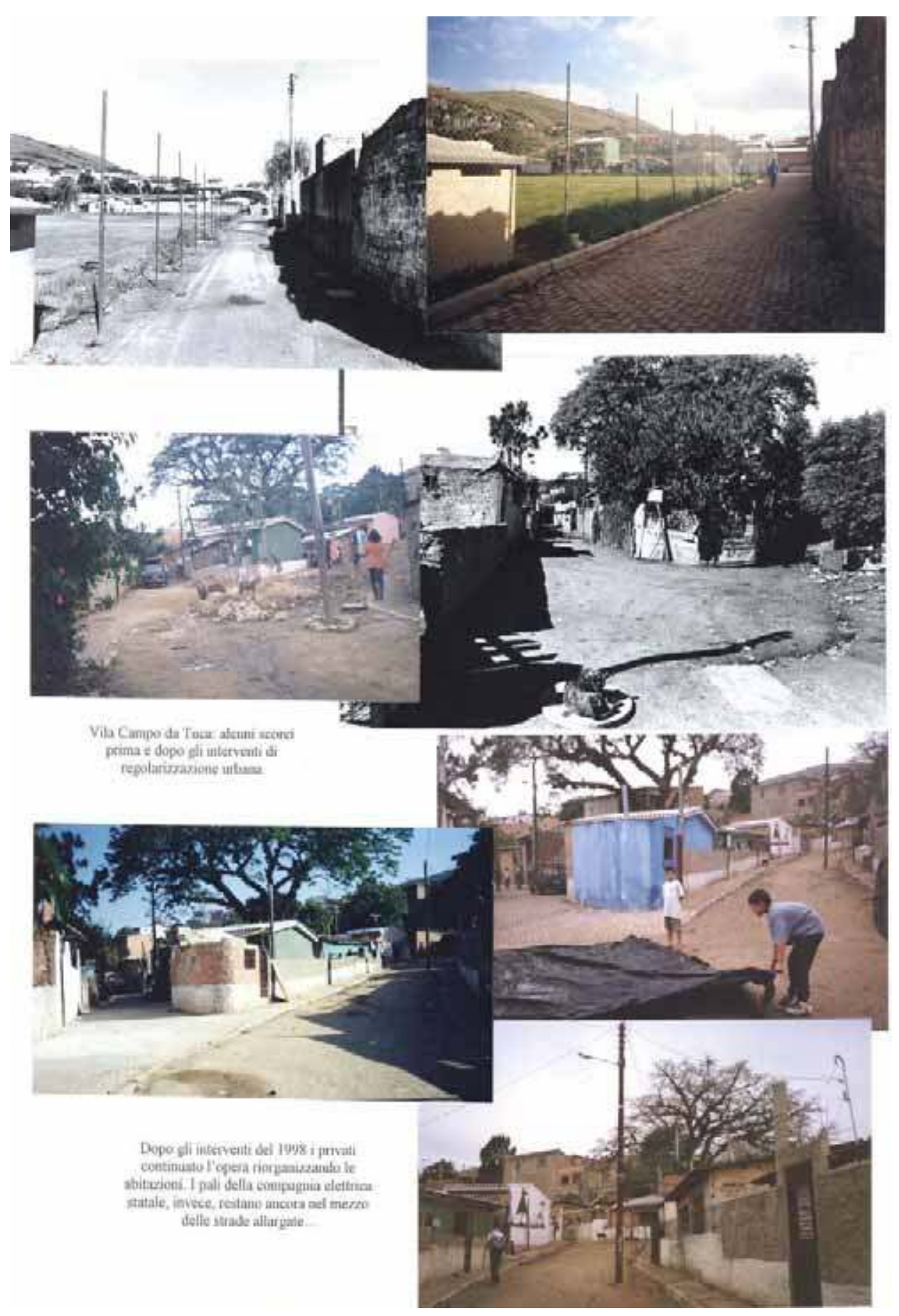


516 Fig. 65 - Ordine e rispetto del prossimo: è quanto la Regolarizzazione Fondiaria di Vila Campo da Tuca non è stata in grado di introdurre in tutto il quartiere. Nonostante gli sforzi del processo partecipativo, in alcune aree si continua a costruire abusivamente sui pubblici marciapiedi, o persino piantando le fondamenta delle proprie sopraelevazioni dentro l'abitazione del vicino...

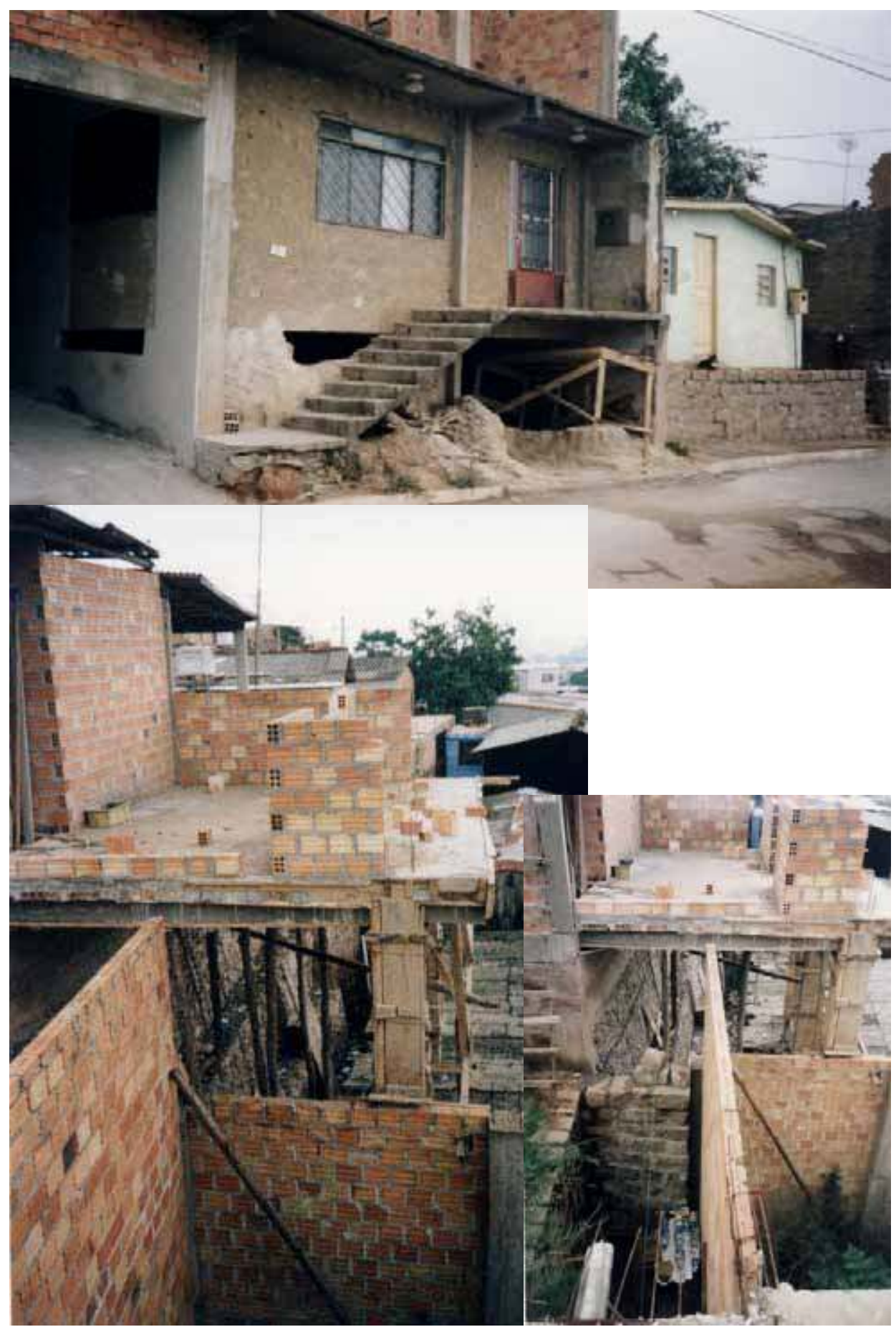


Fig. 66 - L'antica ubicazione della favela Vila Cai-Cai, sul lungolago. Nel 1995 gli abitanti della baraccopoli sono stati rialloggiati - dopo un lungo processo di negoziazione nell'area detta Cavalhada, mentre al posto della favela è stato immediatamente costruito un parco urbano. La rapidità con cui è stata concretizzata la nuova sistemazione pubblica ('condivisa' dagli abitanti della zona) è stata stimolata dal timore di una nuova rioccupazione dei terreni appena sgomberati. Alle famiglie che non volevano recarsi nel nuovo insediamento (dove un regolamento condiviso dalla maggioranza degli abitanti impediva di portare animali domestici) è stata data la possibilità di avere un terreno più lontano, autocostruendosi però l'abitazione.
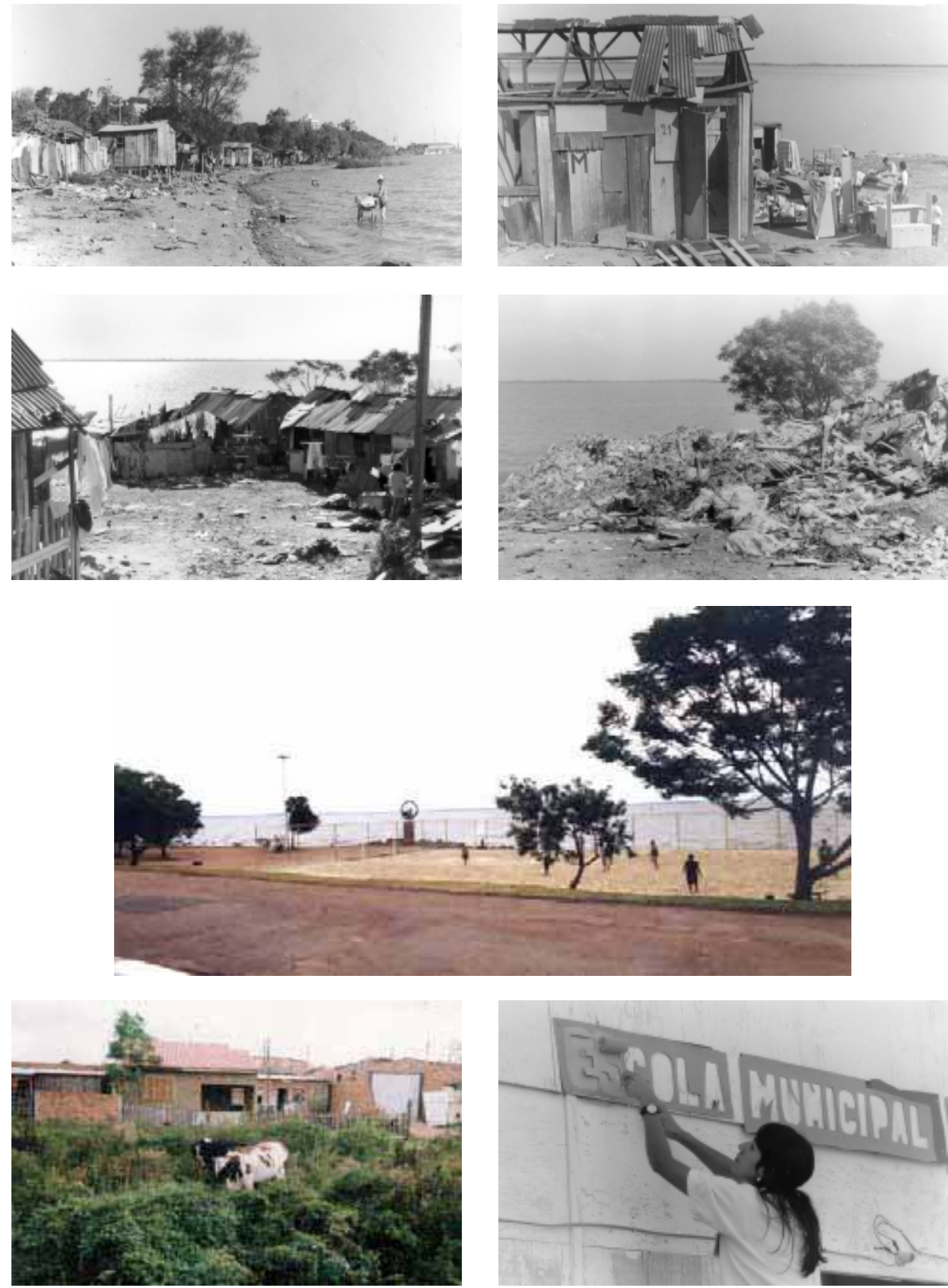

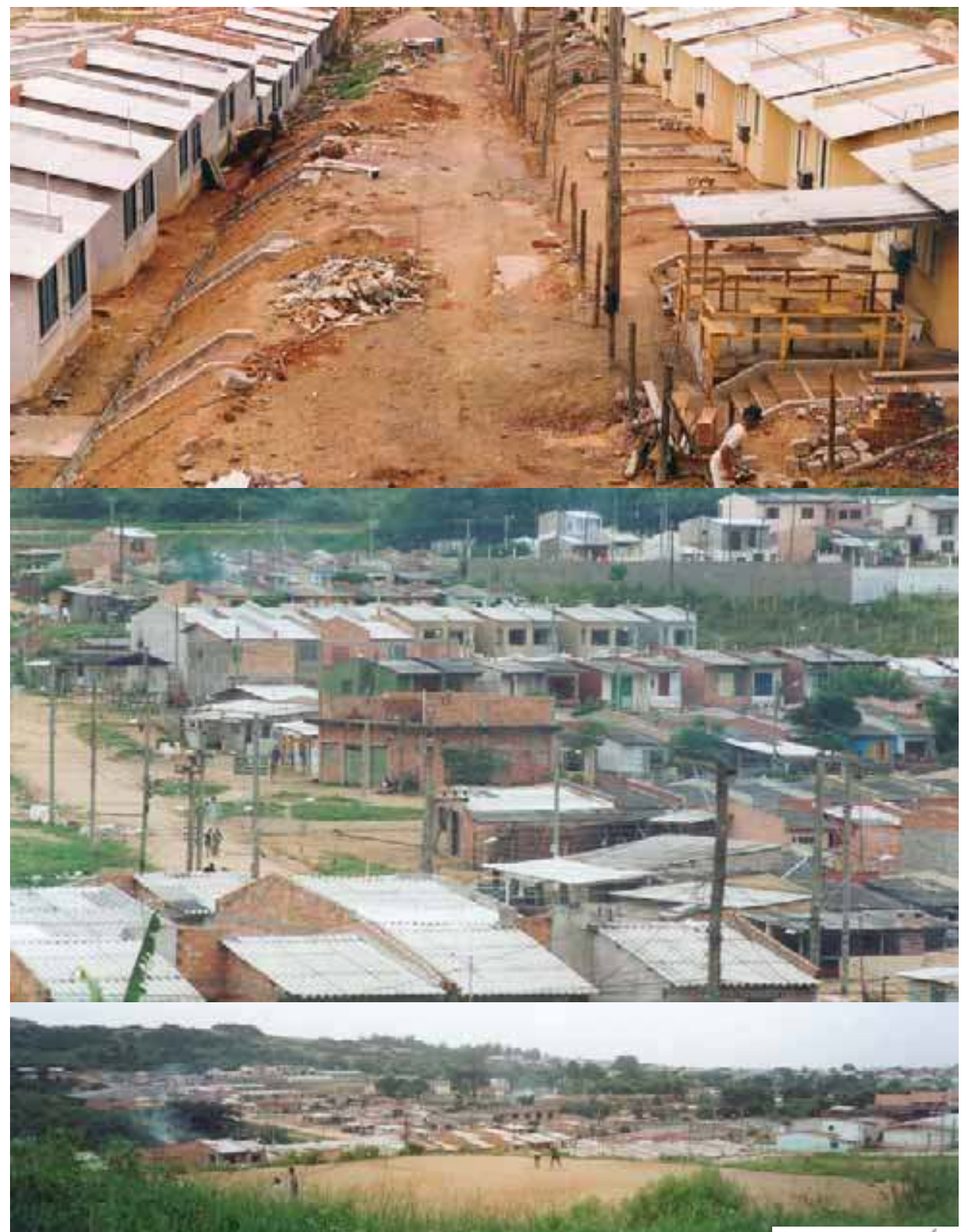

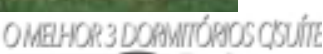

Fig. 67 - L'insediamento della Cavalhada, che ha accolto gli abitanti della Vila Cai-Cai, ha continuato ad ampliarsi dopo il 1995, ospitando persone che abitavano in altre 'aree di rischio' della città di Porto Alegre. Mescolare gruppi provenienti da zone diverse della città ha, però, generato problemi di ordine pubblico, a causa delle difficoltà di reciproco relazionamento. Nonostante le difficoltà (che hanno portato ad una progressiva 'rifavelizzazione spontanea' della Cavalhada), l'urbanizzazione dei nuovi quartieri popolari ha trascinato uno sviluppo speculativo di quartieri residenziali ad alto reddito nelle vicinanze (cfr. volantino a destra).

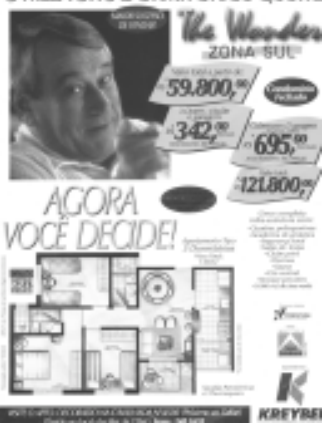




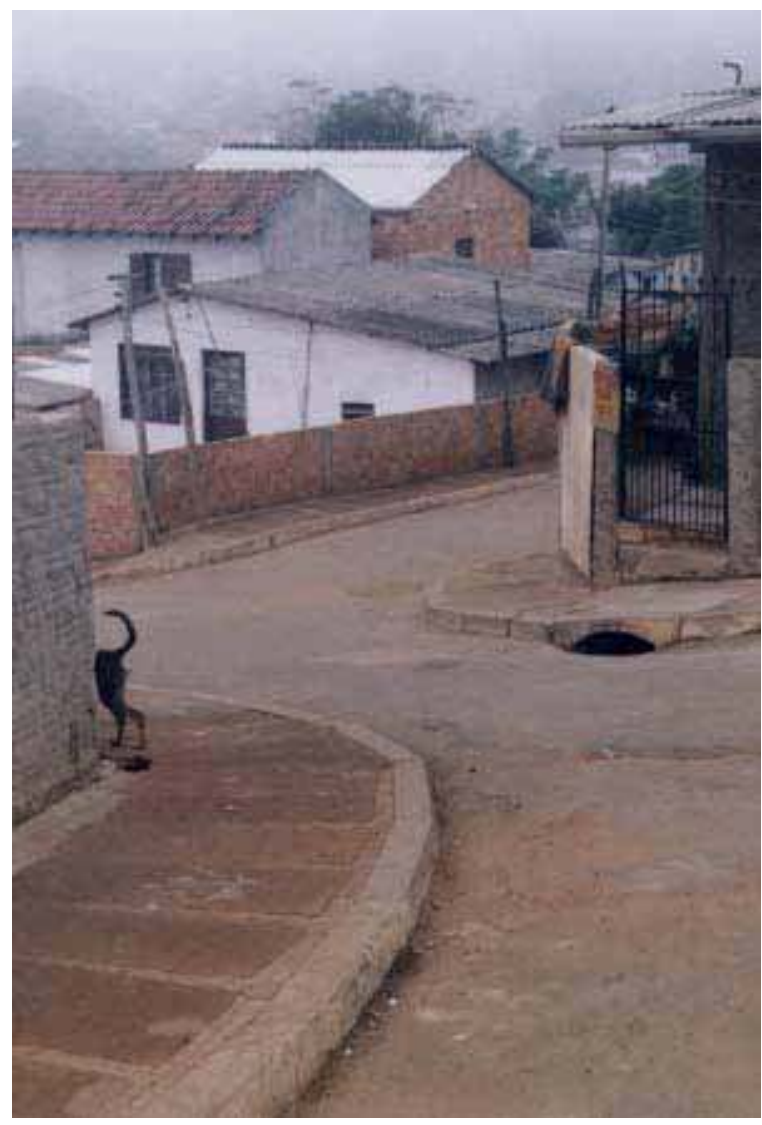

Fig. 68 - L'occupazione di Vila Malvina - realizzata da un gruppo coeso di abitanti provenienti dall'interno dello Stato del Rio Grande do Sul - è avvenuta con modalità che ne hanno favorito il processo di regolarizzazione fondiaria, centrato sulla valorizzazione degli spazi pubblici e delle zone verdi sottratte al disboscamento dell' area dagli stessi abitanti.

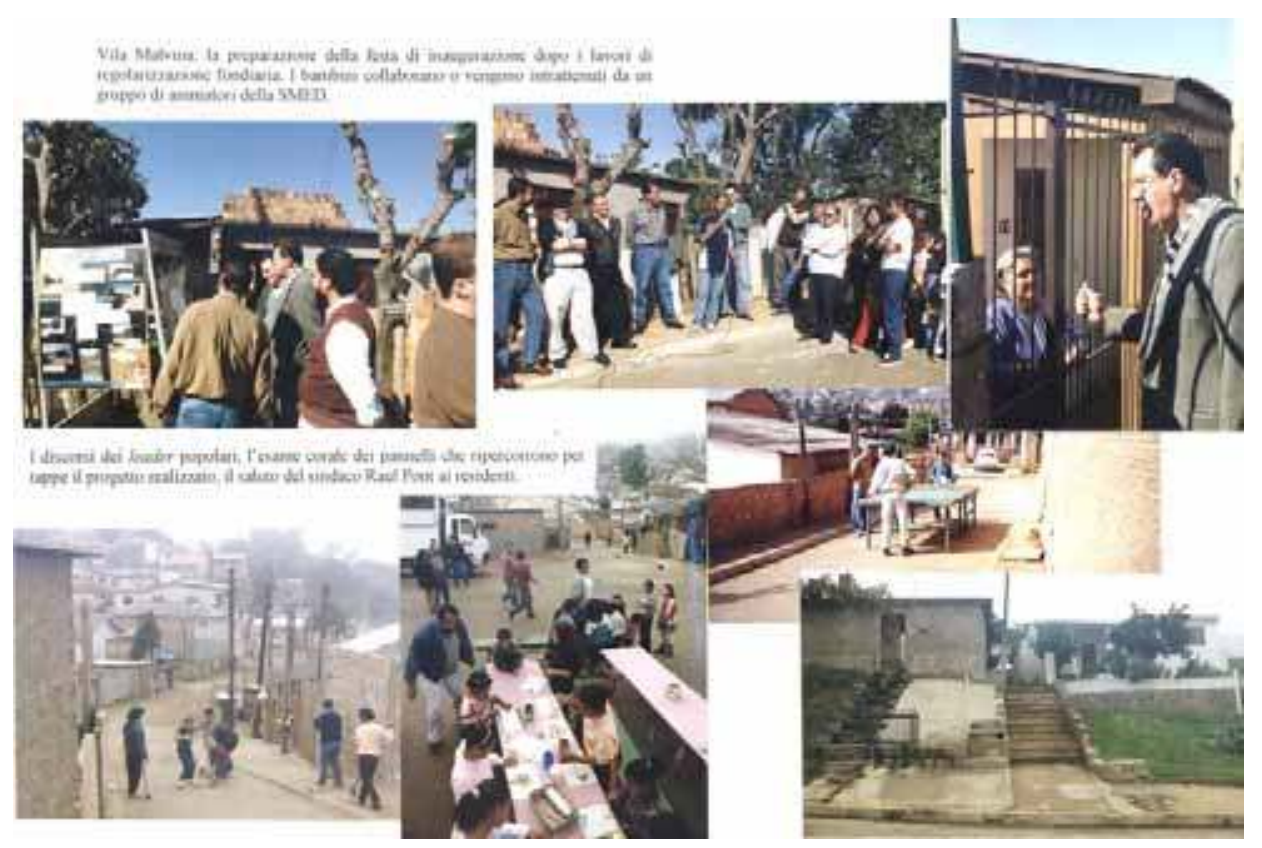


520 Fig. 69 - Alcune baraccopoli intorno all'Ippodromo del quartiere Cristal sono state rialloggiate nel 1998 a spese di un'impresa privata, in cambio della concessione per la costruzione del supermercato BIG. Nelle immagini, alcuni scorci delle difficili condizioni di vita degli insediamenti a lato dell'ippodromo. Le immagini a fondo pagina rappresentano l'ultima baraccopoli rimasta (oggi in via di smantellamento) tra quelle che la realizzazione del centro commerciale prevedeva di rimuovere (foto Allegretti, 1998/2003).
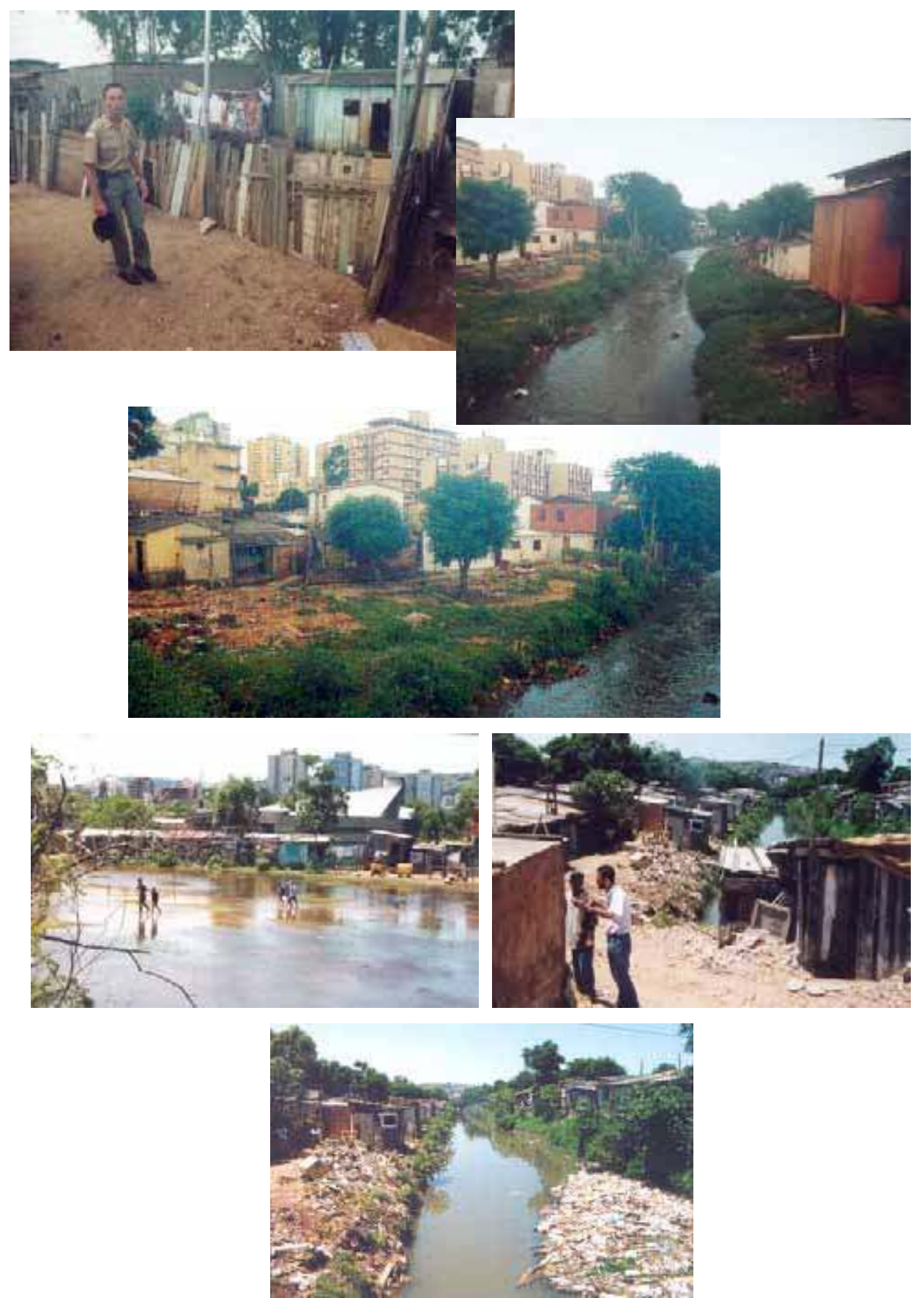
Fig. 70 - Baraccopoli del Cristal in via di regolarizzazione, dove gli abitanti (tramite il Bilancio Partecipativo) sono riusciti ad ottenere alcuni servizi ed il miglioramento degli spazi pubblici.
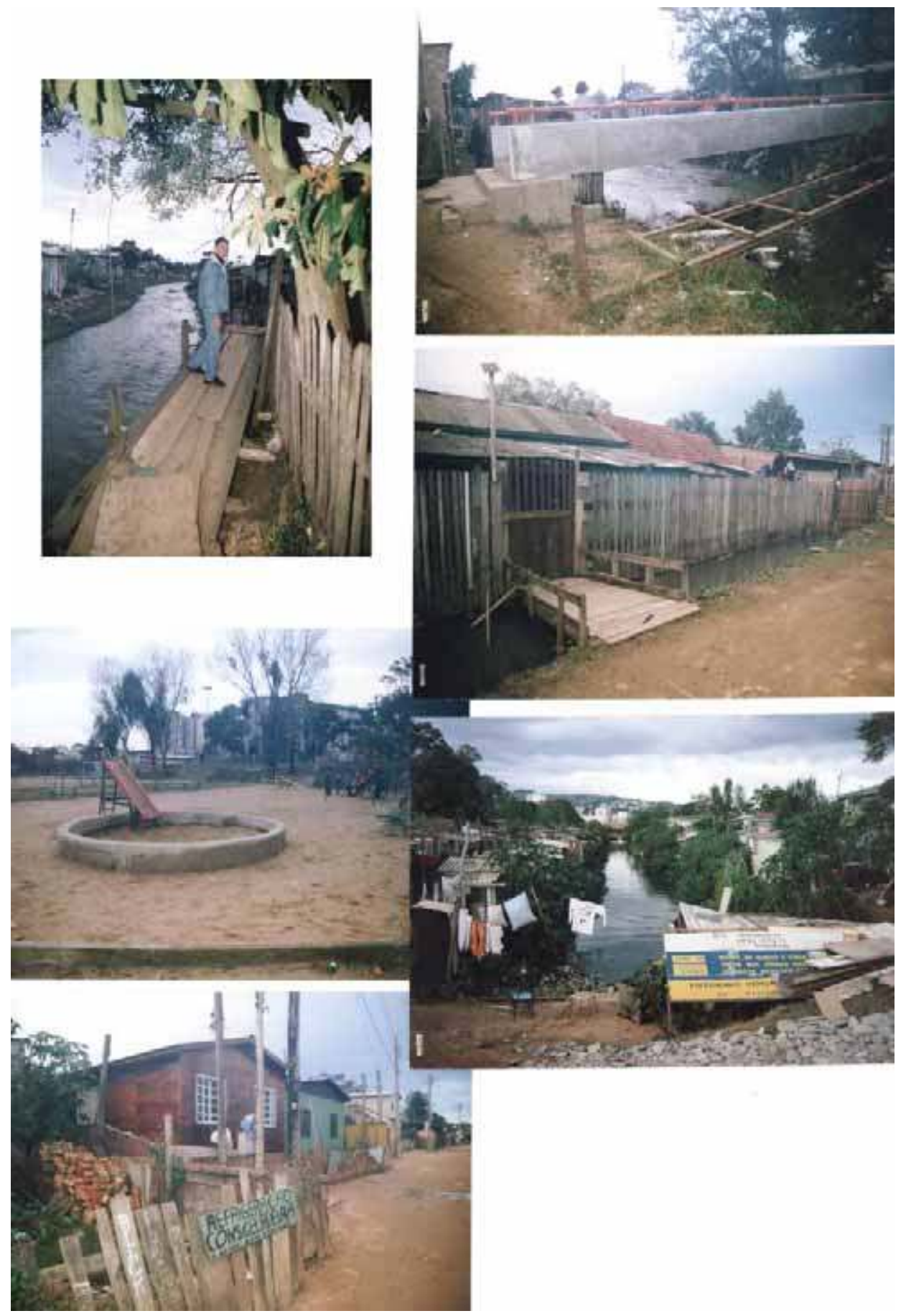
522 Fig. 71 - L'insediamento di Vila Nova, poco dopo il trasferimento degli abitanti reinsediati a spese dell'impresa costruttrice del supermercato BIG (novembre 1998). Più sotto, lo stesso quartiere dopo 3 mesi, ormai alterato da ampliamenti busivi utilizzati soprattutto per ospitare attività commerciali e laboratori artigiani, necessari alla sopravvivenza degli abitanti. Il volantino distribuito dal'impresa - che spiegava come 'usare' le case e le loro dotazioni tecnologiche - non è stato sufficiente a fermare lo stravolgimento dell'impianto originario. Non solo - infatti - non ha avuto effetto deterrente su di essi, ma anche come forma di 'educazione ambientale' è stata considerata piuttosto blanda e inefficace.

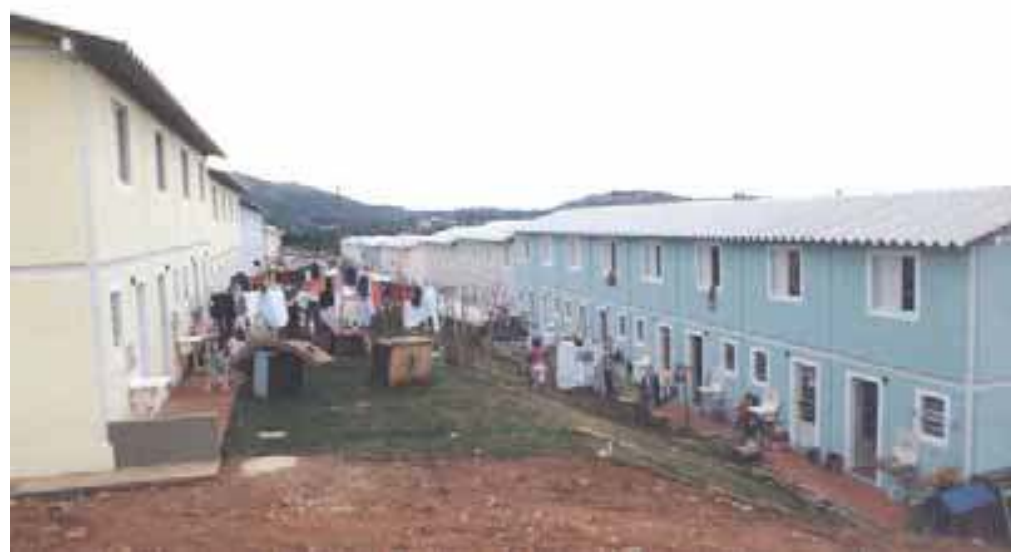

Saiba o que esta po dentro das paredes.
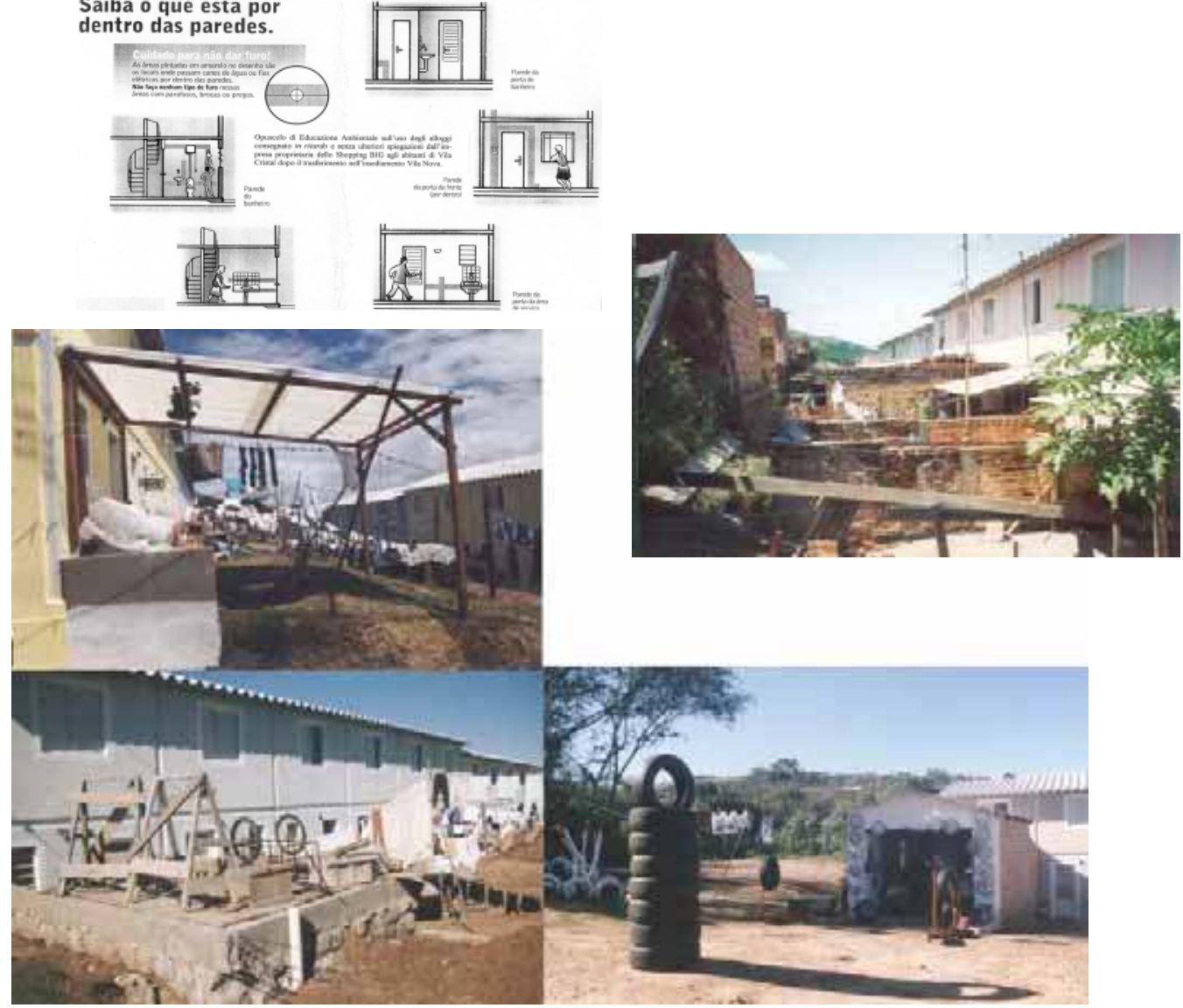
Fig. 72 - Costruzione di alcune casette prefabbricate di emergenza nell' area Rubem Berta, e libretto fornito dal Dipartimento alla Casa su come ampliarle nel modo più razionale. L'apertura del DEMHAB verso l'autocostruzione di ampliamenti e sopraelevazioni da parte dei mutuatari è stata quasi una necessità, visto che i lavori procedevano comunque illegalmente per porre rimedio alla ristrettezza degli pazi delle abitazioni popolari.

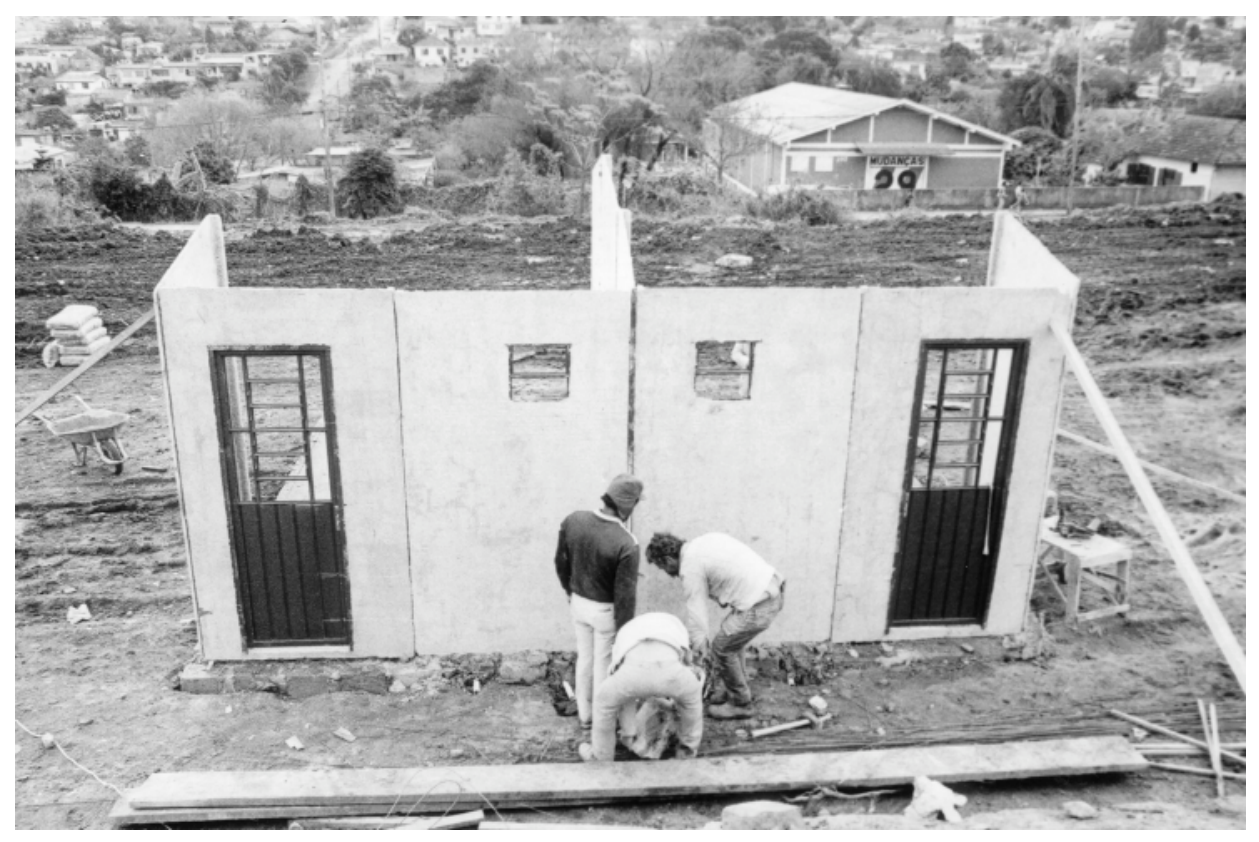

Projeto Original

Proposta para Ampliações

'Libretto dell'utente': l'Ente Pubblico suggerisce ipotesi di autoampliamento per minimizzare i danni agli alloggi pubblici
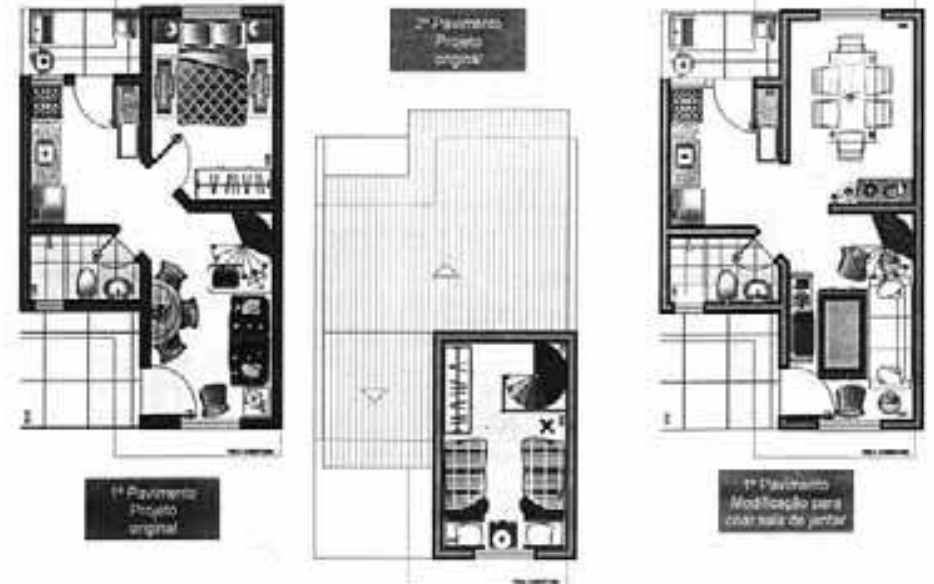

Reinsediamento Costa e Silva del DEMHAB

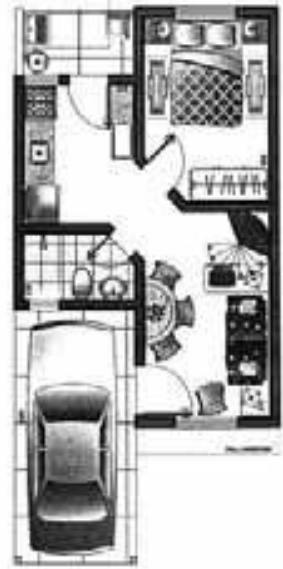


524 Fig. 73 - La favela sul 'Morro da Cruz' prima che gli abitanti decidessero - nel Bilancio Partecipativo - la costruzione della grande scalinata che ha superato lo scoscendimento, e i sistemi di drenaggio per evitare gli allagamenti (foto tratta da Genro e De Souza, 2002). L'opera - visibile nelle foto a colori del 2002 - è considerata il maggior simbolo della capcità dell'O.P. di collegare la città formale e la città informale.
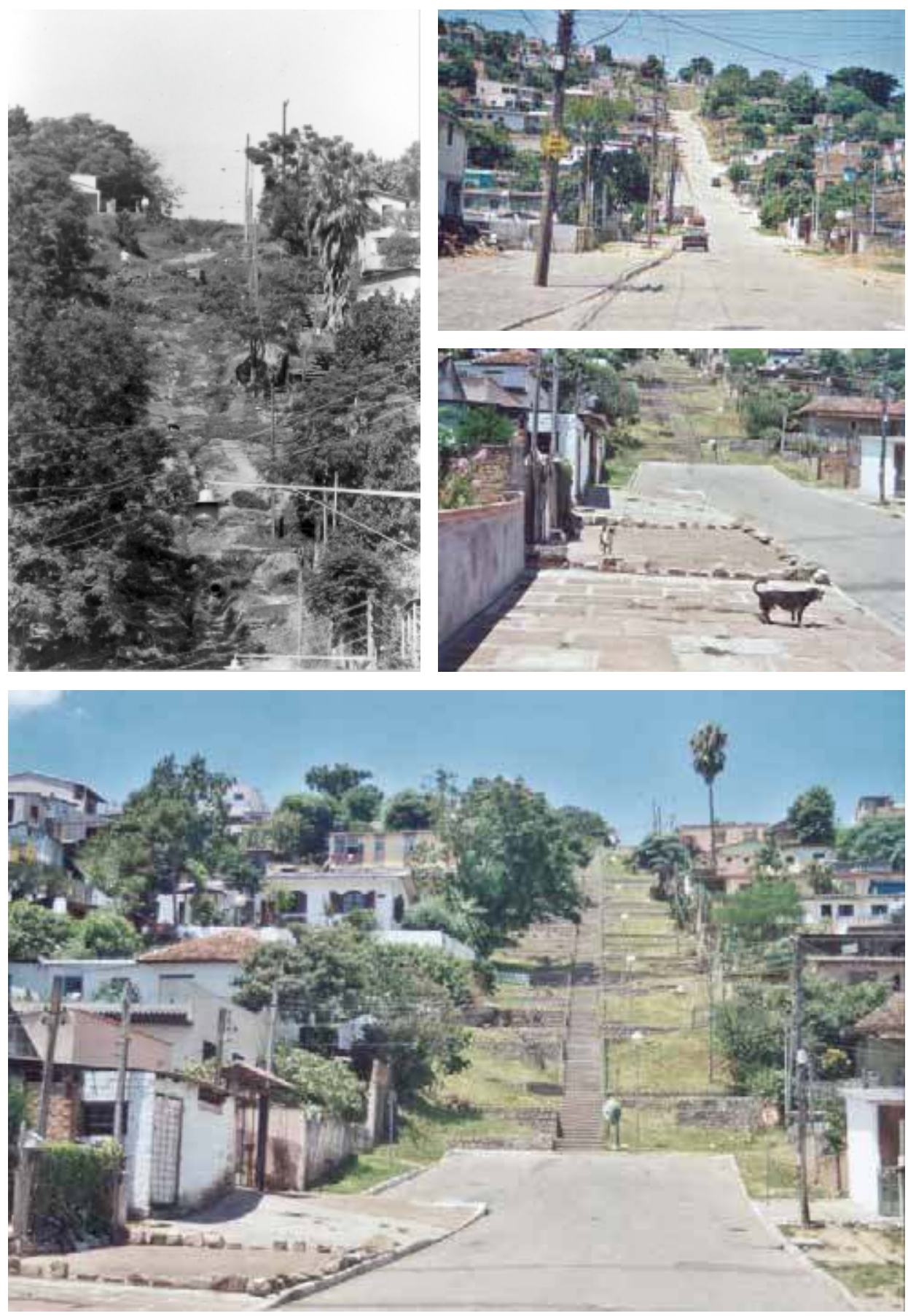
Fig. 74 - Vendite illegali ed occupazioni recenti (simbolico-dimostrative/temporanee ma anche permanenti) a Porto Alegre.
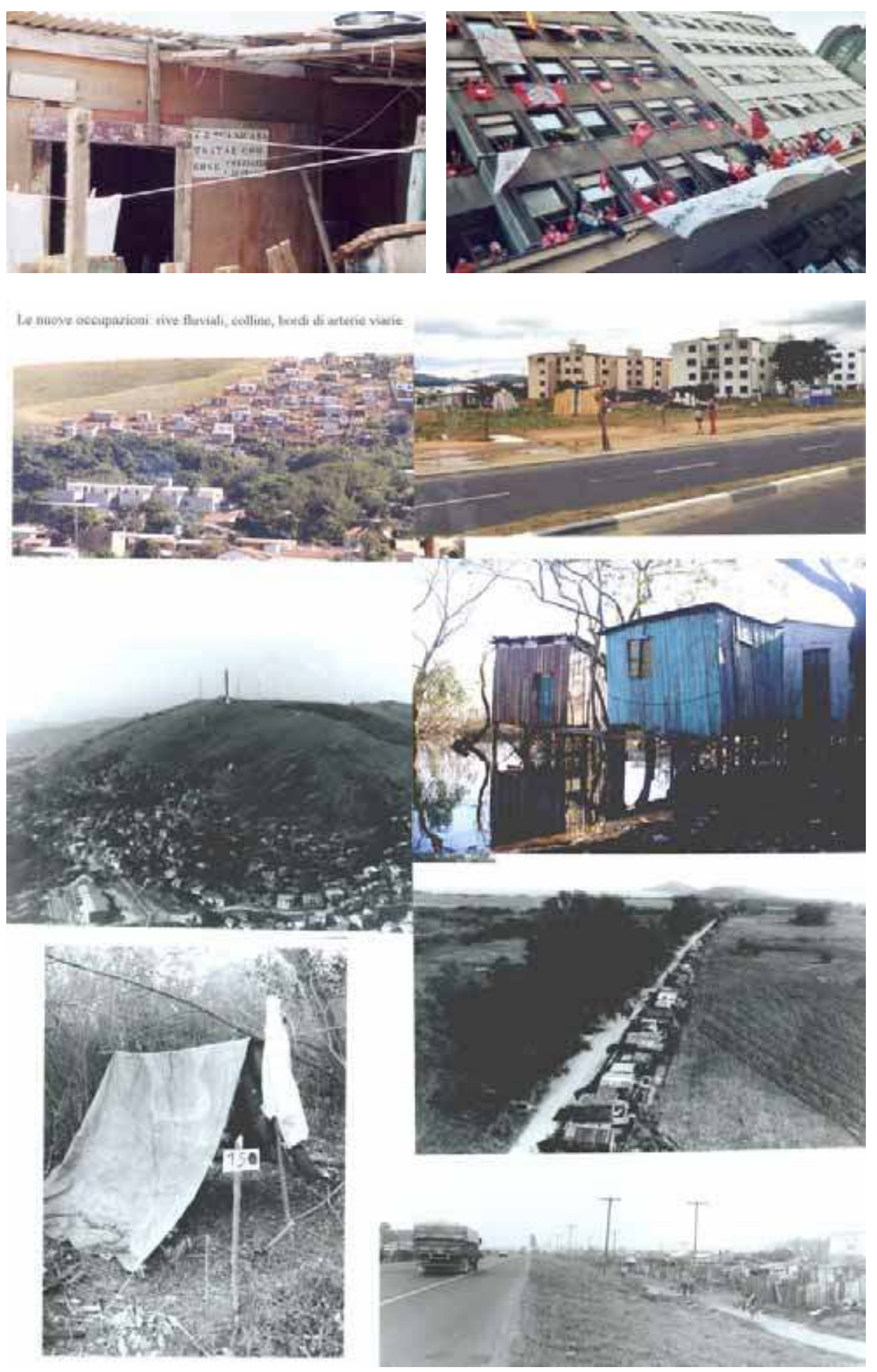
526 Fig. 75 - I pochi 'sgomberi' di aree occupate verificatisi dal 1989 sono avvenuti in seguito ad ordini della magistratura, e sono stati in genere accompagnati da negoziazioni di altre aree che gli occupanti potessero gestire in forme cooperative e in autocostruzione. Nel caso dello sgombero del Loteamento Timbauva (foto in basso, Prefeitura di Porto Alegre) il polso duro usato dal Comune contro un'occupazione proditoriamente avvenuta alla vigilia delle elezioni statali per mettere in difficoltà l'esecutivo municipale, è stato reso necessario dalla volontà di non vanificare le decisioni prese dai cittadini nel Bilancio Partecipativo. L'area era stata, infatti, destinata a soddisfare una richiesta di rialloggiamento per famiglie bisognose residenti in aree di rischio.
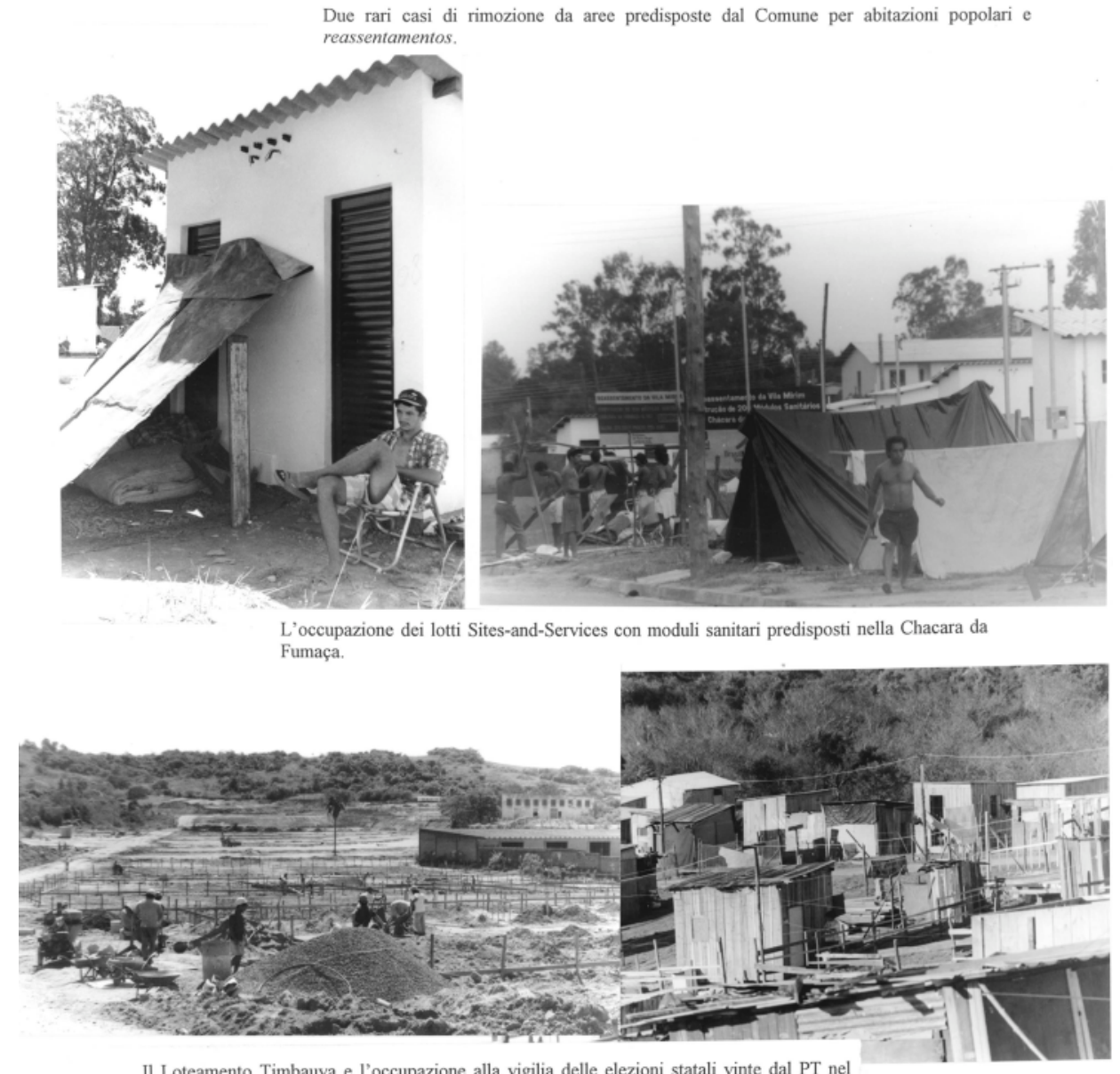
1998 , il sito fu fatto sgomberare dopo una mediazione dell UAMPA.

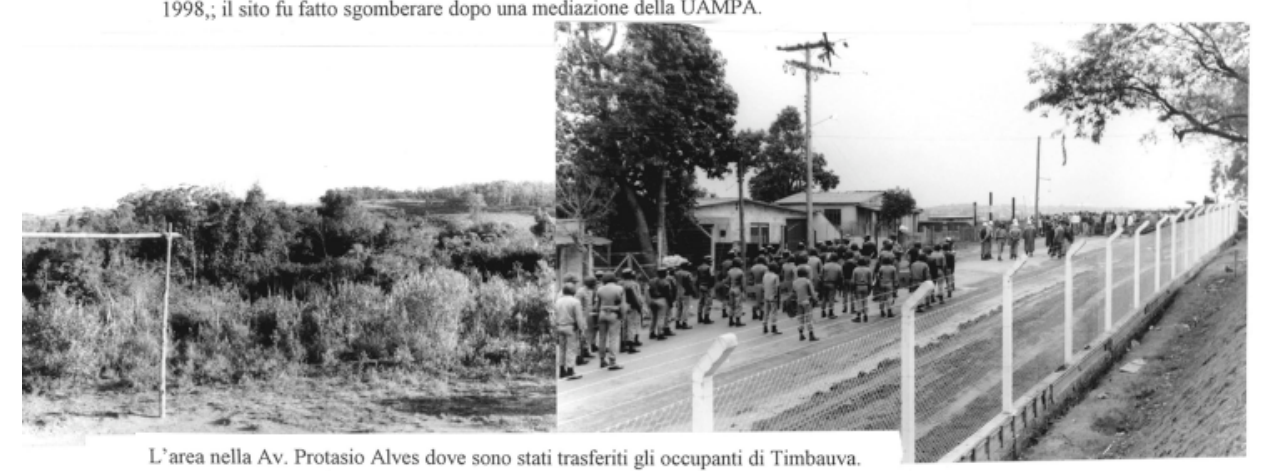



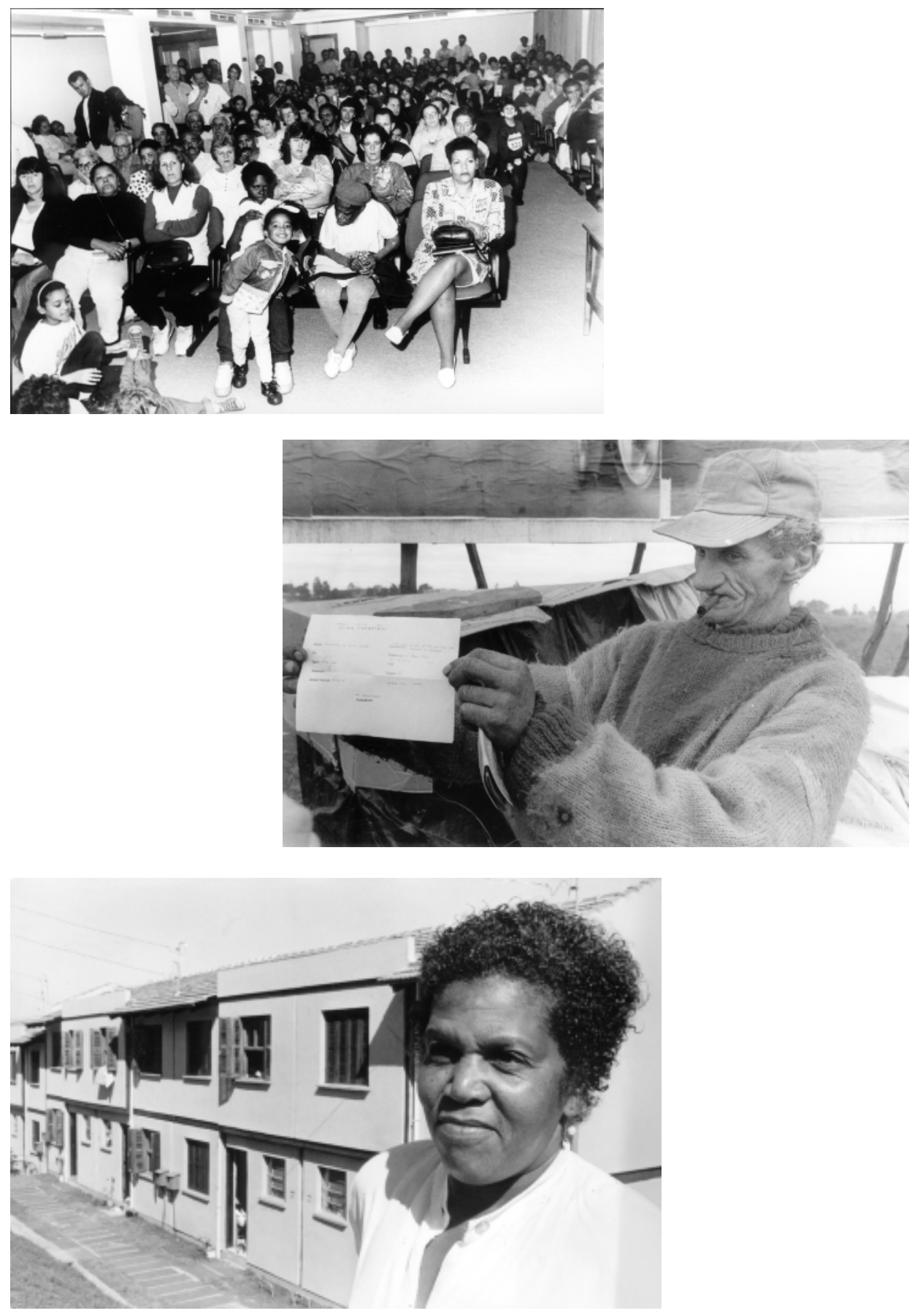

Fig. 76 - Nelle foto del Coordinamento per la Comunicazione del Comune di Porto Alegre, alcune eloquenti immagini del legame tra processi partecipativi e gestione del territorio. In alto un'assemblea di comunità del Bilancio Partecipativo. Al centro: un anziano abitante di una favela mostra orgoglioso il certificato di regolarizzazione fondiaria del lotto dove abita. In basso, la fierezza di un'abitante dell'insediamento autocostruito in mutirao in località Ipe Barracao. 
528 Fig. 77 - Il quartiere popolare di Rubem Berta, progettato dalla COHAB statale, è rimasto parzialmente inconcluso ed è stato occupato nell'aprile del 1987 nell'ambito di un forte movimento popolare di protesta contro la mancanza di abitazioni a basso costo in Brasile. Alcune immagini (tratte dall' archivio ZH) mostrano i giorni dell'occupazione, mentre la pianta (elaborata da D. Rigatti, 1997) evidenzia la parte dell'insediamento regolarmente concessa agli abitanti iscritti nella graduatoria COHAB (in alto), e quella incompiuta occupata (in basso).

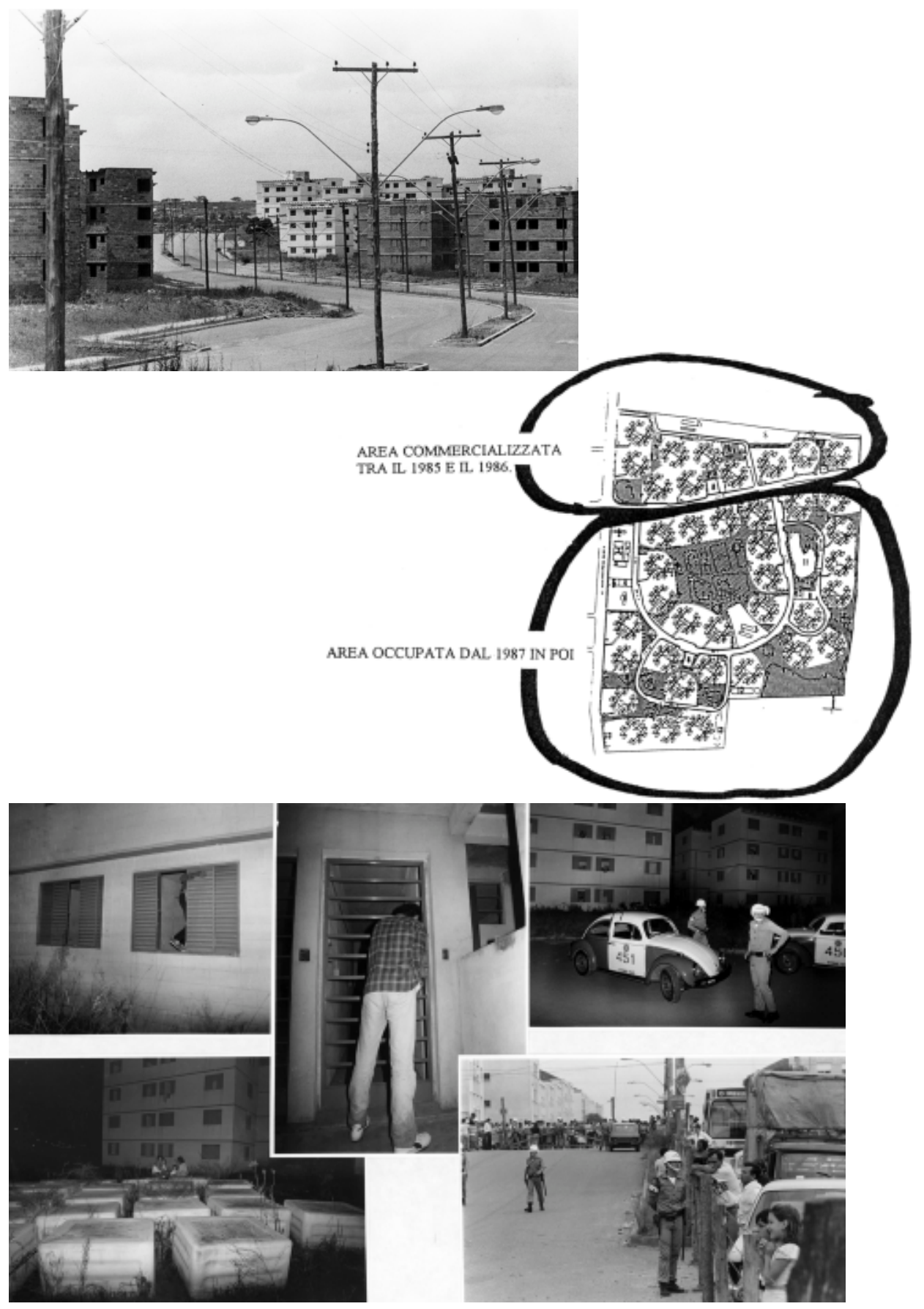


Fig. 78 - Foto aeree del quartiere popolare di Rubem Berta nel 1994, quando cominciò il processo partecipativo che ha portato alla costruzione di un piano condiviso di Regolarizzazione Fondiaria.

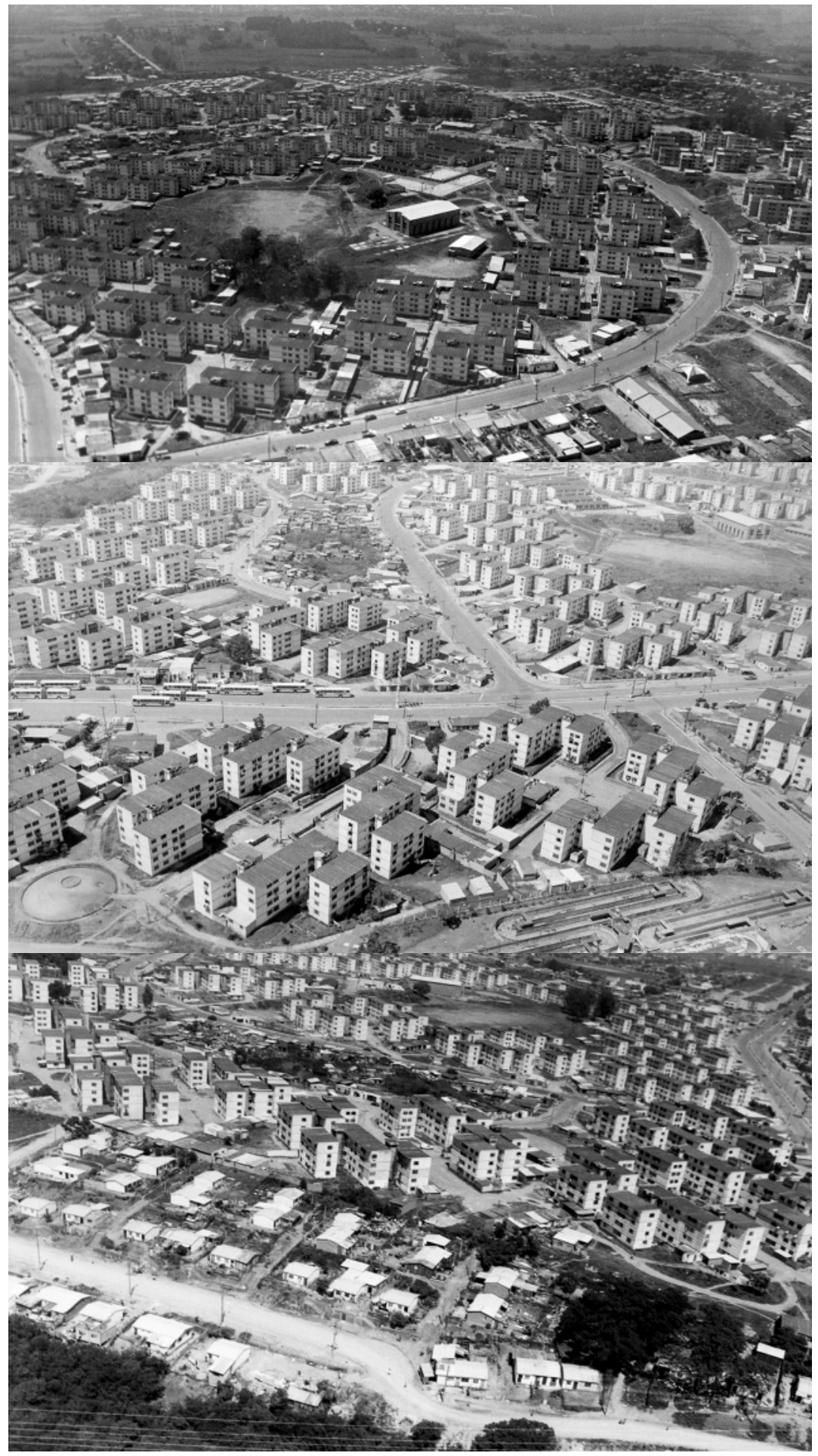


530 Fig. 79- Le elaborazioni (tratte da D. Rigatti, 1997) evidenziano la situazione dello spazio pubblico nel progetto originario di Rubem Berta e dopo l'occupazione del 1987, ed anche una delle tante modalità di occupazione delle aree condominiali originariamente previste. La densificazione - come ha mostrato il processo participativo - ha talora portato anche una razionalizzazione di alcuni percorsi illeggibili nel progetto originario.
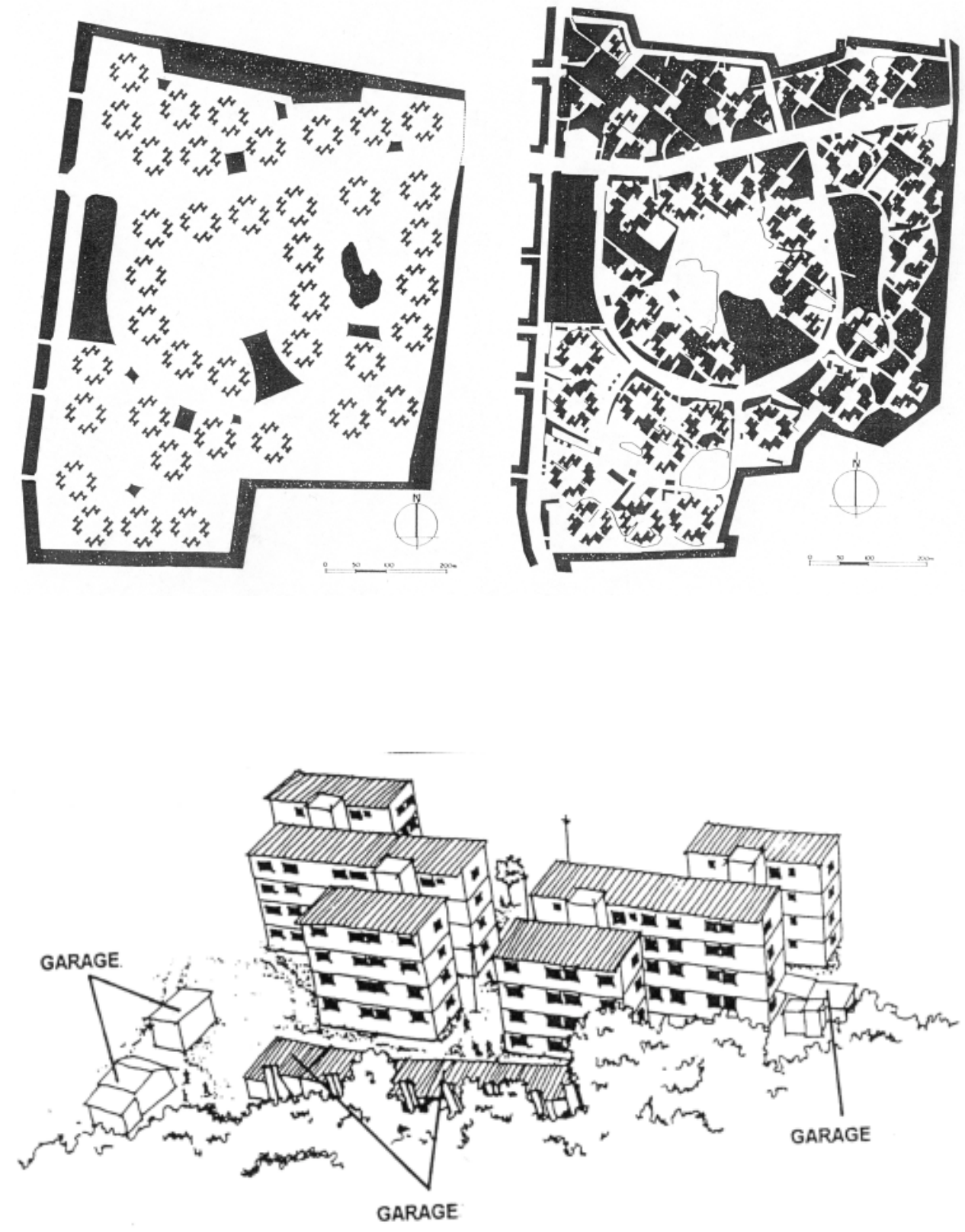
Fig. 80 - L'occupazione ha portato allo stravolgimento della spazialità del progetto originale , specie nelle aree previste libere, ad uso pubblico o condominiale. Su di esso si sono innestati interessanti fenomeni di cura dei luoghi, che hanno contributo al costituirsi di una forte identità locale, espressasi anche in battaglie unitarie per l'ottenimento di attrezzature, servizi e garanzie di maggior sicurezza per gli oltre 30.000 abitanti.
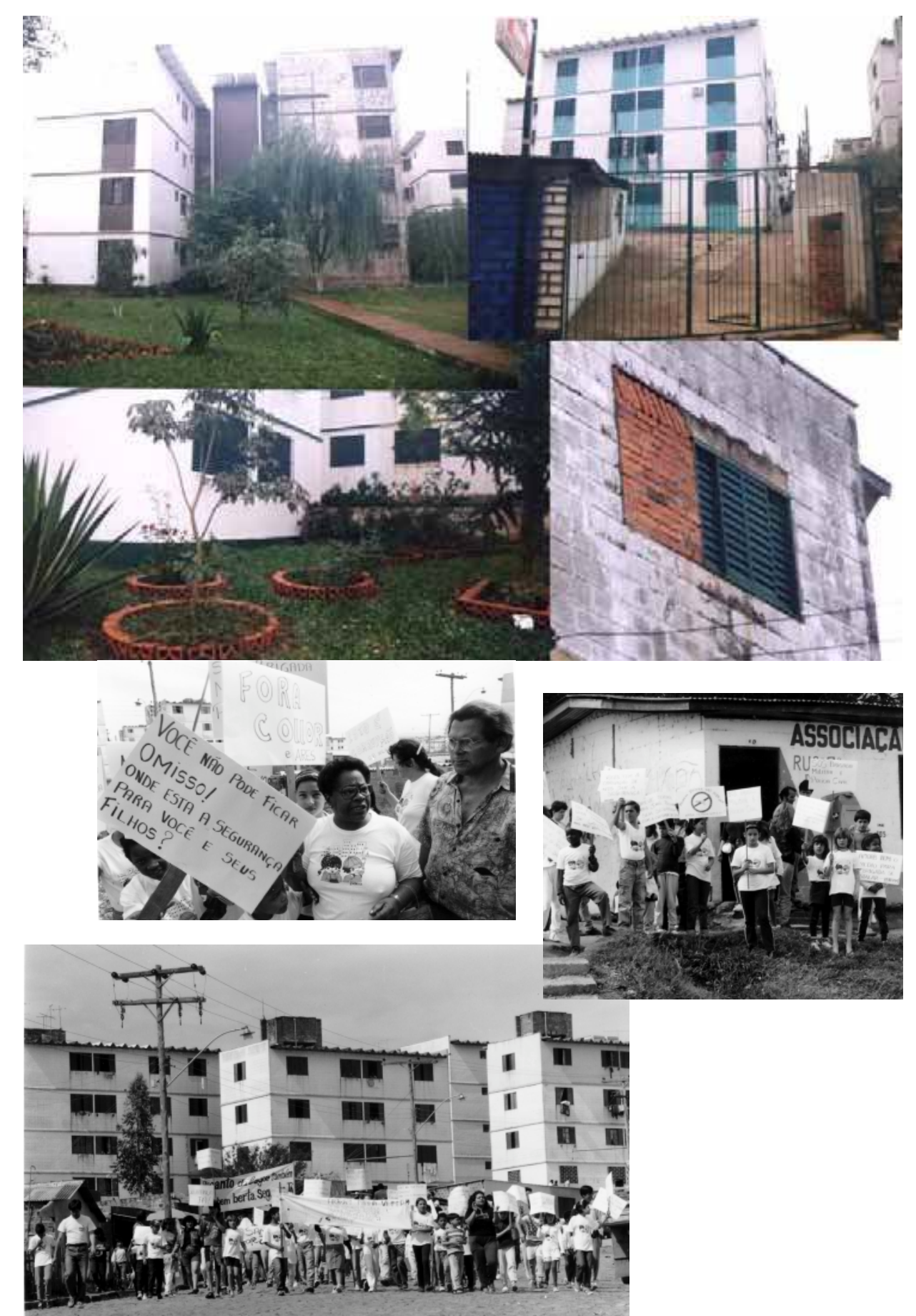
532 Fig. 81 - La scena urbana a Rubem Berta è oggi segnata dal proliferare del commercio informale e da una densità di attività molto maggiore di quella originariamente prevista dal quartiere dormitorio della COHAB.
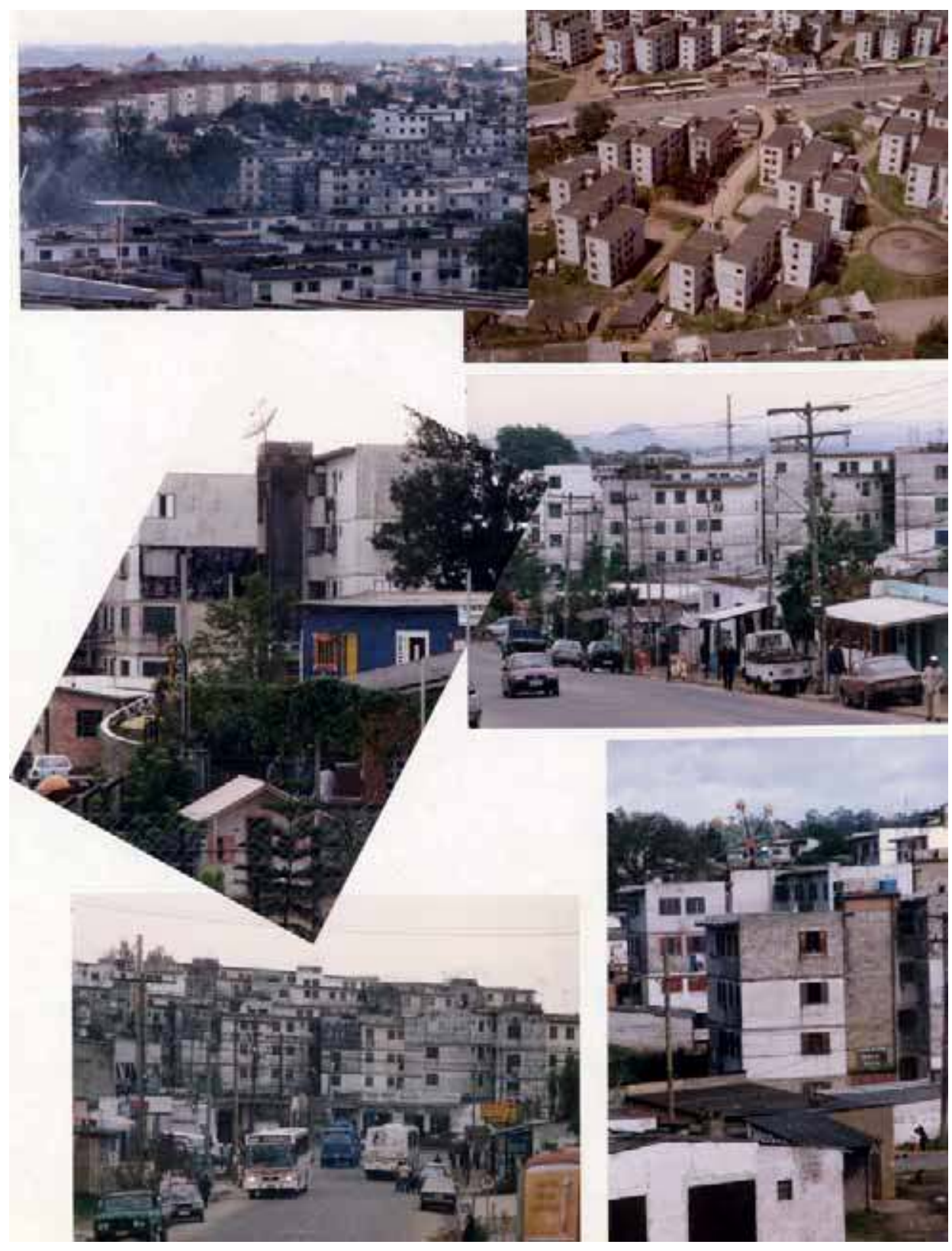
Fig. 82 - Il percorso di progettazione partecipativa è cominciato nel 1995 con la realizzazione di oltre 50 cantieri di lavoro con gli abitanti, il cui obiettivo era conoscere meglio il quartiere e progettarne insieme la regolarizzazione (Foro CCS-SPM).
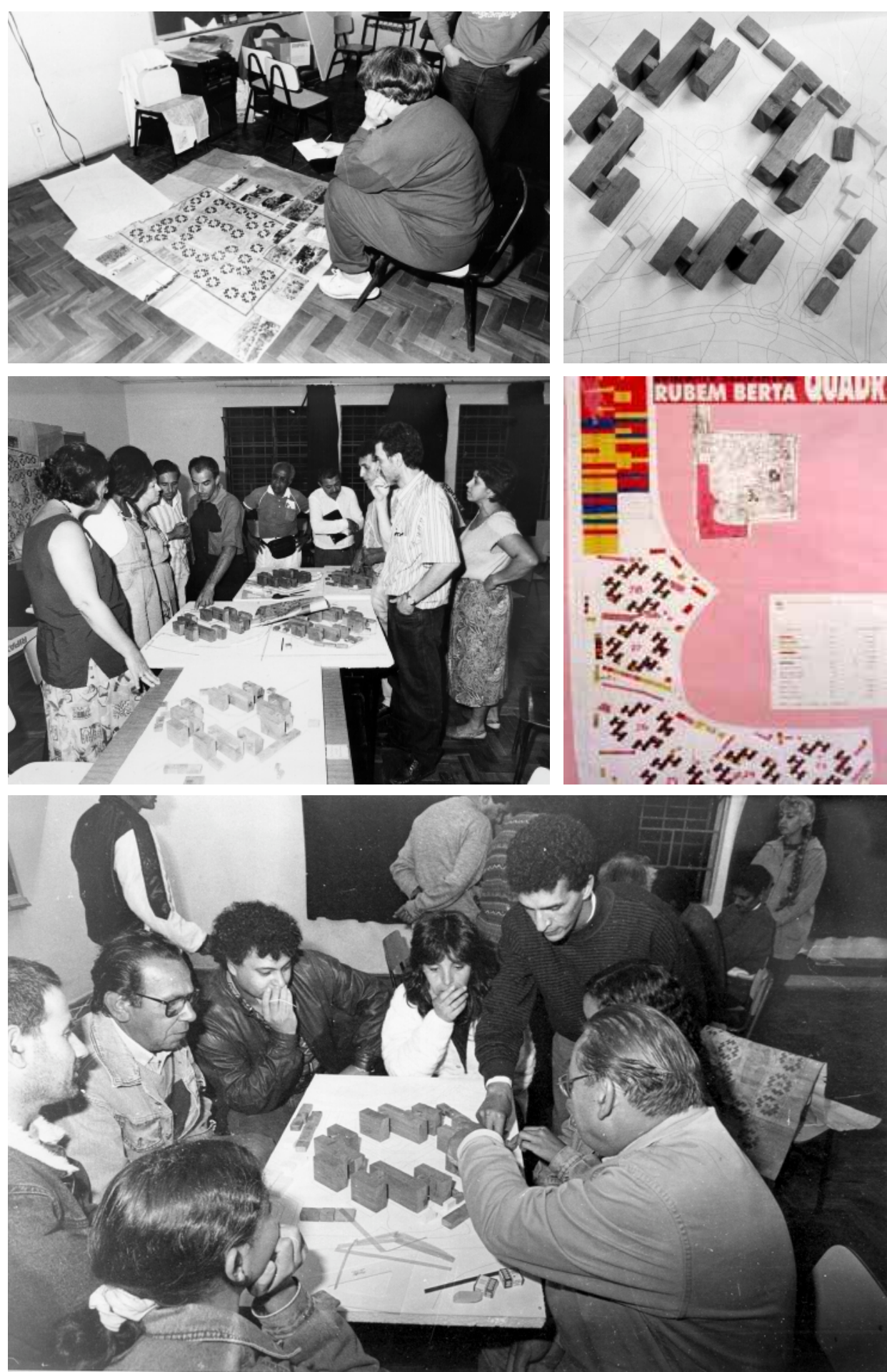
534 Fig. 83 - Le cartografie realizzate nel corso degli Atelier, con l'ausilio dell'Università Federale del Rio Grande do Sul, hanno contribuito alla riprogettazione condivisa del quartiere, approvata nell'ottobre 1998 e leggermente modificata (sempre con il concorso dei cittadini) tra il 1999 e il 2000.
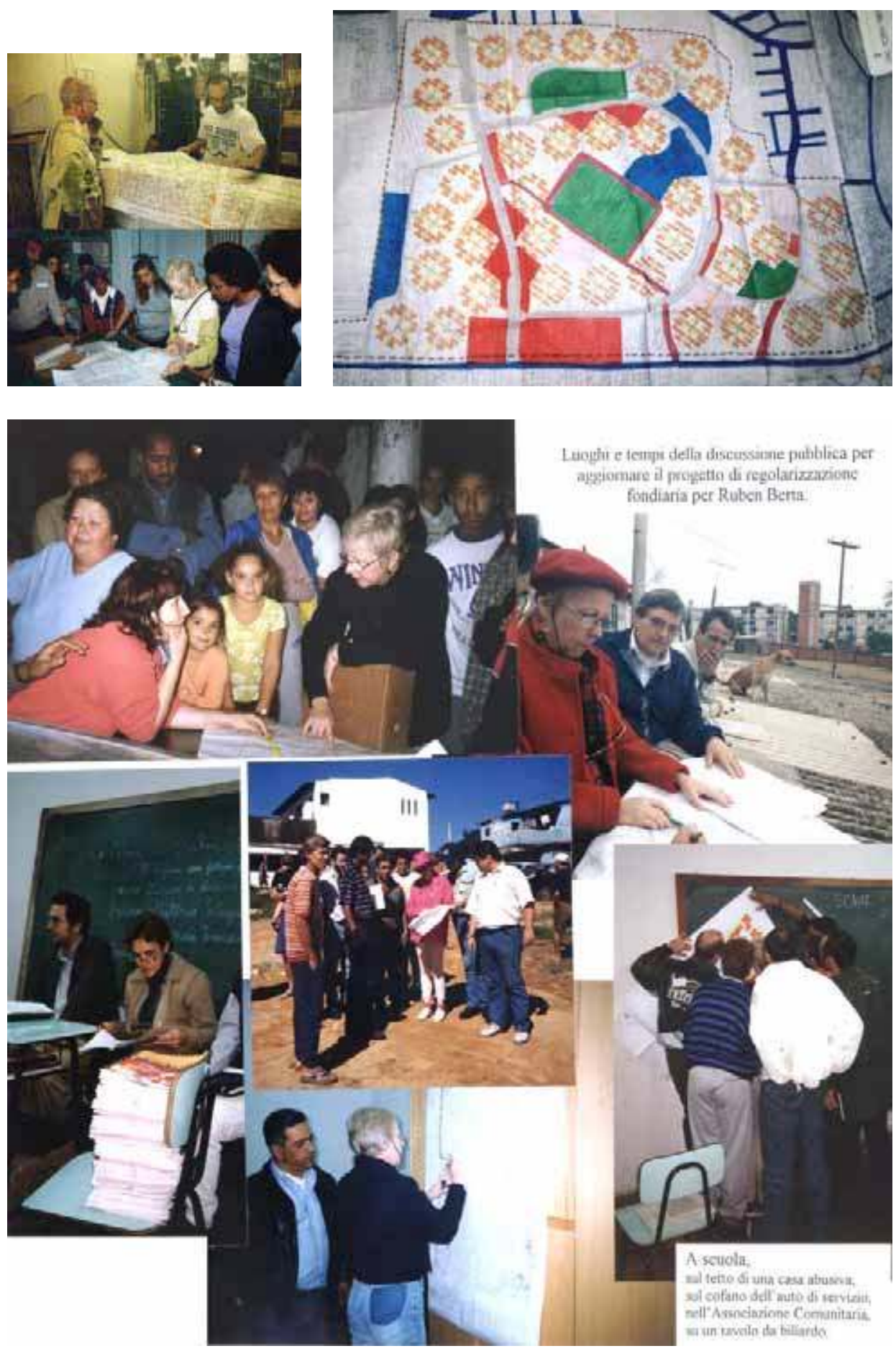
Fig. 84 - In confronto al rilievo del caos urbano che caratterizzava il quartiere di Rubem Berta nel 1995, il progetto emerso dal processo partecipativo presenta una chiara dove le singole comunità insediate possono utilizzare gli affitti dei garage e delle dimore costruite illegalmente sullo spazio condominiale a beneficio degli abitanti di ogni microcomunità.
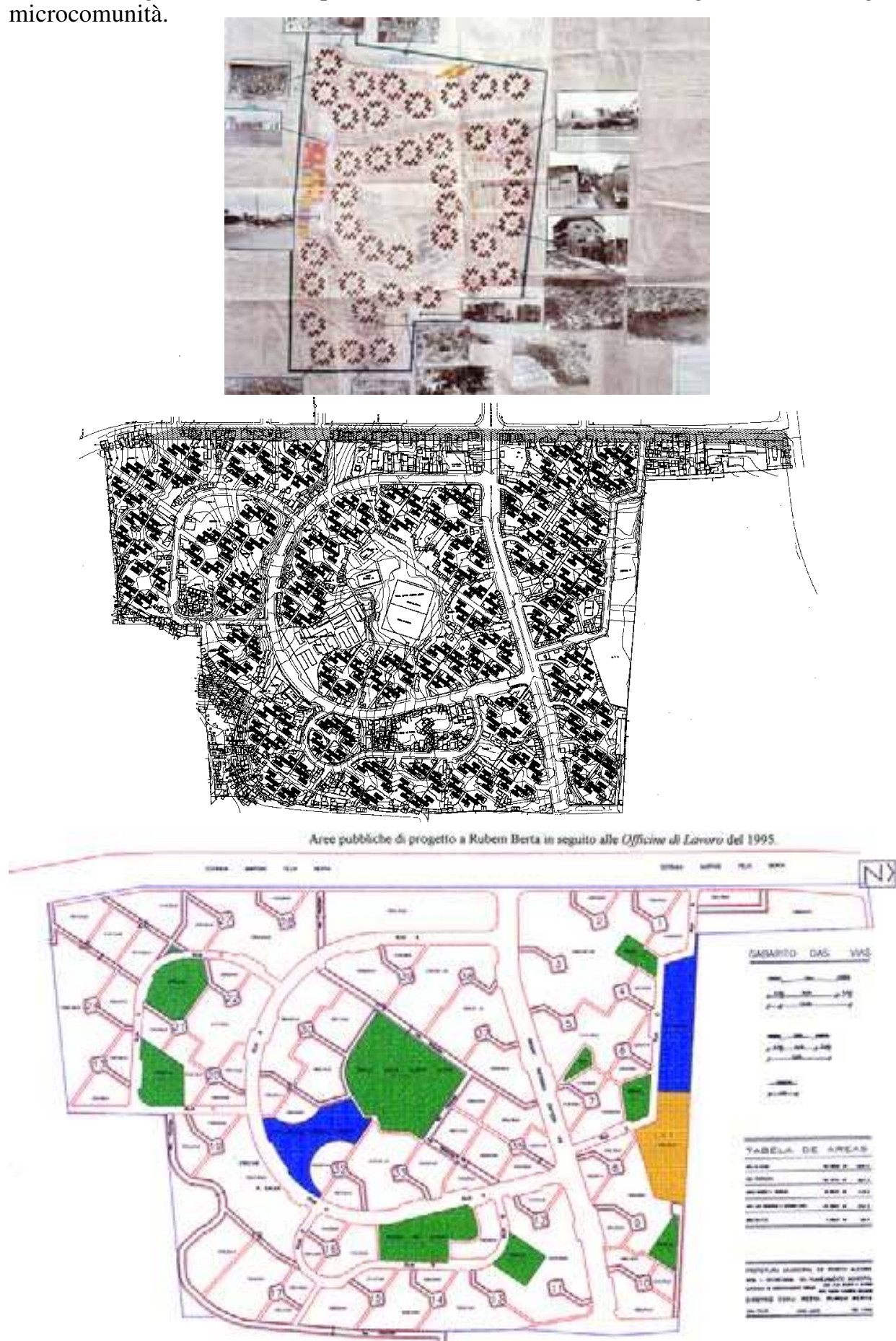

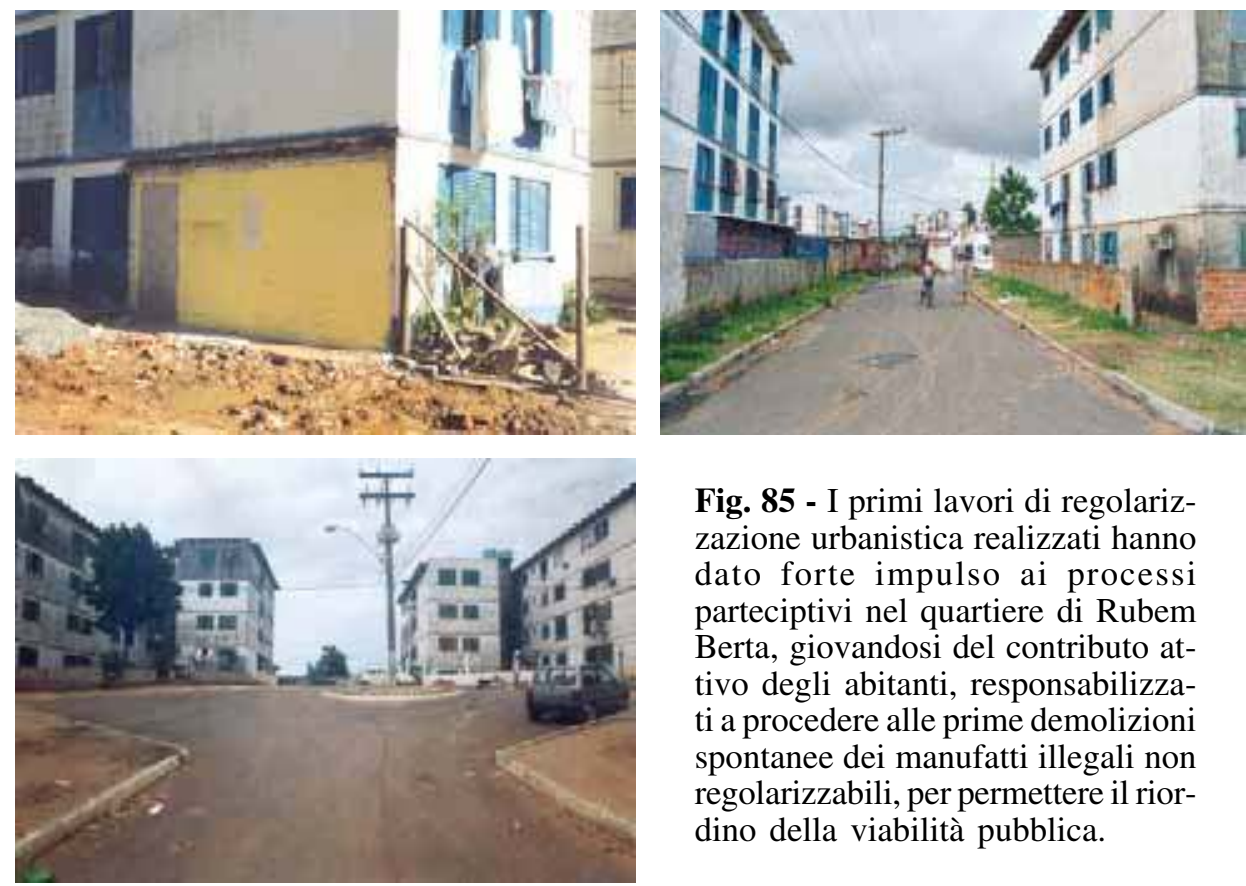

Fig. 85 - I primi lavori di regolarizzazione urbanistica realizzati hanno dato forte impulso ai processi parteciptivi nel quartiere di Rubem Berta, giovandosi del contributo attivo degli abitanti, responsabilizzati a procedere alle prime demolizioni spontanee dei manufatti illegali non regolarizzabili, per permettere il riordino della viabilità pubblica.
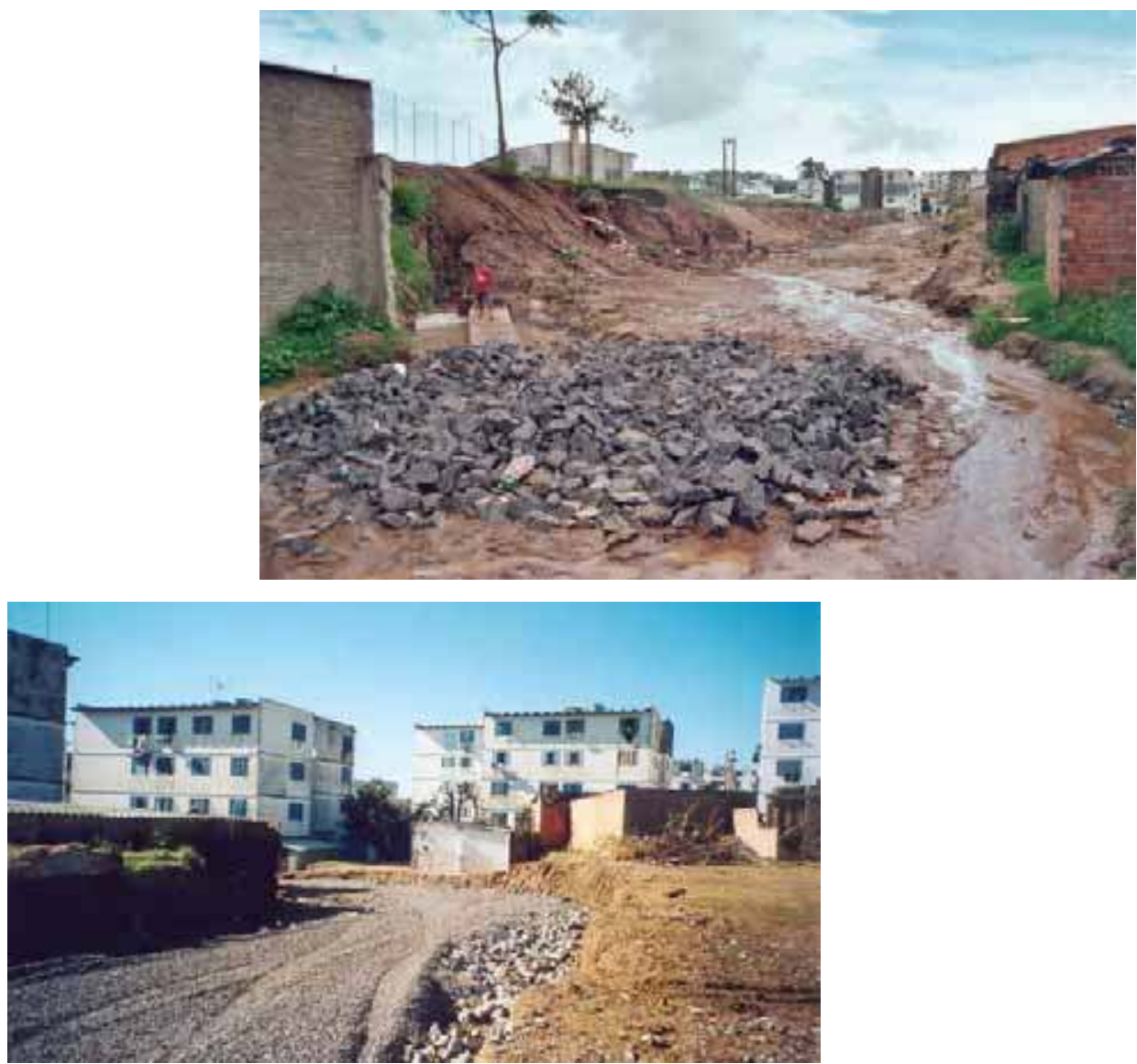
Fig. 86 - La favela su palaftte del Recanto da Lagoa (situata nell'area di Rubem Berta dove era prevista una laguna) ha cominciato ad essere demolita nel 2000. Gli abitanti sono stati rialloggiati a due chilometri di distanza, nel quartiere chiamato Timbauva,

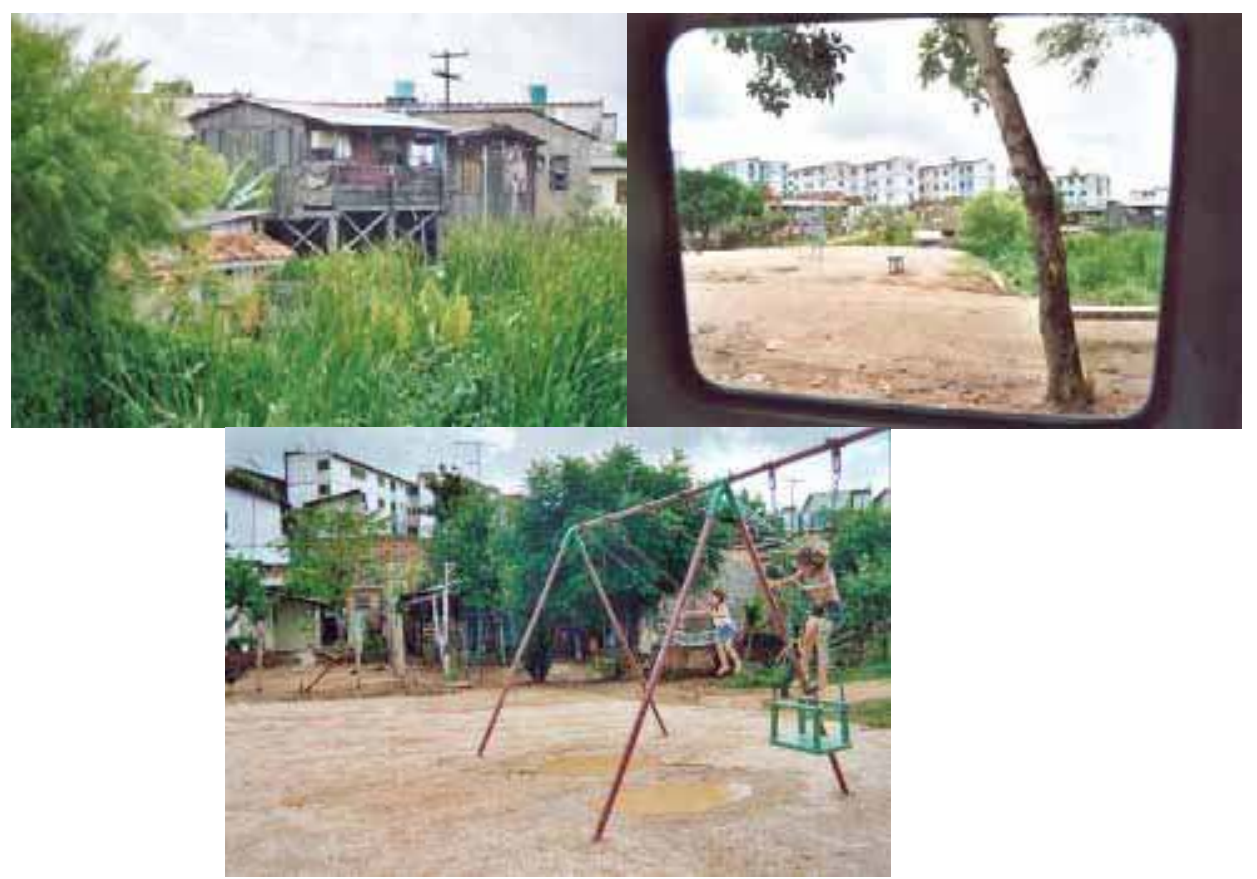

Fig. 87 - L'alternarsi di momenti di accelerazione nel concretizzarsi delle opere previste dal piano di regolarizzazione fondiaria di $\mathrm{Ru}$ bem Berta e di alcuni momenti di stallo degli stessi lavori ha influito sull' andamento della partecipazione degli abitanti nel Bilancio Partecipativo, come risulta evidente dai due grafici a lato (il primo è riferito all'intera Regione Eixo Baltazar, il secondo al solo quartiere di $\mathrm{Ru}$ bem Berta).

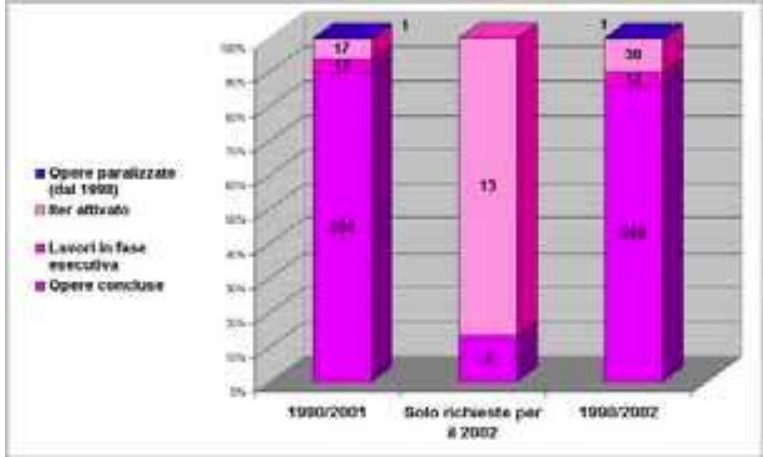

N* di delegati popolari the nel Bilanoio Partecipativo eletti per rappresentare al quartiere di Rubem Berta

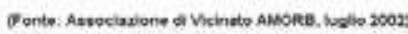

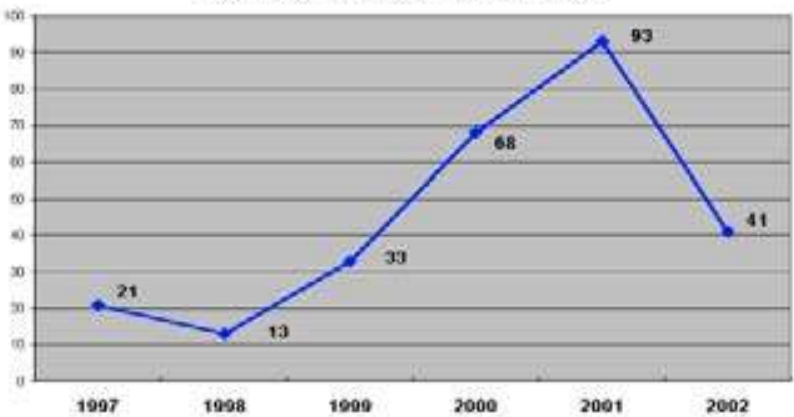


538 Fig. 88 - La sede dell'Associazione di Vicinato di Rubem Berta (AMORB) è stata ricostruita negli ultimi anni dalla comunità, divenendo un centro di servizi per il quartiere (con corsi per anziani e giovani, asilo nido, ambulatorio dentistico) grazie al forte impegno del suo direttivo. Il suo recupero architettonico - realizzato con l'appoggio di alcuni artisti portoalegrensi - la ha trasformata in luogo di riferimento che simboleggia la volontà di recupero dell'intero quartiere, sul modello di quanto avvenuto in altri insediamenti occupati della città (l'ultima foto in basso mostra la stazione locale di Polizia del quartiere Maria Degolada, realizzata dalla stessa artista Maria Tommaselli).
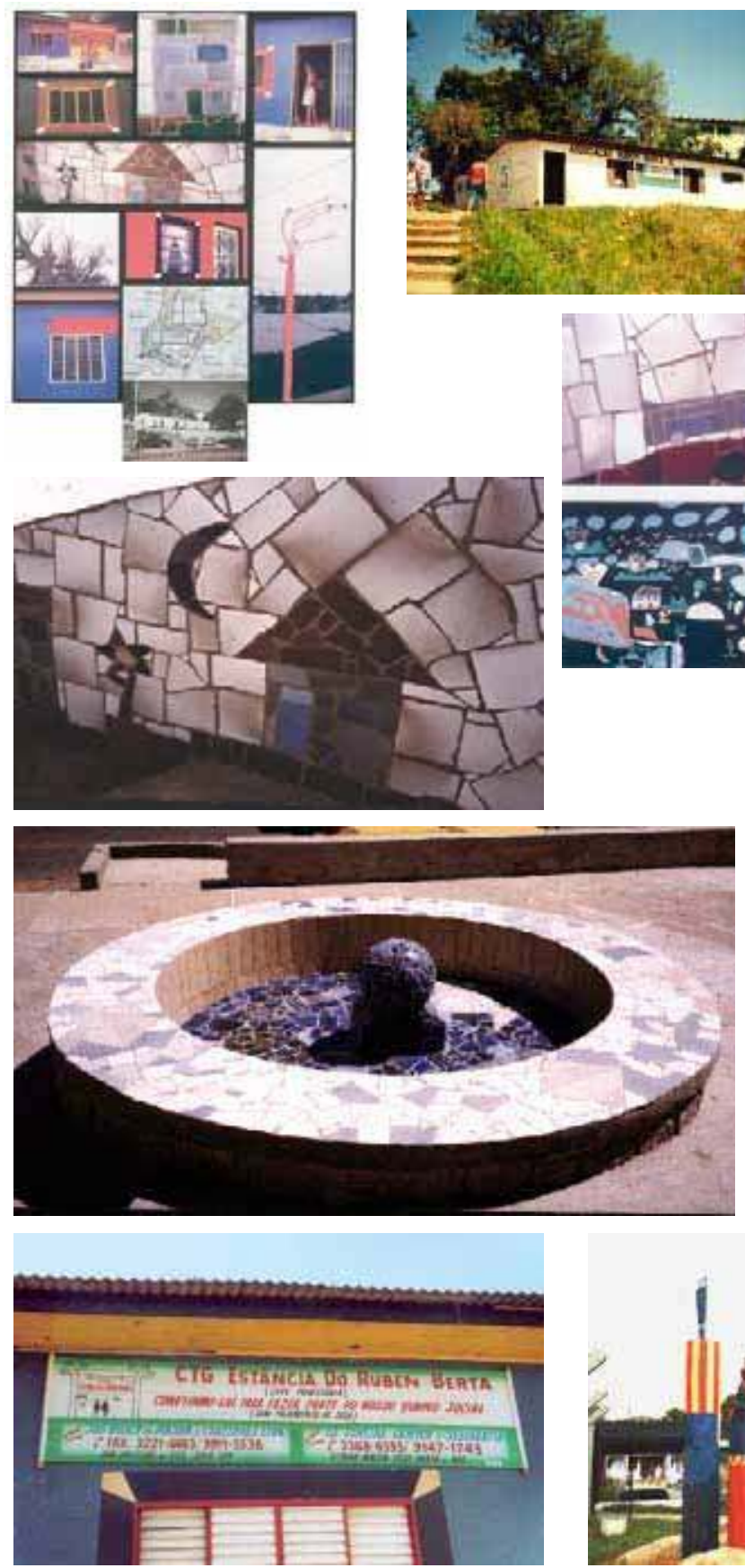
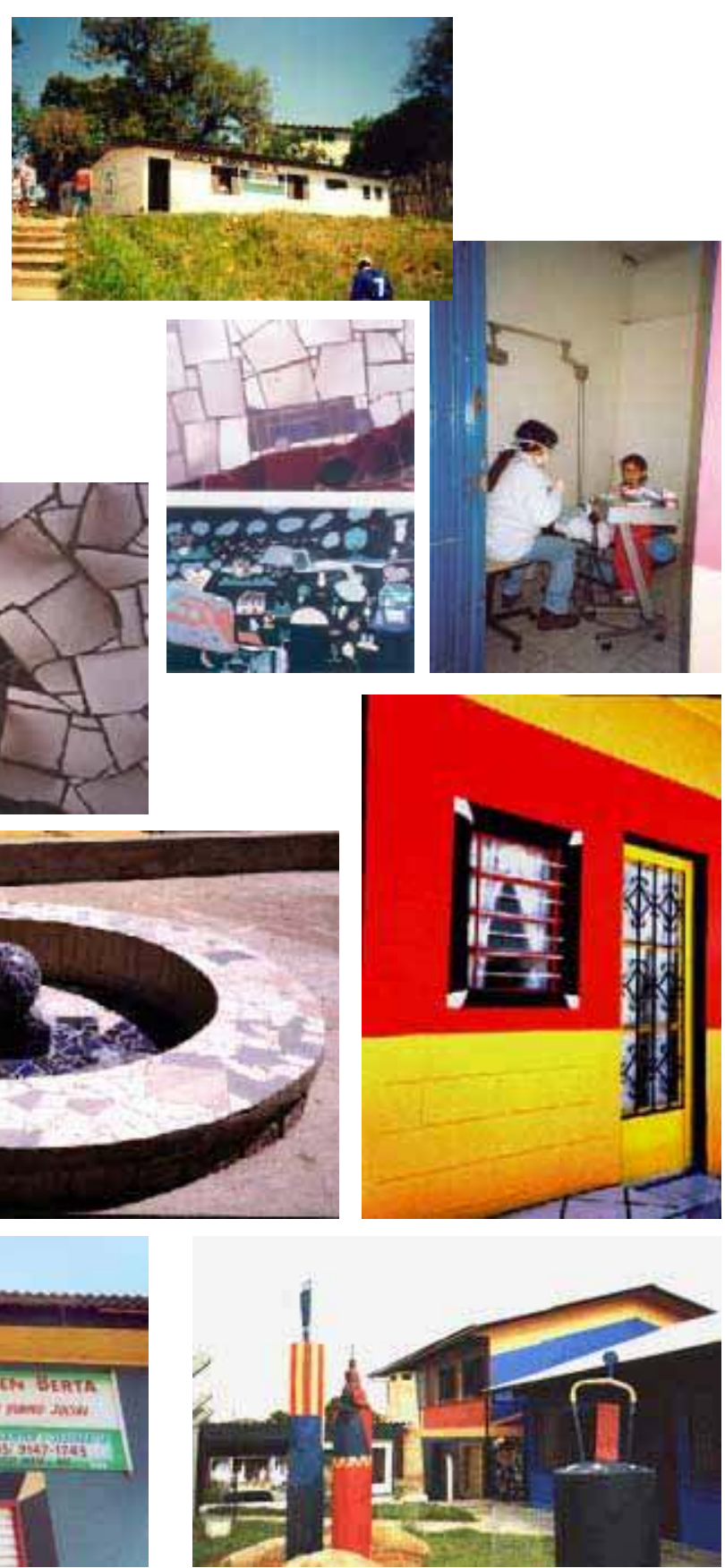


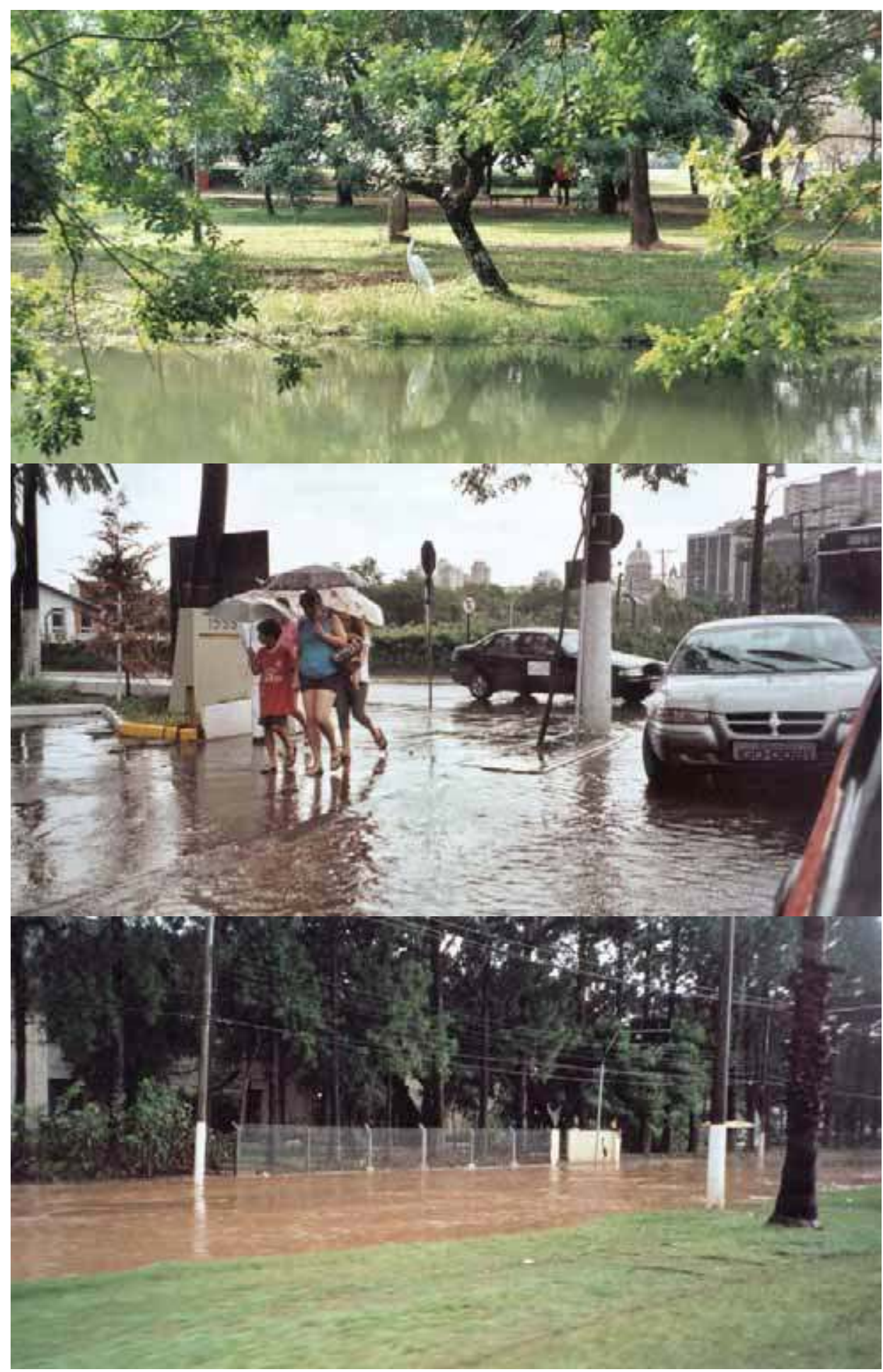

Fig. 89 - PortoAlegre ha un territorio particolare, ricco di spazi verdi all'interno del tessuto costruito, e caratterizzato da forti precipitazioni che - specie nella stagione calda - sovente provocano allagamenti e interruzioni stradali, aggravate dalla difficile topografia cittadina. 

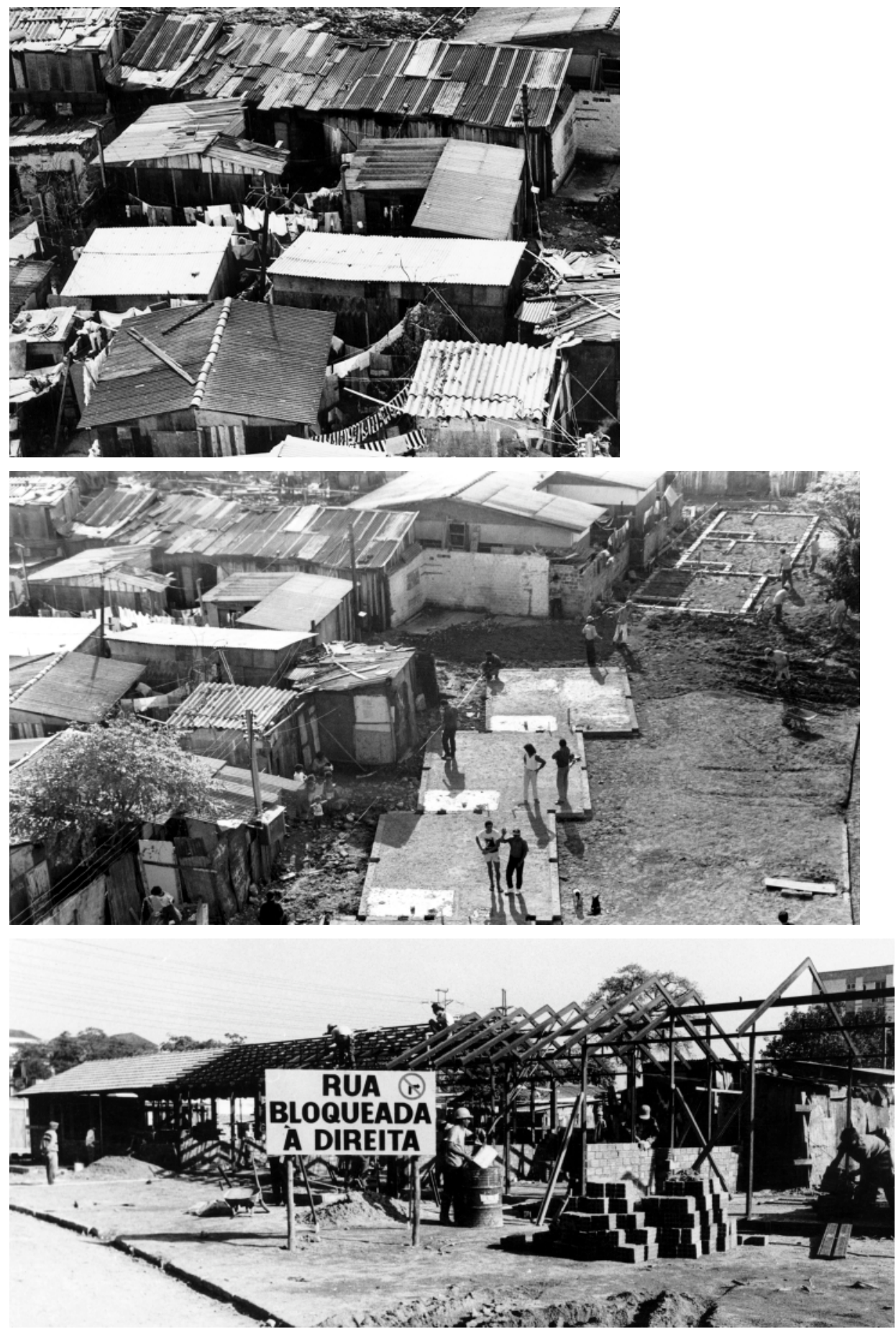

Fig. 90 - 1992: Vila Planetario (oggi Jardim Planetario) è stato il primo esempio di 'rialloggiamento sul posto' di una favela in un'area centrale di grande valorizzazione fondiaria, fortemente contrastato anche in seno alla stessa giunta comunale. In queste immagini dell'Assessorato all'Urbanistica (SPM), si vede la favela come era, e alcune fasi dei lavori di sostituzione con il nuovo insediamento popolare. 

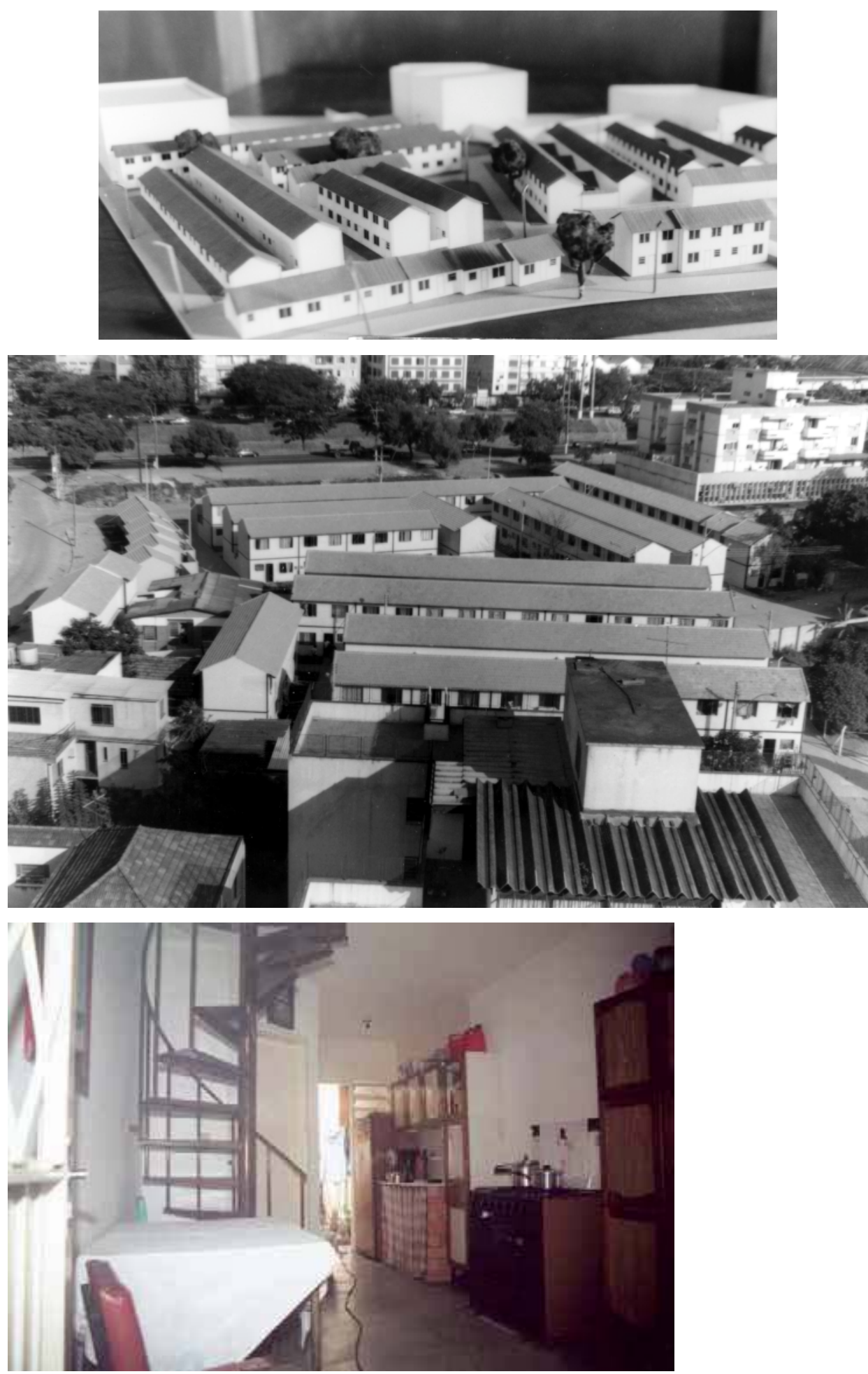

Fig. 91 - Il nuovo Jardim Planetario dopo la ricostruzione (plastico, vista generale dell'insediamento realizzato e un interno delle abitazioni popolari). 
Fig. 92 - Il nuovo Jardim Planetario dopo la ricostruzione.

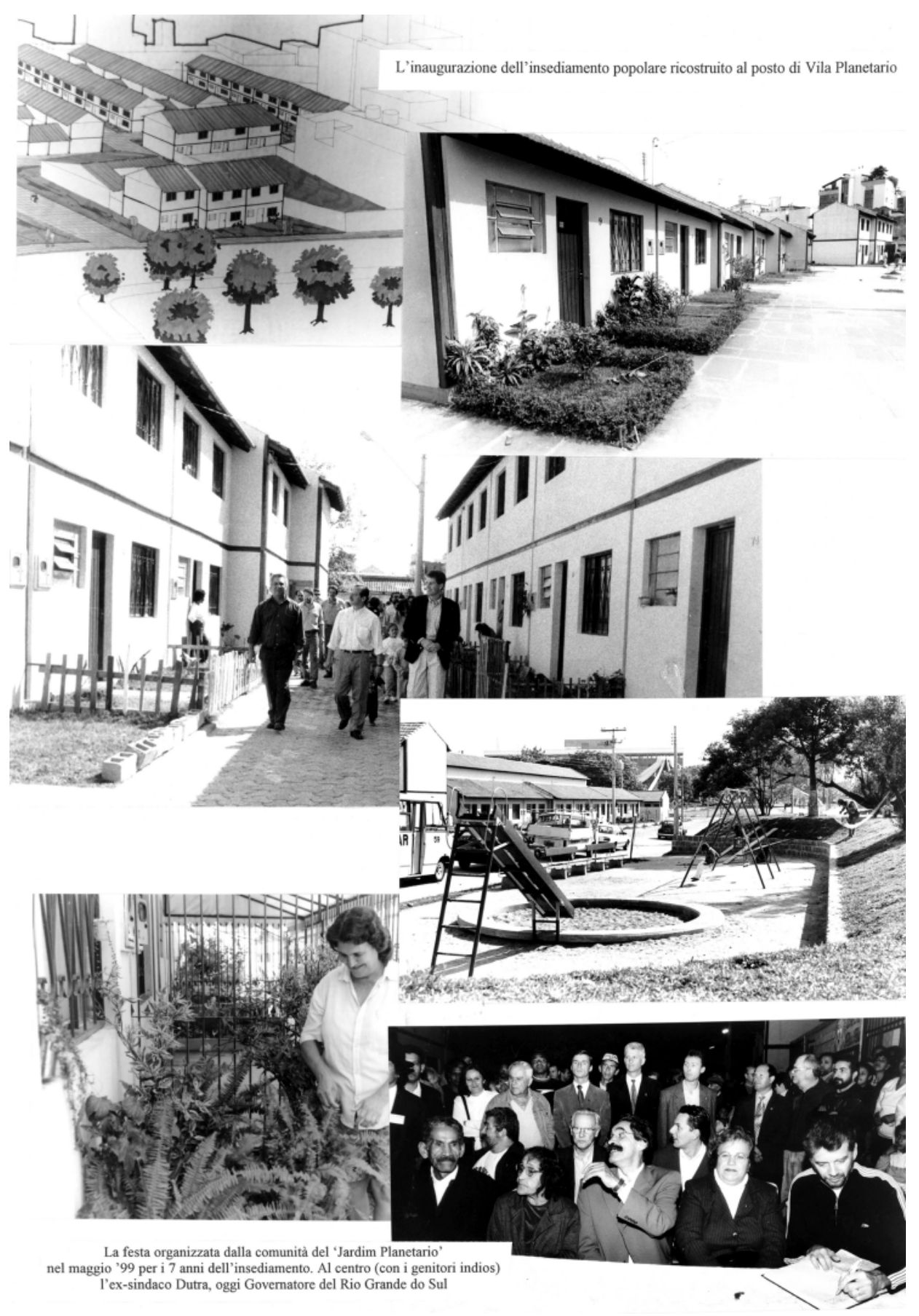




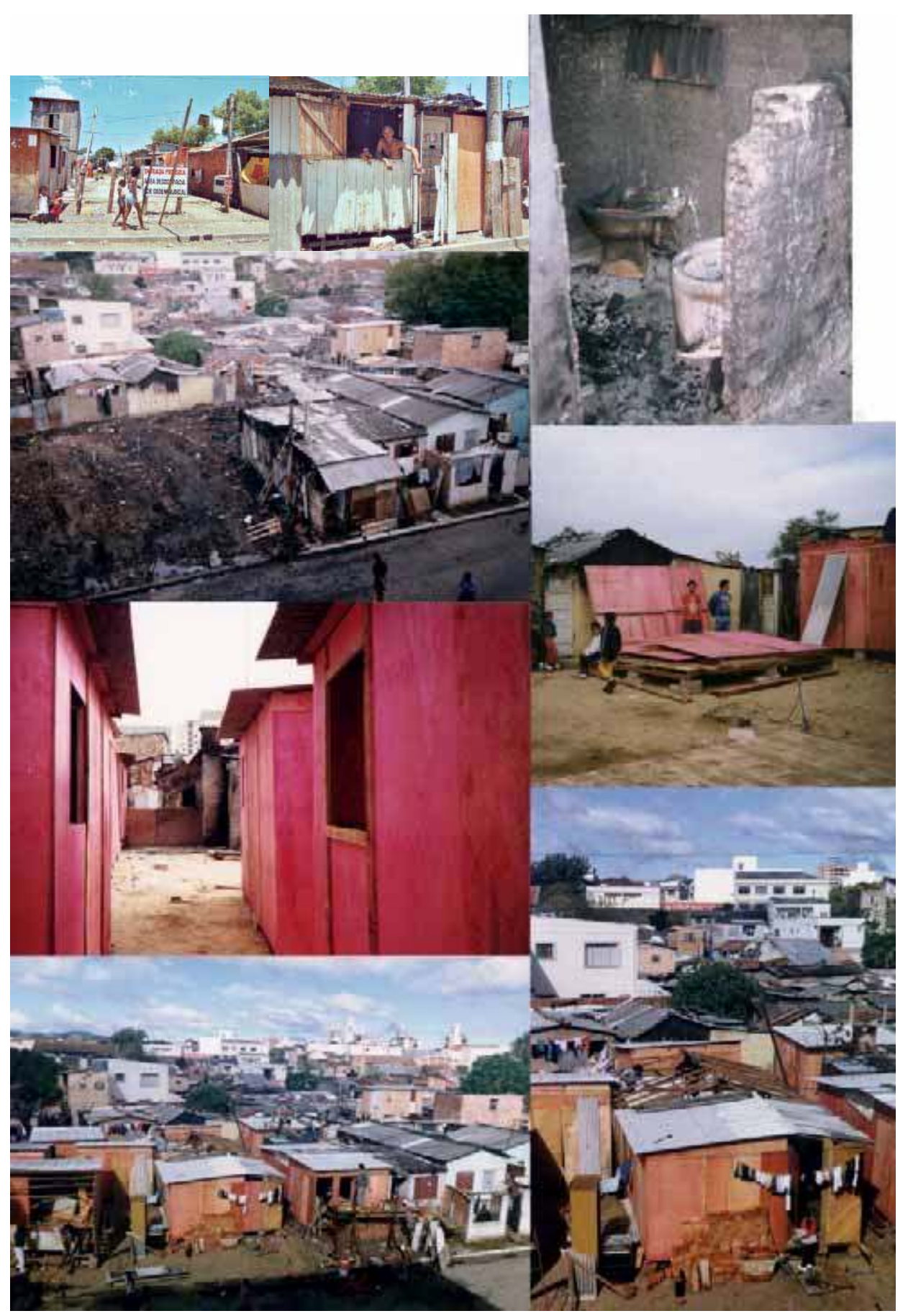

Fig. 93 - Tra le favelas del centro di Porto Alegre che non potranno essere rialloggiate 'in loco' figura Vila Zero Hora, rinata in 5 giorni dalle ceneri di un incendio intorno ai nuclei delle casette rosa di emergenza del DEMHAB (sequenza di foto Allegretti: 3 fasi di ricostruzione nell'aprile '99). L'anno scorso, nel Bilancio Partecipativo gli abitanti sono riusciti ad ottenere i fondi per essere rialloggiati in un'area distante meno di $1 \mathrm{~km}$ da quella dove vivono attualmente. 
544 Fig. 94 - Le foto del DEMHAB-CCS mostrano la favela Vila Lupicinio nel 1998, prima che gli abitanti ottenessero il rialloggiamento sulla stessa area, attraverso la demolizione delle baracche e la costruzione di case popolari.
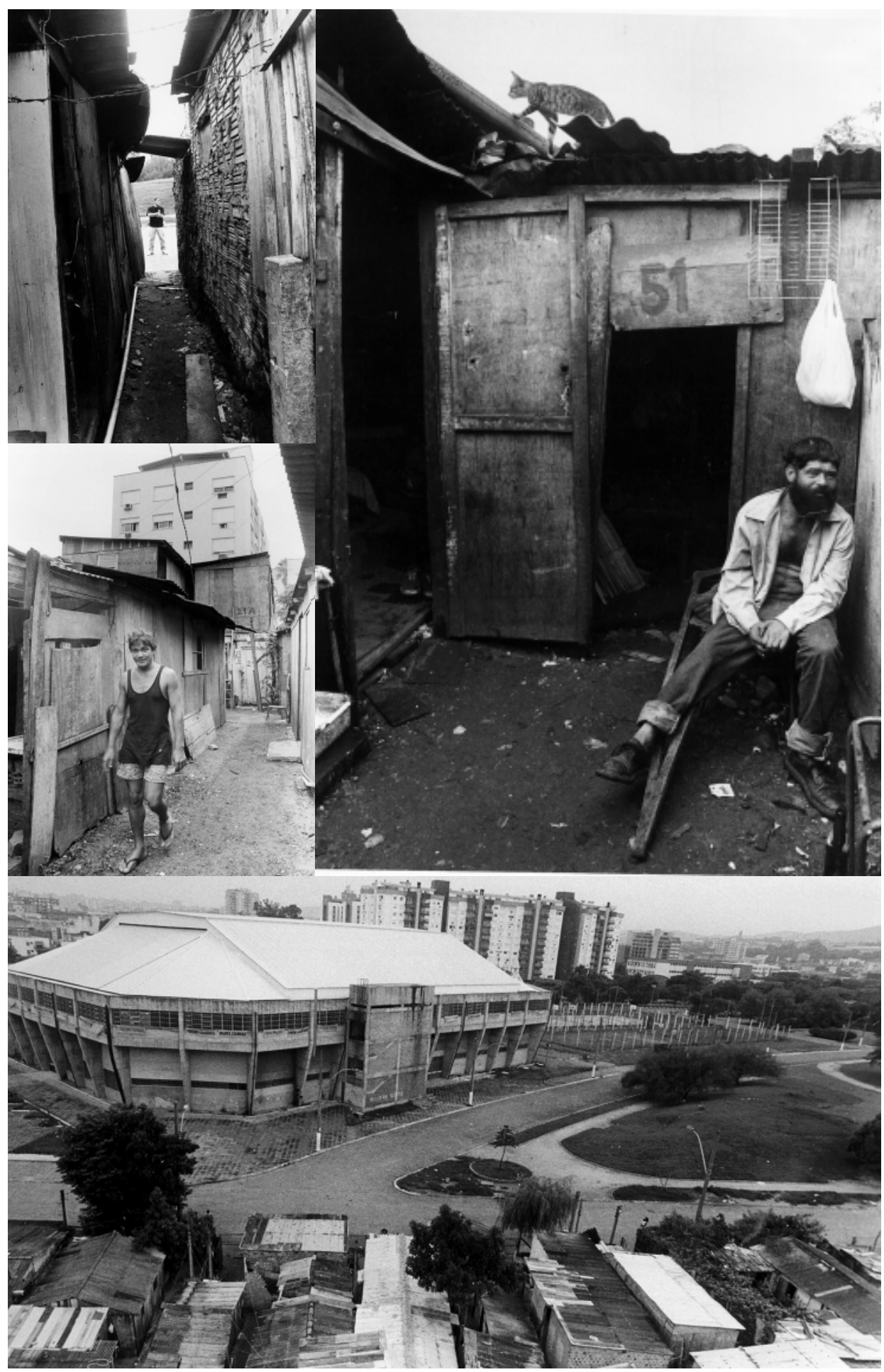

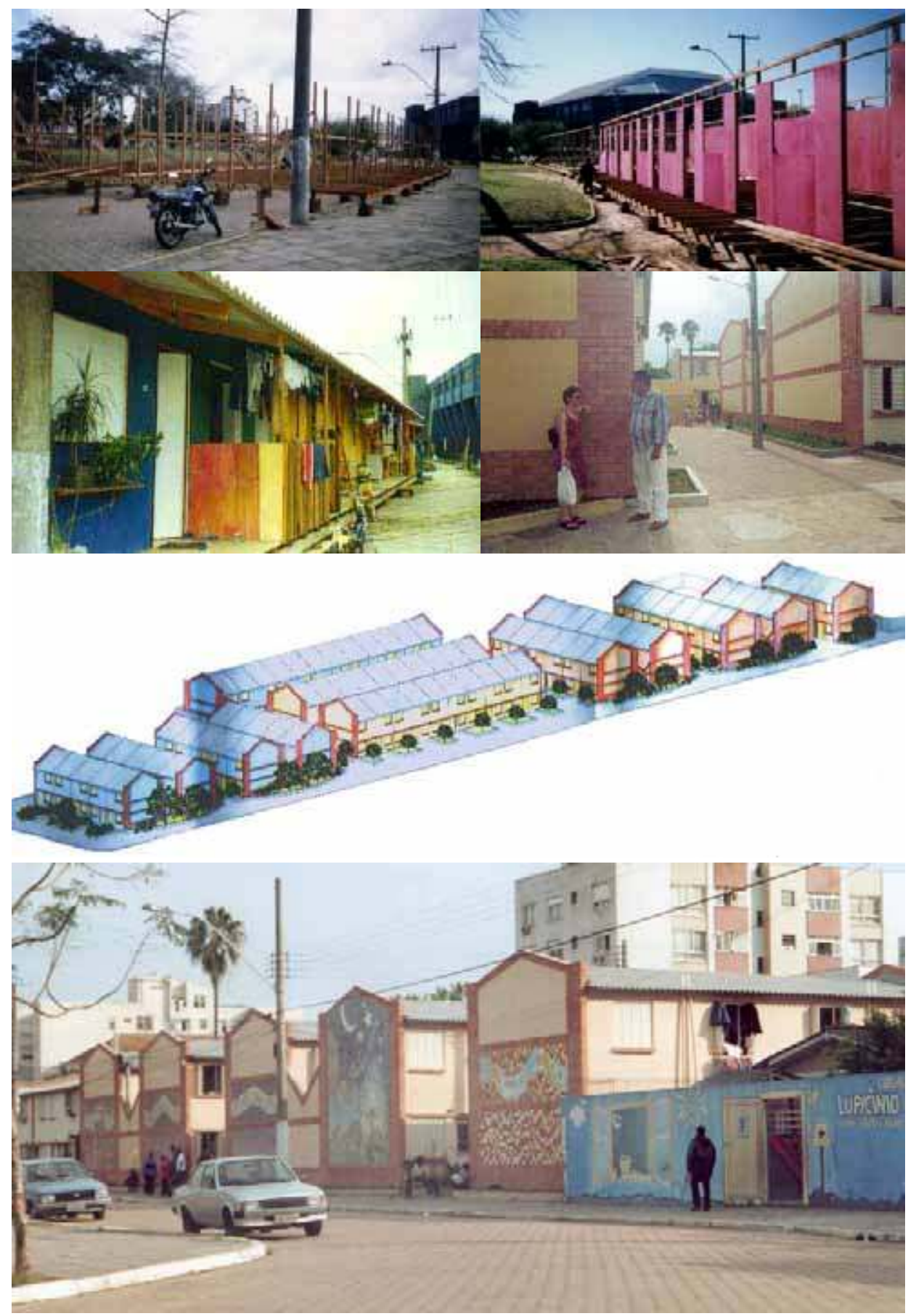

Fig. 95 - I lavori di ricostruzione di Vila Lupicinio Rodriguez sono iniziati alla metà del 1999, con la costruzione delle 'case di passaggio' nella piazza antistante, per alloggiare temporaneamente gli abitanti. Una volta rialloggiati, nel 2000, gli abitanti hanno istoriato le facciate delle stecche di alloggi popolari con dei mosaici rappresentanti la vita del musicista che dà il nome al condominio popolare, e che lo dava anche alla favela che esso ha sostituito. 

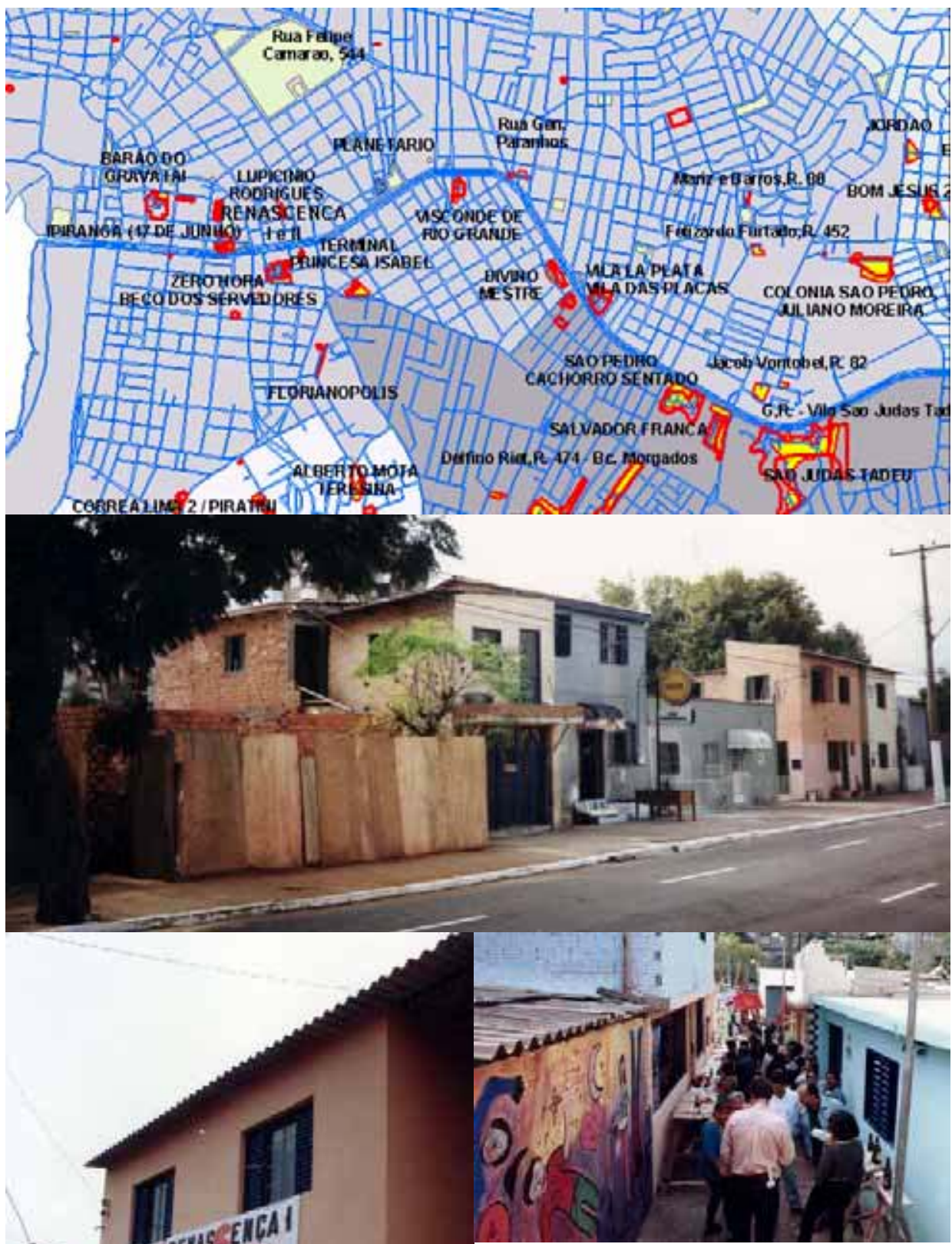

Fig. 96 - Tra le favelas del centro storico di Porto Alegre (immagine in alto) c'è Vila Renascença, ricostruita per fasi successive con il denaro stanziato attraverso il Bilancio Partecipativo, senza necessità di rimuovere tutte le famiglie temporaneamente. Durante i lavori di consolidamento e regolarizzazione fondiaria, gli abitanti hanno istoriato sui muri i volti dei personaggi della comunità che hanno contribuito alla riforma del quartiere. 


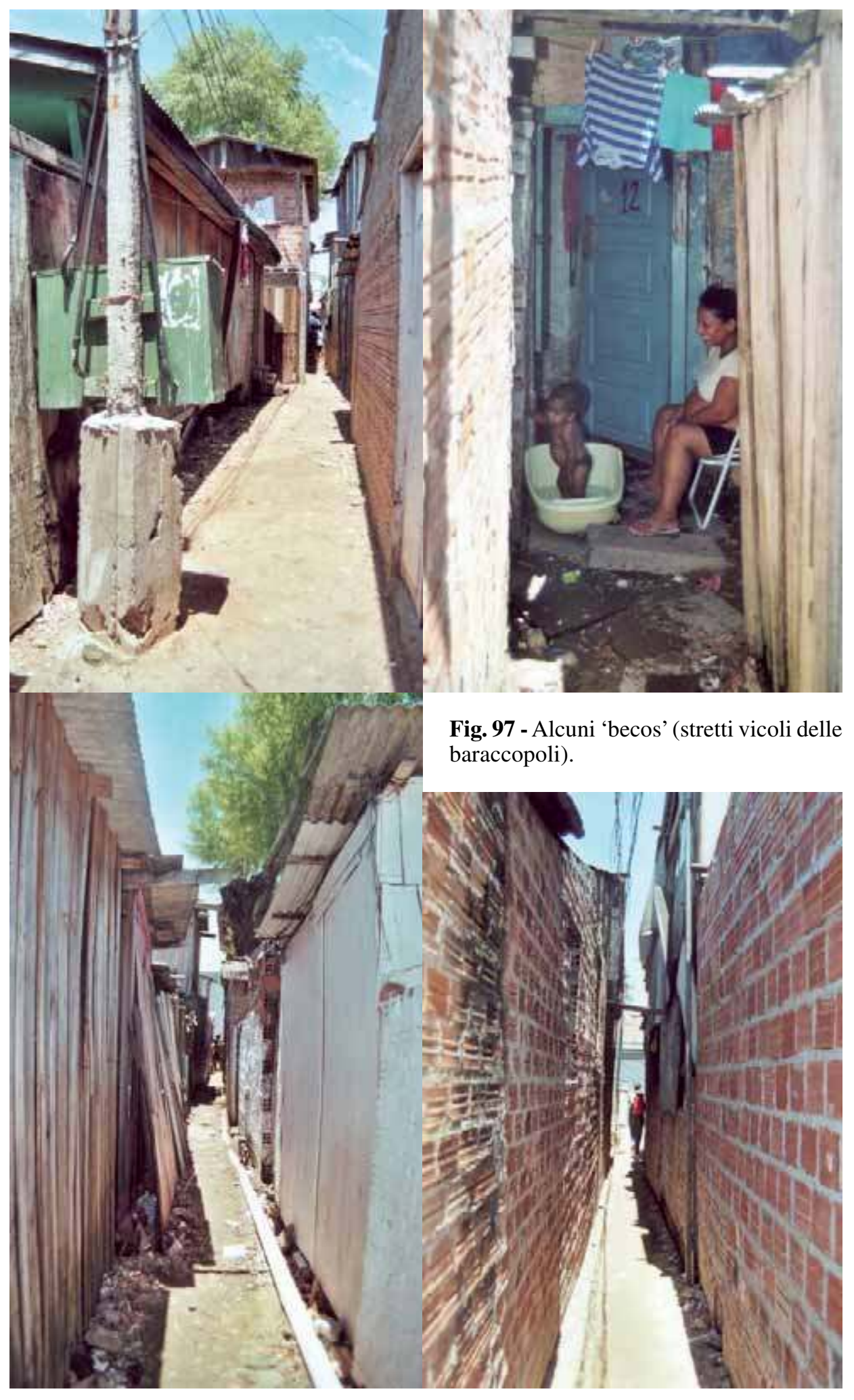




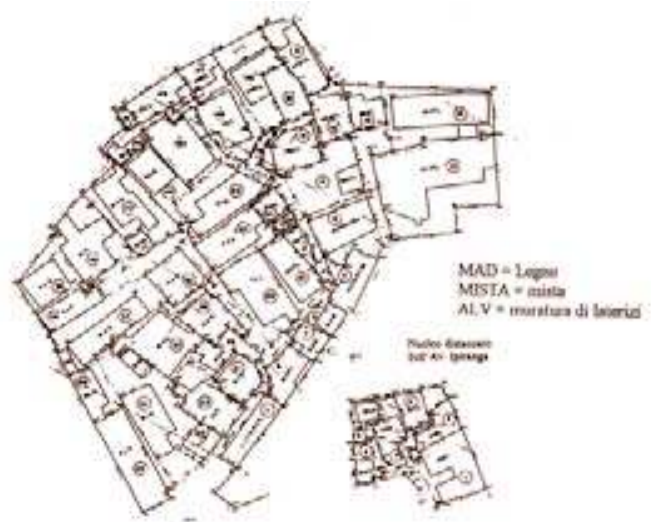

Fig. 98 - Rilievo di Vila das Placas realizzato dal DEMHAB di Porto Algre dopo l'ottenimento dei fondi per il rialloggiamento degli abitanti attraverso il Bilancio Partecipativo. Le foto ritraggono l'area occupata (che prende il nome dai grandi cartelloni stradali serviti a costruire molte case) nel giugno 1999, durante le prime operazioni di demolizione necessarie per costruire il Condominio Popolare 'dos Anjos'.
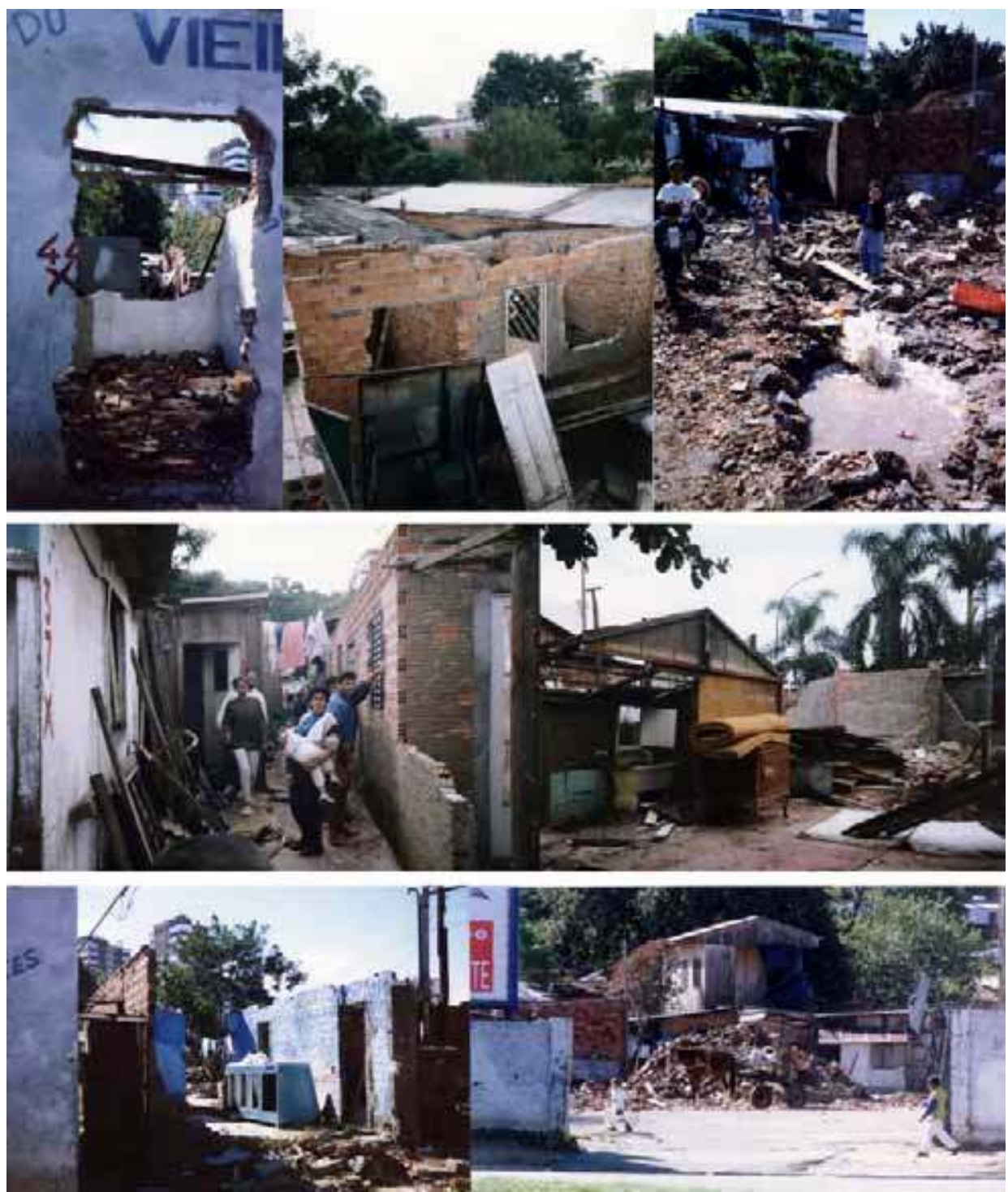
Fig. 99 - Il Condominio Dos Anjos sorto al posto di Vila das Placas è un insediamento popolare alla cui progettazione gli ex-favelados hanno dato un cospicuo contributo creativo. Oggi costituisce un modello per i nuovi 'rialloggiamenti' che il Comune sta realizzando in altre aree occupate del centro storico.
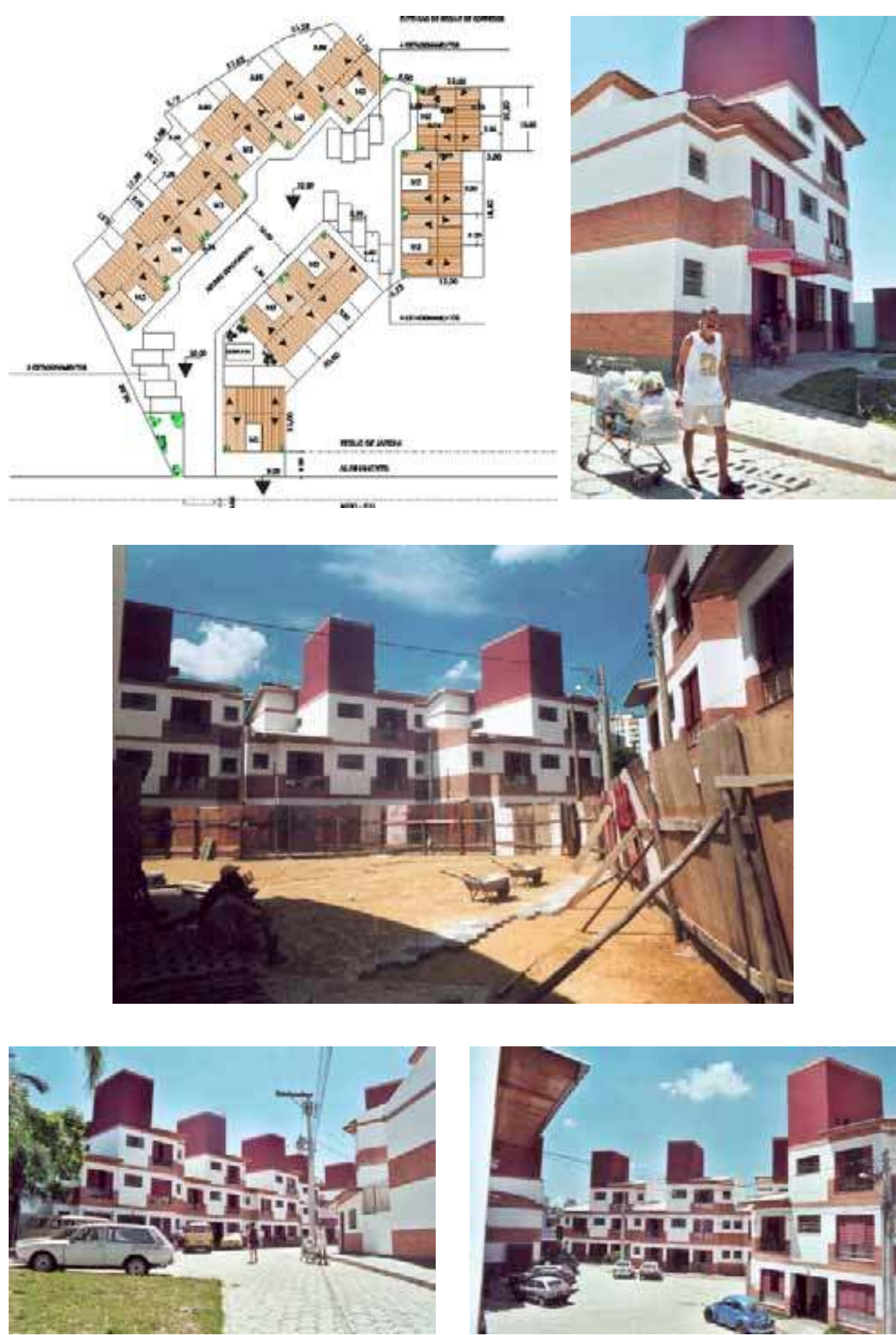
550 Fig. 100 - La favela Vila Mirim è stata demolita nel 1998/99. Il luogo concordato per il reinsediamento degli abitanti è stata la Chacara da Fumaça, anch'essa nella zona nord della città. Sull' area della favela è stata costruita una grande arteria di collegamento che lambisce il Centro Commerciale Iguatemì, volano di un'area ad alta valorizzazione fondiaria.

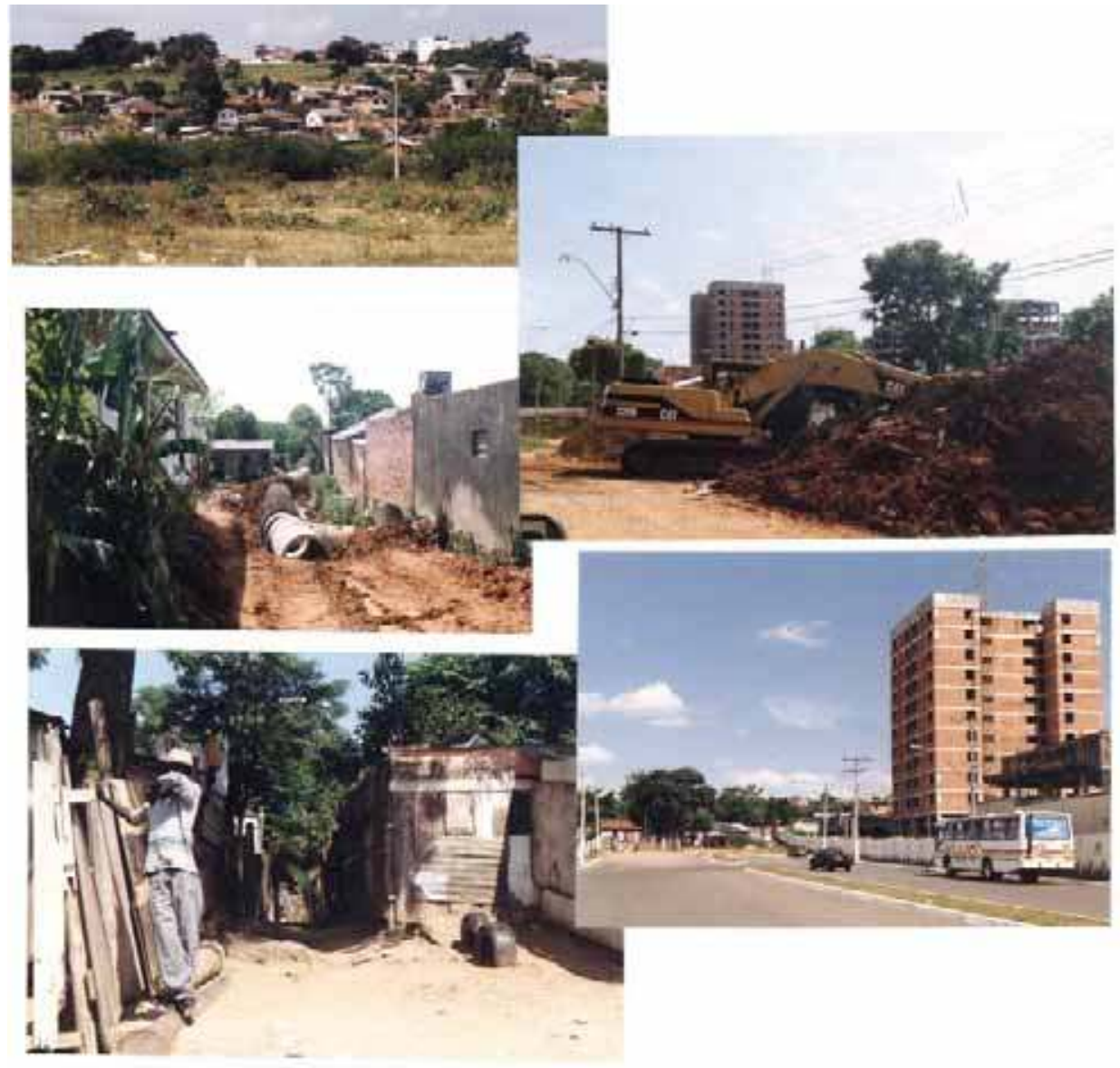

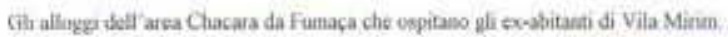

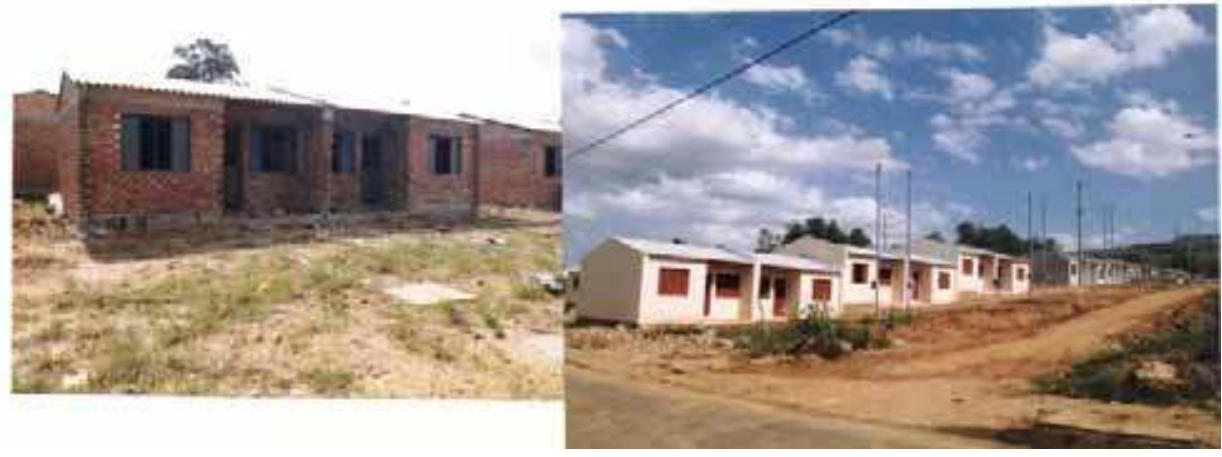




\section{5 \\ Dalla gestione consensuale alla riprogettazione condivisa: la riscossa del territorio nel nuovo Piano di Sviluppo Urbano e Ambientale}

\subsection{Tra Civitas e Urbs: l'abitare come valore urbano}

"Intervenire contemporaneamente sul dettaglio, sul quadro e sulla sua cornice. A partire dal dettaglio, ma con lo sguardo concentrato sul tutto". Nella sintetica definizione di un tecnico di lunga data dell'Assessorato all'Urbanistica' si possono ritrovare il senso, le direttrici di evoluzione e le sfide principali davanti a cui l'Amministrazione e i cittadini di Porto Alegre si trovano in questa fase di crescita della loro esperienza, che può rappresentare l'occasione per un importante 'salto di qualità' nel percorso di trasformazione delle politiche cittadine.

Se, dal 1989, il programma centrale del Fronte Popolare si è prioritariamente focalizzato sulla ricostruzione del ruolo di tutti i suoi concittadini come uomini e come soggetti politici, è stato anche perché su questo terreno pareva indispensabile agire per poter dare alle trasformazioni del territorio 'sostenibilità', ovvero una durata dovuta alla comprensione e all'adesione a quelle trasformazioni da parte di tutti, compresi gli abitanti della città informale per decenni lasciati ai margini della vita pubblica come dello spazio urbano. I modi con cui l'O.P. ha dovuto cambiare faccia e organizzazione nelle diverse parti di una città morfologicamente e socialmente complessa come Porto Alegre sono stati la prova che, se esistevano delle 'resistenze' nel locale, esistevano anche delle 'energie' progressivamente utilizzabili a pro della città; ma, per poterle sfruttare, era necessario partire da un impegno per colmare i maggiori deficit che minavano la coesione del corpo urbano. Nelle parole dell'ex sindaco Tarso Genro:

Dare priorità a questioni come la valorizzazione ambientale e dei beni artistici 10 anni fa sarebbe stata un'azione artificiale. Oggi il combattere per metterle in primo piano riesce a percepirsi come un fatto naturale. Attraverso la radicalizzazione del discorso democratico, la città ha ritrovato il suo amor proprio, facendo emergere nuovi conflitti utili a creare terreno fertile per una complessificazione del discorso urbano (Genro in Alle gretti, 2000b).

Il Comune ha così atteso che il Bilancio Partecipativo entrasse a far parte della cultura politica della città, prima di proporre altri percorsi partecipativi 
552 complementari che - in forma di feed-back - potessero "ossigenarlo", sia stimolando "un'ingerenza più qualificata" ed un intervento diretto dei cittadini nelle decisioni per il territorio ( non 'generico' e capace di andare "oltre il mero ambito dell'indicazione di priorità e gerarchie di urgenze su cui investire" $)$ sia riconoscendo come "la forte radice popolare" rappresenti "condizione necessaria per un'adeguata diagnosi urbana in confronto alle abituali visioni conservatrici dello sviluppo"3.

Nel tempo, quindi, si è reso indispensabile affiancare al progetto di ricostruzione della civitas (la città intesa come organismo sociale) quello di una sempre maggiore attenzione per l'urbs (la città fisica) e per le modalità di interazione costruttiva tra $\mathrm{i}$ due.

Con questi obiettivi, a partire dal marzo 1993, la neoletta amministrazione mise in cantiere un percorso fortemente voluto dal nuovo sindaco Tarso Genro: il progetto 'Porto Alegre PIÙ - Città Costituente'. Esso doveva rappresentare il primo passo per ampliare e approfondire la discussione su un Progetto di Città di medio-lungo termine, intervenendo su alcuni limiti strutturali del Bilancio Partecipativo, il quale rischiava di costituirsi come un meccanismo decisionale 'totalizzante'; non in grado, quindi, di arginare quelle forme implicite di 'ricatto popolare' che possono sorgere dal 'plebiscitarismo', e facendo compiere scelte che sono 'scorciatoie' invece che decisioni complesse e ponderate sulla base di un'attenta analisi della città, anche nelle sue dimensioni territoriale e storico-culturale.

Il processo 'Città Costituente' mirava a dare avvio alla creazione di nuove arene deliberative strutturate, dove tutti gli abitanti potessero appropriarsi del processo di sviluppo urbano, basandosi su conoscenze approfondite e sul rispetto dei criteri della sostenibilità socio-ambientale.

Il nuovo percorso partecipativo fu anche l'occasione per ridare un ruolo significativo all'Assessorato all'Urbanistica (SPM), espropriato nel quadriennio precedente delle sue maggiori competenze tradizionali nel tentativo di arginarne - nell'immediato - lo strapotere, e in attesa di avviare - sul medio periodo - un rinnovamento delle prassi attuative dei suoi tecnici.

L'articolazione inizialmente sfilacciata e incerta di 'Città Costituente' tese a prendere forma rapidamente, strutturandosi in seminari e conferenze che cercavano di ampliare gli orizzonti e la capacità di lettura dei portoalegrensi attraverso l'alternanza di momenti di ascolto di esperienze internazionali e la riflessione sul proprio territorio.

Alla fine del 1993, il processo sfociò in un 'Congresso della Città' (17/19 dicembre 1993). Da questo non solo emerse con chiarezza la necessità di formulare in maniera democratica e "coinvolgente' ${ }^{4}$ un nuovo Piano Regolatore Urbano (coerente con i nuovi indirizzi della politica municipale), ma presero già forma le 9 linee di sviluppo prioritario su cui i cittadini partecipanti volevano fosse articolato il processo di ripensamento e riprogettazione della città e del suo nuovo strumento urbanistico: 1) Città a gestione democratica; 2) Città decentrata e policentrica; 3) Città che combatte disuguaglianze ed esclusione sociale; 4) Città che promuove la qualità della vita e dell'ambiente; 5) Città culturalmente ricca e diversificata; 6) Città attraente e competitiva; 7) Città che promuove il partenariato pubblico/privato; 8) Città dotata di una strategia per autofinanziarsi; 9) Città coordinata con l'area metropolitana (Diretrizes para Porto Alegre, 1994). 
All'interno di questi assi tematici, furono riorganizzate 224 determinazioni su programmi, progetti e azioni mirate a mettere la macchina amministrativa 'al passo' con i processi democratici attivati e con gli obiettivi che ci si poneva nell'intraprendere i nuovi percorsi costituenti: primo fra tutti, la costruzione di strumenti coerenti di articolazione delle azioni puntuali attraverso cui si erano fino ad allora sviluppate le politiche territoriali (specie quella abitativa).

Alle domande e alle proposte emerse nel processo 'Città Costituente' in parte si sta ancora cercando di rispondere oggi. L'importante è che esso abbia attivato iniziative successive (come altri tre 'Congressi della Città's, l'ultimo dei quali ha preso avvio nel luglio 2002) e sottolineato la necessità di pervenire a strategie complessive di sviluppo urbano, condivise da un'ampia maggioranza dei cittadini ${ }^{6}$. Dando avvio e conclusione a quel lungo dibattito democratico che - in 7 anni - ha portato Porto Alegre a dotarsi di un nuovo Piano di Sviluppo Urbano e Ambientale che - dal marzo 2000 - ha sostituito il Piano Regolatore adottato nel 1979, ai tempi della dittatura.

\subsection{Il nuovo PDDUA: un rovesciamento di prospettiva della tradizione pianificatoria}

Il lungo dibattito sociale [...] ha dimostrato che senza una città collettivamente pianificata le condizioni di vita ne rimangono compromesse (Resoluções $\mathrm{III}^{\circ} \mathrm{Con}$ gresso da Cidade, 2000, p. 8).

All'inizio del Novecento, i 40 anni di continuità politica sotto l'amministrazione positivista del PRR garantirono a Porto Alegre l'elaborazione di uno dei primi piani urbanistici del Brasile interessati all'intero territorio cittadino $(1914)^{7}$, alle cui linee "proto-strategiche" ha attinto fino ad oggi l'intera progettazione urbana (de Souza, C., 1997).

Nella seconda lunga occasione di continuità amministrativa della storia portoalegrense - segnata dal governo del Fronte Popolare - la città ha visto elaborare ed approvare (con Legge complementare $n^{\circ}$ 434/99) il Piano di Sviluppo Urbano e Ambientale di Porto Alegre (PDDUA), che rappresenta - sia nei contenuti che nelle modalità di concezione e stesura - una rottura paradigmatica rispetto all'intera tradizione pianificatoria sperimentata in ambito locale, e - in particolare rispetto al Piano Regolatore approvato con Legge 43 nel 1979 (cfr. cap. 4).

Il PDDUA punta, infatti, a ribaltare le caratteristiche di quello strumento urbanistico intrinsecamente tecnocratico, contraddittorio e così incomprensibile da risultare ingiusto, nella misura in cui permetteva solo agli iniziati la sua più conveniente applicazione ${ }^{8}$. Soprattutto, tenta di risolvere i problemi determinati da un impianto intrinsecamente 'normativo' e da una struttura rigida, inadatta cioè ad accompagnare il cammino di una città che non si sveglia mai uguale a come è andata a letto ${ }^{9}$. A queste caratteristiche fondanti del PRG del ' 79 , il nuovo piano contrappone un progetto programmaticamente 'aperto', che scommette sul ruolo propositivo dei nuovi compiti attribuiti all'Assessorato all'Urbanistica e sulla sua capacità di articolare i diversi agenti urbani, presentandosi come un piano permeabile e flessibile al cambiamento, incentrato sulla definizione di obiettivi strategici che prendono forma attraverso 'Progetti Speciali' ed esperienze-trainanti, mirate a democratizzare la fruizione dello spazio urbano sulla base dell'idea 
554 portante che la qualificazione dell'abitare debba costituire il fulcro di ogni politica urbana e l'abitante il centro stesso delle decisioni sullo sviluppo del territorio (Allegretti, 2002d).

Maturato, infatti, in seguito ad un processo di elaborazione partecipativa originatosi dalle risoluzioni del $1^{\circ}$ Congresso della Città, il PDDUA si propone quale strumento per raggiungere un ulteriore livello di radicalizzazione e di qualificazione della democrazia a Porto Alegre, cercando anche di rappresentare un elemento di 'rottura nella continuità'. In tale ottica si pone in connessione diretta con la struttura e la spazializzazione del Bilancio Partecipativo, ma al contempo si appoggia a strutture preesistenti, come il Consiglio Municipale del Piano Regolatore (cfr. § 6.6), ponendosi in linea con altre pratiche locali di gestione della città, indirizzate a propiziare un progressivo 'riempimento di senso' di varie di istituzioni partecipative, spesso 'scatole vuote' create per facciata da regimi tecnocratici o dittatoriali. Ad esse, con il tempo, si sta riuscendo a restituire un peso sostantivo, sia in ragione dell'empowerment stimolato dal Comune,sia grazie alle elaborazioni dei movimenti urbani cittadini.

Il significato del cambiamento di prospettiva che il PDDUA propone non è trascurabile, dal momento che - come ci si può rendere conto esaminando questi primi due anni di sperimentazione - la sua struttura ha fatto sì che esso non si costituisse soltanto come strumento regolatore, quanto piuttosto come occasione e punto di partenza per la costruzione di un complesso sistema di gestione delle trasformazioni territoriali, di cui il Bilancio Partecipativo viene ad essere un tassello, magari 'nodale', ma pur sempre un tassello tra gli altri.

In tale ottica, l'approvazione del PDDUA di Porto Alegre rappresenta occasione per perfezionare il passaggio dal Bilancio Partecipativo all'Urbanistica Partecipativa (ovvero dalla 'gestione consensuale' alla 'riprogettazione condivisa' del territorio cittadino). Inoltre costituisce un 'luogo' in grado di rafforzare le possibilità di intervento sul territorio del potere municipale, legando quest'ultimo ad un ruolo attivo e permanente della società civile all'interno di un Sistema Municipale di Gestione dell'Urbanistica che dà enfasi ad istanze decisionali, nelle quali si sviluppa una stretta relazione dialogica tra abitanti e tecnici comunali, mirata al permanente e costruttivo confronto tra i saperi popolari e i saperi professionali.

Approfondire, oggi, la conoscenza di questo strumento urbanistico è forse prematuro, dal momento che la sua messa a dimora pare ancora lenta e molte 'intuizioni' attendono di essere riprese, sperimentate e sviluppate nella prassi della gestione quotidiana. È però già possibile rilevarne alcune peculiarità interessanti, che illuminano sul ribaltamento di ottica che propone rispetto al Piano Regolatore che ha sostituito, e sulla coerenza delle politiche urbane di questi 14 anni.

\subsubsection{Le fasi di costruzione del nuovo Piano Regolatore}

Gli studi propriamente detti per l'elaborazione del PDDUA sono cominciati in realtà nel 1995, quando anche la cittadinanza ha potuto prender direttamente parte - attraverso vari gruppi di lavoro - ad un processo di elaborazione che si apriva ad accogliere altri sguardi sulla città (Albano, 1998) per tracciare le linee direttrici dello strumento urbanistico, da presentare come base per la discussione al $\mathrm{II}^{\circ}$ Congresso della città previsto per la fine di quell'anno.

In realtà, già nel corso del 1994 le prime ipotesi di articolazione per il nuovo 
strumento regolatore non erano rimaste chiuse all'interno dei gruppi di tecnici municipali, che avevano lavorato alla prima bozza da portare alla discussione pubblica. L'Assessorato all'Urbanistica (SPM) aveva, infatti, riunito in gruppi di lavoro ben 162 organizzazioni rappresentative dei più diversi segmenti della società, seppur secondo una formula 'concertativa' diversa da quegli indirizzi a cui il Bilancio Partecipativo da ormai 6 anni andava abituando gli abitanti di Porto Alegre.

Peraltro, alcuni dei gruppi di lavoro così costituiti (come quello sui 'Piani Regionali') avevano fin da subito propiziato intensi contatti fra i tecnici comunali e i cittadini, giovandosi della mediazione delle nuove figure dei Coordinatori delle Relazioni con la Comunità del Bilancio Partecipativo, e con l'obiettivo esplicito di pervenire ad una raccolta di dati sui diversi territori locali, che permettesse una rappresentazione il più completa possibile dei molti volti di Porto Alegre.

L'elaborazione di 'carte percettive' di ogni Regione dell'O.P. fu individuata come strumento utile a condensare visivamente i percorsi strutturanti, i punti emergenti naturali e costruiti, le prospettive, i luoghi di incontro fra centralità, gli usi predominanti ma anche i principali conflitti e le potenzialità che potevano guidare la stesura del Piano Regolatore (Rigotti, 1998). In base alle caratteristiche diverse delle varie aree furono anche elaborate 21 carte tematiche in scala 1:15.000, con informazioni settoriali su densità, popolazione, acqua, luce, fogne, mobilità, piazze, parchi, edilizia, vuoti urbani, rendita familiare, ed anche sulle vilas e i nuclei clandestini.

Nel 1996, con la consulenza dell'Università Federale del Rio Grande do Sul e l'appoggio del Forum Latinoamericano de Ciências Ambientais (FLACAM) cominciò così a strutturarsi una prima versione del PDDUA - diversa da quella poi approvata - che arrivò ad essere discussa in seno al Consiglio Comunale. Ma nel marzo del 1997, sulla base di una relazione della Consulta Tecnica dello stesso Consiglio - e a motivo di alcune pertinenti critiche ricevute - il Comune ritirò il progetto, concedendosi oltre un anno di tempo per perfezionarlo, anche attraverso l'organizzazione di seminari, dibattiti e atelier di lavoro, che servirono ad emendare soprattutto il Regolamento Edilizio di accompagnamento (Dispositivos de Controle das Edificações).

Il gesto clamoroso servì, per certi versi, a richiamare l'attenzione della società civile su un processo di concertazione, a cui fino ad allora essa non pareva aver partecipato con molto trasporto. Del resto, anche il tentativo di avviare un dibattito partecipativo sul Piano Regolatore, all'interno dei Forum regionali dell'O.P., aveva evidenziato la difficoltà del Comune nel mobilitare le persone su temi di politica pubblica, di cui la cittadinanza raramente arrivava a comprendere chiaramente i propositi, anche a causa della presenza di norme molto dettagliate (come quelle sulla larghezza e la pendenza delle strade o sulle dimensioni dei lotti) che non comunicavano molto agli abitanti sul modo in cui un documento simile potesse cambiare la loro vita quotidiana.

Uno dei grossi limiti del processo è stato proprio la mancata traduzione del 'gergo dei pianificatori' in un linguaggio comprensibile e accessibile a tutti gli abitanti. Il diluirsi dell'interesse dei rappresentanti di quartiere fece infatti sì che nel processo di costruzione del Piano assumessero ruoli attivi e propositivi soprattutto le organizzazioni settoriali e di categoria, o al massimo le ONG, che per lo più erano costituite da cittadini dotati di un livello medioalto di istruzione formale, pur facendosi spesso portavoce di interessi del- 
l'intera collettività come quelli in materia di ambiente ${ }^{10}$. E di questo è rimasta traccia in non pochi formalismi e sezioni 'criptiche' dello strumento, specie negli annessi alle norme di Piano.

Solo tardivamente, constatando questa naturale 'scrematura' determinatasi all'interno di un processo di discussione formalmente aperto a tutti, l'Amministrazione Popolare ha cercato di correggere il tiro della comunicazione. In questo quadro sono da leggersi sia l'approntamento (anche sul sito web del Comune di Porto Alegre) di 'glossari' esplicativi e di traduzioni 'in vulgata' delle terminologie tecniche e di tutti i 169 articoli delle norme tecniche di Piano, sia anche il 'gesto forte' che l'Esecutivo Municipale scelse di fare nel 1997 ritirando dal Consiglio Comunale la proposta di PDDUA appena inviatagli. Fu chiaro - infatti - che, solo attraendo nuovi partecipanti attraverso seminari, dibattiti e atelier di maggior comprensibilità che in passato, si sarebbe potuto considerare il Piano come la reale espressione dell'intero corpo sociale, visto che nella bozza intermedia parevano ancora prevalere punti di vista e suggerimenti degli 'interessi forti' che avevano intravisto nel Piano la possibilità di recuperare alcuni dei benefici sottratti loro dal Bilancio Partecipativo negli anni precedenti ${ }^{11}$.

Seppur a seguito di queste vicende vi sia stata una crescita nel coinvolgimento di fasce diverse di cittadini al dibattito sulla seconda bozza, è in realtà solo in concomitanza con l'approvazione del Piano in Consiglio Comunale che la constatazione della struttura 'aperta' scelta dallo strumento, e il suo procedere per progetti, hanno aperto reali opportunità ai cittadini di entrarvi in contatto, discutendone singoli punti più facilmente comprensibili che non il suo insieme.

\subsubsection{Dalla città informale all'informalità del piano}

Quando il processo di discussione sul nuovo piano ha preso avvio, lo strumento regolatore del '79 appariva ormai quasi inservibile, per numerose ragioni sia politiche che tecniche ${ }^{12}$. Una però, soprattutto, lo rendeva del tutto incongruente con lo sviluppo recente delle politiche urbane centrato sulla valorizzazione del capitale sociale e sulla costruzione di un 'diritto alla città per tutti': già al suo nascere - nel cercare di prevedere minuziosamente tutte le situazioni che potevano darsi nella dinamica di sviluppo della città - esso aveva trascurato proprio una delle principali, ovvero quella della crescita della città spontanea. Certo, il Piano del 1979 aveva creato le Aree Funzionali di Recupero Urbano (AFRUs) ed obbligato alcuni insediamenti 'illegali' ad operazioni di regolarizzazione secondo parametri urbanistici differenziati; ma - al di là del non aver supportato le imposizioni con norme in grado di renderle operative - nel complesso aveva solo tentato di sovrapporre le sue ragioni e i suoi schemi alla realtà incontrata sul proprio cammino, lasciando inalterato un modello di occupazione del suolo marcato da enormi vuoti urbani a funzione speculativa e da aree di preservazione naturale inutilizzate e senza controllo, 'terre di nessuno' alla mercé delle invasioni dei poveri che il Piano mirava a spostare in periferia ${ }^{13}$.

Riconoscendo questo scarto tra la realtà e le previsioni dello strumento precedente, il PDDUA (elaborato parallelamente alla realizzazione delle mappe di censimento completo della città informale pubblicate nel luglio 1999) si imposta su un attento esame della reale situazione abitativa dei 300.000 abitanti della Porto Alegre spontanea (equi valenti alla popolazione delle città maggiori dell'interno dello Stato) e cerca di predisporre strumenti e progetti adatti a facilitarne il reinserimento nella 'città di diritto'. 
La nuova ottica muove dal lemma-guida "Tudo é cidade" [tutto è città] e riconosce che il territorio abitato non si struttura solo per via di norme. Per questo cerca di articolare la dimensione economico-sociale a quella territoriale della gestione dei suoli, disegnando uno strumento regolatore che rispetti le continue e dinamiche trasformazioni della città, e dando nuova forza ad alcuni strumenti normativi (come le AEIS o il Solo Criado), che articola con singoli progetti e programmi-pilota mirati ad inserire l'abitazione di interesse sociale (a pari dignità di altri interventi di strutturazione del territorio) nell'ambito di un impegno prioritario per realizzare la funzione sociale della proprietà urba$n a$, più volte messa al centro della Costituzione Federale del 1988.

Un simile approccio spiega come mai - ancora durante il percorso di formulazione, dettagliamento e approvazione del PDDUA - siano stati messi in cantiere alcuni Progetti Integrati pilota di portata transdisciplinare, il cui coordinamento è stato affidato a 3 diversi assessorati. La loro presenza - in 'attuazione variata' del vecchio strumento regolatore - ha avuto il duplice scopo di sperimentare in corso d'opera alcune ipotesi da inserire nel piano, ma anche di agevolare la 'comunicabilità' di uno strumento di cui è difficile spiegare ai cittadini il significato nella propria esistenza quotidiana (Abers, 1998a), a meno che non si riesca ad associarlo a progetti concreti e visibili che ne chiariscano l'utilità.

Poche cose nel piano sono strutturate, le altre sono indicazioni di percorso su cui innestare progetti specifici, con standard diversi e infrastruttura progressiva. L'idea è di pianificare attraverso progetti e persone in essi coinvolte, incluse le comunità locali della città informale. La parte delle norme è solo una delle linee-guida di un piano-processo di natura strategica. Questo non deve far pensare che sia un modello desunto da formule straniere riadattate. E un modello che aderisce bene ai processi del Bilancio Partecipativo, cioè a qualcosa che abbiamo fatto nostro e adattato nel tempo, radicandolo nella città (Menegassi, a pud Alle gretti 2000a).

Al fondo di una simile struttura, che sembra perfezionare i suoi contenuti 'per tentativi' ed 'approssimazioni', vi sono indubbiamente sia la fiducia nell'acquisita capacità del corpo sociale e di quello tecnico-politico di gestire le trasformazioni spontanee, sia la cosciente accettazione "della possibilità che le analisi e le proiezioni scientificamente elaborate possano, davanti alla differenziazione della realtà, mostrarsi fragili e insostenibili", richiedendo comunque "un continuo processo di valutazione e rivalutazione" (Pilla, 1998).

Questa formula adattabile è stata scelta proprio per contrasto con il passato, che ha dato origine a prodotti estremamente definiti ma non eseguibili, che nell'attesa vedevano andare in pezzi gli stessi presupposti su cui si fondavano, in particolare nelle aree che hanno visto prendere piede la città informale (Alibio, 1999i)

Per questa via 'adattiva', il PPDDUA pare ricercare una capacità di "autoregolazione che muove dalla scala del quartiere" e diviene garanzia di sostenibilità, auto-governo ed omogeneità di fini nella diversità dei modi; includendo - come ha ben espresso il direttore del FLACAM, che ha svolto il ruolo di principale consulente esterno nell'orchestrazione del processo pubblico di costruzione del nuovo strumento regolatore - la stessa "produzione informale della città [...] come parte fondamentale della politica del piano" (Pesci, 1998). Una simile ottica, che dà conto della profonda differenza di sguardo del PDDUA rispetto agli strumenti urbanistici che lo hanno preceduto, trova con- 
558 ferme in alcune 'illuminazioni' che costellano il piano, e che in parte attendono di essere sviluppate nel tempo, sulla base di sperimentazioni concrete.

Una di queste è contenuta nell'articolo 76 della Legge di approvazione del Piano, che tratta di possibili partenariati tra il Comune e gli 'urbanizzatori sociali' ${ }^{14}$, come ipotesi per aumentare il ventaglio delle risposte in materia di politiche municipali dell'alloggio, a partire da iniziative provenienti dal territorio.

Che tipo di attori siano questi ultimi, il PDDUA non lo stabilisce con precisione, pur lasciando intendere che si tratti di 'lottizzatori irregolari' che possono tramutarsi - in virtù di un accordo con l'Amministrazione - in un "imprenditore immobiliare, registrato al Comune al fine di mettere in opera realizzazioni di interesse sociale in aree identificate dal Municipio", soprattutto AEIS ed Aree di Occupazione Prioritaria (AUOPs), ovvero aree con potenziale di uso intensivo in zone periferiche e fuori mercato, dove altri soggetti privati non hanno interesse ad intervenire.

L'evidente scopo di ipotizzare un simile partenariato è di reintegrare in una collaborazione fattiva con l'Amministrazione la capacità di queste figure di produrre alloggi a basso costo, anche all'interno del mercato immobiliare formale (e non solo attraverso quello informale, come da molti è stato fatto irregolarmente in passato) attraverso specifici 'accordi di programma'. Questi sono atti a garantire più elevata qualità degli interventi e - per il Comune - oneri di urbanizzazione più facilmente preventivabili di quanto non accada oggi, ogni volta che le varie comunità chiedono la regolarizzazione fondiaria di Loteamentos irrugalares o clandestinos, prodotti da lottizzatori che agiscono a diversi gradi di illegalità, spesso lontano da qualsiasi area urbana infrastrutturata ${ }^{15}$.

Il tentativo di far gradualmente transitare una parte della produzione informale (e dei suoi produttori) verso un quadro di legalità ${ }^{16}$ appare coerente sia con un'esperienza amministrativa che ha scelto di operare "per processi di gestione più che di creazione" (Menegassi 1999i, apud Allegretti 2000a), sia con i presupposti del nuovo PDDUA. Questo, infatti, introduce sovente novità che poi non elabora, lasciandone la definizione a fasi di approfondimento successivo, così come non definisce per tutte le aree precise previsioni di 'uso dei suoli', lasciandone la definizione a momenti successivi per non stimolare la speculazione d'attesa. Anche in questo caso, il piano non dettaglia la proposta di creare accordi con gli "urbanizzatori sociali", ma si accontenta di 'lanciarla', lasciando che si apra un dibattito sul tema, sulla base del quale pervenire ad una proposta di Legge Comunale da approvarsi successivamente (come attualmente sta accadendo ${ }^{17}$ ).

Un simile modo di procedere per strutturazioni e dettagliamenti successivi connota varie altre proposte del PDDUA. I suoi rischi sono quelli già sottolineati a proposito della 'struttura informale' del Bilancio Partecipativo: ovvero che si crei uno strumento che potrebbe essere un' arma rischiosa nelle mani della variabilità politica, qualora un nuovo esecutivo non garantisse quella 'apertura democratica' delle forme di gestione e controllo sulla pianificazione che in questi anni l'Amministrazione Popolare ha veicolato.

\subsection{3 'Corridoi di centralità' e gestione ambientale: due novità di contenu- to del PDDUA}

Nella sua forma aperta e flessibile all'arricchimento progressivo dei suoi contenuti, il PDDUA approvato nel 1999 dettaglia alcuni suoi assi strategici di 
rinnovamento dei modi di leggere e gestire i processi pianificatori locali, a cui vale la pena accennare.

Sebbene non appaia così innovatore da eliminare completamente lo schema di lettura e previsione basato sulla zonizzazione e la normazione dell'uso e dell'occupazione del suolo (peraltro prevista in ambito nazionale), il PDDUA propone norme più chiare che facilitano la comprensione della morfologia urbana e dei suoi livelli di centralità, legandoli attraverso "corridoi di centralità" intervallati da "spazi aperti all'incontro": un modo di "democratizzare la fruizione dello spazio urbano' e di distribuire attività diversificate e servizi in stretta relazione con la residenza, che la stessa struttura urbana di Porto Alegre consolidatasi per nuclei (spesso monofunzionali e monotematici) esige con forza, e che il piano del ' 79 prendeva in considerazione a livello più che altro di esigenza formale e comunque poco approfondita.

Proprio in quest'ottica di 'risemantizzazione' di vecchi concetti, il Gruppo di lavoro sul Piano denominato "Policentrismo e Zonizzazione degli Usi" ha lavorato sui due temi contemporaneamente, con il fine di evitare punti di vista monolitici e garantire un piano dalle prospettive realmente tese al decentramento, al policentrismo e alla sostenibilità ambientale (Albano, 1998). Il PRG del '79 proponeva una struttura 'teorica' di polarizzazione urbana basata su Poli e corridoi di Commercio e Servizi classificati in 5 livelli a seconda della loro specializzazione funzionale: un'idea probabilmente aggiunta tardivamente in base a constatazioni empiriche sulla città esistente, mescolate a proiezioni di sviluppo sperate (Krafta, 1998).Il PDDUA - a partire dall'osservazione dell'autonomo sviluppo multipolare subito da una città territorialmente frammentata come Porto Alegre - annulla quel tipo di classificazione rigida e punta (fin dal nome di 'corridoi di centralità') a riconoscere porzioni lineari del territorio ad assetto variabile, che non privilegiano in prima istanza alcun tipo preciso di attività, ma lasciano libertà di iniziativa, riservandosi di vagliare le proposte al momento del 'naturale' addensarsi dell'attività.

Del resto, comparando con l'oggi i 34 poli definiti e classificati nel 1979, si nota che la maggior parte di essi presentano un grado diverso di centralità rispetto alla classificazione. Solo il $20 \%$ mantengono il ruolo svolto all'interno del quadro disegnato dal vecchio PRG, mentre il $37 \%$ avrebbe oggi mutato di categoria secondo i criteri di mescolanza 'quantitativa' delle attività allora esposti, ed il restante $43 \%$ avrebbe subito variazioni di entità drammatiche (Krafta, 1998) ${ }^{18}$, anche in ragione dell'imprevisto sviluppo di centri dell'area metropolitana come la giovane città di Alvorada, che hanno indotto molti cambiamenti nello sviluppo dei principali assi cittadini.

Da allora ad oggi, quindi, una rivalutazione delle "centralità" lette in senso ampio - che contempli quindi nozioni come densità, concentrazione, flussi, animazione e varietà di attività (Albano, 1998) - costituisce un dovere, che pare trascinare con sé:

1) una radicale modifica del sistema degli indici di sfruttamento, a cui non viene più richiesto di stimolare in modo differenziato attività oggi lette solo come rappresentazione delle diverse funzioni di una stessa area (Albano, 1998).

2) una diversa concezione della rete della mobilità, che - puntando all'ampliamento del Modello Operativo Trasversale a detrimento di quello attuale 'centripeto' - recupera le vie pubbliche anche come luoghi di 'estensione dell'abitazione' (sul modello di quanto insegnato dalla città informale) e al 
contempo tende a sottomettere l'attuale modello radiocentrico della maglia viaria di base ad uno "a trama lineare" in grado di favorire l'equalizzazione dell'offerta di centralità, la mescolanza delle atti vità, la diversità e leggibilità del tessuto urbano, specie della rete degli spazi pubblici, e dell'integrazione metropolitana (Ribeiro e Bianchi, 1998) ${ }^{19}$.

3) una perdita di significato di alcuni binomi dicotomici, come l'opposizione città/campagna (intesa in senso tradizionale) ${ }^{20}$ o quello patrimonio naturale/ culturale, considerati come un unico volto delle nuove 'centralità' da valorizzare, anche raccogliendo la richiesta dei produttori agricoli di mantenere ed espandere l'area di produzione primaria (in particolare frutticoltura, ortaggi e fiori) e di considerare tali zone come "aree di miglioramento della qualità della vita", integrate fra le diverse funzioni del centro abitato.

Da riflessioni analoghe muove anche la costruzione della politica ambientale del PDDUA.

Il Piano del 1979 - pur innovativo rispetto ad altri piani dell'epoca - si era limitato ad incorporare variabili ambientali al Modello Spaziale che proponeva, attraverso la creazione di aree funzionali, a trattamento differenziato in ragione delle loro caratteristiche naturali specifiche ${ }^{21}$. Inoltre, non era andato oltre la proposizione di un'unica forma di gestione (di tipo vincolistico/ protezionistico) di tutte le aree classificate sotto la categoria della "Preservazione Permanente", propiziando appena una piatta trascrizione degli articoli 2, 3 e 9 del Codice Forestale Federale (Legge 4771/65).

Il verificarsi, negli anni, di conflitti fra la 'preservazione permanente' - intesa come negazione di qualsiasi utilizzo - e la ricerca di equilibri fra l'ambiente naturale e costruito (sommatisi all'uso improprio determinato dalla crescita della città informale proprio nelle aree di maggior pregio, che apparivano più come 'terre di nessuno' che come 'proprietà della collettività') ha fatto sì che il PDDUA abbia scelto una strada diversa su cui fondare la propria politica ambientale. Il 'processo costituente' del piano ha così suggerito di optare per un abbandono delle aree "congelate" e senza destinazione (Pavlick, 1998), introducendo nel PDDUA alcune variazioni di concezione, sotto forma, per ora, di criteri, principi e direttrici da assumersi gradualmente. A partire dal riconoscimento dell'interdipendenza e complementarità delle diverse regioni del Municipio e della necessità del rispetto della biodiversità e di un attivo impegno verso tutte le specie minacciate di estinzione (in particolare di quelle significative all'interno degli ecosistemi originali del luogo e dei sistemi caratteristici di paesaggio).

Il fatto di lasciare il Piano 'aperto' all'introduzione di modifiche successive sui temi della valorizzazione - e non più solo della protezione - dell'ambiente naturale, non rimanda al futuro ogni innovazione di contenuto. Accanto al permanere di alcune aree soggette solo agli interventi necessari alla conservazione degli equilibri locali (in genere quelle meno facilmente occupabili anche per la difficile situazione orografica e per la mancanza di collegamenti con la città) viene, infatti, introdotto il concetto di "Gestione della Conservazione" che contribuisce alla definizione di 'spazi di preservazione', dove stabilire attività legate alla ricreazione, al riposo o anche alla residenza con obbligo di produzione agricola, purché non distruttive delle risorse naturali presenti nell'area e non pregiudizievoli della conservazione (trasformativa) del paesaggio locale. E importante che - nell'indicare le linee di sviluppo della Strategia di Quali- 
ficazione del Patrimonio Naturale e i suoi concetti-guida (ma anche alcuni sottoprogetti, come quelli di recupero delle aree dismesse e degradate, o quelli di promozione della 'conservazione energetica') il PDDUA di Porto Alegre non rimandi indefinitamente a studi posteriori che sussidieranno il monitoraggio della sua attuazione, ma stabilisca per l'Amministrazione termini definiti per la definizione dettagliata dei criteri di approccio e dei gradi di vincolo da stabilire per le aree da proteggere. A partire dall'acquisizione di conoscenze approfondite dei diversi territori, che permettano di definire problemi e potenzialità locali per contribuire alla risoluzione delle principali necessità globali della città (Pavlick, 1998).

In tale quadro, il PDDUA prevede la celere elaborazione di un "Piano di Gestione Ambientale" (oggi in corso di studio anche in un'apposita Conferenza Municipale sull'Ambiente, prevista per l'inizio del 2003) attraverso il confronto e la riorganizzazione coerente dei vari piani settoriali di risanamento, salute, energia, protezione ambientale, arborizzazione ecc.

Per quanto la moltiplicazione di strumenti possa lasciare dubbiosi circa i rischi di burocratizzazione eccessiva del sistema di protezione ambientale, va riconosciuto che, nella particolare situazione di Porto Alegre, la cautela adottata nella pianificazione degli interventi in campo ambientale può essere letta come un atto perspicace, per evitare l'adozione di misure premature che verrebbero disattese in blocco.

L'elaborazione in prima istanza settoriale delle misure di valorizzazione dell'ambiente è quindi proposta come indispensabile 'trapasso dolce' per un'acquisizione del know-how, dei dati e del necessario livello di diffusa coscienza ambientale che sola può dare una reale efficacia allo strumento del 'Piano di Gestione Ambientale', che dovrebbe racchiudere "le direttrici integrate di orientamento delle azioni prioritarie di qualificazione ambientale".

\subsubsection{Un'architettura complessa per la gestione partecipativa dei processi di Piano}

Il PDDUA - frutto di un'ampia concertazione dove la partecipazione popolare si è espressa più attraverso istituzioni consolidate della società civile, che non nella forma individuale o familiare a cui l'O.P. ha abituato la città - appare oggi come un vasto 'patto territoriale in costruzione progressiva' ("la sintesi possibile' di cui parlano gli slogan scelti per lanciarlo), la cui complessità cerca, in parte, di rispondere anche ai timori di una sua 'indefinitezza'.

Esso si articola in strategie, che segnano i grandi obiettivi da raggiungere a medio e lungo termine in sequenza progressiva $a^{22}$, e in progetti ed azioni a breve termine che costituiscono opportunità per "tornare concretamente a progettare". Essendo stato concepito a partire da un'opzione di tipo 'strategico' (sulla base di espliciti riferimenti alle modalità sperimentate da Bohigas a Barcellona oltre un decennio prima), è comprensibile che esso bilanci gli aspetti di regolamentazione normativa (che occupano circa 1/3 del Piano e sono stati il frutto delle più complesse contrattazioni tra i diversi partecipanti al processo costituente) con i restanti $2 / 3$ dedicati alla costruzione di scenario, alla piattaforma di valori e obiettivi e alle procedure di gestione e controllo della sua messa in opera: tutti punti risultati oggetto di una sostanziale convergenza tra forze sociali e professionali.

Proprio in conseguenza delle priorità emerse nel corso dei Congressi cittadi- 
562 ni e dall'analisi critica delle quotidiane procedure della routine progettuale svolta nell'ambito dell'Amministrazione, per i tecnici incaricati della proposta pubblica del nuovo piano le maggiori sfide alla sua concezione si sono materializzate proprio nell'articolazione di questi due livelli, e nel tentativo di contemperare la necessità di flessibilizzazione delle norme e quella di giungere ad una semplificazione della normativa (Pilla, 1998) ${ }^{23}$.

Oggi, relazione e norme di piano risultano divise in quattro parti differenzia$\mathrm{te}^{24}$, che in futuro dovranno integrare quelle relative ai piani di settore (Piano dei Trasporti, Piano delle Urbanizzazioni Primarie, ecc.); una struttura nel complesso abbastanza tradizionale che, già nella prima parte, fa esplicito riferimento ad un Modello Spaziale che presenta la città divisa in due grandi aree, una di Occupazione Intensiva e una di Occupazione Rarefatta ${ }^{25}$, impostate non tanto su una previsione disciplinare quanto sul riconoscimento della realtà esistente ${ }^{26}$. La parte forse più interessante del PDDUA - che in questo si ispira al modello concettuale del Global Plan of Action, suggerito dall'Agenda di Istanbul Habitat II - resta pertanto il $\mathrm{II}^{\circ}$ capitolo, riguardante le norme per la definizione di un Sistema Municipale di Gestione della Pianificazione aperto e permanente (fig. 101), il cui compito è di controllare e gestire democraticamente una struttura di piano che punta a far tesoro della definizione progressiva delle sue regole. Questo sistema complesso si articola in 4 programmi fondamentali ${ }^{27}$ e si incentra su percorsi di "Regionalizzazione della Pianificazione" che ricordano un po' quelli messi in atto a San Paolo durante la gestione guidata dall'esponente del PT Luiza Erundina (1989-1992).

Come già accennato, a Porto Alegre, tale percorso fa riferimento alle 16 regioni urbane già autoidentificate e sperimentate nell'ambito del Bilancio Partecipativo, accorpandole in 8 RGPs - Regioni di Gestione della Pianificazione (fig. 60) ${ }^{28}$ : a ciascuna di esse corrisponde uno degli 8 Forum Regionali, istanza principale del Sistema Municipale di Gestione della Pianificazione. I Forum - che funzionano in base ad un Regolamento Interno flessibile, sul modello di quello del Bilancio Partecipativo - sono organismi a carattere deliberativo al cui interno la complementarità fra conoscenze e saperi è "necessaria per fare della diversità una ricchezza e al contempo opporre contrappunti tecnici a ogni rischio di deriva demagogica in agguato nei processi partecipativi ${ }^{2}{ }_{29}$. Tra le loro attribuzioni, vi è discutere tutti i progetti privati che generano impatti sui territori locali, suggerire perimetrazioni di AEIS, approvare la sdemanializzazione di aree pubbliche ad esse destinate, e - soprattutto - elaborare un Piano di Azione Regionale che contenga idee strategiche per lo sviluppo di zona e al contempo connetta e dia coerenza alle singole azioni progettuali individuate anche tramite il contributo del Bilancio Partecipativo. Importante è anche il ruolo attivo nella revisione periodica dei confini delle Regioni di Gestione della Pianificazione, che "Sono stati stabiliti in prima istanza per renderli leggibili, ma con l'idea di superarli: e già iniziano i seminari congiunti intorno a bacini idrografici, con l'idea di lavora per fusioni e ricongiungimenti" (De Araújo, 2002i).

Sotto il profilo della composizione, gli 8 Forum Regionali sono costituiti al massimo da 31 membri, uno dei quali è il 'coordinatore d'area' scelto tra tecnici di quadro dell' Assessorato all'Urbanistica "al fine di integrare professionalmente nell'implementazione delle linee politiche programmatiche un settore di tecnici a lungo messi volutamente da parte, contribuendo con- 
temporaneamente a qualificare [...] una discussione che per il resto avviene soprattutto tra persone a cui non è richiesta nessuna qualificazione professionale" (Eunice d'Araujo, apud Allegretti, 2002d). Degli altri componenti, 18 sono rappresentanti della comunità eletti direttamente nelle Assemblee Plenarie Regionali $^{30}$ (9 per ognuna delle 2 regioni di bilancio presenti nella Regione di Pianificazione), 1 rappresentante del CAR (Centro Amministrativo Regionale, organo di decentramento locale della burocrazia amministrativa) e 2 rappresentanti di ogni Regione (titolare e supplente) che dovranno rappresentare la Regione di Pianificazione nel CMDUA (vedi sotto). Di questi ultimi, il titolare coordina il Forum stesso, mentre i 2 rappresentanti del Comune (CAR e SPM) non hanno diritto al voto per garantire al Forum la sua autonomia.

Gli altri 9 sono rappresentanti di organizzazioni della società civile che operano nella Regione in settori attinenti al tema della progettazione del territorio e della valorizzazione e tutela dell'ambiente. I membri di queste entità sono eletti in un'Assemblea Municipale di tutti i gruppi ed organizzazioni sociali già attive anteriormente al processo di costituzione dei Forum, ovvero ONG, sindacati, istituzioni accademiche e organizzazioni comunitarie che lavorano in ambiti tematici distinti e complementari ${ }^{31}$.

Gli 8 Forum, così composti, mescolano per certi versi aspetti partecipativi e della tradizionale concertazione, portando però il dibattito in un ambito rigorosamente 'pubblico'. Volendo, essi hanno modo di convocare un Forum Interregionale di Pianificazione che metta insieme più Forum di Regioni diverse per discutere di porzioni vaste del territorio comunale).

All'inizio del 2000 gli 8 Forum hanno eletto, in assemblee plenarie pubbliche, 1/3 dei membri del Consiglio Municipale del Piano di Sviluppo Urbano e Ambientale (CMDUA). Quest'ultimo non è un organismo di nuova creazione, ma la "risemantizzazione" del Consiglio Municipale del Piano Regolatore creato il 3 marzo 1939 come 'commissione consultiva', riformato nel 1955 e nel 1979, ed ormai ridotto ad organo di mera valutazione dei processi (Cfr. § 6.6).

La Legge istitutiva del nuovo PDDUA non solo gli restituisce un ruolo progettuale, ma gli conferisce il significato di canale privilegiato per un intervento attivo della società nella gestione pubblica delle trasformazioni cittadine, per il perfezionamento dei meccanismi partecipativi di raccolta, trattamento e trasmissione delle informazioni, e per la valutazione dell'impegno cittadino nei confronti dell'attuazione del Piano stesso. Spetta inoltre a questo organismo la prima valutazione dei progetti di outlet, centri commerciali ed altri grandi investimenti realizzati attraverso 'operazioni concertate', così come l'applicazione dello strumento del 'Solo Criado' (cfr. cap. 11) che serve ad arricchire i fondi per costruire alloggi popolari.

In tale ottica, la sua struttura viene completamente ridefinita rispetto al passato. Non più rapporti numerici 'sbilanciati' tra rappresentanti istituzionali, esponenti delle categorie economiche professionali e organizzazioni della società civile $^{32}$, ma una composizione equilibrata fatta di 25 membri: un coordinatore appartenente all'Assessorato all'Urbanistica (SPM), 8 esponenti politici (suddivisi tra i diversi livelli governativi), 8 rappresentanti della società civile organizzata ed 8 cittadini scelti dalle Regioni di Gestione della Pianificazione (fig. 60). Nell'economia del Sistema Municipale di Gestione della Pianificazione, CMDUA e Forum - locali e tematici - servono a garantire in modo aperto, esplicito e trasparente l'espressione di rappresentanza/conflittualità fra di- 
verse letture della problematica urbana.

Non essendo il ruolo dei Forum precisamente individuato nei documenti di piano, essi sono ancora strutture di tipo 'informale'. Nel 2000 si sono compiuti esperimenti di 'capacitazione' e 'autoregolazione' per rodarne composizione e funzionamento, che potranno poi modificarsi nel tempo. A metà del 2001, la Giunta Municipale di Porto Alegre ha inviato al Consiglio Comunale una Proposta di Legge di regolamentazione delle attribuzioni di questi organismi, che condensava le proposte emerse nei primi due anni di sperimentazione e retroagiva anche sullo Statuto Municipale; ma ha deciso di ritirarla, nel momento in cui si è compreso che era più coerente con l'articolazione democratica delle politiche cittadine che il tema fosse messo in discussione pubblica nel $\mathrm{IV}^{\circ}$ Congresso della Città dedicato al tema "Democrazia e Gestione dello Stato", il cui processo costituente è cominciato nel luglio 2002 e si concluderà nel giugno 2003 (fig. 109).

Se il Piano Regolatore del '79 aveva tentato di scavalcare e frammentare il blocco dei movimenti urbani, proponendo forme di partecipazione spazializzate, in contrasto con le loro centralità di riferimento (violando così le regole basilari dell'autonomia della società civile dalla sfera organizzativa delle istituzioni), il nuovo PDDUA supera ogni criterio di pianificazione locale 'per isole artificiali' e punta ad esaltare la coesione dei cittadini organizzati, valorizzandola come energia costruttiva: anche per questo viene scelto di riferirsi alla regionalizzazione dello spazio originatasi all'interno del $\mathrm{Bi}$ lancio Partecipativo nei modi visti nel cap. 8.

Per rafforzare la 'polifonia decisionale', al livello globale di pianificazione (di cui è responsabile il CMDUA) e a quello regionale (che gestisce l'elaborazione dei Piani di Azione Regionale), viene affiancato un livello locale di partecipazione alle azioni pianificatorie e progettuali. La sua base spaziale è costituita dalle Unità di Strutturazione Urbana (UEUs), comparti minimi di verifica delle scelte ereditati dal vecchio Piano e mantenuti nel PDDUA per favorire una 'transizione morbida': al loro interno commissioni locali autorganizzate potranno proporre variazioni di indici, usi, altezze e regolamenti da far poi approvare alle relative Regioni di pertinenza.

\subsection{Il Progetto Integrato della Lomba: un percorso esemplare delle nuo- ve sfide?}

Le varie forme di consultazione contenute nel PDDUA - ed obbligatorie per il processo amministrativo - sono il modo individuato durante il lungo "processo costituente' per dare voce a tutti gli abitanti dei diversi territori cittadini, indipendentemente dai loro diritti formali. Al loro livello più basso (UEUs), esse hanno un valore consultivo ed avvengono in forma rapida e diffusa per non appesantire troppo i processi decisionali; ma le loro indicazioni possono essere registrate dai Forum popolari delle varie Regioni e dal CMDUA, che hanno un carattere 'deliberante' nella costruzione dei processi pianificatori. In questo quadro, i Piani Regionali di Azione (PARs) costituiscono 'luoghi densi' e 'operativi' nel previsto processo pianificatorio, come specifica l'art. 43 della L.C. 434/99 nel definirli insiemi di azioni "che promuovano lo sviluppo di ogni regione, partendo dall'analisi delle loro singolarità" e "adeguandosi alle direttrici generali proposte per la cittă’. La loro redazione va, infatti, al di là della 
semplice elaborazione di dettaglio del PDDUA, per farsi indispensabile strumento per proporne miglioramenti, adeguamenti e riformulazioni attraverso "una dinamica continuativa e sistematica". Essi sono - inoltre - lo spazio di attribuzione delle competenze ai tecnici e ai cittadini, organizzati anche in commissioni di accompagnamento e controllo dei lavori sul territorio, in connessione con i processi attivati a scala locale dal Bilancio Partecipativo.

La redazione di questi Piani sta avvenendo lentamente. e secondo i principi della 'ricercazione' indicati dal PDDUA, a partire dalle sperimentazioni già avviate in alcune Regioni. Essi serviranno a costruire una 'metodologia di lavoro', nel rispetto di quel principio ispiratore delle politiche cittadine che Fedozzi (2000, p 59) ha definito "la pratica come criterio di veritő", per il quale "lavorare sui progetti è come creare dei precedenti giuridici 'in positivo' su cui aggiornare e rivedere la pianificazione, di cui nel Piano esistono solo linee strategiche condivise" (De Oliveira, 2001i, apud Allegretti 2002d). La Lomba do Pinheiro è una delle aree di Porto Alegre dove dal marzo del 1998 sta venendo condotto un progetto-pilota sperimentale (Progetto Integrato di Sviluppo Sostenibile della Regione Lomba do Pinheiro) per la costruzione di uno dei primi Piani di Azione Regionale, in parallelo alla messa in cantiere di diversi azioni puntuali che ne comporranno il quadro.

La Lomba è una Regione del Bilancio Partecipativo $\left(\mathrm{n}^{\circ} 4\right)$, che fa parte della RGP $n^{\circ} 7$, insieme al Partenon. Il lavoro in questa zona di oltre 47.000 abitanti (un'area rururbana di confine verso la parte orientale povera dell'area metropolitana, caratterizzata da notevoli risorse ambientali minacciate da un'occupazione irregolare dei suoli di crescente invasività) ha preso le mosse dall'avvertita necessità di tecnici e cittadini di lavorare a partire da una nuova rappresentazione dei territori locali che compongono la Regione, evitando - come in passato - di leggerli "come isole separate dal corpo urbano", ma facendo in modo che essi siano "attraversati, percorsi, analizzati percettivamente, vissuti e studiati come parti interrelate e ricche di interfacce con $i$ quartieri e le regioni confinanti, con le linee di comunicazione cittadine, con le barriere e $i$ valori naturali e sociali condivisi tra livelli contigui di vicinato" (ibidem). Durante il processo di revisione della prima bozza del PDDUA, i partecipanti al processo costituente hanno individuato questa Regione come un'area di particolare interesse, e il Comune - già nel 1998 - ha attivato un'equipe integrata inter-assessorati' (SMAM, SPM, DEMHAB) con l'idea di elaborare 'un'esercitazione' legata all'articolo 33 sui 'progetti speciali'. Il lavoro sulla Regione 7 Lomba/Partenon doveva servire a costruire un ponte tra la 'metodologia partecipativa' alla base dell'O.P., e quella con cui si voleva rafforzare ed arricchire i processi urbanistici. Inoltre il progetto era visto come terreno ideale di formazione professionale per i tecnici del Comune, ma anche come occasione per raccogliere informazioni sul territorio locale, diffondere i contenuti del costruendo PDDUA ed articolare le visioni tecniche contraddittorie e scoordinate, superando i feudi che rendevano impossibile la collaborazione fra Assessorati e, spesso, anche tra settori all'interno degli stessi. Nel corso dei 5 anni di lenta evoluzione del progetto per la Lomba, il programma di 'empowerment' di cittadini e tecnici - a partire dalla costruzione di un Forum di progettazione - si è articolato in fasi, contribuendo poi in maniera consistente al disegno del lavoro dei diversi Forum Regionali che oggi compongono il Sistema Municipale di Gestione della Pianificazione: 
566 1) In un primo tempo si è favorita la conoscenza reciproca tra i diversi attori partecipanti al Forum e quella della realtà di cui dovevano occuparsi. Allo scopo, il Comune e alcune organizzazioni della società civile hanno proposto il ricorso a tecniche di animazione teatrale e a laboratori nelle scuole dell'obbligo della zona (gite, costruzione di mappe percorribili e di modellini tridimensionali dell' area) ${ }^{33}$ e, soprattutto, un metodo di 'attraversamento permanente' del territorio (De Oliveira, 2002i-I; figg. 107-108). Per quasi un anno, lunghe e ripetute passeggiate sono state pianificate su mappe a scala diversa, per costruire percorsi di attraversamento tematico della realtà, in base a degli indicatori sommari di giudizio: numero e qualità delle attrezzature, concentrazione commerciale, viabilità, pregio e conservazione dei quartieri storici, riferimenti visivi, varietà di paesaggi, nuovi e vecchi spazi di interazione sociale. Questi sono serviti anche da collegamento con una serie di temi e criteri di valutazione introdotti e discussi nel processo di Piano (animazione, vitalità e pluralità variegata delle attività locali in ogni area). I primi dubbi e le prime richieste emerse nel Forum sono serviti ad orientare le visite e a costruire i tragitti: le 'Oficinas de mapas' si sono così trasformate in percorsi 'reali', che hanno costruito veri e propri 'moduli di osservazione empirica' (ibidem).

2) In seguito, si è lavorato ad una ricostruzione collettiva dell'origine e dell'evoluzione della città', attraverso la lettura e l'aggiornamento di testi (tra cui i quaderni storici 'Memorias dos bairros' realizzati negli anni precedenti dal Comune in molti degli 82 quartieri cittadini) e per mezzo di seminari con esperti, mirati a collocare la regione nel contesto urbano generale e ad approfondire il suo apporto al tutto. Si sono realizzate anche visite al nuovo Museo della Città e studi dell'Atlante Ambientale di Porto Alegre, strumento interattivo realizzato nel ' 98 dal Comune e dall'Università Federale per recuperare i saperi specialistici dispersi nelle varie sedi accademiche, rendendoli intelligibili ai cittadini e predisponendo corsi di formazione dei docenti. Per poi spiegarlo nelle scuole e cercare di arricchirlo per il futuro di una seconda edizione, realizzata 'dal basso' dalle scolaresche dei diversi quartieri ${ }^{34}$.

3) Il terzo modulo ha analizzato brevemente il ruolo storico di Porto Alegre capitale nell'evoluzione dello Stato del Rio Grande do Sul.

4) Il quarto modulo si è soffermato sulla storia dei piani regolatori e della legislazione urbanistica di Porto Alegre, per far comprendere meglio ai partecipanti in che cosa un PRG influisce sulla vita quotidiana di ognuno e su quella amministrativa, elemento che era stato alla base della scarsa partecipazione di cittadini della società civile non organizzata alla costruzione del PDDUA (almeno in rapporto alle presenze rilevate annualmente nel Bilancio Partecipativo).

5) L'ultimo modulo si è incentrato sulla conoscenza del processo generatore dell'attuale PRG, sulla sua lettura e comprensione e sulle sue possibilità di integrazione con l'O.P.. A dimostrazione di quest'ultimo punto, tra dicembre 2000 e gennaio 2001 il Forum Regionale della Regione RGP n ${ }^{\circ}$ LombaPartenon ha identificato richieste da inserire nell'elaborazione nel Piano Pluriennale 2002-2005, riunendosi con i Forum dei Delegati regionali dell'O.P., allo scopo di coordinare le azioni principali che il Piano dovrà prevedere per l'intera area.

Attualmente, l'intero ciclo del processo conoscitivo - anche attraverso la creazione del giornale locale "Construindo a Lomba do futuro" e di quello comunale "Parceiro" [partner] che informa i cittadini interessati ai Forum Re- 
gionali di Pianificazione - è nella fase di trasmissione ad un pubblico più ampio di quello che vi ha preso parte, per valorizzare quanto appreso ed elaborato dai cittadini durante i primi 2 anni. Parallelamente, però, si è cominciato un lavoro di sistematizzazione della conoscenza e di prima elaborazione progettuale, che oggi va confluendo nella creazione del primo Piano di Azione Regionale che possa indicare - agli altri 7 ancora molto indietro una metodologia teorica e pratica di lavoro.

\subsubsection{Autoprogettualità all'opera nel 'Recreio da Divisa'}

Già nel 1999, il Forum legato al Progetto integrato della Lomba aveva segnalato due azioni prioritarie da portare avanti: la costruzione di un Piano Urbanistico Ambientale che risolva i conflitti tra sviluppo della Regione e protezione naturale, e una esperienza abitativa pilota.

Per il primo, nel 2000 sono state definite le specifiche analisi di settore da condurre nel rispetto dell'art. 55 del PDDUA sugli elementi condizionanti per l'attuazione di progetti speciali. Si è, poi, cominciata l'opera di pressione all'interno del Bilancio Partecipativo per finanziarle gradualmente: alcune (come i rilievi naturalistici) sono state finanziate subito dal COP ed appaltati all'Università Federale, altri (come il rilievo delle occupazioni informali sui suoli) sono stati affidati ad equipe interne al Comune, per accelerare i tempi di conclusione della fase ricognitiva, su cui dovrà fondarsi la progettazione partecipativa del Piano Urbanistico Ambientale.

In parallelo - proprio per non lasciare che la lentezza, con cui le varie tappe del lavoro si susseguono, determini una disaffezione dei cittadini per il progetto - è stato aperto un presidio fisso nella scuola Alfonso Guerriero Lima, con il compito di implementare soprattutto l'altro e più visibile percorso progettuale: quello del progetto sperimentale di recupero abitativo nell'area Recreio da Divisa, un terreno di occupazione in forte pendenza che gli stessi abitanti hanno contribuito a dividere in tre zone con 'livelli di rischio' differenti.

L'area - abitata da 611 famiglie che l'avevano occupata a partire dal 1990- è stata resa regolarizzabile nel 1999 da uno scambio di terreni del DEMHAB con l'impresa Guerino e la conquista, nel Bilancio Partecipativo 2000, dei fondi per il rilievo sociale e topografico. Questo ha rivelato situazioni molto differenti tra le sue parti in termini di precarietà abitativa (attraverso una carta di rilievo dei diversi materiali costruttivi prevalenti nelle varie parti), di sicurezza idrogeologica e di organizzazione degli spazi pubblici e viari. Parallelamente all'avvio della richiesta di registrazione dell'area come AEIS, 3 commissioni popolari nominate dai residenti dei tre settori si sono unite all'equipe comunale del Progetto Integrato Lomba per presentare le loro proposte di recupero dell'insediamento, secondo una prassi abbastanza innovativa che "ha invertito temporalmente $i$ suggerimenti provenienti dall'autoprogettualità dei cittadini e quelli ipotizzati dai tecnici comunali, partendo dalle proposte degli abitanti" (De Oliveira, 2002i). Le prime linee del progetto elaborato dalla comunità e dai tecnici del Comune conviene con la necessità di rimuovere 120 famiglie che risiedono in parti a forte rischio e di 'rinaturalizzare' i terreni liberati, per utilizzarli come presidio naturale nei confronti della sicurezza del resto dell'abitato. Lo stesso gruppo misto di lavoro ha anche individuato un'area vicina, dove reinsediare gli abitanti evacuati, limitando loro l'allontanamento eccessivo dalle reti lavorative e amicali 
autorganizzate, che di per sé "rappresentano un forte contributo contro l'esclusione sociale", come ribadito nei verbali di alcune riunioni del Gruppi di Lavoro. In seguito, le commissioni di abitanti hanno contribuito ad identificare soluzioni tipologiche innovative per le case, che dovranno ospitare le famiglie evacuate, e a studiare soluzioni tipologiche per l'autorecupero della abitazioni da regolarizzare e per gli spazi pubblici in pendenza, al fine di minimizzare la necessità di movimenti di terra ${ }^{35}$. Esse hanno poi organizzato la popolazione perché partecipasse numerosa alle assemblee del Bilancio Partecipativo 2001, da cui la comunità del Recreio da Divisa ha ottenuto i fondi per l'urbanizzazione primaria della parte di insediamento da regolarizzare. Nel seguito del lavoro, queste commissioni stanno risultando degli insostituibili mediatori per ampliare il livello di partecipazione al progetto ed arricchirne i contenuti, integrando alle idee progettuali le necessità di sviluppo economico e di generazione di reddito, che dal 5 agosto 2002 hanno preso la forma di corsi di formazione organizzati dal Comune per avviare la costituzione di cooperative e microimprese che lavorino sul tema della produzione di conserve biologiche, erbe medicinali e mattoni ecologici: con l'obiettivo di riflettere sulla necessità di un approccio integrato ai progetti di inclusione sociale, ma ponendo anche le basi per la valorizzazione economica delle peculiarità dell'area e del Parco Saint'Hilaire, un'area di protezione naturale di 940 ettari, 240 dei quali destinati dal PDDUA a un parco ricreativo che già mensilmente ospita circa 35.000 visitatori $^{36}$.

A questo proposito, oggi si discute con l'Assessorato all'Industria e Commercio (SMIC) della possibilità di sperimentazione in loco di un programma di "Agricoltura urbana", che permetta ai capifamiglia, spesso donne, di produrre cooperativamente ma intorno a casa, per non doversi recare lontano dai figli in terreni lavorati collettivamente. L'idea - nata dai residenti - propone un collegamento con il "Centro Agricolo Dimostrativo" comunale, per sperimentare l'innovazione dotandola del marchio biologico 'D.O.C.', che essa garantisce già a chi coltiva prodotti biologici entro il perimetro del parco Saint'Hilaire.

Di particolare interesse pare anche il modo in cui viene trattato dentro la commissione locale il tema degli interventi sull'area di rischio e del trattamento dei materiali delle case sgomberate: gli abitanti stessi hanno, infatti, sottolineato la necessità di un immediato e visibile riutilizzo a fini naturalistici (con impegno al controllo da parte della comunità dei residenti tutto intorno), per evitare che come sovente accade - un' area "restituita ma non riutilizzata" possa diventare stimolo a nuove occupazioni provenienti dall'esterno della comunità.

La commissione mista - che si riunisce ogni 15-20 giorni - ha anche autorganizzato la messa in opera di un "Laboratorio sui conflitti e le potenzialità", identificando sia le aree di tensione e i possibili conflitti tra usi del suolo attuali e valorizzazione dell'ambiente, che le potenzialità territoriali da sviluppare. Precedentemente, la SPM - a cui era stato richiesto di coordinare il Laboratorio per garantirne l'imparzialità - aveva elaborato uno studio simile insieme al DEMHAB, ma non ne ha rivelato l'esistenza fino a che non è stato pronto quello autoprodotto dalla comunità locale. I due elaborati sono risultati molto simili; persino nell'identificare come il maggior ostacolo la carenza di 'agilità' delle strutture pubbliche nel tradurre in opere concrete una "volontà democratica di cambiamento", da entrambi rilevata come visibile (e identificata come maggiore potenzialità del progetto, insieme al valore ambientale della zona). 
Da questo Laboratorio se ne è originato spontaneamente un altro che gli ha dato continuità, dedicato a stilare "Il programma delle necessità" del quartiere. I coordinatori tecnici del Comune hanno accettato di buon grado la proposta, segno della crescente volontà dei residenti di offrire un contributo a identificare problemi e valori comunitari: e i risultati sono stati incoraggianti, andando a rafforzare l'idea della necessità di un'azione pubblica integrata, che operi al contempo sui problemi fisico-spaziale e su quelli lavorativi e sociali. In seguito, attingendo ogni volta a dubbi e stimoli suscitati dagli atelier precedenti, la comunità ha richiesto l'organizzazione di un terzo Laboratorio "sull' organizzazione del quartiere", di un quarto sulla "vocazione economica dell' area" e di un quinto (ad ottobre 2002) sulle "tipologie abitative legabili a potenzialità di generazione di reddito": in quest'ultimo - costruito con modalità itineranti tra le dimore dei residenti in aree di rischio e di protezione naturale - sono state discusse con il DEMHAB delle ipotesi di prototipi abitativi flessibili ed espandibili, a modifica e integrazione di quelli già sperimentati nel Loteamento Costa e Silva.

$\mathrm{Su}$ questa maturazione della discussione (che ha comunque riguardato una fetta minoritaria degli abitanti) i tecnici del GT cercano ora di innestare tre sfide principali, che nelle attuali condizioni non paiono facilissime da vincere:

1) rafforzare la partecipazione comunitaria, che negli workshop autorganizzati dalle Commissioni di Residenti non ha superato le 30 persone su una popolazione di 661 famiglie (circa 3000 persone). Per questo è stata identificata la necessità di rafforzare la presenza di figure come i Consulenti Comunitari e gli Assistenti Sociali del DEMHAB, e di portare avanti piccoli risultati concreti che diano fiducia ai cittadini sugli esiti di un processo partecipativo a cui - in ambito pianificatorio - erano disabituati;

2) accrescere la coscienza ambientale degli abitanti. Attualmente, infatti, le famiglie che abitano in area di protezione ambientale - a differenza di quelle che stanno in zone di rischio - non paiono disposte ad accettare il reinsediamento altrove;

3) aumentare l'apertura dei residenti della comunità verso l'esterno. Già in passato vi furono scontri tra gli occupanti di antica data e quelli che via via arrivavano. Oggi, un obiettivo del progetto è permettere il reinsediamento, ai margini del quartiere del Recreio da Divisa, di poco più di 50 famiglie che devono essere sgomberate dalla Regione Cristal (le ultime rimaste a vivere in area di rischio dopo il progetto del supermercato BIG, cfr, cap 13). I residenti sono stati chiamati dal Comune ad esprimersi su un atto di solidarietà verso cui per ora non paiono bendisposti; ed agire senza il loro consenso pare pericoloso, visto che altrove - in altre occasioni - la mancata approvazione previa da parte della comunità locale ha generato tensioni successive tra vecchi e nuovi abitanti. Con lo scopo di far maturare la discussione, nell'agosto 2002 la SPM e il DEMHAB hanno organizzato un autobus di residenti del Recreio da Divisa per visitare le condizioni di alloggio estremamente precarie i cui i futuri vicini attualmente vivono. Nei prossimi mesi il Comune prevede di riproporre il tema, sperando che possa maturare una soluzione.

\subsubsection{Verso la costruzione di un Piano di Azione Regionale}

L'esperienza-pilota del Progetto Integrato di Sviluppo Sostenibile va assumendo un valore paradigmatico per l'intera Regione di Pianificazione $\mathrm{n}^{\circ} 7$. 
570 Esso, infatti, ha stimolato la creazione di vari gruppi tematici di lavoro, costituitisi su suggerimento degli abitanti della Regione (regolarizzazione fondiaria dei nuclei abitativi spontanei, sistema viario strutturante, sistema degli spazi aperti, risistemazione della via João Oliveira Remião al fine di valorizzare aree di centralità pubblica, sviluppo economico, ecc.). La loro varietà evidenzia la molteplicità di scale di lettura a cui viene trattata la pianificazione dell'area nel tentativo di concludere rapidamente il primo Piano di Azione Regionale cittadino attraverso "un percorso democratico esemplare che possa essere di orgoglio per le comunità locali e di stimolo ed esempio per altre Regioni di Gestione della Pianificazione” (Fuentefria, 2002i).

Se oggi è difficile valutare tutti gli esiti che questa esperienza-pilota potrà portare sui contenuti delle trasformazioni territoriali che il Progetto Integrato è chiamato a stimolare (visto soprattutto che poche elaborazioni sono a uno stadio di definizione di quello del Recreio da Divisa), in termini di percorso è già possibile identificare alcune conquiste significative ${ }^{37}$ :

1) dopo anni in cui a Porto Alegre gli interventi 'integrati' sono stati concepiti come tali soprattutto nelle fasi progettuali, per la prima volta - su un'area 'sensibile' dal vasto potenziale naturalistico - si è realizzata anche una 'diagnosi integrata' dei problemi socioeconomici, abitativi ed ambientali, in un'ottica 'finalizzata' all'identificazione e ad un progetto di valorizzazione delle peculiarità territoriali;

2) il lavoro svolto insieme alla popolazione è stato impostato e strutturato con coerenza, su un lasso temporale durevole, in un'ottica di arricchimento delle conoscenze sul luogo e del successivo progetto, e non solo ai fini di facilitare l'intervento del Comune e la gestione e manutenzione dei suoi interventi; 3) il ruolo di coordinamento attribuito alla SPM, nello sviluppo di un'azione importante per l'evoluzione del nuovo sistema pianificatorio comunale ha permesso non solo una visibile crescita "professionale ed umana" dei tecnici coinvolti, ma soprattutto "il recupero di una centralità all'intemo di processi progettuali e non più solo di controllo", favorendo "una progressiva e positiva ricostruzione di identità di un settore del Comune ormai da oltre 10 anni espropriato del suo ruolo propositivo e frustrato dalla poca connessione delle sue mansioni con il progetto politico e sociale dell'amministrazione" (De Oliveira, 2002i, I). Durante il percorso progettuale, si è evidenziato il formarsi di una minoranza di tecnici che riescono a portare avanti un lavoro creativo, approfittando di opportunità parallele di formazione e aggiornamento professionale che il processo di costruzione del PDDUA ha offerto ad alcuni ${ }^{38}$ (soprattutto all'interno della FLACAM e della UFRGS, le due istituzioni formative maggiormente coinvolte); 4) l'integrazione di livelli progettuali settoriali o puntuali con punti vista globali sullo sviluppo del territorio regionale e municipale, sembrano aver favorito un'acquisizione di coscienza significativa da parte delle comunità coinvolte, sia sui temi dell'ambiente che della democratizzazione della pianificazione del territorio locale, proiettata su spazi e tempi (di medio-lungo termine) più ampi di quanto verificatosi in passato. Lo rivelano alcune interviste a rappresentanti popolari del Forum della Regione di Pianificazione $n^{\circ} 7$, un'osservazione diretta di alcune tappe del processo ${ }^{39}$, e la battagliera partecipazione di alcuni rappresentanti al $1^{\circ}$ Congresso Nazionale per il Diritto alla Città tenutosi a San Paolo il 15/17 ottobre 2001, dove ha preso avvio una campagna popolare per richiedere al governo federale un Consiglio Nazionale sulle Politiche Urbane, a 
cui demandare l'implementazione della neonata legge sullo "Statuto della città"; 5) nel corso del progetto è maturata un'idea importante: costruire uno strumento complesso (il Piano di Gestione Urbana e Ambientale) che - per serietà di articolazione - possa intervenire a modificare in futuro i contenuti del PDDUA, a partire da elaborazioni provenienti dal territorio locale. Inoltre, la nascita della proposta di un 'Parco Lineare', con funzioni produttive ecocompatibili lungo il corso di un immissario del lago che sta al centro del Parco Saint'Hilaire (lungo un' area abitata di estrazione popolare e in parte informale), evidenzia la crescita di una sensibilità che guarda alla protezione ambientale come un contributo alla qualità della vita di tutti i giorni, e non più solo in termini di 'nemica dello sviluppo';

6) il dialogo con le commissioni di cittadini, sperimentato nel progetto del Recreio da Divisa, fornisce delle indicazioni mirate a ridimensionare "il falso problema del conflitto tra protezione ambientale e sviluppo, individuando alcune possibilità di urbanizzazione eco produttiva ${ }^{40}$ ", ed evidenziando anche "l'astoricità della permanenza di un conflitto reale, ed inutile, tra visioni distinte di dipartimenti comunali diversi, che cela forse più un conflitto amministrativo che non di lettura del territorio" (De Oliveira, 2002i-II);

7) la pratica del dialogo, non solo nelle sedi istituzionali definite per i percorsi partecipativi (come il Bilancio Partecipativo), ma 'spostato sul campo' attraverso un 'corpo a corpo' dei tecnici con i diversi territori locali, pare contribuire lentamente ad un salto di qualità significativo nella ricostruzione di una fiducia dei cittadini nelle istituzioni, seppur necessita di dedizione da parte di chi segue ogni progetto, per mantenere con costanza un dialogo ravvicinato con i cittadini, e specialmente con le categorie più deboli41

A questi esiti positivi potrà certo attingere il Piano di Azione Regionale della RGP $n^{\circ}$ 7. Sulla sua formulazione sta lavorando in questi mesi il relativo Forum Regionale, con l'ambizione di elaborare al suo interno altri strumenti di analisi e gestione del territorio tali da poter gradualmente retroagire sui contenuti e i processi attuativi del PDDUA, a partire dalla ricchezza che la multiscalarità dell'approccio sta offrendo ad alcuni dei primi progetti sperimentali, messi in atto per tentarne un'attuazione aderente alle peculiarità del territorio e in linea con le elaborazioni progettuale che provengono dal suo capitale sociale. Un elemento di fiducia constatato dal Gabinetto di Coordinamento della Pianificazione è che - anche nelle Regioni dove mancano progetti sperimentali in corso - "la concretezza del mandato dei consiglieri, la ciclicità e la routine degli incontri dei Forum - ogni settimana o, nella maggior parte dei casi, ogni 15 giorni - sta riuscendo a rendere visibile e concreto anche il Piano, che teoricamente è uno strumento più astratto che temevamo non riuscisse ad essere compreso" (De Araújo, 2002i).

\subsection{Una imperfezione stimolante: alcune osservazioni conclusive}

Il Piano di Sviluppo Urbano e Ambientale di Porto Alegre, uscito nel 1999 dal lungo e travagliato 'processo costituente' è tutt'altro che uno strumento perfetto. A partire da un suo aspetto 'schizofrenico' che, ad elaborati strategici, a mappe sintetiche e ad intuizioni che lasciano spazio a una loro definizione progressiva, accosta un'ampia serie di dettagliatissimi annessi normativi 
572 di taglio prescrittivo riguardanti - ad esempio - le classificazioni e i profili viari, il sistema dei parcheggi coperti, gli elenchi dei parametri urbanistici relativi a diverse centinaia di Unità di Strutturazione Urbana, o quelli dei luoghi esenti da obblighi di arretramento stradale per sistemazioni a verde. Quest'aspetto di 'conflitto' è forse perdonabile, visto che i dati quantitativi e i dettagliamenti di usi del suolo e di indici sono - in fondo - una parte minoritaria del PPDUA. Del resto, esso - pur non riuscendo a risolvere del tutto queste incoerenze di impianto (che riflettono in parte il difficile compromesso elaborato, nel corso del processo costituente, per mettere d'accordo culture politiche e tecniche molto distanti) - costituisce una conquista coerente con il percorso intrapreso dalla città nell'ultimo quindicennio. La sua formulazione riesce, infatti, a sostituire l'enfasi sul controllo normativo con una tutela basata sulla partecipazione sociale come meccanismo di adattamento continuo, appoggiato sulla 'concertazione' intesa non quale mero spazio di mediazione di interessi, ma quale luogo di apprendistato graduale alla democrazia e di comprensione della città come un tutto complesso. A tal fine, gli organi del governo locale sono passati da un sistema di controllo che penalizza ciò che si allontana dalle previsioni di piano a promotori di cambiamenti desiderabili.

Il PDDUA, inoltre, sembrerebbe in grado di favorire (grazie ad una nuova concezione del paesaggio come funzionamento ecosistemico dinamico) un graduale ma efficace reincorporamento della questione ambientale nella pianificazione delle soluzioni sui problemi sociali più emergenti, così come il reincorporamento del tema dello sviluppo economico nel sociale: un concetto vicino a quello che Polanyi definiva "embedding" e che già era stato indicato come necessario dal Piano di Sviluppo Economico costruito nel $I^{\circ}$ Congresso Cittadino del '93, in base allo studio delle economie popolari e solidali sviluppatesi in città.

Il PDDUA rovescia la prospettiva del precedente strumento disegnato nel 1979, riconoscendo le baraccopoli come laboratori di creatività; giovandosi della parallela redazione di approfondite 'Mappe della città spontanea', cerca di propiziare una visione territoriale policentrica centrata sul riconoscimento dei 'valori urbani', non limitandosi a censire le emergenze ambientali e storico/architettoniche della città formale, ma riconoscendo l'informale come 'luogo della ricerca di una dignità', e istituzionalizzando metodologie di dialogo produttivo con i suoi abitanti.

Il recupero dialogico del sapere collettivo, come luogo di identificazione dei valori dell'abitare si traduce nel reincorporamento della politica della Casa in quella Urbanistica (risolvendo uno 'scarto' secolare tipico del Brasile e di molti altri paesi) e nella sperimentazione di strumenti di governo dei suoli coraggiosi, finora avversati dalla magistratura per la mancanza di una legge, che oggi 'lo Statuto della Città' per fortuna colma (cfr, cap. 11). Fondamentale è anche il riconoscimento delle 101 Aree Speciali di Interesse Sociale (a cui vanno sommate le molte altre oggi in via di riconoscimento formale), ovvero territori occupati da gruppi sociali svantaggiati, a cui è concessa una maggiore flessibilità nell'applicazione di norme e standard cittadini per regolarizzarle, a patto di curarne la funzione sociale di inclusione ed estensione del diritto alla città, oltre che le interfacce con le zone vicine, sovente ignorate dalla 'frettolosità' degli interventi decisi nell'O.P..

Così, attraverso il coordinamento di strumenti e politiche diverse, il PDDUA pare mettere a frutto 14 anni di sperimentazioni di strumenti a contenuto 
redistributivo e con inversione della logica escludente della produzione e del consumo dell'habitat, a favore di quella dell'abitare veramente i luoghi (Menegassi, 1998). E cerca di recuperare - attraverso il raggiungimento di una sostenibilità socio-politica - quei valori territoriali e ambientali che gli strumenti precedenti, in apparenza centrati su di essi (ma in realtà legati solo ad un morfologismo settoriale incapace di sollecitare 'adesione attiva' ai valori proposti), avevano finito per mettere in secondo piano.

Il PDDUA pare, inoltre, diffondere un'idea non-conservazionista di cultura come processo di produzione della città nei suoi vari aspetti, che rivaluta le "centralità", leggendole con parametri diversi come densità, concentrazione, flussi, animazione e poliedricità delle attività

In esso, l'idea di 'gestire' trasformazioni spontanee (incluse quelle indotte da meccanismi di mercato e di emulazione non rigorosamente pre-disegnate sul Piano) non pare essere rinuncia al governo del territorio; pare piuttosto accettazione della possibilità che le analisi e le proiezioni scientificamente elaborate possano richiedere un continuo processo di valutazione e rivalutazione. A fronte di questa 'umiltà' del Piano, si riafferma la necessità di guidare il costante riallineamento dei percorsi seguiti, senza perdere di vista il punto di arrivo, "facendo del 'gestire' un atto di continuo 'ri-pianificare' piuttosto che un 'non-pianificare'” (Pilla, 1998). A questo scopo, al Piano si affianca un Sistema di Valutazione del Funzionamento Urbano, strumento di monitoraggio e di supporto alle decisioni municipali di lungo e medio termine, ma anche demistificazione delle immagini generiche attraverso la proposizione di azioni concertate, nuova metodologia di lavoro per articolare i macro-obiettivi, disegnati per la città, con le domande puntuali dei progetti specifici (Pilla, 1998).

Con tali scopi, il PDDUA si costituisce come piano-processo di matrice strategica in permanente rielaborazione, entro cui la pianificazione normativa può essere anche riassorbita, non rappresentando più che una fra le diverse strategie messe in atto: una sfida propositiva lanciata a tutti i settori della comunità a generare proposte attraverso progetti concreti, evitando le grandi definizioni a priori (ibidem). Perciò esso assume una natura 'esperienziale' (Allegretti, 2002d), incentrata sulla definizione di obiettivi strategici che prendono forma attraverso Progetti Speciali ed esperienze-trainanti, mirate a disseminare nuovi livelli di centralità in un corpo cittadino già per vocazione policentrico, definendone le caratteristiche di sistemi di relazioni fra attività, utenti e localizzazioni.

Se il Bilancio Partecipativo rappresenta un poderoso strumento di riforma politica contestualizzato in adesione alle peculiarità del contesto socio-territoriale, il PDDUA si interroga sulle trasformazioni qualitative innescate in termini morfotipologici e di vivibilità degli spazi, a seguito dell' ascolto non solo delle richieste, ma anche delle 'soluzioni' messe in moto dagli abitanti, sia in modo spontaneo che coordinato.

Esso pare cominciare a colmare la mancanza di una filosofia generale di azione che riconnetta con coerenza globale (sotto il profilo della corporeità dei progetti) interventi puntuali, che spesso nel passato sono stati messi in cantiere in modo estemporaneo sotto l'urgenza della necessità.

Talora, fino ad oggi, la logica 'ricattatoria', imposta da un'alta partecipazione popolare ai nuovi processi di democratizzazione delle decisioni, ha stimolato il Comune a non provare neppure a esaminare e/o contrastare le solu- 
574 zioni prospettate sulla base di un immaginario 'colonizzato' da modelli abitativi esogeni o centrati sul mito individualista della 'casa di proprietà', ereditato dalla propaganda del ventennio di regime militare (Maricato, 1987).Il nuovo Piano - favorendo per la prima volta un inserimento critico della politica degli alloggi in quella di pianificazione territoriale (Alfonsin, 1998) si potrà rivelare strumento indispensabile per "reintrodurre la riflessione nell'azione" (Allegretti, 2000a) e portare la conoscenza delle dinamiche urbane al di là di quella prodotta durante l'azione solo ai fini dell'azione stessa.

Nella formula di ricercazione adottata dal 1989 a oggi, infatti, il sapere prodotto sulla città è rimasto spesso debole, asistemico, non esposto come indagine, sacrificato a una cultura prevalentemente orale che ha messo la memoria urbana 'in pericolo' (come abbiamo visto in alcune delle vicende raccontate nel cap. 14). In tal senso, lo strumento urbanistico che dal 2000 ha cominciato ad essere sperimentato, arricchito e dettagliato, pare anche adatto a veicolare una ridefinizione del ruolo dei professionisti nei progetti urbani, verso una progettualità sociale, multidisciplinare e comunicativa,in grado di far comprendere a tutti questioni finora ignorate perché ritenute 'più teoriche che pratiche'. Certo, l'efficacia di molti meccanismi messi in moto dal Piano resta da verificare; specie per quanto concerne figure o strumenti ancora indefiniti come il "Progettista Concertatore Municipale", gli 'urbanizzatori sociali' o il "Piano di Gestione Ambientale".

Eppure, l'apertura flessibile del PDDUA alle trasformazioni attraverso la concertazione democratica (coerente con la linea di tendenza messa in moto dalla creazione del Bilancio Partecipativo) pare una garanzia del fatto che la progressiva definizione delle 'scatole ancora vuote' che ne connotano alcune parti, si costituisca col tempo in reali miglioramenti dello strumento regolatore. Resta però anche il dubbio che la definizione in progress di alcune regole divenga arma pericolosa nel caso di un mutamento politico e nelle mani della competitività fra attori territoriali.

La partecipazione popolare può avere luogo, e dare esiti non 'guidati', soltanto laddove siano garantite condizioni dignitose ed efficienti per la gestione dell'urbanistica e dello sviluppo locale, ovvero vi siano informazione e formazione adeguata della popolazione, mirate a far sì che essa si inserisca nei processi decisionali con la capacità di comprendere, ad un buon livello, ciò che è in discussione e ciò che deve essere deciso in ogni sede, con le sue diverse implicazioni.

Finora il meccanismo partecipativo creato a Porto Alegre pare ben oliato ed equilibrato, ma in futuro non è escluso che l'eccessivo moltiplicarsi di istanze di consultazione/decisione possa indebolirle reciprocamente, contribuendo ad un riflusso nell'interesse dei cittadini per la costruzione e il controllo delle trasformazioni nei loro spazi di vita, specie in conseguenza di alcuni ostacoli frapposti da meccanismi burocratici antiquati alla concretizzazione dei progetti decisi dalla popolazione.

Forse è arrivato il momento che la radicale riforma amministrativa che Porto Alegre attende da oltre 14 anni non sia rimandata oltre, pur rappresentando essa un tema spinoso e costoso (in termini politici) per la coalizione che governa la città. Il $\mathrm{IV}^{\circ}$ Congresso della Città può essere l'occasione per immaginare ed avviare questo nuovo tassello della trasformazione delle politiche cittadine: e, per l'Amministrazione, può essere il luogo dove trovare il sostegno popolare necessario per trasformare in realtà questa tanto ventilata ipotesi. 

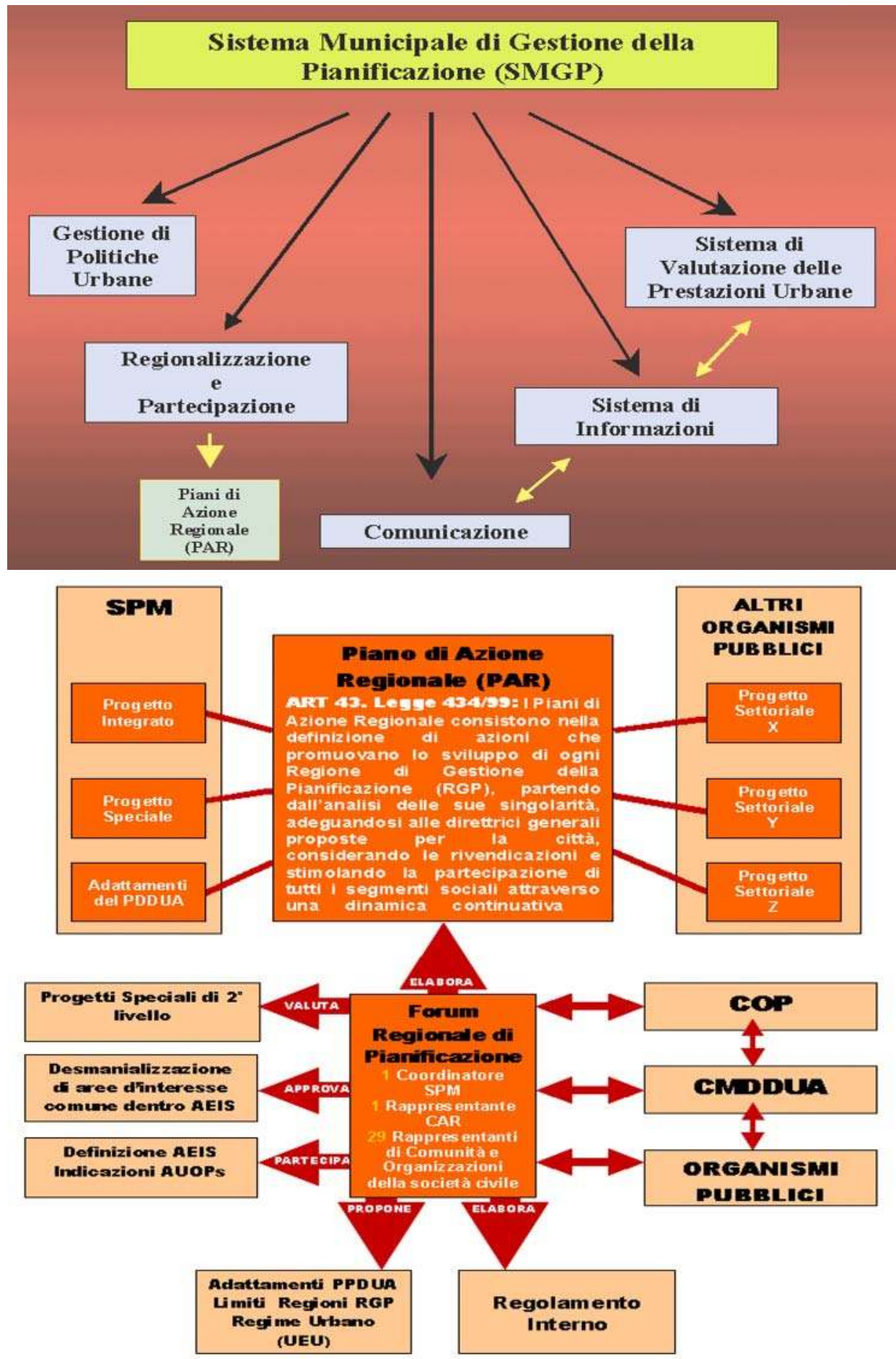

Fig. 101 - Il nuovo Sistema di Gestione della Pianificazione mette in campo varie istanze decisionali che danno un ruolo progettuale importante alla società civile, come i Piani Regionali di Azione (PARs) e il CMDUA (Consiglio Municipale del Piano di Sviluppo Urbano e Ambientale). Le elaborazioni degli schemi traducono e aggiornano alcuni organogrammi SPM, 2002. 
Fig. 102 - Il nuovo Piano di Sviluppo Urbano e Ambientale di Porto Alegre (PDDUA) è stato costruito con i cittadini tra il 1993 e il 1999. Il suo impianto è di tipo strategico ed esperienziale: esso avanza, infatti, per progetti pilota e continue discussioni pubbliche. È attento alla comprensibilità dei linguaggi, al punto che ogni articolo delle Norme Tecniche è tradotto in 'vulgata', come evidenziato dall'immagine tratta dal sito Internet del Comune di Porto Alegre. Alcuni elaborati di estremo dettaglio (come quello sui profili viari sotto esposto) rappresentano un retaggio di vecchie modalità pianificatorie che appesantiscono un poco i documenti di indirizzo.

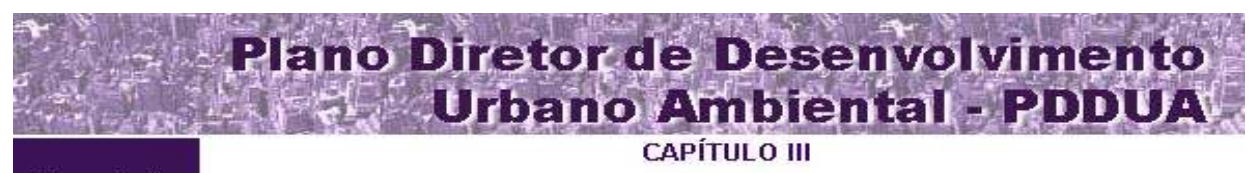

Dos Mecanismos de Participação na Gestão, de Informação e de Avaliação

Art. 44. Além da participaçã́o global da comunidade na gestão do planejamento urbano, a qual se dará através do. CMDUA, fica assegurada a participação comunitária em nível regional e local, na forma a ser definida em lei.

Th necessária releitura da cidade

\section{LEI COMENTADA}

Art. 44 - As pessoas participam da gestão do Planejamento da seguinte forma:

I - No nivel Global: com um representante de cada uma das oito regiốes no Conselho Municipal, juntamente com os outros representantes governamentais e nẩo governamentais;

II - No nivel Regional: dentro de cada uma das oitn Regiōes de

Planejamento a comunidade vai se organizar para debater, decidir e propor questôes relativas ao Plano Diretor, que serão depnis levadas pelo seu representante para o Conselho Municipal, para aprovaçao ou não. Caberá também aos moradores a elaboraçẫo do Plano de Ação Regional.

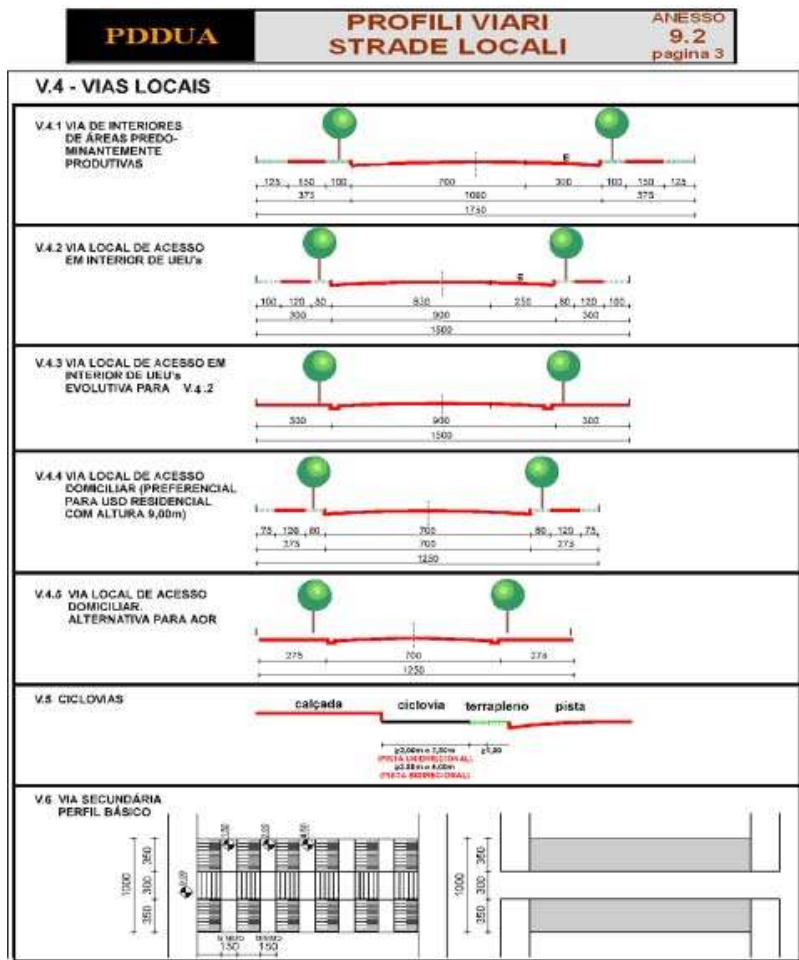


Fig. 103 - Il nuovo Piano di Sviluppo Urbano e Ambientale di Porto Alegre (PDDUA). L'elaborato rappresenta le aree di zonizzazione, evidenziando quelle ad occupazione intensiva e gli assi viari strutturanti.

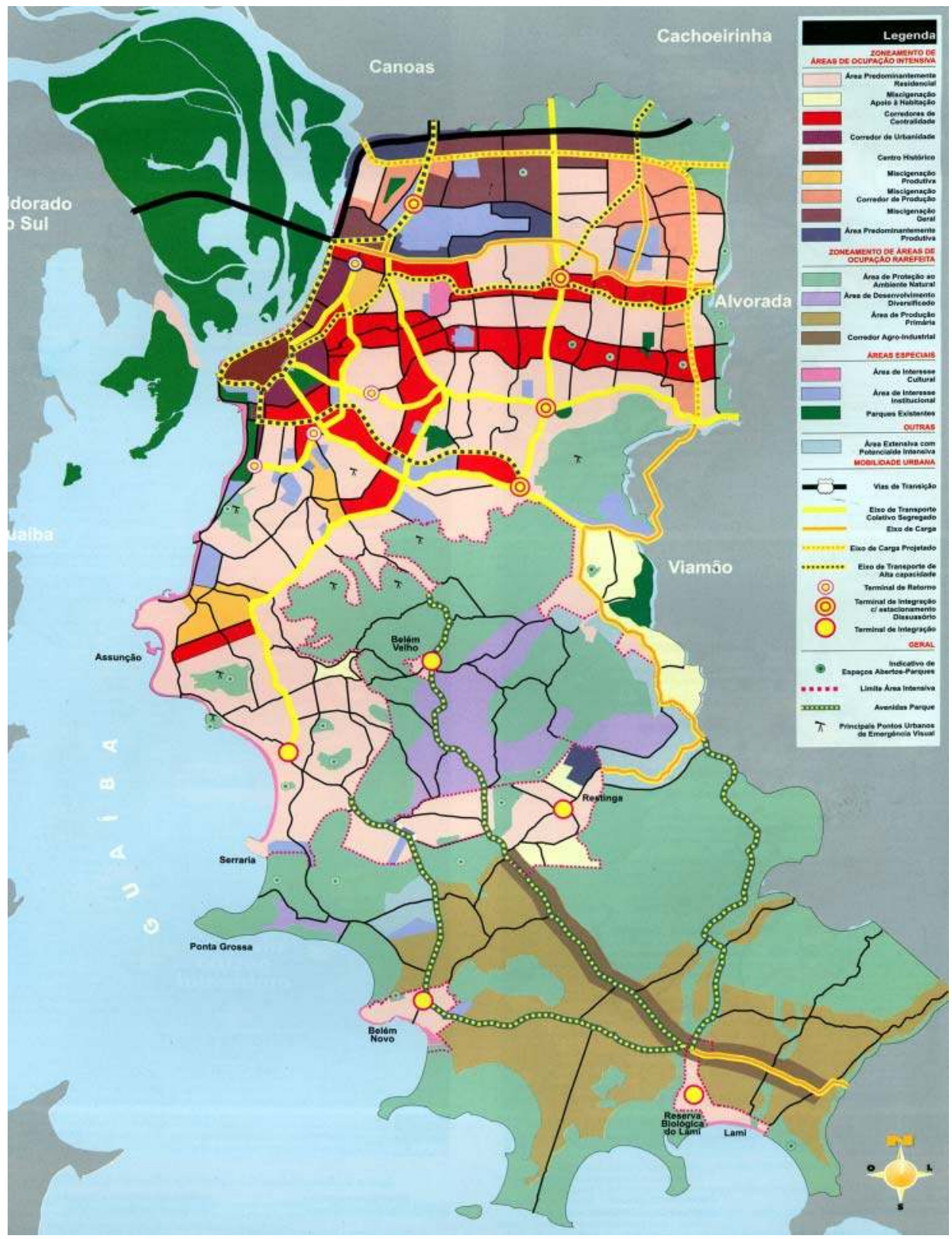


Fig. 104 - L'elaborato del PDDUA rappresenta le aree speciali di urbanizzazione, in particolare i 'corridoi di centralità', i 'progetti integrati' e le maggiori aree residenziali informali da recuperare, utilizzando lo strumento delle AEIS. Accanto ad ogni progetto individuato si identificano i principali soggetti attuatori che dovranno interagire per dar corpo ai diversi tipi di intervento.

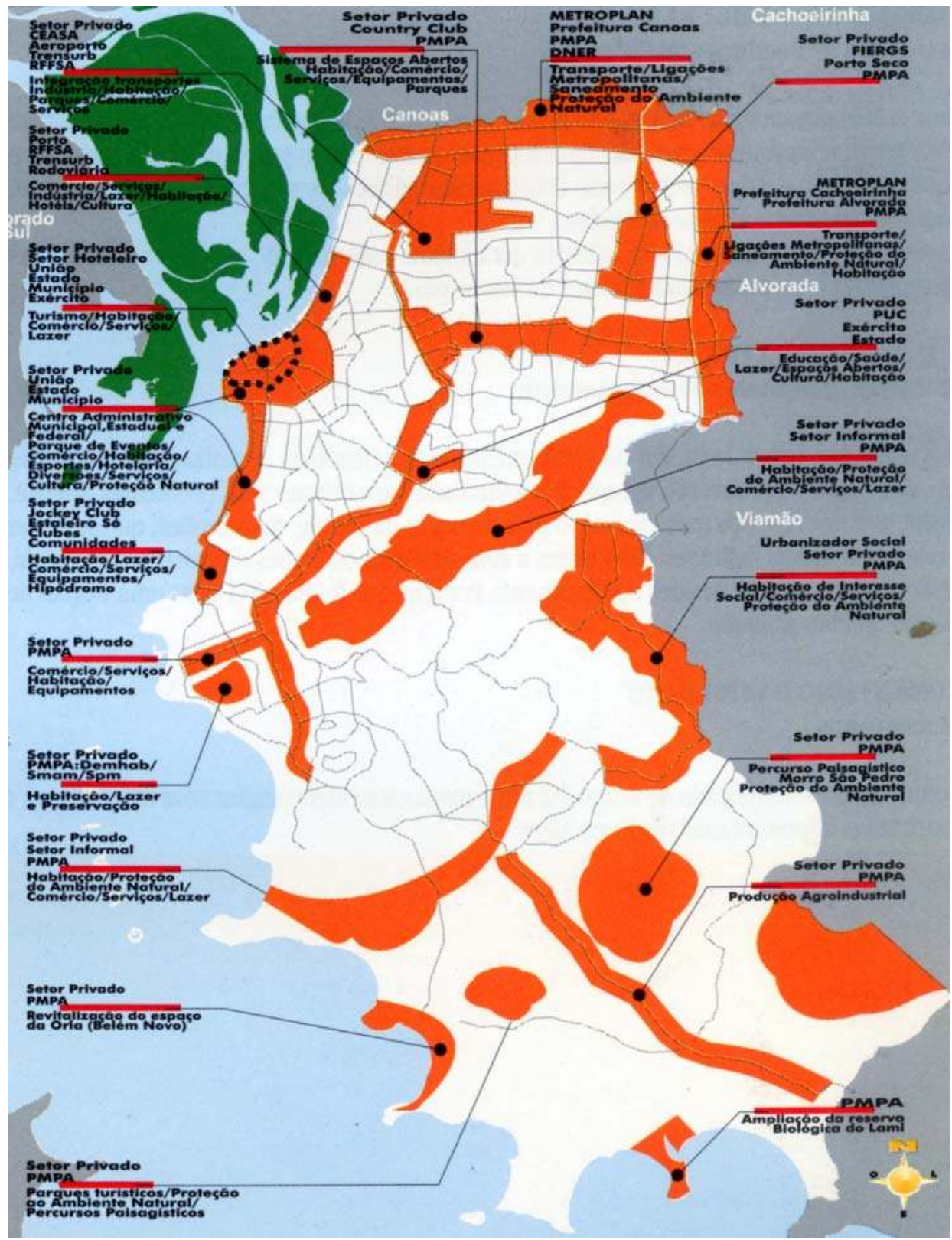


Fig. 105- L'elaborato del PDDUA individua le macrozone in cui la città è suddivisa in base alla morfologia di sviluppo assunta nelle sue stratificazioni storiche.

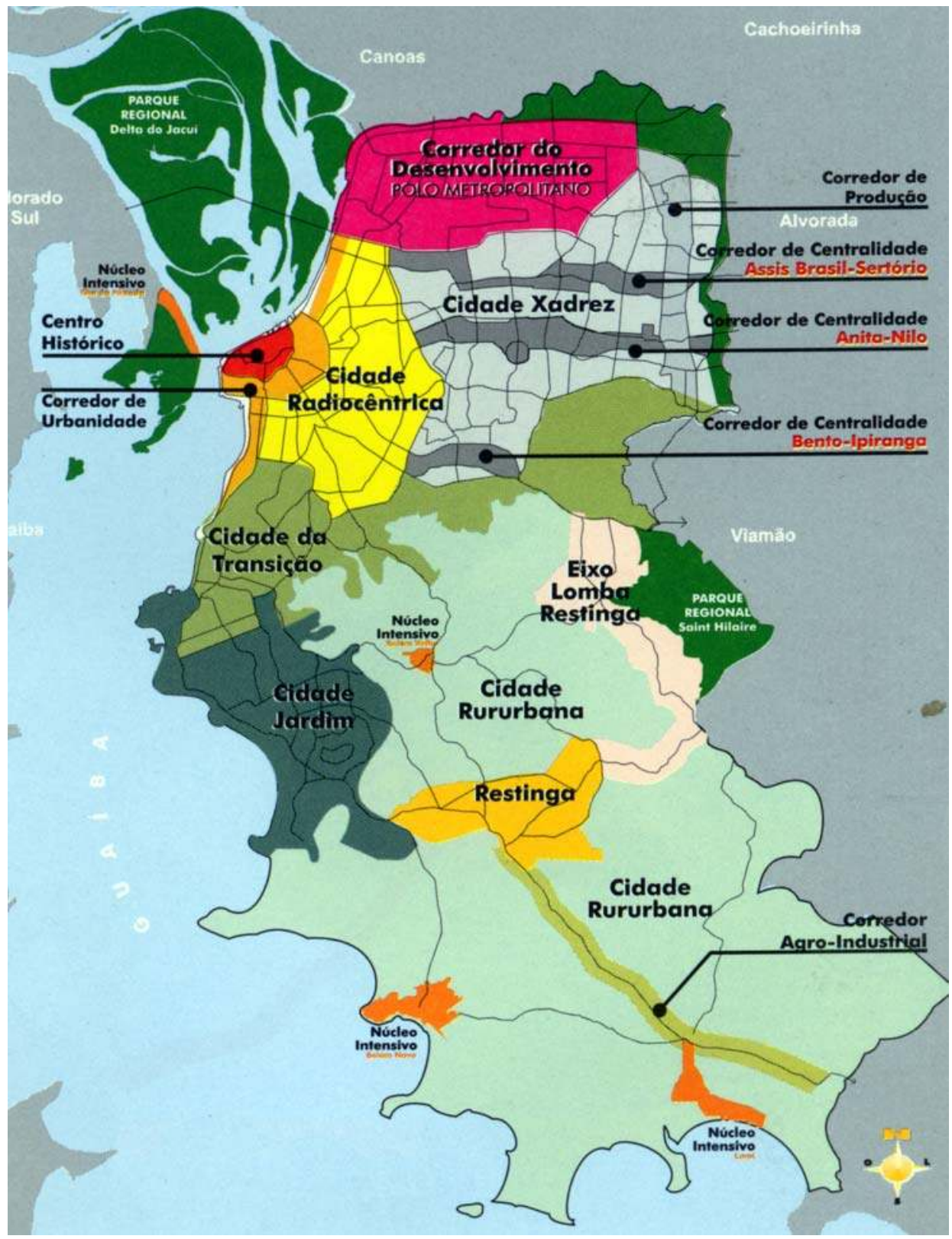


Fig. 106 - L'elaborato del PDDUA individua le principali 'risorse territoriali' includendo (oltre alle aree di interesse naturalistico e ai maggiori tessuti costruiti di interesse storicoartistico) anche alcune zone di particolare 'densità sociale' come la Restinga, quartiere di casermoni popolari, nato come luogo di raccolta degli abitanti espulsi nell'ultimo trentennio da diverse aree occupate della città: esso, oggi, presenta un'alta densità aggregativa e forti fermenti culturali legati all'associazionismo e ai movimenti popolari.

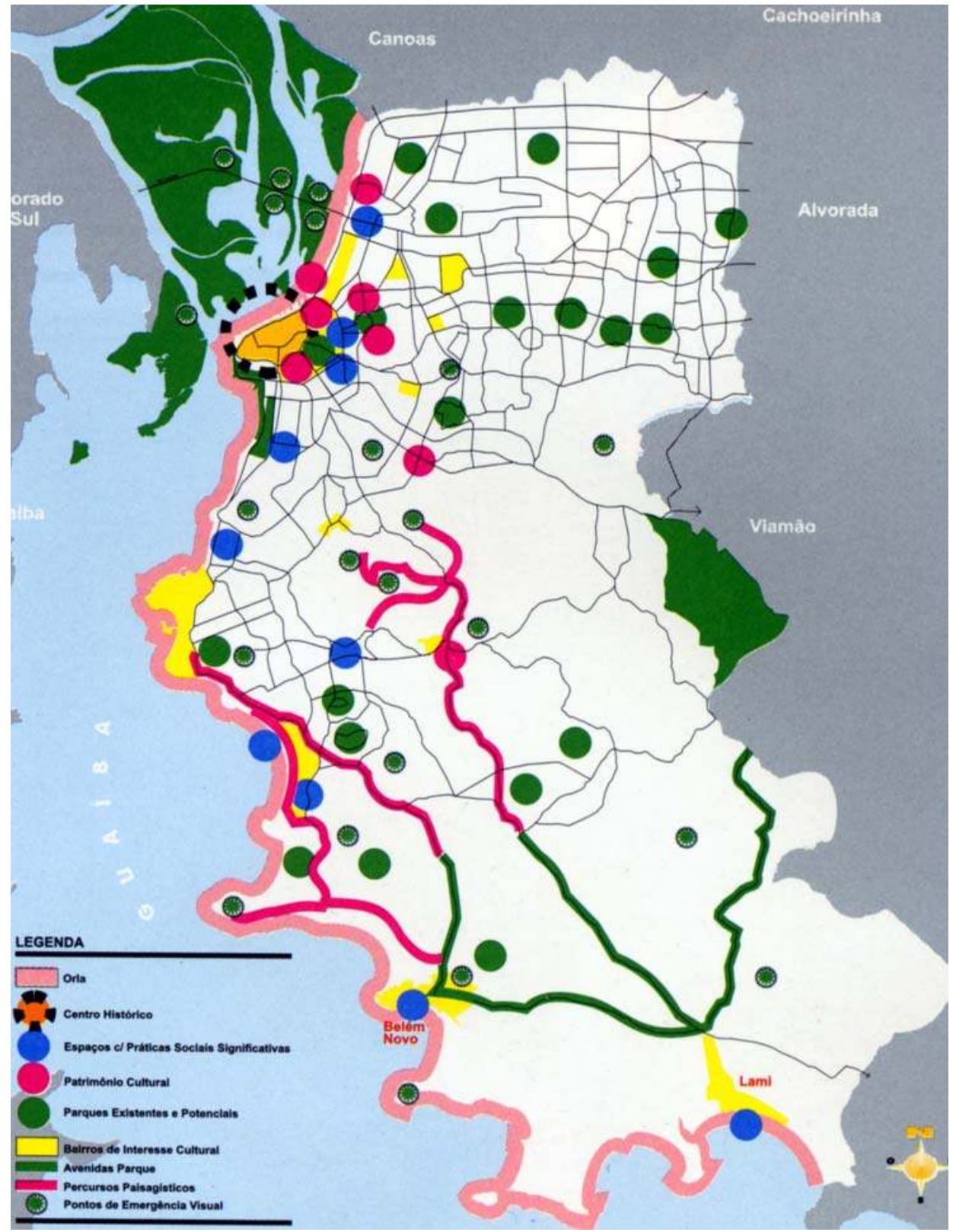


Fig. 107 - Il Progetto di Sviluppo Integrato della Lomba do Pinheiro è un'azione concreta per retroagire sul Piano Strategico, attraverso la costruzione di una metodologia partecipativa che possa dare avvio ai primi Piani Regionali di Azione (Immagini: GT Lomba, SPM).

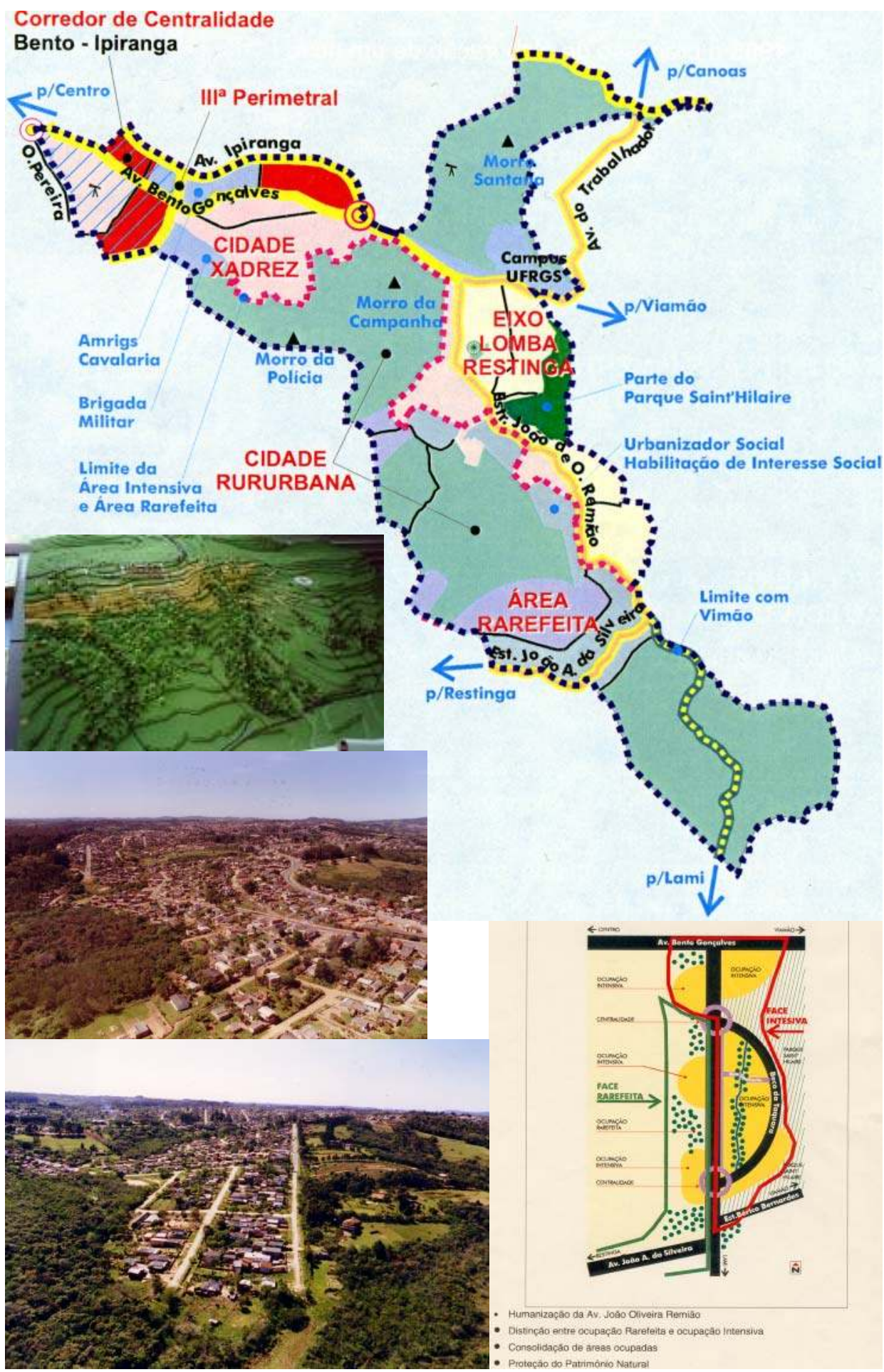


582 Fig. 108 - Il Progetto di Sviluppo Integrato della Lomba do Pinheiro prevede azioni di formazione degli abitanti, e momenti di analisi e coprogettazione. Le visite sul campo, la progettazione partecipativa con le scuole e l'utilizzo di linguaggi comunicativi come quello del 'teatro di strada' rappresentano una costante di questo progetto-pilota, la cui equipe tecnica è coordinata dall’ Arch. Cleia De Oliveira (Immagini: GT Lomba, SPM).

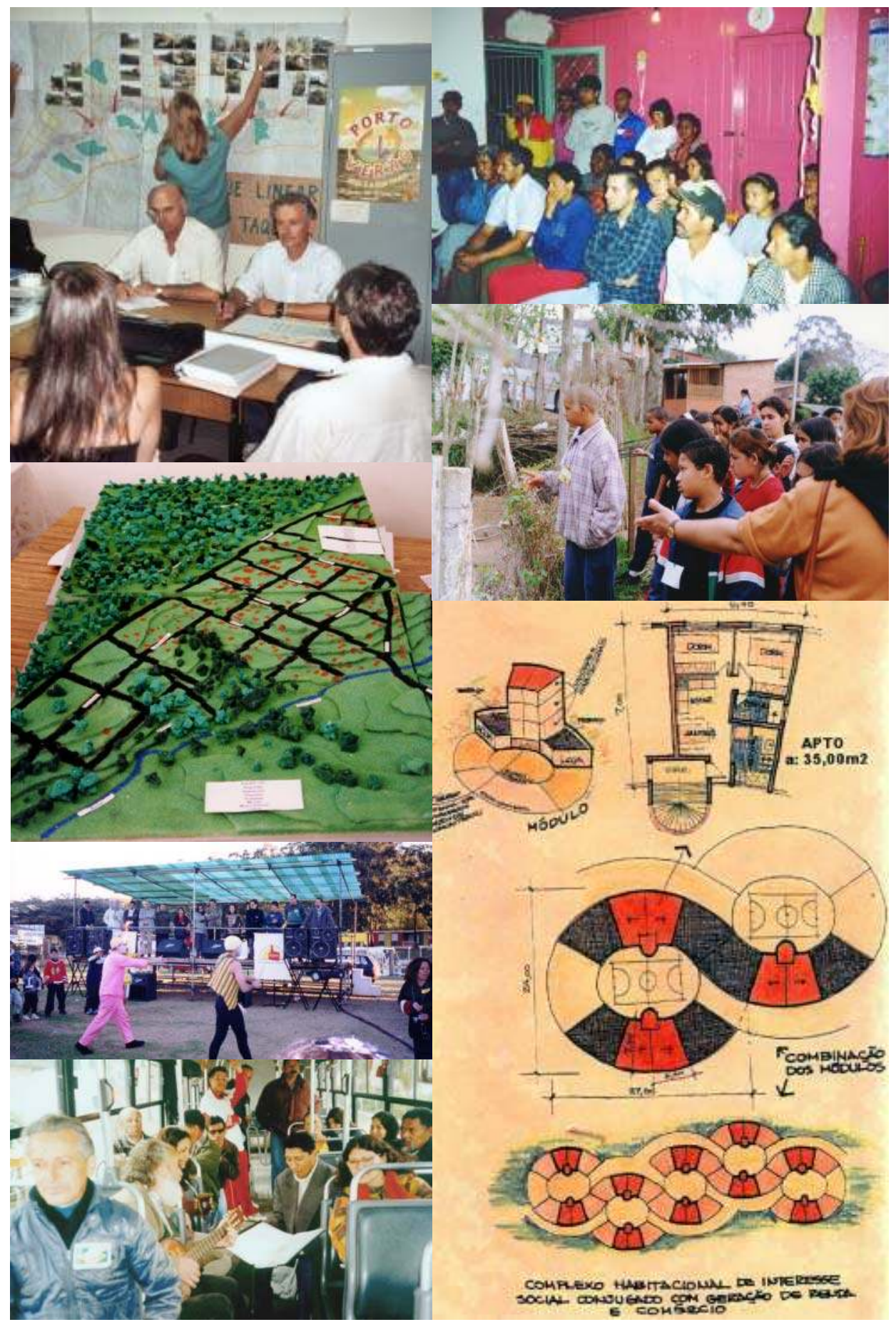


Fig. 109 - Il IV Congresso della Città (come i primi 3 che lo hanno proceduto) coinvolge per quasi un anno l'intero territorio nella discussione su temi strutturali per lo sviluppo urbano. L'evento, stavolta, è un processo di discussione a tappe dedicato a perfezionare la struttura amministrativa ed il rapporto tra democrazia diretta e democrazia rappresentativa.
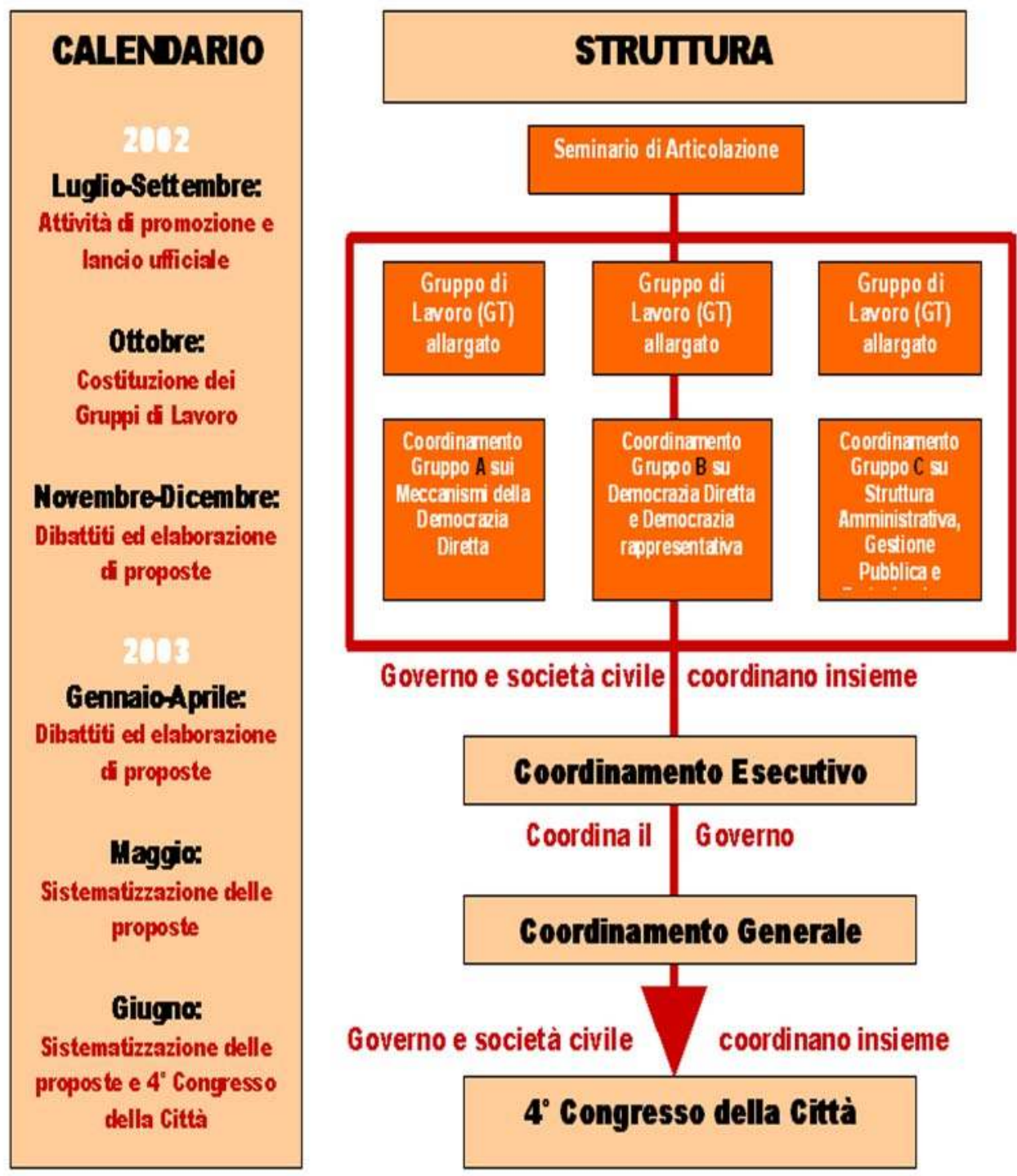
${ }^{1}$ Non riportando la fonte della citazione, rispettiamo la volontà di restare anonimo dell'interlocutore, un professionista che si è sempre posizionato criticamente nei confronti della coalizione che guida la città, ma che oggi riconosce di aver compiuto un percorso professionale e personale di maturazione proprio all'interno di quel progetto politico.

${ }^{2}$ Alfonsin e Allegretti, 2003.

${ }^{3}$ Resoluções $I I I^{\circ}$ Congresso da Cidade, 2000, p. 7

${ }^{4}$ La parola portoghese 'abrangente' non è di facile resa in italiano; indica sia l'onnicomprensività di un processo che la sua capacità di ampio coinvolgimento, attraverso obiettivi e percorsi multipli.

${ }^{5} \mathrm{Il} \mathrm{I}^{\circ}$ Congresso ha avuto 1500 partecipanti e 548 delegati; nel 1995 il $\mathrm{II}^{\circ}$ Congresso ("O lugar de toda as coisas" ) ha avuto 2700 partecipanti e 331 delegati nel suo appuntamento finale; il III $^{\circ}$ ("Construindo a Cidade do Futur") tra il novembre 1999 e il maggio 2000 ha contato 7000 partecipanti e 1780 nella sola assemblea finale dedicata al tema "partecipazione popolare e qualità della vita" (26,27, 28 maggio 2000). I Dati sono della CCS della PMPA

${ }^{6}$ La Carta di Porto Ale gre "Inventando o futuro" (siglata il 19/12/93 dal $1^{\circ}$ Congresso della città) si conclude così: "La costruzione della città del futuro deve essere un'invenzione collettiva dei suoi abitanti. I cittadini portoalegrense hanno accettato la sfida di sognare e si sono avventurati nell'inventare un futuro migliore per la nostra città. C'è bisogno di andare avanti. Tanto importante quanto inventarlo, è concepire $i$ suoi percorsi e costruirlo".

${ }^{7} \mathrm{E}$ non solo alle sue parti più nobili, come in Brasile era costume generale ancora a quell'epoca.

${ }^{8}$ Cfr. Müzell Jardim, V. (1998).

${ }^{9}$ Burmeister, N. (1998); Dal piano del '79 il tasso di crescita annuale della popolazione è stato dell' $1.06 \%$, quello delle auto del 5\%; oggi Porto Alegre è la terza città del Brasile per valore del rapporto abitanti/auto (2,23 ab/auto)

${ }_{10}$ In realtà un gruppo di lavoro del Programma di Pianificazione Urbana e Regionale della UFRGS guidato dalla Prof. Marisa Wagner ha mostrato - operando nel quartiere di Glória - come fosse possibile tradurre le istanze del Plano Diretor in termini facilmente comprensibili per la maggioranza dei partecipanti attraverso alcuni seminari preparatori sulle questioni tecnico/legali coinvolte; il lavoro per dimostrare anche ai meno 'avvertiti' come la struttura fisica può modificare la crescita economica di un'area e la sua qualità della vita era quindi possibile, ma forse è mancata la volontà politica per portarlo avanti.

${ }^{11}$ Questo era vero soprattutto per il Nuovo Regolamento Edilizio, scritto sulla base di una forte partecipazione di imprese e associazioni di categoria.

${ }^{12}$ Tra le ragioni di insufficienza del Piano (che nel tempo costrinse all'emanazione di Resoluções Interpretativas, Decretos e Atas per fronteggiare situazioni non contemplate in linea diretta dalla L 43/79) vi erano il continuo conflitto tra visioni settoriali che in teoria avrebbero dovuto essere complementari, le troppe alterazioni dello strumento (molto rigido) apportate per rispondere a necessità puntuali, e la revisione del 1987 che proponeva una visione contrastante rispetto alla configurazione originaria e alle intenzioni del Piano del '79, e in questo 'scontro' dava forma ad una legislazione complessa, contraddittoria, incoerente e spesso addirittura incomprensibile. Inoltre, studi sullo Sviluppo Economico di Porto Alegre rivelavano ormai che 1'80,5\% delle industrie della capitale possedeva meno di 400 mq di stabilimento, a fronte di un misero $6,2 \%$ con più di 1500 : tali caratteristiche apparivano ormai perfettamente compatibili con l'attività residenziale, al punto da ribaltare molti degli stessi principi del Piano del '79 in direzione di una mescolanza delle attività su scala cittadina in grado di riequilibrare alcune storture evidenziatesi nel tempo.

${ }^{13}$ Menegassi, J. (1998).

${ }^{14} \mathrm{Al}$ ruolo di simili figure si accenna anche negli articoli 32, 57, 61 .

${ }^{15}$ Così come sono sulla carta oggi, tali aree non permettono parcellamenti, ipoteticamente concedibili - solo a fini di abitazione popolare - dietro richiesta dei lottizzatori e la sigla di uno specifico accordo 'di caso' col Comune.

16 "I costruttori clandestini sono soggetti reali di sviluppo della città, di 'sviluppo fattivo e reale' intendo, e a dispetto della loro accezione deformante o persino criminale. Soprattutto lo sono stati in passato, quando le Istituzioni annaspavano cercando soluzioni teoricamente perfette ai grandi problemi. Solo due atteggiamenti sono possi- 
bili nei loro confronti: eliminarli, che frantumerebbe un processo sovente positivo di autodistribuzione del reddito, o collocarli come pedine del gioco sotto il regime dell'Istituzione. [...] Integrare questi 'attori sociali' sminuendo i loro effetti distorcenti è certo un atteggiamento più maturo" (Genro, 1999i, apud Allegretti 2001b).

${ }^{17} \mathrm{Al}$ momento, vi è un Progetto di Legge in corso di valutazione in Consiglio Comunale, presentato il $1^{\circ}$ novembre 2002 ed elaborato da un Gruppo di Lavoro interno al Forum dell'Abitazione, insieme a vari organismi comunali e ad organizzazioni della società civile come il Sinduscon, l'Istituto e il Sindacato degli Architetti, il Forum delle Cooperative, alcuni Forum Regionali di Pianificazione e la Caixa Economica Federal. Nel progetto si definisce l'urbanizzatore sociale' come una 'funzione pubblica sussidiaria' che può essere svolta da imprenditori appositamente registrati in un Catasto Municipale degli Urbanizzatori Sociali, o da cooperative di autogestione abitativa. I termini di accordo con il Comune - secondo la proposta - dovranno garantire la verifica da parte del contraente pubblico dei requisiti sociali dei futuri abitanti, perché l'area possa essere considerata una HIS (produzione di Abitazioni di Interesse Sociale) ed eventualmente essere registrata come AEIS o urbanizzata in maniera progressiva. Per poter accedere ai benefici dell'accordo con il Comune e godere di una priorità nelle procedure valutative ed approvative, l'urbanizzatore sociale dovrà garantire prezzi di vendita concordati, e la cessione di aree all'ente pubblico nei termini dell'accordo di volta in volta sottoscritto (che può comportare anche una contropartita in attrezzature pubbliche); in cambio il Comune si occuperà di finanziare eventuali studi di natura ambientale da realizzarsi nelle aree prescelte. La proposta esplicita il divieto per l'urbanizzatore di imporre agli acquirenti (in caso di semplici progetti di parcellamento di terreni) la scelta di particolari progetti edilizi o materiali da costruzione da lui indicati, in modo da evitare forme di 'servitù' oggi spesso imposte nell'ambito delle lottizzazioni informali. Progetti del genere - pur lodevoli - lasciano sempre molti dubbi su quale effetti collaterali sul variare dei processi informali possa determinare la 'cooptazione' in ambito formale di operazioni prima svolte al di là di regole concordate.

18 Ad esempio, il Plano Diretor del '79 conferiva al polo 'Azenha' la maggior importanza dopo il centro storico; in un ordine immediatamente inferiore vi erano i poli di Assis Brasil e Moinhos de Vento, poi Petrópolis, Voluntários da Pátria e Osvaldo Aranha. Oggi i poli Moinhos e Osvaldo appaiono i più 'densi' dopo il centro storico, seguiti da quelli di Farrapos (che svolge un importante ruolo strategico nella città per la grande accessibilità dall' area metropolitana, la sua forma a "L" e le sue caratteristiche spaziali), Cristóvão, João Pessoa/Azenha, Menino Deus e Voluntários.

${ }^{19}$ In quest'ottica, gli interventi proposti dal PDDUA comprendono anche una 'riclassificazione delle vie" (con Vias de Transição, Arteriais, Coletoras, Locais, Exclusivas para Pedestres, Ciclovias e Secundárias) che meglio riveli il ruolo da ognuna di esse svolto all'interno della struttura cittadina, potenzi la funzione del trasporto di massa e delle aree pedonali e ciclabili, stratifichi e gerarchizzi il traffico pesante, crei 'parcheggi scambiatori' e stimoli alla costruzione di parcheggi come elemento importante per la riqualificazione ambientale e per riconquistare le vie pubbliche a detrimento dell'uso come parcheggi privati.

${ }^{20}$ Il "Diagnóstico do Meio Rural do Município de Porto Alegre", coordinato dalla SMIC e terminato nel 1994, ha coperto con la sua analisi quasi l'80\% della zona rurale, portando alla luce molte contraddizioni nell'uso di queste aree, rivelandone spesso il carattere pienamente urbano. Secondo lo studio, il $19,5 \%, 44,8 \%$ e $26,2 \%$, sono rispettivamente destinati a produzione/commercio, residenza/sussistenza e tempo libero.

${ }^{21} \mathrm{Nel}$ PRG del '79 l'introduzione del concetto di Área Funcional (aree di protezione di particolari valori, sostenute da liste puntuali di beni da preservare) si era costituita come categoria innovativa per l'epoca, permettendo il riconoscimento della necessità di azioni dirette e propositive in determinati settori di attività urbana, proponendo un trattamento adeguato alla protezione dei loro valori specifici con impatti positivi sul complesso urbano e la collettività (Cabral e Almeida, 1998). Ai limiti teorici e previsionali di questo sistema di pianificazione si unirono carenze organizzative di ambito amministrativo, come la mancata creazione del "Sistema Municipal de Planejamento e Coordenação do Desenvolvimento Urbano" previsto (art. 39) per elaborare precisazioni e specifiche da affiancare al Piano.

${ }^{22}$ Le 4 Strategie-base sarebbero: Strutturazione Urbana (il sistema di spazi pubblici e il suo ruolo di articolazione sociale); Mobilità (il sistema di corridoi e servizi di trasporto 
che dovrebbero garantire l'aumento dell'uso del trasporto pubblico e diminuire l'impatto delle auto private); Qualificazione dell'Ambiente Naturale (la conservazione degli ecosistemi e delle risorse naturali, per dare a Porto Alegre anche un paesaggio di alta qualità in aggiunta all'alta qualità di vita già largamente riconosciuta); Promozione Economica (ruolo forte del Comune nella creazione e tutela di imprese economiche capaci di generare posti di lavoro e sostenibilità ambientale)

${ }_{23}$ "Semplificare era necessario dal momento che una legge complessa non può che ingenerare un sistema di pianificazione monco, lento, ambiguo, entro cui il possesso centralizzato del suo contenuto facilita la corruzione ed impedisce il controllo da parte dei cittadini; flessibilizzare perché si tende a riconoscere che, per quanto "futurologi" siano gli urbanisti, le loro proposte non [...] comprenderanno mai la molteplicità della realtà"(Pilla, 1998).

${ }^{24}$ Parte I - Sullo Sviluppo Urbano Ambientale; Parte II - Il Sistema di Pianificazione; Parte III - Il Piano Regolatore; Parte IV - Disposizioni Finali e Transitorie

${ }^{25}$ La cosiddetta "Cidade Rururbana" rappresenta quasi il $70 \%$ dell'intero territorio, e incorpora l'Área Urbana de Ocupação Extensiva e la Zona Rural del PRG del '79, con attività anche di riposo e turismo, educazione e uso residenziale a bassa densità.

${ }^{26}$ Il mantenimento della densità attuale di queste due aree è reso esplicito dalle norme restrittive previste per la suddivisione dei lotti e dal rafforzamento delle Aree di Protezione naturale, in associazione con i sistemi di monitoraggio immaginati per il loro rispetto.

${ }^{27}$ Gestione delle Politiche Urbane; Regionalizzazione e Partecipazione; Sistema di Informazioni; Comunicazione ed Educazione Ambientale

${ }^{28}$ Quasi tutte le Regioni sono accorpate due a due; solo la Regione Centro è da sola, mentre le Regioni dell'OP Gloria, Cristal e Cruzeiro sono fuse tutte e tre nella Regione $\mathrm{n}^{\circ} 5$ di Pianificazione

${ }^{29}$ Intervista alla coordinatrice dell'equipe tecnica interregionale di 8 persone Eunice d'Araujo, interfaccia fra livelli decisionali politici e tecnici in nome della sua doppia qualifica di tecnico/politico (in Allegretti, 2002d).

${ }_{30}$ Cioè le assemblee in cui ogni Regione di Pianificazione vota e sceglie il suo rappresentante nel CMDUA.

${ }^{31}$ In ognuno sono state elette 9 entità per un totale di 72 rappresentanti distribuiti nei Forum Regionali, che ne completano le strutture e scelgono poi i loro rappresentanti a livello cittadino.

${ }_{32} \mathrm{Nel}$ periodo di funzionamento tra il 1939 e il 1942 (quando fu bocciato il progetto di PRG dell'architetto Gladosh) il Consiglio aveva 16 membri. L'11 giugno 1955 la Legge 1413 previde (art. 19, capitolo V) che il Consiglio comprendesse 11 membri, 6 dei quali funzionari comunali di carriera e 5 rappresentanti di ordini professionali e organizzazioni di classe (art. 20). Il 7 novembre del 1979 il Consiglio del Piano Regolatore fu sostituito dal CMPDDU - Consiglio Municipale del Piano di Sviluppo Urbano, comprendente 21 membri e aperto alla presenza di 4 rappresentanti della comunità cittadina scelti dalle organizzazioni comunitarie nelle 4 Regioni della città. A questo ampliamento corrispose uno svuotamento di funzioni: il CMPDDU passò a discutere di questioni puntuali e non più di sviluppo.

${ }^{33} \mathrm{Nel}$ dicembre 200 si è anche formato un gruppo teatrale (Equipe do futuro) di studenti della scuola municipale Alfonso Guerriero Lima che hanno messo in scena ricostruzioni di memoria e scenari di futuro per la Lomba.

${ }^{34}$ Cfr. E. Menegat (1999i, apud Allegretti 2000a).

${ }^{35}$ Ad esempio, le strade parallele alle curve di livello hanno i marciapiedi di destra e sinistra a due livelli altimetrici ancora diversi. Non solo, la commissione mista ha proposto al Comune di creare marciapiedi di 1,2 metri (in genere usati solo nella regolarizzazione dell'esistente) per dare continuità ed uniformità al complesso che sarà costituito dalla favela regolarizzata e dalle case del reinsediamento.

${ }^{36}$ Construindo a Lomba do Futuro, no 4/2001, p.p. 1-3 e 8-11).

${ }^{37}$ Il Progetto di recente è stato selezionato per un premio dalla Fondazione Getulio Vargas di San Paolo, ed è divenuto oggetto di un articolo della rivista argentina "Ambiente"

38 "Non siamo un'elite fortunata; abbiamo solo colto l'opportunità offertaci per sfruttare un momento di crescita, ma accettando anche un peso che altri rifiutano perché fare un corso mentre lavori raddoppia le cose da fare. I, ad esempio, sto andando in 
pensione, e non avevo bisogno di un titolo professionale in più. Ma - dopo 27 anni in Comune - volevo smettere di fare lavori incompleti, e fare una tesi su un progetto concreto come quello della Lomba, mi costringeva anche ad arricchire l'azione e a darle un aspetto multiscalare. E non si viene coinvolti per caso in un progetto integrato: io è dal '95 che mi occupavo dell'area portandoci vari colleghi, e alla fine sono stato scelto anche per un impegno dimostrato. Altrove - come nel IV distretto - per la mancan$z$ a di tecnici 'dedicati' dei progetti simili sono falliti. Il fattore umano in fondo rappresenta spesso la differenza in un risultato" (Fuentefria, 2002i)

39 "Credo, anche, che sia stato demistificato il lavoro delle comunità con i tecnici, dato che questi prima non amavano mettere in discussione la loro competenza e compartirla con la popolazione. Oggi questo già sta avvenendo, dato che essi sanno che devono lavorare insieme alla comunità e assorbire il sapere popolare. Perché non esiste il sapere scientifico, esiste invece il sapere popolare. Attualmente [...] la popolazione si è appropriata di quello che sarà il futuro della città. La pianificazione partecipativa deve essere a lungo termine, deve mutare la coscienza delle persone e la loro ideologia" (Eduíno Mattos, coordinatore del Forum della Regione 7, su "Parceiro" gennaio 2002) ${ }^{40}$ Cfr. "Proteção ambiental com urbanização ecoprodutiva" di José G. Fuentefria (2002), FLACAM, La Plata.

41 "Tutte le volte che andavamo nel Recreio ci dicevano: siete qui per le elezioni? Quando ci hanno visto ricomparire dopo il voto si sono stupiti. Oggi andiamo lì 5 giorni su 7, e siamo sempre gli stessi: cosi garantiamo presenza reale ma anche continuità e memoria al progetto. Il punto è che non basta la costanza di un tecnico. Bisognerebbe che ognuno di noi potesse fare una sola cosa per volta e dedicarsi a quella. Durante un progetto speciale è possibile, ma correntemente no. E il rischio è di spegnere piccoli fuochi prima che diano frutto"(De Oliveira, 2002i-I). 

Sezione Quinta

Apprendendo dal Sud del mondo 



\section{6 \\ Una realtà in cammino}

\subsection{Un cambiamento in corso d'opera}

"Finestra sull'utopia. Lei è all'orizzonte" dice Fernando Birri. "Mi avvicino di due passi, Lei si allontana di due passi. Cammino per dieci passi e l'orizzonte si sposta dieci passi più in là. Per quanto io cammini non la rag giungerò mai. A cosa serve l'utopia? Serve a questo: a camminare" (Eduardo Galeano, 1998).

Questa 'biografia territoriale' ha preso le mosse dall'analisi di una 'doppia rottura' (sfasata nel tempo) che in Brasile ha dato forma ad alcuni importanti cambiamenti degli interventi pubblici nell'ambito delle relazioni tra città formale e città autocostruita:

1) La prima si lega all'abbandono della pratica del 'rimuovere per promuovere'. In riferimento ad un quadro internazionale in rapido movimento, lo si può datare, all'incirca, tra il 1975 ed il 1979, quando il sistema nazionale centralizzato [SFH] - che dal '64 dirigeva in Brasile le Politiche della Casa, e a cui si conformavano passivamente molti Enti Locali - propose l'applicazione per gradi delle principali strategie dell' 'approccio combinato' della World Bank ${ }^{1}$.

2) La seconda rottura è avvenuta circa dieci anni più tardi, quando la neonata Nuova Repubblica ha elaborato la sua Costituzione, dedicando al tema della Riforma Urbana un valido capitolo di principi, spesso mai tradotti in leggi specifiche, ma sulla base dei quali hanno preso forma Costituzioni Statali, Statuti Municipali, Leggi Complementari e Programmi di intervento locali, che hanno cercato di affrontare creativamente molte delle sfide poste dalla crescita accelerata della città spontanea e dal progressivo complessificarsi di concetti complementari come il deficit e l'inadeguatezza abitativa, ma anche la povertà e l'esclusione sociale.

Per il Brasile, non sarebbe azzardato dire che, con l'entrata in vigore della Legge sullo "Statuto della Città" nel settembre 2001, si è aperta una nuova fase: quella del 'consolidamento in azioni' di alcuni principi nodali della Costituzione (come quello della "funzione sociale della città e della proprietă’), ma anche quella del 'confronto' e del 'ripensamento collettivo' di stru- 
592 menti e di politiche che, finora, sono state sperimentate in diversi contesti locali (a dispetto delle incertezze e della vulnerabilità che dava loro il quadro normativo) e che ora potranno espandersi e perfezionarsi grazie alla nuova legislazione, ed arricchirsi degli scambi tra esperienze.

All'interno di questo quadro in movimento (arricchito da un trasformarsi su scala mondiale del ruolo dei territori urbani e delle modalità della gestione locale) la scelta di Porto Alegre - come luogo di disamina degli esiti di questa serie di 'rotture' - ha un particolare significato.

Pur con la sua peculiare articolazione sociospaziale, Porto Alegre era una città per molti aspetti tradizionale nel 1988, e per molti versi lo resta ancora. Soprattutto visto come la hanno segnata alcuni macrofenomeni che hanno caratterizzato l'intero Brasile sotto il profilo del deficit di abitabilità e della crescita della città informale, con i suoi modelli 'adattivi' di colonizzazione dei vuoti urbani, con le sue tipologie abitative e le sue maglie viarie 'informali' sempre più orientate (come nei parcellamenti irregolari o in molte occupazioni programmate) ad imitare i modelli del formale nella speranza di poter essere presto assimilate alla 'città di diritto' in virtù del loro apparentamento físico e del rispetto di alcune norme che ne hanno strutturato l'evoluzione.

Ciò che oggi fa distinguere Porto Alegre da altre città (anche sotto il profilo dell'organizzazione urbana) è che le diverse 'rotture' paiono aver teso ad innestarsi su un solido sostrato di continuità, individuabile soprattutto nel rispetto tributato alle tradizioni culturali locali e all'autonoma e crescente capacità organizzativa mostrata, nel corso del secolo scorso, dai movimenti urbani cittadini. Così, anche la riforma del 1989 è riuscita a dare "forma locale ad una battaglia per valori assoluti" (Baierle, 1999i, apud Allegretti 2000a).

In tale ottica, questo libro (fedele al suo impegno originario di 'aderire alle cose' raccontando fatti, esaminando azioni e riorganizzando memorie, anche quelle recuperabili solo da documenti informali e interviste) ha cercato di raccontare come a Porto Alegre anche l'ambito dell'informalità urbana non sia stato esaminato con l'ottica distorta "dell'intervento nella favela" (come in molte altre città), ma secondo un approccio centrato sul "riconoscimento delle differenze fra le favelas", che oggi ha trovato espressione in alcuni testi pubblicati dal Comune e dedicati a ricostruire gradualmente storie e figure dei diversi ambiti territoriali informali ${ }^{2}$.

La politica dei 'piccoli passi' - incarnata da realizzazioni come la scalinata di Santa Maria sul Morro da Cruz, che trasforma in immagine folgorante la ricerca di uno stretto legame tra città formale e città autocostruita (fig. 73) - ha accompagnato questo processo di trasformazione, a cui ha creato notevoli resistenze un'ingegneria istituzionale sviluppatasi per tradizione sulla creazione di uno scarto fra i campi del politico e del sociale. Crescendo, l'Amministrazione di Porto Alegre non si è limitata, però, a questa politica, ma ne ha colto il contributo a 'reinterpretare' il valore e le dimensioni degli interventi sul territorio, in base a una nuova ottica di lettura e a scale differenti di priorità. A partire dalla convinzione, ben espressa nella risoluzione finale del $3^{\circ}$ Congresso della Città, che "La cultura politica della partecipazione che si sviluppa qui [a Porto Alegre] è una delle "grandi

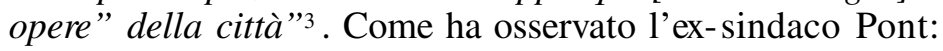

In realtà il Governo, in costante collaborazione con i suoi cittadini, non si è limitato a realizzare e portare avanti piccole opere, o interventi emergenziali. Il Comune ha fatto e 
fa anche grandi opere dirette all'interesse della cittadinanza tutta, che deve essere il discriminante del giudizio sulla grandezza di un'opera. Alcune [...] mostrano che si possono fare grandi opere anche se non del tipo tradizionalmente considerato tale: stazioni di trattamento fognario, riforme su vasta scala delle reti di salute pubblica o di scolarità (specie nell'ambito di base) non hanno nulla da invidiare ai grandi ponti del passato o ai centri congressi legati al nome di un sindaco. Questa nuova 'grandezza', più vicina alle necessità, va letta nell'ampliarsi del controllo municipale su tutta la città reale, e nella traslazione di ruolo dell'Istituzione verso la promozione e il coordinamento degli interventi. Promuovere investimenti 'diffusi' a livelli ben superiori agli abituali si retroalimenta, creando condizioni perché i micro e medi impresari assumano e costruiscano insieme questi spazi. Si è tentato di creare il mito che il PT fa solo opere semplici nella periferia, ma - a parte che questo non sarebbe una vergogna se crea democrazia sostantiva in tutta la città - bisogna rinnovare con onestà i presupposti della lettura e del giudizio. Tra le opere che possiamo annoverare come nostre è giusto infatti contare anche opere da noi solo incentivate o cofinanziate, visto che i meriti di una costruzione non si limitano a chi ha investito fondi ma toccano chi ha creato le condizioni per quell'investimento, lo ha promosso, approvato, coordinato. Si deve poi tener conto che spesso le piccole opere locali decise nell'O.P. richiedono alle spalle contemporanee opere complementari (più vaste ma meno visibili per i diretti interessati) che le rendano fattibili. Come il capillare necessita della vena, una rete locale di acqua o di fogne, in un quartiere, richiede reti più vaste e stazioni di trattamento alle spalle, e la costruzione di queste può avere effetto moltiplicatore su nuovi interventi locali (Pont, 1999i, apud Allegretti 2000b).

È proprio a partire da simili osservazioni che questo capitolo, avviandosi verso la conclusione, presenta alcune recenti linee di trasformazione delle politiche di Porto Alegre, che si propongono di fare da 'ponte' verso lo scenario più vasto dove la città si trova inserita. A tale scopo, il capitolo presenta due facce. Nella prima parte, è dedicato all'esame sintetico di alcuni 'nodi problematici' che l'esperienza di trasformazione territoriale degli ultimi 14 anni evidenzia. Nella seconda, saranno - invece - accennate alcune linee di un cambiamento qualitativo che si può ravvisare nella fase più recente dell'esperienza stessa. E evidente che il discorso non può pretendere di essere esaustivo, sia a motivo del punto di vista da cui questa analisi muove, sia della complessità del tema $\mathrm{e}$ dei suoi legami con trasformazioni di più vasta portata (culturali, economiche $\mathrm{e}$ istituzionali), sia in ambito locale che in quello nazionale ed internazionale. Inoltre, quelli che saranno indicati non sono mutamenti consolidati e valutabili a distanza di tempo nei loro effetti primari e collaterali, ma semplici 'linee di cambiamento', 'correzioni di rotta' che hanno come denominatore comune una dose comprensibile di incertezza relativa ai propri sviluppi.

\subsection{Il Bilancio Partecipativo al di là dei propri limiti}

A me lascia scettico dover 'per forza' ricercare dei limiti ad un' esperienza come questa, facendolo 'in astratto'. Non perché non ce ne siano, tutt'altro...E' che è difficile parlare di limiti 'in assoluto'. Il rilevamento di un limite è un'operazione 'finalizzata'. Cioè avviene in rapporto ad un obietti vo o a un punto di vista. Tu mi dovresti dire da che punto di vista vuoi evidenziare dei limiti (la formulazione teorica del progetto? La sua gestione pratica? Lo sviluppo di caratteri replicabili in altri contesti?) oppure in che settore ti interessa trovare qualcosa che va migliorato (la qualità degli interventi sul territorio? La distribuzione delle risorse ai più deboli? La garanzia della proprietà privata? Il trasformarsi del rapporto tra stato e cittadino? La crescita degli individui in un processo collettivo?) e allora potremmo discuterne. Perché, di solito, molti di questi obiettivi confliggono: si può puntare sull'uno o sull'altro o cercare una modalità intermedia - un compromesso - perché 
ognuno parzialmente si realizzi. Credo che l'esperienza di Porto Alegre ci insegni, questo con la sua continua crescita... (intervista a M.A. Dilly, ex Consigliere Popolare dell'O.P., Regione Cristal, 2001i).

Nel fare i meritati elogi del processo di democratizzazione in atto a Porto Alegre si corre spesso il rischio di opacizzare le difficoltà e gli ostacoli che sono parte di un'esperienza storicamente innovatrice e ricca di innegabili progressi, ma che non può certo dirsi "esente dalle contraddizioni della propria epoca" (B. Alfonsin, 1998a). Del resto, la stessa Amministrazione Popolare ha sempre tenuto a dichiarare che quello che trova il suo centro nell'O.P. "non è un sistema perfetto e concluso. Anzi, al contrario, possiede problemi e vizi che esigono una costante vigilanza, ridiscussione e perfezionamento" (Prefeitura de Porto Alegre, 1997). Questo è vero non solo per quanto attiene il processo di Bilancio Partecipativo in sé, ma soprattutto per quello che riguarda i suoi rapporti con le singole politiche di settore (a partire da quelle legate al tema della casa e del recupero della città informale) e il coinvolgimento dei tecnici nella loro attuazione.

Se oggi è sostanzialmente raro trovare analisi obiettive del Bilancio Partecipativo che ne sottolineino aspetti critici o limiti di intervento sul territorio, non è, quindi, perché essi non esistano, né perché essi siano soverchiati da quelli positivi che ne fanno il paradigma di un incontro costruttivo possibile 'a mezza strada' tra società civile e istituzioni, o una 'prova vivente' di una 'utopia possibile' (esaltata con simmetrico ottimismo sia da gruppi e movimenti urbani di 'base' che da istituzioni internazionali). La natura problematica dell'esperienza (implicita ed immanente nella saldatura che propone tra democrazia diretta e rappresentativa) permane, infatti, in tutta la sua attualità; così come, guardando l'O.P. separatamente dall'articolato contesto in cui agisce, è ovvio rilevarne il limite di strumento di mera redistribuzione delle risorse urbane, e quindi di 'coperta corta' in rapporto alle possibilità di produrre nuova ricchezza e sviluppo locale.

Il punto è che la struttura flessibile ed 'adattiva' che la città di Porto Alegre ha scelto per governare i suoi processi decisionali partecipativi sembra in grado di dare soluzione a molti dei problemi che via via possono venire rilevati, producendo con continuità elaborazioni e modalità differenti di organizzazione dei processi. E, visto che - anche per la maggioranza di chi vi è impegnato direttamente - questa capacità di auto-riaggiustamento è percepita come 'vitale' ("Il giorno che smetterà di evolvere, si autodistrug geră", cfr. V. D. Braseiro, apud Solidariedade, 2003), a molti di coloro che li leggono 'da fuori' può sembrare che ogni notazione critica invecchi rapidamente, superata da una capacità di cambiamento che renderebbe superfluo 'fermarla su carta'. Per questo - volendo noi accennare ad alcuni limiti del Bilancio Partecipativo e delle modalità di realizzazione degli interventi che supporta cercheremo di scindere due ordini diversi di limiti: quelli 'strutturali' e quelli che si potrebbero definire come "peccati veniali".

\subsubsection{Alcuni 'peccati veniali' del Bilancio Partecipativo}

Riguardano ambiti problematici che annualmente vengono messi in discussione, tentando di risolverli attraverso modifiche al Regolamento Interno del Bilancio Partecipativo. Essi toccano, soprattutto, questioni di scoordinamento tra fasi di discussione del bilancio e cariche elettive popolari dell'O.P., l'eterno dibattito tra ipotesi di remunerazione e rischi di professionalizzazione dei 
rappresentanti popolari, la mancanza di sovrapposizione temporale tra le cariche di anni consecutivi (che può togliere continuità e fluidità al dibattito), l'eccessiva rigidità della durata delle assemblee e gli spazi troppo ampi attualmente lasciati all'esposizione di informazioni generali (a detrimento dell'approfondimento della discussione), ma anche aspetti di grigiore ritualistico nei rigidi copioni di molte riunioni, o il fatto che - nelle assemblee pubbliche - l'aspetto intellettuale e culturale dell'incontrarsi risulti eccessivamente relegato al ruolo di appendice fornita dal settore governativo, mancando così di esprimere in modo genuino aspetti della cultura popolare, che pure è valutata dall' Amministrazione come un campo strategico ${ }^{4}$.

Da alcuni Consiglieri e Delegati appartenenti all'opposizione politica, viene anche ribadita la necessità di una maggior chiarezza delle regole con cui gli interventi dei vari rappresentanti popolari sono messi all'ordine del giorno nel COP; in modo da fugare ogni dubbio che vi possano essere 'manipolazioni dei giochi' (Santos, 1999i, apud Allegretti, 2000a) o la creazione di un 'clima di accerchiamento' che vada a scapito della libera espressione dei 'dissenzienti'. Alcuni limiti del processo di maggior 'sostanza' sono stati affrontati nell'aprile 2001 dal Grupo de Trabalho de Modernização do Orçamento Participativo (cfr. cap. 8), e si è cercato di porvi rimedio con una revisione del ciclo che - a distanza di un anno - non sembra aver soddisfatto tutti, anche per il fatto che - come osservano alcuni rappresentanti popolari - "Il progetto è stato messo insieme da un pugno di universitari e di tecnici. Subito dopo è stato presentato alla popolazione. Ma il nostro spazio di riflessione è stato troppo corto" (Solidariedade, 2003).

Se il cambiamento organizzativo è stato ben accetto per quanto concerne il rafforzamento del ruolo del Forum dei Delegati nella fase di approvazione del Piano degli Investimenti (prima deciso e sottoscritto dal COP senza ulteriori verifiche con la propria 'base'), le critiche più coese sono state mosse alla fine del 2002 - soprattutto su tre punti:

1) L'anticipazione dell'elezione dei Consiglieri ad una fase anteriore alla scelta delle priorità d'investimento da parte dei cittadini attenua i 'vincoli di mandato' su cui questi venivano nominati fino al 2001;

2) La sostituzione del secondo turno di assemblee plenarie con un'unica assemblea municipale non pare aver sortito lo sperato effetto di dinamizzazione dell'OP, visto che (anche per ragioni logistiche legate all'accentramento) nel luglio 2002 ci si sono recati solo Delegati e Consiglieri più motivati, e ben pochi cittadini;

3) Con la nuova collocazione delle 'assemblee di comunità' - dove si decidono le opere da finanziare - molti hanno percepito il rischio che si indichino opere che - non rientrando poi tra le prime tre priorità - non verranno poi finanziate; o - per contro - che si formulino richieste ritenute più in linea con le priorità che si presume potranno risultare vincenti, ma che in realtà "non corrispondono realmente alle urgenze della regione"(R. Marques, apud Solidariedade, 2003).

Per certi versi, dalle prime valutazioni informali del nuovo ciclo adottato nel 2002 (di cui si avrà conferma solo durante il dibattito per l'approvazione del nuovo Regolamento Interno in vigore dal marzo 2003) sembrerebbe che il cambiamento - come già accaduto altre volte - sia stato percepito dalla popolazione come un passo indietro, che ha spostato il momento realmente decisionale del processo "in una grande assemblea la cui ampiezza non risulta 
596 compatibile con delle discussioni approfondite", diminuendo il ruolo delle più raccolte - ma anche più agguerrite - riunioni di comunità, di quartiere $o$ di microregione, a vantaggio di un ciclo "forse più democratico, ma certo meno qualificato e meno imperniato sulle discussioni" (Rangel, ibidem). Uno scontento montante pare riguardare anche un altro tema che finora è mutato molto nei Regolamenti Interni del Bilancio Partecipativo degli ultimi anni, ma senza passare per una reale adesione e comprensione dei cittadini: quello dei 'criteri tecnici', modificati di solito su indicazione degli assessorati e delle autarchie del Comune, seppur approvati dal COP.

L'approvazione, anno dopo anno, di criteri tecnici sempre più puntuali, si rivolta oggi contro il processo, bloccando la realizzazione di opere indispensabili [...] La popolazione ha la sua parte di responsabilità: è lei stessa che ha approvato questi criteri, senza forse misurarsi con le loro conseguenze. "Io dico sempre che i criteri tecnici sono la forma più elegante che il governo ha trovato per giustificare il fatto che non realizzerà una certa operazione" spiega Miro (Solidariedade, 2003).

Su queste osservazioni - che implicitamente rilevano 'un recupero di terreno' da parte della discrezionalità decisionale del Comune (che lascia spesso 'in coda' opere approvate da tempo, scavalcandole con nuove richieste ${ }^{5}$ ) se ne innesta un'altra, che riflette sulle conseguenze 'frenanti' che può passare ad avere anche la ricerca di equità distributiva, qualora "si trasformi in un mito dell'uguaglianza ad ogni costo" (dos Santos Duarte, 1999i-II, apud Allegretti 2000a). Ad esempio, se un consigliere dell'O.P. porta dati aggiornati sulle carenze abitative o l'aumento reale della popolazione nella sua Regione, queste non possono essere prese in considerazione dal COP per valutare emergenze ed esigenze della stessa in rapporto alle altre, se anche gli altri dati non sono 'aggiornati' alla stessa data. In questo caso, la ricerca di una maggior vicinanza con le necessità della popolazione tentata dal Consigliere si scontra con un aspetto 'formale' dell'O.P., che tiene le azioni dell'Amministrazione distanti dalla realtà delle situazioni concrete in cui versano i cittadini. La formalizzazione di questo 'scarto' dal reale si può rintracciare nei criteri tecnici dell'O.P., dove si fa riferimento specifico alla fonte di dati (l'IBGE) che si può prendere in considerazione per determinare le priorità di intervento che emergono dal confronto fra i delegati e i consiglieri del Bilancio Partecipativo. Oggi nel COP esiste una Commissione per l'aggiornamento dei dati, ma è certo che la voce dei Criteri Tecnici riferita all'IBGE andre bbe eliminata dal Regolamento Interno dell'O.P., tanto più a motivo dei difetti di quel tipo di dati e della lentezza con cui vengono aggiornati dall'ente erogatore.

Tra i rappresentanti popolari, valutazioni duplici riscuote, invece, la maggiore novità introdotta nel 2001: la partecipazione via Internet. Nell'apprezzarne, infatti, il contributo dato all'estensione delle modalità di interazione dei cittadini con l'O.P., si tende a sottolinearne il rischio di creatrice " $d i$ un dibattito a due velocità" (Solidariedade, 2003) e - soprattutto - si rileva che, non essendo state previste regole da seguire per la valutazione delle domande arrivate via Internet (che, finora, nessuno è andato a sostenere di persona nelle assemblee dell'O.P.), esse tendono a restare lettera morta, cosicché l'ampliamento del processo resta appunto 'virtuale': più una misura pubblicitaria che un reale contributo alle decisioni sugli investimenti pubblici. 
Per ragioni non dissimili, la stessa moltiplicazione del dibattito fra Istituzioni e cittadinanza (che in assoluto rappresenta un apporto positivo alla qualità della discussione) comincia ad essere letta da alcuni anche come "strumento di frammentazione e polverizzazione della cittadinanza attiva esistente nella città" (De olho no Orçamento n. 7/98), anche in considerazione del fatto che "è difficile discutere politiche senza discutere di risorse" e, siccome discutere politiche è il compito principale affidato ai Consigli settoriali (che si configurano come strutture proprie di partecipazione intorno a dipartimenti e assessorati), vi è il concreto rischio che la presenza di tali strutture finisca per legittimare il margine di arbitrio del Comune intorno ad una parte dei fondi municipali. Ad esempio, quelli gestiti dalle Assemblee Tematiche e quelli destinati alle priorità oltre la terza, dove la forza delle strutture di articolazione del Comune finisce per essere preponderante e prevaricare i criteri di carenza, popolazione e priorizzazione che costituiscono gli strumenti di decisione e controllo in mano alla popolazione per l'allocazione della percentuale maggiore di fondi di investimento. In tal senso, le critiche hanno un duplice obiettivo; da un lato l'Amministrazione, le cui strutture mostrano di aver cominciato furbescamente a riorganizzarsi per recuperare "almeno una fetta del potere perduto" (Osores, 1999i, apud Allegretti 2000a), dall'altro la stessa acquiescenza di molti cittadini che non comprendono che la continua riconferma della 'triade storica' pavimentazione-casa-urbanizzazione nelle prime posizioni dell' Orçamento Participativo può costituire un rischio, offrendo il braccio a strategie "che cercano di far rientrare furbescamente dalla finestra temi già usciti dalla porta" (Osores, 2002i).

In particolare, le strutture partecipative oggi più criticate dai cittadini paiono i Forum Regionali dei Servizi, che dovrebbero riunire costruttivamente gli abitanti e i responsabili dei servizi municipali, e spesso finiscono per trasformarsi solo "in un mezzo per la popolazione di esprimere la sua insoddisfazione", ma "in nessun caso le permettono di intervenire nel funzionamento" (Solidariedade, 2003). Peraltro, spesso la constatazione dello 'sfrangiarsi' e dell'indebolirsi di alcuni canali partecipativi non sembra risolversi in una richiesta di riduzione del numero, quanto - soprattutto nell'ottica critica della cittadinanza - in una ricerca di maggior qualificazione degli stessi, anche attraverso una riforma della burocrazia municipale che aumenti la possibilità di un controllo popolare su settori che ancora restano 'feudi' del decisionismo tecnico, indebolendo così - per vie traverse - la stessa incisività di molte scelte assunte in seno all'O.P..

Questo genere di problematiche attengono, indubbiamente, ad una dialettica tra logiche diverse che vengono a contatto e si confrontano nel Bilancio Partecipativo (quella delle istituzioni e quella dei cittadini). Non possono perciò rimandare ad una soluzione univoca, ma la loro soluzione spesso attiene ad una 'scelta' che viene congiuntamente compiuta nel reimpostare annualmente le regole e le modalità di svolgimento dei processi. Comunque, è sempre possibile intervenirvi di anno in anno, attraverso modifiche 'di tentativo' al ciclo e al Regolamento Interno dell'O.P. e di altre arene deliberative, a patto che in sede di emendamento vi sia "un costante e simmetrico impegno dei rappresentanti popolari e dell'Amministrazione nel perseguire effettivi miglioramenti del funzionamento dei processi, e non solo il tentativo di entrambi di "portare acqua al proprio mulino"' (Samtos da Silva, 2002i). 
In questi anni di sperimentazione, il Bilancio Partecipativo è parso evidenziare anche alcuni 'limiti' che paiono difficilmente eliminabili o correggibili solo con una trasformazione interna, dal momento che attengono alla sua natura di strumento negoziale e periferico. Essi sono, però, passibili di strategie di 'attenuazione', attraverso politiche che ne allarghino l'interdipendenza con altri processi di democratizzazione delle scelte territoriali e con le fasi dell'elaborazione di dettaglio e della gestione per tappe dei progetti urbani.

Tra questi 'limiti strutturali' dell'O.P. rientra, in primo luogo, il rischio che esso diffonda opportunità ineguali di accesso al potere decisionale che nella pratica attribuisce alla popolazione partecipante; problema che - se estremizzato - secondo alcuni teorici può rischiare di rendere le decisioni partecipative meno 'democratiche' addirittura di quelle prese nei consessi eletti per via rappresentativa, dove è comunque rappresentato un ampio ventaglio di forze politiche (Sartori, 1987). Su questo punto, come abbiamo visto nel cap. 9, vi è però stata - fin dagli esordi del processo - una costante 'attenzione critica' che, nel tempo, ha portato cambiamenti visibili sia nella sua struttura interna che nelle politiche che ne connettono le scelte al territorio.

Alla base di questa 'attenzione' vi è sempre stata la considerazione che, di per sé, il Bilancio Partecipativo (in quanto strumento a partecipazione volontaria) non è in grado di garantire che le decisioni vadano a vantaggio veramente dei cittadini più bisognosi, anche perché i diversi 'costi' della partecipazione risultano più alti per le famiglie che non hanno possibilità che un loro membro si dedichi con impegno alle attività di discussione, controllo, approvazione o correzione dell'operato istituzionale, così come per coloro che possiedono una minore istruzione e - in conseguenza - meno fiducia in sé e nella propria capacità di imporsi nel confronto di opinioni o nella 'conquista' degli interventi istituzionali nel proprio quartiere. Questo 'nodo problematico' è stato affrontato e riaffrontato nel tempo, stimolando anche un concreto impegno dell'Amministrazione a favorire l'approvazione di aiuti materiali (informazione porta-a-porta, trasporti collettivi gratuiti e organizzati, approntamento di servizi di intrattenimento dei bambini durante le assemblee, ecc.) e - soprattutto - di 'regole sulle decisioni' che andassero a garanzia di risposte rivolte, in prima istanza, ai cittadini più bisognosi, e non solo ai più organizzati.

Parallelamente, il Bilancio Partecipativo ha dovuto affrontare anche un tema complementare: quello dell'auto-esclusione delle fasce medio-alte della popolazione dai dibattiti, con la chiara coscienza che "la priorizzazione di coloro che hanno maggiori carenze [...] non deve significare l'esclusione dei più, ma esattamente ciò che è, ossia, "priorizzazione""(Rompendo nossos limites, 2001). Un tema, quello del loro coinvolgimento, che pare ancora lungi dal trovare un soddisfacente riequilibrio, forse anche perché "la classe medioalta [...] è una categoria sociale meno rivendicatrice e che, anche se ha dei bisogni, partecipa difficilmente alle associazioni di quartiere [...] è molto disunita [...], attende senza andare a cercarsi le cose", mentre "il Bilancio Partecipativo, al contrario, richiede una forte implicazione, una disponibilità" (E. Rizzo, apud Solidariedade, 2003).

Un altro limite strutturale fortemente avvertito è il fatto che il Bilancio Partecipativo tende di per sé a non occuparsi dei cittadini futuri (che nasceranno o 
che si trasferiranno in città) e di quelli di passaggio, ma solo di quelli esistenti e residenti, e tanto più nella misura in cui sono 'attivi' e partecipanti al processo. In tal senso, non sa esprimere "una politica globale [...] una politica di anticipazione che, ad esempio, permetta di evitare nuove occupazioni irregolari" o "comunque di assicurare politiche globali di lotta all'esclusione". I rilievi in questa direzione, mossi ad esempio nel lungo capitolo "I limiti del Bilancio Partecipativo: la nostra diagnosi" di un testo recentemente scritto da un gruppo di cittadini a lungo impegnatisi nell'O.P. come rappresentanti popolari (Solidariedade, 2003), non hanno - in realtà - una stretta attinenza con il Bilancio Partecipativo, perché ne mettono in evidenza un limite 'costitutivo' che solo può essere risolto affrontandolo su altri piani delle politiche territoriali. Non è un caso che alcune delle soluzioni, ipotizzate per cercare di porre rimedio a questo limite 'dall'intemo del processo', non convincano neppure gli stessi proponenti. Ad esempio, destinare una quota fissa del bilancio agli investimenti in ambito sociale (così come avviene, per Statuto, con la sanità o l'educazione) viene visto come un rischio di far avanzare approcci politici paternalisti a discapito di una reale democrazia partecipativa, che in questi 14 anni ha cercato di dimostrare che la risposta ai bisogni primari degli abitanti non può scindersi da una conquista di reali diritti di cittadinanza; di cui fa parte, al momento del compimento delle scelte, anche la stessa capacità dei partecipanti all'O.P. di responsabilizzarsi in maniera solidale nei confronti dei segmenti sociali più deboli.

In tale ottica, anche la proposta di mettere da parte dei fondi di investimento da riservare alle emergenze, alle situazioni disperate, alle eventualità che la crescita degli abitanti e il mancato arrestarsi dei fenomeni migratori possono comportare. Al momento la stessa popolazione - attraverso i suoi rappresentanti - si è ripetutamente opposta a sottrarre quote di investimento al controllo dell'O.P. come avviene in altre città (come Belo Horizonte) dove al vaglio del Bilancio Partecipativo sono sottoposte solo percentuali dal 50 all' $80 \%$ della quota di capitale delle spese comunali. Lo mostrano le ripetute levate di scudi contro le proposte di Consiglieri Comunali che hanno tentato di formalizzare in Legge l'O.P. sottraendogli anche il controllo sul 50\% (o su fette minori) degli investimenti. Lasciare libertà di movimento ampia alla Giunta e al Consiglio Comunale appare alla popolazione "un ritorno all'indietro, alla discrezionalità di molte scelte su base politica" (Baierle, 1999i, apud Allegretti 2000a). In conclusione, i cittadini - dopo 14 anni di partecipazione attiva alle scelte democratiche - lo considererebbero un appiglio offerto al riaffacciarsi di clientelismi, come anche di piccole furbizie tentate in passato quando - sicuri di poter contare su fondi di emergenza consistenti ed esterni al meccanismo di selezione dell'O.P. - singoli cittadini o intere comunità si gettavano artificiosamente in situazioni di emergenza estrema, scavalcando le forme di decisione democratica e di 'etica dell'impegno' (ad es. con incendi dolosi e simili). Oggi, anzi, c'è una tendenza - da parte delle comunità impegnate a partecipare all'O.P. - a cercare di aumentare per il futuro i margini del controllo popolare sulla gestione economico-finanziaria del Comune: una reazione quasi spontanea ad un altro limite strutturale che va evidenziandosi nel Bilancio Partecipativo: ovvero il progressivo diminuire, nel tempo, dei fondi di investimento su cui i cittadini sono chiamati a dettagliare le scelte (figg. 41-43), soprattutto di quelli non pre-impegnati per la prosecuzione di impegni assunti negli anni precedenti. Le soluzioni che lo stesso movimento popolare cerca di individuare per fre- 
600 nare l'inesorabile e progressiva 'erosione' di questi margini (che è aggravata dalla congiuntura internazionale come dalla progressiva deresponsabilizzazione delle istituzioni nazionali e statali su temi legati al welfare), stanno fuori dall'O.P., e non sempre sono praticabili. Nel 2001, ad esempio, è stata rigettata dal Consiglio Comunale di Porto Alegre una richiesta di aumento delle imposte locali sugli immobili (IPTU), e non è probabile che il nuovo progetto che andrà in discussione nel 2003 abbia miglior sorte. Parimenti, non è risultato possibile intaccare i fondi destinati alla 'Riserva di Contingenza', una voce prevista dalla Legge Federale, che rappresenta circa il 5\% delle entrate comunali e serve a coprire eventuali imprevisti ed emergenze che si dovessero verificare.

Davanti a questa avvertita 'impotenza', la reazione manifestata da una parte del COP è stata quella di chiedere un rafforzamento generale del ruolo di controllo popolare su tutto l'insieme delle politiche economiche e fiscali del governo locale. Oggi, l'art. 2 del Regolamento Interno dell'O.P. prevede che il "Consiglio del Bilancio Partecipativo [..] pianifichi, proponga, controlli e deliberi sulle entrate e le uscite di Bilancio del Municipio di Porto Alegre", e già alla fine del 2000 - in occasione della riformulazione delle regole che presiedono al processo - un gruppo di Consiglieri ha proposto una Commissione capace di analizzare le entrate e le uscite di ogni servizio pubblico locale, "in un'ottica di risultato, simile alla pratica delle imprese pubbliche" (Solidariedade, 2003). La dialettica tra poteri ha fatto la sua comparsa nel momento in cui il Comune ha spiegato di non poter imporre 'obblighi di risultato' ai suoi funzionari, ma alla fine il Regolamento Interno del 2001 porta traccia del dibattito all'articolo 10 ( $\S$ VI, VII, VIII) nel prevedere un rafforzamento del ruolo del COP sul controllo delle politiche fiscali e di bilancio del governo, nel loro insieme. Eppure, al 2003 il COP non ha ancora attivato la Commissione di Controllo sulle entrate e le uscite, forse anche a motivo della necessità di ulteriore impegno e formazione specifica che un ruolo così 'tecnico' di monitoraggio richiede di acquisire.

Un altro limite 'congenito' che il Bilancio Partecipativo evidenzia, riguarda il rapporto tra impegno delle scelte e tempi del loro compimento.

Come già accennato al cap. 9 , è ormai piuttosto chiaro che l'importanza rivestita dal settore del 'bilancio' - per dar forza a nuovi processi decisionali partecipativi - sta anche nel fatto che esso, per sua intima natura, si presta ad una temporalizzazione chiara e vincolante per il compimento delle scelte, che può aiutare a trasformare $\mathrm{i}$ 'conflitti' territoriali in progetto e stimolare $\mathrm{i}$ cittadini ad estrarre essi stessi dal confronto di tesi e antitesi emergenti nel processo partecipativo una 'sintesi', ovvero una scelta ponderata che possa essere proposta all'Amministrazione. Non importa che tutto avvenga a fine anno, quando il Comune ha chiaro su quante risorse reali potrà contare nell'esercizio successivo: anzi, è basilare che la partecipazione dei cittadini non sia ridotta ad 'evento' concentrato in pochi giorni, ma i processi di discussione si distendano nel corso dell'intero anno, anche in quei periodi in cui ancora l'Amministrazione non è in grado di valutare con certezza le sue entrate per l'anno successivo. Del resto, il coinvolgimento dei cittadini è strategico soprattutto nella costruzione di gerarchie di 'priorità condivise' su cui - negli ultimi mesi dell'anno - verranno poi prese dettagliatamente (con l'ausilio del COP e del Forum dei Delegati) tutte le decisioni principali di spesa che interessano la città. 
A Porto Alegre, dove il Bilancio Partecipativo tende a configurarsi come un percorso di coinvolgimento dei cittadini nel perfezionamento per gradi dei documenti di bilancio (e in particolar modo dei Piani degli Investimenti in Opere e Servizi), lo scandire i gradi e le tappe di questo perfezionamento, è percepito come contributo fondamentale per evitare l'isterilimento e l'allungamento a dismisura dei dibattiti tra cittadini e amministrazione: tanto è vero che la temporalizzazione delle diverse fasi di consegna e dettagliamento delle proposte che cittadini, Giunta e Consiglio Comunale devono rispettare, è specificata nel Regolamento Interno dell'O.P. e - in parte - persino nello Statuto Municipale. Un limite strutturale del Bilancio Partecipativo è però che - a dispetto di queste attenzioni - esso imprime alle scelte compiute una linea dei tempi segnata da rallentamenti ed accelerazioni improvvise, che finiscono per influire negativamente sullo sviluppo delle politiche e dei programmi puntuali di intervento del Municipio, oltre che sul complesso delle attese dei cittadini e sugli stimoli ad una loro attiva partecipazione alle scelte per il territorio.

Dei rallentamenti, nei capitoli precedenti si sono offerti vari esempi, anche attraverso i racconti di alcuni luoghi in trasformazione: in particolare, per quanto concerne la Politica della Casa che - pur essendo spesso tra le prime tre priorità cittadine - "resta il tallone d'Achille del Bilancio Partecipativo", presentando ancora oggi "ritardi di oltre cinque anni" che "da qui a qualche anno - se si continua così" faranno sì che "il debito sociale del Dipartimento alla Casa verso la città sarà forse più importante che davanti al Bilancio Partecipativo" (Miro, apud Solidariedade, 2003). Per quanto concerne le 'accelerazioni', esse intervengono spesso in fase successiva all'approvazione dei progetti nei Piani degli Investimenti. Non riguardano cioè direttamente il Bilancio Partecipativo, ma vi influiscono in forma di 'feed back' facendo percepire come 'ingiuste' certe sue distorsioni. Specialmente se un'opera è finanziata da enti estemi (Unione, Stato, BID, World Bank, cooperazione internazionale ecc.) sarà, infatti, spesso necessario agire per concretizzarla in tempi brevi per non perdere il finanziamento stesso.

Per non vanificare la fatica compiuta dalla popolazione e dal Comune in anni di battaglie, si affrettano - quindi - i processi proprio in fase progettuale. Ovvero resta poco tempo per una progettazione veramente 'partecipata' secondo le linee che teoricamente sarebbero più coerenti con il programma di governo dell'Amministrazione Popolare e con la stessa 'moltiplicazione del dialogo' prevista dall'O.P. Soprattutto, l'aspetto progettuale finisce - spesso - per essere sacrificato a 'ragioni ulteriori', cioè al superamento dei vincoli burocratici, legali e finanziari che si presentano in corso d'opera sotto forma di contrattempi.

In questo quadro, talora la stessa ricerca di 'giustizia distributiva' e di 'democraticità sostantiva' si evidenzia non solo come maggiore conquista del Bilancio Partecipativo, ma anche come 'limite strutturale' del meccanismo stesso, nella misura in cui 'forgia' un tipo di processo all'interno del quale si tende a distribuire il più possibile le risorse sulle diverse parti del territorio urbano:

Certo, ribaltare il 'tanto a pochi' di un tempo, nel 'poco a tanti' di oggi, provoca minore di ingiustizia sociale e territoriale, ma - per altri versi - va a scapito dell'approfondimento dei sing oli progetti. Anche questo, però, genera un effetto importante, perché abituata noi cittadini a pensare i progetti nel tempo, come una conquista che richiede tappe e impegno costante per arrivare al risultato qualitativo che sogniamo. Anzi, forse, abituare tutti a pensare nel tempo, è - pensandoci bene - uno dei pregi maggiori dell'O.P. (Santos da Silva, 2002i). 
16.2.3 Alcuni limiti nell'attuazione delle scelte puntuali sul terreno della città informale

Come evidente da quanto detto finora, sarebbe difficile - e, forse, improduttivo - voler esaminare l'esperienza di Porto Alegre, cercando di individuare limiti e risorse del Bilancio Partecipativo 'isolatamente' dall'intreccio delle politiche e dei processi di democratizzazione istituzionale al cui centro si trova, visto che essi tendono continuamente ad interagirvi e a riflettersi sulla percezione che del suoi ruolo hanno sia i cittadini che l'Amministrazione. $\mathrm{E}$, invece, più agevole rintracciare alcuni limiti che intervengono 'a valle' delle decisioni assunte in sede di Bilancio Partecipativo, e leggerne l'incapacità di 'allinearsi' con l'approccio che ha cercato di diffondere in questi 14 anni. Esaminando - ad esempio - l'insieme delle politiche che a Porto Alegre hanno perseguito in maniera più diretta l'obiettivo di reintegrare la città informale nella 'città' reale (anche sotto il profilo della restituzione dei diritti di cittadinanza ai suoi abitanti) è possibile rintracciare alcuni 'scarti' emergenti, a cui vale la pena accennare rapidamente, pur senza pretese di esaustività e sottolineando che alcuni di essi hanno teso progressivamente a mitigarsi in periodo recente: 1) A lungo è esistito certamente uno 'scarto' fra le modalità di conduzione del Bilancio Partecipativo (ritenuto spesso di per sé garanzia sufficiente di recupero della dignità degli abitanti della città informale) e gli interventi urbanistico-architettonici proposti al suo interno. Le modalità di attuazione di molti di essi hanno, infatti, veicolato un'errata identificazione fra società e città informale, dando per scontato che il ri-accoglimento della prima nella città di diritto significasse automaticamente il miglioramento delle condizioni dell'altra. Questioni di 'linguaggio' e comunicazione, hanno ulteriormente indebolito il dialogo mirato alla messa in opera di progetti condivisi dai beneficiari, e hanno ridimensionato l'impeto posto sulla 'progettazione partecipata', facendo optare sovente per una progettazione solo 'accompagnata' (e con scarso ausilio di strumenti metodologici affinati). E questo - nel corso degli anni - ha lasciato in molti cittadini l'idea che l'O.P. sia un sistema non del tutto coerente, incapace di trarre tutte le conseguenze dai propri presupposti ideali e metodologici, così come il caso Rubem Berta $(\S 14.3)$ illustra.

2) Almeno fino al 1999, si è evidenziato un sostanziale 'scollamento' tra gli interventi puntuali realizzati sul territorio e una più vasta politica di riassetto e riequilibrio urbano.

3) La mancanza di un'adeguata riforma della macchina amministrativa ha pregiudicato la corretta valorizzazione di alcune professionalità e l'aggiornamento dei loro saperi in direzione di una maggior coerenza con le principali linee di programma dell'Amministrazione Popolare. Ad esempio, solo di recente si può riscontrare un'inversione della tendenza all' 'impoverimento' del ruolo degli architetti nella ricostruzione di quella 'città unica' che i processi-quadro di democratizzazione delle Istituzioni mirano ad accreditare.

4) Almeno fino al 1996, la Politica Pubblica della Casa - quella che ha come destinatari gli strati più poveri della popolazione - ha teso ad appiattirsi ambiguamente sul recupero degli insediamenti spontanei. Inoltre, ha teso a restare scissa dalla politica urbanistica, cosicché molti interventi localizzati sono sembrati 'astrarsi' dal contesto fisico in cui operavano, almeno tanto quanto la loro portata sociale innovativa si inseriva, invece, con coerenza nel dibattito socioeconomico in atto in città. 
5) Si può riscontrare un'assenza di politiche pubbliche di genere 'coscienti' ${ }^{6}$ legate alla Politica della Casa, che tengano conto delle esigenze talora differenziate dei due sessi e al contempo contribuiscano a sradicare alcune relazioni di dominazione, ingiustizia ed esclusione. Cosa grave, in particolare davanti alla fattiva constatazione che, nei programmi di Regolarizzazione Fondiaria come nell'O.P., si verifica una partecipazione più attiva e costante da parte delle donne, in particolare di quelle che si trovano a guidare da sole le proprie famiglie.

Sul terreno degli interventi puntuali sul territorio, queste 'lacune' tendono a riflettersi in:

1) un sostanziale disinteresse per i modi di organizzare lo spazio propri degli insediamenti spontanei (conseguenza di una lettura 'in negativo' dei loro valori simbolico/funzionali) e - quindi - in una sovrapposizione su di essi di modelli di intervento 'eteronomi', seppur non definibili come 'imposti' perché sempre fatti approvare alla popolazione direttamente interessata.

2) una 'discrasia improduttiva' tra le visioni di differenti organismi comunali, ad esempio tra il modo di operare legato alle continue emergenze del DEMHAB, quello più 'legalista' della SPM (che vorrebbe condurre fino in fondo ogni intervento di Regolarizzazione Fondiaria non accontentandosi dell'urbanizzazione e della suddivisione in lotti, ma portando le pratiche fino alla registrazione dei contratti di vendita o CDRU presso il Catasto). Così, spesso, invece che costituirsi una collaborazione e una complementarità fra approcci, tende a stabilirsi una forte tensione, che vede la SPM - che avrebbe dalla sua parte le ragioni della legalità - sacrificata sotto il profilo dell'interesse politico al suo operato; al punto che molti dirigenti e tecnici al suo interno lamentano di essere presi in considerazione dalla politica urbana solo in virtù del costituire "un passaggio obbligato della catena burocratica" (Almeida, 1999i, apud Allegretti 2000a). Questa differenza di posizioni, si riflette anche nei modi differenti di concepire i progetti che lavorano sulla città informale: ovvero, mentre il DEMHAB tende a lavorare per 'isole galleggianti', cioè per carte che rappresentano solo gli insediamenti e non il loro intorno (Di Lima, 1999i, apud Allegretti 2000a), la SPM tende a lavorare su carte dove traccia direttrici e prolungamenti viari e aree comuni senza neppure aver davanti la topografia della favela su cui altri dovranno lavorare.

3) un'estromissione della riflessione nell'azione che - finora - non ha reso frequente la messa in discussione (nel dialogo con i cittadini) dei modelli abitativi tradizionali e delle forme 'estensive' di occupazione del territorio. Per contro, questa estromissione ha teso a far sì che, nel processo di progettazione diffusa e interattiva dello spazio urbano, la 'conoscenza' dei tecnici e del governo locale per i caratteri peculiari della città si sia spesso concentrata solo su quella prodotta durante l'azione ai fini dell'azione stessa. Questa formula di 'ricercazione', sbilanciata sul versante dell'azione, è rimasta a lungo incapace di stimolare la costruzione di archivi di memorie sugli interventi urbani, determinando il concreto rischio che la macchina pubblica e i suoi tecnici non 'apprendano' da errori del passato, essendo pressati da continue emergenze che rallentano la riflessione su come migliorare la qualità degli interventi.

Nel tempo, è andato evidenziandosi una sorta di 'scarto' tra una politica flessibile, concreta e tendenzialmente rapida nel rispondere alle molte 
emergenze (seppur con i limiti che abbiamo via via evidenziato), e la possibilità di elaborare una riflessione teorico-metodologica di supporto all'azione. Ciò non significa che il risultato delle riflessioni 'informali' (soprattutto di quelle realizzate durante il 'corpo a corpo' tra tecnici ed abitanti) sia andato perso. Esso ha, però, teso a non andare oltre il suo limite di 'sapere asistemico', incerto dei propri risultati e delle proprie conclusioni, oltre che custodito da pochi. È rimasto, cioè, essenzialmente confinato come apprendimento dei soli attori interagenti durante le varie fasi di costruzione di politiche e progetti: non si è trasmesso al loro esterno.

Questa sostanziale mancanza di 'metodo' nel condurre interventi e progetti è co-responsabile di un altro limite delle Politiche del Comune di Porto Alegre nell'ambito delle questioni della Casa e del recupero della città spontanea, che potremmo definire come 'mancanza di continuità'. A differenza di quanto è finora accaduto nell'ambito delle direttive politiche dell' Amministrazione Popolare nelle sue diverse gestioni, sul piano dei progetti il cambiamento di un tecnico si è sempre rivelato deleterio per le 'interruzioni di continuità' determinate nella realizzazione degli stessi. Questa è, peraltro, causata in gran parte dalla mancanza di abitudine ad una cultura scritta legata al progettare, che non sia limitata ai documenti meramente burocratici.

Trovare documenti scritti riguardanti singoli progetti, nonostante la proliferazione di materiale sui 'programmi' e le 'linee politiche di azione' dell'Amministrazione, è - a volte - un'operazione ardua. Questo risulta stranamente vero soprattutto per progetti-pilota (i 'reassentamentos' della Cavalhada, Vila Nova, Vila Tripa) e, soprattutto, per quelli più 'contestati' come il caso di Vila Planetario il cui materiale è per fortuna rimasto almeno al progettista, visto che la SPM e il DEMHAB - nel tempo - si sono scaricati a vicenda la responsabilità della costruzione, al punto da rendere impossibile ritrovarne testimonianza. Per questo, nel lavoro di ricostruzione delle storie del cap. 14, ci siamo dovuti spesso appoggiare ad osservazioni informali o interviste con $\mathrm{i}$ tecnici e gli abitanti, per poter raccogliere notizie più precise.

Forse, per cominciare a colmare questi deficit, sarebbe sufficiente che l'Amministrazione Popolare 'osasse' costruire partenariati con altre forze sociali finora poco valorizzate, specie nell' ambito della reintegrazione della città informale. Abbiamo avuto modo di vedere che gli aspetti maggiormente positivi di interazione dell'Amministrazione Comunale di Porto Alegre con altre Istituzioni 'collaboranti' non sono decollate che raramente, a differenza di quanto accaduto proficuamente in città come Belo Horizonte o Fortaleza. I casi delle sinergie create con l'ONG CIDADE, o con la FASE/RS per il monitoraggio dei processi di O.P. sono stati rari esempi di cooperazione ben riuscita e continuativa. Un altro caso - che ha suscitato diffusi malumori nelle istituzioni accademiche locali - è stata la collaborazione con la FLACAM in occasione della stesura finale del nuovo Piano Regolatore Urbano e Ambientale; e - in una prima fase - è stato proficuo ed arricchente anche il ruolo giocato dalla UFRGS nel progetto 'Centro de Bairro',in particolare nell'area di Rubem Berta ( $\$ 14.3)$ Per il resto, i tentativi di ulteriori collaborazioni su specifici programmi - soprattutto di natura urbanistica e architettonica - non si sono fino ad oggi mostrate particolarmente proficue; talora, come nel caso della GTZ/METROPLAN ( $\$ 14.2$ ) sono state semplici sovrapposizioni o passaggi di consegne senza quasi interazione, a dispetto della sostanziale unità di intenti dei rispettivi programmi. Altrove, come nei ripetuti 
tentativi del DEMHAB per coinvolgere la UFRGS nella riprogettazione di favelas cittadine, sono stati rapporti addirittura fallimentari, specie dopo le polemiche innescate dai 'controprogetti' polemici proposti da alcuni architetti per Vila Planetario e Vila das Placas.

Ma vi sono stati anche episodi di sordità alle reciproche esigenze, come nel caso della 'progettazione partecipata' portata avanti dal Nucleo di Urbanistica Comunitaria della Facoltà di Architettura dell'Università Federale nella Regione della Gloria, dopo la traduzione in linguaggio comune di astrusi questionari dell'Amministrazione (Wagner, 1998i, apud Allegretti 2000a). La collaborazione migliore tra Comune e Università si è avuta in ambiti esterni a quello architettonico ed urbanistico, ad esempio nell'ambito dell'Assistenza Sociale e Sanitaria, con la realizzazione di 'presidi avanzati' delle diverse università di Porto Alegre in alcune favelas cittadine. Le rinegoziazioni che attualmente sono in atto con la Facoltà di Architettura della UFRGS stanno venendo semplificate dal nuovo rettore Wrana Panizzi, che per anni si è occupata della città informale nell'area metropolitana di Porto Alegre, e per l'interessamento di sing oli docenti che si trovano ad essere tutori di tecnici comunali in corsi post-laurea. Con la Facoltà di Architettura dell'Università privata Ritter dos Reis si è, invece, positivamente concluso il rapporto per la progettazione della Vila Tecnologica ( $\$ 16.4 .3$ ).

Per quanto attiene gli ordini professionali, il Comune di Porto Alegre non ha fatto molti tentativi concreti per un loro coinvolgimento nell'ampia e massiva politica di riorganizzazione della città informale; non ha, pertanto, fatto virtù della necessità che in Brasile ogni Amministrazione ha di muoversi ad ogni passo attraverso licitazioni, per trasformarle in un contributo propositivo e creativo al proprio programma di azione.

Concludendo, se si eccettuano le diverse forme di coinvolgimento della società civile in partenariati informali, si potrebbe dire che vi è stato un approccio quasi 'autarchico' (o, perlomeno, 'autocentrato') del Comune di Porto Alegre al tema, come se avesse voluto tenere per sé difficoltà e glorie della sua meritoria opera di recupero della città autorganizzata "senza confidare in altri se non nelle sue limitate forze" (Turkienicz, 1999i, apud Allegretti 2000a). E, a dire il vero, spesso ne sfugge il perché, se non leggendolo in continuità con l'ostilità che l'Amministrazione Popolare pare sempre aver mostrato per ogni forma di delega, privatizzazione e terziarizzazione. La mancata 'contaminazione' con approcci e modi di operare diversi dal proprio (sovente metodologicamente ben supportati, come abbiamo visto nel caso della GTZ) ha fatto sì che il Comune di Porto Alegre - in mancanza di forze, personale, tempi e finanziamenti sufficienti - si sia trovato spesso ad operare nell'ambito delle Politiche della Casa e della Regolarizzazione Fondiaria con un'apparente mancanza di metodo; in particolare ha mostrato l'incapacità di collegare gli interventi puntuali a valutazioni ex-ante ed ex-post che garantissero il radicamento dei progetti nei contesti locali specifici a cui erano destinati, e l'osservazione dei risultati ottenuti in termini di sostenibilità dell'intervento, di soddisfazione dei beneficiari e di ottimizzazione delle risorse, almeno nei casi di progetti-pilota. Per le stesse ragioni il DEMHAB non ha arricchito il suo scarno e ormai datato abaco degli alloggi-tipo a cui i tecnici atting ono durante i 'reassentamentos', le regolarizzazioni fondiarie ed i mutirões. Ovvero ha rinunciato a miglioramenti che certo collaborazioni esterne avrebbero potuto garantire con aumenti di costi non necessariamente elevati se riassorbiti in accordi chiari circa diritti, doveri e ruoli dei partner in 
gioco. Cosa che - finora - non pare essere accaduta, anche "per un costante equivoco teso allo sfruttamento reciproco, soprattutto tra il Comune l'Università" (Turkienicz, 1999i, apud Allegretti 2000a) .

Questo approccio - antitetico rispetto a quello seguito a Rio de Janeiro dal Programma Favela.Bairro, che ha ottenuto alcuni dei suoi risultati più interessanti proprio mettendo in contatto aree informali e giovani professionisti privati (cfr. Allegretti 2000a e 2001a) - può ritenersi concausa della difficoltà di risolvere anche un altro 'punto critico' che si riscontra a Porto Alegre: i problemi che si verificano nelle fasi di realizzazione dei progetti sul terreno della città informale, di rado gestiti dal Comune in economia e quasi sempre appaltati ad imprese private, le quali intervengono su rilievi topografici e opere architettoniche o urbanistiche, ma restando escluse dalle 'fasi creative'. I ritardi e gli strascichi causati ai lavori ${ }^{8}$ - che, agli occhi degli abitanti, sovente compromettono i risultati visibili dell'impegno profuso dal Comune - sono in parte dovuti al fatto che

[...] ancora non esistono imprese e tecnici qualificati per la regolarizzazione dell'esistente, per qualcosa che è in uso anche mentre lo costruisci. Gli ingegneri sono per lo più formati a lavorare su aree libere. I lavori di riforma sono delicati; devono rispettare parte delle case, ricostruire, ricucire. È come lavorare col restauro, per cui noi non abbiamo molta tradizione. Per certi versi è peggio del restauro perché avviene in luoghi vivi; spesso non si possono eliminare le persone, si deve entrare nella loro vita, disturbarli, distruggere alberi con cui hanno una relazione affettiva, entrare in alloggi di trafficanti, accettare le complicazioni 'culturali' della relazione con l'umbanda e i riti afro, che a volte vengono strumentalmente usati come scusa a copertura d'altro. E noi abbiamo anche bisogno di chiedere alle imprese la capacità di relazionarsi con la comunità che - spesso in maniera critica - accompagna quotidianamente i loro movimenti, e costituisce l'occhio vigile del potere pubblico sui privati (Dantas Machado, 1999i, apud Allegretti 2000a).

In tale quadro, si evidenzia la necessità di una formazione e di un costante aggiornamento dei tecnici e dei professionisti non solo del Comune ${ }^{9}$ ma anche privati, di cui la Municipalità deve comunque servirsi per mancanza di energie proprie. Questo presupporrebbe un approfondimento della discussione sul tema dell'informalità (nei suoi limiti e potenzialità) anche con la comunità scientifica, con le istituzioni di formazione e le categorie professionali; cosa che risulta difficile finché non si oltrepassa questa sorta di 'autosufficienza' che l'Amministrazione Popolare pare implicitamente ostentare nell'appoggiarsi ancora solo timidamente a segmenti sociali che avrebbe tutto l'interesse a coinvolgere maggiormente nel proprio lavoro, come accade altrove ${ }^{10}$.

Un ultimo punto critico, attiene alla mancanza di sistemi di controllo che inibiscano almeno stravolgimenti dei progetti in fase di post-occupazione. Non è solo il concetto di 'prevenzione dei danni' a far poca breccia su questo punto; vi è alle spalle (soprattutto da parte della SMOV che in teoria sarebbe la responsabile principale dei controlli) un'istintiva mancanza di interesse per le aree 'non regolarizzate', ovvero - stante il grado di legalizzazione finora raggiunto a Porto Alegre - per tutte quelle che ancora appartengono alla città informale.

\subsection{Potere pubblico e città informale in una 'wild zone'}

La costruzione della devianza permette ad alcune attività di localizzarsi in un un'economia politica di trasgressione [...] La 'wild zone' è quello spazio definito come privo di regole. [...] La 'wild zone' è un riconoscimento del margine da parte del 
centro ed un' ammissione strategica di fallimento. È un fallimento che serve da punto di riferimento nella costruzione delle opposizioni di ordine e disordine, regolamentazione e deregolamentazione, Legge e trasgressione. La 'wild zone', come potenziale luogo di transizione affermativa all'interno dell'urbano, deve essere avvicinata con cura per evitare la seduzione attraverso la costruzione ideologica (Chris Stanley, 1999).

Nel contesto di Porto Alegre, può la città informale essere considerata come un luogo potenziale di una costruzione alternativa del desiderio e dell'identità, come insieme di spazi che non sono senza legge, ma piuttosto "sono gli spazi dei senza-legge per costruire il dissenso come forma di resistenza" (Stanley, 1999) e, al contempo, la resistenza come dissenso?

Dall'esame delle politiche messe in opera in questi 14 anni, parrebbe che una risposta positiva a questo quesito sia stata tra le principali intuizioni dell'Amministrazione Popolare che oggi (e forse solo oggi) si può rintracciare in alcune 'linee di apertura' - ancora nebulose - a cui tenteremo di accennare nei prossimi paragrafi. In questo sta, forse, la principale differenza dalle molte alte amministrazioni che meritoriamente stanno portando avanti sul territorio "interventi non convenzionali” (Magalhães, 1997), dando loro un raggio di copertura quantitativa tale da trasformarli in prototipi di nuove politiche urbanistiche e in interventi che si avviano a diventare i nuovi 'approcci convenzionali' dei prossimi decenni.

Se l'Amministrazione Popolare di Porto Alegre si è mostrata un passo avanti rispetto alla maggior parte delle amministrazioni metropolitane del Brasile, è per non essersi limitata a guardare al 'problema sociale' che le favelas rappresentano solo in termini che ne assicurassero la territorializzazione e quindi "il controllo urbano attraverso la razionalità della legittimazione" (Stanley, 1999), ma cominciando a cogliere il loro potenziale di non dissipare - ma semmai di rinforzare - il legame tra centro e margini, distribuendo il margine nel centro e connotando il margine come centro, non solo nell'inquadramento politico generale, ma anche negli interventi puntuali sulla trasformazione dello spazio.

Attraverso l'O.P., la recente costruzione del nuovo PDDUA e (ma solo in misura minore) alcuni progetti specifici di intervento sul territorio, a Porto Alegre si sta oggi tentando la 'scoperta' di alcuni aspetti del mondo dell'informale inteso quale spazio interstiziale o, meglio, parallelo alla 'realtà maggioritaria', come qualcosa di vicino a quello che Foucault (1994) chiama Heterotopia, dove è possibile cogliere episodi che costituiscono "una narrativa del dissenso" (Stanley, 1999) e fanno emergere percorsi di discorso alternativi, ed un bacino di potenzialità per la crescita della città intera.

Ciò sembra potersi leggere in modo 'programmatico' soprattutto nelle strategie della SMIC, (l'Assessorato all'Industria e Commercio, cfr. §), seppur la sua la traiettoria ha un margine di ambiguità, correndo parallela a quella di ambito economico a livello internazionale, dove il riconoscimento e la valorizzazione delle strategie dell'informale precede di un passo gli altri campi dell'azione, e con l'ambizione non troppo celata di recuperare margini di energia creativa da riassorbire nell'ambito delle leggi formali dell'economia di mercato.

Porto Alegre non ha fatto un'apologia delle favelas; anzi, la coalizione di governo, partendo dal riconoscimento che la città informale più che rappresentare "una disfunzione del sistema, è l'espressione fisica delle sue contraddizioni" (Genro, 1999i, apud Allegretti 2000a), ha tentato con evidenza di riassorbirla nella 'città di diritto' anche a costo di alcune forzature della sua natura organizzativa e spaziale. Però, vi è stato - al con- 
tempo - un riconoscimento positivo di alcuni aspetti legati all'informalità. Nelle parole dell'ex-sindaco Genro:

Da un lato ci toccava imporre, in certe circostanze, la dura legalità giuridico/formale, dall'altro ci pareva necessario flessibilizzare in maniera sovversiva per permettere a questi soggetti di costruire una 'legalità adiacente', parallela (Genro, 1999i, apud Alle gretti 2000b).

Sviluppando rapidamente un'intuizione - che richiederebbe ben altro spazio e approfondimento per essere corroborata - si potrebbe affermare che, nel percorso per il reinglobamento della città spontanea in quella 'di diritto' compiuto a Porto Alegre, si è determinata una sorta di 'contaminazione' biunivoca, a livello di alcune strategie messe in opera dalla città formale e da quella informale. È come se, nel tentativo di favorire una 'correzione di tiro' di diversi aspetti dell'informalità, l'Amministrazione Popolare vi si fosse trovata 'invischiata', riuscendo per questa via a coglierne nel profondo l'essenza, quel "concetto-guida di necessità" che è alla base dei "principali paradigmi organizzatori dello spazio dell'informale" (Bueno, 1999i, apud Allegretti 2000a).

Questo è forse accaduto perché, nel cercare di concludere i suoi programmi a beneficio della cittadinanza, la stessa Amministrazione Popolare si è trovata più volte di fronte alla 'necessità: quella di accettare una 'legalità adiacente' (Genro, 1999i, apud Allegretti 2000a), una legalità 'minore' o 'parallela' centrata sul bisogno e "la buona fede" (Panizzi, 1993). È come se, in 14 anni di governo, il Comune di Porto Alegre a vesse introiettato alcuni aspetti di quella "legge nomadica" caratteristica della città informale, la cui evoluzione - a dispetto del carattere essenzialmente anti-nomadico della Legge - attesta l'inevitabilità del "fallimento della sorveglianza come meccanismo di controllo" (Stanley, 1999). Più volte il formale ha mostrato di arrivare a permeare l'informale con alcuni suoi modi di agire; ad esempio, le strade delle occupazioni dell'ultimo ventennio si sono allargate e rettificate per apparentamento con la città legale (Panizzi, 1984) e i lottizzatori abusivi hanno firmato contratti giuridicamente inutili (i cosiddetti contratos frios) per dare una parvenza di formalità ai loro illeciti. Paradossalmente, talora, l'agire informale ha addirittura costituito l'anticamera della legalizzazione:

Spesso i Servizi Sciali dello Stato - e perfino quelli municipali - rispondendo alle pressioni della comunità passano sui piedi del piano adottato e legale per trasformarsi essi stessi, in un certo qual modo, in invasori, e far giungere a quella comunità i servizi richiesti (Krafta, 1993).

Le grandi imprese privatizzate, sovente intervengono in modo informale in aree irregolari per allacciare la luce, o addirittura la NET (la Tv via cavo); e le bollette di questi servizi proditoriamente erogati diventano veicoli di formalizzazione, nel momento in cui servono a dimostrare lo 'storicizzarsi' della permanenza di una famiglia in un luogo; "e sono documenti importanti per innestare le regolarizzazioni fondiarie e ancor di più l'usucapione" (Alibio, 1999i, apud Allegretti 2000a).

Altre volte è stato, invece, il formale che, nel tentare di penetrare nell'informale, ne è rimasto parzialmente 'contagiato'. In questo senso l'Amministrazione Popolare di Porto Alegre si è a tratti trovata ad operare in una sorta di zona grigia, o'wild zone' (come la chiama Stanley), divenuta inconscio punto di riferimento 
"nella costruzione delle opposizioni di ordine e disordine, regolamentazione e deregolamentazione, Legge e trasgressione" (Stanley, 1999). E questa si è, forse involontariamente, costituita come il fulcro di un principio di azione a base umanistica che - a partire dalla pratica - si avvia a ridefinire alcune gerarchie di valori, e non lo fa proditoriamente o in modo vacillante, ma appoggiandosi ad alcune definizioni 'forti' e altrove largamente inapplicate della Costituzione progressista del 1988, prime fra tutte quelle sulla 'funzione sociale della città $e$ della proprietà', messe in opera attraverso il costituirsi progressivo di un legame fra le Politiche della Casa e quelle di riorganizzazione a livello urbano, e attraverso la sperimentazione di nuovi strumenti giuridici il cui contenuto progressista è stato di recente consacrato dalla Legge sullo "Statuto della Città" (cfr. cap. 11). "Abrir maõs" [permettere, concedere] è diventato in certi frangenti la strategia inevitabile dell'Amministrazione. Ad esempio: tra le critiche più frequentemente mosse al DEMHAB sugli interventi di Regolarizzazione Fondiaria condotti in molte 'vilas', vi è il fatto che - fino ad oggi - essi terminano, per lo più, con la stipula dei contratti di Concessione del Diritto Reale d'Uso, "con quel Reale che assume un significato di 'di fatto' e non 'di diritto', perché essendo concessa in aree pubbliche - il DEMHAB ha spesso poco interesse a condurre la pratica fino in fondo, arrivando a registrarla in Catasto. Il che potrebbe rivelarsi grave, ad esempio, nel caso del venir meno della volontà politica, ovvero in un eventuale ricambio istituzionale" (Ribeiro Jordão, 1999i, apud Allegretti 2000a). Se ci si chiede perché questo avvenga, e perché a tutt'oggi non si sia condotta fino alla registrazione al Catasto nessuna pratica di Regolarizzazione Fondiaria eseguita su baraccopoli costruite in terreni pubblici ${ }^{11}$, le risposte potrebbero essere varie: pigrizia, pressappochismo, disinteresse reale, persino una forma strisciante di 'ricatto' verso la popolazione (intesa a far sentire ai cittadini il proprio "status" di sicurezza come dipendente dalla volontà politica di 'questa' Amministrazione) oppure più semplicemente 'necessità', mancanza di forze reali e di interazione produttiva fra organismi per portare fino in fondo le operazioni di regolarizzazione fondiaria, oltre - cioè - la loro fase di riorganizzazione urbanistica e dei lotti.

Le Cooperative Abitative tentano tutte di adeguarsi alla Leg ge secondo le prassi correnti, nessuna fa richiesta di AEIS; eppure, neppure la COOMETAL è riuscita a portare avanti il processo fino a registrare al Catasto il parcellamento. Iniziano legalmente, prima o poi si disperano, desistono, entrano nell'informalità. Perché la legislazione, sommata alla situazione finanziaria degli aderenti, ostacola di fatto il cammino della legalità. Soprattutto nella fase dei cosiddetti 'expedientes filhote' [pratiche-cucciolo], una per ogni tema (acqua, fogne, garanzie finanziarie); perché qui il Municipio ipoteca il $60 \%$ del lotto. È un'ipoteca formale; mai il Comune è intervenuto nei fallimenti. Ma tanto basta; le persone non vogliono lotti ipotecati e da quel momento molti prendono altre strade [...] Posso dire lo stesso del DEMHAB. Nel tempo ha cercato di adeguarsi al Plano Diretor usando molto la legge delle AEIS, ma poi ha iniziato a non terminare i procedimenti, tralasciando - dopo l'EVU e le prime opere - i progetti complementari che servono per la registrazione al Catasto. Questo lascia insicurezza di fatto nelle persone, che però raramente la avvertono in senso psicologico e lasciano correre, e il DEMHAB può occuparsi di opere urgenti altrove, invece che perdere energie e dedicare tecnici a seguire iter lunghi che giudica sterili. Questo è un controsenso: il DEMHAB è parte del Comune, ma è il primo a 'lasciar dormire' la legge. Il Planetario in teoria non esiste ufficialmente; nessuno ha documenti, ed è una delle prime regolarizzazioni. [...] Le cose restano in un 'limbo' pericoloso, ma i cittadini si sentono con le spalle coperte, perché i loro terreni glieli ha dati il DEMHAB. [...] Forse perché noi della 
SPM lavoriamo anche con la città legale, non riusciamo a sintonizzarci con questo modo di fare, e crediamo che il Comune debba agire tutto dentro la Legge per poter poi esigere legalità dai cittadini (Almeida, 1999i).

Il brano dell'intervista, riportata in Allegretti (2000a), chiarisce bene il meccanismo che si è instaurato a Porto Alegre, e che ha ramificazioni a diversi livelli dei processi di regolarizzazione fondiaria. In particolar modo per la parte che riguarda la regolarizzazione degli alloggi costruiti sopra i lotti. In realtà, nessuna Legge Nazionale promuove l'autocostruzione, e la presenza di un tecnico firmatario dei progetti e di altri che ne controllino l'esecuzione sarebbe sempre teoricamente indispensabile. Ecco perché anche i progetti di mutirões sono firmati da architetti del DEMHAB, ed i lavori - eseguiti da operai non specializzati - sono sotto il costante controllo di professionisti incaricati. Sulle regolarizzazioni fondiarie, invece, sembra non esserci controllo, così come sulle costruzioni nei lotti Sites-and-Services o negli ampliamenti di moduli sanitari ed unità abitative nei 'reassentamentos'. In particolare, le fasi di costruzione degli alloggi arrivano tardissimo alla regolarizzazione; e molte nascono direttamente irregolari anche in aree concesse dal Comune. Il fenomeno non è nuovo, se già 20 anni fa Guareschi (1980) propose una distinzione fra tipologie di 'vilas' dove - oltre a quelle clandestine (di invasione) e irregolari (dove ad un permesso iniziale del Comune era seguita una totale mancanza di rispetto per regolamenti e prescrizioni) - figuravano le cosiddette 'vilas' del DEMHAB, categoria contraddittoria riferita a progetti abitativi per popolazione a basso reddito curati dall'ente pubblico, dove la maggioranza degli alloggi finiva per restare precaria; una sorta di favela istituzionalizzata da un intervento percepito come legalizzatore, ma in realtà rimasto fuori da binari di reale regolarizzazione.

Un ruolo non estraneo a questo stato di cose lo ha svolto indubbiamente in questi anni anche l'O.P., come luogo dove vengono convogliate pressioni politiche ed urgenze pratiche della popolazione con ritmi spesso incalzanti rispetto alle forze e ai tempi 'naturali' dell'Amministrazione. Se nel corso degli ultimi anni l'O.P. è cresciuto nell'educazione alla legalità non lo deve solo ad una volontà precisa dell'Amministrazione, ma anche a fattori 'esterni', come le richieste di organi finanziatori, o i problemi posti dalla giustizia, che hanno provocato un mutamento ponderato di prospettiva.

Vi ha giocato, più che una vera volontà legalista, anche la furbizia. Prima c'era una richiesta di pavimentazione in area informale? Bene, se la si accoglieva nell'O.P. si pavimentava tutto. A fine intervento spuntavano i proprietari - fino ad allora intelligentemente tenutisi da parte - e chiedevano ed ottenevano l'espropriazione indiretta, per giunta - magari - con un aumento di valore dovuto all'intervento del Comune. Così l'O.P. si è adeguato ad un grado maggiore di legalità ed ha inserito dei criteri tecnici chiari di partenza (Almeida, 1999i, a pud Allegretti 2000a).

Percorsi simili non sono peculiari di Porto Alegre, ma accadono più o meno dovunque ci si debba relazionare con la città informale. Ciò che, forse, differenzia Porto Alegre da altre realtà è la filosofia (ibidem) che sembra affacciarsi gradualmente dietro questo incontro con 'le necessità', sul terreno di una 'wild zone'. Questa filosofia insorgente è forse solo un'intuizione, e non ha condotto per ora a variazioni nei modelli abitativi o di organizzazione spaziale delle aree in via di reinserimento nella città di diritto; ma ha avuto 
un primo risultato pratico nel contributo offerto a ricollocare il concetto di 'informale' dal piano della 'a-formalità' a quello dell' 'assenza di rigidità formale'. Ovvero in un ambito di 'apertura', che sta fuori dai binari di molte regole stabilite in passato e mai riviste in relazione al mutare dei tempi, ma non è necessariamente 'privo di regole' (cioè anarchico), anzi, che rimarca l'importanza della norma giuridica - anche evasa e non sanzionata su vasta scala - come "strumento-base per pervenire ad una ri-definizione degli statuti di 'irregolarità"'; come base, cioè, per una riformulazione di se stessa a partire dall'osservazione - di cui viene ad essere giudice - della capacità dell'irregolarità di mediare conflitti e conciliare interessi diversi (Duhau, 1995).

A Porto Alegre, l'accettazione dell'informale come interlocutore 'degno' ai vari livelli del dialogo cittadino non ha quindi, comportato una delega all'autoregolamentazione, semmai ha rivelato una fiducia nelle capacità di autoimporsi delle regole. Non è stato quindi letto solo come 'mancanza' di qualcosa (come è spesso avvenuto nell' ambito dell' organizzazione fisica dello spazio), quanto come 'possesso di qualcosa in più', generalmente non riconosciuto dal mondo delle regole ingabbiate e immutabili: la capacità di lasciarsi condurre mantenendo uno sguardo critico verso il mondo delle regole. A questa valutazione dell'informale - costruita sempre più per addizione che non per sottrazione - il Bilancio Partecipativo ha certo offerto, per via implicita, una sistematizzazione, a partire dalla stessa flessibilità della sua struttura costitutiva e dal suo grado minimo di tutela formale:

La flessibilità è un gradino superiore all'informalità, che ha dei minimi e dei massimi diversamente accettabili. Forse il modo di lavorare di questa amministrazione non è strettamente legalista, nel senso di aderire ad ogni passaggio di regole che ne sovradeterminano l'operato; ma è certo che questo modo di fare è attento ad innestare il senso dei doveri civici sull'ottenimento progressivo e sostantivo dei diritti di cittadinanza per gli abitanti della città informale (Borges, 1999i, apud Allegretti 2000a).

\subsection{Verso un graduale superamento dei propri limiti}

Solo chi non cammina non ha bisogno di domandarsi dove porta il cammino (Tiago Alberino, in Caminhar...para onde? Paulus Ed., San Paolo)

Se a Porto Alegre il Bilancio Partecipativo fa oramai parte della cultura politica della città, è altrettanto chiaro che la mera ed immutata prosecuzione nel tempo di processi già rodati potrebbe tendere alla stagnazione e alla decadenza (anche degenerando in un clientelismo di sinistra) se non controllato, adeguato e perfezionato nel tempo. E' pertanto avvertita l'urgenza di ossigenare costantemente il percorso di democratizzazione dell'amministrazione, anche rendendo possibile "un'ingerenza sempre più qualificata degli attori che costruiranno la città sulla base dei percorsi che essa sta intraprendendo" (Alfonsin, Allegretti, 2003).

Del resto, la considerazione che in questi anni sembra aver guidato la sinergia tra Amministrazione Popolare e movimenti urbani è che il decentramento non può essere concepito come una semplice e statica "misura amministrativa", ma deve "rappresentare una delle condizioni della democratizzazione dello Stato", il cui "quantitativo democratico" interessa maggiormente del contributo all'efficienza ottenibile dalle stesse politiche successivamente attivate (IBASE, 1995). Su questa base, prima l'O.P. e poi altre istanze (come, 
612 di recente, i Forum Regionali per la costruzione dei Piani di Azione urbanistici) hanno cercato di configurarsi come processi "cumulativi" (Gret, Sintomer, 2002, p. 132), strumenti di perfezionamento e crescita parallela delle istituzioni, della cittadinanza nel suo complesso e, in particolare, delle organizzazioni della società civile, la cui tendenza - specie in un contesto di crisi economica - può essere quella di appiattirsi su rivendicazioni di tipo immediatista, confondendo la giusta salvaguardia di una posizione di indipendenza organizzativa davanti al governo e ai partiti con l'autonomia politico-ideologica davanti alla società in generale. Ciò spiega perché, una volta che i suoi partecipanti hanno superato il grado dell'autocoscienza che - con Gramsci - potremmo definire 'economico-corporativo', tali strumenti tendano a farsi portavoce di uno spirito che cerca di superare gli interessi appena economici, cominciando ad agire in termini politici, ideologici e di concezioni del mondo, attraverso la formazione di una capacità tecnico-organizzativa e politico-organizzativa diffusa.

In questo quadro, il processo decisionale partecipativo formulato e più volte ampliato a Porto Alegre in questi 14 anni, non ha puntato a mettere in discussione solo singole strategie di azione, ma spesso lo stesso concetto di bene pubblico, ridefinito relazionalmente come risultante di tensioni prodotte da quell'incontro tra diversità irriducibili che genera talvolta risultati imprevedibili e stimoli creativi frutto di necessità diverse.

Partendo da alcuni punti fermi - riassunti nel 'Diritto alla città per tutti' l'Amministrazione Popolare ha chiarito alcuni valori ritenuti non negoziabili, per aprire poi un dibattito mirato alla definizione progressiva del 'bene comune' cioè dei fini del governo urbano. Questo bene comune è stato inteso "non come un dato considerato costituito prima e al di fuori del processo di piano/di politiche" (Crosta, 1998), ma piuttosto come un valore composto dalla combinazione di presupposti necessari dell'agire e di esiti eventuali - talora non intenzionali prodotti dall'agire stesso (secondo un percorso del tipo rappresentato sotto).

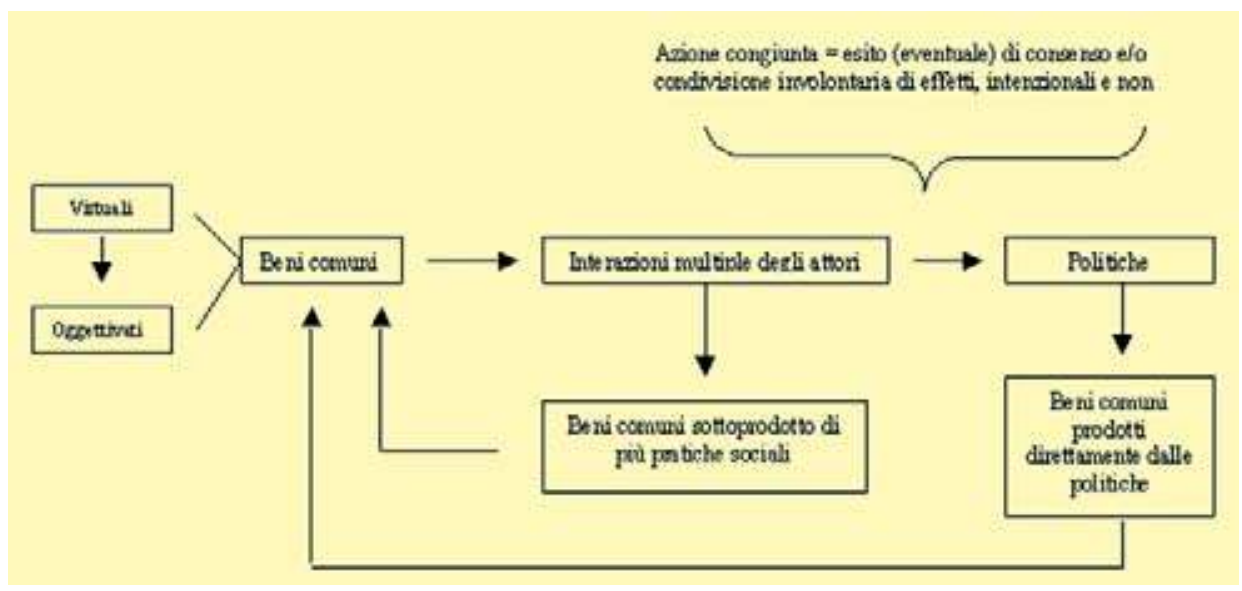

Le stesse incertezze mostrate su alcuni temi dal Fronte Popolare, sono state indispensabili presupposti per lo sviluppo di soluzioni e processi decisionali condivisi. L'esempio principale è quello dell'O.P: solo nebulosamente evocato in periodo elettorale come "partecipazione diretta della popolazione alle scelte finanziarie' (senza ulteriori gradi di definizione), è stato successivamente costruito e perfezionato nel corso degli anni nell'interazione con i movimenti popolari organizzati prima, e la cittadinanza tutta poi. Un altro 
esempio emblematico è rappresentato dalla Politica dei trasporti su cui la coalizione "non aveva nessuna idea al momento della vittoria elettorale" (Brunet, 1999i, apud Allegretti 2000a) e che in poco tempo fu impostata grazie al contributo creativo degli stessi dipendenti responsabilizzati per fornire un apporto decisivo a livello di scelta 'politica' - in modo tale che ancora oggi una città territorialmente complessa come Porto Alegre è pluripremiata per l'ottimo funzionamento del sistema trasportistico ${ }^{12}$, e questo, dal 1990, non più annoverato dai cittadini tra le priorità problematiche della città.

In sostanza, il Comune di Porto Alegre ha scelto per govemare la sfida costituita dall'interagire continuo con i propri cittadini, la via dell'azione congiunta, della corresponsabilizzazione, di un operare politico che non è sommatoria di azioni individuali di attori già pre-coordinati e con un ruolo immutabile, ma è risposta risultante da diverse intenzionalità interagenti, che sovente hanno quadri di riferimento differenziati.

In questo processo, la partecipazione - criterio raccomandato ormai nei documenti di tutte le istituzioni Internazionali e finanziarie, soprattutto come strumento di pax sociale e mezzo per far accettare misure ridotte ed interventi minimi degli enti pubblici - è stata individuata dall'Amministrazione Popolare non come strumento di acquisizione di un assenso, ma come mezzo di produzione di senso e al contempo di consenso (inteso quale 'senso in comune') per le stesse politiche; senza ridurre quindi quest'ultimo a oggetto di strategia, ma riconoscendone la natura interattiva ed eventuale, frutto di una costruzione "multipla, di lungo periodo, non specifica, più "allargata", e che tende a presentarsi come "strategia senza attore" (Crosta, 1998). O, meglio - nel caso di Porto Alegre -, come strategia con un attore al contempo 'unico e molteplice', ovvero quel "cittadino-artefice della costruzione collettiva della città e dei suoi strumenti di governo" a cui si rivolgono "non solo i diversi processi partecipativi, ma anche le strategie per promuoverli, che cercano di coinvolgere noi abitanti sempre puntando a dare del Bilancio Partecipativo l'immagine di una potente creazione collegiale, che è nata ed evolve insieme a noi" (Dilly, 2001i) ${ }^{13}$.

Come già accennato, alcuni dei maggiori limiti con cui l'esperienza di Porto Alegre ha dovuto confrontarsi in questi anni, hanno a avuto ed hanno a che vedere con caratteristiche 'strutturali' dei vari strumenti utilizzati, oltre che con una lunga tradizione di governo urbano bisognosa di radicali riforme. Considerando questi limiti almeno parzialmente 'correggibili', e allo scopo di diminuirne il peso sull'efficacia e l'efficienza delle azioni intraprese, l'Amministrazione Popolare e i cittadini di Porto Alegre - di concerto - hanno scelto di affrontarli attraverso una strategia di 'accerchiamento', ovvero puntando sulla moltiplicazione delle arene deliberative, degli spazi di controllo sociale sull'operato delle istituzioni e delle occasioni di contatto diretto sul territorio tra i rappresentanti del Comune (a livello politico e tecnico) e gli abitanti.

Questo processo di continuo riadattamento e superamento dei limiti evidenziatisi nel tempo è avvenuto su due piani paralleli: quello della revisione quotidiana delle strumenti e delle prassi di intervento sul territorio (a partire dalla riformulazione annuale delle regole che presiedono al processo del Bilancio Partecipativo) e quello del loro 'riorientamento strategico'.

Quest'ultimo ha comportato la messa in opera di veri e propri 'processi costituenti' di riflessione sulle modalità di funzionamento del governo urbano e sui contenuti da dare alle strategie dello sviluppo. Così sono nati i percorsi 
614 conclusisi con i primi 3 Congressi della Città, e così è stato concepito il $\mathrm{IV}^{\circ}$, sul tema della 'Gestione Democratica dello Stato', che si concluderà nel giugno 2003 dopo quasi un anno di seminari, laboratori e assemblee sparsi per la città. Come abbiamo già accennato, in vista di queste occasioni, l'Amministrazione Popolare e il Consiglio Comunale hanno spesso sospeso l'iter di alcune autonome elaborazioni su temi portanti per la vita cittadina, rimettendo le proposte al giudizio di spazi pubblici di dibattito e co-elaborazione delle regole di funzionamento del Comune: è il caso, quest'anno, di tre temi fondamentali come la riforma amministrativa della macchina comunale, la formalizzazione dei processi di pianificazione territoriale condivisa e il decentramento. Tutti e tre questi temi, che saranno dunque affrontati collegialmente negli spazi aperti del $\mathrm{IV}^{\circ}$ Congresso della Città, hanno mostrato in questi ultimi anni la necessità di un lavoro attento di riflessione e reindirizzo. In particolare, il tema del 'decentramento': la creazione progressiva degli 8 Centri Amministrativi Regionali (fortemente sollecitati dai movimenti popolari come occasione di "decentralizzare $i$ servizi per migliorane l'efficacia nelle Regioni e sviluppare un controllo delle comunità sul low funzionamento", cfr. Matos, apud Solidariedade, 2003) non ha sortito, infatti, nessuno degli effetti sperati. E non solo per una mancanza di investimento (da parte del Comune) in strutture e in decentramento decisionale, ma anche perché i vari meccanismi di dialogo diretto tra cittadini e vertici istituzionali hanno naturalmente rafforzato agli occhi dei primi il ruolo del 'centro'. Cosicché, oggi, è necessario un profondo ripensamento del ruolo dei CAR, i cui coordinatori tendono ad essere percepiti appena come dei "bracci politici del governo nelle regioni, degli strumenti di controllo della popolazione, [...] pompieri della municipalità [che] domano i focolai d'incendio, permettono solo di calmare le acque quando la pressione aumenta" (ibidem).

Per quanto riguarda, invece, le modalità con cui vengono affrontati nel quotidiano i limiti che abbiamo rilevato nell'azione istituzionale sul territorio, la proposta che molti tecnici oggi avanzano e iniziano ad attuare è quella di affiancare all'O.P. forme di pre-pianificazione o pre-progettazione - almeno in alcune aree più carenti o 'strategiche' della città - in modo da evitare che gli interventi siano scelti dai cittadini e progettati come 'isole' fuori da piani generali, ma favorendo invece una discussione più stretta e decantata fra abitanti e tecnici. Queste forme di progettazione preventiva non rappresenterebbero uno spreco, ma - anzi un'ottimizzazione di energie capace di suggerire interventi e ipotesi da incrociare, e di offrire ai cittadini - cui peraltro resterebbe l'ultima parola sulle decisioni elementi di giudizio in più nel discutere e approvare le proprie priorità.

Parallelamente, viene portato avanti un lavoro di riflessione comune, attraverso eventi che toccano da vicino singole politiche come i Forum sulla Cultura, sulla Scuola o sull'Assistenza Sociale, ma anche le Conferenze Municipali sull'Ambiente o sulla Casa, dove la capacità critica e l'autoprogettualità dei cittadini e di tutti i dipendenti dei singoli assessorati e dipartimenti diviene elemento portante per mettere in campo (come abbiamo visto) ventagli di soluzioni innovative e differenziate per affrontare problemi e limiti che non si riusciva a superare con le strategie tradizionalmente utilizzate. Non va, poi, dimenticato che Porto Alegre sta attraversando un momento molto importante per un riequilibrio dei problemi manifestatisi e un consolidamento delle forme di democratizzazione ulteriore delle istituzioni e delle politiche locali: quello segnato dalla costruzione condivisa dei primi Piani di 
Azione Regionali per l'attuazione e il dettagliamento del Piano di Sviluppo Urbano e Ambientale (cap. 15), ma anche dal dibattito sulle tematiche internazionali portate dall'ospitalità offerta ai primi 3 Forum Sociali Mondiali, e dalla riflessione sulla sconfitta subita dal Fronte Popolare nell'ottobre 2002 nelle elezioni Statali del Rio Grande do Sul, che hanno dato risultati non imprevedibili, ma certo in controtendenza rispetto al resto del Paese.

In una tale situazione, vale la pena di accennare brevemente - per punti - ad alcune linee di tendenza che stanno gradualmente mutando il quadro di alcune politiche 'nodali' per l'Amministrazione di Porto Alegre, ed appaiono come 'sintomi' di un cammino in atto da guardare con rinnovato interesse.

\subsubsection{Le trasformazioni nella scuola}

Quando l'Amministrazione Popolare entrò in carica nel 1989, vi erano 29 scuole municipali (con 24.232 alunni), mentre già alla fine della seconda gestione (nel 1996) ve ne erano 86 (con 42.309 alunni) e oggi sono salite a 90 (con 55.746 alunni $^{14}$ ).

Come abbiamo visto, nello Statuto Municipale sono stati inseriti dei vincoli minimi di spesa per il settore educativo (cfr. cap. 10), come impegno del Comune ad una politica di supplenza attiva nei confronti del progressivo disimpegno di altri livelli istituzionali ${ }^{15}$. Questo ha, ovviamente, garantito un'erogazione di fondi costante al settore a cui è corrisposto un importante impegno qualitativo al miglioramento delle strutture e alla riformulazione dell'impostazione del servizio offerto. Nel 1993 è stato avviato il progetto Scuola Cittadina, incentrato sulla gestione democratica e la qualità dell'insegnamento; attraverso di esso, la SMED ha innescato un processo di partecipazione diretta della cittadinanza (professori, alunni, genitori e impiegati) nell'assunzione di molte delle decisioni riguardanti il settore. Nel 1995 è stata realizzata la Costituente Scolastica, a cui hanno partecipato 4 gruppi tematici misti di ogni scuola: i risultati hanno determinato un'intera riorganizzazione del sistema (in Brasile decentrato) elaborata ai fini della permanenza dell'educando e del riscatto del senso di cittadinanza (Pozzobon, 1998). Il Congresso Costituente a cui - 1 anno e 1/2 dopo - hanno preso parte 500 delegati (eletti in una precedente e articolata fase dibattimentale) ha stabilito le nuove direttrici pedagogiche, centrate sulla non-esclusione e su 3 cicli formativi, divisi per età ma con eccezioni intese a rispettare i ritmi, i tempi e le esperienze differenti degli educandi, attraverso corsi intensivi e laboratori didattici-pedagogici individualizzati per gli alunni 'sfasati', in modo da reinserirli in tempi rapidi nella loro fascia di età. Già dal 1996, 8 scuole-pilota hanno cominciato a funzionare per cicli, e l'innovazione si è ampliata rapidamente (soprattutto alle aree più 'difficili'), dopo che la neonata scuola-modello Monte Cristo è riuscita a promuovere tutti gli alunni e ha azzerato l'abbandono scolastico. Quest'ultimo, tra il 1995 e il 1998, è così sceso dal 5,68\% allo 0,97\% nelle scuole municipali, mentre le promozioni sono salite dal $74 \%$ all' $89 \%$ (SMED, 2001).

$\mathrm{Su}$ queste basi si è estesa una rapida moltiplicazione di istanze democratiche puntuali interrelate con l'O.P. (le elezioni dei presidi, le Commissioni sul Decentramento dei fondi, i Consigli Scolastici misti che decidono dei progetti pedagogici delle varie scuole e dal '98 sono organi deliberativi e persone giuridiche indipendenti). Questa si è poi ampliata, supportando una fitta rete di asili gestiti dalle singole comunità, specie nelle favelas, le cui strutture la sera spesso si trasformano in sale da ballo, panifici e centri comunitari: il 
616 loro numero è passato dai 40 del 1993 ai 118 del 2000 (con 7.835 alunni che si sommano ai 4.849 degli asili comunali), ed essi ricevono fondi mensili per la manutenzione delle strutture, mentre la SMED forma i loro insegnanti ed impiegati, garantendo anche - su richiesta - assistenza pedagogica e contabile. Il Programma MOVA ha, poi, sviluppato in molte aree marginali corsi di formazione serali per giovani e adulti ${ }^{16}$ (SEJA), incentrati sul riscatto della piena cittadinanza. Anch'essi si articolano in cicli con regole di convivenza e frequenza stabilite collettivamente, e non è prevista la bocciatura, perché "se la scuola rispetta ciò che ognuno sa, non ci può essere bocciatura; anche perché ognuno ha un suo processo di apprendimento"17. L'attento esame delle bocciature registrate nelle scuole delle aree più marginali, ha portato la SMED ad innescare un processo di riformulazione del curriculum scolastico a seconda dei caratteri delle diverse scuole, e a creare un servizio di formazione permanente e di appoggio ai professori per rapportarsi con le situazioni di disagio.

Oggi il tema della formazione culturale e professionale sta diventando una nuova frontiera di riflessione e dibattito per i movimenti urbani. Già dal primo anno, l'O.P. a livello statale ha mostrato un interesse vivo e battagliero per giungere ad un coordinamento del lavoro tra livelli istituzionali diversi ed avvicinare sul territorio scuole superiori e corsi di formazione al lavoro; anche al fine di minimizzare l'interruzione degli studi da parte dei più bisognosi, spesso scoraggiati dalla centralizzazione dei 'servizi più rari' in ambito urbano.

Dal 1998, la Rete Scolastica Municipale ha un proprio processo di Bilancio Partecipativo, in cui genitori, alunni, professori e funzionari elaborano il Piano Annuale degli Investimenti ed un progetto di interesse per l'intera comunità cittadina; in parallelo si è attivato un processo di decentramento di fondi ai Consigli Scolastici, mentre presso l'Assessorato competente è attivo un Forum consultivo, a cui partecipano anche le università cittadine e della Regione Metropolitana, per ampliare il discorso oltre i confini comunali e la fase della scuola dell'obbligo. Dall'ottobre 2001 Porto Alegre ha ospitato due edizioni del Forum Mondiale della Scuola e dell'Università, dove proposte pedagogiche diverse sono entrate proficuamente a confronto, mettendo al centro il tema dell'auto-educazione popolare che da vari decenni vede il Brasile in una posizione di avanguardia a livello internazionale.

\subsubsection{La città dei bambini e l'educazione ambientale: luoghi di convergen- za per interventi coordinati}

Per due anni consecutivi (nel 1999 e nel 2000), Porto Alegre ha vinto il Premio Sindaco Bambino, un riconoscimento (a cui concorrevano 182 comuni brasiliani sugli 800 che hanno siglato la Carta del Progetto) che viene attribuito dalla 'Fondazione ABRINQ per i Diritti del Bambino', dall'Unicef e dalla Fondazione Ford a quelle municipalità "che aprono percorsi per offrire a bambini e giovani un nuovo livello di cittadinanza" attraverso "esperienze creative e innovatrici" ${ }^{18}$. Porto Alegre, del resto, è stata la prima capitale brasiliana a creare, nel 1991, il Consiglio dei Diritti del Fanciullo e dell'Adolescente (CMDCA), un organo deliberativo responsabile della formulazione e del coordinamento di politiche municipali per l'infanzia e la gioventù che oggi è composto da 21 membri: (7 rappresentanti del Governo Municipale e 14 della società civile). Ha poi creato 8 Consigli Tutelari che operano nelle diverse Regioni di Pianificazione della città e - nel 1999 - attraverso il logo 
"Ligada na Galera" (che ogni anno fa delle assemblee di rendicontazione pubblica) ha messo insieme 24 Progetti diversi di assistenza, educazione e appoggio medico e sportivo ai bambini: tra questi il Bilancio Partecipativo del settore "Scuola Cittadina" (a cui hanno partecipato nel 2000 oltre 12.000 ragazzi, genitori e docenti) e la realizzazione dell' "Agenda 21 Mirim" che coinvolge annualmente oltre 3000 bambini nella progettazione di azioni per la tutela e la valorizzazione dell'ambiente naturale, che - come già detto - a Porto Alegre rappresenta una componente preponderante del paesaggio urbano.

I progetti sono diventati 35 nel 2000: il più importante, tra i nuovi, è certamente il "Segnale Verde per le Elemosine" che si occupa di bambini di stra$\mathrm{da}$, offrendo anche sostegno economico alle famiglie bisognose con bambi$\mathrm{ni}$, in cambio di garanzie sulla frequenza scolastica.

Nel 2001 - in linea con uno dei tre assi portanti del programma politico della nuova giunta (lotta alla povertà assoluta) - la FASC ha triplicato i servizi di assistenza ai minori di strada, portandolo da 8 a 24 ore al giorno, e ha esteso il Programma di Reddito Minimo a 800 nuove famiglie con bambini e adolescenti a rischio. Nello stesso anno, Porto Alegre ha rinnovato l'adesione al Programma "Sindaco Bambino" per il periodo 2001-2004, ed è tra i 749 comuni (sui 1542 iscritti al programma: 48\%) ad aver realizzato la "Mappa cittadina del Bambino e dell'Adolescente 2001 e 2002".

Un aspetto interessante di questi progetti attenti all'infanzia è che essi rientrano in politiche di assessorati diversi, ma convergono verso un unico Programma che stimola organismi autonomi a cooperare nel progettare le diverse azioni. Inoltre, l'approccio scelto non pare voler ridurre i bambini a 'parametro' per la misurazione della qualità della vita, ma (a partire da una realtà estremamente frammentata e differenziata nella richiesta di opere e servizi) cerca di articolarne i punti di vista con quelli di un panorama complesso di altri soggetti. Ed attribuisce loro anche delle 'responsabilità' (come all'interno del Bilancio Partecipativo della Scuola) che contribuiscano ad una loro graduale maturazione e al formarsi di una coscienza di cittadinanza attiva. In particolar modo, negli ultimi 5 anni, i bambini (ed in particolare quelli che vivono nelle aree cittadine più povere) svolgono un ruolo fondamentale di "moltiplicatori sociali' all'interno dei Programmi di Educazione Ambientale, che ormai i diversi assessorati mettono in piedi - grazie alle loro equipe specializzate in formazione ambientale - sia nelle scuole della città che, sul campo, in ognuna delle aree dove il Comune intervenga con opere di costruzione (reinsediamento, regolarizzazione fondiaria, fognature, scoli pluviali, pavimentazioni ecc.).

Il DMAE ha attivato la sua equipe di educatori (3 sociologi e una pedagoga) nel 1997, utilizzando una voce del finanziamento PROSANEAR che risultava "incontrollabile e con costi gonfiati se affidata alle imprese" (Real, 1999i, apud Allegretti, 2000a); nel 1999 essa si è accresciuta, ed oggi è formata da un tecnico coordinatore, 5 sociologi e 6 stagisti di discipline diverse che collaborano strettamente con i 4 Agenti Comunitari del Dipartimento, ognuno responsabile delle relazioni con 4 regioni dell'O.P.. Per la sua opera di formazione, l'Equipe ha predisposto una serie di plastici smontabili usati nelle riunioni di formazione comunitaria (fig. 114) ${ }^{19}$ ed un teatrino dedicato alla comunicazione con le famiglie, soprattutto attraverso la mediazione dei bambini: attraverso la rappresentazione di una famiglia comune e la figura eroica di un cane saputello che insegna ai suoi padroni, vengono veicolate regole di comportamento per 
618 ottimizzare l'uso delle infrastrutture nelle aree regolarizzande, ma anche una maggiore comprensione globale del valore dell'ambiente e delle risorse naturali. Uno spazio particolare è dedicato al riciclaggio, di cui viene sottolineato il significativo legame con i progetti della SMIC per la creazione di occupazione e reddito (quindi con una possibilità di utilità individuale, oltre che comunitaria); in tale ottica, viene sovente valorizzato il ruolo dei 'papeleiros', non solo in senso economico, ma anche come 'produttori di coscienza ecologi$c a^{\prime}$ (E. Menegat, 1999i, ibidem).

Attraverso i seminari di formazione nelle 'vilas' (legati ad eventi traumatici o a conquiste della comunità nell'O.P., per aumentame la risonanza e l'impatto sulla comunità) si sono ottenute alcune importanti conquiste. Se "prima molte comunità informali chiedevano fogne ma pensavano allo smaltimento delle piogge, che è prerogativa del DEP" oggi vi è stata una crescita di comprensione su diverse questioni tecniche. Addirittura, alcune comunità hanno cercato autonomamente di "supplire allo scoordinamento di alcune norme tecniche dei vari Dipartimenti” (Real, 1999i, ibidem). Ad esempio, il DEP proibisce di disporre grate protettive davanti alle bocchette di scolo pluviale, aumentando il numero di intasamenti dovuti alla caduta di oggetti. Molte comunità di 'vilas' in via di regolarizzazione, cogliendo lo spirito della formazione ambientale ricevuta, hanno autonomamente deciso di non rispettare questa regola; e hanno disposto da sole piccole grate da cui rimuovere i materiali eventualmente depositatisi davanti, col risultato di ottenere un calo delle chiamate per manutenzione al DEP, che - a quanto pare - "non ha però ancora tratto le conseguenze da queste esperienze" (Casa Nova, apud Allegretti 2000a).

La valutazione dei risultati del Programma di Educazione Ambientale è oramai un lavoro che il DMAE non compie più da solo, ma articolandosi con $\mathrm{i}$ Centri di Salute della Famiglia locali, con il DMLU e con il DEP. Nel 1999, la Relazione Finale del "Progetto di Partecipazione Comunitaria e Educazione Sanitaria e Ambientale in Comunità beneficiate da opere del DMAE", - basandosi su una ricerca approfondita in 14 'vilas' di Porto Alegre appena urbanizzate - ha mostrato l'alta incidenza del lavoro di formazione degli abitanti sulla diminuzione degli interventi di manutenzione richiesti al $\mathrm{Nu}-$ cleo di Conservazione delle Reti, ossia sull'ottimizzazione dell'utilizzo delle forze dell'organismo pubblico. Essa ha messo in moto un orientamento nuovo a considerare i vantaggi dell'educazione ambientale nella valutazione dei costi e benefici dei progetti, favorendo una ripresa - a distanza di tempo - degli esperimenti portati avanti con successo nel '95 durante la 'Gestione ampliata' del trasferimento di Vila Cai-Cai, dove il lavoro di formazione ambientale aveva dato risultati notevoli, facendo anche leva sulla riscoperta di tradizioni dei luoghi di origine di molti vileiros.

I seminari formativi sul funzionamento e la costruzione di reti fognarie e idriche sono stati sovente anche l'occasione per stringere rapporti di partenariato del Comune con le comunità locali. Ad esempio, dal 1997 il DMAE trasmette nozioni tecniche per formare 'Commissioni di Accompagnamento dei Lavori' composte da abitanti che eseguano un controllo vigile sull'opera delle imprese private che hanno in appalto dal Comune le opere, costituendosi come "un'ulteriore forma di sviluppo del senso di cittadinanza" ed un prezioso aiuto per il governo locale in un ambito di relazioni sovente 'spinoso'.

Similmente, la SMAM ha puntato a svolgere alcune sue azioni con la colla- 
borazione e la responsabilizzazione degli abitanti di diverse comunità locali nei confronti del loro ambiente, ovviando - nel contempo - alla mancanza di energie e personale di vigilanza: così il Programma di Conservazione dei Morros è, oggi, affidato ad un partenariato con le comunità di alcune delle favelas più antiche ubicate nelle vicinanze dei singoli colli interessati.

La gente osserva, vigila e telefona per avvertirci di occupazioni incipienti o di altre forme di pericolo. Sfruttiamo per questo un meccanismo che abbiamo verificato efficace; gli invasori con 15-20 anni alle spalle non lasciano che nessun altro invada. Lo scarto temporale è come se li facesse sentire cittadini formali. Molti hanno avuto tempo di realizzare alle proprie spalle un apprendistato circa l'utilità della natura. Vedono i nuovi occupanti come persone dequalificate, ed usano termini come 'vagabondo' o 'marginale' che chiariscono un particolare ethos delle relazioni fra occupanti di ieri e di oggi. In nome di un obiettivo comune abbiamo fatto molti accordi del genere. Specie nella Lomba, nel Morro da Policia, nel Partenon, dove il movimento popolare ha acquisito forti componenti ambientaliste, o come nella Restinga durante la fase di Progettazione del Parco Industriale quando si è avuta una forte battaglia popolare per prevenire l'insediamento eventuale di imprese inquinanti (Eliane Menegat, 1999i, apud Allegretti 2000a).

Oggi, programmi specifici di Educazione Ambientale stanno nascendo, o talora - risorgendo, in diversi altri organismi municipali. Il DEMHAB, nel 2001 ha realizzato con costanza momenti di formazione in 5 nuovi condomini popolari (a beneficio di 600 residenti re-insediati da vilas diverse), e in alcuni parcellamenti regolarizzandi (a beneficio di 4000 persone), accompagnando il lavoro con corsi nelle scuole e formazione di 'agenti moltiplicatori'.

L'equipe di Educazione Ambientale della SMAM è un nucleo operativo piccolo (8 persone incluso il personale della biblioteca ecologica nel Parco Moinhos de Vento), ma si somma ad altre equipe con sede presso la 'vigilanza ambientale' dell'Assessorato alla Salute, il DMLU e il DEP, dove la filosofia dei corsi d'acqua tombati da un paio d'anni ha ceduto il posto a quella della permanenza all'aria aperta, accompagnata da corsi di educazione ambientale. Fino al 1998 l'equipe della SMAM coordinava gli altri assessorati intorno al Programma Guaiba Vive dipendente dal Gabinetto del Sindaco; poi questo è passato allo Stato nell'ambito del Programma Pro-Guaiba e l'Equipe ambientale ha preso a svolgere un ruolo che sta contribuendo a riorientare alcuni indirizzi della SMAM, che le avevano spesso procurato l'ostilità degli altri organismi pubblici, da cui era considerata sempre e solo "l'assessorato 'contro', quello dei 'no"' (ibidem).

Alcuni approcci paiono addirittura innovativi, specie quelli che stanno maturando all'interno dei lavori sul campo in varie favelas in via di rimozione e reinsediamento nell'ambito dei programmi di disinquinamento del Lago Guaiba e dei suoi immissari. Ad esempio, nella recente rimozione di Vila da Fonte, l'Equipe della SMAM ha condotto un lavoro articolato, incentrato non solo sul concreto obiettivo dell'uso più razionale delle opportunità offerte dal nuovo insediamento, ma su una coscientizzazione a più vasto raggio della nozione di ambiente, anche come luogo di vita costruito dai suoi abitanti nel quotidiano. Di questo lavoro ha fatto parte anche una valorizzazione della creatività dei manufatti autocostruiti e per quasi 15 anni abitati dai vileiros, dei loro materiali e dei loro colori, per cercare di estrapolare insieme alla popolazione "quali elementi di appropriazione dello spazio si 
potranno traslare nelle nuove abitazioni standardizzate per migliorarle $e$ farle sentire più 'proprie' senza materialmente trasportare le baracche dentro i nuovi alloggi, come in molti casi è successo" (Eliana Menegat, 1999i, apud Allegretti 2000a). A questo scopo, è stata realizzata una documentazione fotografica sulla scorta delle linee estetiche indicate da Achutti (1996) ed un'altra parallela raccolta - come già era avvenuto in altre 'vilas' - "dando le macchine fotografiche agli stessi vileiros perché scelgano le loro visuali sulle case che hanno costruito e modificato nel tempo" (id.).

Va rilevato, infine, che l'ambito dell'educazione ambientale (seppur con declinazioni diverse) sta attualmente mostrandosi come un vettore possibile di coordinamento fra l'opera di diversi organismi municipali che agiscono sul territorio della città informale. Di recente, sono state affinate le misure per coordinare meglio le richieste dell'O.P. relative all'infrastrutturazione di 'vilas', per evitare di operare 'a goccia a goccia', razionalizzando - invece - gli interventi dei diversi organismi e motivando questa necessità alla popolazione in modo chiaro con i vantaggi concreti (economici e di redistribuzione dei lavori) che una simile ottimizzazione può portare anche alle comunità locali.

Oggi, nelle regolarizzazioni fondiarie, il nostro orientamento (condiviso dagli altri dipartimenti, sempre se le condizioni finanziarie lo permettono) è diventato, così, quello di non costruire mai le reti fognarie da sole, ma di unirle sempre a moduli sanitari, per ottimizzare a lungo termine gli interventi. Spesso, sennò, finisce per collegarvisi solo il 30-40\% dei vileiros, e non solo si hanno costi alti e benefici ridotti, ma si rischia di portare lo sporco in casa delle persone attraverso fognature che essi usano impropriamente. Così si supera anche il problema che per portare la fogna nelle case ci vuole il beneplacito degli abitanti, e non sempre lo danno se in cambio non gli offri benefici visibili come un modulo sanitario è (Real, 1999i, apud Allegretti 2000a).

Gran parte del merito di questo nuovo impulso al coordinamento è riconosciuto proprio alle proficue relazioni orizzontali createsi tra le Equipe Ambientali e Comunitarie dei diversi organismi, e alla capacità del loro lavoro di incidere concretamente sul risparmio stimolando "alla razionalizzazione $e$ all'ottimizzazione degli oneri di urbanizzazione" (Pestana, 1999i, apud Allegretti 2000a). In tale ottica, il fatto che ogni dipartimento abbia una sua equipe non costituisce una diseconomia dal punto di vista della qualità che induce negli interventi; anzi, parrebbe addirittura un vantaggio, tanto più data l'esistenza - dal 1993 - di un Forum di coordinamento delle varie squadre di educatori.

Insegniamo gli uni agli altri, partendo da punti di vista ed esperienze diverse. Così siamo riusciti a creare un coordinamento sul lavoro che rompe con il particolarismo feudale della lotta fra Dipartimenti. Direi che le equipe di Educazione Ambientale sono isole felici, e potrebbero essere anche un elemento-guida di un rinnovamento. Non c'è fra noi la paura di entrare nel terreno altrui. Semmai c'è il desiderio di imparare insieme cose che da soli avremmo più difficoltà ad apprendere. Del resto, nei lavori 'educativi' non possono esserci frontiere di settore. La gente chiede e noi dobbiamo rispondere. La chiamiamo 'educazione ambientale informale' perché non passa attraverso le istituzioni formali di insegnamento, ma la vita vissuta. Certo, parallelamente abbiamo un lavoro con le scuole, ma l'arricchimento ci viene dagli interventi sul campo, specie nella città informale. Qui si deve fare un lavoro di 'ricerca dell'attenzione' del pubblico. A Vila das Fontes stiamo trovando questa difficoltà. Cercavamo di fare un lavoro integrato col DEMHAB parlando dell' Abbazia del Diluvio, il corso d'acqua da disinquinare che motiva lo spostamento della favela. Ci siamo accorti che la gente è preoccupata d'altro, delle case standardizzate e piccole, dell'insicurezza del trasloco. E ci siamo resi conto che discute- 
re sul luogo da cui andranno via non ha senso; è bene discutere su dove andranno. Questa vicenda ci ha aiutato a ridirezionare la nostra idea dell'Educazione Ambientale, come qualcosa che deve spiegare criticamente cosa sta succedendo, e aiutare a rendere il più naturale possibile ciò che accadrà. Così, spesso, ora facciamo gite sui colli con chi vive nei vicoli chiusi peggiori, per abituarlo lentamente a capire nuove dimensioni, a cogliere la città nella sua molteplicità (Eliane Menegat, 1999i, apud Allegretti 2000a).

Oggi, l'attenzione all'Educazione Ambientale ha teso a promuovere la creazione di strumenti significativi come l'Atlante Ambientale di Porto Alegre, nato dal desiderio di "coniugare politica e vita vissuta con il sapere scientifico" $(\text { ibidem })^{20}$. Ma - soprattutto - ha contribuito ad una moltiplicazione dell'uso attento degli strumenti di 'valutazione di impatto' di alcune delle opere realizzate in città dall'Amministrazione o dai privati, anche dando un'interpretazione 'ampia' alle previsioni della Risoluzione CONAMA-IBAMA 001/1986 sull'obbligatorietà degli studi e delle relazioni di impatto ambientale (RIMA) ${ }^{21}$.

Spesso - al di là delle questioni ambientali - tali studi hanno manifestato un crescente interesse per l'impatto socio-economico delle realizzazioni. In particolare, dal 1999, ha preso avvio una sistematica opera di valutazione riguardante i nuovi grandi stabilimenti commerciali (cfr. $§ 13.4 .2$ ), che è alla base anche di una importante disposizione municipale approvata il 18 gennaio 2001 che mirando a tutelare il piccolo e medio commercio - vieta nuove costruzioni di ipermercati e supermercati con superfici utili superiori a $1500 \mathrm{mq}$ su tutto il territorio cittadino, ad eccezione dei Corridoi di Produzione identificati dal nuovo Piano di Sviluppo Urbano e Ambientale (Legge Complementare 462/2001).

\subsubsection{Lo stimolo dei 'finanziamenti virtuosi': l'accesso di Porto Alegre e Vila Tecnologica}

Il caso Vila da Fonte, citato nel precedente paragrafo, è un esempio interessante di una nuova 'congiuntura' positiva che sta contribuendo ad un progressivo arricchimento delle linee di azione del Comune di Porto Alegre per quanto attiene agli interventi nell'ambito della città informale. Si tratta di un finanziamento Fonplata per la pulizia del fiume Diluvio, che ha permesso il re-insediamento dell'intera favela - 125 famiglie che finora scaricavano nel fiume le loro acque nere - nel Loteamento Santa Paula nella Regione Lomba do Pinheiro. A prescindere dal fatto che indica una "via alternativa e indiretta" (Torino, 1999i, apud Allegretti 2000a) per finanziamenti nel settore dell'alloggio - in un momento in cui vi è una grande difficoltà di reperirne nell'ambito delle Politiche della Casa -, esso costituisce un caso interessante per il tipo di vincoli che introduce nell'azione degli organismi comunali; chiede, infatti, precise garanzie per quanto attiene i programmi di educazione ambientale dei cittadini interessati, e forza ad un coordinamento diretto fra dipartimenti differenti in direzione di un 'intervento integrato'. Rende quindi necessario dare corpo a linee di azione che già da tempo a Porto Alegre stavano facendosi largo, anche se più come programmi puntuali che come metodologia codificata di lavoro.

In una direzione analoga di 'induzione esterna' al superamento di alcuni limiti e barriere che caratterizzano certi aspetti dell'operato dell'Amministrazione Popolare - con particolare attinenza all'intervento nell'ambito della città informale - si collocano oggi altri programmi a finanziamento speciale che assumono la forma di 'finanziamenti virtuosi' (Pont, apud Allegretti 
622 2000b). Del resto, il ricorso ad interventi 'esterni' del genere diventa sempre più indispensabile; dalla risoluzione 2521/98 del Consiglio Monetario Nazionale $^{22}$, infatti, le Istituzioni Finanziarie Pubbliche non possono più prestare denaro a fondo perduto ad enti pubblici, cosa che ha determinato la cancellazione dei fondi Pró-Moradia e Pró-Saneamento del '98 e del '99. Solo attraverso queste nuove fonti, il DEMHAB riuscirà - nel 2003 - a far fronte all'impegno costituito dalla rielezione del tema Politica della Casa a prima priorità cittadina, passando dall'investimento di 19 milioni di $\mathrm{R} \$$ compiuto nel 2002 ad uno di 49 milioni per l'esercizio successivo (dati: DEMHAB, dicembre 2002). Tra i programmi attuati o in attuazione grazie a questi 'finanziamenti virtuosi' vale la pena sottolinearne soprattutto due:

\section{A) Vila Tecnologica}

Riguarda un concorso indetto dal DEMHAB (sul modello di quanto già attuato a Curitiba) nell'ambito del Programma Speciale di Incentivo alle Nuove Tecnologie per tentare di stimolare le imprese locali di Porto Alegre a proporre innovazioni nel campo dell'abitazione sociale a basso costo, non legandole tanto ad un rinnovamento dei modelli abitativi ${ }^{23}$, bensì con attenzione alle tecnologie di realizzazione. Un Consiglio formato da vari enti pubblici e della società civile ${ }^{24}$ il 30 aprile del 1999 ha pre-selezionato 5 soluzioni tecnico-costruttive diverse per abitazioni popolari, proposte già dal 1997 da varie ditte concorrenti. I prototipi sono stati realizzati su un'area-campionario che è poi entrata a far parte del nuovo quartiere, impiantato su un progetto urbanistico elaborato - con un anomalo impianto ellissoidale - da alcuni docenti della Facoltà di Architettura dell'Università Luterana, ${ }^{25}$ e poi modificato per evitare che - al suo interno - una vasta area vuota per attrezzature comuni (ancora non finanziate) rischiasse di divenite terreno di occupazione irregolare. Nel 2001 sono state ultimate le 101 abitazioni realizzate sul modello dei prototipi, e nel maggio 2002 si è conclusa la valutazione attuata dalla CIENTEC (con la collaborazione di dipartimenti universitari come il NORIE, che mancavano di strumenti per realizzarla in proprio). La novità principali di questa operazione-pilota sono di vario tipo: soprattutto di ordine metodologico, visto che i prototipi realizzati non sono stati valutati come particolarmente innovativi (Cabistani, 2002i). Innanzitutto Vila Tecnologica ha rappresentato il primo vero tentativo del Comune di Porto Alegre (se si escludono alcune operazioni interrelate con 'reassentamento' di famiglie, che prevedevano però una completa delega alle imprese sulla costruzione dei nuovi insediamenti) di coinvolgere le categorie professionali private in un progetto di Politica Abitativa già prima della fase di licitazione delle opere. In secondo luogo, è stato un progetto che ha coordinato il lavoro - su piani e in tappe diverse - di differenti entità della Società civile, comprese 3 diverse università cittadine ${ }^{26}$ accanto a vari organismi comunali. In terzo luogo, ha previsto un'interessante fase di 'valutazione dei risultati' inclusa nel processo costruttivo, che riguarderà 10 delle 101 famiglie dell'insediamento ( 2 per ogni tecnologia e concentrate in un'area con divieto di ampliarsi) ${ }^{27}$ per un periodo di due anni, anche se solo ai fini della redazione di una 'certificazione di tecnologia'. In quarto luogo, la scusa del concorso a base tecnologica - strumento mai usato prima dal DEMHAB - è servita a sorpassare alcuni divieti di finanziamenti tradizionali: ad esempio, la Caixa Economica Federal nel Rio Grande do Sul non finanzia costruzioni in cemento, mentre a Vila Tecnologica una delle tecnologie selezionate è in blocchetti di cemento $^{28}$. Infine, questo progetto-pilota appare innovativo perché per la prima 
volta ripensa concretamente un'intera zona della città intomo all'Avenida Assis Brasil, collegandosi con altri progetti puntuali nei dintorni. Tra questi ve ne è soprattutto interessante da sottolineare: il Progetto del Loteamento Pampa II, una AEIS di tipo 3 (area disoccupata) da costruirsi con vecchi fondi PróMoradia '98, destinata a 243 famiglie da trasferire dalla vicina area Humaità/ Navegantes ${ }^{29}$. Oggi è stata ultimata in un'area contigua a Vila Tecnologica accanto all'originario Loteamento Pampa I, una serie di vecchi casermoni popolari tipici dell'epoca del SFH ormai in disfacimento e oggetto di un intervento di recupero. Proprio in relazione a questi insediamento, la Vila Tecnologica si è dimostrata un caso interessante, capace di portare un'ulteriore ventata di novità su un altro fronte, oltre a quelli finora evidenziati: quello di una più articolata riflessione sugli aspetti urbanistici.

Il progetto d'insieme della Vila Tecnologica - criticato da più parti - non viene dal DEMHAB, ma dall'Università Luterana, la ULBRA. Ed ha un'urbanistica variata, con disposizione ellissoidale degli alloggi intorno a un vuoto centrale. Quando sono stata incaricata di progettare la parte urbanistica del Loteamento Pampa II, quel disegno anomalo mi ha dato l'occasione di capire che potevo osare ciò che finora non mi era riuscito di far passare. Ovvero la ricerca di forme di disposizione urbanistica dell'intorno più vicine ai tradizionali modi di concepirla delle favelas, con le loro strade gerarchicamente ordinate e le curve per superare i pendii. Ho capito che la Vila Tecnologica poteva darmi un aiuto per inserirmi tra le maglie della burocrazia che domina il sistema delle approvazioni, e fare qualcosa che potesse meglio accogliere i vileiros che qui saranno trasferiti. Così [...] mi sono buttata (Carpenedo, 1999i, apud Allegretti 2000a).

Per la prima volta in un 'reassentamento' del DEMHAB di Porto Alegre le strade hanno perso la classica maglia a scacchiera ippodamea; tutto converge con linee sinuose verso la scuola-cuore del quartiere, a cui è stato dato un valore simbolico, prendendo spunto anche dall'autorganizzazione data dagli abitanti nell'occupazione di Vila Malvina, una delle aree occupate costruite secondo un ideale comunitario piuttosto marcato.

L'idea era di distribuire più piazzette integrate con la scuola sui vari lati, ma la SMAM ha boccia to l'idea per le complicazioni manutentive. Veramente io avevo pensa to all'appropriazione e alla cura da parte degli abitanti, ma forse ho peccato di romanticismo. Ho così do vuto sopprimere le due piazzette verdi che legavano la Vila Tecnologica a questa. [...] Oggi, dopo 10 anni di lavoro sull'informale, stanno nascendo i primi progetti innovativi anche da un punto di vista del disegno urbano, ma ci scontriamo con un clima ancora non propizio, fatto di vecchie concezioni urbanistiche restrittive [...] Qui nel DEMHAB avverto molta resistenza a queste forme curve con visuali sfuggenti. È come se ci sentissero dentro una colpa, la mancanza di una possibilità di controllo dei futuri abitanti. Io credo tuttavia che questo resti il modello migliore possibile che può anche evitare la necessità di puxadinhos fatti solo per differenziare le abitazioni. E comunque può compensare la povertà tipologica delle abitazioni. Io spesso sono costretta a veder usate le stesse case-modello in parti diversissime di città. Cerco di riorganizzarle spazialmente secondo schemi diversi, ma non possono essere infiniti. E finché sarò la sola a lavorare qui dentro sull'urbanistica dei 'reassentamento' mi imporrò per portare avanti questa breccia che mi sembra si sia aperta (Carpenedo, 1999i, apud Allegretti 2000a).

Il Loteamento PAMPA è un caso raro di AEIS applicata ad un parcellamento e non ad una Vila, ma dipende dalla sua storia di area occupata e disoccupata. Vi abiteranno 275 famiglie $(243+$ le prime 32 re-insediate in una prima 
624 fase) i cui lotti (di 4x16 e non 5x20 come al solito, con case-base di 32,25 $\mathrm{mq}$ ampliabili in orizzontale e verticale) occuperanno $62,75 \%$ dello spazio; il resto va a scuole, piazze e parcheggi, con accorgimenti per minimizzare i rischi di nuove occupazioni. L'idea delle piazzette piccole di facile appropriazione da parte degli abitanti (non approvate) voleva essere uno stimolo ad una collaborazione degli abitanti nel monitoragio dell'area.

L'esperimento dell'adiacente Vila Tecnologica è stato portato avanti: nel 2001 la CIENTEC ha realizzato un prototipo del tipo SIPECAL in materiale riciclato (blocchi laterizi prodotti con le ceneri di residui dell'industria petrolchimica) secondo un vecchio progetto a lungo accarezzato dal DEMHAB in seguito ad un finanziamento europeo nel settore dell'energia - anni fa ventilato e poi ritirato per la sperimentazione di materiali innovativi prodotti con scarto produttivi. La II $^{\circ}$ Tappa di Vila Tecnologica prevede ora la realizzazione di 61 unità del nuovo tipo sperimentato, che si andranno ad inserire nel Progetto Integrato dell'Entrata della Città (PIEC), che altrove prevede, però, l'uso di materiali diversi.

B) Progetto Integrato dell'Entrata della Città (PIEC)

La riprogettazione di una grossa regione nord-occidentale della città ha preso le mosse da due riflessioni: la constatazione dell'addensamento di sacche di miseria lungo gli assi stradali principali che collegano Porto Alegre all'area metropolitana (con popolazioni poco attive nell'OP per la loro marginalità estrema) e la necessità di ampliamento dell'aeroporto Salgado Filho.

Il primo risultato concreto di questa ipotesi di lavoro è stato l'aver favorito un raro intervento di notevoli dimensioni concordato fra Comune e Stato, facilitato dal nuovo Governo del Fronte Popolare (che ha governato tra il 1998 e il 2002). Dapprima ci si è concentrati nel coordinare le azioni su due tappe: l'apertura del Viale Severo Dullius (che ha toccato 125 famiglie accampate sull'area dove era previsto il duplicamento, di competenza del Comune) e la riallocazione di circa 2000 famiglie delle favelas chiamate Vila Dique e Vila Nazaré, il cui 'reassentamento' è divenuto impegno della neonata Secretaria Estadual de Habitação (che ha mosso i primi passi nel maggio 1999), e di Vila Floresta, che sta venendo reinsediate altrove ad opera della INFRAERO, la società che gestisce l'aeroporto ${ }^{30}$. La collaborazione si è poi estesa al concepimento di altri progetti dove lo Stato ha in genere garantito l'acquisizione o la cessione delle aree, preferendo lasciare al DEMHAB - che ha un'equipe maggiore - la progettazione. In particolare, si è estesa al Programma Integrato dell'Entrata della Città (PIEC), il più grande ed ambizioso programma di recupero e riprogettazione urbana dell'Amministrazione Popolare, che tocca 25 comunità di baracche (SESI, Tio Zeca Areia, ecc.) che si trovano in aree di proprietà dello Stato, il quale parteciperà logisticamente al progetto ma senza offrire contributi economici diretti.

Il PIEC prevede la riqualificazione di una grande parte del quartiere Humaitá, articolandosi su 5 assi di azione: 1) il consolidamento della situazione abitativa di circa 800 famiglie, e il reinsediamento di 3061 famiglie che abitano in area di rischio e comunque in situazione di estremo disagio; 2) il riordino della viabilità lungo l'Avenida Castelo Branco e la superstrada BR-290 in direzione Aeroporto; 3) la riqualificazione urbana e paesaggistica dell'accesso da Nord alla città in modo da integrarlo all'ambiente naturale e allo scenario urbano dell'intorno; 4) l'approntamento di programmi centrati sulla generazione di nuovi posti di lavoro per famiglie che in media non raggiungono i 3 Salari Minimi di reddito; 5) lo sviluppo e la qualificazione della partecipazione comunitaria in 
un'area finora poco integrata ai processi di decisione democratica e bisognosa del supporto di programmi di educazione ambientale ed assistenza sociale per poter acquisire un livello minimo di autoprogettualità.

Il Programma ha una durata prevista di 5 anni ed un costo di 143 milioni di R\$ (55 milioni di US\$) finanziati nelle diverse tappe da organismi diversi, tra cui il Fonplata e il BID (attraverso il programma Habitar Brasil), e con una contropartita molto impegnativa del Comune di Porto Alegre: 50\% (27,5 milioni di US\$). Riguarda le Regioni 1 e 2 del Bilancio Partecipativo, ed è previsto che intervenga a beneficio di circa 14.000 persone, in un'area dove 16.300 abitano in baraccopoli su un totale di circa 48.500 abitanti (34\% secondo i dati DEMHAB, luglio 2002). La partenza è avvenuta nel 2002, con una serie di programmi di Educazione Ambientale per le famiglie interessate da 'reassentamento' e vedrà la realizzazione delle prime opere fisiche tra maggio e luglio del 2003: 413 nuovi alloggi ${ }^{31}$ a beneficio delle famiglie oggi residenti nell'area del prolungamento da tempo previsto per l'asse urbano Viale Voluntarios da Patria ${ }^{32}$. L'operazione di riordino dell'accesso cittadino - secondo gli studi preliminari fatti dal Comune di Porto Alegre - proseguirà poi in 3 tappe, di cui il BID finanzierà a fondo perduto la prima, corrispondente al 'reassentamento' di 789 famiglie. La necessità di garantire una cospicua contropartita municipale ha costretto il DEMHAB a lavorare sul medio termine (prassi quasi sconosciuta per il Dipartimento) per tentare di elaborare il complesso programma da presentare ai diversi finanziatori esterni. In secondo luogo ha convinto il Comune alla creazione di un nucleo di discussione integrato interassessorati con coordinamento a rotazione. Infine, ha stimolato i partecipanti di questo ad immaginare un finanziamento innovativo a tappe per un progetto integrato da richiedere a più istituzioni internazionali della cui fiducia Porto Alegre - come Comune ben organizzato e 'buon pagatore' (Genro, 1999i, apud Allegretti 2000b) - da tempo gode.

Il BID ha chiesto un Piano Strategico con definizione di priorità; questo modo di procedere è contrario alla prassi sviluppata da oltre 10 anni a Porto Alegre. Perciò stiamo chiedendo di poter legare l'intervento ai Piani Regionali che lavorano con le aree di rischio, e soprattutto al Bilancio Partecipativo, che è un processo ormai ben strutturato. Fare una mappa 'degli insediamenti subnormali' (che peraltro già abbiamo) ed identificarli numericamente per procedere ad una scala di priorità come vuole il BID sarebbe una sconfitta, per noi. E se ci chiedono che tipologie progettuali vogliamo usare per le nuove abitazioni, risponderemo: 'Vogliamo fare uno studio delle diverse tipologie dell'universo delle favelas'. Pertanto la situazione attuale è una sfida per capire di quanto credito godiamo per poter imporre un nostro percorso, peraltro rodato, ad un ente finanziatore che comunque ha mostrato sempre grande interesse per il nostro modo di amministrare la città. Credo che sia un'occasione fondamentale per ribaltare le vecchie forme di finanziamento e di progettazione degli alloggi dove la comunità arriva sempre dopo, nelle fasi successive alla decisione che l'opera andrà fatta (Menegassi, 1999i, apud Alle gretti 2000a).

Una simile procedura si è scontrata con vari ordini di difficoltà. Il primo è il fatto che il Programma di Finanziamento riguarda anche altre città inserite dentro una linea ministeriale comune, ed era difficile pensare che il BID potesse accettare un cambiamento delle carte in tavola solo per un richiedente. Il secondo è stato il timore che l'Amministrazione Popolare ha sempre mostrato nel discutere con la popolazione di progetti ancora non precisamente finanziati, a causa delle aspettative (spesso vane) che può generare l'informare la popolazione di opportunità 
626 ancora incerte. In tal senso, è venuta incontro all'idea del Comune di Porto Alegre (intenzionato a discutere con la popolazione del finanziamento e del progetto senza però creare aspettative puntuali localizzate) la pluralità delle fonti di finanziamento a cui il progetto dovrà attingere nel suo complesso. Il Fondo Finanziario per lo Sviluppo del Bacino del Prata (Fonplata) ha già accettato, infatti, in passato una maggiore flessibilità nel passaggio tra progetti di massima e progetti di dettaglio, che garantisce un'apertura all'accompagnamento della progettazione da parte dei cittadini: e sarà attraverso i suoi fondi che verranno finanziate oltre 2000 delle unità abitative.

Metodologicamente, l'obiettivo di questa azione di sondaggio fatta dal Comune di Porto Alegre - seppur tra mille cautele - è di grande interesse, nella misura in cui ha tentato di proporre a delle Istituzioni Internazionali 'dal basso' (l'ambito municipale) l'accettazione di un proprio modo di gestire la città senza dover accettare per forza (solo in nome dell'appoggio finanziario ricevuto) procedure eterodirette di governo del territorio. In questo sondaggio, il Comune ha fatto leva sull'interesse ed il rispetto mostrato in passato dal BID per l'esperienza di Porto Alegre nella gestione del Bilancio Pubblico, che la stessa Banca nel 1996 ha valutato come inseribile in futuro fra le pre-condizioni per ottenere finanziamenti diretti ad organismi pubblici periferici ${ }^{33}$.

La strategia messa in atto dal Comune ha fatto anche leva su una progressiva flessibilizzazione di alcune regole generali che - in altri contesti ${ }^{34}$ - persino Istituzioni come la Banca Mondiale hanno accettato, ad esempio supportando azioni di 'economia protetta' a vantaggio dell'inserimento di attori locali nella realizzazione dell'intervento in deroga alle regole della libera concorrenza. In ogni caso, si è posta in linea con alcuni processi condotti negli ultimi anni, quali - ad esempio - la pubblica discussione cittadina realizzata circa le condizioni del prestito concesso dallo stesso BID a Porto Alegre per la realizzazione della III Circonvallazione, altro esempio - tra l'altro - di 'finanziamento virtuoso' nei confronti dei programmi complementari di Pavimentazione Comunitaria $(\S 10.5)^{35}$. Alla fine, il Comune ha ottenuto di diluire su due fasi l'accordo con il BID per il primo anno di lavori (per la prima è già stato firmato il contratto, per la seconda sta venendo progressivamente disegnato il progetto) mentre vi sarà più tempo per dettagliare con il Fonplata il progetto delle restanti unità di abitazione nuove e delle zone soggette a regolarizzazione fondiaria. In ogni caso, come prima azione - coerentemente con la sua impostazione mirata primariamente alla sostenibilità ambientale - il Fonplata ha chiesto la realizzazione dell'EIA-RIMA, ovvero dello Studio di Impatto Ambientale dell'intero progetto, la cui comosa relazione conclusiva è stata consegnata a metà del 2002 ed è attualmente in corso di valutazione. Particolare interesse viene tributato al Jardin Linear che corre accanto alla favela Dona Teodora, in via di regolarizzazione: esso dovrebbe, infatti, costituire una barriera vegetale per proteggere le abitazioni dall'inquinamento delle strade di scorrimento veloce, ma il suo miglioramento è legato all'incisività con cui saranno condotti i Programmi di Educazione Ambientale.

Nella mediazione, anche il DEMHAB ha dovuto contenere alcune ambizioni iniziali: ad esempio, i progetti dei vari 'reassentamentos' non saranno condiscussi con i beneficiari in ogni tappa, ma saranno semplicemente fatti approvare in fase finale: in ogni caso si comporranno di abitazioni-tipo già comprese nel catalogo di prototipi che è possibile consultare nei processi di Bilancio Partecipativo. Questo perché la maggioranza dei finanziamenti (specie quelli del BID) sono stati alla 
fine erogati su progetti approvati e in gran parte già a scala di dettaglio. La parte rimasta 'aperta' alla discussione con i cittadini è comunque quella più complessa, contenente alcuni edifici a 4 piani (120 appartamenti sul totale di 3800 nuovi da realizzare); attualmente, pare quasi inevitabile che vengano realizzati, per poter diminuire la densità dell'area e permettere la collocazione di attrezzature comuni e di spazi per il tempo libero. Ma - certo - se si vorrà convincere i cittadini ad abitare in edifici in linea senza contatto diretto con il suolo, bisognerà lavorare molto sull'organizzazione comunitaria.

Il lavoro di accompagnamento comunitario del PIEC è comunque uno dei primi ad essere partito, già anteriormente all'acquisizione di certezze sui finanziamenti: è stata costituita una commissione di 40 persone ( 2 per ogni 'vila') da cui - ormai da oltre un anno - passano tutte le principali decisioni: a partire da quelle sull'ordine con cui i lavori interesseranno ogni comunità. (A questo scopo, la Commissione ha stabilito alcuni criteri di priorità, in base alle necessità tecniche di aprire alcune strade per poter avviare i lavori, all'esistenza di richieste già approvate nel Bilancio Partecipativo, e alla carenza sociale dei diversi insediamenti. Questi principi - semplici e razionali - erano alla base del cronogramma già ipotizzato dal DEMHAB; ben comunicate, sono state approvate dai cittadini e hanno lasciato invariato l'ordine dei lavori proposto (e in realtà già sottoposto agli enti finanziatori). Si è scelto collegialmente di non iniziare i lavori a partire da quelle comunità che già avevano guadagnato nell'O.P. i fondi per il reinsediamento, attendendo di avere disponibile una cifra più grossa per iniziare con un buon ritmo (Frare, 2002.).

È interessante notare che il ruolo del BID, in rapporto alla partecipazione comunitaria al progetto, è stato avvertito complessivamente come positivo e costruttivo, all'interno del DEMHAB, in quanto "ci forza ad assistere il 100\% delle famiglie e non solo quelle più interessate a discutere con noi; inoltre, richiedendo una documentazione scritta su tutti i processi, ci abitua a sistematizzare un dialogo finora avvenuto in maniera informale [...] seppur contrae un po' troppo i tempi delle decisioni da prendere" (Casa Nova, 2002i). Questo invito a 'sistematizzare' i modi del coinvolgimento comunitario si è tradotto in corsi di formazione per leader comunitari e in una "messa in discussione delle rappresentanze tradizionali per favorire la creazione di nuovi moltiplicatori sociali e aumentare $i$ risultati in direzione di una reale rappresentatività delle istanze delle varie comunitâ" (Frare, 2002i). Attualmente è in discussione anche un nuovo partenariato con la GTZ tedesca, per formare i tecnici comunali su tecniche di 'visioning' e 'pianificazione per obiettivi' (come già fu fatto nel 1997).

Inoltre, alla Commissione Comunitaria di 40 membri, è stata affiancata una sub-commissione di 10 membri impegnata a proporre azioni diverse di mobilitazione delle comunità interessate, e ad accompagnare e ri-orientare gli incontri con le famiglie in ogni zona. Essa serve a garantire che venga svolto un lavoro uniforme di coinvolgimento comunitario (senza sacrificare nessuna area), definisce i criteri per combattere attivamente le forme di vendita illegale di lotti e appartamenti nel territorio interessato dal PIEC, e monitora le fasi di censimento e 'congelamento' delle liste di cittadini ammessi ai benefici, che vengono attuate dal Comune.

La portata dei cambiamenti di metodo che questo Progetto Integrato va apportando nelle strategie operative del $\mathrm{DEMHAB}$, è già visibile da prima che esso partisse. Non è, infatti, un caso se nel Relatório de Atividades 2001, il 
628 DEMHAB comincia a rilevare l'importanza di costruire un ordinato archivio di tutte le pratiche portate avanti in città e delle relazioni di scambio con $\mathrm{i}$ cittadini (p. 133), e registra la partecipazione di suoi rappresentanti a 52 riunioni del Forum cittadino sulle Politiche Sociali e a 38 del Gruppo di Lavoro (coordinato dalla FASC)che sta elaborando la "Mappa dell'esclusione socia$l e "$ di Porto Alegre. Ma - soprattutto - nel 2001 ha preso avvio un progetto che corregge decisamente il tiro di prassi frettolose del passato: infatti, a cavallo tra il 2001 e il 2002, il potenziamento dell'Unità di Servizio Sociale è servito a far partire un progetto di "Valutazione dei processi di re-insediamento" che toccherà tutte le realizzazioni del DEMHAB, con lo scopo di costituire una banca dati per migliorare i propri programmi di intervento. Dal giugno 2001 il progetto (di cui purtroppo non sono ancora consultabili le conclusioni) ha preso avvio in 11 quartieri finanziati dal Programma Prò-Moradia della Caixa Economica Federal (Relatório de Atividades 2001, p. 137).

Inoltre - nel tentativo di attutire alcuni problemi diffusi nella fase di realizzazione degli interventi concreti - il DEMHAB e altri dipartimenti hanno cominciato ad accordarsi con molte imprese appaltatrici perché contrattino una parte della manodopera nelle 'vilas' dove lavorano: ciò, infatti, spesso - al di là dei benefici alle persone - garantisce meglio i risultati del lavoro sia per la ditta (che vede ridursi furti di materiali e vandalismi) che per l'ente pubblico. Ovviamente si tratta di accordi consensuali, visto che - per la normativa brasiliana - il Comune non può imporre simili richieste in fase di licitazione né ad appalto assegnato.

\subsubsection{Guardando oltre se stessi: $i$ primi feed-back}

Dal 1990 in poi (e soprattutto a partire dal ' 96 , quando è stata inclusa tra le 43 Best Practices più significative di gestione urbana catalogate dall'ONU), l'esperienza di Porto Alegre ha iniziato ad essere al centro dell'attenzione internazionale nell'ambito di una politica di 'diplomazia parallela' condotta dal Comune a livelli e in sedi diverse, dalla Comunità del Mercosul - dove è stata presa a modello per vari esperimenti, soprattutto in Argentina - alla World Bank, dal BID a molte città europee che (in Spagna e in Francia soprattutto) mantengono ancora oggi solide relazioni di interscambio con l'Amministrazione Popolare. Parallelamente, esperienze di emulazione e adattamento del Bilancio Partecipativo hanno cominciato a nascere in diversi paesi e in moltissime città del Brasile, spesso servendosi di consulenze dirette di rappresentanti del Comune di Porto Alegre, altrove attingendo alle elaborazioni sistematizzate in Programmi di interscambio e analisi comparata, come il PGU-ONU per l'America Latina e i Caraibi.

Questa 'apertura al mondo' di Porto Alegre ha avuto essenzialmente un verso, diretto da Porto Alegre verso fuori: almeno per quanto concerne il Bilancio Partecipativo. Dal 2001 (in coincidenza con il primo Forum Sociale Mondiale) qualcosa ha, forse, iniziato a muoversi in una direzione inversa. Un segno 'eclatante' è stata l'organizzazione, da parte del Comune, del seminario ' $L$ 'O.P. visto dai suoi ricercatori" che - nel maggio 2001 - ha riunito diversi studiosi provenienti da parti diverse del mondo, per riflettere su limiti e opportunità del Bilancio Partecipativo, anche con gli occhi di chi ha avuto modo di esaminare esperienze diverse e/o complementari. In seguito, il $2^{\circ} \mathrm{FSM}$, il $9^{\circ}$ Congresso IRGLUS, il $\mathrm{II}^{\circ}$ Congresso Brasiliano di Diritto Urbanistico, ed altre occasioni sfruttate da molti rappresentanti dell'Amministrazione Popolare, delle sue strutture tecniche e spesso - anche di suoi cittadini, si sono rivelate sempre più opportunità per uno 
'scambio a due direzioni' tra esperienze, anche sul piano dell'arricchimento del principale 'biglietto da visita' (l'O.P. appunto) della capitale gaúcha.

In questi ultimi due anni si è così reso sempre più visibile un processo di 'apertura all'esterno' e di 'condivisione' dei propri percorsi sperimentali, messo in movimento con gradualità dopo che Porto Alegre aveva mantenuto a lungo una posizione più defilata, incentrata su una sorta di 'autarchia sperimentatrice' (Allegretti, 2002b) e - al massimo - attenta alla comunicazione e alla promozione internazionale dei risultati ottenuti nel proprio percorso di riforma dei meccanismi decisionali di livello locale. Non è ancora un processo 'conclamato', ma certo vi è una linea di tendenza che va rafforzandosi in questa direzione.

In realtà, forse, l'apertura 'progressiva' di Porto Alegre ad accogliere come feedback alcune interessanti trasformazioni determinate dall'adattamento della sua esperienza ad altri contesti, sono iniziate prima del 2001. Ad esempio, guardando a Santo André, città dell'area metropolitana paulista che costituisce oggi uno degli esempi più interessanti di Bilancio Partecipativo in tutto il Brasile. Qui, da quando nel '97 il Bilancio Partecipativo ha ripreso (dopo l'interruzione durante una gestione politica non guidata dal fronte Popolare), il momento della consegna delle priorità è un momento di festa, realizzato riunendo in una sorta di passeggiata carnevalesca le scuole di samba della città in un percorso metaforico che va dal Comune al Consiglio Comunale a simboleggiare la popolazione come trait-de-union fra il Potere Esecutivo e quello Legislativo Municipale. Questo fatto, che - tra l'altro - è servito ad attrarre nuove persone al dibattito e ha costretto anche la stampa più restia a parlarne - è stato guardato come un'idea interessante, tanto più che l'idea delle 'carovane' e degli 'attraversamenti di gruppo' del territorio non si limita a quel momento del ciclo dell'O.P. ma costituisce elemento portante perché i Delegati e Consiglieri popolari prendano coscienza delle necessità delle diverse parti di città. Il suggerimento è stato colto, e - dal 2000 - le 'carovane' sono diventate elemento di verifica delle concrete situazioni territoriali, non solo nell' ambito del Bilancio Partecipativo, ma anche e soprattutto dentro ai Forum Regionali di Gestione della Pianificazione legati al nuovo PDDUA. $\mathrm{Nel}$ 2002, poi, nel tentativo di cancellare quel velo di 'serioso grigiore veterocomunista' (Allegretti, 2000a) che avvolgeva a Porto Alegre la fase di consegna delle priorità nel secondo turno delle Assemblee Regionali e Tematiche, si è introdotta una festa pubblica per la presentazione dei nuovi Consiglieri dell'O.P. e la consegna delle 'priorità' effettuata dalla comunità al Sindaco a luglio. Il risultato non è stato eccelso, anche perché si è compartimentato l'evento in un luogo chiuso, invece che farlo svolgere negli spazi aperti della città e chiamando a raccolta l'autoprogettualità delle scuole di samba e delle associazioni comunitarie: è comunque un passo interessante in una linea di cambiamento.

Per Porto Alegre - dal 1999 - è stata importante anche la nascita del Bilancio Partecipativo Statale (OP/RS) messo in piedi dal nuovo governo guidato da Olivio Dutra. Esso ha, infatti, rappresentato una sfida, non solo perché ha permesso di leggere l'O.P. comunale come in uno 'specchio deformante', ma anche perché è stato uno stimolo (che non sempre è stato colto, a differenza che in altre città dell'interno dello Stato) a coordinare tempi e modi dei dibattiti, per non disperderne il potenziale di complementarietà tra livelli istituzionali diversi. E non moltiplicare all'eccesso la richiesta di impegno ai cittadini. Di grande interesse sarebbe osservare come il Bilancio Partecipativo Statale, partendo da una formula desunta da quella di Porto Alegre, ha via via trovato un suo cammino peculiare adattandosi 
630 ad un territorio tanto più vasto e diversificato e alle caratteristiche del suo capitale sociale. Ma, solo per esaminare questa esperienza 'a termine' (che pare essersi chiusa con l'entrata in carica del nuovo governo nel gennaio 2003), ci vorrebbe un libro intero; per questo, rimandando ad altri scritti sul tema (cfr. dos Santos Marques, da Silva Porto e Fiorissi, 2002 e Allegretti 2001b,c), ci basterà sottolineare due elementi innovativi di questa esperienza che sarebbe opportuno che 'filtrassero' in quella di Porto Alegre, attraverso una specifica riflessione:

1) Il primo riguarda il modo con cui - nelle 775 assemblee svolte annualmente $^{36}$ nei 497 comuni e nelle 23 Regioni dello Stato - i rappresentanti governativi istituivano programmaticamente un legame tra le possibilità di investimento del bilancio annuale e 'scenari alternativi' di entrate finanziarie possibili, in tal modo costruendo strategie di supporto per l'approvazione di riforme tributarie o tariffarie da far approvare nell'Assemblea Legislativa Statale;

2) Il secondo riguarda la maggior attenzione per l'interazione tra i diversi poteri sul territorio (in particolare Legislativo ed Esecutivo). Seppur dovuta non ad una scelta strategica, ma alla necessità di non 'svuotare di senso' alcune istituzioni partecipative create dalla Giunta precedente (come i Consigli di Sviluppo Regionale -COREDES), la rete di arene deliberative creatasi nel Rio Grande do Sul è risultata particolarmente interessante. In particolare perché, allo strumento dell'O.P/RS (con il suo valore deliberativo nell'ambito dei poteri e delle competenze dell'Esecutivo statale), si è aggiunto - nel settembre $1999^{37}$ - il Forum Democratico, per accompagnare il lavoro di formulazione normativa del Potere Legislativo e i lavori di monitoraggio sul bilancio e sul Piano Pluriennale. Seppur detto Forum ha rappresentato solo un organismo consultivo dell'Assemblea Legislativa, esso ha riproposto il tema della necessità di affiancare forme di democrazia diretta a tutte le articolazioni della democrazia rappresentativa. Inoltre, al Fonum e all'O.P. si affiancava un utile strumento deliberativo (creato il 14/1/999 con Legge 11305) composto di Commissioni di Valutazione dei Servizi Pubblici Statali (CASEPEs), più efficace nel suggerire soluzioni e reindirizzo della gestione rispetto ai Forum dei Servizi di Porto Alegre.

Se quest'ottica di 'apprendimento' da altre esperienze troverà conferma nei prossimi anni, Porto Alegre avrebbe molti esempi a cui guardare con interesse per arricchire i propri modi di gestire politiche ed istanze di democrazia diretta.

Ad esempio, potrebbe osservare i "Congressi della Città" di Belém do Pará, processi permanenti in cui i cittadini e l'Amministrazione assumono insieme le posizioni ufficiali su eventi che superano l'ambito municipale, e la popolazione può indicare mozioni 'di sfiducia' per la revoca di membri della Giunta che dipendono da scelte del Sindaco. Oppure, potrebbe esaminare alcuni degli aspetti interessanti della Regolarizzazione Fondiaria attuata a Rio de Janeiro nel Programma Favela-Bairro (Allegretti, 2001a), o i programmi di microcredito per il recupero degli alloggi in aree informali di Fortaleza "Casa Melhor", che danno supporto - sì - a logiche di produzione e consolidamento familiare dell'alloggio, ma sottomettono la concessione dei prestiti alla creazione di Commissioni Comunitarie che garantiscono collegialmente la restituzione dei prestiti dei privati prima che altri gruppi di abitanti della stessa area possano accedere a fasi successive di finanziamento.

Ancora, se Porto Alegre volesse assumere un orizzonte più ampio di osservazione, potrebbe guardare con interesse ad esperienze europee di Bilancio 
Partecipativo, come quelle tedesche o spagnole in cui - in alcuni momenti del percorso decisionale delicati - si recuperano antichi meccanismi della democrazia greca (come l'estrazione casuale di commissioni di cittadini). O, ancora, potrebbe riflettere sui modi in cui strumenti più 'tradizionali' della democrazia rappresentativa (come i sondaggi-inchiesta di Bobigny o i referendum consultivi di Milton Keynes) sono stati 'risemantizzati', non considerandoli dei meri strumenti di 'conta' delle opinioni dei cittadini, bensì utilizzandoli come l'evento conclusivo di percorsi dibattimentali pubblici che hanno a lungo coinvolto in precedenza istituzioni locali e cittadini ${ }^{38}$.

Infine, potrebbe cominciare a porsi l'obiettivo di rispondere alle critiche che vengono mosse alla gestione poco partecipativa di alcuni servizi urbani e alla scarsa incidenza dei Forum dei Servizi (cfr. Solidariedade, 2003), analizzando esperienze di città che - come la finlandese Hameenlinna - hanno a lungo lavorato su approcci partecipativi (seppur di tipo 'manageriale') alla gestione dei servizi (inclusi i tanti forzatamente privatizzati), perfezionando insieme ai cittadini interessanti sistemi di scrittura e monitoraggio collettivo del rispetto di 'Carte dei Servizi', con ottimi risultati in termini di 'soddisfazione degli utenti' e di 'democrazia di prossimità'. E, parallelamente, hanno creato Piani e Progetti di Sviluppo dei Servizi che - coinvolgendo tutta l'organizzazione dei servizi stessi, oltre che gli utenti - hanno suggerito non tanto di abolire i livelli gerarchici, bensì di affidare i compiti e le attribuzioni ai funzionari seguendo le modalità tipiche della 'contrattazione per progetti' (e non più tramite l'imposizione di ordini da eseguire), riuscendo così a trasformare in migliorie nel funzionamento dei servizi una riforma interna della burocrazia municipale.

\subsubsection{Un nuovo livello di autoprogettualità?}

Nel corso di questo libro, abbiamo più volte rilevato i diversi contributi portati dall'intervento dei cittadini di Porto Alegre nella costruzione delle regole e dei contenuti di politiche e strumenti di governo locale; non solo nel Bilancio Partecipativo e nei Forum di Pianificazione, ma anche - ormai sempre di più - nei Congressi Cittadini, nei Forum e nei Consigli Tematici e - soprattutto - nel 'corpo a corpo' che si crea quotidianamente sul territorio tra gli abitanti ed i rappresentanti dell'Amministrazione Comunale, sia di livello politico che tecnico.

In tutte queste occasioni positive di 'interazione tra progettualità', si è anche evidenziato un rischio: quello di una diminuzione dell'autonoma capacità progettuale da parte dei cittadini, che pure hanno o si possono creare spontaneamente occasioni per esprimersi e mettere alla prova la propria capacità di autorganizzazione senza stare costantemente sotto il controllo di rappresentanti municipali. Lo stesso Regolamento Interno dell'O.P. prevede che almeno una riunione mensile del COP avvenga in assenza di esponenti del Comune; ma non sempre i rappresentanti popolari approfittano a sufficienza di queste opportunità per elaborare strategie e proposte indipendenti ed organizzare la propria forza e la propria capacità propositiva intorno ad esse.

L' attenzione pressoché 'totalizzante' rivolta negli ultimi anni al Bilancio Partecipativo e alle altre (tante, forse troppe?) istanze di coinvolgimento decisionale dei cittadini hanno esposto i diversi strumenti di interazione con le istituzioni al rischio di esercitare un 'monopolio sul dibattito cittadino' che parrebbe togliere agli abitanti la forza e la volontà di riversare energie anche in altre istanze di discussione: intanto quelle dai risultati meno 'immediati' e 
632 - soprattutto - quelle autorganizzate, come i movimenti popolari.

Il complessificarsi progressivo delle strutture partecipative inserite nelle politiche comunali non genera solo il rischio di una confusione tra le varie arene deliberative con i loro diversi modi di rappresentanza e le loro differenti regole di funzionamento. Rischia anche di determinare un flesso nella partecipazione, di far conto su un'infinita capacità di impegno pubblico dei cittadini che non corrisponde, però, alle loro forze reali. Non solo, rischia di premiare soprattutto quelle istanze dibattimentali che hanno un ruolo maggiormente decisionale ed intervengono su tematiche concrete, visibili e più 'produttive' agli occhi dell'abitante. Questo è un problema che emerge come molto sentito sia dalle critiche dei movimenti popolari organizzati che dal testo "Porto Alegre, Les voix de la démocratie. Le budget participatif raconté au quotidien" che (proprio perché scritto da cittadini comuni impegnati nell'O.P.) può leggersi non tanto quanto una critica all'Amministrazione Popolare, quanto piuttosto come un'autocritica all'incapacità finora mostrata dagli abitanti di Porto Alegre di reagire ai rischi di un 'appiattimento' della propria progettualità sulle istanze di co-gestione urbana.

$\mathrm{Nel}$ sottolineare lo 'svuotamento progressivo' dell'autonomia dei "principali soggetti" del processo di Bilancio Partecipativo, il testo non solo chiede al Comune di veder riconosciuta la "capacità autonoma della popolazione organizzata di condurre la sua propria riflessione" al di là dei limiti del proprio coinvolgimento egoistico nelle scelte da compiere, ma chiede anche ai cittadini stessi di meritarsi questo riconoscimento, aprendosi ad una maggiore solidarietà, allargando i propri orizzonti oltre la propria casa e il proprio quartiere, anche rifiutando - se necessario - la cooptazione dei leader comunitari più vivaci alla politica ufficiale o - almeno - organizzandosi per formarne continuamente di nuovi (Solidariedade, 2003).

Il testo è, però, interessante soprattutto perché non si ferma a queste critiche o a queste esortazioni: piuttosto indica e costruisce una strada. Raccontando il tenue filo che lega alcune conquiste recenti dei cittadini all'autonomia organizzativa mostrata nei primi anni del Bilancio Partecipativo, quando - ancora nel '92 - la UAMPA non era solo "uno strumento politico d'opposizione" (Amaral, apud Solidariedade, 2003) e i diversi Consigli Popolari e le Unioni di 'Vilas' della città si riunivano ogni settimana all'Usina do Gasometro "per discutere della congiuntura politico-economica ed elaborare strategie per mostrarsi uniti". Poi, la creazione dei Forum dei Delegati ha fatto naturalmente estinguere i Consigli Popolari, svuotandoli con "l'attrattiva di una richiesta e di una conquista immediata" (ibidem).

Oggi, molti Consigli Popolari vanno risorgendo, ma non riescono ad avere sedi, luoghi e mezzi per produrre la loro controinformazione, e la loro rinascita è resa difficile dal fatto che il Comune e i media di opposizione si contendono il duopolio dell'informazione. Forse "ogni regione dovrebbe ricevere una somma determinata per poter mantenere un funzionamento burocratico efficace del movimento" (Cupini, ibidem) azzarda qualche voce nel testo: ma, per altri, il solo accostamento tra le parole 'burocrazia' e 'movimento' è una pietra tombale sulla possibilità di rivitalizzare forme indipendenti di organizzazione della cittadinanza, che sappiano elaborare alternative e - accettando di dialogare con le istituzioni nell'OP e nelle altre arene partecipative - non si appiattiscono sulle loro proposte. In ogni caso, nel libro sono evidenziati i fatti che sembrano riannodare i fili con una situazione che sembrava morta 10 anni fa. La Lomba do Pinheiro, il Partenon, 
la Gloria e la Regione Nord hanno riattivato i loro Consigli Popolari; la Cruzeiro ha rafforzato il rapporto tra l'Union de vilas e il Consiglio del Morro SantaTereza. La Regione Humaita-Navigantes-Ilhas ha lanciato una discussione per far rinascere un Consiglio Popolare, mentre altrove si usano sottogruppi dei Forum dei Delegati come occasioni per riunire cittadini desiderosi di articolare le comunità di base o accrescere il loro grado di autonomia nelle proposte da discutere con il Comune. La fase storica è ritenuta matura per affiancare "il Bilancio Partecipativo come movimento di realizzazione e $i$ Consigli Popolari come movimento di riflessione e rivendicazione a lungo termine"(ibidem) facendo sì che "l'O.P. non sia più che un obiettivo tra gli altri di questi forum" e che "si riservi spazio per il Bilancio Partecipativo all'interno della discussione del movimento popolare e non l'inverso". Perché se "è illusorio sviluppare una coscienza cittadina senza prima tentare di rimediare alle urgenze del quotidiano" come insegna "il principio delle comunità ecclesiali di base della Teologia della Liberazione", allora il momento attuale dopo 14 anni di conquiste per cercare di colmare il deficit pregresso di cittadinanza e di attrezzature cittadine - parrebbe quello buono.

Il 14 settembre 2002, l'ONG Solidariedade ha organizzato il $\mathrm{I}^{\circ}$ Incontro Indipendente dei Consiglieri dell'O.P. dal 1989 ad oggi; anche se solo una parte delle circa 800 persone era presente, l'evento è stato molto importante, divenendo un laboratorio legato a 4 assi di riflessione sulle modalità con cui rendere $\mathrm{i}$ rappresentanti popolari più autonomi dal potere municipale, ma anche su temi

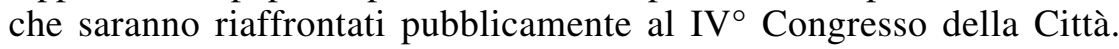

Oggi, nel (forse) rinascente movimento popolare di Porto Alegre, l'idea più diffusa è che non si possa attendere che si verifichi una crisi della democrazia partecipativa, perché i cittadini mostrino di volerla sostenere e di volerla rivitalizzare; è meglio agire ora per ridare forza ad un movimento più autonomo e qualificato nella capacità di fare proposte alternative realistiche e credibili (de Matos, ibidem). Per questo, è fondamentale ripartire - come sembra suggerire il testo di Solidariedade - da quell'autoeducazione popolare che rappresenta una delle tradizioni più gloriose del Brasile, dai tempi di Paulo Freire in poi. Ma, oggi, anche questa deve cambiare: il movimento popolare potrà presentare controproposte efficaci al governo - includendo anche quelle fiscali e di bilancio - solo se saprà entrare in rete con centri di sapere, collaborare con Università, $\mathrm{ONG}$, istituti di ricerca.

Il primo tema su cui Solidariedade e altri movimenti e ONG hanno scelto di partire è uno dei più spinosi: lavorare sulla "matrice generale di bilancio" prima che il governo presenti il suo progetto al COP perché lo valuti e lo emendi. L'idea è che lavorare in parallelo possa servire a contrapporsi al limite dei tempi troppo stretti che fino ad oggi ha segnato molte scelte frettolose dei membri del COP. Ma questo richiede un grosso sforzo di qualificazione tecnica e d'impegno per i cittadini che vogliano cogliere la sfida: e resta pertanto una meta difficile da raggiungere in tempi brevi. Alcuni accordi informali con l'Università - nel giro di qualche mese - potranno chiarire se si può andare avanti su questa strada, o è meglio riprendere il discorso da obiettivi meno ambiziosi.

\subsection{Il consolidamento di un patto sociale condiviso}

L'alleanza a caldo fra classi diverse, nella battaglia urbana, c'è sempre stata, più o meno. Più complesso è fare un'alleanza a freddo, ragionata. Porto Alegre ci sta tentando da anni. In parte ci è riuscita, [...] Ma nel complesso non è semplice far collaborare categorie con 
interessi diversi. Le grandi imprese, specie nel settore edilizio, hanno concordato da subito con l'O.P. perché ha rivitalizzato un settore spento. Individui di classi medie che partecipavano con una singola richiesta se ne sono visti sporadicamente, ma talora ne sono anche usciti soddisfatti. Approvare che Porto Alegre si amministri attra verso l'O.P. è una cosa, prendervi parte è un'altra. (Brunet, 1999i, apud Allegretti 2000a).

Quando nel 1980 - a seguito delle sollevazioni sindacali del 1978 e del mancato appoggio fornito loro dal Movimento Democratico Brasiliano - si formò il Partido dos Trabalhadores, fu presto chiaro che quella formazione eterodossa (Abers, 2000) costituiva una rottura rispetto ai tradizionali gruppi della sinistra politica. Il nuovo movimento sorgeva da una classe lavoratrice formatasi dopo l'avvento della dittatura che, "non avendo esperienza di Stalinismo o populismo, capì sulle basi della propria esperienza di lotta di classe la necessità di un'organizzazione politica indipendente" (Löwy, 1987), ma andava assumendo un volto altamente composito e articolato in correnti. Partendo da queste basi, e portando avanti un'ideologia ufficiale per i primi tempi piuttosto vaga (Abers, 1996), il successo del PT fu dovuto alla sua "inusualmente ricca reinterpretazione dell'importanza del socialismo per la democrazia e viceversa. Insistendo sul diritto degli esclusi di parlare con le loro stesse voci e i loro nomi, il PT allargò la tradizionalmente ristretta concezione della democrazia del Brasile" (Keck, 1992). Da questa nozione - fortemente avversa ad ogni forma di privatizzazione - era fortemente bandita anche ogni collusione con le tradizioni burocratiche di governo, inclusa quella dello statalismo sovietico letto come negazione di quella libertà, di quella varietà di opinioni e di quella tolleranza reciproca che segnavano la stessa origine del movimento.

A tutt'oggi, pur arrivato alla Presidenza della Repubblica, il PT pare costituire ancora "un outsider nel gioco politico brasiliano", con "una vita interna ricca e conflittuale mentre la maggior parte dei partiti sono coalizioni di notabili" (Keck, 1992). La sua struttura organizzativa estremamente decentrata e il suo carattere movimentista hanno portato il PT ad un'idea di democrazia interna che ha permesso alla stessa piattaforma di sorgere 'dal basso verso l'alto' (Löwy, 1987). Partendo da nuclei territoriali e da collegamenti trasversali su base 'tematica', il PT ha cercato nel tempo - e con gradualità - di istituzionalizzare "un sistema "piramidale" di mediazioni attraverso cui il direttivo nazionale è direttamente legato alla base" (Abers, 1996).

Per certi versi è a questa stessa struttura interna che il PT ha fatto riferimento nell'impiantare la sua proposta di democratizzazione delle istituzioni all'indomani delle elezioni del 1988 che gli dettero la vittoria in ben 36 città di dimensione medio-grande del Paese, con la troppo rosea illusione che la semplice conquista del potere avrebbe spontaneamente fatto emergere per iniziativa autonoma dei movimenti comunitari locali una serie di "consigli distrettuali' su cui innestare le nuove proposte di democrazia partecipativa ai vari livelli della vita politica. Come osserva Abers (1996) nella sua accurata e dichiaratamente non neutrale analisi comparata tra le vicende di alcune amministrazioni brasiliane guidate dal PT, il compito risultò ben più difficile, tanto che già dopo il primo anno in varie città il PT si accontentò di restringere la partecipazione popolare a progetti e programmi localizzati.

A Porto Alegre, dove il rapporto di tensione che lega il PT alla sua base elettorale è notevolmente minore che in altre città (Jacobi, 1995) ${ }^{39}$, ciò che favorì il successo del Bilancio Partecipativo furono anche la strategia della 
pazienza adottata nel confrontarsi con dubbi e difficoltà dei primi tentativi di innesto dell'O.P., e la flessibilità mostrata nell'accettare che il meccanismo prendesse forma diversa nei diversi territori. Inoltre, l'Amministrazione Popolare di Porto Alegre, ha saputo ben affrontare "il dilemma della credibilità" (Abers, 1996), proprio facendo leva sulle difficoltà come stimolo creativo e riacquisendo una discreta 'autonomia' attraverso la riorganizzazione completa delle finanze municipali, necessaria ad attivare politiche e progetti-pilota di grande visibilità e richiamo. L'Amministrazione Popolare si è parallelamente impegnata a 'stanare' i cittadini con un'opera di porta a porta, e nel contempo a 'formarli' alla complessità dei meccanismi di gestione pubblica, ottenendo un aumento 'ragionato' e non più 'intuitivo o sentimentale' della propria credibilità.

Questo lavoro impegnativo per rendere la tecnicità accessibile e decifrabile (Abers, 1996) si è articolato a due livelli diversi (quello dei cittadini comuni e quello dei leader organizzati) innescando un interessante 'circolo virtuoso' che ha permesso gradualmente alla partecipazione di andare oltre la semplice elencazione di priorità o di progetti locali sognati e ha costretto l'Amministrazione ad 'aprirsi' e a rendersi sempre di più 'trasparente'. È così che l'O.P. ha teso a strutturarsi secondo una duplice formula coordinata di democrazia assembleare e rappresentativa, il cui risultato è stato che "mentre la maggioranza dei partecipanti ha guadagnato una familiarità di base con i lavori del bilancio cittadino, $i$ loro rappresentanti sono diventati specialisti virtuali in politica del bilancio" (Abers, 1996). Parallelamente a questa crescita qualitativa della partecipazione popolare, il Comune ha dovuto imparare a prevedere $\mathrm{i}$ costi dei progetti con maggior cura $\mathrm{e}$ dettaglio per rispondere alle domande sempre più tecnicamente fondate dei cittadini e dei loro rappresentanti, ed è stato costretto a sviluppare un coordinamento tra assessorati anche attraverso il rinnovamento dei sistemi informatici, per fornire dati e valutazioni integrate' in progress su cui fondare una continua negoziazione fra proposte e controproposte con la cittadinanza.

L'osservazione attenta di queste trasformazioni, non ha solo accresciuto la credibilità delle Istituzioni agli occhi dei cittadini, ma anche viceversa; il Comune di Porto Alegre ha così deciso di non seguire la strada di altri municipi guidati dal PT, e di non sottrarre alcuna percentuale di risorse per investimenti al controllo della popolazione.

Così, anche le scelte di più vasto interesse cittadino non sono state confinate in un modello di selezione 'tecnica', ma la popolazione è stata coinvolta in senso politico nella loro assunzione., e così stimolata ad andare al di là dei propri interessi immediati e a pensare su termini medi e lunghi. In sostanza, ciò che altrove è stato risolto limitando il raggio di azione della partecipazione, a Porto Alegre lo si è demandato ad un confronto diretto fra cittadini e amministrazione sui diversi problemi, "dall'interno del processo partecipativo stesso" (Abers, 1996).

Jacobi (1995), tra le caratteristiche determinanti del rinnovamento dell'esperienza 'petista' a Porto Alegre, ha rilevato il carisma dei suoi sindaci e il loro potere di agglutinamento di tutti coloro "con una certa dose di impegno nei confronti dei problemi della cittă", ma soprattutto la capacità di "non rendere il governo esclusivo e di governare per tutti, a prescindere dalla priorità accordata ad un governo che adotta il punto di vista dei settori popolari'. In città come São Paulo, infatti, la rapida crisi della giunta guidata dal PT (198992) fu dovuta anche al "ritardo nell'ampliare lo spettro delle negoziazioni con i settori più importanti" che impedì una "legittimazione della gestione" 
636 (ibidem). In questo senso, ha giocato a favore dell'Amministrazione Popolare di Porto Alegre anche un certo realismo, liberatosi in tempi rapidi dall'idea che i Consigli Popolari e l'O.P. potessero essere una panacea, pur continuando ad intenderli come una componente indispensabile dell'innovazione per costruire un rapporto di corresponsabilizzazione tra cittadini e istituzioni, e consensi sempre più criticamente fondati e qualificati su cui fondare un ampio patto sociale da ottenersi lavorando in parallelo su diversi fronti. Partendo dall'umile e realista convinzione che da sola un'amministrazione periferica non può pensare di 'compiere una rivoluzione', ma al massimo può offrire misure compensative muovendo i suoi passi a partire dalle attuali disuguaglianze di potere (Abers, 2000b), l'Amministrazione Popolare ha condotto una forma di rivoluzione silenziosa verso la 'redistribuzione', mobilitando le categorie sociali più povere attraverso la focalizzazione del dibattito cittadino su temi immediatamente comprensibili, con meccanismi decisionali chiari, attraverso un lavoro di convincimento minuto fatto da funzionari pubblici adibiti all'opera di cooptazione sul territorio e, infine, producendo opere altamente visibili che potessero stimolare l'interesse di nuovi cittadini attraverso l'effetto-dimostrazione.

L'O.P. si è così costituito come un 'dispositivo' (nell'accezione che ne dà Foucault, 1994: cioè di qualcosa che è nato per "rispondere ad un'urgenza", con una "predominante funzione strategica", e che solo dopo "si costituisce propriamente come tale") ed ha preso piede, a partire dal 'margine', grazie alla 'forza dei legami deboli'40, cioè a reticoli di relazioni interpersonali spesso casuali, a cui continua ad affidarsi per crescere in coesione e diffusione ${ }^{41}$.

"La pietra scartata dai costruttori è diventata testata d'angolo", osservano Calame e Talmant (2001, p. 123) citando le Sacre Scritture. Si è cioè puntato sui più necessitati per avviare un processo aperto a tutti che solo una volta affermatosi avrebbe inevitabilmente attratto anche altri interessi (come era già accaduto negli anni ' 80 ad alcuni Consigli Municipali, subissati di richieste di partecipazione da categorie sociali diverse, che li avevano scoperti come luogo reale del confronto decisionale), e tanto più se si fosse perseverato nel mantenerlo come l'unica istanza reale per l'assunzione di decisioni a livello cittadino, da cui non si poteva fare a meno di passare per ottenere un qualsiasi appoggio finanziario da parte del Municipio.

Questo non significa che l'Amministrazione Popolare prevedesse automatismi nell'accettazione diffusa del progetto così come era; ne è una prova la creazione delle Assemblee Tematiche, una proposta mirata esplicitamente ad attrarre al dibattito sul bilancio un nuovo pubblico socialmente diverso, anche recuperando alcuni fondi a vantaggio della 'città come un tutto'. L'Amministrazione ha così sagacemente intuito che i meccanismi 'tematici' e 'areali' potevano adattarsi facilmente a diversi target di cittadini da convogliare nel dibattito ${ }^{42}$. Così, oggi cominciano a leggersi i primi movimenti organizzati di quartieri altoborghesi che si riuniscono e fondano comitati per difendere nell'O.P. alcune esigenze relative alla conservazione di alcuni aspetti dei loro ambiti di vita. Nel complesso, quello a cui - dentro e fuori dal Bilancio Partecipativo - l'Amministrazione Popolare di Porto Alegre ha mostrato molta attenzione è stata la costruzione di un largo patto sociale (di cui gli impiegati comunali hanno col tempo costituito un elemento non secondario) mirato a sostenere genuinamente la difesa e la promozione della forte identità cittadina che correva il rischio di essere messa in crisi dalla congiuntura politico/economica nazio- 
nale, e a disegnare un supporto politico allargato, non solo come garanzia per il Fronte Popolare della possibilità di continuare a governare, ma anche come 'facilitatore' dello stesso operare quotidiano sulla città.

Volendo riassumere in poco spazio un'interazione complessa e delicata, si potrebbe dire che nel tempo si è avuta la nascita graduale di una "coalizione alternativa" (Abers, 2000) di sostegno politico all'operato del Fronte Popolare, che - oltre a riunire vasti settori popolari e parte della classe media 'progressista' - ha conquistato nuove forze frammentando il fronte dell'elite economica. Se la promozione della funzione sociale della città ha, infatti, danneggiato una parte di questo 'fronte ostile' (ovvero la componente meno dinamica, attestata sui guadagni di tipo passivo-speculativo), la raggiunta autonomia finanziaria ottenuta per questa via ha reso possibili investimenti in opere e servizi che hanno portato all'Amministrazione il supporto di molti dei settori più dinamici dell'impresa e del professionismo privato. Si è quindi ricreato 'a freddo' (Brunet, 1999i, apud Allegretti 2000a) un meccanismo di 'convergenza di interessi' fra categorie sociali diverse all'interno di un 'progetto' più o meno condiviso ma sistematicamente aperto alla discussione e alla critica, i cui risultati hanno garantito il raggiungimento di obiettivi non solo positivi per singoli gruppi, ma sovente per l'intera collettività. Del resto, già nel 1990, alla fine del documento di autocritica del PT A Hora das definições estrategicas, era scritto:

[...] Dovremo lottare per un'attiva cooperazione dei settori dell'impresa, mirando alla realizzazione di progetti che interessino al settore privato ma che siano capaci di servire, come finalità ultima, l'interesse pubblico. La permanente ricerca di consenso, non deve, però, compromettere l'autorità dell' Amministrazione Popolare nel perseguire l'interesse pubblico [...] solo una politica centrata sugli interessi delle maggioranze popolari può far sì che progetti privati - e anche quelli che, concretamente, stanno costruendo la città e cercando di orientare, di fatto, lo sviluppo urbano - passino ad essere permeati di criteri che servono, in ultima istanza, l'interesse pubblico Questa linea di azione strategica cerca di [...] contribuire all'alterazione della correlazione fra forze, stabilita storicamente nella lotta per la produzione e appropriazione dello spazio urbano, in favore dei settori democratici e popolari. Per questo, affronterà la relazione particolarista che le classi dominanti hanno con la città, e che è generatrice di ingiustizie (PT, 1990).

È tale 'convergenza di interessi' che pare finora aver garantito all'Amministrazione di Porto Alegre un vasto supporto diretto in tempi elettorali (al punto che nel 1996 la vittoria si è avuta direttamente al primo turno), ma anche un appoggio indiretto - esercitato attraverso pressioni e strategie di controllo popolare sull'operato dei membri del Consiglio Comunale - che ha aiutato a far passare varie Leggi Comunali in materie su cui non poteva aversi intervento diretto dell'Esecutivo. Secondo Abers (2000b), addirittura dal settore delle imprese edilizie (tradizionalmente conservatore ed in passato coinvolto nella corruzione politica) sono giunti appoggi velati ma fattivi all'approvazione di aumenti di imposte utili ad accrescere l'impegno all'investimento urbanisticoedilizio dell'Amministrazione, mentre altri settori hanno rinunciato ad ingaggiare campagne attive contro il Comune. Per quanto attiene la classe media, il suo appoggio è stato direttamente stimolato dall'Amministrazione Popolare con un'accorta politica di manutenzione di servizi di alta qualità nel centro cittadino e nei quartieri borghesi (trasporti pubblici, raccolta dei rifiuti - inclusa quella differenziata che oggi tocca il $90 \%$ della città - manutenzione delle strade e del verde pubblico) che le ha permesso di offrire all'opinione pub- 
638 blica un'immagine di 'efficienza e competenza' (ibidem), giovandosi dell' anelito a politiche 'democratiche', 'trasparenti' e 'socialmente giuste' emerso in corrispondenza dello scandalo che nel '92 portò all'impeachment del Presidente Collor. Attraverso questo modo di operare, un'esperienza di governo complessivamente radicale e di impianto dichiaratamente socialista è riuscita a guadagnarsi un vasto seguito senza dover cedere a eclatanti compromessi, senza rinunciare ai suoi principi essenziali, ma portando avanti i suoi obiettivi a vantaggio di una 'massa critica' composta da settori molto diversi della cittadinanza, in modo che, "invece di costituire un fardello politico che ha suscitato un'opposizione, delle politiche partecipative e ridistributive sono risultate una risorsa che ha aiutato a generare appoggio politico" intorno ad un progetto non imposto come modello ideale ma costruito trasformando le condizioni al contorno in modo da renderlo realizzabile (Abers, 2000b).

\section{Note}

${ }^{1}$ Fino ad allora, alcuni settori della società credevano che la costruzione su larga scala, la prefabbricazione, l'industrializzazione e la razionalizzazione della costruzione potessero promuovere la diminuzione dei costi della casa e diminuire il deficit abitativo; dagli anni '60 fu però chiaro che solo attraverso l'auto-aiuto, i mutirões e lo sviluppo comunitario si sarebbe potuto superare il problema. Oggi resta intatto il dubbio che entrambi rappresentino approcci sorti comunque dalla necessità delle classi medie nazionali di trasmettere ai favelados una determinata concezione della società, "in modo che considerassero che il proprio quotidiano potesse essere migliorato mediante sforzo proprio e ausilio comunitario dentro un regime" (Pastemak Taschner, 1997)

${ }^{2}$ Cfr la serie di quaderni "Memoria dos Bairros" e il "Mapa da Irregularidade Fundiaria de Porto Alegre".

${ }^{3}$ Resoluções III $^{\circ}$ Congresso da Cidade, 2000, p. 7

${ }^{4}$ Cfr. De Olho no Orçamento $\mathrm{n}^{\circ} 7 / 98$

5 "Chi decide della realizzazione di una richiesta conquistata nell'O.P.?", chiede Felisberto Luisi, ex Consigliere della Regione Centro, e membro di Solidariedade. "I tecnici dei servizi municipali" Ed è proprio con l'appoggio dei criteri tecnici che essi possono invalidare una richiesta già calendarizzata. Un'operazione contemplata nel piano degli investimenti del 1997 dovrebbe essere prioritaria rispetto ad una conquista dell'esercizio 2001" (Solidariedade, 2003).

${ }^{6}$ Il termine, usato da B. Alfonsin (1997), viene spiegato dall'autrice con la convinzione che "ogni politica pubblica è alla fine di genere, anche quelle che operano con supposta neutralità, visto che non considerare uno dei/delle soggetti coinvolti è una forma determinata di azione politica".

${ }^{7}$ Con l'Università la relazione è stata finora ambigua da entrambi i lati. Più volte il DEMHAB ha tentato di formalizzare rapporti di collaborazione, ma lo ha fatto con accordi non chiarissimi quanto a ruolo e doveri dei due partner. Soprattutto lo ha fatto "con un approccio spesso errato alla questione del 'chi deve dare cosa"” (Mayer, 1999i, apud Allegretti 2000a). "Chiamare l'Università pensando di lucrare sul mancato guadagno di un'Istituzione Pubblica, ciò̀ su una collaborazione gratuita, è un errore, una furbizia stolta. Non stimola nessuno, e può dare adito a tentativi personali di lucrare sul rapporto da parte di chi ritiene ing iusto fare progetti non retribuiti. Quello che si dovrebbe fare è cercare di valorizzare ogni partner per le sue qualità specifiche. Il DEMHAB può certo insegnare a noi dell'ambito accademico ad agire nella pratica e ad intervenire sulle emergenze nella realtà concreta, noi possiamo offrire una sistematizzazione metodologica per gli interventi, studiare gli ambienti locali dove agire e le loro peculiarità e curare la valutazione e il monitoraggio dei progetti ed il loro consolidamento una volta impiantati. Questa possibilità di essere utili reciprocamente non deve farci nascondere che certo l'Università e il DEMHAB agiscono con tempi, obiettivi e urgenze diverse: uno ha il tempo della riflessione e l'altro dell'azione, uno ha più energie numeriche, l'altro ha poche gambe. Ma credo che un accordo a 
mezza via si possa trovarlo, solo a volerlo" (Turkienicz, 1999i, apud Allegretti 2000a). 8 "Nel contratto con le imprese ci sono termini da rispettare per $i$ contraenti; e c'è anche un lasso di tempo per cui l'impresa resta impegnata e responsabile della costruzione non a regola d'arte. Ma ad opera conclusa [...] non resta un fondo permanente per porre rimedio a tutti $i$ 'vizi occulti' [...]. Perciò non è raro che abbiamo problemi con imprese che nelle favelas pensano di poter fare le cose con meno impegno. Di rescissioni di contratti ne abbiamo massimo 2 o 3 all'anno; le trattenute servono" (Dantas, 1999i, apud Allegretti 2000a).

${ }^{9}$ Io sono stata mandata dalla SPM ad un corso all'IBAM, Istituto Brasiliano di Assistenza ai Municipi; il corso di regolarizzazione mi ha cambiato la mentalità, sarebbe bene mandarci tutti $i$ nostri tecnici ma purtroppo non ci sono forze per farlo. Ad esempio, i tecnici del DEMHAB neppure sapevano del corso, e noi l'abbiamo fatto in 2 su 4 (Ribeiro Jordão, 1999i, apud Allegretti 2000a).

${ }^{10}$ Tra l'altro, il tentativo di collaborazione 'formativa' fatto dal DEMHAB con la Università UNISINOS in un corso sul Cooperativismo Abitativo ha dato buoni risultati, e potrebbe essere replicato su altri temi.

${ }^{11}$ Dati: DEMHAB, luglio 2002.

12 Nel 1999 l'impresa pubblica Carris è stata premiata dall'ANTP (Associazione Nazionale del Trasporto Pubblico) come miglior impresa di trasporto urbano del Paese; ha ricevuto il premio "Trânsito modelo" della rivista "Quatro Rodas", e il maggior gradimento popolare del "Top of Mind" della rivista "Amanha". Ha inoltre guadagnato la certificazione internazionale di qualità ISO 9002.

${ }^{13}$ Quella del processo 'senza padri' è un'idea comunque discutibile; non si può, infatti, negare che - pur nella forma peculiare assunta - la filosofia e le trasformazioni avvenute nell'O.P. abbiano un gran numero di 'ispiratori teorici' (da Gramsci a Castoriadis, dalla pedagogia di Paulo Freire a Padre Lebret, fino agli Experimental Workshops on Theory of Organization di Clodomir Santos de Moraes), come si ricava dalla lettura di Fedozzi (1997, 2000) o Menegat (1995). Il tema, comunque, meriterebbe uno specifico approfondimento. ${ }_{14}^{14}$ Dati SMED, 2000.

15 Già dal 1949, tra l'altro, vi era un accordo che impegnava il Comune ad investire il $20 \%$ delle sue entrate fiscali per la costruzione e la manutenzione degli edifici delle scuole Statali (Pozzobon, 1998). L'accordo si è chiuso nel 1986.

${ }^{16} 1.696$ persone sono state seguite nel 2000 (dati SMED)

${ }^{17}$ Liana Rocha, coordinatrice del SEJA, citata in Pozzobon (1998).

${ }^{18}$ Cfr. "Premio Prefeito da Criança 1999", Fundação ABRINQ, 2000.

${ }^{19}$ Uno di questi rappresenta, l'una accanto all'altra, due abitazioni che mostrano i risultati dei comportamenti corretti e scorretti nei confronti dell'utilizzo delle infrastrutture idrico/sanitarie sulla qualità della vita domestica.

20 "Ma molti, specie in ambito accademico, non hanno accettato l'operazione, l'hanno considerata un'ibridazione con l'emergenza, una contaminazione fra ritmi diversi da non favorire. E invece unire politica e insegnamento è tutta la linea di Governo dell'Amministrazione Popolare" (Eliane Menegat, 1999i, apud Allegretti 2000a).

${ }^{21}$ Ad esempio, utilizzando la libertà di manovra data dall'art. $2^{\circ}$, comma XV che invita a valutazioni di impatto (anche sulle caratteristiche estetiche del paesaggio) per "Progetti urbanistici sopra $i$ looha o in aree considerate di rilevante interesse ambientale a detta [...] degli organi municipali e statali competenti".

${ }^{22}$ Lo scopo era favorire la privatizzazione ed evitare nuovi indebitamenti pubblici. In tal senso la Risoluzione è passata sopra la $\mathrm{n}^{\circ} 78$ del Senato Federale che prevedeva criteri di analisi per stabilire quali comuni davano migliori garanzie di restituzione dei fondi.

23 "Eppure sarebbero proprio le tipologie abitative da rinnovare. Noi oggi lavoriamo con un tipo di case tutte uguali che non tengono conto delle famiglie diverse e delle loro attività. Si prende una media ponderata di famiglie con 20 e $40 \mathrm{mq}$ e si fanno case di 32 che non giovano all'uno e a volte sono superflue per l'altro. Su questo abbiamo molto da progredire. Abbiamo 40 modellini di case-tipo diversi ma che sembrano tutte uguali. Non dovrebbero certo creare grosse differenze, ma sennò a cosa ci serve avere le ricerche sulla composizione familiare, la provenienza e il tipo di occupazione degli abitanti che l'Unità di Ricerca del DEMHAB fa in ogni caso di 'reassentamento'?" (Cabistani, 1999i, apud Allegretti 2000a).

${ }^{24}$ I rappresentanti di 3 università, Sindacati e Associazioni di categoria, DEMHAB, SPM, SMIC e Caixa Economica Federal. 
${ }^{25}$ Le 5 tecnologie sono le uniche ritenute adatte dopo una selezione durata oltre 1 anno e mezzo; non suggeriscono grandi innovazioni, ma almeno si adattano al clima e non prenderanno fuoco (Cabistani, 1999i, apud Allegretti 2000a). Le ditte hanno realizzato in media 20 unità in due casi; 45 in un altro; 11 in un terzo e 5 nel tipo di tecnologia più costosa; il totale è di 101 abitazioni. Le tipologie sono embrioni, casette a due piani, o ad uno.

${ }^{26}$ La scelta non è di tipo ideale, ma è dovuta alla necessità di disporre di laboratori di tecnologia dei materiali. Le università sono la UFRGS, la Ulbra e la CIENTEC

${ }^{27}$ In realtà le famiglie da reinsediare sono 96; il programma ufficiale del DEMHAB prevede 5 unità destinate alle 'visite pubbliche'.

${ }_{28}$ Un'altra tecnologia è in struttura metallica mista, tipo quella dell' Archel usata al Planetario; poi ce 'è una in pannelli di mattoni leggeri, una di legno con spuma di poliuretano e chiuse con laminato tipo Eucatex e resine epossidiche che sembra di mattoni. Tutte prevedono montaggio rapido e durabilità, parametri-guida delle scelte.

${ }_{29}$ Il primo lotto prevede di ospitare 32 famiglie (104 persone) che attualmente vivono sull'area della futura Vila Tecnologica, con finanziamento PRO-MORADIA '98 (tagliato). ${ }^{30}$ Cfr. Zero Hora, 13/1/1999.

${ }^{31}$ I lotti saranno di 33,5 mq e le unità abitative di $42 \mathrm{mq}$ distribuiti su due piani; l'altezza massima (nelle sole zone più dense) sarà di 4 piani.

${ }^{32}$ Dopo i primi tre parcellamenti, sui 21 previsti (di cui 3 acquisiti da privati), saranno costruiti quelli che rialloggeranno le 'vilas' di Papeleiros che si trovano nel centro storico, a ridosso della stazione degli autobus, e successivamente Vila Esperança, Vila IAP, Vila A.J. Renner, Nossa Senhora da Paz e Nossa Senhora Aparecida

${ }^{33}$ Cfr. Zero Hora, 6/6/1996.

${ }^{34}$ È il caso del recupero della Riviera Azzurra a Salvador Bahia, cfr Zanuttini, 2002 (e, soprattutto, i brani dell'intervista ad Ivo Imparato, task manager della World Bank per l'merica Latina).

${ }^{35}$ Cfr. De Olho no Orçamento, $\mathrm{n}^{\circ}$ 7, 1998.

${ }^{36}$ Il dato si riferisce al 2002; nel 1999 erano 644 e nel 2000 erano 670.

${ }^{37}$ Con Risoluzione del Parlamento statale $\mathrm{n}^{\circ} 27771$

${ }^{38} \mathrm{Nel}$ caso della città francese di Bobigny (2001) i questionari sono stati redatti in più lingue e 'accompagnati' nelle famiglie da agenti popolari precedentemente formati dall'amministrazione per svolgere opera di accompagnamento e mediazione con i cittadini. Nel caso della città inglese di Milton Keynes, il referendum del febbraio 1999 chiedeva ai cittadini di scegliere tra tre opzioni di politica fiscale, per ognuna delle quali (nei mesi di discussione precedente nei quartieri, e in sede di votazione) veniva chiaramente disegnato uno 'scenario' di servizi e attrezzature realizzabile a fronte di ogni fascia di aumento della pressione fiscale prevista. Alla fine i cittadini (che hanno risposto alla convocazione al $44,7 \%$, cifra altissima visto le elezioni municipali del ' 98 avevano raccolto solo il $26 \%$ degli aventi diritto) hanno scelto di supportare un aumento delle tasse del 9,8\%. Cfr. Geoff Snelson (1999); Le Référendum sur le Budget de MiltonKeynes (Grande-Bretagne), in www.budget-participatif.org .

${ }^{39} \mathrm{Si}$ pensi che altrove ben 12 dei 36 sindaci eletti nel 1988 hanno lasciato il partito o ne sono stati espulsi nel 1993.

${ }^{40}$ L'incisività del concetto è di Granovetter 1973 (ma tradotto in italiano nel 1999):

${ }^{41}$ Le teorie sociologiche sulla forza dei legami deboli da quasi 30 anni osservano che di solito coloro che adottano precocemente un'innovazione - i cosiddetti early innovators - per lo più sono individui 'marginali', che rischiano meno dei soggetti in posizione 'centrale', sono meno frenati da conformismi e apparenze sociali e agiscono spinti dalla necessità per poi scoprire (o talora neppure rendersi conto) di aver aperto una nuova strada che anche altri percorreranno: di essere stati quindi dei ponti locali.

${ }^{42}$ L'esperienza ha mostrato che i'temi' generali sono risultati condivisi soprattutto tra gli abitanti della città formale; un tipo di operatività per ambiti di prossimità fisica si è rivelato, invece, più congeniale a chi ancora aveva problemi di infrastrutturazione nelle sue aree di residenza. 

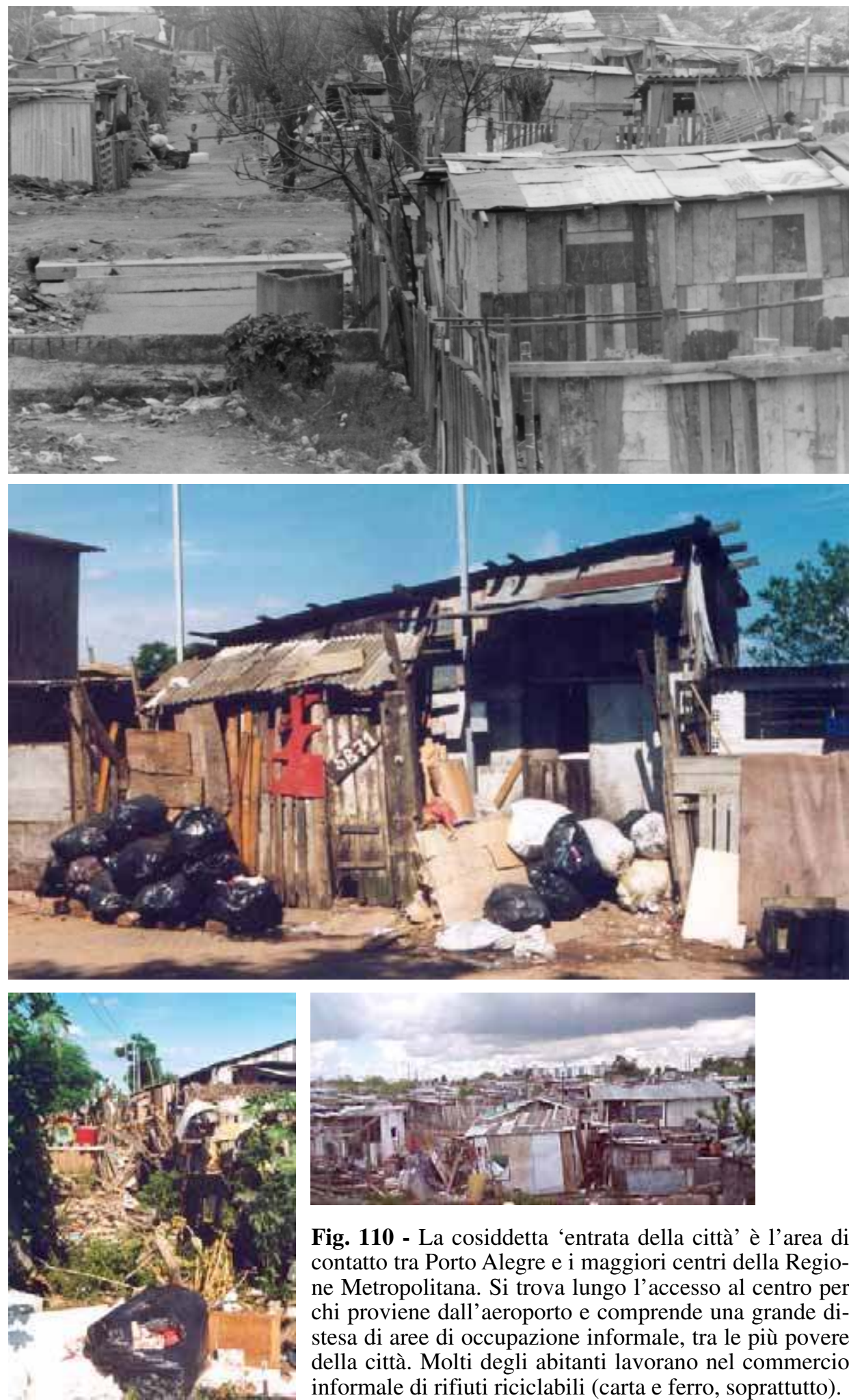

Fig. 110 - La cosiddetta 'entrata della città' è l'area di contatto tra Porto Alegre e i maggiori centri della Regione Metropolitana. Si trova lungo l'accesso al centro per chi proviene dall'aeroporto e comprende una grande distesa di aree di occupazione informale, tra le più povere della città. Molti degli abitanti lavorano nel commercio informale di rifiuti riciclabili (carta e ferro, soprattutto). 
642 Fig. 111 - Il Progetto Integrato di Entrata della Città (PIEC) è partito nel 2002, con lo scopo di realizzare interventi integrati di recupero urbano/abitativo/sociale/economico nell' area più povera della città. $\mathrm{Al}$ suo interno vengono a trovarsi anche alcuni insediamenti recuperati nell'ultimo quinquennio, come il Loteamento Pampa, di cui qui vediamo alcune immagini. Oggi, a soli tre anni dalla costruzione delle abitazioni popolari, gli ampliamenti autocostruiti e le trasformazioni apportate dagli abitanti vanno 'rifavelizzando' parte dell'insediamento.

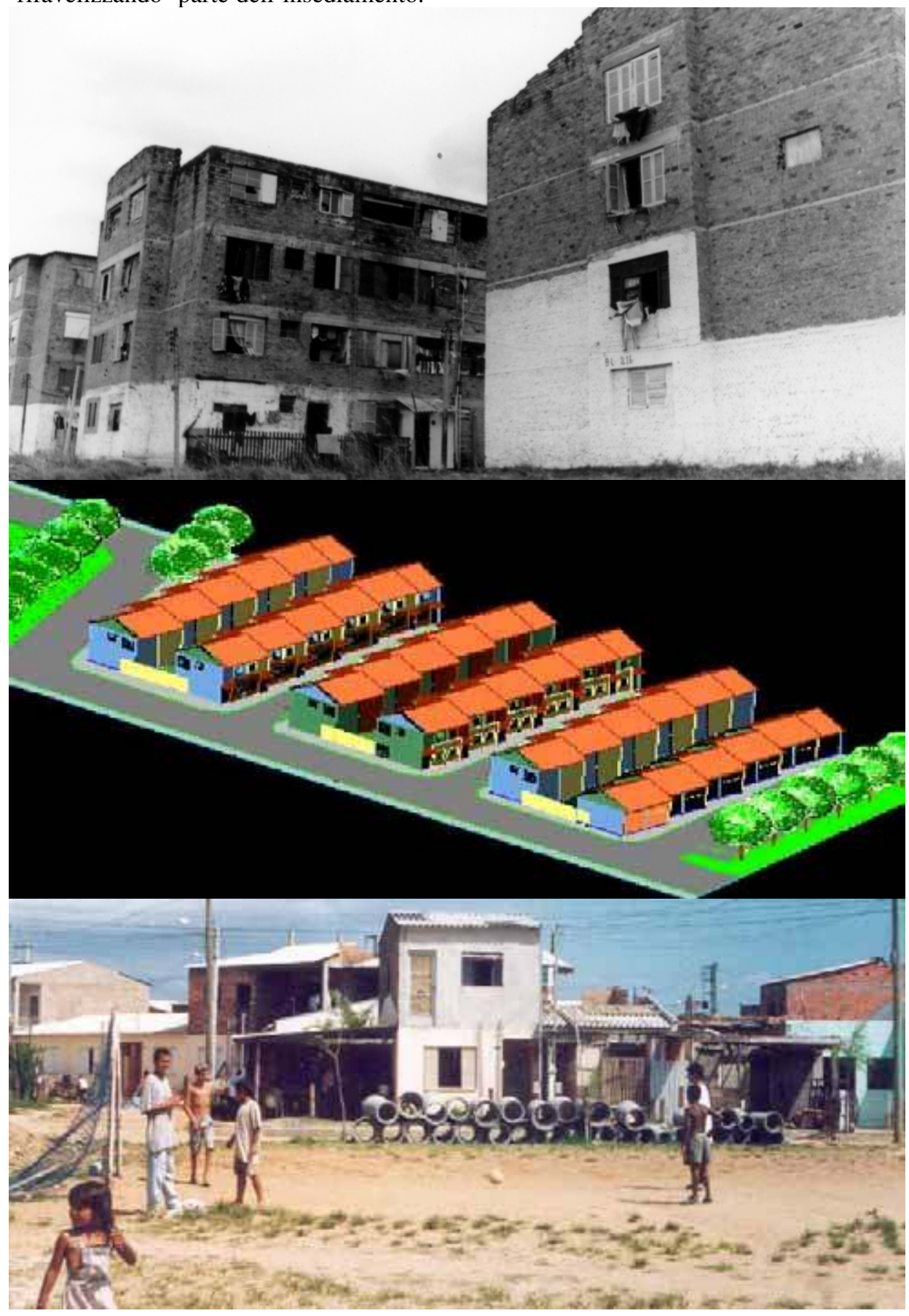


Fig. 112 - L'esperimento-pilota di Vila Tecnologica si inserisce anch'esso all'interno del perimetro del PIEC. Realizzato sulla base di un concorso tra varie imprese locali, ha costruttive. Il suo lotto di case-campione originarie è oggi adibito a funzioni pubbliche.
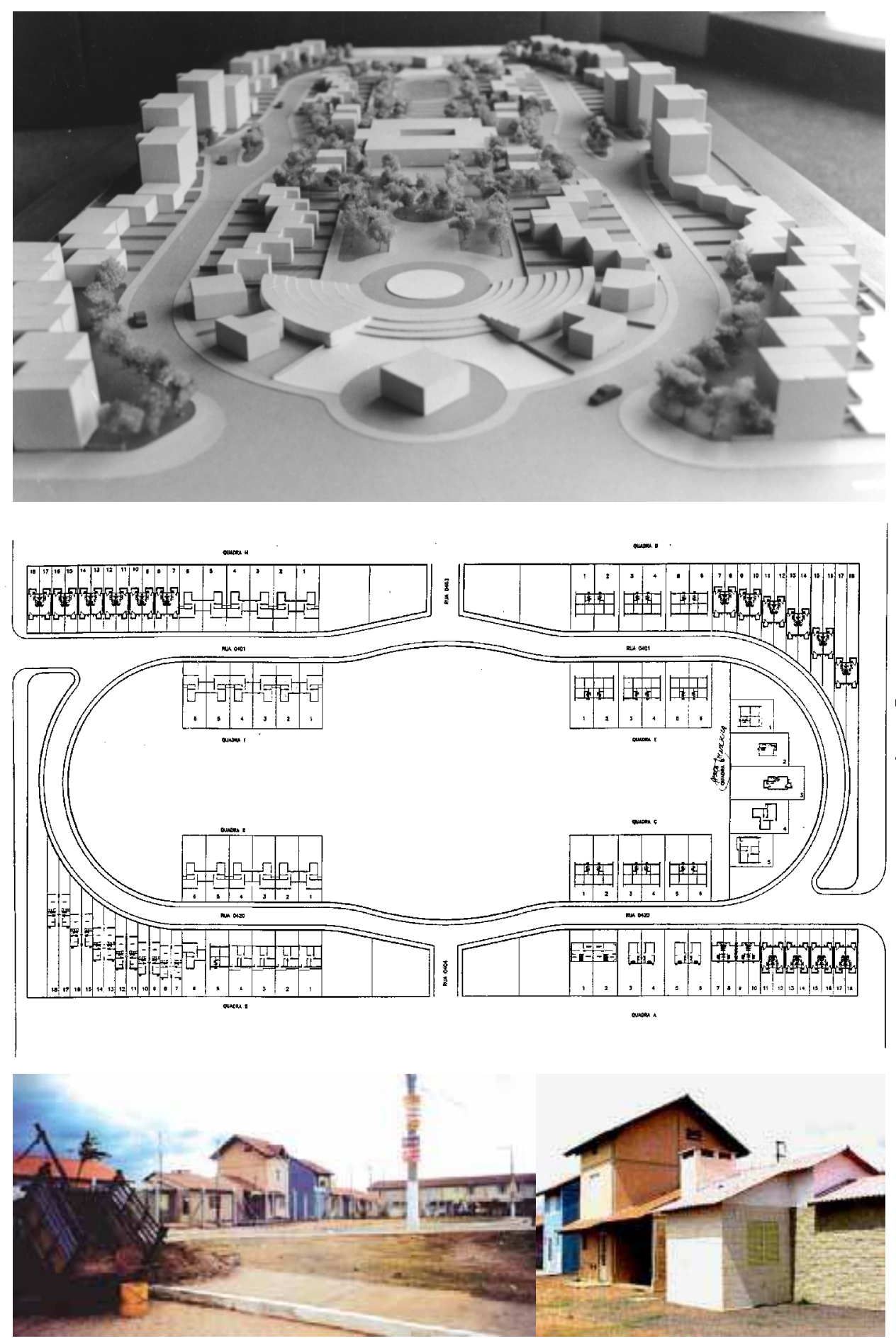
644 Fig. 113 - Il Progetto Integrato di Entrata della Città (PIEC) prevede una forte partecipazione comunitaria (ed un' apposita commissione popolare) per concordare con gli abitanti progetti e priorità realizzative.
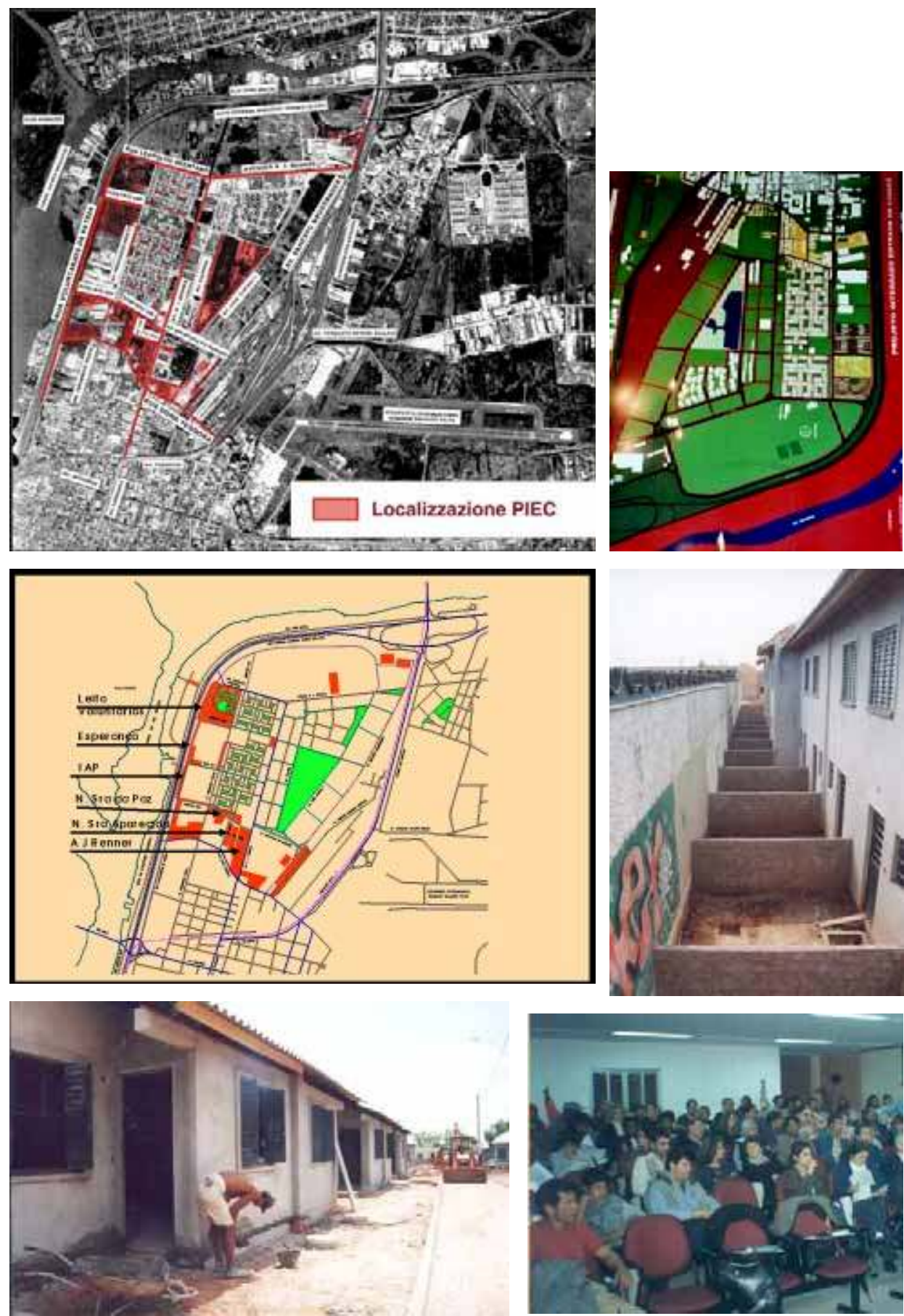
Fig. 114 - Politiche per l'infanzia ed educazione ambientale rappresentano oggi temi strategici per il coordinamento delle azioni svolte dal Comune di Porto Alegre. L'obiettivo è di costruire un Piano di Gestione Ambientale secondo lo schema individuato durante la costruzione del PDDUA. Le foto in basso rappresentano alcuni momenti di co-progettazione che coinvolgono i bambini delle scuole (impegnati anche nella costruzione del Bilancio Partecipativo della Scuola) ma anche i plastici e le rappresentazioni di burattini usate dal Comune per i programmi di Educazione Ambientale.
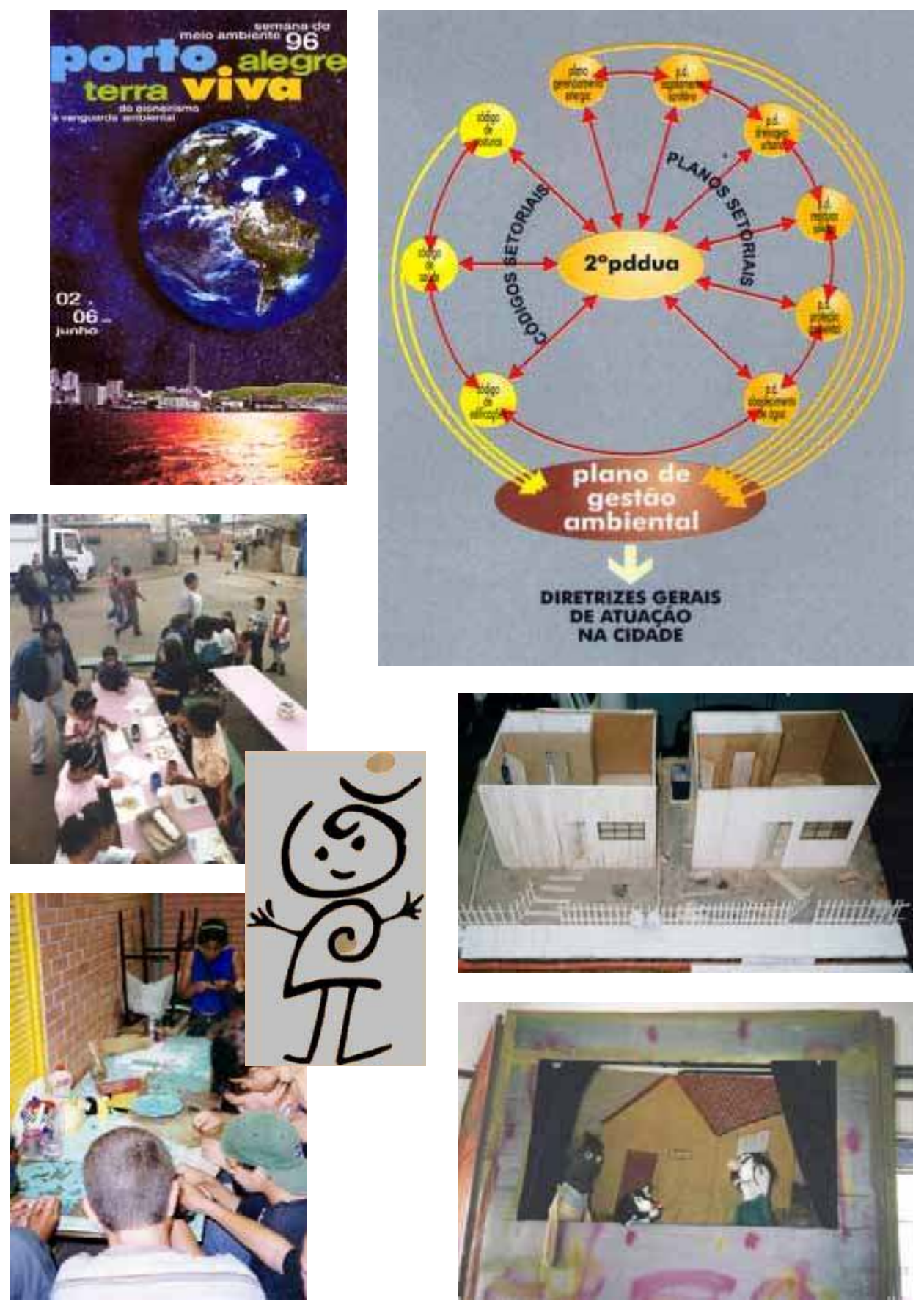
646 Fig. 115 - Con l'organizzazione delle prime tre edizioni del Forum Sociale Mondiale, Porto Alegre si avvia verso un ampliamento del dibattito con i cittadini, su questioni di interesse sovralocale. Parallelamente, è in atto un processo di costruzione di reti con altre città per lo scambio di esperienze virtuose di gestione urbana. Lo stesso Bilancio Partecipativo va modificandosi, osservando le diverse modalità con cui il processo attecchisce e si radica in realtà territoriali diverse (il logo in basso a destra è tratto dal Bilancio Partecipativo di Santo Andrè).

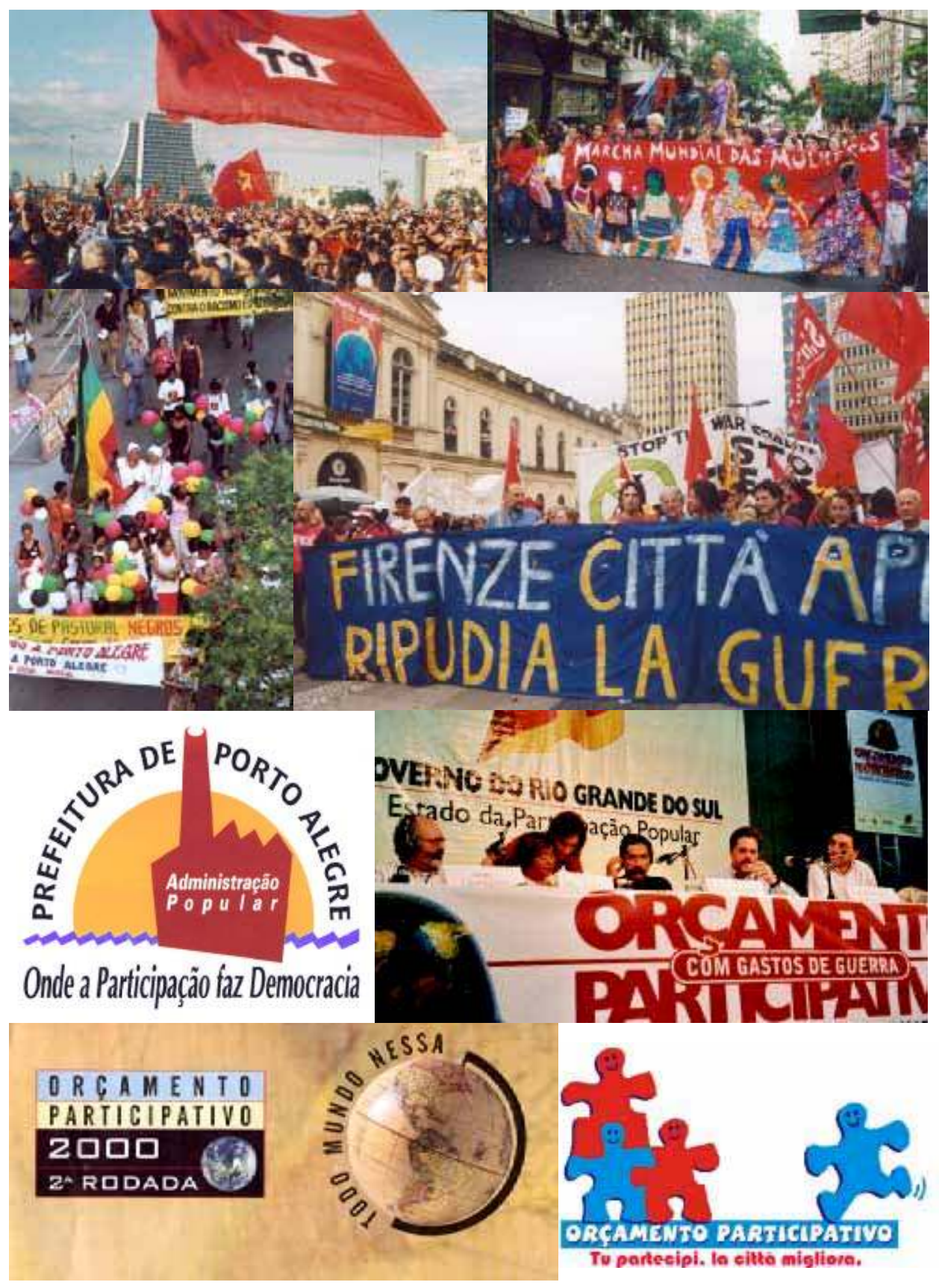


Fig. 116 - Dal 1999 al 2002 il Bilancio Partecipativo è stato messo in opera anche a livello Statale, nello Stato del Rio Grande do Sul e poi in alcuni altri. L'aspettativa creata dall'esperienza di Porto Alegre è stata basilare per generare un "effetto-trascinamento". Nato come una trasposizione dell'O.P. della capitale su scala più ampia, il Bilancio Prtecipativo del Rio Grande do Sul (OP/RS) ha poi assunto una struttura e caratteristiche proprie, in molti casi riuscendo a coordinarsi con i processi analoghi di vari municipi.

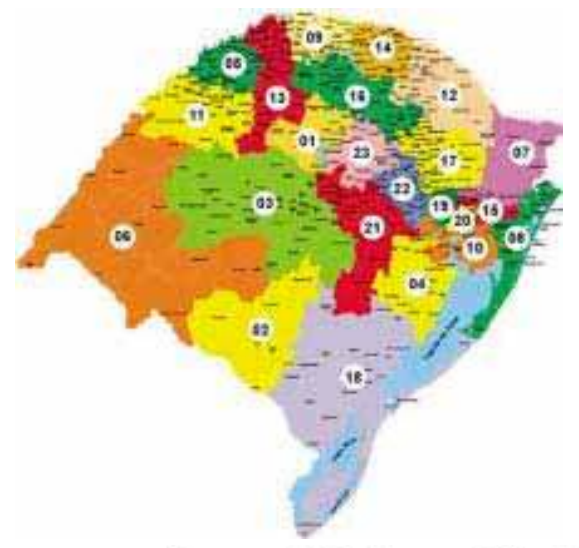

Le 23 Regioni nello stato del Rio Grande do Sul e la struttura di andamento annuale del ciclo di discussione pubblica del Bilancio

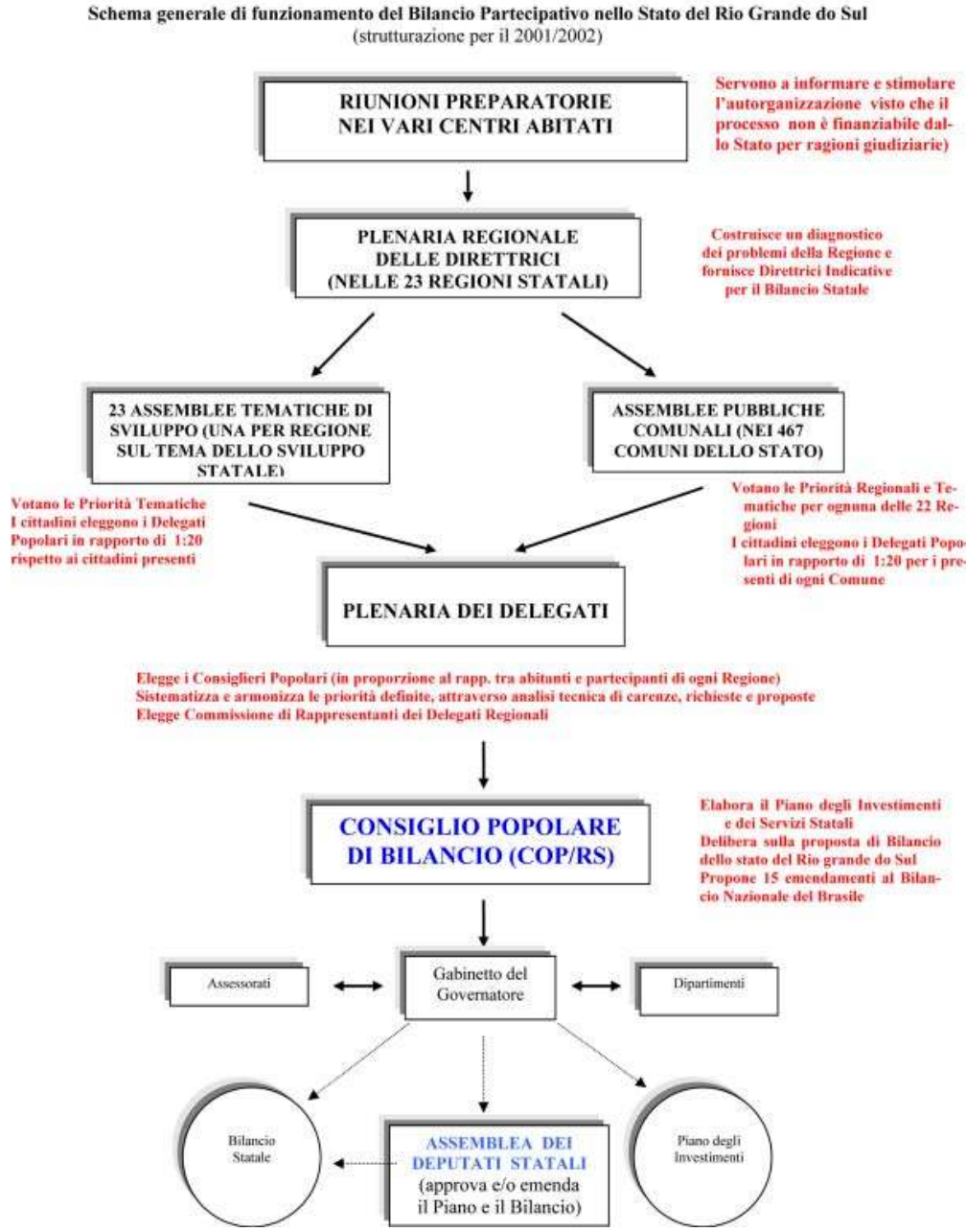


648 Fig. 117 - Alcuni dati sul Bilancio Partecipativo (OP/RS) a livello Statale, nello Stato del Rio Grande do Sul (2002).

Graduatoria delle Priorità Tematiche (Tematica dello Sviluppo) 2002

\begin{tabular}{|c|c|c|}
\hline POSIZIONE & TEMA INDIICATO DAI CITTADINI & PUNTEGGIO \\
\hline $1^{\circ}$ posto & Educazione & 612.601 \\
\hline 2 posto & Agricoltura & 494.266 \\
\hline 3 posto & Creazione di Occupazione e Reddito & 410.219 \\
\hline 4 posto & Trasporto e Viabilita & 264.749 \\
\hline 5 posto & $\begin{array}{l}\text { Ambiente, gestione urbanistico ambientale } \\
\text { e risanamento }\end{array}$ & 116,070 \\
\hline 6 posto & Sviluppo del Turismo & 40.249 \\
\hline 7 posto & Scienzx e Tecuologia & 24.392 \\
\hline $8^{5}$ posto & Minerali ed Fnergia & 21.781 \\
\hline 9 posto & $\begin{array}{c}\text { Gestioni e Azioni di Qualificaione dell'uso } \\
\text { e dell'occupazione del suolo }\end{array}$ & 14.620 \\
\hline
\end{tabular}

Graduatoria delle Priorità Tematiche (Opere e Servizi) 2002

\begin{tabular}{|c|c|c|}
\hline POSIzIONE & TEMA INDICATO DAI CITADINI & PUNTEGGIO \\
\hline $1^{\circ}$ posto & Educazione & 558.606 \\
\hline $2^{\circ}$ posto & Samita & 315.274 \\
\hline $3^{5}$ posto & Trasporto e Vlabillta & 312.943 \\
\hline $4^{\circ}$ posto & Agricoltura & 262.245 \\
\hline $5^{\circ}$ posto & Carezza & 158.612 \\
\hline $6^{\circ}$ posto & Gestione Ambientale e Risanamento & 123.817 \\
\hline $7^{\circ}$ posto & Assistenza Sociale e Promozione della & 47.090 \\
\hline $8^{\circ}$ posto & Cittadinanza & 17.498 \\
\hline $9^{\circ}$ posto & Cultura & 4.368 \\
\hline $10^{\circ}$ posto & Energia & 427 \\
\hline
\end{tabular}

II primo quadriennio di Bilancio Partecipativo (OP/RS)

\begin{tabular}{|c|c|c|c|c|c|c|}
\hline Anno & $\begin{array}{c}\text { Numero } \\
\text { totale di } \\
\text { Assemblee }\end{array}$ & $\begin{array}{c}\text { Numero } \\
\text { totale di } \\
\text { participant } \\
\text { i }\end{array}$ & $\begin{array}{c}\text { Numero totale } \\
\text { di Delegati } \\
\text { popolari eletti }\end{array}$ & $\begin{array}{c}\text { Numero } \\
\text { totale di } \\
\text { elettori dello } \\
\text { Stato }\end{array}$ & $\begin{array}{c}\text { \% di } \\
\text { partedpanti, } \\
\text { sul totale } \\
\text { degli elettori }\end{array}$ & $\begin{array}{c}\text { \% degli } \\
\text { investimenti } \\
\text { discussi, sul totale } \\
\text { del bilancio }\end{array}$ \\
\hline 1999 & 644 & 190.000 & 8.460 & 6.846 .077 & 2,77 & 3,63 \\
\hline 2000 & 670 & 281.926 & 13.987 & 7.112 .134 & 3,96 & 4,24 \\
\hline 2001 & 735 & 378.340 & 18.601 & 7.112 .134 & 5,32 & 4,36 \\
\hline 2002 & 775 & 333.040 & 16.145 & 7.352 .181 & 4,52 & $\begin{array}{c}\text { Dato non ancora } \\
\text { pubblicato }\end{array}$ \\
\hline
\end{tabular}

Dati: Secretaria da Fazenda do Fstado do Rio Grande do Sul (da: Dos Santos Marques, L, da Silva Porto, S, Fiorissi S. 20002) 


\section{7 \\ Una conclusione aperta}

Iniettare riflessioni sulle esperienze empiriche nell' attuale dibattito sulla democrazia deliberativa può [...] ampliarne gli orizzonti immaginativi, oltre che immettervi un po' di realismo (Fung e Wright, 2001).

Tensione progettuale e sfida costruttiva. Si può pensare di raccontare cosa la città di Porto Alegre rappresenta oggi per una crescente moltitudine di persone di paesi diversi,senza raccontare il suo percorso urbano?

Forse no, ma sarebbe stimolante. Vorrebbe dire, infatti, ricominciare a discutere di temi 'nodali' per la costruzione e la gestione quotidiana del territorio, a partire dalle nostre forze e dalle nostre riflessioni. Misurando, così, quanto siamo stati capaci di apprendere dall'osservazione dei limiti delle nostre democrazie, forse più diverse e locali di quanto abbiamo finora riconosciuto, accecati (come spesso siamo) dal desiderio di identificare un modello 'generalista' valido ovunque e in ogni tempo.

Il nostro augurio è ovviamente un'ipotesi per assurdo, tanto più che è proprio questa la prima 'sfida' che l'insegnamento di Porto Alegre pone ad un occidente sviluppato spesso protervo: accettare il contributo propositivo che gli giunge da uno dei Sud del mondo, un'opportunità di mettere costruttivamente in discussione dei concetti basilari la cui staticità, nell'ultimo secolo, abbiamo spesso scambiato per acquisito equilibrio, quando non addirittura per intoccabile perfezione raggiunta.

Queste riflessioni hanno contribuito a definire non solo i contenuti, ma anche la 'forma' di questo libro, che non è un 'prontuario' di modalità e tecniche per la configurazione di percorsi di democrazia partecipativa, e neppure un saggio argomentativo dalla strutturazione classica, ma una 'biografia territoriale'. Ovvero una narrazione che segue il percorso di un'esperienza avvenuta in un preciso luogo e in un preciso momento, cercando di evidenziare suggerimenti e spunti di riflessione su temi che ognuno di noi potrà, poi, tornare ad affrontare nei diversi contesti a cui sente di appartenere. Un approccio di questo tipo ci è parso rispettoso dell'umiltà sperimentatrice con cui Porto Alegre ha messo a disposizione di tutti il suo cammino di cre- 
scita, e - al contempo - ci è sembrato che potesse facilitare l'accettazione di questa emozionante 'sfida' a riprendere un cammino di arricchimento interpretativo ed organizzativo delle nostre politiche territoriali.

Per poter raccogliere questo stimolo è, comunque, necessario mettere da parte ogni atteggiamento pregiudiziale verso ciò che proviene da luoghi distanti dai nostri. Ciò vuol dire operare contestualmente in due direzioni complementari: rifuggire le posizioni denigratorie o scettiche che fanno del relativismo culturale l'alibi per giustificare l' 'esotizzazione' e il 'confinamento' (quando non l'esilio!) di ogni positiva sperimentazione che viene da contesti arbitrariamente etichettati come non sviluppati, ma anche mettere da parte gli atteggiamenti che propugnano la mitizzazione acritica di qualsiasi esperienza che provenga dal Sud del pianeta, esaltandola come portatrice di purezza e originalità, ancor prima di averne proposto un'attenta contestualizzazione spazio-temporale.

Purtroppo, in questi ultimi anni, l'esperienza di Porto Alegre è stata spesso oggetto di letture che partivano - alternativamente - da uno di questi due opposti atteggiamenti: entrambi uniti da una prospettiva di osservazione tendenzialmente strumentalista e 'autocentrata' che ha finito per precludersi possibilità di conoscenza e comprensione più approfondite.

Il nome di Porto Alegre ha, così, teso ad assumere un valore simbolico, che ne ha oscurato le lezioni e i meriti reali, quelli concretamente conquistati sul campo della riforma dell' azione politico-amministrativa ${ }^{2}$. Questa 'esaltazione' ha generato (anche internamente alla sinistra) delle contro-reazioni di segno uguale e contrario, le quali - pur tributando all'esperienza ammirazione e rispetto - hanno teso ad 'isolarla' in un 'ghetto' di irreplicabile singolarità. La lettura schizofrenica offerta in tal modo (specialmente nel contesto italiano, dove ancora è povera la ricerca sul tema) ha finito per indebolire l'incisività degli insegnamenti che sarebbe possibile trarre da un'attenta ricostruzione del contesto e del momento in cui l'esperienza si è sviluppata, così come da una sua analisi comparata con altri percorsi di sperimentazione che si muovono in un'analoga direzione nel dibattito su democrazia e governo locale.

Oggi è, pertanto, indispensabile guardare a Porto Alegre in maniera più distaccata, e - di conseguenza - anche più approfondita e più lucida.

Questo richiamo è, forse, l'unica conclusione possibile per un testo che non voleva e non vorrebbe chiudersi, sognando di restare aperto a rielaborare in corso d'opera un magma di informazioni e di stimoli che in questo momento si trova in piena ebollizione, e va 'contagiando' contesti lontani e diversi da quelli dove si ambienta la narrazione che sta nel suo centro.

La speranza è che questo libro offra spunti di riflessione che possano arricchirsi in futuro di ulteriori ricerche e dibattiti, magari giovandosi di analisi comparate di altre realtà, dove i principi e i valori che hanno fatto da fulcro all'esperienza di Porto Alegre vanno assumendo forme organizzative diverse ed ispirando politiche coerenti con l'appassionante molteplicità di differenze e peculiarità, che caratterizza ogni contesto locale.

\subsection{La sfida di Porto Alegre}

Nell'appendice $\mathrm{n}^{\circ} 5$ di questo testo, abbiamo voluto sintetizzare alcune considerazioni emergenti da una recentissima inchiesta dell'Associazione Nazionale dei Comuni Italiani che dà conto di un trasformarsi dell'immaginario 
dei cittadini relativamente al ruolo e ai modi con cui dovrebbe muoversi il 'governo locale', inteso nella sua duplice accezione di 'istituzioni' e di 'modi di governare' (o 'governanza' ${ }^{3}$ ), cioè del binomio che in ambito anglosassone si designa con i termini di government and governanc' ${ }^{4}$.

L'inchiesta, infatti, evidenzia la sfida propositiva costituita dall'esistenza di uno scarto interpretativo (tra 'società politica' e 'società civile') circa il tema del coinvolgimento degli abitanti nelle politiche di costruzione e trasformazione del territorio. Leggerla può essere utile a collocare alcuni insegnamenti che emergono dalla vicenda di Porto Alegre, in un quadro di valenza più generale, dove possano essere messi a disposizione di altre esperienze in corso d'opera. In particolar modo, per quanto riguarda un tema 'nodale' della vicenda che questo libro ripercorre: quello della necessità di creare nuovi spazi pubblici non statali che affianchino i percorsi della democrazia rappresentativa connotandosi anche come momento di ricostruzione della politica cittadina, e come 'luogo' in cui sfera pubblica e sfera individuale possano incontrarsi con rinnovata fiducia reciproca ed arricchirsi vicendevolmente, senza che l'esaltazione della singolarità dei cittadini-individui sacrifichi la dimensione collettiva e solidale dell'agire.

Una simile riflessione appare sempre più necessaria al cospetto di alcune dinamiche che vanno interessando molti paesi (a partire da quelli dell'Unione Europea) in un momento in cui l'elezione diretta dei Sindaci e dei Presidenti di Regioni e Province (o dei loro corrispondenti nei paesi con articolazione amministrativa diversa da quella italiana) tende ad esaltare il primato della 'decisionalità' in ambito locale e il rafforzamento delle componenti tecnico-professionali rispetto a quelle politiche, proprio mentre il ruolo sociale svolto dai partiti e da altre forme tradizionali di aggregazione appare sempre più ridotto. Queste dinamiche parallele sembrano rendere urgente la ricerca di nuovi strumenti di mediazione e relazione tra cittadini e istituzioni, che siano in grado di colmare il vuoto aperto nella rappresentanza, e al contempo di valorizzare al meglio le propensioni degli abitanti verso nuove forme di attivismo che vanno sorgendo, oscillanti tra la soggettivizzazione dell'impegno politico del singolo e il costituirsi di nuovi soggetti collettivi di aggregazione.

Questa oscillazione non si configura come un ossimoro o una contraddizione schizofrenica di un mutamento sociale ormai assestato. Costituisce, semmai, il segno di una ricerca (ancora in corso) di nuove forme di equilibrio che rispondano alle ansie indotte dai fenomeni di globalizzazione e dal livellamento generalizzato prodotto dai mezzi di comunicazione. I quali, proponendo su scala planetaria gli stessi modelli di riferimento, paiono minacciare "uno dei fondamenti della civiltà europea: l'individualità in senso forte e classico" (ANCISWG, 2002, p. 35), generando così movimenti in direzioni differenti, nel tentativo di conciliare la necessità di nuove forme di coesione sociale e assunzione collettiva delle scelte con le opportunità di libera espressione del singolo.

È da questa apparente contraddizione che vale, forse, la pena di partire, per comprendere sia l' 'eccezionalità' che la 'normalità' dell'esperienza di Porto Alegre, ricollocandola in un panorama che in pochi decenni ha subito - su scala mondiale - un mutamento epocale in pieno svolgimento, del quale ci interessa enucleare sinteticamente solo alcune linee di tendenza. Ben sapendo che è difficile cogliere esattamente il senso di trasformazioni ancora in corso, e che comunque - anche a fronte di processi che prefigurano orizzonti completamente inediti - è sempre possibile riscontrare la persistenza di modelli, strategie, 
pratiche e istituzioni, che sembrano attestare una sostanziale continuità tra passato e presente, quando non una vera e propria 'resistenza' al cambiamento ${ }^{5}$. In questo quadro, vale certo la pena di riprendere alcuni insegnamenti che l'esperienza di Porto Alegre può offrire come 'valore aggiunto' per stimolare e far riflettere i promotori di esperienze, che nei nostri contesti locali stanno partendo o ancora 'brancolano nel buio', seppur con qualche intuizione creativa e molte buone intenzioni.

In questo passaggio interpretativo va mantenuta piena coscienza dell'ostacolo culturale che - per certi versi - le radici illuministe ed antistoriciste della nostra democrazia rappresentano, per chi si proponga di apprendere da esperienze sviluppatesi in paesi periferici o in transizione. Esse hanno, infatti, contribuito a configurare un tipo di cultura politica al cui centro stanno le opportunità e le garanzie di libera espressione delle capacità politiche individuali, le quali - in certo qual modo - spiegano anche la distanza che la democrazia rappresentativa formale ha posto tra il cittadino comune e i 'decisori' politici.

$\mathrm{Su}$ questa cultura politica ha attecchito e si è riprodotta nel tempo una crescente 'pigrizia' delle nostre istituzioni nell'interpretare le normative al di fuori dei loro formalismi, retroilluminandole continuamente della ratio legis alla base della loro formulazione. Questa 'adesione alla lettera' è forse oggi uno dei maggiori ostacoli - anche nei nostri contesti locali - a 'sperimentare' nuovi ed incisivi strumenti di democrazia diretta, che affianchino quelli della democrazia delegata. L'attesa che altri sperimentino e il timore di muoversi per primi (aprendosi ad ipotetiche contestazioni su campi in cui risulti ancora assente una giurisprudenza già consolidata) paiono divenire la regola che muove (anzi, che non muove) le nostre istituzioni, col rischio che la pigrizia si trasformi in viltà, e l'immobilismo contribuisca all'avvizzimento della democrazia rappresentativa,dilatando all'eccesso la sua distanza dagli abitanti.

Su questo, hanno vari insegnamenti da darci le molte esperienze che provengono dal margine e dalla periferia, come l'esperienza di Porto Alegre (specie se letta in rapporto alla recente approvazione della legge brasiliana sullo "Statuto della città", cfr. cap. 11). Esse ci mostrano, infatti, che bisogna osare, che bisogna sapere e volere innovare ispirandosi ai concetti 'ampi' contenuti nelle costituzioni e negli statuti, dato che il ventaglio di possibilità creative che sta tra ciò che la legge già disciplina puntualmente e ciò che essa non vieta specificamente è sovente molto grande. E - soprattutto - esse ci suggeriscono di puntare sul dialogo con la creatività degli abitanti e sulla valorizzazione della loro autoprogettualità, 'rischiare' sulla quale - come il caso di Porto Alegre insegna - può portare a risultati estremamente positivi per l'intera collettività.

\subsection{Porto Alegre dentro il quadro di riassestamento della democrazia liberale}

Ogni cosa al mondo è messa in discussione, dalla letteratura all'ecologia, dalle galassie in espansione all'effetto serra, dal trattamento dei rifiuti alla congestione del traffico. Solo i sistemi democratici ancora non vanno soggetti a discussione, come se fossero dati, acquisiti definitivamente ed intoccabili per natura fino alla fine dei tempi" (José Saramago, discorso di chiusura del Forum Sociale Mondiale di Porto Alegre, 5 febbraio 2002).

Tra gli esiti politici più rilevanti (e più ambigui) della storia contemporanea vi sono certamente le contraddizioni insanabili apertesi nel modello di svi- 
luppo imperante che ha tentato di conciliare il liberalismo politico e il liberismo economico associando lo Stato Minimo ad un inarrestabile estensione delle relazioni mercantili. Ma vi è anche il contrasto che ha preso forma tra il diffondersi dei regimi democratici e la crisi che, contestualmente, va segnandone le sorti, come se il momento della loro "massima estensione rappresentasse la condizione per il loro realizzarsi e questa, allo stesso tempo, [rappresentasse la condizione] della loro crisi e del loro svuotamento" (Sader, 2002, p. 651). A ben guardare, questo contrasto non costituisce un paradosso. Proprio il "naturalizzarsi" della democrazia liberale come "orizzonte storico più avanzato del mondo" (ibidem, p. 653) ha, infatti, storicamente coinciso con lo svuotamento di alcuni dei suoi legati fondamentali, offuscati dal prendere piede di una ideologia sempre più tesa ad identificare il cittadino con il consumatore e i processi elettorali con il mercato. Essa ha, infatti, messo inevitabilmente in moto processi di smoralizzazione politica e di privatizzazione esacerbata delle relazioni sociali, con conseguente disinteresse per ciò che è pubblico ed ovvie ricadute in termini di disaffezione del cittadino per la politica, tradottesi dapprima in fenomeni di forte astensionismo elettorale e più di recente - nella rinascita di nuove e diverse forme di impegno militante. Per certi versi, se oggi si va aprendo un processo di "messa in discussione" dell'articolazione e dello sviluppo delle democrazie liberali, lo si deve in gran parte agli esiti prodotti dal processo evolutivo storico che le ha marcate, e dalle relazioni che le loro istituzioni politiche rappresentative sono andate stabilendo - nel corso dei processi di trasformazione e ristrutturazione che le hanno riguardate - con l'ambito dell'economico.

Nell'ultimo trentennio, infatti, l'invasività delle relazioni mercantili ha prevalso sulla stessa riforma dello Stato, che ha "cessato di essere sinonimo di una sua democratizzazione, per confondersi con la riduzione delle proprie funzioni regolatrici, con il suo riallineamento all'obiettivo [...] dell'aggiustamento fisca$l e^{96}$. La conseguenza di questa mercantilizzazione delle prospettive di lettura ed evoluzione della democrazia (come anche della cultura) ha teso gradualmente a mettere in ombra il tema dei diritti, parallelamente indebolendo molti movimenti sociali e generando un riflusso nel privato e nella ricerca di soluzioni individuali, di cui il proliferare delle nuove forme di religiosità e la letteratura dell'auto-aiuto sono solo alcuni dei sintomi più evidenti (ibidem).

È seguendo questo percorso dei diritti (di quelli sostanziali, prima ancora che di quelli formali), e del loro rapporto con l' 'invasività totalizzante' dell'economico, che ha preso avvio un ampio dibattito critico sulle degenerazioni che, nel tempo, hanno foggiato molti esiti della democrazia liberale. E non è un caso che gli spazi dove quest'opera di 'decostruzione critica' ha preso forma in maniera più decisa ed incisiva siano stati soprattutto i paesi periferici o in via di sviluppo, cioè i "territori particolarmente toccati dalle ristrutturazioni neoliberiste" (Sader 2002, p. 656) e "dalla voracità con cui la globalizzazione egemonica ha divorato non solo le promesse di progresso, di libertà, di uguaglianza, di non discriminazione [...] ma anche la stessa idea di una lotta per il loro conseguimento"(Sousa Santos, 2002, p. 17). Lì, infatti, il "sentimento di 'esclusione sociale' - risultato della perdita di diritti"- ha non solo favorito un ripensamento critico della democrazia, ma "ha teso a promuovere nuove forme di organizzazione, di protesta e di coscienza di vincolo".

La riflessione creatasi all'interno di questo percorso - in transito dalla "resi- 
stenza' alla 'alternativa' - è servita anche a riflettere su come, in fondo, in epoca di produzione fordista la struttura dei 'diritti' e l'accesso alla condizione di cittadinanza abbiano teso ad essere mediate dal lavoro, al cui ambito di significato quasi tutto il ' 900 ha legato le principali forme di rappresentanza del cittadino, dando loro il valore di 'rappresentanze generali'. È risultato quindi naturale che tali rappresentanze tendessero a ridursi a rappresentanze solo 'parziali', nel momento in cui il passaggio dal fordismo al postfordismo ha innescato una diffusa crisi del protagonismo sociale del lavoro (Magnaghi, 2000). Questo, infatti, è divenuto al contempo 'totale e pervasivo', ma socialmente invisibile nello spazio pubblico ${ }^{7}$, in quanto progressivamente privato dei suoi luoghi di rappresentazione e svuotato dei suoi criteri di coesa rappresentanza, a motivo della centralità acquisita dai fenomeni di esternalizzazione, decentramento produttivo e frammentazione delle figure professionali.

La riflessione di questi ultimi anni ha dovuto prendere coscienza di come il fordismo - attraverso il peso dato nel dialogo sociale ad alcune forme di rappresentanza degli interessi dei cittadini (in primis quelle sindacali e poi le forze del Terzo Settore organizzato, che hanno cercato di rilevarne gli spazi) - abbia contribuito a rafforzare, assieme alla coesione sociale, anche le forme della democrazia rappresentativa, a scapito delle espressioni della democrazia diretta.

In tale ottica, non è difficile comprendere come mai l'avvento del postfordismo - con la crisi dei 'presupposti' che l'ha accompagnato - abbia aperto delle nuove opportunità anche alla valorizzazione del ruolo di 'ravvivamento democratico' attribuibile al ricorso a forme di democrazia diretta, rendendo in parallelo necessario affiancar loro delle politiche sociali sganciate dall'inserimento dei beneficiari nei sistemi di lavoro ${ }^{8}$ e centrate sulla creazione di legami reticolari di cooperazione tra le nuove forme atomizzate e le nuove figure professionali del lavoro, e - soprattutto - sulla costruzione di nuovi 'luoghi' per la loro rappresentazione.

In un certo senso, la presa di coscienza del processo di 'decostruzione' che ha colpito molte delle consolidate strutture sociali di rappresentanza ha reso indispensabile non solo la riorganizzazione della produzione, del mondo del lavoro e della struttura sociale, ma anche il progressivo e radicale ripensamento della politica. E non solo di quella che ha caratterizzato i tre quarti del Novecento, ma dell'intera politica moderna strutturatasi - fino all'affermarsi delle grandi democrazie occidentali - intorno all'asse verticale del binomio comando-obbedienza. Nel nuovo panorama, infatti, è apparsa sempre più indispensabile la creazione di nuove arene politiche, incentrate sulla prevalenza delle relazioni orizzontali, in cui le rappresentanze dei partecipanti possano non essere predisposte anteriormente ai processi stessi, ma costruirsi contestualmente ad essi, così favorendo il passaggio da pratiche politiche essenzialmente 'concertative' (in cui i soggetti sono chiamati ad un tavolo di discussione in virtù della loro capacità di rappresentare forze economiche o particolari classi e/o segmenti sociali) a pratiche maggiormente 'partecipative', cioè aperte al libero intervento di ogni abitante o - in taluni casi - di particolari categorie-obiettivo. In seno ad un simile processo (che meriterebbe ben altri approfondimenti rispetto a questo rapido accenno, inevitabilmente schematico e riduttivo) sono andate prendendo corpo trasformazioni sovente contraddittorie delle pratiche di governo del territorio ${ }^{9}$, che - nei casi più significativi - hanno cercato di porsi nella prassi come elemento di riequilibrio di apparati socio-istituzio- 
nali "le cui dinamiche di inclusione sono ancora mediate dal lavoro inteso come impiego, come occupazione a tempo pieno, garantita, continuativa e stabile" e in cui si continua a "subordinare la titolarità dei diritti di cittadinanza e in ultima analisi il diritto all'esistenza, al fatto di essere lavoratore o lavoratrice" (De Giorgi, 2002, p. 104), nonostante una spinta diffusa a ristrutturare i rapporti di produzione proprio sulla base della riduzione e precarizzazione del lavoro. Per certi versi, è proprio la "contraddizione fra i requisiti che la costituzione formale della cittadinanza continua a richiedere astrattamente di soddisfare, e le risorse che la costituzione materiale postfordista predispone concretamente" (ibidem, 105) che ha contribuito ad alimentare la riflessione sulla possibilità di riaffermare il ruolo dello 'Stato di diritto' attraverso una ristrutturazione dei modi in cui si organizza l'interazione tra i cittadini (non più disposti ad accettare di essere letti come meri destinatari di politiche $\mathrm{e}$ servizi) e le amministrazioni. E questo proprio a partire dagli ambiti locali, già impegnati in trasformazioni imponenti sul fronte delle priorità di governo (con la collocazione della promozione territoriale in posizione centrale rispetto alle più tradizionali politiche socioterritoriali di loro competenza) e su quello delle modalità di gestione dei servizi, con il passaggio (sovente imposto da organismi politici di livello superiore) da forme tradizionali di gestione diretta a criteri privatistici incentrati sullo snellimento dell'amministrazione pubblica e sull'affidamento a terzi.

La riflessione su diritti e democrazia, infatti, ha preso indubbiamente le mosse in seno alla 'società civile', e in particolare in quei paesi periferici o semiperiferici dove particolarmente evidente appariva lo scarto tra "diritti sanciti formalmente, però abitualmente negati nella realtà", e modalità organizzative di una democrazia incapace di rinnovarsi approfondendo la "relazione tra cittadini e decisioni del potere politico" e offrendo opportunità di "riscatto" a minoranze politiche, etniche o di genere (Sader, 2002, p. 657).

$\mathrm{Ma}$, ben presto, tale riflessione ha incontrato sul suo cammino una rispondenza nell'inizio di un percorso autoriflessivo cominciato da una parte minoritaria ma non certo insignificante - della classe politica, in particolar modo tra gli amministratori locali i cui ambiti di governo - in parallelo alla crisi degli Stati-Nazione e al diffondersi dei miti della 'governance' e della 'sussidiarietà verticale' - sono risultati attraversati da una consistente trasformazione delle funzioni, dei diritti e delle responsabilità.

Tali mutamenti hanno dato impulso graduale a riforme e sperimentazioni mirate ad un più attivo coinvolgimento dei cittadini nell'assunzione di scelte riguardanti il territorio locale, che - seppur con motivazioni diverse da caso a caso - spesso è possibile ricondurre ad alcuni assi di significato prioritari quali:

1) la necessità di compensare la fragile legittimazione elettorale (ormai tendenzialmente decrescente) mediante la ricerca di consenso su singole questioni;

2) la necessità di prevenire le proteste e i conflitti che sovente emergono davanti a scelte 'calate dall'alto', mettendo in opera progetti maggiormente condivisi già in fase di costruzione delle scelte ${ }^{10}$. Esistono anche casi di politiche pubbliche che non producono 'giochi a somma positiva', in cui la creazione di processi partecipativi può essere avvertita come fondamentale ma non dirimente, perché la scelta finale produce comunque scontento in alcuni segmenti della società (ad esempio i casi di ubicazione di nuovi inceneritori, cimiteri o impianti di compostaggio) ${ }^{11}$ ed altri casi in cui una politi- 
ca pubblica appare irrealizzabile senza il coinvolgimento dei cittadini (ad esempio la raccolta selettiva dei rifiuti).

È proprio dall'incontro di gruppi in cammino (società civile e società politica di ambito locale) che hanno preso origine - a latitudini diverse del pianeta, ma con particolare forza in America Latina - alcune delle più interessanti sperimentazioni di socializzazione della politica e del potere di ambito locale portate avanti nell'ultimo ventennio, di solito classificate con la definizione forse non correttissima di "democrazia partecipativa" e generalmente incentrate sull'assunzione propositiva dell'alternativa gramsciana, secondo cui esisterebbero due tipi possibili di politici: coloro che si adoperano per diminuire la distanza tra governanti e governati e coloro che si adoperano per superarla.

\subsubsection{Porto Alegre come 'parte' di un 'tutto' in trasformazione}

Implicitamente o esplicitamente, la riflessione comune sulla necessità di 'ravvivare' e 'ridemocratizzare la democrazia' (Sousa Santos, 2002) mette in discussione la concezione individualista del mondo e della politica situata alla base del liberalismo, dove al "carattere sacro e simbolico" del voto (Sader, 2002, p. 658) corrisponde "l'autonomizzazione del politico" che, "estremizzata nella relazione tra la passività degli elettori e l'estremo attivismo monopolizzato dall'élite politica governante", rischia di trasformare la politica stessa “in un'attività privata, esercitata da professionisti [...] responsabili della 'gestione' della società per mezzo dello Stato - sempre più considerato come un'impresa”, rinnovando così "le teorie delle élite, deificando la politica e isolandola dalle relazioni sociali"(ibidem).

In tale contesto di rilettura critica, lo stesso termine di 'partecipazione' (per il liberalismo sostanzialmente limitato all'esercizio dei diritti di voto, e quindi alla formulazione di una 'delega' per il governo dei diversi livelli dello stato) ha necessitato di una revisione, prima di potersi imporre come il 'cuore' di esperienze di "democrazia partecipativa" intese a rompere il circolo vizioso sopra indicato, e a riscattare la dimensione pubblica e cittadina della politica. La ricerca di nuove strade per coinvolgere i cittadini nelle scelte per il territorio, ha preso avvio quasi ovunque dall'ambito municipale, un livello di governo 'minore' (Bobbio, 2002, p. 4) a causa dei limiti finanziari e funzionali imposti dagli stati centrali e/o dai livelli di governo regionale, ma non certo 'minore' dal punto di vista concettuale, soprattutto considerando che di solito i comuni "consentono una partecipazione alla vita pubblica e alle scelte collettive che altre istituzioni più lontane difficilmente permetterebbero ${ }^{12} " \mathrm{e}$ mostrano "una maggiore capacità innovativa dei governi centrali" (ibid.), spesso sperimentando in periferia molte delle innovazioni che saranno poi riprese o rielaborate dagli stati nazionali ${ }^{13}$.

Il caso di Porto Alegre trattato in questo libro rappresenta un'emblematica convergenza di queste due ragioni, a riprova di come l'acquisito dinamismo dei governi locali (intesi come insieme di attività e soggetti che contribuiscono a formulare e mettere in opera politiche pubbliche locali) possa costituire un punto di osservazione decisivo per capire i processi di trasformazione che stanno investendo la democrazia.

Esso costituisce, di certo, una 'punta avanzata' delle molte proposte di democrazia partecipativa sperimentate nell'ultimo decennio, in quanto - materializzandosi in un progetto complesso che mette in tensione su più piani il 
sistema democratico rappresentativo - sembra non limitarsi a mobilitare settori sociali interessati a partecipare della costruzione delle politiche pubbliche o a fare della partecipazione uno strumento di trasparenza per "dare più vigore ad una democrazia liberale debilitata" (Sader, 2002, p. 659). Piuttosto, punta a proporre alternative di organizzazione del sistema politico ${ }^{14}$, focalizzando la sua azione "sul rafforzamento dei diritti di cittadinanza, sul riscatto dell'importanza dello spazio politico e sul significato degli interessi pubblici”, attraverso la costruzione di un nuovo 'fulcro' per l'azione riformatrice imperniato su "una nuova sfera pubblica rinnovata" (ibidem, p. 670) e sull'avvicinamento dei poli della tradizionale dicotomia governanti/governati.

È da queste caratteristiche che l'esperienza locale di Porto Alegre ha tratto la forza che l'ha proiettata sul piano nazionale ed internazionale. Dal fatto, ad esempio, che le sue sperimentazioni non sono state "una combinazione di esercitazioni formali di cosiddetta "ingegneria istituzionale" - speculazioni vuote in termini sociali e politici concreti -, ma [si sono] basate sulla crisi reale vissuta in una metropoli media della semiperiferia capitalista, pertanto dotate di un margine di generalizzabilità molto maggiore che se si fossero ubicate in un polo estremo del sistema" ${ }^{\prime 5}$. Ma, soprattutto, dall'a ver centrato la sua sperimentazione su una vera riforma politica, che ha condotto a riformulare le relazioni del governo con la cittadinanza, collocare le diverse istituzioni che interagiscono a livello locale sotto il controllo diretto della popolazione, stimolare forme di mobilitazione permanente dei suoi cittadini (senza ridurre la partecipazione ad evento 'una tantum' e su un unico tema) e quindi - alla fine - puntare alla costruzione di percorsi di esercizio del potere che nella pratica si sono rivelati configgenti "non solo con i modelli politici liberali [...] ma con la dinamica stessa del capitalismo, tanto più nella sua fase neoliberale, in cui i meccanismi del mercato e della libertà della proprietà privata primeggiano su tutto"16.

A dispetto di queste peculiarità, che ne spiegano la centralità simbolica acquisita all'interno di un ampio processo di rilettura e di reinvenzione dei modi di mettere all'opera i principi fondanti della democrazia, il caso di Porto Alegre non può certo considerarsi un esempio 'isolato' rispetto a questo panorama in trasformazione. E neppure poteva considerarsi tale agli esordi dell'esperienza nel 1989, visto che da oltre un ventennio in continenti diversi (come ad esempio in Nordamerica, in Inghilterra e nei paesi scandinavi) andavano sperimentandosi interessanti forme di co-decisione tra cittadini ed amministrazioni locali, specialmente nel settore dell'advocacy planning, dell'urbanistica partecipata e - successivamente - delle politiche sociali e sanitarie, in cui il complessificarsi delle richieste di personalizzazione dei servizi rendeva sempre più necessaria una percezione precisa dei differenti bisogni della cittadinanza. Sarebbe inopportuno, in questa conclusione di discorso, cercare di 'classificare' e 'collocare' l'esperienza di Porto Alegre nell' ambito di una 'scala di livelli di coinvolgimento dei cittadini nelle scelte' che tenesse conto delle centinaia di sperimentazioni e strategie realizzate in luoghi molto diversi del pianeta. Le modalità con cui il coinvolgimento dei cittadini nelle politiche locali va storicamente prendendo forma sono, infatti, molteplici ${ }^{17}$, così come estremamente vario è - al loro interno - il ruolo assunto dalle amministrazioni coinvolte (che possono restare reali decisori o assumere un ruolo più defilato di semplici coordinatori o facilitatori di processi decisionali delegati ai cittadini o alle organizzazioni rappresentative della cosiddetta 'società civile'). 
Cercare di 'mettere ordine' in questo quadro di complessità, per proporre una breve sistematizzazione di questo magma in ebollizione di sperimentazioni diverse, sarebbe solo una chimera, per lo più motivabile solo con la volontà di ricondurre in un ambito 'universalizzante' osservazioni ed analisi che, volutamente, abbiamo collegato ad una 'biografia territoriale'.

L'esito di una simile operazione non solo risulterebbe insignificante in rapporto all'esperienza di Porto Alegre (che, come si è visto, cela al suo interno forme diverse e molteplici di coinvolgimento dei cittadini, non limitate solo allo strumento più visibile del Bilancio Partecipativo) ma non potrebbe che rivelarsi frettoloso, incompleto e superficiale, mentre l'interesse del tema merita ben altro spazio e attenti studi comparativi, ad esso specificamente dedicati.

Limitando però lo sguardo ad uno spettro di esperienze più ristretto, che in qualche modo presenti caratteristiche e spunti 'apparentabili' rispetto agli assi portanti su cui si è lavorato a Porto Alegre, si può comunque proporre una riflessione significativa. Non allo scopo di nominare né di descrivere tali esperienze, ma per dar conto di un quadro di sperimentazioni di riforme partecipative che stanno cambiando il governo locale. E che, oltre a porre delle problematiche comuni su cui sarà bene riflettere, tendono ad innestarsi su assi di intervento e 'nodi di significato' a cui - per 'affinità' - è possibile accostare l'esempio di Porto Alegre ed altre significative esperienze di bilanci partecipativi. Senza - con ciò - volerne ridurre la ricchezza ('appiattendole' o 'costringendole' dentro schemi di lettura unici o precostituiti) ma, anzi, nella speranza che una messa a rete ed 'travaso di stimoli' possano retroagire su una maturazione di sperimentazioni diverse.

\subsubsection{Le 'arene deliberative’ come categoria complessa}

Se il coinvolgimento diretto dei cittadini nelle scelte di govemo "resta un'esperienza minoritaria [...] e non si configura (ancora?) come una prassi consolidata e indiscussa" (Bobbio, 2002, p. 207), esso appare - nondimeno - come un fenomeno in costante ampliamento, supportato dalla circolazione internazionale di notizie su un crescente numero di "buone pratiche", le più interessanti tra le quali hanno l'ambizione di porsi come ipotesi di vivificazione e reinvenzione della democrazia. Le più interessanti tra queste pratiche sono certamente quelle che si potrebbero raggruppare sotto la definizione di 'arene deliberative ${ }^{\prime 18}$, che rappresentano istanze centrate sulla costruzione di 'spazi fisici' riconoscibili (fissi o itineranti), esposti al pubblico e noti nella loro collocazione, dove si strutturano processi diffusi nel tempo (e non, quindi, semplici 'eventi') di 'democrazia deliberativa', intesi come confronti e discussioni, finalizzati non necessariamente alla costruzione di una posizione comune ma - almeno - alla "ricerca di un accordo"19 tra posizioni differenti riguardanti politiche o progetti per il territorio locale.

Come è chiaro, una categoria così definita è piuttosto vasta, dal momento che non chiarisce né l'oggetto specifico né l'ampiezza di contenuti dei dibattiti, né il tipo di pubblico che vi prende parte (o - almeno - che si prevede vi prenda parte), né - soprattutto - le relazioni di vincolo esistenti tra le decisioni eventualmente assunte nel corso dei processi e la loro concretizzazione da parte dei decisori politici, eletti all'interno del sistema di democrazia rappresentativa che governa il territorio.

É, del resto, ovvio che saranno questi tre ultimi elementi a rendere possibile 
in un secondo tempo un dettagliamento della maggiore o minore incisività delle esperienze che si collocano entro questa ampia categoria (così come è quasi intuitivo immaginare i processi di Bilancio Partecipativo in una posizione di estrema 'rilevanza' all'interno della categoria, a motivo dell'ampiezza e dell'inclusività dei dibattiti, della rilevanza dei temi discussi e del mutuo vincolo creatosi - ancorché soprattutto nella prassi del governo locale - tra le arene dei cittadini e le autorità municipali). Nonostante ciò, riteniamo sufficiente proporre un primo inquadramento di questa ampiezza, per due ragioni:

1) La prima è che una simile classificazione - pur tenendo fuori dal novero i casi di processi-evento (una tantum) e quelli non strutturantisi in spazi pubblici visibili e riconoscibili - si mostra 'rispettosa' della necessità di non costruire scale preordinate per la lettura delle diverse esperienze di democrazia diretta. Senza, infatti, condurre a quello che Sousa Santos (2000) chiama "lo spreco delle esperienze" (che può intervenire quando si scartino a priori oggetti di studio potenzialmente arricchenti, ma che non rientrano nell'ambito di ipotesi di lettura predefinite), una tale classificazione invita semmai ad esaminare le potenzialità e i limiti di ogni sperimentazione, ricordandoci che "in democrazia non esistono schemi puri e schemi impuri", perché "ogni esperimento può compiere tentativi diversi e rimettersi in causa (per evolvere o per scomparire)" ${ }^{20}$, e che ogni esperienza andrebbe contestualizzata nei luoghi, nei tempi e nelle specifiche situazioni socioculturali dove ha preso forma. Tale classificazione 'ampia' lascia aperta la possibilità che al suo interno si costruiscano griglie di analisi e classificazione ulteriore più dettagliate ${ }^{21}$.

2) La seconda riguarda la possibilità di 'estrapolare' dalle varie esperienze di questa ampia categoria alcuni assi di articolazione che appartengono al loro patrimonio comune, lavorando sui quali è possibile immaginare una maggior definizione dei percorsi partecipativi attivati nei differenti contesti.

In particolare, il patrimonio comune delle esperienze che si può far rientrare tra le 'arene deliberative' può ritenersi costituito essenzialmente dalle seguenti caratteristiche ${ }^{22}$ :

a) Tali esperienze (talora sviluppatesi per ragioni ideologiche, ma diffusesi soprattutto per motivazioni pratiche e grazie alla 'presa sul cittadino', che gli esiti stessi delle pratiche partecipative sono in grado di garantire) si pongono come strumento di 'messa in tensione' della democrazia rappresentativa. Non si propongono quindi di soppiantarne il ruolo, ma di agire come un suo 'contrappunto', distinguendo le proprie modalità di intervento da essa, e al contempo accompagnandone le scelte, convivendo con essa in una maniera dialettica che sia in grado di apportare alla costruzione delle politiche pubbliche le energie e la linfa vitale che è possibile trarre, sia dalla valorizzazione dei 'conflitti' territoriali, che dagli esiti di 'pacificazione negoziata' che tali processi riescono talora a raggiungere.

b) In un simile quadro, le esperienze di questo genere tendono a polemizzare con ogni forma di 'democrazia delle maggioranze,23, pertanto contrapponendosi ai 'referendum locali' in quanto basati su un metodo 'aggregativo' che tende a 'contare le opinioni' (pro o contro un progetto o una politica) senza permettere loro di crescere ed articolarsi all'interno di una discussione tra tesi non omogenee. Nella maggioranza dei casi i processi attivati entro le 'arene deliberative' si incentrano proprio sulla fase di discussione, mirando 
prioritariamente a confrontare soluzioni e a trovare compromessi o alternative nuove ad un problema (mediante un avvicinamento per 'approssimazione'), piuttosto che a votare per dirimere definitivamente una questione. Se ad un voto si deve arrivare (come accade nelle scelte delle priorità del Bilancio Partecipativo) è fondamentale che esso sia previsto fin dall'inizio e con un calendario temporale certo: il passaggio imprevisto di un processo dal carattere dibattimentale a quello decisionale tende ad essere accettato solo se a pronunciarsi a suo favore è la stragrande maggioranza dei partecipanti.

c) La 'democraticità' di tali esperienze si esprime nell'obiettivo di puntare a coinvolgere (almeno in linea propositiva) tutti i soggetti direttamente o indirettamente interessati dalle scelte in discussione all'interno del processo partecipativo. Essa tende perciò ad avversare altre forme decisionali basate su tavoli 'ristretti' e negoziati, che si limitino meramente a proporre 'scambi' o compensazioni tra soggetti direttamente interessati. L'inclusività distingue le 'arene deliberative' dalla tendenza ad escludere o limitare l'accesso ai luoghi delle decisioni che caratterizza la democrazia formale: essa può non essere concretamente raggiunta (restando la partecipazione volontaria), ma - almeno in linea tendenziale - si deve cercare di approssimarcisi il più possibile, garantendo che in ogni dibattito siano rappresentati tutti i possibili punti di vista che riguardano il tema in discussione $^{24}$, seppur non necessariamente nelle proporzioni in cui essi sono rappresentati nella società. Nel caso che il processo preveda un voto finale per dirimere la questione all'ordine del giorno, si può ricorrere a strumenti come l'estrazione casuale di 'commissioni deliberanti' di cittadini, sul modello di quanto in uso nelle polis greche, e di recente recuperato nelle citizens jury o in alcuni esperimenti di Bilancio Partecipativo in Germania e Spagna ${ }^{25}$.

d) I processi del genere si imperniano solitamente su strutture 'artificiali', ovvero istanze create in maniera 'finalizzata' per discutere specifici temi. Indipendentemente dall'ampiezza di questi ultimi (che - come nel caso del Bilancio Partecipativo - può anche essere notevole in quanto localizzata allo 'snodo' di più politiche e progetti), esse devono quindi possedere un 'oggetto' chiaro, trovando forza propulsiva per far partire i processi proprio nella 'delimitazione' dei temi affrontati. Questo differenzia tali istanze da un modello del tipo 'soviet', centrato su un'assemblea in partenza 'sovrana' su ambiti decisionali diversi; ma non toglie che, nel tempo, il loro concreto funzionamento possa costituire un volano potente per un ampliamento dei contenuti dibattimentali e perfino dei poteri decisionali delle stesse. Alla base di ciò può esservi una sagace considerazione sulla disabitudine dei cittadini al coinvolgimento ampio, per cui si preferisce 'dosare' (almeno inizialmente) le richieste di partecipazione, salvo poi definire nuove strutture parallele per ampliare gli ambiti del coinvolgimento.

e) La durata temporale dei processi attivati, così come il loro oggetto, devono essere chiaramente definiti alla partenza del percorso: se ne può prevedere uno scioglimento in rapporto agli obiettivi raggiunti, o sulla base di limiti reimpostati, o - ancora - un andamento ciclico (come nel caso del Bilancio Partecipativo). In alcuni casi si possono predisporre percorsi brevi (4-5 giorni) seppur di estrema densità, o con un'articolazione temporale più 'rilassata' e distesa nel tempo.

f) Analizzando le 'ricorrenze' di simili esperienze si deve riconoscere una preponderanza di forme di 'creazione dall'alto' (ovvero di promozione da parte delle istituzioni locali) dei processi. O almeno di 'attivazione iniziale' - 
sotto forma di opportunità di 'empowerment' (cioè di rafforzamento attivo) dei cittadini. Ciò non esclude né che la società civile possa esercitare 'dal basso' pressioni perché i processi siano attivati, né che una forma di 'legittimazione reciproca' tra ' 1 'arena deliberativa' e gli spazi della democrazia rappresentativa si elabori proprio nella co-costruzione delle regole di strutturazione del percorso dibattimentale; più rari sono invece i casi di 'arene' direttamente costruite e gestite da organizzazioni della società civile ${ }^{26}$. In ogni caso, se è vero che lo sviluppo di processi deliberativi di questo genere è facilitato in contesti dove è possibile valorizzare un capitale sociale preesistente (connotato da spirito civico e propensione all'impegno sul territorio) ${ }^{27}$ vi è una relazione non sempre decisiva tra la preesistenza di simili condizioni e l'attecchimento dei processi partecipativi, come dimostrano molti casi di Bilancio Partecipativo sia in città della zona nordorientale del Brasile che in alcune cittadine tedesche ${ }^{28}$. Talora, fra gli elementi che agevolano il radicamento e lo sviluppo di simili processi vi è la presenza di forti conflitti o di imponenti deficit arretrati di diritti reali da colmare o - come nel caso brasiliano - la coabitazione di poteri legislativi ed esecutivi con maggioranze diverse ${ }^{29}$. Sempre, invece, un forte peso nell'espansione dei processi è detenuto dall'atteggiamento e dalla volontà politica delle amministrazioni coinvolte, il cui impegno a tener conto dei punti di vista di queste arene costituisce il miglior incentivo al loro sviluppo.

g) Un 'nodo centrale' risulta soprattutto la presenza di regole per l'accesso e la discussione chiare, trasparenti e rigorose (ancorché flessibili al cambiamento, ma solo in lassi di tempo predeterminati, come avviene negli esperimenti di Bilancio Partecipativo, che rivedono le loro regole organizzative all'inizio di ciascun ciclo di discussione). Le regole garantiscono di non trovarsi davanti a processi 'spontanei' e 'disorganizzati', e la sorveglianza sul loro rispetto da parte di ogni partecipante può essere gestita dalla comunità e dall'amministrazione insieme, o da soggetti 'esterni' appositamente contrattati. In un certo senso 'il buon disegno' di un processo può servire a recuperare svantaggi di partenza, per processi che si radicano in contesti segnati da sostanziali deficit di capitale sociale da coinvolgere attivamente nel 'lancio' dei percorsi dibattimentali o decisionali. h) Quasi tutte le esperienze più significative risultano al contempo 'strutturate e informali', ovvero 'non regolate dalla legge' e prive di un reale potere giuridico. Nella maggioranza dei casi esse non sono quindi 'deliberanti', ma semplicemente 'deliberative'; vale a dire, le decisioni che eventualmente prendono hanno funzione formalmente consultiva nei confronti dell'autonoma capacità decisionale delle istituzioni della democrazia rappresentativa. Il caso dell'informalità giuridica del Bilancio Partecipativo di Porto Alegre (cfr. § 9.2) è per certi versi emblematico e allusivo non solo di esperienze consimili, sviluppatesi in paesi dove si riflette il valore tradizionalmente ricoperto dalle culture orali e dalle azioni informali, ma anche della maggior parte delle sperimentazioni avvenute in contesti occidentali, aventi tradizioni maggiormente legaliste e formaliste. Per certi versi, "il loro grado di informalità rappresenta la forza di queste arene, rappresentando l'informalità delle relazioni tra gli individui che viene quasi istintivamente contrapposto all'ingessatura tradizionale delle istituzioni della democrazia formale" 30 . Del resto, esse agiscono in parallelo alla democrazia rappresentativa, legittimandola proprio in virtù di un funzionamento che si pone dichiaratamente come diverso, e cerca di sviluppare ed imporre i contenuti elaborati nella 
'prassi del governo', garantendo che essi filtrino nelle politiche attraverso 'patti d'onore' (vincolanti nei fatti più che formalmente) stabiliti con le istituzioni della democrazia rappresentativa, e particolarmente con gli Esecutivi municipali. Nella maggioranza dei casi si individua una forma di 'minima tutela formale' dei processi attraverso l'inserimento di un accenno che li riguarda negli Statuti municipali, a livello di principi (così come nel caso di Porto Alegre).

i)Nella maggioranza dei casi storicamente esaminabili, i processi che si sviluppano in forma di 'arene deliberative' prevedono l'assistenza da parte di mediatori professionisti e figure 'esterne' agli interessi suscitati dalla 'posta in gioco', in modo che i partecipanti avvertano tutelata l'obiettività di svolgimento dei percorsi dibattimentali o decisionali. Nel contesto latino-americano, le ricorrenze di questo tipo paiono minori che in Occidente e in Africa, e sovente si hanno tavoli di co-gestione misti a cui prendono parte rappresentanti della cittadinanza insieme ad esponenti della democrazia rappresentativa. In ogni caso, i 'mediatori' (professionali o 'di parte') simboleggiano un importante slittamento di significato dei processi che, alla classica mediazione politica 'occulta', tendono a sostituire forme aperte e trasparenti di negoziazione in nuovi spazi pubblici.

\subsubsection{Porto Alegre come invito all'ascolto del territorio locale}

Il nuovo municipio può rappresentare "il laboratorio" in cui l'amministrazione locale rafforza la propria autonomia progettuale dando forza alla progettualità sociale emergente, vincolando le proprie decisioni a nuovi istituti di democrazia diretta, legittimando questi ultimi a deliberare sul futuro del proprio territorio; gli attori sociali dell'altro mondo in costruzione potrebbero trovare in questi istituti le sedi dove integrare le specificità dei propri progetti amplificandone sinergicamente la portata (A. Magnaghi, 2002).

Nelle caratteristiche sopra elencate (che - non va dimenticato - non sono 'regole fondative' delle esperienze ma costituiscono piuttosto un'estrapolazione a posteriori di aspetti che risultano similari in casistiche spesso molto diverse) si possono senza dubbio ritrovare alcuni 'nodi portanti' dell'esperienza di Porto Alegre esposta in questo libro.

Ciò che però non può emergere con chiarezza da un simile elenco sono le peculiarità e le modalità di interazione e abbinamento tra queste caratteristiche, che sono proprio quelle che concorrono a determinare la maggiore o minore innovatività, il grado di radicalità attuativa e soprattutto la centralità o la marginalità del ruolo attribuito da ogni esperienza ai momenti partecipativi nel quadro complessivo della politica urbana.

Nel caso di Porto Alegre - ad esempio - restano in ombra alcune coerenze del percorso di costruzione, evoluzione e gemmazione del Bilancio Partecipativo, che hanno contribuito ad allontanarne le scelte dalle tendenze medie prevalenti in altri contesti. In particolare per la messa al centro delle politiche urbane di un processo partecipativo di carattere 'deliberante', la moltiplicazione del dibattito su numerosi piani paralleli e la 'radicalità' che ha connotato l'impostazione di singole politiche di settore (come quelle scolastiche, urbanistiche o della sicurezza).

Ma vi è soprattutto un aspetto fondante nel caso di Porto Alegre che merita essere rilevato per gli spunti propositivi che può offrirci, ed ha a che vedere con quello che abbiamo definito 'l'oggetto implicito' di questo libro: il ruolo portante 
attribuito all'autoprogettualità degli abitanti, cioè di tutti coloro che (indipendentemente dai diritti formali di cui sono portatori) contribuiscono quotidianamente alla costruzione, allo sviluppo materiale e alla crescita culturale della città. A partire, infatti, da una fiducia nell'intelligenza sociale ${ }^{3 l}$ che ha rappresentato forse il motore principale delle sperimentazioni locali, sia il processo di Bilancio Partecipativo che gli altri in seguito strutturatisi hanno preso forma (a partire da slogan chiari ma da progetti originariamente 'informi') proprio attraverso la co-costruzione delle regole e della spazializzazione dei processi da parte dei cittadini coinvolti e delle diverse organizzazioni della società civile e di quella politica. La scelta dell'Amministrazione Popolare è stata fin dal 1989 quella di confidare nella capacità dei cittadini di progettare e costruire (al di là della protesta e della pressante richiesta di colmare i deficit sociali della città), e di saper superare gli egoismi o i corporativismi per accedere a forme di cooperazione e di solidarietà negoziata.

Come abbiamo visto, non in tutti i momenti il processo di interazione è stato facile e immediatamente produttivo: spesso, anzi, il Comune ha dovuto esercitare in modo visibile il suo ruolo di guida e garanzia (almeno morale) dei processi di trasformazione urbana per raddrizzare rischi di piccole derive populiste o egoistiche generate dalla 'competizione' tra territori locali o dal loro 'corporativismo', così - peraltro - mostrando di non intendere il coinvolgimento dei cittadini nell'assunzione delle scelte come una forma di delega o di scarica-barile di proprie responsabilità istituzionali.

Il valore 'deliberante' sempre riconosciuto - nei fatti - al Bilancio Partecipativo e ad altre istanze partecipative, è comunque la migliore dimostrazione di come la fiducia nell'intelligenza sociale sia rimasta nel tempo inalterata, anzi abbia teso a trarre profitto dai 'salti di qualità' che la progressiva maturazione dei cittadini (evidenziatasi dentro i processi partecipativi) andava permettendo. È da leggersi in questa linea di tendenza l'importanza progressivamente crescente attribuita a tutti gli spazi decisionali pubblici di taglio 'collettivo', a scapito sia dei tavoli concertativi a partecipazione ristretta (inclusi quelli tra sindacato e amministrazione sulle politiche salariali e di impiego), sia degli spazi in cui veniva tradizionalmente praticato l'ascolto individuale dei cittadini (come le udienze private di sindaco e assessori).

Questo percorso, a Porto Alegre, si è strutturato come opportunità di 'condiscenza' (cioè di apprendimento mutuo) tra la 'società politica' e le differenti componenti della cosiddetta 'società civile', ed ha privilegiato alcuni assi di riflessione prioritari, tra cui:

1) la valorizzazione della relazione dialettica tra poteri e resistenze, tra azione conformista e azione ribelle (le nuove forme del dialogo con gli occupanti della città informale; le sperimentazioni di formule come la costruzione delle cooperative e i 'mutirões', i programmi di inclusione per molti tipi di lavoratori informali);

2) la co-costruzione delle regole e delle peculiarità che connotano gli spazi locali della democrazia diretta, distinguendoli da ed integrandoli con gli istituti e i momenti di scelta della democrazia rappresentativa (in particolare la caratterizzazione dei 'vincoli di mandato' che distinguono i delegati e i consiglieri popolari del Bilancio Partecipativo e del sistema di pianificazione territoriale partecipativa dall'operato dei consiglieri comunali);

3) la revisione e la riformulazione permanente dell'assetto e delle regole 
664 degli strumenti partecipativi per l'indirizzo delle politiche generali e di settore, e la verifica reiterata della necessità di stabilire dei vincoli formali tra essi e lo Statuto Municipale e le Leggi Comunali;

4) l'ampliamento del pubblico dei diversi processi partecipativi perché il modello di base del tipo 'una testa un voto' (che privilegia il cittadino-individuo seppur inquadrandone la presenza entro spazi collettivi) non si mostrasse escludente, ma anzi trovasse gradualmente un ruolo per tutte quelle organizzazioni pre-esistenti della società civile che inizialmente non si riusciva a coinvolgere in maniera attiva, valorizzandone i saperi accumulati e le peculiarità;

5) la trasformazione della 'comunicazione' in momento di interazione e scambio tra linguaggi diversi, e in occasione di scambio biunivoco di informazioni e punti di vista tra i vari attori dei processi urbani. Un percorso, questo, ancora bisognoso di affinamenti, ma che inizia a contare conquiste importanti, come la costituzione del Projeto Memoria (cfr. § 9.4) e - più di recente - la pubblicazione del libro Porto Alegre, Les voix de la démocratie. Le budget participatif raconté au quotidien (cfr. § 16.4.5) un testo che cerca di proporre una lettura non intellettualizzata del Bilancio Partecipativo di Porto Alegre, raccontandone - per la prima volta - i limiti e le sfide in maniera lucida, non attraverso la voce di politici, tecnici o ricercatori, ma attraverso l'autoanalisi di cittadini ed ex-consiglieri e delegati popolari, riunitisi nel 2001 nella ONG Solidariedade, nata per trarre alimento dalla 'crescita' sperimentata da ognuno durante i 14 anni di impegno nel processo democratico in corso.

Il perseguimento contestuale di questi diversi obiettivi ha comportato nel tempo un lavoro su più fronti, che non sempre ha dato risultati contestuali. Ad esempio, la valorizzazione delle aggregazioni sindacali e di categoria e dell'associazionismo già esistente in città (ma non facente capo a quello che viene chiamato 'movimento comunitario', composto soprattutto da Associazioni di vicinato, Club di madri, Consigli Pastorali e simili) è stata portata avanti con sistematicità solo a partire dal 1993-1994, in coincidenza con la creazione delle Assemblee Tematiche del Bilancio Partecipativo e con l'avvio del processo 'Città Costituente' e della progettazione del nuovo Piano di Sviluppo Urbano e Ambientale.

In questo percorso, va dato atto all'Amministrazione Popolare del merito di aver investito con sistematicità nel progetto di democratizzazione del governo locale, sia attraverso investimenti economici appositamente finalizzati, sia attraverso una progressiva riorganizzazione della struttura amministrativa municipale (ancora incompleta, ma indispensabile per rendere incisivi e flessibili i sistemi decisionali partecipativi) che ha favorito un attento e costante ascolto dei cittadini e delle loro organizzazioni associative e rappresentative, portato avanti grazie alla costruzione della rete di agenti facilitatori esaminata nel cap. 11.

Queste attenzioni hanno reso possibile uno degli esiti forse più importanti del percorso portoalegrense, visibile se si guarda retrospettivamente alle sue linee di sviluppo: ovvero uno 'slittamento' di senso - graduale ma inesorabile - della lettura generalizzata del concetto di 'politiche pubbliche', transitato dall'accezione semplicistica di 'politiche attuate dagli enti pubblici' (in concerto e in maniera giustapposta e scoordinata) verso un'idea più ricca ed inclusiva che - riferendosi alla filosofia generale che ispira lo Statuto comunale - guarda anche agli effetti che determinano sulla collettività territoriale 
le azioni di soggetti sociali autorganizzati che intervengono a modificare settori importanti della vita pubblica, sortendo effetti 'pubblici' in maniera diretta o indiretta, specialmente stimolando la predisposizione o il riorientamento di politiche municipali.

Simili acquisizioni - che fanno parte di un bagaglio cresciuto gradualmente nel corso degli ultimi anni dell'esperienza di Porto Alegre (anche anteriormente ai 14 annidi Amministrazione Popolare, come si intuisce dal cap. 6) sono 'sfide' che parlano in modo chiaro e attraverso valori e principi di comprensibilità universale anche ai nostri complessi contesti locali. Non escluso quello del nostro Paese, che va attraversando un momento di trasformazione che merita di essere attentamente osservato ${ }^{32}$, come dimostrano l'inchiesta riportata nell'appendice $\mathrm{n}^{\circ} 5$ ed alcuni esperimenti di democratizzazione del governo locale che stanno venendo attuati in diverse municipalità ${ }^{33}$.

Questo appare evidente, qualora si immagini - nell'oggi di un nostro contesto urbano di dimensioni medio-grandi - la costruzione di un'arena deliberativa di caratteristiche simili al Bilancio Partecipativo di Porto Alegre. Uno sguardo 'sincronico' e disattento gettato - a partire dalla lettura della situazione attuale - solo sulla complessa ingegneria istituzionale che oggi lo connota, renderebbe praticamente impensabile una sua riproposizione hic et nunc. Non solo per la complessità apparente della 'macchina' che compone il processo, ma anche (come è stato sovente sostenuto in pubblici dibattiti ${ }^{34}$ ) per la inibente richiesta 'giacobina' di impegno pubblico attento e assiduo, che paiono richiedere ai cittadini i percorsi partecipativi attivati ormai nell'ambito di tutte le politiche urbane. Ciò che solo una disamina diacronica del processo portoalegrense può restituire ad un'attenta valutazione è come sia la complessità attuale di articolazione del Bilancio Partecipativo (cfr. figg. 21/23), sia la moltiplicazione dei processi che ne emulano gli esiti in singoli ambiti del governo locale, costituiscano il frutto di richieste di 'garanzia' e di 'ampliamento della capacità deliberativa' dei cittadini, che solo un'articolazione strutturata delle modalità di decisione pubblica potevano portare. L'esito - in sintesi - non solo di un attento processo di 'ascolto' del tessuto sociale, ma anche di un approfondimento della trasformazione storica e dei caratteri peculiari delle forme di aggregazione presenti a Porto Alegre, ma anche di politiche di inclusione e di sperimentazione diverse e complementari, mirate a coinvolgere costruttivamente un sempre maggior numero di cittadini e gruppi tra loro diversi nei processi di deliberazione pubblica e di costruzione del territorio, rispettando le differenze che connotano il capitale sociale locale e le energie che ogni diverso soggetto può e vuole mettere in gioco.

Come questo libro ha mostrato, l'esperienza di Porto Alegre suggerisce diversi spunti di riflessione alle amministrazioni locali che, anche nei nostri contesti territoriali, volessero operare per costruire un 'terreno fertile' al concepimento di forme strutturate di coinvolgimento dei cittadini nelle 'politiche pubbliche'. Il primo è, certamente, la necessità di dedicare attenzione all' 'ascolto del 'capitale sociale locale', investendo energie e tempo nel ripercorrere e rappresentare le diverse modalità di aggregazione e di impegno collettivo che hanno storicamente segnato ogni diverso territorio.

Questo vuol dire guardare all'oggi con la volontà di costruire percorsi il più possibile inclusivi e accoglienti, cioè agire non solo sulla costruzione di 'strumenti' di coinvolgimento, ma su 'politiche' che costituiscano il presupposto 
di un coinvolgimento solido e non solo eventuale. Per riprendere gli spunti che emergono tra le righe del testo sperimentale Insurgent City ${ }^{35}$, questa attenzione dovrebbe portare a costruire una tassonomia di azioni 'virtuose' che prendesse in attenta considerazione soggetti ed opportunità partecipative diverse, a partire dalle "insurgent planning practices", ossia da quelle ipotesi "di città all'opera, pratiche altemative di città che cercano di investire tutti gli aspetti della struttura urbana, micro-utopie in corso di realizzazione" che connotano i patrimoni socioculturali di un territorio con le differenti capacità di autorganizzazione e i loro diversi gradi di protagonismo e di istituzionalizzazione.

Per iniziare un coinvolgimento effettivo della cittadinanza nelle politiche territoriali, bisognerebbe - quindi - partire dalla volontà di leggere e riconoscere senza pregiudizi (cioè senza giudizi costruiti 'a priori' sulla base di contatti episodici ed incomprensioni ideologiche) quelle iniziative di resistenza/ trasformazione che si oppongono alla città esistente (e alla sua struttura organizzativa e di potere) ma, nello stesso tempo, positivamente costruiscono i primi congegni di una città alternativa e differente, in particolar modo (ma l'elencazione è solo un suggerimento, non volendo né potendo essere esaustiva, se non in riferimento a singole realtà locali):

1) le "insurgent living practices", cioè quelle arti della resistenza e della sopravvivenza individuale che costituiscono il livello più diffuso e atomizzato di progettualità territoriale, per lo più ad opera di 'cittadini negati' (immigrati, clochard, abitanti della città informale, ma paradossalmente anche bambini e lavoratori pendolari...) e comunque di soggetti che proprio per il loro stare ai margini del 'diritto alla città' (ovvero borderline) sono particolarmente sensibili ai comportamenti amministrativi. L'attivazione di politiche di inclusione e di progetti sociali integrati costituisce spesso il presupposto discriminante non solo perché i soggetti portatori di tali pratiche possano 'partecipare' della costruzione cosciente del territorio, ma anche perché la loro espulsione dallo spazio pubblico non ne proietti alcuni nell'illegalità, azzerando il loro contributo propositivo al 'fare società';

2) i soggetti plurali che potremmo definire "conflittuali o antagonisti", ovvero organizzazioni che producono comportamenti collettivi in ragione di veri e propri programmi politici, i quali spesso determinano o riorientano le politiche pubbliche aggredendo 'elementi di struttura' del territorio (ad esempio la speculazione fondiaria o il problema dell'alloggio attraverso occupazioni simboliche o stabili di spazi). Se nel caso di Porto Alegre è stato più agevole coinvolgere simili soggetti nel progetto di costruzione di un'alternativa al progetto politico delle amministrazioni comunali antecedenti al 1988, nei nostri contesti questo è forse un obiettivo più complesso: per simili soggetti, infatti, il coinvolgimento in meccanismi istituzionalizzati di mediazione spesso non è uno strumento soddisfacente di dialogo, e può causare rotture e fughe di aderenti verso nuovi soggetti, 'antagonisti' anche rispetto a singole vittorie e risultati precedentemente conseguiti. In tale ottica, sarebbe più opportuno immaginare politiche sperimentali di coinvolgimento su concreti progetti sperimentali (come l'autocostruzione, l'autorecupero, forme cooperative di produzione e vendita, sperimentalismo mediatico o culturale) dove poter convogliare le energie positive e costruttive e la creatività di simili raggruppamenti;

3) i 'comitati spontanei' a base locale (ormai molto diffusi in contesto europeo), la cui debolezza politico-ideologica è al contempo un limite e un'op- 
portunità, nella misura in cui favorisce il superamento informale di barriere di classe e di appartenenza politica, in nome di comuni problemi ed obiettivi localizzati in un preciso spazio. Come il caso di Porto Alegre dimostra, è importante ribaltare i rischi di appiattimento egoistico o di corporativismo localistico spesso impliciti nell'azione di tali soggetti, non accontentandosi del loro coordinamento (che spesso non nasce da una volontà di mediazione, bensì dalla ricerca di maggior presa nei confronti delle istituzioni) ma coinvolgendoli in progetti locali integrati dove scoprire punti di vista diversi e complementari e contribuire alla concezione di politiche pubbliche innovative;

4) associazioni e ONG a carattere tematico; la valorizzazione del loro ruolo progettuale dovrebbe poterne integrare le azioni nel quadro di politiche, forum e progetti integrati intesi ad un miglioramento della 'vivibilità urbana', per evitare che restino confinate nella protesta 'di genere';

5) cantieri sociali $^{36}$, ovvero comunità coese che nel tempo hanno già saputo elaborare punti di vista integrati e maturi sui luoghi ed azioni progettuali e costruttive. L'esperienza di Porto Alegre dimostra che risulta basilare trovare formule che ne valorizzino l'esperienza ed il ruolo sul piano cittadino, costruendo laboratori di quartiere ed altre 'sponde istituzionali' per potenziare i benefici del loro lavoro collettivo;

6) nei nostri contesti, va anche tenuto conto dell'esistenza dei quartieri e di altre forme di decentramento decisionale (non esistenti in Brasile) che operano 'all'interno delle istituzioni'. Essi, talora, riescono ad avere un buon funzionamento ma raramente rappresentano - come la legge prevedrebbe istituti di reale partecipazione dei cittadini alle scelte che contano sul territorio. Fondamentale, rispetto a questi soggetti collettivi, sarebbe un rafforzamento dei loro poteri e delle loro competenze;

7) non si deve, infine, dimenticare il potenziale costruttivo di partecipazione implicito in alcuni strumenti urbanistici di ambito generale (PRG, Piani e progetti strategici) o di ambito attuativo, come i cosiddetti 'programmi complessi' ${ }^{37}$. Nella mancanza di istituti permanenti di co-decisione, le potenzialità di simili strumenti restano spesso non realizzate o limitano i momenti partecipativi ad 'eventi una tantum' che servono ad 'intuire' dei quadri problematici consensuali, ma senza arrivare a definire né progetti né scenari condivisi a cui informare le proprie scelte.

Riguardo a queste due ultime categorie, spesso ci si domanda se per 'rinvigorire' la credibilità delle istituzioni democratiche sia meglio puntare a 'riattivare' e 'ridare senso' ad istanze partecipative già storicamente sperimentate sul nostro territorio (i consigli circoscrizionali ne sono un esempio) o piuttosto guardare a 'modelli innovativi' di istituzioni partecipative sperimentati altrove nel mondo, individuandone le linee di riproducibilità nel nostro contesto.

Probabilmente non esiste una risposta univoca a questo dubbio. Certo, un processo di 'riempimento di senso' di istituzioni esistenti che ancora non hanno saputo esplicare tutte le loro potenzialità sarebbe - in linea teorica - auspicabile; ma la scelta può solo fondarsi sulla valutazione del grado di 'legittimazione residua' che le diverse esperienze locali hanno lasciato ad istanze politiche partecipative già esistenti, $\mathrm{o}$ alla credibilità che è possibile ridare loro attraverso l'attribuzione di reali competenze e il forte impegno a tradurre in azioni concrete le scelte maturate all'intemo dei processi di coinvolgimento dei cittadini.

Il caso di Porto Alegre - che può essere valutato essenzialmente come una 
"maniera di pensare l'articolazione tra democrazia diretta e democrazia rappresentativa" 38 piuttosto che come un modello di messa in opera della prima - ha offerto la sua peculiare risposta, che non è detto vada generalizzata. Esso offre, infatti, un'indicazione precisa per i casi in cui la 'legittimazione residua' di istanze partecipative preesistenti che non hanno mai realmente funzionato sia molto scarsa: ripartire da processi percepibili dai cittadini come 'innovativi' può essere un motore potente per accedere in un secondo tempo ad una 'risemantizzazione' di arene partecipative temporaneamente 'congelate' in attesa di ricostruire una fiducia degli abitanti nella possibilità di incidere realmente sui processi decisionali politico-amministrativi. A Porto Alegre è esattamente quanto avvenuto con i Consigli Municipali settoriali e con il Piano Regolatore strategico (e - a livello di Stato - con i Consigli Regionali di Sviluppo), che hanno potuto riacquistare senso e peso solo dopo alcuni anni di sperimentazione dell'innovazione rappresentata dal Bilancio Partecipativo: questo, infatti, si è rivelato un formidabile motore di trasformazione ('detonante' anche rispetto alla sua comunicabilità mediatica) in quanto - occupandosi di distribuzione di risorse per lo più originate dalle tasse degli abitanti (o da tariffe dei servizi pubblici) - ha colpito l'immaginario sociale per il suo valore al contempo simbolico e pratico, percepito come 'segnale forte' della reale volontà di cambiamento da parte delle istituzioni, cioè come luogo potenziale di primaria importanza per la ricostruzione del rapporto tra cittadini e politica.

\subsection{Por to Alegre dentro il quadro in trasformazione delle politiche terri- toriali locali}

"O si riesce a far parte della globalizzazione, o se ne sta fuori. Stare fuori è assai facile, spesso lo si è già. Complicato è entrarci, o semplicemente restarci, perché i posti disponibili sono pochi. Ė una competizione che può non piacere, ma è certo che è meglio parteciparvi che essere semplici spettatori. Nella città dei paesi in via di sviluppo non è possibile mobilitare le risorse necessarie (forse non sufficienti) per stare dentro alla globalizzazione, senza trovare un punto di incontro tra i diversi interessi da cui muovere per la costruzione di una città inclusiva (Balbo, 2002, p. 288).

Quanto osservato nei paragrafi precedenti riguardo alla crisi che colpisce la democrazia liberale proprio nel momento della sua massima espansione apparente (Eisenstadt, 2002) è valido anche in altri ambiti. Infatti, proprio nel momento in cui "un vento di democrazia sempre più forte soffia sul mondo" (Osmont, 2002), i territori locali assistono all'aggravarsi di fenomeni di squilibrio, polarizzazione, frammentazione ed esclusione sociale, che vanno accompagnando la liberalizzazione dei mercati e la privatizzazione dei servizi imposte come 'misure naturali' dalla globalizzazione dei mercati economico-finanziari e dall'arretramento della presenza dello Stato nello svolgimento di azioni redistributive e nella gestione delle politiche di benessere sociale.

In questo quadro (segnato da perturbazioni, instabilità e imprevedibilità che vedono il crearsi e lo sgonfiarsi di "bolle finanziarie" e di parallele "bolle fondiarie" 39 le cui crisi improvvise generano continuamente nuove forme di povertà nei diversi angoli del pianeta, spesso cancellando d'un colpo l'esistenza stessa di intere classi medie), l'obiettivo delle politiche urbane - incluse quelle urbanistiche - sembra naturalmente quello di cercare nuovi ruoli, riarticolandosi secondo due direttrici apparentemente inconciliabili: la ne- 
cessità di contribuire a rendere le città il miglior supporto possibile per lo sviluppo, e la necessità di potenziarne la funzione sociale ${ }^{40}$.

Spesso i due obiettivi tendono ad essere compresenti nel discorso politico, ancorché il secondo venga di norma subordinato al primo, nel tentativo di facilitare sviluppo delle infrastrutture, pacificazione sociale e condizioni di competitività del territorio, attraverso il reincorporamento del maggior numero possibile di abitanti nei processi di produzione di ricchezza. Così, la forza d'urto dell'obiettivo di costruire una "città inclusiva per tutti" viene a perdersi, sottraendo all'intervento urbano la sua dimensione maggiormente 'politica' e sottomettendolo all'ossessiva ricerca di una 'efficienza economica'. Questa, a sua volta, tende a generare forme di 'esclusione selettiva' che fanno sì che anche l'integrazione degli abitanti e di porzioni 'eccentriche' di città avvenga per 'parti' ${ }^{41}$ o 'per categorie', selezionate in base alle loro potenzialità di accrescere o meno la produttività urbana, una volta entrate a pieno titolo nella 'cittadinanza formale'.

Nella maggior parte dei casi, le regole con cui queste trasformazioni si susseguono, e le modalità con cui le politiche urbane tendono a mettere al centro il conseguimento di alti livelli di attrattività e competitività per i territori locali, sono definite a livello internazionale dagli organismi di aiuto allo sviluppo, e modulano la ricerca di risposte sui criteri dell'efficienza economica e del rendimento del capitale investito, per lo più forgiandosi sulle caratteristiche di un modello di sviluppo urbano unico e valido ad ogni latitudine. Questo è tanto più vero per le realtà urbane, e in particolare per quelle situate nei paesi in via di sviluppo, che per la globalizzazione economica si trovano quasi obbligate ad entrare in competizione tra loro per raccogliere l'interesse di investitori stranieri, venendo per di più sottomesse alla 'condizionalità degli aiuti', che spesso si traduce nella lettura della città come uno tra gli altri elementi che partecipano del meccanismo dell'aggiustamento strutturale, con le sue misure restrittive imposte non solo come necessarie ma spesso - erroneamente - anche come 'sufficienti' (Osmont, 2002, p. 16).

È in tale panorama che vengono a svilupparsi vere e proprie 'mode' indotte (quando non imposte) in contesti molto diversi da quelli in cui hanno preso avvio. È il caso, ad esempio, del recente 'boom' di riscoperta dei centri storici in America Latina o in paesi asiatici e africani, il cui recupero ha risposto più "all'esigenza di offrire agli investitori stranieri qualcosa da "vendere", nel senso ampio del termine, ma anche in quello stretto" (cfr. Balbo, 2002, p. 282) che non ad una sentita esigenza di salvaguardia e valorizzazione delle proprie testimonianze storico-culturali. I risultati di queste operazioni - in termini qualitativi - sono spesso la miglior denuncia di questa 'induzione' del fenomeno, seppur va loro riconosciuto il merito di aver stimolato progetti di recupero che talora sono intervenuti in tempo a limitare lo scempio di importanti patrimoni dell'umanità.

Lo stesso può dirsi per il marketing urbano, insieme di tecniche promozionali di origine aziendale ormai consacrate da mercati e poli formativi internazionali appositamente costituiti. Mutuate dall'occidente, esse sono ormai divenute 'centrali' anche nelle amministrazioni locali dei paesi in via di sviluppo (in particolare nelle maggiori 'città globali' del capitalismo finanziario $^{42}$ e nei centri che vivono di turismo) in quanto considerate indispensabili per non restare ai margini dei flussi finanziari internazionali. 
670 Un discorso analogo vale, infine, anche per il mito della 'pianificazione strategica', recuperato a metà degli anni '80 - a seguito dell'esemplare utilizzo nella trasformazione della Barcellona olimpica - dopo aver subito una sorta di abbandono nel periodo in cui tendeva a trionfare l' 'urbanistica del progetto'. A partire dall'elaborazione della City Development Strategy del 1999 (programma di promozione dello sviluppo economico locale e di lotta alla povertà urbana inserito nel programma Cities Alliance), la Banca Mondiale ha adottato la 'pianificazione strategica' come forma privilegiata di azione trasformativa di ambito locale (cfr. cap. 2), sottolineandone i contenuti di "contratto politico tra le istituzioni pubbliche e la società civile". L'ha, infatti, ritenuta capace di affrontare le contraddizioni dello sviluppo attraverso una mobilitazione di energie vitali dai settori economici pubblici e privati, da quelli tecnici e da quelli comunitari (Borja, 1998), ma al contempo ne ha asservito gli esiti ad una logica di "liberismo trionfante" e di "corporate governance', sulla base della quale seleziona le città e i progetti da finanziare, supportando ed inasprendo in tal modo lo squilibrio dei poteri decisionali interni ai partenariati costituitisi. In conseguenza di questa scelta della World Bank, la pianificazione strategica va oggi diffondendosi a macchia d'olio su scala planetaria, spesso imponendo le sue regole a contesti impreparati ad affrontarne la complessità e mutuando soluzioni arbitrariamente estrapolate dall'esperienza-modello di Barcellona senza valutare quanto il successo di quella fu dovuto al convergere di una congiuntura e di condizioni al contorno molto favorevoli, quali la presenza di "un governo municipale forte della sua legittimità democratica dopo la fine della dittatura, per il quale lavorava un gruppo di consulenti che avevano preso direttamente parte ai conflitti urbani aperti al tempo della dittatura, e che aveva fatto leva su una società civile anch'essa legittimata dalle proprie lotte" (Osmont, 2002, p. 25).

\subsubsection{Controcorrente?}

La città è senza dubbio alcuno una società politica [...] locale, nel senso pieno e classico del termine, e soltanto iniziative che vengono da una volontà politica forte, definite a differenti scale territoriali, possono autorizzare a sperare in un'inversione di tendenza, a ridare fiato cioè alla prospettiva di una gestione sociale della città, fondata sulla solidarietà e non sulla ricerca del profitto. Questo si può ottenere soltanto se, in primo luogo, tale volontà politica discenda da analisi rigorose e non da discorsi ideologici che privano la maggioranza della popolazione della capacità di decidere in piena coscienza; in secondo luogo a condizione che l'agire urbano e urbanistico sia a servizio di politiche concrete, elaborate a partire da una conoscenza rigorosa e documentata della realtà, non l'applicazione tecnicistica di modelli esogeni di tipo universale. In questo sta la vera idea del "progetto di città", un progetto che nasce da un "contratto politico" (Osmont, 2002, pp. 26-27).

Giudicare l'esperienza di Porto Alegre rappresenti un'elaborazione 'rivoluzionaria o 'riformista' è un dilemma che lasciamo volentieri alla sensibilità delle lettrici e dei lettori: e non solo perché troviamo la forzosa contrapposizione dicotomica tra le due letture irritante e fuorviante per una reale comprensione del processo, ma anche perché speriamo che questo libro offra sufficienti strumenti perché chi legge possa formulare delle linee di giudizio politico, in cui a noi non interessa addentrarci.

Riteniamo, invece, utile rilevare come - da quanto detto finora - emergano 
elementi dell'esperienza messa in opera in questi 14 anni a Porto Alegre, che vanno certamente 'controcorrente' rispetto alla direzione che "l'egemonismo della globalizzazione neoliberista" (Sousa Santos, 2002) pare indicare anche ai progetti di governo nei territori locali.

Infatti, le politiche messe in atto a Porto Alegre sembrano aver puntato a contrastare (nel loro complesso, e non attraverso singoli programmi di settore) i meccanismi dell' 'inclusione selettiva' che sono propri anche della lotta alla povertà, quando inquadrata in una concezione liberista. Esse hanno, difatti, colto la possibilità di non appiattire l'uno sull'altro i concetti di povertà ed esclusione urbana, riconoscendo che "si può essere poveri senza essere esclusi, perché comunque si appartiene ad un sistema di reti sociali e di meccanismi di solidarietă", e che - viceversa - è anche possibile l'opposto, dato che a volte "l'essere parte dell'esclusione significa poter accedere a lavori che, per motivi diversi, altri gruppi rifiutano o, per ragioni sociali, non possono svolgere" (Balbo, 2002, p. 284).

In ogni caso, a Porto Alegre si è lavorato con attenzione sulla triplice accezione del concetto di esclusione (sociale, dai servizi urbani e politico-decisionale), operando affinché la riduzione dell'esclusione dalla rappresentanza politica e dall'assunzione di decisioni costituisse un 'nodo prioritario di intervento', in grado di retroagire positivamente sugli altri due aspetti. E ciò è avvenuto soprattutto a partire dalle politiche abitative ed urbanistiche che come abbiamo visto - hanno contestualmente:

1) riconosciuto esplicitamente le colpe dei modelli segregativi scelti in passato, e quelle delle previsioni impostate sul disconoscimento del reale evolversi del territorio urbanizzato e sulla inflessibilità dei modi usati nel confrontarsi con esso (attraverso espulsioni e deportazioni massive degli abitanti della città informale);

2) valutato obiettivamente la 'città irregolare' come una componente inscindibile del capitalismo liberista, e non come una sua deviazione da binari interpretativi corretti. In tal senso la si è riconosciuta e accettata come l'unica possibile risposta d'emergenza storicamente datasi (per lungo tempo) davanti all'assenza di alternative praticabili e all'impostazione di politiche d'intervento pubblico nella costruzione di alloggi a basso costo, mutuate dai paesi del Nord del mondo, ma assolutamente inadatte ai contesti in via di sviluppo;

3) valutato obiettivamente la carenza dei servizi e delle infrastrutture in molte parti della città come la perversa conseguenza di una storica combinazione tra la mancanza di volontà politica verso l'inclusione sociale e "l'adozione di standard e soluzioni tecniche incompatibili con le risorse, pubbliche e private, disponibili" (Balbo, 1999);

4) proceduto ad un riconoscimento diffuso dell'informalità urbana, in modo che non escludesse i suoi abitanti dalla comunità cittadina (a partire dal suo ruolo di istituzione politica) e costituisse il presupposto per il loro passaggio dalla condizione che i francofoni definisco di "citoyen" a quella di "citadin" 5) ricercato l'integrazione delle attività informali (con l'esclusione di quelle illecite), riconoscendone il ruolo di porzione dinamica dell'economia (spesso asservita alla produttività proprio dell'economia formale, cfr. Sassen, 1997), di meccanismo indispensabile di redistribuzione delle risorse del territorio e di fattore di integrazione sociale e contenimento della conflittualità; 6) messo infine in questione l'opportunità del "trasferimento in loco" di stru- 
menti che potevano aver funzionato in società sviluppate, cercando (una volta eventualmente deciso di emularne l'utilizzazione) di adattarne i principi alle coerenze del territorio e della società locale.

Ovviamente, questi elementi hanno agito solo come punti di partenza, e non hanno rappresentato in toto le politiche urbanistiche della città brasiliana, venendo gradualmente ad inserirsi in un quadro integrato di interventi incentrati sulla costruzione del 'diritto alla città' attraverso meccanismi decisionali 'inclusivi', che sono stati capaci (come abbiamo visto) di risemantizzare concetti come 'la governance', il 'marketing urbano' o la 'pianificazione strategica', non asservendoli ad ottiche di pura competizione con altri territori, ma mettendoli al servizio del territorio e dei suoi cittadini, attraverso politiche redistributive collegate tra loro nel processo del Bilancio Partecipativo.

In certo qual modo, è possibile affermare che l'esperienza di governo partecipativo dei diversi aspetti del territorio ha puntato a costituirsi come il luogo di 'riequilibrio' delle distorsioni della cosiddetta 'società di mercato', intesa come effetto collaterale ed invasivo dell'eccessiva esaltazione dell'economia di mercato che (come affermato nel vertice ONU di Copenaghen del '95) può portare la società a valutare tutto nei soli termini dell'efficienza e dell' ottimizzazione delle risorse.

Questo 'riequilibrio' ha presupposto ciò che - al nascere del Bilancio Partecipativo a Porto Alegre nel 1989 - l'Amministrazione aveva definito ' $l$ 'indispensabile inversione delle priorità', ovvero la necessità di 'sbilanciare' temporaneamente il governo del territorio a favore dei gruppi più deboli della società, per poter ambire alla costruzione di una vera 'giustizia distributiva'. Non è un caso che processi simili al Bilancio Partecipativo siano stati in genere sperimentati in società con forti squilibri sociali, e che - anche in Europa - le più recenti esperienze che si ispirano a quella di Porto Alegre tendano a costruire la propria forza a partire da iniziative 'mirate' che puntano al coinvolgimento nelle decisioni dei bambini e degli adolescenti, degli immigrati, degli abitanti dei quartieri più poveri, o dei molti che esprimono un 'non-voto' come protesta e non come forma di disinteresse per la gestione del territorio.

In quest'ottica, l'amministrazione di Porto Alegre non ha perseguito - almeno in un primo tempo - l'imperativo alla 'pacificazione sociale', contenuto in molte raccomandazioni internazionali riguardanti il governo e lo sviluppo locale, né la ricerca prioritaria di ampi consensi che, forse, l'avrebbe condotta ad una immobilità in grado solo di scontentare tutti (Allegretti, 2002b). Ha scelto piuttosto la via di una valorizzazione 'aperta' e 'pubblica' del conflitto urbano, per farne costruttivamente emergere le tensioni propositive e le energie da contraddizione.

Con il tempo, la scelta è apparsa ben ponderata. Lo 'squilibrio iniziale' degli orientamenti delle politiche (attuato come forma di discriminazione positiva dei più deboli) nel medio termine ha, infatti, recuperato un forte dinamismo territoriale, che è servito a ricostruire un 'patto a vasto spettro' tra categorie diverse di cittadini, incluse talune inizialmente scettiche su scelte non dichiaratamente in loro favore.

Per altri versi, la necessità di concentrare inizialmente tutti gli sforzi sulla ricostruzione dei cittadini come esseri umani e come soggetti politici (ricercando quindi la 'sostenibilità' nella sua accezione politica e sociale) ha dato buon esiti anche su un altro piano, permettendo di costruire solidi 'moltipli- 
catori sociali' attraverso cui poter migliorare l'economia, l'ambiente e l'ulteriore valorizzazione delle risorse naturali e socioculturali del territorio. A medio termine, infatti, il programma politico mirato contestualmente ad estendere a tutti gli abitanti il "diritto alla città" e a contrastarne "l'esclusione selettiva", ha permesso alla città di ottimizzare gli sforzi per raggiungere obiettivi di sostenibilità ambientale e territoriale, intesa come 'durabilità' dovuta alla comprensione e all'adesione alle trasformazioni da parte della maggioranza dei cittadini. Infatti, temi come la protezione dell'ambiente o delle memorie storiche, che - all'inizio dell'esperienza - apparivano agli esclusi come un lusso e un privilegio superfluo 'per ricchi' (e non come misure positive per la loro stessa qualità di vita), sono stati gradualmente colti dai più nella loro centralità, grazie all'operazione pedagogico/sociale svolta all'interno dei processi partecipativi. E il passaggio concettuale dal miglioramento degli spazi di vita all'impegno su obiettivi strategici riguardanti la valorizzazione del territorio e dell'ambiente nel loro complesso (che difficilmente avrebbe potuto essere lineare) è stato guidato attraverso un dialogo costante e la messa in atto di interventi 'visibili', capaci di 'educare' gradualmente i cittadini meno avvertiti.

Per certi versi, quindi, negli ultimi 14 anni Porto Alegre ha operato con una logica inversa rispetto a molti altri contesti locali, che hanno preferito incamminarsi sulla strada dell'estensione del "diritto alla città" a partire prioritariamente da interventi sul territorio, e specialmente dalla riqualificazione fisico-sociale dei tessuti urbani autocostruiti.

Nel seguire queste linee, la stessa impostazione politica data al governo della città ha subito dei cambiamenti, costruendo 'una via propria', parzialmente difforme anche rispetto ad alcune direttrici seguite a livello nazionale dallo stesso PT, che non sempre è riuscito ad incorporarne tutti i più significativi punti di vista "a dimostrazione della scomodità e delle perturbazioni" che ancora provocano, "a chi si proponga di governare senza alterare le strutture generali di potere nella società" (Sader, 2002, p. 669), molte innovazioni che, "pur non immuni da tentativi di cooptazione e di controllo sociale [...] possiedono una riserva di capacità di mobilitazione popolare che può funzionare come contrappunto a quegli intenti" (ibidem, p. 677).

Questo 'percorso' ha comportato dapprima una critica aperta alle concezioni classiche dei partiti comunisti di ispirazione sovietica (e, in particolare, alla burocratizzazione e al mito dello sviluppo con il loro impianto economicista). Successivamente - anche attraverso una graduale evoluzione della concezione che vedeva inizialmente nel Bilancio Partecipativo solo un 'palliativo', un progetto temporaneo 'di transizione' verso la 'rivoluzione socialista' - vi è stato anche un allontanamento dall' approccio 'insurrezionalista' alla proposta storica classica del "dualismo dei poteri" (Sader, 2002, p. 671). E - parallelamente - anche dall'approccio allendiano, generalmente definito come 'la via pacifica al socialismo', di cui si evidenziavano negativamente l'eccesso di potere dato alle strutture statali esistenti e il ruolo fagocitante delle forme già strutturate di rappresentanza popolare come i sindacati, troppo centrati sul legame tra diritti e lavoro e di taglio essenzialmente 'corporativo' (e pertanto escludente).

Secondo noi ha poco senso, oggi, voler 'incasellare' l'esperienza di Porto Alegre in categorie politiche che appaiono sorpassate nel momento stesso in cui le si nomina. Certo è che "non si è trattato di sostituire il leninismo con concezioni socialdemocratiche", ma semmai di centrare la nuova esperien- 
za politica (che, non dimentichiamolo, ha forti elementi di origine movimentista, a partire dalla composizione di realtà diverse che in Brasile ha dato origine al PT) sulla "ricerca di emancipazione sociale della cittadinanza attraverso un ampliamento della sfera pubblica” (Sader, 2002, 678). Obiettivo che - di per sé (sia detto a beneficio di coloro che non riescono a prescindere nel loro giudizio dalla dicotomia riformismo/rivoluzione) - è ben più 'radicale' delle modalità con cui si sono sviluppate innovazioni come il Bilancio Partecipativo, il cui taglio (talora bollato come 'meramente riformista'44 nei giudizi dati da alcune forze della sinistra che - per lo più - mostrano contemporaneamente di ignorarne le reali caratteristiche ${ }^{45}$ ) è conseguenza della naturale dinamica di sviluppo di un percorso di riforma maturato in seno ad una forza di governo, inevitabilmente trovatasi a dover mediare tra le proprie ideologie ispiratrici e la necessità di amministrare concretamente e al meglio una metropoli delle dimensioni e della complessità di Porto Alegre.

Per concludere, vale la pena rilevare come, nell'affrontare il percorso di costruzione di questo peculiare Progetto di Città, fondato sull'individuazione progressiva di una condizione di equilibrio tra l'obiettivo della città produttiva e quello della città inclusiva (Balbo, 2002), Porto Alegre ha teso ad entrare in un'ottica di 'ribaltamento dialettico' del concetto stesso di democrazia. Non è un rovesciamento già compiutamente realizzato, ma certo vi è un significativo 'slittamento' di senso, che va avvicinandosi ad una posizione interpretativa in cui "il mandato stesso della democrazia rappresentativa sarebbe rappresentato dal costruire la decisione insieme ai cittadini attraverso la democrazia diretta" ${ }^{46}$.

Inoltre, attraverso lo sviluppo della sua esperienza quasi quindicennale, Porto Alegre si è riservata la possibilità di dare un significato chiaro ad alcune di quelle espressioni che Ivan Illich chiamava "termini ameba", a causa del loro uso sproporzionato alla capacità di definirne significati univoci, densi e concretamente incisivi: sviluppo locale sostenibile, partecipazione, partenariato, società civile. L'aver colto questa opportunità ci appare forse, oggi, come uno dei contributi più interessanti offerti a livello internazionale da questa esperienza; tanto più nella misura in cui la certezza di alcuni suoi valori fondanti si è accompagnata ad un agire fondato sul 'dubbio metodologico', che pare aver rigettato l'idea di un prêt-à-penser per la città (Osmont, 2002, p. 28), offrendo un esempio estremamente importante da cogliere proprio nel momento in cui guardiamo con interesse ad alcuni strumenti che Porto Alegre ha elaborato ed affinato. Nelle parole di Olivio Dutra, primo sindaco e primo governatore 'petista' della capitale gaúcha:

La nostra coscienza è cresciuta in direzione del protagonismo comunitario. Il modo 'Petista' di governare non è un 'prêt-à-porter', una ricetta pronta e definita, un' esperienza che si basta e si esaurisce in se stessa. La permanente necessità di comprovazione, la messa in discussione dei suoi paletti, lo scambio con altre esperienze democratico-popolari lo rendono un'opera aperta, in permanente perfezionamento. Il protagonismo è contrario all'autoritarismo e al servilismo (Dutra, apud Allegretti, 2000b).

\subsubsection{Porto Alegre: verso un proprio Progetto Locale}

Nelle città dei PVS, dove senso di appartenenza, coesione sociale e concetto di cittadinanza risultano sempre più deboli, l'inclusività appare ogni giorno più difficile da costruire con gli strumenti di governo tradizionali (Balbo, 2002, p. 288). 
Sostenere che Porto Alegre si sottrae del tutto al quadro disegnato da questo insieme di elementi di pressione e di 'tecniche', suggerite o, più spesso, imposte su scala internazionale agli ambiti locali (e in particolare ai territori urbani), sarebbe un'affermazione mendace.

Non può quindi che essere parte di un 'mito' irrealistico e fallace l'immagine di una Porto Alegre "regno dell'utopia socialista" che si sottrae "magicamente' alle ricadute dei fenomeni economici globalizzati che segnano la fisicità di molti territori locali (dalla deindustrializzazione alla terziarizzazione urbana, dalla costruzione di grandi centri commerciali alla crescita delle catene di 'fast food' americani) e che riesce non solo a sopravvivere, ma addirittura ad affermarsi come uno dei centri vitali del pianeta, divenendo persino modello positivo iper-citato dagli ultimi Rapporti sullo Sviluppo Umano dell'UNDP (2001, 2002), dai programmi di 'best practices' di governo urbano dell'ONU e persino della stessa Banca Mondiale.

D'altro canto, sarebbe una mistificazione in mala fede veicolare l'immagine di Porto Alegre come 'città globale' in tutto e per tutto inserita nelle logiche dello sviluppo urbano di matrice neoliberista. Come anche sarebbe riduttivo (come taluni oppositori politici dell'amministrazione in carica fanno) affermare che la città brasiliana si sia limitata a mettere in atto una strategia di mera 'mitigazione' dei modelli di sviluppo urbano neoliberista, visto che ciò presupporrebbe:

1) una sostanziale adesione ai loro contenuti e ai loro obiettivi (e - al massimo - la profusione di un forte impegno nell'impostare progetti intesi, appunto, a 'mitigarne' determinati effetti di squilibrio nell'ambito locale, ad esempio a svantaggio dell'ambiente, dell'autonoma capacità di governo delle istituzioni locali, o di categorie socialmente più deboli);

2) il mantenere la cosiddetta "società civile" o suoi particolari segmenti come referenti primari delle proprie politiche (connotandole così come azione filantropica di soggetti 'inclusi' verso soggetti 'esclusi'), invece che porre il Potere Pubblico come oggetto centrale dell'azione riformista intrapresa.

Come si può dedurre da quanto esposto in questo libro, nessuno dei due presupposti può essere onestamente collegato all'esperienza di Porto Alegre. L'impostazione delle politiche di 'inclusione sociale' messe in atto negli ultimi 14 anni, infatti, non sembra aver rincorso gli effetti di una "vera macchina di produzione dell'esclusione rinunciando ad un attacco ai processi di accumulazione del capitale" (Sader, 2002, p. 674) né ha rinunciato alle battaglie "per l'affermazione di diritti universali e la ricostruzione degli individui come cittadini", così contribuendo ad isolarli come individui di una 'società civile" e finendo - magari - per essere funzionale alla logica mercantile che affermava di voler contestare.

Tutto al contrario, anzi. Per certi versi, proprio il fatto di chiamare i cittadini a decidere sulle scelte urbane legittima l'inversione delle 'priorità di investimento', in un quadro che trascende le tecniche 'adattive' di miglior ripartizione delle risorse dentro un'invariata logica neoliberista. Così come è vero il contrario: la creazione di 'nuovi strumenti di governo territoriale' è inseparabile da una volontà politica progressista che ne informi i contenuti centrandosi sull'inversione delle priorità. Senza quest'ultima, infatti, anche gli strumenti di 'azione partecipativa' restano di per sé 'neutri', o - peggio possono trasformarsi in mezzi di 'conservazione' al servizio della 'costruzione di consenso', della 'democrazia dei sondaggi' e - in ultima analisi - di 
una 'progaganda sui processi decisionali' che costituisce una mera formula di marketing territoriale che vende proclami ma non contenuti.

Pertanto, ciò che distingue la vicenda di Porto Alegre da altri esempi è, principalmente, il fatto che la riforma che ha portato il Bilancio Partecipativo al cuore delle politiche comunali ha puntato a contrastare la tradizionale separazione (costitutiva del modello liberale) tra i campi del sociale e del politico, ricostituendo i diritti di cittadinanza proprio a partire dalle necessità sociali degli abitanti, "ma al contempo iscrivendole sul piano politico, per non neutralizzarle sul piano del sociale - come era tipico dei governi populisti latinoamericani e della loro concezione corporativa dello Stato" (Sader, 2002, p. 671). Proprio il tentativo di costruire creativamente nuove relazioni dirette tra gli ambiti dell'economico, del sociale, del culturale e del politico, rientra anzi tra gli aspetti più fertili e potenzialmente 'eversivi' ${ }^{47}$ presenti in una riforma delle politiche che ha posto nel suo centro la trasformazione dello Stato e della tradizionale relazione tra governanti e governati, mettendo in tensione la democrazia rappresentativa attraverso processi partecipativi incentrati su un progetto di 'emancipazione' della cittadinanza e su una concezione 'estesa' della sovranità popolare, tradizionalmente confinata nel momento del voto ${ }^{48}$.

Per far ciò, il Fronte Popolare che amministra Porto Alegre dal 1989 ha dovuto superare la tradizionale incapacità delle amministrazioni di taglio 'liberale' di prendere in carico gli impulsi provenienti dalla mobilitazione dei ceti popolari e dei movimenti organizzati, valorizzandone viceversa il capitale sociale attraverso un attivo coinvolgimento non solo nei processi di distribuzione del reddito, ma anche in quelli di co-costruzione delle regole e della spazializzazione di tali processi.

Inoltre, si è favorito un importante passaggio semantico che - dopo i primi anni di sperimentazione del Bilancio Partecipativo in forma quasi di 'politica settoriale' - ha fatto di questo processo democratico (all'incirca a partire dal 1993) un vero e proprio nucleo di radicale riforma democratica dello Stato e delle politiche cittadine; facendolo retroagire sia sulla trasformazione di tutte le altre strutture decisionali locali (tavoli di concertazione, commissioni tematiche, redazione dei piani urbanistici e di sviluppo economico) sia, seppur con esiti meno sensibili, sui meccanismi di alterazione delle strutture generali di potere consolidatesi nella società locale.

Non bisogna, del resto, dimenticare che quando in questo testo ci riferiamo all'esperienza di Porto Alegre non intendiamo limitarci allo 'strumento' del Bilancio Partecipativo per cui la città brasiliana è principalmente nota in ambito internazionale, ma vogliamo riferirci ad un'esperienza di gestione politica articolata (di cui il Bilancio Partecipativo costituisce solo un tassello, seppur 'nodale') che si è sviluppata intorno ad alcuni valori ed obiettivi chiari, assumendo il concetto di 'governo locale' in un'accezione ampia, cosciente del fatto che la messa in opera delle politiche pubbliche locali non può essere il frutto esclusivo del solo ente di governo locale (inteso come istituzione specifica), ma il prodotto di interazioni complesse tra soggetti differenti, che hanno finalità diverse. Seppur con un punto di partenza locale ed un'attenzione particolare per le ricadute locali di ogni azione, quindi, l'esperienza che Porto Alegre ha condotto negli ultimi 14 anni allude con evidenza ad un 'progetto' più ampio (dove l'aspetto politico è stato preponderante rispetto a quello semplicemente 'amministrativo', pur senza tralasciare la centralità di 
quest'ultimo), che ha operato parallelamente su più piani. E di cui, quindi, insieme alle sperimentazioni di strumenti e politiche di ambito locale (cfr. capp. 12/14) hanno fatto parte attiva elementi diversi, come l'impegno nel coordinamento dei livelli di azione con l'esperienza politica affine tentata nello Stato del Rio Grande do Sul tra il 1999 e il 2002 (con i risultati di alterna incisività cui abbiamo accennato nel testo), l'impegno all'interno del movimento di 'Riforma Urbana'"49, che ha prodotto nel 2001 la legge nazionale detta "Statuto della Città", ma anche il ruolo ricavatosi da Porto Alegre all'interno del Mercosul e della rete economico-culturale delle Mercociudades, e i contributi attivi offerti nell' ambito del 'Movimento per una nuova Globalizzazione' ospitando le prime 3 edizioni del Forum Sociale Mondiale e del Forum delle Autorità Locali per l'Inclusione Sociale, e le prime 2 del Forum Mondiale dell'Educazione, della Scuola e dell'Università. Tutte occasioni queste ultime - per aprire la città alla prosecuzione di un dialogo tra cittadini ed amministrazione che travalichi l'ambito della costruzione del locale come universo chiuso ed autosufficiente, guardando invece concretamente alle relazioni con ciò che sta 'al di fuori', e che contribuisce in maniera determinante a costruirlo attraverso i vincoli, gli stimoli e le ricadute che i fenomeni globali e il trasformarsi degli stili di vita determinano su ogni territorio.

In un quadro di azione così articolato, non è raro imbattersi in elementi (e nelle relative terminologie che li descrivono) che lasciano da pensare, nella misura in cui fanno riferimento a 'concetti chiave' dell'impianto politicoeconomico del neoliberismo ${ }^{50}$, e vengono ormai autoadottati o imposti su scala mondiale (per cooptazione o come elemento di scambio per il finanziamento da parte di organismi internazionali bilaterali o multilaterali) sia alle politiche nazionali che a quelle di ambito locale.

Del resto, l'esperienza di Porto Alegre negli ultimi 14 anni non si è sottratta ad un quadro internazionale in trasformazione, in cui ai governi locali spetta in maniera crescente non solo l'attuazione di misure di benessere e redistribuzione sociale e la promozione di politiche di pianificazione e gestione territoriale, trasportistica ed edilizia, ma anche la promozione economica del territorio con i suoi corollari di tecniche e strategie spesso mutuate dall'ambito aziendale (Bobbio, 2002, p. 201): come il marketing urbano, la cura dell'immagine della città, la costruzione di relazioni internazionali (la cosiddetta 'diplomazia parallela ${ }^{51}$ ), l'alleanza con gruppi privati per il miglioramento di infrastrutture e servizi, o la creazione e l'accoglienza di eventi internazionali in grado di attrarre l'interesse di investitori e visitatori. Ed è per questa via - per l'appartenenza cioè ad un quadro di relazioni più vaste del proprio locale, che in qualche modo ne garantiscono anche la sopravvivenza - che anche nell'esperienza di Porto Alegre non pochi di questi elementi appaiono presenti.

Quello a cui resta importante guardare è il modo in cui questi elementi sono presenti in un'esperienza urbana la cui peculiarità non sta nell'aver voltato le spalle ad un panorama a cui la città veniva a trovarsi legata (da reti di relazioni intergovernative, da vere e proprie imposizioni provenienti da livelli superiori di governo o da scelte ereditate dalle passate amministrazioni), ma nell'aver dato avvio ad una strategia di 'appartenenza cosciente' ad un contesto più vasto, che l'amministrazione ha messo sul piatto della discussione pubblica con la cittadinanza, perché esso non fosse 'subito' o considerato un 'dato naturale' immodificabile ${ }^{52}$. 
678 L'esperienza di Porto Alegre non è quindi 'immune' dalla presenza di elementi di urban marketing, pianificazione strategica, ecc.. Dovremmo, al limite, anche chiederci: poteva forse esserlo, se non a prezzo di restare 'ai margini' del panorama internazionale, nel quale oggi va invece collocandosi saldamente al centro? Forse per rispondere a questa domanda sarebbe necessario un lungo dibattito. E un altro libro, che indagasse più in dettaglio questioni (come la propaganda urbana, la politica economico/finanziaria o la costruzione delle relazioni internazionali) che in questo hanno solo potuto essere 'sfiorate' da rapidi accenni.

Ciò su cui, però, ci interessa richiamare brevemente l'attenzione è, semmai, come lo spirito, le modalità e il livello di priorizzazione temporale di alcune scelte si siano posti come elemento distintivo di una differenza e (in certi casi) della non-appartenenza dell'esperienza di Porto Alegre allo spirito del tempo. Ovvero di una mancata adesione alle motivazioni e agli obiettivi di quello spirito neoliberista, che riaffiora continuamente dietro le strategie di intervento sulla città, stimolate e materialmente supportate da istituzioni finanziarie internazionali come la Banca Mondiale, le cui modalità di azione in perenne trasformazione celano un'identità di fondo dei contenuti e "dell'ossessione" per la produttività, il profitto urbano e la competizione tra città, letta come parte fondante delle strategie economiche regionali e nazionali (Osmont, 2002, p. 26).

Guardando all'esperienza di Porto Alegre dall'esterno (magari attraverso le pubbliche lodi presenti negli schedari di best practices del World Bank Institute $^{53}$ ), potrebbero oggi ritrovarsi molti degli elementi nodali di quelle 'pre-condizioni strutturali' per lo sviluppo locale che la Banca Mondiale da oltre un decennio va imponendo ai contesti locali che richiedono l'appoggio suo e di altre istituzioni collegate (cfr. cap. 2): la riduzione delle inefficienze e dei costi di transazione, la buona gestione del territorio, la qualità della vita (livability) necessaria al funzionamento della città, la sua bankability che si traduce in 'affidabilità di credito' (creditworthiness). Una simile constatazione deriva però solo da una lettura 'a posteriori'. Infatti, il raggiungimento di simili esiti non ha fatto parte degli 'obiettivi originari' dell'amministrazione di Porto Alegre, centrati piuttosto su quella 'inversione di priorità' (indispensabile per giungere ad una reale inclusione urbana degli strati più deboli $\mathrm{e}$ tradizionalmente abbandonati della popolazione), che già nei programmi del PT per le elezioni municipali del 1985 (cfr. Wefort, 1986) figurava come il vero 'perno' degli obiettivi della coalizione che sarà solo più tardi responsabile dell'attivazione dei processi di Bilancio Partecipativo. Si potrebbe anzi sostenere che a Porto Alegre, come in altri casi, dove il Bilancio Partecipativo ha portato efficienza gestionale, credibilità economico-finanziaria e riduzione di sprechi (oltre che crescita di popolarità per le giunte promotrici), questi esiti sono stati spesso più un effetto collaterale (Allegretti, 2002b, p. 83) che l'obiettivo delle riforme fatte. "I risultati conseguiti sono stati cioè più ampi di quelli perseguiti (democratizzazione istituzionale, inversione delle priorità, giustizia distributiva), ma i due piani del discorso andrebbero tenuti doverosamente distinti" (ibidem).

Del resto, se "l'ultima mutazione della governance urbana" indotta dalle imposizioni della Banca Mondiale in molte città ha teso "a tecnicizzare al massimo la questione della città, vista essenzialmente sotto il profilo economico in una prospettiva di forte concorrenza" (Osmont, 2002), Porto Alegre sem- 
bra aver puntato all'obiettivo opposto, cioè ad una 'ripoliticizzazione' delle politiche urbane, non solo per quanto attiene la centralità data alla costruzione di nuovi nessi tra ambito sociale politico, ma anche per quanto attiene più specificamente il bilancio (Lopes Sousa, 2000) ${ }^{54}$ e le politiche finanziarie, dove è inclusa anche la serie di discussioni pubbliche impostate dal 1997 per dibattere su vincoli e opportunità per la città di alcuni grandi prestiti internazionali. In tale quadro suonano illuminanti le parole dell'ex-sindaco Genro:

Credo che le relazioni con entità come la Banca Interamericana di Sviluppo o la Banca Mondiale debbano essere sempre e inevitabilmente solo di interesse, a partire dai criteri collocati come giusti dalla città; a partire da qui si possono stabilire relazioni di interesse reciproco, ma la stima difficilmente sarà a due sensi. Non è possibile prendere una posizione isolazionista come non si può cedere ai loro criteri; la cosa migliore è essere ben accetti e lottare dall'interno senza farsi sopraffare. A Porto Alegre abbiamo molti finanziamenti o semplici riconoscimenti da parte di queste istituzioni. Eppure non ci hanno mai chiesto di privatizzare nulla o di cambiare politica. Anche perché abbiamo spinto sulla trasparenza e sulla partecipazione che loro almeno formalmente chiedono. Il segreto è essere efficienti, e soprattutto dei buoni pagatori. Noi lo siamo, e per questo hanno interesse a lavorare con noi (in Alleg retti, 2000b, p. 302).

Analogamente, l'analisi delle motivazioni e delle trasformazioni politiche dell'esperienza di Porto Alegre permette di 'ricollocare' nella loro giusta posizione altri strumenti.

Ad esempio il marketing urbano, che ha cominciato a svolgere una funzione di promozione internazionale più visibile intorno al 1996 (in coincidenza con la presenza del sindaco di Porto Alegre al vertice ONU di Istanbul sugli Insediamenti umani), ma ha mantenuto un ruolo importante soprattutto nei confronti della creazione di una 'coscienza collettiva' e di un senso di appartenenza alla città nel suo complesso (come in occasione dei tre Congressi della Città che si sono svolti a partire dal 1993), oltre che per la promozione e la diffusione dei processi partecipativi attivati sul territorio. In fondo, il modello di marketing sperimentato a Porto Alegre pare estraneo all'estremizzazione della logica della 'concorrenza tra città', costituendosi essenzialmente come servizio per la promozione dello sviluppo locale e per una maggior coesione socioculturale al suo interno; soprattutto, esso non tende a mettere in atto quegli squilibri che altrove portano a spendere più fondi nella pubblicizzazione degli interventi, piuttosto che nella loro messa in opera, anche per l'attento controllo e i tagli di budget costantemente apportati dalla cittadinanza e dal consiglio comunale (cfr. capp 9-10), spesso con l'obiettivo implicito di minimizzarne il valore di legittimazione politica della maggioranza al governo.

Valutandolo in tale quadro, l'impegno profuso nella pubblicizzazione delle azioni municipali - ai limiti dell'aggressività per chi, da fuori, entri in contatto con la città - tende a ridimensionarsi, sia perché appare equilibrato nel novero delle voci di spesa, sia perché non veicola solo intenzioni programmatiche ma contenuti forti e reali. Se - come ha scritto Marco Revelli - "la rinuncia da parte dello stato al proprio ruolo di rappresentanza comporta da parte di esso un di più di rappresentazione", ovvero "la costruzione di una realtà virtuale in cui simulare le mosse di una politica che non è", (cfr. Allegretti, 2002b, p. 81) il recupero della "logica di luogo", che l'amministrazione di Porto Alegre va mettendo al centro di un progetto politico di 
ricostruzione del rapporto di fiducia reciproca con la popolazione, ha reso innecessario questo di più di rappresentazione fittizia, facendo sì che la rappresentanza e la rappresentazione non vivessero un processo di divaricazione, ma procedessero di pari passo nel diffondere - in maniera 'decisa e visibile' - la conoscenza di una reale trasformazione delle relazioni tra politica e cittadini, già di per sé simmetricamente 'decisa e visibile' (ibidem, p. 82). È questo, forse, il senso più profondo di quello che si può chiamare 'marketing urbano', secondo l'accezione datane in questi anni dall'esperienza di Porto Alegre.

Considerazioni analoghe si possono fare riguardo al tema della costruzione dei grandi 'shopping centres', a cui nel testo abbiamo fatto già riferimento, evidenziando come le strategie adottate negli ultimi anni per l'accoglimento delle richieste di radicamento in città di simili strutture abbiano mostrato una progressiva maturazione, indirizzata (attraverso l'uso di strumenti urbanistici ad hoc ed il collegamento con le rappresentanze popolari dell'OP) ad un'opera pubblica di forte indirizzo, e a una negoziazione di contropartite ambientali e (soprattutto) sociali, elaborate insieme alla cittadinanza. Per quanto attiene, invece, l'adozione del modello dello 'strategic planning' per la redazione dei Piani di Sviluppo Economico e del Piano di Sviluppo Urbano e Ambientale, va osservato come la temporalizzazione della scelta (realizzata intorno al 1993) illumini su un'adesione ai principi di quel modello di intervento, tutt'altro che acritica. Sebbene il riferimento all'esperienza di Barcellona appaia più volte esplicitato nei documenti di corredo dei due strumenti, essa non è stata assunta come 'modello' astorico e atopico da imitare, ma è stato prima valutato il peso che poteva giocare la somiglianza tra alcuni degli elementi di contesto presenti a Porto Alegre e quelli che avevano determinato il successo dell'esperienza catalana (cfr. § 17.3). Soprattutto, l'uso dello 'strategic planning' è stato mediato da un approccio esperienziale/sperimentativo (cfr. Allegretti, 2002d), ed è stato proposto, e poi 'attenuato', solo in una fase della storia cittadina in cui poteva venire legato con coerenza a un complesso di riforme del governo locale già sperimentate, e a un processo di maturazione della cittadinanza (forse ancora in corso, ma certo già potentemente avviato attraverso i successi del Bilancio Partecipativo) che potesse dare 'sostenibilità' alle modalità di utilizzo e agli esiti del nuovo processo di pianificazione strategica.

Da queste rapide osservazioni, non è azzardato trarre la conclusione, che la strada più significativa che l'esperienza di Porto Alegre - valutata nel suo complesso - pare indicarci, è quella della costruzione di un 'proprio' Progetto di Città, che - nella mancanza di risposte univoche da offrire ai dilemmi urbani per contrastare le tendenze all'esclusione - sappia partire dall'utilizzo propositivo delle peculiarità socioterritoriali del contesto locale (e dalle sue interrelazioni con i contesti contigui e i livelli istituzionali superiori a cui si rapporta), e che muova dalla ridefinizione dei modi di rappresentanza dei singoli individui e dei loro gruppi di aggregazione. Considerando che parlare di 'urban governance' vuol dire "assumere l'ipotesi della città come soggetto sociale e politico complessivo", dove i concetti di partecipazione e partenariato implicano prima di tutto il "riconoscimento di tutti e delle differenti capacità, possibilità e aspirazioni" nella costruzione di un comune Progetto di città capace di "ricomporre gli interessi dei singoli intorno a una nuova identità urbana collettiva, a un ricostituito senso di appartenenza, a una ristabilita convergenza su, e a partire da, un territorio" (Balbo, 2002, p. 288). 
${ }^{1}$ In fondo, la modernizzazione del 'mito del buon selvaggio' cela abbastanza chiaramente un punto di vista 'autocentrato', sebbene in questo caso muova non da un atteggiamento di avvertita supremazia culturale, ma dal disagio e dal senso di colpa di una civiltà 'invadente'.

${ }^{2}$ Come ha scritto l'ex-sindaco Genro (2001), in particolare la 'mitizzazione' del Bilancio Partecipativo ha teso a trasformarla "in una specie di icona di una città esotica [...] dove la sinistra ha funzionato" riducendone così l'importanza e "isolandola come una "merce" che può essere consumata solo da una singola città".

${ }^{3}$ Cfr. Martinotti (1999, a cura di), pg. 11.

${ }^{4}$ Nella lettura giuridica italiana, il govemo in senso 'soggettivo' e 'oggettivo' (cfr. U. Allegretti, 2002)

${ }^{5}$ Del resto, ben di rado è sociologicamente possibile individuare il momento preciso in cui si determinano rotture radicali, transizioni e passaggi di paradigma.

${ }^{6}$ Cfr. Sader, 2002, pg. 654.

${ }^{7}$ Il passaggio dal fordismo al postfordismo - negli ultimi decenni del '900 - ha comportato non solo una perdita di certezze e lo straripamento del mondo del lavoro fuori dalle mura dei 'grandi contenitori' che lo avevano ospitato, ma la stessa sparizione dell'idea di fabbrica a vantaggio di un'idea di territorio inteso come spazio diffuso di produzione e 'unità naturale di business'. Cfr. Revelli (2001).

${ }^{8}$ Un esempio sono le politiche di 'reddito minimo' o 'cittadinanza garantita' tentate in diversi contesti.

${ }^{9}$ Sulla scorta degli studi di Foucault, De Giorgi (2002) ha, ad esempio, approfondito uno dei temi in cui in occidente si è sviluppata una maggior regressione della gestione del territorio nel passaggio dal fordismo al postfordismo, ovvero quello delle istituzioni di pena, segnate dal passaggio dall'economia politica della pena (in cui i dispositivi di controllo avevano una funzione di razionalizzazione disciplinare della produzione, mirando alla trasformazione delle devianze e al loro trattamento scientifico ai fini di una reintegrazione nel ciclo produttivo) a 'regimi di pratiche' fondate solo sul principio di autoconservazione della società e sulla 'gestione del rischio', che si traducono nella "possibilità sconfinata di reprimere tutto ciò che costituisce una minaccia" (pg. 99). Se, in passato, il passaggio dalla 'sovranità che proibisce' alla 'governamentalità che regola, ordina e dispone' aveva puntato su pratiche di sicurezza mirate a garantire il corretto funzionamento dell'apparato di governo e il principio della massimizzazione economica su cui si reggeva, oggi si ha la tendenza a mettere in campo tecnologie di controllo e limitazione preventiva dell'accesso che "migrano verso un regime di sorveglianza e contenimento preventivo di intere classi di soggetti, rinunciando così a qualsiasi sapere sugli individui" (pg. 108) e adottando una razionalità "attuariale" centrata su "indici di probabilità che consentono di ricondurre determinati soggetti a specifiche classi pericolose" $\mathrm{e}$ sulla "identificazione (ma meglio sarebbe dire "invenzione") di classi di soggetti considerate produttrici di rischio, potenzialmente devianti e pericolose per l'ordine costituito" (pg. 114). Afferma De Giorgi (pg. 112) che le "popolazioni problematiche, vale a dire il surplus di forza lavoro determinato dalla ristrutturazione capitalistica postfordista, sono gestite sempre meno con gli strumenti di regolazione "sociale" della poventà e sempre più invece con $i$ dispositivi di repressione penale della devianza" determinando quella transizione dallo Stato Sociale allo Stato Penale di cui parla il sociologo Loic Wacquant (2000) quando analizza la "criminalizzazione della miseria funzionale all'imposizione della condizione salariale precaria e sottopagata". In tale ottica, i centri di detenzione per migranti oggi diffusi in tutta Europa costituiscono forse il 'modello' a cui si ispireranno le nuove carceri postfordiste in quanto "dispositivi preposti al contenimento di una popolazione eccedente e di un surplus di forza lavoro dequalificata" che "prescindono esplicitamente dalla consumazione di un reato, dalle caratteristiche individuali di chi vi è rinchiuso e da qualunque finalità rieducativi o correzionale, per orientarsi invece allo 'stoccaggio' di intere categorie di individui considerate a rischio" (ibidem).

${ }^{10}$ Bobbio (2002, p. 207) affaccia correttamente l'ipotesi che - al di là di queste motivazioni prevalenti - nel motivare l'apertura dei governi locali verso forme partecipative sia da riconoscere anche una spinta che le concezioni privatistiche del New Public Management hanno offerto nel favorire una nuova considerazione del ruolo dei cittadini, o almeno dei cittadini-clienti e dei cittadini-consumatori, specialmente in relazione al- 
l'utilizzo di servizi monopolistici dove l'opzione dell' 'exit' (ossia il rivolgersi altrove) non è praticabile.

${ }^{11}$ Cfr. Bobbio e Zeppetella (1999) o Bobbio (2002).

${ }^{12}$ La città, più di ogni altra istituzione, può legittimamente pretendere di costituire la migliore unità per lo sviluppo della democrazia (Dahl, 1967, pg. 964).

${ }^{13}$ Le altre ragioni sono la gestione di servizi che hanno una diretta influenza sulla vita dei cittadini, il fatto di rappresentare un nodo fondamentale nella divisione territoriale dei poteri che il rapporto tra globalizzazione e decentramento va favorendo, e le loro relazioni con gli altri molteplici centri di potere che interagiscono nel governo della complessa società contemporanea (cfr. Bobbio, 2002, pg. 4-5).

${ }_{14}$ Per molti aspetti, essa costituisce la prima compiuta materializzazione delle formulazioni teoriche di Nicos Poulantzas (1981) sulla combinazione di democrazia diretta e rappresentativa.

${ }^{15}$ Sader, 2002, p. 670.

${ }^{16}$ Ibidem.

${ }^{17}$ Esse possono andare dai casi più semplici di mera consultazione dei cittadini - o di parte di essi - affinché esprimano il proprio punto dei vista su progetti già predisposti dalle amministrazioni (come nel caso delle public inqueres anglosassoni) o le proprie reazioni su un tema particolare (come nei cosiddetti sondaggi deliberativi o Deliberative Opinion Polls), fino ad esperienze più complesse in cui gli abitanti sono chiamati a partecipare della risoluzione negoziale di conflitti (soprattutto ambientali) o viene loro riconosciuto il potere di discutere e negoziare i contenuti di un progetto con gli enti locali. Addirittura, in certi casi viene totalmente delegato alle comunità destinatarie di un intervento pubblico il compito di definirne i contorni progettuali e gestionali, oppure singole politiche vengono affidate alla valutazione di gruppi di utenti di un servizio o di 'cittadini comuni' per lo più estratti a sorte. Esempi di questo tipo sono i cosiddetti citizens panels, le citizens juries o le planunnungzelle (queste ultime operano entro alcuni programmi urbanistici tedeschi); le conférences des citoyennes o le consensus conferences servono invece a dirimere questioni delicate (ad esempio che implicano problematiche ancora controverse da un punto di vista tecnologico, come quelle che toccano i temi degli OGM o delle onde elettromagnetiche).

${ }^{18}$ Cfr. intervento di Luigi Bobbio al convegno "Reinventare la democrazia" (Parma, 67 dicembre 2002), i cui atti sono in corso di pubblicazione da parte della Provincia di Parma e della locale università.

${ }^{19}$ Il processo di costruzione della decisione appare più importante della decisione stessa che verrà poi assunta.

${ }^{20}$ Intervento di J. B. Picheral al Convegno "Reinventare la Democrazia", Parma, 6/7 dicembre 2002.

${ }^{21}$ A questo proposito, sono estremamente grato al dibattito originatosi nella Rete Internazionale DRD, che ha portato alla costruzione di una 'griglia di lettura' delle esperienze partecipative locali che - sotto forma di domande e di ambiti di riflessione - offre uno strumento flessibile e perfettibile di riflessione, che abbiamo scelto di riportare per intero in appendice.

${ }^{22}$ Nel seguito faremo sostanzialmente riferimento all'articolazione di base proposta da L. Bobbio nel succitato convegno, seppur articolando alcuni temi 'densi' accorpati invece da Bobbio.

${ }^{23}$ Ibidem.

${ }^{24}$ Un modo può essere quello di verificare che nessuno lamenti di essere escluso dall'arena di discussione e/o decisione.

${ }^{25}$ L'estrazione - in linea tendenziale - è un modo per cercare di mettere a confronto le opinioni di cittadini comuni che (presumibilmente) pervengono al momento della decisione senza un'idea precisa o un pre-concetto sul tema esaminato.

${ }^{26}$ Un caso tra i più interessanti è quello di Manchester, dove alcune organizzazioni comunitarie (su stimolo dell'ONG 'Community Pride') hanno costruito delle regole e un forum decisionale per ripartire tra loro un fondo speciale del governo centrale per gli anni 2001-2004 (il Fondo di Rinnovamento dei Quartieri (NRF) destinato alle 88 municipalità più povere del Regno Unito). A questo scopo, esse hanno usato e ricontestualizzato matrici costruite sul modello di quelle del Bilancio Partecipativo di Porto Alegre.

${ }^{27}$ Questo spiegherebbe la localizzazione preferenziale di molti dei più interessanti processi partecipativi in contesti come il Canada o i Paesi Scandinavi.

${ }^{28}$ Cfr. L'ultimo capitolo di Herzberg (2002). 
${ }^{29}$ Il metodo elettorale comunale brasiliano e l'assenza di premi di maggioranza determinano questa situazione di conflitto e non allineamento tra poteri con maggioranze diverse.

${ }^{30}$ Comunicazione di Luigi Bobbio, 6-7 dicembre 2002.

${ }^{31} \mathrm{O}$ intelligenza collettiva, come in Calame e Tasmant (2001, p. 145)

32 Per certi versi il momento di trasformazione appare quasi schizofrenico (cfr. Allegretti, 2003). Da un lato - specie a livello di discorso politico a scala nazionale - le opposte tendenze verso il federalismo e la ricentralizzazione dello Stato sembrano sopraffarsi e smentirsi quotidianamente. Dall'altro, il Paese è attraversato da una serie di 'movimenti' contestuali che (interagendo tra loro costruttivamente) possono alludere nel breve termine ad un'apertura verso cambiamenti concreti nelle pratiche di governo del territorio - specie a livello locale - in direzione di una maggiore 'democratizzazione della democrazia' che aiuti colmare la distanza tra amministratori e cittadini:

1) la forte crescita (a scala nazionale e locale) di movimenti e aggregazioni di cittadini che chiedono con forza l'attivazione di percorsi strutturati di partecipazione alle scelte (forum sociali, coordinamenti di comitati, ecc.);

2) un interessamento diffuso nei confronti della conoscenza e dell'analisi di strumenti di 'vivificazione' della democrazia come i Bilanci Partecipativi, da parte di amministrazioni locali, pochissime delle quali finora sono riuscite ad uscire dalla fase di 'riflessione sul tema' per passare a quella della formulazione di ipotesi concrete di emulazione nel nostro contesto o - perlomeno - di costruzione di quelle 'scelte preliminari' indispensabili (trasparenza, comunicatività dei documenti di bilancio, studio della società locale e dei suoi modi di aggregazione, avvio di un dialogo con i movimenti popolari) per gettare le basi per una cocostruzione di regole condivise su cui impostare processi partecipativi;

3) una recente trasformazione dell'ordinamento giuridico, che invita alla verifica di compatibilità di nuovi istituti di democrazia diretta (bilanci partecipativi, costituenti partecipative teritoriali, ecc.) con le previsioni normative del Testo Unico di Riforma degli Enti Locali (TUEL, 267/2000) e della Riforma del Titolo V della Costituzione.

33 Il Comune di Grottammare (l'unico finora balzato alle cronache nazionali per aver messo in atto dal 1994 estesi processi di partecipazione popolare che hanno toccato anche la discussione di alcune voci di bilancio, in due turni di discussione annuale) è certamente il municipio che si trova in una situazione di sperimentazione più avanzata (Cfr. Intenista di Sandro Morelli al Sindaco Massimo Rossi, su 'Quale Stato', mensile CGIL, ${ }^{\circ} 2 / 2002$ ). Altri comuni (come Roma, Piacenza, Napoli, Comacchio e Pieve Emanuele) hanno già formalizzato l'interesse per una sperimentazione su medio termine di processi di Bilancio Partecipativo attraverso la costruzione di esplicite 'deleghe' cittadine per l'avvio di proposte su ipotetiche modalità di sperimentazione. A Roma, un importante lavoro 'preliminare' sta realizzandosi nel Municipio XI, forte delle nuove deleghe affidate alle circoscrizioni in seguito all'approvazione del testo Unico sugli Enti Locali ( $\mathrm{n}^{\circ}$ 267/2000). Diverse sono comunque le esperienze che meritano attenzione critica: un regesto in arricchimento progressivo è sul sito: www.unifi.it/lapei/cantiere.html .

${ }^{34} \mathrm{E}$ un peccato che non siano disponibili gli atti della conferenza preserale 'Democrazia partecipativa' tenutasi 1'8/11/2002 nella Sala della Ronda della Fortezza da Basso, durante il $\mathrm{I}^{\circ}$ Forum sociale Europeo di Firenze. Si potrebbero così recuperare alcune acute osservazioni in proposito dello storico Paul Ginsborg.

${ }_{35}$ Cfr. Giancarlo Paba (a cura di, 2002), ma anche l'intervento dello stesso curatore al seminario del Laboratorio per la Democrazia di Firenze, tenutosi nel Dipartimento di Urbanistica dell'Università di Firenze il 25/11/2002.

${ }_{36}$ Rubiamo questa immagine pregnante al testo di G. Paba, contenuto in Magnaghi (1998).

${ }^{37} \mathrm{Nel}$ contesto italiano, la letteratura generalmente annovera vari strumenti di valenza urbanistica, quali: i Programmi integrati (art. 18 L. 203/91; Del. CIPE 20.12.91), i Programmi integrati d'intervento (art. 16 L. 179/92), i Programmi di recupero urbano (Decreto Ministeriale 1/12/94; art. 11 L. 493/93), Programmi di riqualificazione urbana (Decreto Ministeriale 21.12.94 ; L. 179/92) ed altri strumenti di 'programmazione negoziata'(secondo la definizione del Decreto Interministeriale 32/95), come i Patti territoriali (Legge n. 662/ 1996, Decreto Legge n. 173/1998, Deliberazioni CIPE 21 marzo 1997 e 11 novembre 1998), i Contratti di quartiere (Del. CER 05.06.97; finanziamenti: L. 449/97; art. 2 L. n. 662/97) e i Prusst-Programmi di riqualificazione urbana e sviluppo sostenibile del territorio (Decreto Ministeriale 8/10/1998). Un potenziale partecipativo importante è ravvisabile anche nei 'Piani sociali di Zona' (art. 19 della Legge 328/2000) e in alcuni programmi finanziati dall'Unione Europea come i Pic Urban (Gazzetta Ufficiale Unione Europea n. C 180/02 
Luglio '94 e n. C 200/04, Luglio 1996) che - gestiti dalla DG XVI - puntano al miglioramento delle condizioni di vita in aree di forte disagio sociale e ambientale mediante azioni integrate di carattere innovativo.

${ }^{38}$ Intervento di J. B. Picheral al Convegno "Reinventare la Democrazia", Parma, 6/7 dicembre 2002.

${ }^{39}$ Osmont, 2002, pg. 15.

${ }^{40}$ Negli anni '80 le teorie dello 'Stato duale' avevano raggiunto un momento di diversificazione significativa, riflettendo per certi versi la situazione di due dei paesi 'centrali' nella costruzione delle relative teorie interpretative. Così, secondo l'inglese Saunders (1981) il ruolo principale delle amministrazioni locali risiede nell'occuparsi di 'consumi sociali', ossia delle politiche del welfare che riguardano la riproduzione delle condizioni di vita dei lavoratori, mentre lo Stato centrale si occupa di 'investimenti sociali', ovvero delle decisioni che riguardano la produzione capitalistica, stabilendo le condizioni essenziali per lo sviluppo economico. L'americano Petersop (1981) applicava invece al suo contesto di origine la teoria 'dualista', sostenendo che le città non possono prendere decisioni di tipo redistributivo (come i sussidi o la tassazione progressiva) per evitare che gruppi sociali e attività abbandonino il loro territorio, ma devono occuparsi prioritariamente di promuovere lo sviluppo economico delle loro comunità attraendo investimenti e promuovendo l'attività edilizia. Oggi si direbbe che - a livello planetario - si vada diffondendo un modello di governo che porta le amministrazioni locali a dover contemporaneamente occuparsi di welfare, sviluppo economico e territorio in stretta interdipendenza.

${ }^{41}$ Balbo (2002) analizza - ad esempio - la costruzione dei 'corridoi intelligienti' di fibre ottiche o linee telefoniche che - in pesi dell'Africa o dell'Asia - si sviluppano collegando centri storici e singole aree periferiche o centri dell'intorno urbano, 'scavalcando' tutto quanto si trovi nel mezzo.

${ }^{42}$ Cfr. Sassen, 1997.

${ }^{43}$ Come spiega la Osmont (2002, pg. 26), la cittadinanza (citoyenneté) è condizione formale che può ridursi anche al mero esercizio del voto quinquennale e del pagamento delle imposte, mentre la 'citadinité' costituisce una condizione reale di cittadinanza fondata sull'adesione ad un comune contratto di diritti e doveri e sul riconoscimento di spazi pubblici di mediazione con le istituzioni, dove poter esercitare un controllo democratico che serva anche da elemento di continuità tra la politica locale e quella nazionale.

44 "Può accadere che una iniziativa che in un dato paese, in una data comunità, in un dato momento, è vista come controegemonica possa essere vista in un altro paese o in un altro momento come egemonica" (Sousa Santos, 2002, pg. 23). Talora, poi, essa può essere "cooptata dalla globalizzazione egemonica".

${ }^{45}$ Anche in partiti che formalmente hanno preso a cuore il tema del Bilancio Partecipativo, spesso appaiono documenti duri che divulgano attacchi proditorii al 'mero riformismo' del processo, e diffondono dati imprecisi sul tema (cfr., ad esempio, il $4^{\circ}$ documento di minoranza uscito dal Congresso dei Giovani Comunisti di Rifondazione Comunista in Italia, tenutosi all'inizio di luglio 2002, in allegato a "Liberazione" del 6 luglio 2002).

${ }^{46}$ Intervento di J. B. Picheral al Convegno "Reinventare la Democrazia", Parma, 6/7 dicembre 2002.

${ }^{47}$ Con il termine intendo 'protesi propositivamente ad una trasformazione radicale delle regole vigenti'.

${ }^{48}$ L'art. 97 dello Statuto Comunale di Porto Alegre afferma che "la sovranità popolare si manifesta quando a tutti sono assicurate condizioni degne di esistenza" e che essa sarà esercitata attraverso il voto, ma anche il plebiscito, il referendum, l'iniziativa popolare, la partecipazione alle decisioni del Municipio e al perfezionamento delle istituzioni, l'azione di controllo sulla pubblica amministrazione e la tribuna popolare.

${ }^{49} \mathrm{Cfr}$. www.direitoacidade.org.br .

${ }^{50}$ Meglio sarebbe forse dire: economico-politico.

${ }^{51}$ Nell'analisi di questa questione preferiamo non addentrarci, richiedendo essa competenze e studi specifici che non abbiamo al momento a disposizione. Vi è però l'impressione che questo tema presenti oggi elementi controversi che possono riservare in futuro a Porto Alegre delle 'sacche di resistenza' (di cui esistono già segni di formazione) all'eccessivo protagonismo che la città va assumendo, ad esempio all'interno di alcune reti di sindaci e città. Sarebbe importante che la città - coerentemente con il rifiuto (finora affermato e praticato) dei principi liberisti della concorrenza accesa tra territori locali - ponesse attenzione a non voler 'accentrare' troppo su di sé le diverse reti di 
diplomazia parallela di cui è promotrice o aderente, valutando che il meccanismo della 'rete' ha la sua ragione proprio nel non possedere un 'centro fisico' e nell'offrire uguali possibilità (itineranti o a rotazione) ai suoi diversi membri.

${ }_{52}$ Questo è quanto avviene nella maggioranza dei contesti locali, dove non solo il contesto della 'globalizzazione' è considerato un dato inalterabile (e in gran parte lo è, stanti le relazioni reticolari createsi tra i diversi contesti anche grazie all'apporto positivo delle nuove tecnologie), ma le stesse linee su cui essa si articola sono considerate 'dati immodificabili' invece che 'scelte di campo' che è possibile reindirizzare.

${ }^{53} \mathrm{Cfr}$. http://www. worldbank.org/wbi

${ }^{54}$ Se nell'Ottocento le procedure di bilancio si sono formate come strumento di organizzazione delle finanze pubbliche, dapprima con funzione di controllo del legislativo sull'esecutivo (ai vari livelli di governo) e poi con un ruolo sempre più marcato di strumento di amministrazione, gestione ordinaria e soprattutto di sua 'razionalizzazione scientifica', esse hanno finito per essere progressivamente caricate di un valore quasi 'politicamente neutro' e puramente tecnico che è ovviamente una mistificazione tesa a celare il loro forte contenuto di 'luoghi primari di scelta politica'. Il Bilancio Partecipativo ha rimesso apertamente l'accento sul bilancio come strumento di controllo dei cittadini sui propri eletti, che deve farsi 'trasparente e intelligibile'; e soprattutto ne ha recuperato visibilmente il contenuto politico di luogo in cui si tratta di decidere dei 'fini' del governo urbano, prima ancora che dell'ottimizzazione dei mezzi per il loro raggiungimento. 

APPENDICl 



\section{Appendice 1 \\ Elenco degli acronimi e delle sigle usati nel testo}

ABB; Associação de Brinquedos do Brasil = Assoc. Brasiliana dei Giocattoli

ABC; Agenzia di Cooperazione Brasiliana

ABI; Associazione Brasiliana della Stampa

AC (pl. ACs); Consiglieri o Agenti ComunitariADIR; Area di Influenza Diretta (raggio $1000 \mathrm{~m})$

AEIS; Area Speciale di Interesse Sociale

AGAPAN; Associazione Gaucha di Protezione dell'Ambiente Naturale

AM (pl. AMs) ; Associações de Moradores, Associazioni di Vicinato o di Residenti.

AMORB; Associazione di Residenti di Rubem Berta

ANSUR; Articolazione Nazionale del Suolo Urbano

AP; Amministrazione popolare (è il govemo guidato dal Fronte popolare a Porto Alegre)

APO; valutazione post-occupatoria

ARENA; Aliança Renovadora Nacional = partito dei militari al potere dopo il golpe del 1964

ASCORB; Associazione di Commercianti di Rubem Berta

AUOP; Area Urbana di Occupazione Prioritaria (soggetta ad IPTU progressivo nel tempo)

BADESUL; Banca del Rio Grande do Sul

BID; Banca Interamericana di Sviluppo

BIRD ; Fondo speciale della Banca Mondiale

BM; Brigada Militar

BNDES; Banca Nazionale dello Sviluppo

BNH; Banca Nazionale dell'Abitazione, istituita nel 1964

CAR; Centro Amministrativo Regionale

CC (pl. CCs); Cargo de Confiança; impiegato pubblico (spesso tecnico) designato su incarico di fiducia

CCS ; Coordinamento della Comunicazione Sociale del Comune di Porto Alegre

CEBs ; Comunità Ecclesiali di Base

CECOOPH; Central das Cooperativas Habitacionais de Por to Alegre

CEEE; Compagnia Statale di Elettricità del Rio Grande do Sul

CEF; Cassa Economica Federale;

CEI; Campagna Federale di Sradicamento delle Invasioni

CES ; Coefficiente di Equivalenza Salariale

CEU ; Cadastro do Expediente Unico (Catasto che contiene tutta la storia di ogni immobile)

CHs ; Cooperative d'Abitazione

CLs; Commissioni Locali di Sanità

CM; Câmara Municipal; Consiglio Comunale

CMCDA; Consiglio Municipale del bambino e dell'adolescente

CMDUA; Consiglio Municipale di Sviluppo Urbano e Ambientale 
CMPDDU; Consiglio Municipale del Piano Regolatore di Sviluppo Urbano

CMS; Consiglio Municipale di Sanità

CNBB; Conferenza Nazionale dei Vescovi del Brasile

CNDU; Consiglio Nazionale di Sviluppo Urbano

CNPU; Commissione Nazionale di Politica Urbana e Regioni Metropolitane (poi sostituita dal CNDU)

COHAB ; Compagnia Statale per l'Abitazione

CONAM; Confederazione Nazionale delle Associazioni di Quartiere

CONDEL; Consiglio Deliberativo dell'UAMPA

CONSEPRO; Consiglio di Sicurezza (rete federale e statale)

CONTRAN; Comitato Nazionale Brasiliano sui Trasporti e la circolazione

COP ; Consiglio del Bilancio Partecipativo (ex Consiglio Municipale del Piano di Governo e Bilancio);

COPs; Consiglieri dell'Orçamento Participativo (membri del COP)

CORSAN ; Compagnia Riograndense di Risanamento

CP; Commissione paritaria di revisione dei meccanismi dell'Orçamento Participativo

CPPCV; Contratto Privato di Promessa di Compravendita

CPs ; Consigli Popolari

CPS; Commissione di Parcellamento dei Suoli

CRC; Coordinamento delle Relazioni Comunitarie (Assessorato Comunale alla Partecipazione)

CRI; Catasto

CROP (pl. CROPs); Coordinatore Regionale delle assemblee dell'O.P.

CT ; Commissione Tripartita dell'Orçamento Participativo

CTs ; Coordinatori Tematici dell'Orçamento Participativo

CTT; Centros de Transbordo e de Transferência (parcheggi scambiatori)

CUR; Coordinamento di Urbanizzazione e Regolarizzazione Fondiaria del DEMHAB

CURA ; Comunità Urbana per il Recupero Accelerato

CUT ; Centrale Sindacale Unica dei Lavoratori

DEMHAB ; Dipartimento Municipale alla Casa

DEP ; Dipartimento per gli Scoli Pluviali

DM; Dichiarazione Municipale, equivale al nostro Certificato Urbanistico Edilizio

DMAE; Dipartimento Municipale per l'Acqua e le Fognature

DMCP; Dipartimento Municipale per la Casa Popolare (poi DEMHAB dal 1965)

DMLU; Dipartimento Comunale per la Pulizia Urbana

DOPs; Delegati dell'Orçamento Participativo

EVU; Studio di fattibilità urbanistica (progetto generale)

FABES ; Assessorato alla Famiglia e al Benessere sociale

FASC ; Fondazione di Assistenza Sociale e Comunitaria

FASCOM; Forum dei Consiglieri Comunitari dei vari Assessorati

FASE/RS ; Federazione di Organismi per l'Assistenza Sociale e Educativa del Rio Grande do Sul

FAU ; Facoltà di Architettura e Urbanistica

FCVS; Fondo di compensazione delle variazioni salariali

FEDERASUL; Federazione delle Associazioni Commerciali del Rio Grande do Sul

FEE ; Fondazione di Economia e Statistica

FGT ; Fondazione Gaúcha per il Lavoro

FGTS; Fondi di Garanzia per Tempo di Servizio, sistema di risparmio obblig atorio

FHC; Fernando Henrique Cardoso, ex-presidente del Brasile

FIBGE; Fondazione dell'Istituto Brasiliano di Geografia e Statistica

FIPE; Fondazione Istituto di Ricerche Economiche

FLACAM; Forum Latino Americano di Scienze Sociali e Ambientali

FMDU; Fondo speciale municipale del Comune di Porto Ale gre per lo sviluppo urbano

FMI ; Fondo Monetario Internazionale

FNA; Federazione Nazionale degli Architetti

FNE; Federazione Nazionale degli Ingegneri

FP; Fronte Popolare, blocco costituito da PT, PSB, PCB e PSDB

FRACAB; Federazione Rio-Grandense delle Associazioni Comunitarie e degli Amici del Quartiere

FROPs; For um tematici dei delegati dell'O.P. 
FUNCOMPRAS; Fondo speciale municipale del Comune di Porto Alegre per gli Acquisti Collettivi

FUNCULTURA; Fondo speciale municipale del Comune di Porto Alegre per la Cultura FUNDASUL; Fondazione statale di azione sociale e comunitaria del Rio Grande do Sul FUNDOPIMES; Programma integrato di miglioramenti Sociali finanziato dal BADESUL FUNMERCADO; Fondo speciale municipale di Porto Ale gre per il Mercato Pubblico

FUNPROARTE; Fondo speciale municipale di Porto Ale gre di appoggio all'educazione artistica e culturale

GAPLAN ; Gabinetto di Pianificazione del Comune di Porto Alegre

GATE; Gruppo di Azioni e Tattiche Spaziali; Policia de Choque (simili ai nostri NOCS).

GERM; Gruppo Esecutivo della Regione Metropolitana di Porto Alegre (poi divenuto

Metroplan)

GGA; Gruppo di Gestione delle AEIS

GPR ; Sistema Integrato di Gestione dei Progetti, gestito dal GAPLAN

GT; Gruppo di Lavoro

GTZ; Società Tecnica per la Cooperazione Tedesca

HIS; Abitazione di Interesse Sociale

IA; indice di fabbricabilità

IAB; Istituto degli Architetti del Brasile

IAPs; Institutos de Aposentadoria e Pensão (Istituti Pensionistici)

IBGE; Istituto Brasiliano di Geografia e Statistica

ICC; Istituzione di Credito Comunitario - Portosol

INSS ; Istituto Nazionale di Sicurezza Sociale

IPTR ; Imposta Territoriale Rurale

IPTU; Imposta sui Terreni e i Beni Immobili Urbani

ISSQN; Imposta su Servizi di Ogni Natura

L.O.M.; Lei Organica $=$ Statuto della città

LC; Legge Complementare (di ambito municipale)

LDO; Legge delle Direttrici di Bilancio

LIBRAS ; Lingua Brasiliana dei Segni, usata dai sordomuti per comunicare

MASTER ; Movimento degli Agricoltori Senza terra

MDB; è il movimento di opposizione controllato dal regime militare (vi confluirono PTB e MTR).

MERCOSUL; Mercado Comum da América do Sul

METROPLAN; Fondazione Metropolitana di Pianificazione dello Stato del Rio Grande do Sul

MNLM; Movimento Nazionale di Lotta per la Casa

MOVA; Movimento di Alfabetizzazione

MST; Movimento dei SenzaTerra

MTR; Movimento Trabalhista Renovador, confluì insieme al PTB (da una cui costola era nato) nel MDB.

NAS; Nuclei di Appoggio Socio-familiare

NRL; Nucleo di Regolarizzazione dei Parcellamenti del DEMHAB di Porto Alegre

O.P.; Bilancio Partecipativo

OP/RS; Bilancio Partecipativo Statale in vigore nel Rio Grande do Sul

PAR ; Programma di individuazione delle Aree di Rischio

PD; Plano Diretor, ovvero Piano Regolatore (PRG)

$\mathrm{PdC} ;$ Policia de Choques = celerini

PDDUA; Piano di Sviluppo Urbano e Ambientale

PDS ; Partido Democratico Socialista

PDT ; Partido Democratico Trabalhista (formazione di centro-sinistra populista erede del PTB)

PGM; Procuradoria Geral do Municipio, è l'Ufficio Legale del Comune

PI ; Piano degli Investimenti (annualmente decisi in sede di O.P.)

PIB ; Produto Interno Bruto (=PIL)

PIS; Piani degli Investimenti in Opere e Servizi del Bilancio Partecipati vo Statale

PL ; Partito Liberale

PLANDEL; Piano del Parco Statale del Delta dello Jacuí

PMPA; Comune di Por to Alegre

PO; Plano de Obras, Piano degli interventi Comunali 
PRF; Programma di Regolarizzazione Fondiaria

PROCEMPA ; Companhia de Processamento de Dados do Município de Porto Alegre PROFILURB ; Finanziamento di Lotti Urbanizzari (site \& service) creato nel giugno del 1975

PROMORAR; Programma di sradicamento della Subabitazione creato nel 1979

PRORENDA URBANO; Programma di Cooperazione fra ABC e Ministero per la Cooperazione Tedesco

PRR; Partito Repubblicano Rio-Grandense

PS; Posto de saúde, presidio sanitario dell'AMPA, l'Associazione dei cittadini di Porto Alegre

PSB ; Partito Socialista Brasiliano

PSF; Programma di Salute della Famiglia

PT; Partido dos Trabalhadores;

PTB ; Partido Trabalhista Brasileiro (formazione di centro-sinistra populista, estinta nel 1964)

PUC ; Pontificia Università Cattolica

PUR; Permesso d'uso remunerato

RGP; Regione di Gestione della Pianificazione

RGS; Rio Grande do Sul

RH ; politica delle 'risorse umane'

RI; Regolamento Interno del Bilancio Partecipativo

RMPA; Regione Metropolitana di Porto Alegre

ROP; Regioni dell'O.P.

S\&S ; Sites \& Services

SABs; Sociedades de Amig os de Bairro (Associazioni di Amici del Quartiere)

SECAR ; Assessorato Straordinario per la Captazione di Risorse

SEJA; Corsi di alfabetizzazione per adulti

SFH ; Sistema Financeiro de Habitação, smantellato nel novembre del 1986.;

SFS ; Sistema Financeiro per l'Urbanizzazione primaria

SIMPA; Sindacato degli Impie gati Comunali

$\mathrm{SM}$; salario minimo (attualmente $230 \mathrm{R} \$$ )

SMAM ; Assessorato Comunale all'Ambiente

SMC ; Assessor ato Comunale alla Cultura

SME ; Assessorato Comunale allo Sport

SMED ; Assessorato Comunale all'Istruzione

SMF ; Assessorato Comunale alle Finanze

SMIC ; Assessor ato Comunale all'Industria e al Commercio

SMOV ; Assessorato Comunale ai Lavori Pubblici e alle Opere Viarie

SMS ; Assessorato Comunale alla Sanità

SMT ; Assessorato Comunale ai Trasporti

SPM ; Assessor ato Comunale all'Urbanistica

SUS; Sistema Unico di Sanità, nato da un accordo fra Stato del Rio Grande do Sul e Comune di Porto Alegre

UAMPA ; Unione delle Associazioni di Vicina to (o di Residenti) di Porto Alegre

UDN ; União Democràtica Nacional

UEE ; Unione statale degli studenti

UEUs; Unità di Strutturazione Urbana (unità minime del PDDUA)

UFRGS ; Università Federale del Rio Grande do Sul

UFRJ ; Università Federale di Rio de Janeiro

UPE; Unità di Ricerca Sociale del DEMHAB

USAID ; Agenzia USA per lo sviluppo Internazionale (anche AID)

USP; Università di São Paulo

ZEIS; Zone speciali di interesse sociale 


\section{Appendice 2 \\ Dizionario della terminologia usata nel pro- cesso di Bilancio Partecipativo}

Da alcuni anni, il Comune di Porto Alegre realizza e distribuisce un 'dizionario sintetico' dei principali termini che formano il "linguaggio corrente" del "Bilancio Partecipativo" $(\mathrm{OP})$. Di seguito si riportano quelli che riteniamo fondamentali, nella fedele traduzione di quanto divulgato dall'amministrazione:

:: Assemblea Municipale - Grande incontro della popolazione, che ha luogo a luglio, per l'insediamento dei nuovi consiglieri dell'OP e per la consegna al Governo della lista delle priorità da dare alle opere e ai servizi richiesti per tutta la città. In questa assemblea municipale viene dedicato dello spazio alla discussione di temi di carattere generale, come ad esempio il $4^{\circ}$ Congresso della Città.

:: Centro Amministra tivo Regionale (CAR) - Org ano di decentramento politico e amministrativo del Comune. Oltre ad organizzare il processo di Bilancio Partecipativo a livello regionale, accoglie anche le richieste di servizio delle Regioni. Attualmente vi sono 8 CAR, distribuiti per la città.

:: Consiglieri - Sono i rappresentanti delle Regioni o delle Tematiche che compongono il Consiglio del Bilancio Partecipativo. Veng ono eletti nelle proprie comunità regionali due titolari e due supplenti per ognuna delle 16 regioni e delle 6 tematiche. L'elezione avviene durante il Turno Unico, che ha luogo fra la seconda metà del mese di aprile e il mese di maggio.

:: Consiglio del Bilancio Partecipativo (COP) - Organo massimo di deliberazione del Bilancio Partecipativo (OP), composto dai Consiglieri eletti nelle Regioni e nelle Tematiche, da un rappresentante dell'Unione delle Associazioni dei Residenti di Porto Alegre (UAMPA) e da un rappresentante del Sindacato degli Impiegati Comunali (Simpa), oltre a due rappresentanti del Comune $\mathrm{i}$ quali non hanno però diritto di voto nelle delibere. Il COP pianifica, propone, controlla e delibera sull'insieme delle entrate e delle uscite del bilancio. Inoltre, il COP rivede annualmente il Regolamento Interno dell'OP.

:: Coordinatore Regionale dell'O.P. (CROP) - E' il rappresentante del Comune nelle Regioni. La funzione del CROP è quella di accompagnare le discussioni e la definizione delle priorità e delle opere per le Regioni della città. Inoltre, supporta il processo di diffusione del Bilancio Partecipativo, insieme al Gabinetto di Pianificazione (GAPLAN).

:: Coordinatore Tematico dell'OP (CT) - Svolge le stesse funzioni dei CROPs, ma applicate all'ambito delle Assemblee Tematiche. 
:: Coordinamento delle Relazioni Comunitarie (CRC) - E' l'organo comunale responsabile per le politiche di relazione con la comunità. E' inoltre l'organo responsabile del processo dell'OP, insieme al GAPLAN.

:: Criteri - Sono le regole approvate dal Consiglio del Bilancio Partecipativo; si suddividono in criteri generali (determinano il procedimento di distribuzione delle risorse per l'intera città) e tecnici (utilizzati dai singoli organi del Comune per analizzare le richieste e verificarne la fattibilità).

:: Delegati - Sono i rappresentanti diretti della popolazione nel processo di partecipazione popolare. Vengono eletti dalla popolazione in riunioni che si realizzano fra maggio e luglio nelle Regioni e nelle Tematiche, nella proporzione di uno ogni dieci partecipanti. Hanno propri Forum per incontrarsi.

:: Richiesta - E' l'opera o il servizio definito dalla popolazione, di competenza del Comune.

:: Forum dei delegati - Sono riunioni dell'insieme dei delegati scelti dalla popolazione. Tali incontri possono essere Regionali o Tematici. Può essere eventualmente convocata una plenaria generale con tutti i delegati per discutere su un argomento di interesse generale.

:: Gabinetto di Pianificazione (GAPLAN) - Il GAPLAN è il responsabile dell'elaborazione della Proposta di Bilancio, della Legge sulle Direttrici di Bilancio (LDO), del Piano Pluriennale e del Piano annuale degli Investimenti e Servizi. Il suo lavoro è il risultato delle richieste della comunità e delle proposte presentate dal Governo. E' inoltre l'organo responsabile del coordinamento, dell'elaborazione e dell'esecuzione del bilancio del Comune e, insieme al Coordinamento delle Relazioni Comunitarie, coordina politicamente il processo di OP

:: Piano degli Investimento e dei Servizi (PI) - E' la pubblicazione annuale che contiene tutte le richieste di opere e servizi definiti dalla popolazione nell'OP e approvate dal Consiglio del Bilancio Partecipativo.

:: Piano Pluriennale - Ogni quattro anni, stabilisce gli obiettivi e le direttrici generali che guidano le azioni del governo.

:: Plenaria Regionale - Riunione degli abitanti interessati alla discussione e alla definizione delle priorità di una data Regione.

:: Plenaria tematica - Riunione degli interessati alla discussione e alla definizione delle azioni, delle politiche e delle opere di un dato tema e delle direttrici globali per la città. Come esempio di priorità tematica si può citare il restauro del Mercato Pubblico (richiesta della Tema tica di Sviluppo Economico e Tributi) e la Terza Perimetrale - la più grande opera avviata a Porto Alegre (richiesta della Tematica di Trasporto e Viabilitâ).

:: Proposta di Bilancio - Previsione delle entrate e delle uscite, che prende in considerazione l'esecuzione delle opere e dei servizi di responsabilità del Comune.

:: Regolamento Interno (RI) - Insieme delle regole che determinano il funzionamento del Bilancio Partecipativo.

:: Turno Unico - E' l'insieme delle plenarie regionali e tematiche, che hanno luogo dalla seconda metà di aprile fino al mese di maggio. Durante questi incontri, il Governo presenta il rappor to sugli investimenti dell'anno precedente, in forma scritta e audiovisi va. Durante il Turno Unico, la popolazione vota le priorità per tutta la città, elegge i suoi consiglieri e definisce il numero di delegati, nella proporzione di uno ogni dieci partecipanti ad ognuna delle 16 Plenarie Regionali e delle 6 Plenarie Tematiche dell'OP. 


\section{Appendice 3}

\section{II sistema dei Consigli Municipali nella 'città della partecipazione popolare'}

Nel tempo, gli esiti positivi raggiunti dal Bilancio Partecipativo hanno innescato la creazione di nuove istanze di partecipazione a disposizione dei cittadini per intervenire nelle politiche pubbliche 'di settore'. Nei 14 anni di governo dell'Amministrazione Popolare a Porto Alegre sono stati costituiti molti consigli municipali tematici, oltre a diversi forum, commissioni, gruppi di lavoro e istanze di decisione nelle più diverse aree di intervento. Di seguito sono elencati i principali Consigli a carattere 'deliberante' esistenti nella capitale gaúcha.

Consiglio Politico del Governo - È un organismo ampio ed eterogeneo, formato da cittadini della società civile organizzata politicamente 'indipendenti'. A differenza degli altri, non ha carattere deliberante e i suoi membri non sono eletti dalla società. Svolge funzioni di 'uditore' del Sindaco ed esercita una specie di controllo pubblico non statale sull'azione del governo, con sede presso il Potere Esecutivo Centrale. E' un progetto mirato a rendere più forte l'immagine della città come laboratorio politico di un progetto di democrazia partecipativa che vuole porsi come riferimento internazionale.

Consiglio Municipale dei Diritti del Fanciullo e dell'Adolescente (CMDCA), - Porto Alegre è stata la prima capitale brasiliana a crearlo, nel 1991. E' un organismo deliberante responsabile della formulazione e del coordinamento di politiche municipali per l'infanzia e la gioventù. E' composto da 21 membri: 7 rappresentanti del Governo Municipale e 14 della società civile.

Forum Permanente dei Portatori di Handicap - Il forum è stato creato nel ' 93 ed è composto da rappresentanti di organizzazioni di portatori di handicap (PPDs), da membri della comunità in generale e dagli assessorati comunali. Fra le azioni promosse vi sono la lotta per l'accesso di tutti al trasporto collettivo, la creazione della 'Settimana dei disabili' e l'elaborazione della Legge Comunale sull'Accessibilità.

Consiglio Municipale di Assistenza Sociale - E' composto da 45 membri titolari e da 45 supplenti, rappresentanti di organizzazioni della società civile, dei governi municipale e statale, e degli utenti di servizi di assistenza sociale del Comune. L'organismo controlla e partecipa alle decisioni sugli investimenti e sull'elaborazione di politiche di assistenza sociale a Por to Alegre.

Consiglio Municipale di Sanità - Il Consiglio Municipale di Sanità di Porto Alegre, creato nel 1992, interviene nella formulazione e nel controllo della politica sanitaria del Comune, controllando e seguendo lo sviluppo delle azioni e dei servizi del settore. Inoltre, stimola la partecipazione comunitaria e propone criteri per la programmazione e l'esecuzione finanziaria e di bilancio del Fondo Municipale di Sanità. È costituito da 80 consiglieri, 8 del Governo, 6 prestatori di servizi, 24 professionisti della sanità e 42 membri della società civile organizzata, oltre a rappresentanti delle 11 Commissioni Locali di Sanità (CLS). 
Consiglio Municipale di Accesso alla Terra e alla Casa - Dal 1995 è composto da 27 consiglieri che si riuniscono almeno una volta al mese per proporre e deliberare sulle direttrici, sui piani e sui programmi della Politica della Casa, oltre a vigilare sulla loro esecuzione. L'obiettivo è incentivare la partecipazione diretta della comunità nell'amministrazione delle politiche dell'alloggio. Oltre ai rappresentanti dei diversi assessorati municipali e degli organismi che si occupano di alloggi a livello statale e federale, è composto da rappresentanti di organizzazioni di categoria e di quelle comunitarie di residenti.

Consiglio Municipale dell'Ambiente - Messo in opera nel 1996, dispone sull'implementazione del Sistema Municipale dell'Ambiente (SISMAM) e sulla Politica Municipale dell'Ambiente. E' costituito da 27 membri con mandati rinnovabili ogni due anni. Ha competenza per proporre e formulare le politiche municipali dell'ambiente e per seguire la loro esecuzione; per discutere, proporre e formulare norme, criteri e standard relativi al controllo e al mantenimento della qualità dell'ambiente e per deliberare sulle multe e sulle licenze ambientali emesse dal Potere Pubblico Municipale. Può inoltre proporre direttici e norme di applicazione del Fondo per la Difesa dell'Ambiente, presentare proposte per la riformulazione del Piano Regolatore di Sviluppo Urbano e Ambientale e di quello di Risanamento del Municipio, e proporre la creazione di Unità di Conservazione.

Consiglio Municipale dell'Educazione - Creato nel 1991, è composto da 15 consiglieri titolari e 15 supplenti. Di questi, 12 sono rappresentanti della società civile eletti al suo interno, e 3 sono indicati dall'Esecutivo Municipale. E incaricato della regolamentazione del Sistema Municipale di Insegnamento, oltre a discutere e controllare la messa in opera delle politiche educative costruite insieme alla società.

Consiglio Municipale della Cultura - Creato nel 1997, ha 33 membri, di cui solo 5 sono del Governo. Scultori, pittori, disegnatori, musicisti, intellettuali, scrittori, poeti, attori, cineasti, fotografi, imprenditori e produttori, individualmente o attraverso organizzazioni che si occupano della produzione e della promozione della cultura, si mobilitano per decidere sulle politiche culturali della città..

Consiglio Municipale dell'Agricoltura e dell'Approvvigionamento - Creato nel 1996, ha 17 membri che partecipano all'elaborazione, alla valutazione e al controllo delle azioni e delle politiche per lo sviluppo della produzione e per il rifornimento di Porto Alegre tramite i prodotti provenienti dall'agricoltura o dall'allevamento. Tale controllo avviene insieme all'iniziativa privata. L'organo ha come obiettivo democratizzare la conoscenza e le nuove tecniche agricole, incentivando l'introduzione e l'adattamento alla realtà locale di metodi già esistenti e sperimentati altrove. Inoltre, è responsabilità del Consiglio suggerire le politiche di captazione e di allocazione delle risorse. Esso interferisce sulla politica di produzione di beni agricoli e di allevamento e su quella di rifornimento attuata dall'Amministrazione Municipale, collaborando per lo sviluppo sostenibile dell'agricoltura a Porto Alegre.

Consiglio Municipale di Sviluppo Urbano e Ambientale - Il Consiglio è composto da 25 membri e svolge un ruolo propositivo, formulando politiche, piani e proposte per Porto Alegre. Cura l'applicazione delle direttive del Piano Regolatore dello Sviluppo Urbano Ambientale (PDDUA), suggerisce modifiche e incentiva le discussioni sulla città. Inoltre, il Consiglio (CMDUA) esamina, discute e approva progetti di grandi opere che siano proposti sia dal potere pubblico che dall'iniziativa privata. Provvede inoltre all' applicazione del Solo Criado (cfr. cap. 11), strumento urbanistico che genera risorse per la costruzione di alloggi popolari.

Altri Consigli - Vi sono, poi, il Consiglio Municipale dei Diritti Umani, i Consigli Tutelari, il Consiglio Municipale dell'Anziano, il Consiglio Municipale dei Diritti della Donna, il Gruppo di Lavoro Anti-Razzismo (GTA), i Consigli Regionali di Assistenza Sociale, il Consiglio Municipale delle Tossicodipendenze, il Consiglio su Piazze e Parchi, il Consiglio Deliberativo del Dipartimento Municipale di Acque e Fognature, il Consiglio Deliberativo del Dipartimento Municipale di Nettezza Urbana, il Consiglio Municipale di Scienza e Tecnologia, il Consiglio Municipale del Patrimonio Storico e Culturale, il Consiglio Municipale dei Contribuenti, il Commissione Municipale per l'Occupazione, il Consiglio Municipale per la Gestione del Personale, il Consiglio Municipale dello Sport, il Forum sul Turismo, il Forum Municipale sul Tempo Libero, il Forum Municipale sul Calcio. 

www.budget-participatif.org)

\title{
Griglia di esposizione e interpretazione di esperienze partecipative
}

\author{
(formulata in occasione dell'Incontro Internazionale di
}

\section{Scambio del 29 Gennaio 2002)}

Per cercare di capire meglio un'esperienza di democratizzazione delle politiche locali, che implichi la creazione di arene deliberative e forum di dibattiti, potrà essere utile porsi le seguenti domande:

- L'esperienza è nata da un'iniziativa dall'alto (gli eletti) o dal basso (la popolazione organizzata), o da un soggetto intermedio, o dall'incontro di due o tre luoghi d'iniziativa?

Si tratta di comprendere i meccanismi che permettono di innovare nell'approfondimento della democrazia

- L'esperienza garantisce l'indipendenza di espressione della popolazione? Quali sono i dispositivi messi in atto per evitare manipolazioni da parte dei politici?

- Può partecipare la totalità della popolazione? Anche i giovani? E gli immigrati?

- In quali forme la popolazione è chiamata a partecipare?

. C'è l'elezione di "rappresentanti" o di "delegati" degli abitanti che partecipano al processo, o designazione da parte dei politici, oppure sono espressi da associazioni designate? Qual è la durata del loro mandato?

Si tratta di vedere se si ricostruisce un'altra democrazia della rappresentanza senza potere o una democrazia con un potere effettivo.

- Come sono state elaborate le "regole" del dispositivo (dei dispositivi)? Unicamente dai politici? Dalla popolazione? Sono state co-eleborate?

Questa è una questione essenziale che indica la direzione del processo.

- Quali sono i meccanismi che impediscono la confisca del potere da parte di "abitanti di professione"? La revocabilità? E in quali condizioni? Non rinnovo del mandato per più di una volta? Cambiamento delle regole, e da parte di chi?

- Quali garanzie offre il potere politico? La trasparenza? L'impegno preliminare di rispettare le decisioni della popolazione organizzata nel processo? Diffusione delle informazioni durante tutte le tappe del processo?

- In quale modo il potere politico (gli eletti) riorganizza l'autorità amministrativa (la municipalità, la Regione, lo Stato, ...) per mettere in atto questo tipo di processo? E come si riorganizzano gli organi deliberativi degli eletti?

Queste questioni etiche e politiche sono essenziali per garantirsi contro le derive clientelari...

- Quali campi sono affrontati? Tutti? Una parte? Le spese di investimento? Di funzionamento? Le entrate? Le imposte e tasse sono oggetto di dibattito democratico e di co- 
698 decisione? In quale modo?

$\grave{E}$ necessario verificare che il processo affronti davvero la condivisione del potere, la co-decisione.

- Il processo è apertamente orientato verso la popolazione più povera e indigente? Al centro del processo partecipativo c'è la "discriminazione positiva"?

Si tratta di verificare se questi processi operano davvero a beneficio dell'immensa maggioranza della popolazione.

- Quale influenza può avere il contesto politico, sociale ed economico in un processo di pianificazione partecipativa?

- In un contesto di violenza e di cambiamento politico, come è possibile garantire la continuità dei processi di partecipazione?

$\grave{E}$ necessario interrogarsi sui freni costituiti da una situazione di crisi (guerra, violenza, povertà, ...) nel Sud come nel Nord, e su come, all'opposto, processi partecipativi possono essere costruttori di pace, di coesione sociale, di ritrovata cittadinanza.

- In quale modo si opera affinché la popolazione non resti rinchiusa nel quartiere quando definisce le priorità di bilancio e/o di azione? In quale modo I problemi di tutta la città (o di tutta la regione, o di tutto lo Stato) sono presi in considerazione, sono dibattuti e divengono oggetto di co-decisione?

- In quale modo il processo articola il locale con il globale? In quale modo nel processo, nelle assemblee di base, si manifesta questo legame? Oppure è sistematicamente negato o rinviato ai politici?

Si deve esaminare se questi processi si collocano o meno nel quadro della lotta contro la mondializzazione neoliberista, e come.

- Per quali aspetti il processo è un processo di "coscientizzazione", di "educazione alla cittadinanza", di formazione, di "costruzione di capacità"? Di comprensione "politica" dei problemi del mondo?

L'obiettivo è sapere se ci si trova all'interno di un processo che punta all'educazione come pre-condizione, oppure all'azione come mezzo di coscientizzazione e di mobilitazione sociale e politica. E questo in quali forme avviene? 


\section{Appendice 5 \\ Verso una nuova sensibilità diffusa? Una postilla 'italiana'}

Le città $[\ldots]$ hanno bisogno di pensieri lunghi, azioni concrete e immediate e di una strategia globale di investimento sociale (ANCI-SWG, 2002, p. 55)

Il 20 novembre 2002, l'Osservatorio sull'Italia dei Comuni dell'Associazione Nazionale Comuni d'Italia (ANCI) ha presentato pubblicamente un'indagine realizzata dalla SWG dal titolo "La città che vorrei", che offre un quadro significativo di un 'clima' in trasformazione nel nostro Paese, indagando sulla centralità delle amministrazioni locali nell'immaginario dei cittadini, e sul mutare della 'percezione' del loro ruolo come motori di sviluppo economico-culturale e di maturazione delle coscienze, ma anche come soggetti di una riorganizzazione in senso autonomista e federalista dello stato, oltre che destinatari delle crescenti domande di socialità degli abitanti. Certo, quello dell'ANCI non è uno studio scientifico condotto su un periodo di lunga durata, ma un sondaggio; ${ }^{1}$ eppure riveste un notevole interesse proprio perché - in due periodi diversi - ha indagato non tanto su trasformazioni fattuali di comportamenti, quanto piuttosto sul mutare della 'rappresentazione' del Comune e delle sue forme di governo nell'immaginario dei cittadini, fotografando una domanda sociale ed una percezione che:

1) alludono ad un trasformarsi della lettura del rapporto tra 'società politica' e 'società civile' che chiede alle istituzioni di creare nuovi spazi di partecipazione attiva alle scelte territoriali (come luoghi di indicazione positiva per co-costruire le politiche e non come mere istanze di ascolto del disagio e delle esigenze degli abitanti)

2) rivelano il costituirsi di un humus fertile per la sperimentazione di strumenti innovativi di gestione delle trasformazioni urbane che permettano ai cittadini un impegno attivo e diretto nella costruzione delle scelte (senza limitarne le possibilità a quella di esprimersi 'a posteriori' su scelte già assunte) ed aiutino la democrazia rappresentativa ad uscire dalla crescente crisi di legittimazione (se non proprio di legittimità) che, da qualche decennio, va colpendone molti istituti.

Senza ovviamente soffermarci ad esaminare le diverse parti dell'inchiesta, ci pare opportuno sottolinearne alcuni 'nodi' significativi per il clima di trasformazione dell'immaginario sociale che sottolineano.

\section{Una diffusa domanda di partecipazione}

Nonostante la riforma costituzionale entrata in vigore il 9/11/2001 stenti a trovare un'effettiva traduzione nella riorganizzazione dell'ordinamento statale e delle relazioni tra livelli di governo, l'inchiesta ANCI-SWG rivela l'attualità diffusamente avvertita di alcuni suoi 'nodi di senso' (quali l'aver sancito un ruolo-cardine per le amministrazioni locali) e rivela un immaginario sociale che collima con il progressivo rafforzamento degli esecutivi municipali ${ }^{2}$ veicolato dal recente trasformarsi della normativa elettorale.E si concentra sulle richieste di attiva partecipazione come elemento 'discriminante' per il raggiungimento 
di una "democrazia locale vitale e funzionante" che si ponga "come il motore dello sviluppo, così come di un nuovo rapporto tra cittadini e istituzioni" (Vandelli, 2000). È quest'ultimo tema - soprattutto - a costituire il principale elemento di interesse dell'inchiesta, ricomparendo (sotto specie differenti) in più punti della stessa, sia nelle domande 'chiuse' degli intervistatori, che - specialmente - ai primi posti del gradimento dei cittadini interpellati. Così, richiesti di giudicare 'lo stile di governo' dei propri amministratori locali al di là dei loro programmi, ${ }^{3}$ gli intervistati - in una scala gerarchica di 'desiderabilità' individuano al primo posto delle caratteristiche 'assolutamente essenziali' di un ipotetico 'Sindaco ideale' la capacità di ascolto $(85 \%)$ seguita dalle capacità di interpretare al meglio ed incarnare i valori della sua città (rispettivamente $73 \%$ e $60 \%$ ) e - a breve distanza - dalla disponibilità a "chiedere il contributo e la partecipazione di tutti i cittadini per migliorare la città' $(65 \%)$. Meno interesse riscuotono abilità politiche inserite dentro una lettura più tradizionale del ruolo istituzionale del sindaco (quella che l'inchiesta chiama 'la politica politicata') e - soprattutto - quelle centrate sul decisionismo e sull'imposizione delle scelte o sulla pacificazione paternalistica dei conflitti. ${ }^{4}$

All'interno di un simile quadro, l'inchiesta sottolinea l'emergere di una richiesta di 'avvicinabilità' degli amministratori locali, ${ }^{5}$ unita alla capacità di porsi come "punto di riferimento" - sia per gli elettori della stessa parte politica che per gli altri - e di saper contestualmente muoversi su due piani paralleli: "progettare il futuro e pensare al presente, ai piccoli problemi della quotidianità", cioè "programmare città maggiormente vivibili" e al contempo "muoversi a partire da progettualità minime, senza attendere futuribili meraviglie" ovvero "fare subito, ma all'interno di un progetto coordinato $e$ chiaro" (ANCI-SWG, 2002, p. 17 e grafico 24).

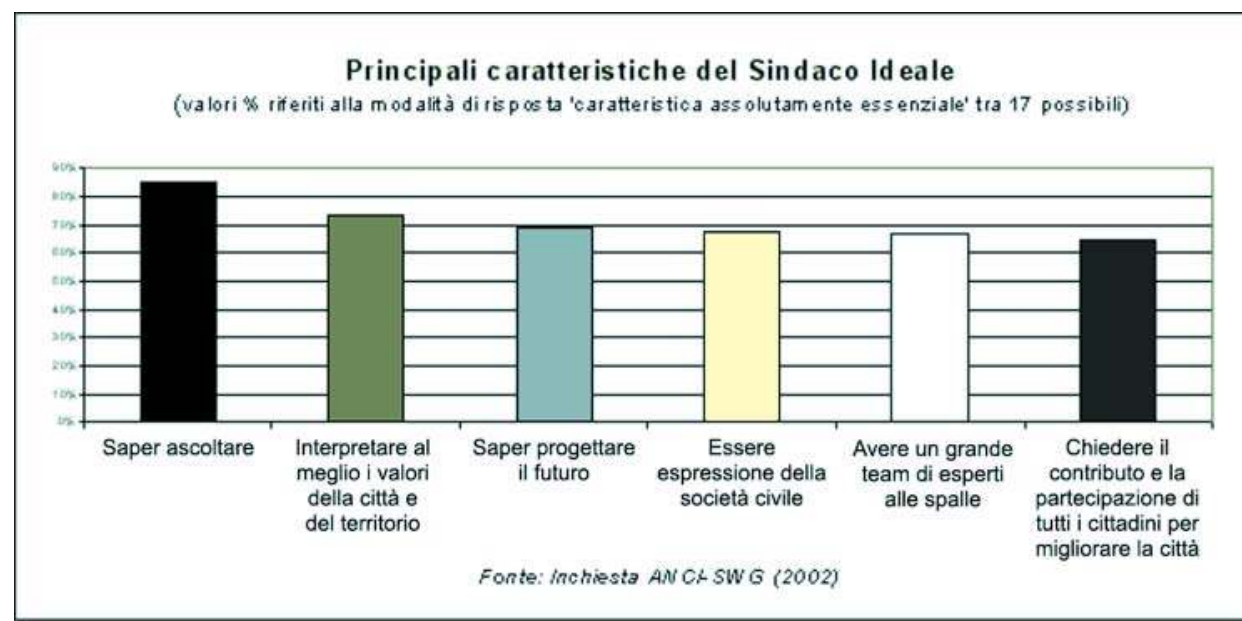

In parti diverse dell'inchiesta, la convergenza e la ridondanza delle 'ricorrenze' su esigenze consimili espresse dai cittadini, dà la misura del prevalere di alcune tematiche nodali come quella della partecipazione, individuata dagli intervistati anche come uno dei principali assi strutturanti del concetto di 'qualità della vita' ${ }^{6}$ Del resto, l'informazione sulle attività per il territorio $(24 \%)$ ed il coinvolgimento nelle scelte decisionali $(20 \%)$ sono indicate anche tra le richieste prioritarie dei cittadini agli amministratori locali, e si sommano ad una richiesta di "fiducia" degli amministratori nei confronti dei cittadini (9\%) e della loro capacità di costruire e fornire conoscenze e strategie utili alle politiche locali. ${ }^{7}$ Tra gli aspetti più interessanti che la ricerca ANCI-SWG rivela, vi è il fatto che la richiesta di forte coinvolgimento attivo della cittadinanza nelle decisioni per il territorio non "pregiudica la percezione del contributo che la politica può offrire al governo della città", venendo questa interpretata non più come "avversaria della società civile" ma come "una delle componenti del vivere civico". In modo deciso, dall'inchiesta emerge quindi un forte processo di trasformazione in atto nelle relazioni tra cittadini e politica (o meglio, dei cittadini verso la politica), che richiede una ridefinizione delle rispettive identità e la presa in carico dell'affermarsi di nuovi valori post-materialisti e di una 
domanda di "partecipazione non istituzionalizzata, eterodossa nei mezzi e nelle finalità" (Raniolo, 2002, p. 137), "una richiesta di coinvolgimento di tipo decisionale, sia rispetto alle possibilità di contare nella definizione delle issues programmatiche, sia rispetto alla scelta delle persone destinate a rappresentare i cittadini" (ANCI-SWG, 2002, p. 22).

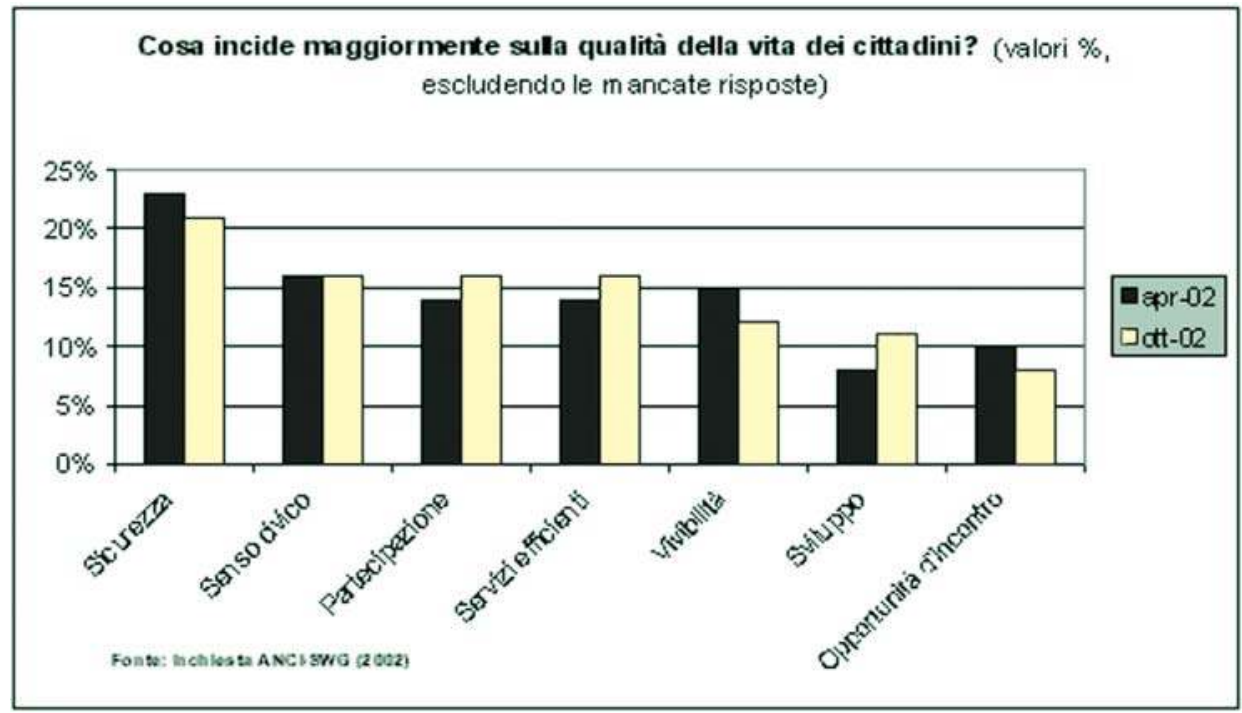

In tale quadro, lo stesso concetto di rappresentanza pare trasformarsi, divenendo "voglia di confronto stabile con le istituzioni e ricerca di nuove forme di istituzionalità locale, in cui governabilità e servizi efficienti (costruiti sui bisogni reali e in continua evoluzione) sono strettamente connessi e garantiti dalla promozione e dalla tutela di nuovi ed estesi diritti a tutti i cittadini" (id., p. 22).

\section{Una richiesta di nuovi contenuti per le politiche}

Negli esiti dell'indagine ANCI-SWG, il risveglio del protagonismo civico pare accompagnarsi alla crescente importanza assegnata dagli intervistati a temi come il senso civico e la cura della città che - in termini di 'contenuti' e di 'esiti' delle politiche paiono assumere una crescente centralità. $\mathrm{E}$ così evidenziano il crearsi di dinamiche di riappropriazione dell'identità urbana e di spinta alla responsabilizzazione e a forme di solidarietà negoziata che fanno parte di quella fenomenologia della partecipazione come processo pedagogico di crescente apprendimento che Robert Dahl (1967) ha chiamato "strati di politicizzazione" e che si ritrovano anche nella parte dell'inchiesta dedicata alle caratteristiche della città ideale.

Da quest'ultima, infatti, emerge un graduale mutare dei valori di fondo nella percezione della città e dell' atteggiamento verso l'amministrazione, alla ricerca di "un nuovo patto sociale locale che sia perno di una identità comunitaria multipolare e, al contempo, fonte di sicurezza, stabilità e vivibilità", e che dia spazio alle "tensioni" e alle "energie sociali"superando l'ottica del semplice "senso di appartenenza' ad un ambito locale" per dar forma "all'innovata propensione aggregativa che soggetti, con interessi simili, esprimono per 'intraprendere un viaggio attraverso la vita"' (ANCI-SWG, 2002, p. 31). ${ }^{9} \mathrm{Al}$ centro di questa trasformazione - che punta a rifocalizzare l'attenzione sul capitale umano, e a garantire a tutti gli abitanti "uguaglianza delle opportunità" e "dei punti di partenza" (CENSIS, 2001) attraverso l'assistenza differenziata e personalizzata alle moderne esclusioni e alle crescenti solitudini, e attraverso la cooperazione e l'attivazione delle risorse delle persone - non pare esserci l'individuo, bensì la città-comunità intesa come valore progressivo e propulsivo, che può soddisfare:

la ricerca di un modello che tenga insieme temi come solidarietà e autorealizzazione, riconoscimento dei diritti individuali ed equità sociale, possibilità di sviluppo e sostenibilità ambientale e sociale, bisogno di autonomia della società e funzione 
pubblica del governo locale [...] E, non a caso, la città che immaginano gli italiani è una realtà solidale, che con dinamicità pensa ai giovani, si avvale degli anziani come risorsa e guarda al futuro [...] in cerca di una nuova coesione sociale, di un nuovo senso di comunanza e di identità; una realtà attraversata dalle paure tipiche della società post-industriale, ma disposta ad aprirsi, a ridisegnarsi e ripensarsi. Una società che individua nella meritocrazia e nella chiusura individualista i principali nemici della coesione sociale e interpreta l'inclusione come una opportunità [...] che esprime molto più della semplice ricettività di immigrati e disagiati, ma assume la valenza di un'idea di cittadinanza, ampia, con nuovi diritti-doveri, obblighi sociali e opportunità (ANCI-SWG, 2002, p. 32-34).

Dall'indagine pare inoltre emergere la rappresentazione di una città desiderata dove il quotidiano assurge a "spazio privilegiato per le esperienze di innovazione" (idem, p. 32) che - nella proiezione di immaginario a cui l'inchiesta dà forma - costituiscono "antidoto" al darwinismo che connota le recenti trasformazioni sociali, possono stimolare scelte che favoriscono le modifiche dei comportamenti individuali ${ }^{10}$ e rappresentano una "risposta alla necessità di definire un nuovo humus sociale e relazionale fondato sulla condivisione e la gestione del rischio, sullo sviluppo e l'investimento sul capitale umano, sulla creazione di nuove forme di solidarietà locale e, soprattutto, di legami generazionali" (ibidem, p. 34).

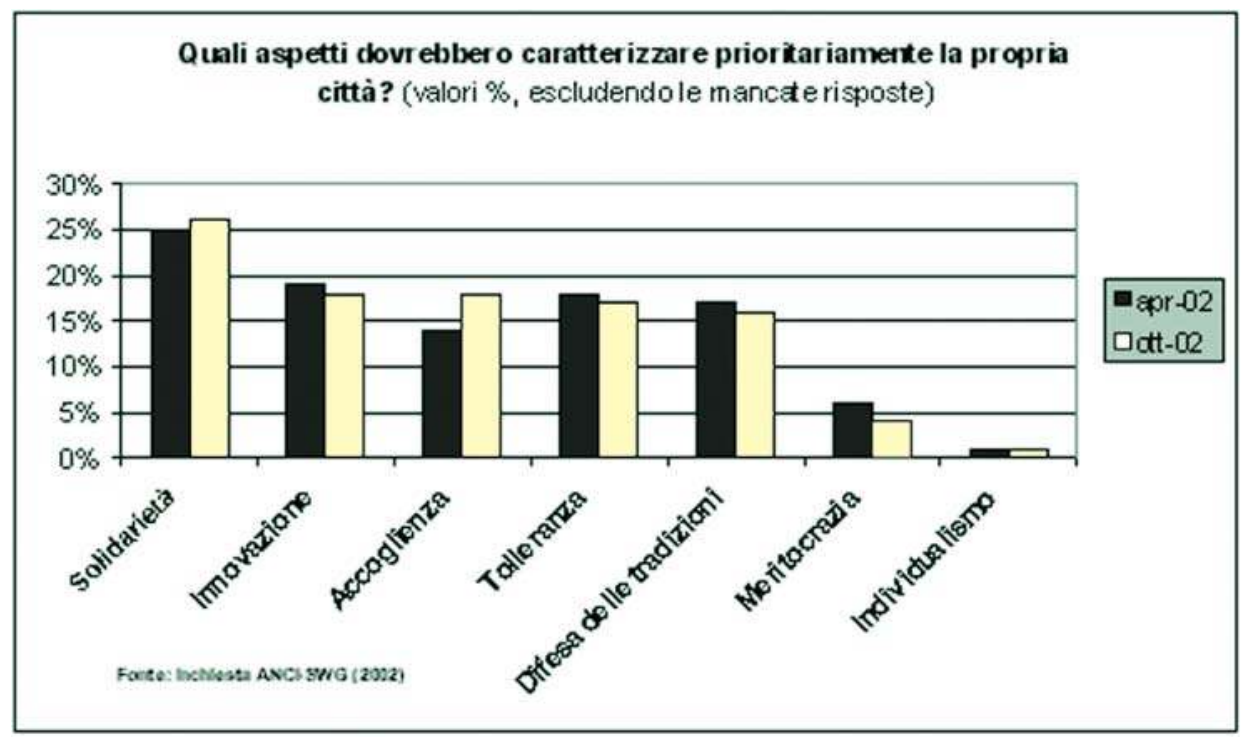

Questi dati non stupiscono, se letti in rapporto ai modelli partecipativi che - tra le righe dell'inchiesta ANCI - sembrano cominciare a prendere gradualmente forma, a partire da una modalità di partecipazione soggettiva (dove i cittadini ambiscono a "contare e ad essere protagonisti", p. 23) ma non per questo necessariamente individualista, visto che la maggioranza assoluta degli intervistati sottolinea la necessità di un dialogo con soggetti collettivi e istanze aggregative, come ad esempio i comitati spontanei il cui ruolo nel tempo si sta trasformando da "sintomi della crisi di rappresentanza politica, o [...] dei tradizionali strumenti di articolazione e aggregazione degli interessi" (Bobbio, Zeppetella, 1999) a nuovi spazi e canali politici-organizzativi attraverso i quali i cittadini protesi verso l'attivismo locale vanno esprimendo in maniera via via più compiuta la propria necessità di trasformazione dei modi di governo e rappresentanza. ${ }^{11}$ Mentre si evidenzia la crisi delle forme di democrazia rappresentativa anonima e plebiscitaria, ma anche di istituti tradizionali di compartecipazione alle scelte territoriali basati su regole affini e limitati ad approvazioni o bocciature 'a posteriori' (come l'abusato referendum, che non pare più rivestire molte capacità attrattive agli occhi dei cittadini) ${ }^{12}$ si delinea quindi, in parallelo, una ricerca di nuovi spazi di relazione pubblica. Spazi in cui ogni abitante possa agire "non solo come parte del tutto, ma come parte per il tutto", a partire 
da aree "neutre" in cui "si azzerano le appartenenze politiche per costruirne di nuove" e il cui carattere informale consenta "una forte flessibilità e libertà di manovra" (ANCISWG, 2002, p. 25) e permetta di esprimere "il proprio potenziale di autorganizzazione sociale" (Habermas, 1990).

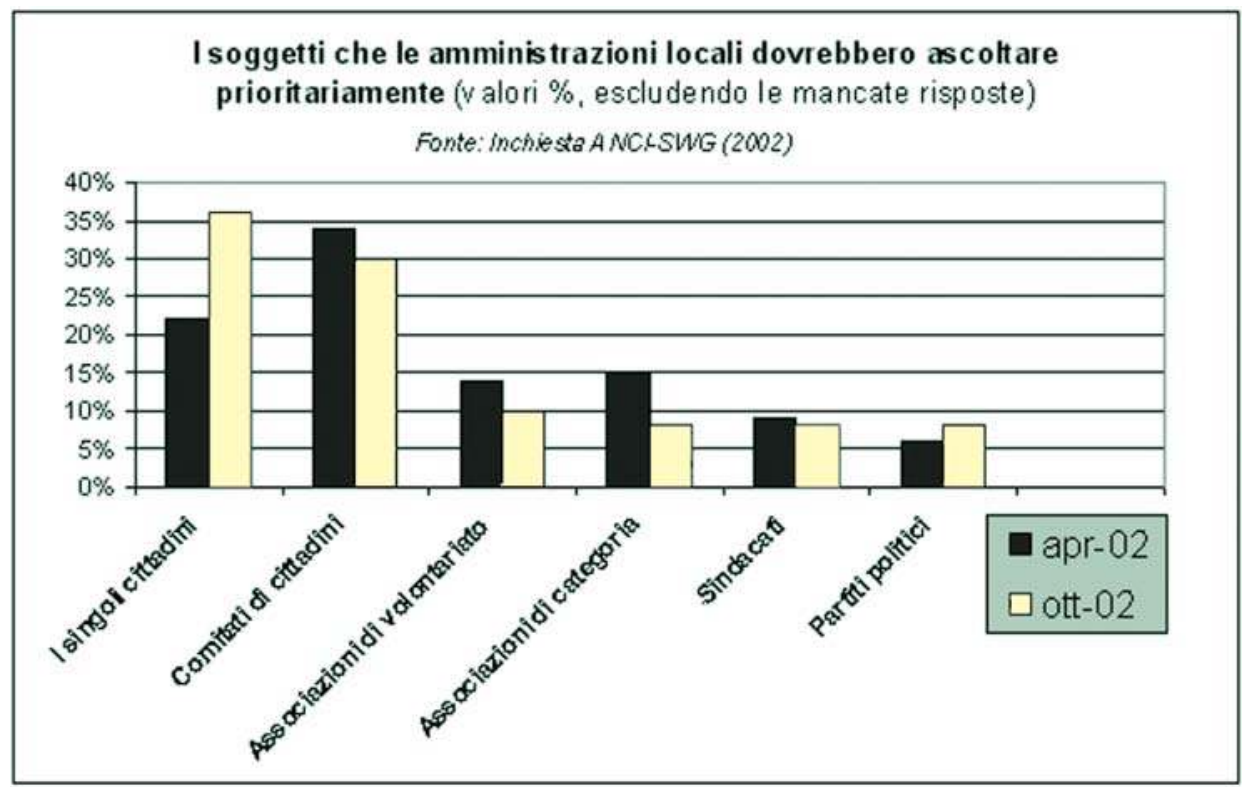

\section{Uno 'scarto' da colmare tra rappresentanti e rappresentati}

L'inchiesta ANCI-SWG si chiude rilevando la persistenza di uno 'scarto interpretativo' tra la visione della città e dell'amministrazione locale restituita dai cittadini e quella offerta dal campione dei 181 sindaci intervistati. Questo scarto emerge in particolare sui temi del coinvolgimento degli abitanti nelle scelte territoriali, anche se vi sono variazioni tra amministratori di metropoli e di città medie o piccole. ${ }^{13}$ Sebbene, infatti, tutti gli interpellati assegnino priorità allo scambio diretto con i cittadini, la maggior parte ha la tendenza a concepirlo "come un dialogo specifico e particolare, che nasce si sviluppa dall'ascolto del singolo" (p. 72) nonostante che - richiesti di indicare realtà associative a cui rapportarsi - i sindaci delle realtà medio-piccole si mostrino più vicini al sentire dell'opinione pubblica riconoscendo ai comitati e al volontariato un ruolo maggiore che non i sindaci delle città-capoluogo, più inclini ad indicare 'entità' tradizionali come le associazioni di categoria, i partiti politici e i sindacati come controparti da ascoltare prioritariamente nei processi partecipativi e consultivi.

Così - ad un'omissione della società intervistatrice (che non ha previsto nell'inchiesta una risposta che guidasse gli interpellati verso l'indicazione di forme di rappresentanza civica che si formino all'interno dei processi partecipativi, invece che preesistere agli stessi $)^{14}$ - si somma un punto di vista 'non allineato' tra amministratori e società civile, che evidenzia l'esistenza di differenze non secondarie nell'interpretazione delle possibili modalità di partecipazione dei cittadini alla costruzione delle politiche e alla trasformazione del territorio. Uno 'scarto' che si riconferma nella sottostima attribuita dai sindaci alla "partecipazione dei cittadini alle scelte per la città", al "senso civico" e alle "opportunità d'incontro tra i cittadini" nell'ambito degli elementi strutturanti della 'qualità della vita, e che esige di essere colmato proprio a partire dalla costruzione di un nuovo rapporto dialogico di ascolto reciproco con gli abitanti dei territori amministrati. Magari attraverso un coinvolgimento diretto nei 'progetti di sviluppo della città' a cui il $26 \%$ dei sindaci di città-capoluogo (e il 16\% di quelli di città medio-piccole) attribuisce una funzione centrale per facilitare la costruzione di un ruolo attivo e propositivo della società senza ridursi a spazio di mera protesta o lamentazione.

In ogni caso, l'inchiesta ANCI-SWG fornisce agli amministratori una preziosa conferma sulla sostanziale disponibilità dei cittadini italiani a pagare più imposte locali per vedersi garantita una maggiore qualità urbana, seppur tale disponibilità appare esplicita- 
mente subordinata a gestioni trasparenti e partecipative e a miglioramenti reali e visibili, in particolar modo nei settori di servizi non primari (visto che su quei servizi che paiono ormai ritenuti 'acquisiti' i cittadini interpellati non paiono più disposti a sacrifici per investire nuove energie). ${ }^{15}$

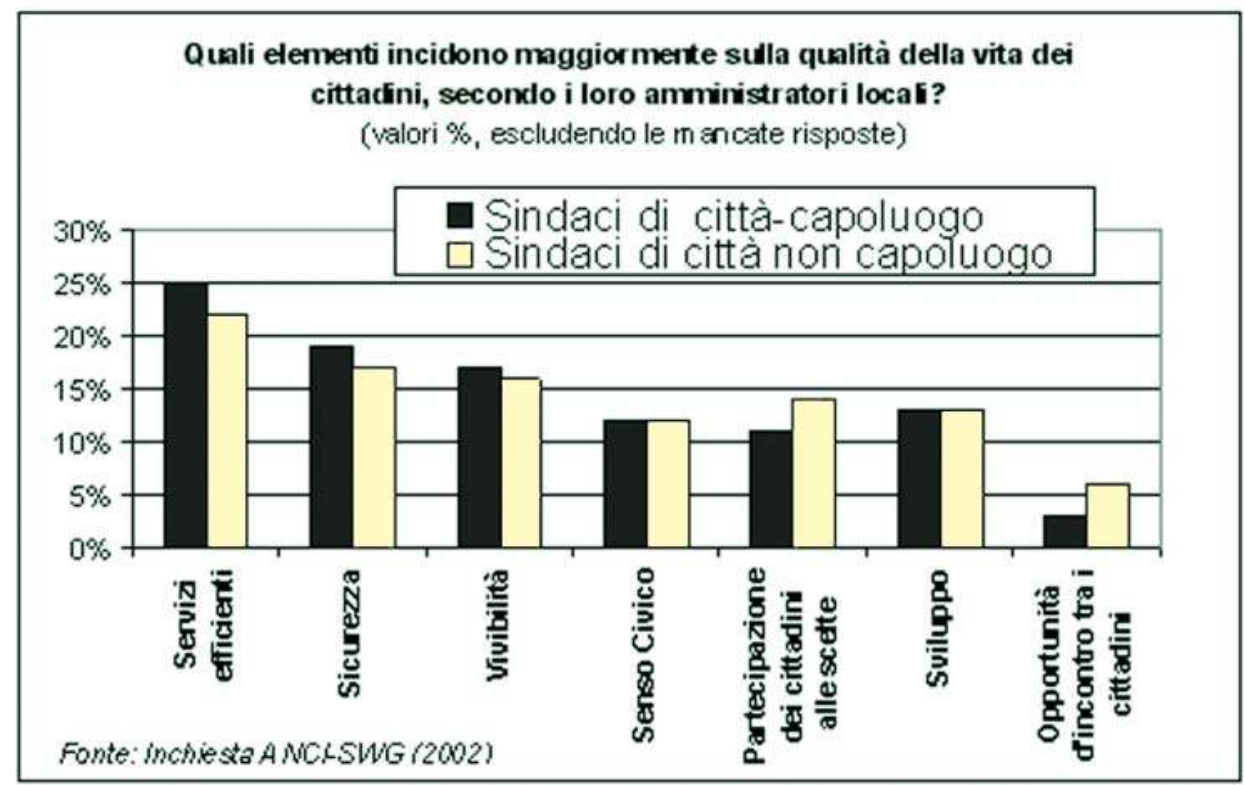

${ }^{1}$ La rilevazione (coordinata da Fabiana Vidoz) è stata condotta su tre campioni di residenti in Italia, in due fasi temporali: $\bullet 1000$ soggetti maggiorenni (20 marzo/4 aprile 2002), 600 soggetti maggiorenni (3/10 ottobre 2002), 181 sindaci (22 ottobre/4 novembre 2002) attraverso interviste telefoniche, effettuate tramite il sistema C.A.T.I. e condotte nella fascia oraria mattutina e pomeridiana. I campioni contattati sono campioni "per quote", estratti dalla lista dei nominativi riportati sugli elenchi telefonici dell'intera rete nazionale, rappresentativi dell'universo di riferimento (popolazione italiana maggiorenne). Per l'individuazione delle unità finali sono stati utilizzati metodi di tipo casuale (come per i campioni probabilistici), rispetto a tre diversi livelli di stratificazione:-zona geografica,-classe di ampiezza demografica del comune,-sesso. Le interviste ai Sindaci sono state realizzate, secondo un criterio di casualità, nella parte relativa alle città non capoluogo campionate (120 interviste - sulla base di una stratificazione per zona geografica e dimensione del centro campione). I Sindaci delle città capoluogo sono stati tutti contattati: 58 sono stati poi intervistati.

${ }^{2}$ Come percezione soggettiva, il $46 \%$ dei rispondenti indica di sentirsi rappresentato al meglio dal sindaco della propria città (grafico 2, pag. 15) e il 63\% ritiene che i suoi concittadini ripongano nel sindaco la fiducia maggiore (grafico 1, pag. 15, con valore invariato tra aprile e ottobre 2002).

${ }^{3}$ L'inchiesta dà per scontato che lo 'stile di governo' (prodotto della crescente tendenza alla personalizzazione della politica) sia un elemento ormai di centrale importanza nell'immaginario cittadino, e assommi fattori umani (simpatia, disponibilità, capacità dialogica e presenza), politici (conoscenza, storia, esperienza, team), amministrativi (determinazione, capacità di ascolto, ricerca e dialogo, idipendenza, autorevolezza e autorità), etici (idealità e visione del mondo) e mediatici (capacità comunicativa ed espressiva, presenza e immagine) (ANCI-SWG, 2002, pg. 16).

${ }^{4}$ Meno interesse come caratteristiche 'assolutamente essenziali' riscuotono il 'saper navigare nel difficile mondo della politica' (55\%), il 'farsi sempre rispettare' (51\%), l'amministrare 'come un buon padre di famiglia' (46\%), l'essere 'personalità forte e di prestigio' (44\%), il 'saper raggiungere i compromessi necessari' (37\%) o 'imporre le proprie idee con decisione' (33\%).

${ }^{5}$ Vi è anzi un'esplicita richiesta di legame con la società civile, che ogni Sindaco dovrà rappresentare e incarnare (68\% come mostrato nel grafico soprastante). 
${ }^{6}$ La permanenza della 'sicurezza' in vetta ai fattori di qualità della vita è stemperata dalla nuova accezione che essa sembra assumere, ad esempio nelle tabelle 17 e 18 (la 17 è peraltro formulata in modo tendenzioso, ed appiattisce sulla 'securizzazione' il concetto di sicurezza), che evidenziano come il tema del controllo della criminalità tenda a slittare verso il significato di "conquista" del territorio da parte della legalità, e certezza di comportamenti, coniugandosi con elementi di senso civico, cura del territorio e partecipazione attiva alla vita urbana, che affondano le radici soprattutto nella tolleranza, nell'accoglienza e in un rinnovato impegno educativo e preventivo (cfr. pgg. 49-52 dell'inchiesta).

${ }^{7}$ Cfr. grafico ${ }^{\circ} 4$, pg. 18

${ }^{8}$ Cfr. ANCI-SWG (2002); pg. 17

${ }^{9}$ L'ultima espressione è di R. Wurthnow (Sharing the Journey, Free Press, New York, 1994) citato in Giddens (2001), pg. 85.

${ }^{10}$ La coscienza che solo intervenendo sui costumi quotidiani e gli stili di vita delle persone si potranno mutare le condizioni della vivibilità è presente in più punti dell'indagine, ad esempio nella tabella 15 (pg. 45) sulle possibili soluzioni ai problemi dell'inquinamento.

${ }_{11}$ Nell'esegesi di questi dati non concordo del tutto con la versione proposta dalla SWG, che calca troppo la mano sulla 'soggettivizzazione dell'impegno', mentre ritengo importante sottolineare come la sommatoria delle richieste che vanno in direzione di un rapporto 'non individualizzato' con l'istituzione sia maggiormente significativa.

${ }^{12}$ Nella tab. 8 (pg. 27) dell'indagine ANCI-SWG, la graduatoria degli strumenti reputati come miglior garanzia per la partecipazione dei cittadini alle scelte dell'ente locale appare il seguente: incontri periodici tra amministrazione e cittadini: $30 \%$ nell'ottobre 2002 (era 28\% in aprile); verifiche periodiche dell'opinione dei cittadini: $24 \%$ (26\% in aprile), forme di partecipazione ai progetti di sviluppo della città: $20 \%$ (18 in aprile), referendum consultivi: $16 \%$ (14 in aprile); canali di contatto diretto e continuo con gli amministratori: $10 \%$ (era $14 \%$ in aprile).

${ }^{13}$ La curatrice dell'inchiesta le esplicita ma non le espone dettagliatamente a pg. 71 del testo. ${ }^{14} \mathrm{Vi}$ è, a rigore, anche un'altra omissione. I cittadini - a differenza dei sindaci - non sono suddivisi per tipologia di contesto urbano di appartenenza, ma costituiscono una categoria unica. Manca quindi la possibilità di verificare più in dettaglio una corrispondenza con i loro rispettivi amministratori nell'interpretazione delle modalità di partecipazione. ${ }^{15}$ In particolare, alla domanda sui servizi per migliorare visibilmente i quali un cittadino sarebbe disposto a maggiori esborsi, gli intervistati hanno collocato ai primi posti, nell'ordine: servizi sociali, vigilanza sul territorio, viabilità, pulizia delle strade e del suolo pubblico, verde pubblico, attività e servizi culturali, raccolta dei rifiuti, recupero e restauro di edifici e opere pubbliche, erogazione acqua, erogazione gas, erogazione elettricità. 



\section{Interviste a testimoni privilegiati ci- tate nel testo (con relativo ruolo al- l'epoca delle interviste)}

Alfonsin De Moraes, Betania (19998i, 1999i, 2001i, 2002i), avvocato, saggista, ex-membro del PRF e consulente della SPM, oltre che attivista ONG "Acesso".

Alfonsin Távora, Jacques (1998i); avvocato difensore di Sem Terra e occupanti di terre in varie cause nell' area metropolitana di Porto Alegre, presidente della ONG "Accesso";

Alibio, Wanderlei (1999i), architetto del Nucleo di Regolarizzazione dei Parcellamenti del Demhab;

Almeida, Rosane (1999i), architetto, coordinatrice dell'Unità di Parcellamento dei Suoli della SPM

Amaral, Sergio (1999i), Consigliere dell'O.P. per la Regione Cristal; vari incontri

Anton, Flavio José (1999i), da 30 anni sociologo dell'Unità di Ricerca del DEMHAB

Baierle ,Sergio (1999i); attivista della ONG CIDADE e autore di vari testi sull'O.P.

Barbosa, Sebastião (1999i), economista, consulente dell'Assessore della SMIC, per due anni membro del GT Rubem Berta

Benfatto, Lydia (1999i, 2002i), Coordinatrice dell'Ecoop, l'equipe delle Cooperative del Demhab

Borges, Edison (1999i), ex Coordinatore Regionale dell'O.P. nella Regione Eixo Baltazar;

Brunet, Luciano (1999i); ex responsabile della CRC per le Assemblee Tematiche

Bueno, Laura Machado (1999i); architetto e ricercatrice dell'università di São Paulo

Cabistani, Luis Omero (1999i, 2002i); Coordinatore della Sovrintendenza ai Progetti e alle Opere del DEMHAB di Porto Alegre, intervista del 20/5/ 1999

Camargo, Pereira, Reginaldo (1999i); ex presidente dell'Associazione di Abitanti (AMORB) Rubem Berta; 
Campos, Denise (1999i, 2001i), architetto del CUR e progettista del Condominio Lupicinio Rodrigues

Carpenedo, Silvia (1999i); da 3 anni urbanista dell'Unidade de Projeto Urbanisticos del DEMHAB,

Carvalho, Maria Suelina (1999i); addetta ai servizi giornalistici del DEMHAB,

Casanova, Cora, architetto del DEMHAB, coordinatrice del Nucleo di Regolarizzazione Fondiaria

Cechin, padre Antonio (1999i); si occupa dei lixeiros autorganizzati nelle isole del lago Guaiba

Coutinho, Cassia (1999i); ex Responsabile Projeto Memoria della CCS (1999i)

Cúnico Nelson (1999i); ex-coordinatore CAR Norte e ora vice-assessore CRC

Dantas Machado, Gladimiro (1999i); ex Soprintendente per la gestione economica del DEMHAB

De Araújo Eunice (2001i, 2002i), pedagoga e coordinatrice dell'Equipe dei Coordinatorui Tecnici degli 8 Forum Regionali di Gestione della Pianificazione. Lavora per la SPM

De Oliveira Cleia (1999i, 2001i, 2002i); architetto della SPM, coordinatrice del Programma di Sviluppo Integrato della Lomba do Pinheiro.

De Souza Prof. Celia F. (1998i); architetto, docente presso il Dottorato di Urbanistica della UFRGS

Di Lima, Norma (1999i); architetto della GTZ/METROPLAN addetto al programma PRORENDA URBANO/RS dal 1990 al 1995

Dias Pedro da Hora (1999i); ex Presidente della UAMPA

Dilly Marco Antonio (1999i, 2001i, 2002i); poliziotto, ex Consigliere Regione Cristal dell'O.P., tra i fondatori dell'ONG Solidariedade

Duarte, Cleo (1999i); Presidente dell'Associazione del Commercio Rubem Berta e ex-Cop dell'OP

Dutra Olivio (1999i); ex sindaco di Porto Alegre ed ex Governatore del Rio Grande do Sul, attuale Ministro delle Città

Franceschelli, Lucilda (1999i); architetto del Dip. Progetti della COHAB/RS, attualmente libera professionista in uno studio che ha molti appalti dal Comune di Porto Alegre per rilievi topografici

Frare, Marly (1999i, 2001i, 2002i); Assistente Sociale del DEMHAB da 5 anni,

Fuentefria, José Guilherme, 2002i, urbanista della SPM, lavora al Progetto Integrato Lomba do Pinheiro

Genro, Tarso (1999i, 2001i); avvocato, ex-sindaco di Porto Alegre e oggi Segretario di Stato Federale per lo Sviluppo Economico

Gonzeles, Sergio (1999i); ex Coordinatore della Pianificazione Strategica del GAPLAN

Guimaraes Vicente (1999i); architetto del PRF nella ricostruzione di Vila Planetario

Helmann, Fabio (1999i); Sovrintendente per l'Azione Comunitaria del DEMHAB

Kem, André (2002i), responsbile per la SPM sul tema delle AUOPs

Lange, Udo (1999i); coordinatore del Progetto PRORENDA URBANO/RS

Luisi adv. Felisberto (1998i); avvocato, ex presidente ASCOOPLAN e COP dell'OP.

Magadan, Telmo Borba (1998i); urbanista, ex-presidente dell'IBA (Istituto 
Brasiliano degli Architetti);

Mallmann Susana (19998i, 1999i, 2001i, 2002i); architetto della SPM, responsabile del Programma di Urbanistica Partecipata Rubem Berta

Marques Lires (1999i); Liquidatrice COHAB ed ex direttrice del DEMHAB

Martins, Cesar (1999i); avvocato e coordinatore della Commissione di Negoziazione del DEMHAB

Matte, Marcus (2002i), avvocato del DEMHAB

Mayer, Rosirene (1999i); architetto, ex coordinatrice del Programma di Ajuda Mutua

Menegassi Jaqueline (1999i); architetto della COHAB, poi DEMHAB, SPM e SEHAB

Menegat, Eliana (1999i); coordinatrice dell'equipe di Educazione Ambientale della SMAM

Menegat, Elizete (1999i); architetto, ricercatrice presso l'UFRJ di Rio de Janeiro, dottoranda in urbanistica, intervista del 9/6/1999

Mincato, don Ramiro (1999i); Segretario del Vescovo di Novo Hamburgo;

Moraes, Lùcia (1999i); architetto, opera a Goiania

Osores, Artìg as (1999i, 2002i); coordinatore del Movimento Nazionale di

Lotta per la Casa di Alvorada, promotore e organizzatore di numerose occupazioni di terra nell'area metropolitana

Passos Cordeiro, André (2002i), Coordinatore della CRC

Pereira De Paula, Ledir (2002i), sociologo del DEMHAB, responsabile del Programma Mutirão

Pereira Fragas, Julio Cesar (1999i); Agente Comunitario della Regione Centro di Porto Alegre

Pestana Carlos Neto (19998i, 1999i, 2001i, 2002i); Direttore del DEMHAB Pont Raul (1999i); ex-sindaco di Porto Alegre e Prof. Sociologia UNISINOS;

Portela, Florisbaldo (1999i); ex membro dell'estinta Associazione Rubem Berta I

Pozzobon Regina (1999i, 200i, 2002i); ingegnere, attivista della ONG CIDADE

Radagabech De Mello, Samira (1999i); Sociologa della COHAB/RS e oggi della SEHAB/RS

Rangel Miguel (1999i); ex-Delegato e Consigliere dell'O.P. del quartiere Restinga

Real, Ary (1999i); ingegnere dell'ASSEC [Assessoria de Saneamento Comunitario] del DMAE

Ribeiro Jordão, Kelly (1998i e 1999i) architetto, Commissione di Parcellamento dei suoli SPM

Ribeiro, Candido Ivan (1999i); Presidente dell'AM Recanto da Lagoa, a Rubem Berta

Rigatti Decio (1998i e1999i); architetto e urbanista, coordinatore del Programma di Post-laurea in Pianificazione urbana alla UFRGS e autore di una Tesi di Dottorato su Rubem Berta;

Saikoski Carlos, Fatima (1999i); assistente Sociale del DEMHAB

Sant'Ana Helena (1999i);- antropologa e autrice di una Tesi di Mestrado sulla 'Logica dell'Abitazione Riciclabile' nella Favela Cai Cai a Porto Alegre;

Santos da Silva, Paulinho (1999i, 2001i, 2002i); Presidente dell'Associazione di Abitanti Rubem Berta COHAB

Saraiva, Celoir (1999i); presidentessa della Cooperativa di Riciclaggio del 
Loteamento Cavalhada, incontro non strutturato il 1/5/1999

Silva, Sonia Maria da (1999i, 2001i, 2002i), architetto CUR e progettista del Condominio dos Anjos

Torino, Rafael (1999i); economista, ex Vice-Assessore della SECAR

Tramontina, Clarice (1999i, 200i, 2002i); psicopedagoga della scuola della Cavalhada

Turkievicz, Benamy (1999i); architetto e Professore del PROPAR/UFRGS, ex coordinatore del Progetto Centro di Bairro Jardim Leopoldina

Wagner, Marisa (1998i), docente di urbanistica presso la UFRGS

Wendler, Pedro Gabriel (1998i; 1999i); ex Consigliere per la Cooperazione Internazionale e la Raccolta di Fondi del Sindaco di Porto Alegre (SECAR, Assessorato Speciale) 


\section{Bibliografia citata}

AA.VV. (1980), Caracterização geral das Favelas de Porto Alegre. PMPA, Porto Alegre

AA.VV. (1998), A necessária releitura da cidade. PMPA, Porto Alegre

AA.VV. (2002), Regularização da Terra e Moradia. O que é e Como Implemementar, Instituto Pólis, San Paolo

Abers, R. (1996), From ideas to practice. The Partido dos Trabalhadores and Participatory Governance in Brasil. In: Latin American Perspectives, n. 91 , vol. 23

Abers, R. (1997a), Inventando a democracia: distribuição de recursos públicos através da participação popular em Porto Alegre, RS. Anais do $7^{\circ}$ Encontro Nacional da ANPUR, vol. 3

Abers, R. (1997b), Learning democratic practice: distributing government resources through popular participacion in Porto Alegre, Brasil. In: M. Douglas, J. Friedmann (a cura di), Cities for citizens: planning the rise of civil society in a global age. John Wiley \& Sons, Chichester (UK)

Abers, R. (1998a), Do clientelismo à cooperação: governos locais, políticas participativas e organização da sociedade civil em Porto Alegre. In: Cadernos IPPUR, vol. XII, n.1, pp.47-78

Abers, R. (1998b), La participation populaire à Porto Alegre au Brésil. Les Annales de la Recherche Urbaine, pp. 80-81

Abers, R. (2000a), Inventing Local Democracy. Lynne Rienner Publishers, Londra

Abers, R. (2000b), Practicing Radical Democracy - Lessons from Brazil. In: Plurimondi, n. 2

Abitare (1998), numero monografico sul Brasile, n. 374

Abrams C. (1964), Man's struggle for Shelter in a Urbanizing World. MIT Press, Cambridge, Mass.

Achutti, L.E. (1996), Fotoetnografia, Um estudo de antropologia visual sobre cotidiano, lixo, trabalho, em uma vila popular da cidade de Porto Alegre. Tesi di «Mestrado». Istituto di Filosofia e Ciencias Humanas, UFRGS 
AD - Architectural Design (1963), numero speciale su Dwelling resources in Latin America, a cura di John F.C. Turner, n. 8

Agache, D.A. (1930), Cidade do Rio de Janeiro, extensão, remodelação, embellezamento. Foyer Bresilien, Parigi

AGAS (1991), anno XI, n. 100, settembre

Aguiar, D.(1998), Colisões urbanas: continuidades e descontinuidades. Anais do $\mathrm{V}^{\circ}$ Seminario do Urbanismo e da Historia da Cidade, PUC, Campinas

Albanez, O. (1997), Orçamento, planejamento e participação comunitária a nível municipal. In: Boletim de Direito Municipal, vol. 13, n. 2, pp. 9095

Albano Fortini, M.T. (1998), Policentralidade e Zoneamento de Usos. In: AA.VV., A necessária releitura da cidade

Albuquerque, A. (1931), Sessão inaugural. Annales do $1^{\circ}$ Congresso de Habitação, San Paolo, Escolas Ptrofissionaes do Lyceu Coração de Jesus, pp. 21-23

Alfonsin, B. (1997), Direito à moradia: instrumentos e experiências de regularização fundiária nas cidades brasileiras. IPPUR/FASE-GTZ-UFRJ, Rio De Janeiro

Alfonsin, B. (1998a), Adicionando complexidades ao binômio "Participação Popular e Desenvolvimento local”. Convegno Municipio, Democracia y poder local: la experiência de Porto Alegre, Buenos Aires, 18/19 novembre

Alfonsin, B. (1998b), Uma Cidade Democrática em Tempos de Globalização. In: AA.VV., A necessária releitura da cidade

Alfonsin, B. (2002), Intervento al corso di formazione "Indicatori e strumenti di nuova democrazia territoriale: il Bilancio Partecipativo”, Trento 7-11 maggio 2002

Alfonsin, B., Allegretti, G. (2003), Dalla 'gestione consensuale' alla 'riprogettazione condivisa' del territorio. In: D. Della Porta, L.Mosca (a cura di), Globalizzazione e Movimenti Sociali, Manifestolibri, Roma

Alfonsin, B., Femandes E. (2003, a cura di), A lei e a ilegalidade na produção do espaço urbano, Del Rey/Lincoln Institute, Belo Horizonte

Alfonsin, J. (1997), A reforma agraria como modalidade de concretização dos direitos econômicos, sociais, culturais e ambientais. In: Revista de Informação legislativa, Senado Federal, n. 136

Aliani, A.H., Yap, K.S. (1990), The incremental development scheme in Hyderabad. An innovative approach to low income housing. In: Cities, maggio 1990, Butterworth \& Co Publ.

Allegretti, G. (2000a), Verso una colloquialità tra città informale e città formale: ipotesi di lettura di un'esperienza esemplare. Il percorso di Porto Alegre (Brasile) fra la ricostruzione del 'Diritto alla città' e l'integrazione del tessuto urbano autorganizzato. Tesi di Dottorato in Progettazione Urbana, Territoriale e Ambientale, Università degli Studi di Firenze

Allegretti, G. (2000b), Informality as a culture of dialogue: three Mayors of Porto Alegre face to face. In: Plurimondi, n. 3, Dedalo, Roma

Allegretti, G. (2001a), Favela con vista. L'integrazione a Rio. In: Carta, n. 15 , Roma

Allegretti, G. (2001b), Bilancio partecipativo e gestione urbana: l'esperienza brasiliana di Porto Alegre. In: M. Carli (2001, a cura di), Il ruolo delle 
Assemblee elettive. Giappichelli Editore, Torino, vol. I,pp. 551- 579

Allegretti, G. (2001c), Brasile: un salto di scala nella democrazia diretta. In: Testimonianze, n. 117, pp.110-127

Allegretti, G. (2002a), Fatti, non parole! Sindaci a confronto con la democrazia diretta. In C.Jampaglia, T.Bendinelli (a cura di), Porto Alegre. Il Forum Sociale Mondiale. Feltrinelli, Bologna

Allegretti, G. (2002b), Il Bilancio Partecipativo. Sbilanciare la politica per riequilibrare il territorio. Mappe di Movimenti, Asterios, Trieste, pp. 7586

Allegretti, G. (2002c), Opportunità e contraddizioni del Bilancio Partecipativo di Porto Alegre: una politica vista da un progetto. In: La Nuova Città, n. 6/7, Fiesole

Allegretti, G. (2002d), L'abitare come valore urbano nel nuovo piano 'esperienziale' di Porto Alegre (Brasile). In: Urbanistica, n. 119

Allegretti, G. (2003a), Participation in urban planning decision-making in Italy: new challenges for local authorities and citizens organisations. Atti del $9^{\circ}$ Congresso IRGLUS, Building the legal foundation of the democratic city, Porto Alegre, 16/18 luglio 2002, edizioni PGU/ONU, Quito

Allegretti, G. (2003b), Autoprogettualità come paradigma urbano. L'insegnamento di Porto Alegre, Alinea, Firenze

Allegretti, G., Picheral J. B. (2002), Il Bilancio Partecipativo in ambito europeo: tra resistenza al cambiamento e innovazione delle politiche territoriali. Carta/IntraMoenia, collana "Cantieri”, Napoli, pp. 327-348

Allegretti, U. (2002), Diritti e Stato nella mondializzazione. Città Aperta, Troina

Almeida de Soares, M.(1993), Porto Alegre no contexto regional: a questão da habitação e do transporte. In: W. Panizzi, J. Rovatti, (a cura di), Estudos Urbanos

Alonso, J.A.F., Bandeira, P.S. (1988), A desinustrialização de Porto Alegre: causas e perspectivas. In: Ensaios FEE, vol. 9, n. 1, FEE, Porto Alegre

Alvarez, S.E. (1997), Reweaving the fabric of collective action: social movements and challenges to 'actually existing democracy' in Brazil. In: Fox \& Starn, Between resistance and revolution: cultural politics and social protest. Rutgers University Press, Brunswik, New Jersey

ANCI-SWG (2002), La città che vorrei. Inchiesta dell'Osservatorio sull'Italia dei Comuni dell'Associazione Nazionale Comuni d'Italia. ANCI, Società Tipografica Romana srl, Pomezia

Andreasen, J. (1987), Urban-Rural ties and their impact on Urban Housing. Royal Danish Academy of Fine Arts

Andreatta, H. (1997), Orçamento Participativo Porto Alegre. Você è quem faz uma cidade de verdade. PMPA, Porto Alegre

Angotti, T.(1996), Latin American urbanization and planning. In: Latin American Perspectives, vol. 23, n. 4, pp. 12-34

Annali del $5^{\circ}$ Incontro Nazionale ANPUR (1993). Belo Horizonte

Arnstein, S. (1969), A ladder of citizen participation. In: Journal of the American Institute of Planners, n.35, pp. 216-224

Arretche, M. (1990), Intervenção do Estado e setor privado: o modelo brasileiro de politica habitacional. In: Espaço e Debates, n. 31

Arruda, K.F. (1998), A democracia participativa na Constituição Federal de 
1988. In: C.A. Oliveira da Silva et al., Democracia, participação e orçamento. IBAM, Rio de Janeiro

Atos do $1^{\circ}$ Seminario Programa de Ajuda Mutua - Construção Solidaria (1996). DEMHAB/PMPA, Por to Alegre

Augustin, A.F. (1994), A experiência do O.P. na Administração Popular da Prefeitura Municipal de Porto Alegre. In: C.H. Horne, (a cura di), Porto Alegre: o desafio da mudança

Avritzer, L. (1996), A moralidade da democracia. Perspectiva, San Paolo.

Avritzer, L. (2002), Modelos de deliberação democratica: uma análise do orçamento participativo no Brasil. In: Sousa Santos, B. de (2002, a cura di), Democratizar a democracia. Os caminhos da democracia participativa. Civilização Brasileira, Rio de Janeiro

AVSI/UNCHS (1995), Os desafios da cidade informal (1995). Atti del Seminário Internacional, 11/15 settembre, Belo Horizonte

Ayres, R.L. (1983), Banking on the poor. MIT Press, Cambridge Massachusett

Azevedo, S. de, Andrade, L.A. de (1982), Habitação e Poder: da Fundação da Casa Popular ao Banco Nacional de Habitação. Zahar, Rio de Janeiro

Azevedo, S. de (1996), A crise da politica habitacional: dilemas e perspectivas para o final anos 90. In: L.C. Queiroz Ribeiro, A crise da moradia nas grandes cidades. UFRJ, Rio de Janeiro

Baierle, S. (1992a), Um novo princípio ético-político: prática social e sujeito nos movimentos populares urbanos em Porto Alegre nos anos 80. Tesi di « Mestrado». UNICAMP, Campinas

Baierle, S. (1992b), A crise da Uampa. In: Movimentos Populares Urbanos. FASE/CIDADE, Porto Ale gre, pp.43-65

Baierle, S. (1996), Porto Alegre, Pólis no Terceiro Mundo? A emergência de um novo princípio Etico-Político nos movimentos populares urbanos em Porto Alegre. In: Cadernos da CIDADE, vol. 1, n. 2

Baierle, S. (1997), Un novo princípio ético-político: pratica social e sujeito nos movimentos populares urbanos em Porto Alegre nos anos 80. Dep. De Ciência Política, UNICAMP, Campinas

Baierle, S. (1998), The explosion of Experience: the Emergence of a New Ethical-Political Principle in Popular Movements in Porto Alegre, Brazil. In: S. Alvarez (a cura di), Cultures of politics, politics of cultures. Revisioning Latin American Social Movements. Westview Press

Baierle, S. (1999), Democracia radical e cidadania: a "economia moral" dos sujeitos. In: L.H. Da Silva (a cura di), Século XXI: qual conhecimento? qual currículo? Vozes, Petrópolis

Baiocchi, G, (2000a), Synergizing civil society; the politics of democratic decentralization in Porto Alegre, Brazil. International Conference on Democratic Decentralization, Trivandam, Kerala, India

Baiocchi, G. (2000b), The dynamism of the unorganized: lessons from the PT in Porto Alegre. In: D. Chavez e B. Goldfrank (a cura di), The Left and the City. Latin American Bureau, Londra

Baiocchi, G, (2001a), From militance to citizenship; the workers' party, civil society, and the politics of participatory governance in Porto Alegre, Brazil. PhD Thesis, Department of Sociology. Madison, University of Wisconsin, Wisconsin

Baiocchi, G, (2001b), Activism, participation, and politics: the Porto Alegre 
experiment and deliberative democratic theory. In: Politcs \& Society, marzo

Baken, R-J., Linden, J. van der (1993), 'Getting the incentives right': banking on the informal sector - a critique of the World Bank thinking on lowincome housing delivery in third world cities. In: Third World Planning Review, vol 15, n. 1, pp. 1-22

Bakos, M. (1986), A continuidade administrativa no Governo Municipal de Porto Alegre, 1897-1937. Tesi di dottorato. ILFCH/USP, San Paolo

Bakos, M. (1988), A habitação em Porto Alegre: problemas e projetos administrativos (1897-1937). UFRGS/IFCH, Porto Alegre

Bakos, M. (1990), Porto Alegre: sala de visitas do Rio Grande do Sul. In: D.O. Leitura, n. 102

Balbo, M. (1995), Povera grande città. Franco Angeli, Milano

Balbo, M. (1996), Le città secondo Habitat II. In: Urbanistica, n. 107

Balbo, M. (1999), L'intreccio urbano, Franco Angeli, Milano

Balbo, M. (2002, a cura di), La città inclusiva. Argomenti per la città dei $P V S$. Franco Angeli, Milano

Balducci, A. (2001), La partecipazione nel contesto delle nuove politiche urbane. In: D. Bianchi, E. Zanchini, Ambiente Italia 2001. Edizioni Ambiente, Milano, pp.59-71

Balibar, E. (1993), Le frontiere della democrazia. Manifestolibri, Roma

Bamberger, M. (1979), The role of self-help housing in low-cost shelter programmes for the Third World. Built Environment, vol. 8-2

Bamberger, M. (1988), The role of community participation in development planning and project management. EDI Policy Seminar, Report No.13, World Bank, Washington

Bamberger, M., Gonzales-Polio E., Sae-Hau, U. (1982), Evaluation of Sites and Services Project. The evidence from El Salvador. The World Bank Publ., Washington D.C.

Banca Mondiale (1971), Rapporto annuale 1970. The World Bank Press, Washington D.C.

Banca Mondiale (1972), Urbanisation. Washington D.C.

Banco Mundial (1978), Projetos de Lotes Urbanizados. BNH, Rio de Janeiro

Barbano F. (1999), Pluralismo. Un lessico per la democrazia. Bollati Boringhieri, Torino.

Barbosa de Araújo, R.M. (1993), A vocação do prazer - A cidade e a família no Rio de Janeiro Republicano. Ed. Rocco, Rio de Janeiro

Barbosa Machado, E. (1987), A politica habitacional e o Sistema Financeiro de Habitação no Brasil (1964-77). Tesi di Dottorato. Facoltà di Sociologia, Università di Bielefeld

Barbosa Machado, E. (1993), Novos espaços culturais e formação de capital fixo em Porto Alegre: lendo a cidade a partir da crítica à economia política. In: W. Panizzi, J. Rovatti, (a cura di), Estudos Urbanos

Barbosa, R., Morães, L., Cabannes, Y. (1997), Tenant today, posseiro tomorrow. In: Environment and Urbanization, vol. 9, n. 2

Barcellona P. (1993), Lo spazio della politica: tecnica e democrazia. Editori Riuniti, Roma.

Barcellos, T. (1986), Segregação urbana e mortalidade em Porto Alegre. 
Secretaria de Coordenação e Planejamento, Fundação de Economia e Estatística, Porto Alegre

Baum, W., Baum, T., Stokes, M. (1987), Investir dans le développement. Les leçons de l'expeérience de la Banque Mondiale. Economica pour la Banque Mondiale, Parigi

Bauman, Z. (1999), La società dell'incertezza. Il Mulino, Bologna

Bechelloni, G. (2002), La svolta comunicativa. Ipermedium, Napoli

Benetti, P. C. (1998), Substituir ou integrar a favela ao bairro? O exemplo da Ladeira dos Funcionarios-Parque Sào Sebastião, Caju, Rio de Janeiro$R J$. Rio de Janeiro

Benevides de Mesquita, M. V. (1991), A cidadania ativa: referendum, plebiscito e iniciativa popular. Ática, San Paolo

Bertacchini, E. E. (2003), Scelte collettive e Bilanci Partecipativi: il caso brasiliano, Tesi di Laurea, Universita' degli studi di Torino, Facoltà di Economia, Torino

BIDEXTRA (1997), [special issue], Renascença Urbana, BID, Whashington D.C.

Bobbio, L. (2002a), I governi locali nelle democrazie contemporanee. Laterza, Roma-Bari

Bobbio, L. (2002b), "Non rifiutarti di scegliere”: un'esperienza di democrazia deliberativa. In: Stato e Mercato, n. 1

Bobbio, N. (1984), Il futuro della democrazia. Einaudi, Torino

Bobbio, L., Zeppetella, A. (1999, a cura di), Perché proprio qui? Grandi opere e opposizioni locali. Franco Angeli, Milano

Bogus, L. (1980), Vila do encontro: a cidade chega à periferia. Tesi di «Mestrado». PUC/SP

Bonin, L.C. (1993), A regularização fundiária e a democratização do solo urbano. In: W. Panizzi, J. Rovatti, (a cura di), Estudos Urbanos

Borba Villanova, S. (1993), Transformações recentes na área central de Porto Alegre. Apontamentos para uma discussão. In: W. Panizzi, J. Rovatti, (a cura di), Estudos Urbanos

Borghi, V. (2000), Progettazione come impresa sociale. Franco Angeli, Milano

Borja, J. (1998), Las ciudades y el planeamiento estrategico. Una reflexión europea y latinoamericana. In: Urbama, n. 22, Caracas

Bretaudeau, H.(1986), La Banque mondiale. PUF, Parigi

Buchabui, J. S. (1994), Reforma administrativa e mudança no modelo de gestão. In: C.H. Home, (a cura di), Porto Alegre: o desafio da mudança

Bueno Machado de Mello, L. (1995), Metodos de ação planejada em favela. Relazione alla CEAP/PUCCAMP, Campinas

Bueno Machado de Mello, L. (1998), Qualidades Estéticas e Sócio-ambientais do Espaço Criado pela Favela. Trabalho Programado 4, Curso De Pós Graduação - Estruturas Ambientais Urbanas, FAU/USP, San Paolo

Burgess, R.(1985), The Limits of State Self-Help Housing Programmes. In: Development and Change, vol. 16

Burgos Baumann, M. (1998), Dos parques proletarios ao Favela-Bairro: as politicas públicas nas favelas de Rio de Janeiro. In: A. Zaluar, M. Alvito, (a cura di), Um seculo de Favela

Burmeister, N. (1996), O desafio da cidade. In: Zero Hora, 1/6/1996 
Burmeister, N. (1998), A necessária releitura da Cidade. In: AA.VV., A necessária releitura da cidade

Cabannes, Y. (1997), From community development to housing finance: from Mutiroes to Casa Melhor in Fortaleza, Brazil. In: Environment and Urbanization, vol. 9, n. 1, pp. 31-58

Cabral, G., Almeida de Soares M. (1998), Instrumentos de Intervenção Propositiva no Planejamento de Porto Alegre. In: AA.VV., A necessária releitura da cidade

Caccia Bava, S. (2001), A reapropriação das cidades In: Um outro mundo urbano è possivel (gennaio 2001), edizione speciale Cadernos Le Monde Diplomatique, Istituto Pòlis, San Paolo, pp. 18-21

Calame, P., Talmant A. (2001), A queestão do Estado no coração do futuro. Vozes, Petrópolis

Camargo, M. (1989), Porto Alegre: a experência da Administração Popular. In: $E M$ TEMPO, n. 236

CAMP-Centro de Assessoria Multiprofessional (1987), Diagnóstico do Movimento Popular, Porto Alegre

Campello, T. (1994), A política salarial dos servidores públicos de Porto Alegre no Governo Olívio Dutra. In: C.H. Horne (a cura di), Porto Alegre: o desafio da mudança

Cardoso, F. H. (1990), Desafios da social democracia na América Latina. In: Novos Estudos, n. 28

Carrion Kroeff, O. B. (1993), Descentalização e democratização do poder local. In: W. Panizzi, J. Rovatti, (a cura di), Estudos Urbanos

Carvalho de Rezende, M. A. (1995), Cidade Escassa e violência urbana. In: Serie Estudos, n. 91, Rio de Janeiro

Casé, P. (1996), Favela. Relume Dumarà Ed., Rio de Janeiro

Cassel, G., Verle, J. (1994a), A politica tributaria e de saneamento financeiro da Administração Popular. In: C.H. Horne, (a cura di), Porto Alegre: o desafio da mudança

Cassel, G., Verle, J. (1994b), Receita e capacidade de pagamento da Prefeitura Municipal de Porto Alegre, 1973-92. In: C.H. Horne, (a cura di), Porto Alegre: o desafio da mudança

Cassen, B. (1998), Démocratie participative à Porto Alegre - une expérience exemplaire du Brésil. In: Le Monde Diplomatique, agosto, p. 3

Cassen, B. (2001), Il tranello della "governance». In: Le Monde Diplomatique, giugno

Castells, M. (1982), Squatters and politics in Latin America. In: H.I. Safa (1982), Towards a political economy in Third World Conutries. Oxford University Press, Delhi

Castells, M. (1983), The city and the grassroots. Arnold, Londra

Castells, M. (1993), A questão urbana. Paz e Terra, Rio de Janeiro

Castells, M., Borja, J. (1996), As cidades como atores politicos. In: Novos Estudos, n. 45

Castells, Manuel (1983), The city and the grassroots, London, Arnold.

Castex, J., Panerai, P.(1971), Notes sur l'estructure de l'espace urbain. In: L'Architecture d'Aujourd'hui, n. 153

Castoriadis, C. (1979), Introdução: socialismo e sociedade autônoma. In: Socialismo ou barbárie. O conteúdo do socialismo. Brasiliense, San Paolo, 1983 
718 Castoriadis, C. (1987), As encruzilhadas do labirinto II: os dominios do homem. Paz e Terra, Rio de Janeiro

Castoriadis, C. (1991), A instituição imaginária da sociedade. Paz e Terra, Rio de Janeiro

Castoriadis C. (2001), La rivoluzione democratica. Teoria e progetto dell'autogoverno. Elèuthera, Milano

Cavalcanti, D.(1998), Presupuesto participativo y processo de capacitacióndemocracia en movimiento. In: Pobreza urbana y desarrollo, anno 8, n. 17, pp. 58-64

CCS/PMPA (1999a), Vazios Urbanos. In: Informe Direto, novembre

CCS/PMPA (1999b), Politica Habitacional. In: Informe Direto, novembre

Ceci, A. M. (1996), L'Habitat agenda. In: Urbanistica, n.107

CENSIS (2001), Rapporto sulla situazione sociale del paese 2001. Franco Angeli, Milano

Cesar, G. (1970), História do Rio Grande do Sul: povoado colonial. Globo, Porto Alegre

Chavez, D, Goldfrank, B. (2000, a cura di), The Left and the City. Latin American Bureau, Londra

CIDADE (1996), O.P. em Porto Alegre (1989-1996), Seminario su NGO Public Sector Partnership for Poverty Reduction, Whashington, D.C., 2125 ottobre

CIDADE (1997a), Desdobrando o Orçamento de Porto Alegre. Stampa in proprio, Porto Alegre

CIDADE (1997b), O ciclo do Orçamento Participativo. Stampa in proprio, Porto Alegre

CIDADE , PMPA (2002),.Quem é o público do Orçamento Participativo 2000. PMPA, Porto Alegre

Ciudades (1991). In: Nueva Sociedad, n. 114, pp. 76-159

Clemente A., Ramirez L. (1985, a cura di), Abitazione e periferie urbane nei Paesi in Via di Sviluppo. Franco Angeli, Milano

COHAB (1987), Retrospectiva da ocupação do Conjunto Habitacional Rubem Berta. Documento interno. Porto Ale gre

Cohen, J., Sabel, C. (1997), Directly-Deliberative Polyarchy. In: European Law Journal, vol. 3, n. 4, pp. 313-342

Comas Dias, C. E., Bohrer, G. (1998), Dispositivos de Controle, Planos Diretores e uma Celeuma sem Base. In: AA.VV., A necessária releitura da cidade

Comas Dias, C.E. (1993), Plano Diretor de Porto Alegre: alguns acertos e muitas dúvidas. In: W. Panizzi, J. Rovatti, (a cura di), Estudos Urbanos

COMATHAB (2001), O diagnóstico da situação habitacional de Porto Alegre. PMPA, Porto Alegre

Commissão de Parcelamento do Solo/SPM (1992), Parecer, n. 464. Documento interno. SPM 21/7/1992, Porto Ale gre

Constituição da República Federativa do Brasil (1987), Saraiva, San Paolo

Conway D. (1982), Self-help housing: the commodity nature of housing and amelioration of the housing deficit: continuing the Turner-Burgess debate. In: Antipode, vol. 14

COOMETAL (1996), Estatuto Social da Cooperativa Habitacional COOTRACOM. Cooperativa de Trabalho da COOMETAL, Porto Alegre 
Crosta, P.L.(1998), Politiche. Quale conoscenza per l'azione territoriale. Franco Angeli, Milano

D’Avila, N. (1996), Orçamento mais Participativo. In: Zero Hora, 12/4/1996

D'Avila, N.(2000), DEMHAB - Com ou sem tijolos, a história das políticas habitacionais em Porto Alegre. Unidade Editorial da Secretaria Municipal da Cultura, Porto Alegre

Da Matta, R. (1995), On the Brazilian urban poor. University of Notre Dame. Helen Kellogg Institute for International Studies Publ., Notre Dame, Indiana

Dahl, R.A. (1989), La democrazia economica. Il Mulino, Bologna

Dahl, R.A. (2000), Sulla democrazia. Laterza, Roma-Bari

Dahrendorf, R.(1977), Cittadini e partecipazione al di la' della democrazia rappresentativa? In: Il cittadino totale: Partecipazione, eguaglianza e liberta' nelle democrazie d'oggi, Centro di ricerca e documentazione Luigi Einaudi, Torino

Dahrendorf, R. (2001), Dopo la democrazia. Intervista a cura di A. Polito. Laterza, Roma-Bari

Daniel, C. (1991), As administrações democráticas e populares em questão. Santo André . Manoscritto

Daniel, C.(1990), Poder Local no Brasil urbano. In: Espaço e Debates, vol. 8, n. 24

Day, D. (1997), Citizen participation in the planning process: An essentially contested concept. In: Journal of Planning Litterature, vol.1, n. 3

De Moura Sobreira, A. (1995), Espacio urbano, derecho y conflictos colectivos en Brasil. In: Revista Mexicana de Sociolog;a, vol. 57, n. 1, pp. 53-69

De Oliveira, F. B. (1940), La casa proletaria. In: Urbanismo e Viação, n. 7, pp. 187-197

Dematteis, G. (1996), Progetto implicito: il contributo della geografia umana alle scienze del territorio. Franco Angeli, Milano

DEMHAB (1966), Levantamento universal e as necessidades sociohabitacionais de Porto Alegre. PMPA, Porto Alegre

DEMHAB (1973), Malocas: diagnostico evolutivo das sub-habitações no Municipio de Porto Alegre. Emma, Porto Alegre

DEMHAB (1993), Seminario do Governo. Politica Urbana e Habitacional. Porto Alegre

DEMHAB, (1996), Informe Direto - Politica Habitacional. PMPA, Porto Alegre

DEMHAB (1997a), $1^{\circ}$ Conferencia Municipal de Habitaçãao. Conclusões e Recomendações. PMPA, Porto Ale gre

DEMHAB (1997b), Formas de produção da habitação. Documento das PreConferencias Regionais 14/9/97, Porto Alegre

DEMHAB (1998a), Programa habitacional de construção por ajuda mutua. PMPA, Porto Alegre

DEMHAB (1998b), Avaliação do programa de ajuda mutua. Documento interno. PMPA, Porto Alegre

DEMHAB (1998c), Avaliação do trabalho social desenvolvido na vila campo da tuca, PMPA, 5/11/1998

DEMHAB (1998d), Regularização fundiaria. PMPA, Porto Alegre

DEMHAB (1999), Mapa da irregularidade fundiaria de Porto Alegre. PMPA, Porto Alegre

DEMHAB (2001), Diagnostico da situação habitacional. PMPA, Porto Alegre 
720 Dewey, J. (1954), The public and its problems. Swallow Press, Ohio University Press, Athens

Di Baia, M. (2002), Politiche e pratiche di sostenibilita' urbana: il caso di Barcellona e Porto Alegre. Tesi di Laurea. Fac. di Architettura, Università di Napoli Federico II, Napoli

Diniz, E. (1982), Voto e maquina política: patronagem e clientelismo no Rio de Janeiro. Paz e Terra, Rio de Janeiro

Diniz, E. (1995), Governabilidade, Democrazia e Reforma do estrado: os desafios da construção de uma nova ordem no Brasil dos anos 90. In: DADOS, vol. 38

DMCP (1964), Levantamento Socio-Economico nas Vilas e Agrupamentos Marginais de Porto Alegre. PMPA, Porto Alegre

Doberstein, Arnoldo Walter (1988), Porto Alegre: 1898-1920. Estatuária fachadista e monumental, ideologias e sociedade. Tesi di «Mestrado». PUCRS, Porto Alegre

Doimo, A.M. (1990), Movimentos Sociais e Conselhos ppulares: desafio de insitucionalidade democrática. XIV Encontro da ANPOCS, Caxambu, MG

Dos Santos, C. N. Ferreira, Vogel, A. (1985, a cura di), Quando a rua vira casa, Projeto Arquitetos Associados, San Paolo

Dryzek, J.S. (1990), Discursive Democracy: Politics, Policy, and Political Science. Cambridge University Press, Cambridge

Duarte, C. R. et al. (1996), Favela, um bairro. Propostas Metodologicas para Intervenção Publica em Favelas di Rio de Janeiro. Grupo Habitat, ProEditores, San Paolo

Duhau, E. (1995), Estado de derecho e irregularidad urbana. In: Revista Mexicana de Sociologia, n. 1, Città del Messico

Dunn , J. (1995), La democrazia: storia di un'idea politica dal VI sec. a.C. ad oggi.Marsilio, Venezia.

Durham, E.R.(1984), Movimentos Sociais: A Construção da Cidadania. In: Novos Estudos, n. 10

Dutra, O. (1994), Prefacio. In: C.H. Horne (a cura di), Porto Alegre: o desafio da mudança

Dutra, O., Genro, T. (1989), O desafio de administrar Porto Alegre: contribução ao debate. PMPA, Porto Alegre

Eisenstadt, S. N. (2002), Paradossi della democrazia. Verso democrazie illiberali? Il Mulino, Bologna

Elster, J. (1993), Argomentare e negoziare. Anabasi, Milano

Elster, J. (1998, a cura di), Deliberative Democracy. Cambridge University Press, Cambridge

Elzinga, K. (1981), Evaluating the evaluation game. SADEC, Stockholm

Enzensberger, H. M. (1999), Zig Zag.Einaudi, Torino

Estatuto da União das Associações de Moradores de Porto Alegre. Registrato al Cartório de Registro Especial il 19/12/1984.

FASE/RS (1989), A Lei 195/88. Porto Alegre, maggio

Fathy, H. (1980), Costruindo com o povo. Arquitetura para os pobres. Editora da Universidade de São Paulo, (ed. originale, 1973)

Fedozzi, L. (1990), A reforma administrativa e a democratização do executivo, uma nova lei para a participação popular, s.e., Porto Alegre

Fedozzi, L.(1994), Poder local e governabilidade: o caso de Porto Alegre. 
In: Proposta, anno 22, n. 62, pp.23-29

Fedozzi, L. (1997), Orçamento participativo: reflexões sobre a experiência de Porto Alegre. Tomo Editorial, Porto Alegre

Fedozzi, L. (2000a), O Poder da Aldeia. Gênese e história do Orçamento Participativo de PortoAlegre. Tomo Editorial, Porto Ale gre

Fedozzi, L. (2000b), Orçamento Participativo de Porto Alegre. Elementos para um debate conceitual. In: N. Fischer, J. Moll, (a cura di), Por uma nova esfera pública. Vozes, Rio de Janeiro

Fedozzi, L., Castro Filho, E.D.(1989), Parecer sobre a L.C. n. 195/88. PMPA, Porto Alegre

Feld, L. P., Kirchgässner, G. (2001), Does direct democracy reduce public debt? Evidence from Swiss municipalities, in: "Public Choice", 109/2001, p. 347-370.

Fernandes, E. (1995), Law and urban change in Brazil. Aldershot, Avebury Fernandes, E. (1997), Access to urban land and housing in Brazil: In:Three Degrees of Illegality', Working Paper WP97EF1, Lincoln Institute of Land Policy, Cambridge, MA.

Fernandes, E. (1998), Direito e urbanizacao no Brasil. In: E. Fernandes (a cura di), Direito Urbanistico, Del Rey, Belo Horizonte

Fernandes, E. (2001), Combining tenure policies, urban planning and city management in Brazil. Annual Conference of the Society for Latin American Studies - 6-8 Aprile 2001, University of Birmingham

Fernandes, E. (2002), Dal Codice Civile allo 'Statuto della Città': brevi note sulla traiettoria del Diritto Urbanistico in Brasile. In: La Nuova Città, n. 6/7, Fiesole

Ferreira, F. (1979), Planejamento sim e não. Um modo de agir num mundo em permamente mudança. Paz e Terra, Rio de Janeiro

Ferretti Brum, R. (1984), Uma casa nas costas. Análise do movimento social urbano em Porto Alegre. Tesi di «Mestrado». UFRGS, Porto Alegre

Fondazione João Pinheiro, Centro de Estatística e Informações (2001), Déficit Habitacional no Brasil 2000. Rio de Janeiro

Font, J. (a cura di) (2001), Ciudadanos y decisiones públicas.Ariel, Barcelona Forester, J. (1999), The Deliberative Practitioner: Encouraging Participatory Planning Processes. MIT Press

Fortunati, J., Hohlfeldt, A.(2001), O fascínio da estrela. Trajetória e contradições do Partido dos trabalhadores. Mercado Aberto, Porto Alegre

Foucault, M. (1975), Surveiller et Punir, naissance de la prison Gallimard, Parigi. Trad. It. Sorvegliare e punire. Einaudi, Torino

Foucault, M. (1986), Microfísica do poder. Graal, Rio de Janeiro

Foucault, M. (1994), Eterotopia. Ed. Millepiani

Franco da Costa, S. (1983), Porto Alegre e seu comércio. Associação Comercial de Porto Alegre, Porto Alegre

Franco da Costa, S. (1988), Porto Alegre. Guia Histórico. Ed. Da Universidade, Porto Alegre

Franco da Costa, S. (1996), Júlio de Castilhos e sua época, Editora da Universidade/UFRGS, Porto Alegre, $3^{\circ}$ ed.

Friedmann, J. (1992), Empowerment: the Politics of Alternative Development. Basil Blackwell, Boston

Friedmann, J. (2000), The good City: In defense of utopian thinking. In: International Journal of Urban and Regional Research, n. 2, pp. 460-472 
722 Fruet Maya, G. (1991), Conflict, continuity and community interaction in a City public housing agency, Porto Alegre, Brazil. Tesi di Master in City Planning. MIT, Cambridge, Mass.

Fuchs, D., Klingrmann, H.D. (1995), Citizens and the State. Oxford University Press, Oxford, New York

Fuchs, F. D. (1994), Participativo e problema viario. In: Zero Hora, 27/9/ 1994

Fung, A., Wright, E. (1999), Experiments in empowered deliberative democracy. Working Paper, Wisconsin University

Fung, A., Wright, E.O. (2001a, a cura di), Deepening democracy. Institutional Innovations. In: Empowered Participation, aprile 2001, in www.scs.wisc.edu/ wright/DeepDem.pdf

Furtado, C. R. (1993), "Gentrification" e o processo de (re)struturação urbana recente em Porto Alegre. In: W. Panizzi, J. Rovatti, (a cura di), Estudos Urbanos

Gadotti, M., Otaviano, P. (1989), Pra Que PT: Origem, projeto e consolidação do Partido dos Trabalhadore. Cortez, San Paolo

Galbraith, J. K. (1980). Théorie de la pauvreté de masse. Gallimard, Parigi

Garayp, De Castilhos N. R. (1980), Casas para quem? Tesi di «Mestrado». UFRGS, Porto Alegre

Genro T., de Souza U. (2002), Il Bilancio partecipativo. L'esperienza di Porto Alegre. A cura di G. Allegretti, S. Ricciardi. Edizioni La Ginestra, Limbiate

Genro, T. (1993), A cidade constituinte e a senhora. In: Zero Hora, 11/5/ 1993

Genro, T. (1994), Utopia possível. Artes e Ofícios, Porto Alegre

Genro, T. (1996a), Novo papel das cidades. In: Zero Hora, 29/05/1996

Genro, T. (1997), Porto da cidadania. Artes e Ofícios, Porto Alegre

Genro, T. (1998), El mundo globalizado y el Estado necessario. In: Pobreza urbana desarrollo, anno 8, n. 17, pp.11-16

Genro, T. (2001), Participação e suas reformas. In: Zero Hora, 20 /6/2001, Porto Alegre

Genro, T., Alonso, J.A.F. (1996), Novas condições e oportunidades para alianças entre governo e sociedade civil na luta contra a pobreza. Manoscritto, Porto Alegre

Ghezzi et al. (1987), Aspetti Politici e Tecnologici della Questione Abitativa Brasiliana. In: Tecnologie per lo Sviluppo Urbano e Suburbano, E.A. Fiere di Bologna, Faenza

Giacomoni, J. (1992), O Orçamento Participativo da Prefeitura Municipal de Porto Alegre. In: Orçamento público. Atlas, 4a ed., San Pablo, 1992

Giacomoni, J. (1994), A comunidade como instância executora do planejamento: o caso do orçamento participativo de Porto Alegre. In: Revista de Administração Pública, Rio de Janeiro, 28(2), pp. 47-59

Giambiagi, F. (1984), $O$ mito do orçamento participativo. In: Jornal do Brasil, 11/06/1997, San Paolo

Giddens, A. (2001), La terza via. Est, Milano

Giusti, M. (1995), Urbanistica e terzo attore. Ruolo del pianificatore nelle iniziative di autopromozione territoriale degli abitanti, L'Harmattan Ita- 
lia, Torino

Goday, L. (1999), El presupuesto participativo como una herraienta fundamental

participación ciudadana. In: Respondabilidad, n. 23, p. 5

Godoy, A. (1923), Algumas ideias sobrea a remodelação das cidades. Annales do Primeiro Congresso Brasileiro de Higiene, Rio De Janeiro

Gohn Marcondes, M.da G. (1985), A Força da periferia - A luta das mulheres por creches em São Paulo. Vozes, Petrópolis

Gohn, M.G. (1999), Conselhos populares: participação e gestão de bens coletivos. Anales del XIII Encuentro Anual de la Asociación Nacional de Posgrado en Ciencias Sociales, Caxambu, pp. 12-13

Gordillo, A. (1982), La admistration paralela. Cuadernos Civitas, Madrid

Governa, F. (1996), Il milieu urbano. L'identità territoriale nei processi di sviluppo. Franco Angeli, Milano

Gramsci, A. (1977), Gli intellettuali e l'organizzazione della cultura. Editori Riuniti, Roma

Granotier B. (1980), La planète des bidonvilles. Perspectives de l'explosion urbaine dans le tiers monde. L'Histoire immediate, Seuil, Parigi

Granovetter, M. (1999), La forza dei legami deboli e altri saggi. Liguori, Napoli

Grau, E. R. (1983), Direito urbano. In: Revista dos Tribunais, San Paolo

Gret, M., Sintomer, Y. (2002), Porto Alegre, une démocratie participative. La Découverte, Parigi

Grupo de Trabalho de Modernização do Orçamento Participativo (2001), Rompendo nossos limites. PMPA, Porto Ale gre ,18/4/2001

GT Rubem Berta/PMPA (1999), Relatorio Grupo de Trabalho Tecnico Rubem Berta. PMPA, Porto Alegre

Guareschi, P. (1980), Urban Social Movements in Brazilian Squatter Settlements. Tesi di Master. University of Wisconsin

Guimaraens, M.E. (1998), A Competência Municipal e o $2^{\circ}$ Pddua. In: AA.VV., A necessária releitura da cidade

Guimaraens, M.E. (2002), Instrumentos urbanisticos e fiscais de captação de mais valias urbanas. A experiência de Porto Alegre. IX Workshop IRGLUS Direito e Espaço urbano, 17-19/7, Porto Alegre

Guimarães, V. (1992a), Para à avaliação de impacto a ser conduzida na Vila Planetario. SPM, Porto Alegre

Guimarães, V. (1992b), Notas sobre o parecer n. 464. Documento interno. SPM, Porto Alegre, 7/8/1992

Guimarães, V. (1998), Design urbano: uma modesta, mas valida, contribuição para a defesa contra a criminalidade nas grandes cidades. Manoscritto, Porto Alegre

HA - Habitat Agenda dell'ONU (1996). http://www.undp.org/un/habitat

Habermas, J. (1987a), Teoria de la acción comunicativa: racionalidad de la acción e racionalizacción social. Taurus, Madrid, t.1

Habermas, J. (1987b), A nova intrasparência: a crise do estado de Bemestar social e o esgotamento das energias utópicas. In: Novos Estudos, n. 18

Habermas, J. (1997), Droit et démocratie. Gallimard, Parigi

Hardoy, J.E, Satterthwaite, D.(1989), Squatter citizen: life in the urban third world. Earthscan Publications, Londra 
724 Harms, H. (1982), Historical perspectives on the practice and purpose of self-help housing. In: P. Ward (a cura di), Self-help housing: a critique. Mansell, Londra

Harvey, D. (1989), From managerialism to entrepreneurialism: the transformation in urban governance in late capitalism. In: Geografiska Annaler, 71B, pp. 3-17

Harvey, David (1982), O trabalho, o capital e o conflito de classes emtorno do ambiente construido nas sociedades capitalistas avançadas. In: Espaço e Debates, pp. 6-35

Heller, A. (1989), O cotidiano e a história. Paz e Terra, Rio de Janeiro

Herzberg, C (2002), Der Bürgerhaushalt Von Porto Alegre. Ed. Lit, Monaco/ Amburgo/Londra

Herzberg, C., Kasche, C. (2002), Il Bilancio Partecipativo: costruzione di un altro mondo?. In La Nuova Città, $\mathrm{n}^{\circ}$ 6/7, Fiesole

Hillier, B., Hanson, J. (1984), The social logic of space. Cambridge University Press, Londra

Hirschfeldt, R.V. (1986), Shopping center. O templo do consumo. Abrasce, Rio de Janeiro

Hirschmann, A.O. (1991), Deux siècles de rhétorique réactionnaire. Fayard, Parigi

Horne, C.H (1994), Porto Alegre: o Desafio da Mudança. Editora Ortiz, Porto Alegre

IAB/RS (1983), Manifestação do Instituto de Arquitetos do Brasil - Dep. Do Rio Grande do Sul, sobre a intervenção na área de mercado municipal. Porto Alegre

IBASE (1995), Democracia nas grandes cidades: a gestão democrática da Prefeitura de Porto Alegre. Rio de Janeiro

IBASE, Coordenação de Elaboração e Ação Politica, Democracia nas grandes cidades: a gestão democratica da Prefeitura de Porto Alegre. Rio de Janeiro

IBGE (2001), Censo Demográfico 2000: Resultados do universo (2001). Dias da Cruz Ed., Rio de Janeiro

IBGE divulga os dados finais do censo (1992). In: Zero Hora, 20/1/1992, Porto Alegre, p. 29

Illich, I. (1974), La convivialità. Mondadori, Milano

Illich, I. (1985), Lavoro-ombra. Mondadori, Milano

Isasa de Mello, M.G. (2002), Uma leitura da cidade: Prioridade e demandas do OP 1992/2001. In: PMPA, Relatorio de Indicadores Sociais de Porto Alegre - Ano IV-2001, Porto Alegre

Jaccoud, L. (1991), Lutas Sociais: populismo e democracia: 1960/64. In: A. Paviani (a cura di), Movimentos Populares em Brasília. Ed. Universidade de Brasilia, Brasilia

Jacobi, P. (1989), Movimentos Sociais e Políticas Públicas. Cortez, San Paolo Jacobi, P. (1990), Descentralizaçãao da gestãao municipal: a inovação em debates. In: Espaço e Debates vol. 10, n. 30

Jacobi, P. (1995), Alcances y lìmites de los gobiernos locales progressistas en Brasil. Las alcadías petistas. In: Revista Mexicana de Sociología, n. 2/ 1995

Jockymann, S.(1999), Orçamento Participativo. In:Jornal VS, 15-6-99 
Keck, M. (1992), Brazil's PT: Socialism as radical democracy. In: NACLA, Report on the Americas, n. 5

Keller, S. (1979), El vecindàrio urbano, una perspectiva sociològica. Siglo XXI Ed., Mexico

Kowarick, L. (1979), A espoliação urbana. Paz e Terra, Rio de Janeiro

Kowarick, L.(1987), Movimentos sociais urbanos: uma análise da literatura. In: Revista Brasileira de Ciências Sociais, San Paolo, vol.1, n.3, pp. $38-50$

Krafta, R. (1986), Desenho urbano e regulamentação urbanistica. In: B. Turkienicz, Malta, D. (a cura di), Desenho urbano: SEDUR, CNP/FINEP/ PINI, Anais do II SEDUR, San Paolo

Krafta, R. (1993), Os (maduros?) frutos da crise. In: W. Panizzi, J. Rovatti, (a cura di), Estudos Urbanos

Krafta, R. (1998), Estudos configuracionais urbanos, policentralidade e uso do solo. In: AA.VV., A necessária releitura da cidade

Laclau, E. (1986), Os novos movimentos sociais e a pluralidade do social. In: Revista Brasileira de Ciências Sociais, n. 2, vol. 1, pp. 41 - 47

Lagos, R. A.(1995), Formalizing the Informal Sector: Barriers and Costs. In: Development and Change, vol. 26, n. 1, Oxford

Latouche, S. (1993), Il pianeta dei naufraghi (1993). Bollati Boringhieri, Torino

Latouche, S. (1997), L'altra Africa. Tra dono e mercato. Bollati Boringhieri, Torino

Leaf, M. (1997), The many agendas of Habitat II. In: Cities, vol. 14, n. 1

Leeds, A., Leeds, E. (1978), A Sociologia do Brasil Urbano. Zahar, Rio de Janeiro

Leeds, E. (1998), Cocaína e poderes paralelos na periferia urbana brasileira: ameaças à democratização em nivel local. In: A. Zaluar, M. Alvito, (a cura di), Um seculo de Favela

Lefebvre, H. (1974). La production de l'espace. Anthropos, Parigi, 1981

Lefebvre, H. (1983), La revolución urbana. Alianza Ed., Madrid

Liedke Filho, E.D., Ferretti Brum, R. (1993), O primeiro Plano Diretor de Desenvolvimento Urbano de Porto Alegre. In: W. Panizzi, J. Rovatti, (a cura di), Estudos Urbanos

Lima Ferreira, H. (1973), História político-econômica e industrial do Brasil. Cia Editora Nacional, Rio de Janeiro

Lima, G. (1993a), Uma aventura Responsàvel. Sagra DC-Luzzatto Ed, Porto Alegre

Lima, G. (intervista a, 1993b), A comunidade diz onde investir. In: Zero Hora, $19 / 1 / 1994$

Lima, G.(intervista a, 1993c), Chegou a hora da instituzionalização. In: Zero Hora, 20/1/1993

Linden, J. van der (1986), The sites and services approach revisited: solution or stopgap to third world housing shortage. Gower, Aldershot

Linden, J. van der (1989), Successful Supply of Plots for the Poor: the case of Hyderabad. In: Urban Research, n. 22, Amsterdam

Linden, J. Van der (1994), Incremental servicing and housing : the potential of a solution to land supply for urban low-income groups. In: Third World Planning Review [special issue], vol. 16, n. 3, pp. 223-324 
726 Linn, J. (1983), Cities in a developing world,. Oxford University Press, New York/Oxford/Londra

Lojikine, J. (1981), O estado capitalista e a questão urbana. Martins Fontes, San Paolo

Lopez, L.R.(1983), História do Brasil contemporâneo.Porto Alegre, Mercado Aberto Ed.

Löwy, M. (1987), A new type of party: the Brazilian PT. Latin American Perspectives, n. 14

Lucco, E. (2002), L'esperienza del 'Bilancio Partecipativo' di Porto Alegre. Tesi di Laurea. Università degli Studi di Torino, Facoltà di Scienze Politiche, Torino

Macedo de Riopardense, F. (1968), Porto Alegre - Origem e Crescimento. Ed. Sulina, Porto Alegre

Macedo de Riopardense, F. (1982), Porto Alegre: aspectos culturais. SMEC, Divisão de Cultura

Macedo de Riopardense, F. (1993), História de Porto Alegre. Ed. da Universidade, Porto Alegre

Maciel Moreira, J. (1914), Rapporto della Commissione per i miglioramenti e gli abbellimenti della Capitale, all'Intendente municipale dr. José Montaury de Aguiar Leitão, Porto Alegre

Maciel Moreira, J. (1928), Melhoramentos de Porto Alegre. In: Revista Egatea

Magalhães, P. (1997), L'esperienza brasiliana nell'autocostruzione di abitazioni popolari: uno studio comparativo. In: G. G. Rizzo (a cura di), Ricchezza e marginalità nella città sub-tropicale

Magnaghi A. (1992), Il territorio non è un asino. In: Eupolis 8/9, San Gimignano, Siena

Magnaghi A (1998, a cura di), Il Territorio dell'abitare. Franco Angeli, Milano

Magnaghi A. (1998, a cura di), Il territorio degli abitanti. Società locali e autosostenibilità. Dunod-Masson, Milano

Magnaghi A (1999a), Come il "fare società" sia il solo antidoto alla guerra. In:Carta, giugno

Magnaghi, A. (1999b), Territorial Heritage: A Genetic Code for Sustainable Development, in AAVV, Possible Urban Worlds. Urban Strategies at the End of the 20th Century, Birkhäuser-Verlag, Basel

Magnaghi A (2000), Il Progetto locale. Bollati Boringhieri

Magnaghi A. (2001, a cura di), Rappresentare i luoghi. Metodi e tecniche, Alinea, Firenze

Mallmann S, Oliveira de Hauschild, C. B., Turkienicz, B. (1995), Recuperação urbanística de conjunto residencial. In: AVSI/UNCHS (1995), Os desafios da Cidade Informal (1995), Atti del Seminário Internacional, 11/ 15 settembre 1995, Belo Horizonte

Malusardi F. (1996), La sostenibilità degli insediamenti umani al 'City Summit' di Istanbul. Bollettino DPTU n. 12/13, Roma

Marasquin, M. (1991, a cura di), Vazios urbanos - Análise e proposta. SPM/ SDU, Porto Alegre

Marcussen, L. (1982), Settlement in Turkey. FSC Publ., Copenhagen

Marianno J., Amarante, A.P., Campello, A. (1941), O problema do Rio de Janeiro, contribuição do Rotary Club ao $1^{\circ}$ Congresso Brasileiro de Urbanismo. In: Urbanismo e Viação, n. 4 
Maricato, E. (1987), Política Habitacional no Regime Militar. Do milagre brasileiro à crise econômica. Vozes, Petrópolis

Maricato, E. (1996a), Habitação - um diagnostico da situação fundiária urbana brasileira. Relatório ao Habitat II do Governo Brasileiro

Maricato, E. (1996b), Metrópole na periferia do capitalismo. Editora HUCITEC, San Paolo

Maricato, E., Moraes, M.L. (1986), Longe das câmeras de Tv (o mutirão de Goiás). In: Arquitetura e Urbanismo, agosto

Marquetti, A.(2000), Participatory budgeting in Porto Alegre. In: Indicator S A, Johannesburg, vol.17, n.4, pp.71-78

Marquetti, A.(2001), Democracia, eqüidade e eficiência: o caso do orçamento participativo em Porto Alegre. Intervento al Seminario $O$ OP visto pelos seus pesquisadores. PMPA, Porto Alegre

Marshall, T.H. (1976), Cidadania, classe social e status. Zahar, Rio de Janeiro

Mascaró, J. L. (1998), Adensamento e Infra-Estrutura Urbana. In: AA.VV., A necessária releitura da cidade

Mascaro, L. (1983), Espaço e uso no habitat popular. Dottorato in Urbanistica. UFRGS/PROPAR/CNDU, Porto Alegre

Matus, C. (1989), Adeus, Senhor Presidente: planejamento, antiplanejamento e governo. Litteris, Recife

McNamara, R. (1982), The McNamara years at the World Bank: major policy addresses of Robert McNamara 1968-1981. Con prefazione di L. Senghor e H. Schmidt. World Bank ed., Baltimora / Londra

Medauar, O., Dias Menezes, F. (2002), Estatuto da cidade. Ed. Revista dos Tribunais, San Paolo

Medeiros, L. (1951), Vilas de Malocas. Saggio di Sociologia Urbana, Facoltà di Economia, Porto Alegre

Médici, A. C. , Marques, R.M. (1992), O processo orçamentário e a participação popular. Manoscritto

Medvedovski, N.S. (1993), Invasões dos conjunto habitacionais X programa PROÁREAS: duas faces de uma mesma moeda. In: W. Panizzi, J. Rovatti, (a cura di), Estudos Urbanos

Mello de Fagundes, J. (1918), Habitações coletivas: o cortiço. Egatea. In: Revista da Escola de Engenharia de Porto Alegre, settembre, Porto Alegre

Mellucci, A.(1994), Passaggio d'epoca. Feltrinelli, Milano

Menegassi, J. (1998), Habitação de interesse social no contexto do desenvolvimento urbano. In: AA.VV., A necessária releitura da cidade

Menegassi, J. (1999), Projeto Humaitá - A Politica Habitacional De Porto Alegre. SPM, Porto Alegre

Menegat, E.M. (1995), "Coragem de mudar": fios condutores da participação popular na gestão urbana em Porto Alegre. Tesi di «Mestrado». Universidade Federal do Rio de Janeiro/IPPUR, Rio de Janeiro

Menegat, E.M. (1998), Movimentos sociais e inovações na democratização da gestão urbana em Porto Alegre. In: Proposta, n. ${ }^{\circ}$ 78, pp. 48-54

Menegat, R. (1998, a cura di), Atlas ambiental de Porto Alegre. UFRGS/ PMA/INPE, Porto Alegre

METROPLAN (1988), Região metropolitana de Porto Alegre: informações e análises. FEE, Porto Alegre

METROPLAN/GTZ (1997), Plano de desenvolvimento local integrado - 
Comité de Desenvolvimento Vila Campo da Tuca. Documento conclusivo programma PRORENDA URBANO/RS, Porto Alegre

Mirabella, M. (2003), Il Bilancio Partecipativo, Tesi di Laurea, Facoltà di Economia, università di Cà Foscari, Venezia

Mohr, U. (1998), Cidade e patrimônio natura. In: AA.VV., A necessária releitura da cidade

Moll, J. (1998), Redes sociais e processos educativos: um estudo dos nexos da educação de adultos com o movimento comunitário e as práticas escolares no Morro Alto (Porto Alegre). Tesi di Dottorato. UFRGS/FACED, Porto Alegre

Monteiro, C. (1995), Porto Alegre: Urbanização e modernidade. A Construção social do espaço urbano. EDIPUCRS, Porto Alegre

Moraes, J.C. (1990), Movimento Comunitário, UAMPA e Articulações Regionais, Porto Alegre. Manoscritto

Moriconi-Ebrard, F. (1996), Megalopoli, un incubo sproporzionato. Errori di previsione e angosce ingiustificate. In Le monde diplomatique, luglio

Moura da Silva, P. L. (1993), Um movimento em busca de poder. Tesi di «Mestrado». UFF

Moura de Sobreira, A. (1993), Organizaciones no-gubernamentales y acceso al suelo en la Región Metropolitana de Recife, Brasil. In: A. Azuela (a cura di), La urbanización popular y el orden jurídico en América Latina. Universidad Nacional Autonoma de Mexico, Mexico

Moura de Sobreira, A. (1995), Espacio urbano, derecho y conflitos colectivos en Brasil. In: Revista Mexicana de Sociologia, n. 1/95, Città del Messico

Moura de Souza, M.S. (1989), Limites à participação popular na gestão da cidade: o projeto dos conselhos populare em Porto Alegre. Tesi di «Mestrado». PROPUR/UFRGS, Porto Alegre

Mumford, L. (1950), Mumford on Geddes. In Architectural Review, 108, p. 83

Müzell Jardim, V. (1998), Um Avanço Coletivo na Relação do Planejamento com a Cidade. In: AA.VV., A necessária releitura da cidade

Müzell, V. Jardim (1995), Planejamento Participativo è meta da reformulação do Plano Diretor. In: PDDU - Informativo da reformulação do Plano Diretor, n. 2, Porto Alegre

Nachmann, R.G. (1977), Positivism and the middle class in Brazil. In: Hispanic American Historical Review, n.57, pp.1-23

Niented, P., Van der Linden, J. (1985), Situation and processes of informal housing in Karachi. Habitat Intl

Nucleo dos Economistas do PT/RS (1992), Para uma administração popular das finanças publicas municipais. In: C.H. Horne (a cura di), Porto Alegre: o desafio da mudança

Nuñez, T., Fedozzi, L. (1993), Quem é quem no orçamento participativo. Interpretação de dados quantitativos da população que participa do $O P$ em Porto Alegre. Manoscritto

Nygaard, P. D. (1993), O planejamento urbano: uma discussão alternativa. In: W. Panizzi, J. Rovatti, (a cura di), Estudos Urbanos

O Plano Diretor Precisa Mudar. In: Zero Hora, 20/10/86

O.P.-Assembleia Municipal (2002), Receitas e despesas. PMPA, Porto Alegre Oliveira de Silveira, C. (1984), Porto Alegre. A cidade e a sua formação. Norma, Porto Alegre 
Oliveira Moraes, A. De (2002), Duas ou três coisas a respeito da Regularização Fundiária, manoscritto, Demhab, Porto Alegre

Oliveira, N. (1989), Vazios urbanos em Porto Alegre: uso capitalista do solo $e$ implicações sociais. FEE, Porto Alegre

Oliveira, N. Barcellos, T. (1990), O Rio Grande do Sul urbano. FEE, Porto Alegre

Oliveira, N., Barcellos, T. (1987), O uso capitalista do solo urbano: notas para a discussão. In: Ensaios, FEE, Porto Alegre, vol. 8, n. 2

Oliveira, N., Barcellos, T. (1993), O conselho municipal do Plano Diretor de Desenvolvimento Urbano de Porto Alegre: a participação popular no contexto da reforma urbana. In: W. Panizzi, J. Rovatti, (a cura di), Estudos Urbanos

Oliven, R.G. (1993), Recriando a tradição na cidade: Porto Alegre e o tradicionalismo gaúcho. In: W. Panizzi, J. Rovatti, (a cura di), Estudos Urbanos

O.N.U., Technical Advisory Committee (1996), Best Practices and Local Leadership Programme, CD ROM

Osmont, A.(1995), La Banque mondiale et les villes. Karthala, Parigi

Osmont, Annik (2002), La città efficiente. In: M. Balbo (a cura di), La città inclusiva. Argomenti per la città dei PVS. Franco Angeli, Milano

Outtes, J. (1997), Regolare la società attraverso la città: la genesi dell'Urbanistica in Brasile e Argentina (1905-1945). In: Storia Urbana, n. 78

Paba, G. (1996), Progettare insieme. Partecipazione e comunità nella città d'oggi. In: I confini della città, Periodico trimestrale della Fondazione Michelucci, anno IV, N.8

Paba, G. (1998), I cantieri sociali per la ricostruzione della città. In A. Magnaghi (a cura di), Il territorio degli abitanti. Dunod, Milano

Paba, G. (2002, a cura di), Insurgent city. Racconti e geografie di un'altra Firenze. Mediaprint, Livorno

Pacheco De Aguiar, R. (2001), O cidadão está nas ruas. Represntações e práticas acerca da cidadania republicana em Porto Alegre (1889-1991). Editora da Universidade/IFCH, Porto Alegre

Paiva E. (1943), Expediente urbano de Porto Alegre. Imprensa Oficial, Porto Alegre

Paiva Pereira, E. (1947), Algumas sugestões para o estudo do Plano Diretor de Porto Alegre. In: Boletim Municipal, Porto Alegre, n. 27, p. 5

Paloscia R. (1990), Riqualificazione delle Aree Metropolitane. Franco Angeli, Milano

Paloscia, R. (1989), Esperienze di Planning in Gran Bretagna: alcuni ambiti di ricerca. Bollettino IPTU, 1989/90, Firenze

Paloscia, R., Anceschi, D.(1996, a cura di), Territorio, ambiente e progetto nei Paesi in Via di Sviluppo. Franco Angeli, Milano

Panizzi, W, Rovatti, J. (1993, a cura di), Estudos Urbanos. PMPA, Ed. da Universidade, Porto Alegre

Panizzi, W. M. (1981), Organização da população favelada em Porto Alegre: uma experiência do Propur VIII em Atelier. UFRGS, Facoltà di Architettura, Porto Alegre

Panizzi, W. M. (1984), L'Accés au sol e au logement dans un espace segregé: l'aire metropolitaine de Porto Alegre. Tesi di dottorato. Université de Pa- 
ris XII, Institut d'Urbanisme, Parigi

Panizzi, W. M. (1989), Entre cidade e estado, a propriedade e seus direitos. In: Espaço e Debates, vol. 10, n. 26

Panizzi, W. M. (1989), L’illégalité des pratiques sociales d'accés au sol et au logement dans un contexte de crise. Revue Tiers-Monde, Parigi, 30

Panizzi, W. M. (1990), Da legalidade para a ilegalidade: a formação de microterritórios urbanos. In: N. Oliveira, T. Barcellos, O Rio Grande do Sul urbano. FEE, Porto Alegre

Panizzi, W. M. (1993), Áreas de invasão: lugar de moradia provisoria? In: W. Panizzi, J. Rovatti, (a cura di), Estudos Urbanos

Pasquino, G. (1997), La democrazia esigente. Il Mulino, Bologna

Pavlick, I.(1998), $2^{\circ}$ Pddu e a Proteção do Patrimônio Natural. In: AA.VV., A necessária releitura da cidade

Payer, C. (1982), The World Bank. A critical analysis. Monthly review Press, New York

Payne, G. K. (1984), Low-income Housing in the Developing World. The role of Sites and Services and Settlement Upgrading. John Wiley and Sons

PDT (1985), Plano de governo: eleições-85. Porto Ale gre

Pearlman, J. (1977), O mito da marginalidade. Favelas e politica no Rio de Janeiro. Paz e Terra, Rio de Janeiro

Peattie, L. (1982), Some second thoughts one sites and services. In: Habitat International, vol. 6

Pereira Lira, R. (1991), Campo e Cidade no Ordenamento Jurídico Brasileiro. Grafica Riex, Rio De Janeiro

Pereira, L. H. (1980), Habitaçãao Popular no Rio Grande Do Sul 18901980. Tesi di Dottorato. UFRGS, Porto Alegre

Pesavento, S. (1977), Un caso regional de autoritarismo: A República Velha Gaúcha. In: Revista do IFCH/UFRGS, n. 5, Porto Alegre

Pesavento, S. (1988), Burguesia Gaúcha. Dominação de capital e disciplina de trabalho. RS: 1889-1930. Mercado Aberto, Porto Alegre

Pesavento, S. (1990), O cotidiano da república. Ed. da Universidade, Porto Alegre, p. 17

Pesavento, S. (1991), Memória Porto Alegre: espaços e vivência. Ed. da Universidade, Porto Ale gre

Pesavento, S. (1997), Entre práticas e representações: a cidade do possível e a cidade do desejo. Manoscritto

Pesci, R. (1998), Cidade sustentável: enfoque global do $2^{\circ}$ PDDUA. In: AA.VV., A necessária releitura da cidade

Pessin, L., Paulon Mainieri, S. (1994), Relações de trabalho e a politica de recursos humanos: desconstruindo a logica da centralização. In: C.H. Horne (a cura di), Porto Alegre: o desafio da mudança

Petrella, R. (2000), intervento al X Meeting dell'INURA, Bruxelles 24-28 maggio

Pilla, C. D. (1998), Uma proposta de simplificação, flexibilização, negociação e participação popular. In: AA.VV., A necessária releitura da cidade

Pini, D. (1982), Vernon Gracie’s Abaji, Nigeria. In: Spazio e Società, vol. 5, n. 20

Pires, V. (2000), Límites y potencialidades del presupuesto participativo. In: Revista Internacional de Presupuesto Público, anno XXVII, no. 42, pp. 
$81-122$

Plamper, H. (2000), Hameenlinna. La citta' finlandese esempio di eccellenza per il management locale. In Azienda Pubblica $\mathrm{n}^{\circ} 6.2000$, pp 737 e segg.

Plamper, H. (2002), Participatory Budgets in Germany, intervento distribuito al $2^{\circ}$ Incontro Internazionale di scambio sul Bilancio Partecipativo, organizzato da DRD e Comune di Bobigny, 26 gennaio 2002, Bobigny.

PMPA (1994), Diretrizes para Porto Alegre. Porto Alegre

PMPA (1980), Plano Diretor de desenvolvimento urbano. Porto Alegre planejar para viver melhor. Porto Alegre

PMPA (1982), Sub-habitação: um estudo preliminar. PMPA, Porto Alegre

PMPA (1997), A experiência do 'Orçamento Participativo em Porto Alegre (1989-1996). In: Democracia e Participação Popular na Esféra Pùblica, marzo, Porto Alegre

PMPA (1990/2002), Plano de investimentos e serviços 1990/2002. PMPA, Porto Alegre

PMPA (1997), Realidade e política habitacional, DEMHAB, Porto Alegre

PMPA (1998), Mapa da irregularidade fundiária de Porto Alegre. DEMHAB, Porto Alegre

PMPA (2001a), Anuário Estatístico 2000. GAPLAN, Porto Alegre

PMPA (2001b), Relatório de indicadores sociais de Porto Alegre. Porto Alegre, n. 4

Pochmann M., Amorim R. (2003), Atlas da exclusão social no Brasil, Cortez Editora, San Paolo

Pont, R. (1985), Da crítica ao populismo à construção do PT. Seriemma, Porto Alegre

Pont, R. (1999), Orçamento è participativo. In: Zero Hora, 11/3/1999

Pontual, P. (2000), O Processo Educativo no Orçamento Participativo: aprendizados dos atores da sociedade civil e do Estado. Tesi di Dottorato. PUC/SP, San Paolo

Porto Alegre (1997), Política Habitacional. $1^{\circ}$ Conferencia municipal de conclusões e recomendações, DEMHAB, PMPA, Porto Alegre, 24/26 ottobre

Porto Alegre Agora (Annate 1989-2001)

Porto Alegre pobre: un terço da população mora em casebres (1990). In: Zero Hora, 13/3/1990, Porto Alegre

Porto Alegre socioeconômica (1998). PMPA, Porto Alegre, Ottobre

Poulantzas, N.(1978), O Estado, o poder, o socialismo. Graal, Rio de Janeiro, 1985

Pozzobon, R. (1995), A cidadania com igualdade plena: um caminho em construção na cidade de Porto Alegre. In: De Olho no Orçamento, vol. 2, n. 3

Pozzobon, R. (1998), Os desafios da gestão municipal democràtica. Porto Alegre. Centro Josué de Castro, Pòlis, San Paolo-Recife

Pradilla E. (1979), Bourgeois ideology and the housing problem: a critique of two ideological theories. In: Ideologia e Sociedad, n. 19

Prefeitura Municipal de São Paulo (1989), Censo das Favelas do Municipio de São Paulo - Caracterização Fisico Espacial. San Paolo

Prefeitura Municipal de São Paulo (1992), Atualização do Censo de Favelas de 1987. San Paolo 
Prefeitura Municipal de São Paulo, Secretaria da Habitação e Desenvolvimento urbano, Superintendencia de Habitação popular (1995), Cortiços na cidade de São Paulo. In: Diario Oficial, 31/5/1995. San Paolo

PT/RS/Grupo de Politica Municipal (1987), Gestão Democratica e Popular. Porto Alegre, novembre

Putnam, R. (1993), Making Democracy Work: Civic Traditions in Modern Italy. Princeton University Press, Princeton

Raffestin, C. (1984),Territorializzazione, Deterritorializzazione, Riterritorializzazione. In: A.Turco (1984), Regione e Regionalizzazione. Franco Angeli, Milano

Representantes das Microrregiões de Porto Alegre (1989), Sobre o processo de discussão do orçamento municipal. Porto Alegre, dicembre

Revelli, M. (2001a), conversazione con Gigi Sullo, Genova è la fine della mediazione politica. Ma il rimedio non va cercato nel passato. In: Carta - Almanacco 'Il primo anno del secolo', 2/8 agosto, Roma, pp. 18-23

Revelli, M. (2001b), Oltre il '900, Einaudi, Torino

Ribeiro de Queiroz, L.C. (1997), Questão urbana, desigualdades sociais e políticas públicas. Relatório de Projeto, UFRJ/IPPUR, Rio De Janeiro

Ribeiro de Queiroz, L.C. (1997), Projeto plano de avaliação do programa favela-bairro. Avaliação das diferenças sociais e urbanas, Relazione Finale, Accordo FINEP/SMH-FUBJ-IPPUR/UFRJ, Instituto de Pesquisa e Planejamento Urbano e Regional, Rio de Janeiro

Ribeiro Torres, A.C. (1991), Movimentos sociais: caminhos para a defesa de uma temática ou os desafios dos anos 90. In: Revista Ciências Sociais Hoje, San Paolo, Véertice, pp. 95-121

Ribeiro Torres, A. C. (1997), Povertà e modemizzazione nelle metropoli brasiliane: un'interpretazione critica. G. G. Rizzo (a cura di), Ricchezza e marginalità nella città sub-tropicale

Ribeiro, R. (1995), Elaboração, monitoria e avaliação de projetos de desenvolvimento. EMBRAPA, Brasília

Rigatti, D. (1991), Morfologia urbana, memoria coletiva e formas de socialidade em Porto Alegre: o centro da cidade. UFRGS/CNP, Porto Alegre

Rigatti, D. (1993), Espaço da cidade e estruturação social. In: W. Panizzi, J. Rovatti, (a cura di), Estudos Urbanos

Rigatti, D. (1995), Apropriação do espaço publico: um estudo comparativo. In: Paesagem Ambiente Ensaios, San Paolo, n. 7

Rigatti, D. (1997), Do espaço projetado ao espaço vivido: modelos de morfologia urbana no Conjunto Rubem Berta. Tesi di Dottorato. FAU/ USP, San Paolo

Riopardense de Macedo, F. (1998), História de Porto Alegre. Editora da Universidade, UFRGS, Porto Alegre

Rizzo, G. G. (1997), Il Brasile recente. Uno studio gerarchico-aggregativo alla grande scala. In: G. G.Rizzo (a cura di), Ricchezza e marginalità nella città sub-tropicale

Rizzo, G. G. (1997, a cura di), Ricchezza e marginalità nella città sub-tropicale. Gangemi, Roma

Roche, J. (1966), Porto Alegre, metrópole do Brasil meridional. In: J. Roche, A. Ab'Saber, Três estudos rio-grandenses. UFRGS, Porto Alegre

Roche, J. (1969), A colomização alemã e o Rio Grande do Sul. Globo, Porto 
Alegre

Rodriguez, A.P., Osório, L.M. (1996), A regularização fundiária em Porto Alegre. In: Cademos da Cidade, Porto Alegre n. 5, vol. 3

Rolnik R., Bonduki, N. (1978), Periferias. In: Cadernos PRODEUR, n. 2, FUPAM, FAUUSP, San Paolo

Rolnik, R. (1988), O que é cidade. Brasiliense, San Paolo

Rolnik R.(1990), Morar, Atuar e Viver. In: Teoria e Debate, n. 9

Rolnik, R. (1994), Planejamento urbano nos anos 90: novas perspectivas para velhos temas. In: Caderno do PPU-FASE, Porto Alegre, pp.10-20

Ronza, R. (1976), Alcune osservazioni per aprire il dibattito sulle tesi di John F. C. Turner. Note a L'abitare autogestito, Jaca Book, Milano, 1978

Rovatti, J. F. (1991), Produção capitalista de moradias em Porto Alegre (anos 80). Dep. de Urbanismo, UFRGS, Porto Alegre

Rubem Berta Informativo (1995). PMPA, Porto Alegre, Novembre

Rudé, G. (1991), A multidão na história: estudo dos movimentos populares na França e Inglaterra 1730-1848. Campus, Rio de Janeiro

Sachs, I. (1993), Un modello di sviluppo alternativo per il Brasile. EMI, Bologna

Sachs, W. (1992, a cura di), The Development Dictionary. Zed Books, Londra

Sachs,W. (1992), Archeologia dello sviluppo. Macroedizioni, S. Martino di Sarsina

Sader, E. (2002), Para outras democracias. In: P.E. Peterson (1981), City limits. University of Chicago Press, Chicago

Sader, E. (2002), Para outras democracias. In: Sousa Santos, B. de (a cura di), Democratizar a democracia. Os caminhos da democracia participativa

Saint-Hilaire de, A. (1974), Viagem ao Rio Grande do Sul 1820-1821. Edição Itatiaia, San Paolo

Salengue, L.M., Marques M. (1993), Reavaliação de planos diretores: o caso de Porto Alegre. In: W. Panizzi, J. Rovatti, (a cura di), Estudos Urbanos

Sandercock, L. (1999), Translations: From Insurgent Planning Practices to Radical Planning Discourses. In: Plurimondi, n. 2, 1999, pp. 37-46

Sant'Ana, M.H. (1994), Uma avaliação das políticas recentes de Desenvolvimento Regional no Brasil: programa de Desenvolvimento da Região Noroeste. In: Revista Econômica do Nordeste, Fortaleza, vol. 25, n. 4, pp. 499-528

Sant'Ana, M. H. (1997), Vila Cai-Cai: a lógica da habitação reciclàve. Dissertazione post-laurea.UFRGS, Porto Alegre

Santos de Souza, B.(1998), Participatory budgeting in Porto Alegre: towards a redistributive justice. In: Politics and Society, vol. 26, n. 4

Santos dos Nelsson, C. (1980), Como projetar de baixo para cima: uma esperiencia em favela. In: Revista de Aministração Municipal, luglio/settembre

Santos Jr, O. A. (1995), Reforma Urbana. Por um novo modelo de planejamento e gestão das cidades. FASE/UFRJ-IPPUR, Rio de Janeiro

Santos, M. (1973), O espaço dividido. San Paolo

Santos, M. (1978), Pobreza urbana. Hucitec, San Paolo

Santos, M. (1979), Espaço e Sociedade. Vozes, Petrópolis

Santos, M. (1986), Tradição, modernidade e cultura na cidade grande. In: 
Santos, M. (1990), Metrópole corporativa fragmentada: o caso de São Paulo. Nobel, Secretaria de Estado da Cultura, San Paolo

Santos, M. (2001), Quem està na frente é o povo. Intervista di Tibùrcio e Caccia Bava. In: Um outro mundo urbano è possivel (gennaio 2001). Edizione speciale di Cadernos Le Monde Diplomatique, Istituto Pòlis, San Paolo, pp. 4-7

Sartori, G. (1977), Liberalismo e democrazia. In: Il cittadino totale: Partecipazione, eguaglianza e libertà' nelle democrazie d'oggi. Centro di ricerca e documentazione Luigi Einaudi, Torino

Sartori, G. (1987), The Theory of democracy revisited. Chatham House, Chatham

Sartori, G. (1993), Democrazia: cosa è. Rizzoli, Milano

Sassen, S. (1997), Le città globali. Il Mulino, Bologna

Saule Jr, N. (1997), Novas perspectivas do direito urbanístico brasileiro. Ordenamento constitucional da política urbana. Aplicação e eficácia do Plano Diretor. Fabris editor, Porto Alegre

Schäffer, N.O. (1993), Do armazém da esquina ao shopping center: a trasformação de consumo em Porto Alegre. In: W. Panizzi, J. Rovatti, (a cura di), Estudos Urbanos

Scherer-Warren, I. (1993), Redes de movimentos sociais. Loyola, San Paolo

Schmidt, D. (1993), A “desidiotização" da cidadania. A formação do cidadão para a coisa pública, atravês de sua participação no processo do orçamento participativo de Porto Alegre, entre 1989 e 1992. Tesi di «Mestrado». UFRGS

Schmidt, D. (2000), A “desidiotização” da cidadania. A dimensão pedagógica do Orçamento Participativo. Intervento al Seminario O OP visto pelos seus pesquisadores. PMPA, Porto Alegre

Schumpeter, J. A.(1984), Capitalismo, socialismo e democrazia. ETAS, Milano

Sclavi, M. (2000), Arte di ascoltare e mondi possibili. Come si esce dalle cornici di cui siamo parte. Le vespe, Milano

Sclavi, M. (2002), Avventure urbane. Fare urbanistica partecipata. Eleuthera, Milano

SEADE (2002), Indice de vulnerabilidade juvenil, SEADE, San Paolo

Sen, A. (2001), Lo sviluppo é libertà. Perché non c'é crescita senza democrazia. Mondadori, Milano.

Sharma, S. K. (1990), An alternative to squatter settlements. In: Open House International, n. 4, vol. 15

Sherer-Warren, I. (1984), Movimentos sociais: um ensaio de interpretação sociológica. UFSC, Florianópolis

Sherer-Warren, I., Krischke, J. P. (1987, a cura di), Uma revolução no cotidiano: os novos movimentos sociais na América Latina. Brasiliense, San Paolo

Siddiqui, T. A., Azhar K. M. (1987), Shelter for the urban Poor. Hyderabad Dev. Authority - UNCHS

Silva da Alfonso, J. (1995) , Direito Urbanistico. $2^{\circ}$ Edição, Malheiros, San Paolo

Silva da Loureiro, J., Paiva, E. P. (1943), Um plano de urbanização. PMPA, Porto Alegre 
Silva da, C. A.(1998, a cura di), Democracia, participação e orçamento. IBAM, ENSUR, Río de Janeiro

Silva da, D. N. (1997), A ação comunicativa no processo do Orçamento Participativo em Porto Alegre: Região Centro. Tesi di «Mestrado». PUCRS, Porto Alegre

Silva Rodrigues, V. (1985), A escola è nossa: uma experiência em vila popular. In: Cademos De Olho na Cidade. n. 5, Porto Alegre

Silva, E. (1993), Porto Alegre: considerações sobre a produçãao da paisagem urbana. In: W. Panizzi, J. Rovatti, (a cura di), Estudos Urbanos

Singer, P. (1977), Desenvolvimento economico e evolução urbana. Cia Editora Nacional, San Paolo

Singer, P. (1989), Planejamento: estrategia de mudança. In: Teoria e Debate, n. 7, PT, jul/set, San Paolo

Sintomer, Y. (1999), La démocratie impossible? Politique et modernité chez Weber et Habermas. La Découv erte, Parigi

SMIC (1999), Plano de Desenvolvimento economico. Crescimento em todos os sentidos. PMPA, Porto Alegre

Smouts, M.-C., (1998), Du bon usage de la gouvernance en relations internationales. In: Revue internationale des sciences sociales, UNESCO, n. 155, marzo 1998

SMOV (1985), Ediçao Comemorativa dos 30 anos da SMOV. Secretaria Municipal de Obras e Viação, Porto Alegre

Sofia J. (2002), FHC prepara programa de casas populares. In: Folha de S.Paulo, 15 luglio 2002, p. A6

Sofia J. (2002), País apresenta déficit urbano de 5,4 milhões de moradias. In: Folha de S.Paulo, 15 luglio 2002, pag. A6

Solidariedade (2003), Porto Alegre, Les voix de la démocratie. Le budget participatif raconté au quotidien Éditions Syllepse/ Démocratiser Radicalement la Démocratie, Parigi

Soto, H. de (1989), The other path: the invisible revolution in the third world. I.B.Tauris \& Co, Londra

Sousa Santos, B. de (1999), Reinventar a democracia; entre o précontratualismo e o pós-contratualismo. In: F. de Oliveira, M.C. Paoli, (a cura di), Os sentidos da democracia. Políticas do dissenso e hegemonia global. Vozes, Petrópolis

Sousa Santos, B. de (2000), A critica da razão indolente: contra o desperdício de experiência. Cortez, San Paolo

Sousa Santos, B. de (2002a), Orçamento Participativo em Porto Alegre: para uma democracia redistributiva. In: Sousa Santos, B. de (a cura di), Democratizar a democracia. Os caminhos da democracia participativa

Sousa Santos, B. de, (2002b, a cura di), Democratizar a democracia. Os caminhos da democracia participativa, Civilização Brasileira, Rio de Janeiro

Souza de Ferraz, C. (1994a), costruindo o espaço de representação, ou urbanismo de representação. Intervento al convegno Imagens da Cidade, Porto Alegre

Souza de Ferraz, C. (1994b), Um resgate da cidade jardim: a Vila do Iapi. UFRGS/FAU, Porto Alegre, 3 Seminario di Storia della città e dell'Urbanistica a São Carlos, San Paolo 
Souza de Ferraz, C. (1997), Fra la città del desiderio e la città del possibile: il Plano Geral des Melhoramentos di Porto Alegre nel 1914. In: Storia Urbana, n. 78

Souza de Ferraz, C., Damásio, C. P.(1991), Urbanismo e modernidade em Porto Alegre: a administração Otávio Rocha. Dep. de Urbanismo/UFRGS, Porto Alegre

Souza de Ferraz, C., Müller, D. M. (1997), Porto Alegre e sua evolução urbana. Editora da Universidade, Porto Alegre

Souza de Ferreira, J.V.(1991), Solo criado: um caminho para minorar os problemas urbanos. In: Temas de Direito Urbanistico 2, Ed. Revista dos Tribunais, San Paolo

Souza de Lopes, M. (1997), Algumas notas sobre a importância do espaço para o desenvolvimento social. Território, n. 3, 1997, pp.13-35

Souza de Lopes, M. (2000) Os orçamentos participativos e a sua espacialidade: uma agenda de pesquisa. Terra Livre, n. 15, pp. 39-58

Souza de Lopes, M. (2002), Territoriality and participatory budgeting: adeguate districting? In: Atti del $9^{\circ}$ Worksop IRGLUS, Law and Urban Space, Porto Alegre, 17-19 luglio 2002

Spalding, W. (1967), Pequena História de Porto Alegre. Sulina, Porto Alegre SPM (1993), Projeto Centro de Bairro. PMPA ed SPM, luglio, Porto Alegre SPM (2000), Porto Alegre - Plano Diretor de Desenvolvimento Urbano Ambiental - lei complementar 434/9. PMPA, Porto Alegre

SPM/PRF (1992), Sobre o projeto fisico-urbanistico da Vila Planetario. Documento interno. Porto Alegre

Sposati, A. (2001), Mapa da exclusão/inclusão social da cidade de São Paulo, PUC-SP/PÓLIS, San Paolo

Stiglitz, J. (2000), Vers un nouveau paradigme pour le développement, in L'economie politique, n. 5, Parigi

Stren, R. (1993), «Urban Management” in development assistance. An elusive concept. In Cities, maggio 1993, pp. 125-138

Sullo P. (2002, a cura di), La democrazia possibile. Il Cantiere del Nuovo Municipio e le nuove forme di partecipazione da Porto Alegre al Vecchio Continente, Cantieri Carta/Edizioni Intra Moenia, Roma-Napoli

Tarozzi, A. (1990), Visioni di uno sviluppo diverso. Gruppo Abele, Torino

Taschner Pasternak, S.(1986), Squatter Settlements: the facts and the policies. In: Espaço e Debates, n. 18

Taschner Pasternak, S.(1997), Favelas e cortiços no Brasil: 20 Anos de Pesquisas e Politicas. In: Cadernos de Pesquisa do LAP, Serie Urbanização e Urbanismo, marzo/aprile, FAU/USP, San Paolo

Tavares, J G. (2000, a cura di), Totalitarismo Tardio: o caso do PT.Mercado Aberto, Porto Alegre

Teixeira, E. C. (1994), O orçamento público como instrumento político. In: Cadernos do CEAS, Salvador, n. 149, pp. 16-30

Teixera E. C. (1996), Orçamento Municipal: A participação da sociedade civil na sua elaboração e execução. Subsídio INESC, maggio, pp.1-20

Telles, V.S. (1987), Movimentos sociais: reflexoes sobre a experiencia dos anos 70. In: I. Sherer-Warren, P. J. Krischke, (a cura di), Uma Revolucao no Cotidiano: Os novos movimentos sociais na America Latina. Brasiliense, San Paolo 
Tipple Graham A., Willis, K.G. (1991), Housing the poor in the developing world : methods of analysis, case studies and policy. Routledge, Londra

Tocqueville, A. de (1992), La democrazia in America. Rizzoli, Milano (ed. originale 1835)

Tomas, F. (1995), La irregularidad en el desarrollo urbano de América Latina. In: Revista Mexicana de Sociologia, n. 1, Città del Messico

Torres Ribeiro A.C., de Grazia G. (2003), Experiências de Orçamento Participativo no Brasil. Periodo de 1997 a 2000, Forum Nacional de Participação Popular/Editora Vozes, rPetrópolis

Touraine A. (1997), Eguaglianza e diversità. I nuovi compiti della democrazia. Laterza, Roma-Bari

Turkienicz, B. (1993), Grades e recuos do Plano Diretor de Porto Alegre. In: W. Panizzi, J. Rovatti, (a cura di), Estudos Urbanos

Turner, J. F. (1965), Lima's barriadas and corralones: suburb versus slums. In: Ekistics, vol. 19

Turner, J. F. (1976), Housing by People. Towards authonomy in building Environments. Marion Boyars, Londra. Trad. It.: Turner, J. F. (1978), L'abitare autogestito, Jaca Book, Milano

Turner, J. F. (1986), Future decisions in housing policies. In: Habitat International, vol. 10, n. 3

Turner, J. F.C. (1972), The reeducation of a professional. Housing as a verb. In: AA.VV., Freedom to build. McMillan, New York

Turner, J. F.C. (1982), Who should do what about housing. In: Gilbert-HardoyRamirez (1982), Urbanization in Contemporary Latin America. John Wiley, Chichester

U.N.C.H.S - Habitat (1991), The incremental development scheme. A case study of Khuda-Ki-Basti in Hyderabad, Pakistan. U.N.C.H.S., Nairobi

U.N.C.H.S (1984), Promoting organized self-help through cooperatives modes of participation. Nairobi

U.N.C.H.S (2000), The Global Campaign for Good Urban Governance. U.N.C.H.S, Nairobi

U.N.C.H.S (2001), Cities in a Globalizing World. Global Report on Human Settlements 2001. Earthscan, Londra

U.N.C.H.S. (1977), Land of human Settlements. New York

UAMPA (1986), Relatório do II Congesso da UAMPA, 4-6 ottobre 1986. Porto Alegre

UAMPA (1990), III Congresso da UAMPA - Proposta de texto base. Porto Alegre

UAMPA (1990), Relatório dos Grupos - IV Congresso da UAMPA. Porto Alegre

U.N.D.P. (2002), Rapporto 2002 sullo sviluppo umano. Rosenberg \& Sellier, Torino

UPE/DEMHAB (1999c), Programma PRO-MORADIA, Projeto de participação comunitaria regularização fundiaria condominio residencial Vila Renascença I. DEMHAB, Porto Alegre

Utzig, J. E. (1996), Notas sobre o governo do PT em Porto Alegre. In: Novos Estudos, n. 45

Utzig, J. E., Guimaraens, R. Democracia e participação popular na esfera pública: a experiência de Porto Alegre. In: N. Bonduki (1996, a cura di), 
Habitat - As práticas bem-sucedidas em habitação, meio ambiente e gestão urbana nas cidades brasileiras. Studio Nobel, San Paolo, pp. 51-57 Utzig, J.E. (1996), Nota sobre el gobiemo del Presupuesto Participativo de Porto Alegre. In: Novos Estudos, n. 45, pp. 209-222

Valladares do Prado, L. (1978), Passa-se uma casa. Analise do programa de remoção de favelas do Rio de Janeiro. Zahar Editores, Rio de Janeiro

Van Lindert, P. (1979), Intra-urbane mobiliteit en het ontstaan van spontane volksbuurten in steden van Latijns Amerika. Institute of Geography, State University, Utrecht

Vandelli, L. (2000), Il governo locale. Il Mulino, Bologna

Verle, J., Brunet, L. (2002, a cura di), Costruyendo un nuevo mundo.Guayi, Porto Alegre

Vila Planetário- Legalização (1991). Rubrica A pedido, p. 26. In: Zero Hora, Porto Alegre, 8 /8/1991

Villas-Bôas, R. (1999, a cura di), Balanço das experiências de orçamento participativo nos governos locais. Pólis, San Paolo

Vittrup, E. (1982), Illegal land occupations in Colombia. FSC Publishing, Copenhagen

Viveret, P.(2001), Por uma soberania ascendente. In: AA.VV. Um outro mundo urbano è possivel (gennaio 2001), edizione speciale Cadernos Le Monde Diplomatique, Istituto Pòlis, San Paolo, pp. 8-9

Wacquant L. (2000), Parola d'ordine: tolleranza zero. La trasformazione dello stato penale nella società neoliberal. Feltrinelli, Milano

Wakely, P. (1996), Viewpoint. Building on the success of Habitat II. In: Third World Planning Review, vol.18

Wefort, F. (1986, a cura di), O modo petista de governar. Brasiliense, San Paolo

World Bank (1983), Learning by doing 1970-1982. World Bank Publ, Washington D. C.

World Bank (1988), Targeted programs for the poor during structural adjustment: a summary of a symposium on poverty and adjustment April 1988. World Bank Publ., Washington D. C.

World Bank (2000), Cities in transition. World Bank urban and local government strategy. World Bank Publ., Washington D. C.

World Bank (2001), World Development Report 2000/2001. Attacking poverty. World Bank Publ., Washington D. C.

World Bank (2003), World Development Report 2003. Sustainable development in a dynamic world, Washington D.C.

Yap, K. S. (1982), Leases, land and local leaders. Free University, Amsterdam

Yin, R. K, (1993), Application of case study research. Sage Pubblications, Beverly Hills

You, N. (1997), Le best practices. In: Urbanistica, n.107

Zagrebelsky G. (1995), Il “Crucifige!” e la democrazia. Einaudi, Torino

Zaluar, A. (1985), A màquina e a revolta: as organizações populares e o significado da pobreza. Brasiliense, San Paolo

Zaluar, A., Alvito, M. (1998, a cura di), Um século de favela. Fundação Getulio Vargas Editora, Rio de Janeiro

Zaniratti, J. A. (2000), Movimento Comunitário de Porto Alegre: em busca de seu novo papel desde 1990. Porto Alegre. Manoscritto disponibile su 
www.zaniratti.net/HISMPO6.htm

Zanuttini, P. (2002), Questa favela è proprio un modello (di sviluppo). In: Il Venerdi, 20/12/ 2002

Zucconi, V. (2001), Pena di morte, quando lo Stato ricorre al linciaggio. In: La Repubblica, 23 giugno 2001 
